\title{
Micro-analytical studies of the petrogenesis of silicic arc magmas in the Taupo Volcanic Zone and southern Kermadec Arc, New Zealand
}

By

Katharine Emma Saunders

A thesis submitted to the Victoria University of Wellington in fulfilment of the requirements for the degree of Doctor of Philosophy in Geology 


\begin{abstract}
The petrogenesis of silicic arc magmas is controversial with end-member models of fractional crystallisation and crustal anatexis having been invoked. A prime example of this is the archetypical continental Taupo Volcanic Zone and the adjacent oceanic Kermadec Arc. Insights into the genesis and timescales of magmatic processes of four continental rhyolitic magmas (Whakamaru, Oruanui, Taupo and Rotorua eruptives) and an oceanic (Healy seamount) rhyodacitic magma are documented through micro-analytical chemical studies of melt inclusions and crystal zonation of plagioclase and quartz. Electron probe microanalysis, laser ablation inductively coupled plasma mass spectrometry and Fourier transform infrared spectroscopy have been used to measure major, trace and volatile element concentrations, respectively, of melt inclusions and crystals.
\end{abstract}

Melt inclusions are high silica (e.g. 74 - $79 \mathrm{wt} \%$ ) irrespective of arc setting and display a wide range of trace element compositions (e.g. $\mathrm{Sr}=17-180 \mathrm{ppm}$ ). Taupo Volcanic Zone melt inclusions exhibit higher $\mathrm{K}_{2} \mathrm{O}$ and $\mathrm{Ce} / \mathrm{Yb}$ relative to Healy melt inclusions reflecting the assimilation of continental lithosphere. Quantitative trace element modelling of melt inclusion compositions: (a) demonstrates that magma genesis occurred through $62-76 \%$ fractional crystallisation at Healy whereas assimilation of continental lithosphere (greywacke) in addition to $60-80 \%$ fractional crystallisation is required for the Taupo Volcanic Zone magmas; and (b) suggests the presence of crystal mush bodies beneath silicic magma chambers in both continental and oceanic arc environments. Water concentrations of melt inclusions ranged between $1.4-5.1 \mathrm{wt} \%$ for the Whakamaru, Taupo and Healy samples. However, the 
inconsistency in the measured molecular water to hydroxyl concentrations of melt inclusions relative to those determined experimentally for groundmass rhyolitic glasses provide evidence for the degassing of inclusions prior to quenching, by diffusion of hydroxyl groups through the crystal host. Thus, partial pressures of water estimated from the inclusions and inferred depths of the crystallising magma bodies are underestimated.

Chemical profiles of mineral zonation, however, indicate a more complex origin of silicic melts than simple fractionation and assimilation. For example, trace element modelling of Whakamaru plagioclase suggests that the three distinct textural plagioclase populations present in Whakamaru samples crystallised from four physiochemically discrete silicic melts. This modelling indicates a strong petrogenetic link between andesitic and silicic magmas from the chemical variation of selected Whakamaru plagioclase crystals possessing high anorthite (45-60 mol \%) cores and low anorthite ( $30 \mathrm{~mol} \%)$ rim compositions and the interaction of greywacke partial melts. Furthermore, Sr diffusion modelling of core-rim interfaces of the same plagioclase crystals indicate the amalgamation of the magma chamber occurred continuously over the 15,000 years preceding the climactic eruption. Conversely, the major element zonation of Taupo plagioclases implies magma genesis occurred solely through assimilation and fractional crystallisation without the incorporation of evolved crystal mush magmas, indicating a spectrum of magmatic processes are occurring beneath the Taupo Volcanic Zone with each eruption providing only a snapshot of the petrogenesis of the Taupo Volcanic Zone. 


\section{Acknowledgements}

First and foremost I must thank my supervisors Joel Baker and Richard Wysoczanski, for their encouragement, advice and especially their unwavering support over the last three years. Furthermore, I would like to thank Joel for initially inspiring me, being there to point out the obvious when required and for providing such a challenging and stimulating research environment. I would like to thank Dan Morgan for his patient (e-mail) tuition, advice and many insightful discussions on the principals of diffusion modelling of minerals and Alex Nichols for the many thought provoking discussions and his hospitality during my visit to the FTIR laboratory at JAMSTEC, Japan. This input will ultimately lead to submission of Chapters 3 and 4 as manuscripts with Alex Nichols and Dan Morgan as co-authors respectively.

Special thanks go to: Ian Wright for his provision of Healy samples and discussions on the nature of magma genesis in oceanic arcs; John Gamble for his support and many discussions on the Taupo Volcanic Zone; Julie Vry for her continuing support, advice and baking; John Patterson for his technical expertise in the running of the electron microprobe; Stewart Bush for his help with sample preparation; Susanne Grigull and Leonie Short for field assistance; Aidan Allan, Sophie Barton and Martin Schiller for help in the initial establishment of the analytical techniques of volcanic glasses in the Geochemistry Laboratory; Rebecca Fisher, Zoe Laing, Hannu Seebeck and Srimathy Sriskantharajah for their discussions and support; Chris Webster for his time proof reading. 
A huge thanks goes to Monica Handler and Yvette Baker for countless cups of tea and for keeping me sane for the last three years. Many thanks go to my various office mates; Ruth, Susanne, Aidan, Alex, Matt, Chelsea, Sophie, Sarah, Elodie and also Evelien, Jess, Annette, Kim, John, Katie, Caell, Matt, John, Cliff, Warren, Mike, Trish, Norbert, Nuala, John, Kay, Chris, Sophia, Lydia, Aratahi Rangers and anyone else I may have forgotten for the adventures, fun and support. Many thanks go to the fantastic general staff both past and present, but especially to Susan Cayless and Gill Ruthven.

Furthermore, I would like to thank Geoff Batt, Martin Menzies, Euan Nisbet and Matthew Thirlwall for providing the early inspiration and for sending me on this journey.

A Commonwealth Scholarship to New Zealand and smaller grants from Victoria University of Wellington Science Faculty Small Research Grants, The Daniel Pidgeon Fund of The Geological Society of London, a Postgraduate bursary from The Mineralogical Society of Great Britain and a Goldschmidt travel award funded this project and for these I am eternally grateful.

Finally, I would like to thank my parents Wendy and Tony and brother Tim (and dogs, Bruno and Nell) for their amazing support, even when I announced I was moving to the antipodes again for a further three years, for without it none of this would have been possible. 


\section{Table of Contents}

Title Page

Abstract ii

Acknowledgements iv

Table of Contents vi

List of Figures $\quad$ xi

List of Tables $\quad$ Xv

Chapter 1: Introduction 1

1.1 Global rhyolitic volcanism 1

$\begin{array}{lr}1.2 \text { Subduction volcanism } & 6\end{array}$

1.3 Melt inclusions: a window into the magmatic evolution 10

1.4 The role of water in silicic magmatism 12

$\begin{array}{ll}1.5 \text { Timescales of silicic magmatic processes } & 14\end{array}$

$\begin{array}{ll}1.6 \text { Geologic background } & 16\end{array}$

1.6.1 Taupo Volcanic Zone, North Island, New Zealand 16

1.6.2 Kermadec Arc, South West Pacific 20

1.7 Objectives of the thesis $\quad 21$

1.8 Structure of this thesis $\quad 23$

Chapter 2: Petrogenesis of large-volume silicic magmas in continental arcs: melt inclusions in Taupo Volcanic Zone and Kermadec Arc rhyolites, South $\begin{array}{lr}\text { West Pacific } & 25\end{array}$

$\begin{array}{lr}\text { Abstract } & 25\end{array}$

2.1 Introduction $\quad 26$

2.2 Regional background and samples $\quad 30$

2.3 Methods $\quad 36$

2.3.1 Sample preparation 36

2.3.2 Electron microprobe analyses $\quad 38$

2.3.3 Laser ablation inductively coupled plasma mass spectrometry 39

2.4 Results $\quad 42$

2.5 Discussion $\quad 49$

2.5.1 Comparison of Healy and Taupo Volcanic Zone melt inclusion compositions 
2.5.2 Petrogenesis of silicic magma at Healy caldera

2.5.3 Petrogenesis of silicic magma in the Taupo Volcanic Zone

2.5.4 Silicic magma generation model for the Taupo Volcanic Zone

2.6 Conclusions

Chapter 3: Water speciation and the degassing of unruptured melt inclusions: case studies from the Taupo Volcanic Zone, New Zealand

3.1 Introduction 66

3.2 Water speciation 68

3.3 Samples and methods 69

3.4 Results 73

$\begin{array}{ll}3.5 \text { Discussion } & 77\end{array}$

3.5.1 Secondary alteration of water speciation in rhyolitic melt inclusions $\quad 77$

3.5.2 Water diffusion and degassing of rhyolitic melt inclusions 82

3.5.3 Initial water concentrations of melt inclusions $\quad 85$

3.5.4 Geobarometry and crystallisation depths of magmas 86

$\begin{array}{ll}3.6 \text { Conclusions } & 91\end{array}$

Chapter 4: The magmatic evolution of the Whakamaru supereruption from crystal specific studies of plagioclase and quartz crystals 92

Abstract $\quad 92$

$\begin{array}{ll}4.1 \text { Introduction } & 93\end{array}$

4.2 Whakamaru supereruption and samples 95

$\begin{array}{lr}4.3 \text { Analytical methods } & 98\end{array}$

4.3.1 Sample preparation $\quad 98$

4.3.2 Electron probe microanalysis $\quad 98$

4.3.3 Laser ablation inductively coupled plasma mass spectrometry 99

$\begin{array}{ll}4.4 \text { Results } & 101\end{array}$

$\begin{array}{ll}\text { 4.4.1 Plagioclase crystals } & 101\end{array}$

4.4.1.1 Group 1 plagioclase crystals $\quad 104$

$\begin{array}{ll}\text { 4.4.1.2 Group } 2 \text { plagioclase crystals } & 104\end{array}$

4.4.1.3 Group 3 plagioclase crystals 106

$\begin{array}{ll}\text { 4.4.2 Quartz crystals } & 106\end{array}$

$\begin{array}{ll}4.4 .3 \mathrm{Fe}-\mathrm{Ti} \text { oxides } & 108\end{array}$ 
4.4.4 Geothermometry

4.5 Diffusion modelling 113

$\begin{array}{ll}\text { 4.5.1 Plagioclase crystals } & 113\end{array}$

4.5.2 Diffusion modelling based on Sr profiles $\quad 115$

$\begin{array}{ll}4.5 .3 \text { Quartz crystals } & 118\end{array}$

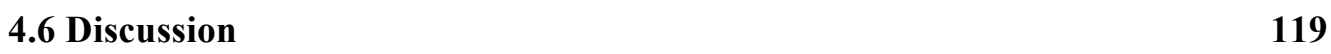

4.6.1 Origins of Group 1 plagioclase crystals 119

4.6.2 Origins of Group 2 plagioclase crystals $\quad 125$

4.6.3 Origins of Group 3 plagioclase crystals 126

$\begin{array}{ll}\text { 4.6.4 Origin of quartz crystals } & 127\end{array}$

$\begin{array}{ll}4.8 \text { Petrogenesis of the Whakamaru magma } & 128\end{array}$

$\begin{array}{ll}4.8 \text { Conclusions } & 133\end{array}$

Chapter 5: Crystal specific studies of Healy and Taupo eruptives: insights into the petrogenesis of silicic arc magmas $\quad 134$

$\begin{array}{ll}\text { Abstract } & 134\end{array}$

5.1 Introduction 134

$\begin{array}{ll}5.2 \text { Results } & 136\end{array}$

5.2.1 Volatile concentrations of Healy melt inclusions 136

5.2.2 Major element composition of plagioclase crystals $\quad 139$

5.3 Discussion $\quad 140$

5.3.1 Pre-eruptive magmatic water concentrations of the Healy magma $\quad 140$

5.3.2 Magmatic temperature and thermal evolution of melts 146

$\begin{array}{ll}\text { 5.3.3 Plagioclase zonation } & 147\end{array}$

5.3.4 Petrogenesis and accumulation of silicic magma at Healy caldera 152

5.3.5 Petrogenesis and accumulation of the 1800 BP Taupo magma 156

$\begin{array}{ll}5.4 \text { Conclusions } & 157\end{array}$

Chapter 6: Synthesis and Conclusions $\quad 158$

$\begin{array}{lr}\text { 6.1 Synthesis } & 158\end{array}$

$\begin{array}{ll}6.2 \text { Conclusions } & 169\end{array}$

$\begin{array}{ll}6.3 \text { Future work } & 170\end{array}$

$\begin{array}{lr}\text { References } & 173\end{array}$

Saunders, 2009 viii 
$\begin{array}{lr}\text { A1.1 Fieldwork and samples } & 215\end{array}$

$\begin{array}{ll}\text { A1.2 Sample preparation } & 217\end{array}$

$\begin{array}{ll}\text { A1.2.1 Melt inclusions } & 217\end{array}$

$\begin{array}{ll}\text { A1.2.2 Crystals } & 218\end{array}$

$\begin{array}{ll}\text { A1.3 Electron microprobe microanalysis } & 218\end{array}$

A1.4 Laser ablation inductively coupled plasma mass spectrometry 222

A1.4.1 Introduction $\quad 222$

A1.4.2 Operating conditions, setup and problems of LA-ICPMS analyses 222

A1.4.2.1 Carrier gas 222

A1.4.2.2 Ablation cell volume 223

A1.4.2.3 Elemental fractionation during transport 223

A1.4.2.4 Interferences 224

$\begin{array}{ll}\text { A1.4.2.5 Analytical conditions } & 229\end{array}$

A1.4.2.6 Elemental concentrations 229

A1.4.2.7 Reference materials 230

A1.4.3 LA-ICPMS of volcanic glasses $\quad 231$

$\begin{array}{ll}\text { A1.4.3.1 Basaltic glasses } & 231\end{array}$

A1.4.3.2 Rhyolitic glasses 236

A1.4.3.3 Analysis of rhyolitic melt inclusions by LA-ICPMS 238

A1.4.4 LA-ICPMS of plagioclase crystals 238

A1.5 Fourier transform infrared spectroscopy 239

$\begin{array}{ll}\text { A1.6 References } & 257\end{array}$

Appendix Two: Diffusion $\quad 262$

A2.1 Diffusion in minerals $\quad 262$

$\begin{array}{ll}\text { A2.2 Fick's Laws } & 264\end{array}$

A2.3 Diffusivity of elements $\quad 265$

$\begin{array}{ll}\text { A2.4 Activity } & 267\end{array}$

A2.5 Diffusion in plagioclase crystals $\quad 270$

A2.6 Residence time of plagioclase crystals 272

A2.6.1 Square-wave model 272

A2.6.2 Spherical diffusion model 275

A2.6.3 Comparison of calculated residence times: square-wave versus spherical models 276

$\begin{array}{ll}\text { A2.7 Sources of errors } & 277\end{array}$ 
A2.7.1 Chemical composition of plagioclase crystals

A2.7.2 Magmatic temperature and diffusivity

A2.7.3 Initial elemental concentrations 278

$\begin{array}{ll}\text { A2.7.4 Equilibrium profiles } & 279\end{array}$

A2.7.5 Identification of diffusional half-widths $\quad 280$

$\begin{array}{ll}\text { A2.8 References } & 280\end{array}$

Appendix Three: Data tables $\quad 284$

Appendix Four: Backscattered and Cathodoluminescence images 379 


\section{List of Figures}

\section{Chapter 1: Introduction}

Figure 1.1 Global map of silicic volcanism $\quad 2$

Figure 1.2 Schematic cross section of a rhyolitic magma reservoir 3

Figure 1.3 Total alkali silica diagram for the classification of volcanic rocks $\quad \mathbf{5}$

Figure $1.4{ }^{86} \mathrm{Sr} /{ }^{87} \mathrm{Sr}$ versus $\varepsilon_{\mathrm{Nd}}$ of global rhyolites $\quad 6$

Figure 1.5 Regional setting of the Tonga-Kermadec subduction system 9

Figure 1.6 Transmitted light photographs of Taupo Volcanic Zone melt inclusions 11

Figure 1.7 Cartoon of crystal zonation and the evolution of a compositional gradient of a core-rim interface $\quad \mathbf{1 6}$

$\begin{array}{ll}\text { Figure 1.8 Caldera centres of the Taupo Volcanic Zone } & 17\end{array}$

\section{Chapter 2: Petrogenesis of large-volume silicic magmas in continental arcs:} melt inclusions in Taupo Volcanic Zone and Kermadec Arc rhyolites, South

\section{West Pacific}

Figure 2.1 Map of Taupo Volcanic Zone and southern Kermadec Arc

Figure 2.2 Transmitted light photomicrograph of melt inclusions from the Taupo Ignimbrite

Figure 2.3 Total alkali silicic diagram of Taupo Volcanic Zone and Healy melt inclusions

Figure 2.4 Major element bivariate diagrams for Taupo Volcanic Zone and Healy melt inclusions

Figure 2.5 $\mathrm{SiO}_{2}$ versus $\mathrm{K}_{2} \mathrm{O}$ plots of melt inclusions distinguished by host

Figure 2.6 Chondrite-normalised rare earth element plot and primitive mantle normalised multi-element diagram of Taupo Volcanic Zone and Healy melt inclusions

Figure 2.7 Trace element diagrams from Taupo Volcanic Zone and Healy melt inclusions

Figure 2.8 $\mathrm{Ba} / \mathrm{Nb}$ and $\mathrm{Ba} / \mathrm{Th}$ versus $\mathrm{SiO}_{2}$ plots of Taupo Volcanic Zone and Healy melt inclusions

Figure 2.9 $\mathrm{Rb} / \mathrm{Sr}$ plotted against $\mathrm{K}_{2} \mathrm{O}$ comparing melt inclusions and pumice compositions

Figure 2.10 Chondrite-normalised rare earth element diagrams illustrating the discussed petrogenetic models

Figure 2.11 Sr versus Ce trace element diagram of Whakamaru melt inclusion 
Figure 2.12 Chondrite-normalised rare earth element diagram for Taupo Ignimbrite melt inclusions and Ruapehu groundmass glass

Chapter 3: Water speciation and the degassing of unruptured rhyolitic melt inclusions: case studies from the Taupo Volcanic Zone, New Zealand

Figure 3.1 Measured water speciation of Whakamaru and Taupo melt inclusions 75

Figure 3.2 Comparison of measured and calculated speciation of melt inclusions $\mathbf{7 8}$

Figure 3.3 Comparison of the calculated measured speciation of Taupo melt

inclusions from the Beer-Lambert law and the Zhang et al. (1997)

calibration

Figure 3.4 Representative spectrographic image of a Whakamaru quartz crystal and melt inclusion

Figure 3.5 Syn-eruptive degassing trend of Whakamaru and Taupo melt inclusions

Figure 3.6 Comparison of $p \mathrm{H}_{2} \mathrm{O}$ and inferred crustal depths of measured water water concentration of Whakamaru and Taupo melt inclusions

\section{Chapter 4: The magmatic evolution of the Whakamaru supereruption from crystal specific studies of plagioclase and quartz crystals}

Figure 4.1 Map of the Taupo Volcanic Zone denoting the location and extent of the Whakamaru Ignimbrite

Figure 4.2 Partial ternary diagram of the Whakamaru plagioclase crystals

Figure 4.3 Representative backscattered images and $X A n, \mathrm{Sr}$ and $\mathrm{Mg}$ of

Whakamaru plagioclase crystals

Figure 4.4 Measured $\mathrm{Sr}, \mathrm{Ba}, \mathrm{La}$ and $\mathrm{Pb}$ concentrations of plagioclase crystals $\quad 105$

Figure 4.5 CL images for a selection of Whakamaru quartz crystals $\mathbf{1 1 0}$

$\begin{array}{ll}\text { Figure 4.6 Probability distributions for each diffusional timescale } & 117\end{array}$

Figure 4.7 Calculated $\mathrm{Sr}$ and $\mathrm{Ba}$ co-existing melt composition for the three defined plagioclase populations at $760{ }^{\circ} \mathrm{C}$

Figure 4.8 Activity of Sr versus activity of $\mathrm{Sr}$ /activity of $\mathrm{Mg}$ for a Group 1 plagioclase crystal

Figure 4.9 Fractional crystallisation model for the generation of Group 1 rim melt compositions

Figure 4.10 A cartoon summarising the timing and growth of Whakamaru plagioclase and quartz crystals studied 
Figure 4.11 Cartoon of the sub-volcanic Whakamaru magma system

Chapter 5: Crystal specific studies of Healy and Taupo eruptives: insights into the petrogenesis of silicic arc magmas

Figure 5.1 $\mathrm{Cl}$ and $\mathrm{Gd}$ versus $\mathrm{SiO}_{2}$ concentrations of Healy melt inclusions 138

Figure 5.2 Measured water speciation of Healy melt inclusions 138

Figure 5.3 Backscattered electron images of Healy plagioclase crystals 141

Figure 5.4 Backscattered electron images of Taupo plagioclase crystals 144

Figure 5.5 Representative $X A n$ and Fe profile of a Healy and Taupo plagioclase

Figure 5.6 Modelled $X A n$ compositions as a function of temperature and $\mathrm{H}_{2} \mathrm{O}$ content of the melt for a Healy plagioclase crystal

\section{Chapter 6: Synthesis and Conclusions}

Figure 6.1 Compositional variability of quartz-hosted Whakamaru melt inclusions

Figure 6.2 Sr versus Be melt concentrations of Taupo Volcanic Zone and Healy magmas

Figure 6.3 Cartoon cross section of the petrogenesis of silicic magmas in the continental Taupo Volcanic Zone and oceanic Kermadec Arc magmas

\section{Appendix 1: Samples and Analytical Methods}

Figure A1.1 Position of sample and standard in the LA-ICPMS ablation cell

Figure A1.2 Elemental fractionation of refractory/volatile elements of BHVO-2G 236

Figure A1.3 Reproducibility of trace elements in ATHO-G

Figure A1.4 Transmission and reflected spectra of melt inclusion glasses

\section{Appendix 2: Diffusion}

Figure A2.1 Diffusion mechanisms of atoms in solids

Figure A2.2 Measured $X A n, \mathrm{Sr}$ and calculated $\mathrm{Sr}$ equilibrium and activity profiles of a Whakamaru plagioclase crystal

Figure A2.3 Square-wave diffusion model after Zellmer et al. (1999)

Figure A2.4 Calculation of the residence times of a plagioclase crystal using the square-wave diffusion model

Figure A2.5 Spherical diffusion model 
Figure A2.6 Comparison of diffusion curves for calculation of residence times using both a square-wave and spherical diffusion model

\section{Appendix 4: Backscattered and Cathodoluminescence images}

Figure A4.1 Backscattered electron images and XAn profiles of Whakamaru plagioclase crystals

Figure A4.2 Backscattered electron images of Whakamaru plagioclase crystals

Figure A4.3 Cathodoluminescence images of Whakamaru quartz crystals 394

Figure A4.4 Backscattered electron images of Healy plagioclase crystals 396

Figure A4.5 Backscattered electron images of Taupo plagioclase crystals 398 


\section{List of Tables}

Chapter 2: Petrogenesis of large-volume silicic magmas in continental arcs: melt inclusions in Taupo Volcanic Zone and Kermadec Arc rhyolites, South West Pacific

Table 2.1 Details of samples analysed in the melt inclusion study

Table 2.2 Standard calibration and reference values for VG2 and scapolite for electron microprobe analysis

Table 2.3 Representative major and trace element data for Taupo Volcanic Zone and Healy melt inclusions

Table 2.4 Representative major and trace element concentrations of Oruanui and and Healy groundmass glass

Table 2.5 Rare earth element distribution coefficients for basaltic magmas 52

Table 2.6 Crystal assemblage for use with fractional crystallisation models 57

Table 2.7 Rare earth element distribution coefficients for rhyolitic magmas

Chapter 3: Water speciation and the degassing of unruptured rhyolitic melt inclusions: case study from the Taupo Volcanic Zone, New Zealand

Table 3.1 Mean anhydrous major element composition of Whakamaru and Taupo melt inclusions

Table 3.2 Measured speciation of Whakamaru and Taupo melt inclusions

Table 3.3 Calculated $\mathrm{T}_{\mathrm{ae}}$ and cooling rates of Whakamaru and Taupo melt inclusions

Chapter 4: The magmatic evolution of the Whakamaru supereruption from crystal specific studies of plagioclase and quartz crystals

Table 4.1 Sample locations and mineralogy of Whakamaru samples

Table 4.2 Standard calibrations and reference values of reference materials used in

EPMA analyses

Table 4.3 Repetitive analyses of STH-G

Table 4.4 Representative major element analyses of plagioclase crystals

Table 4.5 TiO concentrations of quartz crystals

Table 4.6 Fe-Ti oxides major element compositions and calculated temperature and oxygen fugacity 
Table 4.7 Summary of magmatic temperatures estimated from the plagioclase-melt equilibria

Table 4.8 Calculated residence times of Group 1 plagioclase crystals

Table 4.9 Summary of quartz residence times 119

Table 4.10 Proportions of the observed Whakamaru crystal assemblage

Chapter 5: Crystal specific studies of Healy and Taupo eruptives: insights into the petrogenesis of silicic arc magmas

$\begin{array}{ll}\text { Table 5.1 Measured water speciation of Healy melt inclusions } & 137\end{array}$

Table 5.2 Major element composition of X590Ba melt inclusions 151

Table 5.3 Calculated crystallinities of Healy melt inclusions compositions $\quad \mathbf{1 5 3}$

\section{Appendix 1: Samples and Analytical Methods}

Table A1.1 Summary of samples collected for this study

Table A1.2 Typical operating conditions for EPMA analysis of melt inclusions

Table A1.3 Reference values of secondary standards used for EPMA analyses

Table A1.4 Precision and accuracy of basalt glass A99

Table A1.5 Potential interferences for each element and isotope analysed by

\section{LA-ICPMS}

Table A1.6 Justification for the analysed isotope during LA-ICPMS analyses

Table A1.7 Typical analytical conditions for LA-ICPMS analyses

Table A1.8 Trace element concentrations of reference materials

Table A1.9: Initial analyses for BHVO-2G with BCR-2G as calibrations standard

Table A1.10 Analyses of polished BHVO-2G with BCR-2G as the calibration standard

Table A1.11 Analyses of BHVO-2G with BCR-2G as the calibration standard mounted in half circles

Table A1.12 Analyses of BHVO-2G with BCR-2G as the calibration standard mounted in half circles and rotated by $90^{\circ}$

Table A1.13 Analyses of BHVO-2G with BCR-2G as the calibration standard with reduced cell volume

Table A1.14 Analyses of BHVO-2G with BCR-2G as the calibration standard at $10-50 \mu \mathrm{m}$ spot diameters 
Table A1.15 Analysis of ATHO-G with BCR-2G as the calibration standard in reaction cell mode

Table A1.16 Analysis of ATHO-G with BCR-2G as the calibration standard

Table A1.17 Analysis of ATHO-G with NIST SRM 612 as the calibration standard

Table A1.18 Analysis of ATHO-G and NIRST SRM 612 as the calibration standard at 20-50 $\mu \mathrm{m}$ spot diameters

Table A1.19 Analysis of STH-80G and NIST SRM 610 as the calibration standard at $10 \mu \mathrm{m}$ spot diameter

Table A1.20 Analysis of STH-80G and NIST SRM 610 as the calibration standard at a $20 \mu \mathrm{m}$ spot diameter

\section{Appendix 2: Diffusion}

Table A2.1 Pre-exponential and activation energies for selected trace elements in plagioclase crystals

\section{Appendix 3: Data tables}

Table A3.1 Major and trace element compositions of melt inclusions

Table A3.2 Major element compositions of melt inclusions where no trace element data is available

Table A3.3 Major element compositions of groundmass glass adhered to crystals

Table A3.4 Trace element composition of orthopyroxene and plagioclase crystals

Table A3.5 Major element compositions of Taupo melt inclusions plagioclase hosts and representative analyses of Whakamaru plagioclase crystals 311

Table A3.6 Major element profiles of Whakamaru plagioclase crystals

Table A3.7 Major element compositions of core and rim analyses of Whakamaru plagioclase crystals

Table A3.8 Sr, Ba and Mg profiles of Whakamaru plagioclase crystals

Table A3.9 Rare earth elements, $\mathrm{Sr}, \mathrm{Yb}$ and $\mathrm{Pb}$ analyses of Whakamaru plagioclase crystals

Table A3.10 Major element profiles of Healy plagioclase crystals

Table A3.11 Major element profiles of Taupo plagioclase crystals 


\section{Chapter 1}

\section{Introduction}

Oceanic lithosphere is created at mid-ocean ridges and recycled back into the Earth at convergent margins. This subduction of material back into the Earth's mantle is pivotal to the large-scale recycling of elements between the crust, mantle, hydrosphere and atmosphere. The addition of subducted material (i.e. oceanic lithosphere and associated sediment) results in the overriding mantle becoming enriched in fluid and melt mobile elements such as large ion lithophile elements and water. It is this addition of water to the mantle that ultimately drives arc volcanism and the catastrophic eruptions that are common along many continental margins (McCulloch and Gamble, 1991; Lowenstern et al., 2006). The most devastating of these eruptions and perhaps the least well understood are large-volume silicic eruptions. The largest of these eruptions $\left(>450 \mathrm{~km}^{3}\right)$ are termed supereruptions and are a magnitude greater than any volcanic eruption witnessed within recent history (Lowenstern et al., 2006; Miller and Wark, 2008). Of the eighteen known supereruptions to have occurred in the last 2 million years, seventeen of these are derived from arc volcanism (Lowenstern et al., 2006). The most recent and well-documented supereruption is the $26.5 \mathrm{ka}$ Oruanui eruption from the hyper-productive Taupo Volcanic Zone, New Zealand (Wilson, 2001; Mason et al., 2004; Miller and Wark, 2008).

\subsection{Global rhyolitic volcanism}

Large-volume silicic eruptions and supereruptions are not constrained to a single tectonic setting but have been documented globally from continental margins 
such as New Zealand and South America (e.g. Wilson, 2001; Wilson et al., 2006; Lindsey et al., 2001); continental rifts, e.g. Yemen-Ethiopia (e.g. Baker et al., 2000; Ukstins Peate et al., 2003; 2007); and intra-continental plume related volcanism such as Yellowstone, USA (e.g. Christensen, 2001) (Figure 1.1).

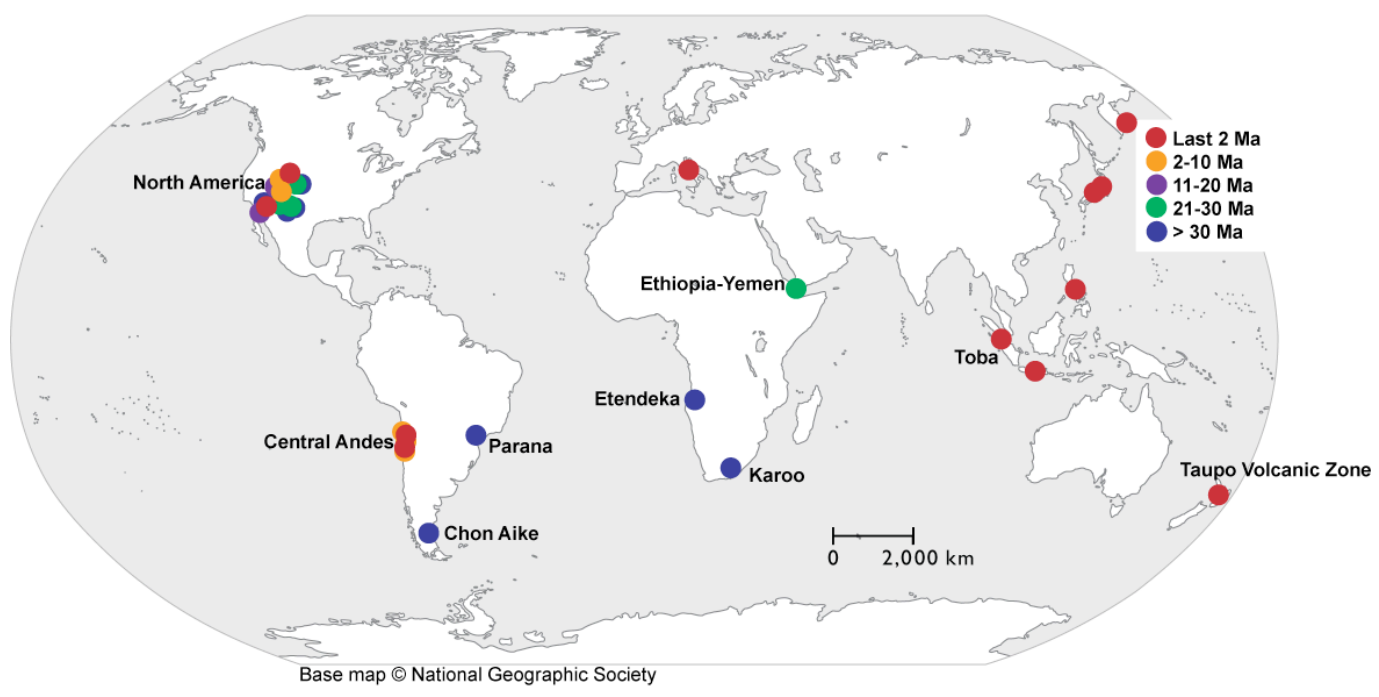

Figure 1.1. Global map of silicic volcanism after Bryan et al. (2002), Mason et al. (2004) and Sparks et al. (2005) illustrating the location of the largest identified and studied rhyolitic eruptions.

Models for the generation of rhyolitic magmatism are ultimately driven by mantle-derived mafic magmas, resident at deeper crustal levels providing thermal energy and supplying at least the initial melt (e.g. Hildreth, 1981; Bachmann and Bergantz, 2004; Miller and Wark, 2008). Extreme fractional crystallisation from this mantle-derived mafic magma ensues and/or the presence of this mafic magma promotes crustal anatexis generating large volumes of silicic magmas (e.g. Hildreth, 1981; Bachmann and Bergantz, 2004; 2008; Annen et al., 2006; Brophy, 2008). These silicic magmas accumulate in the upper crust, forming crystal mush zones, which are magmatic bodies composed of interconnecting semi-solidified crystals and interstitial liquid that are potentially preserved as silicic plutons (e.g. Bachmann and Bergantz, 2004; Glazner et al., 2004; Hildreth 
and Wilson, 2007, Wilson et al., 2006; Lipman, 2007; Bachmann and Bergantz, 2008). The interstitial liquid is extracted from the crystal mush and ponds in an overlying magma chamber (Figure 1.2) providing the large volumes of eruptible magma evacuated during supereruptions (e.g. Bachmann and Bergantz, 2004; Hildreth and Wilson, 2007, Wilson et al., 2006; Bachmann and Bergantz, 2008).

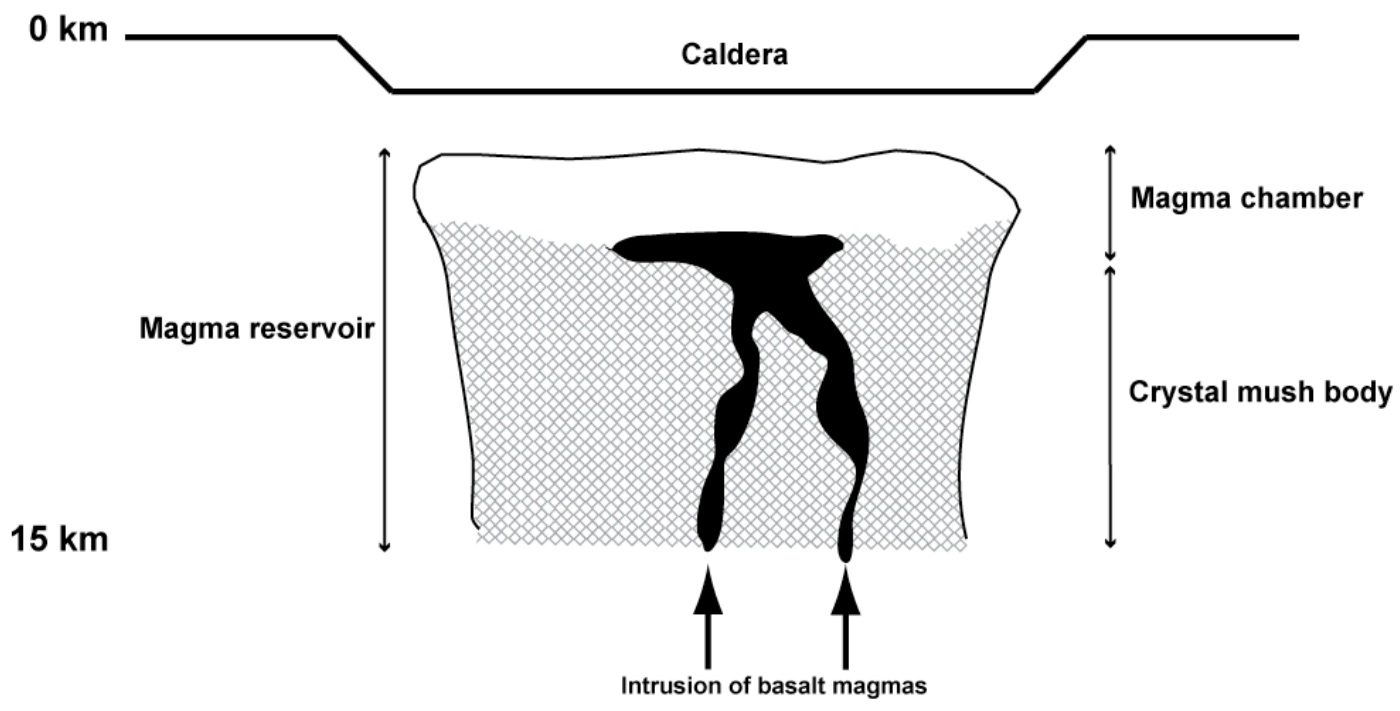

Figure 1.2 Schematic cross section of a rhyolitic magma reservoir after Bachmann and Bergantz (2004, 2008).

This model explains the occurrence of both crystal-poor $(5-10 \%$ volume crystals) rhyolites sourced from the magma chamber and crystal-rich (40-50\% volume crystals, often termed 'monotonous intermediates') dacite/rhyolite magmas originating from semi-formed or rejuvenated crystal mush bodies (e.g. Hildreth, 1981; Lindsey et al., 2001; Bachmann et al., 2002; Bachmann and Bergantz, 2004; Hildreth, 2004; Christensen, 2005; Wilson et al., 2006). The storage of large volumes of silicic melts in crystal mush bodies provides a viable explanation for the failure of geophysical surveys to detect large-volumes of partial melt in shallow $(<6 \mathrm{~km})$ upper crustal magma chambers, underlying 
volcanically active regions of the world (e.g. Bachmann and Bergantz, 2003; Glazner et al., 2004).

Recent studies have indicated that the crystal mush model is applicable for both intra-continental and subduction related rhyolites (e.g. Hildreth and Wilson, 2007; Wilson et al., 2006; Shane et al., 2008). However, many intra-continental rhyolite deposits such as the Bishop Tuff, USA possess strong geochemical fractional crystallisation signatures and systematically zoned deposits (Hildreth, 1981; Hildreth and Wilson, 2007). In comparison, and although similar in chemical composition, Taupo Volcanic Zone rhyolites display only limited chemical variation that lacks any systematic zonation or is chemically 'reversed' (e.g. Hildreth, 1981; Briggs et al., 1993; Brown et al., 1998a; Wilson et al., 2006), implying that a single petrogenetic model may not adequately explain the formation of silicic magmas in all tectonic settings.

One possible mechanism that may account for the disparity in chemical stratification of silicic magmas is the geometry of magma chambers. Slab shaped magma chambers may prevent the separation of crystals from liquid melt, inhibiting the chemical zonation of the chamber (Christensen, 2005). Whereas, cylindrical magma chambers readily promote crystallisation on the wall of the chamber resulting in the migration of more chemically evolved buoyant melt to the top of the magma chamber generating chemical zonation (Christensen, 2005).

Volcanic rock nomenclature in this study is based on the $\mathrm{SiO}_{2}(\mathrm{wt} \%)$ and total alkali contents $\left(\mathrm{Na}_{2} \mathrm{O}+\mathrm{K}_{2} \mathrm{O}\right.$, wt $\left.\%\right)$ of samples using the Total Alkali Silica 
diagram of Le Bas et al. (1986) (Figure 1.3). Rhyolites are typically characterised by high $\mathrm{SiO}_{2}(>69 \mathrm{wt} \%$ ) (Figure 1.3), low $\mathrm{MgO}$ and $\mathrm{Sr}$ concentrations, enriched light rare earth elements concentrations, generally enriched ${ }^{87} \mathrm{Sr} /{ }^{86} \mathrm{Sr}$ and depleted $\varepsilon_{\mathrm{Nd}}$ isotopes (Figure 1.4), high water contents (1-6 wt\%) and are highly viscous compared to mid ocean ridge basalts (e.g. Bowen, 1928; Hildreth, 1981; McCulloch et al., 1994; Graham et al., 1995; Anderson et al., 2000; Ukstins Peate et al., 2005; Wallace, 2005; Wilson et al., 2006). Mineral assemblages are typically a combination of plagioclase, orthopyroxene, quartz, ilmenite, magnetite, K-feldspar, biotite, hornblende, apatite, zircon, clinopyroxene and cummingtonite (e.g. Graham et al., 1995; Anderson et al., 2000; Schmitz and Smith, 2004; Wilson et al., 2006).

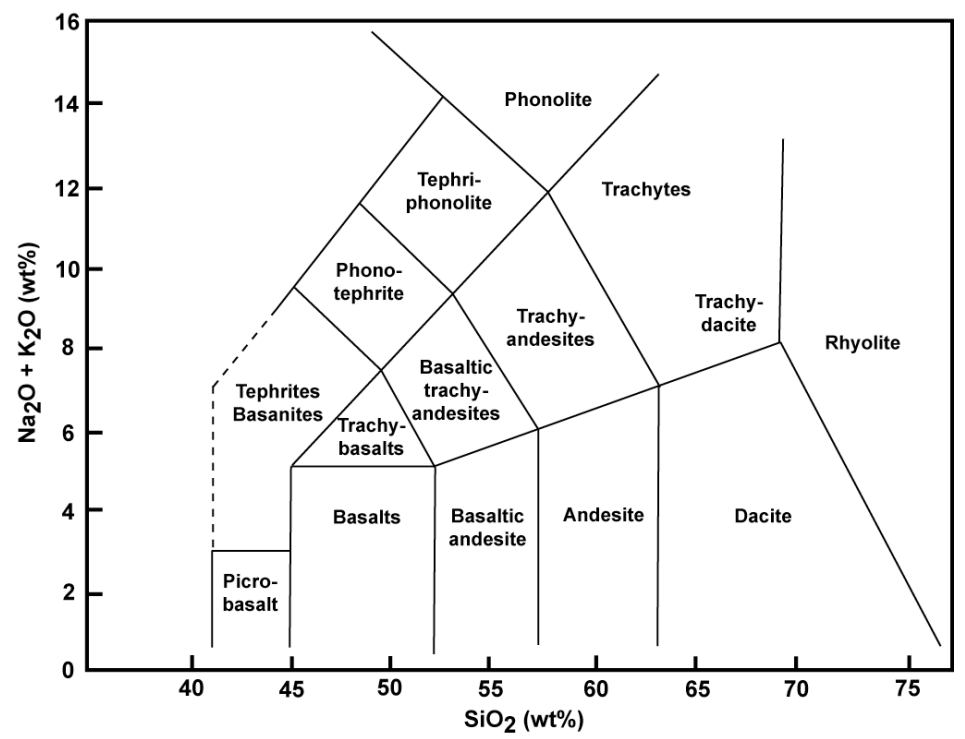

Figure 1.3. Total alkali silica diagram after Le Bas et al. (1986) illustrating the nomenclature of volcanic rock classification used in this study. 


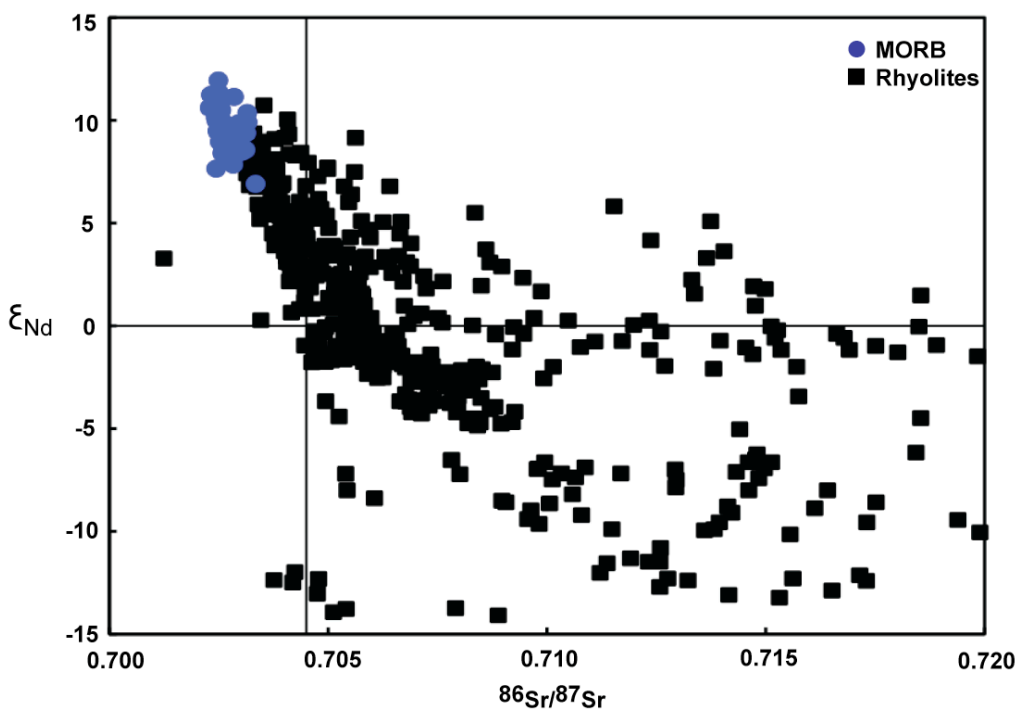

Figure 1.4. ${ }^{86} \mathrm{Sr} /{ }^{87} \mathrm{Sr}$ versus $\varepsilon_{\mathrm{Nd}}$ ratios of global rhyolites compared to mid-ocean ridge basalts (MORB). Data sources: MORB - Ito et al. (1987); Rhyolites: Africa - Ayalew et al. (2002); China - Zhang et al. (2008); Iceland - Martin and Sigmarsson (2007); Italy - Gioncada et al. (2003); Japan - Takagai et al. (1999); Mexico - Albrecht and Goldstein (2000); New Zealand Beresford et al. (2000); Schmidtz and Smith (2004); Sutton et al. (1995); Wilson et al. (2006); South America - Siebel et al. (2000); USA - Hildreth et al. (1991); Heuman et al. (1997); Borg and Clynne (1998); Hammersely and DePaolo (2006). Black lines represent the Bulk Earth isotopic compositions from Zindler and Hart (1986).

\subsection{Subduction magmatism}

Subduction generated mafic magmas are widely recognised to originate from the partial melting of the mantle wedge (e.g. McCulloch and Gamble, 1991; Davis and Stevenson, 1992; Schmidt and Poli, 1998; Annen et al., 2006). The dehydration of the subducting plate and associated sediment package causes the solidus temperature of the overlying mantle to be lowered and allows partial melts to form (e.g. McCulloch and Gamble, 1991). The higher buoyancy of partial melts relative to the surrounding mantle instigates the ascent of these melts towards the surface. As mafic melts ascend crustal processes such as density filtering causes these mafic magmas to stagnate, becoming lodged in the 
crust, and preventing substantial quantities of primary mantle-derived magmas from reaching the surface (e.g. Hildreth, 1981; Annen et al., 2006). In contrast, the ultimate origin of silicic arc magmas is still equivocal. Two widely cited end-member models are fractional crystallisation from primary mantle-derived magmas and crustal anatexis (Ewart and Stipp, 1968; Pearce et al., 1995; Borg and Clynne, 1998; Kawate and Arima, 1998; Brophy et al., 1999; Grove et al., 2003; Smith et al., 2003a,b; Shukuno et al., 2006; Wysoczanski and Tani, 2006). Distinguishing between these two models is difficult, as silicic magmas generated by either model could possess similar chemical signatures (Haase et al., 2006; Brophy, 2008). Furthermore, fractional crystallisation of a primary magma has the potential to trigger crustal melting or assimilation of crustal material, thereby obscuring the original geochemical signature of the source (DePaolo, 1981; Annen et al., 2006). Increasingly, evidence is emerging of multiple crystal populations within magmas that cannot be derived solely from a single source but provide evidence for the recycling of crystals from progenitor melts and the remobilization of crystal mushes (Davidson et al., 2001; Bachmann and Bergantz, 2004; Charlier et al., 2005; Davidson et al., 2007; Jerram and Martin, 2008).

Many of the largest known silicic volcanoes are associated with continental subduction and in areas that are also characterised by regional extension (Jellinek and DePaolo, 2003; Lowenstern et al., 2006). In these settings, intra-crustal magmatism responsible for large-volume silicic eruptions is often expressed at the surface as caldera structures (Houghton et al., 1995). Silicic eruptions range from small volume, $\left(<1 \mathrm{~km}^{3}\right.$ dense rock equivalent [DRE]) local eruptions to 
potentially devastating supereruptions ( $>450 \mathrm{~km}^{3}$ DRE) (Newhall and Self, 1982; Houghton et al., 1995; Mason et al., 2004; Miller and Wark, 2008; Wilson et al., in press). The growth of large inter-crustal magma chambers is favoured in regions with elevated geothermal gradients that heat country rocks, allowing for the expansion of magma chambers with increasing magma volumes (Jellinek and DePaolo, 2003).

The continental Taupo Volcanic Zone in the southwest Pacific with its elevated geothermal gradient and rift setting (Stern, 1987; Wilson et al., 1995) is a prime location for the production of large-volume silicic arc magmas. The region is characterised by thin $(15-25 \mathrm{~km})$, extending $(\sim 8-10 \mathrm{~mm} / \mathrm{yr})$ continental crust resulting in a graben packed structure of volcanic infill with high heat flow of $\sim 700 \mathrm{~mW} / \mathrm{m}^{2}$ (Cole, 1981; Stern, 1987; Houghton et al., 1995; Darby et al., 2000; Harrison and White, 2004). Moreover, in the last 1.6 Ma, eight active caldera centres have been recognised that have produced $>15,000 \mathrm{~km}^{3}$ of rhyolite designating this as the most active silicic magmatic system on Earth (Wilson et al., 1995). Volcanic activity is not continuous, but is characterised by short 25-35 kyr bursts of activity interspersed with $100 \mathrm{kyr}$ periods of quiescence (Allan et al., 2008), although the oceanic record that this is based on could be biased and may not reflect the complete eruptive history of the Taupo Volcanic Zone.

Silicic magmatism is not confined to the continental Taupo Volcanic Zone, but continues to the north of New Zealand along the concomitant oceanic Kermadec Arc (Figure 1.5), where eleven of the eighteen sampled frontal arc Kermadec 
volcanoes in the southern Kermadec arc have been identified as having silicic deposits (Smith et al., 2003a; Wright and Gamble, 1999; Wright et al., 2003, 2006; Hasse et al., 2006).

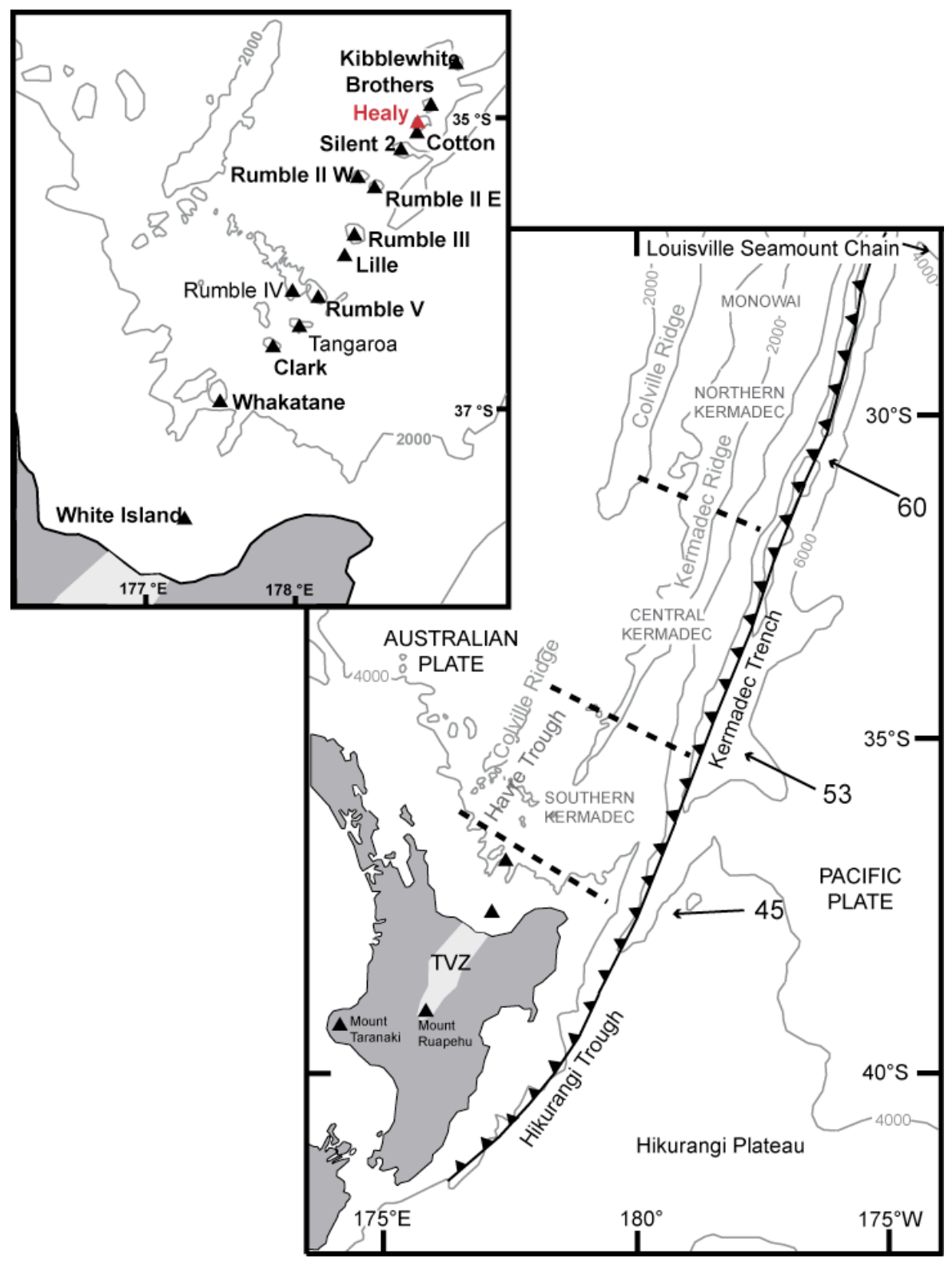

Figure 1.5 Regional setting of the Taupo-Kermadec subduction system. Inset shows the southern Kermadec Arc and location of volcanic centres. Bathymetry is shown for $2000 \mathrm{~m}$ from de Ronde et al. (2001). Plate motions are in mm/yr and taken from Wright et al. (2006).

The presence of continental lithosphere has been proposed as a key component in the production of large volumes of silicic magmas, potentially inhibiting the rise 
of dense mafic melts and thereby promoting the accumulation of crustal magma reservoirs (Jellinek and DePaolo, 2003; Bachmann and Bergantz, 2008). Whilst continental lithosphere may increase the number of potential melt sources and processes that can affect an ascending melt, the abundance of silicic volcanism in oceanic arcs (e.g. Kermadec Arc, South Sandwich Islands, New Britain Island Arc, Izu-Bonin Arc) implies continental lithosphere is not always required to produce silicic arc magmas. However, to generate large-volume eruptions the presence of continental or over- thickened oceanic crust appears to be required in order to insulate the ascending melts at elevated magmatic temperatures for extended periods of time. This allows extensive fractional crystallisation and/or promotes the assimilation or melting of country rock to take place, thereby generating additional melt to feed the magma bodies that are the source of largevolume silicic eruptions.

\subsection{Melt inclusions: a window into magmatic evolution}

Given the complexity of silicic arc volcanism and the presence of potentially multiple crystal populations derived from polygenetic sources (e.g. Davidson et al., 2005), a single liquid line of descent of magmas is improbable. Crushing of bulk rock samples provides an average rock compositions and the analysis of groundmass glass compositions provides information of the final liquid compositions. Any information on the former melt compositions is either erased or obscured providing little evidence of the early magmatic evolution (Sobolev, 1996). An alternative is to analyse melt inclusions (Figure 1.6), which are small bubbles of melt that become trapped during crystal growth (Roedder, 1979; Sobolev, 1996; Danyushevsky et al., 2002). This allows direct analysis of the 
melt compositions at the time the inclusions were sealed from the external melt, which may not be expressed in the final eruptives due to subsequent magmatic processes (e.g. Roedder, 1979; Kent and Elliot, 2002; Blundy et al., in press). Thus, the chemistry of multiple magma batches is potentially sampled as inclusions in different crystal hosts and this may permit the evolution of the melt to be deciphered (Roedder, 1979; Danyushevsky et al., 2002).
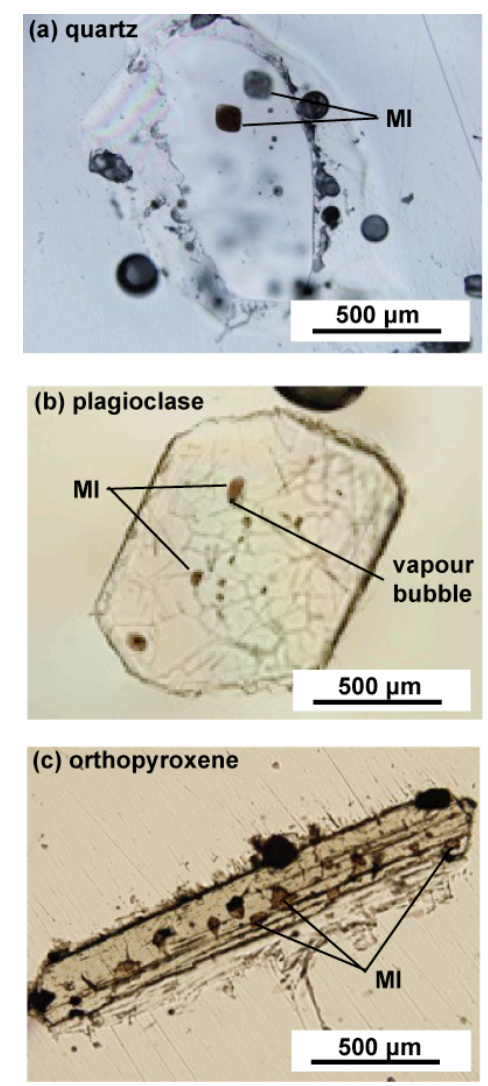

Figure 1.6 Transmitted light photographs of Taupo Volcanic Zone melt inclusions in: (a) quartz; (b) plagioclase and; (c) orthopyroxene hosts. Note the small vapour bubble at the base of the melt inclusion in (b). Melt inclusions are ubiquitous throughout the orthopyroxene crystal. MI = melt inclusion.

A major assumption in melt inclusion studies is that inclusions remain isolated post entrapment, retaining their original compositions and are not modified by subsequent magmatic processes (Sobolev, 1996; Frezzotti et al., 2001). While 
this may be valid for major and trace element concentrations in low temperature silicic magmas, increasingly experimental evidence is questioning this assumption and proposing that crystal hosts are in fact semi-closed systems that permit the diffusive exchange of volatiles and potentially other elements (Spandler et al., 2007; Portnyagin et al., 2008). Therefore, anomalous melt inclusion compositions may in fact reflect diffusive exchange of elements and not the original melt compositions (Spandler et al., 2007). Consequently, but with careful consideration of diffusive processes, melt inclusions can provide fundamental insights into the magmatic evolution that would otherwise be erased or obscured by later magmatic processes.

\subsection{The role of water in silicic magmatism}

Water is the most abundant volatile species in terrestrial magmas and controls the eruptive power and dynamics of a volcanic eruption (Wilson, 1980; Blake, 1984; Zhang, 1999). Melt properties such as viscosity, density, liquidus and solidus temperatures and the crystallising mineral assemblage are also affected by the water content of a melt (e.g. Yoder, 1957; Tuttle and Bowen, 1958; Shaw, 1972; Blake, 1984; Johannes, 1989; Jaupart and Tait, 1990; Ochs and Lange, 1997; Zhang, 1999; Wallace, 2005). Unless magmas are erupted under pressure, as is the case for submarine eruptions, they degas on eruption, erasing all evidence of the pre-eruptive volatile content (e.g., Delaney et al., 1978; Gerlach, 1986; Dixon et al., 1995; Dixon, 1997; Newman and Lowenstern, 2002; Nichols and Wysoczanski, 2007). An exception to this is the volatile concentration of melt inclusions (e.g. Wallace, 2005). Consequently, melt inclusions are routinely analysed in order to determine the pre-eruptive dissolved water content of 
magmas. These studies for example reveal that water concentrations of basaltic arc magmas span a range from below detection limits to $\geq 6 \mathrm{wt} \%$ (e.g. Wallace, 2005).

Stalling and differentiation of mafic magmas within the crust could potentially generate intermediate and evolved magmas with extremely high $\mathrm{H}_{2} \mathrm{O}$ (e.g. $>6$ wt $\%$ ) concentrations (Sparks, 2003). However, measured $\mathrm{H}_{2} \mathrm{O}$ concentrations of melt inclusions from dacitic and rhyolitic arc magmas range between 1-6 wt $\%$ coinciding with $\mathrm{H}_{2} \mathrm{O}$ concentrations of basaltic magmas (Wallace, 2005). This overlapping range of water concentrations of melt inclusions can be attributed to: (1) open system magmatic processes allowing significant amounts of volatiles to be degassed; (2) the generation of arc magmas from crustal fusion resulting in lower observed $\mathrm{H}_{2} \mathrm{O}$ concentrations (Wallace, 2005) or; (3) the diffusive exchange of volatiles with the external melt (e.g. Portnyagin et al., 2008). Given laboratory based experimental evidence indicates (Severs et al., 2007; Portnyagin et al., 2008) diffusive exchange of volatiles occurs between melt inclusions and the external magma post sealing of the inclusion, this process must be recognised and identified to allow the correct pre-magmatic water concentrations to be constrained. This is important to our understanding of volcanic processes, as determination of accurate water concentrations of magmas is fundamental for the application of geobarometry models and the estimation of depths of crystallising magma bodies and the crustal location of magma chambers (e.g. Bacon et al., 1992; Atlas et al., 2005; Gurenko et al., 2005; Nishimura et al., 2005; Lui et al., 2006; Fulignati and Marianelli, 2007; Shane et al., 2007). 


\subsection{Timescales of silicic magmatic processes}

One of the fundamental questions that remain unanswered in relation to largevolume silicic eruptions is the timescale for the petrogenesis and accumulation of large volumes of magma. Differentiation processes in silicic magmas are speculated to occur over a range of timescales. For example, Oligocene supereruption deposits derived from Yemen and Ethiopia post-date the flood basalts that they are derived from by $<1 \mathrm{Myr}$, indicating that the volumes of silicic magma required to feed supereruptions can be generated in $<10^{6}$ years (Baker et al., 1996, 2000; Ukstins Peate et al., 2005, 2007). In contrast, processes such as gravity settling of crystals and the formation of crystal mush bodies occur over timescales of $10^{4}-10^{5}$ years (Bachmann and Bergantz, 2004) and the modelling of fractional crystallisation of both basaltic and rhyolitic magmas in a $10 \mathrm{~km}^{3}$ magma chamber indicate $50 \%$ crystallisation could be achieved in $<3000$ years (Hawkesworth et al., 2000). In comparison, crustal anatexis instigated and driven by mantle-derived mafic melts occurs rapidly with the potential of forming large volumes of melts in relatively short time periods (e.g. $10^{2}-10^{3}$ years) (Bergantz, 1989; Huppert and Sparks. 1988). Thus, detailing the timescales of magmatic processes is fundamental to our understanding of the dynamics of magmatic systems and the prediction of future eruptions.

Some of the earliest investigations into the timescales of the formation of largevolume silicic magmas focused on the residence time of the $760 \mathrm{ka}$ intracontinental Bishop Tuff eruption (Halliday et al., 1989; Christensen and DePaolo, 1993; Christensen and Halliday, 1996). ${ }^{87} \mathrm{Rb}^{87} \mathrm{Sr}$ dating of mineral and glasses from the Bishop Tuff provided evidence for the gradual accumulation of 
a large magma body over a period of 1.7 Myr (Christensen and DePaolo, 1993). However, processes such as mixing could compromise these isochrons (e.g. Hawkesworth et al., 2003). With the advancement in micro-analytical techniques, geochemical analyses of samples could be conducted at even higher spatial resolutions. This allows individual growth zones of zircons to be dated and the longevity of magmas inferred (e.g. Reid et al., 1997; Brown and Fletcher, 1999; Bindeman et al., 2001; Charlier et al., 2005; Reid, 2008). Moreover, this improvement in analytical techniques allows elemental concentrations of zoned crystals to be documented at sufficient precision to allow chemical diffusion gradients between adjacent zones to be modelled, thus constraining the timescales of magmatic processes (Zellmer et al., 1999; Costa et al., 2003; Morgan et al., 2004; Reid, 2008).

If a crystal resides in a magma at a significantly high temperature then diffusion smoothes the compositional gradient between two adjacent crystal zones, homogenising the crystal composition (Figure 1.7). On eruption, the final diffusion profile is quenched into the crystal and if equilibrium has not been attained, the length of time the crystal resided at magmatic temperature can be modelled from Fick's second law, using the appropriate partition coefficients and diffusivities of elements (e.g. Crank, 1976; Blundy and Wood, 1991; Zellmer et al., 1999; Costa et al., 2003; Morgan et al., 2004; Turner and Costa, 2007). The rate of diffusion of elements can vary by over seven orders of magnitude at a given set of conditions (Costa et al., 2003). As a result, modelling of specific elements can provide insights into a range of magmatic processes over different timescales. For example Sr diffusion permits the residence times of plagioclase 
A)

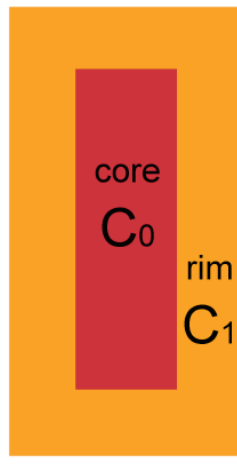

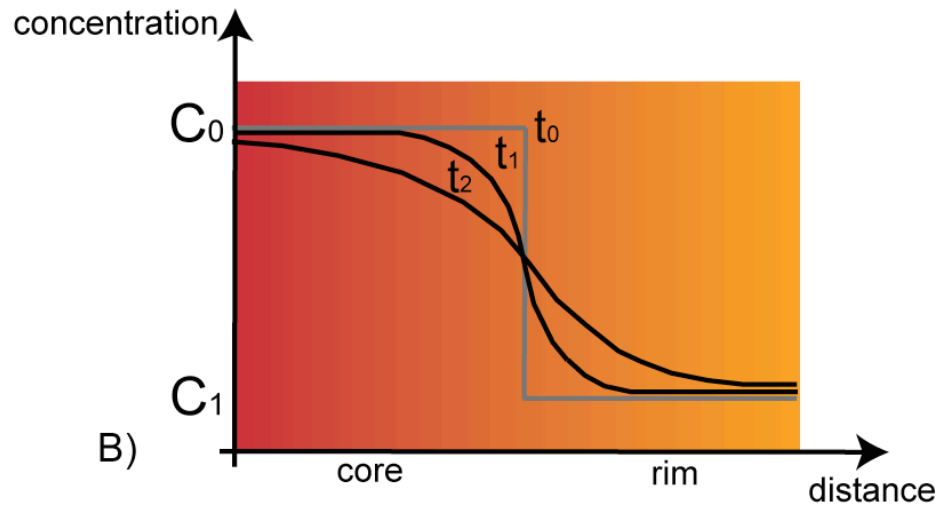

Figure 1.7. A) Cartoon of crystal zonation with an initial core concentration, $\mathrm{C}_{0}$, and initial rim concentration, $\mathrm{C}_{1}$. B) Evolution of the compositional gradient of the core-rim interface over time. Initially a step function is assumed at the rim $\left(\mathrm{t}_{0}\right)$ that is progressively smoothed through diffusion with time $\left(t_{1}\right.$ and $\left.t_{2}\right)$.

crystals in a magma chamber to be calculated whilst Li diffusion in plagioclase crystals can be used to infer the rate of vapour transfer (Zellmer et al., 1999; Kent et al., 2007). Diffusion studies are not restricted to a single crystal phase but can be used to detail magmatic processes in numerous crystals, potentially preserving a record of numerous magmatic processes and therefore, allowing a comprehensive history of the magmatic evolution from a single eruption to be deciphered.

\subsection{Geologic background}

\subsubsection{Taupo Volcanic Zone, North Island, New Zealand}

Arc volcanism is observed along the entire length of the Tonga-KermadecHikurangi convergent margin (Smith and Price, 2006). The hyper-productive Taupo Volcanic Zone is a $300 \mathrm{~km}$ long section of continental arc volcanism generated from the oblique westward subduction of the Pacific plate beneath the overlying Australian plate east of New Zealand (e.g. Stern, 1987; Wilson et al., 1995). 
Rhyolitic volcanism in the Taupo Volcanic Zone commenced at ca. 1.6 Ma in the Mangakino volcanic centre and continues to the present day at the active caldera centres of Taupo and Okataina (Figure 1.8; Houghton et al., 1995; Wilson et al., 1995). Currently, 20 to 30 known caldera-forming eruptions have been recognised originating from eight caldera centres (Figure 1.8), which have been identified through the presence of negative gravity anomalies (Wilson et al., 1984; Houghton et al., 1995; Wilson et al., 1995; Davy and Caldwell, 1998; Cole

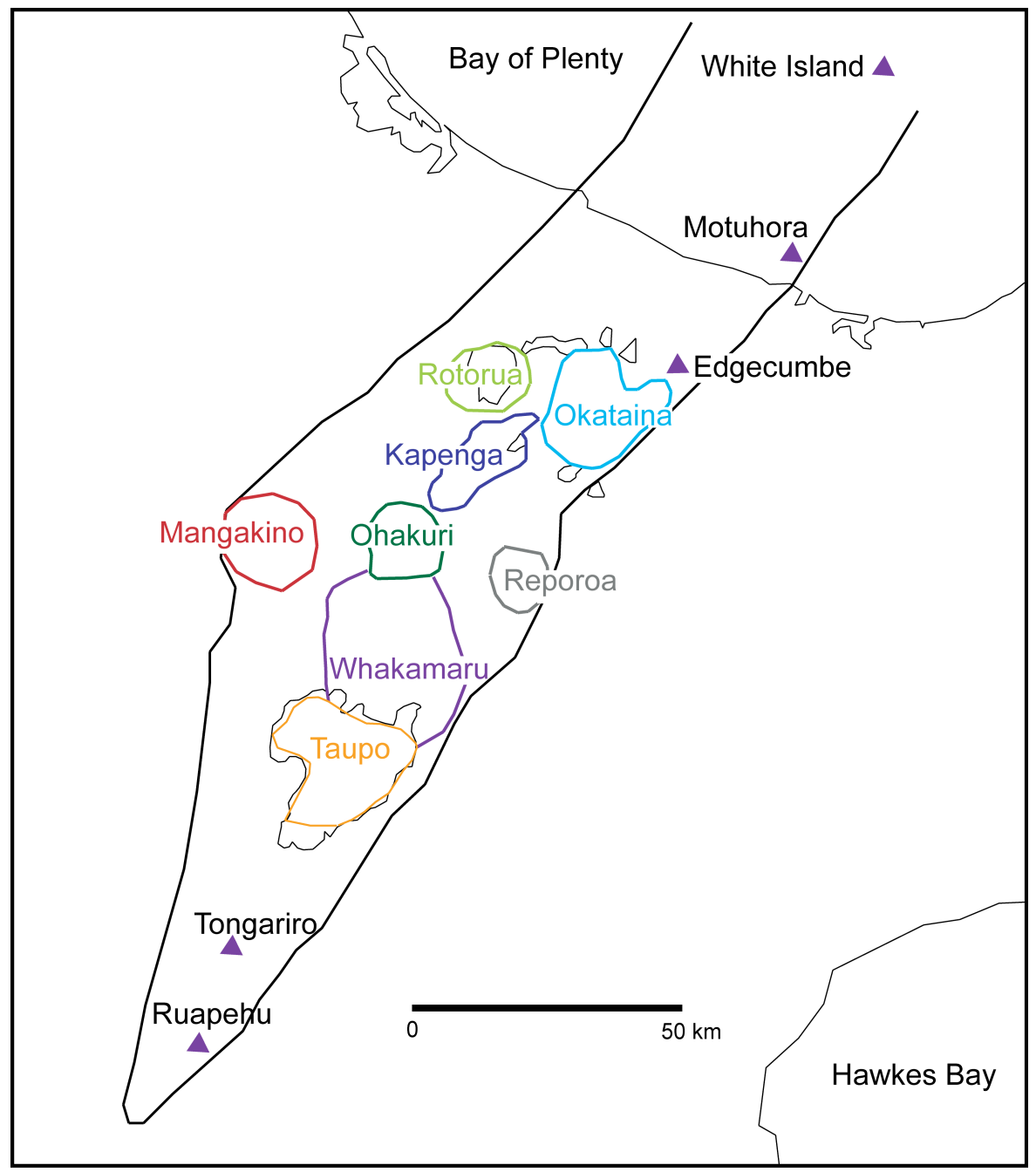

Figure 1.8 Caldera centres of the Taupo Volcanic Zone and major andesitic (purple triangles) centres after Cole et al. (1998) and Wilson et al. (in press). 
et al., 2001; Allan et al., 2008; Wilson et al., in press). Rhyolitic deposits in the Taupo Volcanic Zone are predominantly welded and non-welded ignimbrite and air fall deposits with only minor occurrences of lava flows.

There is a paucity of basaltic volcanic rock $(<1 \%)$ exposed at the surface in the Taupo Volcanic Zone compared to the copious quantities of rhyolite (ca. $94 \%$ ) (Gamble et al., 1990; Graham et al., 1995). Basalt outcrops as small monogenetic scoria cones typically aligned along fault zones (e.g. Rotokawau and Tarawera basalts) (Gamble et al., 1990; Graham et al., 1995). The basalts are porphyritic containing olivine, plagioclase \pm clinopyroxene and orthopyroxene phenocrysts, with groundmass glasses extending to rhyolitic compositions in the most evolved clinopyroxene-bearing basalts (Gamble et al., 1990). Chemical and isotopic signatures of the basalts indicate that they are derived from a subduction modified mantle source (Gamble et al., 1990, 1993; Graham et al., 1995).

Andesitic rocks form a relatively small component (5\%) of the exposed surface magmatism of the Taupo Volcanic Zone (Graham et al., 1995). Exposures are confined to the northern (White Island) and southern extremes (Mt. Ruapehu, Tongariro volcanic centre) of the region, but are also observed as lithics within ignimbrites (Brown et al., 1998b; Cole et al., 1998). Nine distinct crystal-rich andesite types have been petrologically defined from the Taupo Volcanic Zone, from rare low-silica (ca. $52 \mathrm{wt} \% \mathrm{SiO}_{2}$ ) olivine-rich lavas to high silica (ca. $64 \mathrm{wt}$ $\% \mathrm{SiO}_{2}$ ), almost dacitic plagioclase dominated samples (Graham et al., 1995). However, recent in-situ elemental and isotopic studies have demonstrated chemical disequilibrium between the crystal cargo and high-Si groundmass 
glasses of andesites (e.g. Price et al., 2005; Davidson et al., 2007) indicating a more complex magmatic evolution.

The extent and nature of the basement rock of the Taupo Volcanic Zone is equivocal but is of importance as the interaction of, in particular, basement greywacke with the magmatic systems can influence the composition of the magmas. The North Island of New Zealand is underlain by Mesozoic basement comprising a range of deposits from massive turbidites to interbedded sandstones, mudstones and argillites (hereafter termed greywacke), deposited in a deep-water environment (Reid, 1982; Mortimer, 2004). However, several previous studies have argued for the replacement of the greywacke basement with the intrusion of igneous compositions of andesite/diorite (e.g. Cole, 1981; Stern, 1987; Soengkono, 1995). This is partly due to the inability of seismic and gravity surveys to distinguish between greywacke basement and intermediate igneous compositions of andesite/diorite due to the similar densities of both lithologies (Ewart and Stipp, 1968; Stern, 1985, 1987). Recent magnetotelluric studies (Heise et al., 2007) and isotopic studies of zircon and plagioclase crystals (Charlier et al., 2005, 2008) have provided compelling evidence for the presence of underlying greywacke basement throughout the Taupo Volcanic Zone. This is further confirmed by the presence of greywacke in drill holes and the ubiquitous occurrence of greywacke xenoliths within ignimbrites throughout the region (Reid, 1982; Browne et al., 1992; Graham et al., 1992; Cole et al., 1998; Brown et al., 1998a) although the extent and nature of this greywacke basement beneath the Taupo Volcanic Zone remains equivocal. 


\subsubsection{Kermadec Arc, South West Pacific}

The $760 \mathrm{~km}$ long Kermadec Arc $\left(25^{\circ}-36^{\circ} 30^{\prime} \mathrm{S}\right)$ extends northwards from the northern boundary of the Taupo Volcanic Zone to the Tonga Arc (ca. $26^{\circ} \mathrm{S}$ ) in the north, and represents the oceanic section of the Tonga-Kermadec-Hikurangi subduction system (Wright et al., 2006). The predominantly submarine volcanic frontal arc is confined to a $40 \mathrm{~km}$ wide zone consistently located at $100 \mathrm{~km}$ above the subducting slab (Smith and Price, 2006) although arc volcanoes are also present in the back arc Havre Trough (Wysoczanski et al., in press). The Kermadec Arc has been sub-divided into three regions (southern, central, northern) based on changes in arc elevation and lava chemistry (Smith and Price, 2006; Wright et al., 2006) (Figure 1.5). The central Kermadec Arc is characterised by relatively simple stratovolcanoes at water depths $>3.2 \mathrm{~km}$ (Wright et al., 2006). In contrast, the southern and northern Kermadec Arc possess multi-vent volcanic edifices that include submarine calderas at water depths $<2.5 \mathrm{~km}$ (Wright et al., 2006). Volcanic centres are primarily composed of basalt and basaltic andesite ( $\sim 61 \%)$, and andesite $(\sim 9 \%)$ (Smith and Price, 2006). However, recent multibeam mapping and dredging along the Kermadec Arc has revealed the presence of substantial proportions of silicic volcanism $(\sim 30 \%)$ and submarine caldera structures (Wright and Gamble, 1999; Wright et al., 2002, 2006; Smith and Price, 2006). 


\subsection{Objectives of this thesis}

The objectives of this study are to investigate the petrogenesis of large-volume silicic arc magmas, contrasting the different mechanisms operating in both continental and oceanic arc margins. This is achieved through the application of in-situ micro-analytical techniques i.e. electron probe microanalysis (EPMA), laser ablation inductively coupled plasma mass spectrometry (LA-ICPMS) and Fourier transform infrared (FTIR) spectrometry applied to individual magma components of crystal-hosted melt inclusions, groundmass glass and crystals.

Melt inclusions are examined from a range of continental Taupo Volcanic Zone rhyolitic eruptions (330 ka Whakamaru supereruption, 26.5 ka Oruanui supereruption, 15.8 ka Rotorua eruptive and 1800 BP Taupo eruption) representing various age and eruptions sizes $\left(0.4\right.$ to $>1000 \mathrm{~km}^{3}$ DRE) and are compared to the chemical composition of the rhyodacite eruption from the Healy seamount, sourced from the adjacent oceanic Kermadec Arc (Frogatt, 1981; Wilson and Walker, 1985; Brown et al., 1998a; Smith et al., 2004; Wilson et al., 2006). The major and trace element compositions of melt inclusions can be used to: (1) investigate the heterogeneity of the magma during the fractionation of the various crystal phases within individual eruptions; (2) to distinguish source components of the eruptions and whether these change through time; (3) to discriminate between petrogenetic models of fractional crystallisation and crustal anatexis, and (4) to examine the contribution of continental crust in the Taupo Volcanic Zone rhyolites by taking the composition of the Healy melt inclusions as a baseline for silicic petrogenesis due to the absence of continental lithosphere along the Kermadec Arc. 
As water plays such a fundamental role in the genesis of silicic magmas and the subsequent eruption dynamics, dissolved $\mathrm{H}_{2} \mathrm{O}$ and $\mathrm{CO}_{2}$ concentrations of Whakamaru, Taupo and Healy melt inclusions were characterised. The objectives of this are to: (1) constrain the pre-eruptive $\mathrm{H}_{2} \mathrm{O}$ and $\mathrm{CO}_{2}$ concentrations directly prior to eruption, to establish the volatile content required to drive supereruptions; (2) document any heterogeneities in volatile concentrations of individual eruptions, between eruptions and particularly between continental and oceanic silicic eruptions; (3) estimate the depth of the magma immediately prior to eruption through the calculation of saturation pressures; and (4) examine the $\mathrm{H}_{2} \mathrm{O}$ speciation of silicic melt inclusions and contrast this to the known behaviour of water speciation in groundmass rhyolitic glasses.

The chemical composition of melt inclusions whilst providing important constraints on the magmatic evolution, provides only limited information on the timescales of magmatic processes. Therefore the chemical and textural zonation of plagioclase crystals from the Whakamaru, Taupo and Healy eruptions and quartz crystals from the Whakamaru eruption are investigated to: (1) document the changing magmatic conditions derived from the textural observations; (2) identify whether multiple crystal populations are present within each eruption; (3) fingerprint the chemical source of each individual zone of plagioclase crystals; (4) characterise the magmatic processes responsible for the chemical zonation of crystals; and (5) establish the timescales of magmatic processes from the diffusional relaxation of elements across major compositional interfaces. 


\subsection{Structure of this thesis}

Melt inclusions from both continental and oceanic silicic eruptions are firstly examined for major and trace element concentrations to contrast the petrogenesis of silicic magmas in each of these settings. The results of this study are presented in Chapter 2, which is a manuscript that has been submitted for consideration for publication to the Journal of Volcanology and Geothermal Research.

The majority of rhyolitic deposits observed in the Taupo Volcanic Zone are produced by highly explosive eruptions. Hence, the pre-eruptive volatile concentrations of magmas are explored through the investigation of water speciation of melt inclusions from the Whakamaru and Taupo ignimbrites and associated crystal lag deposits from the Taupo Volcanic Zone. The results of this study are presented in Chapter 3 as a draft manuscript to be submitted to Chemical Geology.

Chapter 4 addresses one of the fundamental questions remaining on the timescales of accumulation of large-volumes of eruptible magma and focuses on the 330 ka Whakamaru supereruption (Wilson et al., in press). A study of chemical zonation and diffusion modelling of plagioclase and quartz crystals attempts to constrain the timescales of magmatic processes prior to eruption. This chapter is presented as a draft manuscript to be submitted to Journal of Petrology.

Chapter 5 examines the major element zonation of Healy and Taupo plagioclase crystals and volatile concentrations of Healy melt inclusions. This data is allied with the chemical composition of melt inclusions (Chapter 2) and the insights 
this provides into the petrogenesis of silicic continental and oceanic arc magmas is discussed.

A synthesis of the findings of this thesis and major conclusions are presented and discussed in Chapter 6. Details of analytical methods not included in the chapters of this thesis, the theory behind diffusion modelling, data tables and backscattered and cathodoluminescence images can be found in Appendices $1-4$. 


\title{
Chapter 2
}

\section{Petrogenesis of large-volume silicic magma in continental arcs: melt inclusions in Taupo Volcanic Zone and Kermadec Arc rhyolites, South West Pacific.}

\begin{abstract}
Petrogenesis of large volume silicic magmas at continental arc margins is investigated through microanalysis of four major eruptives of variable size from the archetypical continental Taupo Volcanic Zone to determine if they are produced from assimilation and fractional crystallisation of mafic magmas or by crustal anatexis. We report major and trace element concentrations of melt inclusions from four continental (Whakamaru, Oruanui, Taupo and Rotorua) eruptive units, as well as one oceanic (Healy) eruptive unit from the contiguous Kermadec arc, which provides a baseline to evaluate the contribution of evolved crust to silicic magma petrogenesis in a continental arc setting. Orthopyroxene, plagioclase and quartz hosted melt inclusions and groundmass glass display a range in major element (e.g. $\mathrm{SiO}_{2}=74-79 \mathrm{wt} \%, \mathrm{CaO}=0.2-2.5 \mathrm{wt} \%$ and $\mathrm{FeO}$ $=0-3 \mathrm{wt} \%$ ) and trace element compositions (e.g. Sr $=17-180 \mathrm{ppm}$ and $\mathrm{Ba}=140-1500 \mathrm{ppm})$. Healy melt inclusions are lower in $\mathrm{K}_{2} \mathrm{O}$ and $\mathrm{Ce} / \mathrm{Yb}$ relative to Taupo Volcanic Zone melt inclusions reflecting the lack of continental lithosphere in the oceanic setting. Quantitative trace element modelling of Healy melt inclusions demonstrates that extensive fractional crystallisation (62 - 76\%) is responsible for the magma genesis of the rhyodacitic magma. However, assimilation is required in addition to extensive fractional crystallisation (60 $80 \%$ ) to attain the compositions of Taupo Volcanic Zone melt inclusions. High
\end{abstract}


$\mathrm{Rb} / \mathrm{Sr}$ ratios of melt inclusions compared to published pumice compositions from the same eruptions indicate some crystals were inherited from a more evolved rhyolitic melt that subsequently mixed with a local basement (greywacke) partial melt. These models indicate that assimilation and fractional crystallisation of mafic magmas with variable amounts of mixing with crustal partial melts are able to produce silicic magmas of all sizes in the Taupo Volcanic Zone and that models of pure crustal anatexis are not required.

\subsection{Introduction}

Continental arc margins are a dominant setting for silicic magmatism on Earth, with a growing recognition of the role of oceanic arcs in producing silicic magmas. Nonetheless the petrogenesis of silicic magmas in continental and oceanic arcs is controversial with two end-member models invoked: (1) fractional crystallisation from a basaltic parent (e.g. Graham et al., 1995; Pearce et al., 1995; Grove et al., 2003; Hasse et al., 2006); and (2) crustal anatexis of amphibolitic or tonalitic lower crust, and/or continental or oceanic crust where present (e.g. Borg and Clynne, 1998; Kawate and Arima, 1998; Tamura and Tatsumi, 2002; Smith et al., 2003a and b; Shukuno et al., 2006; Smith et al., 2006; Wysoczanski and Tani, 2006). At continental margins magma storage is commonly characterised by complex plumbing systems allowing for polybaric crystal fractionation and ample opportunity for the recycling of crystals, magma mixing and assimilation of continental crust. This has led to diverse models of silicic magma genesis that include assimilation and fractional crystallisation (AFC) and magma mixing in addition to the end-member fractionation and crustal anatexis models proposed above (Ewart and Stipp, 1968; Graham et al., 
1992; McCulloch et al., 1994; Price et al., 2005; Davidson et al., 2007; Price et al., 2007). Differences in compositions of magmas in oceanic and continental arcs suggest that different magma genesis processes dominate in each of these settings, as large-volume silicic eruptions are a characteristic feature of continental subduction zones whereas basaltic and basaltic andesitic volcanism dominates in oceanic subduction settings (Gamble et al., 1996; Tamura and Wysoczanski, 2006; Wright et al., 2006). There is, however, increasing evidence for voluminous silicic volcanoes and caldera-forming eruptions in oceanic arcs such as New Britain Island Arc, Kermadec Arc, South Sandwich Arc and IzuBonin Arc (e.g. Woodhead et al., 1998; Wright and Gamble, 1999; Tamura and Tatsumi, 2002; Leat et al., 2003; Shukuno et al., 2006; Wright et al., 2006) suggesting that magma petrogenesis may not be substantially different in oceanic and continental arcs.

The Taupo Volcanic Zone of New Zealand and the Kermadec Arc (Figure 2.1) are archetypal examples of continental and oceanic arcs that typify the contentious nature of silicic magma petrogenesis. In the Kermadec arc, both fractional crystallisation and crustal anatexis have recently been proposed as mechanisms for the generation of silicic volcanoes (e.g. Haase et al., (2006) for Brothers Volcano and Smith et al. (2006) for Raoul Volcano, respectively), whilst a host of AFC and crustal melting models have been invoked for the origin of continental Taupo Volcanic Zone silicic magmas (McCulloch et al., 1994; Graham et al., 1995; Charlier et al., 2005: Wilson et al., 2006; Price et al., 2007). Geophysical studies are unable to distinguish between fractionation and anatexis 


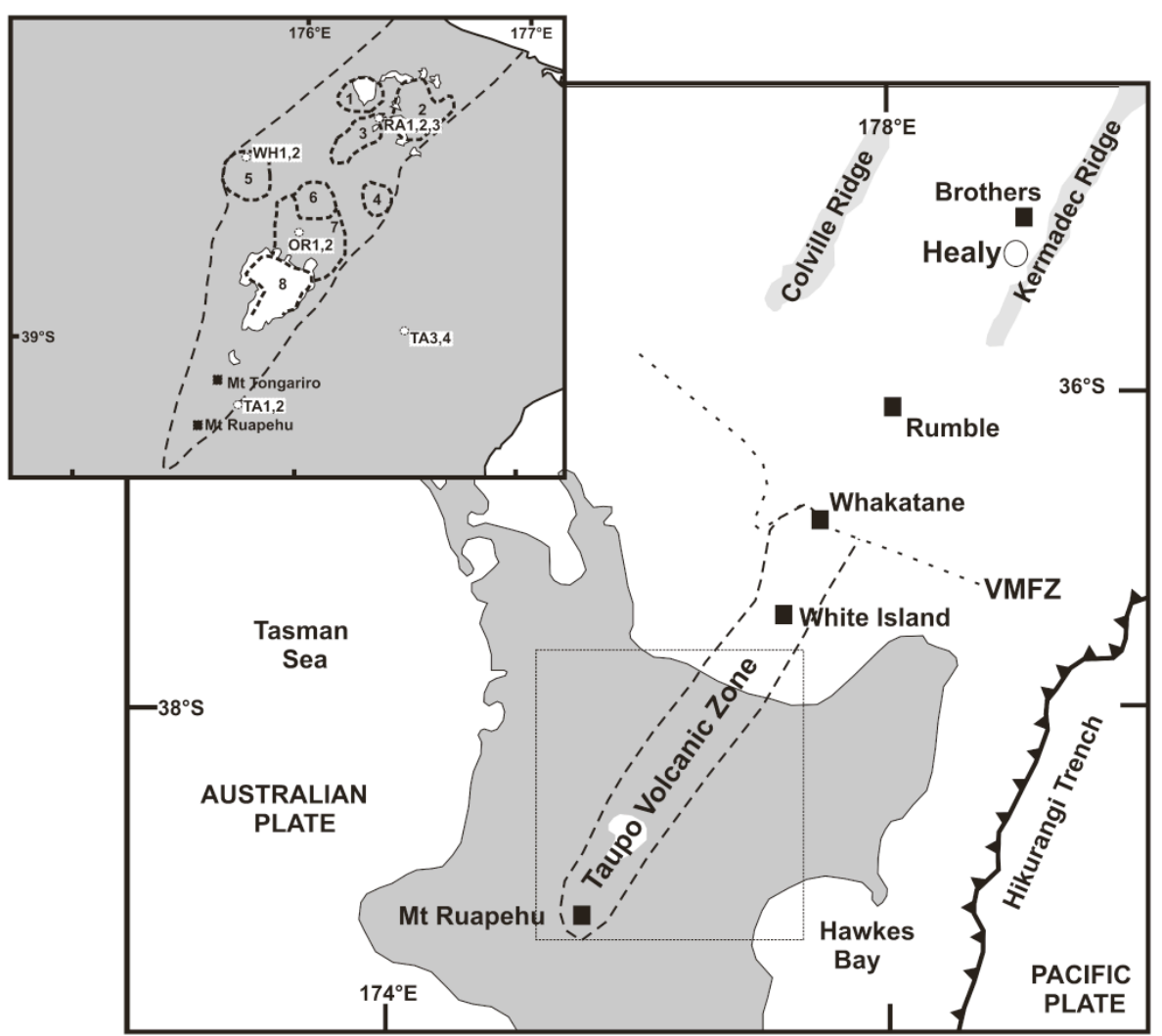

Figure 2.1. Map of Taupo Volcanic Zone and southern Kermadec arc with sample locations (white circles) shown in relation to the known caldera complexes of the Taupo Volcanic Zone. Outline of the Taupo Volcanic Zone - thick dashed line; continental-oceanic crust transition - thin dotted line, from Macpherson et al. (1998). Caldera complexes from Cole et al. (2001): $1=$ Rotorua; 2 = Okataina; 3 = Kapenga; 4 = Reporoa; 5 = Mangakino; 6 = Maroa; $7=$ Whakamaru; $8=$ Taupo.

models. Until recently, limited geophysical evidence for the crustal structure of the Taupo Volcanic Zone has provided little evidence for mafic cumulates in the mid-lower crust fuelling the arguments for crustal anatexis models. However, melting experiments have shown that complete melting of lower crustal rocks would not occur and that crustal anatexis models also require an extensive restite to be present within the crust (Beard and Lofgren, 1991; Wolf and Wyllie, 1994; Rapp and Watson, 1995). Recent seismic surveys of the Taupo Volcanic Zone (Harrison and White, 2006; Stratford and Stern 2006) appear to image a layer of 
intruded or underplated material at the base of the crust beneath the Taupo Volcanic Zone that may be sufficient to account for the cumulative or restite component required by either petrogenetic model.

Distinguishing between the models is complicated as both fractional crystallisation and crustal anatexis produce similar major element compositions (Haase et al., 2006). In continental arcs, assimilation of even small quantities of evolved crust will mask any primary geochemical signature of the melt. This is further complicated by whole rock analysis of silicic pyroclastic rocks, which are composed of a mixture of juvenile, lithic and inherited material (e.g. Brown et al., 1998b; Cole et al., 1998), resulting in average rock compositions rather than liquid compositions of the magma, making source contributions difficult to unravel.

An alternative to analysing bulk rock compositions is to analyse direct samples of trapped melts. As crystals grow during the life cycle of magmatic bodies they incorporate small (typically $<100 \mu \mathrm{m}$ ) pockets of melt that remain trapped within the crystal, and which on eruption are quenched to glass (Roedder, 1979; Sobolev, 1996; Danyushevsky et al., 2002). As these melt inclusions reflect direct samples of the crystallising magma they allow the chemistry of multiple magma sources to be constrained. This has the potential to distinguish between the various models for the origin of silicic magmas in both oceanic and continental arc settings. Published studies of melt inclusions in silicic rocks, however, are limited, with very few studies on Kermadec Arc - Taupo Volcanic 
Zone samples (Dunbar and Kyle, 1993; Schmitz and Smith, 2004; Liu et al., 2006; Shane et al., 2008).

Here we present in situ microanalyses of major and trace elements in melt inclusions from four Taupo Volcanic Zone silicic eruptives of varying size and age (Whakamaru, Oruanui, Rotorua and Taupo) to distinguish source components in large-scale silicic eruptives and distinguish between varying petrogenetic models. We also present data from melt inclusions from one rhyodacitic caldera from the Kermadec Arc (Healy caldera) as oceanic silicic magmas are generated without the potential for contributions from continental crust, allowing a baseline from which to examine the contribution of continental crust in magma genesis in continental arcs. Trace element modelling of the results requires only extensive fractional crystallisation from a basaltic parent to produce the oceanic arc rhyodacite at Healy caldera, whereas the presence of silicic crust in the continental Taupo Volcanic Zone has resulted in both assimilation and partial melting of continental crust in addition to extensive fractional crystallisation. None of the sampled eruptive products can be produced purely by crustal anatexis.

\subsection{Regional background and samples}

Taupo Volcanic Zone is the most active site of silicic magmatism on Earth, having produced more than $15000 \mathrm{~km}^{3}$ of material in the last 1.6 million years (Wilson et al., 1995). Volcanism is dominantly rhyolitic (>97\%), with small volumes of andesitic (2-3\%) and minor dacitic and basaltic volcanism (Cole, 1979; Wilson et al., 1984). Andesitic and basaltic lithics are present in many 
ignimbrite deposits (e.g. Cole et al., 1998; Wilson et al., 2006) suggesting that andesite volcanics underlie and predate the main silicic deposits throughout the Taupo Volcanic Zone. Silicic volcanism in the Taupo Volcanic Zone commenced from the Mangakino caldera (Figure 2.1) and has continued to the present day from eight recognised caldera centres (Wilson et al., 1995), although the large Whakamaru Group ignimbrite sheets erupted since ca. 340 ka cover much of the evidence of earlier eruptive periods (Graham et al., 1995; Wilson et al., 1995; Brown et al., 1998a). Only two of the eight calderas (Taupo and Okataina) are considered to be active. Samples were chosen to represent eruptions of varying volumes $\left(0.4\right.$ to $>1000 \mathrm{~km}^{3}$ dense rock equivalent (DRE)) and age (Table 2.1).

Whakamaru Group ignimbrites are the most voluminous known ignimbrites of the Taupo Volcanic Zone; with volumes exceeding $1000 \mathrm{~km}^{3}$ of magma erupted following a ca. $350 \mathrm{ka}$ lull in caldera-forming activity in the Taupo Volcanic Zone (Wilson et al., 1986; Brown et al., 1998a). The Whakamaru ignimbrite, which is the largest ignimbrite of the Whakamaru Group, has a mineral assemblage consisting of large, resorbed quartz, plagioclase, orthopyroxene and amphibole with smaller amounts of ilmenite, magnetite, K-feldspar and biotite (Brown et al., 1998a). A characteristic, but discontinuous crystal lag at the base of the ignimbrite (Brown, 1994) was sampled as part of this study (WH1), with a second sample (WH2) collected midway through the ignimbrite (from 'layer E' of Briggs, 1976). 


\begin{tabular}{|c|c|c|c|c|c|c|c|}
\hline Eruption & $\begin{array}{l}\text { Latitude } \\
\quad\left({ }^{\circ} \mathrm{S}\right)\end{array}$ & $\begin{array}{l}\text { Longitude } \\
\left({ }^{\circ} \mathbf{E}\right)\end{array}$ & $\begin{array}{l}\text { Age } \\
\text { (ka) }\end{array}$ & $\begin{array}{l}\text { Volume } \\
\text { DRE } \\
\left(\mathbf{k m}^{3}\right)\end{array}$ & $\begin{array}{c}\text { Magma } \\
\text { Temperature } \\
\left({ }^{\circ} \mathrm{C}\right)\end{array}$ & $\begin{array}{l}\text { Crystal } \\
\text { content }\end{array}$ & Mineral phases \\
\hline Whakamaru & & & 340 & $>1000$ & $750-850$ & & \\
\hline WH1 - crystal lag & $38^{\circ} 21.005^{\prime}$ & $175^{\circ} 42.037^{\prime}$ & & & (Fe-Ti oxides) & $50 \%$ & plag $>$ qtz $>$ op $x>$ amp $>$ bt $>$ oxides \\
\hline WH2 & $38^{\circ} 20.849^{\prime}$ & $175^{\circ} 44.026^{\prime}$ & & & & $30 \%$ & plag $>$ qtz $>$ op $x>$ oxides \\
\hline Oruanui & & & 26.5 & 530 & 760 & & \\
\hline OR1 (pumice) & $38^{\circ} 35.840^{\prime}$ & $175^{\circ} 58.685^{\prime}$ & & & (Fe-Ti oxides) & $3 \%$ & plag $>$ qtz $>$ op $x>$ oxides \\
\hline OR2 (matrix) & $38^{\circ} 35.840^{\prime}$ & $175^{\circ} 58.685^{\prime}$ & & & & $10 \%$ & plag $>$ qtz $>$ op $x>$ oxides \\
\hline Rotorua Eruptive & & & 15.8 & 1 & $750-870$ & & \\
\hline RA1 & $38^{\circ} 10.338^{\prime}$ & $176^{\circ} 19.765^{\prime}$ & & & (Fe-Ti oxides) & $5 \%$ & plag $>$ op $x>$ amp $>$ qtz $>$ bt $>$ oxides \\
\hline RA2 & $38^{\circ} 10.327^{\prime}$ & $176^{\circ} 19.716^{\prime}$ & & & & $5 \%$ & plag $>$ qtz $>$ op $x>$ amp $>$ bt $>$ oxides \\
\hline RA3 & $38^{\circ} 10.338^{\prime}$ & $176^{\circ} 19.765^{\prime}$ & & & & $15 \%$ & plag $>$ qtz $>$ opx $>$ bt \\
\hline Taupo & & & 1.8 & 35 & $850-870$ & & \\
\hline TA1 - crystal lag & $39^{\circ} 13.092^{\prime}$ & $175^{\circ} 44.115^{\prime}$ & & & (Fe-Ti oxides) & $50 \%$ & plag $>$ op $x>$ qtz $>$ oxides \\
\hline TA2 - Taupo ignimbrite & $39^{\circ} 13.092^{\prime}$ & $175^{\circ} 44.115^{\prime}$ & & & & $2 \%$ & plag $>$ op $x>$ qtz $>$ oxides \\
\hline TA3 - Taupo Plinian & $38^{\circ} 55.772^{\prime}$ & $176^{\circ} 29.255^{\prime}$ & & & & $1 \%$ & plag $>$ op $x>$ oxides \\
\hline TA4 - Hatepe Plinian & $38^{\circ} 55.772^{\prime}$ & $176^{\circ} 29.255^{\prime}$ & & & & $5 \%$ & plag $>$ oxides $>$ op $x>$ qtz \\
\hline Healy & & & 0.59 & 5 & 950 & & \\
\hline X590 - caldera floor & $34^{\circ} 59.249^{\prime}$ & $178^{\circ} 59.573^{\prime}$ & & & (2-pyroxene) & $3 \%$ & plag $>$ op $x>$ oxides \\
\hline X590/B - caldera floor & $34^{\circ} 59.249^{\prime}$ & $178^{\circ} 59.573^{\prime}$ & & & & $3 \%$ & plag $>$ op $x>$ oxides $>$ amp \\
\hline X609 - north flank & $34^{\circ} 57.490^{\prime}$ & $179^{\circ} 00.522^{\prime}$ & & & & $5 \%$ & plag $>$ op $x>$ oxides $>$ amp \\
\hline
\end{tabular}

Table 2.1. Details of samples analysed in this study. Abbreviations used are: plag = plagioclase; opx = orthopyroxene; oxides $=$ Fe-Ti oxides; qtz $=$ quartz; amp = amphibole; bt = biotite; and DRE = dense rock equivalent. Whakamaru data from Brown et al. (1998a); Oruanui from Charlier et al. (2005) and Wilson et al. (2006); Rotorua eruption from Smith et al. (2004); Taupo from Wilson and Walker (1985), Wilson et al. (2006); and Healy from Wright and Gamble (1999) and Wright et al. (2003). 
The youngest caldera forming eruption of the Taupo Volcanic Zone was the $26.5 \mathrm{ka}$ Oruanui eruption $\left(\sim 530 \mathrm{~km}^{3}\right)$, which formed the caldera of Taupo volcano. The eruption occurred in ten phases over several months (Wilson, 2001; Wilson et al., 2006), with each phase consisting of both pyroclastic fall and flow deposits. The volume of eruptives increased with each successive phase, with the final phase producing half of the total volume. Rhyolite erupted during the initial and final stages of the eruption are indistinguishable in composition suggesting the presence of a large volume $\left(>100 \mathrm{~km}^{3}\right.$ ) weakly zoned magma body prior to eruption (Sutton et al., 1995). Most of the erupted material was rhyolitic pumice, although a small amount $(<1 \%)$ of juvenile basalt-andesitic material was also involved (Wilson, 2001). The pumices contain 3-13\% crystals consisting of the assemblage plagioclase + orthopyroxene + quartz + hornblende + magnetite + ilmenite, with apatite and zircon as accessory minerals (Wilson et al., 2006). Pumice clasts (OR1) and the ash matrix (OR2) from poorly sorted Oruanui Ignimbrite were collected and analysed separately.

Numerous small silicic eruptions followed the Oruanui eruption, reflecting the rapid reorganisation of the magmatic system beneath Taupo volcano (Sutton et al., 1995; Wilson et al., 2006; Charlier et al., 2008). Post-Oruanui magmatism included initial dacitic volcanism followed by the eruption of three distinct rhyolitic magmas (Sutton et al., 1995). The largest of these, and the largest eruption in historic times, is the ca. $1800 \mathrm{BP}$ (Wilson and Walker, 1985) Taupo eruption. 
The Taupo eruption occurred in six distinctive episodes, which in stratigraphic order are: Initial ash $\left(0.015 \mathrm{~km}^{3}\right)$; Hatepe Plinian $\left(6 \mathrm{~km}^{3}\right)$; Hatepe Ash $\left(2.5 \mathrm{~km}^{3}\right)$; Rotongaio Ash $\left(1.3 \mathrm{~km}^{3}\right)$; Taupo Plinian $\left(24.5 \mathrm{~km}^{3}\right)$; and the youngest and most voluminous unit, Taupo Ignimbrite $\left(31 \mathrm{~km}^{3}\right)$ (Froggatt, 1981; Wilson and Walker, 1985). The total erupted volume, which includes re-worked material and primary material beneath Lake Taupo, is estimated at $>105 \mathrm{~km}^{3}$ covering an area of ca. $20000 \mathrm{~km}^{2}$ (Wilson and Walker, 1985). Samples analysed here were collected from crystal rich lenses at the base of the Taupo Ignimbrite (TA1), and pumice from the Taupo Ignimbrite (TA2), Taupo Plinian (TA3) and Hatepe Plinian (TA4). The crystal assemblage consists of plagioclase + orthopyroxene + quartz + ilmenite + magnetite.

Okataina Caldera is the only caldera other than Taupo volcano to produce extensive silicic magmatism since the $26.5 \mathrm{ka}$ Oruanui eruption (Wilson et al., 1995). The smallest (but well preserved) of the nine post-Oruanui eruptive episodes from the Okataina Volcanic centre is the Rotorua eruption at $15.8 \mathrm{ka}$ (Froggatt and Lowe, 1990). The eruption consisted of plinian pumice fall deposits with a minimum volume of $>0.4 \mathrm{~km}^{3}$ DRE (Kilgour, 2002) and late-stage lava domes (Nairn, 1980; Smith et al., 2004). The plinian fall deposits consist of interlayered pumice and fine ash layers (typically 5-10 cm) interpreted to reflect rain-washing or phreatomagmatic activity (Smith et al., 2004). The crystal assemblage is diverse, consisting of plagioclase, quartz, orthopyroxene, hornblende, clinopyroxene, biotite and oxides. Three samples of the Rotorua eruption were collected from Okareka 
Quarry: RA5 and RA6 are pumice from two different beds within the sequence and RA7 is from a crystal rich lens.

Subduction volcanism continues north of the Taupo Volcanic Zone along the length of the Kermadec Arc - Havre Trough where oceanic lithosphere overlies the subducting slab (Smith and Price, 2006). The transition from continental to oceanic arc occurs to the north of the Whakatane and Colville Knolls (Figure 2.1) where an abrupt NW-SE trending deep indenter, the Vening Meinesz Fracture Zone, cuts perpendicular to the arc (Wright, 1994; Smith and Price, 2006). Rates of subduction in the southern Kermadec Arc are approximately $6 \mathrm{~cm} / \mathrm{yr}$, increasing to $10 \mathrm{~cm} / \mathrm{yr}$ in the north towards Tonga (Parson and Wright, 1996; Smith and Price, 2006). Magmatism in both the arc and backarc is dominantly basaltic-andesite although silicic calderas have recently been discovered, mapped and sampled along the frontal arc (e.g. Gamble et al., 1996; Wright et al., 2006; Wysoczanski et al., 2006).

Healy volcano is a recently discovered young composite volcanic complex consisting of a basaltic-andesitic stratovolcano and silicic caldera complex located on over-thicken oceanic crust (Wright et al., 2006). The volcano is approximately $15 \mathrm{~km}$ long and $7 \mathrm{~km}$ wide with a water depth of $1150 \mathrm{~m}$ at the summit. A flat ca. $2.5 \mathrm{~km}$ wide caldera floor is flanked by $200-400 \mathrm{~m}$ high, shallowly inclined walls covered in well-sorted blocks and lapilli. A large proportion of samples recovered from this site, including two samples analysed here (X590 and X609) are rhyodacitic pumiceous clasts that 
represent some of the most silicic compositions recovered from the southern Kermadec Arc (Wright and Gamble, 1999; Wright et al., 2003).

\subsection{Methods}

\subsubsection{Sample preparation}

Blocks of pumice were coarsely crushed using a mortar and pestle, then dry sieved to extract material finer than $1 \mathrm{~mm}$. Fine glass was floated off in water and the remaining material was dried for 12 - 24 hours at $40{ }^{\circ} \mathrm{C}$. Crystal lag deposits were sieved, washed and dried. All samples were further sieved into $1 \mathrm{~mm}-710 \mu \mathrm{m}, 710-500 \mu \mathrm{m}$ and $<500 \mu \mathrm{m}$ fractions. For the majority of samples, the $1 \mathrm{~mm}-710 \mu \mathrm{m}$ fraction was further processed, and for crystal poor samples (e.g. OR1) the $710-500 \mu \mathrm{m}$ fraction was also further processed. Quartz and feldspar were magnetically separated and quartz, plagioclase and orthopyroxene crystals were hand picked under a binocular microscope to obtain crystals containing the largest and least crystallised melt inclusions (melt inclusions with few if any daughter crystals).

Melt inclusions were present in quartz, plagioclase and/or orthopyroxene crystals from the analysed samples. The inclusions are spherical to ellipsoidal in shape and range in size from $10 \mu \mathrm{m}$ to $>300 \mu \mathrm{m}$, the majority being $30-100 \mu \mathrm{m}$ in size (Figure 2.2). Orthopyroxene crystals contain multiple small melt $(10-50 \mu \mathrm{m})$, ilmenite, magnetite and apatite inclusions hosted throughout the crystal (Figure 2.2). Plagioclase and quartz hosted 
melt inclusions are generally larger $(50-100 \mu \mathrm{m})$ and, in some instances, contain a vapour bubble. Plagioclase hosted melt inclusions sometimes occur in an inner rim around the crystal and may represent a period of resorbtion or a slow growth period of the crystal (Figure 2.2). The melt inclusions are brown in colour except for the Whakamaru samples where the majority of melt inclusions are light green, similar to those observed in quartz and feldspars crystals from peralkaline rhyolites from Mayor Island in the northern Taupo Volcanic Zone (Barclay et al., 1996). Matrix glass adhered to the exterior of crystals was also analysed where present.
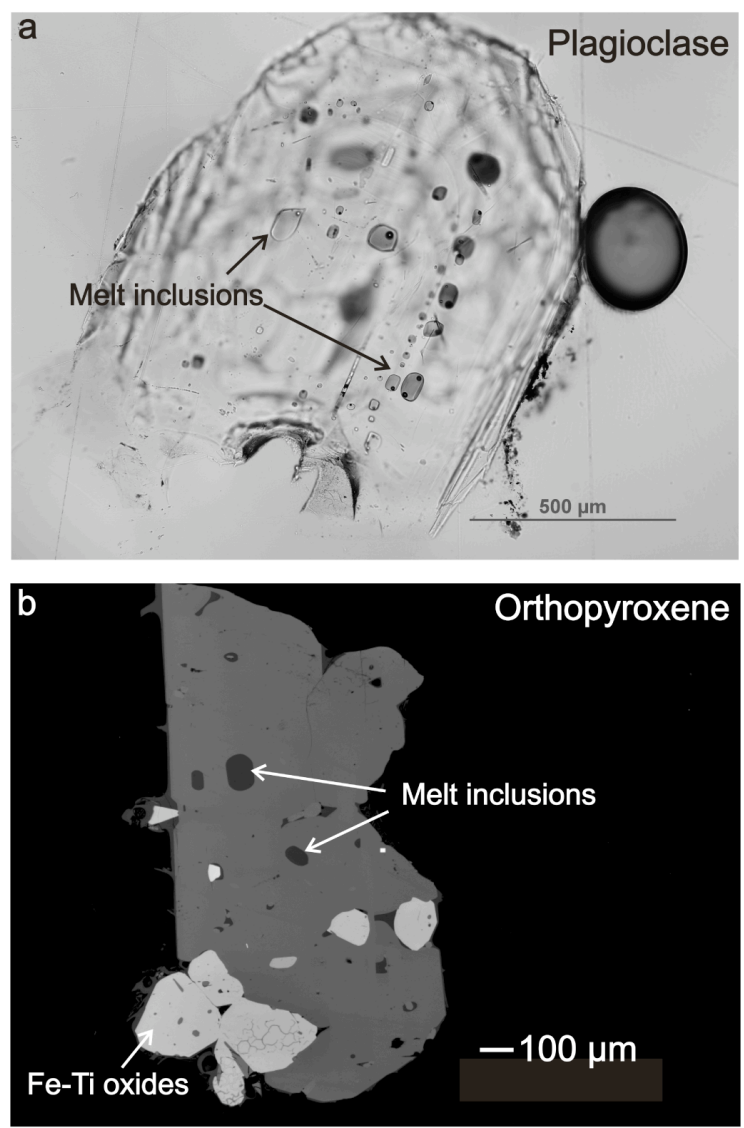

Figure 2.2. a) Transmitted light photomicrograph of melt inclusions in a plagioclase crystal from Taupo Ignimbrite. Small vapour bubbles are observed in some melt inclusions. b) Backscattered electron image of melt inclusions in an orthopyroxene crystal from Taupo Ignimbrite. 
Melt inclusions were exposed for analysis by placing a single crystal in crystal bond cement on a glass slide and then grinding using 600 and 2400 grit $\mathrm{SiC}$ paper, until the inclusion became exposed. Multiple crystals containing exposed melt inclusions were then removed and washed in acetone to remove crystal bond, mounted in epoxy blocks and finely polished using 3 micron and $1 / 4$ micron diamond paste.

\subsubsection{Electron microprobe analyses}

Most major element analyses were determined on a JEOL 733 SuperProbe electron probe microanalyser (EPMA) at Victoria University of Wellington. A subset of Healy inclusions were analysed at the Institute for Research on Earth Evolution, Japan Agency for Marine-Earth Science and Technology. Operating conditions were $15 \mathrm{kV}$ and $8 \mathrm{nA}$, with a $10 \mu \mathrm{m}$ defocused beam. $\mathrm{Na}$ and $\mathrm{K}$ were analysed first with a short count time to minimise volatile loss and ZAF corrections were applied.

\begin{tabular}{lccccc}
\hline & $\begin{array}{c}\text { Average } \\
n=5\end{array}$ & $2 \mathrm{~S} \mathrm{D}$ & \% 2 S D & \% difference & $\begin{array}{c}\text { Reference } \\
\text { values }\end{array}$ \\
\hline $\mathrm{SiO}_{2}$ & 50.91 & 0.45 & 0.9 & 0.2 & 50.81 \\
$\mathrm{TiO}_{2}$ & 1.83 & 0.14 & 7.6 & -0.9 & 1.85 \\
$\mathrm{Al}_{2} \mathrm{O}_{3}$ & 14.02 & 0.17 & 1.2 & -0.3 & 14.06 \\
$\mathrm{FeO}$ & 11.71 & 0.48 & 4.1 & -1.1 & 11.84 \\
$\mathrm{MnO}$ & 0.25 & 0.12 & 42 & 12 & 0.22 \\
$\mathrm{MgO}$ & 7.20 & 0.17 & 2.3 & 7.3 & 6.71 \\
$\mathrm{CaO}$ & 10.85 & 0.27 & 2.5 & -2.5 & 11.12 \\
$\mathrm{Na} 2$ & 2.69 & 0.33 & 12.3 & 2.5 & 2.62 \\
$\mathrm{~K}_{2} \mathrm{O}$ & 0.21 & 0.05 & 24.7 & 8.5 & 0.19 \\
$\mathrm{Cl}^{\#}$ & 1.22 & 0.04 & 3.5 & -15 & 1.43 \\
$\mathrm{SO}_{3}{ }^{\#}$ & 1.32 & 0.41 & 31 & -0.04 & 1.32 \\
$\mathrm{Total}^{1}$ & 99.67 & & & & \\
\hline
\end{tabular}

Table 2.2. Standard calibrations and reference values for VG2 and scapolite for electron probe microanalysis. Reference values taken from Jarosewich et al. (1980). ${ }^{1}$ Total for VG2 only, ${ }^{\text {\# } V a l u e s ~ a r e ~ f o r ~ s c a p o l i t e ~}$ 
Primary calibrations used a mixture of natural and synthetic standards, and VG2 glass and scapolite (Jarosewich et al., 1980) were analysed as secondary standards at the beginning and end of each session to monitor instrumental drift (Table 2.2). Normalisation of data to VG2 and scapolite allows comparison of the data from the two laboratories.

\subsubsection{Laser ablation inductively coupled plasma mass spectrometry}

Trace element concentrations were determined by laser ablation inductively coupled plasma mass spectrometry (LA-ICP-MS) in the Geochemistry Laboratory of Victoria University of Wellington using a NewWave deep UV laser (193 nm solid state) coupled to an Agilent 7500cs ICP-MS with helium as the ablation gas. Samples were analysed using $35 \mu \mathrm{m}$ or $20 \mu \mathrm{m}$ laser spot diameters, a laser repetition rate of $5 \mathrm{~Hz}$ and $60 \%$ power. $\mathrm{CaO}$ was determined by EPMA prior to LA-ICP-MS analysis enabling ${ }^{43} \mathrm{Ca}$ to be used as an internal calibration. NIST 612 glass was used as the primary standard as it provides an excellent matrix match for rhyolitic samples (Baker and Wysoczanski, unpublished data). Prior to each run the MPIDING rhyolitic glass ATHO-G was analysed. Average trace element data obtained for ATHO-G is shown in Table 2.3 along with the reproducibly and recommended reference values (Jochum et al., 2006; GeoRem http://georem.mpch-mainz.gwdg.de/). Full LA-ICP-MS analytical procedures are documented by Allan et al. (2008). 


\begin{tabular}{|c|c|c|c|c|c|c|c|c|}
\hline Sample ID & $\begin{array}{l}\text { WH1 } \\
24-1.1\end{array}$ & $\begin{array}{l}\text { WH1 } \\
39-1.1\end{array}$ & $\begin{array}{l}\text { OR1- } \\
12-1.1\end{array}$ & $\begin{array}{c}\text { OR1 } \\
17-1\end{array}$ & $\begin{array}{c}\text { OR1_- } \\
16.1\end{array}$ & $\begin{array}{l}\mathrm{TA}_{-} \\
41-4\end{array}$ & $\begin{array}{l}\text { TA1 } \\
29-1\end{array}$ & $\begin{array}{l}\mathrm{RA}-1 \\
5-1.1\end{array}$ \\
\hline Host Phase & opx & $\mathrm{qtz}$ & opx & plag & $\mathrm{qtz}$ & opx & plag & opx \\
\hline $\mathrm{SiO}_{2}(\mathrm{wt} \%)$ & 77.96 & 76.51 & 78.62 & 78.52 & 78.15 & 75.76 & 76.39 & 77.24 \\
\hline $\mathrm{TiO}_{2}$ & 0.10 & 0.08 & 0.21 & 0.12 & 0.19 & 0.29 & 0.23 & 0.29 \\
\hline $\mathrm{Al}_{2} \mathrm{O}_{3}$ & 12.45 & 13.18 & 12.25 & 12.56 & 12.74 & 13.37 & 13.55 & 13.91 \\
\hline $\mathrm{FeO}$ & 0.51 & 0.24 & 1.67 & 1.39 & 1.21 & 2.62 & 1.95 & 1.89 \\
\hline $\mathrm{MnO}$ & 0.15 & 0.20 & 0.07 & 0.03 & 0.11 & 0.13 & 0.18 & 0.13 \\
\hline $\mathrm{MgO}$ & 0.04 & 0.04 & 0.17 & 0.15 & 0.16 & 0.28 & 0.25 & 0.25 \\
\hline $\mathrm{CaO}$ & 0.37 & 0.61 & 0.86 & 1.27 & 1.17 & 1.57 & 1.59 & 1.38 \\
\hline $\mathrm{Na}_{2} \mathrm{O}$ & 3.42 & 3.84 & 2.50 & 2.92 & 2.88 & 3.11 & 2.84 & 2.51 \\
\hline $\mathrm{K}_{2} \mathrm{O}$ & 3.77 & 4.98 & 3.29 & 2.59 & 2.77 & 2.48 & 2.82 & 2.20 \\
\hline $\mathrm{Cl}$ & 0.18 & 0.20 & 0.21 & 0.23 & 0.22 & 0.17 & 0.17 & 0.16 \\
\hline $\mathrm{SO}_{3}$ & 0.06 & 0.10 & 0.05 & 0.19 & 0.13 & 0.21 & 0.04 & 0.04 \\
\hline Total & 100.00 & 100.00 & 100.00 & 100.00 & 100.00 & 100.00 & 100.00 & 100.00 \\
\hline $\mathrm{Sc}(\mathrm{ppm})$ & 5.64 & 8.35 & 9.06 & 10.0 & 11.3 & 31.8 & 17.2 & 11.2 \\
\hline $\mathrm{V}$ & 3.65 & 2.28 & 2.62 & 1.96 & 1.81 & 2.09 & 0.987 & 6.28 \\
\hline $\mathrm{Cr}$ & 4.34 & 11.4 & 14.9 & 4.44 & 6.09 & 11.2 & 5.0 & 11.5 \\
\hline $\mathrm{Mn}$ & 188 & 552 & 314 & 445 & 424 & 2221 & 792 & 432 \\
\hline Co & 0.436 & 1.86 & 0.572 & 0.605 & 0.853 & 1.81 & 0.616 & 0.62 \\
\hline $\mathrm{Ni}$ & b.d. & 3.08 & b.d. & 0.912 & 1.07 & 1.80 & 1.31 & 2.45 \\
\hline $\mathrm{Cu}$ & 9.74 & 2.86 & 1.95 & 1.99 & 2.73 & 0.00 & 1.97 & 2.09 \\
\hline $\mathrm{Zn}$ & 9.82 & 50.4 & 27.1 & 48.8 & 44.9 & 183 & 97.0 & 44.7 \\
\hline $\mathrm{Ga}$ & 16.1 & 16.2 & 14.1 & 13.9 & 14.5 & 15.4 & 18.1 & 14.9 \\
\hline $\mathrm{Rb}$ & 223 & 221 & 182 & 112 & 129 & 113 & 125 & 118 \\
\hline $\mathrm{Sr}$ & 62.2 & 45.8 & 56.5 & 95.1 & 92.3 & 141 & 156 & 102 \\
\hline $\mathrm{Y}$ & 21.5 & 17.9 & 17.8 & 24.4 & 24.8 & 38.1 & 34.8 & 21.7 \\
\hline $\mathrm{Zr}$ & 170 & 91.4 & 90.7 & 147 & 133 & 243 & 221 & 150 \\
\hline $\mathrm{Nb}$ & 10.8 & 9.59 & 8.13 & 7.91 & 8.59 & 9.96 & 9.50 & 8.65 \\
\hline Mo & 3.66 & 3.39 & 2.06 & 1.53 & 1.64 & 1.23 & 1.50 & 1.55 \\
\hline Cs & 13.8 & 10.6 & 8.97 & 5.70 & 6.56 & 5.67 & 5.90 & 4.49 \\
\hline $\mathrm{Ba}$ & 1228 & 709 & 766 & 674 & 721 & 722 & 672 & 895 \\
\hline $\mathrm{La}$ & 28.9 & 24.5 & 26.1 & 22.1 & 24.3 & 28.0 & 27.3 & 24.9 \\
\hline $\mathrm{Ce}$ & 64.6 & 52.9 & 48.3 & 47.1 & 50.1 & 63.9 & 67.2 & 46.8 \\
\hline $\operatorname{Pr}$ & 5.28 & 4.48 & 4.36 & 5.09 & 5.35 & 6.76 & 7.12 & 4.74 \\
\hline $\mathrm{Nd}$ & 21.5 & 15.6 & 17.7 & 19.7 & 19.7 & 29.8 & 28.0 & 21.1 \\
\hline $\mathrm{Sm}$ & 3.50 & 3.17 & 3.88 & 3.92 & 4.06 & 5.37 & 6.28 & 3.36 \\
\hline $\mathrm{Eu}$ & 0.137 & 0.363 & 0.440 & 0.709 & 0.715 & 1.36 & 1.33 & 0.61 \\
\hline $\mathrm{Gd}$ & 3.82 & 2.38 & 2.81 & 3.93 & 3.64 & 5.46 & 6.07 & 3.51 \\
\hline $\mathrm{Tb}$ & & 0.483 & & 0.677 & 0.630 & & & \\
\hline Dy & 1.74 & 2.81 & 3.07 & 4.08 & 3.96 & 5.46 & 6.37 & 3.93 \\
\hline Но & & 0.695 & & 0.861 & 0.908 & & & \\
\hline $\mathrm{Er}$ & 2.53 & 1.87 & 1.71 & 2.75 & 2.47 & 3.85 & 3.84 & 2.33 \\
\hline $\mathrm{Tm}$ & & 0.474 & & 0.418 & 0.456 & & & \\
\hline $\mathrm{Yb}$ & 2.25 & 3.86 & 2.36 & 3.06 & 3.04 & 3.98 & 3.65 & 2.75 \\
\hline $\mathrm{Lu}$ & 0.354 & 0.738 & 0.291 & 0.485 & 0.502 & 0.649 & 0.556 & 0.42 \\
\hline Hf & 4.10 & 3.19 & 3.37 & 4.54 & 4.26 & 6.90 & 5.75 & 4.1 \\
\hline $\mathrm{Ta}$ & 2.02 & 1.28 & 1.14 & 0.763 & 0.715 & 0.574 & 0.802 & 0.7 \\
\hline W & 3.56 & 3.86 & 2.19 & 1.41 & 1.94 & 1.99 & 1.80 & 1.51 \\
\hline $\mathrm{Pb}$ & 23.8 & 24.8 & 19.2 & 15.5 & 16.5 & 21.7 & 23.0 & 15.1 \\
\hline Th & 21.6 & 17.7 & 18.9 & 11.8 & 13.4 & 11.2 & 11.1 & 11.0 \\
\hline $\mathrm{U}$ & 5.79 & 4.82 & 4.54 & 2.62 & 3.37 & 2.39 & 3.14 & 2.77 \\
\hline
\end{tabular}

Table 2.3. (continued overleaf). Representative major and trace element data for Taupo

Volcanic Zone and Healy melt inclusions. 


\begin{tabular}{|c|c|c|c|c|c|c|}
\hline $\begin{array}{l}\text { Sample ID } \\
\text { Host Phase }\end{array}$ & $\begin{array}{c}\text { RA2_13 } \\
-3.1 \\
\text { plag }\end{array}$ & $\begin{array}{c}\text { X590_3 } \\
-2 \\
\text { opx }\end{array}$ & $\begin{array}{c}\text { X609_1 } \\
7-1 \\
\text { plag }\end{array}$ & $\begin{array}{c}\text { ATHO- } \\
\text { G } \\
n=5\end{array}$ & $\% 2 \mathrm{SD}$ & $\begin{array}{c}\text { ref } \\
\text { values }\end{array}$ \\
\hline $\mathrm{SiO}_{2}$ & 77.41 & 75.79 & 76.21 & & & \\
\hline $\mathrm{TiO}_{2}$ & 0.19 & 0.39 & 0.40 & & & \\
\hline $\mathrm{Al}_{2} \mathrm{O}_{3}$ & 13.51 & 13.12 & 13.56 & & & \\
\hline $\mathrm{FeO}$ & 1.39 & 2.65 & 2.49 & & & \\
\hline $\mathrm{MnO}$ & 0.12 & 0.27 & 0.04 & & & \\
\hline $\mathrm{MgO}$ & 0.24 & 0.16 & 0.42 & & & \\
\hline $\mathrm{CaO}$ & 1.33 & 1.66 & 2.01 & & & \\
\hline $\mathrm{Na}_{2} \mathrm{O}$ & 2.81 & 3.61 & 2.51 & & & \\
\hline $\mathrm{K}_{2} \mathrm{O}$ & 2.74 & 1.89 & 1.70 & & & \\
\hline $\mathrm{Cl}$ & 0.19 & 0.37 & 0.56 & & & \\
\hline $\mathrm{SO}_{3}$ & 0.07 & 0.09 & 0.09 & & & \\
\hline Total & 100.00 & 100.00 & 100.00 & & & \\
\hline $\mathrm{Sc}$ & 9.5 & 19.4 & 11.6 & 8.83 & 19.6 & 7.00 \\
\hline $\mathrm{V}$ & 4.55 & 9.9 & 5.5 & 3.84 & 12.6 & 3.91 \\
\hline $\mathrm{Cr}$ & 7.5 & 2.9 & 10.8 & 9.07 & 21.9 & 6.1 \\
\hline $\mathrm{Mn}$ & 443 & 2434 & 809 & 859 & 5.84 & 798 \\
\hline Co & 0.599 & 6.20 & 1.12 & 1.32 & 36.3 & 2.13 \\
\hline $\mathrm{Ni}$ & 1.86 & 0.99 & 0.962 & 6.51 & 37.0 & 13.0 \\
\hline $\mathrm{Cu}$ & 2.21 & 8.80 & 4.00 & 15.2 & 5.54 & 18.6 \\
\hline $\mathrm{Zn}$ & 40.1 & 159 & 65.0 & 154 & 3.34 & 141 \\
\hline $\mathrm{Ga}$ & 16.0 & 13.6 & 10.9 & 21.5 & 3.06 & 25.3 \\
\hline $\mathrm{Rb}$ & 97 & 25.4 & 31.0 & 70.1 & 12.0 & 65 \\
\hline $\mathrm{Sr}$ & 140 & 113 & 156 & 92.7 & 5.94 & 94.1 \\
\hline $\mathrm{Y}$ & 19.9 & 37.5 & 45.8 & 94.7 & 6.20 & 94.5 \\
\hline $\mathrm{Zr}$ & 153 & 142 & 254 & 522 & 4.47 & 512 \\
\hline $\mathrm{Nb}$ & 7.84 & 3.24 & 4.82 & 67.5 & 2.84 & 62.4 \\
\hline Mo & 1.59 & 2.13 & 1.89 & 3.63 & 11.1 & 4.8 \\
\hline Cs & 4.47 & 0.77 & 1.11 & 0.904 & 17.9 & 1.1 \\
\hline $\mathrm{Ba}$ & 802 & 811 & 892 & 535 & 1.95 & 547 \\
\hline $\mathrm{La}$ & 19.2 & 11.3 & 12.9 & 54.8 & 5.78 & 55.6 \\
\hline $\mathrm{Ce}$ & 44.4 & 31.0 & 30.0 & 132 & 6.03 & 121 \\
\hline $\operatorname{Pr}$ & 4.36 & 3.89 & 4.27 & 14.8 & 3.00 & 14.6 \\
\hline $\mathrm{Nd}$ & 15.3 & 16.4 & 21.5 & 61.6 & 5.76 & 60.9 \\
\hline $\mathrm{Sm}$ & 2.74 & 4.42 & 6.17 & 14.6 & 10.4 & 14.2 \\
\hline $\mathrm{Eu}$ & 0.770 & 1.06 & 1.18 & 2.50 & 6.28 & 2.76 \\
\hline $\mathrm{Gd}$ & 2.68 & 4.86 & 6.89 & 14.8 & 6.21 & 15.3 \\
\hline $\mathrm{Tb}$ & & & & 2.61 & 3.11 & 2.51 \\
\hline Dy & 2.72 & 6.13 & 7.40 & 16.5 & 3.54 & 16.2 \\
\hline Ho & & & & 3.74 & 6.41 & 3.43 \\
\hline $\mathrm{Er}$ & 1.81 & 4.07 & 4.79 & 10.3 & 1.78 & 10.3 \\
\hline $\mathrm{Tm}$ & & & & 1.70 & 4.40 & 1.52 \\
\hline $\mathrm{Yb}$ & 2.05 & 4.39 & 6.12 & 10.1 & 5.70 & 10.5 \\
\hline $\mathrm{Lu}$ & 0.43 & 0.74 & 0.878 & 1.52 & 12.0 & 1.54 \\
\hline Hf & 4.2 & 3.24 & 6.70 & 12.9 & 3.59 & 13.7 \\
\hline $\mathrm{Ta}$ & 0.4 & 0.26 & 0.268 & 4.15 & 8.84 & 3.90 \\
\hline W & 1.07 & 0.29 & 0.263 & 9.70 & 9.51 & 9.30 \\
\hline $\mathrm{Pb}$ & 14.5 & 4.45 & 5.00 & 5.52 & 6.95 & 5.67 \\
\hline $\mathrm{Th}$ & 8.00 & 2.17 & 3.69 & 7.74 & 7.84 & 7.40 \\
\hline $\mathrm{U}$ & 2.21 & 0.831 & 1.01 & 2.38 & 11.79 & 2.37 \\
\hline
\end{tabular}

All sample data are recalculated on an anhydrous basis. Trace element data for repeat analyses of the standard ATHO-G $(n=5)$ and reference values of Jochum et al. (2006) are also shown. b.d. = below detection limits, spaces indicate element was not analysed. 


\subsection{Results}

A brief petrographic overview and details of the samples studied are summarised in Table 1. Representative major and trace element compositions are presented in Table 2.3 and groundmass glass compositions in Table 2.4.

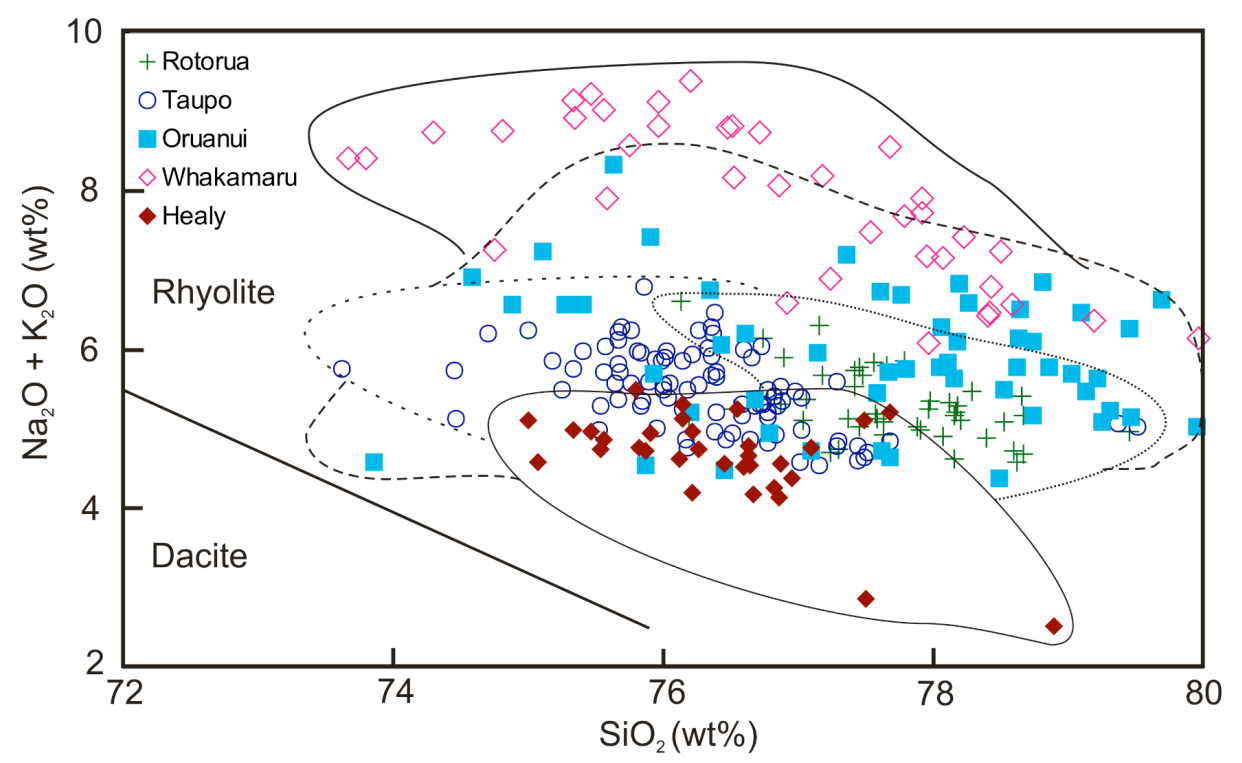

Figure 2.3. Total alkali silica diagram of Taupo Volcanic Zone and Healy melt inclusions. Dacite and rhyolite fields are after Le Bas et al. (1986).

Melt inclusions from all five silicic eruptions are rhyolitic in composition irrespective of setting (Figures 2.3 and 2.4). Where inclusions occur in both plagioclase and orthopyroxene crystals from the same sample, they overlap in composition (Figure 2.5). However, quartz hosted melt inclusions in the Whakamaru and Oruanui samples range to higher $\mathrm{SiO}_{2}$ and $\mathrm{K}_{2} \mathrm{O}$, consistent with quartz crystallising at a different stage of magma formation compared to orthopyroxene and plagioclase. The large difference in $\mathrm{K}_{2} \mathrm{O}$ concentration observed between quartz and orthopyroxene hosted melt inclusions in the Whakamaru ignimbrite is not evident in other major element concentrations. 


\begin{tabular}{|c|c|c|c|c|c|c|}
\hline Sample ID & OR2_23g & $\begin{array}{c}\text { OR1_31g } \\
2\end{array}$ & $\begin{array}{c}\text { OR1_26g } \\
2\end{array}$ & $\begin{array}{c}\text { OR1_24g } \\
2\end{array}$ & $\begin{array}{c}\mathrm{X} 590 / \mathrm{B} \\
6 \mathrm{~g} \\
1\end{array}$ & $\begin{array}{c}\mathrm{X} 590 / \mathrm{B} \\
5 \mathrm{~g} \\
1\end{array}$ \\
\hline $\mathrm{SiO}_{2}$ & 78.25 & 78.07 & 78.54 & 77.75 & 75.61 & 74.95 \\
\hline $\mathrm{TiO}_{2}$ & 0.18 & 0.16 & 0.15 & 0.14 & 0.28 & 0.50 \\
\hline $\mathrm{Al}_{2} \mathrm{O}_{3}$ & 12.43 & 12.35 & 12.29 & 12.95 & 13.50 & 13.56 \\
\hline $\mathrm{FeO}$ & 1.73 & 1.80 & 1.46 & 1.38 & 2.20 & 2.08 \\
\hline $\mathrm{MnO}$ & 0.04 & 0.14 & 0.06 & 0.11 & 0.15 & 0.09 \\
\hline $\mathrm{MgO}$ & 0.13 & 0.11 & 0.10 & 0.12 & 0.39 & 0.39 \\
\hline $\mathrm{CaO}$ & 1.04 & 1.13 & 1.14 & 1.22 & 2.04 & 2.45 \\
\hline $\mathrm{Na}_{2} \mathrm{O}$ & 3.10 & 3.34 & 3.28 & 3.34 & 3.56 & 3.67 \\
\hline $\mathrm{K}_{2} \mathrm{O}$ & 2.76 & 2.62 & 2.67 & 2.68 & 1.57 & 1.71 \\
\hline $\mathrm{Cl}$ & 0.24 & 0.27 & 0.23 & 0.23 & 0.53 & 0.49 \\
\hline $\mathrm{SO}_{3}$ & 0.10 & 0.01 & 0.08 & 0.08 & 0.18 & 0.05 \\
\hline Total & 100.00 & 100.00 & 100.00 & 100.00 & 100.00 & 100.00 \\
\hline $\mathrm{Sc}$ & 3.22 & 9.28 & 8.45 & 7.83 & 24.0 & 20.7 \\
\hline $\mathrm{Ti}$ & 335 & 1020 & 976 & 972 & 0.136 & 0.445 \\
\hline $\mathrm{V}$ & 0.566 & 1.58 & 1.49 & 1.14 & 12.2 & 8.98 \\
\hline $\mathrm{Cr}$ & 1.46 & 6.91 & 6.98 & 5.95 & 33.8 & 45.7 \\
\hline $\mathrm{Mn}$ & 148 & 528 & 420 & 398 & 721 & 856 \\
\hline Co & 0.337 & 1.13 & 0.790 & 0.897 & 3.31 & 2.12 \\
\hline $\mathrm{Ni}$ & 0.215 & 1.59 & 1.45 & 1.96 & 11.0 & 14.6 \\
\hline $\mathrm{Cu}$ & 0.463 & 3.00 & 2.37 & 2.37 & 13.8 & 38.4 \\
\hline $\mathrm{Zn}$ & 15.5 & 59.1 & 49.2 & 41.1 & 52.2 & 56.0 \\
\hline $\mathrm{Ga}$ & 6.46 & 16.4 & 15.4 & 14.8 & 11.2 & 11.1 \\
\hline $\mathrm{Rb}$ & 44.0 & 135 & 132 & 127 & 27.9 & 28.8 \\
\hline $\mathrm{Sr}$ & 33.0 & 80.3 & 86.7 & 88.5 & 99.2 & 115.7 \\
\hline $\mathrm{Y}$ & 18.4 & 19.4 & 22.3 & 22.9 & 28.3 & 28.8 \\
\hline $\mathrm{Zr}$ & 38.9 & 105 & 123 & 127 & 122 & 129 \\
\hline $\mathrm{Nb}$ & 2.26 & 8.51 & 7.86 & 7.16 & 2.47 & 3.05 \\
\hline Mo & 0.391 & 1.63 & 1.66 & 1.75 & 5.90 & 3.62 \\
\hline Cs & 2.13 & 7.15 & 6.61 & 6.06 & 0.747 & 0.864 \\
\hline $\mathrm{Ba}$ & 224 & 677 & 672 & 696 & 533 & 861 \\
\hline $\mathrm{La}$ & 17.6 & 20.0 & 21.8 & 21.8 & 8.19 & 11.29 \\
\hline $\mathrm{Ce}$ & 44.5 & 48.5 & 49.1 & 46.9 & 26.3 & 26.0 \\
\hline $\mathrm{Pr}$ & 5.30 & 4.40 & 5.18 & 4.72 & 3.10 & 2.61 \\
\hline $\mathrm{Nd}$ & 23.7 & 17.9 & 19.1 & 19.3 & 15.0 & 15.5 \\
\hline $\mathrm{Sm}$ & 5.24 & 3.12 & 4.25 & 3.41 & 4.46 & 3.08 \\
\hline $\mathrm{Eu}$ & 0.607 & 0.610 & 0.611 & 0.524 & 0.766 & 0.979 \\
\hline $\mathrm{Gd}$ & 4.66 & 2.83 & 3.37 & 3.48 & 4.42 & 3.35 \\
\hline $\mathrm{Tb}$ & 0.661 & 0.492 & 0.533 & 0.536 & & \\
\hline Dy & 4.07 & 3.27 & 3.67 & 3.94 & 9.27 & 5.03 \\
\hline Ho & 0.721 & 0.610 & 0.836 & 0.751 & & \\
\hline $\mathrm{Er}$ & 1.94 & 2.11 & 2.44 & 2.37 & 3.41 & 2.24 \\
\hline $\mathrm{Tm}$ & 0.279 & 0.344 & 0.366 & 0.388 & & \\
\hline $\mathrm{Yb}$ & 1.51 & 2.43 & 2.45 & 2.69 & 1.86 & 3.72 \\
\hline $\mathrm{Lu}$ & 0.177 & 0.373 & 0.393 & 0.518 & 0.487 & 0.809 \\
\hline Hf & 1.10 & 3.15 & 3.63 & 3.51 & 2.56 & 2.49 \\
\hline $\mathrm{Ta}$ & 0.303 & 0.615 & 0.776 & 0.663 & 0.561 & 0.444 \\
\hline $\mathrm{W}$ & 0.410 & 2.15 & 1.68 & 2.08 & 1.96 & 2.49 \\
\hline $\mathrm{Pb}$ & 5.13 & 17.6 & 15.1 & 15.5 & 2.43 & 4.61 \\
\hline $\mathrm{Th}$ & 3.77 & 10.5 & 11.5 & 12.3 & 1.76 & 1.66 \\
\hline $\mathrm{U}$ & 1.07 & 3.30 & 3.03 & 2.86 & 0.977 & 1.05 \\
\hline
\end{tabular}

Table 2.4. Representative major and trace element concentrations of groundmass glass adhered to the exterior of crystals from the Oruanui and Healy samples. All data are recalculated on an anhydrous basis. 

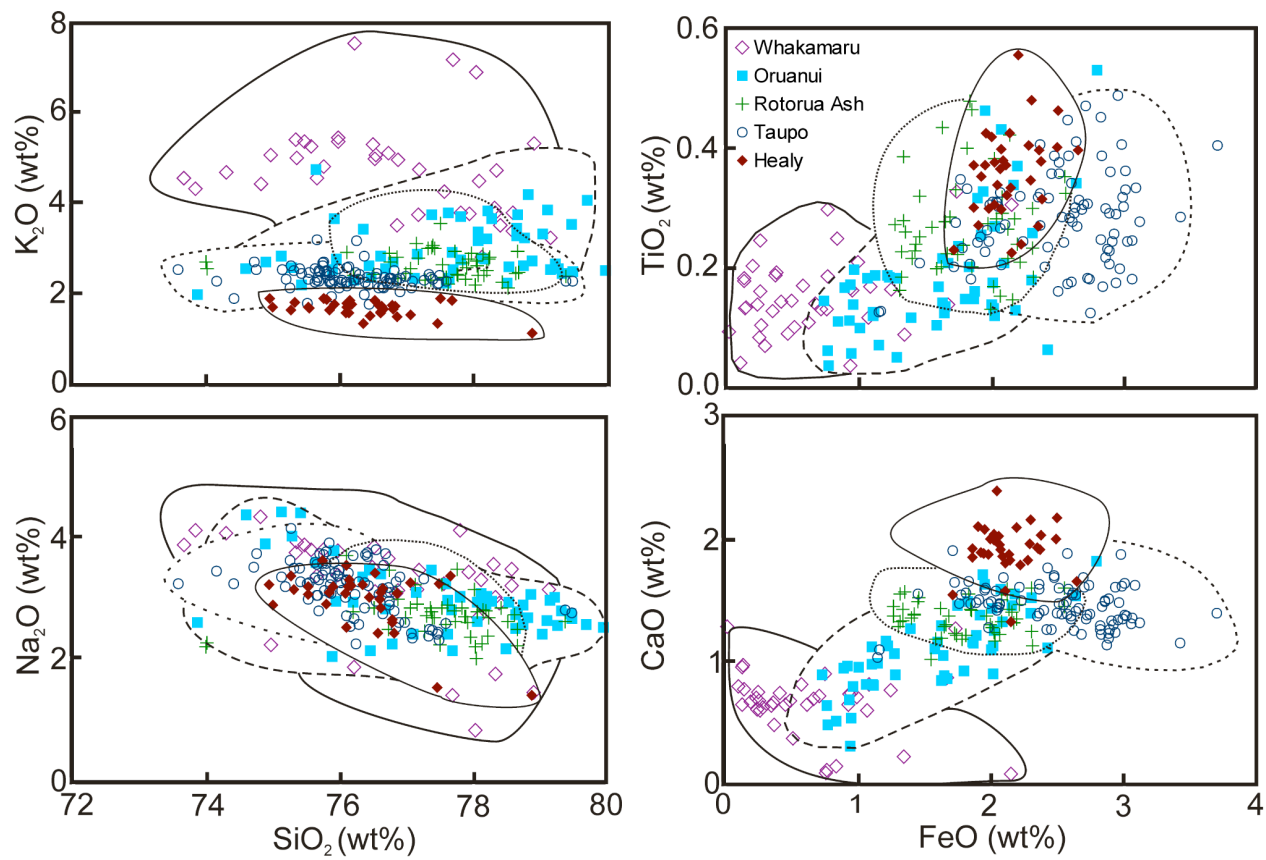

Figure 2.4. Major element bivariate diagrams for Taupo Volcanic Zone and Healy volcano melt inclusions.

Due to the small size $(<25 \mu \mathrm{m})$ of the majority of orthopyroxene hosted melt inclusions there are insufficient data to distinguish any difference in trace element chemistry. Matrix glass compositions are often distinct from the melt inclusion compositions (Figure 2.5). For example plagioclase-hosted melt inclusions in the Rotorua eruptive display $\mathrm{K}_{2} \mathrm{O}$ contents of $2.6-3.1 \mathrm{wt} \%$ in comparison to groundmass glass with $\mathrm{K}_{2} \mathrm{O}$ of 2.2-2.4 wt\% (Figure 2.5). However, Taupo melt inclusions and groundmass glasses compositions coincide (Figure 2.5).

Whakamaru melt inclusion compositions are distinct from those of the smaller volume Taupo and Rotorua eruptions, with higher large ion lithophile element (LILE), light rare earth element (LREE) and $\mathrm{Nb}$ and $\mathrm{Ta}$ contents, and lower $\mathrm{CaO}, \mathrm{FeO}, \mathrm{Zr}$, $\mathrm{Hf}$ and varying heavy rare earth element (HREE) contents, with little or no overlap in composition (Figures 2.4 and 


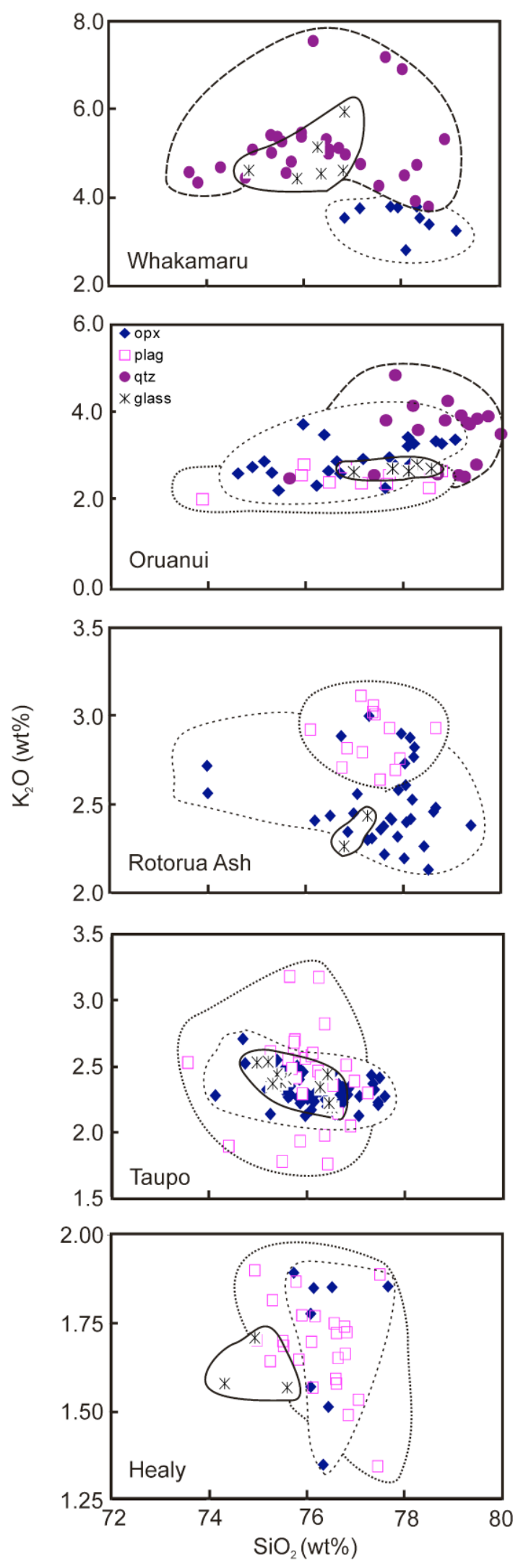

Figure 2.5. $\mathrm{SiO}_{2}$ versus $\mathrm{K}_{2} \mathrm{O}$ plots with melt inclusions distinguished by host crystals and groundmass glass compositions. 
2.6). Whakamaru melt inclusions are also particularly notable for their high $\mathrm{K}_{2} \mathrm{O}(4-6$ wt \%) content.

Rotorua and Taupo melt inclusions are similar, although the latter are less silicic. Oruanui compositions span the range between Whakamaru and Rotorua and Taupo compositions, with some overlap. Healy melt inclusions are distinct from Taupo Volcanic Zone inclusions, with lower $\mathrm{K}_{2} \mathrm{O}$, LILE (except $\mathrm{Ba}$ ), actinides, $\mathrm{Nb}$, Ta and LREE, and higher $\mathrm{CaO}$ and HREE contents (Figures 2.4 and 2.6).
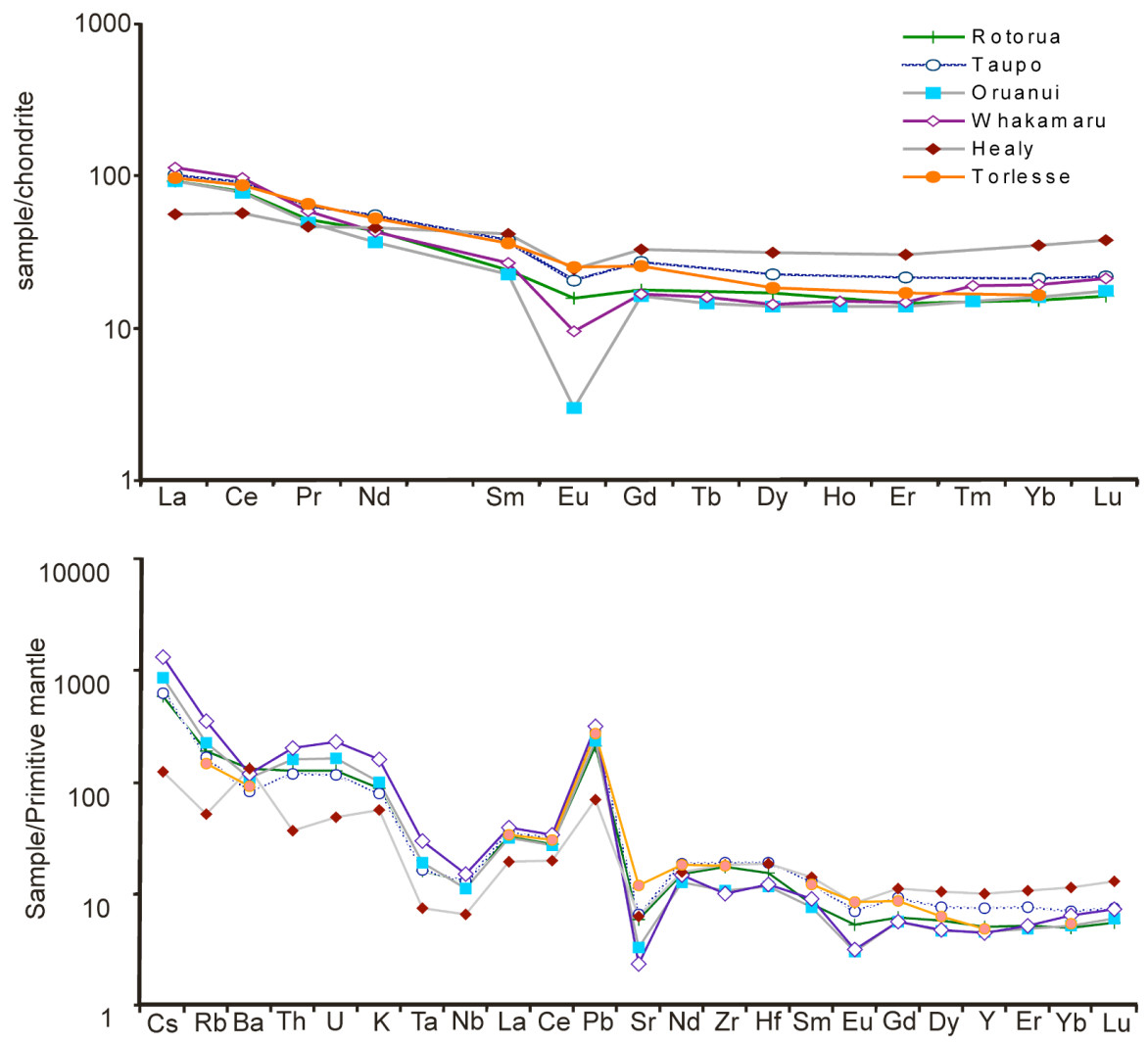

Figure 2.6. Chondrite-normalised rare earth element plot and primitive mantle-normalised multi-element diagram for mean melt inclusion compositions for each studied eruption. Chondrite values are taken from McDonough and Sun (1995) and those for primitive mantle are taken from Sun and McDonough (1989). REE concentrations of Torlesse greywacke are from Reid (1982). 
Positive $\mathrm{Pb}$ anomalies and negative $\mathrm{Sr}$ and $\mathrm{Eu}$ anomalies are observed in all melt inclusions, with Whakamaru inclusions showing the largest anomalies, and Healy the smallest (Figure 2.6). All Taupo Volcanic Zone melt inclusions show a negative Ba anomaly, whereas Healy inclusions have a distinctive positive $\mathrm{Ba}$ anomaly.
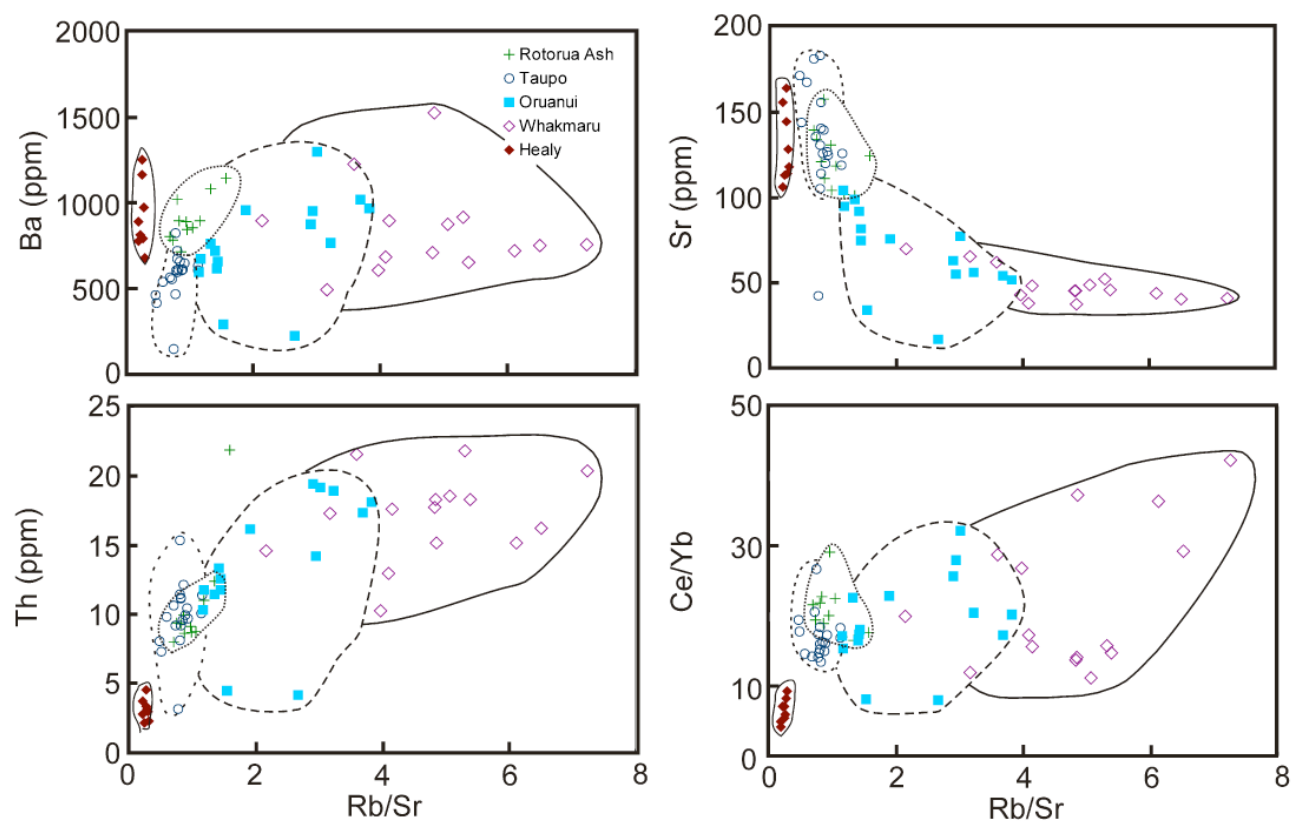

Figure 2.7. Trace element diagrams for Taupo Volcanic Zone and Healy melt inclusions using $\mathrm{Rb} / \mathrm{Sr}$ as a fractionation index.

Selected trace element abundances and ratios are plotted against $\mathrm{Rb} / \mathrm{Sr}$ as an index of fractionation in Figure 2.7, as $\mathrm{Sr}$ shows a general decrease with increasing $\mathrm{Rb} / \mathrm{Sr}$ due to fractionation of plagioclase. Whakamaru inclusions have the highest $\mathrm{Rb} / \mathrm{Sr}$, suggesting that they are the most fractionated melts. Taupo and Rotorua melt inclusions have the lowest and least fractionated $\mathrm{Rb} / \mathrm{Sr}$ ratios of the Taupo Volcanic Zone rhyolites and Oruanui melt inclusions span the range between Whakamaru and Taupo/Rotorua compositions. The enrichment in LREE and depletion of HREE of Taupo 
Volcanic Zone melt inclusions compared to Healy inclusions is reflected in lower $\mathrm{Ce} / \mathrm{Yb}$ ratios (mean of 6.4 for Healy compared to 19.2 for Taupo Volcanic Zone melt inclusions). Absolute Ba concentrations of Healy melt inclusions are similar to those of the Taupo Volcanic Zone melt inclusions but Th contents of Healy melt inclusions are 2.5 times lower than Taupo Volcanic Zone inclusions (Figure 2.7), resulting in a large variation in $\mathrm{Ba} / \mathrm{Th}$ and $\mathrm{Ba} / \mathrm{Nb}$ between Healy and Taupo Volcanic Zone inclusions (Figure 2.8).
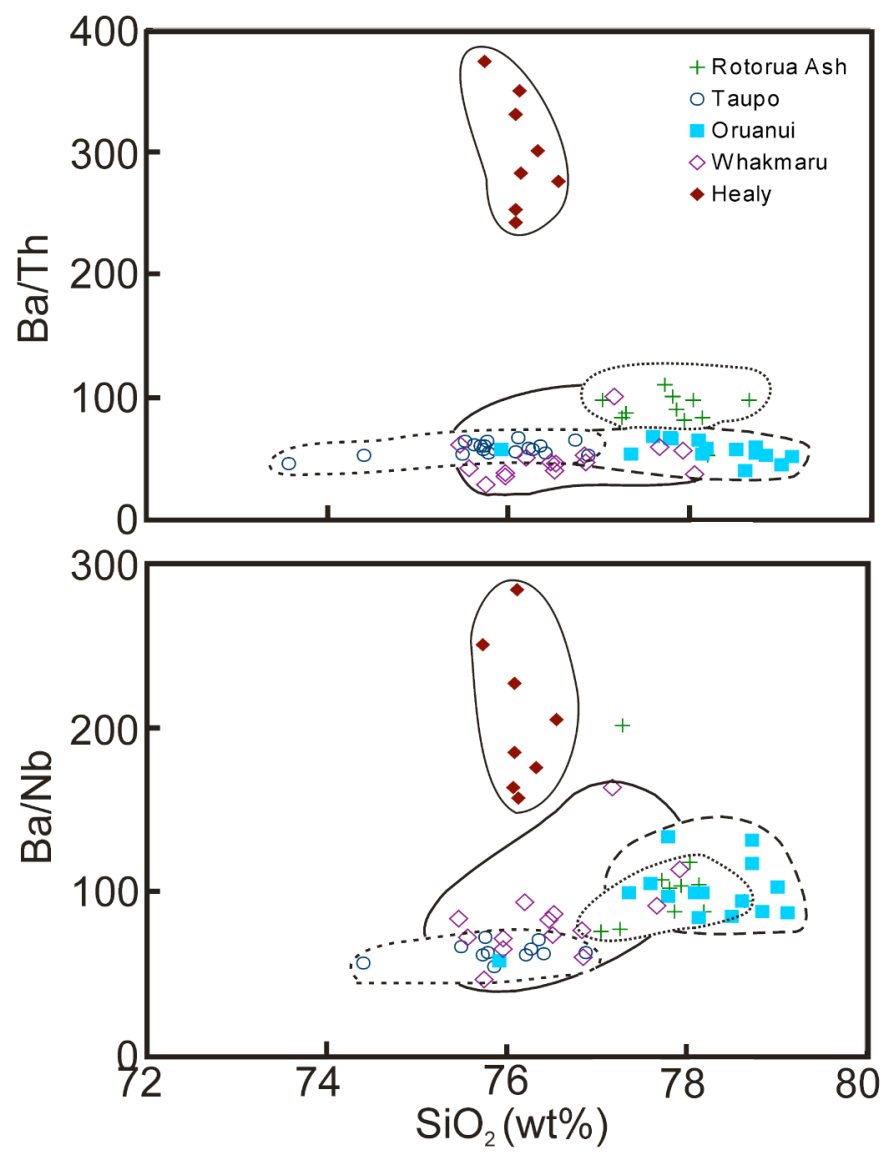

Figure 2.8. $\mathrm{Ba} / \mathrm{Nb}$ and $\mathrm{Ba} / \mathrm{Th}$ plotted against $\mathrm{SiO}_{2}$ for Taupo Volcanic Zone and Healy volcano melt inclusions.

$\mathrm{The} \mathrm{Rb} / \mathrm{Sr}$ ratios of Whakamaru melt inclusions are two to three times higher than reported $\mathrm{Rb} / \mathrm{Sr}$ ratios of the host pumice (mean $\mathrm{Rb} / \mathrm{Sr}$ of 4.8 and 
1.4, respectively) (Figure 2.9) (Brown, 1994). This trend is also evident in Oruanui melt inclusions where $\mathrm{Rb} / \mathrm{Sr}$ ratios are approximately four times higher than in reported pumice compositions (Sutton et al., 1995; Wilson et al., 2006), as previously noted for quartz-hosted Oruanui melt inclusions (Liu et al., 2006). The $\mathrm{Rb} / \mathrm{Sr}$ ratios of Taupo and Rotorua melt inclusions overlap and are slightly higher (up to 1.5 times) than pumice compositions (Figure 2.9) (Sutton et al., 1995; Smith et al., 2004).

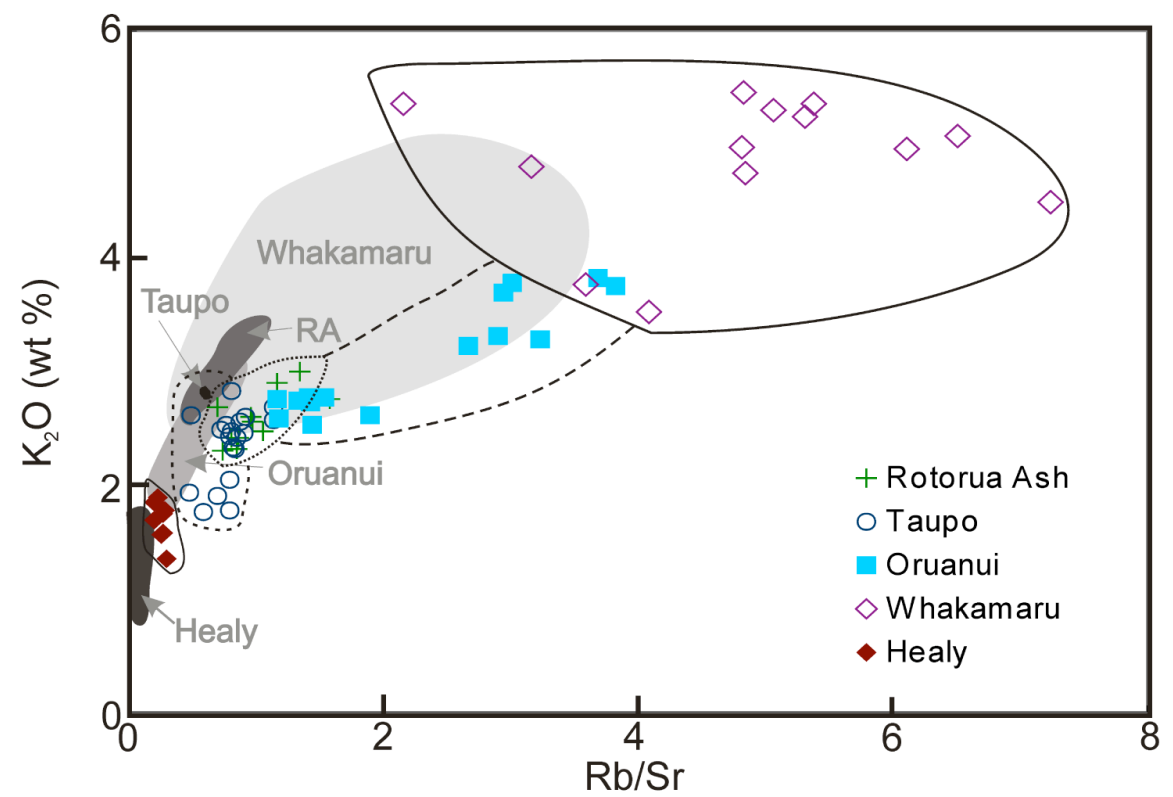

Figure 2.9. $\mathrm{Rb} / \mathrm{Sr}$ plotted against $\mathrm{K}_{2} \mathrm{O}$ comparing melt inclusions and pumice (shaded regions) from the same eruptive units. Pumice data are taken from Sutton et al. (1995), Brown et al. (1998a), Smith et al. (2004) and Wilson et al. (2006).

\subsection{Discussion}

2.5.1 Comparison of Healy and Taupo Volcanic Zone melt inclusion compositions

There are several important differences between the oceanic Healy and continental Taupo Volcanic Zone melt inclusions: (1) Healy REE patterns 
have $\mathrm{Ce} / \mathrm{Yb}$ ratios of ca. 6.4 compared to 19.2 for Taupo Volcanic Zone melt inclusions; (2) HREE concentrations in Healy melt inclusions are 1.8 to 2.5 times higher than Taupo Volcanic Zone melt inclusions; (3) Taupo Volcanic Zone melt inclusions have significantly higher $\mathrm{K}_{2} \mathrm{O}$ (1.4 to 3 times), LILE such as $\mathrm{Cs}, \mathrm{Rb}$, and $\mathrm{Pb}$ (3 to 10 times), and LREE (1.8 times); and (4) Ba shows a positive anomaly in Healy melt inclusions but a negative anomaly in the Taupo Volcanic Zone inclusions (Figure 2.6).

The depletion of elements including $\mathrm{Cs}, \mathrm{Rb}, \mathrm{Pb}$ and LREE and enrichment of Zr, Hf and HREE in Healy samples compared to Taupo Volcanic Zone samples cannot be caused by varying degrees of partial melting or fractional crystallisation. If the relatively high $\mathrm{Zr}$, Hf and HREE concentrations of the Healy samples were produced by lower degrees of partial melting than Taupo Volcanic Zone inclusions, Healy inclusions should also be relatively enriched, not depleted, in LILE and LREE concentrations. Similarly, crystal fractionation increases incompatible trace element abundances but will not strongly fractionate LILE and LREE from HFSE and HREE as observed in Taupo Volcanic Zone inclusions (Figure 2.6). The higher Zr, Hf and HREE contents of Healy inclusions could indicate a less depleted source beneath the Kermadec arc, although this is not complemented by higher $\mathrm{Ta}, \mathrm{Nb}$, LILE and LREE. Furthermore, Gamble et al. (1993) used HFSE modelling of basalts to argue that the mantle source beneath the Kermadec Arc is more depleted than the mantle beneath the Taupo Volcanic Zone. It should be noted, however, that depleted sources are more susceptible to secondary enrichment processes such as from fluids or melts from the descending slab 
(Woodhead et al., 1993), so the greater depletion in Zr, Hf and HREE of Taupo Volcanic Zone magmas may be due to high degrees of partial melting with subsequent enrichment of LILE and LREE by a secondary process. It is likely that the disparity in composition between Healy and Taupo Volcanic Zone melt inclusion compositions is due to the difference in their geological settings, i.e. the lack of continental lithosphere in the oceanic Kermadec Arc. This raises the possibility of crustal assimilation and/or melting.

\subsubsection{Petrogenesis of silicic magma at Healy caldera}

Models of both fractional crystallisation (Haase et al., 2006) and crustal anatexis of oceanic crust (Smith et al., 2003a and b) have been invoked for the generation of Kermadec arc silicic magmas. The lithology of the [overlying] lithosphere beneath Healy precludes assimilation of continental lithosphere, making it an ideal location to investigate the viability of fractional crystallisation in producing rhyodacite from basaltic magmas.

Haase et al. (2006) used major element modelling to demonstrate that the rhyolitic glass from Brothers seamount adjacent to Healy caldera (Figure 2.1) could be produced through extensive fractional crystallisation of plagioclase, olivine, clinopyroxene, amphibole, Fe-Ti oxides and minor amounts of orthopyroxene. Rare earth element modelling of Healy inclusions is shown in Figure 2.10 using a Healy basalt (Wright and Worthington, unpublished data) as the starting composition, mineral proportions similar to those used by Haase et al. (2006), and basaltic 
distribution coefficients from the literature (Table 2.5). The REE modelling indicates that the Healy silicic melts can be produced from basaltic magma through $62-76 \%$ fractional crystallisation of $43.5 \%$ plagioclase, $29 \%$ clinopyroxene, $7.2 \%$ orthopyroxene, $7.2 \%$ magnetite, $7.2 \%$ olivine, $4.4 \%$ amphibole and $1.5 \%$ ilmenite. These results, together with the model of Haase et al. (2006), indicate that at least some of the silicic magmas in the Kermadec arc can be produced from near perfect fractional crystallisation of basaltic magma.

\begin{tabular}{lccccccc}
\hline Basalt & Plag & Opx & Cpx & Amp & Ilm & Mag & O1 \\
\hline La & 0.14 & 0.002 & 0.05 & 0.17 & 0.005 & 0.22 & 0.012 \\
$\mathrm{Ce}$ & 0.09 & 0.003 & 0.098 & 0.26 & 0.006 & 0.26 & 0.009 \\
$\mathrm{Pr}$ & 0.17 & 0.0048 & 0.15 & 0.35 & & & 0.005 \\
$\mathrm{Nd}$ & 0.04 & 0.0068 & 0.4 & 0.44 & 0.008 & 0.3 & 0.004 \\
$\mathrm{Sm}$ & 0.036 & 0.01 & 0.26 & 0.76 & 0.01 & 0.335 & 0.0013 \\
$\mathrm{Eu}$ & 0.73 & 0.013 & 0.6 & 0.88 & 0.007 & 0.36 & 0.0016 \\
$\mathrm{Gd}$ & 0.04 & 0.016 & 0.6 & 0.86 & 0.017 & 0.32 & 0.004 \\
$\mathrm{Dy}$ & 0.055 & 0.022 & 0.7 & 0.78 & 0.028 & 0.28 & 0.014 \\
$\mathrm{Er}$ & 0.041 & 0.03 & 0.6 & 0.68 & 0.046 & 0.22 & 0.008 \\
$\mathrm{Yb}$ & 0.016 & 0.049 & 0.28 & 0.59 & 0.077 & 0.18 & 0.0015 \\
$\mathrm{Lu}$ & 0.025 & 0.06 & 0.1 & 0.51 & 0.1 & 0.18 & 0.0018 \\
\hline
\end{tabular}

Table 2.5. Rare earth element distribution coefficients for basaltic magmas used in the modelling of the trace element concentrations of Healy melt inclusions. Sources: Higuchi and Nagasawa (1969); Frey (1969); Irving and Frey (1984); Martin (1987); McKenzie and O’Nions (1991); and Dunn and Sen (1994).

The sparsely porphyritic nature of the Healy samples suggests that: (1) crystals efficiently settled out of the melt in the magma chamber; or (2) rhyodacitic melt was separated from fractionated material into a secondary magma chamber where only limited fractional crystallisation occurred prior to eruption. 

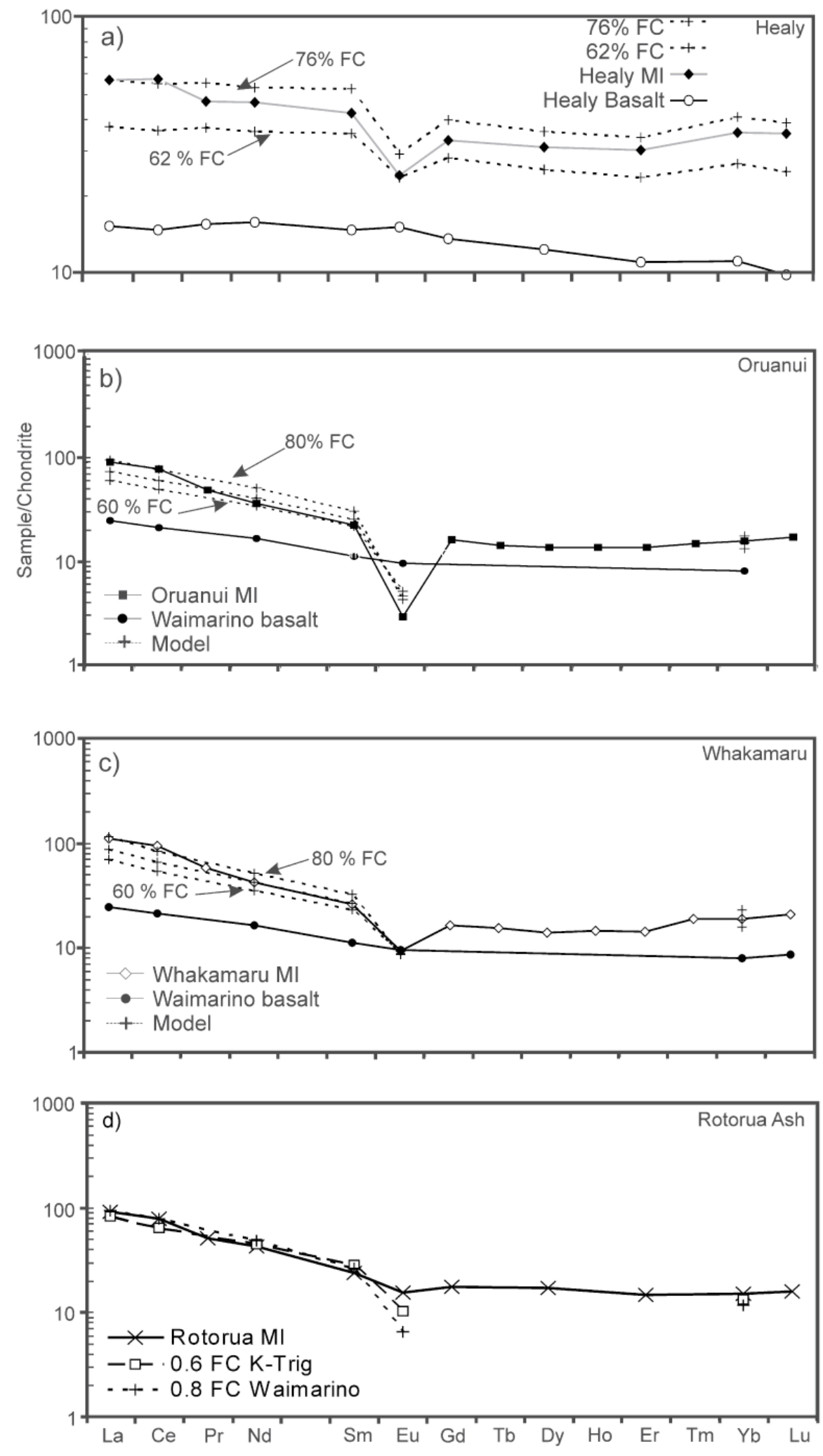

Figure 2.10. Caption overleaf 
Figure 2.10. (Figure overleaf) Chondrite-normalised rare earth element diagrams showing models for producing rhyolitic melt inclusion compositions from a basaltic melt. (a) Healy inclusions by perfect fractional crystallisation from Healy basalt. Proportions of crystallising phases are: $43.5 \%$ plagioclase, $29 \%$ clinopyroxene, $7.2 \%$ orthopyroxene, $7.2 \%$ magnetite, $7.2 \%$ olivine, $4.4 \%$ amphibole and $1.5 \%$ ilmenite. (b) Oruanui ignimbrite by AFC from a Waimarino basalt parent. Proportions of crystallising phases are: plagioclase $70 \%$; orthopyroxene $7 \%$; quartz $9 \%$; ilmenite $4.5 \%$; magnetite $4.5 \%$; amphibole $4.5 \%$; and apatite $0.5 \%$. (c) Whakamaru ignimbrite by AFC from a Waimarino basalt parent. Proportions of crystallising phases are: plagioclase $23.8 \%$; orthopyroxene $9.5 \%$; quartz $28.5 \%$; ilmenite $2.38 \%$; magnetite $2.38 \%$; K-feldspar $9.5 \%$; amphibole $14.3 \%$; and biotite 9.5\%. (d) Rotorua eruption by AFC from a Waimarino basalt parent. Proportions of crystallising phases are: plagioclase $44 \%$; orthopyroxene $15 \%$; quartz $22 \%$; ilmenite $4.1 \%$; magnetite $4.1 \%$; amphibole $6.5 \%$; biotite $3 \%$; and clinopyroxene $1.6 \%$. Also shown is modelling from K-Trig basalt under the same conditions (see text for discussion). Healy basalt composition from Wright and Worthington (unpublished data), Waimarino and KTrig basalts from Gamble et al. (1993).

\subsubsection{Petrogenesis of silicic magma in the Taupo Volcanic Zone}

The predominant country rock in the Taupo Volcanic Zone is greywacke of the Torlesse Supergroup and Waipapa Group (Reid, 1982). Greywacke xenoliths occur in Taupo Volcanic Zone ignimbrites (Brown et al., 1998b; Cole et al., 1998) and the widespread presence of basement greywacke is confirmed by magnetotelluric surveying (Heise et al., 2007) and geophysical modelling (e.g. Stratford and Stern, 2008). Numerous lithologies are present in the greywacke providing a range of possible sedimentary assimilants and partial melts (Reid, 1982).

Assimilation of Torlesse greywacke in Taupo Volcanic Zone magmas is evident even in the most primitive basaltic compositions (Kakuki and Waimarino Basalts: Gamble et al., 1990), resulting in enriched LREE relative to the HREE concentrations (Gamble et al., 1993). The contribution 
of greywacke assimilation or partial melting to silicic magma petrogenesis in the Taupo Volcanic Zone has been suggested from radiogenic and stable isotopic studies. Rhyolites have $\mathrm{Sr}-\mathrm{Nd}$ isotopic compositions (e.g. ${ }^{87} \mathrm{Sr} /{ }^{86} \mathrm{Sr}$ $=0.705236-0.705660)$ that are intermediate between basalt $\left({ }^{87} \mathrm{Sr} /{ }^{86} \mathrm{Sr}=\right.$ $0.703875-0.704364)$ and greywacke basement $\left(\right.$ mean $\left.{ }^{87} \mathrm{Sr} /{ }^{86} \mathrm{Sr}=0.71029\right)$ compositions (McCulloch et al., 1994; Graham et al., 1995), which are inconsistent with either a pure fractional crystallisation or greywacke partial melting model. Oxygen isotope studies further confirm that rhyolites (mean $\delta^{18} \mathrm{O} \sim 8 \%$; Reid, 1982) cannot be attained through progressive fractional crystallisation from a basaltic parent $\left(\delta^{18} \mathrm{O} \sim 6.5 \%\right.$; Reid, 1982) without the assimilation of greywacke $\left(\delta^{18} \mathrm{O} \sim 10-14 \%\right.$; Reid, 1982) or through pure partial melting of Waipapa or Torlesse greywacke (Reid, 1982; McCulloch et al., 1994; Blattner et al., 1996; Macpherson et al., 1998), suggesting that a hybrid model is required.

Contamination of silicic magmas with basement greywacke can be tested through the simple binary mixing of a mean Healy melt inclusion composition, representing an uncontaminated rhyolite, and greywacke of the Torlesse Supergroup (Reid, 1982). Such models suggest that the concentrations of LILE and LREE increase and HREE decrease(s) with progressive addition of greywacke with only $10-20 \%$ greywacke required to obtain similar REE concentrations to measured REE in Taupo melt inclusions. Barium concentrations also decrease relative to LILE, resulting in negative $\mathrm{Ba}$ anomalies. A positive $\mathrm{Ba}$ anomaly, which has been attributed to a slab fluid component in Kermadec arc lavas (Wysoczanski et al., 2006), 
is observed in rhyolitic glasses of the Brothers seamount and is a feature of basalts from the Kermadec arc and Taupo Volcanic Zone (Gamble et al., 1993; Haase et al., 2006; Wysoczanski et al., 2006). The positive Ba anomaly of Taupo Volcanic Zone basalts (Gamble et al., 1993) indicates that the mechanism responsible for the negative $\mathrm{Ba}$ anomalies observed in the Taupo Volcanic Zone rhyolitic magmas is most likely a crustal process as it occurred after the formation of the basaltic magma, but prior to eruption of the rhyolitic magma. This process could occur through either assimilation of greywacke or magma mixing with greywacke partial melts.

Assimilation and fractional crystallisation (AFC) modelling of Taupo Volcanic Zone rhyolitic inclusions, applying the equations of DePaolo (1981) and using the observed crystal assemblages (Table 2.6) and distribution coefficients listed in Table 2.7, demonstrates that REE compositions of Whakamaru and Oruanui ignimbrites can be attained by AFC processes from a basaltic parental magma, with Torlesse greywacke (Reid, 1982; 1983) as the assimilant (Figure 2.10b; 2.10c). The ratio of assimilant to melt fraction ( $\mathrm{r}$ ) is 0.2 , which is consistent with isotopic modelling of Graham et al. (1992) and Price et al. (2007). Modelling of Waimarino basalt as the starting composition produces a good fit for the Whakamaru melt inclusion compositions with $70-80 \%$ fractional crystallisation (Figure $2.10 \mathrm{~b} ; 2.10 \mathrm{c}$ ), and the proportion of phases required to be fractionated (Table 2.6) changes slightly if Kakuki basalt is used as the parental magma. 
Oruanui melt inclusion compositions are also better modelled when the Waimarino basalt is used as the parental magma, requiring $70-80 \%$ fractional crystallisation. Compositions of mafic clasts entrained within the Oruanui ignimbrite (Wilson et al., 2006) produced poor fits for AFC modelling, providing further evidence that these mafic magmas were

\begin{tabular}{lcccccccccc}
\hline Eruption & plag & opx & qtz & ilm & mag & amp & bt & $\begin{array}{c}\text { k- } \\
\text { feld }\end{array}$ & cpx & ap \\
\hline Whakamaru & & & & & & & & & & \\
$\quad$ Waimarino & 23.8 & 9.5 & 28.5 & 2.4 & 2.4 & 14.4 & 9.5 & 9.5 & & \\
$\quad$ Kakuki & 24 & 17.3 & 20.6 & 1.7 & 1.7 & 20.7 & 7 & 7 & & \\
Oruanui $^{1}$ & 70 & 7 & 9 & 4.5 & 4.5 & 4.5 & & & & 0.5 \\
Taupo & 62.5 & 25 & & 6.3 & 6.2 & & & & & \\
Rotorua & 44 & 15 & 22 & 4.1 & 4.1 & 6.5 & 3 & & 1.6 & \\
Ash $^{2}$ & & & & & & & & & & \\
\hline
\end{tabular}

Table 2.6. Crystal assemblages recalculated to $100 \%$ for use with fractional crystallisation models. Additional data are: ${ }^{1}$ Wilson et al. (2006); and ${ }^{2}$ Smith et al. (2004), assuming T1 assemblage. Abbreviations used are: $\mathrm{plag}=$ plagioclase; opx $=$ orthopyroxene; $\mathrm{qtz}=$ quartz; ilm = ilmenite; $\mathrm{mag}=$ magnetite; $\mathrm{amp}=$ amphibole; $\mathrm{bt}=$ biotite; $\mathrm{k}$-feld = $\mathrm{k}$-feldspar; $\mathrm{cpx}=$ clinopyroxene; and ap $=$ apatite .

injected into the magma body at a later stage in the evolution of the magma and did not play a significant role in genesis of the magma, although they may have been important in triggering the eruption (Wilson et al., 2006). Similar AFC models can be calculated for Rotorua and Taupo melt inclusions producing comparable results indicating that $70-80 \%$ fractional crystallisation is required for the generation of rhyolitic melt. However, modelling using a more evolved Taupo Volcanic Zone basalt such as K-Trig (Gamble et al., 1993) as the parental magma produces a better fit for Rotorua and Taupo melt inclusions after $60 \%$ fractional crystallisation and better reproduces the Eu concentrations (Figure 2.10d). 
Progressive AFC of basaltic magma alone cannot, however, explain the observed chemical variation of melt inclusions from within individual suites. Furthermore, $\mathrm{Rb} / \mathrm{Sr}$ ratios of Whakamaru, Oruanui and Rotorua melt inclusions are more enriched than whole rock pumice $\mathrm{Rb} / \mathrm{Sr}$ ratios from the same eruption (Figure 2.9). This suggests that the magma from which the crystals fractionated was more evolved than the magma in which they were erupted, as previously noted for Oruanui melt inclusion compositions (Liu et al., 2006; Wilson et al., 2006).

\begin{tabular}{lcccccccccc}
\hline Rhyolite & \multicolumn{2}{c}{ Oruanui } & \multicolumn{2}{c}{ Healy } & \multicolumn{7}{c}{ Literature } \\
& plag & opx & plag & opx & amp & ilm & mag & $\begin{array}{l}\text { K- } \\
\text { feld }\end{array}$ & bt & ap \\
& & & & & & & & & & \\
\hline $\mathrm{La}$ & 0.17 & 0.01 & 0.29 & 0.002 & 0.36 & 7.1 & 0.66 & 0.1 & 2 & 8 \\
$\mathrm{Ce}$ & 0.12 & 0.03 & 0.20 & 0.01 & 0.68 & 7.8 & 0.71 & 0.06 & 2.82 & 16.6 \\
$\mathrm{Pr}$ & 0.11 & 0.02 & 0.16 & 0.03 & & & & & & \\
$\mathrm{Nd}$ & 0.06 & 0.02 & 0.11 & 0.02 & 1.6 & 7.6 & 0.93 & 0.04 & 2 & 21 \\
$\mathrm{Sm}$ & 0.14 & 0.13 & 0.15 & 0.09 & 2.3 & 6.9 & 1.2 & 0.04 & 1.4 & 20.7 \\
$\mathrm{Eu}$ & 2.46 & 0.14 & 2.28 & 0.09 & 3.2 & 2.5 & 0.91 & 3.3 & 0.85 & 14.5 \\
$\mathrm{Gd}$ & 0.15 & 0.16 & 0.17 & 0.14 & & & & & & \\
$\mathrm{Dy}$ & 0.09 & 0.28 & 0.05 & 0.19 & 4.92 & 4.9 & 2.4 & 0.9 & 0.76 & 16.9 \\
$\mathrm{Er}$ & 0.15 & 0.57 & 0.09 & 0.55 & 7.28 & & & & & \\
$\mathrm{Yb}$ & 0.4 & 1.01 & 0.13 & 0.98 & 1.8 & 4.1 & 0.44 & 0.03 & 0.6 & 9.4 \\
$\mathrm{Lu}$ & 0.54 & 1.19 & 0.00 & 0.78 & 1.8 & 3.6 & 0.3 & 0.02 & 0.6 & 7.9 \\
\hline
\end{tabular}

Table 2.7. Rare earth element distribution coefficients for rhyolitic magmas used in the modelling of the trace element concentrations of Taupo Volcanic Zone melt inclusions. Plagioclase and orthopyroxene distribution coefficients from the Oruanui and Healy samples are determined from this study. Additional sources: Mysen and Virgo (1980); Watson and Green (1981); Nash and Crecraft (1985); and Bacon and Druitt (1988).

Melt inclusion compositions for individual eruptions lie on a mixing line between a parental rhyolitic magma generated by the AFC model described above (hereafter termed 'rhyolitic melt fraction') and a greywacke partial melt. This can be modelled using a greywacke partial melt calculated using 
the greywacke melting model of Reid (1982, 1983), and the least evolved melt inclusion composition as the parental composition.

Whakamaru melt inclusion trends (Figure 2.11) can be obtained by mixing of the end-member rhyolitic melt fraction generated by AFC processes and

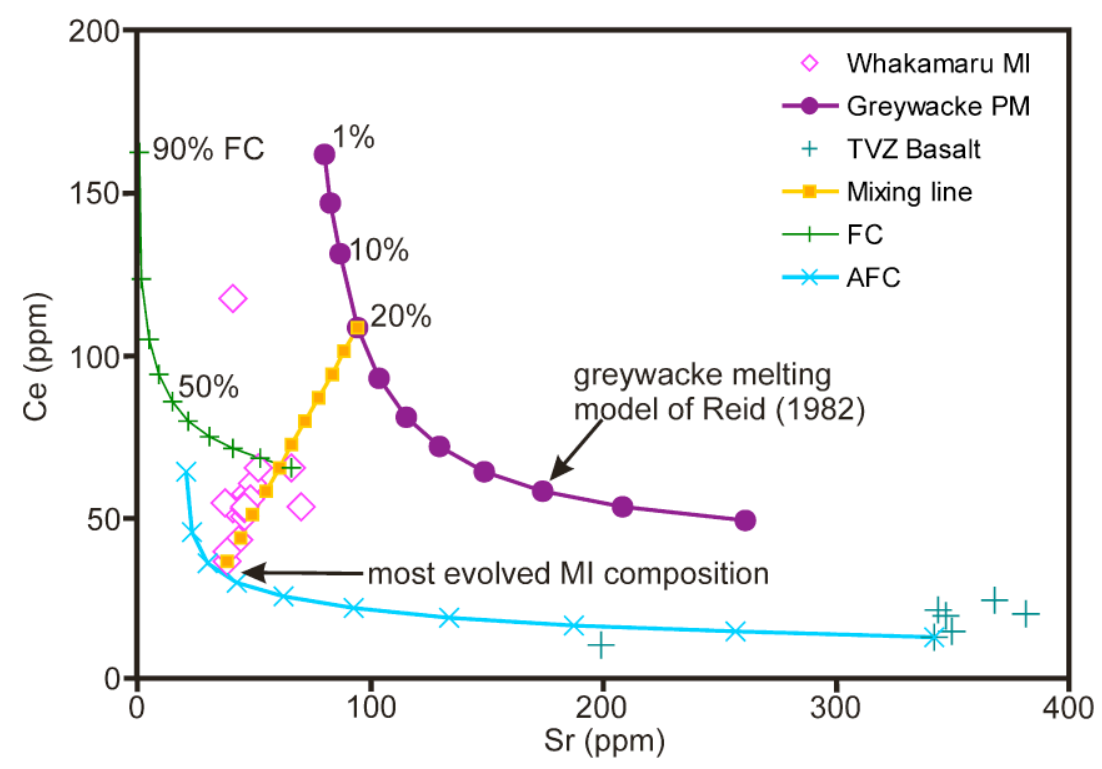

Figure 2.11. Sr versus $\mathrm{Ce}$ trace element diagram showing a magma mixing model to produce Whakamaru melt inclusion variation. Mixing of between 10 and $50 \%$ of a $20 \%$ greywacke partial melt with an evolved rhyolitic melt explains the observed trace element trends (see text for discussion). Compositions of greywacke melts were calculated using the Shaw equation and a Torlesse greywacke composition (Reid, 1982) and perfect fractional crystallisation modelling of melt inclusions was conducted using the observed crystal assemblages (Table 2.6) and distribution coefficients from the literature (Table 2.7).

a $20 \%$ greywacke partial melt. The proportion of partial melt required ranges from $10 \%$ for the most evolved rhyolitic composition (highest $\mathrm{Rb} / \mathrm{Sr}$ ) to $50 \%$ for the least evolved composition (Figure 2.11). Similar mixing trends can be obtained for the Oruanui melt inclusions, with up to $70 \%$ of a $50 \%$ greywacke partial melt required to be added to the rhyolitic melt 
fraction for the most extreme melt inclusion compositions, but the majority of melt inclusions require mixing with only $30-40 \%$ greywacke melts. Rotorua and Taupo melt inclusions show only a minimal contribution from greywacke partial melts.

\subsubsection{Silicic magma generation model for the Taupo Volcanic Zone}

Taupo Volcanic Zone silicic magmas are envisaged here to form through a two-stage process of fractional crystallisation from a basaltic parental magma ( $\geq 80 \%$ ) with coupled assimilation $(20 \%)$ of greywacke country rock, followed by mixing with up to $40 \%$ greywacke partial melt(s) prior to eruption. Any model for silicic magma petrogenesis must provide a mechanism for these processes to occur, for the predominance of silicic magma generation over other compositions, and account for more evolved compositions being the most crystal poor.

Large scale silicic magma bodies evolve over a significant period of time, as evidenced by the $>40$ ka life span of the Oruanui magma (Charlier et al., 2005; Wilson et al., 2006). This allows multiple processes to occur, including AFC, mixing with partial melts of greywacke, and allowing crystal mush zones to develop from which evolved melts are ultimately extracted. Crystal mush zones are bodies of semi-solidified magmas consisting of a 'rigid' framework of $40-50 \%$ interlocking crystals that allow percolation of melts through the crystal network and accumulation of less dense melt above the mush zone (Bachman and Bergantz, 2004, 2008). The framework nature of the crystal mush zone prohibits the migration of 
large proportions of crystals into the upper crustal magma chamber; instead only small (e.g. zircon) and semi-formed crystals are entrained (Bachman and Bergantz, 2004). This process could explain the crystal-poor nature of many silicic eruptives in the Taupo Volcanic Zone and other arcs worldwide, such as the Izu-Bonin arc (Shukuno et al., 2006; Wysoczanski and Tani, 2006). The more crystal rich eruptions (e.g. Whakamaru) may have resulted from a longer residence time in secondary magma chambers where crystal fractionation continued, but without sufficient time for a crystal mush zone to develop.

Geophysical data indicate the presence of solidified/semi-solidified magma bodies at 10-25 km depth beneath known caldera structures in the Taupo Volcanic Zone interpreted to represent crystal mush bodies and partial melts (Heise et al., 2007). Static crystal mush resident in the crust cools more slowly than crystal poor magma (Bachmann and Bergantz, 2004) providing a long term heat source, maintaining the elevated heat flow observed in the Taupo Volcanic Zone (Stern, 1987) and promoting the melting of greywacke country rock. Partial melting of greywacke provides space in the crust to accommodate upper crustal magma chambers and allows mixing of individual melt batches within the crust.

Crystal mush can also be mobilised and erupted to produce andesitic bulk rock compositions, as may be the case for Taupo Volcanic Zone andesites, which have intense disequilibrium textures between the crystal cargo and the rhyolitic groundmass (Gamble et al., 1990; Gamble et al., 2003; Price et 
al., 2005). It should be noted that Taupo melt inclusion compositions overlap with Ruapehu groundmass glass (Price et al., 2005) and both overlap with Torlesse greywacke (Figure 2.12). Applying the same AFC model used previously, Taupo ignimbrite melt inclusions can be modelled from $0-50 \%$ fractional crystallisation of Ruapehu groundmass glass (Figure 2.12), providing evidence for a strong petrogenetic link between Taupo Volcanic Zone silicic magmas and andesites.

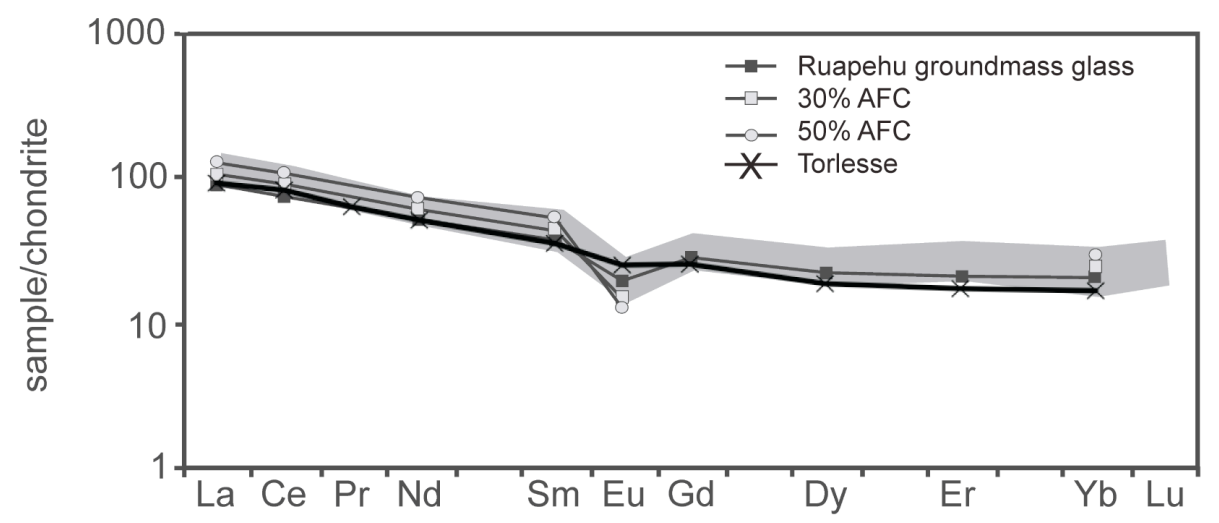

Figure 2.12. Chondrite-normalised rare earth element diagram for $30 \%$ and $50 \%$ AFC modelling to obtain the Taupo Ignimbrite melt inclusion composition using Ruapehu groundmass glass (Price et al., 2005) as the parental composition and assimilating Torlesse greywacke (Reid, 1982). Shaded region represents the range of Taupo Ignimbrite melt inclusion compositions. Proportions of crystallising phases are: plagioclase $62 \%$; orthopyroxene $25 \%$; ilmenite $6.5 \%$; and magnetite $6.5 \%$.

If these crystal rich magmas of andesitic composition with rhyolitic groundmass (e.g. Price et al., 2005; Humphreys et al., 2006) continued to fractionate, the rhyolitic upper part of the crystal mush zone would co-exist with more highly evolved interstitial liquids (high $\mathrm{Rb} / \mathrm{Sr}$ ratios). Crystals that form in this part of the crystal mush would entrap melt inclusions with a highly evolved rhyolitic composition that would subsequently be entrained 
and transported into a secondary upper crustal magma chamber where the magma could mix with greywacke partial melts (lower $\mathrm{Rb} / \mathrm{Sr}$ ratios). This mechanism would also account for melt inclusions having more evolved $\mathrm{Rb} / \mathrm{Sr}$ ratios than pumice from the same eruptions, as observed in Taupo Volcanic Zone silicic deposits.

\subsection{Conclusions}

A combination of new melt inclusion major and trace element data and previously reported data for eruptives from the Taupo Volcanic Zone and Kermadec arc allow the following conclusions to be made on silicic magma genesis in continental and oceanic arcs:

1. The generation of silicic magmas from the oceanic Healy Volcano can be modelled by (62-76\%) fractional crystallisation of a basaltic parental melt.

2. In contrast, quantitative modelling of REE concentrations of Taupo Volcanic Zone melt inclusions indicates a two-stage magma petrogenetic model. Basaltic melts undergo extreme fractionation and assimilation of greywacke country rock at depth $(10-25 \mathrm{~km})$ to form crystal mush zones and rhyolitic magmas. The magma separates from the crystal mush to migrate to secondary magma chambers, where little or no fractionation occurs. Here the magma mixes with varying proportions (10-70\%) of greywacke partial melt(s) prior to eruption. The result is a crystal-poor silicic magma with melt inclusion compositions 
that represent the fractionated rhyolitic melts formed in a mush zone, and whole rock pumice compositions that are a mix of the fractionated melt and greywacke partial melt.

3. The addition of greywacke partial melt provides the volume of material required to feed the large-volume eruptions typical of the last $1.6 \mathrm{Ma}$ of the Taupo Volcanic Zone and to create the larger volume eruptions than those observed in the southern Kermadec Arc where no continental lithosphere is present.

4. The range in parental mafic magma compositions, varying ratios of greywacke assimilant, proportions of fractionation and of phases crystallised, and the degree of mixing of magmas and greywacke partial melts has the ability to produce the entire spectrum of silicic volcanism observed in the Taupo Volcanic Zone. This suggests that pure crustal anatexis does not play a significant part in the generation of large-scale silicic volcanism in continental arcs. 


\title{
Chapter 3
}

\section{The speciation and degassing of water in rhyolitic melt inclusions: case studies from the Taupo Volcanic Zone, New Zealand.}

\begin{abstract}
Water speciation and concentration data have been determined for melt inclusions in crystals from rhyolitic magmas erupted from the Taupo Volcanic Zone, New Zealand. Quartz and plagioclase hosted rhyolitic melt inclusions from the Whakamaru and Taupo ignimbrites, respectively, were analysed for water and carbon dioxide by Fourier transform infrared spectroscopy. Total measured water concentrations range between 1.4-4.4 wt $\%$ for Whakamaru and 1.9-5.1 $\mathrm{wt} \%$ for Taupo melt inclusions, respectively. The melt inclusions have molecular water to hydroxyl concentrations that are inconsistent with the speciation models determined for groundmass rhyolitic glasses. This is interpreted as evidence for a secondary process that alters the water speciation of rhyolitic melt inclusions, but not groundmass glasses. Spectroscopic Fourier transform infrared imaging shows the inclusions are not ruptured during eruption and could provide evidence to indicate water is degassed from inclusions through the crystalline diffusion of hydroxyl groups prior to quenching. This results in a significant underestimation of the partial pressure of water of melt inclusions and thus the inferred depths of the crystallising magma bodies. Revised depths of the crystallising magma bodies based on maximum initial magmatic water concentrations of ca. 8.3 and $8.4 \mathrm{wt} \%$ derived from plagioclase-melt equilibria reconciles geochemical and geophysical evidence that indicate such magmas reside at depths $>6 \mathrm{~km}$.
\end{abstract}




\subsection{Introduction}

Continental silicic arc margins, specifically those surrounding the Pacific Rim, have been the major source of explosive eruptions in the last $2 \mathrm{Myr}$ (Lowenstern, 2006), particularly the hyper-productive Taupo Volcanic Zone of New Zealand. It is the volatile content of these magmas that causes their explosivity and the resulting eruption dynamics. Water is the dominant volatile species in rhyolites and fundamental in the magma generation, influencing the magmatic viscosity, density and composition (e.g. Tuttle and Bowen, 1958; Shaw, 1972; Ochs and Lange, 1997). On eruption volatile species are degassed into the atmosphere erasing any evidence of the initial magmatic water concentrations (e.g. Delaney et al., 1978; Gerlach, 1986; Dixon et al., 1995; Newman and Lowenstern, 2002). An exception may occur in the form of melt inclusions that remain pressurised during eruption, potentially preserving a record of the magmatic water concentration (e.g. Sobolev and Chaussidon, 1996; Wallace, 2005). With the advances in microbeam techniques in the last few decades, melt inclusions as small as $20-30 \mu \mathrm{m}$ can now be characterised for elemental and volatile concentrations (e.g. Bacon et al., 1992; Barclay et al., 1996, 1998; Sobolev and Chaussidon, 1996; Kamenetsky, 1996; Danyushevsky et al., 2002; Hauri et al., 2002; Liu et al., 2006; Nichols and Wysoczanski, 2007). The two most commonly utilised techniques for the characterisation of $\mathrm{H}_{2} \mathrm{O}$ and $\mathrm{CO}_{2}$ in melt inclusions are Fourier transform infrared (FTIR) spectroscopy and secondary ion mass spectrometry (SIMS). The advantage of FTIR spectroscopy is the ability to directly determine the speciation of volatiles, such as the proportion of molecular water (hereafter $\mathrm{H}_{2} \mathrm{O}_{\mathrm{m}}$ ) and hydroxyl groups (hereafter, $\mathrm{OH}^{-}$) in a sample. The speciation of water is significant as it controls the diffusion of water through 
rhyolitic melts and hence dictates the magmatic behaviour and subsequent magmatic dynamics (Zhang et al., 1991).

A number of previous studies have focussed on the characterisation of $\mathrm{H}_{2} \mathrm{O}_{\mathrm{m}}$ and $\mathrm{OH}^{-}$interaction and behaviour in groundmass rhyolitic glasses (e.g. Stolper, 1982; Silver et al., 1990; Zhang et al., 1991; Zhang, 1994; Zhang et al., 1995, 1997a, 2000; Behrens and Nowark, 1997; Ihinger et al., 1999). However, there has been little consideration on whether the behaviour of $\mathrm{H}_{2} \mathrm{O}_{\mathrm{m}}$ and $\mathrm{OH}^{-}$in rhyolitic melt inclusions is consistent with that determined for groundmass glasses or whether the presence of a crystal host causes secondary effects on the final measured concentrations of $\mathrm{H}_{2} \mathrm{O}_{\mathrm{m}}$ and $\mathrm{OH}^{-}$groups. This is significant as much of our knowledge of pre-eruptive magmatic water concentrations are achieved through melt inclusion studies and it is imperative to our understanding of volcanic processes to accurately constrain not only the total water concentrations (hereafter $\mathrm{H}_{2} \mathrm{O}_{\mathrm{t}}$ ) but also the proportions of $\mathrm{H}_{2} \mathrm{O}_{\mathrm{m}}$ and $\mathrm{OH}^{-}$in the melt prior to eruption (Zhang et al., 1997b).

Many large-volume silicic eruptions, including four of the youngest known supereruptions worldwide, have originated from the hyper-productive Taupo Volcanic Zone during the Quaternary (Wilson et al., in press). Here we examine the water speciation of 8 quartz-hosted melt inclusions from the $\sim 330 \mathrm{ka}$ Whakamaru ignimbrite, currently the largest supereruption recognised from the region with estimated volumes $>1500 \mathrm{~km}^{3}$ (Wilson et al., in press), and 31 plagioclase- and orthopyroxene-hosted melt inclusions from the smaller volume $\left(35 \mathrm{~km}^{3}\right) 1800$ years BP Taupo eruption (Wilson and Walker, 1985). The 
measured speciation of melt inclusions are compared to the hypothetical concentrations derived from experimental studies of water speciation in groundmass rhyolitic glasses. We show that there are significant discrepancies and discuss the possible reasons for these, and the implications that this has for our understanding of rhyolitic magma chambers and the depth of the crystallising magma body.

\subsection{Water speciation}

Water occurs as two species in silicate melts, $\mathrm{H}_{2} \mathrm{O}_{\mathrm{m}}$ and $\mathrm{OH}^{-}$groups, with the interaction of these species described by the following equilibrium reaction:

$$
\mathrm{H}_{2} \mathrm{O}_{m}+\mathrm{O} \Leftrightarrow 2 \mathrm{OH}^{-}
$$

where $\mathrm{H}_{2} \mathrm{O}_{\mathrm{m}}$ represents molecular water, $\mathrm{O}$ is an anhydrous oxygen and $\mathrm{OH}^{-}$is a hydroxyl group bonded to a silicate polymer (Stolper, 1982). The corresponding equilibrium constant, $\mathrm{K}$, is defined as;

$$
K=\frac{\left[O H^{-}\right]^{2}}{\left[\mathrm{H}_{2} \mathrm{O}_{m}\right]\left[\mathrm{OH}^{-}\right]}
$$

where brackets indicate activities and can be approximated by mole fractions on a single oxygen basis (Stolper, 1982; Zhang et al., 1991; Zhang, 1999). At low total water concentrations $\left(\mathrm{H}_{2} \mathrm{O}_{\mathrm{t}}\right)$ contents, water is predominantly dissolved as $\mathrm{OH}^{-}$, whereas at higher $\mathrm{H}_{2} \mathrm{O}_{\mathrm{t}}$ contents, $\mathrm{H}_{2} \mathrm{O}_{\mathrm{m}}$ becomes dominant (Stolper, 1982; Silver et al., 1990). The concentration at which $\mathrm{H}_{2} \mathrm{O}_{\mathrm{m}}$ becomes the principal water species varies with bulk composition and cooling rate (Stolper, 1982; Silver et al., 1990; Zhang, 1999; Zhang et al., 1995, 1997a, 2000; Wallace, 2003). As the cooling reaction is a continuous process, the rate of the reaction decreases with decreasing temperature and equilibrium between $\mathrm{H}_{2} \mathrm{O}_{\mathrm{m}}$ and $\mathrm{OH}^{-}$ 
is not always attained prior to quenching (Zhang et al., 1995, 1997a, 2000; 2007 Zhang, 1999). Instead Q, (K at some temperature: Zhang et al., 1991) is substituted for K (Equation 3.2) when reactions do not attain equilibrium (Zhang et al., 1991). This temperature is defined as the apparent equilibrium temperature $\left(\mathrm{T}_{\mathrm{ae}}\right)$ of the reaction recorded by the measured water speciation of glasses and does not represent the magmatic temperature (Zhang et al., 1991; Zhang, 1994; Ihinger et al., 1999).

Experimental studies have demonstrated that $\mathrm{H}_{2} \mathrm{O}_{\mathrm{m}}$ is the primary diffusing water species at low temperatures $\left(400-500^{\circ} \mathrm{C}\right)$ and $\mathrm{OH}^{-}$groups may be produced as a result of the reaction of the diffusing $\mathrm{H}_{2} \mathrm{O}_{\mathrm{m}}$ and the silicate structure (Stolper, 1982; Zhang et al., 1991; 2000). The rate at which water diffuses through a melt is critical as: (1) it controls the formation of bubbles during degassing, thus influencing the subsequent eruption dynamics; and (2) at low temperatures it governs the availability of water for hydration reactions (Zhang et al., 1991).

\subsection{Samples and methods}

The Whakamaru supereruption deposited four ignimbrite sheets (Brown et al., 1998). The most voluminous is the Whakamaru ignimbrite possessing a mineral assemblage of quartz, plagioclase, orthopyroxene, amphibole, ilmenite, magnetite, K-feldspar and biotite (Brown et al., 1998; Chapter 2). Importantly, large $(>50 \mu \mathrm{m})$ melt inclusions are present in quartz crystals. These inclusions are green to brown in colour and frequently host numerous micro-phenocrysts. Water analyses were conducted on non-homogenised melt inclusions (inclusions that have not been homogenised prior to analysis to create inclusions composed 
of $100 \%$ glass) composed of $>90 \%$ glass sampled from the discontinuous crystal lag layer at the base of the ignimbrite.

One of the largest rhyolitic eruptions in historic times from the Taupo Volcanic Zone is the 1800 years BP Taupo eruption (Wilson and Walker, 1985). Samples were taken from the youngest and most voluminous unit, the Taupo ignimbrite, (sample TA2) and associated crystal lag layer (sample TA1). The mineral assemblage consists of plagioclase, orthopyroxene, and Fe-Ti oxides with both plagioclase- and orthopyroxene-hosted melt inclusions analysed for volatile concentrations. Melt inclusions are brown in colour and often include a small vapour bubble.

Whakamaru and Taupo melt inclusions are of rhyolitic composition (Table 3.1) (Chapter 2). Speciation curves are calculated throughout this study using the regular solution model of Ihinger et al. (1999), as experimental studies have shown these models described the experimental data more adequately at high $\mathrm{H}_{2} \mathrm{O}_{\mathrm{t}}(>2.5 \mathrm{wt} \%$ ) than an ideal solution model (Ihinger et al., 1999). A mean molecular weight of anhydrous melt inclusions on a single oxygen basis (Silver et al., 1990) of $31.81 \mathrm{~g} / \mathrm{mol}$ was calculated from melt inclusion compositions.

Full details of sample preparation are given in Chapter 2 with only those specific to FTIR spectroscopy analyses described here. Crystals were adhered to a glass slide using crystal bond cement and polished with 600, 2400 and $4000 \mathrm{SiC}$ grit paper to expose the melt inclusion. The resulting crystal wafer was then turned 
and the opposite side of the inclusion polished to create a doubly exposed inclusion.

\begin{tabular}{ccc}
\hline$(\mathrm{wt} \%)$ & Whakamaru & Taupo \\
\hline $\mathrm{SiO}_{2}$ & 76.56 & 75.96 \\
$\mathrm{TiO}_{2}$ & 0.15 & 0.29 \\
$\mathrm{Al}_{2} \mathrm{O}_{3}$ & 13.1 & 13.5 \\
$\mathrm{FeO}$ & 0.51 & 2.17 \\
$\mathrm{MnO}$ & 0.10 & 0.19 \\
$\mathrm{MgO}$ & 0.05 & 0.30 \\
$\mathrm{CaO}$ & 0.67 & 1.55 \\
$\mathrm{Na}_{2} \mathrm{O}$ & 3.24 & 3.28 \\
$\mathrm{~K}_{2} \mathrm{O}$ & 5.20 & 2.38 \\
$\mathrm{Cl}$ & 0.38 & 0.30 \\
$\mathrm{SO}_{3}$ & 0.04 & 0.05 \\
$\mathrm{Total}$ & 100.00 & 100.00 \\
\hline
\end{tabular}

Table 3.1. Mean anhydrous major element composition of Whakamaru and Taupo melt inclusions.

Water analyses were conducted by FTIR spectroscopy at IFREE, Japan Agency for Marine-Earth Science and Technology (JAMSTEC), Japan. Analytical sessions were conducted over a period of approximately two years. Both conventional FTIR and spectroscopic imaging FTIR analyses of melt inclusions were conducted on a Varian FTS Stingray 7000 spectrometer with a $\mathrm{KBr}$ beamsplitter following the method of Wysoczanski and Tani (2006). The aperture ranged between 10-30 $\mu \mathrm{m}$ square with the majority of analyses conducted at $20 \mu \mathrm{m}$ square. The concentrations of water species in melt inclusions were calculated by a modified Beer-Lambert law (Newman et al., 1986; Ihinger et al., 1994). 
Total water concentrations were determined using the height above background of the overtone of the bending vibration of the $\mathrm{H}_{2} \mathrm{O}_{\mathrm{m}}$ group at $5200 \mathrm{~cm}^{-1}$ and molar absorptivity of $1.861 \mathrm{~mol}^{-1} \mathrm{~cm}$ and $\mathrm{OH}^{-}$concentrations were calculated using the overtone of the stretching and bending of $\mathrm{Si}-\mathrm{OH}^{-}$groups at $4500 \mathrm{~cm}^{-1}$ and molar absorptivity of $1.5 \mathrm{1} \mathrm{mol}^{-1} \mathrm{~cm}$ (Ihinger et al., 1994). Total $\mathrm{H}_{2} \mathrm{O}$ was calculated summing the $\mathrm{H}_{2} \mathrm{O}_{\mathrm{m}}$ concentration from the peak at $5200 \mathrm{~cm}^{-1}$ and $\mathrm{OH}^{-}$ concentration from the peak at $4500 \mathrm{~cm}^{-1}$. When the absorbance was low, the fundamental $\mathrm{OH}^{-}$stretching vibration at $3535 \mathrm{~cm}^{-1}$ and molar absorptivity of $90 \pm$ $21 \mathrm{~mol}^{-1} \mathrm{~cm}$ (Hauri et al., 2002) and the height of the $\mathrm{HOH}$ bending vibration at $1630 \mathrm{~cm}^{-1}$ and molar absorptivity of $56 \pm 21 \mathrm{~mol}^{-1} \mathrm{~cm}$ (Newman et al., 1986) were used to calculate $\mathrm{H}_{2} \mathrm{O}_{t}$ and $\mathrm{H}_{2} \mathrm{O}_{m}$ contents, respectively. $\mathrm{OH}^{-}$concentrations were calculated from the difference in $\mathrm{H}_{2} \mathrm{O}_{\mathrm{t}}\left(3535 \mathrm{~cm}^{-1}\right)$ and $\mathrm{H}_{2} \mathrm{O}_{\mathrm{m}}\left(1630 \mathrm{~cm}^{-1}\right)$. In each case peak heights were determined using a linear baseline; applying a flexicurve baseline produced results consistent with the linear baseline. The molecular $\mathrm{CO}_{2}$ peaks at $2350 \mathrm{~cm}^{-1}$ and the carbonate doublet peaks of $\mathrm{CO}_{3}{ }^{2-}$ at $1515 \mathrm{~cm}^{-1}$ and $1435 \mathrm{~cm}^{-1}$ were analysed (Fine and Stolper, 1985; Ihinger et al., 1994), but were found to be below detection limits. Glass densities were calculated using the method of R. Lange described by Luhr (2001) from electron microprobe analyses of melt inclusion compositions (Chapter 2). These ranged between $2303 \mathrm{~g} / 1$ and $2361 \mathrm{~g} / 1$ and a value of $2350 \mathrm{~g} / 1$ was used for all BeerLambert law calculations, which equates to a maximum of $0.06 \mathrm{wt} \%$ error on the calculated water concentrations. Sample thicknesses of doubly exposed inclusions were determined at the analytical point using interference fringes on reflection spectra (Wysoczanski and Tani, 2006; Nichols and Wysoczanski, 2007). Thicknesses of melt inclusions suspected to retain a thin wafer of the host 
crystal were determined by placing the crystals side-on in crystal bond on a glass slide and then examining them under the microscope. Uncertainties of calculated water concentrations are estimated to be $10 \%$ (e.g. Wysoczanski and Tani, 2006).

\subsection{Results}

Water concentrations range from $1.43-4.43 \mathrm{wt} \%$ for the Whakamaru melt inclusions and 1.91-5.14 wt\% for the Taupo melt inclusions (Table 3.2). Water concentrations of the Taupo inclusions show no variation between the two different samples TA1 and TA2 and overlap with water concentrations determined by Dunbar and Kyle (1993) using SIMS. $\mathrm{CO}_{2}$ was not detected in any of the analysed melt inclusions. Detection limits for $\mathrm{CO}_{2}$ were calculated for individual inclusions by taking the minimum possible detectable absorbance peak as 0.01 (ca. three times background) and the specific melt inclusion thickness. This resulted in average $\mathrm{CO}_{2}$ detection limits of $36 \mathrm{ppm}$ and $53 \mathrm{ppm}$ for Whakamaru and Taupo melt inclusions respectively (Table 3.2).

Variations in the measured speciation of Whakamaru and Taupo melt inclusions are shown in Figure 3.1 and are evaluated against experimentally constrained speciation curves (Ihinger et al., 1999). Natural rhyolitic glasses exhibit measured speciation trends that run parallel to the experimentally determined speciation curves (Newman et al., 1988). However, the measured speciation of Whakamaru and Taupo melt inclusions do not form linear arrays but display a 


\begin{tabular}{|c|c|c|c|c|c|c|c|c|}
\hline Sample & Host & $\begin{array}{l}\mathrm{H}_{2} \mathrm{O}_{\mathrm{m}} \\
(\mathrm{wt} \%)\end{array}$ & $\begin{array}{c}\mathrm{OH} \\
(\mathrm{wt} \%)\end{array}$ & $\begin{array}{l}\mathrm{H}_{2} \mathrm{O}_{\mathrm{t}} \\
(\mathrm{wt} \%)\end{array}$ & $\begin{array}{l}\mathrm{A} 5200 \\
\mathrm{~mm}^{-1}\end{array}$ & $\begin{array}{l}\mathrm{A} 4500 \\
\mathrm{~mm}^{-1}\end{array}$ & $\begin{array}{l}\text { Thickness } \\
(\mu \mathrm{m})\end{array}$ & $\begin{array}{l}\mathrm{CO}_{2} \text { detection } \\
\text { limits }(\mathrm{ppm})\end{array}$ \\
\hline TA1_18-1.1 & opx & 2.27 & 0.30 & 2.57 & 0.547 & 0.063 & 32 & 54 \\
\hline TA1_18-1.1 & opx & 1.84 & 0.68 & 2.52 & 0.442 & 0.139 & 33 & 53 \\
\hline TA1_13 & opx & & & 2.16 & & & & \\
\hline TA1_40 & opx & 1.80 & 0.00 & 1.80 & & & 31 & 56 \\
\hline TA1_41-1.1 & opx & 2.52 & 0.92 & 3.44 & 0.611 & 0.191 & 35 & 50 \\
\hline TA1_41-2.1 & opx & 2.88 & 0.87 & 3.75 & 0.719 & 0.185 & 27 & 64 \\
\hline TA1_41-3.1 & opx & 2.02 & 0.97 & 2.99 & 0.490 & 0.200 & 20 & 87 \\
\hline TA1_29-1.1 & plag & 2.92 & 1.14 & 4.06 & 0.705 & 0.236 & 59 & 29 \\
\hline TA1_29-2.1 & plag & 2.79 & 0.70 & 3.49 & 0.682 & 0.227 & 22 & 79 \\
\hline TA1_30-1.1 & plag & 3.32 & 0.00 & 3.32 & & & 35 & 50 \\
\hline TA1_43-1.1 & plag & 2.35 & 0.71 & 3.06 & 0.570 & 0.147 & 30 & 58 \\
\hline TA1_43-2.1 & plag & 1.92 & 0.72 & 2.64 & 0.465 & 0.150 & 40 & 43 \\
\hline TA1_43-3.1 & plag & 1.90 & 0.69 & 2.59 & 0.460 & 0.143 & 40 & 43 \\
\hline TA1_44-1.1 & plag & 2.08 & 0.23 & 2.31 & & & 39 & 45 \\
\hline TA1_44-2.1 & plag & 1.78 & 0.32 & 2.10 & & & 15 & 116 \\
\hline TA1_50.1 & plag & 2.12 & 1.26 & 3.38 & 0.514 & 0.246 & 50 & 35 \\
\hline TA1_51.1 & plag & 1.81 & 1.21 & 3.01 & 0.438 & 0.236 & 57 & 30 \\
\hline TA1_52.1 & plag & 3.51 & 1.63 & 5.14 & 0.852 & 0.318 & 30 & 58 \\
\hline TA1_53.1 & plag & 1.20 & 1.13 & 2.33 & 0.259 & 0.196 & 35 & 50 \\
\hline TA1_55.1 & plag & 1.83 & 0.58 & 2.42 & 0.443 & 0.115 & 117 & 15 \\
\hline TA1_61.1 & plag & 3.57 & 1.00 & 4.57 & 0.955 & 0.216 & 118 & 15 \\
\hline TA1_76.1 & plag & 2.90 & 1.61 & 4.50 & 0.703 & 0.314 & 95 & 18 \\
\hline TA1_77.1 & plag & 2.10 & 0.78 & 2.88 & 0.495 & 0.149 & 55 & 32 \\
\hline TA1a_8-1.1 & plag & 1.72 & 1.06 & 2.78 & 0.412 & 0.218 & 17 & 102 \\
\hline TA1a_8-2.1 & plag & 2.37 & 0.82 & 3.19 & & & 25 & 70 \\
\hline TA2_22-2.1 & plag & 3.45 & 0.32 & 3.77 & & & 64 & 27 \\
\hline TA2_22-3.1 & plag & 2.03 & 0.12 & 2.15 & & & 22 & 79 \\
\hline TA2_31-1.1 & opx & 3.08 & 0.00 & 3.08 & & & 30 & 58 \\
\hline TA2_31-2.1 & opx & 2.64 & 0.92 & 3.56 & 0.640 & 0.190 & 30 & 58 \\
\hline TA2_32-1.1 & opx & 3.16 & 1.86 & 5.02 & 0.766 & 0.386 & 35 & 50 \\
\hline TA2_32-2.1 & opx & 4.75 & 0.23 & 4.98 & & & 20 & 87 \\
\hline WH1_4-1.1 & qtz & 3.18 & 0.74 & 3.92 & 0.759 & 0.208 & 66 & 26 \\
\hline WH1_19-1.1 & qtz & 1.02 & 0.40 & 1.43 & 0.241 & 0.099 & 80 & 22 \\
\hline WH1_19-3.1 & qtz & 3.06 & 0.03 & 3.07 & & & 30 & 58 \\
\hline WH1_50-1 & qtz & 3.50 & 0.78 & 4.28 & 0.847 & 0.154 & 37 & 47 \\
\hline WH1_51-1 & qtz & 3.07 & 1.36 & 4.43 & 0.745 & 0.265 & 75 & 23 \\
\hline WH1_52-1 & qtz & 2.67 & 0.72 & 3.40 & 0.648 & 0.142 & 48 & 36 \\
\hline WH1_52-2 & qtz & 2.71 & 0.65 & 3.36 & 0.657 & 0.128 & 61 & 28 \\
\hline WH1_53-1 & qtz & 2.57 & 0.89 & 3.46 & 0.623 & 0.174 & 38 & 46 \\
\hline
\end{tabular}

Table 3.2. Measured speciation of melt inclusions from the Taupo eruption (TA1 - crystal lag; TA2 - Taupo ignimbrite) and Whakamaru ignimbrite (WH1). Water concentrations are calculated using the Beer-Lambert law as discussed in the text from the $5200 \mathrm{~cm}^{-1}$ and $4500 \mathrm{~cm}^{-1}$ peaks where shown and using the $3500 \mathrm{~cm}^{-1}$ and $1630 \mathrm{~cm}^{-1}$ for all others. See text for calculation of $\mathrm{CO}_{2}$ detection limits. Abbreviations: $\mathrm{H}_{2} \mathrm{O}_{\mathrm{t}}=$ total water concentrations; $\mathrm{A} 5200=$ peak height at $5200 \mathrm{~cm}^{-1}$ per $\mathrm{mm}$; $\mathrm{A} 4500=$ peak height at $4500 \mathrm{~cm}^{-1}$ per $\mathrm{mm}$. 


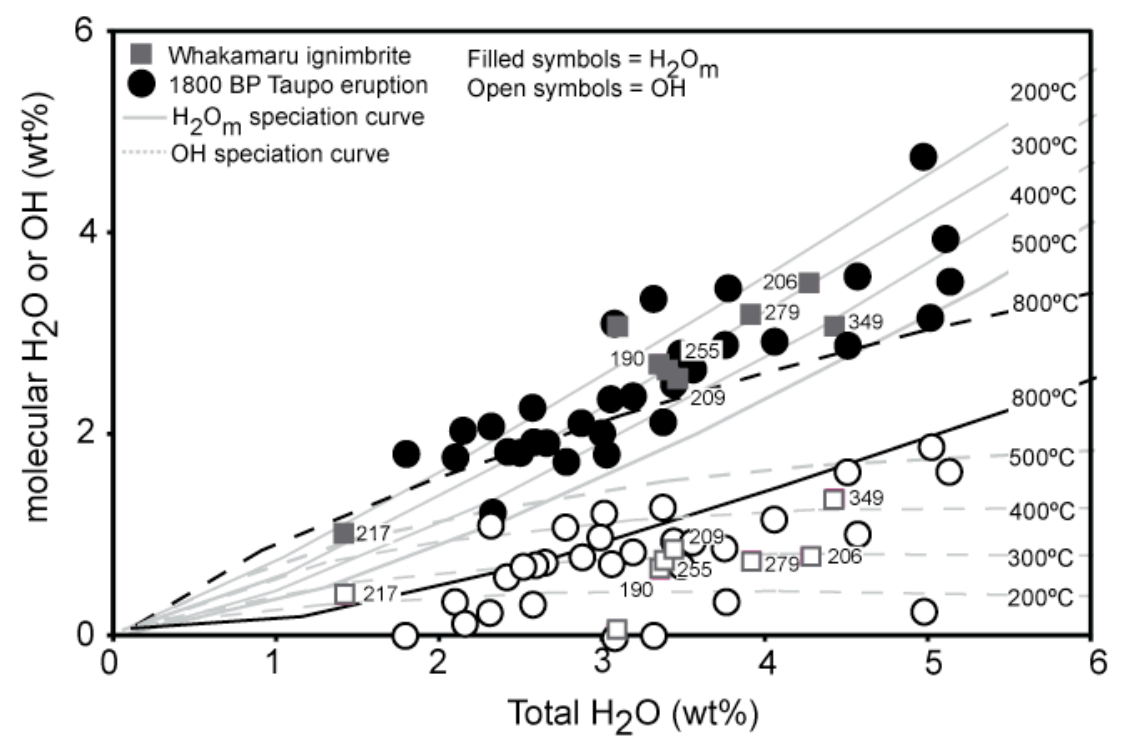

Figure 3.1. Measured water speciation of Whakamaru (squares) and Taupo (circles) melt inclusions. $\mathrm{H}_{2} \mathrm{O}_{\mathrm{m}}$ concentrations are shown by filled symbols and $\mathrm{OH}^{-}$concentrations by open symbols. Speciation curves for $\mathrm{H}_{2} \mathrm{O}_{\mathrm{m}}$ (solid lines) and $\mathrm{OH}^{-}$(dashed lines) are plotted for $200^{\circ} \mathrm{C}$, $300^{\circ} \mathrm{C}, 400^{\circ} \mathrm{C}, 500^{\circ} \mathrm{C}$ (thin lines) and $800^{\circ} \mathrm{C}$ (thick line) using the regular solution model of Ihinger et al. (1999). $\mathrm{T}_{\mathrm{ae}}$ of Whakamaru melt inclusions are shown calculated from the method of Ihinger et al. (1999).

range of speciation spread across a region corresponding to $\mathrm{T}_{\mathrm{ae}}$ of $\leq 500^{\circ} \mathrm{C}$ with no systematic variation (Figure 3.1), consistent with heterogeneous cooling of individual inclusions. Application of the hydrous species geospeedometer (Zhang et al., 2000; Xu and Zhang, 2002) to the measured speciation results in only $28 \%$ of Whakamaru inclusions producing realistic cooling rates (e.g. WH1_51-1= 0.001 years and WH1_4-1.1 = 1580 years) and $40 \%$ of Taupo inclusions indicate extremely slow and unrealistic cooling rates (e.g. TA1_41-1.1 $=57,000$ years) (Table 3.3). Furthermore, $\mathrm{T}_{\mathrm{ae}}$ of Whakamaru melt inclusions calculated directly from the measured absorbances of the $4500 \mathrm{~cm}^{-1}$ and $5200 \mathrm{~cm}^{-1}$ peaks of melt inclusions using the method described of Ihinger et al. (1999) (Table 3.3) are 


\begin{tabular}{|c|c|c|c|c|c|}
\hline Sample & $\mathrm{T}_{\mathrm{ae}}\left({ }^{\circ} \mathrm{C}\right)$ & $\mathrm{Q}(\mathrm{K} / \mathrm{s})$ & $\log q$ & $\begin{array}{c}\text { Pressure } \\
(\mathrm{M} \mathrm{Pa})\end{array}$ & $\begin{array}{c}\text { Depth } \\
(\mathrm{km})\end{array}$ \\
\hline TA1_18-1.1 & 101 & $\mathrm{cc}$ & & 43.3 & 1.63 \\
\hline TA1_18-1.1 & 235 & $2.45 \mathrm{E}-21$ & -20.610 & 41.8 & 1.58 \\
\hline TA1_13 & & & & 31.7 & 1.20 \\
\hline TA1_40 & & & & 22.7 & 0.86 \\
\hline TA1_41-1.1 & 278 & $3.18 \mathrm{E}-10$ & -9.498 & 73.1 & 2.76 \\
\hline TA1_41-2.1 & 256 & $5.37 \mathrm{E}-13$ & -12.270 & 85.3 & 3.22 \\
\hline TA1_41-3.1 & 312 & $2.10 \mathrm{E}-07$ & -6.679 & 56.9 & 2.15 \\
\hline TA1_29-1.1 & 320 & $5.53 \mathrm{E}-05$ & -4.257 & 98.4 & 3.72 \\
\hline TA1_29-2.1 & 313 & $1.02 \mathrm{E}-05$ & -4.991 & 75 & 2.83 \\
\hline TA1_30-1.1 & & & & 68.6 & 2.59 \\
\hline TA1_43-1.1 & 225 & $2.24 \mathrm{E}-30$ & -29.650 & 59.3 & 2.24 \\
\hline TA1_43-2.1 & 247 & $6.10 \mathrm{E}-18$ & -17.215 & 45.5 & 1.72 \\
\hline TA1_43-3.1 & 237 & $6.35 \mathrm{E}-21$ & -20.197 & 43.9 & 1.66 \\
\hline TA1_44-1.1 & & & & 35.8 & 1.35 \\
\hline TA1_44-2.1 & & & & 30.1 & 1.14 \\
\hline TA1_50.1 & 370 & $5.02 \mathrm{E}-03$ & -2.300 & 70.8 & 2.67 \\
\hline TA1_51.1 & 377 & $3.70 \mathrm{E}-03$ & -2.432 & 57.5 & 2.17 \\
\hline TA1_52.1 & 395 & $4.35 \mathrm{E}+00$ & 0.638 & 148.9 & 5.62 \\
\hline TA1_53.1 & 386 & $3.20 \mathrm{E}-04$ & -3.495 & 36.3 & 1.37 \\
\hline TA1_55.1 & 198 & $\mathrm{cc}$ & & 38.9 & 1.47 \\
\hline TA1_61.1 & 268 & $4.02 \mathrm{E}-08$ & -7.395 & 121.4 & 4.58 \\
\hline TA1_76.1 & 416 & $5.29 \mathrm{E}+00$ & 0.724 & 118.1 & 4.46 \\
\hline TA1_77.1 & 239 & $5.93 \mathrm{E}-20$ & -19.227 & 53.2 & 2.01 \\
\hline TA1a_8-1.1 & 358 & $1.73 \mathrm{E}-04$ & -3.761 & 49.9 & 1.88 \\
\hline TA1a_8-2.1 & & & & 63.9 & 2.41 \\
\hline TA2_22-2.1 & & & & 86.2 & 3.25 \\
\hline TA2_22-3.1 & & & & 31.4 & 1.19 \\
\hline TA2_31-1.1 & & & & 60 & 2.27 \\
\hline TA2_31-2.1 & 272 & 7.49E-11 & -10.126 & 77.7 & 2.93 \\
\hline TA2_32-1.1 & 490 & $7.92 \mathrm{E}+02$ & 2.899 & 143 & 5.40 \\
\hline TA2_32-2.1 & & & & 141.1 & 5.33 \\
\hline WH1_4-1.1 & 279 & $1.05 \mathrm{E}-08$ & -7.981 & 89.7 & 3.39 \\
\hline WH1_19-1.1 & 217 & $3.20 \mathrm{E}-24$ & -23.494 & 14 & 0.53 \\
\hline WH1_19-3.1 & & & & 58.2 & 2.20 \\
\hline WH1_50-1 & 206 & $\mathrm{cc}$ & & 105.2 & 3.97 \\
\hline WH1_51-1 & 349 & $1.01 \mathrm{E}-02$ & -1.996 & 111.9 & 4.22 \\
\hline WH1_52-1 & 209 & $\mathrm{cc}$ & & 69.2 & 2.61 \\
\hline WH1_52-2 & 190 & $\mathrm{cc}$ & & 67.8 & 2.56 \\
\hline WH1_53-1 & 255 & $1.67 \mathrm{E}-14$ & -13.778 & 71.5 & 2.70 \\
\hline
\end{tabular}

Table 3.3. Calculated $\mathrm{T}_{\mathrm{ae}}$ and cooling rates of Whakamaru and Taupo melt inclusions. $\mathrm{T}_{\mathrm{ae}}$ is calculated from the method of Ihinger et al. (1999). Cooling rates (Q and log q) are calculated using the spreadsheet supplied from Xu and Zhang (2002). cc in the Q and log q columns indicate the supplied spreadsheet could not calculate a cooling rate. Pressures were calculated using VolatileCalc and magmatic temperatures of $760{ }^{\circ} \mathrm{C}$ and $780{ }^{\circ} \mathrm{C}$ for the Whakamaru and Taupo melt inclusions respectively. Depths are calculated assuming a bulk crustal density of 2700 $\mathrm{Kg} / \mathrm{m}^{3}$. Abbreviations: opx = orthopyroxene; plag = plagioclase; $q \mathrm{tz}=$ quartz. 
inconsistent by $\geq 100{ }^{\circ} \mathrm{C}$ with the $\mathrm{T}_{\mathrm{ae}}$ derived from the location of the same measured speciation in relation to the calculated speciation curves in Figure 3.1.

\subsection{Discussion}

The samples studied here were collected from a limited stratigraphic section for both eruptions. Consequently, the wide scatter in measured speciation and cooling rates are hard to reconcile without invoking a secondary process(es) that alters the $\mathrm{H}_{2} \mathrm{O}_{\mathrm{m}} / \mathrm{OH}^{-}$speciation of rhyolitic melt inclusions. Similar scatter has not been reported from natural rhyolitic groundmass glasses, but has been noted for a selection of quartz-hosted rhyolitic melt inclusions from the Bishop Tuff (Wallace et al., 2003). This modification of $\mathrm{H}_{2} \mathrm{O}_{\mathrm{m}} / \mathrm{OH}^{-}$could potentially have an impact on $\mathrm{H}_{2} \mathrm{O}_{\mathrm{t}}$ and our understanding on the role water plays within the melt, as many calculations (e.g. geospeedometry and saturation pressures) rely on the accurate measurement or determination of speciation from solution models (Zhang et al., 1997b; Zhang et al., 2000; Newman and Lowenstern, 2002; Xu and Zhang, 2002). Measured water speciation of rhyolitic melt inclusions are inconsistent with models that calculate the proportions of $\mathrm{H}_{2} \mathrm{O}_{\mathrm{m}}$ and $\mathrm{OH}^{-}$from the measured $\mathrm{H}_{2} \mathrm{O}_{\mathrm{t}}$ water concentration of natural rhyolitic glasses, for example VolatileCalc (Figure 3.2). This could lead to erroneous saturation pressures, the extent of which is not discussed here.

\subsubsection{Secondary alteration of water speciation in rhyolitic melt inclusions}

Several possible mechanisms could alter the water speciation of rhyolitic melt inclusions from the original glass compositions, including those suggested by Wallace et al. (2003). These mechanisms are: (1) the formation of hydrous 
mineral reservoirs within inclusions; (2) hydration of melt inclusions (Wallace et al., 2003); (3) the calibration method used for the calculation of water concentrations; (4) the time of sealing of melt inclusions; (5) rupturing and/or degassing of melt inclusions; and (6) diffusion of water in or out of inclusions.

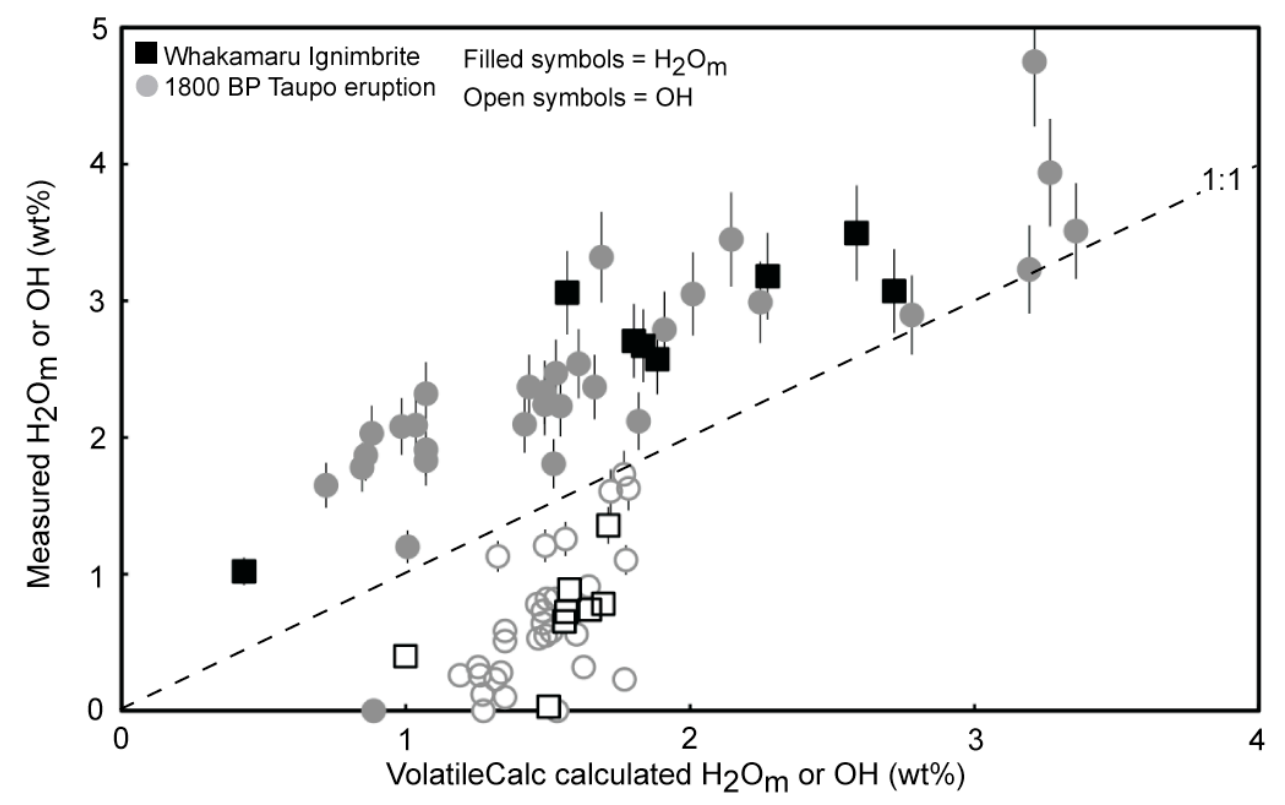

Figure 3.2. Comparison of measured $\mathrm{H}_{2} \mathrm{O}_{\mathrm{m}}$ and $\mathrm{OH}^{-}$concentrations of Taupo melt inclusions (circles) and Whakamaru melt inclusions (squares) and those calculated from $\mathrm{H}_{2} \mathrm{O}_{\mathrm{t}}$ by VolatileCalc (Newman and Lowenstern, 2002) at a magmatic temperature $760{ }^{\circ} \mathrm{C}$ and $780{ }^{\circ} \mathrm{C}$ for the Whakamaru and Taupo magmas, respectively. Error bars of $10 \%$ are shown on the measured water concentrations and the 1:1 line is shown (dashed line).

The discrepancy in measured water speciation of melt inclusions is observed in both Whakamaru melt inclusions that possess micro-crystals and Taupo melt inclusions that display no evidence of micro-crystals. This absence of microcrystals in Taupo melt inclusions eliminates the formation of hydrous minerals reservoirs within inclusions as the primary mechanism for altering the water speciation of melt inclusions. 
Hydration of melt inclusions post-eruption may have affected both Whakamaru and Taupo melt inclusions. This is characterised in groundmass basaltic and rhyolitic glasses by anomalously high $\mathrm{H}_{2} \mathrm{O}_{\mathrm{m}}$ concentrations at constant $\mathrm{OH}^{-}$ concentrations (Pandya et al., 1992; Yokoyama et al., 2007). Although hydration of melt inclusions could explain the relative elevated $\mathrm{H}_{2} \mathrm{O}_{\mathrm{m}}$ concentrations, it cannot account for the associated relative depletion in $\mathrm{OH}^{-}$concentrations (Figure 3.1), precluding the hydration of melt inclusions as a possible mechanism for changing water speciation.

Two main calibration methods are used to calculate the water concentrations of glasses in FTIR spectroscopy: (1) Beer-Lambert calibration (Newman et al., 1986; Ihinger et al., 1994) and; (2) the Zhang et al. (1997b) calibration. The different methods could potentially affect the calculated proportions of $\mathrm{H}_{2} \mathrm{O}_{\mathrm{m}}$ and $\mathrm{OH}^{-}$. Total $\mathrm{H}_{2} \mathrm{O}, \mathrm{H}_{2} \mathrm{O}_{\mathrm{m}}$ and $\mathrm{OH}^{-}$concentrations of Taupo melt inclusions were calculated using both of these calibrations from the $5200 \mathrm{~cm}^{-1}$ and $4500 \mathrm{~cm}^{-1}$ peaks (Figure 3.3). Below $3 \mathrm{wt} \%$ the calculated concentrations agree well, but the agreement is not as good at higher total $\mathrm{H}_{2} \mathrm{O}$ (Figure 3.3). This can be attributed to the uncertainty in the extrapolations of the calibration of Zhang et al. (1997b) to high total $\mathrm{H}_{2} \mathrm{O}$ (> $2.7 \mathrm{wt} \%$ ) (Zhang et al., 1997b; Zhang, 1999). Moreover, irrespective of the calibration used, the same scatter in measured water speciation of Taupo melt inclusions is observed (Figure 3.3), eliminating the calibration method as the source of the discrepancies in $\mathrm{H}_{2} \mathrm{O}_{\mathrm{m}} / \mathrm{OH}^{-}$ratios. 


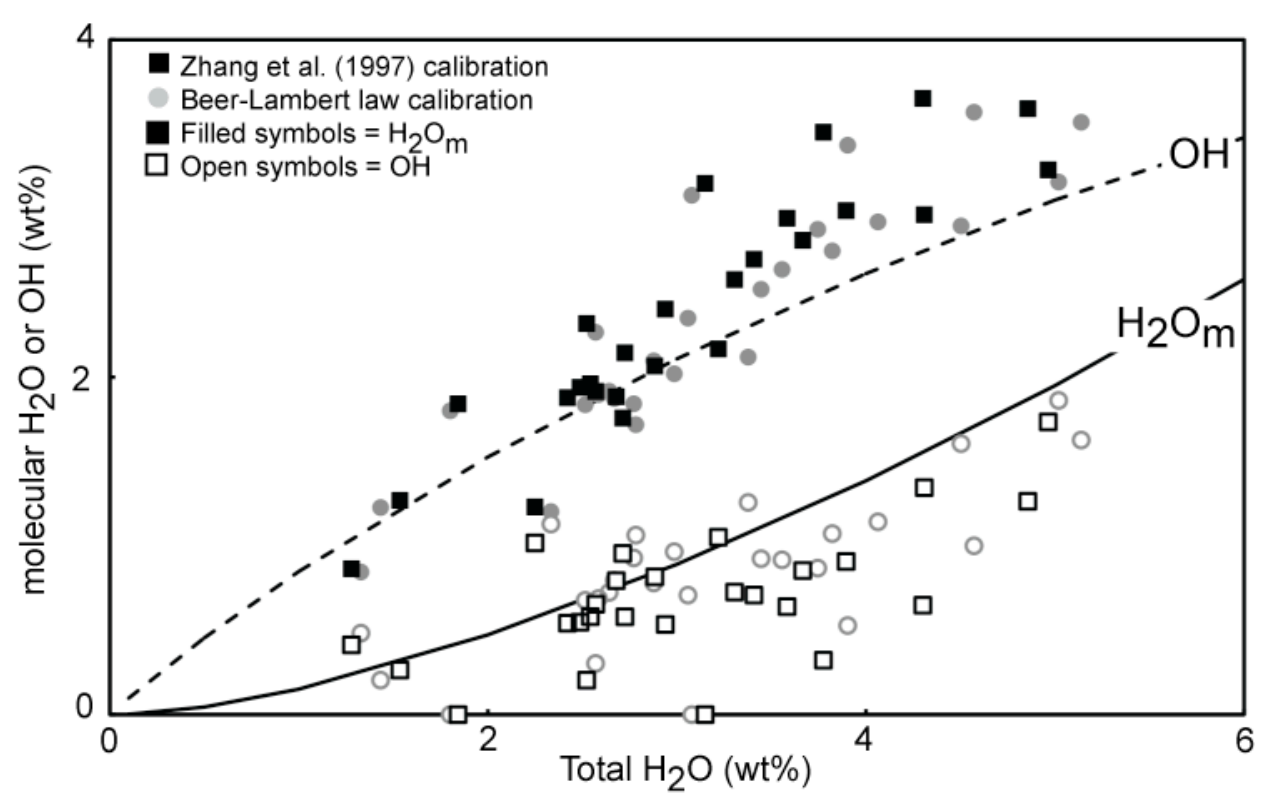

Figure 3.3 Measured speciation of Taupo melt inclusions using the Beer-Lambert law (circles) (Newman et al., 1986; Ihinger et al., 1994) and the Zhang et al. (1997a) (squares) calibration. $\mathrm{H}_{2} \mathrm{O}_{\mathrm{m}}$ are filled symbols and $\mathrm{OH}$ groups are open symbols. The speciation curve for $500^{\circ} \mathrm{C}$ is shown using the regular solution model of Ihinger et al. (1999).

Melt inclusions are not simultaneously isolated from the external magma and could potentially record changing magmatic conditions. However, the major element composition of Whakamaru and Taupo melt inclusions (Chapter 2) within individual eruptions are relatively homogeneous, indicating sealing from the external magma occurred at similar magmatic conditions. Therefore, such a wide range in measured water speciation is hard to reconcile, unless rapid degassing of the melt occurred as the inclusions became sealed and the quenching of inclusions ensued before sufficient time had occurred for the reequilibrium of $\mathrm{H}_{2} \mathrm{O}_{\mathrm{m}}$ and $\mathrm{OH}^{-}$of melt inclusions. The lower relative $\mathrm{OH}^{-}$ concentrations of melt inclusions compared to the modelled $\mathrm{OH}^{-}$speciation curve would suggest that it was the $\mathrm{OH}^{-}$groups that degassed from the melt first. This is inconsistent with the bonded nature of $\mathrm{OH}^{-}$groups to the silicate network implying $\mathrm{OH}^{-}$groups are the least mobile water species and $\mathrm{H}_{2} \mathrm{O}_{\mathrm{m}}$ would 
preferentially degassed, contradictory to the observed water speciation of inclusions.

Previous studies have implied that the rupturing of inclusions prior to quenching has resulted in the recorded degassed signatures (e.g. Cervantes and Wallace, 2003; Wallace et al., 2003; Blundy and Cashman, 2005). Whakamaru and Taupo melt inclusions were examined for evidence of rupturing through spectroscopic FTIR imaging. This technique allows images of the water peak absorbance height $\left(3550 \mathrm{~cm}^{-1}\right)$ to be obtained over an area of $350 \mu \mathrm{m}^{2}$ encompassing both the inclusion and surrounding crystal, allowing water species to be determined at $5 \mu \mathrm{m}$ resolution (Wysoczanski and Tani, 2006). Consequently, the location of dissolved water within the sample can be identified. Ruptured melt inclusions form cracks that radiate out from the inclusion through which volatiles can be lost (e.g. Danyushevsky et al., 2002; Wallace, 2005). Although cracks are present in several of our samples they formed during sample preparation. Inclusions that were ruptured during eruption and not during sample preparation should display evidence of water along these cracks on FTIR images (Figure 3.4), though no evidence of this is observed in any of our FTIR images. Therefore, it is possible to conclude that the analysed melt inclusions from the Whakamaru and Taupo eruptions did not rupture during eruption. As none of the previously discussed mechanisms can adequately explain the observed water speciation of Whakamaru and Taupo melt inclusions, it is proposed that water is loss by diffusion through the crystal host altering the original $\mathrm{H}_{2} \mathrm{O}_{\mathrm{m}} / \mathrm{OH}$ ratio of melt inclusions. 


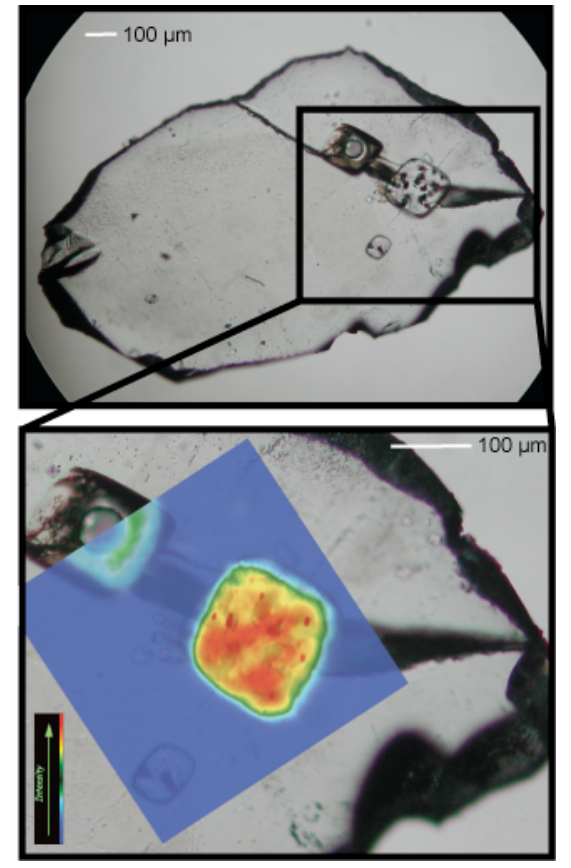

Figure 3.4. Representative spectroscopic image of a quartz crystal and hosted melt inclusions from the Whakamaru ignimbrite. Relative peak height for the $3535 \mathrm{~cm}^{-1}$ band is shown and is a proxy for total water concentrations. Colour intensity reflects the intensity of the peak and the thickness of the sample. Low peak heights (approximating low $\mathrm{H}_{2} \mathrm{O}$ concentrations) are blue and high peak heights (high $\mathrm{H}_{2} \mathrm{O}$ ) are shown in red.

\subsubsection{Water diffusion and degassing of rhyolitic melt inclusions}

Experimental studies examining the diffusion of water from rhyolitic melt inclusions are limited, as the majority of research has focused on olivine-hosted inclusions in basaltic magmas (e.g. Danyushevsky et al., 2002; Hauri, 2002; Massare et al., 2002; Portnyagin et al., 2008). This has shown that small amounts of water $(<1 \mathrm{wt} \%)$ can be lost from olivine melt inclusions from the dissolution of water molecules and the diffusion of $\mathrm{H}_{2}$ though the crystal host in extremely short timescales (e.g. hours) (Danyushevsky et al., 2002; Hauri, 2002). Diffusion of $\mathrm{H}_{2}$ requires a gradient in $f \mathrm{H}_{2}$ to be sustained but this only occurs if a reducing agent is present (Qin et al., 1992). As rhyolitic magmas contain relatively large 
amounts of $\mathrm{H}_{2} \mathrm{O}$ and low $\mathrm{FeO}_{\mathrm{t}}$ concentrations this prevents significant reduction of $\mathrm{H}_{2} \mathrm{O}$ to $\mathrm{H}_{2}$ resulting in the negligible diffusion of $\mathrm{H}_{2}$ in rhyolitic magmas (Qin et al., 1992). Consequently, this indicates that diffusion of $\mathrm{H}_{2}$ cannot account for the large water losses or gains observed in the experiments of Massare et al. (2002) or of Portnyagin et al. (2008) on olivine-hosted melt inclusions and Severs et al. (2007) on quartz-hosted, melt inclusions. The study of Severs et al. (2007) demonstrated that water is lost from quartz-hosted rhyolitic melt inclusions from the Bishop Tuff after just 12-14 hours of heating, and after 63 days an average of only $25 \%$ of the original water concentration remained. This indicates there is a mechanism that transports $\mathrm{H}_{2} \mathrm{O}_{\mathrm{m}}$ and/or $\mathrm{OH}^{-}$between the melt inclusions and the external melt and it seems logical if water molecules can move in one direction, in favourable circumstances, the reverse process could occur increasing the water concentrations of melt inclusions. The addition of water to melt inclusions was observed in the experiments of Portnyagin et al. (2008) of olivine hosted melt inclusions indicating that this is the case. Consequently, it appears that rhyolitic melt inclusions preserve a record of the magmatic water conditions immediately prior to eruption but can provide little evidence for earlier magmatic water concentrations such as at the time the melt inclusion was sealed from the external melt.

FTIR spectroscopy studies have measured structural $\mathrm{OH}^{-}$groups in quartz and orthopyroxene crystals but the presence of structural $\mathrm{H}_{2} \mathrm{O}_{\mathrm{m}}$ is ambiguous (Cordier and Doukhan, 1991; Dobson et al., 1995). Furthermore, $\mathrm{OH}^{-}$is the only structural water species detected in volcanic plagioclase crystals (Johnson and Rossman, 2004; Johnson, 2006). Johnson (2003) measured the $\mathrm{OH}^{-}$diffusion in 
plagioclase crystals and showed that it occurred on a timescale of hours to weeks in a $1 \mathrm{~mm}$ size plagioclase at $800-900^{\circ} \mathrm{C}$ with similar results reported for water diffusion in quartz crystals (Qin et al., 1992). These results suggests that $\mathrm{H}_{2} \mathrm{O}_{m}$ may not be easily accommodated within the crystal structures, which would prohibit the diffusion of $\mathrm{H}_{2} \mathrm{O}_{\mathrm{m}}$ between the melt inclusion and the external melt without reacting to form $\mathrm{OH}^{-}$groups.

It is therefore proposed that $\mathrm{OH}^{-}$is the dominant diffusing species, transporting water between rhyolitic melt inclusions and the external melt after the sealing of inclusions. The water speciation of Whakamaru and Taupo melt inclusions may reflect the diffusion of $\mathrm{OH}^{-}$groups out of inclusions and through the crystal host prior to quenching rather than through the rupturing of melt inclusions. The assorted crystal sizes and variation in the position of melt inclusions in the crystal alters the path length of the $\mathrm{OH}^{-}$groups and could account for the variable range of $\mathrm{H}_{2} \mathrm{O}_{\mathrm{m}}$ and $\mathrm{OH}^{-}$concentrations measured.

Evidence for degassing of melt inclusions can also be gained from the textural appearance of inclusions. The crystallisation of micro-crystals and the formation of shrinkage bubbles inside inclusions can result from the substantial diffusive loss of $\mathrm{H}_{2} \mathrm{O}$ (Johnson et al., 2008) and not from slow cooling as previously attributed (e.g. Danyushevsky, et al., 2002; Wallace, 2005). The prevalent vapour bubbles observed in the Taupo melt inclusions and the micro-crystals in the Whakamaru melt inclusions are interpreted to reflect degassing and do not merely result from the slow cooling of inclusions. During crystallisation, latent heat is released to the surroundings, increasing the melt temperature (Blundy et 
al., 2006). The crystallisation of micro-crystals in the Whakamaru melt inclusions could result in the heating of the entrapped melt, potentially explaining the observed deviations between calculated $\mathrm{T}_{\mathrm{ae}}$ of inclusions and the modelled speciation curves that are not observed in the Taupo melt inclusions.

\subsubsection{Initial water concentrations of melt inclusions}

The extent of degassing cannot be established from FTIR spectroscopy analyses alone, but requires an estimate of the initial melt inclusion water concentration. One possible method to do this is through the application of plagioclase-melt thermometry. Two commonly utilised plagioclase thermometers are those of Housh and Luhr (1991) and Putrika (2005), which are also calibrated to calculate water contents of the melt in equilibrium with the plagioclase crystal. It is noted that neither of these thermometers are highly accurate when predicting water concentrations of natural melts (Putirka, 2005), although the Putirka model produced more realistic estimates of water concentrations compared to reported $\mathrm{H}_{2} \mathrm{O}$ concentrations of hydrous experiments than the Housh and Luhr model (Putrika, 2005 their Figure 6). In addition, the thermometer of Housh and Luhr was calibrated for basaltic and andesitic compositions while the Putirka model was calibrated for basaltic to rhyolitic compositions, and is more suitable for this study.

Initial maximum magmatic water concentrations of Whakamaru and Taupo melt inclusions were tentatively estimated using the Putirka model from the major element composition of plagioclase crystals and mean groundmass glass compositions. Magmatic temperature was determined using the plagioclase-melt 
equilibria and directly substituted back in to calculate the magmatic water concentrations. These results indicate mean magmatic water concentrations of $8.2 \mathrm{wt} \%$ and $8.4 \mathrm{wt} \%$ at the time the plagioclase crystals fractionated for the Whakamaru and Taupo magmas respectively (Table A3.5).

Blundy and Cashman (2005) illustrated that the chemical variation of melt inclusions (e.g. $\mathrm{SiO}_{2}$ concentration) combined with the $\mathrm{H}_{2} \mathrm{O}_{\mathrm{t}}$ content can be used to discriminate between different crystallisation processes. Whakamaru and Taupo melt inclusions display a syn-eruptive degassing trend when the measured water concentrations are plotted against anhydrous $\mathrm{SiO}_{2}$ concentrations (Chapter 2) of inclusions and the calculated initial water estimates (Figure 3.5, after Blundy and Cashman, 2005). Utilising more conservative initial water estimates of $4.4 \mathrm{wt} \%$ and $5.1 \mathrm{wt} \%$, the maximum measured water concentrations of inclusions for the Whakamaru and Taupo inclusions respectively; a degassing trend is still observed (Figure 3.5). This suggests the degassing of inclusions was rapid (e.g. during eruption) with little or no contemporaneous crystallisation (Blundy and Cashman, 2005). Assuming these initial water estimates are realistic, a substantial amount of water has been degassed from the melt inclusion prior to quenching.

\subsubsection{Geobarometry and crystallisation depths of magmas}

One of the most common applications of measured water concentrations of rhyolitic melt inclusions is the application of geobarometry models and inferred depths of the crystallising magma body. If melt inclusions are degassed, the estimated pressures and depths will be underestimated and will only reflect the 
magmatic conditions directly prior to eruption. The depths of earlier episodes of magmatic evolution, such as periods of residence within deeper crystal mush bodies (e.g. Whakamaru melt inclusions, Chapter 4), cannot be determined from the saturation pressures of melt inclusions.

The partial pressures of $\mathrm{H}_{2} \mathrm{O}\left(\mathrm{pH}_{2} \mathrm{O}\right)$ of Whakamaru and Taupo melt inclusions (Table 3.3) have been calculated using VolatileCalc (Newman and Lowenstern, 2002) and a magmatic temperature of $760{ }^{\circ} \mathrm{C}$ and $780{ }^{\circ} \mathrm{C}$ for the Whakamaru and Taupo magmas respectively (Table A3.5). This results in $p \mathrm{H}_{2} \mathrm{O}$ of $14-112 \mathrm{MPa}$ for the Whakamaru melt inclusions and $22-149 \mathrm{MPa}$ for the Taupo melt inclusions (Table 3.3). This constrains the minimum lithospheric depths of the crystallising magma body (assuming a crustal density of $2700 \mathrm{~kg} / \mathrm{m}^{3}$ from Ellis et al., 2007) to a mean depth of $2.7 \mathrm{~km}(0.5-4.2 \mathrm{~km})$ for the Whakamaru magma and $2.6 \mathrm{~km}(0.9-5.6 \mathrm{~km})$ for the Taupo magma (Figure 3.6). As $\mathrm{CO}_{2}$ is below detection limit any estimates of partial pressures are only minimum estimates (e.g. Bacon et al., 1992) and do not take into account the partial pressures of other volatile species such as $\mathrm{Cl}$ and $\mathrm{SO}_{3}$. Assuming that $\mathrm{CO}_{2}$ concentrations of melt inclusions equates to the estimated detection limits (Table 3.2), this would increase the pressure estimates on average by $40 \mathrm{MPa}$ and $90 \mathrm{MPa}$ (equating to an additional $200 \mathrm{~m}$ and $300 \mathrm{~m}$ depth) for the Whakamaru and Taupo melt inclusions, respectively. However, increasing the $\mathrm{CO}_{2}$ concentration to $100 \mathrm{ppm}$, the approximate average measured $\mathrm{CO}_{2}$ concentrations of Oruanui melt inclusions (Liu et al. 2006) increases the inferred depths by ca. $1 \mathrm{~km}$. 

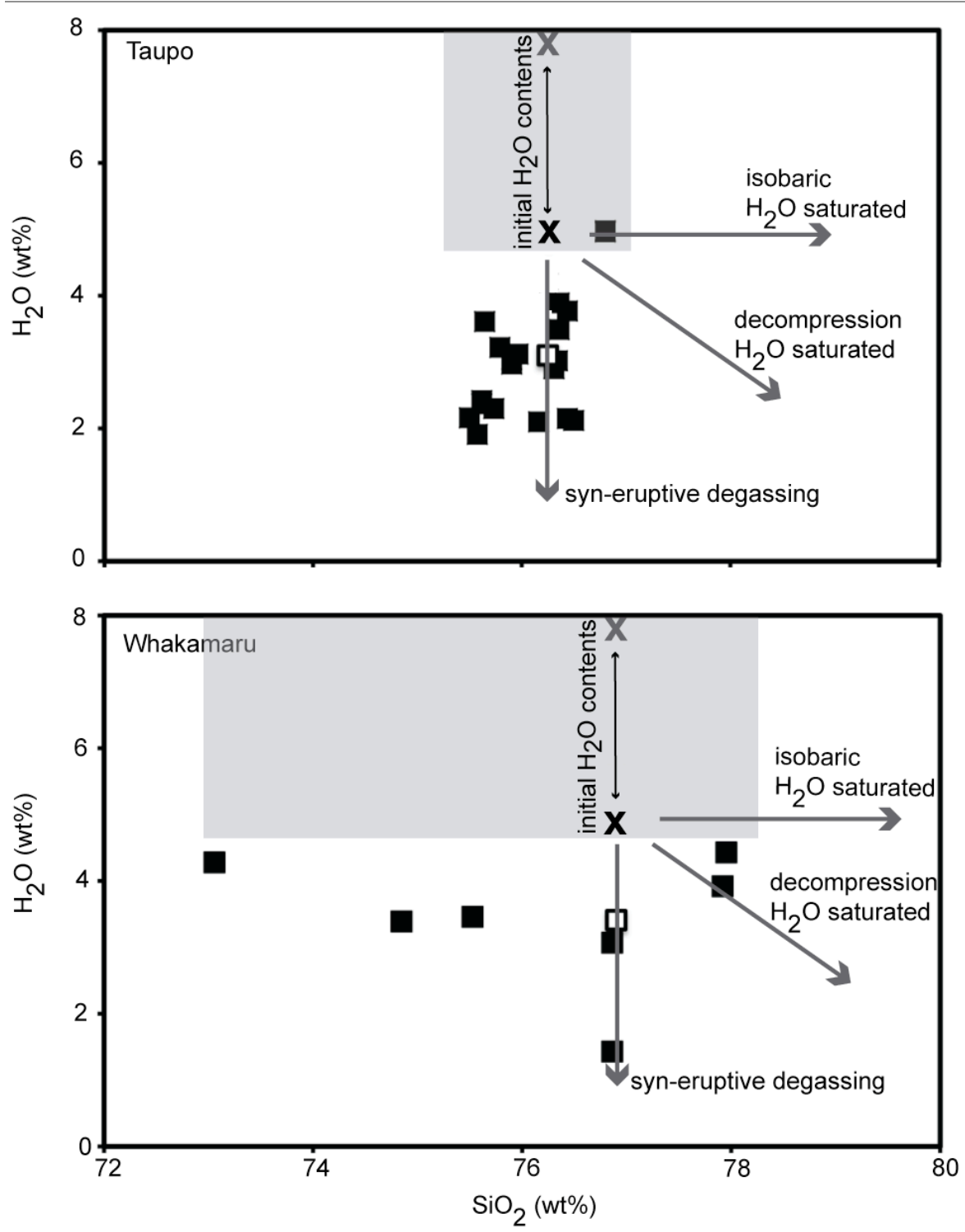

Figure 3.5. Syn-eruptive degassing of melt inclusions after Blundy and Cashman (2005). (a) Taupo melt inclusions and (b) Whakamaru melt inclusions. Grey shaded region indicates estimated initial water concentrations calculated from a combination plagioclase-melt thermometry (grey X) and the maximum measured water content of melt inclusions (black, X) as discussed in the text. White open squares denote the mean melt inclusion compositions.

The geochemically inferred depths of the crystallising Whakamaru and Taupo magma bodies are inconsistent with geophysical studies, which do not detect the presence of partial melt bodies above $6 \mathrm{~km}$ in the Taupo Volcanic Zone (e.g. Ogawa et al., 1999; Sherburn et al., 2003; Heise et al., 2007). A similar inconsistency is noted for the Oruanui eruption by Ellis et al. (2007). The 
chemical composition of Whakamaru melt inclusions suggests inclusions are trapped and sealed at the top of a crystal mush body (Chapters 2 and 4). However, the calculated depths of melt inclusions indicate a mean depth of $2.7 \mathrm{~km}$ and a range of between $0.5-4.2 \mathrm{~km}$. This range of calculated depths centred at $2.7 \mathrm{~km}$ depth would provide insufficient space in which to accommodate the volume of eruptible magma required to feed the Whakamaru eruption in the crust prior to eruption. Similar doubts are also raised for the geochemically inferred depths of the Taupo magma body, which would place the crystallising magma body in a layer of permeable volcanic infill generated by earlier eruptions (e.g. Ogawa et al., 1999; Sherburn et al., 2003; Heise et al., 2007). This would allow for the passive degassing of the magma prior to eruption, preventing the accumulation of sufficient volatiles to drive such an explosive eruption (Sparks, 2003).

However, if the estimated initial water concentrations predicted from plagioclase-melt equilibria and maximum measured water concentrations of melt inclusion are used to calculate the $\mathrm{H}_{2} \mathrm{O}$ of the crystallising magma body, the crustal depths of the crystallising magma bodies are estimated at 4.2-11.1 km for Whakamaru magma and 5.6-11.9 $\mathrm{km}$ for the Taupo magma. This is consistent with the depths estimated from geophysical studies (Figure 3.6) suggesting this is the location for the bulk of magma petrogenesis in the continental Taupo Volcanic Zone. 


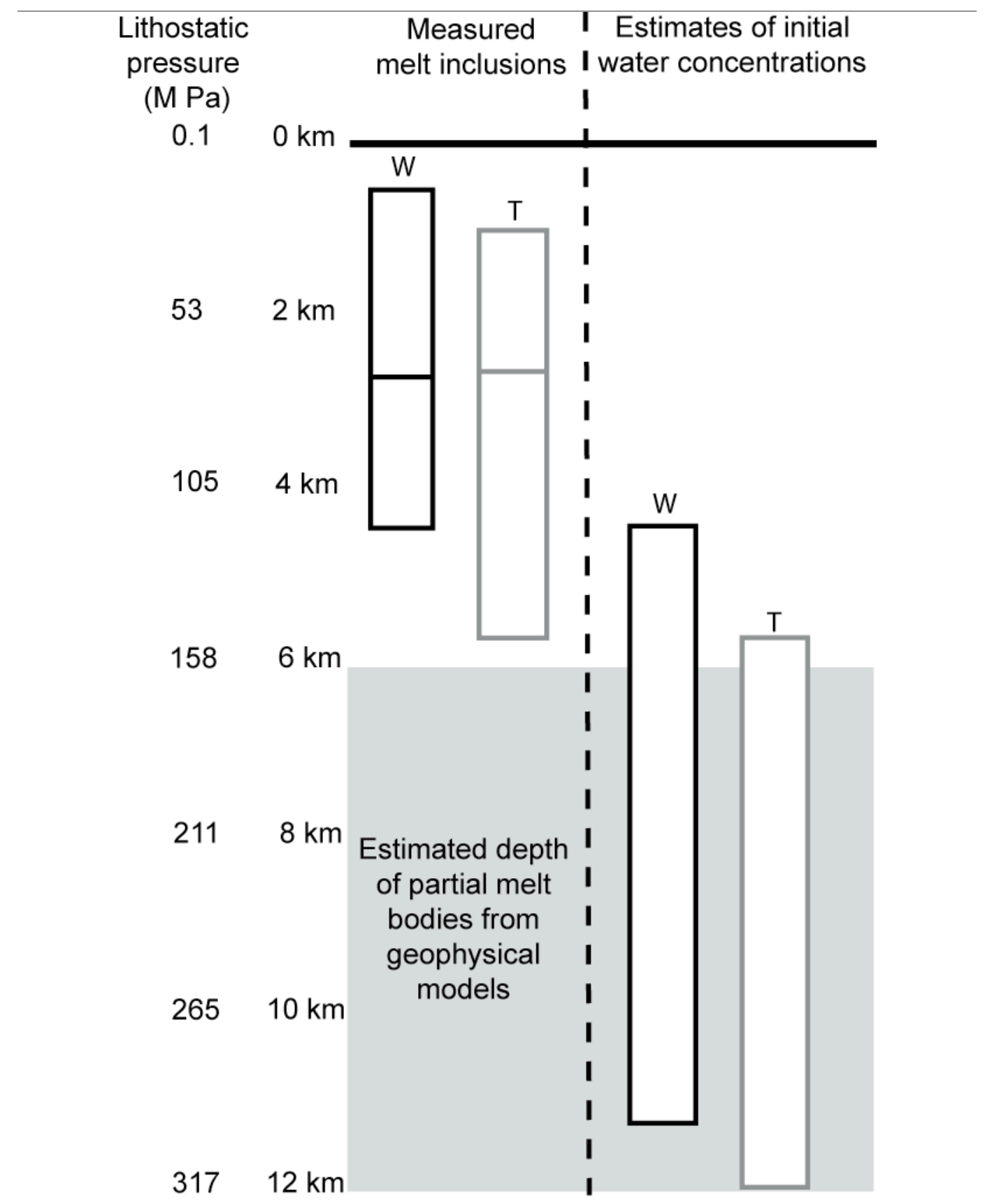

Figure 3.6. Comparison of $\mathrm{HH}_{2} \mathrm{O}$ and inferred crustal depths to magma chamber from the measured water concentrations of Whakamaru (W) and Taupo (T) melt inclusions and initial water concentration estimates as discussed in the text. Depth of partial melt bodies estimated from geophysical studies are taken from Ogawa et al. (1999), Sherburn et al. (2003), Heise et al. (2007). The outline of the boxes indicates the range of observed or calculated concentrations. A horizontal line denotes the mean measured concentrations. A bulk crustal density of $2700 \mathrm{~kg} / \mathrm{m}^{3}$ is used to calculate the crustal depths. 


\subsection{Conclusions}

Whakamaru and Taupo melt inclusions are unruptured yet degassed. The degassing occurs by the diffusion of $\mathrm{OH}^{-}$groups out of the melt inclusion and through the crystal host. This process can be identified by measured $\mathrm{H}_{2} \mathrm{O}_{\mathrm{m}}$ and $\mathrm{OH}^{-}$concentrations inconsistent with those predicted from experimental studies and results in an underestimation of calculated $p \mathrm{H}_{2} \mathrm{O}$ of melt inclusions. Therefore any inferred crystallisation depths of magmas will represent the depth of the magma body immediately prior to eruption. This is not necessary where the bulk of the magma petrogenesis occurred. Tentative initial magmatic water concentrations estimated from plagioclase-melt equilibria, however, reconciles the differences in geochemical and geophysical studies. Further work is required to establish why some melt inclusions appear degassed and others do not and the mechanism(s) that permits degassing to occur.

The degassing of rhyolitic melt inclusions may not occur in all rhyolitic magmas. However, investigation of water speciation from the scientific literature indicates the wide scatter described from the Whakamaru and Taupo melt inclusions are present in other melt inclusions derived from silicic arc magmas (Lowenstern, 1993; Barclay et al., 1996; 1998). Degassing of unruptured rhyolitic arc melt inclusions may thus explain the lack of any obvious relationship between $\mathrm{H}_{2} \mathrm{O}$ concentrations and melt compositions that are observed in intercontinental rhyolitic magmas (Wallace, 2005). 


\title{
Chapter 4
}

\section{The magmatic evolution of the Whakamaru supereruption constrained by microanalytical study of plagioclase and quartz.}

\begin{abstract}
The Whakamaru eruption is the largest known eruption to have originated from the hyper-productive Taupo Volcanic Zone, New Zealand. Major, minor and trace element concentrations of plagioclase crystals and cathodoluminescence images allied with $\mathrm{Ti}$ concentrations of quartz crystals, have been used to determine the chemical zonation of these phases. Three plagioclase populations have been identified: Group 1 crystals with inherited cores of $A n_{45-60}, \mathrm{Ba}$ (115$650 \mathrm{ppm})$ and $\mathrm{La}(3-9 \mathrm{ppm})$ and rims of ca. $A n_{30}, \mathrm{Ba}(450-800 \mathrm{ppm})$ and $\mathrm{La}(7$ - 10 ppm); Group 2 crystals are oscillatory zoned plagioclases of $A n_{30-40}, \mathrm{Ba}$ (450 - $730 \mathrm{ppm})$ and La (8.5 - $9.5 \mathrm{ppm})$ and; rare Group 3 plagioclase crystals with low $\operatorname{Sr}(280-480 \mathrm{ppm})$, cores of $A n_{25-35}$ and rims of $A n_{20-25}$. From the chemical composition of these plagioclase crystals, four physiochemically distinct rhyolitic melts are identified: (1) an andesitic progenitor melt (a more mafic melt of andesitic composition) in which crystallised the cores of Group 1 crystals; (2) a greywacke melt or greywacke protolith melt responsible for overgrowth rims of Group 1 crystal cores; (3) melt derived from the rejuvenation of a mature crystal mush body evidenced from Group 3 plagioclase crystals; and (4) a final rhyolitic melt created by amalgamation from the varying proportions of the first three melts and subsequent fractional crystallisation of a plagioclase-dominant crystal assemblage in an open-system. Sr diffusion modelling of core-rim interfaces of
\end{abstract}


Group 1 crystals implies magma chamber formation in the 15,000 years preceding the climatic eruption, showing that the chamber was potentially an ephemeral feature that formed shortly prior to eruption and which was therefore not present for the entire history of the magma reservoir. Cathodoluminescence imaging of quartz crystals reveals complex zonation, implying a complex evolution of quartz crystals from potentially polygenetic sources. Diffusion modelling of the greyscale intensity of cathodoluminescence images (as a proxy for $\mathrm{Ti}$ content) for a selection of bright core-rim interfaces of quartz crystals, suggests that renewed quartz growth occurred $<80$ yrs prior to eruption and continued towards the climatic eruption.

\subsection{Introduction}

A contemporary view of sub-volcanic magmatic systems is a complex one of interlinked sills, dykes and multi-level storage areas that in a rhyolitic system culminates in a magma reservoir composed of a crystal mush zone and overlying melt-rich magma chamber (Bachmann and Bergantz, 2004; Davidson et al., 2007; Hildreth and Wilson, 2007; Jerram and Davidson, 2007). The magmatic evolution of an eruptive unit is therefore not simple, but may result from the mixing and mingling of discrete magma batches prior to eruption (Davidson et al., 2007; Pabst et al., 2008). Increasingly, upper crustal magma chambers are being considered as ephemeral bodies that can be replenished on much shorter timescales than the actual formation and growth of the magmatic system (e.g. Glazner et al., 2004) or from the rejuvenation of pre-existing crystal mush bodies (e.g. Charlier et al., 2007). These magma chambers are fed from below by large crystal mush bodies that have become stalled within the upper crustal lithosphere 
in a near solid state, and which may represent the early stages of batholith formation (Bachmann and Bergantz, 2003; Glazner et al., 2004; Hildreth and Wilson, 2007; Wiebe et al., 2007). The storage of such large-volumes of silicic magma in the crust in a semi-solid state may explain the scarcity of detected melt bodies through geophysical techniques in active volcanic regions (Bachmann and Bergantz, 2003; 2008; Glazner et al., 2004; Bachmann et al., 2007).

Crystals hosted within volcanic rocks have the ability to record the magmatic evolution within their crystal structure; each magmatic process (e.g. fractional crystallisation, magma mixing, assimilation) depositing a chemical or textural signature within the crystal creating highly zoned crystals (Ginibre et al., 2002a and b; 2004; 2007 Davidson et al., 2007). Identification of these magmatic process(es) responsible for the chemical zonation permits the deciphering and piecing together of processes affecting the evolving magmatic system (Ginibre et al., 2002b and 2007; Jerram and Davidson, 2007). Furthermore, the chemical gradient between two adjacent crystal zones may allow the timescales of these processes to be determined (e.g. Zellmer et al., 1999; Costa et al., 2003; Costa and Chakraborty, 2004; Morgan et al., 2004; 2006; Morgan and Blake, 2006). The longevity of rhyolitic magmatic systems and the timescales over which large-volumes of eruptible magmas sufficient to feed supereruptions accumulate is controversial but is fundamental to our understanding of the dynamics of magma storage (e.g. Halliday et al., 1989; Christensen and DePaolo, 1993; Brown and Fletcher, 1999; Reid, 2003; Charlier et al., 2005; Morgan and Blake, 2006). Diffusion modelling has the advantage over other timescale techniques (e.g. radiometric dating such as $\mathrm{U}-\mathrm{Pb}$ of zircons) in its ability to determine the 
relative timing of a range of magmatic processes from magma degassing to the residence times of crystals prior to eruption (Zellmer et al., 1999; Costa et al., 2003; Kent et al., 2007).

Plagioclase crystallises over the entire igneous compositional spectrum from basalt to rhyolite (Bowen, 1913) and its ubiquitous zonation renders it an ideal candidate to investigate and infer the magmatic evolution of silicic magmas (e.g. Ginibre et al., 2002a; Berlo et al., 2007; Charlier et al., 2008). Recent studies have documented $\mathrm{Ti}$ zonation in quartz crystals, illustrating the potential of quartz crystals to record aspects of the magmatic evolution within their crystal structure (Liu et al., 2006; Wark et al., 2007; Shane et al., 2008).

Here we present major, minor and trace element data for plagioclase and $\mathrm{Ti}$ concentrations of quartz crystals from the $\sim 330$ ka Whakamaru supereruption. We show that both plagioclase and quartz crystals are composed of assorted crystal populations amalgamated from polygenetic sources prior to eruption. Modelling of Sr profiles in a selection of plagioclase crystals and Ti diffusion (using cathodoluminescence intensity as a proxy (e.g. Wark et al., 2007)) in quartz crystals provide insights into the timescales of magmatic processes in the lead up to eruption.

\subsection{Whakamaru supereruption and samples}

The Taupo Volcanic Zone is currently the most productive region of silicic volcanism on Earth (Houghton et al., 1995; Wilson et al., in press). The largest eruption known to originate from this region is the 320-340 ka Whakamaru 
supereruption that occurred in two eruptive periods following a $350 \mathrm{ka}$ hiatus in large-volume explosive rhyolitic volcanism (Houghton et al., 1995; Brown et al., 1998a; Wilson et al., in press). The earlier of these two eruptive periods (ca. 325 ka) deposited the Whakamaru Group ignimbrites, a large-scale crystal-rich, and in places highly welded, group of ignimbrites blanketing a large extent of the central North Island of New Zealand with estimated volumes exceeding 1500 $\mathrm{km}^{3}$ of magma (Briggs, 1976; Brown et al., 1998a; Wilson et al., in press). The largest of these is the Whakamaru ignimbrite, which is the focus of this study (Figure 4.1).

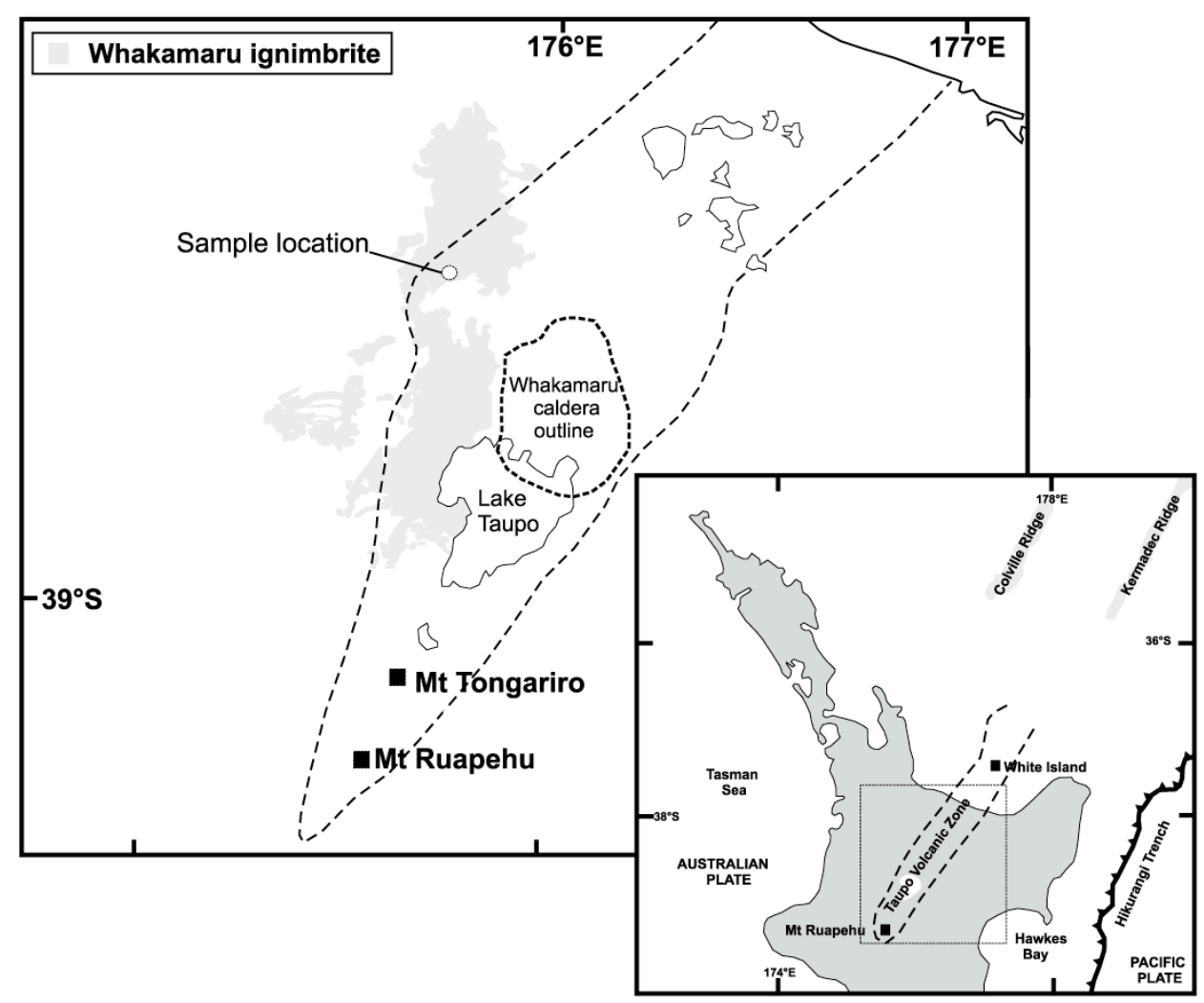

Figure 4.1. Map of the Taupo Volcanic Zone showing the location of the Whakamaru caldera, the extent of the Whakamaru ignimbrite and sample location (white circle) of this study. The extent of the Whakamaru ignimbrite is taken from Brown et al. (1998a). Inset shows the regional setting of the Taupo Volcanic Zone with the outline of the Taupo Volcanic Zone shown by a thick dashed line. 
A previous whole rock study of the Whakamaru group ignimbrites indicate at least four distinct rhyolitic magmas and a high-alumina basalt were involved in the generation of the magma body (Brown et al., 1998a). Zircon geochronology has potentially indicated that the Whakamaru magmatic system was active for at least 250 ka preceding the final catastrophic eruption (Brown and Fletcher, 1999; Charlier et al., 2005).

The mineral assemblage fluctuates through the Whakamaru ignimbrite consisting of quartz, plagioclase, orthopyroxene \pm amphibole, ilmenite, magnetite, Kfeldspar, biotite (Table 4.1) and zircon. A previous study of quartz-hosted melt inclusions indicated at least a proportion of quartz crystals are antecrysts derived from an evolved crystal mush body (Chapter 2). Plagioclase and quartz crystals studied in this work were sampled from the discontinuous crystal lag at the base of the ignimbrite (WH1) and samples (WH2, WH3, WH4, WH5, WH6) were obtained intermittently throughout a ca.100 $\mathrm{m}$ section of the ignimbrite at Maraetai Dam (Figure 4.1; Table 4.1).

\begin{tabular}{|c|c|c|c|c|}
\hline $\begin{array}{c}\text { Sample } \\
\text { No. }\end{array}$ & Latitude & Longitude & $\begin{array}{c}\text { Altitude } \\
\text { (m) }\end{array}$ & Mineralogy \\
\hline WH1 & S $38^{\circ} 21.016^{\prime}$ & E $175^{\circ} 31.020^{\prime}$ & & $\begin{array}{l}\text { plag; qtz; opx; amp; bt; K- spar Fe- } \\
\text { Ti oxides }\end{array}$ \\
\hline WH2 & S $38^{\circ} 20.849^{\prime}$ & E $175^{\circ} 44.206^{\prime}$ & 170 & plag; qtz; opx; Fe-Ti oxides \\
\hline WH3 & S $38^{\circ} 20.953^{\prime}$ & E $175^{\circ} 44.034^{\prime}$ & 250 & $\begin{array}{l}\text { plag; opx; qtz; amp; bt; Fe-Ti } \\
\text { oxides }\end{array}$ \\
\hline WH4 & S $38^{\circ} 20.782^{\prime}$ & E $175^{\circ} 44.033^{\prime}$ & 246 & plag; qtz; opx; amp; Fe-Ti oxides; \\
\hline WH5 & S $38^{\circ} 20.782^{\prime}$ & E $175^{\circ} 44.033^{\prime}$ & 246 & plag; qtz; opx; amp; Fe-Ti oxides \\
\hline WH6 & S $38^{\circ} 20.737^{\prime}$ & E $175^{\circ} 44.110^{\prime}$ & 211 & $\begin{array}{l}\text { plag; qtz; opx; amp; K-spar; Fe-Ti } \\
\text { oxides }\end{array}$ \\
\hline WH7 & S $38^{\circ} 20.799^{\prime}$ & E $175^{\circ} 44.144^{\prime}$ & 196 & plag; qtz; opx; amp; Fe-Ti oxides; \\
\hline
\end{tabular}




\subsection{Analytical methods}

\subsubsection{Sample preparation}

Samples were lightly crushed and sieved and plagioclase, quartz and orthopyroxene crystals were extracted from the $500-1000 \mu \mathrm{m}$ size fraction for analysis, mounted and polished in epoxy blocks (see Chapter 2). In addition, thick $(100 \mu \mathrm{m})$ polished sections of Whakamaru pumices were also prepared and used for plagioclase analyses by microprobe and LA-ICPMS.

\subsubsection{Electron microprobe analyses}

Major elements of plagioclase, quartz and Fe-Ti oxides were determined on the JEOL 733 SuperProbe Electron probe microanalyser (EPMA) at Victoria University of Wellington (VUW). All crystals were analysed at $15 \mathrm{kV}$ accelerating voltage and $12 \mathrm{nA}$ beam current. Plagioclase crystals were analysed with a $10 \mu \mathrm{m}$ spot size at $10 \mu \mathrm{m}$ intervals. Fe-Ti oxides were analysed at the same conditions with a focused beam. Quartz crystals were analysed with long count times of 240 seconds on peak and 120 seconds on background with a focused beam. ZAF corrections (Bence and Albee, 1968) were used for data reduction. Primary calibrations used a mixture of natural and synthetic standards. Secondary standards of basaltic glass A99 (USNM 113498/1) for plagioclase analyses, ilmenite standard USNM 96189 for Fe-Ti oxides analyses (Jaroeswich et al., 1980) and KN18 obsidian glass (S. Malik and D.A. Bungard, reported in Devine et al., 1995) for Ti analyses in quartz were analysed at the beginning and end of each analytical session (Table 4.2). Quality control was applied to the plagioclase data and only analyses with totals between $97-102 \mathrm{wt} \%$ are reported. 
Cathodoluminescence (CL) images of quartz crystals were obtained using a photomultiplier attached to the electron microprobe at the same analytical conditions as described above. Excitation of Ti due to long emission times while collecting CL images can lead to blurry images. However, examination of the images reveals distinct, sharp boundaries are visible, suggesting that this effect is not significant.

\subsubsection{Laser ablation inductively coupled plasma mass spectrometry}

Laser ablation inductively coupled plasma mass spectrometry (LA-ICPMS) analyses of plagioclase crystals were performed in the Geochemical Laboratory at VUW with a NewWave deep UV laser (193 nm solid state) coupled to an Agilent $7500 \mathrm{cs}$ ICP-MS using helium as the carrier gas. $\mathrm{CaO}$ was determined prior to LA-ICPMS analysis by EPMA, enabling ${ }^{43} \mathrm{Ca}$ to be used as the internal standard. Samples were analysed for $\mathrm{Sr}, \mathrm{Ba}$ and $\mathrm{Mg}$ with $20 \mu \mathrm{m}$ laser spot diameters at $20 \mu \mathrm{m}$ intervals along the EPMA profile. Core and rim analyses of rare earth elements (REE), $\mathrm{Y}$ and $\mathrm{Pb}$ were also carried out at 35 or $50 \mu \mathrm{m}$ laser spot diameters, a repetition rate of $5 \mathrm{~Hz}$ and power of $\sim 5.6-6.7 \mathrm{~J} / \mathrm{cm}^{2}$. The NIST SRM 610 glass standard is used as the primary standard and for signal optimisation at the start and throughout each analytical session. NIST SRM 610 reference values are taken as the GeoRem preferred reference values (http:///georem.mpch-mainz.gwdg.de/). Repeat analyses of MPI-DING glass STH-G at $20 \mu \mathrm{m}$ laser spot diameters at the same analytical conditions as described above are given in Table 4.3. This indicates an elemental uncertainty $(2 \sigma)$ of $\pm 6.5 \%$ for $\mathrm{Sr}, \mathrm{Ba}$ and $\mathrm{Mg}$ at $20 \mu \mathrm{m}$ laser spot diameters. We estimate an elemental uncertainty of $(2 \sigma)<10 \%$ for rare earth elements and $\mathrm{Y}$ and $<20 \%$ 


\begin{tabular}{|c|c|c|c|c|c|c|c|c|c|c|c|c|c|c|c|}
\hline & \multicolumn{5}{|c|}{ A99 - Basalt glass } & \multicolumn{5}{|c|}{ Ilmenite standard USNM 96189} & \multicolumn{4}{|c|}{ KN18 - obsidian glass } & \multirow[b]{2}{*}{$\begin{array}{c}\text { ref } \\
\text { values } \\
(\mathrm{wt} \%)\end{array}$} \\
\hline & $\begin{array}{l}\text { Mean } \\
\mathrm{n}=19 \\
(\mathrm{wt} \%) \\
\end{array}$ & $2 \mathrm{SD}$ & $\% 2 \mathrm{SD}$ & $\%$ diff & $\begin{array}{c}\text { ref } \\
\text { values } \\
(\mathrm{wt} \%)\end{array}$ & $\begin{array}{c}\text { Mean } \\
\mathrm{n}=6 \\
(\mathrm{wt} \%)\end{array}$ & $2 \mathrm{SD}$ & $\% 2 \mathrm{SD}$ & $\%$ diff & $\begin{array}{c}\text { ref } \\
\text { values } \\
(\mathrm{wt} \%) \\
\end{array}$ & $\begin{array}{l}\text { Mean, } \\
\mathrm{n}=9 \\
(\mathrm{wt} \%)\end{array}$ & $2 \mathrm{SD}$ & $\% 2 \mathrm{SD}$ & $\% \operatorname{diff}$ & \\
\hline $\mathrm{SiO}_{2}$ & 50.9 & 1.44 & 2.8 & 0.1 & 50.9 & & & & & & 73.2 & 2.67 & 3.6 & -1.8 & 74.6 \\
\hline $\mathrm{TiO}_{2}$ & & & & & & 47.6 & 1.55 & 3.2 & 4.3 & 45.7 & 0.18 & 0.03 & 14 & 1.4 & 0.18 \\
\hline $\mathrm{Al}_{2} \mathrm{O}_{3}$ & 12.4 & 0.57 & 4.6 & -0.4 & 12.4 & & & & & 46.5 & & & & & \\
\hline $\mathrm{FeO}$ & 13.3 & 0.63 & 4.7 & 0.5 & 13.3 & 46.1 & 2.32 & 5.0 & -0.9 & & & & & & \\
\hline $\mathrm{MgO}$ & 5.16 & 0.11 & 2.1 & 1.6 & 5.08 & 0.32 & 0.07 & 22 & 3.1 & 0.31 & & & & & \\
\hline $\mathrm{MnO}$ & & & & & & 4.61 & 0.22 & 4.7 & -3.4 & 4.77 & & & & & \\
\hline $\mathrm{CaO}$ & 9.15 & 0.38 & 4.2 & -1.6 & 9.30 & & & & & & & & & & \\
\hline $\mathrm{Na}_{2} \mathrm{O}$ & 2.60 & 0.19 & 7.2 & -2.2 & 2.66 & & & & & & & & & & \\
\hline $\mathrm{K}_{2} \mathrm{O}$ & 0.84 & 0.07 & 8.2 & 2.7 & 0.82 & & & & & & & & & & \\
\hline Total & 94.5 & & & & 94.5 & & & & & 92.5 & 73.4 & & & & 74.7 \\
\hline
\end{tabular}

Table 4.2. Standard calibrations and reference values of basaltic glass A99, ilmenite standard USNM 96189 (Jaroeswich et al., 1980) and obsidian standard KN15 (S. Malik and D.A. Bungard reported in Devine et al., 1995) for electron microprobe analyses. $\mathrm{n}=$ number of analyses averaged. 
$\mathrm{Pb}$ when analysed at 35 and $50 \mu \mathrm{m}$ laser spot diameters from repeat analysis of STH-G at $35 \mu \mathrm{m}$ laser spot diameters with NIST SRM 612 as the primary standard at the analytical conditions described above (Table 4.3). Correlation between EPMA and LA-ICPMS analytical areas was achieved through detailed backscattered electron images taken before and after both EPMA and LAICPMS analyses.

\begin{tabular}{llcccccc}
\hline Isotope & Element & Spot size & $\begin{array}{c}\text { Mean } \\
\mathrm{n}=5\end{array}$ & 2 SD & \% 2SD & \% diff & $\begin{array}{c}\text { Ref } \\
\text { values }\end{array}$ \\
\hline 24 & $\mathrm{Mg}$ & 20 & 12643 & 155 & 1.23 & 6.43 & 11879 \\
25 & $\mathrm{Mg}$ & 20 & 11234 & 393 & 3.50 & -5.43 & 11879 \\
88 & $\mathrm{Sr}$ & 20 & 486 & 15.6 & 3.21 & 0.773 & 482 \\
137 & $\mathrm{Ba}$ & 20 & 306 & 22.6 & 7.37 & 2.74 & 298 \\
89 & $\mathrm{Y}^{*}$ & 35 & 10.9 & 0.289 & 2.65 & -4.51 & 11.4 \\
139 & $\mathrm{La}^{*}$ & 35 & 11.8 & 0.560 & 4.74 & -1.45 & 12.0 \\
140 & $\mathrm{Ce}^{*}$ & 35 & 25.5 & 0.540 & 2.12 & -2.37 & 26.1 \\
141 & $\mathrm{Pr}^{*}$ & 35 & 2.97 & 0.132 & 4.45 & -7.08 & 3.20 \\
146 & $\mathrm{Nd}^{*}$ & 35 & 13.1 & 1.00 & 7.65 & 0.90 & 13.0 \\
147 & $\mathrm{Sm}^{*}$ & 35 & 2.76 & 0.388 & 2.78 & -0.57 & 2.78 \\
153 & $\mathrm{Eu}^{*}$ & 35 & 0.917 & 0.069 & 7.54 & 0.953 & 0.950 \\
157 & $\mathrm{Gd}^{*}$ & 35 & 2.26 & 0.292 & 12.9 & -12.58 & 2.59 \\
163 & $\mathrm{Dy}^{*}$ & 35 & 2.16 & 0.286 & 13.2 & -2.79 & 2.22 \\
166 & $\mathrm{Er}^{*}$ & 35 & 1.10 & 0.082 & 7.44 & -7.00 & 1.18 \\
172 & $\mathrm{Yb}^{*}$ & 35 & 1.02 & 0.105 & 10.3 & -9.80 & 1.13 \\
175 & $\mathrm{Lu}^{*}$ & 35 & 0.157 & 0.027 & 17.4 & 0.168 & 0.170 \\
208 & $\mathrm{~Pb}^{*}$ & 35 & 8.29 & 0.424 & 5.12 & -19.49 & 10.3 \\
\hline
\end{tabular}

Table 4.3. Repetitive analyses of STH-G at $20 \mu \mathrm{m}$ and $35 \mu \mathrm{m}$ laser spot diameters. Reference values are taken from GeoRem preferred values (http:///georem.mpch-mainz.gwdg.de/). * indicates Baker, unpublished data at $35 \mu \mathrm{m}$ laser spot diameters and NIST SRM 612 as primary standard.

\subsection{Results}

\subsubsection{Plagioclase}

Backscattered electron images of $>100$ plagioclase crystals from 7 samples of the Whakamaru ignimbrite were obtained and revealed subtle yet ubiquitous zoning of crystals (Appendix A4.1 and A4.2). Of these, 61 were analysed for core and rim compositions and major element profiles across 22 crystals (Appendix A3.6 and A3.7) were measured with representative compositions 
given in Table 4.4. Sr, $\mathrm{Ba}$ and $\mathrm{Mg}$ profiles were obtained for 8 of the crystals and spot analyses of REE, $\mathrm{Y}$ and $\mathrm{Pb}$ were obtained for a representative selection of crystals (Appendix A3.8 and A3.9).

\begin{tabular}{lcccccccc}
\hline $\begin{array}{l}\text { Sample } \\
(\mathrm{wt} \%)\end{array}$ & $\begin{array}{c}\mathrm{WH} 1 \\
\mathrm{~h} \_8\end{array}$ & $\begin{array}{c}\text { WH1 } \\
\text { h_38 }\end{array}$ & $\begin{array}{l}\text { WH6 } \\
\text { da_2 }\end{array}$ & $\begin{array}{c}\text { WH6 } \\
\text { da_38 }\end{array}$ & $\begin{array}{c}\text { WH2 } \\
\text { a_3 }\end{array}$ & $\begin{array}{c}\text { WH3 } \\
\text { e_4 }\end{array}$ & $\begin{array}{c}\text { WH2 } \\
\text { g__2 2 }\end{array}$ & $\begin{array}{c}\text { WH3 } \\
\text { b_4 }\end{array}$ \\
\hline Group & 1 rim & 1 core & 1 rim & 1 core & 2 & 2 & 3 & 3 \\
\hline $\mathrm{SiO}_{2}$ & 60.8 & 53.3 & 59.9 & 56.4 & 60.6 & 60.5 & 61.4 & 60.5 \\
$\mathrm{Al}_{2} \mathrm{O}_{3}$ & 25.4 & 29.9 & 24.8 & 28.8 & 24.2 & 24.7 & 24.0 & 24.5 \\
$\mathrm{FeO}$ & 0.31 & 0.24 & 0.21 & 0.20 & 0.30 & 0.28 & 0.24 & 0.17 \\
$\mathrm{CaO}$ & 6.67 & 10.8 & 6.68 & 10.46 & 6.37 & 6.65 & 5.74 & 6.06 \\
$\mathrm{Na}_{2} \mathrm{O}$ & 7.82 & 5.16 & 7.29 & 5.59 & 7.49 & 7.35 & 8.33 & 7.98 \\
$\mathrm{~K}_{2} \mathrm{O}$ & 0.72 & 0.30 & 0.64 & 0.25 & 0.71 & 0.65 & 0.71 & 0.67 \\
$\mathrm{Total}$ & 101.8 & 99.7 & 99.6 & 101.7 & 99.7 & 100.2 & 100.4 & 99.9 \\
$\mathrm{X} \mathrm{An}$ & 0.31 & 0.54 & 0.32 & 0.50 & 0.31 & 0.32 & 0.27 & 0.28 \\
\hline
\end{tabular}

Table 4.4. Representative major element analyses of plagioclase crystals. $X$ An calculated on a mole fraction basis.

Plagioclase crystals are generally euhedral to sub-euhedral and in some instances are fragmented and broken. On the basis of textural observations and anorthite (An) composition (Figure 4.2), plagioclase crystals fall into three Groups, denoted 1, 2, and 3 (Figure 4.3). The most abundant type of plagioclase crystals

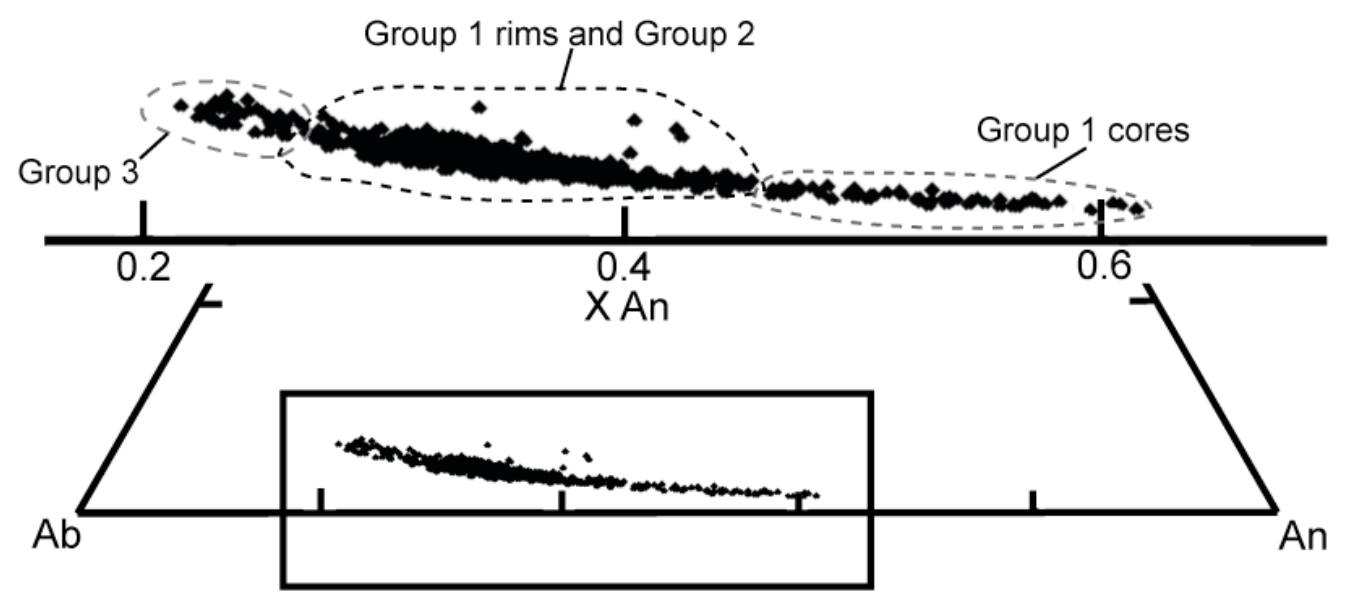

Figure 4.2. Partial ternary diagram of Whakamaru plagioclase crystals and the anorthite composition of the three plagioclase groups are illustrated. Number of analyses $=1246$. 

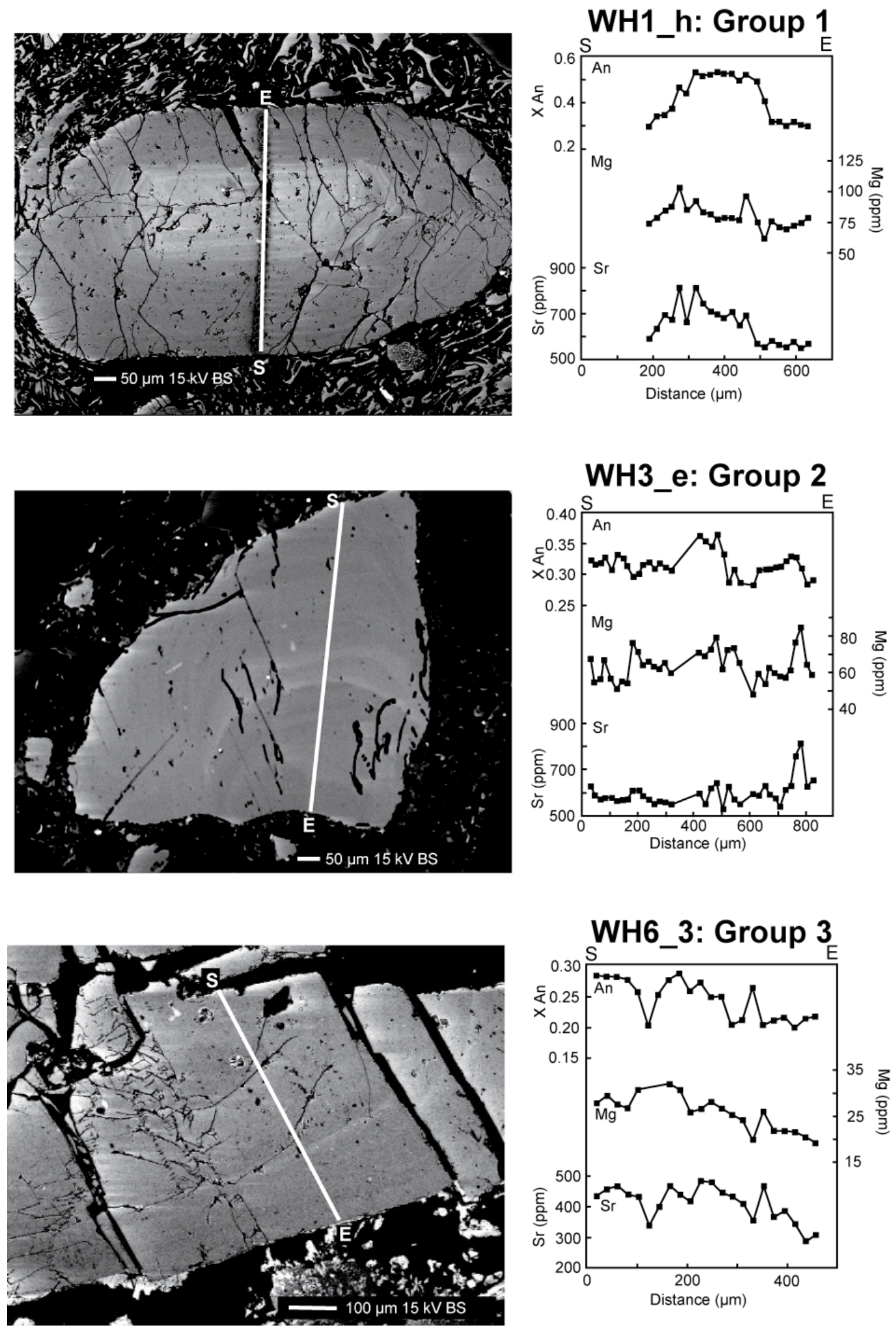

Figure 4.3. Representative backscattered images and $X \mathrm{An}, \mathrm{Sr}$ and $\mathrm{Mg}$ concentrations of each of the plagioclase populations. The start (S) and end (E) of EPMA and LA-ICPMS profiles are shown. 
observed are Group 2 crystals $(77 \%)$ with only relatively minor quantities of Group $1(11 \%)$ and Group $3(12 \%)$ crystals, although the abundance of Group 1 crystals may be biased if the sectioning of crystals was off-centre (Appendix A3.6 and A3.7; Appendix A4.1 and A4.2). There is no observed systematic variation in the abundance of plagioclase populations with stratigraphic height.

\subsubsection{Group 1}

Group 1 crystals are characterised by cores of $A n_{45-60}$ mantled by concentric relatively homogeneous oscillatory-zoned rims of ca. $\mathrm{An}_{30}$ (Figure 4.3). Trace element concentrations of cores and rims are distinct with elevated $\mathrm{Ba}$ (ca. 400$800 \mathrm{ppm}), \mathrm{La}(7-10 \mathrm{ppm})$ and $\mathrm{Ce}(9-13 \mathrm{ppm})$ concentrations of rims compared to cores at similar Sr concentrations (Figure 4.4). Texturally, two distinct core types are observed: (1) crystals with a gradual diffuse core-rim interface such as WH1_h and WH2_b; and (2) crystals with partially resorbed cores and a sharp core-rim interface, for example WH2_d (Appendix A4.1 and A4.2).

\subsubsection{Group 2}

Group 2 plagioclase crystals exhibit pronounced oscillatory zoning with a limited $A n_{30-40}$ composition (Figure 4.3). High $A n$ spikes (ca. $A n_{36-40}$ ) are observed and these correspond to micro-inclusion trails within the crystal. $\mathrm{Sr}$ (dominantly 550$630 \mathrm{ppm}$ ), $\mathrm{Ba}$ (dominantly 450-730 ppm), $\mathrm{Pb}$ and REE concentrations from a single representative Group 2 plagioclase crystal overlap those of Group 1 rims with the exception of four analyses from the region surrounding the core of the crystal that possess anomalously high $\mathrm{Sr}(625-815 \mathrm{ppm})$ and $\mathrm{Ba}(1010-1325$ 

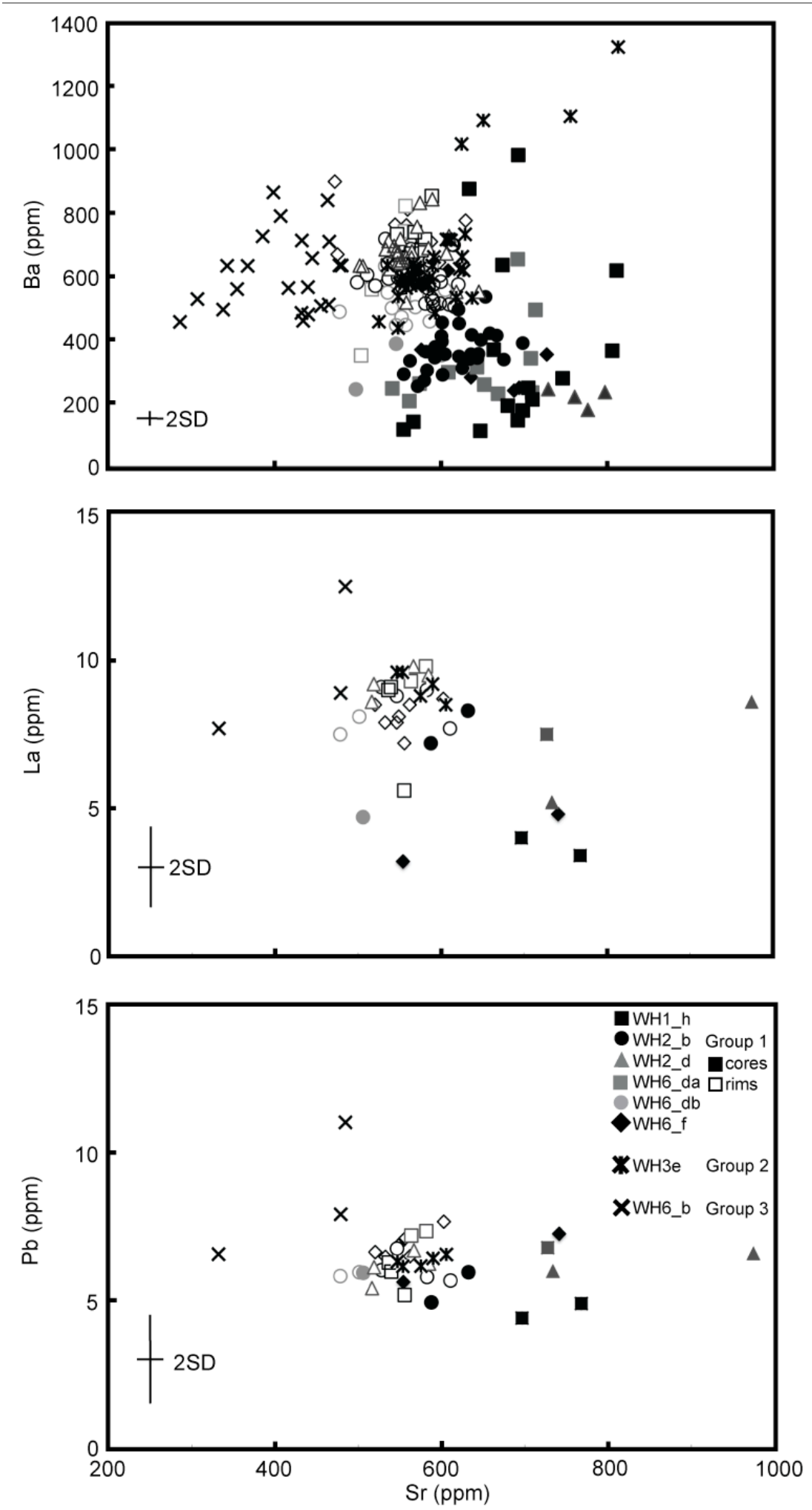

Figure 4.4. Measured $\mathrm{Sr}, \mathrm{Ba}, \mathrm{La}$ and $\mathrm{Pb}$ concentrations of plagioclase crystals. Note only a single representative plagioclase crystal was analysed for trace elements for Group 2 and 3 crystals. 
ppm) concentrations that are not reflected in the $\mathrm{Pb}$ and $\mathrm{REE}$ analyses (Figure 4.4).

\subsubsection{Group 3}

These crystals are characterised by cores of $A n_{25-35}$ and rims of $A n_{20-25}$, and low Sr (280 - $480 \mathrm{ppm})$ and $\mathrm{Mg}(19-32 \mathrm{ppm})$ concentrations compared to Group 1 and 2 plagioclase crystals (Figure 4.4). In addition, $\mathrm{Sr}$ and $\mathrm{Ba}$ are more compatible in Group 3 plagioclases compared to Group 1 and Group 2 crystals. REE concentrations indicate the most extreme concentrations are observed in the crystal core with elevated $\mathrm{Pb}, \mathrm{Eu}$, and $\mathrm{La}$ concentrations relative to Group 1, Group 2 and Group 3 rim concentrations (Figure 4.4).

\subsubsection{Quartz crystals}

CL images reveal complex zonation within Whakamaru quartz crystals (Figure 4.5; Appendix A4.3), demonstrating a growth history just as complex as that of the plagioclase crystals and the presence of multiple populations. Oscillatory zoning is ubiquitous and in some cases is truncated by later overgrowths (e.g. WH1_39), demonstrating the presence of distinct core regions and multiple resorption events. Several quartz crystals (e.g. WH1_37, WH2_3, WH2_6) display a bright $\mathrm{CL}$ rim implying these crystals experienced a common final stage of magmatic evolution; however, the bright CL core of WH1_37 in comparison with those of $\mathrm{WH}_{2} \_3$ and $\mathrm{WH}_{2} \_6$ indicates the early period of magmatic evolution is unique to each crystal. In contrast, crystals WH1_40, 
WH2_4, WH2_5 and WH2_8 exhibit strong oscillatory-zoned rims indicative of fluctuating magmatic conditions during the final stages of quartz growth.

The intensity of CL zoning can be used as a proxy for Ti concentrations with darker regions indicating lower Ti concentrations that result from either a change in magmatic temperature or the Ti activity of the melt (Wark and Spear, 2005). Core and rim concentrations of 14 quartz crystals were analysed for $\mathrm{TiO}_{2}$ concentrations from samples WH1 and WH2 (Table 4.5) and ranged between $0.002-0.049$ wt. $\%$.

\begin{tabular}{|c|c|c|}
\hline Sample & $\begin{array}{c}\mathrm{TiO}_{2} \\
(\mathrm{wt} \%)\end{array}$ & Position \\
\hline WH1_4_Q1 & 0.002 & core \\
\hline WH1_4_Q2 & 0.011 & rim \\
\hline WH1_35_Q1 & 0.009 & core \\
\hline WH1_35_Q2 & 0.029 & rim \\
\hline WH1_36_Q1 & 0.016 & core \\
\hline WH1_36_Q2 & 0.025 & rim \\
\hline WH1_37_Q1 & 0.050 & core \\
\hline WH1_37_Q2 & 0.039 & rim \\
\hline WH1_38_Q1 & 0.027 & core \\
\hline WH1_38_Q2 & 0.049 & rim \\
\hline WH1_39_Q1 & 0.022 & rim \\
\hline WH1_39_Q3 & 0.021 & core \\
\hline WH1_40_Q1 & 0.033 & rim \\
\hline WH1_40_Q2 & 0.029 & core \\
\hline WH2_2_Q1 & 0.022 & core \\
\hline WH2_2_Q2 & 0.034 & rim \\
\hline WH2_3_Q1 & 0.015 & core \\
\hline WH2_3_Q2 & 0.005 & rim \\
\hline WH2_4_Q1 & 0.009 & core \\
\hline WH2_4_Q2 & 0.024 & rim \\
\hline WH2_5_Q1 & 0.021 & core \\
\hline WH2_5_Q2 & 0.013 & rim \\
\hline WH2_6_Q1 & 0.012 & core \\
\hline WH2_6_Q2 & 0.046 & rim \\
\hline WH2_7_Q1 & 0.026 & core \\
\hline WH2_7_Q2 & 0.005 & rim \\
\hline WH2_8_Q1 & 0.007 & core \\
\hline $\mathrm{WH} 2 \_8 \_\mathrm{Q} 2$ & 0.013 & rim \\
\hline
\end{tabular}




\subsubsection{Fe-Ti oxides}

Fe-Ti oxides are present as both free crystals and hosted within orthopyroxene phenocrysts. Free Fe-Ti oxides were not analysed, as it is impossible to determine the relationship of these crystals prior to the crushing of pumices and separation of crystals. Fourteen-orthopyroxene hosted Fe-Ti oxide pairs were analysed from sample WH1 (Table 4.6), with only six of these pairs being fully enclosed in the orthopyroxene crystal allowing homogenisation for the majority of Fe-Ti oxides with the external melt prior to eruption. Equilibrium between oxides was tested using the method of Bacon and Hirschmann (1988) with temperatures and oxygen fugacity $\left(-\log \mathrm{fO}_{2}\right)$ calculated using the ILMAT spreadsheet of Lepage (1998) (Table 4.6).

\subsubsection{Geothermometry}

Fe-Ti oxides are useful probes of magmatic temperature with the ability to record heating events on the timescales of hours to days prior to eruption (Venezky et al., 1999). Therefore, Fe-Ti oxides from WH1 are used to infer a final mean magmatic temperature of $789 \pm 40{ }^{\circ} \mathrm{C}(2 \mathrm{SD})$ (Table 4.6). A longer record of magmatic temperature is potentially preserved in plagioclase and quartz crystals, as these crystallise earlier in the magmatic evolution and major element diffusion is much slower than in Fe-Ti oxides (Grove et al., 1994; Morse et al., 1994; Venezky et al., 1999; Cherniak et al., 2007). Application of plagioclase-melt equilibria of Putirka (2005) permits magmatic temperatures at the time of plagioclase fractionation to be detailed. The presence of three distinct plagioclase populations indicates the existence of multiple magma batches. 


\begin{tabular}{|c|c|c|c|c|c|c|c|c|c|c|c|c|c|c|}
\hline $\begin{array}{l}\text { Ilmenite } \\
(\mathrm{wt} \%)\end{array}$ & $\begin{array}{l}\text { WH1 } \\
\text { O12-1 }\end{array}$ & $\begin{array}{l}{ }^{*} \text { WH1 } \\
\text { O18-1 }\end{array}$ & $\begin{array}{l}{ }^{*} \text { WH1 } \\
\text { O21-2 }\end{array}$ & $\begin{array}{l}{ }^{*} \text { WH1 } \\
\text { O23-2 }\end{array}$ & $\begin{array}{l}{ }^{*} \text { WH1 } \\
\text { O24-1 }\end{array}$ & $\begin{array}{l}{ }^{*} \text { WH1 } \\
\text { O26-2 }\end{array}$ & $\begin{array}{c}\text { WH1 } \\
21-\mathrm{O} 1\end{array}$ & $\begin{array}{c}\text { WH1 } \\
24-\mathrm{O} 2\end{array}$ & $\begin{array}{c}\text { WH1 } \\
26-\mathrm{O} 2\end{array}$ & $\begin{array}{c}\text { WH1 } \\
27-\mathrm{O} 2\end{array}$ & $\begin{array}{l}{ }^{*} \mathrm{WH} 1 \\
30-\mathrm{O} 2\end{array}$ & $\begin{array}{l}\text { WH1 } \\
31 \mathrm{a}-2\end{array}$ & $\begin{array}{r}{ }^{*} \mathrm{WH} 1 \\
32-\mathrm{O} 2\end{array}$ & $\begin{array}{r}{ }^{*} \mathrm{WH} 1 \\
32-\mathrm{O} 3\end{array}$ \\
\hline $\mathrm{SiO}_{2}$ & 0.049 & 0.051 & 0.000 & 0.042 & 0.042 & 0.052 & 0.073 & 0.004 & 0.047 & 0.072 & 0.000 & 0.046 & 0.012 & 0.000 \\
\hline $\mathrm{TiO}_{2}$ & 47.93 & 48.75 & 49.03 & 49.02 & 49.23 & 49.37 & 48.30 & 45.30 & 48.65 & 45.59 & 45.44 & 45.20 & 45.73 & 45.31 \\
\hline $\mathrm{Al}_{2} \mathrm{O}_{3}$ & 0.109 & 0.127 & 0.103 & 0.185 & 0.137 & 0.073 & 0.16 & 0.111 & 0.08 & 0.121 & 0.1 & 0.164 & 0.111 & 0.135 \\
\hline $\mathrm{FeO}$ & 49.88 & 48.79 & 50.53 & 49.57 & 49.13 & 48.61 & 48.26 & 49.96 & 49.38 & 50.09 & 49.86 & 50.19 & 50.02 & 50.80 \\
\hline $\mathrm{MnO}$ & 0.848 & 0.772 & 0.825 & 0.866 & 0.927 & 0.889 & 0.834 & 0.863 & 0.943 & 0.818 & 0.801 & 0.870 & 0.972 & 0.842 \\
\hline $\mathrm{MgO}$ & 1.85 & 1.97 & 1.76 & 1.81 & 1.78 & 1.83 & 1.73 & 1.75 & 1.89 & 1.80 & 1.68 & 1.76 & 1.69 & 1.65 \\
\hline Total & 100.61 & 100.42 & 102.26 & 101.45 & 101.20 & 100.77 & 99.28 & 97.98 & 100.94 & 98.48 & 97.88 & 98.23 & 98.53 & 98.74 \\
\hline $\mathrm{Fe}_{2} \mathrm{O}_{3}$ & 12.10 & 10.20 & 11.60 & 10.60 & 9.90 & 9.20 & 9.60 & 14.70 & 11.00 & 14.50 & 14.20 & 15.00 & 14.30 & 15.40 \\
\hline $\mathrm{FeO}$ & 39.00 & 39.60 & 40.10 & 40.00 & 30.20 & 40.30 & 39.60 & 36.80 & 39.50 & 37.10 & 37.10 & 36.70 & 37.20 & 37.00 \\
\hline Magnetite & WH1 & WH1 & WH1 & WH1 & WH1 & WH1 & WH1 & WH1 & WH1 & WH1 & WH1 & WH1 & WH1 & WH1 \\
\hline$(\mathrm{wt} \%)$ & O12-2 & O18-2 & O21-1 & O23-1 & O24-2 & O26-1 & $21-\mathrm{O} 2$ & $24-\mathrm{O} 3$ & $26-\mathrm{O} 3$ & $27-01$ & $30-\mathrm{O} 1$ & $31 a-1$ & $32-\mathrm{O} 1$ & $32-\mathrm{O} 4$ \\
\hline $\mathrm{SiO}_{2}$ & 0.064 & 0.144 & 0.082 & 0.076 & 0.071 & 0.143 & 0.087 & 0.018 & 0.079 & 0.048 & 0.009 & 0.044 & 0.059 & 0.074 \\
\hline $\mathrm{TiO}_{2}$ & 8.80 & 9.31 & 9.30 & 9.57 & 9.32 & 9.47 & 9.22 & 8.63 & 9.23 & 8.68 & 8.50 & 8.80 & 8.43 & 8.69 \\
\hline $\mathrm{Al}_{2} \mathrm{O}_{3}$ & 1.41 & 1.55 & 1.44 & 1.45 & 1.43 & 1.50 & 1.50 & 1.40 & 1.50 & 1.49 & 1.38 & 1.50 & 1.51 & 1.43 \\
\hline $\mathrm{FeO}$ & 81.52 & 81.22 & 81.72 & 82.28 & 82.08 & 81.49 & 81.93 & 82.82 & 81.53 & 83.45 & 83.49 & 84.33 & 83.42 & 83.61 \\
\hline $\mathrm{MnO}$ & 0.487 & 0.517 & 0.624 & 0.522 & 0.576 & 0.524 & 0.627 & 0.532 & 0.559 & 0.444 & 0.563 & 0.596 & 0.667 & 0.505 \\
\hline $\mathrm{MgO}$ & 0.75 & 0.95 & 0.88 & 0.89 & 0.91 & 0.82 & 0.86 & 0.76 & 0.87 & 0.86 & 0.83 & 0.87 & 0.85 & 0.87 \\
\hline Total & 92.96 & 93.54 & 93.96 & 94.72 & 94.32 & 93.79 & 94.13 & 94.16 & 93.69 & 94.98 & 94.77 & 96.14 & 94.93 & 95.17 \\
\hline $\mathrm{Fe}_{2} \mathrm{O}_{3}$ & 49.20 & 48.30 & 48.90 & 48.90 & 49.20 & 48.20 & 49.10 & 50.50 & 48.70 & 50.90 & 51.30 & 51.50 & 51.30 & 51.00 \\
\hline $\mathrm{FeO}$ & 37.30 & 37.70 & 37.70 & 38.30 & 37.90 & 38.10 & 37.80 & 37.40 & 37.70 & 37.70 & 37.30 & 38.00 & 37.30 & 37.70 \\
\hline Temp $\left({ }^{\circ} \mathrm{C}\right)$ & 793 & 768 & 787 & 779 & 766 & 763 & 764 & 820 & 786 & 814 & 808 & 819 & 807 & 821 \\
\hline $\begin{array}{l}\text { Oxygen } \\
\text { fugacity } \\
\left(\log 10 \mathrm{fO}_{2}\right)\end{array}$ & -13.5 & -14.4 & -13.8 & -14.1 & -14.5 & -14.7 & -14.5 & -12.6 & -13.8 & -12.71 & -12.83 & -12.56 & -12.8 & -12.50 \\
\hline
\end{tabular}



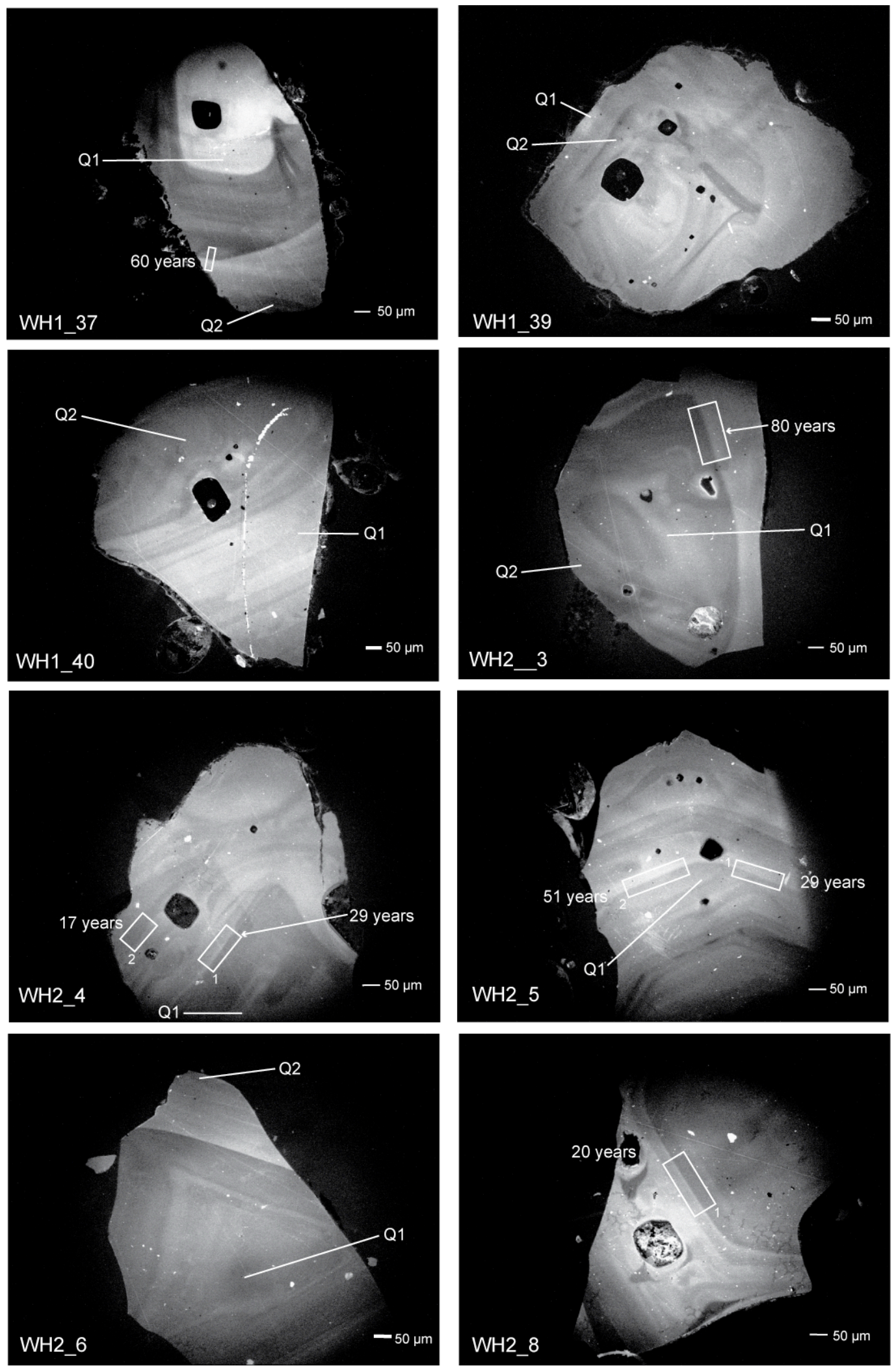

Figure 4.5. CL images for a selection of quartz crystals from WH1 and WH2. White boxes denote areas modelled by diffusion with the respective timescales displayed in years. Locations of point analyses are denoted by Q and relate to Table 4.5 . 
Therefore, to employ a single constant melt composition in association with the plagioclase-melt equilibria may provide erroneous temperature estimates. As Group 1 rims and Group 2 plagioclase crystals appear to be in equilibrium with the groundmass glass (see Section 4.6.1 and 4.6.2) and comprise the majority of crystals, a mean groundmass glass composition (Brown, 1994) is taken as the melt composition and used to calculate magmatic temperatures. A summary of calculated magmatic temperatures is given in Table 4.7 and indicates a mean temperature of $760{ }^{\circ} \mathrm{C}$ for Group 1 rims and Group 2 crystals. Furthermore, this would indicate Group 1 cores fractionated from magma with a temperature of ca. $830{ }^{\circ} \mathrm{C}$ or $950{ }^{\circ} \mathrm{C}$ if, as discussed below, the cores of Group 1 crystals fractionated from an andesitic progenitor melt of dacitic composition. Magmatic temperatures of Group 3 plagioclase crystals are more equivocal. A groundmass glass melt composition yields magmatic temperatures ca. $30^{\circ} \mathrm{C}$ lower than the melt in equilibrium with the Group 1 rims and Group 2 crystals, whilst utilising a melt inclusion composition (see Section 4.6.3) indicates a temperature of ca. 770 ${ }^{\circ} \mathrm{C}$.

Magmatic temperatures can be calculated using the Ti-in-quartz geothermometer (Wark and Watson, 2006). However, it relies on the Ti activity of the melt being accurately constrained. Ti activity was calculated for the Whakamaru magma using the method of Hayden et al. (2007) from the major element composition of melt inclusions (Chapter 2) and groundmass glasses (Brown, 1994). This produced varying and inconsistent estimates of Ti activity of 1.48 for WH1 melt 


\begin{tabular}{|c|c|c|c|c|c|}
\hline Group & Sample & $\mathrm{n}$ & $\begin{array}{l}\text { Minimum } \\
\text { temperature } \\
\left({ }^{\circ} \mathrm{C}\right)\end{array}$ & $\begin{array}{l}\text { Maximum } \\
\text { temperature } \\
\left({ }^{\circ} \mathrm{C}\right)\end{array}$ & $\begin{array}{c}\text { Average } \\
\text { temperature } \\
\left({ }^{\circ} \mathrm{C}\right)\end{array}$ \\
\hline \multicolumn{6}{|l|}{ Rims } \\
\hline 1 & WH1_h & 33 & 724 & 775 & 751 \\
\hline 1 & $\mathrm{WH} 2 \_\mathrm{b}$ & 59 & 718 & 776 & 754 \\
\hline 1 & $\mathrm{WH} 2 \mathrm{~d}$ & 52 & 734 & 793 & 758 \\
\hline 1 & WH6_da & 36 & 739 & 772 & 758 \\
\hline 1 & $\mathrm{WH}^{-} \mathrm{db}$ & 29 & 713 & 807 & 772 \\
\hline 1 & $\mathrm{WH}_{-\mathrm{f}}$ & 52 & 731 & 790 & 761 \\
\hline \multicolumn{6}{|l|}{ Cores } \\
\hline 1 & WH1_h & 28 & 780 & 849 & 830 \\
\hline 1 & $\mathrm{WH} 2 \_\mathrm{b}$ & 49 & 767 & 835 & 812 \\
\hline 1 & $\mathrm{WH}^{2} \mathrm{~d}$ & 22 & 781 & 848 & 828 \\
\hline 1 & WH6_da & 21 & 789 & 844 & 828 \\
\hline 1 & WH6_db & 7 & 789 & 846 & 828 \\
\hline 1 & WH6_f & 10 & 790 & 848 & 832 \\
\hline 2 & WH1 b & 98 & 729 & 796 & 752 \\
\hline 2 & $\mathrm{WH} 2 \_\mathrm{a}$ & 151 & 723 & 798 & 756 \\
\hline 2 & $\mathrm{WH} 2^{-} \mathrm{f}$ & 69 & 741 & 803 & 763 \\
\hline 2 & WH3 & 57 & 744 & 790 & 764 \\
\hline 2 & WH3_d & 58 & 724 & 805 & 778 \\
\hline 2 & WH3_e & 88 & 728 & 795 & 757 \\
\hline 2 & WH5_d & 66 & 749 & 835 & 784 \\
\hline 2 & WH5_f & 61 & 728 & 792 & 760 \\
\hline 2 & WH6 e & 47 & 748 & 791 & 762 \\
\hline 2 & WH6_g & 65 & 735 & 813 & 758 \\
\hline 3 & WH2 g & 42 & 694 & 812 & 747 \\
\hline 3 & $\mathrm{WH} 3 \mathrm{~b}$ & 51 & 663 & 744 & 707 \\
\hline 3 & WH6_b & 42 & 701 & 813 & 748 \\
\hline 3 & WH6 & 90 & 673 & 785 & 732 \\
\hline
\end{tabular}

Table 4.7. Summary of magmatic temperatures estimated from the plagioclase-melt equilibria of Putirka (2005). $\mathrm{n}=$ number of plagioclase analyses from each crystal used to calculate average. Full temperature determinations are given in Appendix A3.6.

inclusions, 0.98 for $\mathrm{WH} 2$ melt inclusions and 1.35 for groundmass glasses; indicating that $\mathrm{Ti}$ activity fluctuated either temporally or spatially within the magma chamber. Consequently, $\mathrm{TiO}_{2}$ was not sufficiently buffered to permit the thermal evolution of quartz crystals to be determined.

This range of calculated magmatic temperatures is interpreted to reflect the changing thermal regime of a cooling magma. Cores of Group 1 plagioclase 
crystals are inferred to fractionate from an initial, hotter (ca. $\left.950{ }^{\circ} \mathrm{C}\right)$ andesitic progenitor melt that with time cooled and differentiates into a cooler $\left(\mathrm{ca} .760{ }^{\circ} \mathrm{C}\right)$ rhyolitic magma, represented by the calculated magmatic temperatures of Group 1 rim and Group 2 plagioclase crystals. Heating of the magma immediately prior to eruption is speculated to have occurred from the slightly elevated mean magmatic temperature of $789^{\circ} \mathrm{C}$ determined from the Fe-Ti oxides.

\subsection{Diffusion modelling}

\subsubsection{Plagioclase crystals}

As plagioclase crystallises, the crystal rim maintains local equilibrium with surrounding melt. Due to the slow, coupled inter-diffusion of $\mathrm{NaSi}-\mathrm{CaAl}$, the original anorthite composition of Whakamaru plagioclase crystals is retained at length scales $>5 \mu \mathrm{m}$ (Blundy and Shimizu, 1991; Grove et al., 1984; Morse et al., 1984). The incorporation of trace elements into plagioclase crystals is governed by well-constrained partitioning relationships (Blundy and Wood, 1991; 1994; Bindeman et al., 1998) that are dependent on temperature melt composition and crystal composition. Disequilibrium can arise between adjacent crystal zones as the result of changing melt temperature or chemistry (leading to net uptake or loss of trace elements from the melt) or changes in major element composition caused by other factors such as pressure or water content. Such changes in the magma conditions (be they pressure, temperature, $\mathrm{H}_{2} \mathrm{O}$ budget or melt composition) result in subsequent plagioclase growth at different anorthite concentrations (e.g. Bowen, 1913; Johannes, 1989; Putirka, 2005; Ginibre et al., 2007) with concomitant step changes in trace element concentrations. The induced disequilibrium of this step change between two adjacent zones is erased 
by a subsequent homogenisation of the trace element concentrations via a diffusion-governed process that will only cease on eruption when the compositional profile is "frozen" into the crystal by the rapid drop in diffusion rates. The chemical potential of elements is the driving force for diffusion, and can be approximated by using standard partition coefficients to translate element abundance into a melt equivalent. The partition coefficients of adjacent crystal zones govern the relative equilibrium concentrations of trace elements between the two regions of the crystal. Therefore, two adjacent zones of plagioclase with differing $A n$ contents will not necessarily possess the same trace element concentrations when fully equilibrated (e.g. Zellmer et al., 1999; Costa et al., 2003), although locally, the chemical potential will be in equilibrium. If equilibrium has not been attained, the length of time a crystal interface resided at magmatic temperature can be modelled with the appropriate solution to Fick's second law and calculated partition coefficients (K) (e.g. Crank, 1976; Zellmer et al., 1999; Costa et al., 2003; Morgan et al., 2004).

Partition coefficients of $\mathrm{Sr}$ and $\mathrm{Ba}$ in plagioclase crystals can be calculated from the relationships determined by Blundy and Wood (1991) and relate the trace element concentration of the plagioclase to the melt they fractionated from:

$$
\begin{aligned}
& R T \ln K_{S r}=26,800-26,700 X_{A n} \\
& R T \ln K_{B a}=10,200-38,200 X_{A n}
\end{aligned}
$$

where $\mathrm{R}$ is the gas constant $\left(8.3145 \mathrm{~J} \mathrm{~mol}^{-1} \mathrm{~K}^{-1}\right)$, $\mathrm{T}$ is the temperature in Kelvin and $X_{A n}$ is the $A n$ content on a mole fraction basis. These partition coefficients can then be used to calculate equilibrium melt concentrations of $\mathrm{Sr}$ and $\mathrm{Ba}$ that would be in instantaneous equilibrium with that crystal zone, following the 
method described by Costa et al. (2003) and the co-existing melt compositions at the time the plagioclase crystallised

\subsubsection{Diffusion modelling based on Sr profiles}

Timescales for the length of time the core-rim interface in Group 1 crystals resided at magmatic temperatures can then be estimated through analysis of $\mathrm{Sr}$ diffusion profiles. Sr diffusion modelling is conducted as the diffusivity of $\mathrm{Sr}$ is well constrained for plagioclase and process appropriate diffusion rates (Zellmer et al. 1999). A simple spherical diffusion model (Crank, 1976) (Equation 4.2) is applied with a radius, $a$, assuming an initially uniform core composition $\left(\mathrm{C}_{1}\right)$ buffered by a constant rim composition $\left(\mathrm{C}_{0}\right)$, with a measured concentration $(\mathrm{C})$ at a distance, $r$ from the centre. As equilibrium is governed by the chemical potential of elements and not concentration, a calculated fictional melt equivalent for $\mathrm{Sr}$ is determined (calculated by dividing measured/equilibrium elemental concentrations) (Zellmer et al., 2003) and substituted for concentration in Equation 4.2.

$$
\frac{C-C_{1}}{C_{0}-C_{1}}=1+\frac{2 a}{\pi r} \sum_{n=1}^{\infty} \frac{(-1)^{n}}{n} \sin \frac{n \pi r}{a} e^{-D n^{2} \pi^{2} t / a^{2}}
$$

Diffusivity of $\mathrm{Sr}(\mathrm{D})$ is assumed to be isotropic within analytical error (Giletti and Casserly, 1994; Zellmer et al., 1999) and calculated following the method described in Zellmer et al. (1999), where the pre-exponential factor, $\mathrm{D}_{0}=10^{-(4.1 \mathrm{XAn}+4.08)}$, activation energy of $276 \mathrm{~kJ} \mathrm{~mol}^{-1}$ and a magmatic temperature of $760{ }^{\circ} \mathrm{C}$ (Section 4.4.4). 
Of the six Group 1 crystals analysed for $\mathrm{Sr}$ diffusion profiles, the core-rim interface in WH2_d and WH6_f decreases in $A n$ by 0.26 mol \% over $30 \mu \mathrm{m}$ and $20 \mu \mathrm{m}$, respectively, and therefore sufficient resolution could not be attained to fully constrain residence times. However, maximum residence times of $<2300$ yrs have been estimated for these two crystals (Table 4.8). The residence times of the other four crystals yield a range of ages from $13.5 \mathrm{ka}$ to $3 \mathrm{ka}$ (Table 4.8). The longest times of ca. $13.5 \mathrm{ka}$ were recorded in crystals WH1_h and WH2_b that possess diffuse boundaries. In comparison, crystals WH6_da and WH6_db possess semi-resorbed cores and return much shorter times in the region of 3000 - 6500 years. This continuum of plagioclase residence times may hint at the frequent mixing of magmas and implies that not all Group 1 cores were incorporated simultaneously into the final magma body.

\begin{tabular}{lcccccc}
\hline Sample & $\begin{array}{c}\text { Maximum } \\
\text { X An }\end{array}$ & $\begin{array}{c}\text { Initial Sr } \\
\text { fictional } \\
\text { melt }\end{array}$ & $\begin{array}{c}\text { Measured } \\
\text { Sr fictional } \\
\text { melt }\end{array}$ & $\mathrm{a}(\mu \mathrm{m})$ & $\mathrm{r}(\mu \mathrm{m})$ & Age (yrs) \\
\hline WH1_h & 0.53 & 2.5 & 1.81 & 200 & 122 & 13500 \\
WH2_b & 0.48 & 1.8 & 1.61 & 488 & 280 & 13500 \\
& & 1.31 & & 300 & 10000 \\
WH2_d & 0.57 & 2.73 & ca. 1.50 & 170 & 145 & $<2300$ \\
WH6_da & 0.52 & 2.09 & 1.28 & 140 & 112 & 6400 \\
WH6_db & 0.55 & 2.16 & 1.28 & 64 & 42 & 3400 \\
& & & 1.59 & & 20 & 3000 \\
WH6_f & 0.58 & 2.74 & ca. 1.64 & 55 & 40 & $<2000$ \\
\hline
\end{tabular}

Table 4.8. Calculated residence times of Group 1 plagioclase crystals from Sr diffusion. Diffusivity of $\mathrm{Sr}$ is calculated at $760{ }^{\circ} \mathrm{C}$ at the highest observed $X \mathrm{An}$. Initial calculated fictional Sr melt equivalent is determined from the core of the crystals and measured calculated fictional Sr melt equivalent is taken at a distance $(r)$ from the centre of the sphere with a radius $(a)$.

Errors are estimated by propagating the $2 \sigma$ temperature uncertainty on the calculated temperatures onto the calculated diffusivities and these are illustrated in Figure 4.6 as probability distributions for each interface modelled. 
Propagating the measured analytical errors of the pre-exponential factor and activation energy onto the calculated diffusivities results in errors that are negligible (e.g. $0.05 \log _{10}$ units for $1 \sigma$ ) compared to the determined errors due to the temperature uncertainties (e.g. $0.209 \log _{10}$ units for $1 \sigma$ ) and gives a combined calculated uncertainty of $0.214 \log _{10}$ units for $1 \sigma$. The probability density function of the entire plagioclase population suggests there is a bimodal distribution in diffusional timescales providing further evidence for the incorporation of plagioclase cores over a period of time or from multiple mixing events.
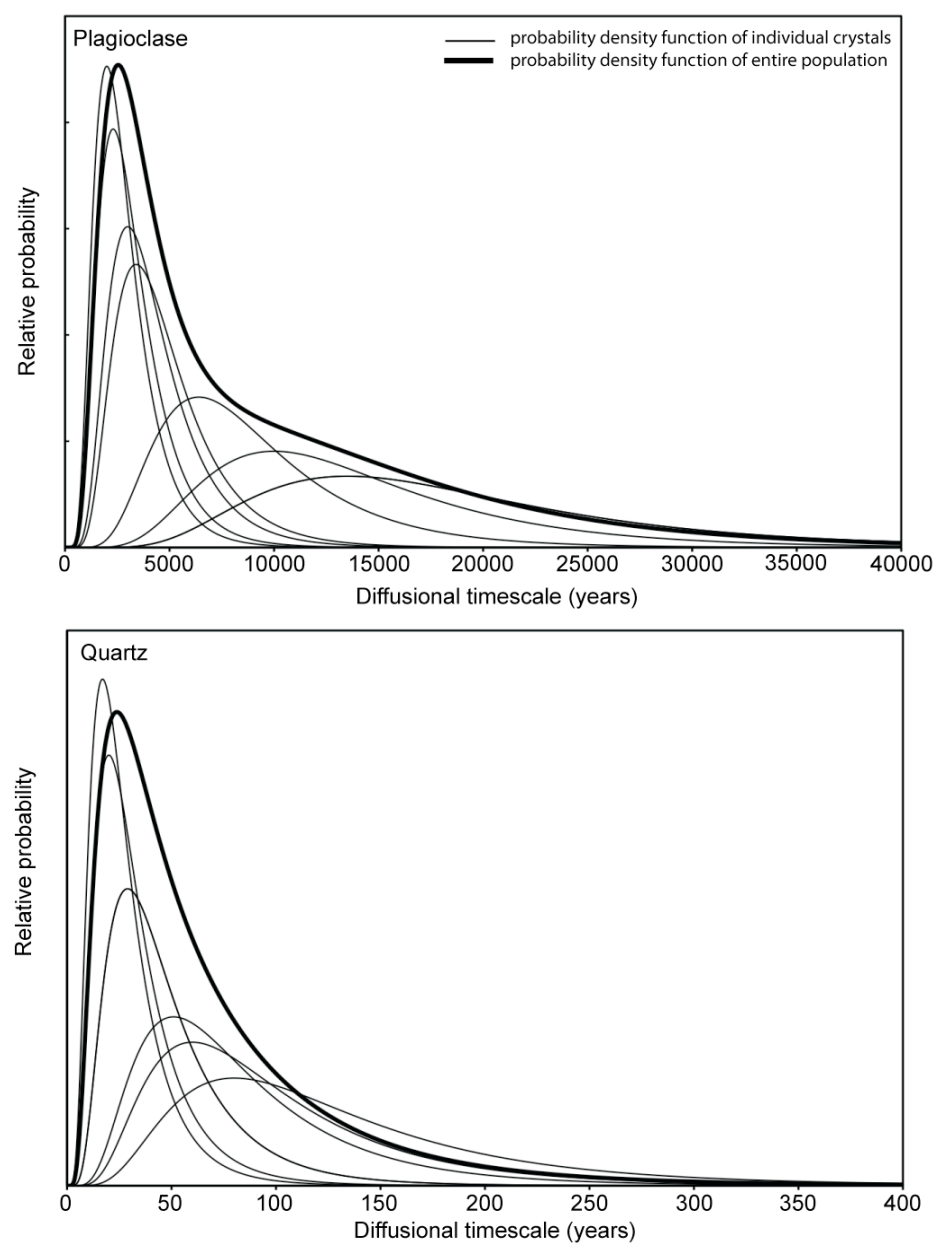

Figure 4.6. Probability distributions of each diffusional timescale calculated in this study as a function of $2 \sigma$ temperature uncertainty of plagioclase and quartz crystals. Thin lines denote the probability distribution for each individual timescale and the thick line denotes the entire population. 


\subsubsection{Quartz crystals}

Several of the imaged quartz crystals display a pronounced zone of high CL intensity at or near the rim of crystals (Figure 4.5). Irrespective of whether the higher-Ti growth zones result from an increase in magmatic temperature or a change in the $\mathrm{Ti}$ activity of the melt, the interfaces between low and high $\mathrm{Ti}$ zones are distinct. Using the $\mathrm{CL}$ intensity as a proxy for $\mathrm{Ti}$ concentration, $\mathrm{Ti}$ diffusion across this interface can be modelled, allowing the timescale between the renewed growth of the quartz crystal and eruption to be estimated (Wark et al., 2007). The rounded nature of the inner crystal cores indicates a period of resorption occurred pre-dating the final growth and therefore the timing of the final recharge event cannot be dated (Wark et al., 2007).

As diffusion only spans a small fraction of the two adjacent regions, a simple, one-dimensional diffusion model is sufficient. A refinement to the diffusion model presented by Morgan et al. (2004) is applied. Ti diffusivity in quartz is calculated using a $\mathrm{D}_{0}$ of $7.01 \times 10^{-8} \mathrm{~m}^{2} \mathrm{~s}^{-1}\left(\log \mathrm{D}_{0}=-7.154 \pm 0.525\right)$, an activation energy of $273 \pm 12 \mathrm{~kJ} \mathrm{~mol}^{-1}$ (Cherniak et al., 2007) and a temperature of $789^{\circ} \mathrm{C}$ derived from Fe-Ti oxides as this best represents the magmatic temperature immediately prior to eruption when this final growth would have occurred. Calculated timescales using a diffusivity of $2.63 \times 10^{-21} \mathrm{~m}^{2} \mathrm{~s}^{-1}$ indicate that the initiation of renewed quartz growth occurred $<80$ years prior to eruption (Figure 4.5; Table 4.9). Errors are calculated in the same manner as described above for Sr diffusion in plagioclase crystals by combining the $2 \sigma$ of our Fe-Ti oxide temperature determinations of $\pm 40 \mathrm{~K}$ onto the calculated diffusivities giving a combined error of $0.25 \log _{10}$ unit for $1 \sigma$. The results are illustrated as probability 
distributions due to the temperature uncertainty in Figure 4.6, which suggests renewed quartz growth, occurred ca. 30-35 years prior to eruption.

\begin{tabular}{lccc}
\hline Sample & $\begin{array}{c}\text { Diffusional } \\
\text { half-width }(\mu \mathrm{m})\end{array}$ & $\begin{array}{c}\text { Residence time } \\
\text { (years) }\end{array}$ \\
\hline WH1_37 & 4.60 & 60 \\
WH2_3 & 5.92 & 80 \\
WH2_4 & 1 & 2.97 & 29 \\
& 2 & 2.38 & 17 \\
WH2_5 & 1 & 2.97 & 29 \\
& 2 & 4.16 & 51 \\
WH2_8 & & 2.97 & 20 \\
\hline
\end{tabular}

Table 4.9. Summary of the diffusional timescales calculated from the smoothing of bright CL rims on quartz crystals. Boundaries modelled are highlighted in Figure 4.5.

\subsection{Discussion}

None of the examined plagioclase or quartz crystals yield identical values for the timescale, indicating that each of these crystals experienced an unique history. However, each crystal population possesses common features that allow the successive magmatic evolution to be unravelled. The compositional variability of the melt bodies from which the plagioclase crystals fractionated is explored by determining the $\mathrm{Sr}$ and $\mathrm{Ba}$ melt compositions in equilibrium with the crystal throughout its growth and comparing these to known melt compositions (Figure 4.7). However, caution must be applied as diffusion does modify the $\mathrm{Sr}$ and $\mathrm{Ba}$ concentrations of plagioclase after crystallisation. Nevertheless, this work exposes the presence of at least four, compositionally-distinct rhyolitic melts during the formation of the Whakamaru magma (Figure 4.7).

\subsubsection{Origins of Group 1 plagioclase crystals}

The documented compositional variability of Group 1 cores and rims points to at least two distinct periods of crystallisation. Importantly, the change in 
composition from core to rim can be used to trace the successive magmatic evolution. The relatively wide variability and high $\mathrm{Sr}$ and $\mathrm{Eu}$, and low $\mathrm{Ba}, \mathrm{La}$ and Ce core concentrations compared to the rims suggests the cores fractionated from a more mafic magma (Figure 4.4). Further evidence for this is gained from the calculated $\mathrm{Sr}$ and $\mathrm{Ba}$ concentrations in the melt, which intersect with the defined composition of andesitic groundmass glasses (Price et al., 2005) at $760{ }^{\circ} \mathrm{C}$. However, the calculated range of $\mathrm{Sr}$ and $\mathrm{Ba}$ melt compositions would encompass the andesitic groundmass glass compositions if the core of the plagioclase crystals fractionated from the magma at an earlier stage of the petrogenetic evolution when the magma was hotter (e.g. ca. $950^{\circ} \mathrm{C}$ ) prior to the cooling of magma (hereafter denoted at Melt 1); the estimated magmatic temperature calculated from plagioclase-melt equilibria (Putirka, 2005) when the andesitic groundmass glass composition is taken as the melt composition. Unfortunately, the limited data for the measured $\mathrm{Sr}$ and $\mathrm{Ba}$ concentrations of andesitic melts from the Taupo Volcanic Zone restricts our evaluation of whether the wide variability of $\mathrm{Sr}$ and $\mathrm{Ba}$ melt concentrations observed in the cores characterises that of the natural melt composition or is instead the result of diffusional modification of the crystal core $\mathrm{Sr}$ and $\mathrm{Ba}$ concentrations.

In contrast, Group 1 rims possess a restricted $\mathrm{Sr}$ (465 -630 ppm), Ba (450-575 ppm), $\mathrm{La}, \mathrm{Ce}$ and $\mathrm{Eu}$ composition and the calculated $\mathrm{Sr}$ and $\mathrm{Ba}$ melt compositions span the known compositional range of Whakamaru group ignimbrite groundmass glasses (Brown, 1994). This therefore, provides compelling evidence for the crystallisation of Group 1 rims from the final host 

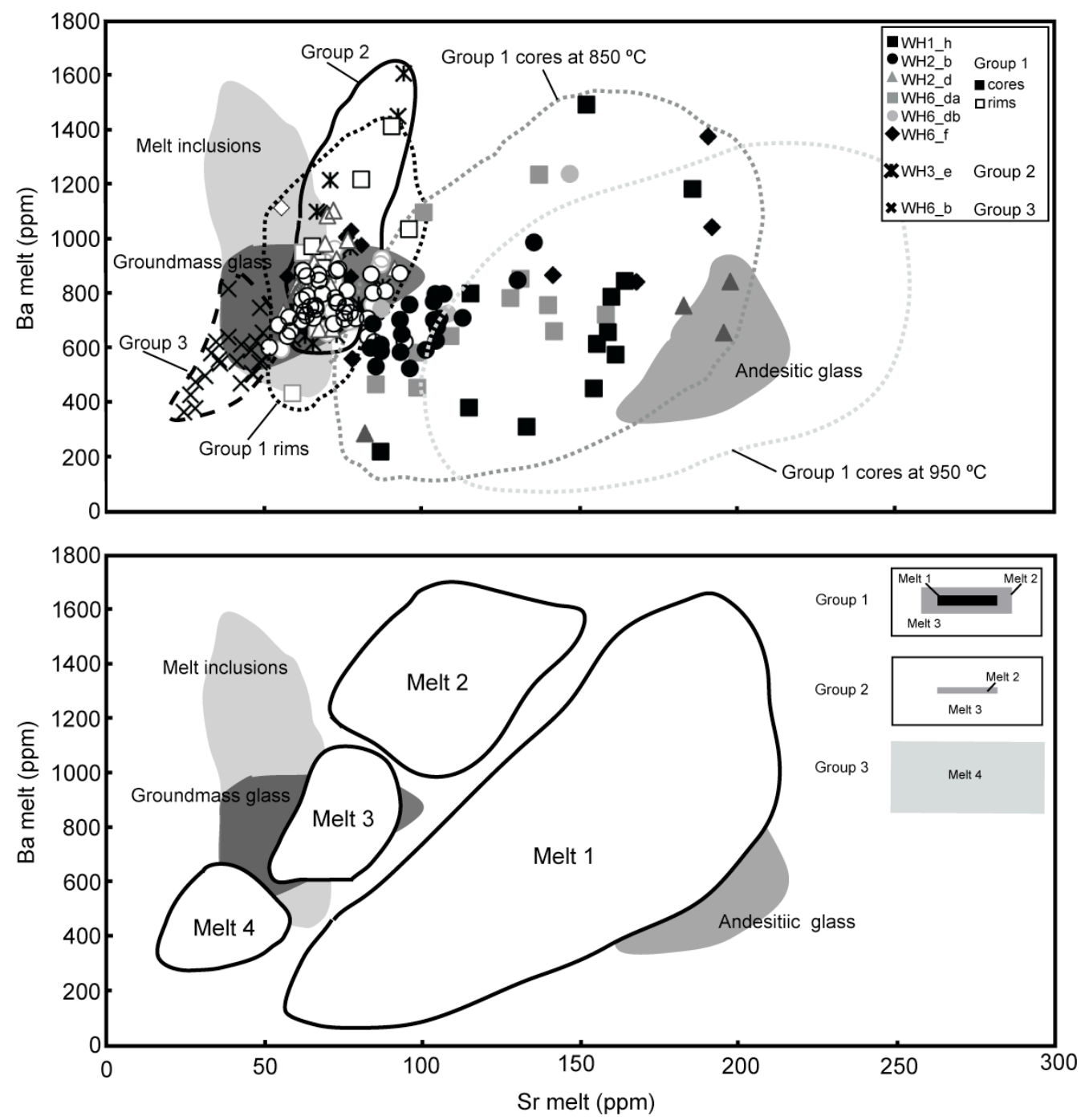

Figure 4.7. (a) Calculated co-existing $\mathrm{Sr}$ and $\mathrm{Ba}$ melt compositions for the three defined plagioclase populations calculated at $760^{\circ} \mathrm{C}$, with the partitioning relationships (Equation 3.1a and 3.1b) of Blundy and Wood (1991) and the measured $\mathrm{Sr}$ and $\mathrm{Ba}$ concentrations of the plagioclase crystals (Appendix A3.8). The melt composition of Group 1 cores at $950{ }^{\circ} \mathrm{C}$ is denoted by a thin grey dashed line. (b) Cartoon of the $\mathrm{Sr}$ and Ba concentrations of the four Melt compositions discussed in the text. The grey shaded regions represent melts of known compositions: dark grey - Whakamaru groundmass glasses (Brown, 1994); medium grey andesitic glasses (Price et al., 2005); and light grey - quartz-hosted melt inclusions (Chapter 2). Insert represents the location of melt compositions in relation to the three plagioclase populations. 
melt (hereafter termed Melt 3) prior to eruption. Furthermore, a third minor melt composition (hereafter denoted Melt 2) is present in some Group 1 crystals. It is most readily distinguished on the basis of calculated $\mathrm{Sr}$ and $\mathrm{Ba}$ melt compositions and the calculated melt equivalent concentration of measured $\mathrm{Sr}$ and $\mathrm{Mg}$ (Figure 4.8) and is located as a thin overgrowth surrounding the core (Figure 4.5).

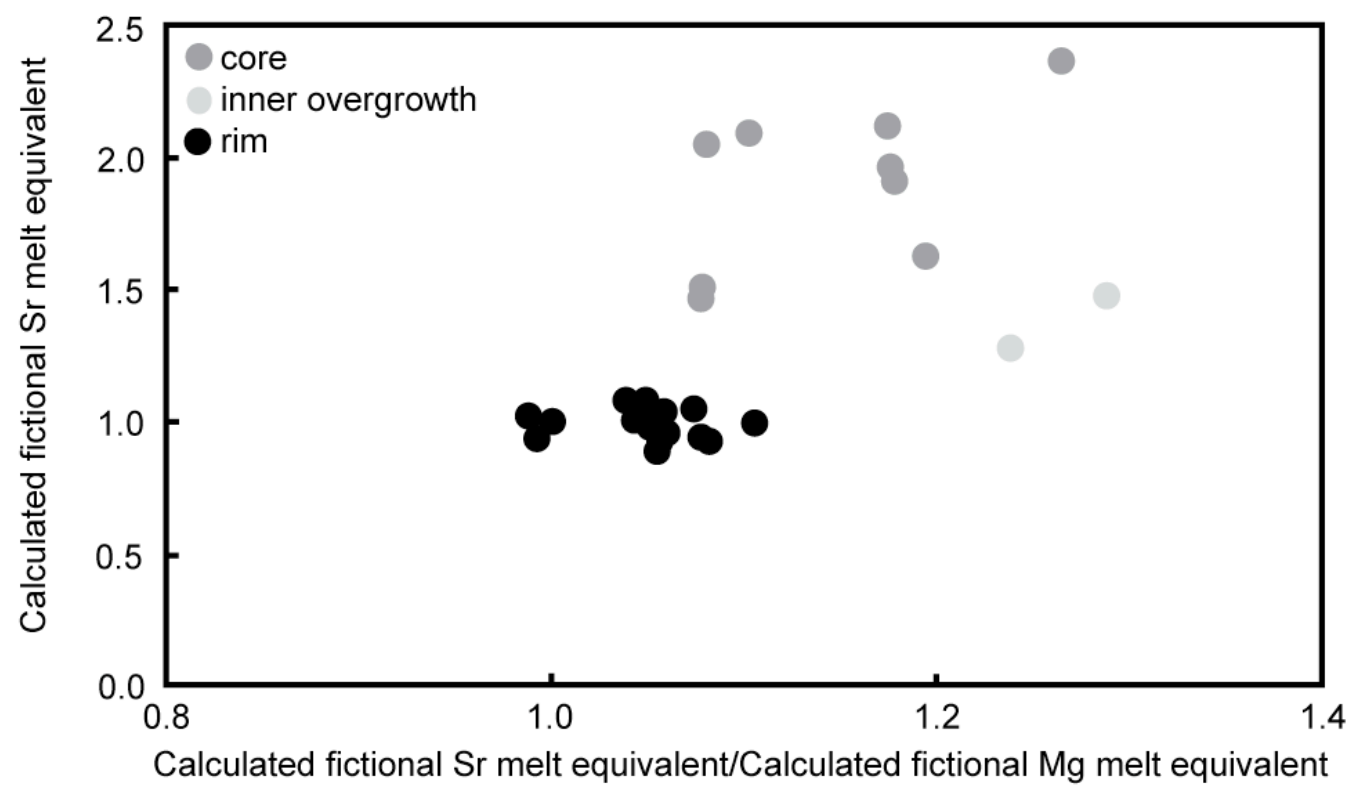

Figure 4.8. Calculated equilibrium melt composition of $\mathrm{Sr}$, normalised to the groundmass glass, versus the ratio of the same value to its $\mathrm{Mg}$ equivalent. Equilibrium of elements with groundmass glass is attained when the value is equal to 1 on each axis. Consequently, the rim analyses that form a group at $(1,1)$ are showing full equilibrium. This then trends to the right, showing that the $\mathrm{Mg}$ in this region is more equilibrated than $\mathrm{Sr}$, whilst the absolute value for $\mathrm{Sr}$ has not changed. In subsequent analyses towards the core, it becomes clear that the normalised, calculated equilibrium melt composition of $\mathrm{Sr}$ is significantly higher, whilst retaining a high ratio to $\mathrm{Mg}$. This implies that the core is significantly less equilibrated for both elements, however markedly more so for $\mathrm{Sr}$.

The core and the rim melts of Group 1 crystals are petrologically linked by the fractional crystallisation of the observed crystal assemblage, similar to patterns described by Berlo et al. (2007) for Mount St. Helens. The crystal assemblage is 
dominated by plagioclase but contains smaller proportions of K-feldspar, biotite, amphibole, and Fe-Ti oxides that may influence the behaviour of $\mathrm{Sr}$ and $\mathrm{Ba}$ in the melt. Conversely, the presence of quartz and orthopyroxene, with $\mathrm{K}_{\mathrm{Sr}}$ and $\mathrm{K}_{\mathrm{Ba}} \sim 0$ will cause an increase in the $\mathrm{Sr}$ and $\mathrm{Ba}$ compositions of the melt. Beginning with a parental melt composition of $160 \mathrm{ppm}$ and $780 \mathrm{ppm}$ of $\mathrm{Sr}$ and Ba respectively, calculated from the core region with the highest $A n$ content, and therefore slowest Sr diffusion (Giletti and Casserly, 1994; Giletti and Shanahan, 1997; Zellmer et al., 1999), combined with a magmatic temperature of $760{ }^{\circ} \mathrm{C}$, the fractionation trend of a crystal assemblage consisting of purely plagioclase with $X A n$ of 0.3 and 0.4 is modelled (Figure 4.9). Fractional crystallisation modelling of the observed crystal assemblage of plagioclase, quartz, orthopyroxene, K-feldspar, biotite, amphibole, and Fe-Ti oxides (Table 4.10) results in a trend parallel to that of the pure plagioclase assemblage, but requires greater degrees of fractional crystallisation (30 - 40\%) compared to $10-20 \%$ fractional crystallisation of a pure plagioclase assemblage to attain a Melt 3 composition (Figure 4.9). Thus, all of the calculated fractionation trends project through the calculated rim melt composition providing strong evidence for the formation of Melt 3 by fractional crystallisation of the observed crystal assemblage from a progenitor andesitic melt (Melt 1) (Figure 4.9). Furthermore, the modelled decrease in $\mathrm{Ba}$ concentrations at low $\mathrm{Sr}$ concentrations $(<50 \mathrm{ppm})$ of the observed crystal assemblage hints at a possible origin of Melt 4 from extreme fractional crystallisation of progenitor andesitic melts from either: (1) the observed crystal assemblage as modelled; or (2) crystallisation of a dominantly plagioclase, quartz and orthopyroxene \pm Fe-Ti oxides assemblage generating Melt 3, with late stage crystallisation of K-feldspar, amphibole and 
biotite significantly reducing the $\mathrm{Sr}$ and $\mathrm{Ba}$ concentrations of the residual melt, to produce Melt 4.

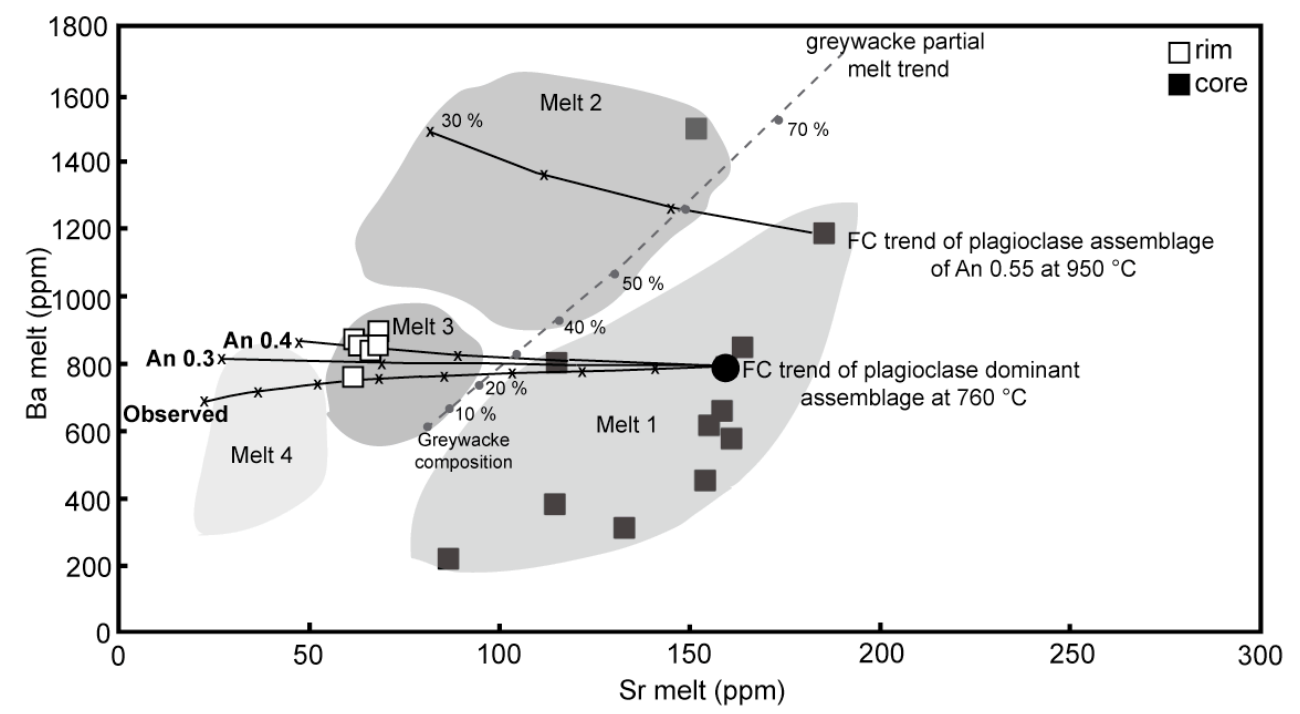

Figure 4.9. Fractional crystallisation model for the generation of Group 1 rim $\mathrm{Sr}$ and $\mathrm{Ba}$ melt compositions (Melt 3 ) from the calculated $\mathrm{Sr}$ and Ba melt composition of Group 1 cores (Melt 1) using WH1_h as an example. A crystal assemblage consisting of pure $A n_{30}$ or $A n_{40}$ plagioclase is modelled and the observed phenocryst assemblage (Table 4.10). Partition coefficients for $\mathrm{Sr}$ and $\mathrm{Ba}$ are calculated from the relationships of Blundy and Wood, (1991) and a magmatic temperature of $760^{\circ} \mathrm{C}$ for $A n_{30}$ and $A n_{40}$ assemblage. Partition coefficients for the observed assemblage are given in Table 4.10. Crosses mark every $10 \%$ of fractional crystallisation from the parental composition (black circle) of $160 \mathrm{ppm} \mathrm{Sr}$ and $783 \mathrm{ppm} \mathrm{Ba}$ and shows that a plagioclase dominate crystal assemblage of $A n_{30-40}$ could generate the Group 1 rim compositions after only $10-20 \%$ crystallisation, in comparison to the observed crystal assemblage which requires $40-55 \%$ crystallisation. Also shown is a possible fractional crystallisation trend illustrating the generation of Melt 2 compositions from a parental Group 1 core melt composition of $185 \mathrm{ppm}$ and $1179 \mathrm{ppm}$ of $\mathrm{Sr}$ and Ba respectively at high magmatic temperatures of $950^{\circ} \mathrm{C}$. The crystal assemblage is dominated by plagioclase with a composition of $A n_{55}$ (as observed in Group 1 cores) and partition coefficients are calculated from the relationships of Blundy and Wood (1991). A greywacke partial melt model (dark grey dashed line) from Reid (1982) is also shown and suggests Melt 2 could be produce by a $40-65 \%$ greywacke partial melt. 
The source of Melt 2 is somewhat ambiguous, but lies on a vector parallel to a possible greywacke partial melt, calculated from the greywacke partial melt model from Reid, (1982) or at least a melt generated from a progenitor greywacke partial melt (Figure 4.9). An alternative origin for this melt is through the fractional crystallisation of a crystal assemblage dominated by plagioclase at high $\left(950^{\circ} \mathrm{C}\right)$ magmatic temperatures from a progenitor core melt (Figure 4.9).

Irrespective of the source of Melt 2, the presence of this melt as a thin overgrowth mantling the core in several crystals suggests a magma mixing event, that may not necessarily have been chamber wide occurred prior to the substantial crystallisation of Group 1 rims.

\begin{tabular}{cccccccccc}
\hline $\begin{array}{c}\text { Modal } \\
\%\end{array}$ & plag & opx & qtz & ilm & mag & k-feld & amp & bt & $\begin{array}{c}\text { Bulk } \\
\mathrm{K}_{i}\end{array}$ \\
\hline & 24 & 17.3 & 20.6 & 1.7 & 1.7 & 7 & 20.7 & 7 & \\
$\mathrm{Sr}$ & 8.46 & 0.00 & & 0.1 & 0.01 & 1.2 & 0.4 & 0.3 & 2.23 \\
$\mathrm{Ba}$ & 0.86 & 0.00 & & & 0.1 & 4.9 & 0.3 & 7 & 1.09 \\
\hline
\end{tabular}

Table 4.10. Crystal assemblage of WH1 recalculated to $100 \%$ for use with the fractional crystallisation model of Group 1 plagioclase crystals. $\mathrm{K}_{\mathrm{Sr}}$ and $\mathrm{K}_{\mathrm{Ba}}$ of plagioclase and orthopyroxene crystals are calculated from the measured $\mathrm{Sr}$ and $\mathrm{Ba}$ concentrations of Oruanui crystals and glass compositions (Chapter 2). $\mathrm{Sr}$ and $\mathrm{Ba}$ are assumed perfectly incompatible where no partition coefficients are shown. $\mathrm{K}_{\mathrm{Sr}}$ and $\mathrm{K}_{\mathrm{Ba}}$ of amphibole and biotite are from Nash and Crecraft (1985), amphibole and magnetite are from Bacon and Druitt (1988) and ilmenite from Ewart and Griffin (1994). Abbreviations used are: plag = plagioclase; opx = orthopyroxene; $\mathrm{qtz}=$ quartz; ilm = ilmenite; mag = magnetite; $\mathrm{k}$-feld $=\mathrm{K}$-feldspar; amp $=$ amphibole; $\mathrm{bt}=$ biotite.

\subsubsection{Origins of Group 2 plagioclase crystals}

The limited compositional variability of Group 2 crystals implies crystallisation from a relatively homogeneous melt. The small oscillations in $A n$ can be accounted for through either thermal perturbations and/or fluctuations in the 
water content of the magma (Ginibre et al., 2002a; Putirka, 2005). Furthermore, the consistency between the composition of the majority of Group 2 crystals and Group 1 rims (Figure 4.4, 4.6) signifies crystallisation from the same or a similar melt body; that is the final melt composition as represented by groundmass glass compositions (Brown, 1994), Melt 3, and denotes Group 2 plagioclases as 'true' phenocrysts (Jerram and Martin, 2008). The only exception being the four analyses at the core of $\mathrm{WH}_{3}$ e, which result in calculated $\mathrm{Sr}$ and $\mathrm{Ba}$ melt compositions that corresponds with a Melt 2 composition (Figure 4.7). Conversely, as WH3_e is the only Group 2 plagioclase for which trace element data has been obtained for, it is unclear whether it is common for Group 2 crystals to have a core composition of Melt 2 or not.

\subsubsection{Origin of Group 3 plagioclase crystals}

Group 3 crystals are distinctive with extremely low $\mathrm{Sr}$ (280-480 ppm), Mg (19$32 \mathrm{ppm}$ ) and $X$ An concentrations but similar REE and $\mathrm{Pb}$ concentrations to Group 1 and Group 2 crystals (Figure 4.4). The core analysis of crystal WH6_b exhibits elevated $\mathrm{La}, \mathrm{Eu}$ and $\mathrm{Pb}$ concentrations compared to the rim, consistent with either a highly evolved igneous or greywacke protolith. Reported $A n$ compositions of greywacke plagioclase crystals indicate two plagioclase populations of $\mathrm{An}_{40-50}$ and $\mathrm{An}_{0-10}$ in the Waipapa terrain and a single plagioclase population of $\mathrm{An}_{0-10}$ in the Torlesse terrain (Reid, 1982), precluding a greywacke protolith origin. Furthermore, an igneous origin is probable as the calculated $\mathrm{Sr}$ and $\mathrm{Ba}$ melt compositions of Group 3 crystals partially overlap the $\mathrm{Sr}$ and $\mathrm{Ba}$ concentrations of quartz-hosted melt inclusions that are interpreted to originate from a mature crystal mush body (Chapter 2) and the calculated melt trend 
overlap and trends towards granitic compositions (e.g. Walker et al., 2007; Wiebe et al., 2007). Therefore it is interpreted that Group 3 crystals are antecrysts derived from a mature and highly evolved crystal mush body, possible formed through the extreme fractional crystallisation of progenitor andesitic melts (see above discussion on fractional crystallisation of Group 1 core and rim melts). It is also noted that there is an increase in compatibility of $\mathrm{Sr}$ and $\mathrm{Ba}$ in Group 3 plagioclase crystals compared to Group 1 and 2 plagioclases and this change in compatibility of elements could contribute to the low $\mathrm{Sr}$ and $\mathrm{Ba}$ melt concentrations recorded by Group 3 plagioclase crystals. Due to the low abundance of K-feldspar and biotite crystals observed in the Whakamaru magma, it is speculated that these crystals may also be potentially inherited from this crystal mush body. The timing and growth of crystals from the various melts in summarised in Figure 4.10.

\subsubsection{Origin of quartz crystals}

The origin of quartz crystals is more difficult to decipher. We can infer the existence of at least two populations or two discrete evolutional pathways for quartz crystals from the presence of bright $\mathrm{CL}$ rims and those crystals with oscillatory-zoned rims. However, little can be interpreted about the early history of these crystals. The observed bright CL rims (e.g. WH1_37, WH2_3) mantling dissolution surfaces indicates mixing into a hotter magma prior to the renewed growth. One possible source for the 'cores' of these crystals is a mature crystal mush body as indicated from the melt inclusion compositions (Chapter 2). In contrast, the second group of quartz crystals with dominantly oscillatory-zoned 
rims may indicate growth from a magma that experienced multiply small recharge events leading to renewed quartz growth.

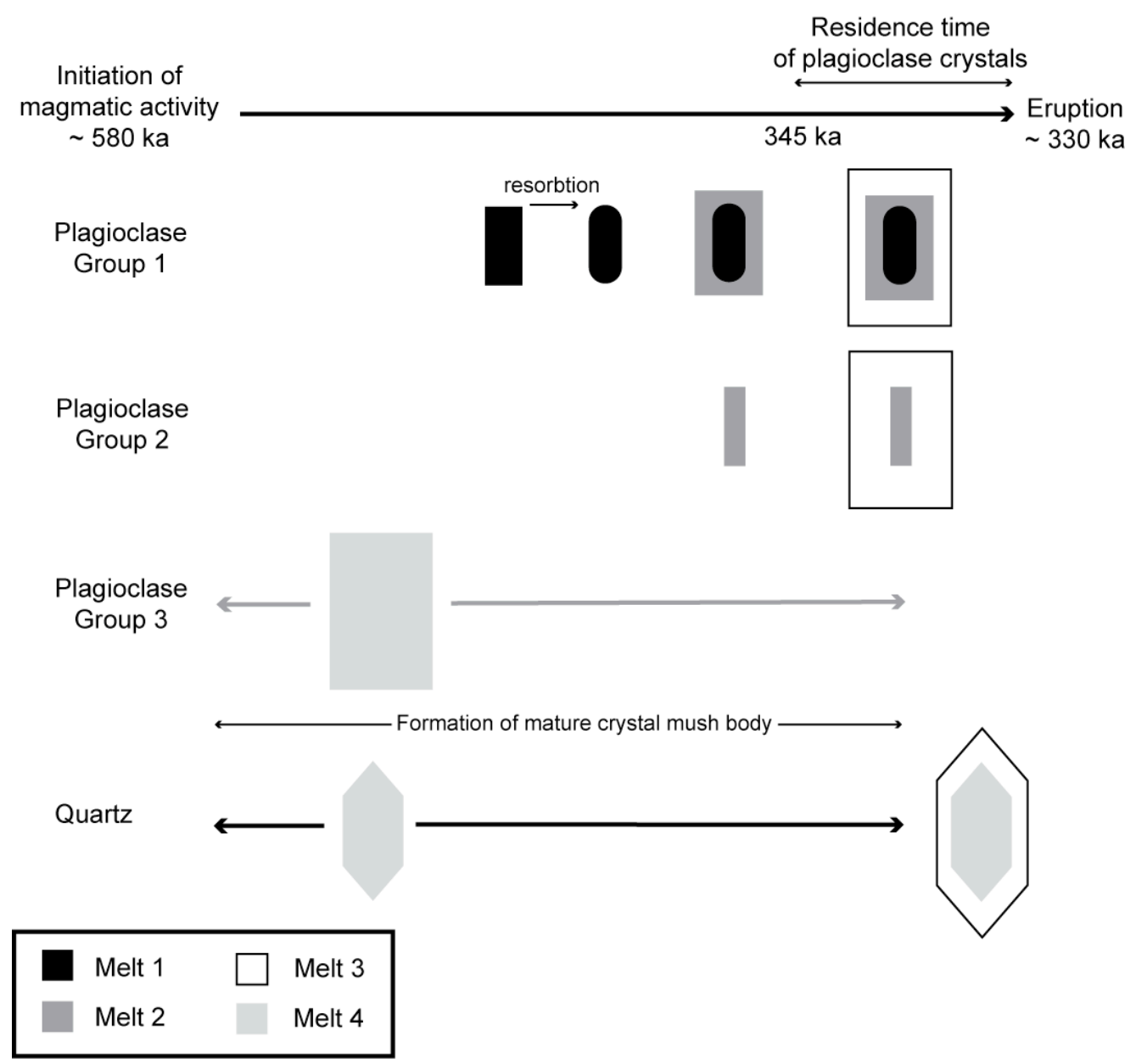

Figure 4.10. A cartoon summarising the timing and growth of Whakamaru plagioclase and quartz crystals studied. Initiation of the magmatic system is assumed to occur 250 ka prior to the eruption from zircon chronology (Brown and Fletcher, 1999). The timing for the growth of Group 3 plagioclase crystals and the quartz cores is unknown, but is speculated to occur during the earlier stages of the magmatic evolution. The timing of the growth of plagioclase and quartz rims are constrained through $\mathrm{Sr}$ diffusion and greyscale intensity of CL images, respectively.

\subsection{Petrogenesis of the Whakamaru magma}

The formation of the Whakamaru magma system commenced at least $250 \mathrm{ka}$ prior to the catastrophic eruption (Brown and Fletcher, 1999). However, evidence indicates the assembly of the magma chamber only occurred in the 
15,000 years (Table 4.8 ) preceding the $330 \mathrm{ka}$ eruption. The assembly of the final Whakamaru magma body was not simple but entailed the mixing and mingling of magmas from multiple sources that varied temporally and spatially within the magmatic system. It is perceived that the earliest history of the magmatic system involved fractional crystallisation of, and assimilation of greywacke country rock by, mantle-derived magmas that eventually formed mature, highly-evolved crystal mush bodies that would later supply Melt 4 compositions to the Whakamaru magma. However, it is speculated that with continued magma supply, further generation of crystal-rich magmas transpired, generating proto-mush bodies (Melt 1) that are witnessed at the surface as high-Si crystal rich andesites (e.g. Price et al., 2005). It is such magma bodies that provide a 'crystal nursery', generating the cores observed in Group 1 plagioclase crystals (Figure 4.11).

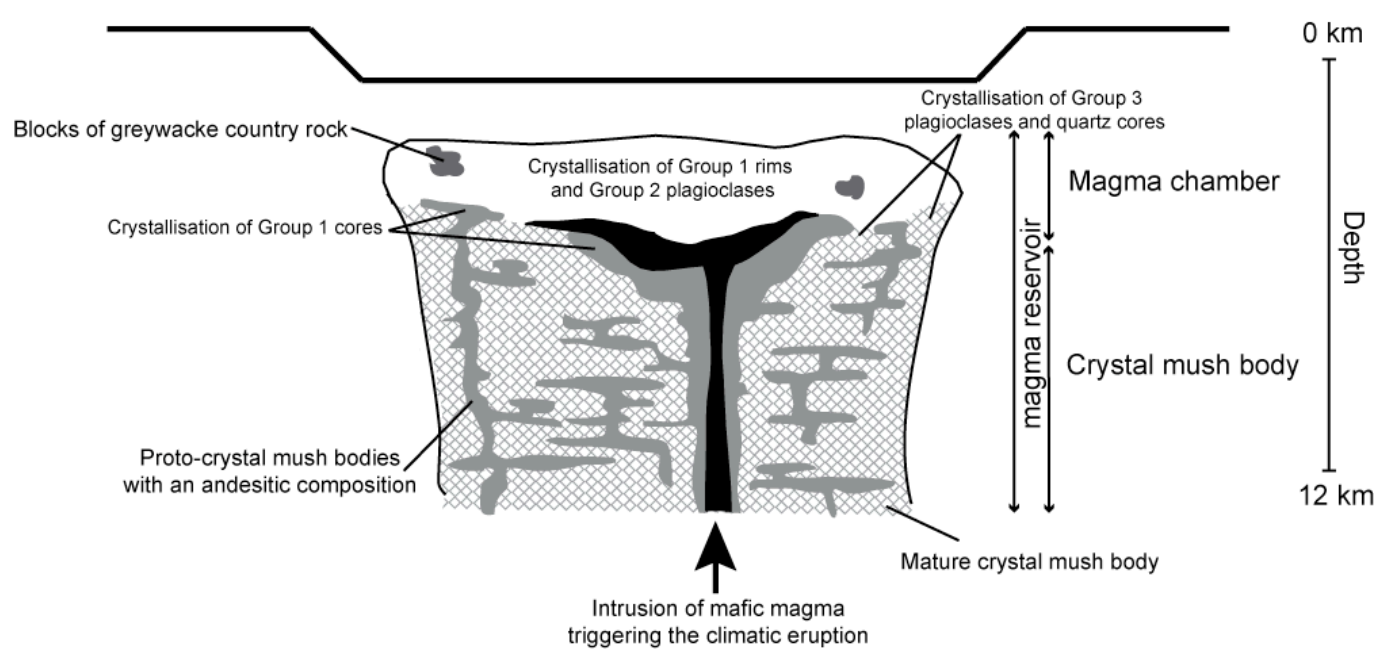

Figure 4.11 Cartoon of the sub-volcanic Whakamaru magma chamber summarising the petrogenetic model discussed in the text. Depths of magma reservoir are estimated from Harrison and White (2004) and are consistent with estimated depths from the initial $\mathrm{H}_{2} \mathrm{O}$ contents of quartz-hosted melt inclusions (Chapter 3). 
At the magmatic conditions observed in the Whakamaru magma (low temperature, high $\mathrm{Si}$ ), pressure exerts little control over the $A n$ composition of plagioclase crystals (Putirka, 2005). During ascent, however, the change in pressure can explain the resorbed and/or rounded texture of Group 1 cores (e.g. Nelson and Montana, 1992; Berlo et al., 2007). It is, therefore, unlikely that the ascent of the magma body can account for change in $A n$ composition between Group 1 plagioclase cores and rims. Plagioclase stability is controlled by the water saturation of the melt and the degree of plagioclase crystallisation increases at low partial pressures of water at shallow levels (Blundy et al., 2006; Berlo et al., 2007). We interpret the overwhelming dominance of Group 2 crystals combined with the coherent Group 1 rim compositions as evidence for a dramatic increase in the amount of plagioclase crystallisation (Berlo et al., 2007). This increase in plagioclase fractionation is driven by the intersecting of the plagioclase liquidus at shallower levels (Berlo et al., 2007) due to the degassing of water previously dissolved in the interstitial liquid, as this liquid is expelled from the andesitic proto-mush body into the overlying magma chamber. Further crystallisation of plagioclase follows but in insufficient proportions to generate a new crystal mush zone. Prior to this, the crystallisation of plagioclase is suppressed due to the high $\mathrm{H}_{2} \mathrm{O}$ concentrations of the andesitic proto-mush body generated from the extreme fractional crystallisation required to generate this magma body. Concurrently, the crystal mush body provide heat to the surrounding greywacke country rock assimilating rocks and generating the third melt composition (Melt 2). 
It is the amalgamation of these melts in varying proportions combined with fractionation crystallisation that generates the final Whakamaru melt compositions. The relative abundance of greywacke melts (Melt 2) observed in plagioclase crystals and Group 3 plagioclases derived from mature crystal mushes (Melt 4) indicate these melts contribute in much smaller proportions than the andesitic progenitor melt (Melt 1) (Figure 4.11). This can be further investigated by considering the oxygen isotope composition of each of these proposed melts and a hypothetical oxygen isotope composition of the mature crystal mush body (Melt 4). Oxygen isotopic studies indicate that rhyolites have a mean $\delta^{18} \mathrm{O} \sim 7.9-8.0 \%$ compared to basalts of $\delta^{18} \mathrm{O} \sim 6.4 \%$, andesites of $\delta^{18} \mathrm{O}$ $\sim 7.7 \%$, and greywacke with $\delta^{18} \mathrm{O}$ of $\sim 12 \%$ (Blattner and Reid, 1982; Reid, 1982). If, as postulated, the mature crystal mush body (Melt 4) was generated through fractional crystallisation from mantled-derived mafic magmas and assimilation of greywacke country rock without further petrogenetic modification, it is reasonable to assume this melt would have a $\delta^{18} \mathrm{O}$ similar to the Taupo Volcanic Zone rhyolites. Therefore, assuming the observed proportions of plagioclase crystals represent the quantity of melt incorporated from each source, a simple mass balance calculation mixing $88 \%$ andesite melt estimated from the abundance of Group 1 and 2 crystals with a $3 \%$ greywacke melt as evident from the high Sr overgrowths on some Group 1 cores and $9 \%$ mature crystal mush melt results in a final $\delta^{18} \mathrm{O}$ melt composition of $7.9 \%$ consistent with the measured $\delta^{18} \mathrm{O}$ of $7.8 \%$ of the Whakamaru ignimbrite (Blattner and Reid, 1982). 
The zonation of plagioclase and quartz crystals and residence times of Group 1 plagioclases imply that the mixing of these magmas occurred continually until the final eruption. Moreover, diffusion modelling of CL intensity of quartz crystals provides evidence that the final quartz growth occurred $<80$ years prior to the catastrophic eruption. We speculate that this is likely to be due to the intrusion of a hot mafic magma into the base of the magma chamber as evidenced by the elevated magmatic temperatures calculated from Fe-Ti oxide thermometry and the rounded nature of plagioclase crystals indicating they are actively resorbing as the eruption commenced. Additionally, Brown et al. (1998a) observed high-alumina basalt, as both mixed pumices and as basaltic scoria indicating the presence of such a magmatic composition existed in the Whakamaru magma prior to eruption. Hornblende crystals present within the mixed pumices are euhedral, indicating the mixing of basaltic and rhyolitic magmas transpired immediately prior or during eruption (Brown et al., 1998a). Intrusion of mafic magmas into silicic magma bodies is commonly implied to trigger volcanic eruptions (e.g. Pallister et al., 1992; Synder, 2000; Ginibre et al., 2007; Martin et al., 2008). In small magmatic systems that cannot buffer the incoming magma volume this recharge can cause almost immediate eruption (e.g. Ginibre et al., 2007; Martin et al., 2008) while in larger systems there may be a response delay or no eruption at all. Large density contrasts exist between the mafic and silicic magmas and this prevents the substantial mixing of these melt bodies, but promotes the exsolution of volatiles that are then free to diffuse through the overlying magma, heating as it goes (Synder, 2000; Bachmann and Bergantz, 2003; Wark et al., 2007). Therefore, it is conceivable that the time elapsed since the renewed quartz growth preserves a record of the time delay 
required for sufficient secondary processes to transpire in order to trigger the Whakamaru eruption.

\subsection{Conclusions}

Chemical and textural zonation of plagioclase and quartz crystals provides evidence of four distinct rhyolitic melt bodies fuelling the generation of the final Whakamaru supereruption. The magmatic evolution occurred over a period exceeding 250 ka (Brown and Fletcher, 1999), however, Sr diffusion modelling of core-rim interfaces of Group 1 plagioclase crystals indicate that meltdominant magma chambers bodies may be an ephemeral feature or at the least form relatively shortly prior to eruption in timeframes of $<15,000$ years. In contrast, diffusion modelling of bright CL rims of quartz crystals details the initiation of renewed quartz growth $<80$ years prior to eruption implying mixing of magmas continued until the climatic eruption. 


\title{
Chapter 5
}

\section{Crystal specific studies of Healy and Taupo eruptives: insights into the petrogenesis of silicic arc magmas}

\begin{abstract}
The petrogenesis of silicic arc magmas from the oceanic Kermadec Arc (Healy seamount) and continental Taupo Volcanic Zone (1800 BP Taupo eruption) is examined here through the major element zonation of plagioclase crystals. Healy plagioclase crystals display limited fluctuating anorthite concentrations of 40 - 50 mol \%, dissolution interfaces and rare high anorthite cores. In contrast, Taupo plagioclase crystals possess both low (35 - $38 \mathrm{~mol} \%)$ and high (48 - $50 \mathrm{~mol} \%)$ anorthite cores mantled by rims with $35-40 \mathrm{~mol} \%$ anorthite. Application of plagioclase-melt equilibria illustrates that anorthite variability in both Healy and Taupo plagioclase crystals can be achieved through a combination of fractional crystallisation and the cryptic mixing of chemically similar magmas, indicating the same petrogenetic processes occur in both oceanic and continental arc magmas. In addition, water and chlorine concentrations of plagioclase-hosted Healy melt inclusions provide evidence for the degassing of the Healy magma prior to eruption.
\end{abstract}

\subsection{Introduction}

Healy seamount is the most silicic submarine caldera yet documented in the southern Kermadec Arc, and is characterised by pumices of dominantly rhyodacitic compositions (Wright and Gamble, 1999). The ubiquitous occurrence of these highly vesiculated pumices mantling the topography of the volcanic edifice, allied with the presence of a $\sim 3 \mathrm{~km}$ wide, flat-floored, caldera has 
provided compelling evidence for a single subaqueously quenched pyroclastic eruption (Wright and Gamble, 1999; Wright et al., 2003).

In contrast, Taupo Volcano in the continental Taupo Volcanic Zone has been active for $>40 \mathrm{kyr}$ with numerous silicic eruptions recognised prior to and after the 26.5 ka Oruanui supereruption (Wilson and Walker, 1985; Sutton et al., 1995; 2000; Wilson et al., 2006; Charlier et al., 2005, 2008). Since the Oruanui supereruption, 28 eruptions have occurred from the Taupo volcano, in three distinct periods (11.8 - 9.5 ka; $7.05-2.75 \mathrm{ka} ; 2.15-1.74 \mathrm{ka})$ with the $1800 \mathrm{BP}$ Taupo eruption being the largest of these (Sutton et al., 2000). Whole rock and mineralogical studies have detailed compositional and isotopic variability between these three eruptive periods and the Oruanui eruption, providing evidence for short repose intervals and the complete reorganisation of the magmatic system beneath Taupo volcano (Sutton et al., 2000; Wilson et al., 2006).

The petrogenesis of Healy and Taupo silicic magmas was examined through a chemical study of plagioclase- and orthopyroxene- hosted melt inclusions (Chapter 2). These geochemical data demonstrate that Healy silicic melt was generated through extensive fractional crystallisation from a mantle-derived basalt parent consistent with a study of volcanic glasses from the neighbouring Brothers volcano (Haase et al., 2006). In comparison, the major, trace and volatile element concentrations of orthopyroxene- and plagioclase- hosted Taupo melt inclusions demonstrates an origin through extensive fractional crystallisation and assimilation of greywacke country rock (Chapter 2). 
Here, additional geochemical evidence in the form of major element zonation of Healy and Taupo plagioclase crystals are presented together with the water concentrations of Healy melt inclusions. These data provide further insight into the petrogenesis of silicic magmas in continental and oceanic silicic arc magmas. Analytical methods and samples are described fully in the previous chapters and are only summarised here.

\subsection{Results}

\subsubsection{Volatile concentrations of Healy melt inclusions}

Orthopyroxene- and plagioclase- hosted melt inclusions were previously analysed for $\mathrm{Cl}$ and $\mathrm{SO}_{3}$ by electron probe microanalysis (EPMA) (Chapter 2). In addition, $\mathrm{H}_{2} \mathrm{O}$ and $\mathrm{CO}_{2}$ contents for a selection of plagioclase-hosted melt inclusions were analysed by Fourier Transform Infrared Mass Spectrometry (FTIR) using the methods described in Appendix A.1.5 (Table 5.1).

Chlorine ranges between $0.33-0.66 \mathrm{wt} \%$, displaying a negative trend with increasing $\mathrm{SiO}_{2}$ (Figure 5.1; Appendix 3, Table A3.1; A3.2), and $\mathrm{Cl}$ concentrations in plagioclase and orthopyroxene hosts overlap. This is consistent with either fractionation of a Cl-rich mineral such as apatite or the degassing of $\mathrm{Cl}$ from a continuously cooling melt. Apatite is observed as inclusions in all crystal phases (Wright et al., 2003), however, rare earth elements compatible in apatite display positive trends with $\mathrm{SiO}_{2}$ (e.g. Figure 5.1) suggesting apatite crystallisation was not the central process controlling the evolution of $\mathrm{Cl}$ in the 


\begin{tabular}{cccccccccc}
\hline Sample & $\begin{array}{c}\mathrm{MI} \\
\text { thickness } \\
(\mu \mathrm{m})\end{array}$ & $\begin{array}{c}\mathrm{H}_{2} \mathrm{O}_{\mathrm{m}} \\
(\mathrm{wt} \%)\end{array}$ & $\begin{array}{c}\mathrm{OH}^{-} \\
(\mathrm{wt} \%)\end{array}$ & $\begin{array}{c}\mathrm{H}_{2} \mathrm{O}_{\mathrm{t}} \\
(\mathrm{wt} \%)\end{array}$ & $\begin{array}{c}\mathrm{A} 5200 \\
\mathrm{~mm}^{-1}\end{array}$ & $\begin{array}{c}\mathrm{A} 4500 \\
\mathrm{~mm}^{-1}\end{array}$ & $\begin{array}{c}p \mathrm{H}_{2} \mathrm{O} \\
(\mathrm{M} \mathrm{Pa})\end{array}$ & $\begin{array}{c}\text { Depth } \\
(\mathrm{km})\end{array}$ & $\begin{array}{c}\mathrm{CO}_{2} \\
\text { detection } \\
\text { limits }(\mathrm{ppm})\end{array}$ \\
\hline X590-15.1 & 71 & 2.41 & 1.69 & 4.10 & 0.585 & 0.329 & 92.5 & 3.08 & 24 \\
X590-16.1 & 55 & 3.02 & 0.91 & 3.93 & 0.721 & 0.184 & 85.4 & 2.81 & 32 \\
X590-16.2 & 44 & 3.81 & 0.91 & 4.72 & 0.933 & 0.171 & 120 & 4.13 & 40 \\
X590B-15.1 & 27 & 3.35 & 1.22 & 4.56 & 0.813 & 0.238 & 112 & 3.85 & 64 \\
X590B-15.2 & 21 & 3.20 & 1.30 & 4.50 & 0.776 & 0.255 & 110 & 3.74 & 83 \\
X590B-15.3 & 18 & 2.77 & 1.35 & 4.12 & 0.672 & 0.264 & 93.3 & 3.11 & 97 \\
X590B-15.4 & 18 & 2.38 & 1.31 & 3.69 & 0.578 & 0.256 & 75.9 & 2.45 & 97 \\
X590B-16.1 & 69 & 2.00 & 0.83 & 2.83 & 0.485 & 0.163 & 46.5 & 1.34 & 25 \\
X590B-16.2 & 24 & 3.35 & 1.73 & 5.07 & 0.813 & 0.338 & 137 & 4.77 & 72 \\
X609-1 1.1 & 48 & 1.38 & 0.17 & 1.56 & 0.323 & 0.104 & 15.6 & 0.17 & 36 \\
X609-1 2.1 & 31 & 0.00 & 0.00 & 2.82 & 0.929 & 0.161 & 46.2 & 1.33 & 56 \\
X690-20 1.1 & 31 & 3.15 & 0.93 & 4.08 & 0.758 & 0.252 & 91.6 & 3.04 & 56 \\
X609-25.1 & 35 & 2.74 & 0.64 & 3.38 & 0.662 & 0.126 & 64.5 & 2.02 & 50 \\
X609-25.2 & 20 & 2.66 & 0.79 & 3.45 & 0.645 & 0.155 & 67.0 & 2.11 & 87 \\
\hline
\end{tabular}

Table 5.1. Measured water speciation of plagioclase hosted Healy melt inclusions. Analytical methods, methods for calculation of $\mathrm{H}_{2} \mathrm{O}$ concentrations and $\mathrm{CO}_{2}$ detection limits are given in Chapter 3. $p \mathrm{H}_{2} \mathrm{O}$ (partial pressure of water) is calculated using VolatileCalc (Newman and Lowenstern, 2002) and a magmatic temperature of $726{ }^{\circ} \mathrm{C}$ (see text). Depths are calculated assuming a bulk crustal density of $2700 \mathrm{Kg} / \mathrm{m}^{3}$ (Case et al., 1973) and assuming an overlying water pressure of $11 \mathrm{MPa}$. A5 $5200 \mathrm{~mm}^{-1}$ and $\mathrm{A} 4500 \mathrm{~mm}^{-1}$ are the absorbance peak per $\mathrm{mm}$ for the $5200 \mathrm{~cm}^{-1}$ and $4500 \mathrm{~cm}^{-1}$ peaks respectively. Abbreviations: $\mathrm{MI}=$ melt inclusions $\mathrm{H}_{2} \mathrm{O}_{\mathrm{m}}=$ molecular water; $\mathrm{OH}^{-}=$hydroxyl; $\mathrm{H}_{2} \mathrm{O}_{\mathrm{t}}=$ total water.

melt. Experiments have shown that $\mathrm{Cl}$ is partitioned into co-existing hydrous fluids only after $\mathrm{H}_{2} \mathrm{O}$ saturation is attained (Cline and Bodnar, 1991; Sun et al., 2007), thus providing evidence for $\mathrm{H}_{2} \mathrm{O}$ saturation of the magma and indicating that $\mathrm{Cl}$ is degassed from Healy melts.

Total $\mathrm{H}_{2} \mathrm{O}$ concentrations of Healy melt inclusions range from $1.56-5.07 \mathrm{wt} \%$ (Figure 5.2) and $\mathrm{CO}_{2}$ is below detection limits (Table 5.1). Similar trends in measured water speciation are observed in Healy melt inclusions (Figure 5.2) as are displayed in Whakamaru and Taupo melt inclusions (Chapter 3). Thus, as the speciation does not form coherent linear trends parallel to the experimentally determined speciation curves (e.g. Ihinger et al., 1999) it is highly probable that 

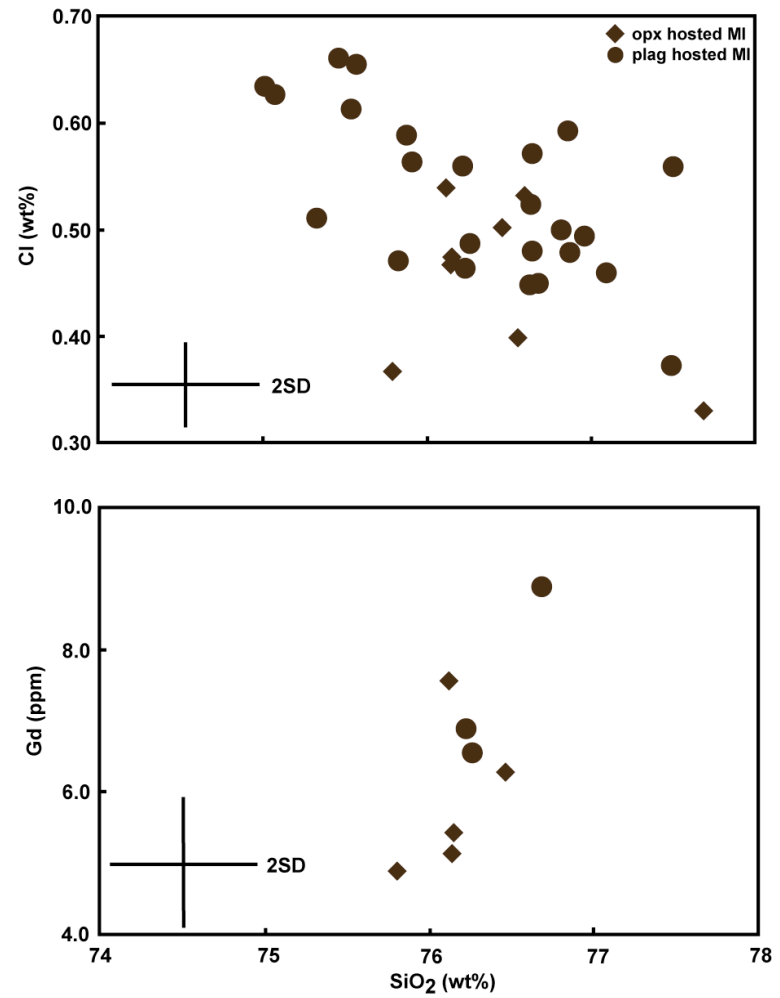

Figure 5.1. $\mathrm{Cl}$ and $\mathrm{Gd}$ concentrations of Healy melt inclusions plotted against $\mathrm{SiO}_{2}$ as a fractionation index. Orthopyroxene hosted inclusions are shown as diamonds and plagioclase hosted inclusions as circles. opx $=$ orthopyroxene; $p l a g=$ plagioclase.

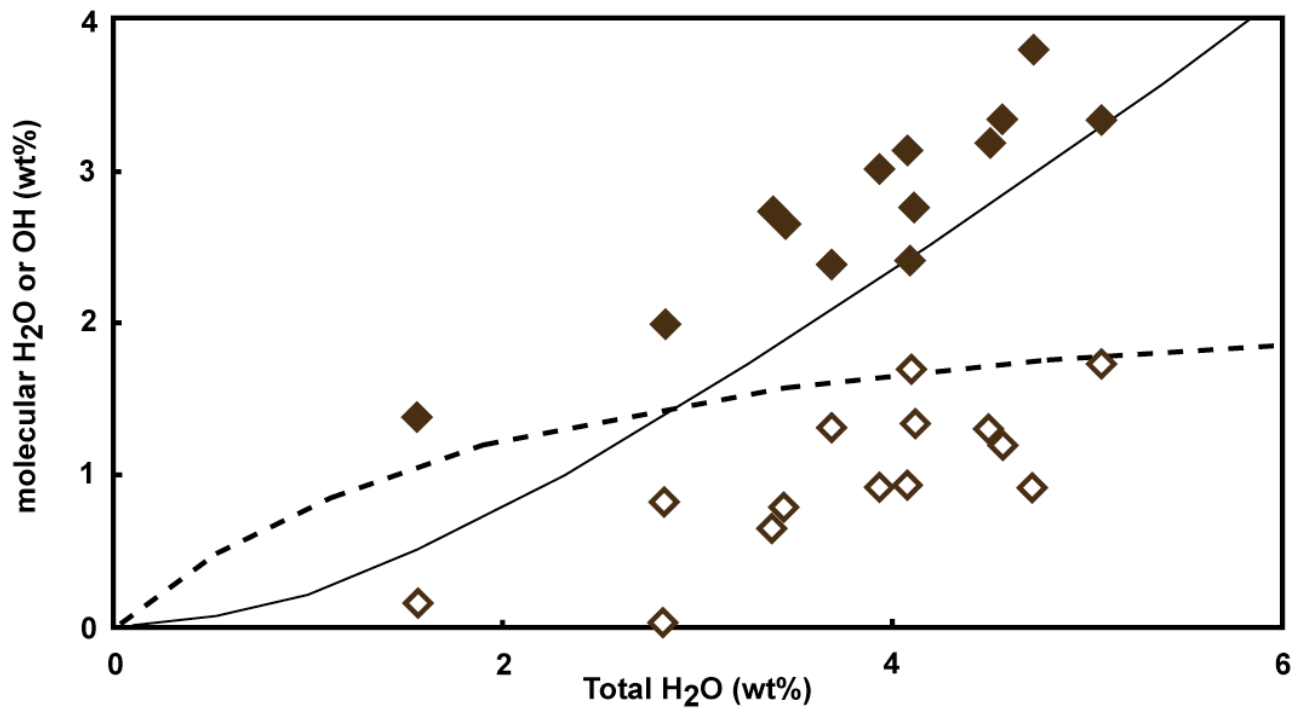

Figure 5.2. Measured water speciation of Healy melt inclusions. Filled symbols are molecular $\mathrm{H}_{2} \mathrm{O}$ and open symbols $\mathrm{OH}^{-}$concentrations. Speciation curves for molecular $\mathrm{H}_{2} \mathrm{O}$ (solid line) and $\mathrm{OH}^{-}$(dashed line) are shown for magmatic temperature calculated using VolatileCalc (Newman and Lowenstern, 2002). 
Healy melt inclusions have degassed through diffusion of $\mathrm{H}_{2} \mathrm{O}$ with the external melt prior to quenching and preserve only a record of magmatic water concentrations directly prior to eruption (see Chapter 3 for a full discussion on the water speciation and degassing of rhyolitic melt inclusions). The partial pressure of water $\left(p \mathrm{H}_{2} \mathrm{O}\right)$ from melt inclusions was calculated using the VolatileCalc algorithm of Newman and Lowenstern (2002) and an inferred minimum depth of crystallising magma attained assuming $\mathrm{H}_{2} \mathrm{O}$ saturation (Table $5.1)$.

\subsubsection{Major element composition of plagioclase crystals}

Despite the evidence from melt inclusions for the generation of the Healy and Taupo magmas through extreme fractional crystallisation (and assimilation) processes (Chapter 2), phenocrysts are sparse and rarely exceed 5 percent volume (Sutton et al., 1995; Wright et al., 2003). The most prolific phenocryst phase is plagioclase, which forms euhedral grains approximately $0.5-1.0 \mathrm{~mm}$ in size.

Backscattered electron images of 28 Healy and 37 Taupo plagioclase crystals were acquired. Major element profiles across 12 Healy plagioclases from three samples (X590, X590B and X609; Table 2.1; Figure 5.3; Table A3.9; Figure A4.4) and 14 Taupo plagioclases from the Taupo ignimbrite (TA2) and associated crystal lag (TA1), Taupo Plinian (TA3) and Hatepe Plinian (TA4) were performed by EPMA using the methods described in Chapter 4 (Figure 5.4; Table A3.10; Figure A4.5). 
Symmetrical oscillatory zoning ca. $5-50 \mu \mathrm{m}$ in width is observed in all Healy plagioclase crystals and dissolution interfaces are common (Figure 5.3). However, anorthite $(A n)$ variations are limited and oscillate between $A n_{40}$ and $A n_{50}$ with only one example of a high- $A n$ core (X590Ba) observed. In contrast, Taupo plagioclase crystals display subtle zoning ranging from $5-100 \mu \mathrm{m}$ in width of $A n_{35-40}$ and notable cores in numerous crystals. However, with the exception of TA3_q, resorption textures are rare (Figure 5.4). Two core types are identified: (1) rounded low $A n_{35-38}$ cores mantled by an abrupt interface followed by high $A n_{38-40}$ rims (e.g. TA1_a and TA1_d); (2) sub-euhedral high $A n_{c a .48-50}$ cores surrounded by normal zoning (denoted by FC in Figure 5.4) and low $A n_{35-40}$ rims (e.g. TA1_c).

\subsection{Discussion}

\subsubsection{Pre-eruptive magmatic water concentrations of the Healy magma}

The minimum depth of the crystallising magma body prior to eruption can be assessed from the $p \mathrm{H}_{2} \mathrm{O}$ of measured water concentrations of melt inclusions (see Chapter 3). This denotes a mean depth of $2.5 \mathrm{~km}$ for the Healy magma chamber. However, the initial $\mathrm{H}_{2} \mathrm{O}$ concentrations most likely exceed some of the measured values due to: (1) the presence of amphibole in pumices that indicates an initial $\mathrm{H}_{2} \mathrm{O}$ content $>4 \mathrm{wt} \%$ (Eggler, 1972; Annen et al., 2006), and; (2) the spread in measured water speciation (see Chapter 3). Water estimates determined through plagioclase-melt equilibria (Appendix 3, Table A3.9) (Putirka, 2005) and conservative initial estimates taken as the maximum measured water content indicate magmatic water estimates of $5.1-8.8 \mathrm{wt} \%$ for the time plagioclase and orthopyroxene crystals fractionated from the melt (see Chapter 3 for full 

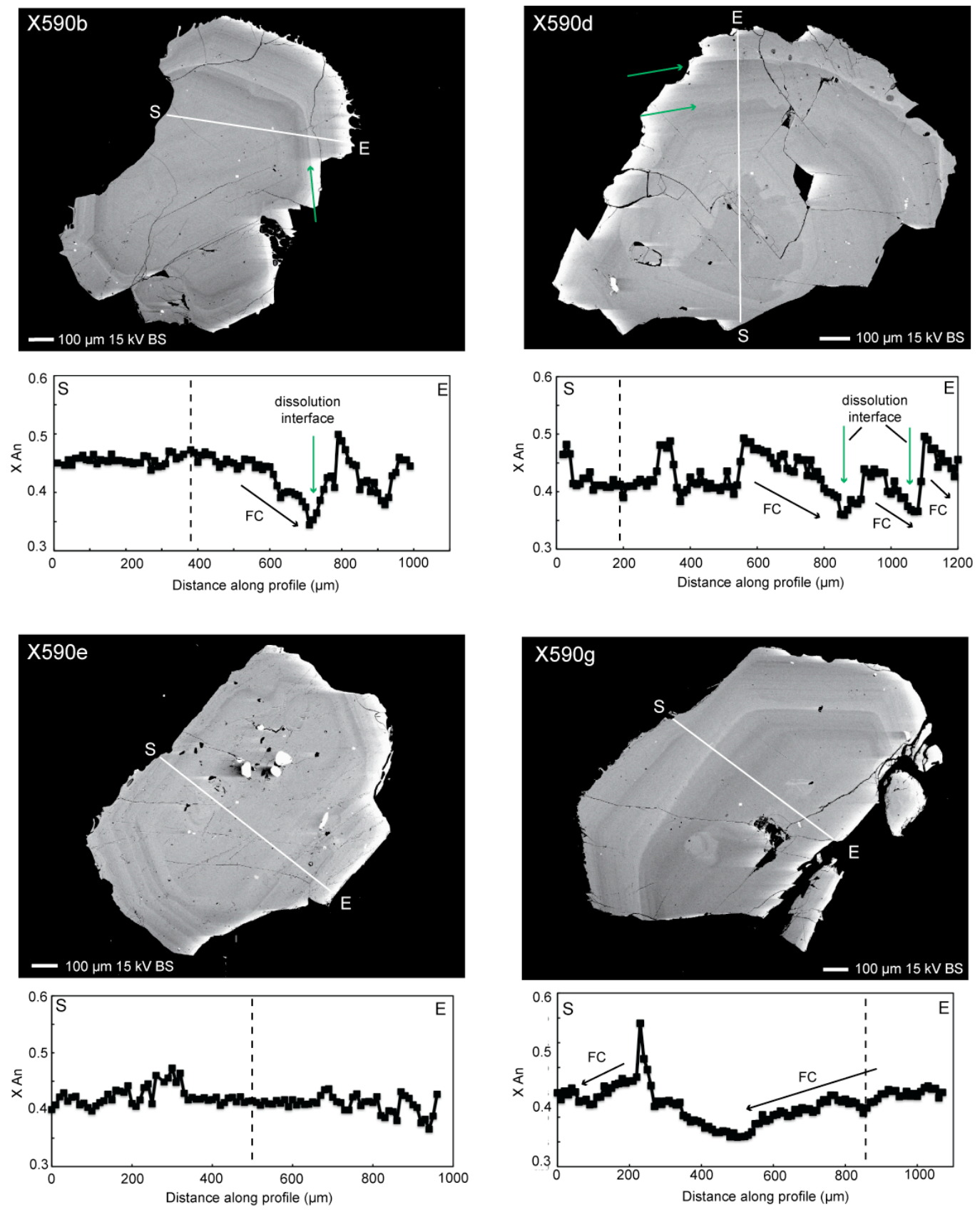

Figure 5.3. Backscattered electron images of Healy plagioclase crystals and anorthite $\left(X_{A n}\right)$ profiles. Start (S) and end (E) of profiles are shown and correspond to the start and end of anorthite profiles and dashed vertical lines, the core of the crystals. Several examples of dissolution surfaces are highlighted by green arrows. FC denotes zones of normal An zoning. 

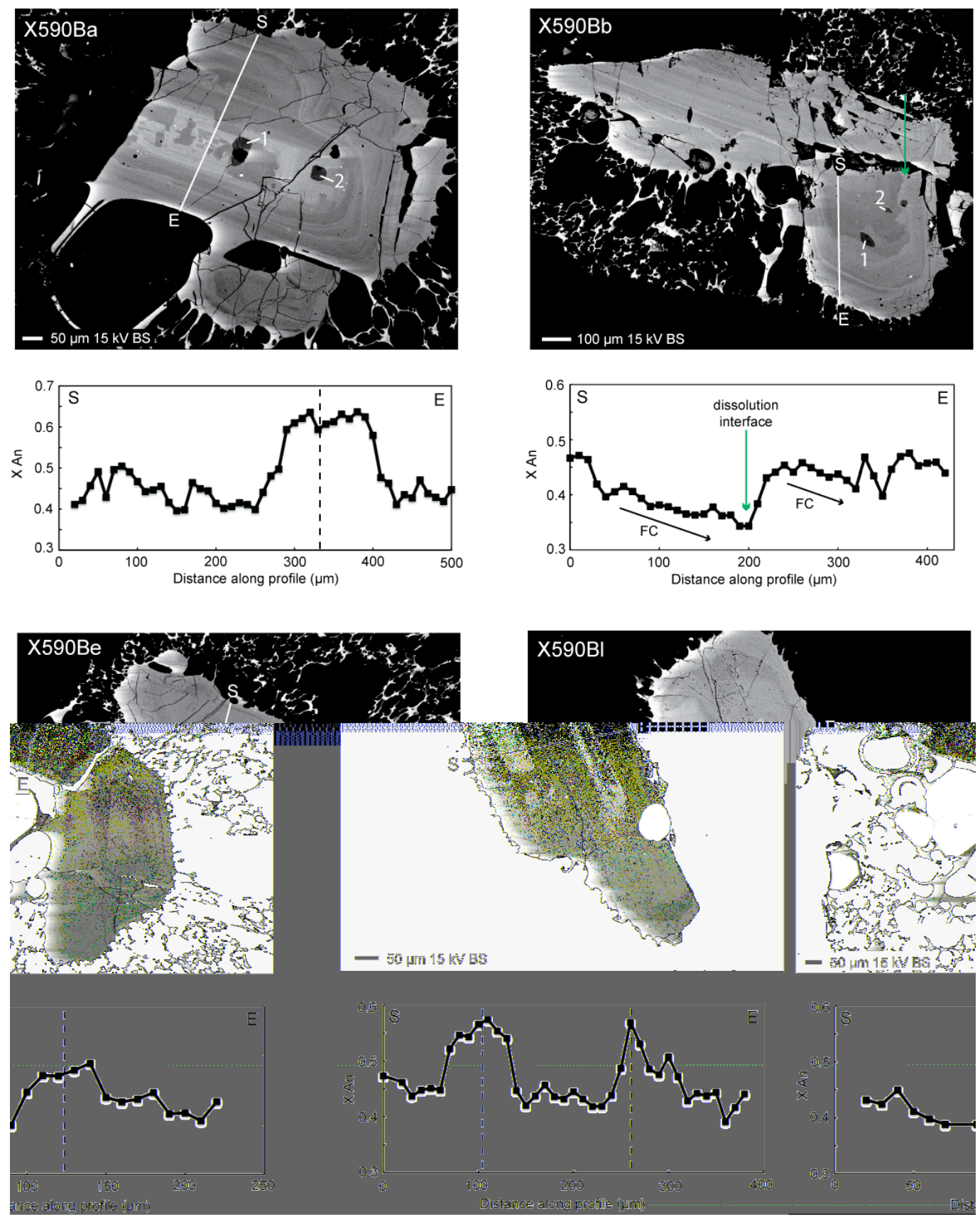

Figure 5.3 continued. 

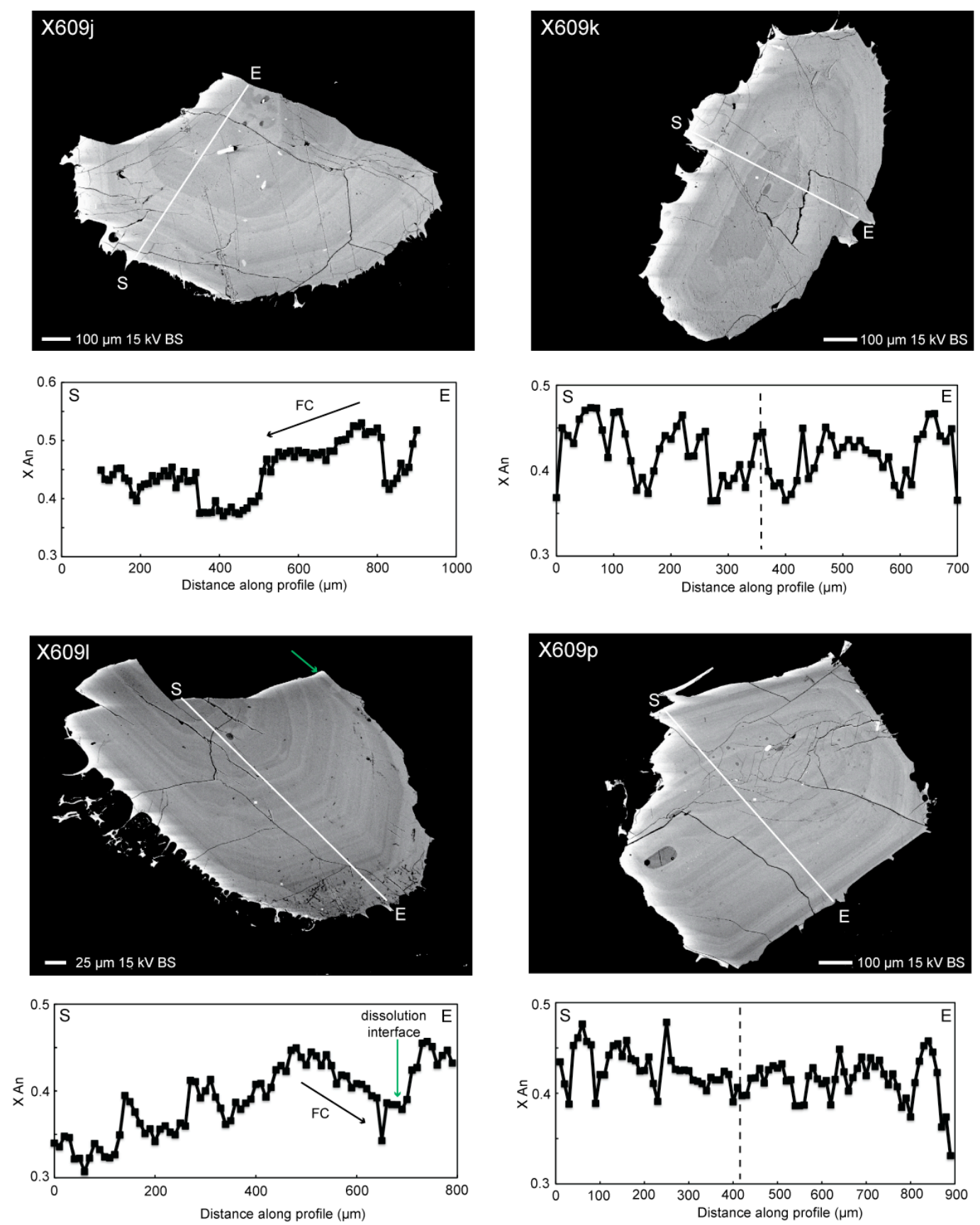

Figure 5.3 continued. 


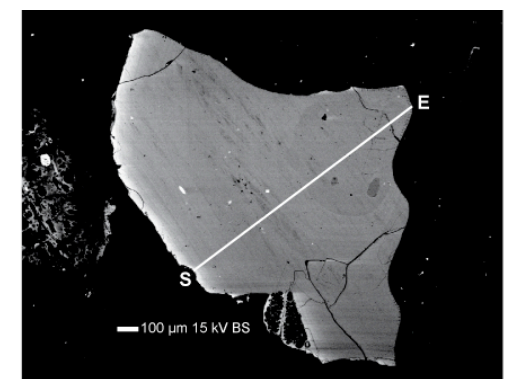

TA1_a

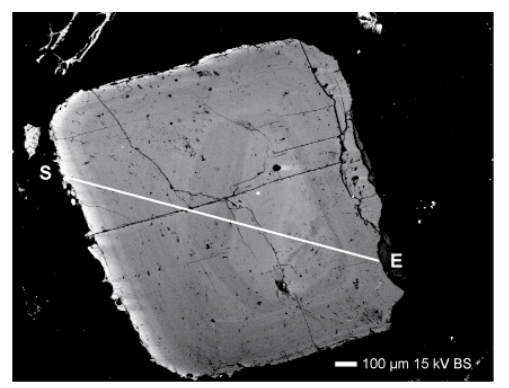

TA1_c
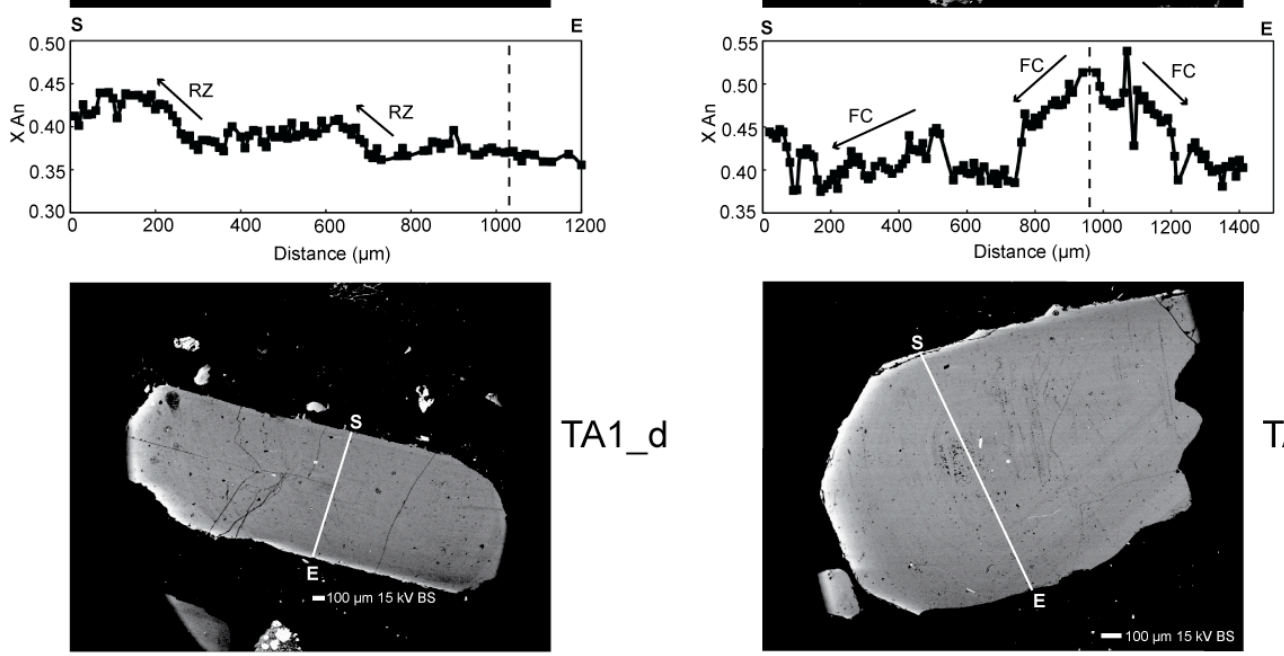

TA1_d

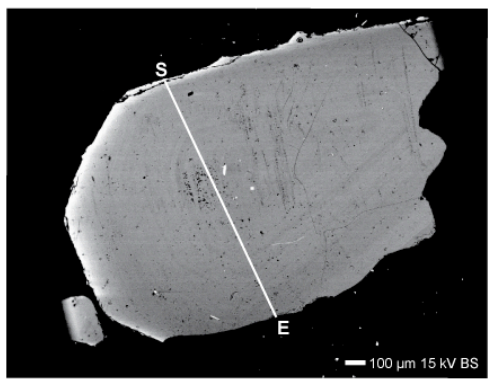

TA1 j
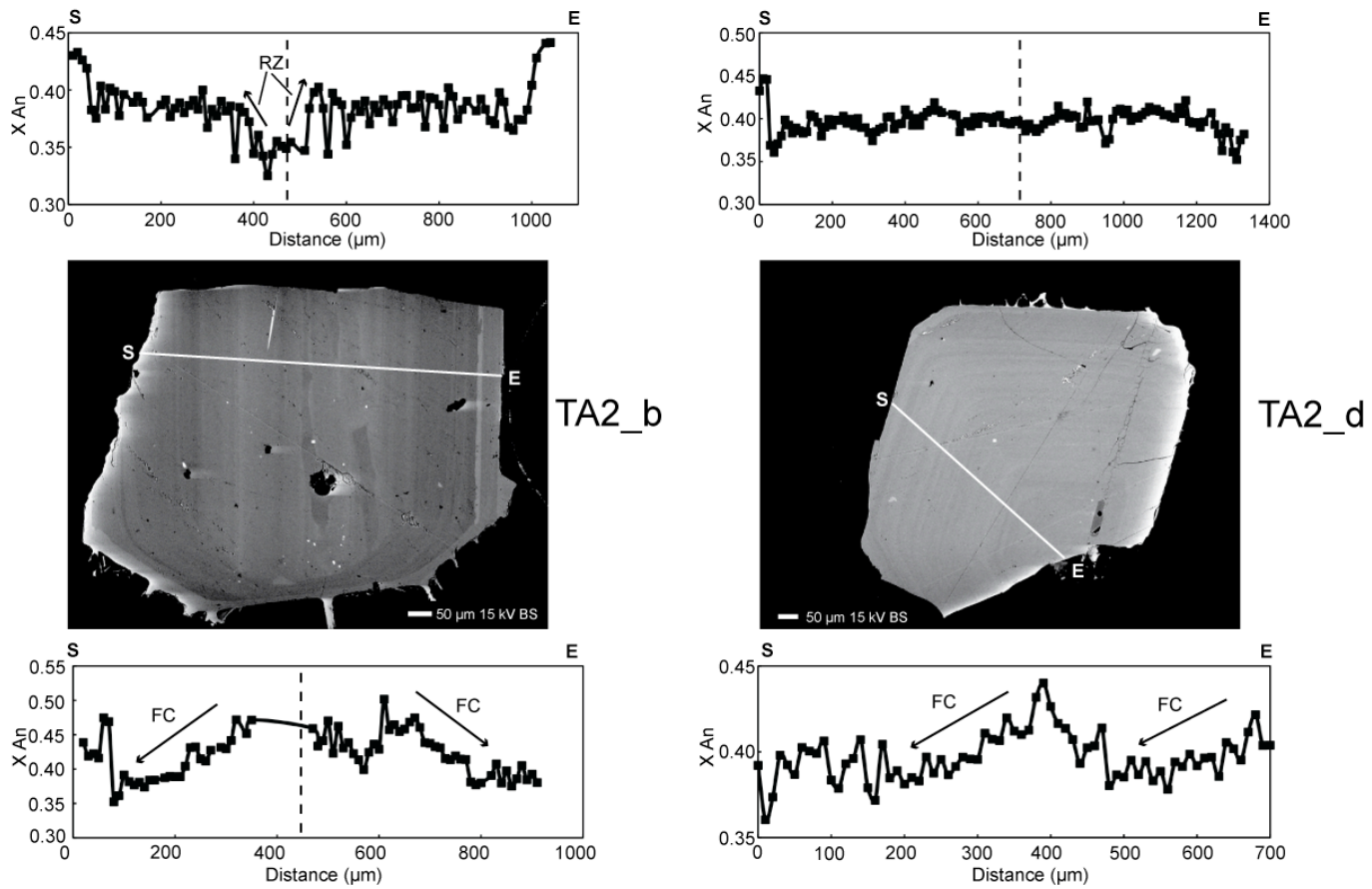

Figure 5.4. Backscattered electron images of Taupo plagioclase crystals and $X_{A n}$ profiles. Start (S) and end (E) of profiles correspond to the start and end of anorthite profiles. Dashed vertical lines represent the core of the crystal. Normal $A n$ zonation is denoted by FC and reverse $A n$ zoning by RZ. 

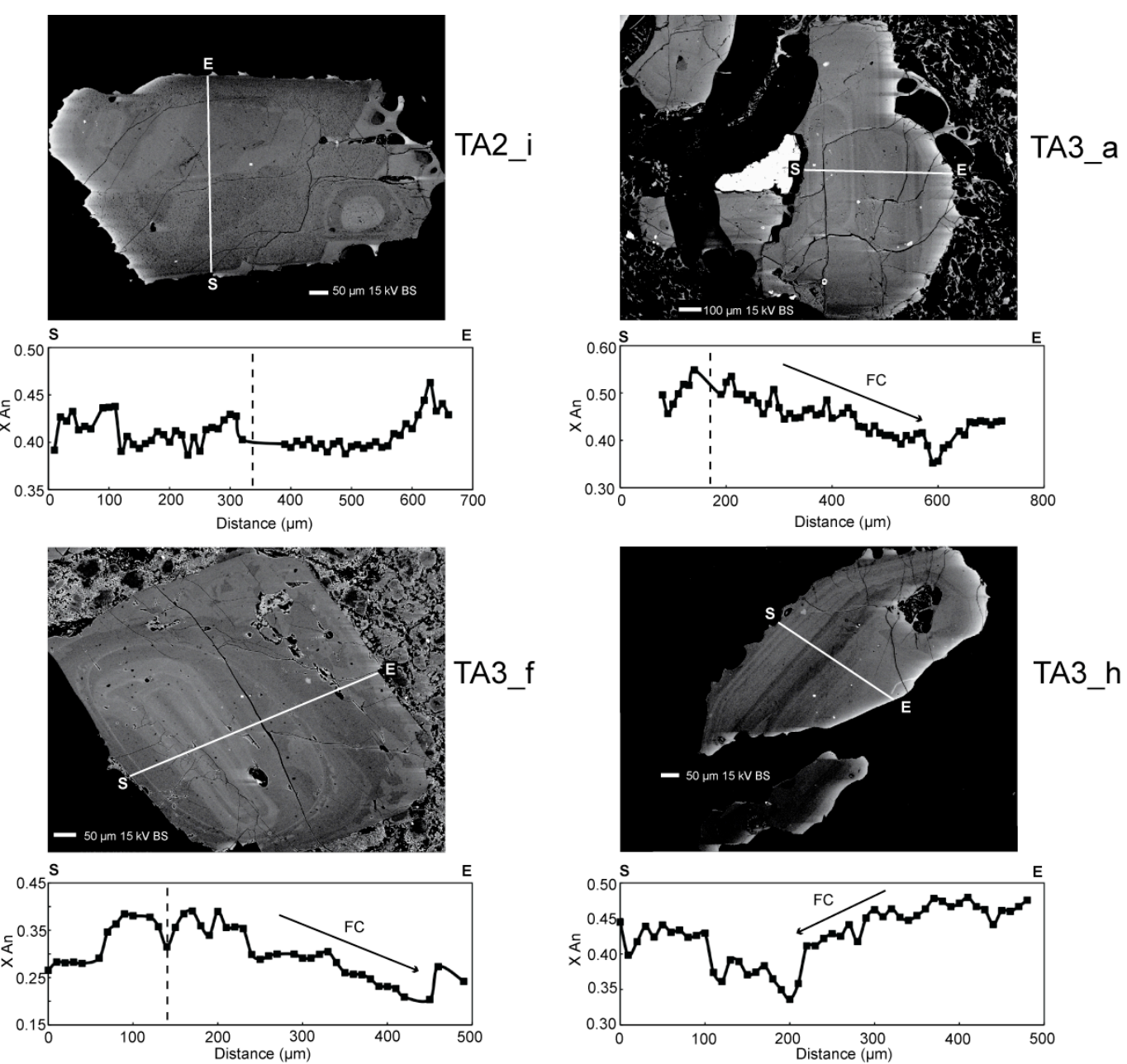

TA3 $h$

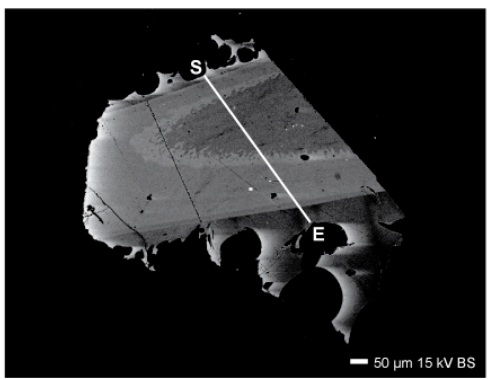

TA3_q
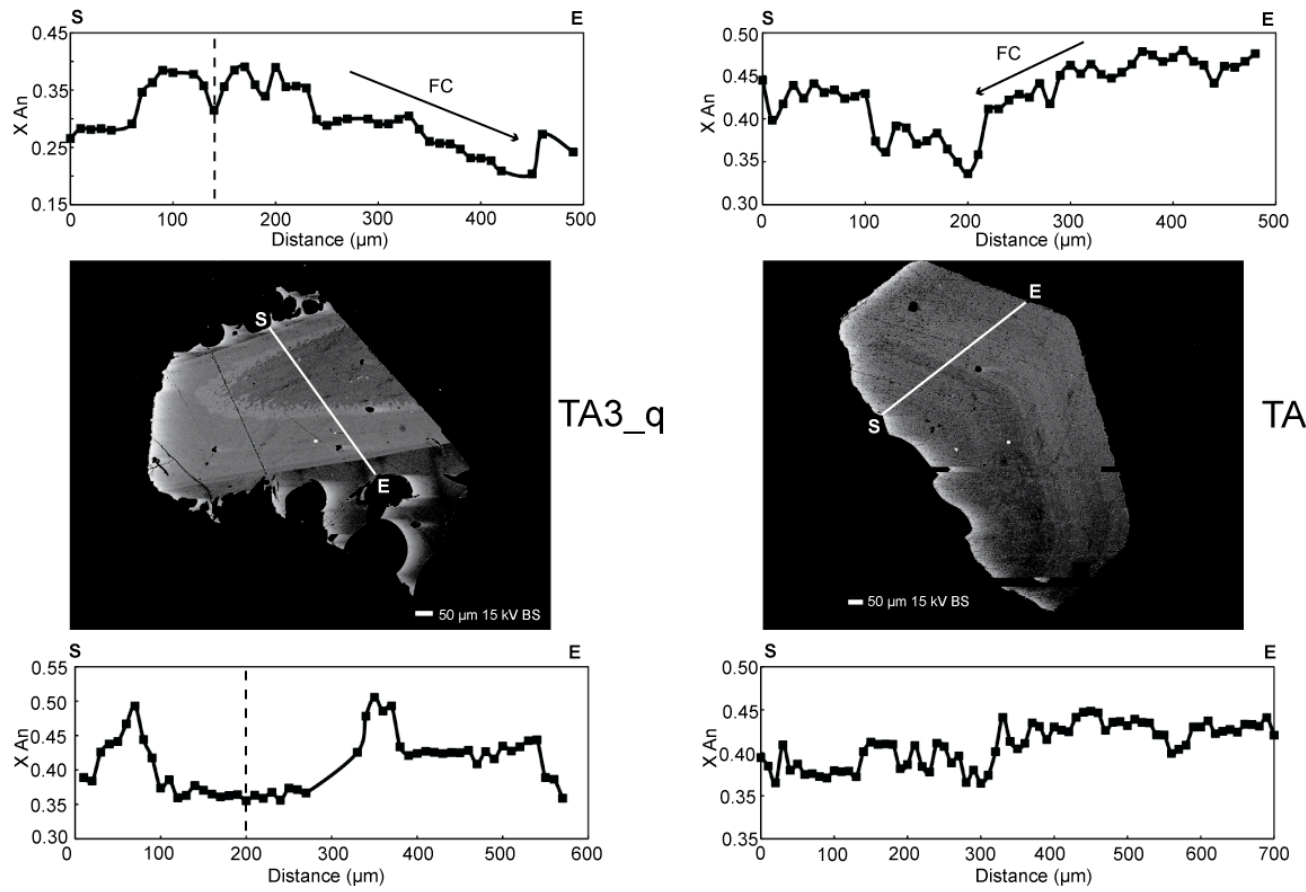

Figure 5.4 continued. 

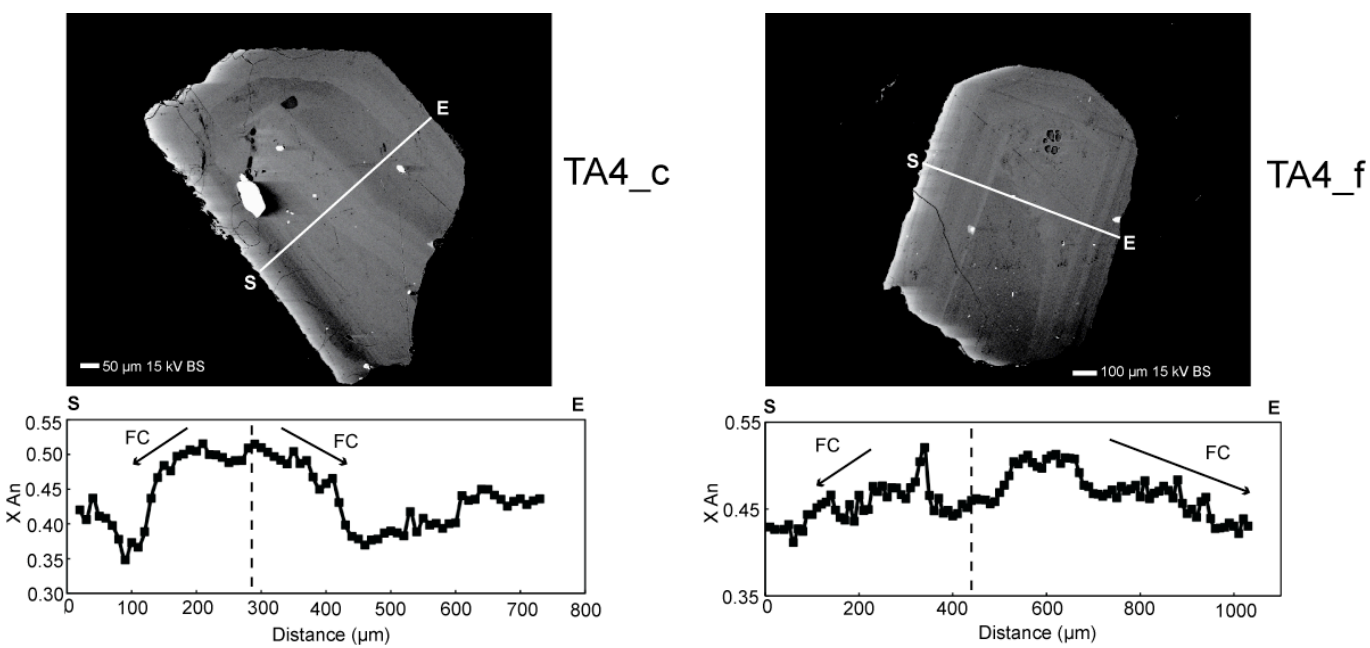

Figure 5.4 continued.

discussion) and infer a former depth of ca. $5.2-12.3 \mathrm{~km}$ for the crystallising magma. This is consistent with the estimated crustal thickness of $16 \mathrm{~km}$ as cited by Haase et al. (2006) from Shor et al. (1971).

\subsubsection{Magmatic temperature and thermal evolution of Healy and Taupo melts}

Magmatic temperatures in this study were determined by plagioclase-melt equilibria (Putirka, 2005) using a melt composition obtained from the mean melt inclusion compositions and pressures of 60 and $100 \mathrm{MPa}$ for the Healy and Taupo magmas respectively (Chapters 2 and 3; Table 5.2).

Temperature estimates range between $670-750{ }^{\circ} \mathrm{C}$ with an average temperature of $725^{\circ} \mathrm{C}$ for Healy plagioclases (Appendix 3, Table A3.9) and $655-798^{\circ} \mathrm{C}$ and a mean temperature of $760{ }^{\circ} \mathrm{C}$ for Taupo plagioclase crystals (Appendix 3, Table A3.10). 
An average plagioclase-melt temperature of $725^{\circ} \mathrm{C}$ for Healy is inconsistent with the magmatic temperature of $950{ }^{\circ} \mathrm{C}$ for Healy pumices calculated by twopyroxene thermometry (Wright et al., 2003). This discrepancy is interpreted to reflect the cooling of the magma body, as it is unlikely these clinopyroxene crystals were in equilibrium with such a high-silica melt. Thus, clinopyroxene crystals could be interpreted as antecrysts (e.g., after Hildreth, 2001 as cited by Charlier et al., 2005 and Jerram and Martin, 2008), fractionated from a progenitor magma that preceded the formation and cooling of the ultimate rhyodacitic magma. Moreover, the prominent rhyolitic compositions of plagioclase- and orthopyroxene- hosted melt inclusions (Chapter 2) are consistent with the lower magmatic temperatures derived from plagioclase-melt equilibria.

In contrast, Sutton et al. (2000) reported Fe-Ti oxides temperatures of 850-860 ${ }^{\circ} \mathrm{C}$, for the Taupo ignimbrite, which represents the magmatic temperature immediately prior to eruption (Venezky et al., 1999; Couch et al., 2003). This is $90-100{ }^{\circ} \mathrm{C}$ higher than the mean plagioclase-melt temperature of $760{ }^{\circ} \mathrm{C}$, providing evidence for the heating of the Taupo magma shortly prior to eruption. This would be most readily achieved through the intrusion of mafic magma into the base of the magma chamber, which would trigger the eruption (e.g. Pallister et al., 1992; Sydner, 2000).

\subsubsection{Plagioclase zonation}

Changes in pressure, temperature, $\mathrm{H}_{2} \mathrm{O}$ content or mixing of magmas modify the magmatic composition and result in new plagioclase growth of different $A n$ 
contents. Healy and Taupo plagioclase crystals exhibit regions of normal $A n$ zoning (illustrated by FC in Figure 5.3 and 5.4). This is where initially Ca-rich plagioclase (high $A n$ ) is crystallised from the melt followed immediately by more Na-rich plagioclase (lower $A n$ ) as the magma differentiates and cools (e.g. Pearce and Kolisnk, 1990; Ginibre et al., 2007). These An patterns thus indicates periods of crystal growth during the cooling of the magma and reverse An zoning is indicative of changing magmatic conditions, for example magma mixing. The magmatic process(es) responsible for this change in $A n$ can be deciphered by considering the relative concentrations of minor and trace elements (e.g. K, Fe, $\mathrm{Mg}$, Sr and $\mathrm{Ba}$ ) that partition into plagioclase crystals during growth, according to well-known partitioning relationships that are not dependent on the melt composition (Longhi et al., 1976; Blundy and Wood, 1994; Bindeman et al., 1998; Ginibre et al., 2002).

Fe concentrations do not vary systematically with $A n$ content in plagioclases from either the Healy or Taupo eruptions (Figure 5.5; Table A3.9; A3.10). This could provide evidence for a change in pressure, temperature, or $\mathrm{H}_{2} \mathrm{O}$ content of the melt rather than magma mixing (Ginibre and Wörner, 2007; Ginibre et al., 2007) but may also reflect an analytical artefact, as the low Fe concentrations of the plagioclase crystals are close to the detection limits of the EPMA. Partitioning of Fe into plagioclase is, however, strongly dependent on the oxygen fugacity of the melt (Longhi et al., 1976; Wilkes and Behren, 1999), and may also be modified further by diffusion after crystal growth. Therefore, Fe concentrations may not provide an accurate representation of the melt composition without further analyses of minor and trace elements to constrain 

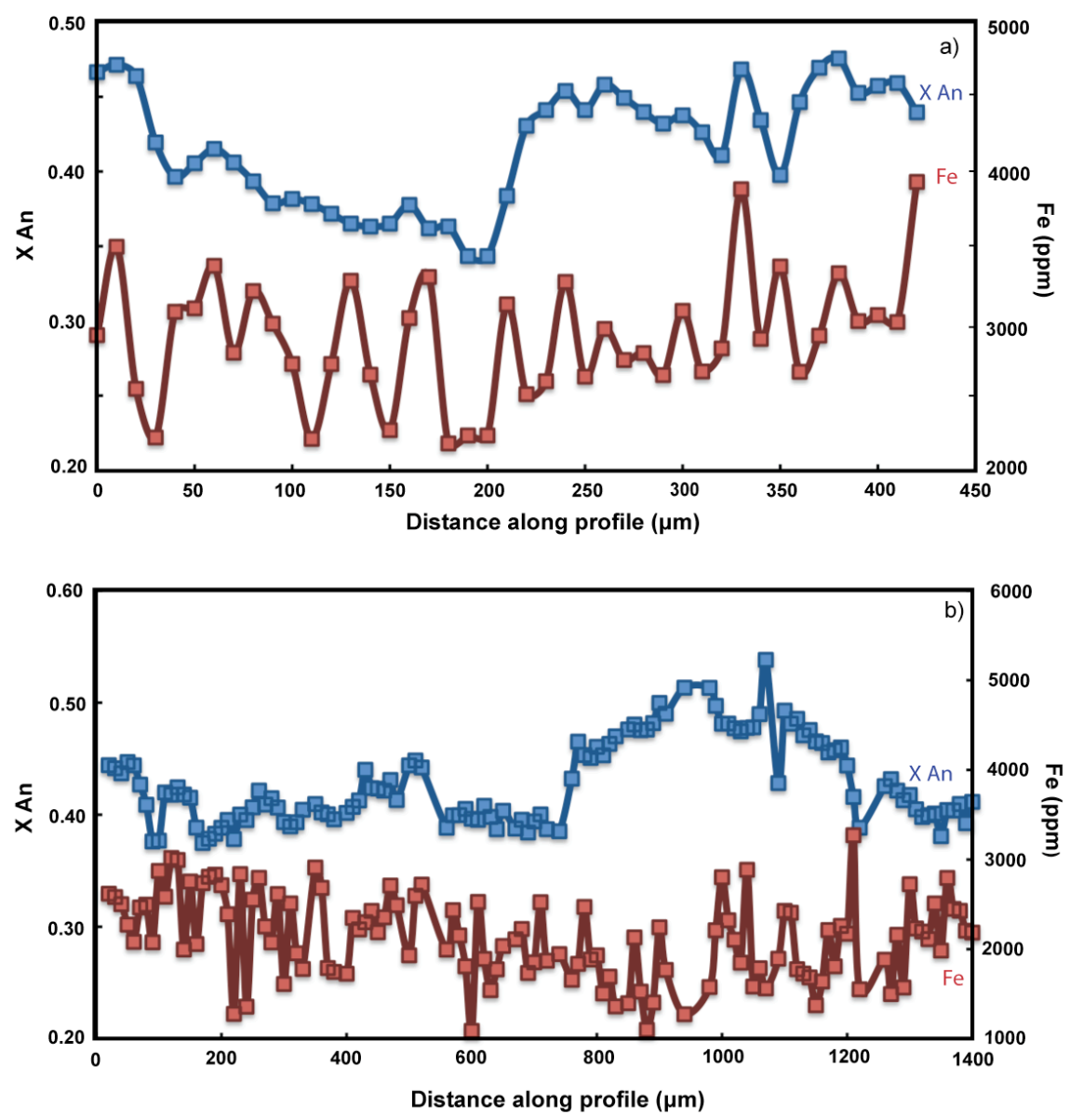

Figure 5.5. Measured $A n$ and Fe concentrations versus the distance along (a) Healy plagioclase $\mathrm{X} 590 \mathrm{Bb}$ and (b) Taupo plagioclase TA1c. Note that Fe concentrations do not vary systematically with $A n$ content.

the behaviour of Fe in the Healy and Taupo plagioclases. Nonetheless, changes in $A n$ can be examined through the application of plagioclase-melt equilibria (Putirka, 2005; Humphreys et al., 2006).

The largest changes in $A n$ in Healy plagioclase crystals are observed at dissolution interfaces and core-rim boundaries (Figure 5.3) and at core-rim interfaces in Taupo plagioclase crystals (Figure 5.4). Melt inclusion compositions on either side of the interface (Figure 5.3; Table 5.2) are indistinguishable providing further evidence for a constant melt chemistry 
throughout the crystallisation of this plagioclase crystal. Homogenisation of melt inclusions within the plagioclase crystal is considered unlikely as the major element composition of both plagioclase- and orthopyroxene- hosted Healy melt inclusions are similar (Figure 2.5) indicating the composition of inclusions is not controlled through host-inclusion exchange (Blundy et al., in press). Pressure variations provide negligible change (i.e. $<0.02 \mathrm{~mol} \%$ ) in $A n$ content at these magmatic compositions and temperatures (Putirka, 2005) and indicates that variations in both temperature and $\mathrm{H}_{2} \mathrm{O}$ content of the melt are required to account for the observed $A n$ gradient in Healy and Taupo plagioclase crystals. This is illustrated schematically by taking the dissolution interface in $\mathrm{X} 590 \mathrm{Bb}$ as an example. Anorthite increases by $11 \mathrm{~mol} \%$ across this interface, from $A n_{34}$ to $A n_{45}$ over $40 \mu \mathrm{m}$ (Figure 5.3, crystal X590Bb). Both an isothermal melt (at 726 ${ }^{\circ} \mathrm{C}$ ), and a melt at a constant water composition (3.7 wt\%), are considered but neither could account for the $11 \mathrm{~mol} \%$ increase in $A n$ alone (Figure 5.6). In addition, an isothermal melt is inconsistent with the calculated temperatures from plagioclase-melt equilibria that indicates a $42{ }^{\circ} \mathrm{C}$ rise across this interface (Appendix 3, Table A3.9) implying changes in both temperature and magmatic $\mathrm{H}_{2} \mathrm{O}$ concentrations are required to account for the $A n$ gradient.

The abundance of normal $A n$ zoning displayed in Taupo plagioclase crystals (Figure 5.4) implies fractional crystallisation plays a fundamental role in the petrogenesis of the Taupo magma consistent with the modelling of the melt inclusion chemistry (Chapter 2). The presence of both high $A n_{48-50}$ and low $A n_{35-38}$ cores suggests cores are incorporated into the Taupo magma from 


\begin{tabular}{lcccc}
\hline & X590Bb_1 & X590Bb_2 & X590Ba_1 & X590Ba_2 \\
\hline $\mathrm{SiO}_{2}$ & 80.48 & 79.12 & 77.58 & 77.29 \\
$\mathrm{TiO}_{2}$ & 0.26 & 0.30 & 0.38 & 0.36 \\
$\mathrm{Al}_{2} \mathrm{O}_{3}$ & 12.43 & 13.00 & 13.53 & 13.34 \\
$\mathrm{FeO}$ & 1.21 & 1.70 & 2.23 & 2.20 \\
$\mathrm{MnO}$ & 0.06 & 0.14 & 0.20 & 0.22 \\
$\mathrm{MgO}$ & & & 0.42 & 0.42 \\
$\mathrm{CaO}$ & 1.37 & 1.67 & 1.81 & 2.00 \\
$\mathrm{Na}_{2} \mathrm{O}$ & 2.59 & 2.50 & 1.53 & 2.52 \\
$\mathrm{~K}_{2} \mathrm{O}$ & 1.60 & 1.57 & 2.17 & 1.65 \\
$\mathrm{Total}$ & 100.00 & 100.00 & 100.00 & 100.00 \\
\hline
\end{tabular}

Table 5.2. Measured anhydrous major element composition of melt inclusions in X590Ba and X590Ba. Melt inclusions numbers correspond to the labelled melt inclusions in Figure 5.3. $\mathrm{MgO}$ was not analysed for X590Bb.

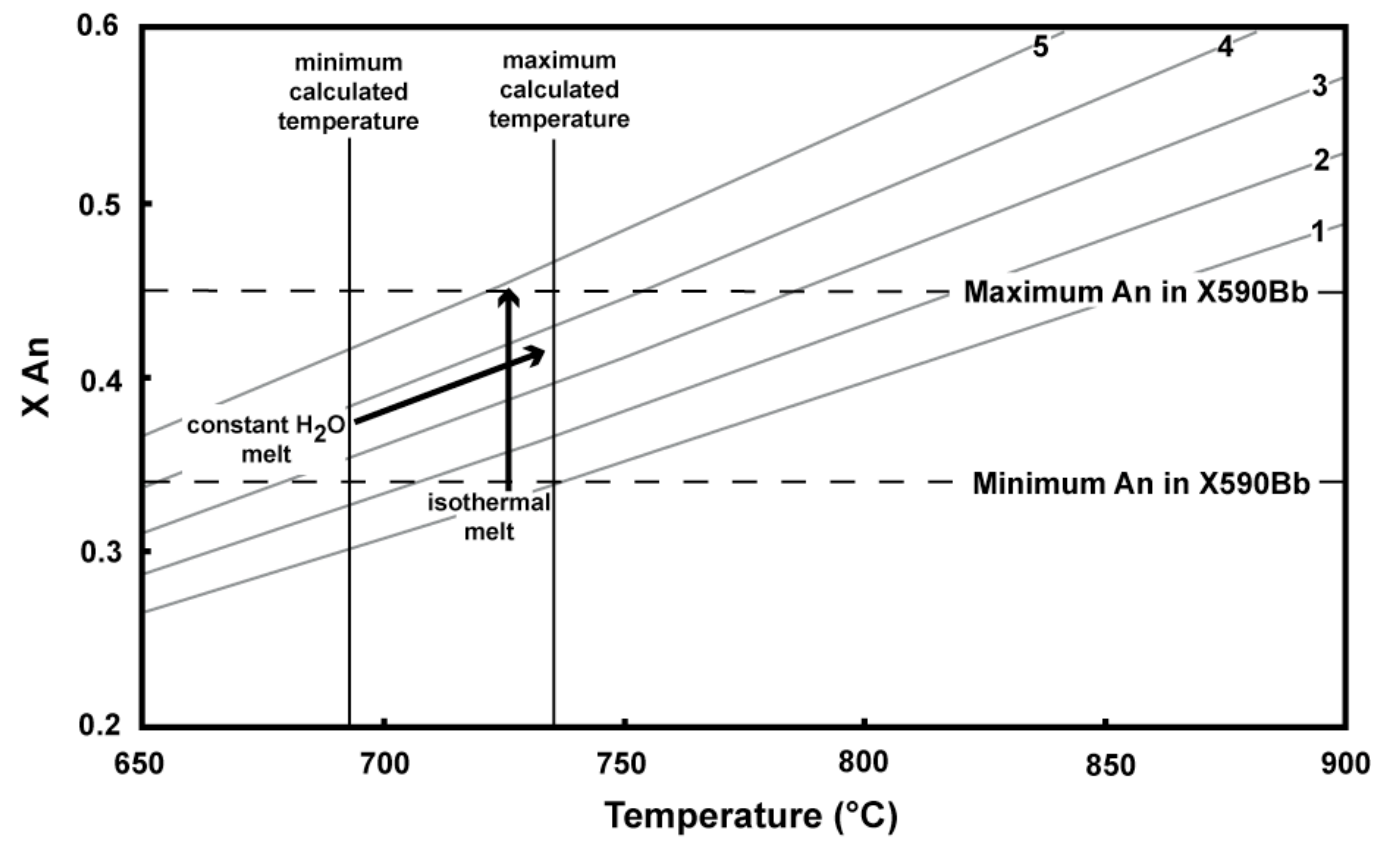

Figure 5.6. Calculated $A n$ variation of Taupo and Healy plagioclases as a function of temperature and $\mathrm{H}_{2} \mathrm{O}$ content, at a pressure of $80 \mathrm{MPa}$ of the melt, using plagioclase-melt equilibria of Putirka (2005). Water content of melt is contoured for 1, 2, 3, 4 and $5 \mathrm{wt} \%$. Illustrated, as an example is the dissolution interface in $\mathrm{X} 590 \mathrm{Bb}$ discussed in the text. Dashed lines are the minimum and maximum measured $A n$ content at either side of the interface. Black lines are the magmatic temperature as calculated by plagioclase-melt equilibria (Putirka, 2005) (Table A3.9). Arrows represent an isothermal melt and a melt with a constant $\mathrm{H}_{2} \mathrm{O}$ concentration. 
multiple sources. Without further geochemical evidence the origin of these cores remain equivocal as the high $A n_{48-50}$ cores overlap the known compositions of Waipapa greywacke plagioclase crystals (Reid, 1982) and the composition of Oruanui plagioclase crystals (Charlier et al., 2008). The paucity of other detritus (e.g. quartz, zircon) from the disaggregation of a greywacke protolith in the same quantities as the plagioclase cores in the Taupo magma suggests cores are incorporated from igneous progenitor melts (Charlier et al., 2005 and 2008). Therefore, it is hypothesised that the high $A n_{48-50}$ cores of Taupo plagioclase crystals are derived from a more mafic progenitor melt and the low $A n_{35-38}$ cores are recycled or rejuvenated from a semi-formed more evolved (e.g. higher silica) crystal mush body.

\subsubsection{Petrogenesis and accumulation of silicic magma at Healy caldera}

Quantitative trace element modelling of Healy melt inclusions demonstrated the formation of Healy rhyodacitic magma through $62-76 \%$ fractional crystallisation originating from a basaltic parental magma (Chapter 2). This process would, however, generate a large quantity of crystals that are not observed in the pumices at the surface. Further evidence for a large crystal residue is gained from calculated crystallinities of the melt, derived from the measured concentrations of highly incompatible elements such as $\mathrm{Rb}$ or $\mathrm{Zr}$ where the minimum partition coefficient of $\mathrm{Rb}$ or $\mathrm{Zr}$ are assumed to be zero, and $\mathrm{Rb}$ and $\mathrm{Zr}$ concentrations of the parental melt are known (Blundy et al., 2006; Blundy et al., in press). For Healy, $\mathrm{Rb}$ and $\mathrm{Zr}$ concentrations of the basaltic parental magma are $6.14 \mathrm{ppm}$ and $44.05 \mathrm{ppm}$, respectively (Wright and Worthington, unpublished data), yielding calculated crystallinities of $0.71-0.85$ from $\mathrm{Rb}$ concentrations and 0.64 - 
0.87 from $\mathrm{Zr}$ concentrations (Table 5.3). This is consistent with the estimated proportion of crystals required for fractional crystallisation to generate this rhyodacitic melt.

\begin{tabular}{lcc}
\hline Sample & $\mathrm{Rb}$ & $\mathrm{Zr}$ \\
\hline X590-2.1 & 0.76 & 0.69 \\
X590-3.2 & 0.80 & 0.73 \\
X590B-6.1 & 0.82 & 0.64 \\
X609-5.1 & 0.83 & 0.79 \\
X609-8.1 & 0.71 & 0.72 \\
X609-17.1 & 0.80 & 0.83 \\
X609-17.2 & 0.83 & 0.80 \\
X609-17.3 & 0.85 & 0.87 \\
\hline
\end{tabular}

Table 5.3. Calculated crystallinity of Healy melt inclusions from $\mathrm{Rb}$ and $\mathrm{Zr}$ concentrations, see text for full details.

These calculated quantities of crystals far exceed the requisite $50 \%$ for the creation of crystal mush bodies (Bachman and Bergantz, 2004, 2008). Therefore, allied with the phenocryst sparse nature of pumices and the occurrence of inherited plagioclase cores, the presence of a mature crystal mush body is perceived at Healy, with the generation of high-silica rhyodacitic melts following large degrees of fractional crystallisation from mantle-derived basalt magmas. These silicic melts pond in an overlying magma chamber above the crystal mush body and provide the eruptible magma feeding subsequent eruptions (e.g., Bachmann and Bergantz, 2004; Miller and Wark, 2008).

Elemental concentrations of melt inclusions and plagioclase zonation indicate the Healy silicic magma possessed a relatively stable melt composition that experienced periodic thermal and volatile perturbations. Therefore a petrogenetic model is proposed whereby the accumulation of large-volumes of rhyodacitic magma at Healy was characterised by small multiple 'cryptic' magma mixing events. This process is where melts of similar compositions but of differing 
oxygen fugacity or volatile compositions are mixed together in small pulses (Humphreys et al., 2006). In the case of Healy, these melt pulses are conceived to be small volumes of interstitial melt that infiltrate the silicic magma chamber from the underlying crystal mush. Additionally, mafic magmas have the potential to intrude into the base of the magma chamber resulting in thermal perturbations and the mass transfer of volatiles with little change in the chemical composition of the overlying silicic magma due to the density and viscosity contrasts of the melt (e.g., Koyaguchi and Kaneko, 1999; Couch et al., 2001; Ruprecht and Wörner, 2007). This could provide a viable mechanism producing the $A n$ gradients within plagioclase crystals without a significant change in melt composition, with the intrusion of a larger than normal quantity of mafic magma into the magma chamber to trigger the eventual eruption of Healy (e.g., Pallister et al., 1992; Ginibre et al., 2007).

In contrast, several previous studies have argued for a crustal anatexis origin of Kermadec Arc silicic magmas, specifically silicic magmas from Raoul and Macaulay Island in the northern Kermadec's (Smith et al., 2003 a and b; Smith et al., 2006; Wright et al., 2006). This was on the basis of: (1) the chemical heterogeneity of silicic magmas between adjacent volcanic centres; (2) the aphyric nature of samples; (3) that substantial volumes of silicic magma cannot be generated through fractional crystallisation processes alone and; (4) the delay in occurrence of silicic eruptions after the initiation of basaltic volcanism. Yet all of these points can be justified through the generation and presence of a crystal mush body by fractional crystallisation processes. Crystal mush bodies resident beneath each volcanic edifice have an unique magmatic evolution, crystallising 
similar mineral assemblages, but with differing proportions of minerals that would result in distinct melt compositions. This provides a possible explanation for the geochemical heterogeneities between neighbouring silicic volcanoes such as the Healy and Brothers seamounts (southern Kermadec Arc). In addition, the framework nature of the crystal mush model permits a significant proportion of the fractionated crystals to remain in the crust with only high-silica interstitial melt, percolating through and accumulating in the overlying magma chamber where crystallisation is limited prior to eruption; thus justifying the aphyric nature of some silicic eruptives. Furthermore, large-volumes of rhyolitic magmas $\left(>850 \mathrm{~km}^{3}\right)$ produced by fractional crystallisation from mantle-derived basalt magmas occurred $<1 \mathrm{Ma}$ after extensive basaltic flood volcanism from the Oligocene Afro-Arabian flood volcanics (Baker et al., 2000; Ukstins Peate et al., $2005,2007)$. This shows that considerable volumes of silicic magmas can be generated in relatively short timescales by fractional crystallisation. The time lapse of $10^{6}$ years proposed by Smith et al. (2003b) as evidence for the preconditioning of the ocean crust for anatexis could represent the time required for fractional crystallisation processes to generate the observed silicic magmas. Brophy (2008) also demonstrated through covariations of $\mathrm{La}$ and $\mathrm{Yb}$ concentrations with $\mathrm{SiO}_{2}$, that the generation of Raoul Island and Macaulay Island silicic magmas was by fractional crystallisation processes and not crustal anatexis of amphibolite lower crust as proposed by Smith et al. (2003 a and b, 2006), providing further evidence for the genesis of silicic arc magmas in the Kermadec Arc through dominantly fractional crystallisation processes. 


\subsubsection{Petrogenesis and accumulation of 1800 BP Taupo magma}

Taupo melt inclusion compositions overlap the Ruapehu groundmass glass compositions (Price et al., 2005) and rare earth element modelling showed these melts can be petrogenetically related through assimilation of greywacke and fractional crystallisation processes (Chapter 2). The abundance of normal $A n$ zoning in Taupo plagioclase crystals indicates fractional crystallisation processes are fundamental during the magmatic evolution. However, not all $A n$ variations result from fractional crystallisation, with plagioclase-melt equilibria indicating that changes in both the magmatic temperature and water concentrations are periodically required to account for these. The relatively consistent melt inclusion and groundmass glass compositions suggest any mixing of magmas is likely to be cryptic (Humphreys et al., 2006) and the aphyric nature of the Taupo pumices (Sutton et al., 1995) may suggest large quantities of crystals are retained within the crust during eruption providing evidence for the presence of a juvenile crystal mush body of similar composition as the final melt. However, it must be noted that the Taupo Ignimbrite possesses a discontinuous crystal lag deposit that could potentially account for the crystal poor nature of Taupo pumices. Additionally, there is evidence from the discrepancies in the calculated magmatic temperatures of plagioclase-melt equilibria and Fe-Ti oxides for the heating of the Taupo magma prior shortly prior to eruption. This most probably reflects the intrusion of a mafic magma into the base of the magma chamber, which would have triggered the eruption (e.g. Pallister et al., 1992; Sydner, 2000). 


\subsection{Conclusions}

Elemental concentrations of melt inclusions and plagioclase zonation indicates fractional crystallisation is fundamental in the generation of both Healy and Taupo silicic magmas. The limited compositional variability of melt inclusions and plagioclase crystals within individual eruptions from both Healy and Taupo suggests a petrogenetic model whereby the accumulation of large volumes of silicic magma in upper crustal magma chambers occurs through the cryptic mixing of multiple small melt batches derived from underlying crystal mush zones. This suggests that, irrespective of the continental or oceanic arc setting, fractional crystallisation is potentially the dominant mechanism responsible for the genesis of silicic arc magmas and that the compositional differences observed between Healy and Taupo magmas are due to the assimilation of continental lithosphere in the Taupo Volcanic Zone (Chapter 2). 


\section{Chapter 6}

\section{Synthesis and Conclusions}

\subsection{Synthesis}

The petrogenesis of large-volume silicic magmas from the hyper-productive continental Taupo Volcanic Zone and the oceanic Kermadec Arc were examined in this study though the chemical composition of rhyolitic melt inclusions (Chapters 2 and 3) and the chemical and textural zonation of plagioclase and quartz crystals (Chapters 4 and 5).

Major element composition of melt inclusions from the five rhyolitic eruptions studied (Whakamaru, Oruanui, Rotorua, Taupo and Healy) typically overlap (Figure 2.4) and cannot be used to discriminate between the individual eruptions or the end-member petrogenetic models of fractional crystallisation and crustal anatexis. Trace element concentrations of melt inclusions, however, can distinguish between the individual eruptions and indicate that the Whakamaru magma, the oldest and largest eruption studied, was the most evolved at the time of eruption (Figure 2.7). Furthermore, the chemical diversity observed between the continental Taupo Volcanic Zone melt inclusions and oceanic Healy melt inclusions, for example the lower $\mathrm{K}_{2} \mathrm{O}$ and $\mathrm{Ce} / \mathrm{Yb}$ concentrations of Healy melt inclusions, can be explained through the absence of continental lithosphere overlying the subducting slab in the Kermadec Arc. The generation of the silicic magma at Healy can be quantitatively modelled through $62-76 \%$ fractional crystallisation from a basaltic parent melt (Chapter 2). Allied with this is the high 
calculated crystallinities of Healy melt inclusion compositions and the abundance of normal An zoning of Healy plagioclase crystals (Chapter 5). This provides compelling evidence for the presence of a juvenile crystal mush body and the magmatic evolution of the rhyodacitic magma at Healy through fractional crystallisation processes (Chapter 5).

There is a close resemblance between middle to heavy rare earth element trends of Healy and Taupo melt inclusions (Figure 2.6), signifying a common origin for these continental and oceanic silicic arc magmas. However, quantitative trace element modelling of continental melt inclusion compositions using a simple fractional crystallisation model cannot explain both the LREE (e.g. La $=7-53$ ppm) and HREE (e.g. $\mathrm{Yb}=1.5-5.5 \mathrm{ppm}$ ) concentrations. The modelling is consistent with assimilation of continental lithosphere (greywacke country rock) in addition to extreme fractional crystallisation $(60-80 \%)$ from basaltic parental magmas is required to attain the Taupo Volcanic Zone melt inclusion compositions. Although Taupo melt inclusion compositions can be attained by using this model, a better reproducibility of calculated and observed trace element concentrations is achieved when the Ruapehu groundmass glass composition (Price et al., 2005) is substituted as the parental composition (Figure 2.12). Coupled with the overlapping calculated $\mathrm{Sr}$ and $\mathrm{Ba}$ melt compositions of Whakamaru Group 1 plagioclase cores and Ruapehu groundmass glass compositions (Chapter 4) this provides strong evidence of a petrogenetic link between Taupo Volcanic Zone rhyolites and andesites, dominantly through fractional crystallisation (and assimilation) processes (Chapters 2 and 5). 
A more complex origin for the Whakamaru, Oruanui and Rotorua rhyolitic magmas than exclusively fractional crystallisation and assimilation of greywacke country rock is implied from the enriched $\mathrm{Rb} / \mathrm{Sr}$ ratios of melt inclusions in comparison to whole rock pumice compositions (Figure 2.9). For these eruptions, melt inclusions and crystal hosts are interpreted to be derived from a more evolved melt and incorporated into the final magma prior to eruption (Chapter 2). A mature crystal mush origin of these crystals is inferred due to the crystal sparse nature of erupted pumices and the strong fractional crystallisation signatures of melt inclusions that reflect and preserve a record of the interstitial melt composition. Trace element modelling of the compositional variation of melt inclusions within individual eruptions indicate that this interstitial liquid was mixed with greywacke partial melts prior to eruption, resulting in the entire compositional spectrum of melt inclusions (Chapter 2).

Crystal zonation supports the amalgamation of crystals in magmas from multiple sources (Chapters 4 and 5). For example, CL imaging of Whakamaru quartz crystals (Figure 4.5 and A4.3) revealed distinct cores and rims that allowed the location of melt inclusions in relation to these zones to be identified. This exposes distinct compositional variation between melt inclusions located in the cores of the crystal and those in the rims (Figure 6.1). With the exception of the melt inclusion located in the core of the crystal WH1_37, the most evolved melt inclusions are located in the core of the quartz crystals and the least evolved at the rims. 

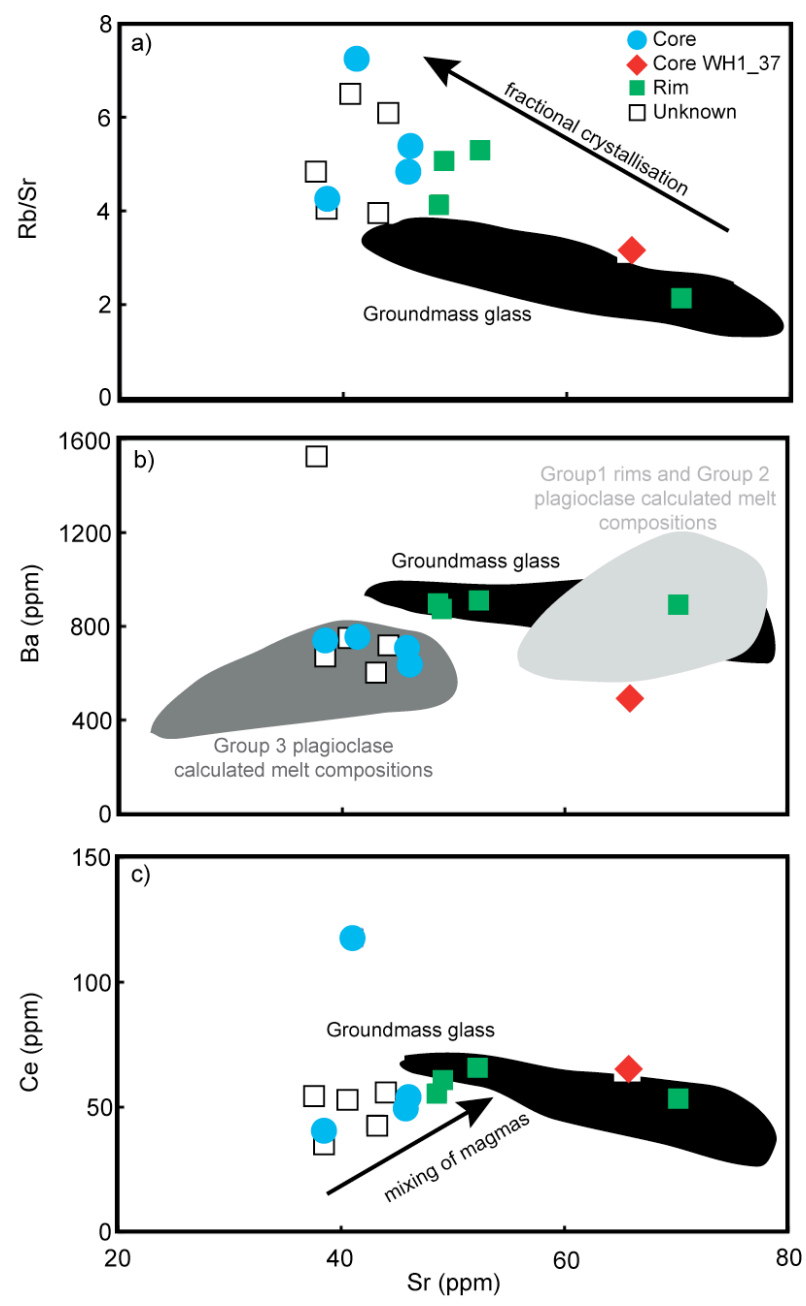

Figure 6.1. Compositional variation of quartz-hosted Whakamaru melt inclusions. Location of melt inclusions is based on the presence of core (blue circles and red diamond) and rim (green squares) regions identified by $\mathrm{CL}$ imaging of crystals (Figure 4.5 and A4.3). Melt inclusions hosted in crystals where CL images were not obtained are shown by open black squares. Note that melt inclusions in the core of crystals are more evolved (with the exception of WH1_37) than melt inclusions in the rim. Shaded regions denote groundmass glass compositions (black) (Brown, 1994), calculated melt compositions in equilibrium with Group 3 plagioclases (dark grey) and Group 1 rims and Group 2 plagioclase crystals (light grey).

Melt inclusions hosted in the rim of quartz crystals display compositions similar to groundmass glass compositions (Brown, 1994), demonstrating that the most recent quartz growth occurred while resident in the host magma. The timing of the final quartz growth is constrained from the greyscale intensity of CL images. This growth occurred $<80$ years prior to eruption (Chapter 4 ) suggesting that the 
incorporation of the quartz cores and thus crystal mush, into the magma transpired only a short time prior to eruption.

Chemical and textural zonation of Whakamaru plagioclase crystals reveals the presence of three distinct plagioclase populations. Calculation of co-existing $\mathrm{Sr}$ and $\mathrm{Ba}$ melt compositions of the low $A n$ plagioclase population (Group 3) indicates these plagioclase crystals fractionated from a low $\mathrm{Sr}(25-50 \mathrm{ppm})$ melt whose composition is consistent with the melt inclusions located in the core of quartz crystals (Figure 6.1). These crystals are inferred to originate from a crystal mush body (Chapter 4). Furthermore, similar trace element modelling of Group 1 plagioclase crystals (possessing inherited cores of $A n_{45-60}$ ) demonstrate the crystallisation of cores occurred from progenitor andesitic melts, whereas the rims and Group 2 plagioclase crystals fractionated from the final host melt contemporaneously with the rims of quartz crystals.

These observations provide a second possible source for the origin of the less evolved melt that mixed with the interstitial crystal mush melt to generate the chemical heterogeneity of melt inclusions observed within individual eruptions (Chapter 2). Instead of the interstitial melt mixing with a greywacke partial melt, the interstitial melt could have combined with a less evolved rhyolitic melt (e.g. $\mathrm{Sr}=58-93$ ppm Group 3 melt composition with a consistent melt composition to the groundmass glass) generated through fractional crystallisation of a plagioclase dominant crystal assemblage (Chapter 4) (Figure 6.1). This would indicate that the majority of greywacke assimilation occurred prior to the generation of the initial rhyolitic magmas, during the petrogenesis of basaltic and 
andesitic magmas and the growth of the crystal mush body. This model is consistent with the $\mathrm{Pb}$ isotopic compositions of Taupo Volcanic Zone glass tephra shards that indicate assimilation of greywacke basement occurred during the early stages of magmatic evolution (Allan, 2008). Sr and $\mathrm{Pb}$ isotopic analyses of Whakamaru melt inclusions and specific zones of plagioclase crystals were unable to be conducted in this current study and so the origin of the melt that combined with the interstitial crystal mush melt to create the compositional heterogeneity of the Whakamaru melt inclusions remains ambiguous. However, several Group 1 plagioclase crystals provide evidence for an overgrowth rim surrounding the core that is characterised by high Ba (e.g. $1200-1590$ ppm) potentially representing a greywacke partial melt (Chapter 4). As demonstrated for the overgrowth rims of Oruanui plagioclase crystals that possess extremely radiogenetic ${ }^{86} \mathrm{Sr} /{ }^{87} \mathrm{Sr}$ (e.g. maximum ${ }^{86} \mathrm{Sr} /{ }^{87} \mathrm{Sr}=0.70764$ compared to whole rock pumice of $\left.{ }^{86} \mathrm{Sr} /{ }^{87} \mathrm{Sr}=0.7055\right)($ Charlier et al., 2008), the timing of the input of greywacke melts and incorporation of crystal mush magmas varies from eruption to eruption.

Major element compositions of Taupo plagioclase- and orthopyroxene- hosted melt inclusions and groundmass glasses overlap (Figure 2.5) indicating all three phases are co-genetic and crystallised from the same magma body. As discussed above, quantitative modelling of melt inclusion compositions indicates the Taupo magma is derived through assimilation of greywacke country rock and fractional crystallisation from an andesitic progenitor melt (Chapter 2). However, the absence of a low An plagioclase population in the Taupo magma (Chapter 5), allied with the relatively homogenous melt inclusion compositions, indicate 
magma genesis did not involve the incorporation of a crystal mush magma. Consequently, it is interpreted that the genesis of the 1800 BP Taupo magma (the least evolved continental melt inclusion composition) occurred through dominantly fractional crystallisation and assimilation of greywacke country rock from a precursor parental andesitic melt at approximately 5-12 km depth (Chapters 2, 3 and 5).

A similar petrogenetic evolution is inferred for the Rotorua eruptive. However, the slightly enriched $\mathrm{Rb} / \mathrm{Sr}$ ratios of Rotorua melt inclusions relative to whole rock pumices allied with the lower $\mathrm{Sr}(102-158 \mathrm{ppm})$ and higher $\mathrm{Ba}$ (717 - 1086 ppm) concentrations of melt inclusions (Figure 6.2) suggest magma genesis also required the amalgamation of small degrees of crystal mush magmas (Chapter 2).

The larger-volume Whakamaru and Oruanui magmas contain polygenetic crystal populations derived from multiple sources of: (1) andesitic progenitor melts; (2) greywacke partial melts and; (3) mature crystal mush (plutonic) bodies, amalgamated together in differing proportions prior to eruption (Chapter 4; Charlier et al., 2008). These three melt sources are reflected in the $\mathrm{Sr}$ and $\mathrm{Ba}$ concentrations of Oruanui melt inclusions that fall into three discrete groups: (1) high $\mathrm{Sr}(75-105 \mathrm{ppm})$ melts that are potentially generated from the fractional crystallisation of andesitic parental melts, as discussed for the Taupo magma; (2) high $\mathrm{Ba}(710-1218 \mathrm{ppm})$ melts that may represent a greywacke melt but, as discussed above, without $\mathrm{Sr}$ or $\mathrm{Pb}$ isotopic compositions this remains equivocal, and; (3) low $\mathrm{Sr}(<40 \mathrm{ppm})$ and $\mathrm{Ba}(<290 \mathrm{ppm})$ concentrations, similar to the Whakamaru Melt 4 compositions inferred to reflect fractionation of crystal hosts in a crystal mush body (Figure 6.2). 


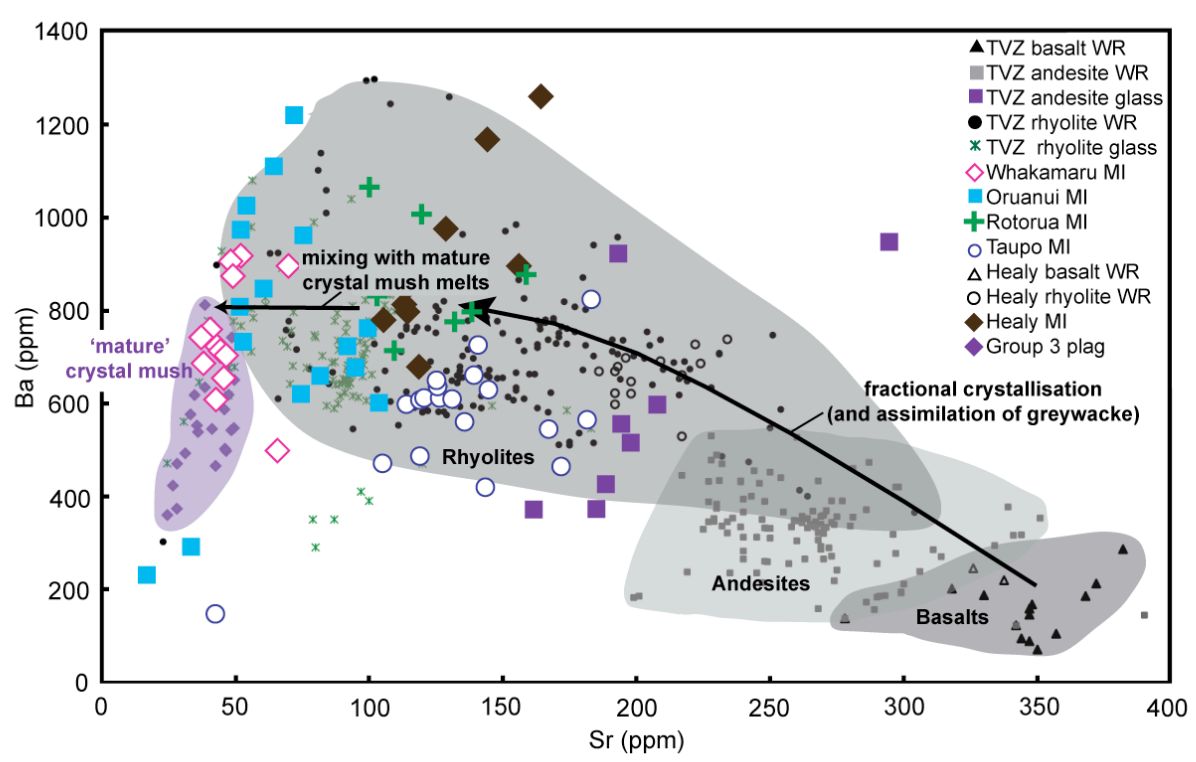

Figure 6.2. Sr versus Ba concentrations of Taupo Volcanic Zone and Healy magmas. Shaded regions represent whole rock compositions of basalts (dark grey), andesites (light grey) and rhyolites (medium grey). Groundmass and melt inclusion glass compositions are shown in colour. Whakamaru Group 3 calculated $\mathrm{Sr}$ and Ba melt compositions are in purple (Chapter 4). Data sources: Graham and Hackett (1987); Graham and Worthington (1988); Patterson and Graham (1988); Gamble et al. (1993 and 1999); Nairn (1992); Briggs et al. (1993); Cole et al. (1998); Donoghue et al. (1995); Sutton et al. (1995 and 2000); Brown et al. (1998); Krippner et al. (1998); Waight et al. (1999); Nakagawa et al. (1998 and 2002); Smith et al. (2002; 2004 and 2006); Price et al. (2005); Shane et al. (2005); Wilson et al. (2006).

Measured water concentrations of Whakamaru, Taupo and Healy melt inclusions allied with the fluctuating $A n$ contents of Taupo and Healy plagioclase crystals require both a change in magmatic water concentration and temperature to account for the $A n$ variation, suggesting that the magmatic water concentration was not constant but changed during evolution of the magma body (Chapters 3 and 5). The measured $\mathrm{H}_{2} \mathrm{O}_{\mathrm{m}}$ and $\mathrm{OH}^{-}$concentrations of melt inclusions provide evidence for the degassing of the magma prior to eruption and indicate that the magma was resident at shallow (e.g. $<4 \mathrm{~km}$ ) crustal depths for at least a short period of time prior to eruption (Chapters 3 and 5). However, estimation of the initial magmatic water concentrations for the Whakamaru, Taupo and Healy 
eruptions range between $4.4-8.8 \mathrm{wt} \%$, implying a significant proportion of the petrogenesis of these silicic magmas occurred at a depth of $4-12 \mathrm{~km}$.

The assembly of the eruptible magma body required to feed the Whakamaru supereruption is estimated to have occurred continuously over the 15,000 years preceding the final climatic eruption (Chapter 4). This period is significantly shorter than that proposed by zircon chronology for the formation of the Whakamaru magmatic system (Brown and Fletcher, 1999; Charlier et al., 2005), providing evidence that magma chambers are ephemeral features of magma reservoirs and are only formed shortly prior to eruption. This timescale is, however, significantly longer than the maximum residence times of 1010-2750 years for the Taupo eruption, estimated from the repose intervals between volcanic eruptions from Taupo Volcano (Sutton et al., 2000). It is therefore speculated that the larger volume eruptions, for example the Whakamaru and Oruanui supereruptions, assembled over extended time periods, which increased the probability for the injection and mixing of magmas from secondary sources such as crystal mush magmas and greywacke partial melts. However, it remains equivocal as to why eruptions are triggered at certain times.

Evaluation of magmatic temperatures obtained from plagioclase-melt equilibria and Fe-Ti oxides implies that Whakamaru and Taupo magmas temperatures rose prior to eruption (Chapters 4 and 5), most likely due to the intrusion of a hotter (and more mafic) magma into the base of the magma chamber. This is further illustrated by the presence of high Ti rims (bright CL intensity) on a selection of Whakamaru quartz crystals that can indicate either a rise in magmatic 
temperature or a change in the Ti activity of the melt (Wark and Watson, 2006).

The absence of late-stage growth of high $A n$ rims on plagioclase crystals (Chapter 4 and 5) indicates that the substantial mixing of magmas prior to eruption did not occur and that it was the mass transfer of volatiles that heated the overlying magma (e.g. Koyaguchi and Kaneko, 1999; Couch et al., 2001; Ruprecht and Wörner, 2007). It was only when an anomalous volume of hotter magma was intruded into the magma chamber that an eruption was triggered.

It is thus concluded that the rhyolitic magmas in the continental Taupo Volcanic Zone are generated through fractional crystallisation (and assimilation of greywacke country rock) of a plagioclase dominant crystal assemblage from andesitic progenitor melts (Figure 6.3). Furthermore, the heterogeneity of rhyolitic magmas is produced from the mixing of greywacke partial melts and the incorporation of crystal mush magmas generating the most evolved compositions (Figure 6.2 and 6.3). Thus, it is the presence and assimilation of continental lithosphere within the Taupo Volcanic Zone that generates the observed compositional heterogeneity of silicic magmas between the continental Taupo Volcanic Zone and oceanic Kermadec Arc (Figure 6.3).

Figure 6.3. (Figure overleaf) Cartoon cross section of the petrogenesis of silicic magmas in the continental Taupo Volcanic Zone and oceanic Kermadec Arc. Crystal mush bodies (grey diamonds) are generated through extreme fractional crystallisation in the Kermadec Arc (Chapters 2 and 5) and through assimilation of greywacke country rock and fractional crystallisation in the Taupo Volcanic Zone. These crystal mush bodies are envisaged to the zoned from mafic compositions at deeper crustal levels to silicic compositions at shallow crustal depths. Magma chambers are considered to be ephemeral features generated in the lead up to eruption and may not be present for the entire history of the magma reservoir. 

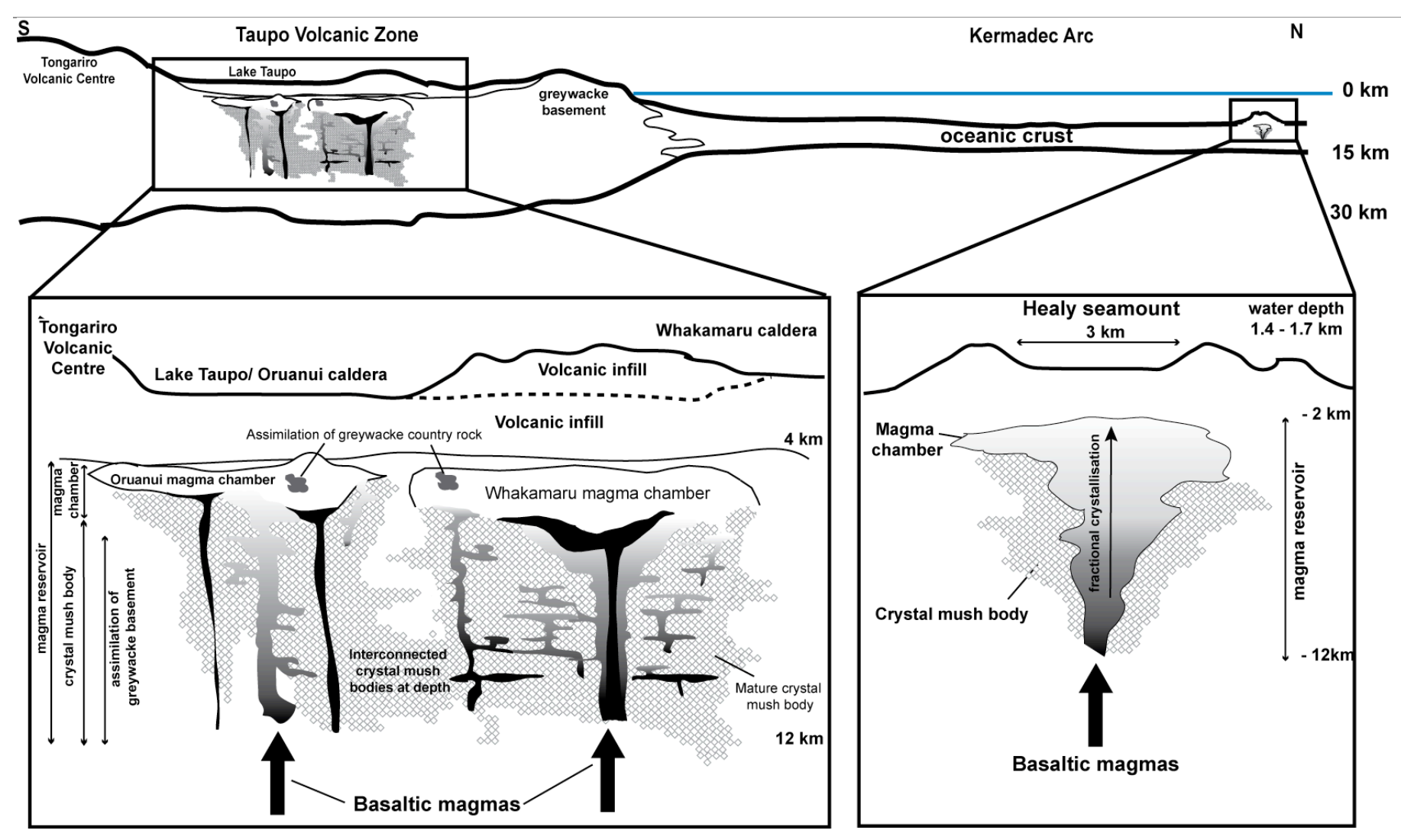

Legend

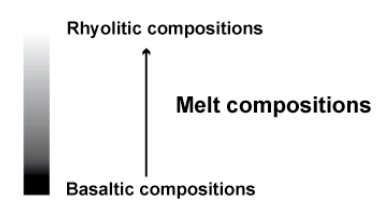

Figure 6.3 (Caption overleaf) 


\subsection{Conclusions}

A combination of elemental concentrations of melt inclusions and crystal specific studies of plagioclase and quartz crystals have shown that:

1. Fractional crystallisation is the dominant magmatic process responsible for the formation of silicic magmas in both the continental Taupo Volcanic Zone and neighbouring oceanic Kermadec Arc (Chapters 2, 3 and 5). Quantitative modelling of trace element compositions of melt inclusions demonstrates the generation of the silicic magma from the oceanic Healy seamount occurred by $62-76 \%$ fractional crystallisation from a basaltic parental melt. In contrast, assimilation of greywacke country rock ( $\mathrm{r}=0.2$ in AFC modelling, Chapter 2) combined with extensive fractional crystallisation $(60-80 \%)$ is required to produce the compositions of Taupo Volcanic Zone melt inclusions (Chapter 2).

2. Continental silicic magmas in the Taupo Volcanic Zone have more complex histories than silicic magmas in the Kermadec Arc and are generated from the amalgamation of discrete magma batches from polygenetic sources. This is most evident in the largest volume evolved magmas such as the Whakamaru Ignimbrite (Chapters 2, 4 and 5).

3. It is the presence of continental lithosphere that provides the additional melt sources required to generate large-volume silicic eruptions in the Taupo Volcanic Zone compared to the relatively small volume silicic eruptions observed in the Kermadec Arc (Chapters 2 and 5).

4. The magma reservoir model for the generation of silicic magmas (e.g. Bachman and Bergantz, 2004; 2008) is applicable to oceanic as well as continental silicic arc magmas and can provide a viable explanation for 
many of the geochemical features observed in the Taupo Volcanic Zone and Kermadec Arc silicic magmas.

5. The relatively homogenous compositions of the studied magmas conceals the presence of polygenetic magma sources in whole rock studies, requiring in-situ crystal specific studies to discriminate between various sources (Chapters 2, 4 and 5).

6. The measured water speciation of Whakamaru, Taupo and Healy melt inclusions are inconsistent with the speciation trends derived experimentally for groundmass rhyolitic glasses. Investigation into this inconsistency was interpreted to represent the degassing of melt inclusions prior to quenching. It is concluded that the measured water speciation of melt inclusions records the dissolved water concentration of the respective magmas immediately prior to eruption but provides no information about the dissolved magmatic water content at the time the melt inclusions were sealed from the external magma (Chapter 3).

\subsection{Future work}

Many questions still remain unanswered about the petrogenesis of silicic arc magmas in the continental Taupo Volcanic Zone and oceanic Kermadec Arc. In particular:

1. What are the timescales for the formation of magma reservoirs, especially the timing of the creation of the final magma chamber that feeds the eruption? Does the timescale change with eruption volume or geologic setting. 
2. What was the timing of the input of greywacke partial melts and/or the bulk assimilation of country rock (e.g. greywacke) in the continental Taupo Volcanic Zone magmas?

3. What were the proportions of crystal mush magmas incorporated into silicic magmas in both continental and oceanic subduction environments?

4. What was the extent of crystal mush bodies beneath the Taupo Volcanic Zone and Kermadec Arc?

5. What is the petrogenetic relationship between the Taupo Volcanic Zone andesites and rhyolites?

These problems could be investigated through further in-situ crystal specific studies detailing the trace element and isotopic studies of crystal zonation. In particular studies on:

1. $\mathrm{Sr}$, and $\mathrm{Pb}$ isotopic compositions of melt inclusions and specific zones of crystals, to detail the source of multiple melt components of rhyolite, andesite and basalt magmas. This would for example reduce the ambiguity of the Melt 2 plagioclase composition (Chapter 4).

2. The major and trace element composition of melt inclusions and groundmass glasses of both Taupo Volcanic Zone and Kermadec Arc andesites and basalts. However, these mafic melt inclusions would first have to be examined carefully for signs of diffusive homogenisation of inclusions with the external melt. This would permit detailed examination of magmatic processes linking basaltic and andesitic magmas and andesitic and rhyolitic magmas in arc environments. 
3. Examination of textural and chemical zonation of plagioclase crystals from rhyolite, andesite and basalt magmas. This would decipher the magmatic evolution of the entire compositional spectrum observed in the Taupo Volcanic Zone and Kermadec Arc and unravel the timing of the input of greywacke country rock to silicic magmas.

4. Diffusional timescales for the zoning of crystals (e.g. olivine, pyroxene, plagioclase and quartz) allowing timescales of magmatic processes to be constrained and providing information on whether this changes between eruptions.

5. Crystal specific study of the Kaingaroa Ignimbrite, known to contain significant proportions of andesitic as well as rhyolitic components (e.g. Nairn et al., 1994). This would allow the relationship between andesitic and rhyolitic magmas in the Taupo Volcanic Zone to be examined in detail, deciphering the petrogenetic processes involved.

Finally, water speciation of rhyolitic melt inclusions was found to be inconsistent with the predicted speciation trends of groundmass rhyolitic glasses (Chapter 3). However, it remains equivocal as to whether or not this inconsistency in water speciation is confined to high-silica melt inclusions and what triggers the degassing of some melt inclusions and not others. To investigate this further, water speciation in a range of samples from basalt to rhyolite melt inclusions and co-genetic groundmass glasses, from a range of geological environments, would need to be examined to establish how widespread this phenomenon is. 


\section{References}

Albrecht, A., and Goldstein, S.L., 2000. Effects of basement composition and age on silicic magmas across an accreted Terrane-Precambrian crust boundary, Sierra Madre Occidental, Mexico. Journal of South American Earth Sciences, 13: 255-273.

Allan, A.S.R., 2008. An elemental and isotopic investigation of Quaternary silicic Taupo Volcanic Zone tephras from ODP Site 1123: chronostratigraphic and petrogenetic applications. MSc thesis, Victoria University of Wellington, Wellington, New Zealand.

Allan, A.S.R., Baker, J.A., Carter, L., and Wysoczanski, R.J., 2008. Reconstructing the Quaternary evolution of the world's most active rhyolitic system: insights from a $\sim 1.65 \mathrm{Myr}$ deep ocean tephra record sourced from Taupo Volcanic Zone, New Zealand. Quaternary Science Reviews, 27: 2341-2360.

Anderson, A.T., Swihart, G.H., Artioli, G. and Geiger, C.A., 1984. Segregation vesicles, gas filtering-pressing, and igneous differentiation. Journal of Geology, 92: 55-72.

Anderson, A.T., Davis, A.M. and Lu, F., 2000. Evolution of Bishop Tuff rhyolitic magma based on melt and magnetite inclusions and zoned phenocrysts. Journal of Petrology, 41(3): 449-473.

Annen, C., Blundy, J.D. and Sparks, R.S.J., 2006. The genesis of intermediate and silicic magmas in deep crustal hot zones. Journal of Petrology, 47(3): 505-539.

Atlas, Z.D., Dixon, J.E., Sen, G., Finny, M., and Martin-Del Pozzo, A., L., 2005. Melt inclusions from Volcán Popocatépetl and Volcán de Colima, 
Mexico: Melt evolution due to vapor-saturated crystallization during ascent. Journal of Volcanology and Geothermal Research, 153:221-240.

Ayalew, D., Barbey, P., Marty, B., Reisberg, L., Yirgu, G., and Pik, R., 2002. Source, genesis and timing of giant ignimbrite deposits associated with Ethiopian continental flood basalts. Geochimica et Cosmochimica Acta, 66: 1429-1448.

Bachmann, O., and Bergantz, G.W., 2003. Rejuvenation of the Fish Canyon magma body: A window into the evolution of large-volume silicic magma systems. Geology, 31(9): 789-792.

Bachmann, O., and Bergantz, G.W., 2004. On the origin of crystal-poor rhyolites: extracted from batholithic crystal mushes. Journal of Petrology 45(8): 1565-1582.

Bachmann, O. and Bergantz, G., 2008. The Magma Reservoirs That Feed Supereruptions. Elements, 4(1): 17-21.

Bachmann, O., Dungan, M.A., and Lipman, P.W., 2002. The Fish Canyon magma body, San Juan Volcanic Field, Colorado: Rejuvenation and eruption of an upper-crustal batholith. Journal of Petrology, 43(8): 14691503.

Bachmann, O., Miller, C.F., and de Silva, S.L., 2007. The volcanic-plutonic connection as a stage for understanding crustal magmatism. Journal of Volcanology and Geothermal Research, 167: 1-23.

Bacon, C.R.I., and Druitt, T.H., 1988. Compositional evolution of the zoned calc-alkaline magma chamber of Mount Mazama Crater Lake, Oregon. Contributions to Mineralogy and Petrology 98(2): 224-256. 
Bacon., C.R., and Hirschmann, M.M., 1988. Mg/Mn partitioning as a test for equilibrium between coexisting Fe-Ti oxides. American Mineralogist, 73: 57-61.

Bacon, C.R., Newman, S. and Stolper, E., 1992. Water, $\mathrm{CO}_{2}, \mathrm{Cl}$, and F in melt inclusions in phenocrysts from three Holocene explosive eruptions, Crater Lake, Oregon. American Mineralogist, 77: 1021-1030.

Baker, J.A., Snee, L., and Menzies, M., 1996. A brief Oligocene period of flood volcanism: implications for the duration and rate of continental flood volcanics at the Afro-Arabian triple junction. Earth and Planetary Science Letters, 138: 39-55.

Baker, J.A., MacPherson, C.G., Menzies, M.A., Thirlwall, M.F., Al-Kadasi, M., and Mattey, D.P., 2000. Resolving crustal and mantle contributions to continental flood volcanism, Yemen; Constraints from mineral oxygen isotope data. Journal of Petrology, 41:1805-1820.

Barclay, J., Carroll, M.R., Houghton, B.F., and Wilson, C.J.N., 1996. Preeruptive volatile content and degassing history of an evolving peralkaline volcano. Journal of Volcanology and Geothermal Research, 74: 75-87.

Barclay, J., Rutherford, M.J., Carroll, M.R., Murphy, M.D., Devine, J.D., Gardner, J., and Sparks, R.S.J., 1998. Experimental phase equilibria constraints on pre-eruptive storage conditions of the Soufriere Hills magma. Geophysical Research Letter, 25: 3437-3440.

Beard, J.S., and Lofgren, G.E., 1991. Dehydration melting and water-saturated melting of basaltic and andesitic greenstones and amphibolites at 1, 3, and $6.9 \mathrm{~kb}$. Journal of Petrology, 32(2): 365-401.

Behrens, H., and Nowak, M., 1997. The mechanisms of water diffusion in polymerized silicate melts. Contributions to Mineralogy and Petrology, 126: 377-385. 
Bence, A.E., and Albee, A.L., 1968. Empirical correction factors for the electron microprobe analysis of silicates and oxides. Journal of Geology, 76: 382403.

Beresford, S.W., Cole, J.W., and Weaver, S.D., 2000. Weak chemical and mineralogical zonation in the Kaingaroa Ignimbrite, Taupo Volcanic Zone, New Zealand. New Zealand Journal of Geology and Geophysics, 43: 639650.

Bergantz, G.W., 1989. Underplating and Partial Melting: Implications for Melt Generation and Extraction. Science, 245(4922): 1093-1095.

Berlo, K., Blundy, J., Turner, S., and Hawkesworth, C., 2007. Textural and chemical variation in plagioclase phenocrysts from the 1980 eruptions of Mount St. Helens, USA. Contributions to Mineralogy and Petrology, 154: 291-308.

Bindeman, I.N., Davis, A.M. and Drake, M.J., 1998. Ion microprobe study of plagioclase-basalt partition experiments at natural concentration levels of trace elements. Geochimica et Cosmochimica Acta, 62(7): 1175-1193.

Bindeman, I.N., Valley, J.W., Wooden, J.L. and Persing, H.M., 2001. Postcaldera volcanism: in situ measurement of $\mathrm{U}-\mathrm{Pb}$ age and oxygen isotope ratio in Pleistocene zircons from Yellowstone caldera. Earth and Planetary Science Letters, 189(3-4): 197-206.

Blank, J.G., Stolper, E.M., and Carroll, M.R., 1993. Solubilities of carbon dioxide and water in rhyolitic melt at $850^{\circ} \mathrm{C}$ and 750 bars. Earth and Planetary Science Letters, 1993: 27-36.

Blake, S., 1984. Volatile oversaturation during the evolution of silicic magma chambers as an eruption trigger. Journal of Geophysical Research, 89: 8237-8244. 
Blattner, P., and Reid, F., 1982. The origin of lavas and ignimbrites of the Taupo Volcanic Zone, New Zealand in the light of oxygen isotope data. Geochimica et Cosmochimica Acta, 46: 1417-1429.

Blattner, P., RuiZhong, H., Graham, I.J., Houston-Eleftheriadis, C., 1996. Temperatures and isotopic evolution of silicic magmas, Taupo Volcanic Zone and Coromandel, New Zealand. New Zealand Journal of Geology and Geophysics 39(3): 353-362.

Blundy, J.D. and Shimizu, N., 1991. Trace-element evidence for plagioclase recycling in calc-alkaline magmas. Earth and Planetary Science Letters, 102(2): 178-197.

Blundy, J.D. and Wood, B.J., 1991. Crystal-chemical controls on the partitioning of $\mathrm{Sr}$ and $\mathrm{Ba}$ between plagioclase feldspar, silicate melts, and hydrothermal solutions. Geochimica et Cosmochimica Acta, 55(1): 193209.

Blundy, J.D., and Wood, B.J., 1994. Prediction of crystal-melt partition coefficients from elastic moduli. Nature, 372: 452-454.

Blundy, J. and Cashman, K., 2005. Rapid decompression-driven crystallization recorded by melt inclusions from Mount St. Helens volcano. Geology, 33(10): 793-796.

Blundy, J., Cashman, K., and Humphreys, M., 2006. Magma heating by decompression-driven crystallization beneath andesite volcanoes. Nature, 443: 76-80.

Blundy, J., Cashman, K., and Berlo, K., in press. Evolving magma storage conditions beneath Mount St. Helens inferred from chemical variations in melt inclusions from the 1980-1986 and current eruptions. In Sherrod, D.R., et al., eds., A volcano rekindled: The first year of renewed eruption 
at Mount St. Helens, 2004-2006: U.S. Geological Survey Professional Paper (in press).

Borg, L.E., Clynne, M.A., 1998. The petrogenesis of felsic calc-alkaline magmas from the southernmost Cascades, California: origin by partial melting of basaltic lower crust. Journal of Petrology, 39(6): 1197-1222.

Bowen, N.L., 1913. The melting phenomena of plagioclase feldspars. American Journal of Science, 35: 577-599.

Bowen, N.L., 1928. The evolution of igneous rocks. Princeton University Press. pp 332.

Briggs, N.D., 1976. Recognition and correlation of subdivisions within the Whakamaru ignimbrite, central North Island, New Zealand. New Zealand Journal of Geology and Geophysics, 19: 463-501.

Briggs, R.M., Gifford, M.G., Moyle, A.R., Taylor, S.R., Norman, M.D., Houghton, B.F., and Wilson, C.J.N., 1993. Geochemical zoning and eruptive mixing in ignimbrites from Mangakino volcano, Taupo Volcanic Zone, New Zealand. Journal of Volcanology and Geothermal Research, 56: 175-203.

Brophy, J.G., Whittington, C.S. and Park, Y.R., 1999. Sector-zoned augite megacrysts in Aleutian high alumina basalts: implications for the conditions of basalt crystallization and the generation of calc-alkaline series magmas. Contributions to Mineralogy and Petrology, 135(2-3): 277-290.

Brophy, J.G., 2008. A study of rare earth element (REE)-SiO $\mathrm{S}_{2}$ variations in felsic liquids generated by basalt fractionation and amphibolite melting: a potential test for discriminating between two different processes. Contributions to Mineralogy and Petrology, 156: 337-357. 
Brown, S.J.A., 1994. Geology and geochemistry of the Whakamaru group ignimbrites, and associated rhyolite domes, Taupo Volcanic Zone, New Zealand. PhD thesis, University of Canterbury, Christchurch, 288 pp.

Brown, S.J.A., and Fletcher, I.R., 1999. SHRIMP U-PB dating of the preeruption growth history of zircons from the $340 \mathrm{ka}$ Whakamaru Ignimbrite, New Zealand: Evidence for $>250$ k.y. magma residence times. Geology, 27: 1035-1038.

Brown, S.J.A., Wilson, C.J.N., Cole, J.W., and Wooden, J., 1998a. The Whakamaru group ignimbrites, Taupo Volcanic Zone, New Zealand: evidence for reverse tapping of a zoned silicic magmatic system. Journal of Volcanology and Geothermal Research, 84(1-2): 1-37.

Brown, S.J.A., Burt, R.M., Cole, J.W., Krippner, S.J.P., Price, R.C., and Cartwright, I., 1998b. Plutonic lithics in ignimbrites of Taupo Volcanic Zone, New Zealand; sources and conditions of crystallisation. Chemical Geology 148: 21-41.

Browne, P.R.L., Graham, I.J., Parker, R.J. and Wood, C.P., 1992. Subsurface andesite lavas and plutonic rocks in the Rotokawa and Ngatamariki geothermal systems, Taupo Volcanic Zone, New Zealand. Journal of Volcanology and Geothermal Research, 51: 199-215.

Bryan, S.E., Riley, T.R., Jerram, D.A., Stephens, C.J., and Leat, P.T., 2002. Silicic volcanism: An undervalued component of large igneous provinces and volcanic rifted margins. In Menzies, M.A., Klemperer, S.L., Ebinger, C.J., and Baker, J (Editors). Volcanic rifted margins. Geological Society of America Special Paper, 362: 97-118.

Case, J.E., Ryland, S.L., Simkin, T., and Howard, K.A., 1973. Gravitational evidence for a low-density mass beneath the Galápagos Islands. Science, 181: $1040-1042$. 
Cervantes, P., and Wallace, P., 2003. Magma degassing and basaltic eruption styles: a case study of $\sim 2000$ year BP Xitle volcano in central Mexico. Journal of Volcanology and Geothermal, 120: 249-270.

Charlier, B.L.A., Wilson, C.J.N., Lowenstern, J.B., Blake, S., Van Calsteren, P.W., and Davidson, J.P., 2005. Magma generation at a large, hyperactive silicic volcano (Taupo, New Zealand) revealed by U-Th and U-Pb systematics in zircons. Journal of Petrology, 46(1): 3-32.

Charlier, B.L.A., Bachmann, O., Davidson, J.P., Dungan, M.A., and Morgan, D.J., 2007. The upper crustal evolution of a large silicic magma body: Evidence from crystal-scale $\mathrm{Rb}-\mathrm{Sr}$ isotopic heterogeneities in the Fish Canyon magmatic system, Colorado. Journal of Petrology, 48: 18751894.

Charlier, B.L.A., Wilson, C.J.N., and Davidson, J.P., 2008. Rapid open-system assembly of a large silicic magma body: time-resolved from cored plagioclase crystals in the Oruanui eruption deposits, New Zealand. Contributions to Mineralogy and Petrology, 156: 799-813.

Cherniak, D.J., Watson, E.B., and Wark., D.A., 2007. Ti diffusion in quartz. Chemical Geology, 236: 65-74.

Christensen, J.N. and DePaolo, D.J., 1993. Time scales of large volume silicic magma systems - Sr isotopic systematics of phenocrysts and glass from the Bishop Tuff, Long Valley, California. Contributions to Mineralogy and Petrology, 113(1): 100-114.

Christensen, J.N. and Halliday, A.N., 1996. Rb-Sr ages and $\mathrm{Nd}$ isotopic compositions of melt inclusions from the Bishop Tuff and the generation of silicic magma. Earth and Planetary Science Letters, 144(3-4): 547-561. 
Christiansen, R.L., 2001. The Quaternary and Pliocene Yellowstone Plateau volcanic field of Wyoming, Idaho and Montana. USGS Professional Paper, 729: 1-146.

Christiansen, E.H., 2005. Contrasting processes in silicic magma chambers: evidence from very large volume ignimbrites. Geological Magazine, 142: 669-681.

Cline, J.S., and Bodnar, R.J., 1991. Can economic porphyry copper mineralization be generated by a typical calc-alkaline melt. Journal of Geophysical Research - Solid Earth and Planets, 96: 8113-8126.

Cole, J.W., 1979. Structure, petrology, and genesis of Cenozoic volcanism, Taupo Volcanic Zone, New Zealand - a review. New Zealand Journal of Geology and Geophysics, 22: 631-657.

Cole, J.W., 1981. Genesis of Lavas of the Taupo Volcanic Zone, North Island, New Zealand. Journal of Volcanology and Geothermal Research, 10: 317-337.

Cole, J.W., Brown, S.J.A., Burt, R.M., Beresford, S.W., and Wilson, C.J.N., 1998. Lithic types in ignimbrites as a guide to the evolution of a caldera complex, Taupo volcanic centre, New Zealand. Journal of Volcanology and Geothermal Research, 80(3-4): 217-237.

Cole, J.W., Gamble, J.A., Burt, R.M., Carroll, L.D., and Shelley, D., 2001. Mixing and mingling in the evolution of andesite-dacite magmas; evidence from co-magmatic plutonic enclaves, Taupo Volcanic Zone, New Zealand. Lithos, 59: 25-46.

Cordier, P., and Doukhan, J.C., 1991. Water speciation in quartz: A near infrared study. American Mineralogist, 76: 361-369. 
Costa, F., and Chakraborty, S., 2004. Decadel time gaps between mafic intrusion and silicic eruption obtained from chemical zoning patterns in olivine. Earth and Planetary Science Letters, 227: 517-530.

Costa, F., Chakraborty, S. and Dohmen, R., 2003. Diffusion coupling between trace and major elements and a model for calculation of magma residence times using plagioclase. Geochimica et Cosmochimica Acta, 67(12): 2189-2200.

Couch, S., Sparks, R.S.J., and Carroll, M.R., 2001. Mineral disequilibrium in lavas explained by convective self-mixing in open magma chambers. Nature, 411: 1037-1039.

Couch, S., Sparks, R.S.J., and Carroll, M.R., 2003. The kinetics of degassinginduced crystallization at Soufrière Hills Volcano, Montserrat. Journal of Petrology, 44: 1477-1502.

Crank, J., 1976. The mathematics of diffusion. Oxford University Press, 414pp.

Danyushevsky, L.V., McNeill, A.W., and Sobolev, A.V., 2002. Experimental and petrological studies of melt inclusions in phenocrysts from mantlederived magmas: an overview of techniques, advantages and complications. Chemical Geology, 183: 5-24.

Darby, D.J., Hodgkinson, K.H. and Blick, G.H., 2000. Geodetic measurement of deformation in the Taupo Volcanic Zone, New Zealand: the North Taupo Network revisited. New Zealand Journal of Geology and Geophysics, 43(2): 157-170.

Davidson, J., Tepley, F., Palacz, Z. and Meffan-Main, S., 2001. Magma recharge, contamination and residence times revealed by in situ laser ablation isotopic analysis of feldspar in volcanic rocks. Earth and Planetary Science Letters, 184(2): 427-442. 
Davidson, J.P. Hora, J.H. Garrison, J.M., and Dungan, M.A., 2005. Crustal forensics in arc magmas. Journal of Volcanology and Geothermal Research, 140: 157-170.

Davidson, J.P., Morgan, D.J., Charlier, B.L.A., Harlou, R., and Hora, J.M., 2007. Microsampling and isotopic analysis of igneous rocks: implications for the study of magmatic systems. Annual Review of Earth and Planetary Sciences, 35(1): 273-311.

Davis, J.H., and Stevenson, D.J., 1992. Physical model of source region of subduction zone volcanics. Journal of Geophysical Research, 97:20372070.

Davy, B.W. and Caldwell, T.G., 1998. Gravity, magnetic and seismic surveys of the caldera complex, Lake Taupo, North Island, New Zealand. Journal of Volcanology and Geothermal Research, 81(1-2): 69-89.

Delaney, J.R., Muenow, D.W. and Graham, D.G., 1978. Abundance and distribution of water, carbon and sulfur in the glassy rims of submarine pillow basalts. Geochimica et Cosmochimica Acta, 42: 581-584.

DePaolo, D.J., 1981. Trace-element and isotopic effects of combined wallrock assimilation and fractional crystallization. Earth and Planetary Science Letters, 53(2): 189-202.

DeRonde, C.E.J., Baker, E.T., Massoth, G.J., Lupton, J.E., Wright, I.C., Feely, R.A., and Greene, R.R., 2001. Intra-oceanic subduction-related hydrothermal venting, Kermadec volcanic arc, New Zealand. Earth and Planetary Science Letters, 193: 359-369.

Devine., J.D., Gardner, J.E., Brack, H.P., Layne, G.D., and Rutherford, M.J., 1995. Comparison of microanalytical methods fro estimating $\mathrm{H}_{2} \mathrm{O}$ contents of silicic volcanic glasses. American Mineralogist, 80:319-328. 
Dixon, J.E., 1997. Degassing of alkalic basalts. American Mineralogist, 82: 368378.

Dixon, J.E., Stolper, E.M., and Delaney, J.R., 1988. Infrared spectroscopic measurements of $\mathrm{CO}_{2}$ and $\mathrm{H}_{2} \mathrm{O}$ in Juan de Fuca ridge basaltic glasses. Earth and Planetary Science Letters, 90: 87-104.

Dixon, J.E., Stolper, E.M. and Holloway, J.R., 1995. An experimental study of water and carbon dioxide solubilities in mid-ocean ridge basaltic liquids. Part I: Calibration and solubility models. Journal of Petrology, 36: 16071631.

Dobson, P.F., Skogby, H. and Rossman, G.R., 1995. Water in boninite glass and coexisting orthopyroxene: concentration and partitioning. Contributions to Mineralogy and Petrology, 118(4): 414-419.

Donoghue, S.L., Gamble, J.A., Palmer, A.S., Stewart, R.B., 1995. Magma mingling in an andesite pyroclastic flow of the Pourahu member, Ruapehu Volcano, New Zealand. Journal of Volcanology and Geothermal Research, 68: 177-191.

Dunbar, N.W., and Kyle, P.R., 1993. Lack of volatile gradient in the Taupo plinian-ignimbrite transition: evidence from melt inclusion analysis. American Mineralogist, 78: 612-618.

Dunn, T., and Sen, C., 1994. Mineral/matrix partition coefficients for orthopyroxene, plagioclase, and olivine in basaltic to andesitic systems: a combined analytical and experimental study. Geochimica et Cosmochimica Acta, 58(2): 717-733.

Eggler, D.H., 1972. Amphibole stability in $\mathrm{H}_{2} \mathrm{O}$-undersaturated calc-alkaline melts. Earth and Planetary Science Letters, 15: 38-44. 
Ellis, S.M., Wilson, C.J.N., Bannister, S., Bibby, H.M., Heise, W., Wallace, L., and Patterson, N., 2007. A future magma inflation event under the rhyolitic Taupo volcano, New Zealand: Numerical models based on constraints from geochemical, geological, and geophysical data. Journal of Volcanology and Geothermal Research, 168(1-4): 1-27.

Ewart, A., and Stipp, J.J., 1968. Petrogenesis of the volcanic rocks of the Central North Island, New Zealand, as indicated by a study of ${ }^{87} \mathrm{Sr} /{ }^{86} \mathrm{Sr}$ ratios, and St, Rb, K, U and Th abundances. Geochimica et Cosmochimica Acta, 32: 699-736.

Ewart, A., and Griffin, W.L., 1994. Application of Proton-Microprobe data to trace element partitioning in volcanic-rocks. Chemical Geology, 117: 251284.

Fine, G., and Stolper, E., 1985. The speciation of carbon dioxide in sodium aluminosilicate glasses. Contributions to Mineralogy and Petrology, 91: 105-121.

Fogel, R.A. and Rutherford, M.J., 1990. The solubility of carbon dioxide in rhyolitic melts: A quantitative FTIR study. American Mineralogist, 75: 1311-1326.

Frey, F.A., 1969. Rare earth abundances in a high-temperature peridotite intrusion. Geochimica et Cosmochimica Acta, 33(11): 1429-1447.

Frezzotti, M.-L., 2001. Silicate-melt inclusions in magmatic rocks: applications to petrology. Lithos, 55(1-4): 273-299.

Froggatt, P.C., 1981. Stratigraphy and nature of Taupo Pumice Formation. New Zealand Journal of Geology and Geophysics, 24: 231-248.

Froggat, P.C., and Lowe, D.J., 1990. A review of late Quaternary silicic and some other tephra formation from New Zealand - their stratigraphy, 
nomenclature, distribution, volume and age. New Zealand Journal of Geology and Geophysics, 33 (1): 89-109.

Fulignati, P., and Marianelli, P., 2007. Tracing volatile exsolution within the 472 AD "Pollena" magma chamber of Vesuvius (Italy) from melt inclusion investigation. Journal of Volcanology and Geothermal Research, 161: 289-302.

Gamble, J.A., Smith, I.E.M., Graham, I.J., Kokelaar, B.P., Cole, J.W., Houghton, B.F., and Wilson, C.J.N., 1990. The petrology, phase relations and tectonic setting of basalts from Taupo Volcanic Zone, New Zealand and the Kermadec Island Arc - Havre Trough, SW Pacific. Journal of Volcanology and Geothermal Research, 43: 235-270.

Gamble, J.A., Smith, I.E.M., McCulloch, M.T., Graham, I.J., and Kokelaar, B.P., 1993. The Geochemistry and petrogenesis of basalts from the Taupo Volcanic Zone and Kermadec Island-Arc, SW Pacific. Journal of Volcanology and Geothermal Research, 54(3-4): 265-290.

Gamble, J., Woodhead, J., Wright, I., and Smith, I., 1996. Basalt and sediment geochemistry and magma petrogenesis in a transect from oceanic island arc to rifted continental margin arc: The Kermadec Hikurangi Margin, SW Pacific. Journal of Petrology, 37(6): 1523-1546.

Gamble, J.A., Wood, C.P., Price, R.C., Smith, I.E.M., Stewart, R.B., and Waight, T., 1999. A fifty year perspective of magmatic evolution on Ruapehu Volcano, New Zealand: Verification of open system behaviour in an arc volcano. Earth and Planetary Science Letters, 170: 301-314.

Gamble, J.A., Price, R.C., Smith, I.E.M., McIntosh, W.C., and Dunbar, N.W., 2003. $\mathrm{Ar}^{40} / \mathrm{Ar}^{39}$ geochronology of magmatic activity, magma flux and hazards at Ruapehu volcano, Taupo Volcanic Zone, New Zealand. Journal of Volcanology and Geothermal Research, 120(3-4): 15-29. 
Gerlach, T.M., 1986. Exsolution of $\mathrm{H}_{2} \mathrm{O}, \mathrm{CO}_{2}$ and $\mathrm{S}$ during eruptive episodes at Kilauea volcano, Hawaii. Journal of Geophysical Research, 91: 1217712185.

Giletti, B.J. and Casserly, J.E.D., 1994. Strontium diffusion kinetics in plagioclase feldspars. Geochimica et Cosmochimica Acta, 58(18): 37853793.

Giletti, B.J., and Shanahan T.M., 1997. Alkali diffusion in plagioclase feldspar. Chemical Geology, 139: 3-20.

Ginibre, C., and Wörner, G., 2007. Variable parent magmas and recharge regimes of the Parinacota magma system (N. Chile) revealed by $\mathrm{Fe}, \mathrm{Mg}$ and $\mathrm{Sr}$ zoning in plagioclase. Lithos, 98: 118-140.

Ginibre, C., Kronz, A. and Wörner, G., 2002a. High-resolution quantitative imaging of plagioclase composition using accumulated backscattered electron images: new constraints on oscillatory zoning. Contributions to Mineralogy and Petrology, 142(4): 436-448.

Ginibre, C., Wörner, G., and Kronz, A., 2002b. Minor- and trace-element zoning in plagioclase: implications for magma chamber processes at Parinacota volcano, northern Chile. Contributions to Mineralogy and Petrology, 143: 300-315.

Ginibre, C., Wörner, G. and Kronz, A., 2004. Structure and dynamics of the Laacher See magma chamber (Eifel, Germany) from major and trace element zoning in sanidine: a cathodoluminescence and electron microprobe study. Journal of Petrology, 45: 2197-2223.

Ginibre, C., Wörner, G. and Kronz, A., 2007. Crystal Zoning as an Archive for Magma Evolution. Elements, 3(4): 261-266. 
Gioncada, A., Mazzuoli, R., Bisson M., and Pareschi, M.T., 2003. Petrology of volcanic products younger than $42 \mathrm{ka}$ on the Lipari-Vulcano complex (Aeolian Islands, Italy): An example of volcanism controlled by tectonics: Journal of Volcanology and Geothermal Research, 122: 191220.

Glazner, A.F., Bartley, J.M., Coleman, D.S., Gray, W., and Taylor, R.Z., 2004. Are plutons assembled over millions of years by amalgamation from small magma chambers? GSA Today, 14: 4-11.

Graham, I.J., and Hackett, W.R., 1987. Petrology of Calc-alkaline lavas from Ruapehu Volcano and related vents, Taupo Volcanic Zone, New Zealand. Journal of Petrology, 28: 531-567.

Graham, I.J., and Worthington, T.J., 1988. Petrogenesis of Tauhara dacite (Taupo Volcanic Zone, New Zealand) - Evidence for magma mixing between high-alumina andesite and rhyolite. Journal of Volcanology and Geothermal Research, 35: 279-294.

Graham, I.J., Gulson, B.L., Hedenquist, J.W., and Mizon, K., 1992. Petrogenesis of late Cenozoic volcanic rocks from the Taupo Volcanic Zone, NewZealand, in the light of new lead isotope data. Geochimica et Cosmochimica Acta, 56(7): 2797-2819.

Graham, I.J., Cole, J.W., Briggs, R.M., Gamble, J.A., and Smith, I.E.M., 1995. Petrology and petrogenesis of volcanic rocks from the Taupo Volcanic Zone - a review. Journal of Volcanology and Geothermal Research, 68(13): $59-87$.

Grove, T.L., Baker, M.B. and Kinzler, R.J., 1984. Coupled CaAl-NaSi diffusion in plagioclase feldspar: Experiments and applications to cooling rate speedometry. Geochimica et Cosmochimica Acta, 48(10): 2113-2121. 
Grove, T.L., Elkins-Tanton, L.T., Parman, S.W., Chatterjee, N., Muntener, O., and Gaetani, G.A., 2003. Fractional crystallization and mantle melting controls on calc-alkaline differentiation trends. Contributions to Mineralogy and Petrology, 145(5): 515-533.

Gurenko, A.A., Trumbull, R.B., Thomas, R., and Lindsay, J.M., 2005. A melt inclusion record of volatiles, trace elements and $\mathrm{Li}-\mathrm{B}$ isotope variations in a single magma system from the Plat Pays Volcanic Complex, Dominica, Lesser Antilles. Journal of Petrology, 46: 2495-2526.

Haase, K.M., Stroncik, N., Garbe-Schonberg, D., and Stoffers, P., 2006. Formation of island arc dacite magmas by extreme crystal fractionation: an example from Brothers Seamount, Kermadec Island arc (SW Pacific). Journal of Volcanology and Geothermal Research, 152(3-4): 316-330.

Halliday, A.N., Mahood, G.A., Holden, P., Metz, J.M., Dempster, T.J., and Davidson, J.P., 1989. Evidence for long residence times of rhyolitic magma in the Long Valley magmatic system: the isotopic record in precaldera lavas of Glass Mountain. Earth and Planetary Science Letters, 94(3-4): 274-290.

Hammersley, L., and DePaolo, D.J., 2006. Isotopic and geophysical constraints on the structure and evolution of the Clear Lake volcanic system. Journal of Volcanology and Geothermal Research, 153: 331-356.

Harrison, A.J. and White, R.S., 2004. Crustal structure of the Taupo Volcanic Zone, New Zealand: Stretching and igneous intrusion. Geophysical Research Letters, 31: L13615.

Harrison, A., and White, R.S., 2006. Lithospheric structure of an active backarc basin: The Taupo Volcanic Zone, New Zealand. Geophysical Journal International, 167(2): 968-990. 
Hauri, E., 2002. SIMS analysis of volatiles in silicate glasses, 2: isotopes and abundances in Hawaiian melt inclusions. Chemical Geology, 183: 115141.

Hauri, E., Wang, J., Dixon, J.E., King, P.L., Mandeville, C., and Newman, S., 2002. SIMS analysis of volatiles in silicate glasses 1. Calibration, matrix effects and comparisons with FTIR. Chemical Geology, 183: 99-114.

Hawkesworth, C.J., Blake, S., Evans, P., Hughes, R., MacDonald, R., Thomas, L.E., Turner, S.P., and Zellmer, G., 2000. Time scales of crystal fractionation in magma chambers - Integrating physical, isotopic and geochemical perspectives. Journal of Petrology, 41(7): 991-1006.

Hawkesworth, C., George, R., Turner, S., and Zellmer, G., 2003. Estimating the times scales of magmatic processes. In DeVivo, B., and Bodnar, R.J., (Editors) Melt inclusions in volcanic systems: Methods, applications and problems. Developments in Volcanology, 5: 23-43.

Hayden, L.A., and Watson, E.B., 2007. Rutile saturation in hydrous siliceous melts and its bearing on Ti-thermometry of quartz and zircon. Earth and Planetary Science Letters, 258: 561-568.

Heise, W., Bibby, H.M., Caldwell, G., Bannister, S.C., Ogawa, Y., Takakura, S., and Uchida, T., 2007. Melt distribution beneath a young continental rift: The Taupo Volcanic Zone, New Zealand. Geophysical Research Letters, 34: L14313.

Heuman, A., and Davis, G.R., 1997. Isotopic and chemical evolution of the postcaldera rhyolite system at Long Valley, California. Journal of Petrology, 38: 1661-1678.

Higuchi, H., and Nagasawa, H., 1969. Partition of trace elements between rockforming minerals and the host volcanic rocks. Earth and Planetary Science Letters, 7(3): 281-287. 
Hildreth, W., 1981. Gradients in silicic magma chambers: implications for lithospheric magmatism. Journal of Geophysical Research, 86: 1015310192.

Hildreth, W., 2004. Volcanological perspectives on Long Valley, Mammoth Mountain, and Mono Craters: several contiguous but discrete systems. Journal of Volcanology and Geothermal Research, 136: 169-198.

Hildreth, W., and Wilson, C.J.N., 2007. Compositional zoning of the Bishop Tuff. Journal of Petrology, 48(5): 951-999.

Hildreth, W., Halliday, A.N., and Christiansen, R.L., 1991. Isotopic and chemical evidence concerning the genesis and contamination of basaltic and rhyolitic magma beneath the Yellowstone Plateau volcanic field. Journal of Petrology, 32: 63-138.

Houghton, B.F., Wilson, C.J.N., McWilliams, M.O., Lanphere, M.A., Weaver, S.D., Briggs, R.M., and Pringle, M.S., 1995. Chronology and dynamics of a large silicic magmatic system: Central Taupo Volcanic Zone, New Zealand. Geology, 23(1): 13-16.

Housh, T.B., and Luhr, J.F., Plagioclase-melt equilibria in hydrous systems. American Mineralogist, 76: 477-492.

Humphreys, M.C.S., Blundy, J.D., and Sparks, R.S.J., 2006. Magma Evolution and Open-System Processes at Shiveluch Volcano: insights from Phenocryst Zoning. Journal of Petrology, 47(12): 2303-2334.

Huppert, H.E., and Sparks, S.J., 1988. The generation of granitic magmas by intrusion of basalt into continental crust. Journal of Petrology, 29(3): 599624.

Ihinger, P.D., Hervig, R.L. and McMillan, P.F., 1994. Analytical methods for volatiles in glasses. In: M.R. Carroll and J.R. Holloway (Editors), 
Volatiles in magmas. Mineralogical Society of America, Washington, pp. 517.

Ihinger, P.D., Zhang, Y. and Stolper, E.M., 1999. The speciation of dissolved water in rhyolitic melt. Geochimica et Cosmochimica Acta, 63(21): 35673578 .

Irving, A.J., and Frey, F.A., 1984. Trace element abundances in megacrysts and their host basalts: constraints on partition coefficients and megacryst genesis. Geochimica et Cosmochimica Acta, 48(6): 1201-1221.

Jarosewich, J.A., Nelen, J.A., and Norberg, J.A., 1980. Reference samples for electron microprobe analysis. Geostandards Newsletter, 4 (1): 43-47.

Jaupart, C. and Tait, S., 1990. Dynamics of eruptive phenomena. In: J. Nicholls and J.K. Russell (Editors), Modern methods of Igneous petrology: understanding magmatic processes. The Mineralogical Society of America, Washington, D.C., pp. 213-236.

Jellinek, A.M. and DePaolo, D.J., 2003. A model for the origin of large silicic magma chambers: precursors of caldera-forming eruptions. Bulletin of Volcanology, 65(5): 363-381.

Jerram, D.A. and Davidson, J.P., 2007. Frontiers in textural and microgeochemical Analysis. Elements, 3(4): 235-238.

Jerram, D.A., and Martin, V.M., 2008. Understanding crystal populations and their significance through the magma plumbing system. In Annen, C., and Zellmer, G.F., (editors). Dynamics of Crustal Magma Transfer, Storage and Differentiation. Geological Society of London Special Publications, 304: 133-148.

Jochum, K. P., Stoll, B., Herwig, K., Willbold, M., Hofmann, A.W., Amini, M., Aarburg, S., Abouchami, W., Hellebrand, E., Mocek, B., Raczek, I., 
Stracke, A., Alard, O., Bouman, C., Becker, S., Dücking, M., Brätz, H., Klemd, R., de Bruin, D., Canil, D., Cornell,D., de Hoog, C-J., Dalpé, C., Danyushevsky, L., Eisenhauer, A., Gao, Y., Snow, J.E., Groschopf, N., Günther, D., Latkoczy, C., Guillong, M., Hauri, E.H., Höfer, H.E., Lahaye, Y., Horz, K., Jacob, D.E., Kasemann, S.A., Kent, A.J.R., Ludwig, T., Zack, T., Mason, P.R.D., Meixner, A., Rosner, M., Misawa, K., Nash, B.P., Pfänder, J., Premo, W.R., Sun, W.D., Tiepolo, M., Vannucci, R., Vennemann, T., Wayne, D., and Woodhead, J., 2006. MPI-DING reference glasses for in situ microanalysis: new reference values for element concentrations and isotope ratios. Geochemistry, Geophysics, Geosystems, 7: Q02008, doi:10.1029/2005GC001060.

Johannes, W., 1989. Melting of plagioclase-quartz assemblages at 2 kbar water pressure. Contributions to Mineralogy and Petrology, 103: 270-276.

Johnson, E.A., 2003. Hydrogen in nominally hydrous crustal minerals. $\mathrm{PhD}$ thesis, California Institute of Technology, Pasadena, California.

Johnson, E.A., 2006. Water in Nominally Anhydrous Crustal Minerals: Speciation, Concentration, and Geologic Significance. Reviews in Mineralogy and Geochemistry, 62(1): 117-154.

Johnson, E.A. and Rossman, G.R., 2004. A survey of hydrous species and concentrations in igneous feldspars. American Mineralogist, 89(4): 586600 .

Johnson, E.R., Wallace, P.J., Cashman, K.V., Granados, H.D. and Kent, A.J.R., 2008. Magmatic volatile contents and degassing-induced crystallization at Volcán Jorullo, Mexico: Implications for melt evolution and the plumbing systems of monogenetic volcanoes. Earth and Planetary Science Letters, 269(3-4): 477-486. 
Kamenetsky, V., 1996. Methodology for the study of melt inclusions in Crspinel, and implications for parental melts of MORB from FAMOUS area. Earth and Planetary Science Letters, 142(3-4): 479-486.

Kawate, S., and Arima, M., 1998. Petrogenesis of the Tanzawa plutonic complex, central Japan: exposed felsic middle crust of the Izu-BoninMariana arc. Island Arc, 7(3): 342-358.

Kent, A.J.R. and Elliot, T.R., 2002. Melt inclusions from Marianas arc lavas: implications for the composition and formation of island arc magmas. Chemical Geology, 183: 263-286.

Kent, A.J.R., Blundy, J., Cashman, K.V., Cooper, K.M., Donnelly, C., Pallister, J.S., Reagan, M., Rowe, M.C., and Thornber, C.R., 2007. Vapor transfer prior to the October 2004 eruption of Mount St. Helens, Washington. Geology, 35(3): 231-234.

Kilgour, G.N., 2002. The nature and dynamics of the Rotorua Eruptive Episode, Okataina Volcanic Centre, Taupo Volcanic Zone. MSc thesis, University of Waikato, Hamilton, New Zealand.

Koyaguchi, T., and Kaneko, K., 1999. A two-stage thermal evolution model of magmas in continental crust. Journal of Petrology, 40: 241-254.

Krippner, S.J.P., Briggs, R.M., Wilson, C.J.N., and Cole, J.W., 1998. Petrography and geochemistry of lithic fragments in ignimbrites from the Mangakino Volcanic Center: Implications for the composition of the subvolcanic crust in western Taupo Volcanic Zone, New Zealand. New Zealand Journal of Geology and Geophysics, 41: 187-199.

Leat, P.T., Smellie, J.L., Millar, I.L., and Larter, R.D., 2003. Magmatism in the South Sandwich arc. In: R.D. Larter, P.T. Leat (Editors), Intra-Oceanic subduction systems: tectonic and Magmatic Processes. Geological Society of London Special Publication 219, London, pp. 285-313. 
Le Bas, M.J., Le Maitre, R.W., Streckeisen, A., and Zanettin, B., 1986. A chemical classification of volcanic rocks based on the total alkali-silica diagram. Journal of Petrology, 27: 745-750.

LePage, L.D., 2003. ILMAT: an Excel worksheet for ilmenite-magnetite geothermometry and geobarometry. Computers and Geosciences, 29:673678.

Lindsey, J.M., Schmitt, A.K., Trumbull, R.B., de Silva, S.L., Siebel, W., and Emmermann, R., (2001). Magmatic evolution of the La Pacana caldera system, Central Andes, Chile: compositional variation of two cogenetic large-volume felsic ignimbrites. Journal of Petrology, 42: 459-486.

Lipman, P.W., 2007. Incremental assembly and prolonged consolidation of Cordilleran magma chambers: Evidence from the Southern Rocky Mountain volcanic field. Geosphere, 3(1):42-70.

Liu, Y., Anderson, A.T., Wilson, C.J.N., Davis, A.M., and Steele, I.M., 2006. Mixing and differentiation in the Oruanui rhyolitic magma, Taupo, New Zealand: evidence from volatiles and trace elements in melt inclusions. Contributions to Mineralogy and Petrology, 151(1): 71-87.

Longhi, J., Walker, D., and Hays, J.F., 1976. Fe and Mg in plagioclase. Proceedings of the $7^{\text {th }}$ Lunar Science Conference, Geochimica et Cosmochimica Acta supplement, 1281-1300.

Lowenstern, J.B., 1993. Evidence for a copper-bearing fluid in magma erupted at the Valley of Ten Thousand Smokes, Alaska. Contributions to Mineralogy and Petrology, 114: 409-421.

Lowenstern, J.B., 2003. Melt Inclusions Come of Age: Volatiles, Volcanoes, and Sorby's Legacy. In: B. De Vivo and R.J. Bodnar (Editors), Melt inclusions in volcanic systems: Methods, applications and problems Developments in Volcanology, 5: 1-21. 
Lowenstern, J.B., Smith, R.B. and Hill, D.P., 2006. Monitoring super-volcanoes: geophysical and geochemical signals at Yellowstone and other large caldera systems. Philosophical Transactions of the Royal Society A: Mathematical, Physical and Engineering Sciences, 364(1845): 20552072.

Luhr, J., 2001. Glass inclusions and melt volatile contents at Parícutin Volcano, Mexico. Contributions to Mineralogy and Petrology, 142(3): 261-283.

Macpherson, C.G., Gamble, J.A., and Mattey, D.P., 1998. Oxygen isotope geochemistry of lavas from an oceanic to continental arc transition, Kermadec-Hikurangi margin, SW Pacific. Earth and Planetary Science Letters, 160(3-4): 609-621.

Martin, E., and Sigmarsson, O., 2007. Crustal thermal state and origin of silicic magma in Iceland: The case of Torfajökull, Ljosufjökull and Snaefellsjökull volcanoes. Contributions to Mineralogy and Petrology, 153: 593-605.

Martin, H., 1987. Petrogenesis of Archaean trondhjemites, tonalites, and granodiorites from eastern Finland: major and trace element geochemistry. Journal of Petrology, 28: 921-953.

Martin, V.M., Morgan, D.J., Jerram, D.A., Caddick, M.J., Prior, D.J., and Davidson, J.P., 2007. Bang! Month-scale eruption triggering at Santorini volcano. Science, 321: 1178.

Mason, B.G., Pyle, D.M., and Oppenheimer, C., 2004. The size and frequency of the largest explosive eruptions on Earth. Bulletin of Volcanology, $66: 735-748$.

Massare, D., Metrich, N. and Clocchiatti, R., 2002. High-temperature experiments on silicate melt inclusions in olivine at $1 \mathrm{~atm}$ : inference on 
temperatures of homogenization and $\mathrm{H}_{2} \mathrm{O}$ concentrations. Chemical Geology, 183: 87-98.

McCulloch, M.T. and Gamble, J.A., 1991. Geochemical and geodynamical constraints on subduction zone magmatism. Earth and Planetary Science Letters, 102: 358-374.

McCulloch, M.T., Kyser, T.K., Woodhead, J.D., and Kinsley, L., 1994. Pb-Sr$\mathrm{Nd}-\mathrm{O}$ isotopic constraints on the origin of rhyolites from the Taupo Volcanic Zone of New Zealand - Evidence for assimilation followed by fractionation from basalt. Contributions to Mineralogy and Petrology, 115(3): 303-312.

McDonough, W.F., and Sun, S.S., 1995. The Composition of the Earth. Chemical Geology, 120(3-4): 223-253.

McKenzie. D., and O'Nions, R.K., 1991. Partial melt distributions from inversion of rare earth element concentrations. Journal of Petrology, 32(5): 10211091.

Miller, C.F. and Wark, D.A., 2008. Supervolcanoes and their explosive supereruptions. Elements, 4(1): 11-15.

Morgan, D.J., and Blake, S., 2006. Magmatic residence times of zoned phenocrysts: introduction and application of the binary element diffusion modelling (BEDM) technique. Contributions to Mineralogy and Petrology, 151: 58-70.

Morgan, D.J., Blake, S., Rogers, N.W., DeVivo, B., Rolandi, G., Macdonald, R., and Hawkesworth, C.J., 2004. Time scales of crystal residence and magma chamber volume from modelling of diffusion profiles in phenocrysts: Vesuvius 1944. Earth and Planetary Science Letters, 222: 933-946. 
Morgan, D.J., Blake, S., Rogers, N.W., DeVivo, B., Rolandi, G., and Davidson, J.P., 2006. Magma chamber recharge at Vesuvius in the century prior to eruption of A.D. 79. Geology, 34: 845-848.

Morse, S.A., 1984. Cation Diffusion in Plagioclase Feldspar. Science, 225(4661): 504-505.

Mortimer, N., 2004. New Zealand's Geological Foundations. Gondwana Research, 7: 261-272.

Mysen, B.O., and Virgo, D., 1980. Trace element partitioning and melt structure: An experimental study at $1 \mathrm{~atm}$ pressure. Geochimica et Cosmochimica Acta, 44(12): 1917-1930.

Nakagawa, M., Wada, K., Thordarson, T., Wood, C.P., and Gamble, J.A., 1999. Petrologic investigations of the 1995 and 1996 eruptions of Ruapehu Volcano, New Zealand: Formation of discrete and small magma pockets and their intermittent discharge. Bulletin of Volcanology, 61: 15-31.

Nakagawa, M., Wada, K., and Wood, C.P., 2002. Mixed magmas, mush chambers and eruption triggers: Evidence from zoned clinopyroxene phenocrysts in andesitic scoria from the 1995 eruptions of Ruapehu Volcano, New Zealand. Journal of Petrology, 43: 2279-2303.

Nash, W.P., and Crecraft, H.R., 1985. Partition coefficients for trace elements in silicic magmas. Geochimica et Cosmochimica Acta, 49(11): 2309-2322.

Nairn, I.A., 1980. Source, age, and eruptive mechanisms of Rotorua Ash. New Zealand Journal of Geology and Geophysics 23: 193-207.

Nairn, I.A., 1992. The Te Rere and Okareka eruptive episodes - Okataina Volcanic Centre, Taupo Volcanic Zone, New Zealand. New Zealand Journal of Geology and Geophysics, 35: 93-108. 
Nairn, I.A., Wood, C.P., and Bailey, R.A., 1994. The Reporoa Caldera, Taupo Volcanic Zone: source of the Kaingaroa Ignimbrite. Bulletin of Volcanology, 56: 529-537.

Nelson, S.T., and Montana, A., 1992. Sieve-textured plagioclase in volcanic rocks produced by rapid decompression. American Mineralogist, $77: 1242-1249$.

Newhall, C.G. and Self, S., 1982. The volcanic explosivity index (VEI): An estimate of explosive magnitude for historical volcanism. Journal of Geophysical Research, 87: 1231-1238.

Newman, S., Stolper, E.M. and Epstein, S., 1986. Measurement of water in rhyolitic glasses: calibration of an infrared spectroscopic technique. American Mineralogist, 71: 1527-1541.

Newman, S., Epstein, S. and Stolper, E., 1988. Water, carbon dioxide, and hydrogen isotopes in glasses from the ca. 1340 A.D. eruption of the Mono Craters, California: Constraints on degassing phenomena and initial volatile content. Journal of Volcanology and Geothermal Research, 35(1-2): 75-96.

Newman, S. and Lowenstern, J.B., 2002. VOLATILECALC: a silicate melt$\mathrm{H}_{2} \mathrm{O}-\mathrm{CO}_{2}$ solution model written in Visual Basic for excel. Computers \& Geosciences, 28: 597-604.

Nichols, A.R.L. and Wysoczanski, R.J., 2007. Using micro-FTIR spectroscopy to measure volatile contents in small and unexposed inclusions hosted in olivine crystals. Chemical Geology, 242(3-4): 371-384.

Nishimura, K., Kawamoto, T., Kobayashi, T., Sugimoto, T., and Yamashita, S., 2005. Melt inclusion analysis of the Unzen 1991-1995 dacite: implications for crystallization processes of dacite magma. Bulletin of Volcanology, 67: 648-662. 
Ochs III, F.A., and Lange, R., 1997. The density of hydrous magmatic liquids. Science, 283: 1314-1317.

Ogawa. Y., Bibby, H.M., Caldwell, T.G., Takakura, S., Uchida, T., Matsushima, N., Bennie, S.L., Tosha, T., and Nishi, Y., 1999. Wide-band magnetotelluric measurements across the Taupo volcanic zone: preliminary results. Geophysical Research Letters, 26: 3673-3676.

Pabst, S., Wörner, G., Civetta, L., and Tesoro, R., 2008. Magma chamber evolution prior to the Campanian Ignimbrite and Neapolitan Yellow Tuff eruptions (Campi Flegrei, Italy). Bulletin of Volcanology, 70: 961-976.

Pallister, J.S., Hoblitt, R.P., and Reyes, A.G., 1992. A basalt trigger for the 1991 eruption of Pinatubo volcano? Nature, 356: 426-428.

Pandya, N., Muenow, D.W. and Sharma, S.K., 1992. The effect of bulk composition on the speciation of water in submarine volcanic glasses. Geochimica et Cosmochimica Acta, 56(5): 1875-1883.

Patterson, D.S., and Graham, I.J., 1988. Petrogenesis of andesitic lavas from Mangatepopo Valley and Upper Tama Lake, Tongariro Volcanic Centre, New Zealand. Journal of Volcanology and Geothermal Research, 35: 1729.

Parson, L.M., and Wright, I.C., 1996. The Lau-Havre-Taupo back-arc basin: a southward-propagating, multi-stage evolution from rifting to spreading. Tectonophysics, 263(1-4): 1-22.

Pearce, J.A., Baker, P.E., Harvey, P.K., and Luff, I.W., 1995. Geochemical evidence for subduction fluxes, mantle melting and fractional crystallization beneath the South Sandwich-Island Arc. Journal of Petrology, 36(4): 1073-1109. 
Pearce, T.H., and Kolisnik, A.M., 1990. Observation of plagioclase zoning using interference imaging. Earth Science Reviews, 29: 9-26.

Portnyagin, M., Almeev, R., Matveev, S. and Holtz, F., 2008. Experimental evidence for rapid water exchange between melt inclusions in olivine and host magma. Earth and Planetary Science Letters, 272: 541-552.

Price, R.C., Gamble, J.A., Smith, I.E.M., Stewart, R.B., Eggins, S., and Wright, I.C., 2005. An integrated model for the temporal evolution of andesites and rhyolites and crustal development in New Zealand's North Island. Journal of Volcanology and Geothermal Research, 140(1-3): 1-24.

Price, R.C., George, R., Gamble, J.A., Turner, S., Smith, I.E.M., Cook, C., Hobden, B., and Dosseto, A., 2007. U-Th-Ra fractionation during crustallevel andesite formation at Ruapehu volcano, New Zealand. Chemical Geology, 244 (3-4): 437-451.

Putirka, K.D., 2005. Igneous thermometers and barometers based on plagioclase + liquid equilibria: Tests of some existing models and new calibrations. American Mineralogist, 90(2-3): 336-346.

Qin, Z., Lu, F. and Anderson, A.T., 1992. Diffusive reequilibration of melt and fluid inclusions. American Mineralogist, 77: 565-576.

Rapp, R.P., and Watson, E.B., 1995. Dehydration melting of metabasalt at 8-32Kbar - implications for continental growth and crust-mantle recycling. Journal of Petrology, 36(4): 891-931.

Reid, F.E., 1982. Geochemistry of Central North Island greywackes and genesis of silicic magmas. $\mathrm{PhD}$ thesis, Victoria University of Wellington, Wellington, 329 pp. 
Reid, F., 1983. Origin of the rhyolitic rocks of the Taupo Volcanic Zone, New Zealand. Journal of Volcanology and Geothermal Research, 15(4): 315338.

Reid, M.R., 2003. Timescales of magma transfer and storage in the crust. In Rudnick, R.L., (editors) The Crust, Treatise on Geochemistry 3, Elsevier, Oxford, pp 167-193.

Reid, M.R., 2008. How Long Does It Take to Supersize an Eruption? Elements, 4(1): 23-28.

Reid, M.R., Coath, C.D., Mark Harrison, T. and McKeegan, K.D., 1997. Prolonged residence times for the youngest rhyolites associated with Long Valley Caldera: ${ }^{230} \mathrm{Th}-{ }^{238} \mathrm{U}$ ion microprobe dating of young zircons. Earth and Planetary Science Letters, 150(1-2): 27-39.

Roedder, E., 1979. Origin and significance of magmatic inclusions. Bulletin of Mineralogy, 102: 487-510.

Ruprecht, P., and Wörner, G., 2007. Variable regimes in magma systems documented in plagioclase zoning patterns: El Misti stratovolcano and Andahua monogenetic cones. Journal of Volcanology and Geothermal Research, 165: 142-162.

Schmitz, M.D., and Smith, I.E.M., 2004. The petrology of the Rotoiti eruption sequence, Taupo Volcanic Zone: an example of fractionation and mixing in a rhyolitic system. Journal of Petrology, 45(10): 2045-2066.

Schmidt, M.W., and Poli, S., 1998. Experimentally based water budgets for dehydrating slabs and consequences for arc magma generation. Earth and Planetary Science Letters, 163: 361-379.

Severs, M.J., Azbej, T., Thomas, J.B., Mandeville, C.W. and Bodnar, R.J., 2007. Experimental determination of $\mathrm{H}_{2} \mathrm{O}$ loss from melt inclusions during 
laboratory heating: Evidence from Raman spectroscopy. Chemical Geology, 237(3-4): 358-371.

Shane, P., Smith, V.C., and Nairn, I.A., 2005. High temperature rhyodacites of the 36 ka Hauparu pyroclastic eruption, Okataina Volcanic Centre, New Zealand: Change in a silicic magmatic system following caldera collapse. Journal of Volcanology and Geothermal Research, 147: 357-376.

Shane, P., Martin, S.B., Smith, V.C., Beggs, K.F., Darragh, M.B., Cole, J.W., and Nairn, I.A., 2007. Multiple rhyolite magmas and basalt injection in the $17.7 \mathrm{ka}$ Rerewhakaaitu eruption episode from Tarawera volcanic complex, New Zealand. Journal of Volcanology and Geothermal Research, 164: 1-26.

Shane, P., Smith, V.C., and Nairn, I., 2008. Millennial timescale resolution of rhyolite magma recharge at Tarawera volcano: insights from quartz chemistry and melt inclusions. Contributions to Mineralogy and Petrology, 156(3): 397-411.

Shaw, H.R., 1972. Viscosities of magmatic silicate liquids; an empirical method of prediction. American Journal of Science, 272(9): 870-893.

Sherburn, S., Bannister, S. and Bibby, H., 2003. Seismic velocity structure of the central Taupo Volcanic Zone, New Zealand, from local earthquake tomography. Journal of Volcanology and Geothermal Research, 122(1-2): 69-88.

Shukuno, H., Tamura, Y., Tani, K., Chang, Q., Suzuki, T., and Fiske, R.S., 2006. Origin of silicic magmas and the compositional gap at Sumisu submarine caldera, Izu-Bonin arc, Japan. Journal of Volcanology and Geothermal Research, 156: 187-216.

Shor, G.G., Kirk, H.K., and Menard, H.W., 1971. Crustal structure of the Melanesian Area. Journal of Geophysical Research, 76: 2562-2586. 
Siebel, W., Schnurr, W.B., Hahne, K., Kraemer, B., Trumbull, R., Van den Bogaard, P., and Emmermann, R., 2000. Geochemistry and isotope systematics of small to medium volume Neogene-Quaternary ignimbrites in the southern central Andes: Evidence for derivation from andesitic magma source. Chemical Geology, 171: 213-237.

Silver, L.A. and Stolper, E., 1985. A thermodynamic model for hydrous silicate melts. Journal of Geology, 93: 161-178.

Silver, L.A., Ihinger, P.D. and Stolper, E., 1990. The influence of bulk composition on the speciation of water in silicate glasses. Contributions to Mineralogy and Petrology, 104: 142-162.

Singer, B.S., Dungan, M.A. and Layne, G.D., 1995. Textures and Sr, Ba, Mg, Fe, $\mathrm{K}$ and $\mathrm{Ti}$ compositional profiles in volcanic plagioclase -clues to the dynamics of calc-alkaline magma chambers. American Mineralogist, 80(7-8): 776-798.

Sisson, T.W. and Bacon, C.R., 1999. Gas-driven filter pressing in magmas. Geology, 27(7): 613-616.

Smith, I.E.M., and Price, R.C., 2006. Tonga-Kermadec arc and Havre-Lau backarc system: their role in the development of tectonic and magmatic models for the western Pacific. Journal of Volcanology and Geothermal Research, 156(3-4): 315-331.

Smith, I.E.M., Worthington, T.J., Stewart, R.B., Price, R.C., and Gamble, J.A., 2003a. Felsic volcanism in the Kermadec Arc, SW Pacific: crustal recycling in an oceanic setting. In: R.D. Larter, P.T. Leat (Editors), IntraOceanic Subduction Systems: Tectonic and Magmatic Processes. Geological Society of London Special Publication 219: 99-118. 
Smith, I.E.M., Stewart, R.B., and Price, R.C., 2003b. The petrology of a large intra-oceanic silicic eruption: the Sandy Bay Tephra, Kermadec Arc, Southwest Pacific. Journal of Volcanology and Geothermal Research, 124: 173-194.

Smith, I.E.M., Worthington, T.J., Price, R.C., Stewart, R.B., and Maas, R., 2006. Petrogenesis of dacite in an oceanic subduction environment: Raoul Island, Kermadec arc. Journal of Volcanology and Geothermal Research, 156(3-4): 252-265.

Smith, R.L., 1979. Ash-flow magmatism. In Chapin, C.E., and Elston, W.E., (Editors), Ash-flow Tuffs. Geological Society of America Special Publication, 180:5-17.

Smith, V.C., Shane, P., and Smith, I.E.M., 2002. Tephrostratigraphy and geochemical fingerprints of the Mangaone subgroup tephra beds, Okataina Volcanic Centre, New Zealand. New Zealand Journal of Geology and Geophysics, 45: 207-219.

Smith, V.C., Shane, P., and Nairn, I.A., 2004. Reactivation of a rhyolitic magma body by new rhyolite intrusion before the 15.8ka Rotorua eruptive episode: implications for magma storage in the Okataina Volcanic Centre, New Zealand. Journal of the Geological Society of London, 161: 757772.

Smith, V.C., Shane, P., Nairn, I.A., and Williams, C.M., 2006. Geochemistry and magmatic properties of eruption episodes from Haroharo linear vent zone, Okataina Volcanic Centre, New Zealand during the last 10 Kyr. Bulletin of Volcanology, 69: 57-88.

Sobolev, A.V., 1996. Melt inclusions in minerals as a source of principle petrological information. Petrology, 4(3): 209-220.

Sobolev, A.V. and Chaussidon, M., 1996. H2O concentrations in primary melts from supra-subduction zones and mid-ocean ridges: Implications for $\mathrm{H} 2 \mathrm{O}$ 
storage and recycling in the mantle. Earth and Planetary Science Letters, 137(1-4): 45-55.

Soengkono, S., 1995. A magnetic model for deep plutonic bodies beneath the central Taupo Volcanic Zone, North Island, New Zealand. Journal of Volcanology and Geothermal Research, 68: 193-207.

Spandler, C., O’Neill, H.St C., Kamenetsky, V.S., 2007. Survival times of anomalous melt inclusions from element diffusion in olivine and chromite. Nature, 447: 303-306.

Sparks, R.S.J., 2003. Dynamics of magma degassing. In, Oppenheimer, C., Pyle, D.M., and Barclay, J. (eds). Volcanic degassing. Geological Society, London, Special Publications, 213(1): 5-22.

Sparks, R.S.J., Self, S., Grattan, J.P., Oppenheimer, C., Pyle, D.M. and Rymer, H., 2005. Supereruptions: global effects and future threats. Report of a Geological Society of London Working Group, The Geological Society of London, 24pp.

Stern, T.A., 1985. A back-arc basin formed within continental lithosphere: the Central Volcanic Region of New Zealand. Tectonophysics, 122: 385-409.

Stern, T.A., 1987. Asymmetric back-arc spreading, heat flux and structure beneath the Central Volcanic Region of New Zealand. Earth and Planetary Science Letters, 85: 265-267.

Stolper, E., 1982. The speciation of water in silicate melts. Geochimica et Cosmochimica Acta, 46(12): 2609-2620.

Stratford, W.R., and Stern, T.A., 2006. Crust and upper mantle structure of a continental backarc: central North Island, New Zealand. Geophysical Journal International, 166(1): 469-484. 
Stratford, W.R., and Stern, T.A., 2008. Geophysical imaging of buried volcanic structures within a continental back-arc basin: the Central Volcanic Region, North Island, New Zealand. Journal of Volcanology and Geothermal Research, 174: 257-268.

Sun, S.S., and McDonough, W.F., 1989. Chemical and isotopic systematics of oceanic basalts: implications for mantle composition and processes. In: A.D. Saunders, M.J. Norry (Editors), Magmatism in Ocean Basins. Geological Society of London Special Publication, 42: 313-345.

Sun, W.D., Binns, R.A., Fan, A.C., Kamenetsky, V.S., Wysoczanski, R., Wei, G.J., Hu, Y.H., and Arculus, R.J., 2007. Chlorine in submarine volcanic glasses from the eastern Manus basin. Geochimica et Cosmochimica Acta, 71: 1542-1552.

Sutton, A.N., Blake, S., and Wilson, C.J.N., 1995. An outline geochemistry of rhyolite eruptives from Taupo Volcanic Centre, New-Zealand. Journal of Volcanology and Geothermal Research, 68(1-3): 153-175.

Sutton, A.N., Blake, S., Wilson, C.J.N., and Charlier, B.L.A., 2000. Late Quaternary evolution of a hyperactive rhyolite magmatic system: Taupo volcanic centre, New Zealand. Journal of the Geological Society, London, 157: 537-552.

Synder, D., 2000. Thermal effects of the intrusion of basaltic magma into a more silicic magmas chamber and implications for eruption triggering. Earth and Planetary Sciences, 175: 257-273.

Takagai, T., Orihashi, Y., Naito, K., and Watanabe, Y. 1999. Petrology of a mantle-derived rhyolite, Hokkaido, Japan. Chemical Geology, 160: 425445. 
Tamura, Y., and Tatsumi, Y., 2002. Remelting of an andesitic crust as a possible origin for rhyolitic magma in oceanic arcs: an example from the IzuBonin Arc. Journal of Petrology, 43(6): 1029-1047.

Tamura, Y., and Wysoczanski, R., 2006. Silicic volcanism and crustal evolution in oceanic arcs: Introduction. Journal of Volcanology and Geothermal Research, 156(3-4): v-vii.

Turner, S. and Costa, F., 2007. Measuring Timescales of Magmatic Evolution. Elements, 3(4): 267-272.

Tuttle, O.F. and Bowen, N.L., 1958. Origin of granite in the light of experimental studies in the system $\mathrm{NaAlSi}_{3} \mathrm{O}_{8}-\mathrm{KASi}_{3} \mathrm{O}_{8}-\mathrm{SiO}_{2}-\mathrm{H}_{2} \mathrm{O}$. Geological Society America Memoir, 74.

Ukstins Peate, I., Baker, J.A., Kent, A.J.R., Al-Kadasi, M., Al-Subbary, A., Ayalew, D., and Menzies, M., 2003. Correlation of Indian Ocean tephra to individual Oligocene silicic eruptions from Afro-Arabian flood volcanism. Earth and Planetary Science Letters, 211: 311-327.

Ukstins Peate, I., Baker, J.A., Al-Kadasi, M., Al-Subbary, A., Knight, K.B., Riisager, P., Thirlwall, M.F., Peate, DW., Renne, P.R., and Menzies, M.A., 2005. Volcanic Stratigraphy of large-volume silicic pyroclastic eruptions during Oligocene Afro-Arabian flood volcanism in Yemen. Bulletin of Volcanology, 68: 135-156.

Ukstins Peate, I., Kent, A.J.R., Baker, J.A., and Menzies, M.A., 2007. Extreme geochemical heterogeneity in Afro-Arabian Oligocene tephras: Preserving fractional crystallization and mafic recharge processes in silicic magma chambers. Lithos, 102: 260-278.

Venezky, D.Y., and Rutherford, M.J., 1999. Petrology and Fe-Ti oxide reequilibration of the 1991 Mount Unzen mixed magma. Journal of Volcanology and Geothermal Research, 89:213-230. 
Waight, T.E., Price, R.C., Stewart, R.B., Smith, I.E.M. and Gamble, J.A., 1999. Stratigraphy and geochemistry of the Turoa area, with implications for andesite petrogenesis at Mt. Ruapheu, Taupo Volcanic Zone, New Zealand. New Zealand Journal of Geology and Geophysics, 42: 513-532.

Wallace, P.J., 2005. Volatiles in subduction zone magmas: concentrations and fluxes based on melt inclusion and volcanic gas data. Journal of Volcanology and Geothermal Research, 140(1-3): 217-240.

Wallace, P.J., Dufek, J., Anderson, A.T. and Zhang, Y., 2003. Cooling rates of Plinian-fall and pyroclastic-flow deposits in the Bishop Tuff: inferences from water speciation in quartz-hosted glass inclusions. Bulletin of Volcanology, 65: 105-123.

Walker Jr., B.A., Miller, C.F., Lowery Claiborne, L., Wooden, J.L., and Miller, J.S., 2007. Geology and geochronology of the Spirit Mountain batholith southern Nevada: Implications for timescales and physical processes of batholith construction. Journal of Volcanology and Geothermal Research, 167: 239-262.

Wark, D.A. and Spear, F.S., 2005. Ti in quartz: Cathodoluminescence and thermometry. Geochimica et Cosmochimica Acta, 69: A592.

Wark, D.A., and Watson, E.B., 2006. TitaniQ: A titanium-in-quartz geothermometer. Contributions to Mineralogy and Petrology, 152: 743754.

Wark, D.A., Hildreth, W., Spear, F.S., Cherniak, D.J., and Watson, E.B., 2007. Pre-eruption recharge of the Bishop magma system. Geology, 35(3): 235238. 
Watson, E.B., and Green, T.H., 1981. Apatite/liquid partition coefficients for the rare earth elements and strontium. Earth and Planetary Science Letters, 56: 405-421.

Wiebe, R.A., Wark, D.A., and Hawkins, D.P., 2007. Insights from quartz cathodoluminescence zoning into crystallisation of the Vinalhaven granite, coastal Maine. Contributions to Mineralogy and Petrology, 154: 439-453.

Wilke, M., and Behrens, H., 1999. The dependence of the partitioning of iron and europium between plagioclase and hydrous tonalitic melt on oxygen fugacity. Contributions to Mineralogy and Petrology, 137: 102-114.

Wilson, C.J.N., 2001. The 26.5 ka Oruanui eruption, New Zealand: an introduction and overview. Journal of Volcanology and Geothermal Research, 112: 133-174.

Wilson, C.J.N., and Walker, G.P.L., 1985. The Taupo Eruption, New Zealand: 1. General aspects. Philosophical Transactions of the Royal Society of London Series A: Mathematical, Physical and Engineering Sciences, 134(1529): 199-228.

Wilson, C.J.N., Rogan, A.M., Smith, I.E.M., Northey, D.J., Nairn, I.A., and Houghton, B.F., 1984. Caldera volcanoes of the Taupo Volcanic Zone, New Zealand. Journal of Geophysical Research, 89 (B10): 8463-8484.

Wilson, C.J.N., Houghton, B.F., and Lloyd, E.F., 1986. Volcanic history and evolution of the Maroa-Taupo area central North Island. In: I.E.M. Smith (Editor), Late Cenozoic volcanism in New Zealand. Royal Society of New Zealand Bulletin, pp. 194-223.

Wilson, C.J.N., Houghton, B.F., McWilliams, M.O., Lanphere, M.A., Weaver, S.D., and Briggs, R.M., 1995. Volcanic and structural evolution of Taupo Volcanic Zone, New Zealand: a review. Journal of Volcanology and Geothermal Research, 68: 1-28. 
Wilson, C.J.N., Blake, S., Charlier, B.L.A., and Sutton, A.N., 2006. The 26.5 ka Oruanui eruption, Taupo volcano, New Zealand: development, characteristics and evacuation of a large rhyolitic magma body. Journal of Petrology, 47(1): 34-69.

Wilson, C.J.N., Gravley, D.M., Leonard, G.S. and Rowland, J.V., in press. Volcanism in the central Taupo Volcanic Zone, New Zealand: tempo, styles and controls, Studies in Volcanology: The Legacy of George Walker. The Geological Society of London, London.

Wilson, L., 1980. Relationships between pressure, volatile content and ejecta velocity in three types of volcanic explosion. Journal of Volcanology and Geothermal Research, 8(2-4): 297-313.

Wolf, M.B., and Wyllie, P.J., 1994. Dehydration-melting of amphibolite at 10 Kbar - the effects of temperature and time. Contributions to Mineralogy and Petrology, 115(4): 369-383.

Woodhead, J., Eggins, S.M., and Gamble, J., 1993. High-field strength and transition element systematics in island-arc and back-arc basin basalts: evidence for multiphase melt extraction and depleted mantle wedge. Earth and Planetary Science Letters, 144(4): 491-504.

Woodhead, J.D., Eggins, S.M., and Johnson, R.W., 1998. Magma genesis in the New Britain island arc: further insights into melting and mass transfer processes. Journal of Petrology, 39(9): 1641-1668.

Wright, I.C., 1994. Nature and tectonic setting of the southern Kermadec submarine arc volcanoes: an overview. Marine Geology, 118(3-4): 217236. 
Wright, I.C., and Gamble, J.A., 1999. Southern Kermadec submarine caldera arc volcanoes (SW Pacific): caldera formation by effusive and pyroclastic eruption. Marine Geology, 161: 207-227.

Wright, I.C., Stoffers, P., Hannington, M., de Ronde, C.E.J., Herzig, P., Smith, I.E.M., and Browne, P.R.L., 2002. Towed-camera investigations of shallow-intermediate water-depth submarine stratovolcanoes of the southern Kermadec arc, New Zealand. Marine Geology, 185(3-4): 207218.

Wright, I.C., Gamble, J.A., and Shane, P.A.R., 2003. Submarine silicic volcanism of the Healy caldera, southern Kermadec arc (SW Pacific): I volcanology and eruption mechanisms. Bulletin of Volcanology, 65(1): $15-29$.

Wright, I.C., Worthington, T.J., and Gamble, J.A., 2006. New multibeam mapping and geochemistry of the $30^{\circ}-35^{\circ} \mathrm{S}$ sector, and overview, of southern Kermadec arc volcanism. Journal of Volcanology and Geothermal Research, 149: 263-296.

Wysoczanski, R.J., and Tani, K., 2006. Spectroscopic FTIR imaging of water species in silicic volcanic glasses and melt inclusions: an example from the Izu-Bonin arc. Journal of Volcanology and Geothermal Research, 156(3-4): 302-314.

Wysoczanski, R.J., Wright, I.C., Gamble, J.A., Hauri, E.H., Luhr, J.F., Eggins, S.M., and Handler, M.R., 2006. Volatile contents of Kermadec ArcHavre Trough pillow glasses: fingerprinting slab-derived aqueous fluids in the mantle sources of arc and back-arc lavas. Journal of Volcanology and Geothermal Research, 152(1-2): 51-73.

Wysoczanski, R.J., Todd, E., Wright, I.C., Leybourne, M., Hergt, J.M., Adam, C., and Mackay, K., in press. Backarc rifting, constructional volcanism 
and possible nascent spreading in the southern Havre Trough backarc rifts (SW Pacific). Journal of Volcanology and Geothermal Research.

$\mathrm{Xu}, \mathrm{Z}$. and Zhang, Y., 2002. Quench rates in air, water, and liquid nitrogen, and inference of temperature in volcanic eruption columns. Earth and Planetary Science Letters, 200(3-4): 315-330.

Yoder, H., S., Jr, Stewart, D., B., and Smith, J., R.. 1957. Ab-An- $\mathrm{H}_{2} \mathrm{O}$, An-Or$\mathrm{H}_{2} \mathrm{O}$, and $\mathrm{Ab}-\mathrm{Or}-\mathrm{H}_{2} \mathrm{O}$ at 5000 bars. Geological Society of American Bulletin, 68(12): 1815.

Yokoyama, T., Okumura, S. and Nakashima, S., 2007. Hydration of rhyolitic glass during weathering as characterised by IR microscpectroscopy. Geochimica et Cosmochimica Acta, 72: 117-125.

Zellmer, G.F., Blake, S., Vance, D., Hawkesworth, C. and Turner, S., 1999. Plagioclase residence times at two island arc volcanoes (Kameni Islands, Santorini, and Soufriere, St. Vincent) determined by $\mathrm{Sr}$ diffusion systematics. Contributions to Mineralogy and Petrology, 136(4): 345-357.

Zellmer, G.F., Sparks, R.S.J., Hawkesworth, C.J. and Wiedenbeck, M., 2003. Magma emplacement and remobilization timescales beneath Montserrat: Insights from $\mathrm{Sr}$ and $\mathrm{Ba}$ zonation in plagioclase phenocrysts. Journal of Petrology, 44(8): 1413-1431.

Zhang, X., Zhang, H-F., Tang, Y-J., Wilde, S.A., and Hu, Z., 2008. Geochemistry of Permian bimodal volcanic rocks from central Inner Mongolia, North China: Implications for tectonic setting and Phanerozoic continental growth in central Asian Orogenic Belt. Chemical Geology, 249: 262-283.

Zhang, Y., 1994. Reaction kinetics, geospeedometry, and relaxation theory. Earth and Planetary Science Letters, 122: 373-391. 
Zhang, Y., 1999. $\mathrm{H}_{2} \mathrm{O}$ in rhyolitic glasses and melts: measurement, speciation, solubility and diffusion. Reviews of Geophysics, 37: 493-516.

Zhang, Y., 2007. Silicate melt properties and volcanic eruptions. Reviews of Geophysics, 45: RG4004

Zhang, Y., Stolper, E.M. and Wasserburg, G.J., 1991. Diffusion of water in rhyolitic glasses. Geochimica et Cosmochimica Acta, 55(2): 441-456.

Zhang, Y., Stolper, E.M. and Ihinger, P.D., 1995. Kinetics of the reaction $\mathrm{H}_{2} \mathrm{O}+$ $\mathrm{O}=2 \mathrm{OH}$ in rhyolitic and albitic glasses: Preliminary results. American Mineralogist, 80: 593-612.

Zhang, Y., Jenkins, J. and Xu, Z., 1997a. Kinetics of the reaction $\mathrm{H}_{2} \mathrm{O}+\mathrm{O}-->2$ $2 \mathrm{OH}$ in rhyolitic glasses upon cooling: Geospeedometry and comparison with glass transition. Geochimica et Cosmochimica Acta, 61(11): 21672173.

Zhang, Y., Belcher, R., Ihinger, P.D., Wang, L., Xu, Z., and Newman, S., 1997 b. New calibration of infrared measurement of dissolved water in rhyolitic glasses. Geochimica et Cosmochimica Acta, 61(15): 3089-3100.

Zhang, Y., Xu, Z. and Behrens, H., 2000. Hydrous species geospeedometer in rhyolite: improved calibration and application. Geochimica et Cosmochimica Acta, 64(19): 3347-3355.

Zhang, Y., Xu, Z. and Wang, H., 2007. Silicate melt properties and volcanic eruptions. Reviews of Geophysics, 45: RG4004.

Zindler, A., and Hart, S., 1986. Chemical geodynamics. Annual Reviews of Earth and Planetary Sciences, 14: 493-571. 


\section{Appendix 1}

\section{Samples and Analytical Methods}

This appendix documents all information pertaining to analysed samples and analytical methods.

\section{A1.1 Fieldwork and Samples}

Samples were collected from the Taupo Volcanic Zone in April 2006. Whole rock ignimbrite, pumice and lavas samples were collected (Table A1.1). A thorough thin section examination revealed the presence or absence of suitable crystals hosting melt inclusions and zoned crystals permitting the samples used in this study to be selected. Individual pumice samples were preferred as synand post- eruptive processes can alter the groundmass, obscuring the original magmatic processes (e.g. Hildreth, 1981; Brown et al., 1998). However, in the more highly welded ignimbrite units (e.g. Whakamaru), separation of pumices could not be achieved for all samples and whole rock ignimbrite samples were obtained and analysed. As this study focused on mineral specific processes it was not as critical to sample individual pumices, but this was preferred where possible.

Dr. Ian Wright from the National Institute of Water and Atmospheric Research (NIWA), presently at the University of Southampton, UK generously provided offshore samples from Healy seamount (Table A1.1). These samples were dredged during a cruise in February 1996 by the RV Tangaroa (Wright and Gamble 1999). 
Appendix 1

\begin{tabular}{|c|c|c|c|c|c|c|c|c|}
\hline $\begin{array}{c}\text { Field } \\
\text { Number }\end{array}$ & $\begin{array}{c}\text { Sample } \\
\text { Number }\end{array}$ & Unit & Latitude & Longitude & $\begin{array}{c}\text { Elevation } \\
(\mathrm{m})\end{array}$ & Brief Description & $\begin{array}{c}\text { Collection } \\
\text { date }\end{array}$ & Volcanic Centre \\
\hline KS 1 & TA1 & Taupo Ignimbrite & $\mathrm{S} 39^{\circ} 13.092^{\prime}$ & E $175^{\circ} 44.115^{\prime}$ & 922 & crystal lag from base of ignimbrite & $08 / 04 / 2006$ & Taupo \\
\hline KS 2 & TA2 & Taupo Ignimbrite & $\mathrm{S} 39^{\circ} 13.092^{\prime}$ & E $175^{\circ} 44.115^{\prime}$ & 922 & pumice from ignimbrite & $08 / 04 / 2006$ & Taupo \\
\hline KS 3 & & Mamaku Ignimbrite & $\mathrm{S} 38^{\circ} 03.343^{\prime}$ & E $176^{\circ} 25.729^{\prime}$ & & welded ignimbrite & $09 / 04 / 2006$ & Rotorua \\
\hline KS 5 & RA1 & Rotorua Ash & $\mathrm{S} 38^{\circ} 10.338^{\prime}$ & E $176^{\circ} 19.765^{\prime}$ & & pumice and lapilli & $09 / 04 / 2006$ & Rotorua \\
\hline KS 6 & RA2 & Rotorua Ash & S $38^{\circ} 10.327^{\prime}$ & E $176^{\circ} 19.716^{\prime}$ & & pumice and lapilli above KS 5 in sequence & $09 / 04 / 2006$ & Rotorua \\
\hline KS 7 & RA3 & Rotorua Ash & $\mathrm{S} 38^{\circ} 10.338^{\prime}$ & E $176^{\circ} 19.765^{\prime}$ & & crystal rich layer within airfall deposits & $09 / 04 / 2006$ & Rotorua \\
\hline KS 8 & & Rhyolite dome, Okataina caldera & $\mathrm{S} 38^{\circ} 10.338^{\prime}$ & E $176^{\circ} 19.765^{\prime}$ & & rhyolite & 09/04/2006 & Okataina \\
\hline KS 9 & WH3 & Whakamaru Ignimbrite & $\mathrm{S} 38^{\circ} 20.953^{\prime}$ & E $175^{\circ} 44.034^{\prime}$ & 250 & crystal rich ignimbrite (top) & $09 / 04 / 2006$ & Whakamaru \\
\hline KS 10 & & Whakamaru Ignimbrite & $\mathrm{S} 38^{\circ} 20.911^{\prime}$ & E $175^{\circ} 43.955^{\prime}$ & 237 & crystal rich ignimbrite & $09 / 04 / 2006$ & Whakamaru \\
\hline KS 11 & WH4 & Whakamaru Ignimbrite & S $38^{\circ} 20.782^{\prime}$ & E $175^{\circ} 44.033^{\prime}$ & 246 & crystal rich ignimbrite & $09 / 04 / 2006$ & Whakamaru \\
\hline KS 12 & WH5 & Whakamaru Ignimbrite & $\mathrm{S} 38^{\circ} 20.782^{\prime}$ & E $175^{\circ} 44.033^{\prime}$ & 246 & crystal rich ignimbrite & $09 / 04 / 2006$ & Whakamaru \\
\hline KS 13 & WH6 & Whakamaru Ignimbrite & S $38^{\circ} 20.737^{\prime}$ & E $175^{\circ} 44.110^{\prime}$ & 211 & crystal rich ignimbrite & $09 / 04 / 2006$ & Whakamaru \\
\hline KS 14 & WH7 & Whakamaru Ignimbrite & S $38^{\circ} 20.799^{\prime}$ & E $175^{\circ} 44.144^{\prime}$ & 198 & crystal rich ignimbrite & $09 / 04 / 2006$ & Whakamaru \\
\hline KS 15 & & Whakamaru Ignimbrite & S $38^{\circ} 20.813^{\prime}$ & E $175^{\circ} 44.151^{\prime}$ & 183 & crystal rich ignimbrite (welded) & $09 / 04 / 2006$ & Whakamaru \\
\hline KS 16 & WH2 & Whakamaru Ignimbrite & $\mathrm{S} 38^{\circ} 20.849^{\prime}$ & E $175^{\circ} 44.206^{\prime}$ & 170 & crystal rich ignimbrite (highly welded) (base) & $09 / 04 / 2006$ & Whakamaru \\
\hline KS 17 & & Poihipi Rd Obsidian & $\mathrm{S} 38^{\circ} 35.154^{\prime}$ & E $175^{\circ} 57.286^{\prime}$ & 658 & obsidian & $10 / 04 / 2006$ & \\
\hline KS 21a & OR1 & Oruanui Ignimbrite & $\mathrm{S} 38^{\circ} 35.840^{\prime}$ & E $175^{\circ} 58.685^{\prime}$ & 611 & pumice & $10 / 04 / 2006$ & Taupo \\
\hline KS 21b & OR2 & Oruanui Ignimbrite & $\mathrm{S} 38^{\circ} 35.840^{\prime}$ & E $175^{\circ} 58.685^{\prime}$ & 611 & ash matrix & $10 / 04 / 2006$ & Taupo \\
\hline KS 24 & & Tauhara Dacite & $\mathrm{S} 38^{\circ} 40.790^{\prime}$ & E $176^{\circ} 10.865^{\prime}$ & 591 & dacite & $10 / 04 / 2006$ & \\
\hline KS 25 & & Taupo Plinian & $\mathrm{S} 38^{\circ} 42.520^{\prime}$ & E $176^{\circ} 07.330^{\prime}$ & 412 & pumice & $11 / 04 / 2006$ & Taupo \\
\hline KS 26 & & Taupo Plinian & S $38^{\circ} 43.026^{\prime}$ & E $176^{\circ} 09.820^{\prime}$ & 584 & pumice & $11 / 04 / 2006$ & Taupo \\
\hline KS 27 & TA3 & Taupo Plinian & S $38^{\circ} 55.772^{\prime}$ & E $176^{\circ} 29.255^{\prime}$ & 711 & airfall deposit & $11 / 04 / 2006$ & Taupo \\
\hline KS 28 & & Taupo Plinian (crystal lag) & S $38^{\circ} 55.772^{\prime}$ & E $176^{\circ} 29.255^{\prime}$ & 711 & crystal lag & $11 / 04 / 2006$ & Taupo \\
\hline KS 29 & TA4 & Hatepe Plinian & $\mathrm{S} 38^{\circ} 55.772^{\prime}$ & E $176^{\circ} 29.255^{\prime}$ & 711 & airfall deposit & $11 / 04 / 2006$ & Taupo \\
\hline KS 30 & & Rangitaiki Ignimbrite & S $38^{\circ} 57.016^{\prime}$ & E $176^{\circ} 31.020^{\prime}$ & 692 & welded ignimbrite & $11 / 04 / 2006$ & Whakamaru \\
\hline WH & WH1 & Whakamaru Ignimbrite & $\mathrm{S} 38^{\circ} 21.005^{\prime}$ & E $175^{\circ} 42.037^{\prime}$ & & crystal lag from basal layer & $04 / 2005$ & Whakamaru \\
\hline X590 & X590 & Healy Volcano & S $34^{\circ} 59.249^{\prime}$ & E $178^{\circ} 59.573^{\prime}$ & $1638-1658$ & pumice & $05 / 02 / 1996$ & Healy \\
\hline $\mathrm{X} 590 / \mathrm{B}$ & $\mathrm{X} 590 / \mathrm{B}$ & Healy Volcano & S $34^{\circ} 59.249^{\prime}$ & E $178^{\circ} 59.573^{\prime}$ & $1638-1658$ & pumice & $05 / 02 / 1996$ & Healy \\
\hline X609 & X609 & Healy Volcano & $\mathrm{S} 34^{\circ} 57.490^{\prime}$ & E $179^{\circ} 00.522^{\prime}$ & $1719-1724$ & pumice with mafics & 07/02/1996 & Healy \\
\hline $\mathrm{X} 612 / \mathrm{B}$ & & Healy Volcano & $\mathrm{S} 34^{\circ} 58.288^{\prime}$ & E $179^{\circ} 02.549^{\prime}$ & $1480-1551$ & grey pumice with flatten fiamme & $07 / 02 / 1996$ & Healy \\
\hline $\mathrm{X} 612 / \mathrm{C}$ & & Healy Volcano & $\mathrm{S} 35^{\circ} 01.172^{\prime}$ & E $178^{\circ} 57.509^{\prime}$ & $1480-1551$ & grey pumice & $07 / 021996$ & Healy \\
\hline
\end{tabular}

Table A1.1. Summary of samples collected for this study. Elevation for Healy samples represents the water depths at the beginning and end of each sample dredge. 


\section{A1.2 Sample preparation}

Blocks of pumice were coarsely crushed using a mortar and pestle and dry sieved to extract material finer than $1 \mathrm{~mm}$. Pumice was floated off by washing with water and the remaining material dried for $12-24$ hours at $40{ }^{\circ} \mathrm{C}$. Crystal lag, matrix material and crushed samples were further sieved into $1 \mathrm{~mm}-710 \mu \mathrm{m}$, $710-500 \mu \mathrm{m}$ and $<500 \mu \mathrm{m}$ fractions and magnetically separated on a Frantz magnetic separator.

\section{A1.2.1 Melt inclusions}

Of the initial six Taupo Volcanic Zone rhyolitic eruptions (Mamaku ignimbrite; Rotorua eruptive; Whakamaru ignimbrite; Rangitaiki ignimbrite; Oruanui ignimbrite; Taupo ignimbrite) sampled and processed for melt inclusions only the Rotorua eruptive, Whakamaru and Oruanui ignimbrites and Taupo samples contained melt inclusions suitable for analysis.

Quartz, plagioclase and orthopyroxene crystals containing the largest melt inclusions were hand picked under a binocular microscope from the $1 \mathrm{~mm}-710$ $\mu \mathrm{m}$ size fraction and the $710-500 \mu \mathrm{m}$ size fraction in the extremely crystal sparse samples. Melt inclusions were exposed by placing a single phenocryst in crystal bond cement on a glass slide and then grinding using 600, 2400 and 4000 grit silicon carbide paper, until the inclusion became exposed. Crystals containing exposed melt inclusions were then removed and washed in acetone to eliminate any excess crystal bond, mounted in epoxy blocks and finely polished using $3 \mu \mathrm{m}$ and $1 / 4 \mu \mathrm{m}$ diamond paste. Melt inclusions that were analysed for $\mathrm{H}_{2} \mathrm{O}$ and $\mathrm{CO}_{2}$ after major element analysis and were removed from the epoxy 
mounts with a fine tip soldering iron. Crystals were washed in acetone, remounted in crystal bond and the parallel surface polished as above. This obtained parallel polished exposed surfaces of the melt inclusions allowing for analysis for $\mathrm{H}_{2} \mathrm{O}$ and $\mathrm{CO}_{2}$ by Fourier transform infrared (FTIR) spectrometry. Transmitted and reflected light photos of each crystal were obtained prior to chemical analysis and used for identification purposes throughout.

\section{A1.2.2 Crystals}

Quartz, plagioclase, orthopyroxene and Fe-Ti oxides were hand picked from the $1 \mathrm{~mm}-710 \mu \mathrm{m}$ size fraction under a binocular microscope. Approximately 15 - 25 crystals were mounted in semi-circular epoxy mounts from each sample. Centres of the crystals were exposed by grinding the epoxy blocks with 600 , 2400 and 4000 grit silicon carbide paper and polished using $3 \mu \mathrm{m}$ and $1 / 4 \mu \mathrm{m}$ diamond paste. Thick polished sections $(100 \mu \mathrm{m})$ of Whakamaru samples were also prepared for plagioclase analyses. These thick sections were examined under a petrographic microscope to identify the most suitable plagioclase crystals and to determine whether the crystals appear in equilibrium with the surrounding phases and groundmass. Crystals were marked with Indian ink for easy identification during electron microprobe analysis. Transmitted light photos and backscattered images of crystals were obtained prior to analysis.

\section{A1.3 Electron microprobe microanalysis}

Major elements were determined on the JEOL 733 SuperProbe Electron Probe Microanalyser (EPMA) using three wavelength dispersive spectrometers at the Analytical Facility, Victoria University of Wellington. Thallium acid phthalate 
(TAP), Pentaerythritol (PET) and Lithium fluoride (LIF) crystals were utilised in spectrometers 1, 2 and 3, respectively. Prior to analysis samples were coated with a $25 \mathrm{~nm}$ thick layer of carbon. The carbon coat was removed from the epoxy mounts by ethanol post EPMA analyses and then dried in air prior to laser ablation inductively coupled plasma mass spectrometry analyses. Operating conditions were $15 \mathrm{kV}, 8 \mathrm{nA}$, and a $10 \mu \mathrm{m}$ defocused beam for melt inclusions and glass adhered to the exterior of crystals, $15 \mathrm{kV}, 12 \mathrm{nA}$ and a focused beam for quartz and Fe-Ti oxide analyses and $15 \mathrm{kV}, 12 \mathrm{nA}$ and a $10 \mu \mathrm{m}$ defocused beam for plagioclase analyses. Primary calibrations were performed daily to optimise operating conditions using a mixture of natural and synthetic standards prior to analysis (Table A1.2). Counting times were optimised for each element for each sample analysed. ZAF corrections were applied to all data (Bence and Albee, 1968).

\begin{tabular}{llccc}
\hline Oxide & $\begin{array}{c}\text { Internal calibration } \\
\text { standard }\end{array}$ & \multicolumn{2}{c}{ Counting time (s) } & Crystal \\
& & $\mathrm{BG}(+/-)$ & Peak & \\
\hline $\mathrm{SiO}_{2}$ & Wollastonite & 10 & 30 & TAP \\
$\mathrm{TiO}_{2}$ & Synthetic $\mathrm{TiO}_{2}$ & 10 & 30 & PET \\
$\mathrm{Al}_{2} \mathrm{O}_{3}$ & Synthetic $\mathrm{Al}_{2} \mathrm{O}_{3}$ & 10 & 30 & TAP \\
$\mathrm{FeO}$ & Synthetic $\mathrm{Fe}_{2} \mathrm{O}_{3}$ & 10 & 30 & LIF \\
$\mathrm{MnO}$ & Synthetic $\mathrm{MnO}_{\mathrm{MgO}}$ & 10 & 30 & LIF \\
$\mathrm{CaO}$ & Synthetic $\mathrm{MgO}$ & 10 & 30 & TAP \\
$\mathrm{Na}$ & Wollastonite & 10 & 30 & PET \\
$\mathrm{K}_{2} \mathrm{O}$ & Jadeite & 5 & 10 & TAP \\
$\mathrm{P}_{2} \mathrm{O}_{5}$ & Orthoclase & 5 & 10 & PET \\
$\mathrm{SO}_{3}$ & Apatite & 10 & 30 & PET \\
$\mathrm{Cl}$ & Celestine & 10 & 30 & PET \\
\hline
\end{tabular}

Table A1.2. Typical operating conditions for EPMA analysis of melt inclusions indicating counting times, internal standard and crystal each element was analysed with. $\mathrm{BG}=$ background count times. 
$\mathrm{Na}$ and $\mathrm{K}$ had a short count time of 5 seconds and were run first to minimised volatile lost during glass analyses. For Ti analyses of quartz, Ti was analysed with count times of 120 seconds on background and 240 seconds on peak.

Secondary standards were run at the beginning and end of each session to monitor for instrumental drift and to normalize results between each analytical session. Secondary standards used were the Smithsonian standards basaltic glass VG2 (USNM 111240/52) for major elements and scapolite (USNM R-600-1) for $\mathrm{Cl}$ and $\mathrm{SO}_{3}$ analyses of melt inclusions, basaltic glass VG-A99 (USNM 113498/1) for plagioclase analyses, ilmenite (USNM 96189) for Fe-Ti oxide analyses (Jarosewich et al., 1980), and comenditic glass (obsidian, KN18) for Ti analyses of quartz (S. Malik and D.A. Bungard as reported in Devine et al., 1995) (Table A1.3).

\begin{tabular}{lccccc}
\hline Oxide $\left(\mathrm{wt}^{*} \%\right)$ & $\mathrm{VG} 2$ & Scapolite & VG-A99 & KN18 & Ilmenite \\
\hline $\mathrm{SiO}_{2}$ & $50.81^{*}$ & 49.78 & $50.9^{*}$ & $74.6^{*}$ & \\
$\mathrm{TiO}_{2}$ & $1.85^{*}$ & & 4.06 & $0.18^{*}$ & $45.7^{*}$ \\
$\mathrm{Al}_{2} \mathrm{O}_{3}$ & $14.06^{*}$ & 25.05 & $12.4^{*}$ & 10.53 & \\
$\mathrm{FeO}$ & $11.84^{*}$ & 0.17 & $13.3^{*}$ & 3.45 & $46.5^{*}$ \\
$\mathrm{MgO}$ & $0.22^{*}$ & & $5.08^{*}$ & 0.01 & $0.31^{*}$ \\
$\mathrm{MnO}$ & $6.71^{*}$ & & 0.15 & 0.06 & $4.77^{*}$ \\
$\mathrm{CaO}$ & $11.12^{*}$ & 13.58 & $9.3^{*}$ & 0.15 & \\
$\mathrm{Na} \mathrm{N}_{2} \mathrm{O}$ & $2.62^{*}$ & 5.20 & $2.66^{*}$ & 5.68 & \\
$\mathrm{~K}_{2} \mathrm{O}$ & $0.19^{*}$ & 0.94 & $0.82^{*}$ & 4.39 & \\
$\mathrm{SO}_{3}$ & & $1.32^{*}$ & & & \\
$\mathrm{Cl}$ & & $1.43^{*}$ & & 0.37 & \\
$\mathrm{Total}^{\mathrm{Tabl}}$ & 99.42 & 97.47 & 98.71 & 99.42 & 92.5 \\
\hline
\end{tabular}

Table A1.3. Reference values of secondary standards used in EPMA analyses. Elements used for normalisation are denoted by *. Sources: VG-A99, VG2, scapolite, ilmenite standard from Jarosewich et al. (1980) and KN18 obsidian glass from S. Malik and D.A. Bungard as reported in Devine et al. (1995). 
A typical example of the precision and accuracy of EPMA data is shown in Table A1.4 for the analysis of the basalt glass standard A99 prior to the analysis of Whakamaru plagioclase.

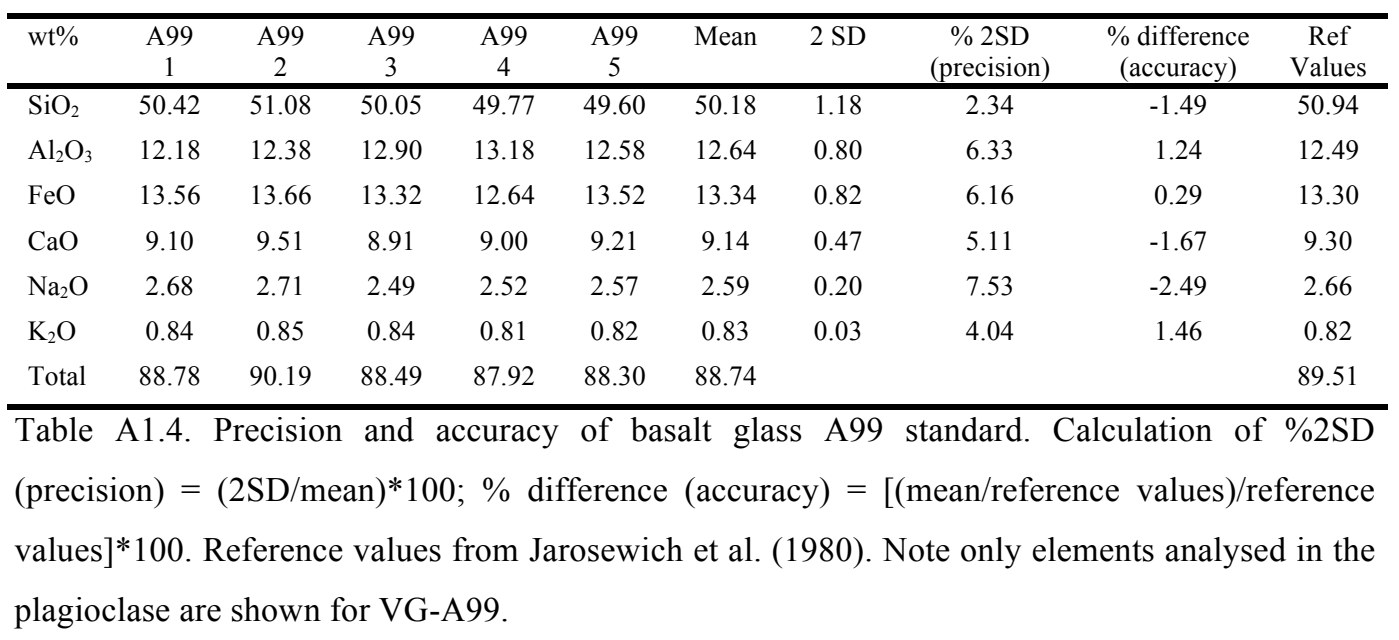

Backscattered electron images of crystals and melt inclusions as appropriate were obtained prior to analysis at the same analytical conditions with a focus beam. Cathodoluminescence (CL) images of quartz crystals were obtained using a photomultiplier attached to the electron microprobe at $12 \mathrm{nA}$ and $15 \mathrm{kV}$. This setup to obtain CL images is a homemade addition to the VUW EPMA by John Patterson. It consists of a tubular adaptor with a perspex light pipe mounted in place of the optical microscope. This connects the optical window on the column directly to the photomultiplier of the secondary electron detector, which allows light emitted from the sample to be detected and a CL image obtained. 


\section{A1.4 Laser ablation inductively coupled plasma mass spectrometry}

\section{A1.4.1 Introduction}

The Geochemical Laboratory at Victoria University of Wellington (VUW), was newly established in 2006 and houses an Agilent 7500cs inductively coupled plasma mass spectrometry (ICPMS) coupled to a NewWave deep UV laser (193 $\mathrm{nm}$ solid state) permitting the laser ablation inductively coupled plasma mass spectrometry (LA-ICPMS) analyses of samples. Prior to analysis of samples it was essential to establish a technique suitable for the analysis of basaltic and rhyolitic glasses in this new laboratory. This consisted of running analyses of well-characterised reference materials until the elemental concentrations were reproduced to a high degree of accuracy and precision. The initial part of the technique development is presented here and was conducted together with Joel Baker, Martin Schiller, Aidan Allan and Sophie Barton.

\section{A1.4.2 Operating conditions, setup and problems of LA-ICPMS analyses}

Several important analytical factors may influence the quality of the data attained by LA-ICPMS analyses and these are highlighted below. For an in-depth review of LA-ICPMS the reader is referred to Durrant (1999), Sylvester (2001), Heinrich et al. (2003) and Günther and Hattendorf (2005).

\section{A1.4.2.1 Carrier gas}

An important factor controlling the amount of ablated material removed from the ablation cell and transported to the ICPMS during analysis is the composition of the carrier gas, as this influences the amount and size of particles removed and 
the path flow through the ablation cell (e.g. Horn and Günther, 2003). For example, ablation in He generates more small particles resulting in an increase in sensitivity recorded by ICPMS analyses compared to when Ar is used solely as the carrier gas (Horn and Günther, 2003). Consequently, a He-Ar mixture was utilised during ablation and for transportation of ablated material to the ICPMS during this study.

\section{A1.4.2.2 Ablation cell volume}

Previous studies have noted that a reduction in volume of the ablation cell is beneficial as it minimises the available area over which ablated material can be dispersed, increasing the chances of material being transported to the ICPMS and also reducing the time required for the flushing of cells between analyses (e.g. Košler and Sylvester, 2003).

\section{A1.4.2.3 Elemental fractionation during transport}

Refractory and volatile elements behave differently during ablation and transport and may become fractionated (Outridge et al., 1997). Decreasing the spot size affects the diameter/depth ratio of the resulting laser pit. At smaller spot sizes the ablation pit becomes deeper compared to its width limiting the amount of ablated material that can escape and subsequently be transported to the ICPMS. This effect is most pronounced when ablating refractory elements such as $\mathrm{Sr}$ and $\mathrm{U}$ compared to more volatile elements such as $\mathrm{Rb}$ or $\mathrm{Pb}$ (Günther and Hattendorf, 2005). The proportion of elemental fractionation can be monitored by observing volatile/refractory element ratios such as $\mathrm{Rb} / \mathrm{Sr}$ or $\mathrm{Pb} / \mathrm{U}$ during ablation (Günther and Hattendorf, 2005). 


\section{A1.4.2.4 Interferences}

Interferences which occur when the analytical signal of an isotope is either enhanced or suppressed due to the occurrence of another element having the same isotopic mass, are one of the greatest limitations of LA-ICPMS analyses (Mason, 2001; Kent and Ungerer, 2005). With a quadruple ICPMS only a single unit mass can be analysed at a time, so all ions or molecules that are present with the same mass/charge ratio are measured simultaneously (Mason, 2001). This can lead to inaccurate determinations of the elemental concentrations of a sample. Interferences are caused by: (1) the overlap of two elements having naturally occurring isotopes of the same mass; (2) isobaric interferences caused by the ionization of molecular species such as oxygen and argon; and (3) doubly charged ions (Mason, 2001; Kent and Ungerer, 2005). Potential interferences that may affect each element analysed are shown in Table A1.5 and the justification for each isotope analysed in this study are given in Table A1.6.

Oxygen is a major constituent of the studied samples and isobaric interferences arise when the ablated ions combine with molecular species, (e.g. oxygen and argon) derived from the sample matrix, plasma or entrainment of atmospheric gases through the system to form polyatomic ion species (Kent and Ungerer, 2005). The maximum oxide production rate at a given plasma condition can be determined by monitoring the strongest known bond for oxides, the Th-O bond (Kent and Ungerer, 2005). The affect of oxide interferences can be determined by monitoring mass 248 , which has no naturally occurring elements but is the mass of the molecule $\mathrm{ThO}^{+}$(Kent and Ungerer, 2005). The $\mathrm{ThO}^{+} / \mathrm{Th}^{+}$ratio was kept to $<2-3 \%$ during analysis. 
Appendix 1

\begin{tabular}{|c|c|c|c|c|c|c|c|}
\hline Isotope & Element & Notes & $\begin{array}{c}\text { Natural } \\
\text { Abundance } \\
(\%)\end{array}$ & $\begin{array}{l}\text { Direct } \\
\text { Interferences }\end{array}$ & $\begin{array}{l}\text { Oxide } \\
\text { Interferences }\end{array}$ & $\begin{array}{l}\text { Ar-based } \\
\text { Interferences }\end{array}$ & $\begin{array}{l}\text { Doubly } \\
\text { Charged }\end{array}$ \\
\hline 6 & $\mathrm{Li}$ & & 7.5 & & $22 \mathrm{Na}$ & $46 \mathrm{Ca}$ & $3 \mathrm{H}$ \\
\hline 7 & $\mathrm{Li}$ & & 92.5 & $7 \mathrm{Be}$ & $23 \mathrm{Na}$ & $47 \mathrm{Ti}$ & \\
\hline 7 & $\mathrm{Be}$ & $\mathrm{C}$ & & $7 \mathrm{Li}$ & $23 \mathrm{Na}$ & $47 \mathrm{Ti}$ & \\
\hline 9 & $\mathrm{Be}$ & $\mathrm{S}$ & $100 \%$ & & $27 \mathrm{Al}$ & $49 \mathrm{Ti}$ & \\
\hline 10 & $\mathrm{Be}$ & & & $10 \mathrm{~B}$ & $26 \mathrm{Mg}, 26 \mathrm{Al}$ & $\begin{array}{l}50 \mathrm{Ti}, 50 \mathrm{~V}, 50 \\
\mathrm{Cr}\end{array}$ & \\
\hline 10 & B & & 19.9 & $10 \mathrm{Be}$ & $26 \mathrm{Mg}, 26 \mathrm{Al}$ & $\begin{array}{l}50 \mathrm{Ti}, 50 \mathrm{~V}, 50 \\
\mathrm{Cr}\end{array}$ & \\
\hline 11 & B & & 80.1 & & $27 \mathrm{Al}$ & $51 \mathrm{~V}, 51 \mathrm{Cr}$ & \\
\hline 24 & $\mathrm{Mg}$ & & 78.99 & & $\begin{array}{l}40 \mathrm{~K}, 40 \mathrm{Ar}, \\
40 \mathrm{Ca}\end{array}$ & $64 \mathrm{Zn}$ & $12 \mathrm{C}$ \\
\hline 25 & $\mathrm{Mg}$ & & 10 & & $41 \mathrm{~K}, 41 \mathrm{Ca}$ & $65 \mathrm{Cu}, 65 \mathrm{Zn}$ & \\
\hline 26 & $\mathrm{Mg}$ & & 11.01 & $26 \mathrm{Al}$ & $42 \mathrm{Ca}$ & $66 \mathrm{Zn}$ & $13 \mathrm{C}$ \\
\hline 40 & $\mathrm{Ca}$ & & 96.941 & $40 \mathrm{Ar}, 40 \mathrm{~K}$ & $56 \mathrm{Fe}$ & $80 \mathrm{Kr}$ & $20 \mathrm{Ne}$ \\
\hline 41 & $\mathrm{Ca}$ & $\mathrm{H}$ & & $41 \mathrm{~K}$ & $57 \mathrm{Fe}$ & $81 \mathrm{Br}, 81 \mathrm{Kr}$ & \\
\hline 42 & $\mathrm{Ca}$ & & 0.647 & & $58 \mathrm{Ni}$ & $82 \mathrm{Kr}$ & $21 \mathrm{Ne}$ \\
\hline 43 & $\mathrm{Ca}$ & & 0.135 & & $59 \mathrm{Ni}(\mathrm{C})$ & $83 \mathrm{Kr}$ & \\
\hline 44 & $\mathrm{Ca}$ & & 2.086 & & $\begin{array}{l}60 \mathrm{Ni}, 60 \mathrm{Co}, \\
60 \mathrm{Fe}\end{array}$ & $84 \mathrm{Kr}, 84 \mathrm{Sr}$ & $22 \mathrm{Ne}, 22 \mathrm{Na}$ \\
\hline 46 & $\mathrm{Ca}$ & & 0.004 & $46 \mathrm{Ti}$ & $62 \mathrm{Ni}$ & $86 \mathrm{Sr}$ & $23 \mathrm{Na}$ \\
\hline 48 & $\mathrm{Ca}$ & & 0.187 & $48 \mathrm{Ti}$ & $64 \mathrm{Zn}$ & $88 \mathrm{Sr}$ & $24 \mathrm{Mg}$ \\
\hline 45 & $\mathrm{Sc}$ & $\mathrm{S}$ & 100 & & & $85 \mathrm{Rb}$ & \\
\hline 46 & $\mathrm{Ti}$ & & 8 & $46 \mathrm{Ca}$ & $62 \mathrm{Ni}$ & $86 \mathrm{Sr}$ & $23 \mathrm{Na}$ \\
\hline 47 & $\mathrm{Ti}$ & & 7.3 & & $63 \mathrm{Cu}$ & $87 \mathrm{Sr}$ & \\
\hline 48 & $\mathrm{Ti}$ & & 73.8 & $48 \mathrm{Ca}$ & $64 \mathrm{Zn}$ & $88 \mathrm{Sr}$ & $24 \mathrm{Mg}$ \\
\hline 49 & $\mathrm{Ti}$ & & 5.5 & & $65 \mathrm{Zn}$ & $89 \mathrm{Y}$ & \\
\hline 50 & $\mathrm{Ti}$ & & 5.4 & $50 \mathrm{Cr}, 50 \mathrm{~V}$ & $66 \mathrm{Zn}$ & $90 \mathrm{Sr}, 90 \mathrm{Zr}$ & $25 \mathrm{Mg}$ \\
\hline 50 & $\mathrm{~V}$ & $\mathrm{H}$ & 0.25 & $50 \mathrm{Ti}, 50 \mathrm{Cr}$ & $66 \mathrm{Zn}$ & $90 \mathrm{Sr}, 90 \mathrm{Zr}$ & $25 \mathrm{Mg}$ \\
\hline 51 & V & $\mathrm{S}$ & 99.75 & $51 \mathrm{Cr}$ & $67 \mathrm{Zn}$ & $91 \mathrm{Zr}$ & \\
\hline 50 & $\mathrm{Cr}$ & & 4.345 & $50 \mathrm{Ti}, 50 \mathrm{~V}$ & $66 \mathrm{Zn}$ & $90 \mathrm{Sr}, 90 \mathrm{Zr}$ & $25 \mathrm{Mg}$ \\
\hline 51 & $\mathrm{Cr}$ & $\mathrm{H}$ & & $51 \mathrm{~V}$ & $67 \mathrm{Zn}$ & $91 \mathrm{Zr}$ & \\
\hline 52 & $\mathrm{Cr}$ & & 83.789 & & $68 \mathrm{Zn}$ & $92 \mathrm{Zr}, 92 \mathrm{Mo}$ & $26 \mathrm{Mg}, 26 \mathrm{Al}$ \\
\hline 53 & $\mathrm{Cr}$ & & 9.501 & $53 \mathrm{Mn}$ & $69 \mathrm{Ga}$ & $93 \mathrm{Nb}$ & \\
\hline 54 & $\mathrm{Cr}$ & & 2.365 & $54 \mathrm{Mn}$ & $70 \mathrm{Ge}$ & $94 \mathrm{Zr}, 94 \mathrm{Mo}$ & $27 \mathrm{Al}$ \\
\hline 53 & $\mathrm{Mn}$ & $\mathrm{C}$ & & $53 \mathrm{Cr}$ & $69 \mathrm{Ga}$ & $93 \mathrm{Zr}, 93 \mathrm{Nb}$ & \\
\hline 54 & $\mathrm{Mn}$ & $\mathrm{B}, \mathrm{R}$ & & $54 \mathrm{Cr}, 54 \mathrm{Fe}$ & & $94 \mathrm{Zr}$ & $27 \mathrm{Al}$ \\
\hline 55 & $\mathrm{Mn}$ & & 100 & & $71 \mathrm{Ga}$ & $95 \mathrm{Mo}$ & \\
\hline 59 & $\mathrm{Co}$ & $\mathrm{S}$ & 100 & $59 \mathrm{Ni}$ & $75 \mathrm{As}$ & $99 \mathrm{Tc}, 99 \mathrm{Ru}$ & \\
\hline 60 & $\mathrm{Co}$ & $\mathrm{H}$ & & $60 \mathrm{Fe}, 60 \mathrm{Ni}$ & $76 \mathrm{Ge}, 76 \mathrm{Se}$ & $100 \mathrm{Mo}, 100 \mathrm{Ru}$ & $30 \mathrm{Si}$ \\
\hline 58 & $\mathrm{Ni}$ & & 68.077 & $58 \mathrm{Fe}$ & $74 \mathrm{Ge}, 74 \mathrm{Se}$ & $98 \mathrm{Mo}, 98 \mathrm{Ru}$ & $29 \mathrm{Si}$ \\
\hline 59 & $\mathrm{Ni}$ & $\mathrm{H}$ & & $59 \mathrm{Ni}, 59 \mathrm{Co}$ & $75 \mathrm{As}$ & $99 \mathrm{Ru}$ & \\
\hline 60 & $\mathrm{Ni}$ & & 26.233 & $\begin{array}{l}60 \mathrm{Fe}(\text { extinct }), \\
60 \mathrm{Co}(\mathrm{B}, \mathrm{R})\end{array}$ & $76 \mathrm{Ge}, 76 \mathrm{Se}$ & $100 \mathrm{Mo}, 100 \mathrm{Ru}$ & $30 \mathrm{Si}$ \\
\hline 61 & $\mathrm{Ni}$ & & 1.14 & & $77 \mathrm{Se}$ & $101 \mathrm{Ru}$ & \\
\hline 62 & $\mathrm{Ni}$ & & 3.634 & & $78 \mathrm{Se}$ & $102 \mathrm{Ru}, 102 \mathrm{Pd}$ & $31 \mathrm{P}$ \\
\hline 63 & $\mathrm{Cu}$ & & 69.17 & & $79 \mathrm{Br}$ & $103 \mathrm{Rh}$ & \\
\hline 65 & $\mathrm{Cu}$ & & 30.83 & & $81 \mathrm{Br}$ & $105 \mathrm{Pd}$ & \\
\hline 64 & $\mathrm{Zn}$ & & 48.6 & & $80 \mathrm{Kr}$ & $104 \mathrm{Ru}, 104 \mathrm{Pd}$ & $\begin{array}{l}32 \mathrm{Si}, 32 \mathrm{P}, \\
32 \mathrm{~S}\end{array}$ \\
\hline 65 & $\mathrm{Zn}$ & $\mathrm{H}$ & & & $81 \mathrm{Br}, 81 \mathrm{Kr}$ & $105 \mathrm{Pd}$ & \\
\hline 66 & $\mathrm{Zn}$ & & 27.9 & & $82 \mathrm{Kr}$ & $106 \mathrm{Pd}, 106 \mathrm{Cd}$ & $33 \mathrm{P}, 33 \mathrm{~S}$ \\
\hline 67 & $\mathrm{Zn}$ & & 4.1 & & $83 \mathrm{Kr}$ & $107 \mathrm{Pd}, 107 \mathrm{Ag}$ & \\
\hline 68 & $\mathrm{Zn}$ & & 18.8 & & $84 \mathrm{Kr}, 84 \mathrm{Sr}$ & $108 \mathrm{Pd}, 108 \mathrm{Cd}$ & $34 \mathrm{~S}$ \\
\hline 69 & $\mathrm{Ga}$ & & 60.108 & & $85 \mathrm{Rb}$ & $109 \mathrm{Ag}$ & \\
\hline 71 & $\mathrm{Ga}$ & & 39.892 & & $87 \mathrm{Rb}$ & $111 \mathrm{Cd}$ & \\
\hline 85 & $\mathrm{Rb}$ & $\mathrm{S}$ & 72.165 & $85 \mathrm{Kr}$ & $101 \mathrm{Ru}$ & $125 \mathrm{Te}$ & \\
\hline 87 & $\mathrm{Rb}$ & & 27.835 & $87 \mathrm{Sr}$ & $103 \mathrm{Rh}$ & $127 \mathrm{I}$ & \\
\hline 84 & $\mathrm{Sr}$ & & 0.56 & $84 \mathrm{Kr}$ & $100 \mathrm{Ru}$ & $\begin{array}{l}124 \mathrm{Xe}, 124 \mathrm{Te}, \\
124 \mathrm{Sn}\end{array}$ & $42 \mathrm{Ca}$ \\
\hline 86 & $\mathrm{Sr}$ & & 9.86 & & $102 \mathrm{Ru}$ & $126 \mathrm{Xe}, 126 \mathrm{Te}$ & $43 \mathrm{Ca}$ \\
\hline 87 & $\mathrm{Sr}$ & & 7 & $87 \mathrm{Rb}$ & $103 \mathrm{Rh}$ & 127 I & \\
\hline 88 & $\mathrm{Sr}$ & & 82.58 & & $\begin{array}{l}104 \mathrm{Ru}, 104 \\
\mathrm{Pd}\end{array}$ & $128 \mathrm{Te}$ & $44 \mathrm{Ca}$ \\
\hline 90 & $\mathrm{Sr}$ & $\mathrm{H}$ & & $90 \mathrm{Zr}$ & $106 \mathrm{Pd}$ & $130 \mathrm{Xe}, 130 \mathrm{Te}$ & $45 \mathrm{Sc}$ \\
\hline 89 & $\mathrm{Y}$ & $\mathrm{S}$ & 100 & & $105 \mathrm{Pd}$ & $129 \mathrm{I}$ & \\
\hline 90 & $\mathrm{Zr}$ & & 51.45 & $90 \mathrm{Sr}(\mathrm{H})$ & $\begin{array}{l}106 \mathrm{Pd}, 106 \\
\mathrm{Cd}\end{array}$ & $130 \mathrm{Xe}, 130 \mathrm{Te}$ & $\mathrm{Sc}$ \\
\hline
\end{tabular}

Table A1.5 


\begin{tabular}{|c|c|c|c|c|c|c|c|}
\hline Isotope & Element & Notes & $\begin{array}{c}\text { Abundance } \\
(\%)\end{array}$ & $\begin{array}{l}\text { Direct } \\
\text { Interferences }\end{array}$ & $\begin{array}{l}\text { Oxide } \\
\text { Interferences }\end{array}$ & $\begin{array}{l}\text { Ar-based } \\
\text { Interferences }\end{array}$ & $\begin{array}{l}\text { Doubly } \\
\text { Charged }\end{array}$ \\
\hline 91 & $\mathrm{Zr}$ & & 11.22 & & $\begin{array}{l}107 \mathrm{Pd}, 107 \\
\mathrm{Ag}\end{array}$ & $131 \mathrm{Xe}$ & \\
\hline 92 & $\mathrm{Zr}$ & & 17.15 & 92 Мo & $\begin{array}{l}108 \mathrm{Pd}, 108 \\
\mathrm{Cd}\end{array}$ & $132 \mathrm{Ba}, 132 \mathrm{Xe}$ & $\mathrm{Ca}, 46 \mathrm{Ti}$ \\
\hline 93 & $\mathrm{Zr}$ & $\mathrm{H}$ & & $93 \mathrm{Nb}$ & $109 \mathrm{Ag}$ & $133 \mathrm{Cs}$ & \\
\hline 94 & $\mathrm{Zr}$ & & 17.38 & 94 Мo & $\begin{array}{l}110 \mathrm{Pd}, 110 \\
\mathrm{Cd}\end{array}$ & $134 \mathrm{Cs}, 134 \mathrm{Xe}$ & $47 \mathrm{Ti}$ \\
\hline 95 & $\mathrm{Zr}$ & & & & $111 \mathrm{Cd}$ & $135 \mathrm{Ba}$ & \\
\hline 96 & $\mathrm{Zr}$ & $\mathrm{H}$ & 2 & $96 \mathrm{Mo}$ & $112 \mathrm{Cd}$ & $136 \mathrm{Ba}, 136 \mathrm{Xe}$ & $48 \mathrm{Ca}, 48 \mathrm{Ti}$ \\
\hline 93 & $\mathrm{Nb}$ & $\mathrm{S}$ & 100 & $93 \mathrm{Zr}$ & $109 \mathrm{Ag}$ & $133 \mathrm{Cs}$ & \\
\hline 92 & Mo & & 14.84 & $92 \mathrm{Zr}$ & $108 \mathrm{Cd}$ & $132 \mathrm{Xe}$ & $46 \mathrm{Ti}, 46 \mathrm{Ca}$ \\
\hline 94 & Mo & & 9.25 & $94 \mathrm{Zr}$ & $\begin{array}{l}110 \mathrm{Pd}, 110 \\
\mathrm{Cd}\end{array}$ & $134 \mathrm{Xe}, 134 \mathrm{Cs}$ & $47 \mathrm{Ti}$ \\
\hline 95 & Mo & & 15.92 & & $111 \mathrm{Cd}$ & $135 \mathrm{Ba}$ & \\
\hline 96 & Mo & & 16.68 & $96 \mathrm{Zr}$ & $\begin{array}{l}112 \mathrm{Cd}, 112 \\
\text { Sn }\end{array}$ & $136 \mathrm{Xe}, 136 \mathrm{Ba}$ & $48 \mathrm{Ca}$ \\
\hline 97 & Mo & & 9.55 & & $113 \mathrm{Cd}, 113 \mathrm{In}$ & $137 \mathrm{Ba}$ & \\
\hline 98 & Mo & & 21.13 & & $114 \mathrm{Sn}$ & $138 \mathrm{Ba}, 138 \mathrm{Ce}$ & $49 \mathrm{Ti}$ \\
\hline 100 & Mo & & 9.63 & $100 \mathrm{Ru}$ & $116 \mathrm{Sn}$ & $140 \mathrm{Ce}$ & $50 \mathrm{~V}, 50 \mathrm{Cr}$ \\
\hline 133 & Cs & $\mathrm{S}$ & 100 & & $149 \mathrm{Sm}$ & $173 \mathrm{Yb}$ & \\
\hline 134 & Cs & $\mathrm{H}$ & & $\begin{array}{l}134 \mathrm{Ba}, 134 \\
\mathrm{Xe}\end{array}$ & $\begin{array}{l}150 \mathrm{Nd}, 150 \\
\mathrm{Sm}\end{array}$ & $174 \mathrm{Hf}, 174 \mathrm{Yb}$ & $67 \mathrm{Zn}$ \\
\hline 137 & Cs & $\mathrm{H}$ & & $137 \mathrm{Ba}$ & $153 \mathrm{Eu}$ & $177 \mathrm{Hf}$ & \\
\hline 130 & $\mathrm{Ba}$ & & 0.106 & $\begin{array}{l}130 \mathrm{Xe}, 130 \\
\mathrm{Te}\end{array}$ & $\begin{array}{l}146 \mathrm{Sm}, 146 \\
\mathrm{Nd}\end{array}$ & $170 \mathrm{Er}$ & $65 \mathrm{Cu}$ \\
\hline 132 & $\mathrm{Ba}$ & & 0.101 & $132 \mathrm{Xe}$ & $\begin{array}{l}148 \mathrm{Nd}, 148 \\
\mathrm{Sm}\end{array}$ & $172 \mathrm{Yb}$ & $66 \mathrm{Zn}$ \\
\hline 134 & $\mathrm{Ba}$ & & 2.417 & $\begin{array}{l}134 \mathrm{Xe}, 134 \\
\mathrm{Cs}\end{array}$ & $\begin{array}{l}150 \mathrm{Nd}, 150 \\
\mathrm{Sm}\end{array}$ & $174 \mathrm{Yb}, 175 \mathrm{Hf}$ & $67 \mathrm{Zn}$ \\
\hline 135 & $\mathrm{Ba}$ & & 6.592 & & $151 \mathrm{Eu}$ & $175 \mathrm{Lu}$ & \\
\hline 136 & $\mathrm{Ba}$ & & 7.854 & $136 \mathrm{Xe}$ & $\begin{array}{l}152 \mathrm{Sm}, 152 \\
\mathrm{Gd}\end{array}$ & $176 \mathrm{Hf}$ & $68 \mathrm{Zn}$ \\
\hline 137 & $\mathrm{Ba}$ & & 11.23 & $137 \mathrm{Cs}(\mathrm{B}, \mathrm{M})$ & $153 \mathrm{Eu}$ & $177 \mathrm{Hf}$ & \\
\hline 138 & $\mathrm{Ba}$ & & 71.7 & $138 \mathrm{La}, 138 \mathrm{Ce}$ & $\begin{array}{l}154 \mathrm{Sm}, 154 \\
\mathrm{Gd}\end{array}$ & $178 \mathrm{Hf}$ & $69 \mathrm{Ga}$ \\
\hline 138 & $\mathrm{La}$ & $\mathrm{H}$ & 0.0902 & $\begin{array}{l}138 \mathrm{Ba}, 138 \\
\mathrm{Ce}\end{array}$ & $\begin{array}{l}154 \mathrm{Sm} \\
154 \mathrm{Gd}\end{array}$ & $178 \mathrm{Hf}$ & $69 \mathrm{Ga}$ \\
\hline 139 & $\mathrm{La}$ & $\mathrm{S}$ & 99.9098 & & $155 \mathrm{Gd}$ & $179 \mathrm{Hf}$ & \\
\hline 138 & $\mathrm{Ce}$ & & 0.25 & $138 \mathrm{Ba}, 138 \mathrm{La}$ & $\begin{array}{l}154 \mathrm{Sm}, 154 \\
\mathrm{Gd}\end{array}$ & $178 \mathrm{Hf}$ & $69 \mathrm{Ga}$ \\
\hline 140 & $\mathrm{Ce}$ & & 88.48 & & $\begin{array}{l}156 \mathrm{Gd}, 156 \\
\mathrm{Gd}\end{array}$ & $180 \mathrm{~W}, 180 \mathrm{Hf}$ & $70 \mathrm{Ge}$ \\
\hline 142 & $\mathrm{Ce}$ & & 11.08 & $142 \mathrm{Nd}$ & $\begin{array}{l}158 \mathrm{Gd}, 158 \\
\text { Dy }\end{array}$ & $182 \mathrm{~W}$ & $71 \mathrm{Ga}$ \\
\hline 141 & $\operatorname{Pr}$ & S & 100 & & $157 \mathrm{Gd}$ & $181 \mathrm{Ta}$ & \\
\hline 142 & $\mathrm{Nd}$ & & 27.13 & $142 \mathrm{Ce}$ & $\begin{array}{l}158 \mathrm{Gd}, 158 \\
\text { Dy }\end{array}$ & $182 \mathrm{~W}$ & $71 \mathrm{Ga}$ \\
\hline 143 & $\mathrm{Nd}$ & & 12.18 & & $159 \mathrm{~Tb}$ & $183 \mathrm{~W}$ & \\
\hline 144 & $\mathrm{Nd}$ & & 23.8 & $144 \mathrm{Sm}$ & $\begin{array}{l}160 \mathrm{Gd}, 160 \\
\text { Dy }\end{array}$ & $184 \mathrm{~W}, 184$ Os & $72 \mathrm{Ge}$ \\
\hline 145 & $\mathrm{Nd}$ & & 8.3 & & $161 \mathrm{Dy}$ & $185 \mathrm{Re}$ & \\
\hline 146 & $\mathrm{Nd}$ & & 17.19 & $146 \mathrm{Sm}$ & 162 Dy, 162 Er & $186 \mathrm{~W}$ & $73 \mathrm{Ge}$ \\
\hline 148 & $\mathrm{Nd}$ & & 5.76 & $148 \mathrm{Sm}$ & 164 Dy, 164 Er & $188 \mathrm{Os}$ & $74 \mathrm{Ge}$ \\
\hline 150 & $\mathrm{Nd}$ & & 5.64 & $150 \mathrm{Sm}$ & $166 \mathrm{Er}$ & $190 \mathrm{Pt}$ & $75 \mathrm{As}$ \\
\hline 144 & $\mathrm{Sm}$ & & 3.1 & $144 \mathrm{Nd}$ & 160 Dy & $184 \mathrm{~W}, 184 \mathrm{Os}$ & $72 \mathrm{Ge}$ \\
\hline 146 & $\mathrm{Sm}$ & $\mathrm{H}$ & & $146 \mathrm{Nd}$ & $162 \mathrm{Dy}, 162 \mathrm{Er}$ & $186 \mathrm{~W}, 186 \mathrm{Os}$ & $73 \mathrm{Ge}$ \\
\hline 147 & $\mathrm{Sm}$ & & 15 & & 163 Dy & $187 \mathrm{Re}, 187 \mathrm{Os}$ & \\
\hline 148 & $\mathrm{Sm}$ & $\mathrm{H}$ & 11.3 & $148 \mathrm{Nd}$ & 164 Dy, 164 Er & $188 \mathrm{Os}$ & $74 \mathrm{Ge}$ \\
\hline 149 & $\mathrm{Sm}$ & $\mathrm{H}$ & 13.8 & & $165 \mathrm{Ho}$ & $189 \mathrm{Os}$ & \\
\hline 150 & $\mathrm{Sm}$ & & 7.4 & $150 \mathrm{Nd}$ & $166 \mathrm{Er}$ & $190 \mathrm{Pt}, 190 \mathrm{Os}$ & $75 \mathrm{As}$ \\
\hline 152 & $\mathrm{Sm}$ & & 26.7 & & $168 \mathrm{Er}$ & $192 \mathrm{Os}, 192 \mathrm{Pt}$ & $76 \mathrm{Se}$ \\
\hline 154 & $\mathrm{Sm}$ & & 22.7 & $154 \mathrm{Gd}$ & $170 \mathrm{Er}$ & $194 \mathrm{Pt}$ & $77 \mathrm{Se}$ \\
\hline 151 & $\mathrm{Eu}$ & & 47.8 & & $167 \mathrm{Er}$ & $191 \mathrm{Ir}$ & \\
\hline 153 & $\mathrm{Eu}$ & & 52.2 & & $169 \mathrm{Tm}$ & $193 \mathrm{Ir}$ & \\
\hline 152 & Gd & & 0.2 & $152 \mathrm{Sm}$ & $168 \mathrm{Er}, 168 \mathrm{Yb}$ & $192 \mathrm{Pt}$ & $76 \mathrm{Se}$ \\
\hline 154 & $\mathrm{Gd}$ & & 2.18 & $154 \mathrm{Sm}$ & $170 \mathrm{Er}$ & $194 \mathrm{Pt}$ & $77 \mathrm{Se}$ \\
\hline 155 & Gd & & 14.8 & & $171 \mathrm{Yb}$ & $195 \mathrm{Pt}$ & \\
\hline 156 & Gd & & 20.47 & 156 Dy & $172 \mathrm{Yb}$ & $196 \mathrm{Pt}, 196 \mathrm{Hg}$ & $78 \mathrm{Se}, 78 \mathrm{Kr}$ \\
\hline 157 & $\mathrm{Gd}$ & & 15.65 & & $173 \mathrm{Yb}$ & $197 \mathrm{Au}$ & \\
\hline
\end{tabular}

Table A1.5 continued 


\begin{tabular}{|c|c|c|c|c|c|c|c|}
\hline Isotope & Element & Notes & $\begin{array}{c}\text { Abundance } \\
(\%)\end{array}$ & $\begin{array}{l}\text { Direct } \\
\text { Interferences }\end{array}$ & $\begin{array}{l}\text { Oxide } \\
\text { Interferences }\end{array}$ & $\begin{array}{l}\text { Ar-based } \\
\text { Interferences }\end{array}$ & $\begin{array}{l}\text { Doubly } \\
\text { Charged }\end{array}$ \\
\hline 158 & $\mathrm{Gd}$ & & 24.84 & 158 Dy & $\begin{array}{l}174 \mathrm{Yb}, 174 \\
\mathrm{Hf}\end{array}$ & $198 \mathrm{Hg}, 198 \mathrm{Pt}$ & $79 \mathrm{Br}$ \\
\hline 160 & Gd & $\mathrm{H}$ & 21.86 & 160 Dy & $\begin{array}{l}176 \mathrm{Yb}, 176 \\
\mathrm{Lu}, 176 \mathrm{Hf}\end{array}$ & $200 \mathrm{Hg}$ & $80 \mathrm{Kr}$ \\
\hline 156 & Dy & & 0.06 & $156 \mathrm{Gd}$ & $172 \mathrm{Yb}$ & $196 \mathrm{Pt}, 196 \mathrm{Hg}$ & $78 \mathrm{Se}, 78 \mathrm{Kr}$ \\
\hline 158 & Dy & & 0.1 & $158 \mathrm{Gd}$ & $\begin{array}{l}174 \mathrm{Yb}, 174 \\
\mathrm{Hf}\end{array}$ & $198 \mathrm{Hg}, 198 \mathrm{Pt}$ & $79 \mathrm{Br}$ \\
\hline 160 & Dy & & 2.34 & $160 \mathrm{Gd}$ & $\begin{array}{l}176 \mathrm{Yb}, 176 \\
\mathrm{Lu}, 176 \mathrm{Hf}\end{array}$ & $200 \mathrm{Hg}$ & $80 \mathrm{Kr}$ \\
\hline 161 & Dy & & 18.9 & & $177 \mathrm{Hf}$ & $201 \mathrm{Hg}$ & \\
\hline 162 & Dy & & 25.5 & $162 \mathrm{Er}$ & $178 \mathrm{Hf}$ & $202 \mathrm{Hg}$ & $81 \mathrm{Br}$ \\
\hline 163 & Dy & & 24.9 & & $179 \mathrm{Hf}$ & $203 \mathrm{Tl}$ & \\
\hline 164 & Dy & & 28.2 & $164 \mathrm{Er}$ & $180 \mathrm{Hf}, 180 \mathrm{Ta}$ & $204 \mathrm{~Pb}, 204 \mathrm{Hg}$ & $82 \mathrm{Kr}$ \\
\hline 162 & $\mathrm{Er}$ & & 0.14 & 162 Dy & $178 \mathrm{Hf}$ & $202 \mathrm{Hg}$ & $81 \mathrm{Br}$ \\
\hline 164 & Er & & 1.61 & $164 \mathrm{Er}$ & $\begin{array}{l}180 \mathrm{Hf}, 180 \\
\mathrm{Ta}, 180 \mathrm{~W}\end{array}$ & $204 \mathrm{~Pb}, 204 \mathrm{Hg}$ & $82 \mathrm{Kr}$ \\
\hline 166 & Er & & 33.6 & & $182 \mathrm{~W}$ & $206 \mathrm{~Pb}, 206 \mathrm{Tl}$ & $83 \mathrm{Kr}$ \\
\hline 167 & Er & & 22.95 & & $183 \mathrm{~W}$ & $207 \mathrm{~Pb}, 207 \mathrm{Tl}$ & \\
\hline 168 & Er & & 26.8 & $168 \mathrm{Yb}$ & $184 \mathrm{~W}, 184 \mathrm{Os}$ & $208 \mathrm{~Pb}, 208 \mathrm{Tl}$ & $84 \mathrm{Kr}, 84 \mathrm{Sr}$ \\
\hline 170 & Er & & 14.9 & & $186 \mathrm{~W}$ & $\begin{array}{l}210 \mathrm{Tl}, 210 \mathrm{~Pb}, \\
210 \mathrm{Bi}, 210 \mathrm{Po}\end{array}$ & $85 \mathrm{Kr}, 85 \mathrm{Rb}$ \\
\hline 168 & $\mathrm{Yb}$ & & 3.05 & $168 \mathrm{Er}$ & $184 \mathrm{~W}, 184 \mathrm{Os}$ & $208 \mathrm{~Pb}, 208 \mathrm{Tl}$ & $84 \mathrm{Kr}, 84 \mathrm{Sr}$ \\
\hline 171 & $\mathrm{Yb}$ & & 14.3 & & $\begin{array}{l}187 \mathrm{Re}, 187 \\
\text { Os }\end{array}$ & $\begin{array}{l}211 \mathrm{~Pb}, 211 \mathrm{Bi}, \\
211 \mathrm{Po}\end{array}$ & \\
\hline 172 & $\mathrm{Yb}$ & & 21.9 & & 188 Os & $\begin{array}{l}212 \mathrm{~Pb}, 212 \mathrm{Bi}, \\
212 \mathrm{Po}\end{array}$ & $86 \mathrm{Sr}$ \\
\hline 173 & $\mathrm{Yb}$ & & 16.12 & & $189 \mathrm{Os}$ & & \\
\hline 174 & $\mathrm{Yb}$ & & 31.8 & $174 \mathrm{Hf}$ & $190 \mathrm{Os}, 190 \mathrm{Pt}$ & $\begin{array}{l}214 \mathrm{~Pb}, 214 \mathrm{Po}, \\
214 \mathrm{Bi}\end{array}$ & $87 \mathrm{Rb}, 87 \mathrm{Sr}$ \\
\hline 176 & $\mathrm{Yb}$ & & 12.7 & $176 \mathrm{Lu}, 176 \mathrm{Hf}$ & $192 \mathrm{Os}, 192 \mathrm{Pt}$ & 216 Po & $88 \mathrm{Sr}$ \\
\hline 175 & $\mathrm{Lu}$ & $\mathrm{S}$ & 97.41 & & $191 \mathrm{Ir}$ & $\begin{array}{l}215 \mathrm{Bi}, 215 \mathrm{At} \\
215 \mathrm{Po}\end{array}$ & \\
\hline 176 & $\mathrm{Lu}$ & & 2.59 & $\begin{array}{l}176 \mathrm{Yb}, 176 \\
\mathrm{Hf}\end{array}$ & $192 \mathrm{Os}, 192 \mathrm{Pt}$ & & $88 \mathrm{Sr}$ \\
\hline 174 & $\mathrm{Hf}$ & & 0.162 & $174 \mathrm{Yb}$ & $190 \mathrm{Os}, 190 \mathrm{Pt}$ & 214 Po & $87 \mathrm{Rb}, 87 \mathrm{Sr}$ \\
\hline 176 & $\mathrm{Hf}$ & & 5.206 & $\begin{array}{l}176 \mathrm{Yb}, 176 \\
\mathrm{Lu}\end{array}$ & $192 \mathrm{Os}, 192 \mathrm{Pt}$ & 216 Po & $88 \mathrm{Sr}$ \\
\hline 177 & $\mathrm{Hf}$ & & 18.606 & & 193 Ir & & \\
\hline 178 & $\mathrm{Hf}$ & & 27.279 & & $194 \mathrm{Pt}$ & 218 At, 218 Po & $89 \mathrm{Y}$ \\
\hline 179 & $\mathrm{Hf}$ & & 13.629 & & $195 \mathrm{Pt}$ & $219 \mathrm{Rn}$ & \\
\hline 180 & $\mathrm{Hf}$ & & 35.1 & $180 \mathrm{~W}, 180 \mathrm{Ta}$ & $196 \mathrm{Pt}, 196 \mathrm{Hg}$ & $220 \mathrm{Rn}$ & $90 \mathrm{Sr}, 90 \mathrm{Zr}$ \\
\hline 180 & $\mathrm{Ta}$ & $\mathrm{H}$ & 0.0012 & $180 \mathrm{~W}, 180 \mathrm{Hf}$ & $196 \mathrm{Pt}, 196 \mathrm{Hg}$ & & $90 \mathrm{Sr}, 90 \mathrm{Zr}$ \\
\hline 181 & $\mathrm{Ta}$ & $\mathrm{S}$ & 99.988 & & $197 \mathrm{Au}$ & & \\
\hline 180 & W & & 0.13 & $180 \mathrm{Ta}$ & $196 \mathrm{Pt}$ & $220 \mathrm{Rn}$ & $90 \mathrm{Zr}$ \\
\hline 182 & $\mathrm{~W}$ & & 26.3 & & $198 \mathrm{Pt}, 198 \mathrm{Hg}$ & $222 \mathrm{Rn}$ & $91 \mathrm{Zr}$ \\
\hline 183 & W & & 14.3 & & $199 \mathrm{Hg}$ & $223 \mathrm{Fr}$ & \\
\hline 184 & $\mathrm{~W}$ & & 30.67 & $184 \mathrm{Os}$ & $200 \mathrm{Hg}$ & $224 \mathrm{Ra}$ & $92 \mathrm{Zr}, 92 \mathrm{Mo}$ \\
\hline 186 & W & & 28.6 & & $202 \mathrm{Hg}$ & $226 \mathrm{Ra}$ & $\begin{array}{l}93 \mathrm{Nb}, 93 \\
\mathrm{Zr}\end{array}$ \\
\hline 204 & $\mathrm{~Pb}$ & $\mathrm{H}$ & 1.4 & $204 \mathrm{Hg}$, & $220 \mathrm{Rn}$ & & $\begin{array}{l}102 \mathrm{Ru}, 102 \\
\mathrm{Pd}\end{array}$ \\
\hline 206 & $\mathrm{~Pb}$ & & & & & & \\
\hline 207 & $\mathrm{~Pb}$ & & 22.1 & $207 \mathrm{Tl}$ & $223 \mathrm{Fr}, 223 \mathrm{Ra}$ & & \\
\hline 208 & $\mathrm{~Pb}$ & & 52.4 & $208 \mathrm{Tl}$ & $224 \mathrm{Ra}$ & & $\begin{array}{l}104 \mathrm{Ru}, 104 \\
\mathrm{Pd}\end{array}$ \\
\hline 228 & Th & $\mathrm{H}$ & & $228 \mathrm{Ac}$ & & & $114 \mathrm{Cd}$ \\
\hline 230 & Th & $\mathrm{H}$ & & & & & $115 \mathrm{In}$ \\
\hline 232 & Th & & 100 & & & & $116 \mathrm{Sn}$ \\
\hline 234 & Th & & & $234 \mathrm{U}$ & & & $117 \mathrm{Sn}$ \\
\hline 234 & $\mathrm{U}$ & & 0.0055 & $234 \mathrm{Th}$ & & & $117 \mathrm{Sn}$ \\
\hline 235 & $\mathrm{U}$ & & 0.72 & & & & \\
\hline 238 & $\mathrm{U}$ & & 99.2745 & & & & $119 \mathrm{Sn}$ \\
\hline
\end{tabular}

Table A1.5. Potential interferences for each element and isotope analysed by LA-ICPMS. Isotopes, abundances and notes are taken from Appendix 2, Treatise on Geochemistry (Turekian and Holland, 2003). Isotopes highlighted in yellow indicate the analysed isotope. Abbreviations: $\mathrm{C}=$ cosmogenetic source; $\mathrm{S}=$ only stable isotope; $\mathrm{B}=$ produced in bombs; $\mathrm{R}=$ produced in nuclear reactors; $\mathrm{H}=$ half-life $<10,000$ years. 


\begin{tabular}{|c|c|c|}
\hline Element & $\begin{array}{c}\text { Isotope } \\
\text { analysed }\end{array}$ & Justification for analysed isotope \\
\hline $\mathrm{Ca}$ & 43 & $\begin{array}{l}\text { The least abundant of the three Ca isotopes }\left({ }^{42} \mathrm{Ca},{ }^{43} \mathrm{Ca},{ }^{44} \mathrm{Ca}\right) \text { without a direct } \\
\text { interference and only a minor oxide interference. }\end{array}$ \\
\hline $\mathrm{Sc}$ & 45 & The only stable isotope, but possible Ar-based interference due to ${ }^{85} \mathrm{Rb}$. \\
\hline $\mathrm{Ti}$ & 47 & Most abundant isotope without a direct interference. \\
\hline $\mathrm{V}$ & 51 & $\begin{array}{l}\text { The only stable isotope, but possible direct interference from }{ }^{51} \mathrm{Cr} \text {, oxide } \\
\text { interference from }{ }^{60} \mathrm{Zn} \text { and Ar-based interference due to }{ }^{91} \mathrm{Zr} \text {. }\end{array}$ \\
\hline $\mathrm{Cr}$ & 53 & Second most abundant isotope with no major direct interferences. \\
\hline Co & 59 & The only stable isotope but with possible oxide interference from ${ }^{75} \mathrm{As}$. \\
\hline $\mathrm{Ni}$ & 60 & $\begin{array}{l}\text { The second most abundant isotope and not affected by direct interferences from } \\
\text { long live isotopes. }\end{array}$ \\
\hline $\mathrm{Cu}$ & 63 & $\begin{array}{l}\text { Is the smaller of the two } \mathrm{Cu} \text { isotopes but is more than twice as abundant than }{ }^{65} \mathrm{Cu} \\
\text { and both isotopes suffer from oxide interference from } \mathrm{Br} \text {. }\end{array}$ \\
\hline $\mathrm{Zn}$ & 66 & $\begin{array}{l}\mathrm{Zn} \text { isotopes do not suffer from direct interferences. }{ }^{66} \mathrm{Zn} \text { is larger and more } \\
\text { abundant than }{ }^{64} \mathrm{Zn} \text { and as both of these isotopes could suffer from oxide } \\
\text { interferences from Kr, }{ }^{66} \mathrm{Zn} \text { is analysed. }\end{array}$ \\
\hline $\mathrm{Ga}$ & 71 & $\begin{array}{l}\text { Gd isotopes have no direct interferences, but }{ }^{71} \mathrm{Ga} \text { is the larger isotope of the two } \\
\text { isotopes. Both } \mathrm{Ga} \text { isotopes can be affect by oxide interferences from } \mathrm{Rb} \text { from, but } \\
{ }^{71} \mathrm{Ga} \text { is affected by }{ }^{87} \mathrm{Rb} \text { which is less abundant than }{ }^{85} \mathrm{Rb} \text {, which causes oxide } \\
\text { inference on }{ }^{69} \mathrm{Ga} \text {. }\end{array}$ \\
\hline $\mathrm{Rb}$ & 85 & The only stable isotope with no major direct interferences. \\
\hline $\mathrm{Sr}$ & 88 & The most abundant and largest $\mathrm{Sr}$ isotope with no direct interferences. \\
\hline $\mathrm{Y}$ & 89 & $\begin{array}{l}\text { The only isotope with no direct interferences, but a possible oxide interference } \\
\text { from }{ }^{105} \mathrm{Pd} \text {. }\end{array}$ \\
\hline $\mathrm{Zr}$ & 90 & $\begin{array}{l}\text { The most abundant and smallest isotope with direct interferences only occurring } \\
\text { from }{ }^{90} \mathrm{Sr} \text {; a very short-lived } 1 / 2 \text { life and not produced in nature. }\end{array}$ \\
\hline $\mathrm{Nb}$ & 93 & $\begin{array}{l}\text { The only isotope. May suffer from a direct interference from }{ }^{93} \mathrm{Zr} \text {, but this is a } \\
\text { minor isotope with a short } 1 / 2 \text { life. Possible oxide interference from }{ }^{109} \mathrm{Ag} \text { and } \mathrm{Ar} \text { - } \\
\text { based interference from }{ }^{133} \mathrm{Ca} \text {. }\end{array}$ \\
\hline Cs & 133 & The only naturally occurring isotope and no direct interferences. \\
\hline $\mathrm{Ba}$ & 137 & $\begin{array}{l}\text { The largest and most abundant } \mathrm{Ba} \text { isotope not affected by a direct interference } \\
\text { from a naturally occurring isotope. }\end{array}$ \\
\hline $\mathrm{La}$ & 139 & The only stable isotope with no direct interferences. \\
\hline $\mathrm{Ce}$ & 140 & Most abundant isotope with no direct interferences. \\
\hline $\operatorname{Pr}$ & 141 & The only stable isotope with no direct interferences. \\
\hline $\mathrm{Nd}$ & 146 & $\begin{array}{l}\text { Is one of the larger more abundant } \mathrm{Nd} \text { isotopes with a possible direct interference } \\
\text { from }{ }^{146} \mathrm{Sm} .\end{array}$ \\
\hline $\mathrm{Sm}$ & 147 & $\begin{array}{l}\text { One of the three } \mathrm{Sm} \text { isotopes }\left({ }^{147} \mathrm{Sm},{ }^{149} \mathrm{Sm},{ }^{152} \mathrm{Sm}\right) \text { without direct interferences. } \\
\text { All three isotopes have possible oxide and Ar-based interference, but }{ }^{147} \mathrm{Sm} \text { is } \\
\text { slightly more abundant, although it is smaller than }{ }^{149} \mathrm{Sm} .\end{array}$ \\
\hline $\mathrm{Eu}$ & 153 & $\begin{array}{l}\text { Neither Eu isotopes have direct interferences, but both have possible oxide and Ar- } \\
\text { based interferences. }{ }^{153} \mathrm{Eu} \text { is the more abundant and larger of the two isotopes. }\end{array}$ \\
\hline Gd & 157 & $\begin{array}{l}\text { One of the two Gd isotopes }\left({ }^{155} \mathrm{Gd},{ }^{157} \mathrm{Gd}\right) \text { without direct interference. }{ }^{157} \mathrm{Gd} \text { is the } \\
\text { more abundant and larger isotope. }\end{array}$ \\
\hline Dy & 163 & $\begin{array}{l}\text { One of the two Dy isotopes }\left({ }^{161} \mathrm{Dy},{ }^{163} \mathrm{Dy}\right) \text { without direct interference, but both } \\
\text { could suffer oxide interference, although }{ }^{163} \mathrm{Dy} \text { is more abundant than }{ }^{161} \mathrm{Dy} .\end{array}$ \\
\hline Er & 166 & Most abundant of the two $\operatorname{Er}\left({ }^{166} \mathrm{Er},{ }^{167} \mathrm{Er}\right)$ isotopes without direct interferences. \\
\hline $\mathrm{Yb}$ & 172 & $\begin{array}{l}\text { Most abundant of the three } \mathrm{Yb} \text { isotopes }\left({ }^{171} \mathrm{Yb},{ }^{172} \mathrm{Yb},{ }^{173} \mathrm{Yb}\right) \text { without direct } \\
\text { interference. }\end{array}$ \\
\hline $\mathrm{Lu}$ & 175 & The only stable isotope with no direct interferences. \\
\hline Hf & 178 & $\begin{array}{l}\text { One of the three } \mathrm{Hf} \text { isotopes }\left({ }^{177} \mathrm{Hf},{ }^{178} \mathrm{Hf},{ }^{179} \mathrm{Hf}\right) \text { without direct interferences and } \\
\text { the most abundant isotope of the three. }\end{array}$ \\
\hline $\mathrm{Ta}$ & 181 & The only stable isotope with no direct interferences. \\
\hline $\mathrm{Pb}$ & 208 & The most abundant long-lived isotope with no major direct isotopic interferences. \\
\hline Th & 232 & The only major isotope with no direct interferences. \\
\hline $\mathrm{U}$ & 238 & The major isotope with no direct interferences. \\
\hline
\end{tabular}

Table A1.6. Justification for the isotopes analysed in this study. Isotope data and relative abundance of isotopes are taken from Appendix 2, Treatise of Geochemistry (Turekian and Holland, 2003). 


\section{A1.4.2.5 Analytical conditions}

Prior to each analytical session, tuning of the LA-ICPMS was conducted on a standard to maximise the operating conditions. Typical conditions for optimisation of BCR-2G resulted in: ca. 20,000 cps on Ce; 2000-3000 cps $\mathrm{Pb}(\mathrm{Pb}$ background ca. $50 \mathrm{cps}$ ); $\mathrm{ThO}^{+} / \mathrm{Th}^{+}<2.5 \%$; and relative standard deviations (RSD) of the monitored isotopes $<5 \%$. Thirty-three trace elements were routinely analysed and are given in Table A1.6. Typical analytical conditions are shown in Table A1.7.

\begin{tabular}{ll}
\hline \multicolumn{2}{c}{ Typical Analytical Conditions } \\
\hline Laser & New Wave deep UV \\
Wavelength $(\mathrm{nm})$ & $193 \mathrm{~nm}$ solid state \\
Spot size $(\mu \mathrm{m})$ & $35 \mu \mathrm{m}$ (unless stated) \\
Repetition rate $(\mathrm{Hz})$ & 5 \\
Energy & $\sim 5.6-6.7 \mathrm{~J} / \mathrm{cm}^{2}$ \\
Carrier Gas & He-Ar mixture \\
Mass spectrometer & Agilent $7500 \mathrm{cs}$ \\
Internal standard & ${ }^{43} \mathrm{Ca}$ \\
Calibration standard & BCR-2G \\
Integration time & $\begin{array}{l}10 \mathrm{~ms} \text { except for }{ }^{95} \mathrm{Mo},{ }^{133} \mathrm{Cs} \\
\text { and }{ }^{141} \mathrm{Pr} \text { to }{ }^{238} \mathrm{U}=20 \mathrm{~ms}\end{array}$ \\
\hline
\end{tabular}

Table A1.7. Typical analytical conditions for LA-ICPMS analyses for basalt glasses

\section{A1.4.2.6 Elemental concentrations}

The sensitivity of an element, $\mathrm{S}_{\mathrm{i}}$, at the mass spectrometer is dependant on instrumental conditions that can vary over an analytical session (Longerich et al., 1996; Heinrich et al., 2003). Therefore, quantification of elemental concentrations of an unknown sample (SAMP) by LA-ICPMS requires both an external standard (STD) and an internal reference element (r), both of known composition that has been established independently (Longerich et al., 1996; 
Heinrich et al., 2003). The external standard is measured throughout an analytical session bracketing the analyses of the unknown. Therefore, the measured count rates of the analysed element for both the external standard and unknown sample together with the internal standard can be used to quantify the elemental concentrations of the unknown sample through the following relationship (Longerich et al., 1996);

$$
\frac{C_{i}^{S A M P}}{C_{r}^{S A M P}}=\frac{C_{i}^{S T D}}{C_{r}^{S T D}} \times \frac{I_{i}^{S A M P} I_{r}^{S T D}}{I_{r}^{S A M P} I_{i}^{S T D}} \times \frac{S_{i}^{S A M P} S_{r}^{S T D}}{S_{r}^{S A M P} S_{i}^{S T D}}
$$

where: $\mathrm{C}$ is the concentration of an element, $i$, or internal standard element, $\mathrm{r}$ of the sample (SAMP) or external standard (STD); I is the background-corrected signal intensity in counts per second of the sample or external standard of an element, $i$, or internal standard, $\mathrm{r}$ (Longerich et al., 1996). The final term in the equation is equal to 1 as the sensitivity ratios are identical for all elements (Longerich et al., 1996; Heinrich et al., 2003). In this study, the internal reference element, $\mathrm{r}$, is taken as the $\mathrm{CaO}$ content of either the reference material (see below) or the measured $\mathrm{CaO}$ concentration of the volcanic glass or mineral determined by EPMA prior to LA-ICPMS analysis (Jackson et al., 1992).

\section{A1.4.2.7 Reference materials}

Well-characterised reference materials are indispensable in LA-ICPMS as they allow for the calculation of trace element concentrations of unknown samples (e.g. Longerich et al., 1996). During ablation, the location of cations and type of chemical bonds within the crystal structure dictates the amount of energy required to free cations from the crystal lattice. Hence, reference materials should be as near as possible to the composition of your unknown to prevent the occurrence of matrix affects. 
Published elemental concentrations of materials vary between analytical techniques and laboratories. Reference materials and values used in this research are listed in Table A1.8 and are the GeoRem preferred values at the time of analyses (Jochum et al., 2006; GeoRem: http://georem.mpch-mainz.gwdg.de). These values have been determined at a number of different institutions and using analytical techniques including LA-ICPMS, secondary ion microprobe spectrometry (SIMS), isotope dilution analysis by thermal ionisation mass spectrometry (TIMS) and multi-collector inductively coupled mass spectrometry (MC-ICPMS).

\section{A1.4.3 LA-ICPMS analysis of volcanic glasses}

\section{A1.4.3.1. Basaltic glasses}

A series of experiments were performed to determine the optimal conditions for LA-ICPMS analyses of basaltic and rhyolitic glass. Basaltic glasses were focussed on first and initially the USGS basaltic reference glasses BCR-2G and BHVO-2G were taken as the standard and "unknown" respectively using the analytical conditions described above. These early LA-ICPMS analyses of volcanic glass consisted of 100 counts that included ca. 45 counts of instrumental background and then 50 counts of ablation. In general, analytical sessions during this period of technique development consisted of analysis of five 'unknowns' with each unknown bracketed by analysis of the external standard.

The initial results of BHVO-2G (Table A1.9) as the unknown indicated better than $10 \%$ precision for the majority of elements. Some of the least precise results were obtained for the rare earth elements (e.g. $\mathrm{Nd}$ and $\mathrm{Gd}$ ). 


\begin{tabular}{|c|c|c|c|c|c|c|c|}
\hline Isotope & Element & $\begin{array}{c}\text { NIST } \\
610\end{array}$ & $\begin{array}{c}\text { NIST } \\
612\end{array}$ & BCR-2G & $\begin{array}{c}\text { BHVO- } \\
2 \mathrm{G}\end{array}$ & $\begin{array}{c}\text { STH-G } \\
\text { (StHs6/ } \\
80)\end{array}$ & ATHO-G \\
\hline 7 & $\mathrm{Li}$ & 485 & 41.5 & 10.5 & 4.7 & 20.7 & 28.6 \\
\hline 9 & $\mathrm{~B}$ & 356 & 34.7 & 7.3 & 5.4 & 11.8 & 5.7 \\
\hline 11 & $\mathrm{Be}$ & 466 & 37.7 & 1.3 & 0.79 & 1.2 & 3.2 \\
\hline 25 & $\mathrm{Mg}$ & 465 & 77 & 21466 & 42992 & 11879 & 621 \\
\hline 43 & $\mathrm{Ca}$ & 11.5 & 11.9 & 7.06 & 11.4 & 5.28 & 1.7 \\
\hline 45 & $\mathrm{Sc}$ & 441 & 41 & 33 & 33 & 11.5 & 7 \\
\hline 47 & $\mathrm{Ti}$ & 434 & 44 & 14100 & 16300 & 421 & 1527 \\
\hline 51 & V & 442 & 39 & 425 & 308 & 90.3 & 3.91 \\
\hline 53 & $\mathrm{Cr}$ & 405 & 36 & 17 & 293 & 16.9 & 6.1 \\
\hline 55 & $\mathrm{Mn}$ & 485 & 38 & 1472 & 1317 & 589 & 821 \\
\hline 59 & $\mathrm{Co}$ & 405 & 35 & 38 & 44 & 13.2 & 2.13 \\
\hline 60 & $\mathrm{Ni}$ & 459 & 38.8 & 13 & 116 & 23.7 & 13 \\
\hline 63 & $\mathrm{Cu}$ & 430 & 37 & 21 & 127 & 41.5 & 18.6 \\
\hline 66 & $\mathrm{Zn}$ & 456 & 38 & 125 & 102 & 67 & 141 \\
\hline 71 & $\mathrm{Ga}$ & 438 & 36 & 23 & 22 & 20.9 & 25.3 \\
\hline 85 & $\mathrm{Rb}$ & 426 & 31.4 & 47 & 9.2 & 30.7 & 65.3 \\
\hline 88 & $\mathrm{Sr}$ & 516 & 78.4 & 342 & 396 & 482 & 94.1 \\
\hline 89 & $\mathrm{Y}$ & 450 & 38.2 & 35 & 26 & 11.4 & 94.5 \\
\hline 90 & $\mathrm{Zr}$ & 440 & 38 & 184 & 170 & 118 & 512 \\
\hline 93 & $\mathrm{Nb}$ & 149 & 40 & 12.5 & 18.3 & 6.94 & 62.4 \\
\hline 95 & Mo & 410 & 38 & 270 & 3.8 & 2 & 4.8 \\
\hline 133 & $\mathrm{Cs}$ & 361 & 42 & 1.16 & 0.1 & 1.75 & 1.08 \\
\hline 137 & $\mathrm{Ba}$ & 435 & 39.7 & 683 & 131 & 298 & 559 \\
\hline 139 & $\mathrm{La}$ & 457 & 35.8 & 24.7 & 15.2 & 12 & 55.6 \\
\hline 140 & $\mathrm{Ce}$ & 448 & 38.7 & 53.3 & 37.6 & 26.1 & 121 \\
\hline 141 & $\mathrm{Pr}$ & 430 & 37.2 & 6.7 & 5.35 & 3.2 & 14.6 \\
\hline 146 & $\mathrm{Nd}$ & 431 & 35.9 & 28.9 & 24.5 & 13 & 60.9 \\
\hline 147 & $\mathrm{Sm}$ & 451 & 38.1 & 6.59 & 6.1 & 2.78 & 14.2 \\
\hline 153 & $\mathrm{Eu}$ & 461 & 35 & 1.97 & 2.07 & 0.953 & 2.76 \\
\hline 157 & $\mathrm{Gd}$ & 444 & 36.7 & 6.71 & 6.16 & 2.59 & 15.3 \\
\hline 159 & $\mathrm{~Tb}$ & 443 & 36 & 1.02 & 0.92 & 0.371 & 2.51 \\
\hline 163 & Dy & 427 & 36 & 6.44 & 5.28 & 2.22 & 16.2 \\
\hline 165 & Ho & 449 & 38 & 1.27 & 0.98 & 0.42 & 3.43 \\
\hline 166 & $\mathrm{Er}$ & 426 & 38 & 3.7 & 2.56 & 1.18 & 10.3 \\
\hline 169 & $\mathrm{Tm}$ & 420 & 38 & 0.51 & 0.34 & 0.172 & 1.52 \\
\hline 172 & $\mathrm{Yb}$ & 445 & 38 & 3.39 & 2.01 & 1.13 & 10.5 \\
\hline 175 & $\mathrm{Lu}$ & 435 & 36.9 & 0.503 & 0.279 & 0.168 & 1.54 \\
\hline 178 & $\mathrm{Hf}$ & 432 & 35 & 4.84 & 4.32 & 3.07 & 13.7 \\
\hline 181 & $\mathrm{Ta}$ & 452 & 40 & 0.78 & 1.15 & 0.42 & 3.9 \\
\hline 182 & W & 445 & 40 & 0.5 & 0.23 & 0.47 & 9.3 \\
\hline 208 & $\mathrm{~Pb}$ & 426 & 38.6 & 11 & 1.7 & 10.3 & 5.67 \\
\hline 232 & Th & 457 & 37.8 & 5.9 & 1.22 & 2.28 & 7.4 \\
\hline 238 & $\mathrm{U}$ & 462 & 37.4 & 1.69 & 0.403 & 1.01 & 2.37 \\
\hline
\end{tabular}

Table A1.8 Trace element concentrations in $\mathrm{ppm}$ and $\mathrm{CaO}$ in $\mathrm{wt}_{\mathrm{t}}^{\mathrm{o}}$ of reference glasses used in this study (GeoRem: http://georem.mpch-mainz.gwdg.de and Jochum et al., 2006). 
In an effort to increase the precision of the obtained data BCR-2G and BHVO$2 \mathrm{G}$ were polished with 600,2400 and 4000 grit silicon carbide paper and $1 / 4 \mu \mathrm{m}$ diamond paste to create a level surface for ablation. Isobaric interferences are known to occur on the middle rare earths due to oxide interferences from the light rare earths (Kent and Ungerer, 2005) and therefore the oxides production rate was closely monitored by analysis of four gadolinium isotopes $\left({ }^{155} \mathrm{Gd},{ }^{156} \mathrm{Gd}\right.$, ${ }^{157} \mathrm{Gd},{ }^{158} \mathrm{Gd}$ ). Results from this set of analyses (Table A1.10) indicate the polishing of the sample and standard improved the quality of data with an increase in precision and accuracy, however, the rare earth elements still displayed only ca. $10 \%$ precision and no significant interferences were observed to occur on the middle rare earth elements, indicating that another factor was controlling the precision of rare earth elements.

Initially samples were mounted in a circular epoxy block and the standard in a rectangular epoxy block and positioned in the ablation chamber as shown in Figure A1.1a. The position of the standard off centre, out of the direct flow of the carrier gas, resulted in inconsistent proportions of ablated sample and standard material being transported to the ICPMS. To eliminate this discrepancy, and to position both the sample and standard as centrally as possible in the direct flow of the carrier gas, both the sample and standard were remounted into semicircular epoxy mounts of $5 \mathrm{~mm}$ thickness (Figure A1.1b). This had the additional benefit that both mounts could now be dropped flush with the top of the ablation cell (Figure A1.1c) allowing for the unhindered flow of gas through the chamber. BHVO-2G was reanalysed with the new configuration of mounts in the ablation 
chamber resulting in an increase in both precision and accuracy for the majority of trace elements, including the rare earth elements (Table A1.11).

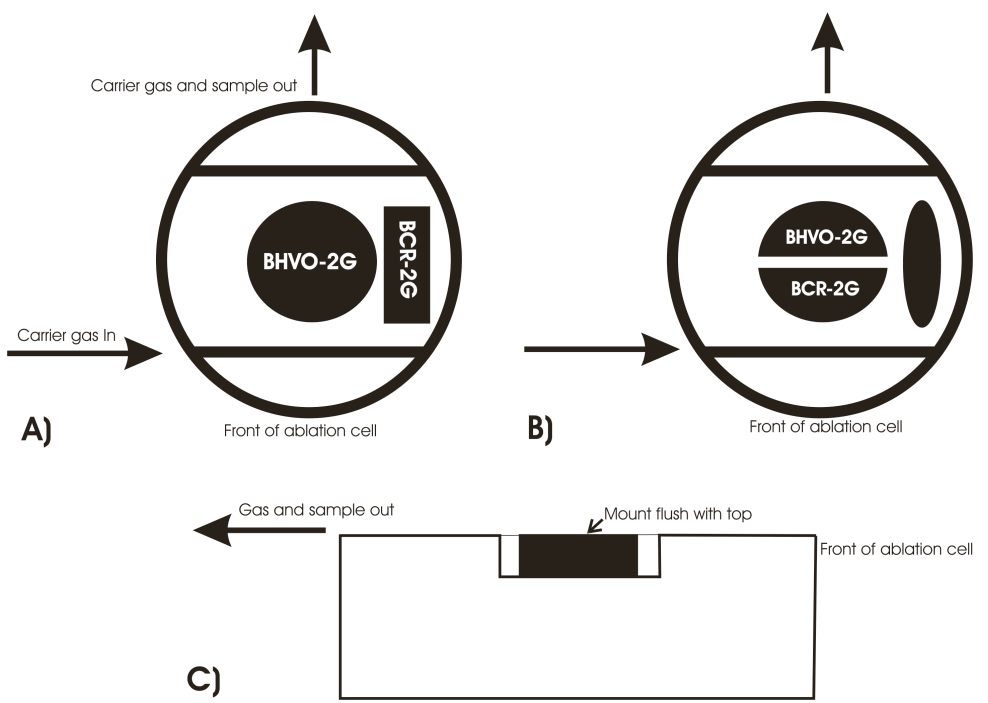

Figure A1.1. Position of the sample and standard in the ablation cell for analysis. A) Initial configuration and shape of epoxy mounts of BHVO-2G and BCR-2G. B) Revised configuration and shapes of mounts with location of block on down flow side of cell reducing the cell volume. C) Profile of ablation cell showing mount flush with top of cell.

It should be noted though, that if the two mounts are rotated $90^{\circ}$ from that shown in Figure A1.1b the precision of the data is greatly reduced (Table A1.12), most probably as a result of the channelling of a proportion of the carrier gas between the epoxy mounts instead of flowing over them. The channel between the two epoxy mounts, had the unfortunate affect of allowing gas to escape into the lower proportion of the ablation chamber that had previously been inaccessible in the earlier experiments and this greatly increased the $\mathrm{Pb}$ background. This was solved simply by placing a piece of tape beneath the mounts preventing access to the lower proportion of the ablation chamber. 
The volume of the ablation cell was reduced by positioning an epoxy block off to one side where previously the standard (BCR-2G) had been located (Figure A1.1) with the result of containing the gas flow within the central portion of the ablation chamber. BHVO-2G was reanalysed with this new arrangement and again results showed a further increase in the precision and accuracy of the obtained elemental concentrations (Table A1.13) indicating the importance of sample configuration within the sample cell.

All the previous experiments were conducted with a spot size of $35 \mu \mathrm{m}$, however, melt inclusions vary in size from $>200 \mu \mathrm{m}$ to $<10 \mu \mathrm{m}$ diameter and therefore it would be advantageous to analyse samples at smaller spot sizes. Conversely, a series of analyses of BHVO-2G were performed with spot sizes spanning between $10 \mu \mathrm{m}$ to $50 \mu \mathrm{m}$ (Table A1.14). These results indicate that a spot size down to $15 \mu \mathrm{m}$ could be implemented and still retain a $10 \%$ accuracy for the majority of elements, with only elements with low concentrations such as Cs requiring a larger spot size in order to acquire sufficient material for analysis (Table A1.14). However, analysis of BHVO-2G at 10, 35 and $50 \mu \mathrm{m}$ spot diameters shows elemental fractionation of volatile/refractory elements increases at smaller spot sizes (Figure A1.2) indicating the largest possible spot size viable should be utilised when analysing samples. 


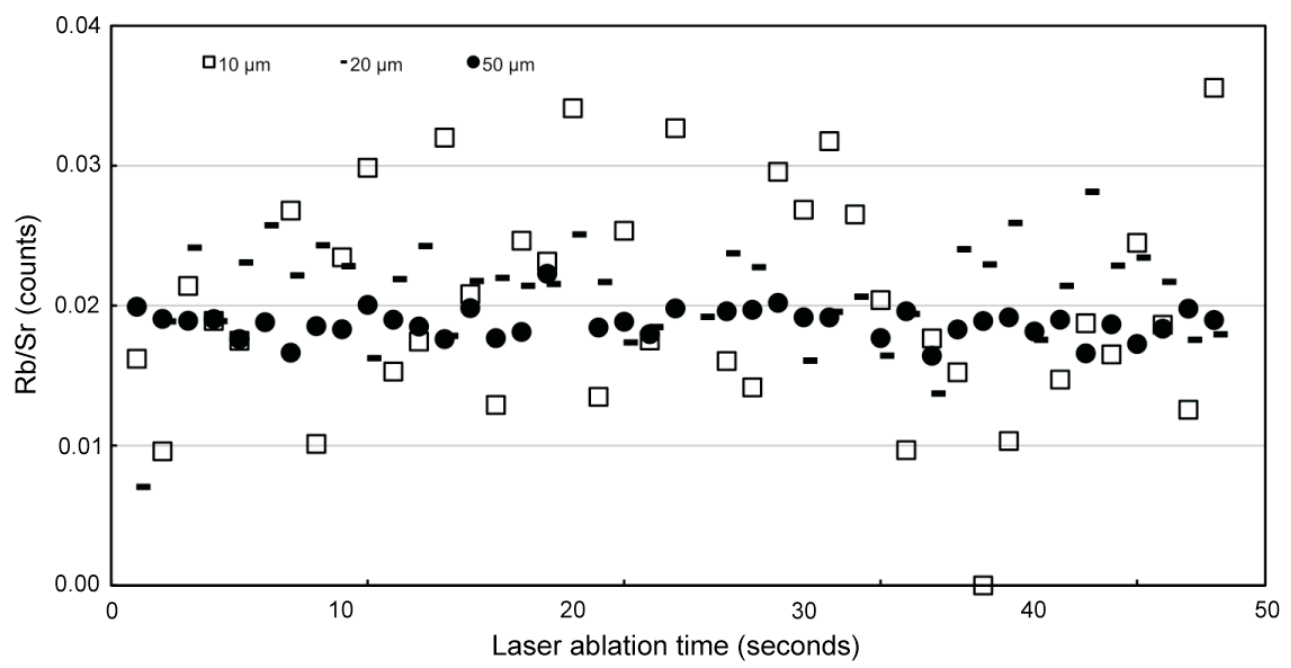

Figure A1.2. Elemental fractionation of refractory/volatile elements at $10 \mu \mathrm{m}, 20 \mu \mathrm{m}$ and $50 \mu \mathrm{m}$ spot sizes displayed by measured $\mathrm{Rb} / \mathrm{Sr}$ ratio (calculated from the analysed counts) of BHVO-2G with increasing ablation time (seconds).

\section{A1.4.3.2. Rhyolitic glasses}

Melt inclusions in this study are sourced from large-volume rhyolites that are characterised by high $\mathrm{SiO}_{2}$ (e.g. $>70 \mathrm{wt} \%$ anhydrous, Chapter 2) and low $\mathrm{CaO}$ (e.g. $<2.5 \mathrm{wt} \%$, Chapter 2) concentrations. Therefore, it was imperative that the same precision and accuracy was attained for LA-ICPMS analyses of rhyolitic glass standards as was achieved for basaltic glass standards to ensure no secondary affects such as elemental fractionation occurred at high-silica compositions that were not previously observed for basaltic compositions. To this end the rhyolitic glass ATHO-G (Jochum et al., 2006) was analysed as the unknown with BCR-2G as the calibration standard.

At the outset, due to the low $\mathrm{CaO}$ concentrations of ATHO-G, analyses were conducted in reaction cell mode (Table A1.15). This reduced the Ca background to compensate for the low Ca compositions of rhyolitic material (Mason, 2001). 
This resulted in a loss of both precision and accuracy of ATHO-G analyses compared to BHVO-2G (Table A1.13). Repeating these analyses without the reaction cell increased the accuracy of the ATHO-G analyses (Table A1.16), however, measured concentrations still lacked the precision and accuracy achieved for BHVO-2G analyses (Table A1.13). Discrepancies were observed between reported $\mathrm{Ba}$, $\mathrm{La}$ and $\mathrm{Eu}$ concentrations of ATHO-G from LA-ICPMS and isotope dilution values (Jochum et al., 2006) indicating that a matrix affect could have occurred between the rhyolitic sample (ATHO-G) and the basaltic reference material (BCR-2G). Consequently, the synthetic glass standard NIST SRM 612 was substituted for BCR-2G and ATHO-G was reanalysed, first with a $35 \mu \mathrm{m}$ spot (Table A1.17) and second with a range of spot sizes $(20-50 \mu \mathrm{m})$ (Table A1.18). Both sets of analyses displayed a significant improvement in both precision and accuracy comparative to those achieved for basaltic glasses (Table A1.13; A1.14).

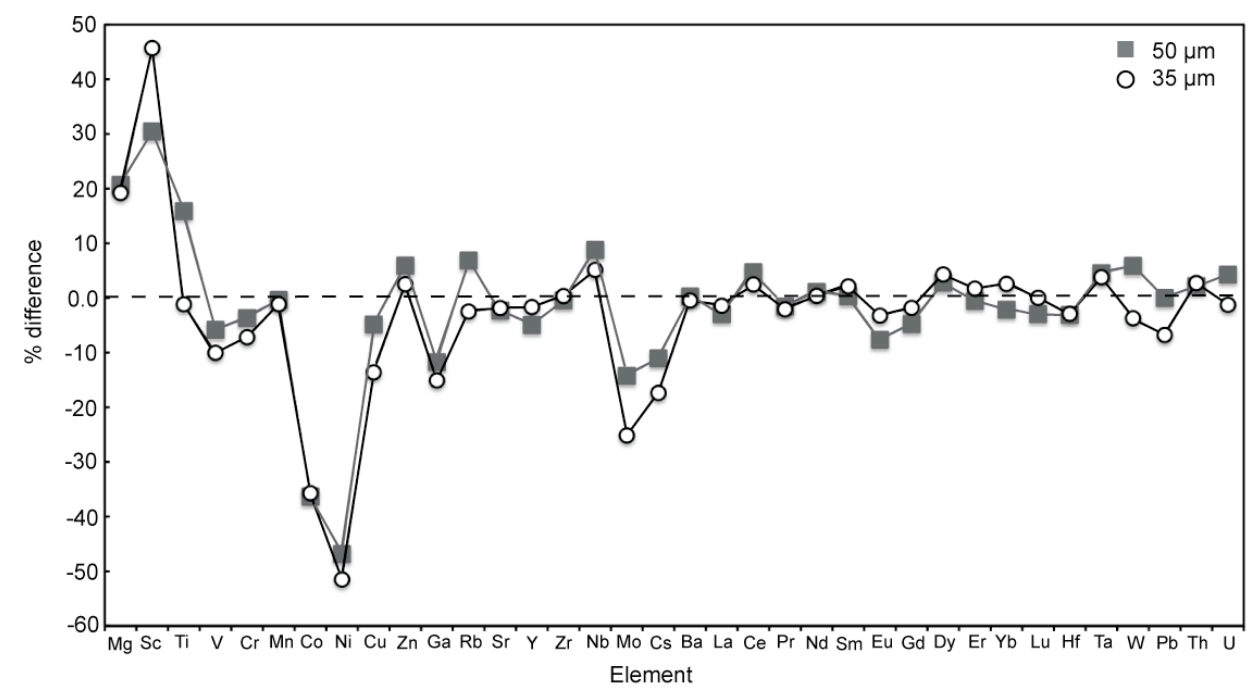

Figure A1.3. Reproducibility of trace element concentrations in ATHO-G at 50 and $35 \mu \mathrm{m}$ spot size. 
The elements that show the least reproducibility (e.g. Cr, Co, Ni) are those that are present in low concentrations and hence have low count rates (Figure A1.3). Therefore, the analysed concentrations of these elements in 'unknown' samples should be treated with caution.

\section{A1.4.3.3. Analysis of rhyolitic melt inclusions by LA-ICPMS}

As a result of the above experiments, rhyolitic melt inclusions in this study were analysed by LA-ICPMS utilising: NIST SRM 612 as the external standard; ${ }^{43} \mathrm{Ca}$ as the internal standard determined prior to LA-ICPMS analysis by EPMA; and background correcting samples to Ca. Melt inclusions were analysed with $35 \mu \mathrm{m}$ spot size decreasing to $20 \mu \mathrm{m}$ spot size only when it was absolutely essential. Since the original development of this methodology, the technique has been further refined and run conditions for volcanic glasses may differ to those presented here (e.g. Baker et al., 2008).

\section{A1.4.4. LA-ICPMS of plagioclase crystals}

The difference in atomic structure of crystals and glasses means the optimal conditions for the ablation of volcanic glasses may not be the same for plagioclase crystals. Unfortunately, the lack of a plagioclase specific standard resulted in the use of glass standards as the external standard during LA-ICPMS analyses for plagioclase crystals, which is not ideal.

Plagioclase was analysed for $\mathrm{Sr}, \mathrm{Ba}$ and $\mathrm{Mg}$ with $20 \mu \mathrm{m}$ spot diameters and REE, $\mathrm{Y}, \mathrm{Sr}$ and $\mathrm{Pb}$ spot analyses were conducted at 35 and $50 \mu \mathrm{m}$ spot diameters. Backscattered electron images taken before and after LA-ICPMS, permitted the 
EPMA and LA-ICPMS profiles to be correlated and the determination of $\mathrm{CaO}$ values for the internal standard (r) resolved.

A series of experiments were performed in order to determine the optimal spot size with which to analyse plagioclase crystals. The reference glass closest in composition to plagioclase is MPI-DING glass STHs6/80-G (hereafter referred to as $\mathrm{STH}-80 \mathrm{G}$ ) was taken as the unknown in these experiments. STH-80G has Sr (482 ppm) and $\mathrm{Ba}(298 \mathrm{ppm})$ concentrations that are expected to be in the region of the $\mathrm{Sr}$ and $\mathrm{Ba}$ concentrations of the plagioclase crystals of interest (Jochum et al., 2006). NIST SRM 610 was chosen as the external standard as $\mathrm{Sr}(515.5 \mathrm{ppm})$ and $\mathrm{Ba}(435 \mathrm{ppm})$ concentrations are nearer to STH-80G and expected plagioclase concentrations than NIST $612(\mathrm{Sr}=76.8 \mathrm{ppm} ; \mathrm{Ba}=39.7$ ppm) (Table A1.8). As plagioclase zonation occurs on scales $<20 \mu \mathrm{m}$, it was desirable to analyse plagioclase crystals at the smallest possible spot size. Analyses of STH-80G were conducted at $10 \mu \mathrm{m}$ and $20 \mu \mathrm{m}$ spot diameters for $\mathrm{Mg}, \mathrm{Ca}, \mathrm{Sr}, \mathrm{Ba}$ and $\mathrm{REE}$, at the same operating conditions as for volcanic glasses, with NIST SRM 610 as the external standard and STH-80G as the 'unknown' (Table A1.19; A1.20). This demonstrated that $\mathrm{Mg}, \mathrm{Ca}, \mathrm{Sr}$ and $\mathrm{Ba}$ could be analysed at $20 \mu \mathrm{m}$ spot diameters whereas it would be preferable to analyse REE at 35 or $50 \mu \mathrm{m}$ spot diameters.

\section{A1.5 Fourier transform infrared spectroscopy}

Water and carbon dioxide analyses of melt inclusions were conducted by both conventional Fourier Transform Infrared (FTIR) spectroscopy and spectroscopic imaging FTIR (Wysoczanski and Tani, 2006). FTIR spectroscopy is a non- 
destructive technique and $\mathrm{H}_{2} \mathrm{O}$ and $\mathrm{CO}_{2}$ analyses can be obtained from the same analytical point as major and trace element compositions. FTIR spectroscopy also has the advantage over other techniques such as SIMS of being able to determine speciation of $\mathrm{H}_{2} \mathrm{O}$ and $\mathrm{CO}_{2}$.

Analyses were conducted on a Varian FTS Stingray 7000 Micro Image Analyser spectrometer with a $\mathrm{KBr}$ beamsplitter at the Institute for Research on Earth Evolution (IFREE), Japan Agency for Marine Earth Science and Technology (JAMSTEC). $\mathrm{N}_{2}$ gas continuously purged the beam path in an attempt to minimise the affect of atmospheric water on the measured spectra (Wysoczanski and Tani, 2006). A background analysis taken through a $\mathrm{KBr}$ plate was conducted prior to each sample at the same analytical conditions as for sample analysis. Samples were placed onto the $\mathrm{KBr}$ plate and both transmission and reflection spectra were acquired (Figure A1.4) with the background spectra subtracted from the sample spectra.

Concentrations of water species were calculated from absorbance bands in the FTIR transmission spectra using the Beer- Lambert Law;

$$
c_{i}=\frac{M_{i} A}{\rho d \varepsilon}
$$

where $c_{i}$ is the concentration of species $i$ in weight $\%, M_{i}$ is the molecular weight of species $i(\mathrm{~g} / \mathrm{mol})$, A is the absorbance (peak height) of the relevant vibration band, $\rho$ is the sample density $(\mathrm{g} / \mathrm{l}), d$ is the thickness of sample $(\mathrm{cm})$ and $\varepsilon$ is the molar absorptivity $(1 / \mathrm{mol}-\mathrm{cm})$. Total water concentrations were determined using the height above background of the overtone of the bending vibration of the $\mathrm{H}_{2} \mathrm{O}_{\mathrm{m}}$ group at $5200 \mathrm{~cm}^{-1}$ and molar absorptivity of $1.861 \mathrm{~mol}^{-1} \mathrm{~cm}$ and $\mathrm{OH}^{-}$ 
concentrations were calculated using the overtone of the stretching and bending of Si-OH' $\mathrm{OH}^{-}$groups at $4500 \mathrm{~cm}^{-1}$ and molar absorptivity of $1.51 \mathrm{~mol}^{-1} \mathrm{~cm}$ (Ihinger et al., 1994). Total $\mathrm{H}_{2} \mathrm{O}$ was calculated summing the $\mathrm{H}_{2} \mathrm{O}_{m}$ concentration from the peak at $5200 \mathrm{~cm}^{-1}$ and $\mathrm{OH}^{-}$concentration from the peak at $4500 \mathrm{~cm}^{-1}$. When the absorbance was low, the fundamental $\mathrm{OH}^{-}$stretching vibration at $3535 \mathrm{~cm}^{-1}$ and molar absorptivity of $90 \pm 21 \mathrm{~mol}^{-1} \mathrm{~cm}$ (Hauri et al., 2002) and the height of the $\mathrm{HOH}$ bending vibration at $1630 \mathrm{~cm}^{-1}$ and molar absorptivity of $56 \pm 21 \mathrm{~mol}^{-1}$ cm (Newman et al., 1986) were used to calculate $\mathrm{H}_{2} \mathrm{O}_{m}$ and $\mathrm{H}_{2} \mathrm{O}_{\mathrm{t}}$ contents, respectively. $\mathrm{OH}^{-}$concentrations were calculated from the difference in $\mathrm{H}_{2} \mathrm{O}_{t}$ (3535 $\left.\mathrm{cm}^{-1}\right)$ and $\mathrm{H}_{2} \mathrm{O}_{\mathrm{m}}\left(1630 \mathrm{~cm}^{-1}\right)$. In each case peak heights were determined using a linear baseline; applying a flexicurve baseline produced results consistent with the linear baseline. The molecular $\mathrm{CO}_{2}$ peaks at $2350 \mathrm{~cm}^{-1}$ and the carbonate doublet peaks of $\mathrm{CO}_{3}^{2-}$ at $1515 \mathrm{~cm}^{-1}$ and $1435 \mathrm{~cm}^{-1}$ were analysed (Fine and Stolper, 1985; Ihinger et al., 1994), but were found to be below detection limits.

In addition, the calibration of Zhang et al. (1997) can be used to calculate molecular $\mathrm{H}_{2} \mathrm{O}\left(\mathrm{H}_{2} \mathrm{O}_{\mathrm{m}}\right)$ concentrations and hydroxyl $\left(\mathrm{OH}^{-}\right)$concentrations from the following relationships;

$$
\begin{aligned}
& H_{2} O_{m}=\delta_{5230} A_{5230} \\
& O H^{-}=\delta_{4520} A_{4520}
\end{aligned}
$$

where,

$$
\begin{gathered}
\delta_{5230}=(\rho / 18.015)\left(a_{0}\right) \\
\delta_{4520}=(\rho / 18.015)\left(b_{0}-b_{1} A_{5230}+b_{2} A_{4520}\right)
\end{gathered}
$$


where $A_{4520}$ is the $4520 \mathrm{~cm}^{-1}$ absorbance (peak height), $\mathrm{A}_{5230}$ is the $5230 \mathrm{~cm}^{-1}$ absorbance (peak height), $\rho$ is the glass density $(\mathrm{g} / \mathrm{l}), a_{0}=0.04217, b_{0}=0.04024$, $b_{1}=0.02011$ and $b_{2}=0.0522$ (Zhang et al., 1997; Ihinger et al., 1999). However, this is only accurate for species concentrations for samples with total $\mathrm{H}_{2} \mathrm{O}$ concentrations below 2.7 wt \% (Zhang et al., 1997; Ihinger et al., 1999; Chapter $3)$.

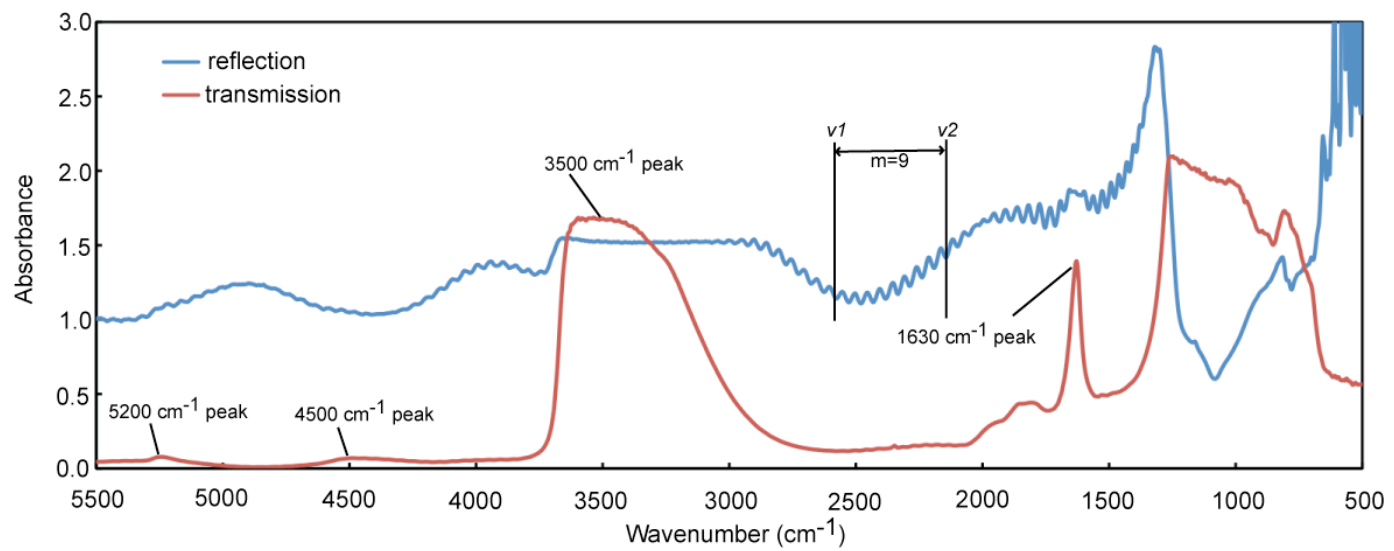

Figure A1.4. Transmission and reflected spectra of a Whakamaru melt inclusion. The four peaks used for the determination of water concentrations are shown and the reflection spectra used for thickness calculations (see text).

Glass density was calculated using the method of R. Lange as described by Luhr (2001) from electron microprobe analyses of melt inclusion compositions (Chapter 2). These ranged between $2303 \mathrm{~g} / 1$ and $2361 \mathrm{~g} / 1$. A value of $2350 \mathrm{~g} / 1$ was used with the Beer-Lambert law for all analyses, which equates to a maximum of $0.06 \mathrm{wt} \%$ error on the calculated water concentrations. Sample thicknesses of doubly exposed inclusions were determined at the analytical point using spacing of interference fringes on reflection spectra (Wysoczanski and Tani, 2006; Nichols and Wysoczanski, 2007). The refractive index (n) and 
sample thickness $(\partial)$ are related to the number of waves $(m)$ over a selected wave number interval $(v 1-v 2)$ by the following relationship (Figure A1.4);

$$
\partial=m / 2 n(v 1-v 2) \quad[\mathrm{A} 1.7]
$$

A refractive index of 1.5 was used for all melt inclusions in this study (Lui et al., 2005). Thicknesses of melt inclusions suspected to retain a thin wafer of the host crystal were determined by placing the crystals side-on in crystal bond on a glass slide and then examining them under the microscope. Uncertainties of calculated water concentrations are estimated to be $10 \%$ (e.g. Dixon et al., 1988). 
Appendix 1

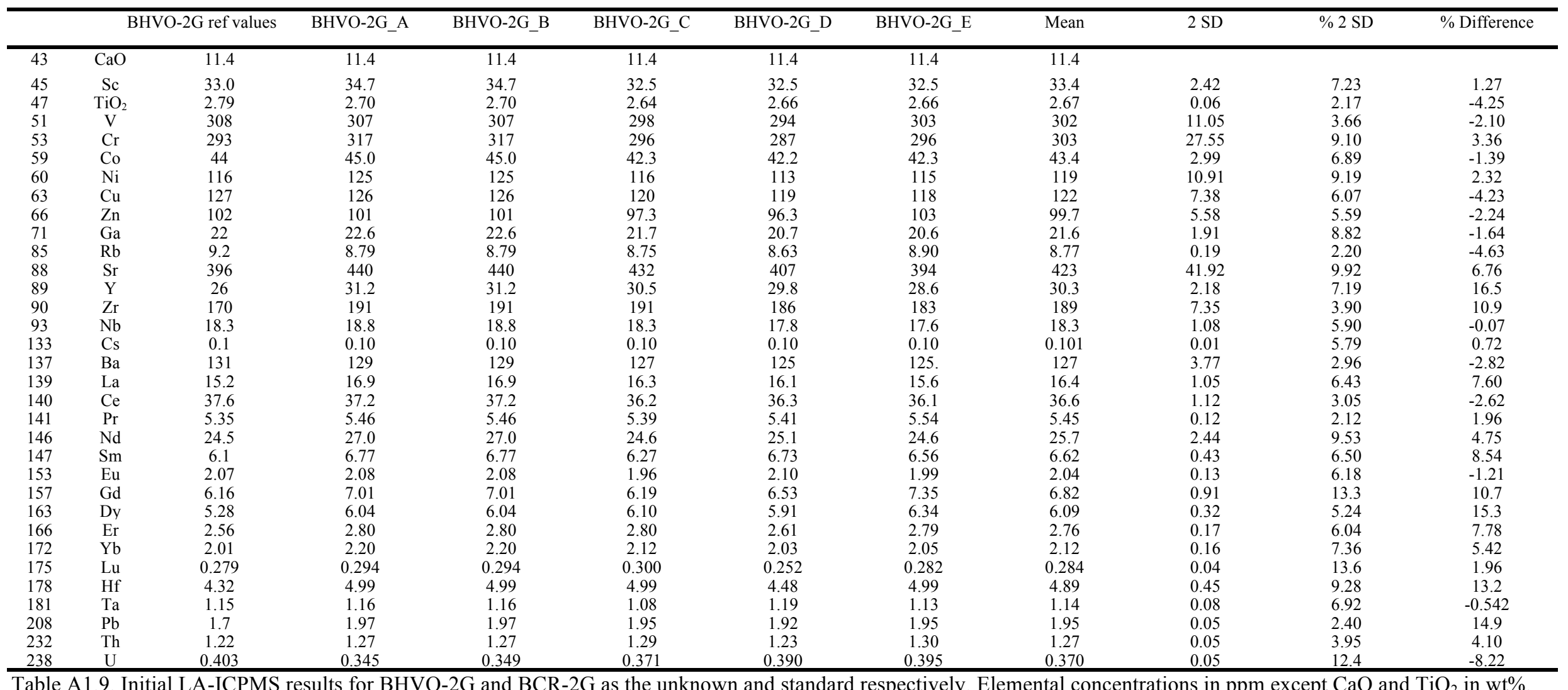


Appendix 1

\begin{tabular}{|c|c|c|c|c|c|c|c|c|c|c|c|}
\hline & & G ref values & BHVO-2G_G & BHVO-2G_H & BHVO-2G_I & BHVO-2G_J & BHVO-2G_K & Mean & $2 \mathrm{SD}$ & $\% 2 \mathrm{SD}$ & $\%$ Difference \\
\hline 43 & $\mathrm{CaO}$ & 11.4 & 11.4 & 11.4 & 11.4 & 11.4 & 11.4 & 11.4 & & & \\
\hline 45 & $\mathrm{Sc}$ & 33.0 & 32.0 & 32.4 & 32.2 & 31.8 & 32.6 & 32.2 & 0.60 & 1.87 & -2.41 \\
\hline 47 & $\mathrm{TiO}_{2}$ & 2.79 & 2.70 & 2.60 & 2.64 & 2.68 & 2.71 & 2.67 & 0.09 & 3.33 & -4.42 \\
\hline 51 & $\mathrm{~V}$ & 308 & 283 & 283 & 282 & 285 & 287 & 284 & 4.13 & 1.45 & -7.75 \\
\hline 53 & $\mathrm{Cr}$ & 293 & 311 & 303 & 283 & 288 & 275 & 292 & 29.7 & 10.2 & -0.43 \\
\hline 59 & Co & 44 & 40.2 & 40.7 & 40.7 & 40.6 & 40.7 & 40.6 & 0.49 & 1.21 & -7.75 \\
\hline 60 & $\mathrm{Ni}$ & 116 & 111 & 109 & 112 & 111 & 114 & 111 & 3.33 & 2.99 & -3.95 \\
\hline 63 & $\mathrm{Cu}$ & 127 & 112 & 111 & 110 & 109 & 118 & 112 & 6.40 & 5.71 & -11.8 \\
\hline 66 & $\mathrm{Zn}$ & 102 & 90.7 & 86.5 & 88.5 & 89.9 & 94.7 & 90.1 & 6.09 & 6.76 & -11.7 \\
\hline 71 & $\mathrm{Ga}$ & 22 & 20.1 & 19.5 & 18.2 & 19.2 & 20.6 & 19.5 & 1.78 & 9.13 & -11.2 \\
\hline 85 & $\mathrm{Rb}$ & 9.2 & 8.20 & 7.93 & 8.32 & 8.25 & 8.59 & 8.26 & 0.48 & 5.78 & -10.2 \\
\hline 88 & $\mathrm{Sr}$ & 396 & 395 & 394 & 392 & 393 & 406 & 396 & 11.5 & 2.91 & 0.03 \\
\hline 89 & Y & 26 & 29.5 & 29.1 & 29.1 & 28.9 & 30.3 & 29.4 & 1.13 & 3.85 & 13.0 \\
\hline 90 & $\mathrm{Zr}$ & 170 & 185 & 182 & 181 & 181 & 187 & 183 & 5.31 & 2.90 & 7.73 \\
\hline 93 & $\mathrm{Nb}$ & 18.3 & 17.5 & 17.4 & 17.4 & 17.1 & 18.1 & 17.5 & 0.76 & 4.32 & -4.28 \\
\hline 133 & $\mathrm{Cs}$ & 0.1 & 0.094 & 0.087 & 0.091 & 0.089 & 0.099 & 0.092 & 0.01 & 9.97 & -8.19 \\
\hline 137 & $\mathrm{Ba}$ & 131 & 125 & 125 & 126 & 127 & 125 & 125 & 1.38 & 1.10 & -4.24 \\
\hline 139 & $\mathrm{La}$ & 15.2 & 16.5 & 16.1 & 16.1 & 15.9 & 16.8 & 16.3 & 0.71 & 4.38 & 6.95 \\
\hline 140 & $\mathrm{Ce}$ & 37.6 & 36.0 & 35.0 & 35.1 & 35.5 & 36.1 & 35.5 & 1.03 & 2.90 & -5.51 \\
\hline 141 & $\mathrm{Pr}$ & 5.35 & 5.39 & 5.25 & 5.46 & 5.51 & 5.57 & 5.44 & 0.25 & 4.57 & 1.62 \\
\hline 146 & $\mathrm{Nd}$ & 24.5 & 25.1 & 24.8 & 25.0 & 25.4 & 25.6 & 25.2 & 0.61 & 2.43 & 2.74 \\
\hline 147 & $\mathrm{Sm}$ & 6.1 & 6.33 & 6.50 & 6.54 & 6.36 & 6.88 & 6.52 & 0.44 & 6.68 & 6.94 \\
\hline 153 & $\mathrm{Eu}$ & 2.07 & 1.96 & 2.07 & 1.97 & 2.07 & 2.14 & 2.04 & 0.15 & 7.50 & -1.30 \\
\hline 155 & $\mathrm{Gd}$ & 6.16 & 5.37 & 5.34 & 5.57 & 5.16 & 5.80 & 5.45 & 0.49 & 8.90 & -11.5 \\
\hline 156 & $\mathrm{Gd}$ & 6.16 & 5.73 & 5.57 & 5.73 & 6.16 & 6.10 & 5.86 & 0.52 & 8.87 & -4.92 \\
\hline 157 & $\mathrm{Gd}$ & 6.16 & 6.42 & 6.75 & 7.03 & 6.70 & 7.41 & 6.86 & 0.75 & 10.9 & 11.4 \\
\hline 158 & $\mathrm{Gd}$ & 6.16 & 6.91 & 6.86 & 6.81 & 6.56 & 6.83 & 6.79 & 0.27 & 3.98 & 10.3 \\
\hline 163 & Dy & 5.28 & 5.86 & 5.77 & 5.81 & 5.63 & 5.99 & 5.81 & 0.26 & 4.51 & 10.1 \\
\hline 166 & Er & 2.56 & 2.74 & 2.76 & 2.70 & 2.74 & 2.98 & 2.78 & 0.22 & 8.00 & 8.72 \\
\hline 172 & $\mathrm{Yb}$ & 2.01 & 2.17 & 2.07 & 2.05 & 2.00 & 2.17 & 2.09 & 0.15 & 7.25 & 4.13 \\
\hline 175 & $\mathrm{Lu}$ & 0.279 & 0.314 & 0.301 & 0.315 & 0.309 & 0.318 & 0.311 & 0.01 & 4.09 & 11.6 \\
\hline 178 & $\mathrm{Hf}$ & 4.32 & 4.74 & 4.54 & 4.71 & 4.84 & 5.01 & 4.77 & 0.35 & 7.35 & 10.4 \\
\hline 181 & $\mathrm{Ta}$ & 1.15 & 1.05 & 1.11 & 1.18 & 1.08 & 1.11 & 1.11 & 0.10 & 9.01 & -3.85 \\
\hline 208 & $\mathrm{~Pb}$ & 1.7 & 1.59 & 1.61 & 1.64 & 1.72 & 1.80 & 1.67 & 0.17 & 10.5 & -1.56 \\
\hline 232 & Th & 1.22 & 1.23 & 1.22 & 1.26 & 1.27 & 1.26 & 1.25 & 0.05 & 3.83 & 2.17 \\
\hline 238 & $\mathrm{U}$ & 0.403 & 0.371 & 0.383 & 0.366 & 0.357 & 0.380 & 0.371 & 0.02 & $\begin{array}{l}5.07 \\
5.73\end{array}$ & -7.85 \\
\hline
\end{tabular}

Table A1.10. Analysis of polished BHVO-2G and BCR-2G as the unknown and standard respectively. Elemental concentrations in ppm except $\mathrm{CaO}_{\mathrm{O}}$ and TiO $\mathrm{O}_{2}$ in $\mathrm{wt} \%$. 
Appendix 1

\begin{tabular}{|c|c|c|c|c|c|c|c|c|c|c|c|}
\hline & & G ref values & BHVO-2G_L & BHVO-2G_M & BHVO-2G_N & BHVO-2G_O & BHVO-2G_P & Mean & $2 \mathrm{SD}$ & $\% 2 \mathrm{SD}$ & $\%$ Difference \\
\hline 43 & $\mathrm{CaO}$ & 11.4 & 11.4 & 11.4 & 11.4 & 11.4 & 11.4 & 11.4 & & & \\
\hline 45 & $\mathrm{Sc}$ & 33.0 & 32.3 & 34.1 & 34.1 & 34.7 & 36.1 & 34.3 & 2.70 & 7.87 & 3.88 \\
\hline 47 & $\mathrm{TiO}_{2}$ & 2.79 & 2.61 & 2.66 & 2.66 & 2.67 & 2.72 & 2.67 & 0.08 & 2.97 & -4.44 \\
\hline 51 & $\mathrm{~V}$ & 308 & 293 & 300 & 300 & 304 & 309 & 301 & 11.2 & 3.71 & -2.14 \\
\hline 53 & $\mathrm{Cr}$ & 293 & 305 & 336 & 336 & 312 & 330 & 324 & 29.0 & 8.95 & 10.6 \\
\hline 59 & Co & 44 & 41.4 & 41.9 & 41.9 & 44.1 & 45.1 & 42.9 & 3.23 & 7.53 & -2.52 \\
\hline 60 & $\mathrm{Ni}$ & 116 & 118 & 122 & 122 & 119 & 127 & 121 & 7.07 & 5.82 & 4.67 \\
\hline 63 & $\mathrm{Cu}$ & 127 & 116 & 113 & 113 & 116 & 122 & 116 & 7.50 & 6.45 & -8.46 \\
\hline 66 & $\mathrm{Zn}$ & 102 & 93.4 & 95.4 & 95.4 & 88.5 & 94.8 & 93.5 & 5.83 & 6.23 & -8.30 \\
\hline 71 & $\mathrm{Ga}$ & 22 & 21.0 & 21.7 & 21.7 & 20.2 & 20.9 & 21.1 & 1.27 & 6.01 & -3.97 \\
\hline 85 & $\mathrm{Rb}$ & 9.2 & 8.72 & 9.10 & 9.10 & 9.01 & 8.90 & 8.97 & 0.33 & 3.64 & -2.54 \\
\hline 88 & $\mathrm{Sr}$ & 396 & 389 & 396 & 396 & 397 & 399 & 395 & 7.46 & 1.89 & -0.189 \\
\hline 89 & $\mathrm{Y}$ & 26 & 31.0 & 31.1 & 31.1 & 31.2 & 30.7 & 31.0 & 0.34 & 1.10 & 19.3 \\
\hline 90 & $\mathrm{Zr}$ & 170 & 189 & 196 & 196 & 192 & 192 & 193 & 5.95 & 3.08 & 13.5 \\
\hline 93 & $\mathrm{Nb}$ & 18.3 & 17.7 & 17.8 & 17.8 & 17.7 & 17.2 & 17.7 & 0.52 & 2.92 & -3.54 \\
\hline 133 & Cs & 0.1 & 0.110 & 0.109 & 0.109 & 0.099 & 0.085 & 0.103 & 0.02 & 21.4 & 2.61 \\
\hline 137 & $\mathrm{Ba}$ & 131 & 126 & 127 & 127 & 123 & 127 & 126 & 3.22 & 2.55 & -3.76 \\
\hline 139 & $\mathrm{La}$ & 15.2 & 16.3 & 16.8 & 16.8 & 16.1 & 16.2 & 16.5 & 0.73 & 4.43 & 8.27 \\
\hline 140 & $\mathrm{Ce}$ & 37.6 & 36.3 & 36.6 & 36.6 & 35.7 & 36.0 & 36.3 & 0.77 & 2.11 & -3.56 \\
\hline 141 & $\mathrm{Pr}$ & 5.35 & 5.24 & 5.36 & 5.36 & 5.59 & 5.54 & 5.42 & 0.28 & 5.24 & 1.31 \\
\hline 146 & $\mathrm{Nd}$ & 24.5 & 25.2 & 25.2 & 25.2 & 26.6 & 26.3 & 25.7 & 1.36 & 5.28 & 5.00 \\
\hline 147 & $\mathrm{Sm}$ & 6.1 & 6.44 & 6.22 & 6.22 & 6.54 & 7.06 & 6.50 & 0.69 & 10.6 & 6.52 \\
\hline 153 & $\mathrm{Eu}$ & 2.07 & 2.06 & 1.99 & 1.99 & 2.15 & 2.05 & 2.05 & 0.13 & 6.37 & -0.97 \\
\hline 155 & $\mathrm{Gd}$ & 6.16 & 6.02 & 5.64 & 5.64 & 5.73 & 6.20 & 5.85 & 0.50 & 8.60 & -5.11 \\
\hline 156 & $\mathrm{Gd}$ & 6.16 & 6.80 & 6.59 & 6.59 & 6.85 & 6.98 & 6.76 & 0.34 & 4.98 & 9.76 \\
\hline 157 & $\mathrm{Gd}$ & 6.16 & 6.91 & 6.77 & 6.77 & 6.70 & 6.99 & 6.83 & 0.24 & 3.50 & 10.8 \\
\hline 158 & $\mathrm{Gd}$ & 6.16 & 6.96 & 6.88 & 6.88 & 6.83 & 7.54 & 7.02 & 0.59 & 8.38 & 13.9 \\
\hline 163 & Dy & 5.28 & 5.89 & 6.40 & 6.40 & 5.80 & 6.03 & 6.10 & 0.57 & 9.28 & 15.6 \\
\hline 166 & Er & 2.56 & 2.93 & 3.15 & 3.15 & 3.02 & 3.06 & 3.06 & 0.19 & 6.08 & 19.7 \\
\hline 172 & $\mathrm{Yb}$ & 2.01 & 2.18 & 2.15 & 2.15 & 2.20 & 2.38 & 2.22 & 0.19 & 8.60 & 10.2 \\
\hline 175 & $\mathrm{Lu}$ & 0.279 & 0.277 & 0.315 & 0.315 & 0.317 & 0.363 & 0.317 & 0.06 & 19.3 & 13.8 \\
\hline 178 & $\mathrm{Hf}$ & 4.32 & 4.99 & 5.19 & 5.19 & 5.41 & 5.17 & 5.19 & 0.30 & 5.69 & 20.1 \\
\hline 181 & $\mathrm{Ta}$ & 1.15 & 1.15 & 1.17 & 1.17 & 1.23 & 1.19 & 1.18 & 0.06 & 5.50 & 2.70 \\
\hline 208 & $\mathrm{~Pb}$ & 1.7 & 1.76 & 1.78 & 1.78 & 1.71 & 1.71 & 1.75 & 0.07 & 3.94 & 2.69 \\
\hline 232 & Th & 1.22 & 1.28 & 1.33 & 1.33 & 1.29 & 1.33 & 1.31 & 0.05 & 3.68 & 7.64 \\
\hline 238 & $\mathrm{U}$ & 0.403 & 0.380 & 0.381 & 0.381 & 0.370 & 0.388 & 0.380 & 0.01 & 3.37 & -5.71 \\
\hline
\end{tabular}

Table A1.10 continued 
Appendix 1

\begin{tabular}{|c|c|c|c|c|c|c|c|c|c|c|c|}
\hline & & G ref values & BHVO-2G_Q & BHVO-2G_R & BHVO-2G_S & BHVO-2G_T & BHVO-2G_U & Mean & $2 \mathrm{SD}$ & $\% 2 \mathrm{SD}$ & $\%$ Difference \\
\hline 43 & $\mathrm{CaO}$ & 11.4 & 11.4 & 11.4 & 11.4 & 11.4 & 11.4 & 11.4 & & & \\
\hline 45 & $\mathrm{Sc}$ & 33.0 & 31.1 & 30.8 & 31.9 & 30.9 & 31.7 & 31.3 & 1.00 & 3.20 & -5.19 \\
\hline 47 & $\mathrm{TiO}_{2}$ & 2.79 & 2.68 & 2.69 & 2.74 & 2.74 & 2.73 & 2.72 & 0.06 & 2.28 & -2.64 \\
\hline 51 & V & 308 & 312 & 309 & 315 & 315 & 311 & 312 & 5.63 & 1.80 & 1.46 \\
\hline 53 & $\mathrm{Cr}$ & 293 & 349 & 329 & 315 & 325 & 308 & 325 & 31.3 & 9.62 & 11.0 \\
\hline 59 & Co & 44.0 & 44.1 & 44.6 & 43.6 & 43.4 & 44.2 & 44.0 & 0.938 & 2.13 & -0.08 \\
\hline 60 & $\mathrm{Ni}$ & 116 & 117 & 127 & 113 & 125 & 120 & 120 & 10.9 & 9.06 & 3.81 \\
\hline 63 & $\mathrm{Cu}$ & 127 & 123 & 124 & 114 & 123 & 125 & 122 & 8.65 & 7.09 & -3.94 \\
\hline 66 & $\mathrm{Zn}$ & 102 & 102 & 104 & 96.4 & 100 & 98 & 100 & 6.37 & 6.36 & -1.83 \\
\hline 71 & $\mathrm{Ga}$ & 22.0 & 21.3 & 21.9 & 19.4 & 21.6 & 21.5 & 21.1 & 1.99 & 9.42 & -3.97 \\
\hline 85 & $\mathrm{Rb}$ & 9.20 & 8.98 & 9.07 & 8.48 & 8.91 & 8.75 & 8.84 & 0.463 & 5.24 & -3.93 \\
\hline 88 & $\mathrm{Sr}$ & 396 & 395 & 399 & 372 & 391 & 395 & 390 & 21.8 & 5.58 & -1.39 \\
\hline 89 & $\mathrm{Y}$ & 26.0 & 26.2 & 26.6 & 25.3 & 26.3 & 25.8 & 26.0 & 1.02 & 3.90 & 0.121 \\
\hline 90 & $\mathrm{Zr}$ & 170 & 166 & 164 & 155 & 169 & 164 & 163 & 10.2 & 6.24 & -3.87 \\
\hline 93 & $\mathrm{Nb}$ & 18.3 & 17.7 & 17.9 & 17.5 & 18.6 & 17.5 & 17.9 & 0.904 & 5.06 & -2.42 \\
\hline 133 & Cs & 0.10 & 0.099 & 0.090 & 0.087 & 0.077 & 0.103 & 0.091 & 0.020 & 22.4 & -8.92 \\
\hline 137 & $\mathrm{Ba}$ & 131 & 131 & 128 & 131 & 130 & 131 & 130 & 2.78 & 2.13 & -0.430 \\
\hline 139 & $\mathrm{La}$ & 15.2 & 15.6 & 14.9 & 14.4 & 15.5 & 15.4 & 15.1 & 1.00 & 6.63 & -0.358 \\
\hline 140 & $\mathrm{Ce}$ & 37.6 & 37.7 & 38.0 & 38.0 & 37.9 & 39.2 & 38.2 & 1.19 & 3.13 & 1.47 \\
\hline 141 & $\mathrm{Pr}$ & 5.35 & 5.33 & 5.10 & 5.18 & 5.45 & 5.52 & 5.32 & 0.347 & 6.53 & -0.638 \\
\hline 146 & $\mathrm{Nd}$ & 24.5 & 24.6 & 24.0 & 21.6 & 23.6 & 24.5 & 23.6 & 2.47 & 10.4 & -3.47 \\
\hline 147 & $\mathrm{Sm}$ & 6.1 & 5.98 & 5.98 & 5.28 & 5.98 & 6.13 & 5.87 & 0.674 & 11.5 & -3.76 \\
\hline 153 & $\mathrm{Eu}$ & 2.07 & 1.98 & 1.98 & 2.00 & 2.05 & 1.99 & 2.00 & 0.060 & 2.99 & -3.28 \\
\hline 157 & $\mathrm{Gd}$ & 6.16 & 6.52 & 6.62 & 6.15 & 6.05 & 6.40 & 6.35 & 0.483 & 7.6 & 3.02 \\
\hline 163 & Dy & 5.28 & 5.18 & 5.00 & 4.98 & 5.09 & 5.10 & 5.07 & 0.168 & 3.31 & -4.00 \\
\hline 166 & Er & 2.56 & 2.63 & 2.53 & 2.44 & 2.64 & 2.49 & 2.55 & 0.173 & 6.79 & -0.523 \\
\hline 172 & $\mathrm{Yb}$ & 2.01 & 1.96 & 1.77 & 1.91 & 2.06 & 1.92 & 1.92 & 0.206 & 10.7 & -4.25 \\
\hline 175 & $\mathrm{Lu}$ & 0.279 & 0.276 & 0.262 & 0.254 & 0.291 & 0.264 & 0.269 & 0.029 & 10.9 & -3.45 \\
\hline 178 & $\mathrm{Hf}$ & 4.32 & 4.59 & 4.45 & 4.05 & 4.33 & 4.54 & 4.39 & 0.431 & 9.81 & 1.70 \\
\hline 181 & $\mathrm{Ta}$ & 1.15 & 1.08 & 1.15 & 1.15 & 1.07 & 1.08 & 1.11 & 0.076 & 6.85 & -3.87 \\
\hline 208 & $\mathrm{~Pb}$ & 1.7 & 1.88 & 1.88 & 2.19 & 1.76 & 1.80 & 1.90 & 0.340 & 17.9 & 11.9 \\
\hline 232 & Th & 1.22 & 1.25 & 1.17 & 1.18 & 1.22 & 1.17 & 1.20 & 0.073 & 6.07 & -1.85 \\
\hline 238 & $\mathrm{U}$ & 0.403 & 0.419 & 0.415 & 0.385 & 0.440 & 0.395 & 0.411 & 0.043 & 10.5 & 1.89 \\
\hline
\end{tabular}

Table A1.11 Analysis of polished BHVO-2G and BCR-2G as the unknown and standard respectively when mounted in half circles. Elemental concentrations in ppm except

$\mathrm{CaO}$ and $\mathrm{TiO}_{2}$ in $\mathrm{wt} \%$. 
Appendix 1

\begin{tabular}{|c|c|c|c|c|c|c|c|c|c|c|c|}
\hline & & G ref values & BHVO-2G_V1 & BHVO-2G_U1 & BHVO-2G_W1 & BHVO-2G_X1 & BHVO-2G_Y1 & Mean & $2 \mathrm{SD}$ & $\% 2 \mathrm{SD}$ & $\%$ Difference \\
\hline 43 & $\mathrm{CaO}$ & 11.4 & 11.4 & 11.4 & 11.4 & 11.4 & 11.4 & 11.4 & & & \\
\hline 45 & $\mathrm{Sc}$ & 33.0 & 30.0 & 30.0 & 30.0 & 30.2 & 30.1 & 30.0 & 0.202 & 0.673 & -8.98 \\
\hline 47 & $\mathrm{TiO}_{2}$ & 2.79 & 2.71 & 2.71 & 2.57 & 2.61 & 2.60 & 2.64 & 0.130 & 4.93 & -5.38 \\
\hline 51 & $\mathrm{~V}$ & 308 & 356 & 356 & 302 & 316 & 331 & 332 & 47.8 & 14.4 & 7.77 \\
\hline 53 & $\mathrm{Cr}$ & 293 & 358 & 358 & 300 & 307 & 329 & 330 & 54.6 & 16.5 & 12.7 \\
\hline 59 & Co & 44.0 & 47.6 & 47.6 & 45.3 & 47.0 & 47.2 & 46.9 & 1.85 & 3.93 & 6.66 \\
\hline 60 & $\mathrm{Ni}$ & 116 & 127 & 127 & 132 & 133 & 124 & 128 & 8.11 & 6.31 & 10.8 \\
\hline 63 & $\mathrm{Cu}$ & 127 & 127 & 127 & 137 & 131 & 133 & 131 & 9.01 & 6.88 & 3.10 \\
\hline 66 & $\mathrm{Zn}$ & 102 & 111 & 111 & 119 & 114 & 105 & 112 & 9.93 & 8.87 & 9.70 \\
\hline 71 & $\mathrm{Ga}$ & 22.0 & 25.2 & 25.2 & 25.0 & 26.2 & 23.6 & 25.0 & 1.86 & 7.43 & 13.7 \\
\hline 85 & $\mathrm{Rb}$ & 9.20 & 10.7 & 10.7 & 9.94 & 11.3 & 9.71 & 10.5 & 1.29 & 12.3 & 13.8 \\
\hline 88 & $\mathrm{Sr}$ & 396 & 446 & 446 & 418 & 447 & 393 & 430 & 48.2 & 11.2 & 8.59 \\
\hline 89 & $\mathrm{Y}$ & 26.0 & 26.5 & 26.5 & 25.0 & 26.7 & 24.7 & 25.9 & 1.89 & 7.31 & -0.466 \\
\hline 90 & $\mathrm{Zr}$ & 170 & 165 & 165 & 158 & 173 & 154 & 163 & 14.3 & 8.81 & -4.19 \\
\hline 93 & $\mathrm{Nb}$ & 18.3 & 17.9 & 17.9 & 17.2 & 19.6 & 17.8 & 18.1 & 1.74 & 9.64 & -1.28 \\
\hline 133 & Cs & 0.10 & 0.106 & 0.106 & 0.098 & 0.104 & 0.111 & 0.105 & 0.009 & 8.9 & 4.94 \\
\hline 137 & $\mathrm{Ba}$ & 131 & 135 & 135 & 129 & 137 & 130 & 133 & 6.96 & 5.21 & 1.82 \\
\hline 139 & $\mathrm{La}$ & 15.2 & 15.2 & 15.2 & 14.6 & 15.1 & 15.2 & 15.0 & 0.507 & 3.37 & -1.02 \\
\hline 140 & $\mathrm{Ce}$ & 37.6 & 43.4 & 43.4 & 41.2 & 38.7 & 41.1 & 41.6 & 3.93 & 9.46 & 10.57 \\
\hline 141 & $\operatorname{Pr}$ & 5.35 & 6.12 & 6.12 & 5.63 & 5.43 & 5.80 & 5.82 & 0.609 & 10.5 & 8.79 \\
\hline 146 & $\mathrm{Nd}$ & 24.5 & 27.2 & 27.2 & 26.3 & 26.4 & 24.5 & 26.3 & 2.17 & 8.23 & 7.44 \\
\hline 147 & $\mathrm{Sm}$ & 6.1 & 6.48 & 6.48 & 6.55 & 6.49 & 5.88 & 6.38 & 0.554 & 8.69 & 4.55 \\
\hline 153 & $\mathrm{Eu}$ & 2.07 & 2.35 & 2.35 & 1.97 & 2.36 & 1.99 & 2.21 & 0.414 & 18.8 & 6.53 \\
\hline 157 & $\mathrm{Gd}$ & 6.16 & 6.34 & 6.34 & 5.67 & 6.38 & 5.52 & 6.05 & 0.841 & 13.9 & -1.81 \\
\hline 163 & Dy & 5.28 & 4.89 & 4.89 & 4.83 & 5.43 & 5.02 & 5.01 & 0.483 & 9.64 & -5.06 \\
\hline 166 & Er & 2.56 & 2.35 & 2.35 & 2.32 & 2.57 & 2.39 & 2.40 & 0.201 & 8.39 & -6.426 \\
\hline 172 & $\mathrm{Yb}$ & 2.01 & 1.81 & 1.81 & 1.85 & 1.93 & 1.75 & 1.83 & 0.132 & 7.21 & -8.90 \\
\hline 175 & $\mathrm{Lu}$ & 0.279 & 0.272 & 0.272 & 0.266 & 0.237 & 0.262 & 0.262 & 0.029 & 10.9 & -6.23 \\
\hline 178 & $\mathrm{Hf}$ & 4.32 & 4.57 & 4.57 & 4.06 & 4.51 & 4.66 & 4.48 & 0.475 & 10.61 & 3.61 \\
\hline 181 & $\mathrm{Ta}$ & 1.15 & 1.13 & 1.13 & 1.07 & 1.14 & 1.10 & 1.11 & 0.056 & 5.02 & -3.23 \\
\hline 208 & $\mathrm{~Pb}$ & 1.7 & 2.21 & 2.21 & 1.94 & 2.06 & 1.92 & 2.07 & 0.278 & 13.5 & 21.6 \\
\hline 232 & Th & 1.22 & 1.18 & 1.18 & 1.08 & 1.22 & 1.16 & 1.17 & 0.106 & 9.13 & -4.47 \\
\hline 238 & $\mathrm{U}$ & 0.403 & 0.425 & 0.425 & 0.395 & 0.432 & 0.422 & 0.420 & 0.028 & 6.76 & 4.22 \\
\hline
\end{tabular}

Table A1.12. Analysis of BHVO-2G and BCR-2G mounted in half circles rotated by $90^{\circ}$. Elemental concentrations in ppm except $\mathrm{CaO}$ and $\mathrm{TiO} \mathrm{O}_{2}$ in $\mathrm{wt} \%$. 
Appendix 1

\begin{tabular}{|c|c|c|c|c|c|c|c|c|c|c|}
\hline \multicolumn{3}{|c|}{ BHVO-2G ref values } & BHVO-2G_AA & BHVO-2G_AB & BHVO-2G_AC & BHVO-2G_AD & BHVO-2G_AE & Mean & $2 \mathrm{SD}$ & $\% 2 \mathrm{SD}$ \\
\hline 43 & $\mathrm{CaO}$ & $\begin{array}{l}11.4 \\
33.0\end{array}$ & 11.4 & 11.4 & $\begin{array}{l}11.4 \\
310\end{array}$ & 11.4 & $\begin{array}{l}11.4 \\
298\end{array}$ & $\begin{array}{l}11.4 \\
307\end{array}$ & & \\
\hline 45 & $\mathrm{Sc}$ & 33.0 & 30.1 & 31.3 & 31.0 & 31.1 & 29.8 & 30.7 & 1.31 & 4.29 \\
\hline 47 & $\mathrm{TiO}_{2}$ & 2.79 & 2.65 & 2.74 & 2.69 & 2.70 & 2.65 & 2.69 & 0.078 & 2.89 \\
\hline 51 & $\mathrm{~V}$ & 308 & 317 & 314 & 305 & 315 & 306 & 312 & 11.8 & 3.77 \\
\hline 53 & $\mathrm{Cr}$ & 293 & 311 & 289 & 299 & 316 & 313 & 306 & 22.5 & 7.36 \\
\hline 59 & Co & 44.0 & 45.1 & 44.7 & 42.4 & 43.4 & 43.4 & 43.8 & 2.16 & 4.94 \\
\hline 60 & $\mathrm{Ni}$ & 116 & 124 & 126 & 123 & 121 & 121 & 123 & 3.99 & 3.24 \\
\hline 63 & $\mathrm{Cu}$ & 127 & 128 & 125 & 118 & 124 & 126 & 124 & 7.95 & 6.39 \\
\hline 66 & $\mathrm{Zn}$ & 102 & 105 & 101 & 95.2 & 97.1 & 97.6 & 99.2 & 7.98 & 8.05 \\
\hline 71 & $\mathrm{Ga}$ & 22.0 & 22.4 & 22.7 & 21.5 & 20.8 & 21.3 & 21.7 & 1.58 & 7.25 \\
\hline 85 & $\mathrm{Rb}$ & 9.20 & 9.05 & 9.26 & 9.07 & 8.57 & 8.96 & 8.98 & 0.508 & 5.66 \\
\hline 88 & $\mathrm{Sr}$ & 396 & 411 & 394 & 384 & 391 & 397 & 396 & 20.0 & 5.06 \\
\hline 89 & $\mathrm{Y}$ & 26.0 & 26.0 & 26.1 & 26.0 & 25.4 & 25.5 & 25.8 & 0.626 & 2.43 \\
\hline 90 & $\mathrm{Zr}$ & 170 & 162 & 170 & 157 & 161 & 166 & 163 & 9.34 & 5.73 \\
\hline 93 & $\mathrm{Nb}$ & 18.3 & 17.7 & 18.5 & 17.3 & 17.4 & 18.1 & 17.8 & 0.982 & 5.52 \\
\hline 133 & Cs & 0.10 & 0.094 & 0.089 & 0.095 & 0.096 & 0.089 & 0.092 & 0.007 & 7.33 \\
\hline 137 & $\mathrm{Ba}$ & 131 & 133 & 131 & 128 & 125 & 130 & 129 & 6.05 & 4.68 \\
\hline 139 & $\mathrm{La}$ & 15.2 & 14.8 & 15.2 & 14.6 & 14.7 & 14.6 & 14.8 & 0.481 & 3.25 \\
\hline 140 & $\mathrm{Ce}$ & 37.6 & 37.3 & 37.5 & 36.8 & 37.8 & 37.3 & 37.3 & 0.721 & 1.93 \\
\hline 141 & $\operatorname{Pr}$ & 5.35 & 5.43 & 5.31 & 5.24 & 5.28 & 5.22 & 5.30 & 0.168 & 3.18 \\
\hline 146 & $\mathrm{Nd}$ & 24.5 & 24.9 & 24.0 & 24.0 & 24.2 & 24.2 & 24.3 & 0.686 & 2.82 \\
\hline 147 & $\mathrm{Sm}$ & 6.1 & 5.97 & 5.87 & 5.87 & 5.66 & 5.90 & 5.85 & 0.236 & 4.03 \\
\hline 153 & $\mathrm{Eu}$ & 2.07 & 1.94 & 1.97 & 1.97 & 2.02 & 1.91 & 1.96 & 0.085 & 4.34 \\
\hline 157 & $\mathrm{Gd}$ & 6.16 & 5.71 & 5.77 & 5.91 & 6.08 & 6.21 & 5.94 & 0.413 & 6.96 \\
\hline 163 & Dy & 5.28 & 5.23 & 5.25 & 5.14 & 5.14 & 4.91 & 5.14 & 0.270 & 5.25 \\
\hline 166 & Er & 2.56 & 2.44 & 2.51 & 2.51 & 2.31 & 2.19 & 2.39 & 0.278 & 11.6 \\
\hline 172 & $\mathrm{Yb}$ & 2.01 & 1.84 & 1.83 & 1.98 & 1.80 & 1.92 & 1.87 & 0.152 & 8.09 \\
\hline 175 & $\mathrm{Lu}$ & 0.279 & 0.240 & 0.266 & 0.272 & 0.261 & 0.257 & 0.260 & 0.024 & 9.39 \\
\hline 178 & $\mathrm{Hf}$ & 4.32 & 4.14 & 4.58 & 4.26 & 3.99 & 4.15 & 4.22 & 0.440 & 10.4 \\
\hline 181 & $\mathrm{Ta}$ & 1.15 & 1.11 & 1.15 & 1.05 & 1.00 & 1.11 & 1.08 & 0.120 & 11.1 \\
\hline 208 & $\mathrm{~Pb}$ & 1.7 & 1.82 & 1.77 & 1.74 & 1.73 & 1.73 & 1.76 & 0.072 & 4.07 \\
\hline 232 & Th & 1.22 & 1.23 & 1.21 & 1.11 & 1.20 & 1.11 & 1.17 & 0.116 & 9.89 \\
\hline 238 & $\mathrm{U}$ & 0.403 & 0.408 & 0.392 & 0.350 & 0.392 & 0.398 & 0.388 & 0.045 & 11.6 \\
\hline
\end{tabular}

Table A1.13. Analysis of BHVO-2G and BCR-2G as the unknown and standard respectively, mounted in half circles with reduced cell volume. Elemental concentrations in ppm except $\mathrm{CaO}$ and $\mathrm{TiO}_{2}$ in $\mathrm{wt} \%$. 
Appendix 1

\begin{tabular}{|c|c|c|c|c|c|c|c|c|c|c|c|c|}
\hline & \multicolumn{2}{|c|}{ BHVO-2G ref values } & \multirow{2}{*}{$\begin{array}{l}\text { BHVO- } \\
2 \mathrm{G} \_\mathrm{AF} \\
50 \mu \mathrm{m}\end{array}$} & \multirow[t]{2}{*}{ \% Difference } & \multirow{2}{*}{$\begin{array}{c}\text { BHVO- } \\
2 \mathrm{G} \_\mathrm{AG} \\
35 \mu \mathrm{m}\end{array}$} & \multirow[t]{2}{*}{ \% Difference } & \multirow{2}{*}{$\begin{array}{c}\text { BHVO- } \\
2 \mathrm{G} \_\mathrm{AH} \\
20 \mu \mathrm{m}\end{array}$} & \multirow[t]{2}{*}{ \% Difference } & \multirow{2}{*}{$\begin{array}{l}\text { BHVO- } \\
2 \mathrm{G}_{-} \mathrm{AI} \\
15 \mu \mathrm{m}\end{array}$} & \multirow[t]{2}{*}{$\%$ Difference } & \multirow{2}{*}{$\begin{array}{l}\text { BHVO- } \\
2 \mathrm{G}_{-} \mathrm{AJ} \\
10 \mu \mathrm{m}\end{array}$} & \multirow[t]{2}{*}{$\%$ Difference } \\
\hline & Spot size & & & & & & & & & & & \\
\hline 43 & $\mathrm{CaO}$ & 11.4 & 11.4 & & 11.4 & & 11.4 & & 11.4 & & 11.4 & \\
\hline 45 & $\mathrm{Sc}$ & 33.0 & 30.8 & -6.53 & 29.9 & -9.29 & 29.6 & -10.4 & 29.2 & -11.4 & 32.3 & -2.01 \\
\hline 47 & $\mathrm{TiO}_{2}$ & 2.79 & 2.65 & -5.01 & 2.58 & -7.56 & 2.48 & -11.0 & 2.60 & -6.90 & 2.65 & -5.01 \\
\hline 51 & $\mathrm{~V}$ & 308 & 313 & 1.67 & 300 & -2.56 & 315 & 2.15 & 300 & -2.58 & 329 & 6.89 \\
\hline 53 & $\mathrm{Cr}$ & 293 & 300 & 2.41 & 271 & -7.51 & 300 & 2.45 & 318 & 8.44 & 327 & 11.7 \\
\hline 59 & Co & 44.0 & 43.9 & -0.326 & 42.3 & -3.89 & 46.1 & 4.83 & 45.1 & 2.49 & 46.2 & 5.00 \\
\hline 60 & $\mathrm{Ni}$ & 116 & 120 & 3.37 & 118 & 1.74 & 127 & 9.42 & 122 & 5.13 & 139 & 19.7 \\
\hline 63 & $\mathrm{Cu}$ & 127 & 124 & -2.37 & 127 & 0.023 & 144 & 13.1 & 127 & 0.359 & 138 & 9.02 \\
\hline 66 & $\mathrm{Zn}$ & 102 & 108 & 5.65 & 103 & 1.36 & 109 & 6.38 & 96 & -5.60 & 102 & -0.164 \\
\hline 71 & $\mathrm{Ga}$ & 22.0 & 21.8 & -0.917 & 21.8 & -0.689 & 24.0 & 9.00 & 23.9 & 8.84 & 26.5 & 20.6 \\
\hline 85 & $\mathrm{Rb}$ & 9.20 & 8.97 & -2.51 & 9.11 & -0.960 & 8.99 & -2.28 & 9.77 & 6.17 & 9.34 & 1.54 \\
\hline 88 & $\mathrm{Sr}$ & 396 & 434 & 9.57 & 388 & -2.12 & 401 & 1.18 & 413 & 4.26 & 404 & 1.95 \\
\hline 89 & $\mathrm{Y}$ & 26.0 & 24.7 & -4.81 & 26.4 & 1.45 & 25.5 & -1.93 & 26.6 & 2.15 & 28.5 & 9.43 \\
\hline 90 & $\mathrm{Zr}$ & 170 & 162 & -4.65 & 161 & -5.39 & 169 & -0.31 & 178 & 4.87 & 188 & 10.3 \\
\hline 93 & $\mathrm{Nb}$ & 18.3 & 17.4 & -4.97 & 18.0 & -1.85 & 19.3 & 5.49 & 18.6 & 1.38 & 18.8 & 2.78 \\
\hline 133 & Cs & 0.10 & 0.107 & 6.88 & 0.095 & -5.36 & 0.168 & 68.4 & 0.199 & 99.5 & 0.501 & 401 \\
\hline 137 & $\mathrm{Ba}$ & 131 & 132 & 0.973 & 129 & -1.82 & 140 & 6.53 & 131 & -0.279 & 130 & -0.83 \\
\hline 139 & $\mathrm{La}$ & 15.2 & 14.9 & -1.99 & 14.8 & -2.59 & 14.8 & -2.71 & 15.8 & 3.89 & 15.3 & 0.77 \\
\hline 140 & $\mathrm{Ce}$ & 37.6 & 37.5 & -0.273 & 37.4 & -0.555 & 39.5 & 5.04 & 38.3 & 1.86 & 36.9 & -1.79 \\
\hline 141 & $\operatorname{Pr}$ & 5.35 & 5.16 & -3.47 & 5.20 & -2.80 & 5.35 & 0.01 & 5.66 & 5.87 & 5.29 & -1.14 \\
\hline 146 & $\mathrm{Nd}$ & 24.5 & 22.9 & -6.39 & 23.7 & -3.12 & 25.4 & 3.63 & 24.7 & 0.730 & 27.3 & 11.5 \\
\hline 147 & $\mathrm{Sm}$ & 6.1 & 5.56 & -8.91 & 5.82 & -4.53 & 5.68 & -6.88 & 5.88 & -3.68 & 6.30 & 3.23 \\
\hline 153 & $\mathrm{Eu}$ & 2.07 & 2.14 & 3.40 & 2.09 & 0.889 & 1.90 & -8.18 & 1.94 & -6.23 & 1.98 & -4.21 \\
\hline 157 & $\mathrm{Gd}$ & 6.16 & 6.09 & -1.21 & 5.86 & -4.89 & 5.37 & -12.9 & 5.94 & -3.52 & 7.96 & 29.3 \\
\hline 163 & Dy & 5.28 & 5.06 & -4.08 & 4.95 & -6.26 & 4.63 & -12.4 & 5.63 & 6.56 & 6.79 & 28.6 \\
\hline 166 & $\mathrm{Er}$ & 2.56 & 2.56 & -0.127 & 2.46 & -3.99 & 2.23 & -12.9 & 2.48 & -2.99 & 1.86 & -27.5 \\
\hline 172 & $\mathrm{Yb}$ & 2.01 & 2.02 & 0.587 & 1.96 & -2.57 & 1.81 & -9.71 & 2.15 & 6.87 & 3.01 & 49.9 \\
\hline 175 & $\mathrm{Lu}$ & 0.279 & 0.249 & -10.6 & 0.251 & -9.98 & 0.222 & -20.4 & 0.283 & 1.41 & 0.474 & 69.7 \\
\hline 178 & $\mathrm{Hf}$ & 4.32 & 4.27 & -1.26 & 4.29 & -0.809 & 4.25 & -1.71 & 4.49 & 3.92 & 5.52 & 27.8 \\
\hline 181 & $\mathrm{Ta}$ & 1.15 & 1.03 & -10.7 & 1.01 & -12.5 & 1.13 & -2.02 & 1.33 & 15.5 & 1.17 & 1.40 \\
\hline 208 & $\mathrm{~Pb}$ & 1.7 & 1.81 & 6.73 & 2.10 & 23.8 & 2.39 & 40.5 & 1.81 & 6.71 & 3.59 & 111 \\
\hline 232 & Th & 1.22 & 1.15 & -5.82 & 1.16 & -4.62 & 1.13 & -7.09 & 1.48 & 21.1 & 1.44 & 18.2 \\
\hline 238 & $\mathrm{U}$ & 0.403 & 0.409 & 1.45 & 0.447 & 11.0 & 0.419 & 3.85 & 0.403 & 0.044 & 0.524 & 30.0 \\
\hline
\end{tabular}

Table A1.14 Analysis of BHVO-2G and BCR-2G at 10-50 $\mu \mathrm{m}$ spot sizes. Elemental concentrations in ppm except $\mathrm{CaO}_{\text {and }} \mathrm{TiO}_{2}$ in wt\%. 
Appendix 1

\begin{tabular}{|c|c|c|c|c|c|c|c|c|c|c|c|}
\hline & & f values & ATHO-G-K12 & ATHO-G-K13 & ATHO-G-K14 & ATHO-G-K15 & ATHO-G-K16 & Mean & $2 \mathrm{SD}$ & $\% 2 \mathrm{SD}$ & \% Difference \\
\hline 43 & $\mathrm{CaO}$ & 1.70 & 1.70 & 1.70 & 1.70 & 1.70 & 1.70 & 1.7 & & & \\
\hline 45 & $\mathrm{Sc}$ & 7.00 & 12.0 & 10.9 & 11.6 & 10.7 & 10.8 & 11.2 & 1.20 & 10.7 & 60.1 \\
\hline 47 & $\mathrm{TiO}_{2}$ & 0.26 & 0.263 & 0.259 & 0.279 & 0.249 & 0.258 & 0.262 & 0.023 & 8.61 & 2.57 \\
\hline 51 & $\mathrm{~V}$ & 3.91 & 3.28 & 3.49 & 3.50 & 3.32 & 3.24 & 3.37 & 0.241 & 7.17 & -13.9 \\
\hline 53 & $\mathrm{Cr}$ & 6.10 & 6.06 & 5.21 & 9.83 & 6.49 & 6.56 & 6.83 & 3.52 & 51.6 & 11.9 \\
\hline 59 & Co & 2.13 & 1.13 & 1.24 & 1.20 & 1.35 & 1.09 & 1.20 & 0.201 & 16.7 & -43.6 \\
\hline 60 & $\mathrm{Ni}$ & 13.0 & 6.79 & 6.13 & 6.63 & 5.68 & 5.74 & 6.19 & 1.01 & 16.4 & -52.4 \\
\hline 63 & $\mathrm{Cu}$ & 18.6 & 18.8 & 20.6 & 18.9 & 18.0 & 17.1 & 18.7 & 2.57 & 13.8 & 0.476 \\
\hline 66 & $\mathrm{Zn}$ & 141 & 135 & 143 & 137 & 129 & 129 & 135 & 11.8 & 8.76 & -4.54 \\
\hline 71 & $\mathrm{Ga}$ & 25.3 & 23.9 & 25.8 & 24.6 & 23.2 & 23.8 & 24.2 & 2.00 & 8.26 & -4.20 \\
\hline 85 & $\mathrm{Rb}$ & 65.3 & 65.5 & 67.9 & 68.4 & 62.2 & 64.8 & 65.7 & 5.08 & 7.72 & 0.684 \\
\hline 88 & $\mathrm{Sr}$ & 94.1 & 96.7 & 94.5 & 97.3 & 90.6 & 90.4 & 93.9 & 6.55 & 6.98 & -0.195 \\
\hline 89 & $\mathrm{Y}$ & 94.5 & 110 & 111 & 120 & 106 & 108 & 111 & 10.53 & 9.49 & 17.4 \\
\hline 90 & $\mathrm{Zr}$ & 512 & 570 & 561 & 578 & 537 & 546 & 558 & 34.5 & 6.17 & 9.07 \\
\hline 93 & $\mathrm{Nb}$ & 62.4 & 64.8 & 64.6 & 66.1 & 61.2 & 62.7 & 63.9 & 3.84 & 6.01 & 2.37 \\
\hline 133 & Cs & 1.08 & 0.938 & 0.964 & 0.950 & 0.847 & 0.851 & 0.910 & 0.113 & 12.4 & -15.8 \\
\hline 137 & $\mathrm{Ba}$ & 559 & 547 & 552 & 566 & 506 & 531 & 540 & 46.0 & 8.51 & -3.33 \\
\hline 139 & $\mathrm{La}$ & 55.6 & 57.0 & 57.9 & 58.7 & 55.1 & 54.3 & 56.6 & 3.70 & 6.55 & 1.76 \\
\hline 140 & $\mathrm{Ce}$ & 121 & 131 & 132 & 133 & 120 & 120 & 127 & 13.1 & 10.3 & 5.00 \\
\hline 141 & $\operatorname{Pr}$ & 14.6 & 15.5 & 15.9 & 16.4 & 15.1 & 14.5 & 15.5 & 1.43 & 9.25 & 6.09 \\
\hline 146 & $\mathrm{Nd}$ & 60.9 & 65.1 & 65.7 & 65.8 & 63.6 & 61.0 & 64.2 & 4.06 & 6.32 & 5.47 \\
\hline 147 & $\mathrm{Sm}$ & 14.2 & 15.2 & 14.9 & 15.7 & 14.5 & 14.5 & 15.0 & 0.95 & 6.38 & 5.36 \\
\hline 153 & $\mathrm{Eu}$ & 2.76 & 2.65 & 2.75 & 2.77 & 2.59 & 2.61 & 2.67 & 0.16 & 6.07 & -3.11 \\
\hline 157 & $\mathrm{Gd}$ & 15.3 & 15.9 & 16.1 & 16.6 & 16.7 & 16.4 & 16.3 & 0.68 & 4.18 & 6.70 \\
\hline 163 & Dy & 16.2 & 17.6 & 17.2 & 19.1 & 17.7 & 17.3 & 17.8 & 1.51 & 8.48 & 9.96 \\
\hline 166 & $\mathrm{Er}$ & 10.3 & 11.6 & 11.3 & 12.8 & 12.2 & 10.6 & 11.7 & 1.69 & $\begin{array}{l}0.70 \\
14.5\end{array}$ & 13.6 \\
\hline 172 & $\mathrm{Yb}$ & 10.5 & 11.2 & 10.5 & 11.0 & 10.4 & 10.6 & 10.7 & 0.677 & 6.31 & 2.20 \\
\hline 175 & $\mathrm{Lu}$ & 1.54 & 1.70 & 1.75 & 1.80 & 1.58 & 1.51 & 1.67 & 0.238 & 14.3 & 8.46 \\
\hline 178 & $\mathrm{Hf}$ & 13.7 & 15.3 & 15.4 & 15.9 & 14.6 & 14.7 & 15.2 & 1.09 & 7.20 & 10.7 \\
\hline 181 & $\mathrm{Ta}$ & 3.9 & 4.00 & 4.00 & 4.13 & 3.80 & 3.70 & 3.93 & 0.349 & 8.87 & 0.731 \\
\hline 208 & $\mathrm{~Pb}$ & 5.67 & 6.49 & 6.40 & 6.63 & 6.09 & 6.45 & 6.41 & 0.403 & 6.28 & 13.1 \\
\hline 232 & Th & 7.4 & 7.58 & 7.84 & 8.21 & 7.38 & 7.72 & 7.75 & 0.618 & 7.97 & 4.67 \\
\hline 238 & $\mathrm{U}$ & 2.37 & 2.28 & 2.45 & 2.40 & 2.27 & 2.37 & 2.35 & 0.153 & 6.51 & -0.777 \\
\hline
\end{tabular}

Table A1.15 Analysis of ATHO-G and BCR-2G as the unknown and standard respectively in reaction cell mode. Elemental concentrations in ppm except CaO and $\mathrm{TiO}_{2}$ in $\mathrm{wt} \%$. 
Appendix 1

\begin{tabular}{|c|c|c|c|c|c|c|c|c|c|c|c|}
\hline & & ATHO-G ref values & ATHO-G3 & ATHO-G4 & ATHO-G5 & ATHO-G6 & ATHO-G7 & Mean & $2 \mathrm{SD}$ & $\% 2 \mathrm{SD}$ & \% Difference \\
\hline 25 & $\mathrm{Mg}$ & 621 & 573 & 580 & 587 & 623 & 596 & 592 & 38.93 & 6.58 & -4.68 \\
\hline 43 & $\mathrm{CaO}$ & 1.70 & 1.70 & 1.70 & 1.70 & 1.70 & 1.70 & 1.70 & & & \\
\hline 45 & $\mathrm{Sc}$ & 7.00 & 9.65 & 9.40 & 9.82 & 9.84 & 9.65 & 9.67 & 0.351 & 3.63 & 38.1 \\
\hline 47 & $\mathrm{TiO}_{2}$ & 0.26 & 0.262 & 0.279 & 0.275 & 0.287 & 0.279 & 0.276 & 0.018 & 6.55 & 8.40 \\
\hline 51 & $\mathrm{~V}^{2}$ & 3.91 & 3.48 & 3.58 & 3.84 & 3.88 & 3.96 & 3.75 & 0.412 & 11.0 & -4.11 \\
\hline 53 & $\mathrm{Cr}$ & 6.10 & 6.92 & 5.58 & 6.14 & 5.40 & 7.03 & 6.21 & 1.50 & 24.1 & 1.84 \\
\hline 59 & Co & 2.13 & 1.51 & 1.50 & 1.49 & 1.47 & 1.65 & 1.52 & 0.142 & 9.29 & -28.4 \\
\hline 60 & $\mathrm{Ni}$ & 13.0 & 8.76 & 8.24 & 7.55 & 8.44 & 8.85 & 8.37 & 1.04 & 12.4 & -35.6 \\
\hline 63 & $\mathrm{Cu}$ & 18.6 & 18.1 & 19.5 & 18.4 & 18.4 & 19.9 & 18.9 & 1.58 & 8.35 & 1.45 \\
\hline 66 & $\mathrm{Zn}$ & 141 & 137 & 139 & 141 & 151 & 145 & 143 & 11.6 & 8.16 & 1.14 \\
\hline 71 & $\mathrm{Ga}$ & 25.3 & 23.2 & 23.6 & 23.5 & 26.1 & 25.1 & 24.3 & 2.47 & 10.2 & -3.96 \\
\hline 85 & $\mathrm{Rb}$ & 65.3 & 68.1 & 69.0 & 67.8 & 72.0 & 75.2 & 70.4 & 6.33 & 8.99 & 7.83 \\
\hline 88 & $\mathrm{Sr}$ & 94.1 & 88.5 & 89.5 & 87.6 & 94.8 & 96.8 & 91.4 & 8.19 & 8.96 & -2.83 \\
\hline 89 & $\mathrm{Y}$ & 94.5 & 102 & 104 & 102 & 111 & 108 & 105 & 7.64 & 7.25 & 11.6 \\
\hline 90 & $\mathrm{Zr}$ & 512 & 529 & 511 & 522 & 555 & 533 & 530 & 33.1 & 6.24 & 3.50 \\
\hline 93 & $\mathrm{Nb}$ & 62.4 & 65.0 & 65.0 & 63.3 & 67.6 & 67.6 & 65.7 & 3.72 & 5.66 & 5.32 \\
\hline 133 & $\mathrm{Cs}$ & 1.08 & 0.938 & 0.965 & 0.925 & 1.04 & 1.11 & 0.995 & 0.154 & 15.5 & -7.9 \\
\hline 137 & $\mathrm{Ba}$ & 559 & 528 & 533 & 530 & 564 & 551 & 541 & 31.7 & 5.86 & -3.16 \\
\hline 139 & $\mathrm{La}$ & 55.6 & 54.2 & 56.9 & 53.9 & 60.2 & 58.1 & 56.7 & 5.32 & 9.39 & 1.91 \\
\hline 140 & $\mathrm{Ce}$ & 121 & 126 & 133 & 130 & 147 & 137 & 135 & 15.6 & 11.6 & 11.2 \\
\hline 146 & $\mathrm{Nd}$ & 60.9 & 57.4 & 63.3 & 62.2 & 67.3 & 64.0 & 62.8 & 7.20 & 11.5 & 3.18 \\
\hline 147 & $\mathrm{Sm}$ & 14.2 & 13.7 & 13.5 & 14.5 & 15.7 & 15.5 & 14.6 & 1.97 & 13.5 & 2.74 \\
\hline 153 & $\mathrm{Eu}$ & 2.76 & 2.54 & 2.70 & 2.84 & 2.95 & 2.70 & 2.74 & 0.312 & 11.4 & -0.58 \\
\hline 157 & $\mathrm{Gd}$ & 15.3 & 16.3 & 15.3 & 14.8 & 17.4 & 17.0 & 16.2 & 2.21 & 13.6 & 5.72 \\
\hline 163 & Dy & 16.2 & 17.3 & 16.5 & 15.7 & 19.0 & 18.6 & 17.4 & 2.82 & 16.2 & 7.59 \\
\hline 166 & Er & 10.3 & 10.9 & 10.5 & 10.2 & 11.4 & 11.6 & 10.9 & 1.14 & 10.5 & 6.3 \\
\hline 172 & $\mathrm{Yb}$ & 10.5 & 10.5 & 10.2 & 10.0 & 11.7 & 11.1 & 10.7 & 1.389 & 13.0 & 1.75 \\
\hline 175 & $\mathrm{Lu}$ & 1.54 & 1.44 & 1.46 & 1.48 & 1.66 & 1.59 & 1.53 & 0.186 & 12.2 & -0.93 \\
\hline 178 & $\mathrm{Hf}$ & 13.7 & 13.6 & 14.2 & 14.1 & 15.6 & 14.6 & 14.4 & 1.52 & 10.5 & 5.4 \\
\hline 181 & $\mathrm{Ta}$ & 3.9 & 3.66 & 3.65 & 3.69 & 3.92 & 3.93 & 3.77 & 0.289 & 7.65 & -3.32 \\
\hline 208 & $\mathrm{~Pb}$ & 5.67 & 6.12 & 5.87 & 6.02 & 6.45 & 6.36 & 6.16 & 0.478 & 7.76 & 8.7 \\
\hline 232 & Th & 7.4 & 7.06 & 7.31 & 7.17 & 7.93 & 7.83 & 7.46 & 0.787 & 10.5 & 0.80 \\
\hline 238 & $\mathrm{U}$ & 2.37 & 2.29 & 2.63 & 2.47 & 2.57 & 2.68 & 2.53 & 0.307 & 12.2 & 6.56 \\
\hline
\end{tabular}

Table A1.16. Analysis of ATHO-G and BCR-2G without the reaction cell. Elemental concentrations in ppm except $\mathrm{CaO}$ and $\mathrm{TiO}_{2}$ in $\mathrm{wt}^{2} \%$. 
Appendix 1

\begin{tabular}{|c|c|c|c|c|c|c|c|c|c|}
\hline & & ATHO-G ref values & ATHO-G A & ATHO-G B & ATHO-G C & Mean & $2 \mathrm{SD}$ & $\% 2 \mathrm{SD}$ & $\%$ Difference \\
\hline 25 & $\mathrm{Mg}$ & 621 & 868 & 997 & 909 & 925 & 131 & 14.2 & 48.9 \\
\hline 43 & $\mathrm{CaO}$ & 1.70 & 1.70 & 1.70 & 1.70 & 1.70 & & & \\
\hline 45 & $\mathrm{Sc}$ & 7.00 & 9.24 & 11.6 & 9.73 & 10.2 & 2.52 & 24.7 & 45.7 \\
\hline 47 & $\mathrm{TiO}_{2}$ & 0.26 & 0.325 & 0.320 & 0.30 & 0.314 & 0.029 & 9.23 & 23.3 \\
\hline 51 & $\mathrm{~V}^{2}$ & 3.91 & 4.49 & 3.90 & 3.37 & 3.92 & 1.12 & 28.5 & 0.239 \\
\hline 53 & $\mathrm{Cr}$ & 6.10 & 13.3 & 18.1 & 12.34 & 14.6 & 6.15 & 42.2 & 139 \\
\hline 55 & $\mathrm{Mn}$ & 798 & 855 & 868 & 816 & 846 & 53.3 & 6.30 & 6.05 \\
\hline 59 & Co & 2.13 & 1.30 & 1.67 & 1.90 & 1.62 & 0.610 & 37.6 & -23.8 \\
\hline 60 & $\mathrm{Ni}$ & 13.0 & 6.58 & 7.67 & 6.15 & 6.80 & 1.56 & 23.0 & -47.7 \\
\hline 63 & $\mathrm{Cu}$ & 18.6 & 17.9 & 20.7 & 18.76 & 19.1 & 2.83 & 14.8 & 2.77 \\
\hline 66 & $\mathrm{Zn}$ & 141 & 156 & 145 & 152 & 151 & 11.0 & 7.3 & 7.20 \\
\hline 71 & $\mathrm{Ga}$ & 25.3 & 20.4 & 21.4 & 20.3 & 20.7 & 1.24 & 5.97 & -18.1 \\
\hline 85 & $\mathrm{Rb}$ & 65.3 & 70.4 & 75.0 & 69.3 & 71.6 & 6.11 & 8.5 & 9.61 \\
\hline 88 & $\mathrm{Sr}$ & 94.1 & 90.8 & 90.0 & 89.7 & 90.2 & 1.19 & 1.32 & -4.19 \\
\hline 89 & $\mathrm{Y}$ & 94.5 & 92.3 & 97.9 & 90.5 & 93.5 & 7.72 & 8.2 & -1.01 \\
\hline 90 & $\mathrm{Zr}$ & 512 & 505 & 538 & 477 & 507 & 61.6 & 12.2 & -1.02 \\
\hline 93 & $\mathrm{Nb}$ & 62.4 & 69.5 & 70.7 & 69.5 & 70 & 1.43 & 2.05 & 12.0 \\
\hline 95 & Mo & 4.80 & 3.73 & 5.37 & 4.77 & 4.62 & 1.67 & 36.0 & -3.68 \\
\hline 133 & $\mathrm{Cs}$ & 1.08 & 0.943 & 1.05 & 0.925 & 0.97 & 0.137 & 14.1 & -9.87 \\
\hline 137 & $\mathrm{Ba}$ & 559 & 551 & 581 & 551 & 561 & 34.4 & 6.14 & 0.344 \\
\hline 139 & $\mathrm{La}$ & 55.6 & 54.8 & 52.6 & 54.6 & 54.0 & 2.46 & 4.56 & -2.91 \\
\hline 140 & $\mathrm{Ce}$ & 121 & 125 & 125 & 124 & 125 & 1.73 & 1.39 & 3.09 \\
\hline 141 & $\mathrm{Pr}$ & 14.6 & 14.8 & 14.4 & 14.5 & 14.6 & 0.405 & 2.78 & -0.259 \\
\hline 146 & $\mathrm{Nd}$ & 60.9 & 61.5 & 64.4 & 56.3 & 60.7 & 8.29 & 13.6 & -0.283 \\
\hline 147 & $\mathrm{Sm}$ & 14.2 & 14.8 & 15.5 & 12.4 & 14.3 & 3.24 & 22.7 & 0.460 \\
\hline 153 & $\mathrm{Eu}$ & 2.76 & 2.58 & 2.65 & 2.59 & 2.61 & 0.078 & 3.01 & -5.53 \\
\hline 157 & $\mathrm{Gd}$ & 15.3 & 15.5 & 14.1 & 13.6 & 14.4 & 2.01 & 14.0 & -5.94 \\
\hline 163 & Dy & 16.2 & 17.4 & 16.4 & 14.5 & 16.1 & 2.96 & 18.4 & -0.64 \\
\hline 166 & Er & 10.3 & 10.5 & 9.9 & 9.69 & 10.0 & 0.802 & 7.99 & -2.58 \\
\hline 172 & $\mathrm{Yb}$ & 10.5 & 9.66 & 11.1 & 9.80 & 10.2 & 1.53 & 15.0 & -3.12 \\
\hline 175 & $\mathrm{Lu}$ & 1.54 & 1.46 & 1.49 & 1.51 & 1.49 & 0.047 & 3.14 & -3.57 \\
\hline 178 & $\mathrm{Hf}$ & 13.7 & 14.4 & 13.3 & 12.3 & 13.3 & 2.05 & 15.4 & -2.71 \\
\hline 181 & $\mathrm{Ta}$ & 3.90 & 4.20 & 4.46 & 3.60 & 4.09 & 0.88 & 21.6 & 4.82 \\
\hline 182 & W & 9.30 & 9.74 & 10.4 & 9.81 & 10.0 & 0.777 & 7.77 & 7.50 \\
\hline 208 & $\mathrm{~Pb}$ & 5.67 & 5.55 & 5.77 & 5.17 & 5.50 & 0.612 & 11.1 & -3.02 \\
\hline 232 & Th & 7.40 & 7.64 & 7.89 & 7.00 & 7.51 & 0.919 & 12.2 & 1.52 \\
\hline 238 & $\mathrm{U}$ & 2.37 & 2.74 & 2.89 & 2.39 & 2.67 & 0.515 & 19.3 & 12.8 \\
\hline
\end{tabular}

Table A1.17. Analysis of ATHO-G and NIST 612 as the unknown and standard respectively. Elemental concentrations in ppm except CaO and $\mathrm{TiO}_{2}$ in wt $\%$. 


\begin{tabular}{|c|c|c|c|c|c|c|c|}
\hline & $\begin{array}{l}\text { Ref } \\
\text { values }\end{array}$ & $50 \mu \mathrm{m}$ & $\% 2 \mathrm{SD}$ & $35 \mu \mathrm{m}$ & $\% 2 \mathrm{SD}$ & $20 \mu \mathrm{m}$ & $\% 2 \mathrm{SD}$ \\
\hline & & $\mathrm{n}=5$ & & $\mathrm{n}=20$ & & $\mathrm{n}=3$ & \\
\hline $\mathrm{Mg}$ & 621 & 750 & 7.16 & 740 & 6.97 & 695 & 11.5 \\
\hline $\mathrm{CaO}$ & 1.70 & 1.70 & & 1.70 & & 1.70 & \\
\hline $\mathrm{Sc}$ & 7.00 & 9.13 & 7.43 & 15.1 & 63.1 & 11.7 & 24.1 \\
\hline $\mathrm{TiO} 2$ & 0.255 & 0.296 & 5.52 & 0.252 & 20.6 & 0.264 & 3.80 \\
\hline $\mathrm{V}$ & 3.91 & 3.68 & 3.02 & 3.52 & 16.5 & 3.22 & 32.3 \\
\hline $\mathrm{Cr}$ & 6.10 & 5.88 & 13.0 & 5.66 & 50.2 & 20.7 & 44.7 \\
\hline Mn & 821 & 818 & 2.42 & 812 & 8.63 & 785 & 15.9 \\
\hline $\mathrm{Co}$ & 2.13 & 1.36 & 19.5 & 1.37 & 18.4 & 1.73 & 21.5 \\
\hline $\mathrm{Ni}$ & 13.0 & 6.91 & 16.8 & 6.30 & 21.3 & 7.74 & 38.6 \\
\hline $\mathrm{Cu}$ & 18.6 & 17.7 & 8.28 & 16.1 & 9.32 & 16.2 & 16.2 \\
\hline $\mathrm{Zn}$ & 141 & 149 & 5.81 & 145 & 14.4 & 144 & 2.35 \\
\hline $\mathrm{Ga}$ & 25.3 & 22.3 & 6.75 & 21.5 & 9.43 & 19.6 & 10.8 \\
\hline $\mathrm{Rb}$ & 65.3 & 69.8 & 7.84 & 63.7 & 6.94 & 59.9 & 8.52 \\
\hline $\mathrm{Sr}$ & 94.1 & 91.9 & 5.27 & 92.4 & 3.38 & 89.8 & 10.3 \\
\hline $\mathrm{Y}$ & 94.5 & 89.8 & 6.35 & 92.9 & 8.61 & 90.3 & 9.08 \\
\hline $\mathrm{Zr}$ & 512 & 510 & 9.41 & 514 & 8.24 & 512 & 10.7 \\
\hline $\mathrm{Nb}$ & 62.4 & 67.9 & 6.58 & 65.6 & 7.55 & 61.1 & 11.2 \\
\hline Mo & 4.80 & 4.12 & 7.94 & 3.59 & 21.3 & 4.10 & 12.8 \\
\hline Cs & 1.08 & 0.961 & 15.8 & 0.892 & 16.7 & 0.951 & 23.8 \\
\hline $\mathrm{Ba}$ & 559 & 560 & 3.1 & 556 & 9.45 & 532 & 0.696 \\
\hline $\mathrm{La}$ & 55.6 & 54.0 & 3.6 & 54.8 & 7.40 & 52.7 & 4.49 \\
\hline $\mathrm{Ce}$ & 121 & 127 & 3.2 & 124 & 6.28 & 117 & 8.54 \\
\hline $\operatorname{Pr}$ & 14.6 & 14.4 & 3.8 & 14.3 & 6.99 & 13.5 & 3.42 \\
\hline $\mathrm{Nd}$ & 60.9 & 61.6 & 3.2 & 61.1 & 7.78 & 58.2 & 9.71 \\
\hline $\mathrm{Sm}$ & 14.2 & 14.2 & 8.3 & 14.5 & 9.80 & 14.5 & 17.1 \\
\hline $\mathrm{Eu}$ & 2.76 & 2.55 & 6.5 & 2.67 & 9.24 & 2.51 & 3.36 \\
\hline $\mathrm{Gd}$ & 15.3 & 14.6 & 11.1 & 15.0 & 9.67 & 14.7 & 30.4 \\
\hline Dy & 16.2 & 16.7 & 2.89 & 16.9 & 7.97 & 16.4 & 9.19 \\
\hline $\mathrm{Er}$ & 10.3 & 10.2 & 6.21 & 10.5 & 7.46 & 9.51 & 14.5 \\
\hline $\mathrm{Yb}$ & 10.5 & 10.3 & 7.77 & 10.8 & 8.35 & 10.8 & 10.4 \\
\hline $\mathrm{Lu}$ & 1.54 & 1.49 & 6.72 & 1.54 & 10.4 & 1.50 & 20.0 \\
\hline Hf & 13.7 & 13.3 & 9.73 & 13.3 & 12.1 & 12.7 & 7.63 \\
\hline $\mathrm{Ta}$ & 3.90 & 4.08 & 4.97 & 4.05 & 8.24 & 3.91 & 5.50 \\
\hline $\mathrm{W}$ & 9.30 & 9.85 & 3.47 & 8.95 & 11.4 & 8.38 & 14.4 \\
\hline $\mathrm{Pb}$ & 5.67 & 5.67 & 4.76 & 5.29 & 13.6 & 4.99 & 4.69 \\
\hline Th & 7.40 & 7.56 & 5.16 & 7.60 & 6.34 & 7.11 & 6.62 \\
\hline $\mathrm{U}$ & 2.37 & 2.47 & 3.07 & 2.34 & 10.5 & 2.28 & 19.2 \\
\hline
\end{tabular}

Table A1.18. Analysis of ATHO-G and NIST 612 as unknown and standard respectively at varying spot sizes. Elemental concentrations in ppm except $\mathrm{CaO}$ and $\mathrm{TiO}_{2}$ in $\mathrm{wt} \%$. 


\begin{tabular}{ccccccccccccccc}
\hline & & $\begin{array}{c}\text { ref values } \\
\text { STH-G }\end{array}$ & KSTHG6 & KSTHG7 & KSTHG8 & KSTHG9 & KSTHG10 & Mean & 2 SD & \% 2 SD \\
difference
\end{tabular}

Table A1.19 Analysis of STH-80G and NIST 610 as unknown and standard respectively at $10 \mu \mathrm{m}$ spot size. Elemental concentrations in ppm except CaO and TiO ${ }_{2}$

in $\mathrm{wt} \%$. 


\begin{tabular}{|c|c|c|c|c|c|c|c|c|c|c|c|}
\hline & & $\begin{array}{l}\text { ref values } \\
\text { STH-G }\end{array}$ & KSTHG1 & KSTHG2 & KSTHG3 & KSTHG4 & KSTHG5 & Mean & $2 \mathrm{SD}$ & $\% 2 \mathrm{SD}$ & $\begin{array}{c}\% \\
\text { difference }\end{array}$ \\
\hline 24 & $\mathrm{Mg}$ & 11879 & 12574 & 12676 & 12625 & 12578 & 12761 & 12643 & 155 & 1.23 & 6.43 \\
\hline 25 & $\mathrm{Mg}$ & 11879 & 11082 & 11187 & 11393 & 11026 & 11481 & 11234 & 393 & 3.50 & -5.43 \\
\hline 43 & $\mathrm{CaO}$ & 5.280 & 5.28 & 5.28 & 5.28 & 5.28 & 5.28 & 5.28 & & & \\
\hline 88 & $\mathrm{Sr}$ & 482 & 480 & 496 & 487 & 490 & 476 & 486 & 15.6 & 3.21 & 0.773 \\
\hline 137 & $\mathrm{Ba}$ & 298 & 297 & 304 & 305 & 326 & 300 & 306 & 22.6 & 7.37 & 2.74 \\
\hline 139 & $\mathrm{La}$ & 12.000 & 11.0 & 12.8 & 12.1 & 11.4 & 12.0 & 11.9 & 1.36 & 11.4 & -1.20 \\
\hline 140 & $\mathrm{Ce}$ & 26.100 & 26.7 & 24.8 & 27.1 & 24.9 & 25.9 & 25.9 & 1.99 & 7.70 & -0.847 \\
\hline 141 & $\operatorname{Pr}$ & 3.200 & 2.70 & 3.19 & 3.01 & 3.11 & 3.20 & 3.04 & 0.414 & 13.6 & -4.98 \\
\hline 146 & $\mathrm{Nd}$ & 13.000 & 11.9 & 13.4 & 13.6 & 11.8 & 10.6 & 12.3 & 2.48 & 20.2 & -5.51 \\
\hline 147 & $\mathrm{Sm}$ & 2.780 & 2.47 & 2.28 & 2.56 & 2.98 & 2.25 & 2.51 & 0.590 & 23.5 & -9.81 \\
\hline 153 & $\mathrm{Eu}$ & 0.953 & 0.714 & 0.872 & 0.737 & 0.987 & 0.786 & 0.819 & 0.224 & 27.3 & -14.0 \\
\hline 157 & Gd & 2.590 & 1.93 & 2.43 & 2.64 & 2.89 & 2.01 & 2.38 & 0.817 & 34.3 & -8.16 \\
\hline 163 & Dy & 2.220 & 1.96 & 1.87 & 1.83 & 2.23 & 1.92 & 1.96 & 0.313 & 15.9 & -11.6 \\
\hline 166 & $\mathrm{Er}$ & 1.180 & 1.34 & 0.865 & 1.33 & 1.02 & 1.22 & 1.16 & 0.415 & 35.9 & -2.12 \\
\hline 172 & $\mathrm{Yb}$ & 1.130 & 1.38 & 1.08 & 1.06 & 0.93 & 1.49 & 1.19 & 0.467 & 39.3 & 5.04 \\
\hline 175 & $\mathrm{Lu}$ & 0.168 & 0.233 & 0.175 & 0.228 & 0.184 & 0.204 & 0.205 & 0.0517 & 25.2 & 21.9 \\
\hline
\end{tabular}

Table A1.20. Analysis of STH-80G and NIST 610 as unknown and standard respectively at $20 \mu \mathrm{m}$ spot size. Elemental concentrations in ppm except CaO and TiO ${ }_{2}$ in wt $\%$. 


\section{A1.4.6 References}

Baker, J.A., Allan, A.S.R., Alloway, B.V., Carter, L., Stevens, M., Wilson, C.J.N., and Wysoczanski, R.J., 2008. Tephra geochemical studies in NZ - New opportunities and pitfalls. Geological Society of New Zealand, New Zealand Geophysical Society, New Zealand Geochemical and Mineralogical Society Joint Annual Conference, Geosciences 2008. Wellington New Zealand, $23^{\text {rd }}-26^{\text {th }}$ November 2008.

Bence, A.E., and Albee, A.L., 1968. Empirical correction factors for the electron microprobe analysis of silicates and oxides. Journal of Geology, 76: 382403.

Brown, S.J.A., Wilson, C.J.N., Cole, J.W. and Wooden, J., 1998. The Whakamaru group ignimbrites, Taupo Volcanic Zone, New Zealand: evidence for reverse tapping of a zoned silicic magmatic system. Journal of Volcanology and Geothermal Research, 84(1-2): 1-37.

Devine, J.D., Gardner, J.E., Brack, H.P., Layne, G.D., and Rutherford, M.J., 1995. Comparison of microanalytical methods fro estimating $\mathrm{H}_{2} \mathrm{O}$ contents of silicic volcanic glasses. American Mineralogist, 80:319-328.

Dixon, J.E., Stolper, E.M., and Delaney, J.R., 1988. Infrared spectroscopic measurements of $\mathrm{CO}_{2}$ and $\mathrm{H}_{2} \mathrm{O}$ in Juan de Fuca ridge basaltic glasses. Earth and Planetary Science Letters, 90: 87-104.

Durrant, S.F., 1999. Laser ablation inductively coupled plasma mass spectrometry: achievements, problems, prospects. Journal of Analytical Atomic Spectrometry, 14: 1385-1403.

Fine, G.J., and Stolper, E.M., 1985. The speciation of carbon dioxide in sodium aluminosilicate glasses. Contributions to Mineralogy and Petrology, 91: 105-121. 
Günther, D., and Hattendorf, B., 2005. Solid sample analysis using laser ablation inductively coupled plasma mass spectrometry. Trends in Analytical Chemistry, 24: 255-265.

Hauri, E., Wang, J., Dixon, J.E., King, P.L., Mandeville, C., and Newman, S., 2002. SIMS analysis of volatiles in silicate glasses 1 . Calibration, matrix effects and comparisons with FTIR. Chemical Geology, 183: 99-114.

Hildreth, W., 1981. Gradients in silicic magma chambers: implications for lithospheric magmatism. Journal of Geophysical Research, 86: 1015310192.

Heinrich, C.A., Pettke, T., Halter, W.E., Aigner-Torres, M., Audétat, Günther, D., Hattendorf, B., Bleiner, D., Guillong, M., and Horn, I., 2003. Quantitative multi-element analysis of minerals, fluids and melt inclusions by laser-ablation inductively-coupled plasma massspectrometry. Geochimica et Cosmochimica Acta, 67: 3473-3496.

Horn, I. and Günther, D., 2003. The influence of ablation carrier gasses Ar, He and $\mathrm{Ne}$ on the particle size distribution and transport efficiencies of laser ablation-induced aerosols: implications for LA-ICP-MS. Applied Surface Science, 207(1-4): 144-157.

Ihinger, P.D., Hervig, R.L. and McMillan, P.F., 1994. Analytical methods for volatiles in glasses. In: M.R. Carroll and J.R. Holloway (Editors), Volatiles in magmas. Mineralogical Society of America, Washington, pp. 517.

Ihinger, P.D., Zhang, Y. and Stolper, E.M., 1999. The speciation of dissolved water in rhyolitic melt. Geochimica et Cosmochimica Acta, 63(21): 35673578 . 
Jackson, S.E., Longerich, H.P., Dunning, G.R., and Fryer, B.J., 1992. The application of laser-ablation microprobe-inductively coupled plasmamass spectrometry (LAM-ICP-MS) to in situ trace-element determinations in minerals. Canadian Mineralogist, 30: 1049-1064.

Jochum, K. P., Stoll, B., Herwig, K., Willbold, M., Hofmann, A.W., Amini, M., Aarburg, S., Abouchami, W., Hellebrand, E., Mocek, B., Raczek, I., Stracke, A., Alard, O., Bouman, C., Becker, S., Dücking, M., Brätz, H., Klemd, R., de Bruin, D., Canil, D., Cornell, D., de Hoog, C-J., Dalpé, C., Danyushevsky, L., Eisenhauer, A., Gao, Y., Snow, J.E., Groschopf, N., Günther, D., Latkoczy, C., Guillong, M., Hauri, E.H., Höfer, H.E., Lahaye, Y., Horz, K., Jacob, D.E., Kasemann, S.A., Kent, A.J.R., Ludwig, T., Zack, T., Mason, P.R.D., Meixner, A., Rosner, M., Misawa, K., Nash, B.P., Pfänder, J., Premo, W.R., Sun, W.D., Tiepolo, M., Vannucci, R., Vennemann, T., Wayne, D., and Woodhead, J., 2006. MPIDING reference glasses for in situ microanalysis: new reference values for element concentrations and isotope ratios. Geochemistry, Geophysics, Geosystems 7: Q02008, doi:10.1029/2005GC001060.

Kent, A.J.R. and Ungerer, C.A., 2005. Production of barium and light rare earth element oxides during LA-ICP-MS microanalysis. Journal of Analytical Atomic Spectrometry, 20: 1256-1262.

Košler, J. and Sylvester, P.J., 2003. Present Trends and the Future of Zircon in Geochronology: Laser Ablation ICPMS. Reviews in Mineralogy and Geochemistry, 53(1): 243-275.

Longerich, H.P., Günther, D., and Jackson, S.E., (1996). Laser ablation inductively coupled plasma mass spectrometric transient signal data acquisition and analyte concentration calculation. Journal of Analytical Atomic Spectrometry, 11: 899-904.

Luhr, J., 2001. Glass inclusions and melt volatile contents at Parícutin Volcano, Mexico. Contributions to Mineralogy and Petrology, 142(3): 261-283. 
Lui, Y., Zhang, Y., and Behrens, H., 2005. Solubility of $\mathrm{H}_{2} \mathrm{O}$ in rhyolitic melts at low pressures and a new empirical model for mixed $\mathrm{H}_{2} \mathrm{O}-\mathrm{CO}_{2}$ solubility in rhyolitic melts. Journal of Volcanology and Geothermal Research, 143: 219-235.

Mason, P., 2001. Expanding the capabilities of laser-ablation ICP-MS with collision and reaction cells. In: Sylvester, P., (Editor), Laser-ablation ICPMS in the Earth Sciences: Principles and applications. Mineralogical Association of Canada, 29: 63-81.

Newman, S., Stolper, E.M. and Epstein, S., 1986. Measurement of water in rhyolitic glasses: calibration of an infrared spectroscopic technique. American Mineralogist, 71: 1527-1541.

Nichols, A.R.L., and Wysoczanski, R.J., 2007. Using micro-FTIR spectroscopy to measure volatile contents in small and unexposed inclusions hosted in olivine crystals. Chemical Geology, 242: 371-384.

Outridge, P.M., Doherty, W., and Gregoire, D.C., 1997. Ablative and transport fractionation of trace elements during laser sampling of glass and copper. Spectrochimica Acta, 52B: 2093-2101.

Smith, B.C., 1996. Fundamentals of Fourier Transform Infrared Spectrometry. CRC Press, Boca Raton, 224pp.

Sylvester, P., (editor), 2001. LA-ICPMS in the Earth Sciences: Principles and applications. Short Course Series 29. Mineralogy Association of Canada.

Turekian, K.K., and Holland, H.D (editors), 2003. Treatise on Geochemistry. Elsevier.

Wright, I.C. and Gamble, J.A., 1999. Southern Kermadec submarine caldera arc volcanoes (SW Pacific): caldera formation by effusive and pyroclastic eruption. Marine Geology, 161: 207-227. 
Wysoczanski, R. and Tani, K., 2006. Spectroscopic FTIR imaging of water species in silicic volcanic glasses and melt inclusions: An example from the Izu-Bonin arc. Journal of Volcanology and Geothermal Research, 156(3-4): 302-314.

Zhang, Y., Belcher, R., Ihinger, P.D., Wang, L., Xu, Z., and Newman, S., 1997. New calibration of infrared measurement of dissolved water in rhyolitic glasses. Geochimica et Cosmochimica Acta, 61(15): 3089-3100.

GeoRem - http://georem.mpch-mainz.gwdg.de

NIST - www.nist.gov 


\section{Appendix 2}

\section{Diffusion}

Diffusion is the relative movement of atoms or molecules that leads to the homogenisation of chemical constituents of a substance in response to chemical or temperature gradients (Brady, 1995; McDougall and Harrison, 1999; Glicksman, 2000; Watson and Baxter, 2007 and references therein). Diffusion occurs on the micro- to macroscopic scale affecting many different processes (Chakraborty, 2008). Diffusion processes of interest here are those that can be used to extract timescales of magmatic processes from chemically zoned crystals in igneous rocks.

\section{A2.1 Diffusion in minerals}

Minerals structures are composed of a fixed regular frameworks of atoms and ions that oscillate (ca. $10^{12}$ times a second) about a fixed position (Putnis, 1992; Watson and Baxter, 2007). Above temperatures of absolute zero, minerals possess point defects and atoms have the potential to obtain sufficient energy to jump and relocate a short distance away (Putnis, 1992; McDougall and Harrison, 1999; Watson and Baxter, 2007). The presence of point defects in the crystal lattice is important as it provides a potential conduit for atoms to diffuse through (Putnis, 1992). The movement of atoms through a crystal can occur by one of several mechanisms (Figure A2.1): (1) vacancy migration, whereby atoms jump into vacant sites in the crystal lattice; (2) interstitial migration, where atoms are sufficiently small and are able to jump and occupy interstitial sites; and (3) exchange of atoms (Putnis, 1992; Giletti and Shanahan, 1997; McDougall and 
Harrison, 1999; Glicksman, 2000; Watson and Baxter, 2007 and references therein).

a)

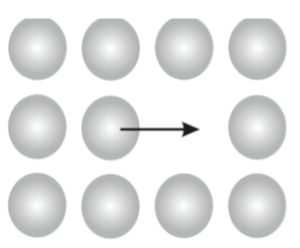

b)

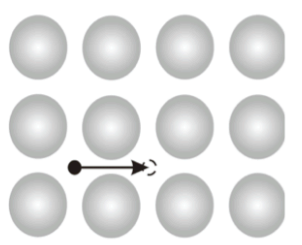

c)

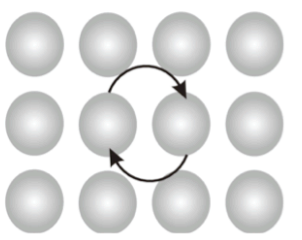

Figure A2.1. Diffusion mechanisms of atoms in solids; (a) vacancy mechanism; (b) interstitial mechanism; (c) exchange of atoms. Adapted from McDougall and Harrison (1999) and Watson and Baxter (2007).

In each instance an energy barrier (activation energy) of the migrating atom must be overcome in order for the atom to migrate (Gill, 1992; Putnis, 1992). Hence, the mechanism by which trace elements diffuse in crystals is dependent on the size and charge of the atom(s) involved and the properties of the host crystal lattice, which differs from mineral to mineral and element to element. For example in plagioclase, $\mathrm{Sr}, \mathrm{K}$ and $\mathrm{Rb}$ diffuse through vacancies, $\mathrm{Li}$ by an interstitial mechanism and $\mathrm{Na}$ and $\mathrm{Ca}$ through a combination of vacancy and interstitial mechanisms (Giletti and Casserly, 1994; Giletti and Shanahan, 1997; Watson and Baxter, 2007). Both $\mathrm{Na}$ and $\mathrm{Ca}$ have the potential to jump into unoccupied interstitial sites, which creates a vacancy permitting for the subsequent diffusion of other elements through the vacancies (Giletti and 
Casserly, 1994). However, Ca atoms require a greater amount of energy to instigate the jump into interstitial sites than $\mathrm{Na}$ atoms. Consequently, the diffusion of elements by the vacancy mechanism is slower in anorthite than in albite (Giletti and Casserly, 1994; Giletti and Shanahan, 1997).

\section{A2.2 Fick's Laws}

The mathematical relationships that describe molecular diffusion in a heterogeneous medium were formalised by Adolf Fick in 1855 who adapted Fourier's Law of Heat Conduction (Brady, 1995; McDougall and Harrision, 1999; Glicksman, 2000; Watson and Baxter, 2007 and references therein). The resulting laws are known as Fick's first and second laws. Fick's first law (Equation A2.1) describes the steady-state diffusion of a species, $i$, in one dimension assuming the concentration gradient in all other directions is zero;

$$
J_{i}=-D_{i} \frac{\partial C_{i}}{\partial x}
$$

where $J_{i}$ is the flux of a species, $i$, through the medium of interest (in atoms per unit time, passing through unit volume), $\mathrm{D}_{i}$ is the diffusivity or diffusion coefficient $\left(\mathrm{m}^{2} \mathrm{~s}^{-1}\right), C_{i}$ is the concentration gradient of $i$ in the $x$ direction.

As timescales of diffusional processes are of relevance to this study, Fick's second law is of greater use as it describes the changing concentration of $i$ with time, $t$ (Equation A2.2);

$$
\frac{\partial C_{i}}{\partial t}=D_{i} \frac{\partial^{2} C_{i}}{\partial x}
$$

Analytical solutions for Fick's laws for numerous geometries and boundary conditions have been obtained and can be found in works such as Carslaw and 
Jaeger (1947) and Crank (1976). The appropriate solution to use in each instance depends on the system being modelled and the amount of diffusion that has occurred (D. Morgan, pers. comm.). For example, modelling of cathodoluminescence (CL) intensity as a proxy for Ti concentrations in quartz crystals (Chapter 3) uses a simple one dimensional diffusion model, as the extent of diffusion on either side of the modelled interface is small in comparison to the thickness of the regions (Doremus, 2002). In contrast, diffusion of $\mathrm{Sr}$ in plagioclase crystals affects a larger extent of the regions bordering the modelled interface (Chapter 4) and therefore a spherical model is more appropriate (see discussion below).

\section{A2.3 Diffusivity of elements}

Diffusion is a thermally activated process (e.g. Brady, 1995) and thus kinetic energy increases with temperature. Accordingly, the probability of an atom to obtain sufficient energy to overcome the energy barrier (activation energy of diffusion, Q) required for the atom to move from one site to another in the crystal lattice increases exponentially with temperature (Putnis, 1992; McDougall and Harrison, 1999; Watson and Baxter, 2007). This energy is provided from the thermal motion of atoms and the probability $(p)$ of an atom in attaining sufficient energy to 'jump' can be expressed by the Boltzmann distribution expression;

$$
p=e^{(-Q / k T)}
$$

where $k$ is the Boltzmann's constant and $T$ is the mean thermal energy (temperature) of the system (Putnis, 1992). When considering the mass transport of atoms this expression becomes;

$$
p=e^{(-Q / R T)}
$$


where $\mathrm{R}$ is the gas constant $\left(8.13451 \mathrm{~J} \mathrm{~mol}^{-1} \mathrm{~K}^{-1}\right)$ (Putnis, 1992). The diffusivity (D) of an element is proportional to the probability of an atom obtaining sufficient energy to 'jump', and the temperature ( $\mathrm{T}$ in Kelvin) (Equation A2.4). Thus the above expression can be rewritten as the familiar Arrhenius equation (Equation A2.5);

$$
D=D_{0} e^{(-Q / R T)}
$$

with the introduction of a rate constant, in this case the pre-exponential factor $\left(D_{0}\right)$ (Putnis, 1992; McDougall and Harrison, 1999; Watson and Baxter, 2007). This pre-exponential factor $\left(\mathrm{D}_{0}\right)$ contains information about the specific medium such as the atomic vibrational frequency, the inter-atomic distance between atomic sites and the fraction of vacancies within the crystal lattice (Putnis, 1992; McDougall and Harrison, 1999; Watson and Baxter, 2007). The pre-exponential factor and activation energy must be determined for each medium and each element of interest before any diffusion modelling can be conducted. Numerous experiments have been conducted to determine the pre-exponential and activation energies of trace elements in plagioclase and those of interest to this study are shown in Table A2.1.

In addition, the diffusivity of trace elements in anisotropic crystals can vary with crystal orientation. Sr diffusion in plagioclase is slightly anisotropic with diffusion normal to the (001) cleavage plane faster than diffusion normal to the (010) cleavage plane by $0.7-1 \log$ units (ca. factor of five to 10 faster) (Cherniak and Watson, 1994). This is close to the uncertainties on these measurements and therefore, $\mathrm{Sr}$ diffusion is assumed to be isotropic during diffusion modelling 
(Giletti and Casserly, 1994; LaTourette and Wasserburg, 1998; Zellmer et al., 1999).

\begin{tabular}{lclcc}
\hline Element & $\mathrm{X} \mathrm{An}$ & $\mathrm{D}_{0}\left(\mathrm{~m}^{2} \mathrm{~s}^{-1}\right)$ & $\mathrm{Q}\left(\mathrm{kJmol}^{-1}\right)$ & Source \\
\hline $\mathrm{Sr}$ & $0-1$ & $\log _{10} \mathrm{D}_{0}=-4.08-4.1 \mathrm{XAn}$ & 276 & 1 \\
$\mathrm{Ba}$ & 0.67 & $1.1 \times 10^{-6}$ & 341 & 2 \\
$\mathrm{Li}$ & $0-1$ & $1.58 \times 10^{-4}$ & 146 & 3 \\
$\mathrm{~K}$ & $0.23-0.67$ & $4.46 \times 10^{-6}$ & 271 & 3 \\
$\mathrm{~Pb}$ & $0.43-0.67$ & $\log \mathrm{D}=-6.94-(266.5 / 2.303 \mathrm{RT})$ & & 4 \\
$\mathrm{Mg}$ & $0-1$ & $\mathrm{D}=\left[2.92 \times 10^{(-4.1 \times \mathrm{XAn}-3.1)} \exp (-266000 / \mathrm{RT})\right]$ & & 5 \\
$\mathrm{OH}$ & $0-1$ & $5.7 \pm 2.5 \times 10^{-4}\left(\right.$ for $\left.800^{\circ} \mathrm{C}\right)$ & 224 & 6 \\
\hline
\end{tabular}

Table A2.1. Pre-exponential and activation energies for selected trace elements in plagioclase. Abbreviations: $\mathrm{X}$ An = plagioclase anorthite composition calculated on a mole fraction basis over which the $\mathrm{D}_{0}$ and $\mathrm{Q}$ are applicable; $\mathrm{D}_{0}=$ pre-exponential factor; $\mathrm{Q}=$ activation energy; $\mathrm{D}=$ diffusivity; $\mathrm{R}$ = gas constant; $\mathrm{T}$ = temperature. Sources: (1) Giletti and Casserly (1994); (2) Cherniak (2002); (3) Giletti and Shanahan (1997); (4) Cherniak (1995); (5) Costa et al. (2003); (6) Johnson (2003).

\section{A2.4. Activity}

Diffusion modelling across phase boundaries of a crystal, for example, between discrete zones of a crystal or the crystal and the external melt, requires consideration of the chemical thermodynamics of the system and the influence of other chemical components on the diffusion of the species of interest (Alberède, 1996; Costa et al., 2003; Zellmer et al., 2003; Watson and Baxter, 2007). Thus, perhaps counter-intuitively, it is not the concentration of the species of interest that diffuses but the species' activity (chemical potential) and this may result in 'uphill' diffusion (Alberède, 1996; Costa et al., 2003; Zellmer et al., 2003; Watson and Baxter, 2007). Activity of a species is the 'effective' concentration and is the energy gradient that drives the atoms in one direction or another during diffusion (Alberède, 1996; Housecroft and Constable, 1997). 
Equilibrium is obtained when the chemical potential of the element of interest across the modelled interface is equal (Fletcher, 1993). This occurs when the thermodynamic quantity of Gibbs free energy $(G)$ of the system is equal to zero (e.g. Gill, 1992; Putnis, 1992; Fletcher, 1993; Brady, 1995) and can be illustrated by considering two adjacent zones of a plagioclase crystal $A$, and $B$, that possess Sr concentrations of $\mathrm{Sr}_{\mathrm{A}}$ and $\mathrm{Sr}_{\mathrm{B}}$ respectively. If a small quantity of $\mathrm{Sr}$ in zone $A$ $\left(\delta \mathrm{Sr}_{\mathrm{A}}\right)$ is transferred to zone $B$ the change in Gibbs free can be written as;

$$
d G=d G^{A}+d G^{B}=\delta S r_{A}\left(\mu_{S r}^{B}-\mu_{S r}^{A}\right)
$$

where $d G$ is the change of Gibbs free energy of the system, $d G^{A}$ and $d G^{B}$ are the change in Gibbs free energy in zones $A$ and $B$ respectively and $\mu_{S r}^{A}$ and $\mu_{S r}^{B}$ are the chemical potential of $\mathrm{Sr}$ in zones $A$ and $B$ respectively (Fletcher, 1993). If $d \mathrm{G}=0$ (i.e. at equilibrium) the $\mathrm{Sr}$ concentration between the two zones will not change as $\mu_{S r}^{A}=\mu_{S r}^{B}$ (Fletcher, 1993). However, if $d G$ is less than zero a spontaneous reaction will occur between the two zones and $\mathrm{Sr}$ will be free to diffuse from zone $A$ to zone $B$ as $\mu_{S r}^{A}>\mu_{S r}^{B}$ (Fletcher, 1993). Therefore, it is the chemical potential of the substance of interest that governs the position of equilibrium of the system at a constant temperature and pressure and not the concentration (Fletcher, 1993).

Activity or a calculated fictional melt composition can be approximated if a standard state for the element of interest can be constrained (Fletcher, 1993). For modelling of elements in crystals this can be taken as the equilibration concentration (see section A2.5). The simplest method for approximating the calculated fictional melt composition of an element is to divide the measured concentration by the equilibrium concentration (Zellmer et al., 2003). This 
allows identification of regions of a crystal that are in local equilibrium (calculated fictional melt composition $\sim 1$ ) and those that are not and display gradients in the calculated fictional melt composition to be recognised. Regions of the crystal that possess time information can be identified by gradients in the calculated fictional melt composition (Figure A2.2) (Zellmer et al., 2003).

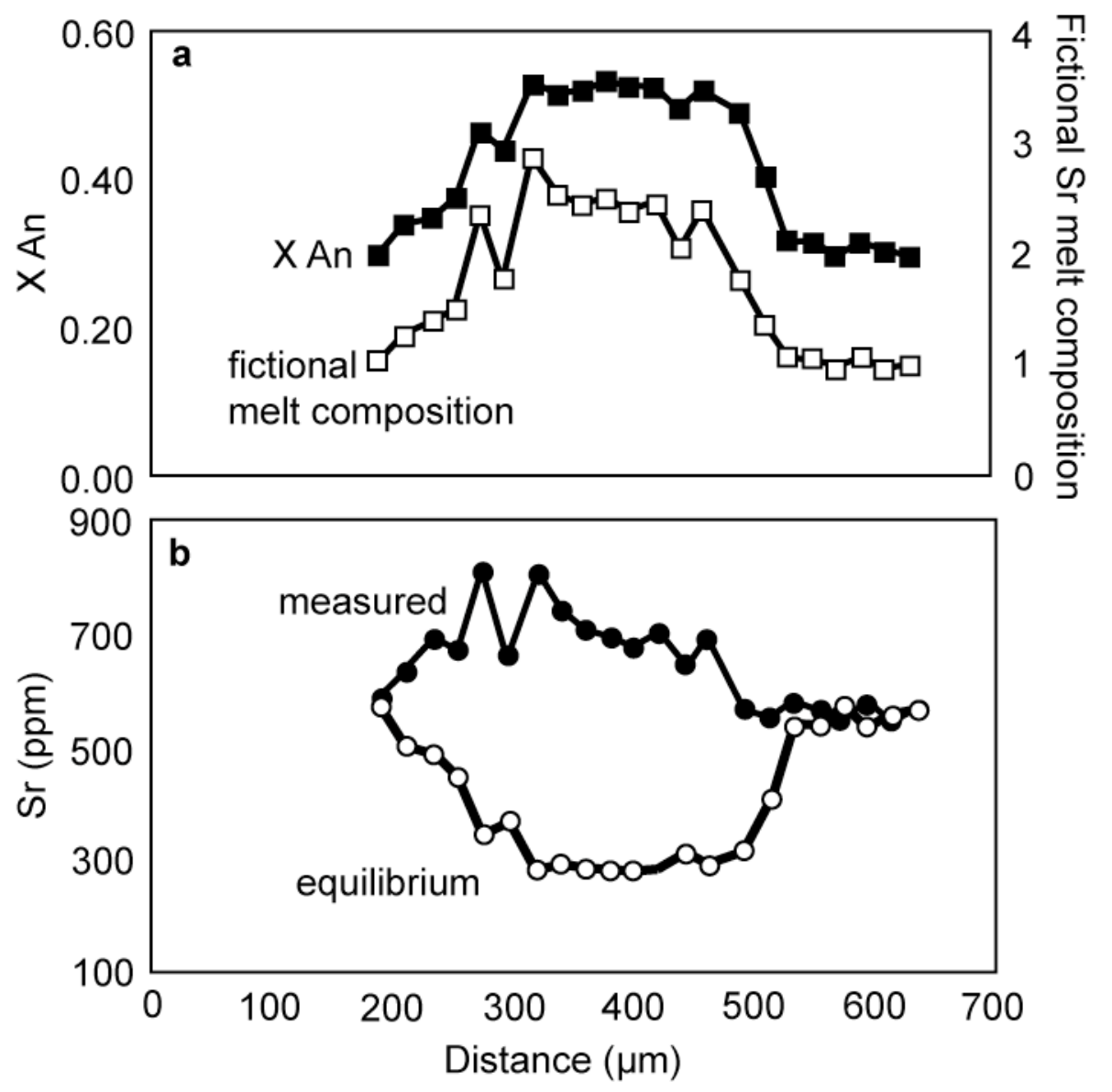

Figure A2.2. a) Measured $A n$ profile and fictional Sr melt composition of a plagioclase crystal from the Whakamaru ignimbrite (Chapter 4). Fictional $\mathrm{Sr}$ melt composition = measured $\mathrm{Sr}$ concentration/equilibrium concentration of Sr. The fictional melt compositon profile indicates the core $(325-450 \mu \mathrm{m})$ and the $\operatorname{rim}(550-670 \mu \mathrm{m})$ of the crystal are in local equilibrium. The gradient in fictional melt composition $(450-550 \mu \mathrm{m})$ indicates where time information is accessible in the profile; b) corresponding measured and equilibrium concentrations of $\mathrm{Sr}$ in the plagioclase crystal. Equilibrium concentrations of $\mathrm{Sr}$ are calculated from the partitioning relationship of Blundy and Wood (1991); $R T \ln K_{S r}=26,800-26,700 X_{A n}$ and the calculated melt composition in equilibrium with the rim of the crystal (see section A2.5). 


\section{A2.5. Diffusion in plagioclase crystals}

During crystallisation of plagioclase, the rim of the crystal is in local equilibrium with the surrounding melt and the plagioclase composition reflects that of the melt (Grove et al., 1984; Morse et al., 1984; Blundy and Shimizu, 1991). The original anorthite composition of the plagioclase is retained due to the very slow (ca. $10^{-28} \mathrm{~m}^{2} \mathrm{~s}^{-1}$ at $800^{\circ} \mathrm{C}$ ) inter-diffusion of $\mathrm{NaSi}-\mathrm{CaAl}$ (Grove et al., 1984; Morse et al., 1984; Blundy and Shimizu, 1991). However, partition coefficients govern the ease with which minor and trace elements are incorporated into plagioclase and these relationships are dominated by the anorthite composition (Blundy and Wood, 1991 and 1994; Bindeman et al., 1998). Conversely, the trace element concentrations of plagioclase crystals, although in equilibrium with the melt they crystallised from, may not be in equilibrium with the anorthite composition (e.g. Blundy and Wood, 1991). With time diffusion will serve to homogenise any compositional heterogeneities and only ceases on eruption when the compositional profile is 'frozen' into the crystal.

Three compositional profiles have been identified and defined in plagioclase crystals: (1) the initial concentration growth profile produced during the growth of the crystal; (2) the equilibrium profile that would result if the trace element concentrations were in equilibrium with the $A n$ content of the plagioclase crystal; and (3) the measured trace element concentration profile that is most likely intermediary between the initial and equilibrium profiles (Zellmer et al., 1999; Costa et al., 2003). The time that an interface within a crystal resided at magmatic temperature can be calculated from the time required for an element to 
diffuse from the initial to the measured concentration profile (Zellmer et al., 1999).

The strong dependence of partition coefficients on the anorthite concentration of plagioclase crystals results in equilibrium profiles that are not flat but reflect the anorthite composition (Zellmer et al., 1999). Plagioclase crystals can be treated as either open or closed systems and this controls the calculated equilibrium concentrations (Zellmer et al., 1999; Costa et al., 2003). Equilibrium profiles in this study are calculated using the open system model of Costa et al. (2003).

Partition coefficients are determined by dividing the concentration of the element, $i$, in the mineral $\left(\mathrm{C}^{\mathrm{min}}\right)$ by the concentration of the element in the liquid $\left(\mathrm{C}^{\text {liq }}\right)$ (Equation A2.7).

$$
K_{i}=\frac{C^{\min }}{C^{l i q}}
$$

The difference in partition coefficients controls the equilibrium values of trace elements in each zone and with the external melt (Blundy and Wood, 1991; Zellmer et al., 1999). Thus by utilising the well-established trace element partitioning relationships on $A n$ content (Equation A2.8) and partition coefficient (Equation A2.7), the melt composition in equilibrium with the rim of the plagioclase crystal can be determined if the magmatic temperature ( $\mathrm{T}$ in Kelvin) is known (Blundy and Wood, 1991; Bindeman et al., 1998).

$$
\begin{aligned}
& R T \ln K_{S r}=26,800-26,700 X_{A n} \\
& R T \ln K_{B a}=10,200-38,200 X_{A n} \quad(\mathrm{~A} 2.8 \mathrm{a}-\mathrm{c}) \\
& R T \ln K_{M g}=-25,700-26,100 X_{A n}
\end{aligned}
$$

This calculated melt composition can then be substituted as the melt composition into Equations A2.7 and A2.8 to determine the equilibrium concentration of the 
element, $i$, throughout the crystal (Zellmer et al., 1999; Costa et al., 2003). This assumes the plagioclase crystal remained an open system post-crystallisation with the ability to exchange trace elements with the external melt (Costa et al., 2003). Thus, the entire crystal is attempting to achieve equilibrium with the final host melt (Costa et al., 2003), irrespective of the prior melt compositions in which the plagioclase resided in or crystallised from.

\section{A2.6 Residence time of plagioclase crystals}

The potential for plagioclase as an archive of magmatic processes has long been recognised and exploited. Residence times of plagioclase crystals have been documented from trace element diffusion employing both square wave (Zellmer et al., 1999; Costa et al., 2003) and spherical (Cherniak, 2002; Kent et al., 2007) solutions to Fick's second law. Here, both models are considered and the residence time of a Whakamaru plagioclase crystal is calculated and compared to establish the most applicable model for use in this study. The spatial resolution of analytical techniques restricts the size of plagioclase regions that are suitable for this type of modelling. Therefore, whilst timescales of magmatic events that result in large-scale chemical zonation of plagioclase crystals can be determined, the duration of processes responsible for the fine-scale oscillatory zonation of crystals cannot currently be resolved.

\section{A2.6.1 Square-wave model}

Zellmer et al. (1999) developed a one-dimensional diffusion model that simplifies the zonation of crystals, homogenising the elemental concentrations across each zone. The model considers the diffusional smoothing of $\mathrm{Sr}$ 
concentrations between two adjacent zones $A$ and $B$ of equal widths $(2 w)$ with constant $\mathrm{Sr}$ diffusivity $\left(\mathrm{D}_{\mathrm{Sr}}\right)$ and initial concentrations of $C_{S r, 0}^{A}$ and $C_{S r, 0}^{B}$ respectively (Zellmer et al., 1999) (Figure A2.3).

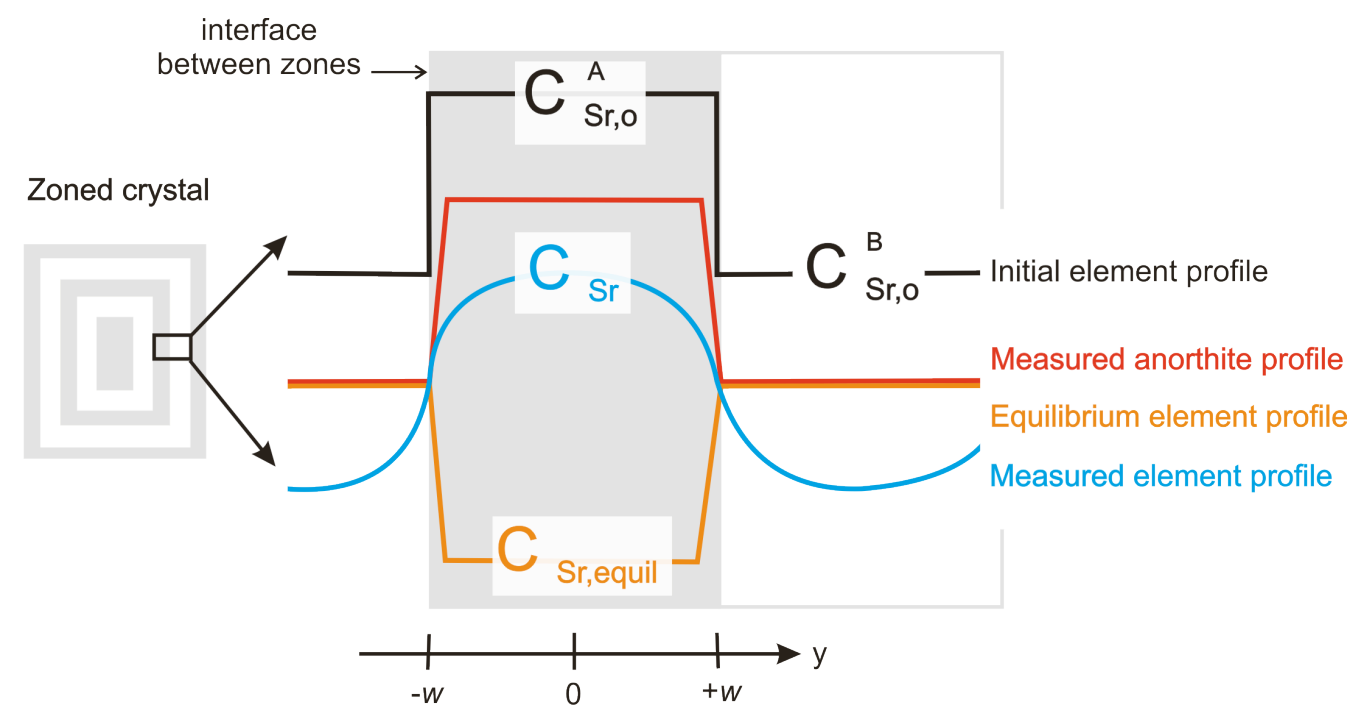

Figure A2.3. Square-wave diffusion model after Zellmer et al. (1999) with the three compositional zones highlighted. Two adjacent zones of equal width $(2 w)$ are modelled with different initial Sr concentrations. Abbreviations: $C_{S r, 0}^{A}$ and $C_{S r, 0}^{B}=$ initial Sr concentrations in zone $A$ and $B$ respectively; $\mathrm{C}_{\mathrm{Sr}}=$ measured $\mathrm{Sr}$ concentration; $\mathrm{C}_{\mathrm{Sr}}$, equil $=$ equilibrium $\mathrm{Sr}$ concentration.

The estimation of the initial elemental concentrations is the largest source of error associated with this type of diffusion model. Zellmer et al. (1999) proposed that a petrological reasonable estimate of the initial maximum $\mathrm{Sr}$ concentrations could be calculated by a factor $\sim 2.5$ from the measured concentration of plagioclase crystals after examination of published $\mathrm{Sr}$ concentrations. The residence time $(t)$ of crystals are calculated from Equation A2.9, the solution to Fick's second law in a layer of half width, $w$, where the edge of the model zone is equal to $\mathrm{y}=+w($ Figure A2.3); 


$$
\frac{C_{S r}-C_{S r, \text { equil }}}{C_{S r, 0}-C_{S r, \text { equil }}}=2 \sum_{n=0}^{\infty} \frac{(-n)^{n}}{\left(n+\frac{1}{2}\right) \pi} e^{-\left(n+\frac{1}{2}\right)^{2} \pi^{2} D_{S r} t / w^{2}} \cos \left(\left(n+\frac{1}{2}\right) \frac{\pi y}{w}\right)
$$

where $\mathrm{C}_{\mathrm{Sr}}$ is the measured $\mathrm{Sr}$ concentration, $\mathrm{C}_{\mathrm{Sr} \text {,equil }}$ is the equilibrium $\mathrm{Sr}$ concentration and $\mathrm{C}_{\mathrm{Sr}, 0}$ is the initial $\mathrm{Sr}$ concentration (Zellmer et al., 1999). The left hand side of Equation A2.9 represents the percentage of the undiffused fraction of the initial concentration at the centre of the model zone and can be plotted against the right hand side of Equation A2.9 allowing the residence time of the crystal to be established (Figure A2.4) (Zellmer et al., 1999).

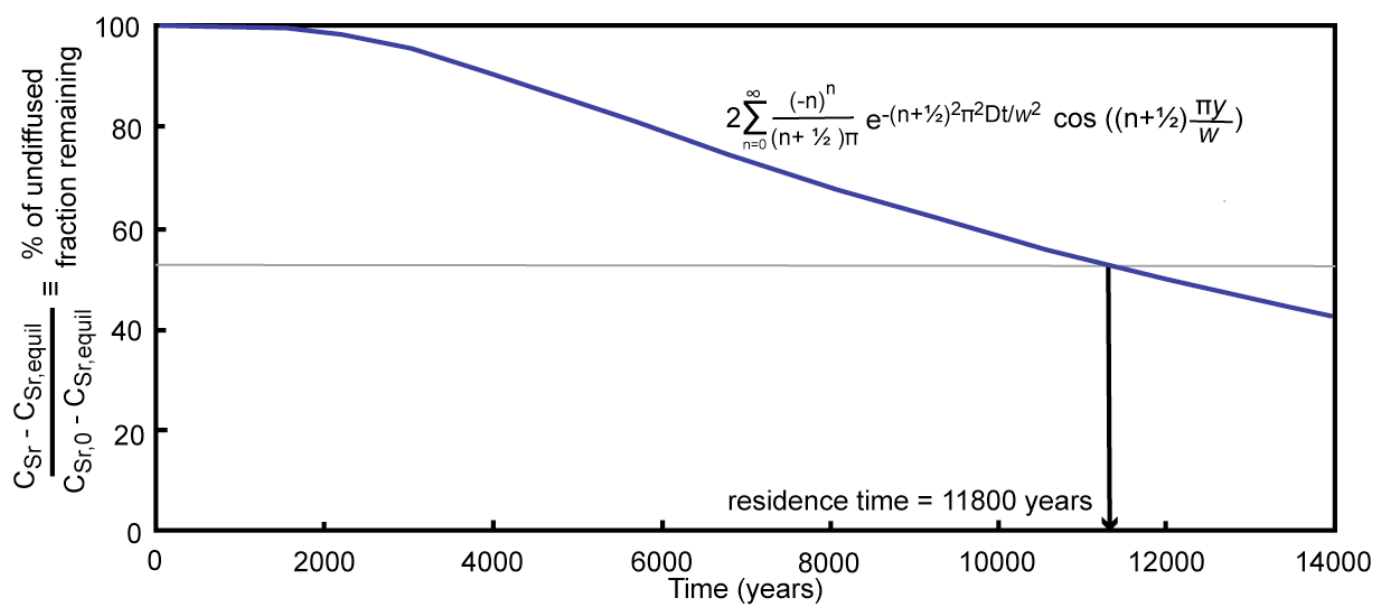

Figure A2.4 Calculation of the residence time of plagioclase crystals using the square-wave model as described by Zellmer et al. (1999). The model curve calculated form the right hand side of Equation A2.9 is shown in blue. A grey line denotes the percentage of the undiffused initial fraction remaining calculated from the measured $\left(\mathrm{C}_{\mathrm{Sr}}\right)$, equilibrium $\left(\mathrm{C}_{\mathrm{Sr} \text {,equil }}\right)$ and initial $\left(\mathrm{C}_{\mathrm{Sr}, 0}\right)$ concentrations of $\mathrm{Sr}$ (left hand side of Equation A2.9). The residence time is determined from the intersection of the blue and grey lines.

As discussed above, the diffusivity of elements that diffuse via a vacancy mechanism (e.g. Sr) is slowest at higher $A n$ compositions in plagioclase (Giletti and Casserly, 1994; Giletti and Shanahan, 1997; Zellmer et al., 1999; Watson and Baxter, 2007). Thus, the calculation of residence times at the highest 
measured $A n$ content results in maximum estimates of timescales assisting in reducing the errors associated with this model (Zellmer et al., 1999).

\section{A2.6.2. Spherical diffusion models}

One of the simplest diffusion models are those constructed for spheres (Figure A2.5) with a radii of $a$, an initial trace element concentration of $\mathrm{C}_{1}$, exposed to a medium with a constant surface concentration of $\mathrm{C}_{0}(\mathrm{Crank}, 1976$; Lasaga, 1998; Cherniak, 2002).

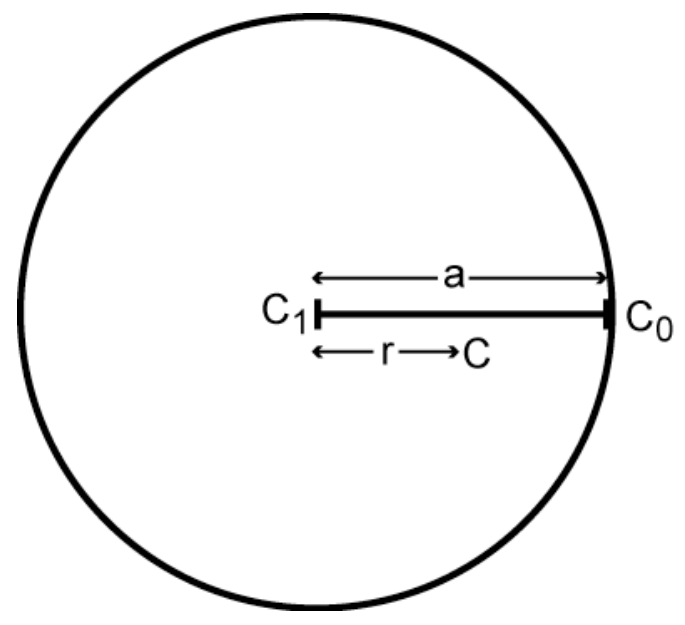

Figure A2.5. Spherical diffusion model. Sphere of radius, $a$, with an uniform initial species concentration of $\mathrm{C}_{\mathrm{i}}$, maintained in a magma of constant surface concentration $\mathrm{C}_{0}$. A point a distance $r$ from the centre of the circle has a species concentration of $\mathrm{C}$ at time $t$.

A point a distance $r$ from the centre of the circle has a species concentration of $\mathrm{C}$, at time $t$ and can be modelled by the solution to Fick's second law shown in Equation A2.10.

$$
\frac{C-C_{1}}{C_{0}-C_{1}}=1+\frac{2 a}{\pi r} \sum_{n=1}^{\infty} \frac{(-1)^{n}}{n} \sin \frac{n \pi r}{a} e^{-D n^{2} \pi^{2} t / a^{2}}
$$


The left hand side of the equation represents the percent of re-equilibration that has occurred and allows a graph similar to Figure A2.4 to be plotted and the residence time of crystals determined.

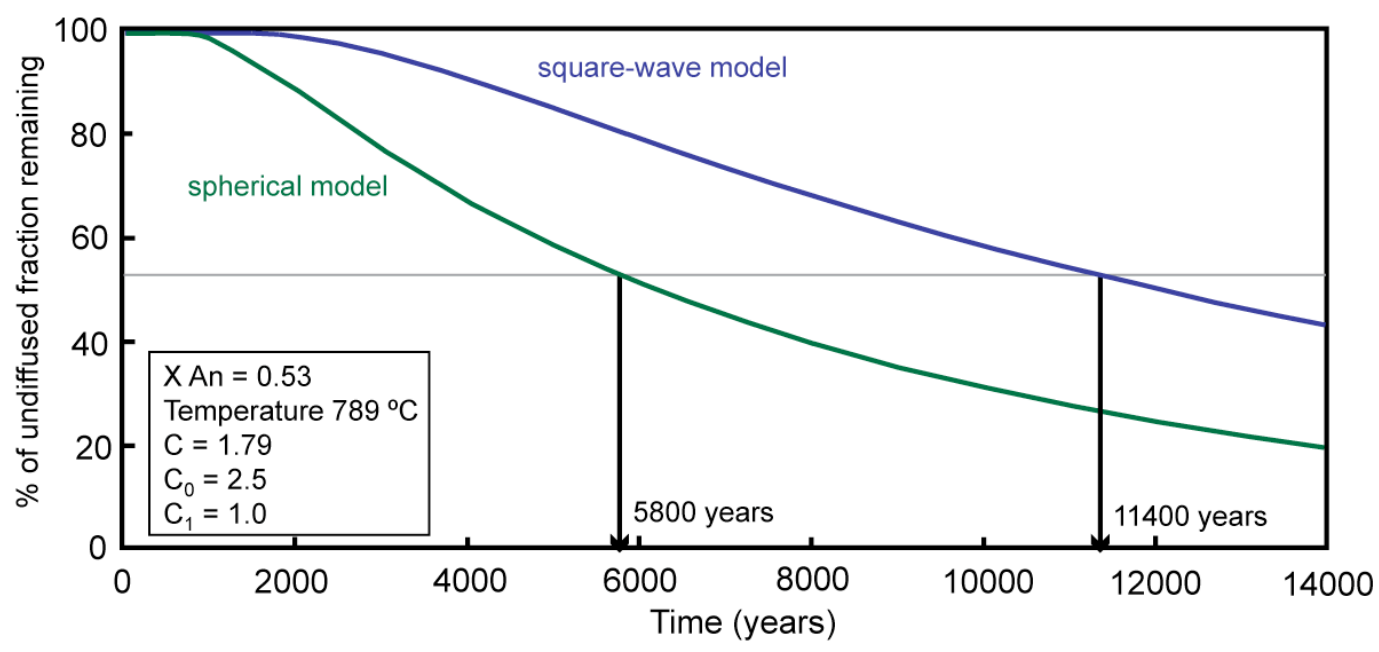

Figure A2.6. Diffusion curves for both the square-wave and spherical models and the residence times calculated from each model. Models assume a maximum $A n=0.53 \mathrm{~mol} \%$, a diffusivity of $1.49 \times 10^{-20} \mathrm{~m}^{2} \mathrm{~s}^{-1}$, an initial fictional $\mathrm{Sr}$ melt composition of 2.5 , an equilibrium fictional melt composition of 1 , a measured concentration of 1.79 and a radius of the sphere (r) or the diffusional half width $(w)$ of $200 \mu \mathrm{m}$.

A2.6.3. Comparison of calculated residence times: square-wave versus spherical models

Both the square-wave model of Zellmer et al. (1999) and the spherical model have been used to calculate the residence time of a plagioclase crystal (WH1_h) from the Whakamaru ignimbrite (Chapter 4) (Figure A2.6). In both instances, the fictional $\mathrm{Sr}$ melt compositon has been substituted for concentration in Equations A2.9 and A2.10. It is clear that there is a discrepancy in residence times calculated from the two models (Figure A2.6), illustrating the importance of applying the most appropriate diffusion model for the problem. The rim-to-rim diffusion in a plane sheet overestimates the time required for diffusion to affect 
the core of the region as the core of the plane sheet overestimates the volume of a crystal core. Crystal cores are volumetrically small in comparison to their surface area and, therefore, will reset significantly faster than the timescales estimated using a plane sheet model. In contrast, a spherical model possesses a large surface area and a volumetrically small core, which more adequately portrays a plagioclase crystal providing a more realistic timescale (D.Morgan, pers. comm.). A spherical model has been implemented to calculate residence times of plagioclase crystals from $\mathrm{Sr}$ diffusion from the Whakamaru Ignimbrite (Chapter 4).

\section{A2.7 Source of errors}

Several sources of error are associated with this type of model, but can be minimised with careful consideration. Errors can be introduced from: (1) the analytical errors of the chemical composition of plagioclase analysis; (2) the magmatic temperature and hence the diffusivity of elements (3) estimation of the initial elemental concentrations; (4) calculation of the equilibrium concentration; and (5) identification of the half width over which diffusion is modelled.

\section{A2.7.1 Chemical composition of plagioclase}

Errors for the composition of the major elements of plagioclase crystals are given in Chapter 4. $\mathrm{CaO}, \mathrm{Na}_{2} \mathrm{O}$ and $\mathrm{K}_{2} \mathrm{O}$ have a two standard deviation $(2 \sigma)$ of 0.38 , 0.19 and $0.07 \mathrm{wt} \%$ respectively, which results in negligible errors for the calculated $A n$ composition ( $\pm 0.008 \mathrm{~mol} \%$ ) of analyses. The variation in $A n$ concentration across a zone is not modelled, but is simplified to the highest measured An composition which will introduce additional uncertainties to the 
calculated residence time (Zellmer et al., 1999). Errors for the trace element composition of plagioclase crystals are given in Chapter 4 and indicate $\mathrm{Sr}$ concentrations are precise to $3 \%(2 \mathrm{SD})$.

\section{A2.7.2 Magmatic temperature and diffusivity}

Magmatic temperatures for the Whakamaru ignimbrite are derived from $\mathrm{Fe}-\mathrm{Ti}$ oxides and plagioclase-melt equilibria (Chapter 4). Errors on magmatic temperatures determined from Fe-Ti oxides are estimated $\pm 30{ }^{\circ} \mathrm{C}$ (Anderson et al., 1993) and from plagioclase-melt equilibria $\pm 23{ }^{\circ} \mathrm{C}$ (Putirka, 2005). This could potentially propagate into substantial errors for the calculated diffusivity. Therefore the diffusivity of a modelled element should always be quoted at the magmatic temperature it was derived from. Experimental data indicates an uncertainty of a factor of 2 may occur on the calculated diffusivity of $\mathrm{Sr}$ in plagioclase (Giletti and Casserly, 1994).

\section{A2.7.3 Initial elemental concentrations}

This is the largest source of error associated with these calculations (Zellmer et al., 1999). Zellmer et al. (1999) suggested a petrologically reasonable maximum estimate was a factor of 2.5 times the measured $\mathrm{Sr}$ concentration, whilst Costa et al. (2003) assumed the central proportions of large zones are unmodified by diffusion and represents a best estimate of the initial concentrations. The former method is likely to overestimate the original elemental concentrations miscalculating the residence times of crystal, with the latter method being more realistic and is the approach used in this study. Additionally, a step function is assumed, which may oversimplify the genuine initial concentrations and 
overestimate the residence times of crystal by a maximum of 5-10\% (Zellmer et al., 1999).

\section{A2.7.4 Equilibrium profiles}

Equilibrium concentrations are calculated from Equations A2.7 and A2.8 and any error in the $A n$ concentration, magmatic temperature or constants will be propagated into the calculated equilibrium concentrations. As long as temperature estimates are known within $\pm 100{ }^{\circ} \mathrm{C}$, Blundy and Wood (1991) estimated uncertainties of $<10 \%$ in $\mathrm{RT} \ln \mathrm{K}_{i}$ space. However, as the relative partition coefficients of adjacent zones of the crystal are of interest, it is likely that the errors on the calculated partition coefficients are minor (Zellmer et al., 1999).

Zellmer et al. (2003) derived equation A2.11 constraining the uncertainties on the calculated equilibrium concentrations where $\sigma \mathrm{C}_{\text {equil }}$ is the error on the calculated equilibrium concentrations, $w$ is a constant $\left(w_{\mathrm{Sr}}=-26700 \pm 1900\right.$ $\mathrm{mol} / \mathrm{J})$ and $\sigma A n$ is the error associated with the $A n$ concentration.

$$
\sigma C_{\text {equil }}=C_{\text {equil }} \frac{w}{R T} \sigma A n \quad(\mathrm{~A} 2.11)
$$

Assuming a magmatic temperature of $789{ }^{\circ} \mathrm{C}$, an error of \pm 0.008 on the $A n$ concentration and a calculated Sr equilibrium concentration of $600 \mathrm{ppm}$ (Figure A2.2) this would equate to an $\sigma \mathrm{C}_{\text {equil }}$ of $< \pm 15 \mathrm{ppm}$. Propagating these uncertainties through to the fictional Sr melt calculations indicates errors of \pm 0.05, which yield negligible errors on the calculated timescales. 


\section{A2.7.5 Identification of diffusional half-width}

Diffusion will homogenise smaller regions faster and therefore it is imperative to correctly identify the area over which diffusion is occurring. For example, increasing or decreasing the radius of the sphere used for modelling the residence time of WH1_h (section A2.6.3) by $10 \mu \mathrm{m}$ results in ages of \pm 1200 years.

\section{A2.8. References}

Albarède, F., 1996. Introduction to Geochemical Modeling. Cambridge University Press, $543 \mathrm{pp}$.

Anderson, D.J., Lindsley, D.H., and Davidson, P.M., 1993. QUILF: A pascal program to assess equilibria among Fe-Mg-Mn-Ti oxides, pyroxenes, olivine and quartz. Computers and Geoscience, 19: 1333-1350.

Bindeman, I.N., Davis, A.M. and Drake, M.J., 1998. Ion microprobe study of plagioclase-basalt partition experiments at natural concentration levels of trace elements. Geochimica et Cosmochimica Acta, 62(7): 1175-1193.

Blundy, J.D. and Shimizu, N., 1991. Trace-element evidence for plagioclase recycling in calc-alkaline magmas. Earth and Planetary Science Letters, 102(2): 178-197.

Blundy, J.D. and Wood, B.J., 1991. Crystal-chemical controls on the partitioning of $\mathrm{Sr}$ and $\mathrm{Ba}$ between plagioclase feldspar, silicate melts, and hydrothermal solutions. Geochimica et Cosmochimica Acta, 55(1): 193209.

Blundy, J.D., and Wood, B.J., 1994. Prediction of crystal-melt partition coefficients from elastic moduli. Nature, 372: 452-454. 
Brady, J.B., 1995. Diffusion data for silicate minerals, glasses and liquids., Mineral Physics and Crystallography, A Handbook of Physical Constants. AGU Reference Shelf 2, pp. 269-290.

Carslaw, H., S., and Jaeger, J., C., 1947. Conduction of heat in solids. Oxford, Clarendon Press, 515pp.

Chakraborty, S., 2008. Diffusion in Solid Silicates: A Toll to Track Timescales of Processes Comes of Age. Annual Reviews of Earth Science, 36: 153190.

Cherniak, D.J., 1995. Diffusion of lead in plagioclase and K-feldspar: An investigation using Rutherford Backscattering and resonant nuclear reaction analysis. Contributions to Mineralogy and Petrology, 120: 358371.

Cherniak, D.J., 2002. Ba diffusion in feldspar. Geochimica et Cosmochimica Acta, 66(9): 1641-1650.

Cherniak, D.J., and Watson, E.B., 1994. A study of strontium diffusion in plagioclase using Rutherford backscattering spectroscopy. Geochimica et Cosmochimica Acta, 58: 5179-5190.

Costa, F., Chakraborty, S. and Dohmen, R., 2003. Diffusion coupling between trace and major elements and a model for calculation of magma residence times using plagioclase. Geochimica et Cosmochimica Acta, 67(12): 2189-2200.

Crank, J., 1976. The mathematics of diffusion. Oxford University Press, 414pp.

Doremus, R.H., 2002. Diffusion of Reactive Molecules in Solids and Melts. A Wiley-Interscience Publication, New York, 293pp. 
Fletcher, P., 1993. Chemical thermodynamics for earth scientists. Geochemistry series. Longman scientific and technical, London, 464 pp.

Giletti, B.J. and Casserly, J.E.D., 1994. Strontium diffusion kinetics in plagioclase feldspars. Geochimica et Cosmochimica Acta, 58(18): 37853793.

Giletti, B.J. and Shanahan, T.M., 1997. Alkali diffusion in plagioclase feldspar. Chemical Geology, 139(1-4): 3-20.

Gill, R., 1992. Chemical fundamentals of Geology. Unwin Hyman, London, 291pp.

Glicksmann, M.D., 2000. Diffusion in solids: Field theory, solid-state principles, and applications. A Wiley-Interscience Publication, 472 pp.

Grove, T.L., Baker, M.B. and Kinzler, R.J., 1984. Coupled CaAl-NaSi diffusion in plagioclase feldspar: Experiments and applications to cooling rate speedometry. Geochimica et Cosmochimica Acta, 48(10): 2113-2121.

Housecroft, C.E. and Constable, E.C., 1997. Chemistry: An integrated approach. Prentice Hall, 1032 pp.

Johnson, E.A., 2003. Hydrogen in nominally hydrous crustal minerals. PhD thesis, California Institute of Technology, Pasadena, California.

Kent, A.J.R., Blundy, J., Cashman, K.V., Cooper, K.M., Donnelly, C., Pallister, J.S., Reagan. M., Rowe, M.C., and Thornber, C.R.. 2007. Vapor transfer prior to the October 2004 eruption of Mount St. Helens, Washington. Geology, 35(3): 231-234.

Lasaga, A.C., 1998. Kinetic theory in Earth Sciences. Princeton Series in Geochemistry, Princeton University Press, pp.728 
LaTourette, T., and Wasserburg, G.L., 1998. Mg diffusion in anorthite: implication for the formation of early solar system planetesimals. Earth and Planetary Science Letters, 158: 91-108.

McDougall, I. and Harrison, T.M., 1999. Geochronology and thermochronology by the ${ }^{40} \mathrm{Ar} /{ }^{39} \mathrm{Ar}$ method. Oxford University Press, New York.

Morse, S.A., 1984. Cation Diffusion in Plagioclase Feldspar. Science, 225(4661): 504-505.

Putnis, A., 1992. Introduction to Mineral Sciences. Cambridge University Press. $460 \mathrm{pp}$.

Putirka, K.D., 2005. Igneous thermometers and barometers based on plagioclase + liquid equilibria: Tests of some existing models and new calibrations. American Mineralogist, 90(2-3): 336-346.

Watson, E.B. and Baxter, E.F., 2007. Diffusion in solid-Earth systems. Earth and Planetary Science Letters, 253(3-4): 307-327.

Zellmer, G.F., Blake, S., Vance, D., Hawkesworth, C. and Turner, S., 1999. Plagioclase residence times at two island arc volcanoes (Kameni Islands, Santorini, and Soufriere, St. Vincent) determined by $\mathrm{Sr}$ diffusion systematics. Contributions to Mineralogy and Petrology, 136(4): 345-357.

Zellmer, G.F., Sparks, R.S.J., Hawkesworth, C.J. and Wiedenbeck, M., 2003. Magma emplacement and remobilization timescales beneath Montserrat: Insights from $\mathrm{Sr}$ and $\mathrm{Ba}$ zonation in plagioclase phenocrysts. Journal of Petrology, 44(8): 1413-1431. 


\section{Appendix 3}

Table A3.1: Major and trace element compositions of melt inclusions

Major element concentrations are given in $\mathrm{wt} \%$ and trace element concentrations are given in ppm. 
Table A3.1

\begin{tabular}{|c|c|c|c|c|c|c|c|c|}
\hline $\begin{array}{l}\text { Sample } \\
\text { ID }\end{array}$ & $\begin{array}{c}\text { WH1_2 } \\
6-1\end{array}$ & $\begin{array}{c}\text { WH1_1 } \\
-5\end{array}$ & $\begin{array}{c}\text { WH1_4 } \\
-1 \\
\text { atz }\end{array}$ & $\begin{array}{c}\text { WH1_8 } \\
-1 \\
\end{array}$ & $\begin{array}{c}\text { WH1_1 } \\
6-1\end{array}$ & $\begin{array}{c}\text { WH1_1 } \\
9-1\end{array}$ & $\begin{array}{c}\text { WH1_3 } \\
5-1 \\
\text { atz }\end{array}$ & $\begin{array}{c}\text { WH1_3 } \\
6-1 \\
\text { atz }\end{array}$ \\
\hline Host & opx & $\mathrm{qtz}$ & $\mathrm{qtz}$ & $\mathrm{qtz}$ & $\mathrm{qtz}$ & $\mathrm{qtz}$ & $\mathrm{qtz}$ & \\
\hline $\mathrm{SiO}_{2}$ & 76.91 & 77.68 & 78.07 & 77.18 & 76.53 & 76.86 & 75.97 & 75.56 \\
\hline $\mathrm{TiO}_{2}$ & 0.11 & 0.19 & 0.16 & 0.14 & 0.17 & 0.16 & 0.13 & 0.12 \\
\hline $\mathrm{Al}_{2} \mathrm{O}_{3}$ & 12.42 & 12.31 & 12.55 & 13.07 & 13.44 & 12.76 & 13.66 & 13.09 \\
\hline $\mathrm{FeO}$ & 0.61 & 0.36 & 0.93 & 0.41 & 0.57 & 0.95 & 0.34 & 1.06 \\
\hline $\mathrm{MnO}$ & 0.06 & 0.10 & 0.07 & 0.06 & 0.07 & 0.03 & 0.08 & 0.09 \\
\hline $\mathrm{MgO}$ & 0.01 & 0.00 & 0.14 & 0.03 & 0.07 & 0.10 & 0.02 & 0.09 \\
\hline $\mathrm{CaO}$ & 0.65 & 0.66 & 0.73 & 0.74 & 0.81 & 0.74 & 0.64 & 0.60 \\
\hline $\mathrm{Na}_{2} \mathrm{O}$ & 3.08 & 1.40 & 2.68 & 3.45 & 3.10 & 3.12 & 3.38 & 3.78 \\
\hline $\mathrm{K}_{2} \mathrm{O}$ & 3.52 & 7.17 & 4.49 & 4.75 & 5.07 & 4.96 & 5.46 & 5.25 \\
\hline $\mathrm{Cl}$ & 2.62 & 0.11 & 0.19 & 0.17 & 0.17 & 0.24 & 0.12 & 0.20 \\
\hline $\mathrm{SO}_{3}$ & 0.01 & 0.00 & 0.00 & 0.00 & 0.00 & 0.02 & 0.04 & 0.04 \\
\hline Total & 100.00 & 100.00 & 100.00 & 100.00 & 100.00 & 100.00 & 100.00 & 100.00 \\
\hline $\mathrm{Sc}$ & 7.96 & 7.58 & 18.0 & 9.60 & 11.63 & 10.56 & 8.27 & 8.77 \\
\hline $\mathrm{V}$ & 1.67 & 1.60 & 9.91 & 4.25 & 2.00 & 3.33 & 1.94 & 2.10 \\
\hline $\mathrm{Cr}$ & 7.99 & 3.35 & 16.0 & 57.0 & 5.64 & 8.48 & 16.1 & 32.6 \\
\hline Mn & 186 & 323 & 744 & 584 & 452 & 402 & 127 & 1047 \\
\hline $\mathrm{Co}$ & 0.206 & 0.843 & 2.73 & 1.23 & 1.38 & 0.621 & 1.78 & 3.25 \\
\hline $\mathrm{Ni}$ & 1.27 & 1.86 & 4.54 & 14.0 & 2.00 & 1.38 & 3.64 & 5.31 \\
\hline $\mathrm{Cu}$ & b.d. & 2.06 & 8.96 & 21.7 & 1.22 & 6.62 & 5.43 & 5.88 \\
\hline $\mathrm{Zn}$ & 10.6 & 30.4 & 89.2 & 46.3 & 48.0 & 45.3 & 7.98 & 77.1 \\
\hline $\mathrm{Ga}$ & 13.2 & 15.3 & 22.2 & 13.1 & 17.0 & 19.4 & 15.9 & 21.3 \\
\hline $\mathrm{Rb}$ & 157 & 171 & 298 & 182 & 264 & 269 & 221 & 277 \\
\hline $\mathrm{Sr}$ & 38.4 & 43.1 & 41.1 & 37.6 & 40.6 & 44.0 & 45.8 & 52.3 \\
\hline $\mathrm{Y}$ & 13.0 & 13.4 & 30.7 & 15.8 & 21.6 & 15.9 & 17.4 & 25.8 \\
\hline $\mathrm{Zr}$ & 80.7 & 102 & 71.5 & 63.4 & 119 & 80.8 & 99.0 & 124 \\
\hline $\mathrm{Nb}$ & 8.93 & 6.61 & 18.9 & 9.35 & 8.67 & 12.1 & 9.90 & 12.7 \\
\hline Mo & 1.06 & 0.769 & 5.39 & 11.29 & 1.38 & 1.80 & 3.79 & 4.54 \\
\hline $\mathrm{Cs}$ & 8.21 & 8.66 & 12.3 & 5.1 & 11.5 & 11.9 & 11.7 & 13.2 \\
\hline $\mathrm{Ba}$ & 686 & 605 & 756 & 1527 & 752 & 720 & 710 & 918 \\
\hline $\mathrm{La}$ & 13.9 & 16.8 & 53.1 & 34.4 & 23.2 & 19.4 & 22.9 & 32.3 \\
\hline $\mathrm{Ce}$ & 36.7 & 43.0 & 118 & 54.5 & 52.6 & 55.6 & 50.7 & 65.5 \\
\hline $\operatorname{Pr}$ & 3.29 & 4.32 & 10.0 & 6.61 & 4.74 & 4.80 & 4.18 & 6.37 \\
\hline $\mathrm{Nd}$ & 13.4 & 11.4 & 39.1 & 20.1 & 17.5 & 15.4 & 15.6 & 23.5 \\
\hline $\mathrm{Sm}$ & 1.84 & 2.93 & 6.63 & 6.34 & 2.72 & 1.89 & 3.70 & 4.92 \\
\hline $\mathrm{Eu}$ & 0.122 & 0.339 & 1.14 & 0.502 & 0.398 & 0.285 & 0.516 & 0.616 \\
\hline $\mathrm{Gd}$ & 1.96 & 1.94 & 4.82 & 3.34 & 2.71 & 2.05 & 3.16 & 4.07 \\
\hline $\mathrm{Tb}$ & & & & & & & 0.533 & 0.715 \\
\hline Dy & 2.78 & 2.58 & 5.64 & 3.29 & 2.96 & 2.30 & 2.98 & 5.43 \\
\hline Ho & & & & & & & 0.678 & 1.06 \\
\hline $\mathrm{Er}$ & 1.63 & 1.64 & 3.46 & 1.83 & 2.36 & 1.35 & 2.08 & 2.94 \\
\hline $\mathrm{Tm}$ & & & & & & & 0.373 & 0.588 \\
\hline $\mathrm{Yb}$ & 2.14 & 1.60 & 2.78 & 1.46 & 1.79 & 1.53 & 3.59 & 4.16 \\
\hline $\mathrm{Lu}$ & 0.218 & 0.378 & 0.502 & 0.293 & 0.368 & 0.236 & 0.539 & 0.695 \\
\hline $\mathrm{Hf}$ & 3.29 & 3.13 & 3.08 & 2.47 & 3.87 & 2.15 & 3.90 & 4.98 \\
\hline $\mathrm{Ta}$ & 0.679 & 0.762 & 1.23 & 0.929 & 1.04 & 0.864 & 1.35 & 1.58 \\
\hline W & 1.97 & 2.14 & 4.51 & 7.05 & 1.81 & 2.67 & 3.40 & 4.27 \\
\hline $\mathrm{Pb}$ & 5.13 & 16.3 & 50.5 & 20.0 & 25.4 & 21.2 & 9.76 & 34.1 \\
\hline Th & 13.0 & 10.3 & 20.4 & 15.2 & 16.2 & 15.2 & 18.3 & 21.8 \\
\hline $\mathrm{U}$ & 3.66 & 3.43 & 6.23 & 3.70 & 4.63 & 4.84 & 5.08 & 5.52 \\
\hline
\end{tabular}


Table A3.1 continued

\begin{tabular}{|c|c|c|c|c|c|c|c|c|c|}
\hline Sample & WH1_ & WH1_ & WH1 & WH1 & WH1 & OR1_ & OR1_ & OR1_ & OR1_ \\
\hline ID & $37-1$ & $38-1$ & $38-2$ & $39-2$ & $40-1$ & $12-1.1$ & $12-2.1$ & $26-1$ & $26-2$ \\
\hline Host & qtz & qtz & $\mathrm{qtz}$ & qtz & qtz & opx & opx & opx & opx \\
\hline $\mathrm{SiO}_{2}$ & 75.75 & 76.48 & 75.46 & 75.96 & 76.20 & 78.62 & 79.02 & 78.74 & 78.10 \\
\hline $\mathrm{TiO}_{2}$ & 0.21 & 0.20 & 0.24 & 0.10 & 0.16 & 0.21 & 0.21 & 0.13 & 0.17 \\
\hline $\mathrm{Al}_{2} \mathrm{O}_{3}$ & 13.02 & 13.06 & 13.68 & 13.46 & 12.88 & 12.25 & 12.18 & 11.97 & 12.57 \\
\hline $\mathrm{FeO}$ & 0.99 & 0.19 & 0.25 & 0.26 & 0.25 & 1.67 & 1.62 & 1.64 & 1.60 \\
\hline $\mathrm{MnO}$ & 0.13 & 0.16 & 0.07 & 0.15 & 0.02 & 0.07 & 0.03 & 0.09 & 0.09 \\
\hline $\mathrm{MgO}$ & 0.13 & 0.01 & 0.00 & 0.06 & 0.04 & 0.17 & 0.10 & 0.10 & 0.11 \\
\hline $\mathrm{CaO}$ & 0.71 & 0.67 & 0.75 & 0.60 & 0.68 & 0.86 & 0.85 & 0.88 & 1.16 \\
\hline $\mathrm{Na}_{2} \mathrm{O}$ & 3.78 & 3.49 & 3.87 & 3.77 & 1.86 & 2.50 & 2.40 & 2.88 & 3.07 \\
\hline $\mathrm{K}_{2} \mathrm{O}$ & 4.81 & 5.31 & 5.36 & 5.36 & 7.53 & 3.29 & 3.32 & 3.23 & 2.78 \\
\hline $\mathrm{Cl}$ & 0.17 & 0.10 & 0.14 & 0.09 & 0.15 & 0.21 & 0.19 & 0.20 & 0.23 \\
\hline $\mathrm{SO}_{3}$ & 0.03 & 0.20 & 0.04 & 0.04 & 0.07 & 0.05 & 0.08 & 0.12 & 0.12 \\
\hline Total & 100.00 & 100.00 & 100.00 & 100.00 & 100.00 & 100.00 & 100.00 & 100.00 & 100.00 \\
\hline $\mathrm{Sc}$ & 10.0 & 10.5 & 20.5 & 7.77 & 7.54 & 9.06 & 10.9 & 44.0 & 53.2 \\
\hline $\mathrm{V}$ & 8.05 & 4.23 & 3.76 & 1.65 & 2.89 & 2.62 & 2.48 & 28.6 & 25.3 \\
\hline $\mathrm{Cr}$ & 26.8 & 23.4 & 79.9 & 15.7 & 12.6 & 14.9 & 6.39 & 9.26 & 10.9 \\
\hline $\mathrm{Mn}$ & 418 & 233 & 129 & 264 & 123 & 314 & 493 & 11854 & 15784 \\
\hline $\mathrm{Co}$ & 3.42 & 2.09 & 4.33 & 1.59 & 1.46 & 0.572 & 1.87 & 51.6 & 58.3 \\
\hline $\mathrm{Ni}$ & 4.61 & 7.46 & 19.7 & 3.02 & 2.55 & b.d. & 1.78 & 8.47 & 11.47 \\
\hline $\mathrm{Cu}$ & 11.75 & 6.49 & 15.6 & 12.9 & 7.96 & 1.95 & 1.27 & 0.85 & 2.03 \\
\hline $\mathrm{Zn}$ & 52.17 & 30.4 & 15.3 & 34.0 & 23.8 & 27.1 & 54.3 & 468 & 626 \\
\hline $\mathrm{Ga}$ & 18.7 & 18.7 & 12.1 & 17.9 & 15.4 & 14.1 & 14.3 & 6.33 & 7.68 \\
\hline $\mathrm{Rb}$ & 208 & 248 & 151 & 248 & 201 & 182 & 184 & 45.4 & 52.3 \\
\hline $\mathrm{Sr}$ & 65.8 & 49.0 & 70.2 & 46.0 & 48.6 & 56.5 & 63.3 & 17.1 & 34.2 \\
\hline $\mathrm{Y}$ & 27.8 & 20.4 & 18.0 & 19.8 & 22.0 & 17.8 & 18.2 & 12.2 & 16.2 \\
\hline $\mathrm{Zr}$ & 190 & 116 & 119 & 96 & 119 & 90.7 & 101 & 32.1 & 50.4 \\
\hline $\mathrm{Nb}$ & 10.7 & 10.5 & 10.7 & 10.0 & 9.58 & 8.13 & 8.51 & 1.92 & 2.91 \\
\hline Mo & 4.71 & 3.17 & 4.08 & 2.52 & 3.02 & 2.06 & 1.54 & 0.973 & 1.37 \\
\hline $\mathrm{Cs}$ & 10.1 & 11.8 & 5.4 & 11.9 & 10.0 & 8.97 & 10.5 & 2.26 & 2.57 \\
\hline $\mathrm{Ba}$ & 493 & 874 & 894 & 653 & 899 & 766 & 874 & 225 & 288 \\
\hline $\mathrm{La}$ & 30.2 & 25.5 & 25.2 & 24.1 & 27.3 & 26.1 & 25.1 & 6.82 & 8.89 \\
\hline $\mathrm{Ce}$ & 65.4 & 60.8 & 53.4 & 53.4 & 55.7 & 48.3 & 52.2 & 14.8 & 20.0 \\
\hline $\operatorname{Pr}$ & 6.39 & 5.41 & 5.48 & 4.95 & 5.24 & 4.36 & 4.75 & 1.36 & 2.00 \\
\hline $\mathrm{Nd}$ & 24.7 & 19.2 & 19.0 & 16.8 & 19.5 & 17.7 & 17.2 & 5.41 & 7.06 \\
\hline $\mathrm{Sm}$ & 5.60 & 4.24 & 4.51 & 3.03 & 3.77 & 3.88 & 2.74 & 1.09 & 1.71 \\
\hline $\mathrm{Eu}$ & 0.982 & 0.741 & 0.766 & 0.524 & 0.469 & 0.440 & 0.358 & 0.201 & 0.220 \\
\hline $\mathrm{Gd}$ & 4.69 & 4.32 & 3.36 & 2.99 & 3.24 & 2.81 & 2.86 & 1.18 & 1.74 \\
\hline $\mathrm{Tb}$ & 0.822 & 0.513 & 0.501 & 0.450 & 0.516 & & & 0.206 & 0.280 \\
\hline Dy & 4.96 & 3.92 & 3.43 & 3.45 & 3.72 & 3.07 & 2.59 & 1.65 & 2.41 \\
\hline Ho & 1.18 & 0.821 & 0.686 & 0.667 & 0.728 & & & 0.453 & 0.608 \\
\hline $\mathrm{Er}$ & 3.55 & 2.79 & 2.65 & 2.00 & 2.27 & 1.71 & 1.74 & 1.69 & 2.25 \\
\hline $\mathrm{Tm}$ & 0.716 & 0.426 & 0.534 & 0.277 & 0.407 & & & 0.249 & 0.275 \\
\hline $\mathrm{Yb}$ & 5.49 & 5.44 & 2.68 & 3.63 & 3.58 & 2.36 & 2.03 & 1.86 & 2.50 \\
\hline $\mathrm{Lu}$ & 1.27 & 0.653 & 0.489 & 0.599 & 0.573 & 0.291 & 0.298 & 0.474 & 0.531 \\
\hline $\mathrm{Hf}$ & 4.72 & 4.78 & 4.06 & 3.84 & 3.76 & 3.37 & 2.51 & 1.05 & 1.62 \\
\hline $\mathrm{Ta}$ & 1.37 & 1.31 & 1.27 & 1.32 & 0.991 & 1.14 & 0.862 & 0.255 & 0.272 \\
\hline W & 5.24 & 3.27 & 3.21 & 3.49 & 2.57 & 2.19 & 2.19 & 1.00 & 1.60 \\
\hline $\mathrm{Pb}$ & 22.9 & 21.5 & 16.6 & 28.1 & 15.0 & 19.2 & 19.9 & 4.92 & 5.50 \\
\hline Th & 17.3 & 18.5 & 14.6 & 18.3 & 17.7 & 18.9 & 19.4 & 4.13 & 4.46 \\
\hline $\mathrm{U}$ & 5.15 & 5.22 & 4.62 & 5.40 & 4.33 & 4.54 & 4.75 & 1.05 & 1.14 \\
\hline
\end{tabular}


Table A3.1 continued

\begin{tabular}{|c|c|c|c|c|c|c|c|c|c|}
\hline $\begin{array}{c}\text { Sample } \\
\text { ID }\end{array}$ & $\begin{array}{c}\text { OR1 } \\
14.1 \\
\text { plag }\end{array}$ & $\begin{array}{c}\text { OR1 } \\
17-2 \\
\text { plag }\end{array}$ & $\begin{array}{c}\mathrm{OR} 1- \\
16.2 \\
\mathrm{qtz}\end{array}$ & $\begin{array}{c}\text { OR1- } \\
16-3 \\
\mathrm{qtz}\end{array}$ & $\begin{array}{c}\text { OR2- } \\
24-1 \\
\text { opx }\end{array}$ & $\begin{array}{c}\text { OR2 } \\
1-2.1 \\
\text { qtz }\end{array}$ & $\begin{array}{c}\mathrm{OR} 2- \\
1-3.1 \\
\mathrm{qtz}\end{array}$ & $\begin{array}{c}\text { OR2 } \\
15-1 \\
\mathrm{qtz} \\
\end{array}$ & $\begin{array}{c}\text { OR2 } \\
15-2 \\
\text { qtz }\end{array}$ \\
\hline $\mathrm{SiO}_{2}$ & 75.93 & 78.74 & 78.86 & 79.14 & 77.80 & 77.61 & 77.76 & 78.19 & 77.36 \\
\hline $\mathrm{TiO}_{2}$ & 0.34 & 0.18 & 0.18 & 0.12 & 0.14 & 0.05 & 0.20 & 0.18 & 0.19 \\
\hline $\mathrm{Al}_{2} \mathrm{O}_{3}$ & 13.13 & 12.35 & 12.29 & 12.67 & 12.84 & 12.67 & 12.87 & 12.37 & 12.32 \\
\hline $\mathrm{FeO}$ & 2.16 & 1.22 & 1.27 & 1.10 & 1.62 & 1.28 & 0.96 & 1.06 & 1.12 \\
\hline $\mathrm{MnO}$ & 0.10 & 0.10 & 0.07 & 0.09 & 0.10 & 0.00 & 0.13 & 0.00 & 0.07 \\
\hline $\mathrm{MgO}$ & 0.33 & 0.15 & 0.12 & 0.10 & 0.15 & 0.15 & 0.06 & 0.09 & 0.13 \\
\hline $\mathrm{CaO}$ & 1.46 & 1.13 & 1.06 & 1.12 & 1.29 & 0.89 & 0.80 & 0.81 & 0.81 \\
\hline $\mathrm{Na}_{2} \mathrm{O}$ & 2.94 & 2.56 & 3.06 & 2.95 & 3.03 & 2.96 & 3.01 & 3.02 & 3.45 \\
\hline $\mathrm{K}_{2} \mathrm{O}$ & 2.76 & 2.62 & 2.72 & 2.53 & 2.74 & 3.78 & 3.69 & 3.83 & 3.75 \\
\hline $\mathrm{Cl}$ & 0.31 & 0.26 & 0.21 & 0.19 & 0.24 & 0.34 & 0.23 & 0.29 & 0.36 \\
\hline $\mathrm{SO}_{3}$ & 0.43 & 0.43 & 0.04 & 0.00 & 0.04 & 0.12 & 0.05 & 0.06 & 0.03 \\
\hline Total & 100.00 & 100.00 & 100.00 & 100.00 & 100.00 & 100.00 & 100.00 & 100.00 & 100.00 \\
\hline $\mathrm{Sc}$ & 17.0 & 9.1 & 10.1 & 10.3 & 8.92 & 27.5 & 7.59 & 9.69 & 10.1 \\
\hline $\mathrm{V}$ & 7.57 & 3.49 & 1.14 & 1.23 & 1.91 & 7.04 & 1.87 & 3.06 & 3.32 \\
\hline $\mathrm{Cr}$ & 6.68 & 8.26 & 4.23 & 6.94 & 5.37 & 51.6 & 12.8 & 10.0 & 9.26 \\
\hline Mn & 606 & 387 & 354 & 385 & 407 & 401 & 338 & 292 & 280 \\
\hline $\mathrm{Co}$ & 1.30 & 1.00 & 0.75 & 0.976 & 1.04 & 0.807 & 0.769 & 1.27 & 1.05 \\
\hline $\mathrm{Ni}$ & 0.977 & 1.79 & 1.23 & 1.26 & 0.966 & 14.1 & 2.42 & 1.62 & 2.22 \\
\hline $\mathrm{Cu}$ & 2.56 & 2.82 & 1.82 & 2.59 & 2.76 & 15.5 & 4.56 & 10.36 & 4.50 \\
\hline $\mathrm{Zn}$ & 79.0 & 32.3 & 42.6 & 44.6 & 45.1 & 50.0 & 25.7 & 42.2 & 39.1 \\
\hline $\mathrm{Ga}$ & 17.8 & 13.5 & 13.4 & 14.1 & 15.8 & 23.8 & 11.7 & 14.8 & 12.9 \\
\hline $\mathrm{Rb}$ & 120 & 144 & 107 & 118 & 132 & 233 & 163 & 200 & 200 \\
\hline $\mathrm{Sr}$ & 104 & 75.9 & 74.9 & 82.0 & 99.2 & 77.3 & 55.5 & 54.2 & 52.2 \\
\hline $\mathrm{Y}$ & 26.1 & 21.8 & 19.7 & 23.3 & 21.0 & 22.8 & 15.0 & 21.5 & 19.9 \\
\hline $\mathrm{Zr}$ & 245 & 134 & 107 & 122 & 157 & 127 & 85.5 & 127 & 120 \\
\hline $\mathrm{Nb}$ & 10.3 & 7.30 & 7.03 & 7.55 & 7.85 & 12.4 & 7.16 & 10.3 & 9.78 \\
\hline Mo & 1.65 & 1.44 & 1.07 & 1.23 & 1.45 & 8.05 & 1.87 & 2.01 & 2.13 \\
\hline $\mathrm{Cs}$ & 5.90 & 7.80 & 5.46 & 6.15 & 6.45 & 8.14 & 7.59 & 9.37 & 8.81 \\
\hline $\mathrm{Ba}$ & 598 & 960 & 619 & 656 & 761 & 1302 & 955 & 1023 & 971 \\
\hline $\mathrm{La}$ & 21.4 & 27.9 & 19.9 & 22.6 & 22.6 & 22.0 & 24.0 & 25.8 & 25.2 \\
\hline $\mathrm{Ce}$ & 52.8 & 58.7 & 43.8 & 47.5 & 50.3 & 73.1 & 46.9 & 58.1 & 53.2 \\
\hline $\operatorname{Pr}$ & 5.15 & 5.17 & 4.24 & 4.84 & 5.13 & 7.37 & 4.26 & 4.80 & 5.00 \\
\hline $\mathrm{Nd}$ & 20.8 & 18.3 & 16.9 & 17.8 & 19.9 & 19.6 & 14.2 & 19.4 & 17.4 \\
\hline $\mathrm{Sm}$ & 4.57 & 3.27 & 3.32 & 3.63 & 4.03 & 3.57 & 2.44 & 3.54 & 3.96 \\
\hline $\mathrm{Eu}$ & 0.641 & 0.443 & 0.642 & 0.616 & 0.667 & 0.643 & 0.343 & 0.408 & 0.380 \\
\hline $\mathrm{Gd}$ & 4.46 & 3.20 & 3.33 & 3.86 & 3.48 & 4.41 & 2.23 & 3.74 & 3.06 \\
\hline $\mathrm{Tb}$ & 0.684 & 0.512 & 0.503 & 0.573 & 0.559 & & & 0.533 & 0.534 \\
\hline Dy & 4.80 & 3.61 & 3.38 & 4.34 & 3.78 & 3.45 & 2.39 & 3.53 & 3.23 \\
\hline Ho & 0.993 & 0.715 & 0.718 & 0.843 & 0.763 & & & 0.804 & 0.613 \\
\hline $\mathrm{Er}$ & 2.83 & 2.13 & 2.32 & 2.66 & 2.09 & 2.71 & 1.57 & 2.19 & 1.87 \\
\hline $\mathrm{Tm}$ & 0.408 & 0.425 & 0.421 & 0.419 & 0.342 & & & 0.371 & 0.336 \\
\hline $\mathrm{Yb}$ & 3.08 & 2.56 & 2.53 & 2.63 & 2.23 & 2.27 & 1.67 & 3.36 & 2.64 \\
\hline $\mathrm{Lu}$ & 0.499 & 0.479 & 0.408 & 0.456 & 0.384 & 0.385 & 0.291 & 0.584 & 0.421 \\
\hline $\mathrm{Hf}$ & 6.03 & 3.51 & 3.17 & 3.80 & 4.27 & 4.22 & 2.63 & 4.76 & 3.58 \\
\hline $\mathrm{Ta}$ & 0.716 & 0.805 & 0.786 & 0.811 & 0.643 & 1.11 & 0.791 & 0.958 & 0.933 \\
\hline W & 1.67 & 1.56 & 1.45 & 1.59 & 1.77 & 2.63 & 1.70 & 3.01 & 2.50 \\
\hline $\mathrm{Pb}$ & 16.6 & 18.2 & 14.0 & 13.9 & 16.1 & 25.5 & 17.8 & 21.4 & 20.1 \\
\hline Th & 10.4 & 16.2 & 11.8 & 12.6 & 11.5 & 19.2 & 14.2 & 17.4 & 18.2 \\
\hline $\mathrm{U}$ & 3.16 & 3.68 & 2.73 & 2.63 & 2.87 & 5.37 & 3.51 & 4.95 & 4.75 \\
\hline
\end{tabular}


Table A3.1 continued

\begin{tabular}{|c|c|c|c|c|c|c|c|c|c|}
\hline Sample & RA1_ & RA1_ & RA1_ & RA1_ & RA2 & RA2_ & RA2_ & RA2_ & RA3 \\
\hline ID & $5-1 . \overline{1}$ & $5-3 . \overline{1}$ & $7-1 . \overline{1}$ & $7-2.1$ & $4-1 . \overline{1}$ & $7-1 . \overline{1}$ & $11-2.1$ & $13-3.1$ & $8-1, \overline{1}$ \\
\hline Host & opx & opx & opx & opx & opx & opx & opx & plag & opx \\
\hline $\mathrm{SiO}_{2}$ & 77.24 & 78.62 & 78.67 & 78.16 & 78.17 & 77.06 & 77.91 & 77.41 & 77.30 \\
\hline $\mathrm{TiO}_{2}$ & 0.29 & 0.44 & 0.27 & 0.28 & 0.24 & 0.13 & 0.46 & 0.19 & 0.30 \\
\hline $\mathrm{Al}_{2} \mathrm{O}_{3}$ & 13.91 & 12.97 & 13.20 & 13.25 & 12.25 & 13.19 & 12.36 & 13.51 & 13.12 \\
\hline $\mathrm{FeO}$ & 1.89 & 1.60 & 1.54 & 1.69 & 2.19 & 1.99 & 1.85 & 1.39 & 2.31 \\
\hline $\mathrm{MnO}$ & 0.13 & 0.07 & 0.11 & 0.06 & 0.00 & 0.44 & 0.50 & 0.12 & 0.08 \\
\hline $\mathrm{MgO}$ & 0.25 & 0.21 & 0.24 & 0.24 & 0.30 & 0.29 & 0.18 & 0.24 & 0.17 \\
\hline $\mathrm{CaO}$ & 1.38 & 1.25 & 1.02 & 1.38 & 1.35 & 1.31 & 1.43 & 1.33 & 1.60 \\
\hline $\mathrm{Na}_{2} \mathrm{O}$ & 2.51 & 1.84 & 2.22 & 2.01 & 2.80 & 2.83 & 2.69 & 2.81 & 2.46 \\
\hline $\mathrm{K}_{2} \mathrm{O}$ & 2.20 & 2.75 & 2.48 & 2.61 & 2.41 & 2.56 & 2.32 & 2.74 & 2.30 \\
\hline $\mathrm{Cl}$ & 0.16 & 0.18 & 0.14 & 0.24 & 0.21 & 0.20 & 0.14 & 0.19 & 0.16 \\
\hline $\mathrm{SO}_{3}$ & 0.04 & 0.07 & 0.12 & 0.07 & 0.07 & b.d. & 0.16 & 0.07 & 0.20 \\
\hline Total & 100.00 & 100.00 & 100.00 & 100.00 & 100.00 & 100.00 & 100.00 & 100.00 & 100.00 \\
\hline $\mathrm{Sc}$ & 11.2 & 17.2 & 7.5 & 11.5 & 7.56 & 13.2 & 4.85 & 9.50 & 4.40 \\
\hline $\mathrm{V}$ & 3.94 & 7.69 & 4.84 & 4.82 & 4.48 & 2.55 & 6.87 & 4.55 & 3.82 \\
\hline $\mathrm{Cr}$ & 11.4 & 57.7 & 7.9 & 18.5 & 21.8 & 12.3 & 10.0 & 7.54 & 0.0 \\
\hline $\mathrm{Mn}$ & 475 & 472 & 423 & 469 & 333 & 486 & 657 & 443 & 418 \\
\hline $\mathrm{Co}$ & 0.570 & 2.38 & 1.02 & 0.694 & 0.429 & 0.730 & 1.60 & 0.599 & 3.37 \\
\hline $\mathrm{Ni}$ & 1.83 & 26.6 & 0.828 & 2.75 & 5.35 & 3.65 & 6.03 & 1.86 & b.d. \\
\hline $\mathrm{Cu}$ & 2.04 & 8.34 & 2.06 & 3.58 & 3.71 & b.d. & b.d. & 2.21 & b.d. \\
\hline $\mathrm{Zn}$ & 48.5 & 64.2 & 39.3 & 50.6 & 43.1 & 60.6 & 50.4 & 40.1 & 45.9 \\
\hline $\mathrm{Ga}$ & 15.6 & 16.3 & 16.1 & 17.1 & 10.1 & 9.24 & 13.9 & 16.0 & 13.6 \\
\hline $\mathrm{Rb}$ & 136 & 196 & 124 & 124 & 96.0 & 101 & 132 & 97 & 98.6 \\
\hline $\mathrm{Sr}$ & 101 & 124 & 119 & 131 & 112 & 105 & 158 & 140 & 134 \\
\hline $\mathrm{Y}$ & 22.2 & 27.8 & 18.2 & 20.1 & 20.2 & 23.9 & 23.9 & 19.9 & 23.1 \\
\hline $\mathrm{Zr}$ & 130 & 246 & 205 & 172 & 211 & 179 & 251 & 153 & 209 \\
\hline $\mathrm{Nb}$ & 5.39 & 13.0 & 9.10 & 7.58 & 6.89 & 11.14 & 10.2 & 7.84 & 10.2 \\
\hline Mo & 1.24 & 3.89 & 0.912 & 1.38 & 1.52 & 1.34 & 2.69 & 1.59 & 0.00 \\
\hline $\mathrm{Cs}$ & 5.12 & 6.73 & 5.18 & 4.91 & 3.50 & 3.81 & 4.63 & 4.47 & 3.17 \\
\hline $\mathrm{Ba}$ & 1085 & 1145 & 856 & 894 & 717 & 843 & 896 & 802 & 783 \\
\hline $\mathrm{La}$ & 23.6 & 27.3 & 18.9 & 19.5 & 18.4 & 25.8 & 23.0 & 19.2 & 17.6 \\
\hline $\mathrm{Ce}$ & 47.3 & 61.9 & 44.4 & 44.3 & 44.3 & 51.9 & 53.1 & 44.4 & 44.4 \\
\hline $\operatorname{Pr}$ & 4.53 & 6.27 & 4.20 & 4.47 & 4.78 & 4.96 & 4.72 & 4.36 & 4.88 \\
\hline $\mathrm{Nd}$ & 18.3 & 20.6 & 18.9 & 17.8 & 18.6 & 18.9 & 22.3 & 15.3 & 24.0 \\
\hline $\mathrm{Sm}$ & 3.94 & 6.26 & 3.22 & 3.35 & 3.36 & 3.47 & 3.92 & 2.74 & 1.91 \\
\hline $\mathrm{Eu}$ & 0.908 & 1.02 & 0.556 & 0.873 & 0.879 & 0.641 & 0.972 & 0.770 & 1.18 \\
\hline $\begin{array}{c}\mathrm{Gd} \\
\mathrm{Tb}\end{array}$ & 2.54 & 5.43 & 2.40 & 3.27 & 4.60 & 3.55 & 4.98 & 2.68 & 2.89 \\
\hline $\begin{array}{l}\text { Dy } \\
\text { Ho }\end{array}$ & 3.92 & 5.40 & 3.35 & 3.12 & 4.25 & 3.29 & 5.57 & 2.72 & 4.89 \\
\hline $\begin{array}{c}\mathrm{Er} \\
\mathrm{Tm}\end{array}$ & 2.54 & 2.74 & 1.97 & 1.82 & 2.54 & 1.92 & 2.12 & 1.82 & 2.88 \\
\hline $\mathrm{Yb}$ & 2.88 & 3.51 & 1.98 & 2.21 & 2.34 & 1.78 & 2.33 & 2.05 & 2.29 \\
\hline $\mathrm{Lu}$ & 0.372 & 0.683 & 0.233 & 0.422 & 0.118 & 0.285 & 0.414 & 0.429 & 0.367 \\
\hline $\mathrm{Hf}$ & 4.07 & 6.95 & 4.78 & 4.48 & 5.44 & 3.70 & 4.69 & 4.17 & 3.69 \\
\hline $\mathrm{Ta}$ & 0.521 & 0.985 & 0.613 & 0.901 & 0.485 & 0.492 & 0.765 & 0.394 & 0.272 \\
\hline W & 1.66 & 2.01 & 1.13 & 1.31 & 2.12 & 1.77 & 1.67 & 1.07 & 1.13 \\
\hline $\mathrm{Pb}$ & 18.0 & 16.2 & 16.3 & 17.6 & 11.4 & 14.5 & 12.8 & 14.5 & 13.5 \\
\hline Th & 12.4 & 21.9 & 8.75 & 9.15 & 8.65 & 8.67 & 9.93 & 8.00 & 9.41 \\
\hline $\mathrm{U}$ & 2.72 & 3.73 & 2.69 & 2.55 & 2.19 & 2.72 & 2.95 & 2.21 & 2.02 \\
\hline
\end{tabular}


Table A3.1 continued

\begin{tabular}{|c|c|c|c|c|c|c|c|c|c|}
\hline $\begin{array}{c}\text { Sample } \\
\text { ID } \\
\text { Host }\end{array}$ & $\begin{array}{l}\text { RA3_- } \\
9-1.1 \\
\text { opx }\end{array}$ & $\begin{array}{c}\text { TA1_3 } \\
0-1.1 \\
\text { plag }\end{array}$ & $\begin{array}{c}\text { TA1_3 } \\
0-2 \\
\text { plag }\end{array}$ & $\begin{array}{c}\text { TA1_3 } \\
4-1 \\
\text { plag }\end{array}$ & $\begin{array}{c}\text { TA1_3 } \\
4-2 \\
\text { plag }\end{array}$ & $\begin{array}{c}\text { TA1_3 } \\
5-1 \\
\text { plag }\end{array}$ & $\begin{array}{c}\text { TA1_3 } \\
5-2 \\
\text { plag }\end{array}$ & $\begin{array}{c}\text { TA1_3 } \\
5-3 \\
\text { plag }\end{array}$ & $\begin{array}{c}\text { TA1_4 } \\
3-3.1 \\
\text { plag }\end{array}$ \\
\hline $\mathrm{SiO}_{2}$ & 77.88 & 76.73 & 76.88 & 75.95 & 74.47 & 76.51 & 75.52 & 77.02 & 76.39 \\
\hline $\mathrm{TiO}_{2}$ & 0.21 & 0.32 & 0.29 & 0.31 & 0.40 & 0.32 & 0.44 & 0.31 & 0.23 \\
\hline $\mathrm{Al}_{2} \mathrm{O}_{3}$ & 12.51 & 13.42 & 13.52 & 13.85 & 14.09 & 13.61 & 13.96 & 13.06 & 13.47 \\
\hline $\mathrm{FeO}$ & 2.22 & 1.97 & 1.79 & 2.43 & 2.98 & 2.21 & 2.57 & 2.04 & 1.92 \\
\hline $\mathrm{MnO}$ & 0.25 & 0.11 & 0.03 & 0.11 & 0.09 & 0.14 & b.d. & 0.14 & 0.08 \\
\hline $\mathrm{MgO}$ & 0.16 & 0.30 & 0.24 & 0.37 & 0.53 & 0.33 & 0.40 & 0.27 & 0.22 \\
\hline $\mathrm{CaO}$ & 1.47 & 1.68 & 1.55 & 1.77 & 1.88 & 1.62 & 1.89 & 1.42 & 1.53 \\
\hline $\mathrm{Na}_{2} \mathrm{O}$ & 2.62 & 2.94 & 2.89 & 3.08 & 3.23 & 3.20 & 3.23 & 3.34 & 3.20 \\
\hline $\mathrm{K}_{2} \mathrm{O}$ & 2.42 & 2.38 & 2.46 & 1.93 & 1.90 & 1.76 & 1.78 & 2.06 & 2.53 \\
\hline $\mathrm{Cl}$ & 0.26 & 0.15 & 0.16 & 0.19 & 0.31 & 0.17 & 0.21 & 0.29 & 0.22 \\
\hline $\mathrm{SO}_{3}$ & b.d. & b.d. & 0.19 & b.d. & 0.12 & 0.14 & b.d. & 0.05 & 0.20 \\
\hline Total & 100.00 & 100.00 & 100.00 & 100.00 & 100.00 & 100.00 & 100.00 & 100.00 & 100.00 \\
\hline $\mathrm{Sc}$ & 18.5 & 17.9 & 16.6 & 15.5 & 19.8 & 14.6 & 18.8 & 14.8 & 11.2 \\
\hline $\mathrm{V}$ & 6.55 & 0.747 & 1.58 & 7.61 & 3.96 & 1.76 & 1.14 & 0.875 & 0.540 \\
\hline $\mathrm{Cr}$ & 11.7 & 9.28 & 4.34 & 14.6 & 13.3 & 2.36 & 4.70 & 4.20 & 7.32 \\
\hline Mn & 484 & 798 & 692 & & & & & & 546 \\
\hline $\mathrm{Co}$ & 1.85 & 0.541 & 0.578 & 1.06 & 0.691 & 0.420 & 0.744 & 0.457 & 0.466 \\
\hline $\mathrm{Ni}$ & 5.69 & 1.94 & 1.74 & 2.48 & 5.32 & 0.365 & 1.30 & 0.57 & 1.01 \\
\hline $\mathrm{Cu}$ & 0.00 & 3.61 & 1.87 & 6.65 & 3.29 & 1.89 & 3.53 & 2.13 & 2.51 \\
\hline $\mathrm{Zn}$ & 48.1 & 119 & 93.3 & 89.4 & 98.9 & 66.0 & 102 & 72.3 & 49.0 \\
\hline $\mathrm{Ga}$ & 14.2 & 20.2 & 16.7 & 17.1 & 17.1 & 15.4 & 23.7 & 16.8 & 11.2 \\
\hline $\mathrm{Rb}$ & 97.1 & 119 & 114 & 80.7 & 125 & 96.6 & 144 & 104 & 82.2 \\
\hline $\mathrm{Sr}$ & 121 & 140 & 127 & 172 & 182 & 168 & 183 & 131 & 105 \\
\hline $\mathrm{Y}$ & 25.9 & 34.8 & 29.9 & 31.9 & 38.4 & 34.8 & 51.2 & 39.8 & 37.3 \\
\hline $\mathrm{Zr}$ & 221 & 234 & 204 & 205 & 274 & 239 & 342 & 255 & 166 \\
\hline $\mathrm{Nb}$ & 9.56 & 10.5 & 9.91 & 8.45 & 9.95 & 8.72 & 12.3 & 9.69 & 7.15 \\
\hline Mo & 4.01 & 1.16 & 1.20 & & & & & & 0.785 \\
\hline Cs & 4.62 & 4.61 & 5.36 & 3.87 & 5.46 & 4.60 & 7.27 & 4.66 & 3.90 \\
\hline $\mathrm{Ba}$ & 1023 & 659 & 610 & 461 & 563 & 540 & 821 & 608 & 466 \\
\hline $\mathrm{La}$ & 23.0 & 22.7 & 23.7 & 21.5 & 24.0 & 23.3 & 35.5 & 27.2 & 24.7 \\
\hline $\mathrm{Ce}$ & 50.0 & 53.5 & 51.3 & 49.0 & 59.8 & 51.1 & 75.2 & 56.2 & 65.6 \\
\hline $\mathrm{Pr}$ & 5.13 & 5.93 & 5.94 & & & & & & 7.96 \\
\hline $\mathrm{Nd}$ & 22.3 & 25.9 & 22.6 & 22.4 & 24.4 & 23.9 & 34.3 & 27.2 & 32.7 \\
\hline $\mathrm{Sm}$ & 3.37 & 5.36 & 4.97 & 5.43 & 5.71 & 4.74 & 7.76 & 5.95 & 8.89 \\
\hline $\mathrm{Eu}$ & 1.22 & 1.17 & 1.31 & 0.829 & 1.32 & 0.904 & 1.56 & 1.26 & 1.26 \\
\hline $\begin{array}{l}\mathrm{Gd} \\
\mathrm{Tb}\end{array}$ & 2.53 & 4.71 & 5.44 & 4.88 & 4.78 & 5.53 & 8.23 & 6.36 & 7.60 \\
\hline $\begin{array}{l}\text { Dy } \\
\text { Ho }\end{array}$ & 5.12 & 4.65 & 5.14 & 5.65 & 6.41 & 5.32 & 8.14 & 6.40 & 6.38 \\
\hline $\begin{array}{c}\mathrm{Er} \\
\mathrm{Tm}\end{array}$ & 2.87 & 3.74 & 3.52 & 3.75 & 3.70 & 3.48 & 5.92 & 4.10 & 3.27 \\
\hline $\mathrm{Yb}$ & 2.29 & 3.29 & 3.17 & 2.52 & 4.21 & 3.51 & 5.34 & 3.81 & 3.76 \\
\hline $\mathrm{Lu}$ & 0.647 & 0.519 & 0.574 & 0.519 & 0.563 & 0.569 & 0.939 & 0.659 & 0.467 \\
\hline Hf & 5.21 & 5.46 & 5.56 & 5.47 & 8.56 & 5.45 & 9.38 & 6.91 & 5.39 \\
\hline $\mathrm{Ta}$ & 0.881 & 0.88 & 0.740 & 0.585 & 0.632 & 0.645 & 0.809 & 0.667 & 0.462 \\
\hline W & 1.50 & 2.00 & 1.74 & & & & & & 0.87 \\
\hline $\mathrm{Pb}$ & 14.9 & 21.6 & 22.0 & 18.0 & 19.2 & 17.4 & 28.3 & 22.2 & 12.4 \\
\hline $\mathrm{Th}$ & 9.32 & 12.2 & 10.5 & 8.05 & 10.7 & 9.84 & 15.4 & 11.5 & 8.11 \\
\hline $\mathrm{U}$ & 2.31 & 2.92 & 2.60 & 2.00 & 2.36 & 2.22 & 3.42 & 2.42 & 2.00 \\
\hline
\end{tabular}


Table A3.1 continued

\begin{tabular}{|c|c|c|c|c|c|c|c|c|c|}
\hline $\begin{array}{c}\text { Sample } \\
\text { ID } \\
\text { Host } \\
\end{array}$ & $\begin{array}{c}\text { TA1_4 } \\
4-2.1 \\
\text { plag } \\
\end{array}$ & $\begin{array}{c}\text { TA2_2 } \\
0-1 \\
\text { plag } \\
\end{array}$ & $\begin{array}{c}\text { TA2_2 } \\
0-2 \\
\text { plag } \\
\end{array}$ & $\begin{array}{c}\text { TA2_2 } \\
2-1 \\
\text { plag } \\
\end{array}$ & $\begin{array}{c}\text { TA2_2 } \\
7-1.2 \\
\text { plag }\end{array}$ & $\begin{array}{l}\text { TA2_2 } \\
7-2.2 \\
\text { plag } \\
\end{array}$ & $\begin{array}{c}\text { TA2_2 } \\
7-3.1 \\
\text { plag }\end{array}$ & $\begin{array}{c}\text { TA4_9 } \\
-5.1 \\
\text { opx } \\
\end{array}$ & $\begin{array}{c}\text { TA4_5 } \\
-7.1 \\
\text { opx } \\
\end{array}$ \\
\hline $\mathrm{SiO}_{2}$ & 75.81 & 75.67 & 73.62 & 76.14 & 76.27 & 76.72 & 76.36 & 75.53 & 76.77 \\
\hline $\mathrm{TiO}_{2}$ & 0.26 & 0.30 & 0.35 & 0.26 & 0.31 & 0.31 & 0.24 & 0.17 & 0.16 \\
\hline $\mathrm{Al}_{2} \mathrm{O}_{3}$ & 13.75 & 13.80 & 13.51 & 13.48 & 12.90 & 12.79 & 13.27 & 13.38 & 13.02 \\
\hline $\mathrm{FeO}$ & 1.96 & 2.05 & 1.76 & 2.06 & 2.05 & 2.02 & 1.99 & 2.57 & 2.50 \\
\hline $\mathrm{MnO}$ & 0.12 & 0.06 & 0.05 & 0.12 & 0.03 & 0.08 & 0.09 & 0.99 & 0.39 \\
\hline $\mathrm{MgO}$ & 0.22 & 0.32 & 0.24 & 0.23 & 0.23 & 0.30 & 0.25 & 0.33 & 0.34 \\
\hline $\mathrm{CaO}$ & 1.61 & 1.45 & 1.48 & 1.45 & 1.59 & 1.51 & 1.29 & 1.49 & 1.39 \\
\hline $\mathrm{Na}_{2} \mathrm{O}$ & 3.38 & 3.58 & 3.23 & 3.29 & 3.76 & 3.44 & 3.59 & 2.98 & 2.88 \\
\hline $\mathrm{K}_{2} \mathrm{O}$ & 2.61 & 2.55 & 2.53 & 2.58 & 2.50 & 2.62 & 2.70 & 2.32 & 2.34 \\
\hline $\mathrm{Cl}$ & 0.26 & 0.16 & 3.22 & 0.26 & 0.20 & 0.17 & 0.21 & 0.18 & 0.17 \\
\hline $\mathrm{SO}_{3}$ & 0.01 & 0.06 & 0.01 & 0.13 & 0.16 & 0.05 & b.d. & 0.05 & 0.02 \\
\hline Total & 100.00 & 100.00 & 100.00 & 100.00 & 100.00 & 100.00 & 100.00 & 100.00 & 100.00 \\
\hline $\mathrm{Sc}$ & 8.6 & 13.9 & 4.55 & 15.0 & 15.3 & 15.5 & 15.0 & 25.9 & 16.8 \\
\hline $\mathrm{V}$ & 0.917 & 0.812 & 0.239 & 1.29 & 0.908 & 1.04 & 0.673 & 1.75 & 0.650 \\
\hline $\mathrm{Cr}$ & 7.95 & 4.65 & 0.535 & 8.24 & 5.33 & 7.50 & 6.49 & 7.67 & 6.42 \\
\hline $\mathrm{Mn}$ & 449 & 770 & 254 & 741 & 743 & 659 & 728 & 2650 & 726 \\
\hline Co & 0.165 & 0.323 & 0.100 & 0.738 & 0.469 & 0.470 & 0.575 & 2.44 & 0.511 \\
\hline $\mathrm{Ni}$ & 1.01 & 1.32 & 0.632 & 1.75 & 0.572 & 1.43 & 0.676 & 1.53 & 1.35 \\
\hline $\mathrm{Cu}$ & 2.04 & 3.08 & 1.14 & 1.47 & 1.69 & 2.75 & 2.18 & 1.56 & 1.80 \\
\hline $\mathrm{Zn}$ & 53.2 & 81.8 & 25.3 & 111 & 68.9 & 80.6 & 112 & 202 & 67.7 \\
\hline $\mathrm{Ga}$ & 11.4 & 14.1 & 3.9 & 17.2 & 15.3 & 15.9 & 18.4 & 15.9 & 13.4 \\
\hline $\mathrm{Rb}$ & 70.4 & 105.0 & 32.2 & 143 & 98.3 & 115 & 135 & 104 & 92 \\
\hline $\mathrm{Sr}$ & 144 & 120 & 42.7 & 126 & 136 & 125 & 119 & 126 & 114 \\
\hline $\mathrm{Y}$ & 18.9 & 28.0 & 25.3 & 31.2 & 28.5 & 29.3 & 28.3 & 34.7 & 30.5 \\
\hline $\mathrm{Zr}$ & 130 & 215 & 56.3 & 216 & 179 & 216 & 200 & 199 & 196 \\
\hline $\mathrm{Nb}$ & 6.80 & 10.4 & 2.08 & 10.5 & 9.99 & 9.33 & 10.1 & 9.04 & 8.43 \\
\hline Mo & 0.805 & 1.40 & 0.52 & 1.15 & 0.785 & 1.35 & 1.33 & 1.19 & 1.89 \\
\hline Cs & 3.36 & 6.10 & 1.19 & 5.59 & 5.25 & 5.10 & 6.35 & 5.05 & 4.81 \\
\hline $\mathrm{Ba}$ & 416 & 608 & 144 & 632 & 557 & 645 & 605 & 611 & 593 \\
\hline $\mathrm{La}$ & 15.4 & 24.3 & 18.4 & 23.6 & 21.1 & 22.3 & 23.5 & 24.1 & 21.1 \\
\hline $\mathrm{Ce}$ & 28.8 & 49.8 & 51.3 & 59.3 & 55.4 & 52.0 & 59.7 & 53.0 & 50.4 \\
\hline $\operatorname{Pr}$ & 3.49 & 5.70 & 6.39 & 5.54 & 4.71 & 5.78 & 6.23 & 5.34 & 5.65 \\
\hline $\mathrm{Nd}$ & 12.9 & 22.7 & 31.1 & 24.0 & 21.6 & 23.5 & 22.3 & 22.9 & 22.6 \\
\hline $\mathrm{Sm}$ & 3.72 & 3.46 & 9.06 & 5.20 & 4.51 & 4.96 & 5.39 & 4.85 & 4.72 \\
\hline $\mathrm{Eu}$ & 0.908 & 0.820 & 1.16 & 1.12 & 0.922 & 1.04 & 1.14 & 1.27 & 0.969 \\
\hline $\begin{array}{l}\mathrm{Gd} \\
\mathrm{Tb}\end{array}$ & 2.96 & 5.64 & 6.13 & 4.14 & 4.32 & 4.77 & 4.60 & 4.66 & 4.91 \\
\hline $\begin{array}{l}\text { Dy } \\
\text { Ho }\end{array}$ & 2.43 & 5.35 & 4.60 & 5.14 & 5.12 & 5.17 & 5.49 & 5.90 & 5.88 \\
\hline $\begin{array}{c}\mathrm{Er} \\
\mathrm{Tm}\end{array}$ & 1.68 & 2.99 & 2.48 & 2.97 & 2.93 & 3.00 & 2.91 & 3.98 & 3.24 \\
\hline $\mathrm{Yb}$ & 1.62 & 3.32 & 1.92 & 3.24 & 2.69 & 3.01 & 3.55 & 3.95 & 3.33 \\
\hline $\mathrm{Lu}$ & 0.274 & 0.523 & 0.309 & 0.611 & 0.402 & 0.512 & 0.539 & 0.656 & 0.499 \\
\hline $\mathrm{Hf}$ & 3.64 & 5.10 & 1.90 & 6.63 & 5.81 & 5.67 & 4.66 & 5.50 & 5.23 \\
\hline $\mathrm{Ta}$ & 0.508 & 0.795 & 0.197 & 0.611 & 0.704 & 0.770 & 0.664 & 0.711 & 0.680 \\
\hline W & 1.32 & 1.65 & 0.709 & 1.58 & 1.76 & 1.54 & 2.04 & 1.71 & 1.24 \\
\hline $\mathrm{Pb}$ & 14.3 & 19.0 & 6.00 & 24.6 & 22.3 & 19.2 & 23.9 & 19.7 & 18.7 \\
\hline $\mathrm{Th}$ & 7.28 & 10.0 & 3.16 & 11.4 & 9.22 & 9.68 & 10.07 & 9.55 & 9.17 \\
\hline $\mathrm{U}$ & 1.90 & 2.41 & 0.81 & 2.93 & 2.33 & 2.27 & 2.68 & 2.49 & 2.36 \\
\hline
\end{tabular}


Table A3.1 continued

\begin{tabular}{|c|c|c|c|c|c|c|}
\hline $\begin{array}{c}\text { Sample } \\
\text { ID } \\
\text { Host }\end{array}$ & $\begin{array}{c}\mathrm{X} 590 / \mathrm{B} \\
-6-1.1 \\
\text { оpx }\end{array}$ & $\begin{array}{c}\mathrm{X} 590 \_2- \\
1 \\
\text { opx }\end{array}$ & $\begin{array}{c}\text { X609_5- } \\
1.1 \\
\text { opx }\end{array}$ & $\begin{array}{c}\text { X609_8- } \\
1 \\
\text { opx }\end{array}$ & $\begin{array}{c}\text { X609_1 } \\
7-2 . \overline{2} \\
\text { plag }\end{array}$ & $\begin{array}{c}\text { X609_1 } \\
7-3.1 \\
\text { plag }\end{array}$ \\
\hline $\mathrm{SiO}_{2}$ & 76.46 & 75.79 & 76.14 & 76.14 & 76.26 & 76.67 \\
\hline $\mathrm{TiO}_{2}$ & 0.42 & 0.39 & 0.24 & 0.27 & 0.42 & 0.42 \\
\hline $\mathrm{Al}_{2} \mathrm{O}_{3}$ & 13.83 & 13.12 & 13.44 & 13.25 & 13.50 & 13.61 \\
\hline $\mathrm{FeO}$ & 1.95 & 2.65 & 2.22 & 2.35 & 2.14 & 2.00 \\
\hline $\mathrm{MnO}$ & 0.00 & 0.27 & 0.14 & 0.24 & 0.10 & 0.09 \\
\hline $\mathrm{MgO}$ & 0.13 & 0.16 & 0.24 & 0.19 & 0.43 & 0.42 \\
\hline $\mathrm{CaO}$ & 2.08 & 1.66 & 1.80 & 1.94 & 1.88 & 2.01 \\
\hline $\mathrm{Na}_{2} \mathrm{O}$ & 3.22 & 3.61 & 3.54 & 3.29 & 3.19 & 2.43 \\
\hline $\mathrm{K}_{2} \mathrm{O}$ & 1.35 & 1.89 & 1.78 & 1.85 & 1.57 & 1.75 \\
\hline $\mathrm{Cl}$ & 0.50 & 0.37 & 0.47 & 0.47 & 0.49 & 0.45 \\
\hline $\mathrm{SO}_{3}$ & 0.03 & 0.09 & 0.00 & 0.01 & 0.01 & 0.14 \\
\hline Total & 100.00 & 100.00 & 100.00 & 100.00 & 100.00 & 100.00 \\
\hline $\mathrm{Sc}$ & 27.5 & 19.4 & 11.9 & 9.93 & 12.0 & 16.7 \\
\hline $\mathrm{V}$ & 19.5 & 9.88 & 9.75 & 4.11 & 14.0 & 9.51 \\
\hline $\mathrm{Cr}$ & 36.7 & 2.92 & 4.85 & 26.3 & 4.23 & 5.59 \\
\hline Mn & 5646 & 2434 & 832 & 583 & 857 & 970 \\
\hline Co & 28.7 & 6.21 & 1.16 & 2.58 & 2.57 & 1.10 \\
\hline $\mathrm{Ni}$ & 8.14 & 0.989 & 1.22 & 24.64 & 2.78 & 1.45 \\
\hline $\mathrm{Cu}$ & 17.0 & 8.85 & 14.9 & 19.6 & 15.9 & 2.88 \\
\hline $\mathrm{Zn}$ & 258 & 159 & 69.9 & 79.5 & 60.5 & 88.8 \\
\hline $\mathrm{Ga}$ & 12.1 & 13.6 & 15.5 & 16.5 & 14.9 & 14.1 \\
\hline $\mathrm{Rb}$ & 34.8 & 25.4 & 35.7 & 20.9 & 36.1 & 42.2 \\
\hline $\mathrm{Sr}$ & 118 & 113 & 129 & 107 & 144 & 164 \\
\hline $\mathrm{Y}$ & 38.7 & 37.5 & 38.3 & 41.1 & 46.2 & 66.1 \\
\hline $\mathrm{Zr}$ & 121 & 142 & 209 & 156 & 222 & 339 \\
\hline $\mathrm{Nb}$ & 3.85 & 3.24 & 4.29 & 4.95 & 4.10 & 6.12 \\
\hline Mo & 4.70 & 2.13 & 2.45 & 2.00 & 1.99 & 3.05 \\
\hline $\mathrm{Cs}$ & 1.18 & 0.77 & 1.02 & 0.732 & 0.895 & 1.21 \\
\hline $\mathrm{Ba}$ & 677 & 811 & 976 & 777 & 1167 & 1255 \\
\hline $\mathrm{La}$ & 11.4 & 11.3 & 13.9 & 9.53 & 16.0 & 18.3 \\
\hline $\mathrm{Ce}$ & 40.4 & 31.0 & 33.2 & 25.6 & 37.9 & 43.7 \\
\hline $\operatorname{Pr}$ & 4.22 & 3.89 & 4.26 & 2.31 & 4.77 & 6.10 \\
\hline $\mathrm{Nd}$ & 18.4 & 16.4 & 18.6 & 22.3 & 23.2 & 29.8 \\
\hline $\mathrm{Sm}$ & 5.35 & 4.42 & 4.30 & 6.85 & 6.46 & 6.30 \\
\hline $\mathrm{Eu}$ & 1.43 & 1.06 & 0.945 & 1.34 & 1.23 & 2.04 \\
\hline $\begin{array}{c}\mathrm{Gd} \\
\mathrm{Tb}\end{array}$ & 6.28 & 4.86 & 5.13 & 5.43 & 6.56 & 8.91 \\
\hline $\begin{array}{l}\text { Dy } \\
\text { Ho }\end{array}$ & 5.10 & 6.13 & 6.53 & 6.01 & 7.02 & 12.44 \\
\hline $\begin{array}{c}\mathrm{Er} \\
\mathrm{Tm}\end{array}$ & 3.66 & 4.07 & 4.32 & 3.91 & 4.90 & 8.23 \\
\hline $\mathrm{Yb}$ & 4.39 & 4.39 & 4.05 & 6.21 & 5.38 & 8.21 \\
\hline $\mathrm{Lu}$ & 0.848 & 0.739 & 0.759 & 0.572 & 0.912 & 1.33 \\
\hline Hf & 3.03 & 3.24 & 5.20 & 3.55 & 5.66 & 9.98 \\
\hline $\mathrm{Ta}$ & 0.300 & 0.258 & 0.246 & 0.316 & 0.289 & 0.373 \\
\hline W & 0.896 & 0.287 & 0.459 & 0.798 & 0.395 & 0.462 \\
\hline $\mathrm{Pb}$ & 3.22 & 4.45 & 5.40 & 3.80 & 5.04 & 6.07 \\
\hline $\mathrm{Th}$ & 2.25 & 2.17 & 2.96 & 2.75 & 3.35 & 4.55 \\
\hline $\mathrm{U}$ & 0.650 & 0.831 & 0.951 & 1.28 & 0.942 & 1.36 \\
\hline
\end{tabular}

All sample data are recalculated on an anhydrous basis. Abbreviations: plag - plagioclase; opx orthopyroxene; qtz - quartz; b.d. - below detection limits. 
Appendix 3

Table A3.2: Major element compositions of melt inclusions where no trace element data is available. Major element concentrations are given in wt \%. 
Table A3.2

\begin{tabular}{|c|c|c|c|c|c|c|c|c|c|c|c|c|c|}
\hline $\begin{array}{c}\text { Sample } \\
\text { ID } \\
\text { Host }\end{array}$ & $\begin{array}{c}\text { WH1_21 } \\
-3 \\
\text { opx }\end{array}$ & $\begin{array}{c}\text { WH1_21 } \\
-8.2 \\
\text { opx }\end{array}$ & $\begin{array}{c}\text { WH1_21 } \\
-8.3 \\
\text { opx }\end{array}$ & $\begin{array}{c}\text { WH1_24 } \\
-2 \\
\text { opx }\end{array}$ & $\begin{array}{c}\text { WH1_25 } \\
-1 \\
\text { opx }\end{array}$ & $\begin{array}{c}\text { WH1_28 } \\
-1 \\
\text { opx }\end{array}$ & $\begin{array}{c}\text { WH1_28 } \\
2.2 \\
\text { opx }\end{array}$ & $\begin{array}{c}\text { WH1_1- } \\
2 \\
\text { qtz }\end{array}$ & $\begin{array}{c}\text { WH1_2- } \\
1 \\
\text { qtz }\end{array}$ & $\begin{array}{c}\text { WH1_5- } \\
1 \\
\text { qtz }\end{array}$ & $\begin{array}{c}\text { WH15_2 } \\
-1 \\
\text { qtz }\end{array}$ & $\begin{array}{c}\text { WH1_5- } \\
3 \\
\text { qtz }\end{array}$ & $\begin{array}{c}\text { WH1_5- } \\
4 \\
\text { qtz }\end{array}$ \\
\hline $\mathrm{SiO}_{2}$ & 77.97 & 77.91 & 78.43 & 78.40 & 78.59 & 79.19 & 77.23 & 77.79 & 77.91 & 79.97 & 78.42 & 78.50 & 78.22 \\
\hline $\mathrm{TiO}_{2}$ & 0.14 & 0.19 & 0.25 & 0.16 & 0.13 & 0.04 & 0.14 & 0.07 & 0.17 & 0.19 & 0.04 & 0.14 & 0.09 \\
\hline $\mathrm{Al}_{2} \mathrm{O}_{3}$ & 12.36 & 12.71 & 12.98 & 12.03 & 12.29 & 11.67 & 12.70 & 13.16 & 12.95 & 12.63 & 13.99 & 12.51 & 12.80 \\
\hline $\mathrm{FeO}$ & 1.66 & 0.76 & 0.83 & 1.24 & 0.75 & 0.93 & 0.66 & 0.29 & 0.40 & 0.37 & 0.10 & 0.49 & 0.46 \\
\hline $\mathrm{MnO}$ & 0.10 & 0.07 & 0.00 & 0.06 & 0.04 & 0.06 & 0.06 & 0.04 & b.d. & 0.02 & 0.02 & 0.05 & 0.06 \\
\hline $\mathrm{MgO}$ & 0.63 & 0.10 & 0.05 & 0.37 & 0.07 & 0.25 & 0.01 & 0.03 & 0.01 & 0.05 & 0.01 & 0.07 & b.d. \\
\hline $\mathrm{CaO}$ & 0.87 & 0.11 & 0.14 & 0.77 & 0.90 & 0.64 & 0.69 & 0.62 & 0.73 & 0.48 & 0.80 & 0.68 & 0.64 \\
\hline $\mathrm{Na}_{2} \mathrm{O}$ & 3.30 & 4.12 & 3.01 & 2.92 & 3.19 & 3.14 & 3.14 & 0.82 & 0.88 & 1.59 & 1.75 & 3.47 & 3.54 \\
\hline $\mathrm{K}_{2} \mathrm{O}$ & 2.80 & 3.79 & 3.79 & 3.52 & 3.39 & 3.24 & 3.76 & 6.87 & 6.85 & 4.56 & 4.73 & 3.77 & 3.90 \\
\hline $\mathrm{Cl}$ & 0.18 & 0.24 & 0.49 & 0.45 & 0.60 & 0.85 & 1.59 & 0.15 & 0.10 & 0.11 & 0.14 & 0.23 & 0.19 \\
\hline $\mathrm{SO}_{3}$ & b.d. & b.d. & 0.02 & 0.08 & 0.05 & b.d. & 0.01 & 0.16 & b.d. & 0.04 & b.d. & 0.09 & 0.10 \\
\hline Total & 100.00 & 100.00 & 100.00 & 100.00 & 100.00 & 100.00 & 100.00 & 100.00 & 100.00 & 100.00 & 100.00 & 100.00 & 100.00 \\
\hline
\end{tabular}


Table A3. 2 continued

\begin{tabular}{|c|c|c|c|c|c|c|c|c|c|c|c|c|c|c|}
\hline $\begin{array}{l}\text { Sample } \\
\text { ID }\end{array}$ & $\mathrm{WH}_{3.2}$ & $\begin{array}{c}\text { WH1_6- } \\
5.2\end{array}$ & $\underset{1}{\mathrm{WH} 1 \_7-}$ & $\begin{array}{c}\text { WH1_7- } \\
2.2\end{array}$ & $\underset{5-2}{\mathrm{WH} 1 \_3}$ & $\begin{array}{c}\text { WH1_3 } \\
5 \_3\end{array}$ & $\begin{array}{c}\mathrm{WH} 2 \_2- \\
1.1\end{array}$ & $\begin{array}{c}\text { WH2_3- } \\
1.1\end{array}$ & $\begin{array}{c}\text { WH2_4- } \\
1.1\end{array}$ & $\begin{array}{c}\text { WH2_5- } \\
1.1\end{array}$ & $\begin{array}{c}\mathrm{WH} 2{ }^{-7}- \\
1.1\end{array}$ & $\begin{array}{c}\text { OR1_8- } \\
1.1\end{array}$ & $\begin{array}{c}\text { OR1_9- } \\
1.1\end{array}$ & $\begin{array}{c}\text { OR1_9- } \\
3.1\end{array}$ \\
\hline Host & $\mathrm{qtz}$ & $\mathrm{qtz}$ & $\mathrm{qtz}$ & $\mathrm{qtz}$ & $\mathrm{qtz}$ & $\mathrm{qtz}$ & $\mathrm{qtz}$ & $\mathrm{qtz}$ & $\mathrm{qtz}$ & $\mathrm{qtz}$ & $\mathrm{qtz}$ & opx & opx & opx \\
\hline $\mathrm{SiO}_{2}$ & 73.79 & 77.54 & 74.74 & 75.58 & 76.72 & 75.33 & 74.81 & 67.98 & 73.66 & 75.35 & 74.30 & 75.91 & 77.58 & 75.41 \\
\hline $\mathrm{TiO}_{2}$ & 0.09 & 0.13 & 0.13 & 0.18 & 0.18 & 0.14 & 0.30 & 0.33 & 0.09 & 0.30 & 0.17 & 0.13 & 0.10 & 0.06 \\
\hline $\mathrm{Al}_{2} \mathrm{O}_{3}$ & 16.13 & 13.71 & 16.43 & 14.84 & 13.06 & 13.87 & 13.37 & 17.01 & 13.30 & 14.03 & 14.19 & 12.52 & 13.66 & 12.57 \\
\hline $\mathrm{FeO}$ & 0.01 & 0.14 & 0.13 & 0.13 & 0.13 & 0.23 & 2.15 & 1.73 & 1.34 & 0.76 & 1.08 & 2.01 & 1.58 & 2.42 \\
\hline $\mathrm{MnO}$ & 0.01 & b.d. & 0.03 & 0.03 & 0.05 & b.d. & 0.03 & 0.15 & 0.05 & 0.05 & 0.15 & 0.15 & 0.08 & 0.10 \\
\hline $\mathrm{MgO}$ & b.d. & 0.11 & b.d. & 0.05 & 0.06 & 0.03 & 0.04 & 0.29 & b.d. & b.d. & 0.13 & 0.19 & 0.19 & 0.80 \\
\hline $\mathrm{CaO}$ & 1.29 & 0.77 & 0.97 & 0.96 & 0.65 & 0.70 & 0.08 & 1.27 & 0.22 & 0.08 & 0.81 & 0.90 & 1.11 & 1.11 \\
\hline $\mathrm{Na}_{2} \mathrm{O}$ & 4.10 & 3.24 & 2.22 & 3.36 & 3.64 & 3.75 & 4.34 & 6.76 & 3.87 & 3.92 & 4.06 & 3.77 & 3.23 & 4.40 \\
\hline $\mathrm{K}_{2} \mathrm{O}$ & 4.32 & 4.25 & 5.05 & 4.55 & 5.11 & 5.40 & 4.44 & 4.32 & 4.56 & 5.00 & 4.68 & 3.65 & 2.24 & 2.18 \\
\hline $\mathrm{Cl}$ & 0.20 & 0.09 & 0.15 & 0.22 & 0.12 & 0.11 & 0.30 & 0.14 & 2.66 & 0.31 & 0.29 & 0.61 & 0.17 & 0.74 \\
\hline $\mathrm{SO}_{3}$ & 0.06 & 0.01 & 0.14 & 0.10 & 0.09 & 0.12 & 0.15 & 0.02 & 0.08 & 0.03 & 0.08 & 0.13 & 0.04 & 0.15 \\
\hline Total & 100.00 & 100.00 & 100.00 & 100.00 & 100.00 & 100.00 & 100.00 & 100.00 & 100.00 & 100.00 & 100.00 & 100.00 & 100.00 & 100.00 \\
\hline
\end{tabular}


Table A3.2 continued

\begin{tabular}{|c|c|c|c|c|c|c|c|c|c|c|c|c|c|c|}
\hline $\begin{array}{c}\text { Sample } \\
\text { ID } \\
\text { Host }\end{array}$ & $\begin{array}{l}\text { OR1_11 } \\
-1.1 \\
\text { opx }\end{array}$ & $\begin{array}{c}\text { OR1_11 } \\
-2.1 \\
\text { opx }\end{array}$ & $\begin{array}{c}\text { OR1_11 } \\
-3.1 \\
\text { opx }\end{array}$ & $\begin{array}{c}\text { OR1 } 12 \\
-3.1 \\
\text { opx }\end{array}$ & $\begin{array}{c}\text { OR1_13 } \\
-1.1 \\
\text { opx }\end{array}$ & $\begin{array}{c}\text { OR1_30 } \\
-1 \\
\text { opx }\end{array}$ & $\begin{array}{c}\text { OR1_30 } \\
-2 \\
\text { opx }\end{array}$ & $\begin{array}{c}\text { OR1_30 } \\
-3 \\
\text { opx }\end{array}$ & $\begin{array}{c}\text { OR1_2- } \\
1.1 \\
\text { plag }\end{array}$ & $\begin{array}{c}\text { OR1_2- } \\
2.1 \\
\text { plag }\end{array}$ & $\begin{array}{c}\text { OR1_2- } \\
3.1 \\
\text { plag }\end{array}$ & $\begin{array}{c}\text { OR1_2- } \\
4.1 \\
\text { plag }\end{array}$ & $\begin{array}{c}\text { OR1_2- } \\
5.1 \\
\text { plag }\end{array}$ & $\begin{array}{c}\text { OR1_5- } \\
1.1 \\
\text { plag }\end{array}$ \\
\hline $\mathrm{SiO}_{2}$ & 75.27 & 74.59 & 75.11 & 77.67 & 74.88 & 77.14 & 78.18 & 76.34 & 77.10 & 78.49 & 76.78 & 77.68 & 77.62 & 75.87 \\
\hline $\mathrm{TiO}_{2}$ & 0.17 & 0.13 & 0.14 & 0.27 & 0.18 & 0.16 & 0.12 & 0.15 & 0.43 & 0.23 & 0.46 & 0.33 & 0.21 & 0.53 \\
\hline $\mathrm{Al}_{2} \mathrm{O}_{3}$ & 13.80 & 14.01 & 13.34 & 12.68 & 12.69 & 13.12 & 12.49 & 13.16 & 12.87 & 12.59 & 12.95 & 13.04 & 12.99 & 13.20 \\
\hline $\mathrm{FeO}$ & 2.00 & 2.17 & 2.00 & 2.02 & 2.30 & 1.87 & 1.64 & 1.86 & 2.07 & 1.75 & 1.95 & 1.94 & 2.09 & 2.79 \\
\hline $\mathrm{MnO}$ & 0.09 & 0.06 & 0.11 & 0.07 & 0.08 & 0.05 & 0.09 & 0.13 & 0.24 & 0.12 & 0.34 & 0.09 & 0.23 & 0.16 \\
\hline $\mathrm{MgO}$ & 0.21 & 0.25 & 0.42 & 0.12 & 0.71 & 0.13 & 0.11 & 0.13 & 0.34 & 0.23 & 0.29 & 0.19 & 0.22 & 0.49 \\
\hline $\mathrm{CaO}$ & 1.44 & 1.56 & 1.10 & 1.13 & 1.40 & 1.15 & 1.05 & 1.16 & 1.60 & 1.46 & 1.63 & 1.71 & 1.33 & 1.83 \\
\hline $\mathrm{Na}_{2} \mathrm{O}$ & 4.01 & 4.36 & 4.42 & 2.80 & 3.88 & 3.09 & 2.89 & 3.34 & 2.40 & 2.17 & 2.24 & 2.13 & 2.40 & 2.04 \\
\hline $\mathrm{K}_{2} \mathrm{O}$ & 2.58 & 2.56 & 2.83 & 2.92 & 2.70 & 2.88 & 3.22 & 3.42 & 2.34 & 2.23 & 2.71 & 2.53 & 2.33 & 2.52 \\
\hline $\mathrm{Cl}$ & 0.30 & b.d. & 0.50 & 0.30 & 0.77 & 0.30 & 0.20 & 0.27 & 0.35 & 0.31 & 0.42 & 0.23 & 0.40 & 0.30 \\
\hline $\mathrm{SO}_{3}$ & 0.02 & 0.09 & 0.02 & 0.01 & b.d. & 0.10 & 0.00 & 0.05 & 0.12 & 0.14 & 0.11 & 0.13 & 0.04 & 0.11 \\
\hline Total & 100.00 & 100.00 & 100.00 & 100.00 & 100.00 & 100.00 & 100.00 & 100.00 & 100.00 & 100.00 & 100.00 & 100.00 & 100.00 & 100.00 \\
\hline
\end{tabular}


Table A3.2

\begin{tabular}{|c|c|c|c|c|c|c|c|c|c|c|c|c|c|c|}
\hline $\begin{array}{c}\text { Sample } \\
\text { ID } \\
\text { Host }\end{array}$ & $\begin{array}{c}\text { OR1_5- } \\
2.1 \\
\text { plag }\end{array}$ & $\begin{array}{c}\text { OR1_5- } \\
3.1 \\
\text { plag }\end{array}$ & $\begin{array}{c}\text { OR1_1- } \\
1.1 \\
\text { qtz }\end{array}$ & $\begin{array}{c}\text { OR1_1- } \\
2.1 \\
\text { qtz }\end{array}$ & $\begin{array}{c}\text { OR1_1- } \\
3.1 \\
\text { qtz }\end{array}$ & $\begin{array}{c}\text { OR1_1- } \\
4.1 \\
\text { qtz }\end{array}$ & $\begin{array}{c}\text { OR2_7- } \\
1.1 \\
\text { opx }\end{array}$ & $\begin{array}{c}\text { OR2_11 } \\
-1.1 \\
\text { opx }\end{array}$ & $\begin{array}{c}\text { OR2 } 11 \\
-2.1 \\
\text { opx }\end{array}$ & $\begin{array}{c}\text { OR2 } 13 \\
-2.1 \\
\text { opx }\end{array}$ & $\begin{array}{c}\text { OR2_24 } \\
-2 \\
\text { opx }\end{array}$ & $\begin{array}{c}\text { OR2_24 } \\
-3 \\
\text { opx }\end{array}$ & $\begin{array}{c}\text { OR2_1- } \\
1.1 \\
\text { qtz }\end{array}$ & $\begin{array}{c}\text { OR2_1- } \\
4.1 \\
\text { qtz }\end{array}$ \\
\hline $\mathrm{SiO}_{2}$ & 73.85 & 76.45 & 79.95 & 79.46 & 79.25 & 79.31 & 76.43 & 76.20 & 76.68 & 78.05 & 78.06 & 76.60 & 78.63 & 78.26 \\
\hline $\mathrm{TiO}_{2}$ & 0.37 & 0.34 & 0.17 & 0.11 & 0.12 & 0.17 & 0.20 & 0.26 & 0.25 & 0.31 & 0.15 & 0.12 & 0.10 & 0.14 \\
\hline $\mathrm{Al}_{2} \mathrm{O}_{3}$ & 15.15 & 13.24 & 12.61 & 12.69 & 12.67 & 12.90 & 13.34 & 13.75 & 13.30 & 12.27 & 12.27 & 13.20 & 12.28 & 12.82 \\
\hline $\mathrm{FeO}$ & 2.19 & 2.64 & 0.93 & 0.92 & 1.10 & 0.89 & 1.82 & 2.30 & 1.92 & 1.89 & 1.80 & 2.02 & 1.00 & 0.73 \\
\hline $\mathrm{MnO}$ & 0.09 & 0.15 & 0.15 & 0.29 & 0.04 & 0.11 & 0.11 & 0.30 & 0.37 & 0.05 & 0.06 & 0.11 & 0.35 & 0.10 \\
\hline $\mathrm{MgO}$ & 0.39 & 0.39 & 0.11 & 0.11 & 0.16 & 0.11 & 0.18 & 0.15 & 0.14 & 0.14 & 0.13 & 0.18 & 0.14 & 0.06 \\
\hline $\mathrm{CaO}$ & 2.99 & 1.54 & 0.69 & 0.96 & 0.98 & 0.95 & 1.49 & 1.53 & 1.38 & 1.21 & 0.92 & 1.26 & 0.96 & 0.89 \\
\hline $\mathrm{Na}_{2} \mathrm{O}$ & 2.60 & 2.13 & 2.52 & 2.66 & 2.55 & 2.78 & 3.45 & 2.92 & 2.82 & 2.61 & 2.93 & 3.40 & 2.71 & 2.95 \\
\hline $\mathrm{K}_{2} \mathrm{O}$ & 1.99 & 2.36 & 2.52 & 2.50 & 2.55 & 2.46 & 2.61 & 2.30 & 2.55 & 3.17 & 3.37 & 2.82 & 3.45 & 3.65 \\
\hline $\mathrm{Cl}$ & 0.23 & 0.54 & 0.24 & 0.28 & 0.31 & 0.27 & 0.28 & 0.12 & 0.23 & 0.24 & 0.22 & 0.18 & 0.30 & 0.30 \\
\hline $\mathrm{SO}_{3}$ & 0.02 & 0.07 & & & & & & & & & 0.10 & 0.11 & 0.06 & 0.09 \\
\hline Total & 100.00 & 100.00 & 100.00 & 100.00 & 100.00 & 100.00 & 100.00 & 100.00 & 100.00 & 100.00 & 100.00 & 100.00 & 100.00 & 100.00 \\
\hline
\end{tabular}


Table A3.2 continued

\begin{tabular}{|c|c|c|c|c|c|c|c|c|c|c|c|c|c|c|}
\hline $\begin{array}{c}\text { Sample } \\
\text { ID } \\
\text { Host }\end{array}$ & $\begin{array}{c}\text { OR2_2- } \\
1.1 \\
\text { qtz }\end{array}$ & $\begin{array}{c}\text { OR2_2- } \\
2.1 \\
\text { qtz }\end{array}$ & $\begin{array}{c}\text { OR2_2- } \\
3.1 \\
\text { qtz }\end{array}$ & $\begin{array}{c}\text { OR2_3- } \\
1.1 \\
\text { qtz }\end{array}$ & $\begin{array}{c}\text { OR2_4- } \\
1.1 \\
\text { qtz }\end{array}$ & $\begin{array}{c}\text { OR2_17 } \\
-1 \\
\text { qtz }\end{array}$ & $\begin{array}{c}\text { OR2_16 } \\
-1 \\
\text { qtz }\end{array}$ & $\begin{array}{c}\text { RA1_2- } \\
1.1 \\
\text { opx }\end{array}$ & $\begin{array}{c}\text { RA1_2- } \\
2.1 \\
\text { opx }\end{array}$ & $\begin{array}{c}\text { RA1_8- } \\
1.1 \\
\text { opx }\end{array}$ & $\begin{array}{c}\text { RA1_8- } \\
2.1 \\
\text { opx }\end{array}$ & $\begin{array}{c}\text { RA1_8- } \\
3.1 \\
\text { opx }\end{array}$ & $\begin{array}{c}\text { RA1_9- } \\
1.1 \\
\text { opx }\end{array}$ & $\begin{array}{c}\text { RA1_11 } \\
-1.1 \\
\text { opx }\end{array}$ \\
\hline $\mathrm{SiO}_{2}$ & 79.69 & 78.81 & 79.09 & 79.21 & 78.65 & 75.63 & 79.45 & 78.08 & 78.20 & 78.67 & 78.52 & 78.16 & 79.45 & 78.12 \\
\hline $\mathrm{TiO}_{2}$ & 0.04 & 0.11 & 0.14 & 0.07 & 0.13 & 0.06 & 0.06 & 0.33 & 0.22 & 0.28 & 0.20 & 0.27 & 0.28 & 0.24 \\
\hline $\mathrm{Al}_{2} \mathrm{O}_{3}$ & 12.15 & 12.33 & 12.02 & 12.37 & 12.15 & 14.30 & 12.01 & 13.26 & 12.92 & 11.88 & 12.39 & 12.54 & 11.50 & 12.72 \\
\hline $\mathrm{FeO}$ & 0.77 & 0.83 & 0.95 & 1.14 & 1.11 & 0.94 & 0.76 & 1.72 & 1.74 & 2.17 & 1.85 & 1.97 & 2.03 & 1.79 \\
\hline $\mathrm{MnO}$ & 0.06 & 0.16 & 0.29 & 0.10 & 0.02 & 0.11 & 0.10 & 0.09 & 0.08 & 0.07 & 0.06 & 0.09 & 0.06 & 0.17 \\
\hline $\mathrm{MgO}$ & 0.04 & 0.10 & 0.07 & 0.12 & 0.12 & 0.04 & 0.08 & 0.18 & 0.22 & 0.25 & 0.26 & 0.22 & 0.20 & 0.24 \\
\hline $\mathrm{CaO}$ & 0.48 & 0.51 & 0.54 & 0.99 & 0.81 & 0.30 & 0.64 & 1.23 & 1.22 & 1.32 & 1.42 & 1.38 & 1.17 & 1.19 \\
\hline $\mathrm{Na}_{2} \mathrm{O}$ & 2.57 & 2.67 & 2.62 & 3.00 & 2.77 & 3.59 & 2.73 & 2.20 & 2.24 & 2.73 & 2.84 & 2.78 & 2.61 & 3.14 \\
\hline $\mathrm{K}_{2} \mathrm{O}$ & 4.06 & 4.18 & 3.86 & 2.65 & 3.75 & 4.74 & 3.53 & 2.73 & 2.88 & 2.46 & 2.26 & 2.40 & 2.38 & 2.19 \\
\hline $\mathrm{Cl}$ & 0.14 & 0.19 & 0.12 & 0.21 & 0.26 & 0.21 & 0.19 & 0.18 & 0.27 & 0.17 & 0.18 & 0.19 & 0.14 & 0.15 \\
\hline $\mathrm{SO}_{3}$ & & & 0.17 & 0.04 & 0.07 & 0.01 & 0.19 & 0.02 & 0.02 & b.d. & 0.01 & 0.01 & 0.18 & 0.06 \\
\hline Total & 100.00 & 100.00 & 100.00 & 100.00 & 100.00 & 100.00 & 100.00 & 100.00 & 100.00 & 100.00 & 100.00 & 100.00 & 100.00 & 100.00 \\
\hline
\end{tabular}


Table A3.2 continued

\begin{tabular}{|c|c|c|c|c|c|c|c|c|c|c|c|c|c|c|}
\hline $\begin{array}{c}\text { Sample } \\
\text { ID } \\
\text { Host }\end{array}$ & RA2_1.1 & $\begin{array}{c}\text { RA2_4- } \\
2.1 \\
\text { opx }\end{array}$ & $\begin{array}{c}\text { RA2_6- } \\
1.1 \\
\text { opx }\end{array}$ & $\begin{array}{c}\text { RA2_6- } \\
2.1 \\
\text { opx }\end{array}$ & $\begin{array}{c}\text { RA2_6- } \\
3.1 \\
\text { opx }\end{array}$ & $\begin{array}{c}\text { RA2_7- } \\
2 . \overline{1} \\
\text { opx }\end{array}$ & $\begin{array}{c}\text { RA2_8- } \\
1.1 \\
\text { opx }\end{array}$ & $\begin{array}{c}\text { RA2_8- } \\
2.1 \\
\text { opx }\end{array}$ & $\begin{array}{c}\text { RA2_8- } \\
4.1 \\
\text { opx }\end{array}$ & $\begin{array}{c}\text { RA2 } 10 \\
-1.1 \\
\text { opx }\end{array}$ & $\begin{array}{c}\text { RA2 } 11 \\
-1.1 \\
\text { opx }\end{array}$ & $\begin{array}{c}\text { RA2 } 11 \\
-3.1 \\
\text { opx }\end{array}$ & $\begin{array}{c}\text { RA2 } 13 \\
-2.2 \\
\text { plag }\end{array}$ & $\begin{array}{c}\text { RA2_13 } \\
-4.2 \\
\text { plag }\end{array}$ \\
\hline $\mathrm{SiO}_{2}$ & 76.19 & 76.87 & 77.45 & 77.58 & 77.04 & 78.18 & 77.63 & 76.53 & 77.37 & 77.79 & 76.77 & 77.63 & 77.46 & 76.74 \\
\hline $\mathrm{TiO}_{2}$ & 0.35 & 0.26 & 0.42 & 0.45 & 0.42 & 0.17 & 0.15 & 0.32 & 0.21 & 0.64 & 0.38 & 0.48 & 0.20 & 0.38 \\
\hline $\mathrm{Al}_{2} \mathrm{O}_{3}$ & 13.49 & 12.97 & 13.03 & 12.61 & 12.79 & 12.32 & 12.74 & 12.91 & 12.90 & 12.47 & 12.72 & 12.85 & 13.15 & 13.49 \\
\hline $\mathrm{FeO}$ & 2.55 & 2.12 & 1.89 & 1.71 & 2.13 & 2.01 & 2.16 & 2.55 & 2.12 & 1.27 & 2.02 & 1.83 & 1.58 & 1.33 \\
\hline $\mathrm{MnO}$ & 0.05 & 0.24 & 0.43 & 0.58 & 0.36 & 0.19 & 0.21 & 0.25 & 0.19 & 0.13 & 0.99 & 0.27 & 0.15 & 0.09 \\
\hline $\mathrm{MgO}$ & 0.40 & 0.38 & 0.30 & 0.32 & 0.36 & 0.25 & 0.39 & 0.44 & 0.32 & 0.16 & 0.18 & 0.17 & 0.26 & 0.25 \\
\hline $\mathrm{CaO}$ & 1.60 & 1.59 & 1.27 & 1.25 & 1.43 & 1.28 & 1.41 & 1.46 & 1.55 & 1.37 & 1.24 & 1.55 & 1.19 & 1.34 \\
\hline $\mathrm{Na}_{2} \mathrm{O}$ & 2.76 & 2.98 & 2.36 & 2.30 & 2.68 & 2.78 & 2.89 & 2.83 & 2.83 & 3.46 & 2.49 & 2.57 & 2.77 & 3.45 \\
\hline $\mathrm{K}_{2} \mathrm{O}$ & 2.41 & 2.34 & 2.68 & 2.84 & 2.45 & 2.52 & 2.22 & 2.43 & 2.31 & 2.41 & 2.88 & 2.37 & 3.02 & 2.71 \\
\hline $\mathrm{Cl}$ & 0.15 & 0.20 & 0.17 & 0.27 & 0.18 & 0.17 & 0.22 & 0.21 & 0.19 & 0.23 & 0.20 & 0.16 & 0.21 & 0.17 \\
\hline $\mathrm{SO}_{3}$ & 0.05 & 0.04 & b.d. & 0.08 & 0.17 & 0.14 & b.d. & 0.07 & 0.02 & 0.06 & 0.12 & 0.11 & 0.02 & 0.05 \\
\hline Total & 100.00 & 100.00 & 100.00 & 100.00 & 100.00 & 100.00 & 100.00 & 100.00 & 100.00 & 100.00 & 100.00 & 100.00 & 100.00 & 100.00 \\
\hline
\end{tabular}


Table A3.2 continued

\begin{tabular}{|c|c|c|c|c|c|c|c|c|c|c|c|c|c|c|}
\hline $\begin{array}{c}\text { Sample } \\
\text { ID } \\
\text { Host }\end{array}$ & $\begin{array}{c}\text { RA2_14 } \\
-1.1 \\
\text { plag }\end{array}$ & $\begin{array}{c}\text { RA2_15 } \\
-1.1 \\
\text { plag }\end{array}$ & $\begin{array}{c}\text { RA2_15 } \\
-2.1 \\
\text { plag }\end{array}$ & $\begin{array}{c}\text { RA2_15 } \\
-3.2 \\
\text { plag }\end{array}$ & $\begin{array}{c}\text { RA2_16 } \\
-1.2 \\
\text { plag }\end{array}$ & $\begin{array}{c}\text { RA2_16 } \\
-2.1 \\
\text { plag }\end{array}$ & $\begin{array}{c}\text { RA2_18 } \\
-1.2 \\
\text { plag }\end{array}$ & $\begin{array}{c}\text { RA2_18 } \\
-2.1 \\
\text { plag }\end{array}$ & $\begin{array}{c}\text { RA2_18 } \\
-3.2 \\
\text { plag }\end{array}$ & $\begin{array}{c}\mathrm{RA}_{-1}{ }^{4-} \\
\text { opx }\end{array}$ & $\begin{array}{c}\text { RA3_8- } \\
2.1 \\
\text { opx }\end{array}$ & $\begin{array}{c}\text { RA3_8- } \\
4.1 \\
\text { opx }\end{array}$ & $\begin{array}{c}\text { RA3_9- } \\
2.1 \\
\text { opx }\end{array}$ & $\begin{array}{c}\text { RA3_9- } \\
3.1 \\
\text { opx }\end{array}$ \\
\hline $\mathrm{SiO}_{2}$ & 77.15 & 77.56 & 77.42 & 77.18 & 76.89 & 76.13 & 78.66 & 77.98 & 77.47 & 78.28 & 77.65 & 77.96 & 78.60 & 77.57 \\
\hline $\mathrm{TiO}_{2}$ & 0.21 & 0.24 & 0.26 & 0.25 & 0.23 & 0.32 & 0.18 & 0.28 & 0.23 & 0.15 & 0.18 & 0.23 & 0.29 & 0.32 \\
\hline $\mathrm{Al}_{2} \mathrm{O}_{3}$ & 12.92 & 13.02 & 13.10 & 13.34 & 13.56 & 13.31 & 12.59 & 13.05 & 13.12 & 12.18 & 12.43 & 12.31 & 12.39 & 12.77 \\
\hline $\mathrm{FeO}$ & 1.40 & 1.42 & 1.35 & 1.45 & 1.42 & 1.45 & 1.32 & 1.33 & 1.32 & 2.06 & 2.32 & 2.30 & 2.08 & 2.08 \\
\hline $\mathrm{MnO}$ & 0.05 & 0.12 & 0.07 & 0.02 & 0.04 & 0.14 & 0.02 & 0.12 & 0.13 & 0.28 & 0.15 & 0.21 & 0.16 & 0.11 \\
\hline $\mathrm{MgO}$ & 0.31 & 0.23 & 0.30 & 0.32 & 0.26 & 0.24 & 0.25 & 0.28 & 0.23 & 0.09 & 0.14 & 0.20 & 0.18 & 0.16 \\
\hline $\mathrm{CaO}$ & 1.36 & 1.39 & 1.57 & 1.52 & 1.38 & 1.49 & 1.32 & 1.43 & 1.55 & 1.22 & 1.13 & 1.25 & 1.33 & 1.51 \\
\hline $\mathrm{Na}_{2} \mathrm{O}$ & 3.21 & 3.21 & 2.68 & 2.90 & 3.10 & 3.70 & 2.48 & 2.60 & 2.68 & 2.67 & 2.23 & 2.69 & 2.61 & 2.84 \\
\hline $\mathrm{K}_{2} \mathrm{O}$ & 3.11 & 2.64 & 3.06 & 2.79 & 2.82 & 2.92 & 2.93 & 2.76 & 3.01 & 2.82 & 3.57 & 2.58 & 2.13 & 2.36 \\
\hline $\mathrm{Cl}$ & 0.22 & 0.14 & 0.19 & 0.23 & 0.30 & 0.25 & 0.19 & 0.17 & 0.20 & 0.20 & 0.19 & 0.22 & 0.20 & 0.22 \\
\hline $\mathrm{SO}_{3}$ & 0.07 & 0.03 & b.d. & b.d. & b.d. & 0.05 & 0.06 & 0.00 & 0.07 & 0.05 & b.d. & 0.05 & 0.05 & 0.08 \\
\hline Total & 100.00 & 100.00 & 100.00 & 100.00 & 100.00 & 100.00 & 100.00 & 100.00 & 100.00 & 100.00 & 100.00 & 100.00 & 100.00 & 100.00 \\
\hline
\end{tabular}


Table A3. 2 continued

\begin{tabular}{|c|c|c|c|c|c|c|c|c|c|c|c|c|c|c|}
\hline $\begin{array}{c}\text { Sample } \\
\text { ID } \\
\text { Host }\end{array}$ & $\begin{array}{c}\text { TA1_7- } \\
2.1 \\
\text { opx }\end{array}$ & $\begin{array}{c}\text { TA1_9- } \\
2.1 \\
\text { opx }\end{array}$ & $\begin{array}{c}\text { TA1_10 } \\
-1.1 \\
\text { opx }\end{array}$ & $\begin{array}{c}\text { TA1_10 } \\
-2.1 \\
\text { opx }\end{array}$ & $\begin{array}{c}\text { TA1_13 } \\
-2.1 \\
\text { opx }\end{array}$ & $\begin{array}{c}\text { TA1_13 } \\
-3.1 \\
\text { opx }\end{array}$ & $\begin{array}{c}\text { TA1_14 } \\
-1.1 \\
\text { opx }\end{array}$ & $\begin{array}{c}\text { TA1_14 } \\
-2.1 \\
\text { opx }\end{array}$ & $\begin{array}{c}\text { TA1_14 } \\
-4.1 \\
\text { opx }\end{array}$ & $\begin{array}{c}\text { TA1_14 } \\
-5.1 \\
\text { opx }\end{array}$ & $\begin{array}{c}\text { TA1_15 } \\
-1.1 \\
\text { opx }\end{array}$ & $\begin{array}{c}\text { TA1_18 } \\
-2.1 \\
\text { opx }\end{array}$ & $\begin{array}{c}\text { TA1_18 } \\
-3.1 \\
\text { opx }\end{array}$ & $\begin{array}{c}\text { TA1_30 } \\
-3 \\
\text { plag }\end{array}$ \\
\hline $\mathrm{SiO}_{2}$ & 75.64 & 76.05 & 75.85 & 76.71 & 75.40 & 75.68 & 75.18 & 74.99 & 75.83 & 75.56 & 76.78 & 75.25 & 76.18 & 76.58 \\
\hline $\mathrm{TiO}_{2}$ & 0.30 & 0.29 & 0.32 & 0.30 & 0.33 & 0.28 & 0.36 & 0.40 & 0.36 & 0.29 & 0.41 & 0.73 & 0.37 & 0.27 \\
\hline $\mathrm{Al}_{2} \mathrm{O}_{3}$ & 13.43 & 12.74 & 12.96 & 12.70 & 12.84 & 13.41 & 13.14 & 13.65 & 13.02 & 13.09 & 12.69 & 13.73 & 13.21 & 13.45 \\
\hline $\mathrm{FeO}$ & 2.69 & 2.89 & 2.98 & 2.85 & 3.09 & 2.61 & 3.01 & 2.37 & 2.51 & 2.94 & 2.64 & 2.47 & 2.51 & 2.10 \\
\hline $\mathrm{MnO}$ & 0.23 & 0.28 & 0.25 & 0.17 & 0.07 & 0.13 & 0.08 & 0.16 & 0.11 & 0.15 & 0.06 & 0.03 & 0.08 & 0.09 \\
\hline $\mathrm{MgO}$ & 0.23 & 0.28 & 0.32 & 0.27 & 0.34 & 0.30 & 0.34 & 0.30 & 0.30 & 0.31 & 0.20 & 0.33 & 0.34 & 0.27 \\
\hline $\mathrm{CaO}$ & 1.69 & 1.52 & 1.62 & 1.50 & 1.63 & 1.55 & 1.64 & 1.60 & 1.60 & 1.61 & 1.41 & 1.69 & 1.48 & 1.69 \\
\hline $\mathrm{Na}_{2} \mathrm{O}$ & 3.33 & 3.46 & 3.09 & 3.08 & 3.48 & 3.25 & 3.34 & 3.73 & 3.46 & 3.28 & 3.16 & 3.19 & 3.25 & 2.95 \\
\hline $\mathrm{K}_{2} \mathrm{O}$ & 2.27 & 2.13 & 2.26 & 2.23 & 2.51 & 2.48 & 2.53 & 2.53 & 2.50 & 2.45 & 2.35 & 2.32 & 2.26 & 2.36 \\
\hline $\mathrm{Cl}$ & 0.15 & 0.26 & 0.18 & 0.18 & 0.22 & 0.19 & 0.24 & 0.22 & 0.25 & 0.26 & 0.21 & 0.26 & 0.24 & 0.19 \\
\hline $\mathrm{SO}_{3}$ & 0.04 & 0.11 & 0.17 & 0.01 & 0.08 & 0.12 & 0.13 & 0.04 & 0.07 & 0.07 & 0.10 & b.d. & 0.07 & 0.05 \\
\hline Total & 100.00 & 100.00 & 100.00 & 100.00 & 100.00 & 100.00 & 100.00 & 100.00 & 100.00 & 100.00 & 100.00 & 100.00 & 100.00 & 100.00 \\
\hline
\end{tabular}


Table A3. 2 continued

\begin{tabular}{|c|c|c|c|c|c|c|c|c|c|c|c|c|c|c|}
\hline $\begin{array}{c}\text { Sample } \\
\text { ID } \\
\text { Host }\end{array}$ & $\begin{array}{c}\text { TA1_31 } \\
-1 \\
\text { plag }\end{array}$ & $\begin{array}{c}\text { TA1_31 } \\
-2 \\
\text { plag }\end{array}$ & $\begin{array}{c}\text { TA1_43 } \\
-1.1 \\
\text { plag }\end{array}$ & $\begin{array}{c}\text { TA1_43 } \\
-2.1 \\
\text { plag }\end{array}$ & $\begin{array}{c}\text { TA1__38 } \\
-1 \\
\text { qtz }\end{array}$ & $\begin{array}{c}\text { TA1_38 } \\
-2 \\
\text { qtz }\end{array}$ & $\begin{array}{c}\text { TA2_1- } \\
1.1 \\
\text { opx }\end{array}$ & $\begin{array}{c}\text { TA2_1- } \\
2 . \overline{1} \\
\text { opx }\end{array}$ & $\begin{array}{c}\text { TA2_1- } \\
3.1 \\
\text { opx }\end{array}$ & $\begin{array}{c}\text { TA2_2- } \\
1.1 \\
\text { opx }\end{array}$ & $\begin{array}{c}\text { TA2_2- } \\
2.1 \\
\text { opx }\end{array}$ & $\begin{array}{c}\text { TA2_2- } \\
3.1 \\
\text { opx }\end{array}$ & $\begin{array}{c}\text { TA2_2- } \\
4.1 \\
\text { opx }\end{array}$ & $\begin{array}{c}\text { TA2_2- } \\
5.1 \\
\text { opx } \\
\end{array}$ \\
\hline $\mathrm{SiO}_{2}$ & 77.03 & 76.85 & 76.36 & 76.01 & 79.52 & 79.37 & 76.02 & 76.22 & 75.70 & 76.36 & 75.76 & 76.65 & 76.59 & 76.33 \\
\hline $\mathrm{TiO}_{2}$ & 0.23 & 0.27 & 0.24 & 0.30 & 0.13 & 0.13 & 0.30 & 0.24 & 0.45 & 0.28 & 0.32 & 0.36 & 0.38 & 0.27 \\
\hline $\mathrm{Al}_{2} \mathrm{O}_{3}$ & 13.85 & 13.68 & 13.66 & 13.58 & 12.72 & 12.86 & 13.23 & 13.05 & 12.80 & 12.60 & 13.25 & 12.76 & 12.55 & 12.95 \\
\hline $\mathrm{FeO}$ & 1.77 & 1.73 & 1.89 & 1.98 & 1.14 & 1.16 & 2.62 & 2.54 & 2.81 & 2.52 & 2.34 & 2.45 & 2.57 & 2.36 \\
\hline $\mathrm{MnO}$ & 0.15 & 0.05 & 0.09 & 0.13 & b.d. & 0.02 & 0.13 & 0.03 & 0.22 & 0.15 & 0.15 & 0.17 & 0.16 & 0.22 \\
\hline $\mathrm{MgO}$ & 0.23 & 0.26 & 0.25 & 0.24 & 0.14 & 0.11 & 0.22 & 0.22 & 0.23 & 0.21 & 0.26 & 0.20 & 0.19 & 0.25 \\
\hline $\mathrm{CaO}$ & 1.55 & 1.65 & 1.49 & 1.48 & 1.03 & 1.09 & 1.25 & 1.47 & 1.29 & 1.39 & 1.37 & 1.26 & 1.38 & 1.40 \\
\hline $\mathrm{Na}_{2} \mathrm{O}$ & 2.60 & 2.78 & 3.26 & 3.36 & 2.76 & 2.80 & 3.69 & 3.71 & 3.89 & 3.77 & 3.76 & 3.54 & 3.72 & 3.67 \\
\hline $\mathrm{K}_{2} \mathrm{O}$ & 2.39 & 2.51 & 2.43 & 2.56 & 2.28 & 2.28 & 2.30 & 2.24 & 2.40 & 2.44 & 2.50 & 2.37 & 2.28 & 2.35 \\
\hline $\mathrm{Cl}$ & 0.20 & 0.14 & 0.22 & 0.26 & 0.20 & 0.19 & 0.22 & 0.24 & 0.21 & 0.24 & 0.18 & 0.19 & 0.15 & 0.20 \\
\hline $\mathrm{SO}_{3}$ & b.d. & 0.08 & 0.10 & 0.10 & 0.09 & b.d. & 0.02 & 0.04 & b.d. & 0.02 & 0.11 & 0.06 & 0.02 & b.d. \\
\hline Total & 100.00 & 100.00 & 100.00 & 100.00 & 100.00 & 100.00 & 100.00 & 100.00 & 100.00 & 100.00 & 100.00 & 100.00 & 100.00 & 100.00 \\
\hline
\end{tabular}


Table A3.2 continued

\begin{tabular}{|c|c|c|c|c|c|c|c|c|c|c|c|c|c|c|}
\hline $\begin{array}{c}\text { Sample } \\
\text { ID } \\
\text { Host }\end{array}$ & $\begin{array}{c}\text { TA2_4- } \\
1.1 \\
\text { opx }\end{array}$ & $\begin{array}{c}\text { TA2_5- } \\
1.1 \\
\text { opx }\end{array}$ & $\begin{array}{c}\text { TA2_6- } \\
2.1 \\
\text { opx }\end{array}$ & $\begin{array}{c}\text { TA2_9- } \\
1.1 \\
\text { opx }\end{array}$ & $\begin{array}{c}\text { TA2_11 } \\
-1.2 \\
\text { opx }\end{array}$ & $\begin{array}{c}\text { TA2_11 } \\
-2.1 \\
\text { opx }\end{array}$ & $\begin{array}{c}\text { TA2_12 } \\
-1.1 \\
\text { opx }\end{array}$ & $\begin{array}{c}\text { TA2_15 } \\
-1.1 \\
\text { opx }\end{array}$ & $\begin{array}{c}\mathrm{KS}_{-1} 15- \\
2.1 \\
\text { opx }\end{array}$ & $\begin{array}{c}\text { TA2_15 } \\
-3.1 \\
\text { opx }\end{array}$ & $\begin{array}{c}\text { TA2_16 } \\
-1.1 \\
\text { opx }\end{array}$ & $\begin{array}{c}\text { TA2 } 16 \\
-2.1 \\
\text { opx }\end{array}$ & $\begin{array}{c}\text { TA2_16 } \\
-3.1 \\
\text { opx }\end{array}$ & $\begin{array}{c}\text { TA2_24 } \\
-1.1 \\
\text { plag }\end{array}$ \\
\hline $\mathrm{SiO}_{2}$ & 76.36 & 74.71 & 76.00 & 75.33 & 75.57 & 76.03 & 76.82 & 76.26 & 74.45 & 75.99 & 75.99 & 75.67 & 75.89 & 76.38 \\
\hline $\mathrm{TiO}_{2}$ & 0.31 & 0.34 & 0.24 & 0.28 & 0.36 & 0.33 & 0.30 & 0.23 & 0.40 & 0.39 & 0.30 & 0.28 & 0.26 & 0.21 \\
\hline $\mathrm{Al}_{2} \mathrm{O}_{3}$ & 12.70 & 13.74 & 12.95 & 13.22 & 13.01 & 13.00 & 12.48 & 12.99 & 13.23 & 13.17 & 13.13 & 13.04 & 13.03 & 13.44 \\
\hline $\mathrm{FeO}$ & 2.65 & 2.60 & 2.91 & 3.42 & 2.90 & 3.01 & 2.99 & 2.87 & 3.71 & 2.83 & 2.68 & 3.12 & 2.93 & 1.46 \\
\hline $\mathrm{MnO}$ & 0.14 & 0.19 & 0.14 & 0.18 & 0.12 & 0.17 & 0.04 & 0.20 & 0.16 & 0.23 & 0.13 & 0.18 & 0.24 & 0.07 \\
\hline $\mathrm{MgO}$ & 0.23 & 0.55 & 0.51 & 0.39 & 0.45 & 0.41 & 0.39 & 0.39 & 0.66 & 0.34 & 0.39 & 0.38 & 0.48 & 0.19 \\
\hline $\mathrm{CaO}$ & 1.44 & 1.35 & 1.33 & 1.15 & 1.26 & 1.38 & 1.35 & 1.14 & 1.41 & 1.23 & 1.23 & 1.32 & 1.31 & 1.57 \\
\hline $\mathrm{Na}_{2} \mathrm{O}$ & 3.73 & 3.51 & 3.22 & 3.62 & 3.49 & 3.12 & 3.09 & 3.28 & 3.46 & 3.34 & 3.41 & 3.54 & 3.31 & 3.74 \\
\hline $\mathrm{K}_{2} \mathrm{O}$ & 2.20 & 2.71 & 2.28 & 2.14 & 2.55 & 2.29 & 2.33 & 2.27 & 2.29 & 2.22 & 2.46 & 2.29 & 2.29 & 2.73 \\
\hline $\mathrm{Cl}$ & 0.15 & 0.23 & 0.21 & 0.22 & 0.23 & 0.18 & 0.21 & 0.36 & 0.20 & 0.17 & 0.27 & 0.18 & 0.25 & 0.20 \\
\hline $\mathrm{SO}_{3}$ & 0.08 & 0.07 & 0.19 & 0.04 & 0.06 & 0.07 & b.d. & 0.01 & 0.04 & 0.08 & 0.01 & 0.02 & 0.02 & b.d. \\
\hline Total & 100.00 & 100.00 & 100.00 & 100.00 & 100.00 & 100.00 & 100.00 & 100.00 & 100.00 & 100.00 & 100.00 & 100.00 & 100.00 & 100.00 \\
\hline
\end{tabular}


Table A3.2 continued

\begin{tabular}{|c|c|c|c|c|c|c|c|c|c|c|c|c|c|c|}
\hline $\begin{array}{c}\text { Sample } \\
\text { ID } \\
\text { Host }\end{array}$ & $\begin{array}{c}\text { TA2_26 } \\
-1.2 \\
\text { plag }\end{array}$ & $\begin{array}{c}\text { TA3_3- } \\
1.1 \\
\text { opx }\end{array}$ & $\begin{array}{c}\text { TA3_3- } \\
2.1 \\
\text { opx }\end{array}$ & $\begin{array}{c}\text { TA3_3- } \\
3.1 \\
\text { opx }\end{array}$ & $\begin{array}{c}\text { TA3_4- } \\
1.1 \\
\text { opx }\end{array}$ & $\begin{array}{c}\text { TA3_4- } \\
2 . \overline{1} \\
\text { opx }\end{array}$ & $\begin{array}{c}\text { TA3_5- } \\
1.1 \\
\text { opx }\end{array}$ & $\begin{array}{c}\text { TA3_5- } \\
2.1 \\
\text { opx }\end{array}$ & $\begin{array}{c}\text { TA3_9- } \\
1.1 \\
\text { opx }\end{array}$ & $\begin{array}{c}\text { TA3_11 } \\
-1.1 \\
\text { opx }\end{array}$ & $\begin{array}{c}\text { TA3_11 } \\
-3.1 \\
\text { opx }\end{array}$ & $\begin{array}{c}\text { TA3_11 } \\
-4.1 \\
\text { opx }\end{array}$ & $\begin{array}{c}\text { TA3_11 } \\
-5.1 \\
\text { opx }\end{array}$ & $\begin{array}{c}\text { TA3_12 } \\
-1.1 \\
\text { opx }\end{array}$ \\
\hline $\mathrm{SiO}_{2}$ & 75.86 & 77.02 & 77.28 & 77.51 & 76.78 & 77.44 & 77.30 & 76.83 & 77.48 & 76.16 & 75.83 & 76.47 & 76.38 & 77.44 \\
\hline $\mathrm{TiO}_{2}$ & 0.21 & 0.24 & 0.25 & 0.17 & 0.20 & 0.24 & 0.18 & 0.18 & 0.21 & 0.47 & 0.27 & 0.39 & 0.28 & 0.18 \\
\hline $\mathrm{Al}_{2} \mathrm{O}_{3}$ & 13.05 & 12.95 & 13.00 & 12.84 & 13.04 & 12.68 & 12.64 & 13.40 & 12.84 & 13.39 & 13.81 & 13.47 & 13.59 & 12.90 \\
\hline $\mathrm{FeO}$ & 2.08 & 3.06 & 2.82 & 2.93 & 2.96 & 3.02 & 3.05 & 2.71 & 2.89 & 2.70 & 2.64 & 2.48 & 2.59 & 2.60 \\
\hline $\mathrm{MnO}$ & 0.04 & 0.13 & 0.09 & 0.18 & 0.14 & 0.04 & 0.09 & 0.10 & 0.09 & 0.18 & 0.11 & 0.08 & 0.12 & 0.18 \\
\hline $\mathrm{MgO}$ & 0.22 & 0.30 & 0.31 & 0.25 & 0.32 & 0.24 & 0.28 & 0.31 & 0.28 & 0.29 & 0.30 & 0.27 & 0.27 & 0.31 \\
\hline $\mathrm{CaO}$ & 1.48 & 1.36 & 1.26 & 1.24 & 1.48 & 1.38 & 1.31 & 1.35 & 1.19 & 1.61 & 1.55 & 1.71 & 1.60 & 1.37 \\
\hline $\mathrm{Na}_{2} \mathrm{O}$ & 4.18 & 2.33 & 2.36 & 2.30 & 2.51 & 2.40 & 2.49 & 2.59 & 2.43 & 2.70 & 2.79 & 2.56 & 2.66 & 2.46 \\
\hline $\mathrm{K}_{2} \mathrm{O}$ & 2.63 & 2.27 & 2.43 & 2.41 & 2.33 & 2.21 & 2.37 & 2.35 & 2.23 & 2.18 & 2.51 & 2.32 & 2.31 & 2.33 \\
\hline $\mathrm{Cl}$ & 0.20 & 0.19 & 0.17 & 0.15 & 0.19 & 0.20 & 0.19 & 0.13 & 0.19 & 0.23 & 0.18 & 0.21 & 0.20 & 0.20 \\
\hline $\mathrm{SO}_{3}$ & 0.06 & 0.16 & 0.02 & 0.01 & 0.06 & 0.15 & 0.11 & 0.05 & 0.17 & 0.09 & b.d. & 0.06 & b.d. & 0.05 \\
\hline Total & 100.00 & 100.00 & 100.00 & 100.00 & 100.00 & 100.00 & 100.00 & 100.00 & 100.00 & 100.00 & 100.00 & 100.00 & 100.00 & 100.00 \\
\hline
\end{tabular}


Table A3.2 continued

\begin{tabular}{|c|c|c|c|c|c|c|c|c|c|c|c|c|c|c|}
\hline $\begin{array}{c}\text { Sample } \\
\text { ID } \\
\text { Host }\end{array}$ & $\begin{array}{c}\text { TA3_12 } \\
-2.1 \\
\text { opx }\end{array}$ & $\begin{array}{c}\text { TA3_13 } \\
-2.1 \\
\text { opx }\end{array}$ & $\begin{array}{c}\text { TA3_15 } \\
-1 \\
\text { plag }\end{array}$ & $\begin{array}{c}\text { TA3_15 } \\
-2 \\
\text { plag }\end{array}$ & $\begin{array}{c}\text { TA3_16 } \\
-1 \\
\text { plag }\end{array}$ & $\begin{array}{c}\text { TA3_16 } \\
-2 \\
\text { plag }\end{array}$ & $\begin{array}{c}\text { TA3_19 } \\
-1 \\
\text { plag }\end{array}$ & $\begin{array}{c}\text { TA4_5- } \\
2.1 \\
\text { opx }\end{array}$ & $\begin{array}{c}\text { TA4_5- } \\
3.1 \\
\text { оpх }\end{array}$ & $\begin{array}{c}\text { TA4_5- } \\
4.1 \\
\text { opx }\end{array}$ & $\begin{array}{c}\text { TA4_5- } \\
5.1 \\
\text { opx }\end{array}$ & $\begin{array}{c}\text { TA4_5- } \\
6.1 \\
\text { орх }\end{array}$ & $\begin{array}{c}\text { TA4_7- } \\
1.1 \\
\text { оpх }\end{array}$ & $\begin{array}{c}\text { TA4_7- } \\
3.1 \\
\text { opx }\end{array}$ \\
\hline $\mathrm{SiO}_{2}$ & 77.68 & 77.16 & 75.67 & 76.68 & 77.28 & 76.39 & 75.94 & 76.14 & 76.77 & 76.64 & 75.67 & 76.59 & 76.87 & 76.18 \\
\hline $\mathrm{TiO}_{2}$ & 0.23 & 0.22 & 0.32 & 0.33 & 0.18 & 0.21 & 0.24 & 0.31 & 0.20 & 0.17 & 0.18 & 0.12 & 0.23 & 0.49 \\
\hline $\mathrm{Al}_{2} \mathrm{O}_{3}$ & 12.88 & 12.97 & 12.94 & 13.72 & 13.12 & 14.06 & 13.58 & 13.21 & 12.90 & 12.95 & 13.16 & 12.80 & 12.66 & 13.37 \\
\hline $\mathrm{FeO}$ & 2.42 & 2.86 & 2.36 & 1.81 & 1.84 & 1.83 & 2.23 & 2.72 & 2.40 & 2.83 & 2.74 & 2.74 & 2.89 & 2.95 \\
\hline $\mathrm{MnO}$ & 0.09 & 0.17 & 0.15 & 0.15 & 0.13 & 0.17 & 0.13 & 0.46 & 0.50 & 0.55 & 0.63 & 0.70 & 0.10 & 0.07 \\
\hline $\mathrm{MgO}$ & 0.35 & 0.28 & 0.39 & 0.23 & 0.20 & 0.23 & 0.26 & 0.31 & 0.32 & 0.30 & 0.35 & 0.26 & 0.23 & 0.25 \\
\hline $\mathrm{CaO}$ & 1.26 & 1.50 & 1.63 & 1.57 & 1.47 & 1.66 & 1.50 & 1.38 & 1.42 & 1.46 & 1.62 & 1.39 & 1.23 & 1.34 \\
\hline $\mathrm{Na}_{2} \mathrm{O}$ & 2.58 & 2.43 & 3.04 & 3.15 & 3.30 & 3.25 & 3.59 & 3.01 & 2.94 & 2.74 & 3.03 & 3.05 & 3.26 & 2.53 \\
\hline $\mathrm{K}_{2} \mathrm{O}$ & 2.27 & 2.13 & 3.18 & 2.15 & 2.30 & 1.98 & 2.30 & 2.26 & 2.23 & 2.14 & 2.35 & 2.14 & 2.28 & 2.24 \\
\hline $\mathrm{Cl}$ & 0.24 & 0.24 & 0.29 & 0.17 & 0.15 & 0.15 & 0.19 & 0.19 & 0.14 & 0.19 & 0.19 & 0.16 & 0.20 & 0.23 \\
\hline $\mathrm{SO}_{3}$ & 0.01 & 0.05 & 0.02 & 0.04 & 0.01 & 0.07 & 0.05 & 0.00 & 0.18 & 0.02 & 0.08 & 0.04 & 0.05 & 0.34 \\
\hline Total & 100.00 & 100.00 & 100.00 & 100.00 & 100.00 & 100.00 & 100.00 & 100.00 & 100.00 & 100.00 & 100.00 & 100.00 & 100.00 & 100.00 \\
\hline
\end{tabular}


Table A3.2 continued

\begin{tabular}{|c|c|c|c|c|c|c|c|c|c|c|c|c|c|c|}
\hline $\begin{array}{c}\text { Sample } \\
\text { ID } \\
\text { Host }\end{array}$ & $\begin{array}{c}\text { X590_1- } \\
1 \\
\text { opx }\end{array}$ & $\begin{array}{c}\text { X590_3- } \\
1.1 \\
\text { opx }\end{array}$ & $\begin{array}{c}\mathrm{X} 590 \_3- \\
3 \\
\text { opx }\end{array}$ & $\begin{array}{c}\text { X590_9- } \\
1.1 \\
\text { plag }\end{array}$ & $\begin{array}{c}\text { X590_9- } \\
2.2 \\
\text { plag }\end{array}$ & $\begin{array}{c}\text { X590_9- } \\
3.1 \\
\text { plag }\end{array}$ & $\begin{array}{c}\text { X590_1 } \\
1-1.1 \\
\text { plag }\end{array}$ & $\begin{array}{c}\text { X590_1 } \\
2-1.1 \\
\text { plag }\end{array}$ & $\begin{array}{c}\text { X590_1 } \\
2-2 . \overline{2} \\
\text { plag }\end{array}$ & $\begin{array}{c}\text { 590B- } \\
\text { 1i1 } \\
\text { plag }\end{array}$ & $\begin{array}{c}\text { 590B- } \\
3 \mathrm{i} 1 \\
\text { plag }\end{array}$ & $\begin{array}{c}\text { 590B- } \\
4 \mathrm{i} 1 \\
\text { plag }\end{array}$ & $\begin{array}{c}\text { 590B- } \\
5 \mathrm{i} 1 \\
\text { plag }\end{array}$ & $\begin{array}{c}\text { 590B- } \\
6 \mathrm{il} \\
\text { plag }\end{array}$ \\
\hline $\mathrm{SiO}_{2}$ & 76.55 & 76.60 & 77.67 & 75.56 & 75.91 & 75.46 & 75.83 & 75.07 & 76.64 & 77.50 & 76.87 & 76.63 & 75.54 & 76.63 \\
\hline $\mathrm{TiO}_{2}$ & 0.37 & 0.31 & 0.22 & 0.30 & 0.37 & 0.36 & 0.27 & 0.46 & 0.37 & 0.34 & 0.32 & 0.33 & 0.38 & 0.30 \\
\hline $\mathrm{Al}_{2} \mathrm{O}_{3}$ & 13.22 & 13.35 & 12.76 & 13.85 & 13.56 & 13.64 & 14.11 & 14.00 & 13.48 & 14.09 & 13.56 & 13.71 & 13.82 & 13.78 \\
\hline $\mathrm{FeO}$ & 2.11 & 2.38 & 2.15 & 2.02 & 2.02 & 2.06 & 1.90 & 2.50 & 1.95 & 2.29 & 2.11 & 2.14 & 2.37 & 1.86 \\
\hline $\mathrm{MnO}$ & 0.39 & 0.14 & 0.12 & 0.15 & 0.13 & 0.16 & 0.07 & 0.11 & 0.11 & 0.15 & 0.13 & 0.15 & 0.13 & 0.07 \\
\hline $\mathrm{MgO}$ & 0.14 & 0.06 & 0.10 & 0.43 & 0.39 & 0.58 & 0.41 & 0.44 & 0.34 & 0.23 & 0.16 & 0.12 & 0.48 & 0.34 \\
\hline $\mathrm{CaO}$ & 1.58 & 2.04 & 1.33 & 2.04 & 2.00 & 2.03 & 2.11 & 2.18 & 1.88 & 1.97 & 1.81 & 1.83 & 1.92 & 1.86 \\
\hline $\mathrm{Na}_{2} \mathrm{O}$ & 3.40 & 3.02 & 3.36 & 3.19 & 3.18 & 3.15 & 2.90 & 2.88 & 2.83 & 1.53 & 3.08 & 2.97 & 3.06 & 3.09 \\
\hline $\mathrm{K}_{2} \mathrm{O}$ & 1.85 & 1.52 & 1.86 & 1.69 & 1.77 & 1.82 & 1.87 & 1.70 & 1.72 & 1.35 & 1.49 & 1.59 & 1.70 & 1.58 \\
\hline $\mathrm{Cl}$ & 0.40 & 0.53 & 0.33 & 0.66 & 0.56 & 0.66 & 0.47 & 0.63 & 0.57 & 0.56 & 0.48 & 0.52 & 0.61 & 0.48 \\
\hline $\mathrm{SO}_{3}$ & b.d. & 0.05 & 0.10 & 0.11 & 0.11 & 0.07 & 0.06 & 0.04 & 0.11 & & & & & \\
\hline Total & 100.00 & 100.00 & 100.00 & 100.00 & 100.00 & 100.00 & 100.00 & 100.00 & 100.00 & 100.00 & 100.00 & 100.00 & 100.00 & 100.00 \\
\hline
\end{tabular}


Table A3.2 continued

\begin{tabular}{|c|c|c|c|c|c|c|c|c|c|c|c|}
\hline $\begin{array}{c}\text { Sample } \\
\text { ID } \\
\text { Host }\end{array}$ & 590B-7i1 & 590B-8i1 & $590 \mathrm{~B}-8 \mathrm{i} 2$ & $\begin{array}{c}\mathrm{X} 590 / \mathrm{B} \\
10-1.1 \\
\text { plag }\end{array}$ & $\begin{array}{c}\mathrm{X} 590 / \mathrm{B} \\
11-1.2 \\
\text { plag }\end{array}$ & $\begin{array}{c}\mathrm{X} 590 / \mathrm{B} \\
13-1.1 \\
\text { plag }\end{array}$ & $\begin{array}{c}\text { X609_14 } \\
-1.1 \\
\text { plag }\end{array}$ & $\begin{array}{c}\text { X609_16 } \\
-1.1 \\
\text { plag }\end{array}$ & $\begin{array}{c}\text { X609_16 } \\
-2.2 \\
\text { plag }\end{array}$ & $\begin{array}{c}\text { X609_18 } \\
-1.1 \\
\text { plag }\end{array}$ & $\begin{array}{c}\text { X609_18 } \\
-2.2 \\
\text { plag }\end{array}$ \\
\hline $\mathrm{SiO}_{2}$ & 76.82 & 75.87 & 76.86 & 77.49 & 76.63 & 76.22 & 77.09 & 78.89 & 75.33 & 75.00 & 76.95 \\
\hline $\mathrm{TiO}_{2}$ & 0.37 & 0.40 & 0.38 & 0.23 & 0.35 & 0.30 & 0.30 & 0.40 & 0.48 & 0.55 & 0.40 \\
\hline $\mathrm{Al}_{2} \mathrm{O}_{3}$ & 13.71 & 13.83 & 13.58 & 13.02 & 13.44 & 13.61 & 12.98 & 12.81 & 13.50 & 13.71 & 13.04 \\
\hline $\mathrm{FeO}$ & 1.86 & 2.07 & 2.08 & 1.71 & 1.92 & 2.07 & 1.98 & 2.35 & 2.30 & 2.20 & 2.28 \\
\hline $\mathrm{MnO}$ & 0.15 & 0.12 & 0.09 & 0.19 & 0.04 & 0.07 & 0.07 & 0.11 & 0.19 & 0.13 & 0.10 \\
\hline $\mathrm{MgO}$ & 0.40 & 0.43 & 0.41 & 0.32 & 0.43 & 0.35 & 0.42 & 0.36 & 0.46 & 0.45 & 0.41 \\
\hline $\mathrm{CaO}$ & 1.92 & 1.96 & 1.87 & 1.55 & 1.90 & 1.92 & 1.88 & 1.93 & 2.16 & 2.10 & 1.84 \\
\hline $\mathrm{Na}_{2} \mathrm{O}$ & 2.60 & 3.09 & 2.42 & 3.24 & 3.15 & 3.20 & 3.24 & 1.40 & 3.36 & 3.22 & 2.64 \\
\hline $\mathrm{K}_{2} \mathrm{O}$ & 1.66 & 1.65 & 1.73 & 1.89 & 1.65 & 1.77 & 1.54 & 1.13 & 1.64 & 1.90 & 1.75 \\
\hline $\mathrm{Cl}$ & 0.50 & 0.59 & 0.59 & 0.37 & 0.45 & 0.46 & 0.46 & 0.57 & 0.51 & 0.64 & 0.49 \\
\hline $\mathrm{SO}_{3}$ & & & & 0.01 & 0.03 & 0.04 & 0.05 & 0.06 & 0.06 & 0.10 & 0.09 \\
\hline Total & 100.00 & 100.00 & 100.00 & 100.00 & 100.00 & 100.00 & 100.00 & 100.00 & 100.00 & 100.00 & 100.00 \\
\hline
\end{tabular}

All sample data are recalculated on an anhydrous basis. Abbreviations: b.d. - below detection limits; opx- orthopyroxene; plag - plagioclase; qtz - quartz 


\section{Appendix 3}

Table A3.3: Major element compositions of groundmass glass adhered to crystals Major element concentrations are given in $\mathrm{wt} \%$ 
Table A3.3

\begin{tabular}{|c|c|c|c|c|c|c|c|c|c|c|c|c|c|c|}
\hline $\begin{array}{c}\text { Sample } \\
\text { ID }\end{array}$ & OR1_8g & RA1_8g & RA2_8g & TA1_9g & $\begin{array}{c}\text { TA1_13 } \\
\mathrm{g}\end{array}$ & $\begin{array}{c}\text { TA1_14 } \\
\mathrm{g}\end{array}$ & $\begin{array}{c}\text { TA1_15 } \\
\mathrm{g}\end{array}$ & TA2_1g & TA2_2g & TA2_5g & $\begin{array}{c}\text { TA2_11 } \\
\mathrm{g}\end{array}$ & $\begin{array}{c}\text { TA3_13 } \\
\mathrm{g}\end{array}$ & $\begin{array}{c}\text { TA3_11 } \\
\mathrm{g}\end{array}$ & TA4_5g \\
\hline $\mathrm{SiO}_{2}$ & 77.02 & 77.35 & 76.80 & 76.55 & 75.40 & 75.36 & 75.60 & 75.52 & 75.44 & 75.22 & 75.33 & 76.48 & 76.34 & 76.43 \\
\hline $\mathrm{TiO}_{2}$ & 0.14 & 0.29 & 0.34 & 0.24 & 0.31 & 0.28 & 0.46 & 0.30 & 0.28 & 0.30 & 0.28 & 0.26 & 0.33 & 0.17 \\
\hline $\mathrm{Al}_{2} \mathrm{O}_{3}$ & 12.50 & 12.82 & 12.69 & 12.85 & 13.60 & 13.70 & 13.01 & 13.54 & 13.40 & 13.58 & 13.40 & 13.61 & 13.60 & 12.84 \\
\hline $\mathrm{FeO}$ & 1.82 & 1.51 & 2.05 & 2.36 & 2.54 & 2.15 & 2.39 & 2.23 & 2.25 & 2.42 & 2.44 & 2.24 & 2.27 & 2.39 \\
\hline $\mathrm{MnO}$ & 0.12 & 0.03 & 0.32 & 0.22 & 0.09 & 0.06 & 0.07 & 0.13 & 0.18 & 0.11 & 0.10 & 0.07 & 0.07 & 0.71 \\
\hline $\mathrm{MgO}$ & 0.21 & 0.34 & 0.46 & 0.30 & 0.34 & 0.35 & 0.32 & 0.47 & 0.42 & 0.60 & 0.71 & 0.26 & 0.20 & 0.21 \\
\hline $\mathrm{CaO}$ & 1.21 & 1.46 & 1.58 & 1.51 & 1.57 & 1.55 & 1.51 & 1.45 & 1.42 & 1.61 & 1.52 & 1.58 & 1.44 & 1.33 \\
\hline $\mathrm{Na}_{2} \mathrm{O}$ & 4.26 & 3.52 & 3.27 & 3.44 & 3.49 & 3.89 & 4.00 & 3.91 & 4.00 & 3.35 & 3.39 & 3.00 & 2.86 & 3.20 \\
\hline $\mathrm{K}_{2} \mathrm{O}$ & 2.61 & 2.43 & 2.26 & 2.19 & 2.35 & 2.35 & 2.41 & 2.38 & 2.44 & 2.53 & 2.54 & 2.22 & 2.35 & 2.44 \\
\hline $\mathrm{Cl}$ & b.d. & 0.21 & 0.16 & 0.22 & 0.27 & 0.20 & 0.21 & 0.20 & 0.17 & 0.14 & 0.19 & 0.20 & 0.22 & 0.16 \\
\hline $\mathrm{SO}_{3}$ & 0.11 & 0.04 & 0.08 & 0.10 & 0.02 & 0.10 & 0.03 & 0.05 & b.d. & 0.14 & 0.10 & 0.01 & 0.26 & 0.11 \\
\hline Total & 100.00 & 100.00 & 100.00 & 100.00 & 100.00 & 100.00 & 100.00 & 100.19 & 100.00 & 100.00 & 100.00 & 100.00 & 100.00 & 100.00 \\
\hline
\end{tabular}

All sample data are recalculated on an anhydrous basis. b.d. - below detection limits. 


\section{Appendix 3}

Table A3.4: Trace element composition (in ppm) of orthopyroxene and plagioclase phenocrysts from the Healy and Oruanui samples. 
Table A3.4

\begin{tabular}{|c|c|c|c|c|}
\hline \multirow[b]{3}{*}{$\mathrm{n}$} & \multicolumn{2}{|c|}{ Healy } & \multicolumn{2}{|c|}{ Oruanui } \\
\hline & opx & plag & opx & plag \\
\hline & 5 & 1 & 2 & 1 \\
\hline $\mathrm{Sc}$ & 52.8 & 5.53 & 55.6 & 3.95 \\
\hline $\mathrm{Ti}$ & 0.16 & 0.02 & 577 & 88.1 \\
\hline V & 20.2 & 0.27 & 31.18 & 0.44 \\
\hline $\mathrm{Cr}$ & 6.29 & 10.1 & 7.80 & 6.08 \\
\hline $\mathrm{Mn}$ & 19442 & 46.52 & 14294 & 30.61 \\
\hline $\mathrm{Co}$ & 59.8 & 0.37 & 66.0 & 0.42 \\
\hline $\mathrm{Ni}$ & 4.08 & 3.09 & 12.7 & 1.05 \\
\hline $\mathrm{Cu}$ & 0.93 & 2.99 & 0.70 & 2.12 \\
\hline $\mathrm{Zn}$ & 634 & 11.6 & 602 & 8.22 \\
\hline $\mathrm{Ga}$ & 2.69 & 25.1 & 2.83 & 21.6 \\
\hline $\mathrm{Rb}$ & 0.16 & 0.38 & 0.11 & 0.28 \\
\hline $\mathrm{Sr}$ & 0.28 & 724 & 0.13 & 610 \\
\hline $\mathrm{Y}$ & 11.06 & 0.37 & 8.46 & 0.34 \\
\hline $\mathrm{Zr}$ & 1.60 & 0.00 & 1.08 & 0.44 \\
\hline $\mathrm{Nb}$ & 0.22 & 0.00 & 0.00 & 0.00 \\
\hline Mo & 0.89 & 0.00 & 0.61 & 0.00 \\
\hline $\mathrm{Cs}$ & 0.03 & 0.10 & 0.03 & 0.06 \\
\hline $\mathrm{Ba}$ & 5.18 & 248 & 0.87 & 139 \\
\hline $\mathrm{La}$ & 0.09 & 2.78 & 0.13 & 3.35 \\
\hline $\mathrm{Ce}$ & 0.15 & 5.13 & 0.15 & 5.46 \\
\hline $\operatorname{Pr}$ & 0.07 & 0.45 & 0.11 & 0.52 \\
\hline $\mathrm{Nd}$ & 0.30 & 1.71 & 0.36 & 1.23 \\
\hline $\mathrm{Sm}$ & 0.33 & 0.57 & 0.52 & 0.56 \\
\hline $\mathrm{Eu}$ & 0.08 & 1.68 & 0.08 & 1.45 \\
\hline $\mathrm{Gd}$ & 0.53 & 0.66 & 0.58 & 0.55 \\
\hline $\mathrm{Tb}$ & & & 0.12 & 0.08 \\
\hline Dy & 1.39 & 0.38 & 1.05 & 0.35 \\
\hline Ho & & & 0.32 & 0.09 \\
\hline $\mathrm{Er}$ & 1.54 & 0.27 & 1.26 & 0.33 \\
\hline $\mathrm{Tm}$ & & & 0.27 & 0.10 \\
\hline $\mathrm{Yb}$ & 2.74 & 0.36 & 2.30 & 0.90 \\
\hline $\mathrm{Lu}$ & 0.50 & 0.00 & 0.44 & 0.20 \\
\hline Hf & 0.20 & 0.00 & 0.46 & 0.00 \\
\hline $\mathrm{Ta}$ & 0.03 & 0.00 & 0.00 & 0.00 \\
\hline W & 0.00 & 0.30 & 0.00 & 0.00 \\
\hline $\mathrm{Pb}$ & 0.22 & 0.92 & 0.21 & 2.61 \\
\hline $\mathrm{Th}$ & 0.04 & 0.00 & 0.17 & 0.25 \\
\hline $\mathrm{U}$ & 0.03 & 0.00 & 0.13 & 0.00 \\
\hline
\end{tabular}




\section{Appendix 3}

Table A3.5: Major element compositions of Taupo melt inclusions plagioclase hosts and representative analyses of Whakamaru plagioclase crystals.

Major element concentrations are given in wt $\%$ 
Table A3.5

\begin{tabular}{|c|c|c|c|c|c|c|c|c|c|}
\hline Sample & TA1_30host & TA1_31host & TA1_31host2 & TA1_31host3 & TA1_35host & TA1_35host3 & TA1_34host2 & TA1_34host3 & TA2_24host1 \\
\hline $\mathrm{SiO}_{2}$ & 58.99 & 58.62 & 60.50 & 59.40 & 58.23 & 58.07 & 55.31 & 59.66 & 58.91 \\
\hline $\mathrm{Al}_{2} \mathrm{O}_{3}$ & 26.50 & 26.62 & 25.78 & 26.17 & 26.98 & 26.99 & 29.22 & 25.90 & 25.31 \\
\hline $\mathrm{FeO}$ & 0.24 & 0.35 & 0.27 & 0.37 & 0.28 & 0.51 & 0.35 & 0.35 & 0.27 \\
\hline $\mathrm{CaO}$ & 9.56 & 9.08 & 7.95 & 8.32 & 9.44 & 9.72 & 11.96 & 8.49 & 7.80 \\
\hline $\mathrm{Na}_{2} \mathrm{O}$ & 6.23 & 6.24 & 6.47 & 6.32 & 5.72 & 5.93 & 4.78 & 6.47 & 6.83 \\
\hline $\mathrm{K}_{2} \mathrm{O}$ & 0.23 & 0.26 & 0.27 & 0.21 & 0.19 & 0.14 & 0.11 & 0.16 & 0.23 \\
\hline Total & 101.75 & 101.18 & 101.23 & 100.79 & 100.83 & 101.36 & 101.73 & 101.04 & 99.36 \\
\hline X An & 0.45 & 0.44 & 0.40 & 0.42 & 0.47 & 0.47 & 0.58 & 0.42 & 0.38 \\
\hline Temp $\left({ }^{\circ} \mathrm{C}\right)$ & 778 & 773 & 758 & 766 & 784 & 785 & 800 & 768 & 755 \\
\hline $\mathrm{H}_{2} \mathrm{O}(\mathrm{wt} \%)$ & 8.40 & 8.38 & 8.33 & 8.31 & 8.44 & 8.40 & 9.02 & 8.28 & 8.25 \\
\hline
\end{tabular}


Table A3.5 continued

\begin{tabular}{|c|c|c|c|c|c|c|c|c|c|c|}
\hline Sample & $\begin{array}{c}\text { TA2_24host } \\
2\end{array}$ & TA2_27host & $\begin{array}{c}\text { TA2 }-27 \text { host } \\
21\end{array}$ & $\begin{array}{c}\text { TA2_26host. } \\
1\end{array}$ & TA2_29host & WHh_2 & WH1h_3 & WH1h_4 & WH1h_34 & WH1h_64 \\
\hline $\mathrm{SiO}_{2}$ & 60.37 & 55.96 & 56.60 & 57.10 & 59.54 & 61.27 & 61.37 & 62.03 & 55.81 & 59.77 \\
\hline $\mathrm{Al}_{2} \mathrm{O}_{3}$ & 25.79 & 26.77 & 28.70 & 24.77 & 26.61 & 25.12 & 25.40 & 24.71 & 29.00 & 25.80 \\
\hline $\mathrm{FeO}$ & 0.19 & 0.30 & 0.47 & 0.41 & 0.42 & 0.25 & 0.31 & 0.31 & 0.23 & 0.31 \\
\hline $\mathrm{CaO}$ & 7.83 & 8.92 & 10.60 & 8.88 & 8.17 & 6.54 & 6.48 & 5.81 & 10.42 & 6.30 \\
\hline $\mathrm{Na}_{2} \mathrm{O}$ & 6.93 & 6.23 & 5.38 & 6.39 & 6.66 & 7.55 & 7.88 & 7.67 & 5.69 & 7.89 \\
\hline $\mathrm{K}_{2} \mathrm{O}$ & 0.23 & 0.18 & 0.16 & 0.22 & 0.22 & 0.78 & 0.68 & 0.82 & 0.29 & 0.72 \\
\hline Total & 101.34 & 98.36 & 101.91 & 97.76 & 101.62 & 101.51 & 102.12 & 101.34 & 101.45 & 100.78 \\
\hline X An & 0.38 & 0.44 & 0.52 & 0.43 & 0.40 & 0.31 & 0.30 & 0.28 & 0.49 & 0.29 \\
\hline Temp $\left({ }^{\circ} \mathrm{C}\right)$ & 752 & 774 & 793 & 771 & 760 & 752 & 749 & 735 & 836 & 744 \\
\hline $\mathrm{H}_{2} \mathrm{O}(\mathrm{wt} \%)$ & 8.30 & 8.33 & 8.64 & 8.33 & 8.30 & 8.14 & 8.10 & 8.22 & 8.46 & 8.13 \\
\hline
\end{tabular}


Table A3.5 continued

\begin{tabular}{cccccccc}
\hline Sample & WH1h_65 & WH1h_66 & WH1b_2 & WH1b_3 & WH1b_4 & WH1b_5 & WH1b_6 \\
\hline $\mathrm{SiO}_{2}$ & 60.46 & 60.23 & 60.12 & 60.55 & 61.03 & 60.51 & 60.47 \\
$\mathrm{Al}_{2} \mathrm{O}_{3}$ & 25.63 & 25.43 & 24.92 & 24.65 & 24.37 & 24.38 \\
$\mathrm{FeO}$ & 0.29 & 0.24 & 0.26 & 0.23 & 0.20 & 0.34 & 24.33 \\
$\mathrm{CaO}$ & 6.27 & 6.08 & 7.00 & 6.58 & 6.42 & 6.16 & 7.22 \\
$\mathrm{Na}_{2} \mathrm{O}$ & 7.44 & 7.50 & 7.17 & 7.37 & 7.54 & 0.04 \\
$\mathrm{~K}_{2} \mathrm{O}$ & 0.69 & 0.72 & 0.66 & 0.68 & 0.67 & 0.62 & 0.71 \\
$\mathrm{Total}$ & 100.78 & 100.19 & 100.13 & 100.06 & 100.22 & 99.47 & 99.39 \\
$\mathrm{X} \mathrm{An}$ & 0.31 & 0.30 & 0.34 & 0.32 & 0.31 & 0.30 & 0.29 \\
$\mathrm{Temp}\left({ }^{\circ} \mathrm{C}\right)$ & 751 & 745 & 769 & 758 & 753 & 750 & 743 \\
$\mathrm{H}_{2} \mathrm{O}($ wt $\%)$ & 8.11 & 8.14 & 8.08 & 8.09 & 8.10 & 8.09 & 8.14 \\
\hline
\end{tabular}

$X$ An calculated on a mole fraction basis $(\mathrm{Ca} /(\mathrm{Ca}+\mathrm{Na}+\mathrm{K})$. Temperature and water estimates were calculated using plagioclase-melt equilibria of Putirka, (2005) assuming a pressure of $100 \mathrm{MPa}$. 


\section{Appendix 3}

Table A3.6: Major element compositions (are given in wt\%) of Whakamaru plagioclase crystals Empty cells indicate no data collected. 
Table A3.6

\begin{tabular}{|c|c|c|c|c|c|c|c|c|c|c|c|c|}
\hline Sample & $\mathrm{SiO}_{2}$ & $\mathrm{Al}_{2} \mathrm{O}_{3}$ & $\mathrm{FeO}$ & $\mathrm{MgO}$ & $\mathrm{CaO}$ & $\mathrm{Na}_{2} \mathrm{O}$ & $\mathrm{K}_{2} \mathrm{O}$ & Total & XAn & $\begin{array}{c}\mathrm{T} \\
\left({ }^{\circ} \mathrm{C}\right)\end{array}$ & G & $\begin{array}{l}\text { Dist. } \\
(\mu \mathrm{m})\end{array}$ \\
\hline WH1b_2 & 60.12 & 24.92 & 0.26 & & 7.00 & 7.17 & 0.66 & 100.13 & 0.34 & 770 & 2 & 20 \\
\hline WH1b_3 & 60.55 & 24.65 & 0.23 & & 6.58 & 7.37 & 0.68 & 100.06 & 0.32 & 759 & 2 & 30 \\
\hline WH1b_4 & 61.03 & 24.37 & 0.20 & & 6.42 & 7.54 & 0.67 & 100.22 & 0.31 & 753 & 2 & 40 \\
\hline WH1b_5 & 60.51 & 24.38 & 0.34 & & 6.16 & 7.45 & 0.62 & 99.47 & 0.30 & 751 & 2 & 50 \\
\hline WH1b_6 & 60.47 & 24.33 & 0.22 & & 6.04 & 7.62 & 0.71 & 99.39 & 0.29 & 743 & 2 & 60 \\
\hline WH1b_7 & 60.36 & 24.46 & 0.30 & & 6.13 & 7.85 & 0.75 & 99.85 & 0.29 & 741 & 2 & 70 \\
\hline WH1b_8 & 60.51 & 24.40 & 0.24 & & 6.04 & 7.72 & 0.70 & 99.61 & 0.29 & 742 & 2 & 80 \\
\hline WH1b_9 & 60.17 & 24.30 & 0.14 & & 6.16 & 7.63 & 0.70 & 99.10 & 0.30 & 746 & 2 & 90 \\
\hline WH1b_10 & 60.12 & 24.17 & 0.18 & & 5.99 & 7.58 & 0.82 & 98.86 & 0.29 & 740 & 2 & 100 \\
\hline WH1b_12 & 60.50 & 24.33 & 0.22 & & 6.24 & 7.52 & 0.63 & 99.43 & 0.30 & 751 & 2 & 120 \\
\hline WH1b_13 & 59.82 & 24.37 & 0.22 & & 6.32 & 7.47 & 0.69 & 98.89 & 0.31 & 752 & 2 & 130 \\
\hline WH1b_14 & 61.27 & 24.70 & 0.26 & & 6.25 & 7.89 & 0.81 & 101.17 & 0.29 & 742 & 2 & 140 \\
\hline WH1b_15 & 60.23 & 24.81 & 0.20 & & 6.67 & 7.44 & 0.70 & 100.05 & 0.32 & 759 & 2 & 150 \\
\hline WH1b_18 & 60.77 & 24.98 & 0.25 & & 6.44 & 7.65 & 0.75 & 100.84 & 0.30 & 750 & 2 & 180 \\
\hline WH1b_19 & 60.88 & 25.10 & 0.14 & & 6.79 & 7.36 & 0.70 & 100.96 & 0.32 & 762 & 2 & 190 \\
\hline WH1b_21 & 59.80 & 24.83 & 0.25 & & 6.30 & 7.58 & 0.77 & 99.53 & 0.30 & 748 & 2 & 210 \\
\hline WH1b_22 & 60.70 & 24.29 & 0.18 & & 6.32 & 7.76 & 0.80 & 100.06 & 0.30 & 745 & 2 & 220 \\
\hline WH1b_23 & 60.66 & 24.20 & 0.23 & & 6.16 & 7.72 & 0.80 & 99.77 & 0.29 & 742 & 2 & 230 \\
\hline WH1b_24 & 61.20 & 24.70 & 0.20 & & 6.26 & 7.37 & 0.72 & 100.45 & 0.31 & 752 & 2 & 240 \\
\hline WH1b_25 & 60.71 & 24.58 & 0.31 & & 6.48 & 7.42 & 0.72 & 100.22 & 0.31 & 755 & 2 & 250 \\
\hline WH1b_26 & 61.11 & 25.03 & 0.33 & & 6.48 & 7.69 & 0.72 & 101.37 & 0.30 & 751 & 2 & 260 \\
\hline WH1b_27 & 60.53 & 24.61 & 0.25 & & 6.12 & 7.45 & 0.71 & 99.67 & 0.30 & 748 & 2 & 270 \\
\hline WH1b_28 & 60.24 & 24.52 & 0.19 & & 6.08 & 7.67 & 0.70 & 99.39 & 0.29 & 744 & 2 & 280 \\
\hline WH1b_30 & 59.98 & 24.61 & 0.18 & & 6.52 & 7.48 & 0.68 & 99.44 & 0.31 & 756 & 2 & 300 \\
\hline WH1b_31 & 59.84 & 24.74 & 0.21 & & 6.40 & 7.57 & 0.73 & 99.49 & 0.31 & 751 & 2 & 310 \\
\hline WH1b_33 & 60.59 & 24.28 & 0.21 & & 6.13 & 7.63 & 0.71 & 99.55 & 0.29 & 745 & 2 & 330 \\
\hline WH1b_34 & 60.61 & 24.40 & 0.21 & & 6.50 & 7.39 & 0.73 & 99.84 & 0.31 & 756 & 2 & 340 \\
\hline WH1b_35 & 60.23 & 24.52 & 0.13 & & 6.47 & 7.48 & 0.77 & 99.59 & 0.31 & 753 & 2 & 350 \\
\hline WH1b_36 & 61.06 & 24.25 & 0.17 & & 6.21 & 7.43 & 0.75 & 99.86 & 0.30 & 749 & 2 & 360 \\
\hline WH1b_37 & 60.71 & 24.54 & 0.23 & & 6.52 & 7.59 & 0.70 & 100.29 & 0.31 & 754 & 2 & 370 \\
\hline WH1b_38 & 59.78 & 24.43 & 0.15 & & 6.09 & 7.56 & 0.75 & 98.77 & 0.29 & 744 & 2 & 380 \\
\hline WH1b_39 & 59.12 & 24.61 & 0.17 & & 6.31 & 7.51 & 0.73 & 98.45 & 0.30 & 750 & 2 & 390 \\
\hline WH1b_40 & 59.25 & 24.89 & 0.17 & & 6.61 & 7.67 & 0.72 & 99.31 & 0.31 & 754 & 2 & 400 \\
\hline WH1b 41 & 59.40 & 24.45 & 0.22 & & 6.50 & 7.45 & 0.73 & 98.75 & 0.31 & 755 & 2 & 410 \\
\hline WH1b_42 & 59.68 & 24.50 & 0.20 & & 6.50 & 7.42 & 0.69 & 98.98 & 0.31 & 756 & 2 & 420 \\
\hline WH1b_43 & 59.52 & 24.40 & 0.32 & & 6.25 & 7.50 & 0.64 & 98.64 & 0.30 & 751 & 2 & 430 \\
\hline WH1b_44 & 59.55 & 24.34 & 0.25 & & 6.40 & 7.52 & 0.74 & 98.80 & 0.31 & 751 & 2 & 440 \\
\hline WH1b_45 & 59.97 & 24.37 & 0.16 & & 6.40 & 7.65 & 0.75 & 99.29 & 0.30 & 749 & 2 & 450 \\
\hline WH1b_46 & 59.96 & 24.38 & 0.23 & & 6.36 & 7.50 & 0.78 & 99.20 & 0.30 & 750 & 2 & 460 \\
\hline WH1b_47 & 59.38 & 24.59 & 0.24 & & 6.53 & 7.49 & 0.74 & 98.96 & 0.31 & 755 & 2 & 470 \\
\hline WH1b_48 & 60.00 & 24.68 & 0.19 & & 6.43 & 7.51 & 0.56 & 99.37 & 0.31 & 757 & 2 & 480 \\
\hline WH1b_49 & 59.63 & 24.49 & 0.22 & & 6.40 & 7.25 & 0.72 & 98.71 & 0.31 & 756 & 2 & 490 \\
\hline WH1b_50 & 60.07 & 24.97 & 0.30 & & 6.52 & 7.43 & 0.66 & 99.94 & 0.31 & 757 & 2 & 500 \\
\hline WH1b_51 & 60.19 & 24.81 & 0.17 & & 6.83 & 7.48 & 0.68 & 100.15 & 0.32 & 762 & 2 & 510 \\
\hline WH1b_52 & 60.39 & 24.52 & 0.21 & & 6.29 & 7.32 & 0.67 & 99.41 & 0.31 & 754 & 2 & 520 \\
\hline WH1b_53 & 59.80 & 24.58 & 0.21 & & 6.24 & 7.70 & 0.74 & 99.27 & 0.30 & 746 & 2 & 530 \\
\hline WH1b_55 & 61.09 & 25.82 & 0.21 & & 6.52 & 7.54 & 0.62 & 101.79 & 0.31 & 757 & 2 & 540 \\
\hline WH1b_56 & 60.23 & 25.62 & 0.28 & & 6.53 & 7.65 & 0.73 & 101.03 & 0.31 & 752 & 2 & 550 \\
\hline WH1b_57 & 61.88 & 26.26 & 0.20 & & 6.76 & 5.14 & 0.66 & 100.90 & 0.40 & 796 & 2 & 560 \\
\hline WH1b_58 & 60.57 & 26.18 & 0.30 & & 6.57 & 7.63 & 0.66 & 101.91 & 0.31 & 755 & 2 & 570 \\
\hline WH1b_61 & 61.87 & 25.07 & 0.17 & & 6.41 & 7.52 & 0.65 & 101.70 & 0.31 & 754 & 2 & 600 \\
\hline WH1b_62 & 60.65 & 25.17 & 0.29 & & 6.47 & 7.59 & 0.73 & 100.89 & 0.31 & 752 & 2 & 610 \\
\hline WH1b_63 & 60.40 & 24.98 & 0.14 & & 6.61 & 7.62 & 0.69 & 100.44 & 0.31 & 755 & 2 & 620 \\
\hline WH1b_64 & 60.30 & 25.10 & 0.26 & & 6.28 & 7.76 & 0.77 & 100.46 & 0.30 & 745 & 2 & 630 \\
\hline WH1b_65 & 61.15 & 25.87 & 0.29 & & 6.29 & 7.67 & 0.71 & 101.97 & 0.30 & 748 & 2 & 640 \\
\hline WH1b 68 & 59.56 & 24.62 & 0.16 & & 6.39 & 7.30 & 0.68 & 98.69 & 0.31 & 756 & 2 & 670 \\
\hline WH1b 72 & 61.85 & 25.92 & 0.18 & & 6.51 & 5.01 & 0.69 & 100.15 & 0.40 & 793 & 2 & 680 \\
\hline
\end{tabular}


Table A3.6 continued

\begin{tabular}{|c|c|c|c|c|c|c|c|c|c|c|c|c|}
\hline Sample & $\mathrm{SiO}_{2}$ & $\mathrm{Al}_{2} \mathrm{O}_{3}$ & $\mathrm{FeO}$ & $\mathrm{MgO}$ & $\mathrm{CaO}$ & $\mathrm{Na}_{2} \mathrm{O}$ & $\mathrm{K}_{2} \mathrm{O}$ & Total & XAn & $\begin{array}{c}\mathrm{T} \\
\left({ }^{\circ} \mathrm{C}\right)\end{array}$ & G & $\begin{array}{l}\text { Dist. } \\
(\mu \mathrm{m})\end{array}$ \\
\hline WH1b_76 & 60.62 & 25.71 & 0.26 & & 6.26 & 7.51 & 0.76 & 101.12 & 0.30 & 748 & 2 & 720 \\
\hline WH1b_77 & 60.14 & 26.11 & 0.25 & & 6.40 & 7.29 & 0.72 & 100.90 & 0.31 & 755 & 2 & 730 \\
\hline WH1b_78 & 60.40 & 26.08 & 0.20 & & 6.62 & 7.46 & 0.72 & 101.49 & 0.32 & 757 & 2 & 740 \\
\hline WH1b_79 & 60.52 & 26.07 & 0.19 & & 6.45 & 7.47 & 0.77 & 101.46 & 0.31 & 753 & 2 & 750 \\
\hline WH1b_80 & 60.60 & 25.88 & 0.14 & & 6.34 & 7.44 & 0.82 & 101.21 & 0.30 & 750 & 2 & 760 \\
\hline WH1b_81 & 61.18 & 25.42 & 0.22 & & 6.23 & 7.52 & 0.69 & 101.25 & 0.30 & 749 & 2 & 770 \\
\hline WH1b_85 & 61.08 & 25.50 & 0.26 & & 6.67 & 7.52 & 0.65 & 101.68 & 0.32 & 759 & 2 & 810 \\
\hline WH1b_86 & 60.83 & 25.60 & 0.22 & & 6.39 & 7.71 & 0.72 & 101.47 & 0.30 & 749 & 2 & 820 \\
\hline WH1b_87 & 60.14 & 25.22 & 0.19 & & 6.35 & 7.57 & 0.67 & 100.14 & 0.30 & 751 & 2 & 830 \\
\hline WH1b_89 & 60.40 & 24.97 & 0.25 & & 6.31 & 7.59 & 0.72 & 100.24 & 0.30 & 749 & 2 & 850 \\
\hline WH1b_90 & 61.57 & 24.34 & 0.13 & & 5.60 & 7.86 & 0.77 & 100.27 & 0.27 & 729 & 2 & 860 \\
\hline WH1b_91 & 63.68 & 25.86 & 0.17 & & 5.69 & 4.73 & 0.69 & 100.81 & 0.38 & 784 & 2 & 870 \\
\hline WH1b_92 & 60.97 & 26.14 & 0.18 & & 6.13 & 7.57 & 0.73 & 101.73 & 0.30 & 746 & 2 & 880 \\
\hline WH1b_93 & 61.34 & 25.61 & 0.26 & & 5.86 & 7.85 & 0.77 & 101.69 & 0.28 & 735 & 2 & 890 \\
\hline WH1b_94 & 61.13 & 26.17 & 0.16 & & 6.18 & 7.17 & 0.74 & 101.55 & 0.31 & 752 & 2 & 900 \\
\hline WH1b_95 & 63.65 & 26.52 & 0.25 & & 6.31 & 7.83 & 0.68 & 105.23 & 0.30 & 747 & 2 & 910 \\
\hline WH1b_96 & 62.12 & 25.60 & 0.20 & & 6.29 & 7.33 & 0.69 & 102.23 & 0.31 & 753 & 2 & 920 \\
\hline WH1b_97 & 61.93 & 25.31 & 0.27 & & 5.91 & 7.35 & 0.79 & 101.56 & 0.29 & 743 & 2 & 930 \\
\hline WH1b_98 & 60.04 & 25.78 & 0.11 & & 6.47 & 7.41 & 0.73 & 100.56 & 0.31 & 755 & 2 & 940 \\
\hline WH1b_100 & 60.87 & 25.04 & 0.19 & & 5.97 & 7.87 & 0.74 & 100.67 & 0.28 & 738 & 2 & 950 \\
\hline WH1b_101 & 61.79 & 25.31 & 0.19 & & 6.00 & 7.66 & 0.78 & 101.74 & 0.29 & 740 & 2 & 960 \\
\hline WH1b_102 & 62.03 & 25.19 & 0.23 & & 6.02 & 7.77 & 0.73 & 101.97 & 0.29 & 740 & 2 & 970 \\
\hline WH1b_104 & 60.42 & 24.69 & 0.30 & & 5.63 & 7.42 & 0.77 & 99.23 & 0.28 & 736 & 2 & 990 \\
\hline WH1b_106 & 60.35 & 24.94 & 0.23 & & 6.35 & 7.33 & 0.69 & 99.89 & 0.31 & 755 & 2 & 1010 \\
\hline WH1b_110 & 61.02 & 25.73 & 0.24 & & 6.53 & 7.70 & 0.65 & 101.86 & 0.31 & 754 & 2 & 1050 \\
\hline WH1b_113 & 60.70 & 25.82 & 0.24 & & 6.71 & 7.25 & 0.59 & 101.31 & 0.33 & 765 & 2 & 1080 \\
\hline WH1b_114 & 60.69 & 26.06 & 0.37 & & 6.50 & 7.52 & 0.69 & 101.84 & 0.31 & 755 & 2 & 1090 \\
\hline WH1b_115 & 60.07 & 25.70 & 0.27 & & 6.97 & 7.57 & 0.61 & 101.18 & 0.33 & 765 & 2 & 1100 \\
\hline WH1h_2 & 61.27 & 25.12 & 0.25 & & 6.54 & 7.55 & 0.78 & 101.51 & 0.31 & 756 & 1 & 20 \\
\hline WH1h_4 & 62.03 & 24.71 & 0.31 & & 5.81 & 7.67 & 0.82 & 101.34 & 0.28 & 738 & 1 & 40 \\
\hline WH1h_7 & 61.20 & 25.27 & 0.27 & & 6.15 & 7.75 & 0.73 & 101.38 & 0.29 & 746 & 1 & 70 \\
\hline WH1h_8 & 59.90 & 25.79 & 0.31 & & 6.56 & 7.63 & 0.73 & 100.91 & 0.31 & 756 & 1 & 80 \\
\hline WH1h_10 & 61.49 & 25.31 & 0.35 & & 6.03 & 7.85 & 0.80 & 101.83 & 0.28 & 740 & 1 & 100 \\
\hline WH1h_11 & 61.25 & 25.29 & 0.31 & & 5.94 & 7.51 & 0.77 & 101.07 & 0.29 & 744 & 1 & 110 \\
\hline WH1h_12 & 61.43 & 25.70 & 0.24 & & 5.97 & 7.68 & 0.77 & 101.79 & 0.29 & 742 & 1 & 120 \\
\hline WH1h_13 & 61.25 & 24.74 & 0.21 & & 5.99 & 7.67 & 0.76 & 100.62 & 0.29 & 743 & 1 & 130 \\
\hline WH1h_14 & 60.95 & 25.19 & 0.26 & & 6.26 & 7.65 & 0.76 & 101.06 & 0.30 & 749 & 1 & 140 \\
\hline WH1h_15 & 59.99 & 25.83 & 0.21 & & 6.48 & 7.57 & 0.67 & 100.76 & 0.31 & 757 & 1 & 150 \\
\hline WH1h_16 & 60.33 & 25.81 & 0.29 & & 6.39 & 7.87 & 0.79 & 101.47 & 0.30 & 748 & 1 & 160 \\
\hline WH1h_22 & 58.92 & 25.51 & 0.36 & & 6.97 & 7.19 & 0.60 & 99.55 & 0.34 & 773 & 1 & 220 \\
\hline WH1h_23 & 58.21 & 26.08 & 0.25 & & 7.39 & 7.31 & 0.56 & 99.80 & 0.35 & 780 & 1 & 230 \\
\hline WH1h_24 & 59.01 & 26.14 & 0.21 & & 7.31 & 7.12 & 0.55 & 100.33 & 0.35 & 781 & 1 & 240 \\
\hline WH1h_25 & 59.35 & 26.87 & 0.25 & & 7.43 & 7.31 & 0.53 & 101.73 & 0.35 & 781 & 1 & 250 \\
\hline WH1h_26 & 58.33 & 26.60 & 0.19 & & 7.44 & 7.26 & 0.49 & 100.30 & 0.35 & 783 & 1 & 260 \\
\hline WH1h_27 & 57.23 & 27.65 & 0.23 & & 8.59 & 6.72 & 0.42 & 100.84 & 0.40 & 809 & 1 & 270 \\
\hline WH1h_28 & 55.23 & 29.13 & 0.29 & & 10.14 & 6.00 & 0.34 & 101.14 & 0.47 & 833 & 1 & 280 \\
\hline WH1h_29 & 55.20 & 29.21 & 0.23 & & 9.82 & 6.13 & 0.36 & 100.95 & 0.46 & 829 & 1 & 290 \\
\hline WH1h_30 & 56.09 & 28.23 & 0.14 & & 9.13 & 6.35 & 0.39 & 100.33 & 0.43 & 820 & 1 & 300 \\
\hline WH1h_31 & 56.76 & 28.32 & 0.29 & & 9.41 & 6.06 & 0.37 & 101.21 & 0.45 & 826 & 1 & 310 \\
\hline WH1h_33 & 54.00 & 30.34 & 0.26 & & 11.38 & 4.96 & 0.23 & 101.16 & 0.55 & 849 & 1 & 330 \\
\hline WH1h_34 & 55.81 & 29.00 & 0.23 & & 10.42 & 5.69 & 0.29 & 101.45 & 0.49 & 839 & 1 & 340 \\
\hline WH1h_35 & 55.71 & 29.63 & 0.30 & & 10.70 & 5.35 & 0.29 & 101.97 & 0.52 & 843 & 1 & 350 \\
\hline WH1h_36 & 54.40 & 30.11 & 0.26 & & 11.51 & 5.15 & 0.26 & 101.70 & 0.54 & 848 & 1 & 360 \\
\hline WH1h_37 & 54.15 & 30.02 & 0.27 & & 10.95 & 5.40 & 0.24 & 101.02 & 0.52 & 846 & 1 & 370 \\
\hline WH1h_39 & 53.88 & 29.83 & 0.33 & & 11.32 & 5.18 & 0.27 & 100.82 & 0.54 & 847 & 1 & 390 \\
\hline WH1h_40 & 53.60 & 28.99 & 0.21 & & 11.12 & 5.28 & 0.28 & 99.48 & 0.53 & 846 & 1 & 400 \\
\hline
\end{tabular}


Table A3.6 continued

\begin{tabular}{|c|c|c|c|c|c|c|c|c|c|c|c|c|}
\hline Sample & $\mathrm{SiO}_{2}$ & $\mathrm{Al}_{2} \mathrm{O}_{3}$ & $\mathrm{FeO}$ & $\mathrm{MgO}$ & $\mathrm{CaO}$ & $\mathrm{Na}_{2} \mathrm{O}$ & $\mathrm{K}_{2} \mathrm{O}$ & Total & XAn & $\begin{array}{c}\mathrm{T} \\
\left({ }^{\circ} \mathrm{C}\right)\end{array}$ & G & $\begin{array}{l}\text { Dist. } \\
(\mu \mathrm{m})\end{array}$ \\
\hline WH1h_48 & 54.21 & 28.06 & 0.29 & & 10.03 & 5.60 & 0.30 & 98.49 & 0.49 & 838 & 1 & 480 \\
\hline WH1h_49 & 54.11 & 29.67 & 0.26 & & 10.95 & 5.47 & 0.27 & 100.73 & 0.52 & 844 & 1 & 490 \\
\hline WH1h_53 & 59.11 & 26.94 & 0.31 & & 7.50 & 7.11 & 0.51 & 101.48 & 0.36 & 785 & 1 & 530 \\
\hline WH1h_54 & 60.74 & 26.01 & 0.25 & & 6.65 & 6.99 & 0.66 & 101.30 & 0.33 & 769 & 1 & 540 \\
\hline WH1h_55 & 60.61 & 25.45 & 0.29 & & 6.31 & 7.56 & 0.72 & 100.94 & 0.30 & 752 & 1 & 550 \\
\hline WH1h_56 & 59.71 & 25.95 & 0.21 & & 6.61 & 7.59 & 0.68 & 100.75 & 0.31 & 759 & 1 & 560 \\
\hline WH1h_58 & 60.23 & 25.76 & 0.34 & & 6.44 & 7.92 & 0.68 & 101.36 & 0.30 & 751 & 1 & 580 \\
\hline WH1h_60 & 60.72 & 26.07 & 0.30 & & 6.68 & 7.40 & 0.71 & 101.88 & 0.32 & 762 & 1 & 600 \\
\hline WH1h_61 & 59.96 & 26.32 & 0.22 & & 6.63 & 7.46 & 0.70 & 101.29 & 0.32 & 760 & 1 & 610 \\
\hline WH1h_62 & 60.63 & 25.30 & 0.26 & & 6.13 & 7.55 & 0.72 & 100.59 & 0.30 & 749 & 1 & 620 \\
\hline WH1h_63 & 60.49 & 26.10 & 0.25 & & 6.52 & 7.41 & 0.68 & 101.44 & 0.31 & 759 & 1 & 630 \\
\hline WH1h_64 & 59.77 & 25.80 & 0.31 & & 6.30 & 7.89 & 0.72 & 100.78 & 0.29 & 747 & 1 & 640 \\
\hline WH1h_65 & 60.46 & 25.63 & 0.29 & & 6.27 & 7.44 & 0.69 & 100.78 & 0.31 & 754 & 1 & 650 \\
\hline WH1h_66 & 60.23 & 25.43 & 0.24 & & 6.08 & 7.50 & 0.72 & 100.19 & 0.30 & 748 & 1 & 660 \\
\hline WH2a_2 & 60.94 & 24.51 & 0.25 & & 6.47 & 7.30 & 0.68 & 100.14 & 0.32 & 758 & 2 & 20 \\
\hline WH2a_3 & 61.06 & 24.20 & 0.31 & & 6.30 & 7.44 & 0.72 & 100.02 & 0.31 & 751 & 2 & 30 \\
\hline WH2a_4 & 60.79 & 24.53 & 0.31 & & 6.53 & 7.39 & 0.61 & 100.16 & 0.32 & 759 & 2 & 40 \\
\hline WH2a_5 & 60.29 & 24.56 & 0.27 & & 6.87 & 7.15 & 0.63 & 99.77 & 0.33 & 768 & 2 & 50 \\
\hline WH2a_6 & 59.73 & 24.30 & 0.24 & & 6.60 & 7.09 & 0.65 & 98.60 & 0.33 & 764 & 2 & 60 \\
\hline WH2a_7 & 59.58 & 24.21 & 0.40 & & 7.16 & 6.99 & 0.67 & 99.01 & 0.35 & 775 & 2 & 70 \\
\hline WH2a_8 & 58.60 & 24.87 & 0.32 & & 7.70 & 6.41 & 0.65 & 98.55 & 0.38 & 792 & 2 & 80 \\
\hline WH2a_9 & 58.98 & 24.90 & 0.19 & & 7.75 & 6.76 & 0.49 & 99.07 & 0.38 & 792 & 2 & 90 \\
\hline WH2a_10 & 58.59 & 25.23 & 0.15 & & 7.85 & 6.47 & 0.46 & 98.74 & 0.39 & 799 & 2 & 100 \\
\hline WH2a_11 & 59.46 & 25.27 & 0.20 & & 7.69 & 6.48 & 0.55 & 99.64 & 0.38 & 794 & 2 & 110 \\
\hline WH2a_12 & 60.10 & 24.32 & 0.37 & & 6.51 & 7.06 & 0.67 & 99.02 & 0.32 & 762 & 2 & 120 \\
\hline WH2a_13 & 60.61 & 24.05 & 0.33 & & 6.66 & 7.06 & 0.57 & 99.27 & 0.33 & 768 & 2 & 130 \\
\hline WH2a_14 & 61.04 & 23.73 & 0.32 & & 6.05 & 7.55 & 0.65 & 99.33 & 0.30 & 746 & 2 & 140 \\
\hline WH2a_15 & 59.99 & 23.94 & 0.28 & & 6.43 & 7.29 & 0.62 & 98.56 & 0.32 & 759 & 2 & 150 \\
\hline WH2a_17 & 59.92 & 23.94 & 0.25 & & 6.32 & 7.20 & 0.63 & 98.26 & 0.31 & 758 & 2 & 170 \\
\hline WH2a_18 & 59.47 & 23.90 & 0.36 & & 6.38 & 7.30 & 0.73 & 98.13 & 0.31 & 755 & 2 & 180 \\
\hline WH2a_19 & 59.91 & 24.16 & 0.28 & & 6.88 & 7.21 & 0.66 & 99.10 & 0.33 & 767 & 2 & 190 \\
\hline WH2a_20 & 59.58 & 24.41 & 0.31 & & 6.88 & 7.04 & 0.61 & 98.83 & 0.34 & 771 & 2 & 200 \\
\hline WH2a_21 & 61.58 & 24.41 & 0.26 & & 6.42 & 7.32 & 0.74 & 100.74 & 0.31 & 755 & 2 & 210 \\
\hline WH2a_22 & 61.00 & 25.14 & 0.29 & & 7.12 & 7.19 & 0.64 & 101.37 & 0.34 & 772 & 2 & 220 \\
\hline WH2a_23 & 60.00 & 25.12 & 0.23 & & 7.67 & 6.64 & 0.55 & 100.21 & 0.38 & 791 & 2 & 230 \\
\hline WH2a_25 & 60.26 & 25.06 & 0.24 & & 7.18 & 7.17 & 0.58 & 100.50 & 0.34 & 775 & 2 & 250 \\
\hline WH2a_26 & 61.68 & 23.67 & 0.24 & & 6.34 & 7.50 & 0.69 & 100.12 & 0.31 & 752 & 2 & 260 \\
\hline WH2a_27 & 61.45 & 23.82 & 0.19 & & 6.18 & 7.37 & 0.72 & 99.72 & 0.30 & 750 & 2 & 270 \\
\hline WH2a_28 & 61.69 & 24.14 & 0.21 & & 6.68 & 7.40 & 0.63 & 100.74 & 0.32 & 762 & 2 & 280 \\
\hline WH2a_30 & 61.74 & 24.85 & 0.26 & & 6.70 & 7.38 & 0.66 & 101.57 & 0.32 & 761 & 2 & 300 \\
\hline WH2a_31 & 60.68 & 25.26 & 0.17 & & 7.25 & 6.83 & 0.51 & 100.69 & 0.36 & 783 & 2 & 310 \\
\hline WH2a_32 & 60.77 & 25.20 & 0.19 & & 7.40 & 7.09 & 0.56 & 101.21 & 0.35 & 780 & 2 & 320 \\
\hline WH2a_33 & 60.79 & 24.83 & 0.28 & & 6.83 & 7.08 & 0.65 & 100.46 & 0.33 & 768 & 2 & 330 \\
\hline WH2a_34 & 60.71 & 24.19 & 0.20 & & 6.64 & 7.28 & 0.67 & 99.69 & 0.32 & 761 & 2 & 340 \\
\hline WH2a_35 & 61.59 & 24.60 & 0.23 & & 6.24 & 7.42 & 0.67 & 100.75 & 0.30 & 751 & 2 & 350 \\
\hline WH2a_36 & 60.63 & 24.81 & 0.15 & & 6.30 & 7.39 & 0.69 & 99.97 & 0.31 & 753 & 2 & 360 \\
\hline WH2a_37 & 61.00 & 25.00 & 0.24 & & 6.63 & 7.45 & 0.67 & 100.98 & 0.32 & 759 & 2 & 370 \\
\hline WH2a_38 & 59.96 & 25.19 & 0.22 & & 6.45 & 7.22 & 0.66 & 99.69 & 0.32 & 759 & 2 & 380 \\
\hline WH2a_39 & 60.20 & 24.88 & 0.20 & & 6.75 & 7.53 & 0.66 & 100.22 & 0.32 & 760 & 2 & 390 \\
\hline WH2a_40 & 61.58 & 24.62 & 0.21 & & 6.34 & 7.44 & 0.77 & 100.96 & 0.31 & 751 & 2 & 400 \\
\hline WH2a_41 & 59.89 & 24.48 & 0.24 & & 6.22 & 7.51 & 0.69 & 99.04 & 0.30 & 749 & 2 & 410 \\
\hline WH2a_42 & 59.82 & 25.44 & 0.30 & & 7.29 & 6.87 & 0.58 & 100.30 & 0.36 & 781 & 2 & 420 \\
\hline WH2a_43 & 72.95 & 15.00 & 0.42 & & 1.92 & 3.78 & 4.94 & 99.00 & 0.13 & & 2 & 430 \\
\hline WH2a_44 & 59.00 & 24.28 & 0.33 & & 6.03 & 7.22 & 0.73 & 97.59 & 0.30 & 749 & 2 & 440 \\
\hline WH2a_45 & 60.33 & 24.39 & 0.22 & & 6.17 & 7.59 & 0.78 & 99.48 & 0.30 & 745 & 2 & 450 \\
\hline WH2a_46 & 60.70 & 24.41 & 0.35 & & 5.97 & 7.65 & 0.76 & 99.84 & 0.29 & 740 & 2 & 460 \\
\hline
\end{tabular}


Table A3.6 continued

\begin{tabular}{|c|c|c|c|c|c|c|c|c|c|c|c|c|}
\hline Sample & $\mathrm{SiO}_{2}$ & $\mathrm{Al}_{2} \mathrm{O}_{3}$ & $\mathrm{FeO}$ & $\mathrm{MgO}$ & $\mathrm{CaO}$ & $\mathrm{Na}_{2} \mathrm{O}$ & $\mathrm{K}_{2} \mathrm{O}$ & Total & XAn & $\begin{array}{c}\mathrm{T} \\
\left({ }^{\circ} \mathrm{C}\right)\end{array}$ & G & $\begin{array}{l}\text { Dist. } \\
(\mu \mathrm{m})\end{array}$ \\
\hline WH2a_50 & 60.04 & 25.34 & 0.29 & & 6.96 & 6.96 & 0.52 & 100.12 & 0.35 & 776 & 2 & 500 \\
\hline WH2a_51 & 60.30 & 25.39 & 0.25 & & 6.82 & 7.29 & 0.55 & 100.60 & 0.33 & 768 & 2 & 510 \\
\hline WH2a_52 & 60.11 & 24.74 & 0.18 & & 6.45 & 7.41 & 0.66 & 99.54 & 0.31 & 756 & 2 & 520 \\
\hline WH2a_54 & 60.03 & 25.07 & 0.18 & & 6.41 & 7.40 & 0.65 & 99.74 & 0.31 & 756 & 2 & 540 \\
\hline WH2a_55 & 59.84 & 24.89 & 0.30 & & 6.52 & 7.45 & 0.67 & 99.67 & 0.31 & 757 & 2 & 550 \\
\hline WH2a_56 & 60.04 & 24.86 & 0.28 & & 6.25 & 7.44 & 0.62 & 99.49 & 0.31 & 753 & 2 & 560 \\
\hline WH2a_57 & 60.11 & 24.76 & 0.26 & & 6.38 & 7.34 & 0.66 & 99.51 & 0.31 & 756 & 2 & 570 \\
\hline WH2a_58 & 60.51 & 24.62 & 0.28 & & 5.96 & 7.60 & 0.73 & 99.70 & 0.29 & 741 & 2 & 580 \\
\hline WH2a_59 & 60.87 & 24.36 & 0.28 & & 6.05 & 7.46 & 0.71 & 99.72 & 0.30 & 746 & 2 & 590 \\
\hline WH2a_60 & 60.20 & 24.48 & 0.19 & & 6.37 & 7.32 & 0.68 & 99.23 & 0.31 & 755 & 2 & 600 \\
\hline WH2a_61 & 60.60 & 24.60 & 0.18 & & 6.28 & 7.48 & 0.75 & 99.90 & 0.30 & 749 & 2 & 610 \\
\hline WH2a_62 & 61.14 & 24.72 & 0.24 & & 5.96 & 7.60 & 0.67 & 100.32 & 0.29 & 743 & 2 & 620 \\
\hline WH2a_68 & 59.70 & 25.04 & 0.23 & & 6.46 & 7.34 & 0.62 & 99.39 & 0.32 & 759 & 2 & 680 \\
\hline WH2a_69 & 61.06 & 24.73 & 0.26 & & 6.18 & 7.50 & 0.71 & 100.44 & 0.30 & 748 & 2 & 690 \\
\hline WH2a_70 & 59.52 & 25.13 & 0.31 & & 7.02 & 6.92 & 0.59 & 99.49 & 0.35 & 776 & 2 & 700 \\
\hline WH2a_71 & 59.83 & 25.11 & 0.16 & & 6.81 & 7.06 & 0.57 & 99.54 & 0.34 & 770 & 2 & 710 \\
\hline WH2a_73 & 59.72 & 24.68 & 0.25 & & 6.41 & 7.48 & 0.72 & 99.25 & 0.31 & 753 & 2 & 730 \\
\hline WH2a_74 & 59.84 & 24.84 & 0.28 & & 6.24 & 7.34 & 0.72 & 99.25 & 0.31 & 752 & 2 & 740 \\
\hline WH2a_75 & 57.80 & 23.95 & 0.29 & & 5.98 & 7.12 & 0.72 & 95.85 & 0.30 & 749 & 2 & 750 \\
\hline WH2a_76 & 60.55 & 24.55 & 0.21 & & 6.37 & 7.30 & 0.76 & 99.74 & 0.31 & 754 & 2 & 760 \\
\hline WH2a_77 & 60.57 & 24.71 & 0.18 & & 6.36 & 7.10 & 0.67 & 99.59 & 0.32 & 759 & 2 & 770 \\
\hline WH2a_78 & 60.49 & 25.05 & 0.17 & & 6.74 & 7.08 & 0.68 & 100.21 & 0.33 & 766 & 2 & 780 \\
\hline WH2a_79 & 59.93 & 25.57 & 0.31 & & 6.78 & 7.18 & 0.58 & 100.34 & 0.33 & 768 & 2 & 790 \\
\hline WH2a_80 & 59.34 & 25.09 & 0.19 & & 6.82 & 7.13 & 0.57 & 99.14 & 0.33 & 770 & 2 & 800 \\
\hline WH2a_81 & 59.50 & 25.62 & 0.20 & & 7.07 & 7.05 & 0.57 & 100.01 & 0.34 & 775 & 2 & 810 \\
\hline WH2a_82 & 60.26 & 25.08 & 0.25 & & 6.69 & 7.44 & 0.69 & 100.41 & 0.32 & 759 & 2 & 820 \\
\hline WH2a_83 & 61.12 & 24.88 & 0.21 & & 6.35 & 7.31 & 0.71 & 100.57 & 0.31 & 754 & 2 & 830 \\
\hline WH2a_84 & 61.32 & 24.95 & 0.21 & & 6.64 & 7.41 & 0.72 & 101.25 & 0.32 & 758 & 2 & 840 \\
\hline WH2a_85 & 60.65 & 25.23 & 0.26 & & 6.58 & 7.42 & 0.72 & 100.85 & 0.32 & 757 & 2 & 850 \\
\hline WH2a_87 & 61.61 & 24.91 & 0.19 & & 6.56 & 7.33 & 0.60 & 101.19 & 0.32 & 761 & 2 & 870 \\
\hline WH2a_89 & 60.87 & 24.39 & 0.24 & & 6.05 & 7.66 & 0.79 & 100.01 & 0.29 & 741 & 2 & 890 \\
\hline WH2a_90 & 60.62 & 24.76 & 0.17 & & 6.42 & 7.42 & 0.74 & 100.12 & 0.31 & 753 & 2 & 900 \\
\hline WH2a_91 & 60.38 & 24.90 & 0.19 & & 6.34 & 7.54 & 0.73 & 100.08 & 0.30 & 750 & 2 & 910 \\
\hline WH2a 92 & 60.90 & 25.00 & 0.14 & & 6.03 & 7.46 & 0.64 & 100.17 & 0.30 & 747 & 2 & 920 \\
\hline WH2a_93 & 60.58 & 24.65 & 0.29 & & 5.96 & 7.55 & 0.71 & 99.72 & 0.29 & 743 & 2 & 930 \\
\hline WH2a_94 & 60.92 & 24.48 & 0.24 & & 6.19 & 7.59 & 0.76 & 100.16 & 0.30 & 746 & 2 & 940 \\
\hline WH2a_95 & 61.08 & 24.52 & 0.25 & & 6.17 & 7.57 & 0.76 & 100.35 & 0.30 & 746 & 2 & 950 \\
\hline WH2a_96 & 61.05 & 24.75 & 0.17 & & 6.10 & 7.08 & 0.77 & 99.93 & 0.31 & 751 & 2 & 960 \\
\hline WH2a_97 & 60.89 & 24.84 & 0.27 & & 6.00 & 7.45 & 0.75 & 100.21 & 0.29 & 744 & 2 & 970 \\
\hline WH2a_98 & 61.06 & 24.64 & 0.30 & & 6.09 & 7.56 & 0.74 & 100.38 & 0.30 & 745 & 2 & 980 \\
\hline WH2a_99 & 59.14 & 25.93 & 0.27 & & 7.32 & 6.93 & 0.61 & 100.21 & 0.36 & 780 & 2 & 990 \\
\hline WH2a_100 & 60.17 & 25.13 & 0.25 & & 6.65 & 7.41 & 0.64 & 100.25 & 0.32 & 760 & 2 & 1000 \\
\hline WH2a_101 & 60.90 & 24.86 & 0.21 & & 6.04 & 7.56 & 0.69 & 100.25 & 0.29 & 745 & 2 & 1010 \\
\hline WH2a_102 & 61.01 & 24.61 & 0.20 & & 6.15 & 7.45 & 0.73 & 100.15 & 0.30 & 748 & 2 & 1020 \\
\hline WH2a_103 & 61.42 & 24.68 & 0.30 & & 6.02 & 7.60 & 0.81 & 100.83 & 0.29 & 741 & 2 & 1030 \\
\hline WH2a_104 & 70.01 & 25.40 & 0.22 & & 5.98 & 7.82 & 0.84 & 110.28 & 0.28 & 736 & 2 & 1040 \\
\hline WH2a_112 & 62.26 & 24.95 & 0.22 & & 6.38 & 7.35 & 0.78 & 101.93 & 0.31 & 753 & 2 & 1120 \\
\hline WH2a_116 & 62.95 & 24.75 & 0.17 & & 6.08 & 7.27 & 0.67 & 101.90 & 0.30 & 750 & 2 & 1160 \\
\hline WH2a_119 & 62.26 & 23.95 & 0.12 & & 6.33 & 7.32 & 0.73 & 100.71 & 0.31 & 753 & 2 & 1190 \\
\hline WH2a_124 & 61.77 & 24.74 & 0.18 & & 6.16 & 7.32 & 0.75 & 100.91 & 0.30 & 749 & 2 & 1250 \\
\hline WH2a_125 & 61.40 & 24.91 & 0.24 & & 6.38 & 7.37 & 0.70 & 101.00 & 0.31 & 754 & 2 & 1260 \\
\hline WH2a_126 & 61.07 & 24.91 & 0.25 & & 6.54 & 7.48 & 0.64 & 100.89 & 0.31 & 757 & 2 & 1270 \\
\hline WH2a_127 & 60.52 & 24.99 & 0.31 & & 6.36 & 7.39 & 0.71 & 100.26 & 0.31 & 753 & 2 & 1280 \\
\hline WH2a_130 & 63.46 & 24.01 & 0.25 & & 5.74 & 6.96 & 0.75 & 101.17 & 0.30 & 746 & 2 & 1320 \\
\hline WH2a_140 & 61.52 & 24.69 & 0.37 & & 6.62 & 7.19 & 0.67 & 101.06 & 0.32 & 762 & 2 & 1420 \\
\hline WH2a_141 & 60.42 & 24.15 & 0.27 & & 6.63 & 6.99 & 0.71 & 99.16 & 0.33 & 765 & 2 & 1430 \\
\hline WH2a_145 & 61.13 & 23.51 & 0.35 & & 5.76 & 7.47 & 0.76 & 98.98 & 0.29 & 738 & 2 & 1470 \\
\hline
\end{tabular}


Table A3.6 continued

\begin{tabular}{|c|c|c|c|c|c|c|c|c|c|c|c|c|}
\hline Sample & $\mathrm{SiO}_{2}$ & $\mathrm{Al}_{2} \mathrm{O}_{3}$ & $\mathrm{FeO}$ & $\mathrm{MgO}$ & $\mathrm{CaO}$ & $\mathrm{Na}_{2} \mathrm{O}$ & $\mathrm{K}_{2} \mathrm{O}$ & Total & XAn & $\begin{array}{c}\mathrm{T} \\
\left({ }^{\circ} \mathrm{C}\right)\end{array}$ & G & $\begin{array}{l}\text { Dist. } \\
(\mu \mathrm{m})\end{array}$ \\
\hline WH2b_4 & 61.43 & 25.04 & 0.31 & & 6.91 & 7.41 & 0.72 & 101.83 & 0.33 & 763 & 1 & 40 \\
\hline WH2b_5 & 61.91 & 25.00 & 0.23 & & 6.51 & 7.50 & 0.68 & 101.82 & 0.31 & 755 & 1 & 50 \\
\hline WH2b_6 & 61.69 & 25.15 & 0.24 & & 6.74 & 7.43 & 0.68 & 101.93 & 0.32 & 761 & 1 & 60 \\
\hline WH2b_7 & 61.63 & 25.22 & 0.15 & & 6.62 & 7.36 & 0.59 & 101.57 & 0.32 & 762 & 1 & 70 \\
\hline WH2b_8 & 61.68 & 24.80 & 0.24 & & 6.26 & 7.50 & 0.74 & 101.21 & 0.30 & 749 & 1 & 80 \\
\hline WH2b_9 & 60.88 & 25.53 & 0.23 & & 6.59 & 7.37 & 0.68 & 101.27 & 0.32 & 759 & 1 & 90 \\
\hline WH2b_10 & 60.44 & 25.22 & 0.27 & & 6.73 & 7.37 & 0.67 & 100.70 & 0.32 & 762 & 1 & 100 \\
\hline WH2b_11 & 60.40 & 24.62 & 0.26 & & 6.42 & 7.42 & 0.61 & 99.72 & 0.31 & 757 & 1 & 110 \\
\hline WH2b_12 & 60.81 & 24.91 & 0.25 & & 6.58 & 7.65 & 0.61 & 100.81 & 0.31 & 756 & 1 & 120 \\
\hline WH2b_13 & 61.37 & 24.61 & 0.33 & & 6.23 & 7.38 & 0.69 & 100.61 & 0.31 & 751 & 1 & 130 \\
\hline WH2b_14 & 60.77 & 24.20 & 0.24 & & 6.42 & 7.26 & 0.70 & 99.58 & 0.31 & 757 & 1 & 140 \\
\hline WH2b_15 & 61.19 & 24.47 & 0.26 & & 6.35 & 7.37 & 0.76 & 100.39 & 0.31 & 752 & 1 & 150 \\
\hline WH2b_17 & 61.60 & 24.92 & 0.20 & & 6.67 & 7.41 & 0.70 & 101.49 & 0.32 & 759 & 1 & 170 \\
\hline WH2b_18 & 60.86 & 25.09 & 0.21 & & 6.58 & 7.75 & 0.66 & 101.14 & 0.31 & 754 & 1 & 180 \\
\hline WH2b_19 & 61.08 & 25.14 & 0.24 & & 6.76 & 7.60 & 0.68 & 101.50 & 0.32 & 759 & 1 & 190 \\
\hline WH2b_20 & 60.68 & 24.66 & 0.29 & & 6.68 & 7.74 & 0.72 & 100.76 & 0.31 & 754 & 1 & 200 \\
\hline WH2b_21 & 61.61 & 24.47 & 0.26 & & 6.35 & 7.48 & 0.66 & 100.83 & 0.31 & 753 & 1 & 210 \\
\hline WH2b_23 & 62.54 & 24.65 & 0.20 & & 5.96 & 7.63 & 0.73 & 101.71 & 0.29 & 741 & 1 & 230 \\
\hline WH2b_26 & 62.86 & 24.15 & 0.25 & & 5.71 & 7.81 & 0.88 & 101.67 & 0.27 & 730 & 1 & 260 \\
\hline WH2b_27 & 62.37 & 23.88 & 0.16 & & 5.31 & 7.91 & 0.89 & 100.51 & 0.26 & 718 & 1 & 270 \\
\hline WH2b_28 & 61.36 & 24.60 & 0.24 & & 6.37 & 7.69 & 0.75 & 101.01 & 0.30 & 748 & 1 & 280 \\
\hline WH2b_29 & 61.84 & 24.63 & 0.30 & & 6.53 & 7.66 & 0.73 & 101.68 & 0.31 & 752 & 1 & 290 \\
\hline WH2b_30 & 61.62 & 24.53 & 0.25 & & 6.40 & 7.60 & 0.76 & 101.16 & 0.30 & 750 & 1 & 300 \\
\hline WH2b_33 & 62.00 & 25.08 & 0.21 & & 6.56 & 7.36 & 0.69 & 101.90 & 0.32 & 758 & 1 & 330 \\
\hline WH2b_36 & 60.85 & 25.30 & 0.30 & & 6.86 & 7.51 & 0.65 & 101.48 & 0.32 & 763 & 1 & 360 \\
\hline WH2b_37 & 60.79 & 25.17 & 0.13 & & 6.82 & 7.42 & 0.67 & 100.99 & 0.32 & 763 & 1 & 370 \\
\hline WH2b_38 & 60.79 & 25.17 & 0.13 & & 6.82 & 7.42 & 0.67 & 100.99 & 0.32 & 763 & 1 & 380 \\
\hline WH2b_39 & 60.25 & 25.50 & 0.28 & & 7.53 & 7.22 & 0.58 & 101.35 & 0.35 & 780 & 1 & 390 \\
\hline WH2b_40 & 59.56 & 25.49 & 0.23 & & 7.08 & 7.32 & 0.57 & 100.24 & 0.34 & 771 & 1 & 400 \\
\hline WH2b_41 & 59.15 & 25.52 & 0.24 & & 7.21 & 7.23 & 0.61 & 99.95 & 0.34 & 774 & 1 & 410 \\
\hline WH2b_42 & 60.29 & 25.20 & 0.27 & & 7.17 & 7.35 & 0.61 & 100.90 & 0.34 & 771 & 1 & 420 \\
\hline WH2b_43 & 60.41 & 25.02 & 0.17 & & 7.08 & 7.15 & 0.60 & 100.44 & 0.34 & 773 & 1 & 430 \\
\hline WH2b_44 & 60.69 & 25.51 & 0.22 & & 6.97 & 7.35 & 0.67 & 101.40 & 0.33 & 767 & 1 & 440 \\
\hline WH2b_45 & 60.85 & 25.13 & 0.26 & & 6.92 & 7.34 & 0.66 & 101.16 & 0.33 & 766 & 1 & 450 \\
\hline WH2b_46 & 60.34 & 25.44 & 0.26 & & 7.50 & 7.08 & 0.62 & 101.24 & 0.36 & 780 & 1 & 460 \\
\hline WH2b_47 & 60.20 & 25.95 & 0.26 & & 7.53 & 7.06 & 0.51 & 101.50 & 0.36 & 784 & 1 & 470 \\
\hline WH2b_48 & 59.36 & 26.00 & 0.24 & & 7.69 & 6.97 & 0.60 & 100.86 & 0.37 & 785 & 1 & 480 \\
\hline WH2b_49 & 60.16 & 25.68 & 0.19 & & 7.28 & 7.39 & 0.56 & 101.26 & 0.34 & 774 & 1 & 490 \\
\hline WH2b_51 & 59.06 & 25.48 & 0.24 & & 7.30 & 7.41 & 0.61 & 100.10 & 0.34 & 773 & 1 & 510 \\
\hline WH2b_52 & 59.68 & 25.49 & 0.20 & & 7.33 & 7.33 & 0.64 & 100.66 & 0.34 & 774 & 1 & 520 \\
\hline WH2b_53 & 58.10 & 25.29 & 0.18 & & 7.66 & 7.12 & 0.54 & 98.89 & 0.36 & 785 & 1 & 530 \\
\hline WH2b_54 & 58.94 & 25.83 & 0.24 & & 7.76 & 6.80 & 0.53 & 100.10 & 0.38 & 791 & 1 & 540 \\
\hline WH2b_55 & 59.58 & 25.85 & 0.24 & & 7.89 & 6.89 & 0.56 & 101.00 & 0.38 & 790 & 1 & 550 \\
\hline WH2b_56 & 60.19 & 26.53 & 0.18 & & 7.78 & 6.69 & 0.56 & 101.93 & 0.38 & 792 & 1 & 560 \\
\hline WH2b_57 & 59.12 & 26.67 & 0.19 & & 7.69 & 6.81 & 0.56 & 101.04 & 0.37 & 789 & 1 & 570 \\
\hline WH2b_59 & 59.25 & 26.72 & 0.22 & & 7.63 & 6.71 & 0.49 & 101.02 & 0.37 & 791 & 1 & 590 \\
\hline WH2b_60 & 59.09 & 26.87 & 0.20 & & 7.97 & 6.70 & 0.48 & 101.30 & 0.39 & 796 & 1 & 600 \\
\hline WH2b_61 & 58.68 & 27.07 & 0.23 & & 8.05 & 6.64 & 0.46 & 101.14 & 0.39 & 799 & 1 & 610 \\
\hline WH2b_62 & 57.76 & 27.07 & 0.28 & & 8.50 & 6.28 & 0.46 & 100.34 & 0.42 & 809 & 1 & 620 \\
\hline WH2b_63 & 57.58 & 27.17 & 0.21 & & 8.46 & 6.54 & 0.42 & 100.38 & 0.41 & 807 & 1 & 630 \\
\hline WH2b_64 & 57.70 & 26.91 & 0.21 & & 8.46 & 6.51 & 0.41 & 100.20 & 0.41 & 807 & 1 & 640 \\
\hline WH2b_65 & 58.04 & 27.11 & 0.22 & & 8.89 & 6.24 & 0.49 & 100.97 & 0.43 & 813 & 1 & 650 \\
\hline WH2b_66 & 57.33 & 27.17 & 0.18 & & 8.99 & 6.29 & 0.40 & 100.35 & 0.43 & 816 & 1 & 660 \\
\hline WH2b_67 & 57.38 & 27.36 & 0.17 & & 8.69 & 6.28 & 0.47 & 100.34 & 0.42 & 811 & 1 & 670 \\
\hline WH2b_68 & 56.98 & 27.04 & 0.17 & & 8.78 & 6.43 & 0.42 & 99.82 & 0.42 & 812 & 1 & 680 \\
\hline WH2b_69 & 58.81 & 26.59 & 0.25 & & 7.76 & 6.85 & 0.58 & 100.84 & 0.37 & 788 & 1 & 690 \\
\hline WH2b_70 & 58.56 & 26.74 & 0.18 & & 8.04 & 6.66 & 0.45 & 100.62 & 0.39 & 799 & 1 & 700 \\
\hline
\end{tabular}


Table A3.6 continued

\begin{tabular}{|c|c|c|c|c|c|c|c|c|c|c|c|c|}
\hline Sample & $\mathrm{SiO}_{2}$ & $\mathrm{Al}_{2} \mathrm{O}_{3}$ & $\mathrm{FeO}$ & $\mathrm{MgO}$ & $\mathrm{CaO}$ & $\mathrm{Na}_{2} \mathrm{O}$ & $\mathrm{K}_{2} \mathrm{O}$ & Total & XAn & $\begin{array}{c}\mathrm{T} \\
\left({ }^{\circ} \mathrm{C}\right)\end{array}$ & G & $\begin{array}{l}\text { Dist. } \\
(\mu \mathrm{m})\end{array}$ \\
\hline WH2b_75 & 57.21 & 27.40 & 0.24 & & 9.10 & 6.23 & 0.45 & 100.63 & 0.44 & 816 & 1 & 750 \\
\hline WH2b_76 & 56.87 & 27.53 & 0.23 & & 9.00 & 6.07 & 0.40 & 100.10 & 0.44 & 819 & 1 & 760 \\
\hline WH2b_77 & 57.44 & 27.07 & 0.21 & & 8.48 & 6.53 & 0.42 & 100.14 & 0.41 & 807 & 1 & 770 \\
\hline WH2b_78 & 57.24 & 27.27 & 0.27 & & 8.74 & 6.21 & 0.46 & 100.18 & 0.43 & 813 & 1 & 780 \\
\hline WH2b_79 & 57.13 & 26.99 & 0.34 & & 8.46 & 6.31 & 0.46 & 99.70 & 0.41 & 808 & 1 & 790 \\
\hline WH2b_80 & 57.98 & 27.02 & 0.28 & & 8.49 & 6.44 & 0.41 & 100.62 & 0.41 & 809 & 1 & 800 \\
\hline WH2b_81 & 57.27 & 27.57 & 0.18 & & 8.93 & 6.22 & 0.41 & 100.57 & 0.43 & 816 & 1 & 810 \\
\hline WH2b_82 & 57.37 & 27.23 & 0.25 & & 8.52 & 6.35 & 0.42 & 100.14 & 0.42 & 810 & 1 & 820 \\
\hline WH2b_83 & 57.03 & 27.80 & 0.18 & & 9.03 & 6.04 & 0.44 & 100.52 & 0.44 & 818 & 1 & 830 \\
\hline WH2b_84 & 57.09 & 27.72 & 0.26 & & 8.92 & 6.20 & 0.41 & 100.60 & 0.43 & 816 & 1 & 840 \\
\hline WH2b_85 & 55.89 & 28.28 & 0.23 & & 9.55 & 5.74 & 0.38 & 100.07 & 0.47 & 828 & 1 & 850 \\
\hline WH2b_86 & 56.46 & 27.60 & 0.35 & & 9.13 & 6.20 & 0.39 & 100.13 & 0.44 & 819 & 1 & 860 \\
\hline WH2b_87 & 56.02 & 27.54 & 0.26 & & 9.09 & 6.12 & 0.39 & 99.42 & 0.44 & 819 & 1 & 870 \\
\hline WH2b_88 & 55.03 & 28.64 & 0.20 & & 10.14 & 5.52 & 0.31 & 99.84 & 0.49 & 836 & 1 & 880 \\
\hline WH2b_89 & 56.02 & 28.17 & 0.19 & & 9.66 & 5.66 & 0.39 & 100.09 & 0.47 & 829 & 1 & 890 \\
\hline WH2b_91 & 56.31 & 28.56 & 0.24 & & 10.10 & 5.65 & 0.37 & 101.22 & 0.49 & 832 & 1 & 910 \\
\hline WH2b_92 & 58.04 & 27.70 & 0.19 & & 8.78 & 6.32 & 0.45 & 101.48 & 0.42 & 812 & 1 & 920 \\
\hline WH2b_93 & 59.80 & 25.92 & 0.26 & & 6.93 & 7.14 & 0.71 & 100.76 & 0.33 & 768 & 1 & 930 \\
\hline WH2b_96 & 56.84 & 28.04 & 0.18 & & 9.70 & 6.10 & 0.37 & 101.24 & 0.46 & 825 & 1 & 960 \\
\hline WH2b_97 & 57.88 & 27.80 & 0.26 & & 9.54 & 5.88 & 0.36 & 101.72 & 0.46 & 827 & 1 & 970 \\
\hline WH2b_100 & 56.68 & 27.91 & 0.30 & & 9.54 & 5.88 & 0.40 & 100.72 & 0.46 & 825 & 1 & 1000 \\
\hline WH2b_101 & 57.43 & 27.26 & 0.16 & & 9.05 & 6.35 & 0.45 & 100.69 & 0.43 & 814 & 1 & 1010 \\
\hline WH2b_103 & 58.11 & 27.37 & 0.29 & & 8.94 & 6.28 & 0.40 & 101.39 & 0.43 & 816 & 1 & 1030 \\
\hline WH2b_104 & 58.71 & 27.18 & 0.20 & & 8.43 & 6.73 & 0.51 & 101.76 & 0.40 & 801 & 1 & 1040 \\
\hline WH2b_105 & 59.45 & 26.87 & 0.28 & & 8.11 & 6.57 & 0.47 & 101.75 & 0.39 & 800 & 1 & 1050 \\
\hline WH2b_110 & 56.96 & 26.49 & 0.24 & & 8.74 & 6.09 & 0.47 & 98.99 & 0.43 & 814 & 1 & 1100 \\
\hline WH2b_111 & 58.26 & 26.72 & 0.18 & & 8.36 & 6.73 & 0.51 & 100.76 & 0.40 & 800 & 1 & 1110 \\
\hline WH2b_112 & 58.69 & 26.43 & 0.23 & & 7.92 & 6.86 & 0.56 & 100.70 & 0.38 & 791 & 1 & 1120 \\
\hline WH2b_113 & 59.23 & 26.26 & 0.24 & & 7.42 & 6.97 & 0.58 & 100.70 & 0.36 & 782 & 1 & 1130 \\
\hline WH2b_114 & 58.91 & 26.16 & 0.23 & & 7.32 & 7.13 & 0.58 & 100.32 & 0.35 & 778 & 1 & 1140 \\
\hline WH2b_115 & 59.60 & 26.01 & 0.21 & & 7.19 & 7.06 & 0.59 & 100.66 & 0.35 & 776 & 1 & 1150 \\
\hline WH2b_116 & 60.69 & 25.44 & 0.19 & & 6.65 & 7.37 & 0.68 & 101.02 & 0.32 & 760 & 1 & 1160 \\
\hline WH2b_117 & 61.35 & 25.05 & 0.22 & & 6.43 & 7.41 & 0.65 & 101.10 & 0.31 & 756 & 1 & 1170 \\
\hline WH2b 118 & 60.48 & 25.22 & 0.17 & & 6.59 & 7.27 & 0.65 & 100.38 & 0.32 & 761 & 1 & 1180 \\
\hline WH2b_119 & 60.89 & 24.74 & 0.28 & & 5.92 & 7.53 & 0.78 & 100.13 & 0.29 & 741 & 1 & 1190 \\
\hline WH2b_120 & 59.79 & 25.73 & 0.24 & & 7.23 & 7.20 & 0.58 & 100.77 & 0.34 & 775 & 1 & 1200 \\
\hline WH2b_121 & 59.91 & 25.81 & 0.21 & & 6.82 & 7.27 & 0.64 & 100.66 & 0.33 & 766 & 1 & 1210 \\
\hline WH2b_122 & 60.66 & 24.88 & 0.19 & & 6.06 & 7.65 & 0.70 & 100.14 & 0.29 & 744 & 1 & 1220 \\
\hline WH2b_123 & 60.06 & 24.76 & 0.20 & & 6.17 & 7.51 & 0.82 & 99.52 & 0.30 & 745 & 1 & 1230 \\
\hline WH2b_124 & 61.33 & 24.75 & 0.23 & & 5.89 & 7.76 & 0.83 & 100.79 & 0.28 & 735 & 1 & 1240 \\
\hline WH2b_126 & 60.55 & 25.01 & 0.23 & & 6.17 & 7.42 & 0.66 & 100.04 & 0.30 & 750 & 1 & 1260 \\
\hline WH2b_127 & 59.70 & 25.13 & 0.22 & & 6.59 & 7.33 & 0.72 & 99.69 & 0.32 & 759 & 1 & 1270 \\
\hline WH2b_128 & 59.87 & 25.29 & 0.31 & & 6.39 & 7.28 & 0.73 & 99.87 & 0.31 & 755 & 1 & 1280 \\
\hline WH2b_129 & 60.74 & 25.03 & 0.23 & & 6.25 & 7.48 & 0.71 & 100.43 & 0.30 & 750 & 1 & 1290 \\
\hline WH2b_130 & 60.38 & 25.23 & 0.23 & & 6.50 & 7.43 & 0.75 & 100.51 & 0.31 & 755 & 1 & 1300 \\
\hline WH2b_131 & 60.16 & 25.47 & 0.26 & & 6.74 & 7.32 & 0.66 & 100.60 & 0.32 & 763 & 1 & 1310 \\
\hline WH2b_132 & 60.22 & 25.49 & 0.30 & & 6.60 & 7.22 & 0.71 & 100.54 & 0.32 & 760 & 1 & 1320 \\
\hline WH2b_133 & 60.46 & 25.10 & 0.15 & & 6.40 & 7.40 & 0.72 & 100.22 & 0.31 & 754 & 1 & 1330 \\
\hline WH2b_135 & 61.29 & 25.54 & 0.24 & & 6.69 & 7.41 & 0.78 & 101.95 & 0.32 & 758 & 1 & 1350 \\
\hline WH2b_136 & 60.31 & 25.66 & 0.27 & & 6.78 & 7.47 & 0.71 & 101.20 & 0.32 & 760 & 1 & 1360 \\
\hline WH2d_1 & 58.74 & 25.04 & & & 6.50 & 7.03 & 0.64 & 97.95 & 0.33 & 763 & 1 & 20 \\
\hline WH $2 \mathrm{~d}$-2 & 58.32 & 25.05 & & & 6.55 & 7.06 & 0.65 & 97.64 & 0.33 & 763 & 1 & 30 \\
\hline WH2d_3 & 57.24 & 25.37 & & & 7.10 & 6.83 & 0.54 & 97.07 & 0.35 & 780 & 1 & 40 \\
\hline WH2d_5 & 58.42 & 25.00 & & & 6.35 & 7.19 & 0.60 & 97.55 & 0.32 & 759 & 1 & 60 \\
\hline WH2d_6 & 58.54 & 24.96 & & & 6.25 & 7.25 & 0.64 & 97.63 & 0.31 & 755 & 1 & 70 \\
\hline WH2d_7 & 58.70 & 24.73 & & & 6.65 & 6.94 & 0.68 & 97.69 & 0.33 & 766 & 1 & 80 \\
\hline
\end{tabular}


Table A3.6 continued

\begin{tabular}{|c|c|c|c|c|c|c|c|c|c|c|c|c|}
\hline Sample & $\mathrm{SiO}_{2}$ & $\mathrm{Al}_{2} \mathrm{O}_{3}$ & $\mathrm{FeO}$ & $\mathrm{MgO}$ & $\mathrm{CaO}$ & $\mathrm{Na}_{2} \mathrm{O}$ & $\mathrm{K}_{2} \mathrm{O}$ & Total & XAn & $\begin{array}{c}\mathrm{T} \\
\left({ }^{\circ} \mathrm{C}\right)\end{array}$ & G & $\begin{array}{l}\text { Dist. } \\
(\mu \mathrm{m})\end{array}$ \\
\hline WH2d_11 & 58.79 & 24.70 & & & 6.15 & 7.67 & 0.77 & 98.09 & 0.29 & 744 & 1 & 120 \\
\hline WH2d_12 & 58.70 & 24.91 & & & 6.25 & 7.20 & 0.67 & 97.73 & 0.31 & 755 & 1 & 130 \\
\hline WH2d_13 & 59.19 & 24.68 & & & 6.35 & 7.23 & 0.77 & 98.23 & 0.31 & 754 & 1 & 140 \\
\hline WH2d_14 & 59.34 & 25.01 & & & 6.05 & 7.37 & 0.64 & 98.41 & 0.30 & 749 & 1 & 150 \\
\hline WH2d_15 & 59.10 & 24.96 & & & 6.28 & 7.21 & 0.66 & 98.20 & 0.31 & 756 & 1 & 160 \\
\hline WH2d_16 & 59.01 & 24.84 & & & 6.37 & 7.24 & 0.74 & 98.20 & 0.31 & 755 & 1 & 170 \\
\hline WH2d_17 & 58.09 & 25.52 & & & 6.61 & 7.20 & 0.56 & 97.98 & 0.33 & 765 & 1 & 180 \\
\hline WH2d_18 & 58.08 & 24.90 & & & 6.53 & 7.41 & 0.72 & 97.63 & 0.31 & 756 & 1 & 190 \\
\hline WH2d_19 & 58.01 & 25.01 & & & 6.47 & 7.13 & 0.66 & 97.28 & 0.32 & 761 & 1 & 200 \\
\hline WH2d_20 & 58.60 & 24.84 & & & 6.45 & 7.30 & 0.70 & 97.88 & 0.31 & 757 & 1 & 210 \\
\hline WH2d_21 & 61.43 & 25.46 & 0.34 & & 6.79 & 7.12 & 0.61 & 101.75 & 0.33 & 768 & 1 & 220 \\
\hline WH2d_22 & 60.10 & 25.01 & 0.18 & & 6.32 & 7.50 & 0.71 & 99.82 & 0.30 & 751 & 1 & 230 \\
\hline WH2d_23 & 60.65 & 24.82 & 0.19 & & 5.74 & 7.65 & 0.78 & 99.83 & 0.28 & 735 & 1 & 240 \\
\hline WH2d_24 & 60.09 & 25.24 & 0.27 & & 6.19 & 7.51 & 0.74 & 100.03 & 0.30 & 747 & 1 & 250 \\
\hline WH2d_25 & 60.21 & 25.01 & 0.20 & & 6.25 & 7.41 & 0.72 & 99.79 & 0.30 & 751 & 1 & 260 \\
\hline WH2d_26 & 59.94 & 24.98 & 0.25 & & 6.44 & 7.62 & 0.67 & 99.89 & 0.31 & 753 & 1 & 270 \\
\hline WH2d_27 & 59.54 & 25.68 & 0.25 & & 7.05 & 6.98 & 0.55 & 100.04 & 0.35 & 776 & 1 & 280 \\
\hline WH2d_28 & 53.99 & 29.72 & 0.28 & & 11.68 & 4.80 & 0.26 & 100.73 & 0.57 & 846 & 1 & 290 \\
\hline WH2d_29 & 53.69 & 29.70 & 0.18 & & 11.77 & 4.98 & 0.23 & 100.55 & 0.56 & 847 & 1 & 300 \\
\hline WH2d_30 & 54.07 & 29.65 & 0.25 & & 11.51 & 4.91 & 0.22 & 100.62 & 0.56 & 847 & 1 & 310 \\
\hline WH2d_31 & 53.28 & 29.82 & 0.21 & & 11.47 & 4.73 & 0.29 & 99.81 & 0.56 & 845 & 1 & 320 \\
\hline WH2d_32 & 54.73 & 29.27 & 0.20 & & 10.70 & 5.09 & 0.28 & 100.27 & 0.53 & 842 & 1 & 330 \\
\hline WH2d_33 & 52.07 & 30.64 & 0.26 & & 12.46 & 4.28 & 0.20 & 99.92 & 0.61 & 848 & 1 & 340 \\
\hline WH2d_34 & 55.48 & 28.70 & 0.26 & & 10.30 & 5.45 & 0.34 & 100.52 & 0.50 & 836 & 1 & 350 \\
\hline WH2d_36 & 59.28 & 26.06 & 0.19 & & 7.48 & 7.05 & 0.57 & 100.62 & 0.36 & 782 & 1 & 370 \\
\hline WH2d_38 & 57.67 & 25.16 & 0.53 & & 6.38 & 6.96 & 0.47 & 97.17 & 0.33 & 767 & 1 & 390 \\
\hline WH2d_39 & 55.48 & 27.43 & 0.26 & & 9.13 & 5.79 & 0.37 & 98.47 & 0.46 & 824 & 1 & 400 \\
\hline WH2d_44 & 58.57 & 26.23 & 0.25 & & 7.33 & 6.84 & 0.49 & 99.70 & 0.36 & 785 & 1 & 450 \\
\hline WH2d_45 & 60.09 & 25.30 & 0.31 & & 6.60 & 7.45 & 0.66 & 100.40 & 0.32 & 758 & 1 & 460 \\
\hline WH2d_46 & 58.52 & 24.84 & 0.35 & & 6.28 & 7.26 & 0.63 & 97.87 & 0.31 & 756 & 1 & 470 \\
\hline WH2d_47 & 60.18 & 25.48 & 0.26 & & 6.55 & 7.38 & 0.70 & 100.56 & 0.32 & 758 & 1 & 480 \\
\hline WH2d_48 & 60.55 & 25.28 & 0.26 & & 6.55 & 7.19 & 0.72 & 100.54 & 0.32 & 760 & 1 & 490 \\
\hline WH2d_49 & 58.33 & 26.05 & 0.24 & & 7.58 & 6.79 & 0.53 & 99.51 & 0.37 & 788 & 1 & 500 \\
\hline WH2d 50 & 55.44 & 28.53 & 0.24 & & 10.87 & 4.93 & 0.28 & 100.29 & 0.54 & 844 & 1 & 510 \\
\hline WH2d_52 & 59.29 & 26.02 & 0.28 & & 6.94 & 7.07 & 0.58 & 100.18 & 0.34 & 773 & 1 & 530 \\
\hline WH2d_53 & 58.73 & 26.66 & 0.22 & & 7.79 & 6.79 & 0.51 & 100.70 & 0.38 & 792 & 1 & 540 \\
\hline WH2d_54 & 56.05 & 27.82 & 0.24 & & 9.55 & 5.94 & 0.33 & 99.93 & 0.46 & 827 & 1 & 550 \\
\hline WH2d_55 & 53.99 & 29.96 & 0.21 & & 11.43 & 4.74 & 0.27 & 100.59 & 0.56 & 846 & 1 & 560 \\
\hline WH2d_56 & 54.03 & 29.67 & 0.23 & & 11.32 & 4.94 & 0.28 & 100.46 & 0.55 & 845 & 1 & 570 \\
\hline WH2d_57 & 53.62 & 29.92 & 0.22 & & 11.89 & 4.80 & 0.24 & 100.69 & 0.57 & 847 & 1 & 580 \\
\hline WH2d_58 & 54.46 & 29.32 & 0.26 & & 10.75 & 5.27 & 0.27 & 100.32 & 0.52 & 842 & 1 & 590 \\
\hline WH2d_59 & 60.77 & 24.92 & 0.24 & & 5.87 & 7.63 & 0.71 & 100.14 & 0.29 & 740 & 1 & 600 \\
\hline WH2d_60 & 59.91 & 24.89 & 0.22 & & 6.31 & 7.47 & 0.72 & 99.52 & 0.30 & 751 & 1 & 610 \\
\hline WH2d_61 & 60.25 & 25.28 & 0.26 & & 6.35 & 7.34 & 0.60 & 100.08 & 0.31 & 757 & 1 & 620 \\
\hline WH2d_62 & 59.04 & 25.76 & 0.21 & & 7.11 & 6.72 & 0.60 & 99.43 & 0.36 & 780 & 1 & 630 \\
\hline WH2d_63 & 60.53 & 25.49 & 0.28 & & 6.86 & 7.26 & 0.56 & 100.98 & 0.33 & 769 & 1 & 640 \\
\hline WH2d_64 & 60.66 & 25.40 & 0.22 & & 6.64 & 7.51 & 0.69 & 101.12 & 0.32 & 757 & 1 & 650 \\
\hline WH2d_65 & 61.08 & 25.02 & 0.28 & & 6.31 & 7.10 & 0.71 & 100.50 & 0.32 & 757 & 1 & 660 \\
\hline WH2d_66 & 60.55 & 25.32 & 0.20 & & 6.41 & 7.25 & 0.64 & 100.36 & 0.32 & 758 & 1 & 670 \\
\hline WH2d_67 & 60.71 & 25.05 & 0.29 & & 6.24 & 7.43 & 0.73 & 100.45 & 0.30 & 750 & 1 & 680 \\
\hline WH2d_69 & 61.17 & 25.33 & 0.29 & & 6.52 & 7.23 & 0.73 & 101.27 & 0.32 & 758 & 1 & 700 \\
\hline WH2d_70 & 61.69 & 25.42 & 0.28 & & 6.51 & 7.21 & 0.63 & 101.74 & 0.32 & 761 & 1 & 710 \\
\hline WH2d_71 & 60.52 & 25.40 & 0.23 & & 6.46 & 7.19 & 0.65 & 100.45 & 0.32 & 760 & 1 & 720 \\
\hline WH2d_72 & 59.97 & 25.04 & 0.31 & & 6.41 & 7.41 & 0.69 & 99.82 & 0.31 & 755 & 1 & 730 \\
\hline WH2d_73 & 59.66 & 25.09 & 0.30 & & 6.48 & 7.36 & 0.68 & 99.57 & 0.31 & 757 & 1 & 740 \\
\hline WH2d_74 & 59.25 & 25.19 & 0.20 & & 6.70 & 7.21 & 0.70 & 99.24 & 0.33 & 763 & 1 & 750 \\
\hline WH2d_75 & 59.77 & 25.51 & 0.27 & & 6.13 & 7.39 & 0.62 & 99.68 & 0.30 & 751 & 1 & 760 \\
\hline
\end{tabular}


Table A3.6 continued

\begin{tabular}{|c|c|c|c|c|c|c|c|c|c|c|c|c|}
\hline Sample & $\mathrm{SiO}_{2}$ & $\mathrm{Al}_{2} \mathrm{O}_{3}$ & $\mathrm{FeO}$ & $\mathrm{MgO}$ & $\mathrm{CaO}$ & $\mathrm{Na}_{2} \mathrm{O}$ & $\mathrm{K}_{2} \mathrm{O}$ & Total & XAn & $\begin{array}{c}\mathrm{T} \\
\left({ }^{\circ} \mathrm{C}\right) \\
\end{array}$ & G & $\begin{array}{l}\text { Dist. } \\
(\mu \mathrm{m})\end{array}$ \\
\hline WH2d_80 & 59.81 & 25.51 & 0.24 & & 6.68 & 7.32 & 0.75 & 100.30 & 0.32 & 760 & 1 & 810 \\
\hline WH2d_81 & 59.65 & 25.45 & 0.25 & & 6.77 & 7.29 & 0.68 & 100.08 & 0.33 & 763 & 1 & 820 \\
\hline WH2d_82 & 60.04 & 25.35 & 0.29 & & 6.31 & 7.45 & 0.77 & 100.22 & 0.30 & 750 & 1 & 830 \\
\hline WH2d_83 & 59.69 & 25.91 & 0.26 & & 6.62 & 7.19 & 0.65 & 100.33 & 0.32 & 763 & 1 & 840 \\
\hline WH2d_84 & 59.55 & 25.58 & 0.23 & & 6.57 & 7.26 & 0.73 & 99.91 & 0.32 & 759 & 1 & 850 \\
\hline WH2f_30 & 57.51 & 26.99 & 0.21 & & 8.00 & 6.86 & 0.52 & 100.08 & 0.38 & 794 & 2 & 20 \\
\hline WH2f_31 & 58.67 & 25.93 & 0.30 & & 6.98 & 7.08 & 0.59 & 99.54 & 0.34 & 773 & 2 & 30 \\
\hline WH2f_32 & 58.36 & 26.47 & 0.20 & & 7.98 & 6.70 & 0.47 & 100.17 & 0.39 & 797 & 2 & 40 \\
\hline WH2f_33 & 60.05 & 25.93 & 0.34 & & 6.77 & 7.09 & 0.57 & 100.75 & 0.33 & 769 & 2 & 50 \\
\hline WH2f_34 & 60.17 & 25.90 & 0.24 & & 6.94 & 7.21 & 0.56 & 101.01 & 0.34 & 771 & 2 & 60 \\
\hline WH2f_35 & 58.51 & 25.43 & 0.23 & & 6.76 & 7.04 & 0.59 & 98.57 & 0.33 & 769 & 2 & 70 \\
\hline WH2f_36 & 59.88 & 25.65 & 0.26 & & 6.42 & 7.06 & 0.69 & 99.96 & 0.32 & 760 & 2 & 80 \\
\hline WH2f_37 & 59.63 & 25.73 & 0.20 & & 6.65 & 7.51 & 0.72 & 100.43 & 0.32 & 757 & 2 & 90 \\
\hline WH2f_38 & 59.36 & 25.64 & 0.24 & & 6.70 & 7.47 & 0.70 & 100.11 & 0.32 & 759 & 2 & 100 \\
\hline WH2f_39 & 59.35 & 25.51 & 0.17 & & 6.63 & 7.40 & 0.61 & 99.67 & 0.32 & 761 & 2 & 110 \\
\hline WH2f_40 & 59.71 & 25.57 & 0.30 & & 6.50 & 7.43 & 0.67 & 100.17 & 0.31 & 757 & 2 & 120 \\
\hline WH2f_41 & 59.24 & 25.18 & 0.23 & & 6.41 & 7.37 & 0.67 & 99.10 & 0.31 & 756 & 2 & 130 \\
\hline WH2f_42 & 59.75 & 25.71 & 0.19 & & 6.66 & 7.36 & 0.64 & 100.31 & 0.32 & 762 & 2 & 140 \\
\hline WH2f_43 & 60.15 & 25.92 & 0.25 & & 6.83 & 7.40 & 0.66 & 101.21 & 0.33 & 763 & 2 & 150 \\
\hline WH2f_46 & 59.21 & 25.59 & 0.24 & & 6.67 & 7.44 & 0.66 & 99.82 & 0.32 & 760 & 2 & 180 \\
\hline WH2f_47 & 59.34 & 25.48 & 0.26 & & 6.43 & 7.29 & 0.65 & 99.46 & 0.32 & 758 & 2 & 190 \\
\hline WH2f_48 & 59.11 & 25.31 & 0.25 & & 6.28 & 7.69 & 0.70 & 99.34 & 0.30 & 748 & 2 & 200 \\
\hline WH2f_49 & 58.96 & 25.80 & 0.15 & & 6.61 & 7.31 & 0.73 & 99.58 & 0.32 & 759 & 2 & 210 \\
\hline WH2f_50 & 59.99 & 25.37 & 0.24 & & 6.22 & 7.26 & 0.68 & 99.75 & 0.31 & 753 & 2 & 220 \\
\hline WH2f_51 & 59.81 & 25.62 & 0.20 & & 6.53 & 7.42 & 0.63 & 100.20 & 0.32 & 758 & 2 & 230 \\
\hline WH2f_52 & 58.98 & 25.79 & 0.25 & & 7.10 & 6.99 & 0.53 & 99.64 & 0.35 & 778 & 2 & 240 \\
\hline WH2f_53 & 60.21 & 26.19 & 0.17 & & 6.91 & 7.20 & 0.66 & 101.33 & 0.33 & 768 & 2 & 250 \\
\hline WH2f_54 & 59.77 & 26.12 & 0.31 & & 6.80 & 7.28 & 0.66 & 100.93 & 0.33 & 765 & 2 & 260 \\
\hline WH2f_55 & 59.72 & 26.06 & 0.25 & & 6.72 & 7.20 & 0.62 & 100.58 & 0.33 & 765 & 2 & 270 \\
\hline WH2f_56 & 59.06 & 25.91 & 0.33 & & 6.58 & 7.34 & 0.63 & 99.85 & 0.32 & 760 & 2 & 280 \\
\hline WH2f_57 & 58.70 & 25.66 & 0.25 & & 6.59 & 7.31 & 0.63 & 99.13 & 0.32 & 761 & 2 & 290 \\
\hline WH2f_58 & 58.86 & 25.86 & 0.22 & & 7.01 & 7.24 & 0.59 & 99.78 & 0.34 & 771 & 2 & 300 \\
\hline WH2f_59 & 58.93 & 26.15 & 0.27 & & 6.78 & 7.34 & 0.61 & 100.09 & 0.33 & 765 & 2 & 310 \\
\hline WH2f_60 & 58.22 & 25.72 & 0.32 & & 6.77 & 7.30 & 0.61 & 98.94 & 0.33 & 765 & 2 & 320 \\
\hline WH2f_61 & 59.63 & 25.65 & 0.30 & & 6.76 & 7.14 & 0.64 & 100.12 & 0.33 & 767 & 2 & 330 \\
\hline WH2f_62 & 60.09 & 25.91 & 0.30 & & 6.75 & 7.31 & 0.70 & 101.05 & 0.32 & 762 & 2 & 340 \\
\hline WH2f_63 & 58.88 & 25.13 & 0.24 & & 6.49 & 7.51 & 0.65 & 98.89 & 0.31 & 756 & 2 & 350 \\
\hline WH2f_64 & 59.85 & 25.97 & 0.26 & & 6.56 & 7.47 & 0.61 & 100.73 & 0.32 & 759 & 2 & 360 \\
\hline WH2f_65 & 59.89 & 25.76 & 0.19 & & 6.86 & 7.29 & 0.65 & 100.65 & 0.33 & 766 & 2 & 370 \\
\hline WH2f_66 & 59.90 & 25.72 & 0.28 & & 6.74 & 7.47 & 0.58 & 100.68 & 0.32 & 763 & 2 & 380 \\
\hline WH2f_67 67 & 60.42 & 25.47 & 0.28 & & 6.18 & 7.41 & 0.66 & 100.41 & 0.30 & 751 & 2 & 390 \\
\hline WH2f_68 & 59.70 & 25.69 & 0.23 & & 6.31 & 7.37 & 0.66 & 99.96 & 0.31 & 754 & 2 & 400 \\
\hline WH2f_69 & 59.12 & 25.41 & 0.34 & & 6.26 & 7.32 & 0.67 & 99.12 & 0.31 & 754 & 2 & 410 \\
\hline WH2f_70 & 59.10 & 25.26 & 0.26 & & 5.94 & 7.40 & 0.72 & 98.67 & 0.29 & 744 & 2 & 420 \\
\hline WH2f_71 & 60.37 & 25.24 & 0.26 & & 5.99 & 7.43 & 0.86 & 100.15 & 0.29 & 741 & 2 & 430 \\
\hline WH2f_72 & 60.48 & 25.13 & 0.22 & & 6.08 & 7.44 & 0.76 & 100.11 & 0.30 & 746 & 2 & 440 \\
\hline WH2f_73 & 60.39 & 25.60 & 0.25 & & 6.38 & 7.58 & 0.73 & 100.92 & 0.30 & 751 & 2 & 450 \\
\hline WH2f_74 & 60.01 & 25.47 & 0.28 & & 6.41 & 7.47 & 0.71 & 100.35 & 0.31 & 753 & 2 & 460 \\
\hline WH2f_75 & 59.73 & 26.01 & 0.24 & & 6.97 & 7.30 & 0.60 & 100.84 & 0.33 & 769 & 2 & 470 \\
\hline WH2f_76 & 60.01 & 25.80 & 0.21 & & 6.53 & 7.45 & 0.74 & 100.73 & 0.31 & 755 & 2 & 480 \\
\hline WH2f_77 & 60.50 & 26.02 & 0.19 & & 6.65 & 7.45 & 0.61 & 101.42 & 0.32 & 761 & 2 & 490 \\
\hline WH2f_78 & 58.65 & 25.54 & 0.30 & & 6.59 & 7.11 & 0.67 & 98.86 & 0.33 & 763 & 2 & 500 \\
\hline WH2f_79 & 60.09 & 25.65 & 0.23 & & 6.30 & 7.38 & 0.67 & 100.33 & 0.31 & 753 & 2 & 510 \\
\hline WH2f_80 & 59.42 & 25.78 & 0.24 & & 6.50 & 7.30 & 0.68 & 99.91 & 0.32 & 758 & 2 & 520 \\
\hline WH2f_81 & 59.98 & 25.62 & 0.38 & & 6.49 & 7.53 & 0.70 & 100.69 & 0.31 & 754 & 2 & 530 \\
\hline WH2f_82 82 & 60.69 & 25.73 & 0.25 & & 6.26 & 7.42 & 0.71 & 101.06 & 0.30 & 751 & 2 & 540 \\
\hline
\end{tabular}


Table A3.6 continued

\begin{tabular}{|c|c|c|c|c|c|c|c|c|c|c|c|c|}
\hline Sample & $\mathrm{SiO}_{2}$ & $\mathrm{Al}_{2} \mathrm{O}_{3}$ & $\mathrm{FeO}$ & $\mathrm{MgO}$ & $\mathrm{CaO}$ & $\mathrm{Na}_{2} \mathrm{O}$ & $\mathrm{K}_{2} \mathrm{O}$ & Total & Xan & $\begin{array}{c}\mathrm{T} \\
\left({ }^{\circ} \mathrm{C}\right)\end{array}$ & G & $\begin{array}{l}\text { Dist. } \\
(\mu \mathrm{m})\end{array}$ \\
\hline WH2f_88 & 59.95 & 26.11 & 0.30 & & 6.85 & 7.03 & 0.59 & 100.82 & 0.34 & 771 & 2 & 600 \\
\hline WH2f_89 & 59.53 & 26.31 & 0.22 & & 6.85 & 7.33 & 0.64 & 100.87 & 0.33 & 765 & 2 & 610 \\
\hline WH2f_90 & 60.86 & 25.76 & 0.27 & & 6.56 & 7.45 & 0.63 & 101.53 & 0.32 & 758 & 2 & 620 \\
\hline WH2f_91 & 60.80 & 25.53 & 0.14 & & 6.04 & 7.58 & 0.77 & 100.86 & 0.29 & 743 & 2 & 630 \\
\hline WH2f_92 & 59.69 & 26.41 & 0.25 & & 6.78 & 7.35 & 0.60 & 101.08 & 0.33 & 765 & 2 & 640 \\
\hline WH2f_93 & 60.44 & 26.02 & 0.27 & & 6.57 & 7.25 & 0.66 & 101.19 & 0.32 & 761 & 2 & 650 \\
\hline WH2f 94 & 60.90 & 25.67 & 0.24 & & 6.38 & 7.42 & 0.59 & 101.20 & 0.31 & 756 & 2 & 660 \\
\hline WH2f_95 & 60.83 & 25.33 & 0.28 & & 6.33 & 7.60 & 0.69 & 101.06 & 0.30 & 750 & 2 & 670 \\
\hline WH2f_96 & 59.52 & 24.99 & 0.39 & & 6.14 & 7.20 & 0.68 & 98.93 & 0.31 & 753 & 2 & 680 \\
\hline WH2f_97 & 59.14 & 25.62 & 0.26 & & 6.78 & 7.26 & 0.62 & 99.68 & 0.33 & 766 & 2 & 690 \\
\hline WH2f_99 & 59.74 & 26.06 & 0.26 & & 6.60 & 7.22 & 0.68 & 100.55 & 0.32 & 761 & 2 & 710 \\
\hline WH2g_x2 & 63.43 & 24.21 & 0.24 & & 5.62 & 7.53 & 0.72 & 101.74 & 0.28 & 735 & 3 & 30 \\
\hline WH2g_x3 & 61.90 & 24.74 & 0.17 & & 5.96 & 7.48 & 0.75 & 100.99 & 0.29 & 743 & 3 & 40 \\
\hline WH2g_x4 & 60.04 & 24.85 & 0.15 & & 6.52 & 6.98 & 0.48 & 99.03 & 0.33 & 769 & 3 & 50 \\
\hline WH2g_x5 & 62.56 & 24.66 & 0.21 & & 6.20 & 7.54 & 0.66 & 101.83 & 0.30 & 749 & 3 & 60 \\
\hline WH2g_x7 & 62.05 & 24.77 & 0.16 & & 6.28 & 7.41 & 0.67 & 101.33 & 0.31 & 753 & 3 & 80 \\
\hline WH2g_x8 & 63.12 & 24.79 & 0.33 & & 6.28 & 6.81 & 0.65 & 101.97 & 0.32 & 762 & 3 & 90 \\
\hline WH2g_x9 & 62.54 & 24.74 & 0.13 & & 6.01 & 7.51 & 0.62 & 101.55 & 0.30 & 747 & 3 & 100 \\
\hline WH2g_x 10 & 62.45 & 24.62 & 0.29 & & 5.97 & 7.36 & 0.66 & 101.35 & 0.30 & 747 & 3 & 110 \\
\hline WH2g_x11 & 61.67 & 24.73 & 0.29 & & 5.98 & 7.31 & 0.60 & 100.59 & 0.30 & 749 & 3 & 120 \\
\hline WH2g_x13 & 62.50 & 24.53 & 0.19 & & 6.26 & 7.32 & 0.64 & 101.44 & 0.31 & 754 & 3 & 140 \\
\hline WH2g_x14 & 59.75 & 24.38 & 0.22 & & 6.13 & 7.36 & 0.61 & 98.44 & 0.30 & 752 & 3 & 150 \\
\hline WH2g_x 15 & 62.98 & 24.43 & 0.27 & & 5.88 & 7.56 & 0.71 & 101.83 & 0.29 & 741 & 3 & 160 \\
\hline WH2g_x16 & 61.84 & 25.31 & 0.21 & & 6.62 & 6.99 & 0.62 & 101.58 & 0.33 & 767 & 3 & 170 \\
\hline WH2g_x17 & 61.59 & 26.18 & 0.19 & & 6.86 & 6.59 & 0.51 & 101.93 & 0.35 & 780 & 3 & 180 \\
\hline WH2g_x19 & 60.36 & 24.17 & 0.17 & & 6.13 & 7.19 & 0.64 & 98.65 & 0.31 & 754 & 3 & 200 \\
\hline WH2g_x20 & 61.58 & 24.95 & 0.20 & & 6.35 & 7.08 & 0.57 & 100.72 & 0.32 & 762 & 3 & 210 \\
\hline $\mathrm{WH} 2 \mathrm{~g} \_\mathrm{x} 30$ & 61.89 & 25.16 & 0.15 & & 6.58 & 7.06 & 0.57 & 101.41 & 0.33 & 766 & 3 & 320 \\
\hline WH3b_4 & 60.54 & 24.98 & 0.17 & & 5.88 & 8.26 & 0.69 & 100.51 & 0.27 & 731 & 3 & 20 \\
\hline WH3b_5 & 60.22 & 25.02 & 0.18 & & 6.02 & 8.09 & 0.72 & 100.25 & 0.28 & 736 & 3 & 30 \\
\hline WH3b_6 & 61.60 & 24.95 & 0.20 & & 5.91 & 8.20 & 0.66 & 101.52 & 0.27 & 733 & 3 & 40 \\
\hline WH3b_7 & 60.89 & 24.92 & 0.17 & & 5.93 & 8.25 & 0.73 & 100.88 & 0.27 & 731 & 3 & 50 \\
\hline WH3b_8 & 59.76 & 25.68 & 0.21 & & 6.63 & 7.71 & 0.61 & 100.60 & 0.31 & 756 & 3 & 60 \\
\hline WH3b_9 & 59.72 & 25.56 & 0.19 & & 6.50 & 7.72 & 0.65 & 100.34 & 0.31 & 753 & 3 & 70 \\
\hline WH3b_10 & 61.39 & 24.89 & 0.23 & & 6.55 & 7.78 & 0.65 & 101.48 & 0.31 & 753 & 3 & 80 \\
\hline WH3b_11 & 61.22 & 25.14 & 0.22 & & 6.39 & 7.89 & 0.60 & 101.46 & 0.30 & 749 & 3 & 90 \\
\hline WH3b_12 & 60.98 & 25.09 & 0.19 & & 6.56 & 7.64 & 0.67 & 101.12 & 0.31 & 755 & 3 & 100 \\
\hline WH3b_13 & 60.97 & 25.24 & 0.20 & & 6.43 & 7.57 & 0.62 & 101.04 & 0.31 & 754 & 3 & 110 \\
\hline WH3b_14 & 61.36 & 25.33 & 0.25 & & 6.42 & 7.65 & 0.65 & 101.66 & 0.31 & 752 & 3 & 120 \\
\hline WH3b_15 & 61.41 & 25.21 & 0.24 & & 6.27 & 7.79 & 0.73 & 101.66 & 0.30 & 745 & 3 & 130 \\
\hline WH3b_16 & 61.97 & 24.78 & 0.22 & & 5.79 & 8.03 & 0.67 & 101.46 & 0.27 & 733 & 3 & 140 \\
\hline WH3b_17 & 62.10 & 24.78 & 0.21 & & 6.16 & 8.00 & 0.66 & 101.89 & 0.29 & 741 & 3 & 150 \\
\hline WH3b_18 & 61.52 & 24.88 & 0.32 & & 6.15 & 7.77 & 0.66 & 101.30 & 0.29 & 745 & 3 & 160 \\
\hline WH3b_19 & 61.60 & 24.67 & 0.30 & & 6.00 & 7.92 & 0.72 & 101.21 & 0.28 & 738 & 3 & 170 \\
\hline WH3b_20 & 61.56 & 24.75 & 0.12 & & 6.12 & 7.87 & 0.70 & 101.11 & 0.29 & 742 & 3 & 180 \\
\hline WH3b_21 & 61.66 & 24.93 & 0.22 & & 6.16 & 7.59 & 0.65 & 101.20 & 0.30 & 748 & 3 & 190 \\
\hline WH3b_22 & 61.35 & 25.45 & 0.24 & & 6.36 & 7.71 & 0.73 & 101.83 & 0.30 & 748 & 3 & 200 \\
\hline WH3b_26 & 61.82 & 24.99 & 0.18 & & 6.11 & 7.89 & 0.67 & 101.65 & 0.29 & 742 & 3 & 240 \\
\hline WH3b_27 & 61.74 & 24.59 & 0.25 & & 5.97 & 7.91 & 0.72 & 101.17 & 0.28 & 737 & 3 & 250 \\
\hline WH3b_30 & 61.37 & 25.21 & 0.21 & & 6.52 & 7.82 & 0.63 & 101.77 & 0.30 & 752 & 3 & 280 \\
\hline WH3b_31 & 60.54 & 25.87 & 0.16 & & 7.27 & 7.36 & 0.64 & 101.83 & 0.34 & 772 & 3 & 290 \\
\hline WH3b_34 & 59.98 & 25.87 & 0.19 & & 7.06 & 7.54 & 0.49 & 101.14 & 0.33 & 770 & 3 & 320 \\
\hline WH3b_36 & 57.12 & 27.42 & 0.24 & & 8.97 & 6.58 & 0.38 & 100.71 & 0.42 & 813 & 3 & 340 \\
\hline WH3b_37 & 58.86 & 26.79 & 0.22 & & 8.32 & 6.76 & 0.42 & 101.36 & 0.40 & 802 & 3 & 350 \\
\hline WH3b_38 & 59.05 & 26.66 & 0.23 & & 8.38 & 6.71 & 0.42 & 101.46 & 0.40 & 803 & 3 & 360 \\
\hline
\end{tabular}


Table A3.6 continued

\begin{tabular}{|c|c|c|c|c|c|c|c|c|c|c|c|c|}
\hline Sample & $\mathrm{SiO}_{2}$ & $\mathrm{Al}_{2} \mathrm{O}_{3}$ & $\mathrm{FeO}$ & $\mathrm{MgO}$ & $\mathrm{CaO}$ & $\mathrm{Na}_{2} \mathrm{O}$ & $\mathrm{K}_{2} \mathrm{O}$ & Total & Xan & $\begin{array}{c}\mathrm{T} \\
\left({ }^{\circ} \mathrm{C}\right) \\
\end{array}$ & G & $\begin{array}{l}\text { Dist. } \\
(\mu \mathrm{m})\end{array}$ \\
\hline WH3b_42 & 61.45 & 25.15 & 0.23 & & 6.35 & 7.74 & 0.66 & 101.57 & 0.30 & 749 & 3 & 400 \\
\hline WH3b_43 & 61.58 & 25.13 & 0.23 & & 6.21 & 7.87 & 0.64 & 101.65 & 0.29 & 745 & 3 & 410 \\
\hline WH3b_44 & 61.88 & 24.98 & 0.18 & & 6.07 & 7.83 & 0.77 & 101.70 & 0.29 & 740 & 3 & 420 \\
\hline WH3b_45 & 62.42 & 24.75 & 0.22 & & 5.93 & 8.04 & 0.62 & 101.96 & 0.28 & 737 & 3 & 430 \\
\hline WH3b_46 & 61.95 & 24.76 & 0.19 & & 6.03 & 7.91 & 0.64 & 101.49 & 0.29 & 741 & 3 & 440 \\
\hline WH3b_47 & 60.72 & 25.70 & 0.18 & & 6.83 & 7.54 & 0.53 & 101.50 & 0.32 & 765 & 3 & 450 \\
\hline WH3b_48 & 60.55 & 25.77 & 0.21 & & 6.62 & 7.80 & 0.55 & 101.49 & 0.31 & 756 & 3 & 460 \\
\hline WH3b_49 & 60.97 & 24.60 & 0.17 & & 6.07 & 7.71 & 0.59 & 100.12 & 0.29 & 746 & 3 & 470 \\
\hline WH3b_50 & 60.38 & 24.53 & 0.21 & & 6.01 & 7.86 & 0.70 & 99.68 & 0.29 & 739 & 3 & 480 \\
\hline WH3b_51 & 60.71 & 24.43 & 0.25 & & 5.83 & 7.73 & 0.68 & 99.62 & 0.28 & 738 & 3 & 490 \\
\hline WH3b_52 & 61.47 & 24.14 & 0.18 & & 5.52 & 7.80 & 0.71 & 99.82 & 0.27 & 729 & 3 & 500 \\
\hline WH3b_53 & 61.88 & 23.50 & 0.21 & & 4.80 & 8.15 & 0.83 & 99.37 & 0.23 & 703 & 3 & 510 \\
\hline WH3b_54 & 62.60 & 23.42 & 0.26 & & 4.77 & 8.13 & 0.91 & 100.09 & 0.23 & 701 & 3 & 520 \\
\hline WH3b_55 & 63.10 & 23.36 & 0.14 & & 4.74 & 7.96 & 0.95 & 100.25 & 0.23 & 702 & 3 & 530 \\
\hline WH3c_7 & 60.01 & 24.87 & 0.20 & & 6.33 & 7.17 & 0.59 & 99.17 & 0.32 & 759 & 2 & 20 \\
\hline WH3c_8 & 60.53 & 24.99 & 0.23 & & 6.40 & 7.31 & 0.64 & 100.09 & 0.31 & 757 & 2 & 30 \\
\hline WH3c_9 & 59.94 & 25.19 & 0.32 & & 6.65 & 7.12 & 0.55 & 99.76 & 0.33 & 767 & 2 & 40 \\
\hline WH3c_10 & 60.56 & 24.39 & 0.29 & & 6.23 & 7.29 & 0.68 & 99.43 & 0.31 & 753 & 2 & 50 \\
\hline WH3c_11 & 60.12 & 24.84 & 0.21 & & 6.58 & 7.31 & 0.60 & 99.66 & 0.32 & 762 & 2 & 60 \\
\hline WH3c_12 & 59.21 & 24.92 & 0.19 & & 6.27 & 7.21 & 0.61 & 98.41 & 0.31 & 757 & 2 & 70 \\
\hline WH3c_13 & 59.08 & 25.03 & 0.25 & & 6.59 & 7.16 & 0.60 & 98.70 & 0.33 & 764 & 2 & 80 \\
\hline WH3c_14 & 59.40 & 25.02 & 0.25 & & 6.51 & 7.32 & 0.60 & 99.11 & 0.32 & 760 & 2 & 90 \\
\hline WH3c_15 & 58.34 & 25.33 & 0.20 & & 6.99 & 7.07 & 0.54 & 98.46 & 0.34 & 774 & 2 & 100 \\
\hline WH3c_16 & 59.12 & 24.61 & 0.25 & & 6.41 & 7.14 & 0.65 & 98.18 & 0.32 & 760 & 2 & 110 \\
\hline WH3c_17 & 59.43 & 24.84 & 0.25 & & 6.07 & 7.38 & 0.70 & 98.67 & 0.30 & 748 & 2 & 120 \\
\hline WH3c_18 & 57.91 & 24.29 & 0.19 & & 6.22 & 7.15 & 0.68 & 96.45 & 0.31 & 755 & 2 & 130 \\
\hline WH3c_19 & 58.89 & 25.16 & 0.27 & & 6.83 & 7.01 & 0.61 & 98.77 & 0.34 & 770 & 2 & 140 \\
\hline WH3c_20 & 59.17 & 24.57 & 0.36 & & 6.07 & 7.24 & 0.66 & 98.07 & 0.30 & 751 & 2 & 150 \\
\hline WH3c_21 & 59.35 & 24.95 & 0.17 & & 6.14 & 7.50 & 0.69 & 98.81 & 0.30 & 748 & 2 & 160 \\
\hline WH3c_22 & 59.06 & 24.87 & 0.23 & & 6.47 & 7.39 & 0.65 & 98.68 & 0.31 & 757 & 2 & 170 \\
\hline WH3c_23 & 58.58 & 24.93 & 0.23 & & 6.47 & 7.18 & 0.63 & 98.02 & 0.32 & 761 & 2 & 180 \\
\hline WH3c_24 & 58.74 & 25.03 & 0.21 & & 6.84 & 6.98 & 0.55 & 98.35 & 0.34 & 773 & 2 & 190 \\
\hline WH3c_25 & 58.82 & 25.34 & 0.19 & & 7.22 & 6.90 & 0.60 & 99.07 & 0.35 & 779 & 2 & 200 \\
\hline WH3c_26 & 58.21 & 25.74 & 0.34 & & 7.56 & 6.71 & 0.49 & 99.04 & 0.37 & 790 & 2 & 210 \\
\hline WH3c_27 & 57.97 & 25.98 & 0.32 & & 7.40 & 6.65 & 0.47 & 98.79 & 0.37 & 789 & 2 & 220 \\
\hline WH3c_28 & 57.75 & 25.82 & 0.30 & & 7.46 & 6.70 & 0.50 & 98.53 & 0.37 & 788 & 2 & 230 \\
\hline WH3c_29 & 58.13 & 25.98 & 0.28 & & 7.35 & 6.74 & 0.51 & 98.99 & 0.36 & 786 & 2 & 240 \\
\hline WH3c_30 & 58.23 & 25.71 & 0.18 & & 7.15 & 6.82 & 0.58 & 98.68 & 0.35 & 780 & 2 & 250 \\
\hline WH3c_31 & 57.82 & 25.70 & 0.17 & & 7.36 & 6.87 & 0.54 & 98.46 & 0.36 & 783 & 2 & 260 \\
\hline WH3c_32 & 57.72 & 25.69 & 0.32 & & 7.26 & 6.82 & 0.50 & 98.32 & 0.36 & 783 & 2 & 270 \\
\hline WH3c_33 & 58.50 & 25.28 & 0.22 & & 7.21 & 6.81 & 0.51 & 98.53 & 0.36 & 783 & 2 & 280 \\
\hline WH3c_34 & 59.94 & 25.10 & 0.19 & & 6.67 & 7.24 & 0.57 & 99.71 & 0.33 & 765 & 2 & 290 \\
\hline WH3c_35 & 60.16 & 24.63 & 0.22 & & 6.16 & 7.40 & 0.66 & 99.23 & 0.30 & 751 & 2 & 300 \\
\hline WH3c_36 & 60.42 & 24.79 & 0.37 & & 6.17 & 7.28 & 0.69 & 99.72 & 0.31 & 752 & 2 & 310 \\
\hline WH3c_37 & 59.73 & 24.61 & 0.23 & & 6.15 & 7.37 & 0.65 & 98.74 & 0.30 & 751 & 2 & 320 \\
\hline WH3c_38 & 59.95 & 24.63 & 0.17 & & 6.16 & 7.42 & 0.68 & 99.01 & 0.30 & 750 & 2 & 330 \\
\hline WH3c_39 & 59.50 & 24.77 & 0.18 & & 6.11 & 7.46 & 0.62 & 98.64 & 0.30 & 750 & 2 & 340 \\
\hline WH3c_41 & 58.99 & 24.61 & 0.21 & & 6.33 & 7.12 & 0.68 & 97.93 & 0.32 & 758 & 2 & 360 \\
\hline WH3c_42 & 60.55 & 25.05 & 0.19 & & 6.67 & 6.92 & 0.54 & 99.92 & 0.34 & 771 & 2 & 370 \\
\hline WH3c_43 & 60.59 & 25.07 & 0.21 & & 6.57 & 7.01 & 0.60 & 100.04 & 0.33 & 766 & 2 & 380 \\
\hline WH3c_44 & 60.31 & 25.11 & 0.19 & & 6.67 & 6.96 & 0.56 & 99.80 & 0.33 & 770 & 2 & 390 \\
\hline WH3c_45 & 60.48 & 25.13 & 0.29 & & 7.00 & 7.07 & 0.58 & 100.54 & 0.34 & 773 & 2 & 400 \\
\hline WH3c_46 & 61.26 & 24.80 & 0.28 & & 6.49 & 7.10 & 0.65 & 100.59 & 0.32 & 762 & 2 & 410 \\
\hline WH3c_47 & 60.74 & 24.55 & 0.31 & & 6.44 & 7.12 & 0.53 & 99.69 & 0.32 & 763 & 2 & 420 \\
\hline WH3c_48 & 60.49 & 24.93 & 0.26 & & 6.90 & 7.14 & 0.52 & 100.24 & 0.34 & 772 & 2 & 430 \\
\hline WH3c_49 & 60.20 & 25.01 & 0.16 & & 6.96 & 7.04 & 0.53 & 99.91 & 0.34 & 774 & 2 & 440 \\
\hline
\end{tabular}


Table A3.6 continued

\begin{tabular}{|c|c|c|c|c|c|c|c|c|c|c|c|c|}
\hline Sample & $\mathrm{SiO}_{2}$ & $\mathrm{Al}_{2} \mathrm{O}_{3}$ & $\mathrm{FeO}$ & $\mathrm{MgO}$ & $\mathrm{CaO}$ & $\mathrm{Na}_{2} \mathrm{O}$ & $\mathrm{K}_{2} \mathrm{O}$ & Total & Xan & $\begin{array}{c}\mathrm{T} \\
\left({ }^{\circ} \mathrm{C}\right) \\
\end{array}$ & G & $\begin{array}{l}\text { Dist. } \\
(\mu \mathrm{m})\end{array}$ \\
\hline WH3c_53 & 60.29 & 24.86 & 0.25 & & 6.40 & 7.37 & 0.57 & 99.74 & 0.31 & 758 & 2 & 480 \\
\hline WH3c_54 & 61.46 & 24.41 & 0.31 & & 6.17 & 7.43 & 0.65 & 100.43 & 0.30 & 751 & 2 & 490 \\
\hline WH3c_55 & 61.70 & 24.20 & 0.25 & & 5.88 & 7.32 & 0.71 & 100.05 & 0.29 & 744 & 2 & 500 \\
\hline WH3c_56 & 61.18 & 24.69 & 0.18 & & 6.58 & 7.24 & 0.58 & 100.45 & 0.32 & 763 & 2 & 510 \\
\hline WH3c_57 & 61.58 & 24.46 & 0.26 & & 6.34 & 7.28 & 0.59 & 100.51 & 0.31 & 758 & 2 & 520 \\
\hline WH3c_58 & 60.05 & 24.98 & 0.21 & & 6.81 & 7.24 & 0.50 & 99.79 & 0.33 & 770 & 2 & 530 \\
\hline WH3d_1 & 58.75 & 25.11 & 0.28 & & 6.59 & 7.66 & 0.57 & 98.96 & 0.31 & 757 & 2 & 20 \\
\hline WH3d_2 & 59.73 & 25.76 & 0.23 & & 6.64 & 7.68 & 0.63 & 100.67 & 0.31 & 757 & 2 & 30 \\
\hline WH3d_3 & 61.02 & 24.66 & 0.29 & & 5.73 & 8.34 & 0.80 & 100.84 & 0.26 & 724 & 2 & 40 \\
\hline WH3d_4 & 60.64 & 24.91 & 0.23 & & 5.71 & 7.98 & 0.74 & 100.21 & 0.27 & 730 & 2 & 50 \\
\hline WH3d_5 & 59.69 & 25.39 & 0.20 & & 6.52 & 7.66 & 0.63 & 100.09 & 0.31 & 754 & 2 & 60 \\
\hline WH3d_7 & 58.61 & 26.44 & 0.26 & & 7.66 & 7.28 & 0.52 & 100.77 & 0.36 & 783 & 2 & 70 \\
\hline WH3d_8 & 58.23 & 26.75 & 0.23 & & 7.97 & 7.12 & 0.56 & 100.85 & 0.37 & 788 & 2 & 80 \\
\hline WH3d_9 & 57.56 & 27.23 & 0.25 & & 8.45 & 6.56 & 0.44 & 100.49 & 0.41 & 806 & 2 & 90 \\
\hline WH3d_10 & 58.03 & 26.93 & 0.24 & & 8.33 & 6.78 & 0.47 & 100.76 & 0.39 & 800 & 2 & 100 \\
\hline WH3d_11 & 59.57 & 25.30 & 0.23 & & 7.31 & 7.24 & 0.64 & 100.30 & 0.35 & 774 & 2 & 110 \\
\hline WH3d_12 & 60.04 & 25.62 & 0.27 & & 6.84 & 7.46 & 0.63 & 100.86 & 0.32 & 764 & 2 & 120 \\
\hline WH3d_13 & 59.29 & 25.46 & 0.24 & & 6.53 & 7.92 & 0.61 & 100.04 & 0.30 & 751 & 2 & 130 \\
\hline WH3d_14 & 59.52 & 25.49 & 0.28 & & 6.43 & 7.67 & 0.63 & 100.03 & 0.31 & 753 & 2 & 140 \\
\hline WH3d_15 & 59.06 & 25.75 & 0.24 & & 6.84 & 7.36 & 0.64 & 99.88 & 0.33 & 765 & 2 & 150 \\
\hline WH3d_16 & 59.75 & 25.60 & 0.31 & & 6.92 & 7.58 & 0.62 & 100.78 & 0.32 & 764 & 2 & 160 \\
\hline WH3d_17 & 60.27 & 25.52 & 0.27 & & 6.99 & 7.44 & 0.57 & 101.05 & 0.33 & 768 & 2 & 170 \\
\hline WH3d_18 & 59.82 & 25.55 & 0.31 & & 6.89 & 7.33 & 0.61 & 100.51 & 0.33 & 767 & 2 & 180 \\
\hline WH3d_19 & 59.52 & 25.82 & 0.19 & & 7.06 & 7.48 & 0.64 & 100.69 & 0.33 & 767 & 2 & 190 \\
\hline WH3d_20 & 59.76 & 26.19 & 0.22 & & 7.12 & 7.42 & 0.56 & 101.28 & 0.34 & 771 & 2 & 200 \\
\hline WH3d_21 & 59.33 & 25.94 & 0.22 & & 7.06 & 7.26 & 0.59 & 100.40 & 0.34 & 771 & 2 & 210 \\
\hline WH3d_22 & 58.51 & 26.43 & 0.24 & & 7.68 & 7.03 & 0.59 & 100.48 & 0.36 & 785 & 2 & 220 \\
\hline WH3d_23 & 58.78 & 26.26 & 0.26 & & 7.25 & 7.17 & 0.58 & 100.29 & 0.35 & 776 & 2 & 230 \\
\hline WH3d_24 & 58.29 & 26.52 & 0.14 & & 7.61 & 7.19 & 0.51 & 100.24 & 0.36 & 784 & 2 & 240 \\
\hline WH3d_25 & 57.79 & 26.90 & 0.29 & & 8.10 & 6.90 & 0.47 & 100.45 & 0.38 & 796 & 2 & 250 \\
\hline WH3d_26 & 57.62 & 26.89 & 0.19 & & 7.93 & 7.06 & 0.53 & 100.22 & 0.37 & 790 & 2 & 260 \\
\hline WH3d_27 & 57.78 & 26.45 & 0.26 & & 7.66 & 6.94 & 0.58 & 99.66 & 0.37 & 786 & 2 & 270 \\
\hline WH3d_28 & 59.15 & 26.38 & 0.26 & & 7.66 & 7.05 & 0.57 & 101.07 & 0.36 & 785 & 2 & 280 \\
\hline WH3d_29 & 58.43 & 26.97 & 0.25 & & 8.38 & 6.97 & 0.48 & 101.47 & 0.39 & 798 & 2 & 290 \\
\hline WH3d_30 & 60.01 & 25.77 & 0.25 & & 7.04 & 7.54 & 0.64 & 101.24 & 0.33 & 766 & 2 & 300 \\
\hline WH3d_31 & 60.55 & 25.46 & 0.19 & & 6.82 & 7.46 & 0.66 & 101.14 & 0.32 & 762 & 2 & 310 \\
\hline WH3d_32 & 59.63 & 25.64 & 0.19 & & 6.67 & 7.66 & 0.66 & 100.44 & 0.31 & 757 & 2 & 320 \\
\hline WH3d_33 & 58.31 & 25.72 & 0.20 & & 7.08 & 7.02 & 0.58 & 98.90 & 0.35 & 775 & 2 & 330 \\
\hline WH3d_34 & 58.61 & 26.08 & 0.29 & & 7.32 & 7.39 & 0.58 & 100.26 & 0.34 & 774 & 2 & 340 \\
\hline WH3d_35 & 58.63 & 26.28 & 0.16 & & 7.20 & 7.39 & 0.57 & 100.22 & 0.34 & 773 & 2 & 350 \\
\hline WH3d_36 & 58.24 & 26.32 & 0.18 & & 7.23 & 7.21 & 0.56 & 99.74 & 0.35 & 776 & 2 & 360 \\
\hline WH3d_37 & 59.51 & 26.27 & 0.17 & & 7.31 & 7.26 & 0.55 & 101.08 & 0.35 & 777 & 2 & 370 \\
\hline WH3d_38 & 59.12 & 26.10 & 0.26 & & 7.62 & 7.20 & 0.54 & 100.83 & 0.36 & 783 & 2 & 380 \\
\hline WH3d_39 & 58.26 & 26.65 & 0.26 & & 7.93 & 7.11 & 0.49 & 100.70 & 0.37 & 790 & 2 & 390 \\
\hline WH3d_40 & 58.04 & 26.93 & 0.14 & & 8.05 & 6.85 & 0.49 & 100.50 & 0.38 & 795 & 2 & 400 \\
\hline WH3d_41 & 57.41 & 27.02 & 0.18 & & 8.50 & 6.85 & 0.46 & 100.43 & 0.40 & 802 & 2 & 410 \\
\hline WH3d_42 & 57.48 & 26.63 & 0.23 & & 7.91 & 6.72 & 0.48 & 99.44 & 0.38 & 795 & 2 & 420 \\
\hline WH3d_43 & 58.48 & 26.31 & 0.15 & & 7.55 & 7.23 & 0.52 & 100.23 & 0.36 & 782 & 2 & 430 \\
\hline WH3d_44 & 57.78 & 26.14 & 0.25 & & 7.62 & 7.16 & 0.53 & 99.49 & 0.36 & 784 & 2 & 440 \\
\hline WH3d_45 & 57.87 & 26.77 & 0.26 & & 7.99 & 6.83 & 0.53 & 100.25 & 0.38 & 793 & 2 & 450 \\
\hline WH3d_46 & 57.45 & 26.72 & 0.23 & & 8.04 & 6.97 & 0.42 & 99.84 & 0.38 & 795 & 2 & 460 \\
\hline WH3d_47 & 57.14 & 26.73 & 0.22 & & 7.87 & 6.77 & 0.49 & 99.22 & 0.38 & 794 & 2 & 470 \\
\hline WH3d_48 & 57.30 & 26.90 & 0.19 & & 8.45 & 6.89 & 0.46 & 100.19 & 0.39 & 801 & 2 & 480 \\
\hline WH3d_49 & 57.74 & 26.86 & 0.30 & & 8.10 & 6.89 & 0.45 & 100.34 & 0.38 & 796 & 2 & 490 \\
\hline WH3d_50 & 57.43 & 26.69 & 0.31 & & 8.34 & 7.03 & 0.46 & 100.27 & 0.39 & 797 & 2 & 500 \\
\hline WH3d_51 & 58.33 & 26.76 & 0.18 & & 8.34 & 6.92 & 0.46 & 100.98 & 0.39 & 799 & 2 & 510 \\
\hline
\end{tabular}


Table A3.6 continued

\begin{tabular}{|c|c|c|c|c|c|c|c|c|c|c|c|c|}
\hline Sample & $\mathrm{SiO}_{2}$ & $\mathrm{Al}_{2} \mathrm{O}_{3}$ & $\mathrm{FeO}$ & $\mathrm{MgO}$ & $\mathrm{CaO}$ & $\mathrm{Na}_{2} \mathrm{O}$ & $\mathrm{K}_{2} \mathrm{O}$ & Total & Xan & $\begin{array}{c}\mathrm{T} \\
\left({ }^{\circ} \mathrm{C}\right) \\
\end{array}$ & G & $\begin{array}{l}\text { Dist. } \\
(\mu \mathrm{m})\end{array}$ \\
\hline WH3d_55 & 59.07 & 26.59 & 0.19 & & 8.11 & 6.98 & 0.54 & 101.48 & 0.38 & 793 & 2 & 550 \\
\hline WH3d_56 & 59.99 & 25.87 & 0.21 & & 7.23 & 7.25 & 0.59 & 101.14 & 0.34 & 774 & 2 & 560 \\
\hline WH3d_57 & 60.39 & 25.74 & 0.27 & & 6.80 & 7.52 & 0.63 & 101.34 & 0.32 & 762 & 2 & 570 \\
\hline WH3d_58 & 59.79 & 25.83 & 0.28 & & 7.01 & 7.26 & 0.60 & 100.77 & 0.34 & 770 & 2 & 580 \\
\hline WH3e_1 & 60.57 & 24.81 & 0.30 & 0.05 & 6.45 & 7.28 & 0.59 & 100.06 & 0.32 & 760 & 2 & 20 \\
\hline WH3e_2 & 60.08 & 25.03 & 0.22 & 0.01 & 6.82 & 7.12 & 0.69 & 99.97 & 0.33 & 766 & 2 & 30 \\
\hline WH3e_3 & 60.62 & 24.78 & 0.22 & 0.03 & 6.77 & 7.47 & 0.65 & 100.54 & 0.32 & 762 & 2 & 40 \\
\hline WH3e_4 & 60.56 & 24.71 & 0.28 & 0.03 & 6.65 & 7.35 & 0.65 & 100.23 & 0.32 & 761 & 2 & 50 \\
\hline WH3e_5 & 61.06 & 24.99 & 0.24 & 0.01 & 6.79 & 7.79 & 0.75 & 101.63 & 0.31 & 755 & 2 & 60 \\
\hline WH3e_6 & 61.11 & 24.97 & 0.24 & 0.03 & 6.75 & 7.43 & 0.68 & 101.21 & 0.32 & 761 & 2 & 70 \\
\hline WH3e_7 & 59.86 & 24.60 & 0.19 & 0.04 & 6.49 & 7.18 & 0.61 & 98.96 & 0.32 & 762 & 2 & 80 \\
\hline WH3e_8 & 60.88 & 24.90 & 0.19 & 0.01 & 6.54 & 7.39 & 0.69 & 100.59 & 0.32 & 757 & 2 & 90 \\
\hline WH3e_9 & 61.05 & 24.94 & 0.18 & 0.01 & 6.93 & 7.27 & 0.72 & 101.09 & 0.33 & 766 & 2 & 100 \\
\hline WH3e_10 & 61.03 & 25.11 & 0.17 & 0.01 & 6.78 & 7.39 & 0.62 & 101.10 & 0.32 & 764 & 2 & 110 \\
\hline WH3e_11 & 61.20 & 24.80 & 0.21 & b.d & 6.49 & 7.58 & 0.70 & 100.97 & 0.31 & 753 & 2 & 120 \\
\hline WH3e_12 & 60.12 & 24.65 & 0.17 & b.d & 6.46 & 7.56 & 0.68 & 99.64 & 0.31 & 753 & 2 & 130 \\
\hline WH3e_13 & 60.06 & 24.92 & 0.18 & 0.01 & 6.99 & 7.25 & 0.60 & 100.01 & 0.34 & 770 & 2 & 140 \\
\hline WH3e_14 & 60.38 & 24.80 & 0.22 & 0.01 & 6.82 & 7.22 & 0.66 & 100.11 & 0.33 & 766 & 2 & 150 \\
\hline WH3e_15 & 60.39 & 24.82 & 0.19 & 0.01 & 6.78 & 7.31 & 0.67 & 100.17 & 0.33 & 764 & 2 & 160 \\
\hline WH3e_16 & 60.38 & 25.03 & 0.24 & 0.00 & 6.77 & 7.24 & 0.62 & 100.28 & 0.33 & 766 & 2 & 170 \\
\hline WH3e_17 & 60.88 & 24.57 & 0.28 & 0.02 & 6.69 & 7.08 & 0.72 & 100.23 & 0.33 & 764 & 2 & 180 \\
\hline WH3e_18 & 60.56 & 24.48 & 0.20 & 0.01 & 6.21 & 7.54 & 0.73 & 99.73 & 0.30 & 748 & 2 & 190 \\
\hline WH3e_19 & 61.45 & 24.19 & 0.16 & 0.03 & 6.33 & 7.69 & 0.74 & 100.59 & 0.30 & 748 & 2 & 200 \\
\hline WH3e_20 & 61.06 & 24.20 & 0.17 & 0.01 & 6.21 & 7.79 & 0.71 & 100.14 & 0.29 & 745 & 2 & 210 \\
\hline WH3e_21 & 60.49 & 24.46 & 0.19 & 0.00 & 6.14 & 7.37 & 0.79 & 99.45 & 0.30 & 747 & 2 & 220 \\
\hline WH3e_22 & 59.65 & 23.96 & 0.99 & 1.12 & 6.92 & 7.08 & 0.80 & 100.52 & 0.33 & 766 & 2 & 230 \\
\hline WH3e_23 & 59.86 & 24.66 & 0.17 & 0.01 & 6.48 & 7.32 & 0.63 & 99.13 & 0.32 & 759 & 2 & 240 \\
\hline WH3e_24 & 60.19 & 24.63 & 0.23 & 0.04 & 6.65 & 7.42 & 0.68 & 99.84 & 0.32 & 759 & 2 & 250 \\
\hline WH3e_25 & 60.02 & 24.61 & 0.17 & 0.04 & 6.64 & 7.34 & 0.68 & 99.52 & 0.32 & 760 & 2 & 260 \\
\hline WH3e_26 & 60.37 & 24.54 & 0.21 & 0.01 & 6.49 & 7.57 & 0.66 & 99.85 & 0.31 & 755 & 2 & 270 \\
\hline WH3e_27 & 60.30 & 24.65 & 0.20 & 0.02 & 6.56 & 7.35 & 0.67 & 99.74 & 0.32 & 759 & 2 & 280 \\
\hline WH3e_28 & 61.24 & 24.43 & 0.25 & 0.04 & 6.50 & 7.26 & 0.70 & 100.41 & 0.32 & 758 & 2 & 290 \\
\hline WH3e_29 & 60.79 & 24.72 & 0.21 & 0.03 & 6.72 & 7.33 & 0.60 & 100.39 & 0.32 & 764 & 2 & 300 \\
\hline WH3e_30 & 61.12 & 24.40 & 0.22 & 0.01 & 6.46 & 7.44 & 0.66 & 100.31 & 0.31 & 756 & 2 & 310 \\
\hline WH3e_31 & 60.64 & 24.54 & 0.29 & 0.02 & 6.25 & 7.57 & 0.64 & 99.95 & 0.30 & 750 & 2 & 320 \\
\hline WH3e_32 & 61.48 & 24.45 & 0.24 & 0.05 & 6.30 & 7.41 & 0.68 & 100.62 & 0.31 & 753 & 2 & 330 \\
\hline WH3e_33 & 60.97 & 24.52 & 0.21 & 0.01 & 6.63 & 7.14 & 0.64 & 100.13 & 0.33 & 764 & 2 & 340 \\
\hline WH3e_34 & 60.59 & 24.47 & 0.22 & 0.05 & 6.67 & 7.29 & 0.65 & 99.96 & 0.32 & 762 & 2 & 350 \\
\hline WH3e_35 & 61.20 & 24.03 & 0.16 & 0.02 & 6.07 & 7.40 & 0.72 & 99.61 & 0.30 & 747 & 2 & 360 \\
\hline WH3e_38 & 61.52 & 24.54 & 0.19 & 0.01 & 6.52 & 7.21 & 0.70 & 100.70 & 0.32 & 759 & 2 & 390 \\
\hline WH3e_39 & 60.25 & 24.69 & 0.23 & 0.00 & 6.48 & 7.25 & 0.66 & 99.55 & 0.32 & 759 & 2 & 400 \\
\hline WH3e_40 & 60.91 & 24.76 & 0.20 & 0.01 & 6.53 & 7.39 & 0.61 & 100.41 & 0.32 & 759 & 2 & 410 \\
\hline WH3e_41 & 60.57 & 24.87 & 0.15 & 0.04 & 6.77 & 7.25 & 0.64 & 100.29 & 0.33 & 765 & 2 & 420 \\
\hline WH3e_42 & 61.44 & 24.85 & 0.27 & 0.04 & 6.88 & 7.03 & 0.60 & 101.11 & 0.34 & 771 & 2 & 430 \\
\hline WH3e_43 & 60.24 & 25.39 & 0.24 & 0.03 & 7.54 & 6.95 & 0.55 & 100.95 & 0.36 & 785 & 2 & 440 \\
\hline WH3e_44 & 59.94 & 25.64 & 0.22 & b.d. & 7.73 & 6.93 & 0.60 & 101.06 & 0.37 & 787 & 2 & 450 \\
\hline WH3e_45 & 59.72 & 25.22 & 0.21 & 0.02 & 7.22 & 6.88 & 0.58 & 99.84 & 0.35 & 780 & 2 & 460 \\
\hline WH3e_46 & 60.59 & 24.86 & 0.18 & b.d. & 6.52 & 7.18 & 0.67 & 100.01 & 0.32 & 761 & 2 & 470 \\
\hline WH3e_47 & 59.96 & 25.04 & 0.23 & 0.01 & 7.09 & 7.00 & 0.63 & 99.97 & 0.35 & 774 & 2 & 480 \\
\hline WH3e_48 & 59.46 & 25.34 & 0.20 & 0.05 & 7.34 & 7.05 & 0.58 & 100.02 & 0.35 & 779 & 2 & 490 \\
\hline WH3e_49 & 59.62 & 25.36 & 0.26 & 0.03 & 7.48 & 6.81 & 0.58 & 100.16 & 0.37 & 785 & 2 & 500 \\
\hline WH3e_50 & 59.13 & 25.95 & 0.19 & 0.05 & 8.11 & 6.84 & 0.52 & 100.80 & 0.38 & 795 & 2 & 510 \\
\hline WH3e_51 & 60.29 & 25.01 & 0.24 & 0.04 & 6.83 & 7.16 & 0.58 & 100.14 & 0.33 & 769 & 2 & 520 \\
\hline WH3e_52 & 62.01 & 23.95 & 0.22 & 0.01 & 5.91 & 7.71 & 0.82 & 100.62 & 0.28 & 737 & 2 & 530 \\
\hline WH3e_53 & 61.78 & 24.33 & 0.16 & 0.04 & 5.90 & 7.58 & 0.76 & 100.53 & 0.29 & 740 & 2 & 540 \\
\hline WH3e_54 & 61.39 & 24.53 & 0.25 & 0.03 & 6.42 & 7.48 & 0.70 & 100.79 & 0.31 & 753 & 2 & 550 \\
\hline
\end{tabular}


Table A3.6 continued

\begin{tabular}{|c|c|c|c|c|c|c|c|c|c|c|c|c|}
\hline Sample & $\mathrm{SiO}_{2}$ & $\mathrm{Al}_{2} \mathrm{O}_{3}$ & $\mathrm{FeO}$ & $\mathrm{MgO}$ & $\mathrm{CaO}$ & $\mathrm{Na}_{2} \mathrm{O}$ & $\mathrm{K}_{2} \mathrm{O}$ & Total & Xan & $\begin{array}{c}\mathrm{T} \\
\left({ }^{\circ} \mathrm{C}\right)\end{array}$ & G & $\begin{array}{l}\text { Dist. } \\
(\mu \mathrm{m})\end{array}$ \\
\hline WH3e_58 & 61.81 & 23.96 & 0.17 & 0.04 & 5.55 & 7.66 & 0.85 & 100.03 & 0.27 & 729 & 2 & 590 \\
\hline WH3e_59 & 61.89 & 23.99 & 0.20 & 0.03 & 6.10 & 7.31 & 0.76 & 100.28 & 0.30 & 748 & 2 & 600 \\
\hline WH3e_60 & 62.38 & 24.10 & 0.17 & 0.02 & 6.01 & 7.66 & 0.75 & 101.11 & 0.29 & 741 & 2 & 610 \\
\hline WH3e_61 & 60.76 & 24.11 & 0.21 & 0.02 & 6.19 & 7.41 & 0.81 & 99.52 & 0.30 & 747 & 2 & 620 \\
\hline WH3e_62 & 61.62 & 24.36 & 0.23 & 0.01 & 5.80 & 7.63 & 0.76 & 100.41 & 0.28 & 737 & 2 & 630 \\
\hline WH3e_63 & 61.82 & 24.24 & 0.22 & 0.01 & 6.06 & 7.45 & 0.77 & 100.57 & 0.30 & 745 & 2 & 640 \\
\hline WH3e_64 & 61.21 & 24.83 & 0.25 & 0.01 & 6.42 & 7.57 & 0.68 & 100.98 & 0.31 & 753 & 2 & 650 \\
\hline WH3e_65 & 61.18 & 24.30 & 0.25 & 0.00 & 6.26 & 7.66 & 0.72 & 100.36 & 0.30 & 747 & 2 & 660 \\
\hline WH3e_66 & 60.24 & 24.51 & 0.18 & 0.03 & 6.44 & 7.50 & 0.74 & 99.64 & 0.31 & 753 & 2 & 670 \\
\hline WH3e_67 & 60.99 & 24.59 & 0.25 & 0.01 & 6.56 & 7.31 & 0.73 & 100.44 & 0.32 & 758 & 2 & 680 \\
\hline WH3e_68 & 60.95 & 24.56 & 0.26 & 0.01 & 6.46 & 7.55 & 0.67 & 100.45 & 0.31 & 754 & 2 & 690 \\
\hline WH3e_69 & 60.80 & 24.58 & 0.24 & b.d. & 6.66 & 7.26 & 0.62 & 100.17 & 0.32 & 764 & 2 & 700 \\
\hline WH3e_70 & 60.89 & 24.53 & 0.16 & b.d. & 6.33 & 7.29 & 0.68 & 99.89 & 0.31 & 755 & 2 & 710 \\
\hline WH3e_71 & 61.45 & 24.55 & 0.20 & 0.04 & 6.31 & 7.20 & 0.68 & 100.43 & 0.31 & 756 & 2 & 720 \\
\hline WH3e_72 & 61.47 & 24.38 & 0.27 & 0.01 & 6.17 & 7.49 & 0.78 & 100.57 & 0.30 & 746 & 2 & 730 \\
\hline WH3e_73 & 60.99 & 24.77 & 0.22 & b.d. & 6.67 & 7.32 & 0.73 & 100.71 & 0.32 & 760 & 2 & 740 \\
\hline WH3e_74 & 60.96 & 24.62 & 0.22 & 0.01 & 6.63 & 7.32 & 0.67 & 100.42 & 0.32 & 761 & 2 & 750 \\
\hline WH3e_75 & 60.93 & 24.82 & 0.20 & 0.03 & 6.75 & 7.17 & 0.66 & 100.55 & 0.33 & 765 & 2 & 760 \\
\hline WH3e_76 & 61.00 & 24.70 & 0.22 & b.d. & 6.62 & 7.45 & 0.77 & 100.75 & 0.31 & 756 & 2 & 770 \\
\hline WH3e_77 & 60.59 & 25.24 & 0.35 & 0.02 & 6.85 & 7.32 & 0.69 & 101.05 & 0.33 & 764 & 2 & 780 \\
\hline WH3e_78 & 60.22 & 24.87 & 0.26 & 0.05 & 7.15 & 7.06 & 0.64 & 100.25 & 0.35 & 774 & 2 & 790 \\
\hline WH3e_79 & 61.35 & 24.54 & 0.23 & 0.04 & 6.35 & 7.31 & 0.75 & 100.57 & 0.31 & 753 & 2 & 800 \\
\hline WH3e_80 & 62.68 & 23.56 & 0.22 & b.d. & 5.87 & 7.65 & 0.83 & 100.81 & 0.28 & 736 & 2 & 810 \\
\hline WH3e_81 & 62.26 & 23.85 & 0.30 & 0.01 & 5.90 & 7.71 & 0.80 & 100.84 & 0.28 & 737 & 2 & 820 \\
\hline WH3e_82 & 62.22 & 23.93 & 0.25 & 0.01 & 5.89 & 7.68 & 0.78 & 100.76 & 0.28 & 738 & 2 & 830 \\
\hline WH3e_83 & 62.07 & 24.11 & 0.19 & 0.03 & 6.01 & 7.58 & 0.81 & 100.79 & 0.29 & 741 & 2 & 840 \\
\hline WH3e_84 & 62.35 & 24.22 & 0.28 & 0.01 & 5.88 & 7.42 & 0.81 & 100.96 & 0.29 & 740 & 2 & 850 \\
\hline WH3e_85 & 61.16 & 23.92 & 0.31 & 0.04 & 5.98 & 7.56 & 0.75 & 99.73 & 0.29 & 742 & 2 & 860 \\
\hline WH3e_86 & 61.38 & 24.15 & 0.20 & 0.01 & 6.02 & 7.47 & 0.84 & 100.07 & 0.29 & 742 & 2 & 870 \\
\hline WH3e_87 & 61.49 & 24.34 & 0.28 & 0.01 & 5.98 & 7.77 & 0.83 & 100.70 & 0.28 & 737 & 2 & 880 \\
\hline WH5d_2 & 61.09 & 25.28 & 0.24 & & 6.75 & 7.34 & 0.56 & 101.25 & 0.33 & 765 & 2 & 20 \\
\hline WH5d_3 & 60.54 & 25.54 & 0.28 & & 6.85 & 7.41 & 0.58 & 101.21 & 0.33 & 766 & 2 & 30 \\
\hline WH5d_4 & 59.85 & 25.68 & 0.30 & & 7.15 & 7.24 & 0.60 & 100.82 & 0.34 & 773 & 2 & 40 \\
\hline WH5d_5 & 60.22 & 25.59 & 0.22 & & 7.22 & 6.88 & 0.50 & 100.63 & 0.36 & 782 & 2 & 50 \\
\hline WH5d_6 & 60.25 & 26.12 & 0.22 & & 7.37 & 6.89 & 0.58 & 101.42 & 0.36 & 782 & 2 & 60 \\
\hline WH5d_15 & 60.43 & 26.25 & 0.30 & & 7.30 & 7.06 & 0.57 & 101.92 & 0.35 & 779 & 2 & 150 \\
\hline WH5d_17 & 59.77 & 26.59 & 0.24 & & 8.14 & 6.70 & 0.46 & 101.90 & 0.39 & 799 & 2 & 170 \\
\hline WH5d_21 & 59.84 & 26.49 & 0.29 & & 7.86 & 6.92 & 0.52 & 101.92 & 0.37 & 791 & 2 & 210 \\
\hline WH5d_22 & 60.63 & 25.66 & 0.30 & & 6.92 & 7.19 & 0.57 & 101.26 & 0.34 & 771 & 2 & 220 \\
\hline WH5d_23 & 59.99 & 26.29 & 0.17 & & 7.64 & 6.79 & 0.44 & 101.32 & 0.37 & 792 & 2 & 230 \\
\hline WH5d_26 & 60.53 & 25.99 & 0.15 & & 7.12 & 7.19 & 0.56 & 101.53 & 0.34 & 774 & 2 & 260 \\
\hline WH5d_27 & 59.59 & 26.61 & 0.16 & & 7.86 & 6.60 & 0.52 & 101.35 & 0.38 & 795 & 2 & 270 \\
\hline WH5d_29 & 59.07 & 26.62 & 0.31 & & 8.32 & 6.70 & 0.51 & 101.53 & 0.40 & 800 & 2 & 290 \\
\hline WH5d_30 & 58.96 & 26.60 & 0.18 & & 8.10 & 6.71 & 0.47 & 101.02 & 0.39 & 798 & 2 & 300 \\
\hline WH5d_31 & 58.90 & 26.67 & 0.20 & & 8.18 & 6.54 & 0.45 & 100.94 & 0.40 & 802 & 2 & 310 \\
\hline WH5d_34 & 58.66 & 27.00 & 0.20 & & 8.36 & 6.55 & 0.44 & 101.22 & 0.40 & 805 & 2 & 340 \\
\hline WH5d_36 & 58.78 & 26.91 & 0.33 & & 8.47 & 6.42 & 0.43 & 101.33 & 0.41 & 808 & 2 & 360 \\
\hline WH5d_37 & 59.75 & 25.98 & 0.19 & & 7.35 & 6.97 & 0.51 & 100.74 & 0.36 & 783 & 2 & 370 \\
\hline WH5d_38 & 60.32 & 25.90 & 0.24 & & 7.18 & 7.08 & 0.53 & 101.26 & 0.35 & 778 & 2 & 380 \\
\hline WH5d_39 & 59.55 & 25.47 & 0.19 & & 6.62 & 7.38 & 0.59 & 99.80 & 0.32 & 762 & 2 & 390 \\
\hline WH5d_40 & 60.27 & 25.37 & 0.17 & & 6.57 & 7.41 & 0.55 & 100.34 & 0.32 & 761 & 2 & 400 \\
\hline WH5d_42 & 60.34 & 26.11 & 0.26 & & 7.14 & 7.29 & 0.53 & 101.67 & 0.34 & 774 & 2 & 420 \\
\hline WH5d_43 & 59.84 & 26.09 & 0.29 & & 7.08 & 7.17 & 0.58 & 101.04 & 0.34 & 773 & 2 & 430 \\
\hline WH5d_44 & 60.37 & 26.11 & 0.21 & & 7.29 & 7.34 & 0.48 & 101.80 & 0.34 & 777 & 2 & 440 \\
\hline WH5d_45 & 60.16 & 26.17 & 0.17 & & 7.18 & 7.17 & 0.49 & 101.33 & 0.35 & 777 & 2 & 450 \\
\hline WH5d_49 & 59.31 & 25.97 & 0.26 & & 7.06 & 6.86 & 0.50 & 99.96 & 0.35 & 780 & 2 & 490 \\
\hline
\end{tabular}


Table A3.6 continued

\begin{tabular}{|c|c|c|c|c|c|c|c|c|c|c|c|c|}
\hline Sample & $\mathrm{SiO}_{2}$ & $\mathrm{Al}_{2} \mathrm{O}_{3}$ & $\mathrm{FeO}$ & $\mathrm{MgO}$ & $\mathrm{CaO}$ & $\mathrm{Na}_{2} \mathrm{O}$ & $\mathrm{K}_{2} \mathrm{O}$ & Total & Xan & $\begin{array}{c}\mathrm{T} \\
\left({ }^{\circ} \mathrm{C}\right)\end{array}$ & G & $\begin{array}{l}\text { Dist. } \\
(\mu \mathrm{m})\end{array}$ \\
\hline WH5d_53 & 59.73 & 26.15 & 0.25 & & 7.47 & 6.88 & 0.47 & 100.97 & 0.36 & 787 & 2 & 530 \\
\hline WH5d_54 & 59.81 & 26.06 & 0.23 & & 7.66 & 7.13 & 0.48 & 101.37 & 0.36 & 786 & 2 & 540 \\
\hline WH5d_55 & 59.54 & 26.04 & 0.31 & & 7.09 & 7.16 & 0.52 & 100.65 & 0.34 & 775 & 2 & 550 \\
\hline WH5d_56 & 59.58 & 25.99 & 0.21 & & 7.18 & 7.24 & 0.54 & 100.74 & 0.34 & 775 & 2 & 560 \\
\hline WH5d_57 & 58.91 & 25.98 & 0.17 & & 6.96 & 7.22 & 0.55 & 99.78 & 0.34 & 771 & 2 & 570 \\
\hline WH5d_58 & 58.94 & 27.12 & 0.17 & & 8.00 & 6.41 & 0.49 & 101.13 & 0.40 & 800 & 2 & 580 \\
\hline WH5d_59 & 58.27 & 27.83 & 0.19 & & 8.84 & 6.20 & 0.37 & 101.70 & 0.43 & 817 & 2 & 590 \\
\hline WH5d_61 & 58.53 & 27.10 & 0.26 & & 9.21 & 6.44 & 0.35 & 101.90 & 0.43 & 818 & 2 & 610 \\
\hline WH5d_62 & 60.63 & 25.99 & 0.35 & & 7.01 & 7.32 & 0.54 & 101.84 & 0.34 & 771 & 2 & 620 \\
\hline WH5d_63 & 61.21 & 25.19 & 0.29 & & 6.48 & 7.60 & 0.63 & 101.41 & 0.31 & 755 & 2 & 630 \\
\hline WH5d_64 & 60.74 & 25.07 & 0.24 & & 5.94 & 7.19 & 0.65 & 99.83 & 0.30 & 749 & 2 & 640 \\
\hline WH5d_65 & 58.84 & 25.59 & 0.20 & & 7.52 & 7.57 & 0.48 & 100.20 & 0.34 & 777 & 2 & 650 \\
\hline WH5d_66 & 58.89 & 25.59 & 0.19 & & 7.19 & 6.72 & 0.58 & 99.15 & 0.36 & 782 & 2 & 660 \\
\hline WH5d_67 & 59.05 & 25.89 & 0.16 & & 7.51 & 6.97 & 0.44 & 100.03 & 0.36 & 787 & 2 & 670 \\
\hline WH5d_68 & 60.54 & 25.95 & 0.23 & & 7.17 & 7.25 & 0.51 & 101.66 & 0.34 & 775 & 2 & 680 \\
\hline WH5d_69 & 59.81 & 26.32 & 0.29 & & 7.53 & 6.97 & 0.49 & 101.41 & 0.36 & 786 & 2 & 690 \\
\hline WH5d_70 & 58.86 & 24.76 & 0.18 & & 6.72 & 7.01 & 0.57 & 98.10 & 0.33 & 770 & 2 & 700 \\
\hline WH5f_1 & 59.98 & 25.07 & 0.25 & & 6.95 & 7.40 & 0.63 & 100.28 & 0.33 & 766 & 2 & 20 \\
\hline WH5f_2 & 60.16 & 25.60 & 0.29 & & 7.03 & 7.29 & 0.67 & 101.05 & 0.33 & 768 & 2 & 30 \\
\hline WH5f_3 & 60.06 & 25.38 & 0.23 & & 6.83 & 7.47 & 0.68 & 100.65 & 0.32 & 762 & 2 & 40 \\
\hline WH5f_4 & 59.62 & 25.38 & 0.22 & & 6.79 & 7.47 & 0.65 & 100.14 & 0.32 & 762 & 2 & 50 \\
\hline WH5f_5 & 60.22 & 24.97 & 0.29 & & 6.59 & 7.47 & 0.66 & 100.19 & 0.32 & 758 & 2 & 60 \\
\hline WH5f_6 & 59.70 & 25.09 & 0.29 & & 6.39 & 7.35 & 0.60 & 99.43 & 0.31 & 757 & 2 & 70 \\
\hline WH5f_7 & 61.34 & 24.27 & 0.23 & & 5.71 & 7.98 & 0.82 & 100.35 & 0.27 & 728 & 2 & 80 \\
\hline WH5f_8 & 59.67 & 25.02 & 0.25 & & 6.72 & 7.38 & 0.68 & 99.72 & 0.32 & 761 & 2 & 90 \\
\hline WH5f_9 & 60.92 & 25.15 & 0.19 & & 6.50 & 7.32 & 0.63 & 100.71 & 0.32 & 759 & 2 & 100 \\
\hline WH5f_10 & 59.90 & 25.22 & 0.31 & & 6.74 & 7.29 & 0.65 & 100.11 & 0.33 & 764 & 2 & 110 \\
\hline WH5f_11 & 59.82 & 25.17 & 0.26 & & 6.72 & 7.31 & 0.66 & 99.93 & 0.32 & 763 & 2 & 120 \\
\hline WH5f_12 & 59.86 & 25.19 & 0.25 & & 6.66 & 7.32 & 0.72 & 100.01 & 0.32 & 760 & 2 & 130 \\
\hline WH5f_13 & 60.26 & 24.80 & 0.26 & & 6.38 & 7.33 & 0.61 & 99.64 & 0.31 & 757 & 2 & 140 \\
\hline WH5f_14 & 60.71 & 24.97 & 0.25 & & 6.30 & 7.38 & 0.67 & 100.28 & 0.31 & 753 & 2 & 150 \\
\hline WH5f_15 & 58.79 & 24.76 & 0.38 & & 6.31 & 7.11 & 1.04 & 98.40 & 0.31 & 749 & 2 & 160 \\
\hline WH5f_16 & 60.84 & 25.00 & 0.27 & & 6.49 & 7.39 & 0.63 & 100.62 & 0.31 & 758 & 2 & 170 \\
\hline WH5f_17 & 60.86 & 24.90 & 0.16 & & 6.34 & 7.66 & 0.73 & 100.66 & 0.30 & 749 & 2 & 180 \\
\hline WH5f_18 & 62.16 & 24.87 & 0.28 & & 6.38 & 7.48 & 0.64 & 101.79 & 0.31 & 754 & 2 & 190 \\
\hline WH5f_19 & 60.66 & 24.92 & 0.29 & & 6.53 & 7.53 & 0.70 & 100.63 & 0.31 & 755 & 2 & 200 \\
\hline WH5f_20 & 61.20 & 25.09 & 0.28 & & 6.48 & 7.50 & 0.65 & 101.20 & 0.31 & 756 & 2 & 210 \\
\hline WH5f_21 & 60.50 & 24.82 & 0.22 & & 5.92 & 7.91 & 0.71 & 100.08 & 0.28 & 736 & 2 & 220 \\
\hline WH5f_22 & 60.74 & 24.59 & 0.19 & & 6.13 & 7.44 & 0.75 & 99.83 & 0.30 & 747 & 2 & 230 \\
\hline WH5f_23 & 62.10 & 23.98 & 0.29 & & 6.46 & 7.62 & 0.69 & 101.14 & 0.31 & 753 & 2 & 240 \\
\hline WH5f_26 & 61.13 & 24.42 & 0.28 & & 5.88 & 7.57 & 0.80 & 100.07 & 0.29 & 739 & 2 & 270 \\
\hline WH5f_28 & 61.13 & 25.52 & 0.30 & & 6.54 & 7.50 & 0.62 & 101.61 & 0.31 & 758 & 2 & 290 \\
\hline WH5f_29 & 61.20 & 25.74 & 0.19 & & 6.67 & 7.25 & 0.71 & 101.77 & 0.32 & 761 & 2 & 300 \\
\hline WH5f_30 & 61.99 & 25.28 & 0.24 & & 6.43 & 7.42 & 0.59 & 101.95 & 0.31 & 757 & 2 & 310 \\
\hline WH5f_31 & 62.59 & 24.74 & 0.24 & & 5.70 & 7.69 & 0.76 & 101.72 & 0.28 & 734 & 2 & 320 \\
\hline WH5f_33 & 62.25 & 24.96 & 0.26 & & 6.09 & 7.60 & 0.72 & 101.89 & 0.29 & 744 & 2 & 340 \\
\hline WH5f_36 & 62.59 & 24.94 & 0.21 & & 5.81 & 7.65 & 0.73 & 101.93 & 0.28 & 738 & 2 & 370 \\
\hline WH5f_42 & 60.24 & 25.75 & 0.26 & & 7.17 & 7.11 & 0.63 & 101.16 & 0.34 & 774 & 2 & 430 \\
\hline WH5f_43 & 60.51 & 25.78 & 0.20 & & 7.46 & 7.13 & 0.60 & 101.68 & 0.35 & 779 & 2 & 440 \\
\hline WH5f_44 & 61.91 & 25.85 & 0.24 & & 7.18 & 6.89 & 0.56 & 102.64 & 0.35 & 779 & 2 & 450 \\
\hline WH5f_45 & 58.61 & 25.06 & 0.15 & & 7.01 & 6.65 & 0.51 & 97.99 & 0.36 & 782 & 2 & 460 \\
\hline WH5f_47 & 59.95 & 26.57 & 0.18 & & 7.56 & 6.72 & 0.48 & 101.46 & 0.37 & 790 & 2 & 480 \\
\hline WH5f_48 & 60.32 & 26.64 & 0.15 & & 7.63 & 6.69 & 0.46 & 101.88 & 0.38 & 792 & 2 & 490 \\
\hline WH5f_50 & 60.18 & 26.18 & 0.22 & & 7.64 & 6.87 & 0.51 & 101.60 & 0.37 & 789 & 2 & 510 \\
\hline WH5f_51 & 59.96 & 26.57 & 0.23 & & 7.76 & 6.85 & 0.49 & 101.86 & 0.37 & 791 & 2 & 520 \\
\hline WH5f_52 & 59.69 & 26.34 & 0.17 & & 7.48 & 6.90 & 0.56 & 101.13 & 0.36 & 784 & 2 & 530 \\
\hline
\end{tabular}


Table A3.6 continued

\begin{tabular}{|c|c|c|c|c|c|c|c|c|c|c|c|c|}
\hline Sample & $\mathrm{SiO}_{2}$ & $\mathrm{Al}_{2} \mathrm{O}_{3}$ & $\mathrm{FeO}$ & $\mathrm{MgO}$ & $\mathrm{CaO}$ & $\mathrm{Na}_{2} \mathrm{O}$ & $\mathrm{K}_{2} \mathrm{O}$ & Total & Xan & $\begin{array}{c}\mathrm{T} \\
\left({ }^{\circ} \mathrm{C}\right)\end{array}$ & G & $\begin{array}{l}\text { Dist. } \\
(\mu \mathrm{m})\end{array}$ \\
\hline WH6b_3 & 62.19 & 24.78 & 0.09 & & 5.85 & 7.77 & 0.65 & 101.32 & 0.28 & 738 & 3 & 30 \\
\hline WH6b_4 & 62.19 & 24.67 & 0.27 & & 5.94 & 7.85 & 0.78 & 101.69 & 0.28 & 736 & 3 & 40 \\
\hline WH6b_6 & 61.73 & 24.98 & 0.32 & & 6.02 & 8.09 & 0.71 & 101.84 & 0.28 & 736 & 3 & 60 \\
\hline WH6b_7 & 61.60 & 25.52 & 0.22 & & 5.74 & 7.70 & 0.70 & 101.49 & 0.28 & 736 & 3 & 70 \\
\hline WH6b_10 & 62.13 & 24.77 & 0.19 & & 5.83 & 8.04 & 0.70 & 101.65 & 0.27 & 733 & 3 & 100 \\
\hline WH6b_12 & 62.71 & 24.49 & 0.24 & & 5.34 & 8.11 & 0.73 & 101.62 & 0.26 & 720 & 3 & 120 \\
\hline WH6b_13 & 63.99 & 23.22 & 0.20 & & 4.25 & 8.60 & 1.07 & 101.32 & 0.20 & 677 & 3 & 130 \\
\hline WH6b_14 & 60.46 & 22.97 & 0.22 & & 4.15 & 8.54 & 0.97 & 97.30 & 0.20 & 677 & 3 & 140 \\
\hline WH6b_15 & 62.13 & 24.45 & 0.23 & & 4.92 & 8.39 & 0.87 & 100.97 & 0.23 & 702 & 3 & 150 \\
\hline WH6b_16 & 63.23 & 24.62 & 0.23 & & 5.40 & 7.67 & 0.73 & 101.88 & 0.27 & 727 & 3 & 160 \\
\hline WH6b_17 & 61.47 & 24.22 & 0.22 & & 5.70 & 7.79 & 0.76 & 100.16 & 0.28 & 732 & 3 & 170 \\
\hline WH6b_18 & 62.32 & 24.78 & 0.29 & & 5.68 & 7.84 & 0.76 & 101.66 & 0.27 & 731 & 3 & 180 \\
\hline WH6b_19 & 60.41 & 23.91 & 0.18 & & 5.77 & 7.47 & 0.84 & 98.58 & 0.28 & 737 & 3 & 190 \\
\hline WH6b_21 & 60.98 & 24.36 & 0.13 & & 5.30 & 8.04 & 0.84 & 99.65 & 0.25 & 717 & 3 & 210 \\
\hline WH6b_22 & 61.18 & 24.63 & 0.21 & & 5.41 & 8.12 & 0.80 & 100.36 & 0.26 & 720 & 3 & 220 \\
\hline WH6b_23 & 60.67 & 24.88 & 0.14 & & 5.56 & 7.86 & 0.72 & 99.82 & 0.27 & 729 & 3 & 230 \\
\hline WH6b_24 & 61.16 & 24.87 & 0.27 & & 5.62 & 7.96 & 0.85 & 100.72 & 0.27 & 726 & 3 & 240 \\
\hline WH6b_25 & 61.77 & 24.22 & 0.14 & & 5.19 & 8.07 & 0.85 & 100.23 & 0.25 & 714 & 3 & 250 \\
\hline WH6b_26 & 62.11 & 24.42 & 0.09 & & 5.04 & 8.12 & 0.85 & 100.63 & 0.24 & 709 & 3 & 260 \\
\hline WH6b_27 & 61.88 & 24.04 & 0.19 & & 5.22 & 7.99 & 0.75 & 100.08 & 0.25 & 718 & 3 & 270 \\
\hline WH6b_28 & 62.30 & 24.15 & 0.17 & & 4.79 & 8.16 & 0.87 & 100.43 & 0.23 & 702 & 3 & 280 \\
\hline WH6b_29 & 62.33 & 24.32 & 0.21 & & 5.02 & 7.87 & 0.85 & 100.60 & 0.25 & 713 & 3 & 290 \\
\hline WH6b_30 & 63.27 & 24.08 & 0.17 & & 4.42 & 8.52 & 0.92 & 101.39 & 0.21 & 686 & 3 & 300 \\
\hline WH6b_31 & 63.33 & 23.38 & 0.17 & & 4.37 & 8.58 & 0.99 & 100.81 & 0.21 & 683 & 3 & 310 \\
\hline WH6b_32 & 62.89 & 23.09 & 0.24 & & 3.92 & 8.38 & 1.02 & 99.53 & 0.19 & 671 & 3 & 320 \\
\hline WH6b_34 & 62.40 & 24.26 & 0.19 & & 4.35 & 8.45 & 1.05 & 100.70 & 0.21 & 682 & 3 & 340 \\
\hline WH6b_35 & 60.02 & 25.56 & 0.17 & & 5.91 & 7.74 & 0.71 & 100.11 & 0.28 & 739 & 3 & 350 \\
\hline WH6b_36 & 61.01 & 24.06 & 0.17 & & 4.79 & 8.10 & 0.80 & 98.94 & 0.23 & 704 & 3 & 360 \\
\hline WH6b_37 & 62.17 & 23.26 & 0.12 & & 3.96 & 8.49 & 0.97 & 98.97 & 0.19 & 672 & 3 & 370 \\
\hline WH6b_38 & 61.98 & 24.08 & 0.16 & & 4.20 & 8.28 & 0.92 & 99.61 & 0.21 & 682 & 3 & 380 \\
\hline WH6b_39 & 62.18 & 23.46 & 0.25 & & 4.75 & 8.24 & 0.99 & 99.86 & 0.23 & 697 & 3 & 390 \\
\hline WH6b_40 & 62.45 & 23.75 & 0.12 & & 4.25 & 8.13 & 0.97 & 99.68 & 0.21 & 685 & 3 & 400 \\
\hline WH6b_41 & 62.24 & 23.29 & 0.18 & & 4.18 & 8.39 & 1.10 & 99.37 & 0.20 & 677 & 3 & 410 \\
\hline WH6b_42 & 62.63 & 23.55 & 0.26 & & 4.10 & 8.58 & 1.03 & 100.15 & 0.20 & 674 & 3 & 420 \\
\hline WH6b_43 & 62.99 & 23.54 & 0.13 & & 4.10 & 8.49 & 1.11 & 100.36 & 0.20 & 673 & 3 & 430 \\
\hline WH6b_44 & 62.82 & 23.70 & 0.11 & & 4.32 & 8.24 & 1.11 & 100.30 & 0.21 & 683 & 3 & 440 \\
\hline WH6b_45 & 62.21 & 23.30 & 0.26 & & 3.76 & 8.54 & 1.06 & 99.13 & 0.18 & 663 & 3 & 450 \\
\hline WH6b_46 & 61.62 & 23.88 & 0.16 & & 4.44 & 8.35 & 1.03 & 99.47 & 0.21 & 686 & 3 & 460 \\
\hline WH6b_47 & 62.91 & 23.65 & 0.16 & & 4.19 & 8.60 & 1.08 & 100.58 & 0.20 & 675 & 3 & 470 \\
\hline WH6b_48 & 62.52 & 23.93 & 0.20 & & 4.49 & 8.30 & 1.05 & 100.49 & 0.22 & 689 & 3 & 480 \\
\hline WH6b_49 & 62.21 & 23.50 & 0.12 & & 4.07 & 8.30 & 0.93 & 99.13 & 0.20 & 678 & 3 & 490 \\
\hline WH6c_2 & 64.02 & 23.49 & 0.14 & & 4.67 & 8.51 & 0.86 & 101.71 & 0.22 & 694 & 3 & 20 \\
\hline WH6c_3 & 64.92 & 22.92 & 0.18 & & 4.16 & 8.45 & 1.10 & 101.72 & 0.20 & 676 & 3 & 30 \\
\hline WH6c_4 & 63.95 & 23.54 & 0.24 & & 4.74 & 8.32 & 0.95 & 101.74 & 0.23 & 697 & 3 & 40 \\
\hline WH6c_5 & 63.39 & 23.32 & 0.25 & & 4.68 & 8.15 & 0.98 & 100.78 & 0.23 & 697 & 3 & 50 \\
\hline WH6c_6 & 63.82 & 23.55 & 0.09 & & 4.66 & 8.48 & 1.04 & 101.64 & 0.22 & 691 & 3 & 60 \\
\hline WH6c_7 & 64.29 & 23.44 & 0.13 & & 4.34 & 8.64 & 0.93 & 101.76 & 0.21 & 682 & 3 & 70 \\
\hline WH6c_9 & 64.22 & 23.22 & 0.11 & & 4.65 & 8.24 & 0.95 & 101.38 & 0.22 & 696 & 3 & 90 \\
\hline WH6c_10 & 64.59 & 23.44 & 0.08 & & 4.73 & 8.12 & 0.89 & 101.87 & 0.23 & 700 & 3 & 100 \\
\hline WH6c_14 & 63.84 & 23.46 & 0.18 & & 4.64 & 8.20 & 0.84 & 101.17 & 0.23 & 698 & 3 & 140 \\
\hline WH6c_15 & 63.98 & 23.35 & 0.14 & & 4.82 & 8.12 & 0.98 & 101.40 & 0.23 & 701 & 3 & 150 \\
\hline WH6c_16 & 64.31 & 23.19 & 0.19 & & 4.67 & 8.32 & 0.98 & 101.68 & 0.22 & 694 & 3 & 160 \\
\hline WH6c_17 & 65.37 & 22.85 & 0.17 & & 4.12 & 8.33 & 1.15 & 101.98 & 0.20 & 676 & 3 & 170 \\
\hline WH6c_18 & 64.92 & 22.98 & 0.23 & & 4.05 & 8.52 & 1.04 & 101.74 & 0.20 & 673 & 3 & 180 \\
\hline WH6c_19 & 63.54 & 23.74 & 0.20 & & 5.01 & 8.22 & 0.93 & 101.64 & 0.24 & 706 & 3 & 190 \\
\hline WH6c_20 & 64.01 & 23.34 & 0.34 & & 4.75 & 8.37 & 0.93 & 101.75 & 0.23 & 697 & 3 & 200 \\
\hline
\end{tabular}


Table A3.6 continued

\begin{tabular}{|c|c|c|c|c|c|c|c|c|c|c|c|c|}
\hline Sample & $\mathrm{SiO}_{2}$ & $\mathrm{Al}_{2} \mathrm{O}_{3}$ & $\mathrm{FeO}$ & $\mathrm{MgO}$ & $\mathrm{CaO}$ & $\mathrm{Na}_{2} \mathrm{O}$ & $\mathrm{K}_{2} \mathrm{O}$ & Total & Xan & $\begin{array}{c}\mathrm{T} \\
\left({ }^{\circ} \mathrm{C}\right)\end{array}$ & G & $\begin{array}{l}\text { Dist. } \\
(\mu \mathrm{m})\end{array}$ \\
\hline WH6c_30 & 62.95 & 24.14 & 0.19 & & 5.32 & 8.11 & 0.94 & 101.65 & 0.25 & 715 & 3 & 300 \\
\hline WH6c_31 & 62.38 & 24.36 & 0.14 & & 5.63 & 7.82 & 0.75 & 101.09 & 0.27 & 730 & 3 & 310 \\
\hline WH6c_32 & 62.74 & 24.53 & 0.25 & & 5.88 & 7.68 & 0.81 & 101.89 & 0.28 & 737 & 3 & 320 \\
\hline WH6c_34 & 63.27 & 23.93 & 0.20 & & 5.36 & 8.01 & 0.78 & 101.55 & 0.26 & 720 & 3 & 340 \\
\hline WH6c_35 & 63.51 & 23.91 & 0.17 & & 5.31 & 8.20 & 0.82 & 101.94 & 0.25 & 716 & 3 & 350 \\
\hline WH6c_36 & 63.34 & 24.15 & 0.26 & & 5.34 & 8.07 & 0.76 & 101.93 & 0.26 & 720 & 3 & 360 \\
\hline WH6c_38 & 62.74 & 24.37 & 0.24 & & 5.70 & 7.95 & 0.82 & 101.82 & 0.27 & 728 & 3 & 380 \\
\hline WH6c_41 & 63.13 & 24.23 & 0.19 & & 5.29 & 8.23 & 0.81 & 101.88 & 0.25 & 715 & 3 & 410 \\
\hline WH6c_42 & 63.47 & 23.91 & 0.13 & & 5.16 & 8.10 & 0.80 & 101.56 & 0.25 & 714 & 3 & 420 \\
\hline WH6c_44 & 62.97 & 23.90 & 0.17 & & 5.53 & 7.89 & 0.74 & 101.20 & 0.27 & 727 & 3 & 440 \\
\hline WH6c_48 & 62.37 & 24.30 & 0.19 & & 5.43 & 8.04 & 0.75 & 101.08 & 0.26 & 722 & 3 & 480 \\
\hline WH6c_49 & 61.27 & 24.67 & 0.23 & & 5.50 & 7.99 & 0.79 & 100.44 & 0.26 & 724 & 3 & 490 \\
\hline WH6c_50 & 62.05 & 24.63 & 0.19 & & 5.72 & 8.08 & 0.74 & 101.40 & 0.27 & 729 & 3 & 500 \\
\hline WH6c_51 & 61.99 & 24.86 & 0.18 & & 6.01 & 7.84 & 0.71 & 101.59 & 0.29 & 739 & 3 & 510 \\
\hline WH6c_52 & 61.39 & 25.37 & 0.19 & & 6.57 & 7.67 & 0.69 & 101.88 & 0.31 & 754 & 3 & 520 \\
\hline WH6c_53 & 61.17 & 25.36 & 0.23 & & 7.21 & 7.27 & 0.61 & 101.85 & 0.34 & 773 & 3 & 530 \\
\hline WH6c_54 & 60.21 & 25.68 & 0.22 & & 7.39 & 7.45 & 0.56 & 101.51 & 0.34 & 775 & 3 & 540 \\
\hline WH6c_55 & 59.87 & 26.46 & 0.21 & & 7.68 & 7.12 & 0.52 & 101.85 & 0.36 & 785 & 3 & 550 \\
\hline WH6c_56 & 59.51 & 26.05 & 0.26 & & 7.69 & 7.08 & 0.62 & 101.21 & 0.36 & 783 & 3 & 560 \\
\hline WH6c_57 & 59.79 & 26.06 & 0.28 & & 7.54 & 7.21 & 0.55 & 101.43 & 0.35 & 781 & 3 & 570 \\
\hline WH6c_58 & 59.88 & 25.64 & 0.12 & & 7.30 & 7.10 & 0.53 & 100.57 & 0.35 & 779 & 3 & 580 \\
\hline WH6c_59 & 59.67 & 25.80 & 0.18 & & 7.19 & 7.13 & 0.59 & 100.56 & 0.35 & 775 & 3 & 590 \\
\hline WH6c_60 & 60.08 & 25.35 & 0.24 & & 7.15 & 7.26 & 0.63 & 100.71 & 0.34 & 772 & 3 & 600 \\
\hline WH6c_61 & 62.05 & 24.74 & 0.23 & & 6.50 & 7.68 & 0.65 & 101.85 & 0.31 & 753 & 3 & 610 \\
\hline WH6c_62 & 61.87 & 25.00 & 0.26 & & 6.20 & 7.67 & 0.72 & 101.73 & 0.30 & 746 & 3 & 620 \\
\hline WH6c_63 & 60.64 & 25.25 & 0.22 & & 6.57 & 7.45 & 0.64 & 100.78 & 0.32 & 758 & 3 & 630 \\
\hline WH6c_64 & 60.95 & 25.20 & 0.29 & & 6.51 & 7.63 & 0.71 & 101.30 & 0.31 & 753 & 3 & 640 \\
\hline WH6c_65 & 60.85 & 24.99 & 0.22 & & 6.88 & 7.48 & 0.69 & 101.11 & 0.32 & 763 & 3 & 650 \\
\hline WH6c_66 & 61.35 & 24.72 & 0.11 & & 5.85 & 7.86 & 0.70 & 100.59 & 0.28 & 736 & 3 & 660 \\
\hline WH6c_67 & 60.31 & 25.37 & 0.16 & & 6.76 & 7.43 & 0.67 & 100.71 & 0.32 & 761 & 3 & 670 \\
\hline WH6c_68 & 60.38 & 25.57 & 0.20 & & 6.94 & 7.38 & 0.62 & 101.07 & 0.33 & 767 & 3 & 680 \\
\hline WH6c_70 & 60.77 & 25.19 & 0.18 & & 6.81 & 7.50 & 0.65 & 101.11 & 0.32 & 762 & 3 & 690 \\
\hline WH6c_71 & 60.86 & 25.06 & 0.24 & & 6.38 & 7.44 & 0.67 & 100.65 & 0.31 & 754 & 3 & 700 \\
\hline WH6c 72 & 61.22 & 25.17 & 0.23 & & 6.66 & 7.30 & 0.63 & 101.20 & 0.32 & 763 & 3 & 710 \\
\hline WH6c_73 & 60.48 & 25.07 & 0.18 & & 6.79 & 7.16 & 0.56 & 100.24 & 0.33 & 769 & 3 & 720 \\
\hline WH6c_74 & 61.55 & 25.22 & 0.28 & & 6.60 & 7.39 & 0.67 & 101.72 & 0.32 & 759 & 3 & 730 \\
\hline WH6c_75 & 61.05 & 25.20 & 0.16 & & 6.78 & 7.70 & 0.66 & 101.55 & 0.32 & 758 & 3 & 740 \\
\hline WH6c_76 & 61.43 & 25.25 & 0.24 & & 6.58 & 7.59 & 0.75 & 101.85 & 0.31 & 754 & 3 & 750 \\
\hline WH6c_77 & 61.16 & 25.21 & 0.24 & & 6.59 & 7.47 & 0.65 & 101.32 & 0.32 & 758 & 3 & 760 \\
\hline WH6c_78 & 60.92 & 25.02 & 0.29 & & 6.36 & 7.48 & 0.62 & 100.70 & 0.31 & 754 & 3 & 770 \\
\hline WH6c_79 & 61.20 & 25.12 & 0.18 & & 6.49 & 7.55 & 0.64 & 101.19 & 0.31 & 755 & 3 & 780 \\
\hline WH6c_80 & 60.64 & 25.36 & 0.20 & & 6.47 & 7.43 & 0.59 & 100.67 & 0.31 & 758 & 3 & 790 \\
\hline WH6c_81 & 60.14 & 25.20 & 0.24 & & 6.48 & 7.56 & 0.63 & 100.26 & 0.31 & 755 & 3 & 800 \\
\hline WH6c_82 & 60.83 & 25.26 & 0.19 & & 6.55 & 7.58 & 0.71 & 101.11 & 0.31 & 754 & 3 & 810 \\
\hline WH6c_83 & 60.80 & 25.12 & 0.27 & & 6.48 & 7.45 & 0.61 & 100.73 & 0.31 & 757 & 3 & 820 \\
\hline WH6c_84 & 61.44 & 25.16 & 0.23 & & 6.52 & 7.51 & 0.73 & 101.58 & 0.31 & 754 & 3 & 830 \\
\hline WH6c_85 & 61.21 & 24.89 & 0.21 & & 6.26 & 7.80 & 0.70 & 101.06 & 0.30 & 746 & 3 & 840 \\
\hline WH6c_86 & 61.34 & 25.02 & 0.17 & & 6.08 & 7.73 & 0.73 & 101.07 & 0.29 & 742 & 3 & 850 \\
\hline WH6c_87 & 61.78 & 25.20 & 0.16 & & 6.34 & 7.74 & 0.66 & 101.88 & 0.30 & 749 & 3 & 860 \\
\hline WH6c_88 & 61.46 & 24.96 & 0.15 & & 6.28 & 7.59 & 0.72 & 101.16 & 0.30 & 749 & 3 & 870 \\
\hline WH6c_89 & 61.43 & 24.80 & 0.18 & & 6.20 & 7.64 & 0.64 & 100.88 & 0.30 & 748 & 3 & 880 \\
\hline WH6c_90 & 61.83 & 24.89 & 0.16 & & 6.05 & 7.81 & 0.73 & 101.49 & 0.29 & 740 & 3 & 890 \\
\hline WH6c_91 & 62.14 & 24.28 & 0.32 & & 6.06 & 7.52 & 0.72 & 101.03 & 0.30 & 745 & 3 & 900 \\
\hline WH6c_93 & 62.56 & 24.72 & 0.25 & & 5.86 & 7.89 & 0.70 & 101.97 & 0.28 & 736 & 3 & 920 \\
\hline WH6da_1 & 60.24 & 25.22 & 0.33 & & 6.58 & 7.39 & 0.58 & 100.35 & 0.32 & 761 & 1 & 20 \\
\hline WH6da_2 & 59.71 & 25.25 & 0.21 & & 6.65 & 7.38 & 0.63 & 99.81 & 0.32 & 761 & 1 & 30 \\
\hline
\end{tabular}


Table A3.6 continued

\begin{tabular}{|c|c|c|c|c|c|c|c|c|c|c|c|c|}
\hline Sample & $\mathrm{SiO}_{2}$ & $\mathrm{Al}_{2} \mathrm{O}_{3}$ & $\mathrm{FeO}$ & $\mathrm{MgO}$ & $\mathrm{CaO}$ & $\mathrm{Na}_{2} \mathrm{O}$ & $\mathrm{K}_{2} \mathrm{O}$ & Total & Xan & $\begin{array}{c}\mathrm{T} \\
\left({ }^{\circ} \mathrm{C}\right)\end{array}$ & G & $\begin{array}{l}\text { Dist. } \\
(\mu \mathrm{m})\end{array}$ \\
\hline WH6da_6 & 61.20 & 25.13 & 0.33 & & 6.33 & 7.77 & 0.66 & 101.41 & 0.30 & 748 & 1 & 70 \\
\hline WH6da_9 & 60.31 & 25.08 & 0.24 & & 6.66 & 7.53 & 0.65 & 100.46 & 0.32 & 759 & 1 & 100 \\
\hline WH6da_10 & 59.87 & 25.31 & 0.22 & & 6.39 & 7.47 & 0.64 & 99.90 & 0.31 & 754 & 1 & 110 \\
\hline WH6da_11 & 60.31 & 26.06 & 0.22 & & 6.78 & 7.40 & 0.66 & 101.43 & 0.32 & 762 & 1 & 120 \\
\hline WH6da_12 & 59.73 & 25.42 & 0.21 & & 6.72 & 7.28 & 0.68 & 100.04 & 0.32 & 763 & 1 & 130 \\
\hline WH6da_13 & 60.70 & 25.56 & 0.25 & & 6.37 & 7.42 & 0.78 & 101.07 & 0.31 & 751 & 1 & 140 \\
\hline WH6da_15 & 60.34 & 24.91 & 0.22 & & 6.68 & 7.51 & 0.61 & 100.26 & 0.32 & 760 & 1 & 160 \\
\hline WH6da_16 & 59.43 & 25.35 & 0.20 & & 6.83 & 7.40 & 0.63 & 99.84 & 0.33 & 764 & 1 & 170 \\
\hline WH6da_17 & 59.52 & 25.41 & 0.22 & & 6.49 & 7.32 & 0.56 & 99.51 & 0.32 & 761 & 1 & 180 \\
\hline WH6da_18 & 59.73 & 25.01 & 0.39 & & 6.13 & 7.44 & 0.60 & 99.31 & 0.30 & 751 & 1 & 190 \\
\hline WH6da_19 & 59.36 & 25.47 & 0.23 & & 6.33 & 7.37 & 0.62 & 99.38 & 0.31 & 755 & 1 & 200 \\
\hline WH6da_27 & 55.37 & 29.53 & 0.27 & & 10.55 & 5.44 & 0.32 & 101.47 & 0.51 & 838 & 1 & 280 \\
\hline WH6da_28 & 55.56 & 29.54 & 0.25 & & 10.48 & 5.43 & 0.35 & 101.61 & 0.51 & 837 & 1 & 290 \\
\hline WH6da_29 & 55.65 & 29.33 & 0.18 & & 10.27 & 5.56 & 0.32 & 101.30 & 0.50 & 836 & 1 & 300 \\
\hline WH6da_30 & 54.94 & 29.95 & 0.24 & & 11.35 & 5.23 & 0.25 & 101.94 & 0.54 & 845 & 1 & 310 \\
\hline WH6da_31 & 53.84 & 29.42 & 0.27 & & 10.98 & 5.25 & 0.25 & 100.01 & 0.53 & 843 & 1 & 320 \\
\hline WH6da_32 & 58.27 & 26.43 & 0.29 & & 7.58 & 6.82 & 0.46 & 99.85 & 0.37 & 790 & 1 & 330 \\
\hline WH6da_33 & 58.05 & 26.68 & 0.27 & & 7.69 & 6.77 & 0.53 & 99.99 & 0.37 & 790 & 1 & 340 \\
\hline WH6da_37 & 56.30 & 29.34 & 0.27 & & 9.88 & 5.74 & 0.28 & 101.82 & 0.48 & 833 & 1 & 380 \\
\hline WH6da_39 & 56.09 & 29.14 & 0.22 & & 9.94 & 5.62 & 0.32 & 101.33 & 0.49 & 833 & 1 & 400 \\
\hline WH6da_40 & 57.15 & 28.58 & 0.45 & & 9.13 & 5.89 & 0.32 & 101.51 & 0.45 & 825 & 1 & 410 \\
\hline WH6da_41 & 58.25 & 27.83 & 0.31 & & 8.72 & 6.44 & 0.43 & 101.97 & 0.42 & 811 & 1 & 420 \\
\hline WH6da_42 & 59.85 & 26.39 & 0.18 & & 7.04 & 7.12 & 0.60 & 101.18 & 0.34 & 773 & 1 & 430 \\
\hline WH6da_43 & 59.95 & 26.10 & 0.27 & & 6.84 & 7.08 & 0.62 & 100.86 & 0.34 & 769 & 1 & 440 \\
\hline WH6da_47 & 60.89 & 25.50 & 0.22 & & 6.64 & 7.57 & 0.59 & 101.41 & 0.32 & 759 & 1 & 480 \\
\hline WH6da_48 & 60.59 & 26.05 & 0.24 & & 6.66 & 7.39 & 0.65 & 101.58 & 0.32 & 761 & 1 & 490 \\
\hline WH6da_49 & 60.59 & 25.71 & 0.21 & & 6.65 & 7.36 & 0.60 & 101.13 & 0.32 & 762 & 1 & 500 \\
\hline WH6da_50 & 60.49 & 26.10 & 0.19 & & 6.90 & 7.38 & 0.62 & 101.67 & 0.33 & 766 & 1 & 510 \\
\hline WH6da_52 & 60.39 & 26.34 & 0.25 & & 7.05 & 7.22 & 0.58 & 101.82 & 0.34 & 772 & 1 & 530 \\
\hline WH6da_55 & 61.11 & 25.51 & 0.30 & & 6.43 & 7.69 & 0.66 & 101.69 & 0.30 & 752 & 1 & 560 \\
\hline WH6da_56 & 59.99 & 25.36 & 0.22 & & 6.90 & 7.43 & 0.63 & 100.52 & 0.33 & 765 & 1 & 570 \\
\hline WH6da_57 & 59.08 & 25.93 & 0.29 & & 6.94 & 7.38 & 0.64 & 100.26 & 0.33 & 766 & 1 & 580 \\
\hline WH6da_58 & 59.31 & 26.26 & 0.26 & & 6.59 & 7.13 & 0.68 & 100.23 & 0.32 & 763 & 1 & 590 \\
\hline WH6da_59 & 60.32 & 26.30 & 0.28 & & 6.84 & 7.40 & 0.61 & 101.75 & 0.33 & 765 & 1 & 600 \\
\hline WH6da_60 & 59.49 & 26.44 & 0.22 & & 6.57 & 7.39 & 0.63 & 100.75 & 0.32 & 760 & 1 & 610 \\
\hline WH6db_2 & 60.18 & 25.93 & 0.29 & & 7.04 & 7.29 & 0.52 & 101.26 & 0.34 & 772 & 1 & 30 \\
\hline WH6db_3 & 58.52 & 26.84 & 0.22 & & 8.19 & 6.78 & 0.47 & 101.02 & 0.39 & 799 & 1 & 40 \\
\hline WH6db_4 & 57.52 & 27.13 & 0.24 & & 8.45 & 6.45 & 0.42 & 100.20 & 0.41 & 808 & 1 & 50 \\
\hline WH6db_5 & 58.55 & 27.04 & 0.27 & & 7.90 & 6.79 & 0.47 & 101.02 & 0.38 & 794 & 1 & 60 \\
\hline WH6db_6 & 58.57 & 26.13 & 0.31 & & 7.32 & 6.77 & 0.56 & 99.66 & 0.36 & 784 & 1 & 70 \\
\hline WH6db_7 & 58.47 & 27.11 & 0.30 & & 7.01 & 7.22 & 0.60 & 100.70 & 0.34 & 771 & 1 & 80 \\
\hline WH6db_8 & 58.64 & 27.34 & 0.18 & & 7.84 & 6.79 & 0.51 & 101.31 & 0.38 & 793 & 1 & 90 \\
\hline WH6db_9 & 58.65 & 27.13 & 0.31 & & 7.76 & 6.74 & 0.56 & 101.15 & 0.38 & 790 & 1 & 100 \\
\hline WH6db_11 & 58.67 & 26.95 & 0.25 & & 7.90 & 6.90 & 0.53 & 101.19 & 0.38 & 791 & 1 & 120 \\
\hline WH6db_12 & 58.19 & 27.54 & 0.22 & & 8.32 & 6.77 & 0.40 & 101.44 & 0.40 & 802 & 1 & 130 \\
\hline WH6db_13 & 58.43 & 27.10 & 0.28 & & 7.88 & 6.91 & 0.49 & 101.09 & 0.38 & 792 & 1 & 140 \\
\hline WH6db_14 & 59.66 & 26.24 & 0.24 & & 6.72 & 7.40 & 0.63 & 100.88 & 0.32 & 762 & 1 & 150 \\
\hline WH6db_15 & 58.45 & 27.23 & 0.24 & & 7.47 & 7.16 & 0.50 & 101.05 & 0.36 & 782 & 1 & 160 \\
\hline WH6db_16 & 59.27 & 27.03 & 0.21 & & 7.62 & 6.86 & 0.49 & 101.48 & 0.37 & 789 & 1 & 170 \\
\hline WH6db_17 & 60.79 & 26.33 & 0.18 & & 6.45 & 7.49 & 0.69 & 101.93 & 0.31 & 754 & 1 & 180 \\
\hline WH6db_19 & 60.38 & 26.20 & 0.26 & & 6.75 & 7.16 & 0.66 & 101.40 & 0.33 & 766 & 1 & 200 \\
\hline WH6db_20 & 56.08 & 28.89 & 0.20 & & 10.29 & 5.71 & 0.34 & 101.51 & 0.49 & 834 & 1 & 210 \\
\hline WH6db_21 & 57.59 & 27.58 & 0.37 & & 8.82 & 6.42 & 0.52 & 101.31 & 0.42 & 809 & 1 & 220 \\
\hline WH6db_22 & 53.36 & 31.38 & 0.24 & & 12.23 & 4.37 & 0.25 & 101.82 & 0.60 & 847 & 1 & 230 \\
\hline WH6db_23 & 53.33 & 31.35 & 0.23 & & 11.80 & 4.84 & 0.28 & 101.82 & 0.56 & 846 & 1 & 240 \\
\hline WH6db_24 & 54.14 & 30.30 & 0.34 & & 10.81 & 5.14 & 0.30 & 101.02 & 0.53 & 842 & 1 & 250 \\
\hline
\end{tabular}


Table A3.6 continued

\begin{tabular}{|c|c|c|c|c|c|c|c|c|c|c|c|c|}
\hline Sample & $\mathrm{SiO}_{2}$ & $\mathrm{Al}_{2} \mathrm{O}_{3}$ & $\mathrm{FeO}$ & $\mathrm{MgO}$ & $\mathrm{CaO}$ & $\mathrm{Na}_{2} \mathrm{O}$ & $\mathrm{K}_{2} \mathrm{O}$ & Total & Xan & $\begin{array}{c}\mathrm{T} \\
\left({ }^{\circ} \mathrm{C}\right) \\
\end{array}$ & G & $\begin{array}{l}\text { Dist. } \\
(\mu \mathrm{m})\end{array}$ \\
\hline WH6db_28 & 60.41 & 26.30 & 0.20 & & 6.61 & 7.41 & 0.63 & 101.55 & 0.32 & 760 & 1 & 290 \\
\hline WH6db_29 & 60.75 & 26.18 & 0.26 & & 6.31 & 7.48 & 0.67 & 101.65 & 0.31 & 752 & 1 & 300 \\
\hline WH6db_31 & 60.70 & 25.99 & 0.24 & & 6.40 & 7.62 & 0.62 & 101.57 & 0.31 & 753 & 1 & 320 \\
\hline WH6db_34 & 60.45 & 26.11 & 0.34 & & 6.63 & 7.21 & 0.64 & 101.38 & 0.32 & 763 & 1 & 350 \\
\hline WH6db_35 & 60.50 & 26.13 & 0.25 & & 6.57 & 7.53 & 0.66 & 101.63 & 0.31 & 757 & 1 & 360 \\
\hline WH6db_36 & 60.01 & 26.09 & 0.37 & & 6.47 & 7.34 & 0.58 & 100.86 & 0.32 & 760 & 1 & 370 \\
\hline WH6db_37 & 60.14 & 25.90 & 0.19 & & 6.40 & 7.38 & 0.75 & 100.75 & 0.31 & 753 & 1 & 380 \\
\hline WH6db_38 & 59.83 & 26.77 & 0.29 & & 6.78 & 7.17 & 0.65 & 101.49 & 0.33 & 766 & 1 & 390 \\
\hline WH6db_39 & 59.96 & 26.75 & 0.34 & & 7.00 & 7.20 & 0.49 & 101.74 & 0.34 & 774 & 1 & 400 \\
\hline WH6e_2 & 59.92 & 25.44 & 0.24 & & 6.58 & 7.43 & 0.61 & 100.22 & 0.32 & 760 & 2 & 30 \\
\hline WH6e_3 & 60.13 & 25.46 & 0.30 & & 6.52 & 7.33 & 0.64 & 100.39 & 0.32 & 759 & 2 & 40 \\
\hline WH6e_4 & 60.85 & 25.83 & 0.25 & & 6.84 & 7.38 & 0.64 & 101.80 & 0.33 & 765 & 2 & 50 \\
\hline WH6e_5 & 61.64 & 24.42 & 0.27 & & 6.79 & 7.05 & 0.55 & 100.72 & 0.34 & 771 & 2 & 60 \\
\hline WH6e_6 & 60.02 & 25.51 & 0.23 & & 7.73 & 6.83 & 0.51 & 100.82 & 0.37 & 790 & 2 & 70 \\
\hline WH6e_7 & 60.72 & 24.75 & 0.18 & & 6.60 & 7.17 & 0.62 & 100.04 & 0.32 & 764 & 2 & 80 \\
\hline WH6e_8 & 61.05 & 24.68 & 0.22 & & 6.57 & 7.22 & 0.64 & 100.37 & 0.32 & 762 & 2 & 90 \\
\hline WH6e_9 & 60.89 & 24.49 & 0.25 & & 6.65 & 7.30 & 0.57 & 100.14 & 0.32 & 764 & 2 & 100 \\
\hline WH6e_10 & 60.59 & 24.75 & 0.24 & & 6.96 & 6.97 & 0.54 & 100.06 & 0.34 & 775 & 2 & 110 \\
\hline WH6e_11 & 60.46 & 24.66 & 0.19 & & 6.65 & 7.32 & 0.65 & 99.92 & 0.32 & 762 & 2 & 120 \\
\hline WH6e_12 & 61.54 & 24.63 & 0.25 & & 6.56 & 7.32 & 0.66 & 100.95 & 0.32 & 760 & 2 & 130 \\
\hline WH6e_13 & 61.75 & 24.80 & 0.16 & & 6.45 & 7.27 & 0.58 & 101.01 & 0.32 & 760 & 2 & 140 \\
\hline WH6e_14 & 62.18 & 24.68 & 0.32 & & 6.62 & 7.26 & 0.61 & 101.67 & 0.32 & 763 & 2 & 150 \\
\hline WH6e_15 & 61.28 & 24.73 & 0.27 & & 6.62 & 7.27 & 0.66 & 100.83 & 0.32 & 761 & 2 & 160 \\
\hline WH6e_16 & 61.69 & 24.67 & 0.21 & & 6.44 & 7.21 & 0.59 & 100.81 & 0.32 & 761 & 2 & 170 \\
\hline WH6e_17 & 61.39 & 24.67 & 0.19 & & 6.86 & 7.49 & 0.64 & 101.25 & 0.32 & 763 & 2 & 180 \\
\hline WH6e_18 & 59.71 & 24.70 & 0.33 & & 6.88 & 7.05 & 0.56 & 99.21 & 0.34 & 772 & 2 & 190 \\
\hline WH6e_19 & 60.65 & 24.29 & 0.26 & & 6.32 & 7.52 & 0.61 & 99.64 & 0.31 & 753 & 2 & 200 \\
\hline WH6e_20 & 60.73 & 24.67 & 0.16 & & 6.30 & 7.50 & 0.63 & 99.98 & 0.31 & 753 & 2 & 210 \\
\hline WH6e_21 & 62.23 & 24.00 & 0.22 & & 6.16 & 7.50 & 0.68 & 100.80 & 0.30 & 749 & 2 & 220 \\
\hline WH6e_22 & 61.82 & 24.30 & 0.18 & & 6.10 & 7.32 & 0.61 & 100.32 & 0.30 & 752 & 2 & 230 \\
\hline WH6e_23 & 62.11 & 24.02 & 0.31 & & 6.03 & 7.33 & 0.67 & 100.46 & 0.30 & 749 & 2 & 240 \\
\hline WH6e_24 & 61.12 & 24.38 & 0.25 & & 6.52 & 7.28 & 0.67 & 100.21 & 0.32 & 759 & 2 & 250 \\
\hline WH6e_25 & 61.61 & 24.54 & 0.24 & & 6.09 & 7.34 & 0.68 & 100.50 & 0.30 & 749 & 2 & 260 \\
\hline WH6e_26 & 61.43 & 24.22 & 0.32 & & 6.45 & 7.28 & 0.75 & 100.46 & 0.31 & 756 & 2 & 270 \\
\hline WH6e_27 & 61.20 & 24.90 & 0.32 & & 7.03 & 7.03 & 0.61 & 101.09 & 0.34 & 774 & 2 & 280 \\
\hline WH6e_28 & 61.60 & 24.62 & 0.28 & & 6.74 & 7.22 & 0.56 & 101.02 & 0.33 & 767 & 2 & 290 \\
\hline WH6e_29 & 60.66 & 24.90 & 0.26 & & 7.20 & 6.79 & 0.51 & 100.31 & 0.36 & 783 & 2 & 300 \\
\hline WH6e_30 & 59.84 & 25.91 & 0.23 & & 7.75 & 6.83 & 0.48 & 101.04 & 0.37 & 791 & 2 & 310 \\
\hline WH6e_31 & 60.83 & 25.56 & 0.30 & & 7.36 & 7.00 & 0.50 & 101.55 & 0.36 & 782 & 2 & 320 \\
\hline WH6e_32 & 60.57 & 25.07 & 0.28 & & 6.85 & 7.03 & 0.58 & 100.38 & 0.34 & 771 & 2 & 330 \\
\hline WH6e_33 & 61.02 & 24.43 & 0.22 & & 6.62 & 7.28 & 0.62 & 100.19 & 0.32 & 762 & 2 & 340 \\
\hline WH6e_34 & 60.76 & 24.96 & 0.26 & & 6.89 & 7.21 & 0.61 & 100.68 & 0.33 & 769 & 2 & 350 \\
\hline WH6e_35 & 60.84 & 24.91 & 0.26 & & 6.76 & 7.24 & 0.52 & 100.53 & 0.33 & 768 & 2 & 360 \\
\hline WH6e_36 & 60.99 & 24.71 & 0.27 & & 6.60 & 7.27 & 0.67 & 100.51 & 0.32 & 761 & 2 & 370 \\
\hline WH6e_37 & 61.00 & 24.33 & 0.29 & & 6.22 & 7.39 & 0.69 & 99.91 & 0.30 & 751 & 2 & 380 \\
\hline WH6e_38 & 60.47 & 24.72 & 0.25 & & 6.76 & 7.19 & 0.61 & 99.99 & 0.33 & 767 & 2 & 390 \\
\hline WH6e_39 & 60.67 & 24.85 & 0.26 & & 6.80 & 7.26 & 0.60 & 100.42 & 0.33 & 767 & 2 & 400 \\
\hline WH6e_40 & 60.70 & 24.37 & 0.28 & & 6.27 & 7.13 & 0.67 & 99.41 & 0.31 & 757 & 2 & 410 \\
\hline WH6e_41 & 60.90 & 24.46 & 0.28 & & 6.67 & 7.24 & 0.67 & 100.20 & 0.32 & 763 & 2 & 420 \\
\hline WH6e_42 & 61.91 & 24.39 & 0.23 & & 6.45 & 7.40 & 0.63 & 101.02 & 0.31 & 757 & 2 & 430 \\
\hline WH6e_43 & 61.67 & 24.45 & 0.19 & & 6.34 & 7.50 & 0.62 & 100.77 & 0.31 & 754 & 2 & 440 \\
\hline WH6e_44 & 61.49 & 24.32 & 0.27 & & 6.30 & 7.33 & 0.66 & 100.37 & 0.31 & 754 & 2 & 450 \\
\hline WH6e_45 & 61.45 & 24.47 & 0.27 & & 6.20 & 7.33 & 0.66 & 100.36 & 0.31 & 752 & 2 & 460 \\
\hline WH6e_46 & 61.41 & 24.04 & 0.26 & & 6.24 & 7.54 & 0.65 & 100.14 & 0.30 & 750 & 2 & 470 \\
\hline WH6e_47 & 61.44 & 24.45 & 0.32 & & 6.47 & 7.21 & 0.59 & 100.48 & 0.32 & 761 & 2 & 480 \\
\hline WH6e_48 & 61.42 & 24.38 & 0.30 & & 6.38 & 7.38 & 0.61 & 100.48 & 0.31 & 757 & 2 & 490 \\
\hline
\end{tabular}


Table 3.6 continued

\begin{tabular}{|c|c|c|c|c|c|c|c|c|c|c|c|c|}
\hline Sample & $\mathrm{SiO}_{2}$ & $\mathrm{Al}_{2} \mathrm{O}_{3}$ & $\mathrm{FeO}$ & $\mathrm{MgO}$ & $\mathrm{CaO}$ & $\mathrm{Na}_{2} \mathrm{O}$ & $\mathrm{K}_{2} \mathrm{O}$ & Total & Xan & $\begin{array}{c}\mathrm{T} \\
\left({ }^{\circ} \mathrm{C}\right)\end{array}$ & G & $\begin{array}{l}\text { Dist. } \\
(\mu \mathrm{m})\end{array}$ \\
\hline WH6f_2 & 59.92 & 24.46 & 0.29 & & 6.68 & 7.37 & 0.63 & 99.34 & 0.32 & 762 & 1 & 30 \\
\hline WH6f_3 & 60.20 & 24.50 & 0.26 & & 6.61 & 7.08 & 0.65 & 99.30 & 0.33 & 764 & 1 & 40 \\
\hline WH6f_4 & 60.80 & 24.50 & 0.31 & & 6.56 & 7.38 & 0.66 & 100.21 & 0.32 & 759 & 1 & 50 \\
\hline WH6f_5 & 61.45 & 24.48 & 0.27 & & 6.47 & 7.12 & 0.59 & 100.38 & 0.32 & 763 & 1 & 60 \\
\hline WH6f_6 & 61.45 & 24.30 & 0.28 & & 6.28 & 7.46 & 0.65 & 100.41 & 0.31 & 752 & 1 & 70 \\
\hline WH6f_7 & 61.50 & 24.25 & 0.31 & & 6.26 & 7.36 & 0.68 & 100.35 & 0.31 & 753 & 1 & 80 \\
\hline WH6f_8 & 61.40 & 24.49 & 0.23 & & 6.52 & 7.32 & 0.57 & 100.54 & 0.32 & 761 & 1 & 90 \\
\hline WH6f_9 & 60.42 & 24.92 & 0.23 & & 6.83 & 7.03 & 0.57 & 99.99 & 0.34 & 771 & 1 & 100 \\
\hline WH6f_10 & 60.64 & 24.93 & 0.27 & & 7.02 & 7.12 & 0.50 & 100.48 & 0.34 & 775 & 1 & 110 \\
\hline WH6f_11 & 59.89 & 25.37 & 0.31 & & 7.23 & 6.92 & 0.55 & 100.26 & 0.35 & 780 & 1 & 120 \\
\hline WH6f_12 & 61.31 & 24.76 & 0.33 & & 6.84 & 6.92 & 0.61 & 100.77 & 0.34 & 772 & 1 & 130 \\
\hline WH6f_13 & 61.62 & 24.22 & 0.15 & & 6.53 & 7.26 & 0.56 & 100.35 & 0.32 & 762 & 1 & 140 \\
\hline WH6f_14 & 60.12 & 24.80 & 0.12 & & 6.79 & 7.07 & 0.59 & 99.49 & 0.33 & 769 & 1 & 150 \\
\hline WH6f_15 & 60.81 & 24.63 & 0.28 & & 6.67 & 7.23 & 0.60 & 100.20 & 0.33 & 765 & 1 & 160 \\
\hline WH6f_16 & 61.22 & 24.78 & 0.38 & & 6.55 & 7.39 & 0.61 & 100.94 & 0.32 & 760 & 1 & 170 \\
\hline WH6f_17 & 60.97 & 24.72 & 0.29 & & 6.69 & 7.23 & 0.55 & 100.43 & 0.33 & 766 & 1 & 180 \\
\hline WH6f_18 & 60.58 & 24.87 & 0.26 & & 6.48 & 7.27 & 0.57 & 100.03 & 0.32 & 761 & 1 & 190 \\
\hline WH6f_19 & 61.64 & 24.47 & 0.30 & & 6.69 & 7.16 & 0.62 & 100.88 & 0.33 & 765 & 1 & 200 \\
\hline WH6f_20 & 60.21 & 24.56 & 0.25 & & 6.36 & 7.30 & 0.66 & 99.35 & 0.31 & 756 & 1 & 210 \\
\hline WH6f_21 & 60.52 & 24.88 & 0.20 & & 6.57 & 7.31 & 0.62 & 100.09 & 0.32 & 761 & 1 & 220 \\
\hline WH6f_22 & 59.88 & 24.59 & 0.05 & & 6.66 & 7.07 & 0.59 & 98.85 & 0.33 & 767 & 1 & 230 \\
\hline WH6f_23 & 60.45 & 24.77 & 0.25 & & 6.37 & 7.26 & 0.68 & 99.77 & 0.31 & 756 & 1 & 240 \\
\hline WH6f_24 & 61.50 & 24.38 & 0.28 & & 6.28 & 7.47 & 0.66 & 100.57 & 0.31 & 752 & 1 & 250 \\
\hline WH6f_25 & 60.85 & 24.59 & 0.27 & & 6.61 & 7.17 & 0.61 & 100.09 & 0.33 & 764 & 1 & 260 \\
\hline WH6f_26 & 61.18 & 24.55 & 0.21 & & 6.65 & 7.16 & 0.60 & 100.35 & 0.33 & 765 & 1 & 270 \\
\hline WH6f_27 & 60.95 & 24.70 & 0.30 & & 6.81 & 6.92 & 0.76 & 100.44 & 0.34 & 767 & 1 & 280 \\
\hline WH6f_28 & 59.45 & 25.76 & 0.27 & & 7.65 & 6.76 & 0.49 & 100.39 & 0.37 & 791 & 1 & 290 \\
\hline WH6f_32 & 60.41 & 25.54 & 0.26 & & 7.67 & 6.90 & 0.59 & 101.37 & 0.37 & 786 & 1 & 330 \\
\hline WH6f_34 & 62.02 & 23.83 & 0.27 & & 5.91 & 7.61 & 0.77 & 100.40 & 0.29 & 739 & 1 & 350 \\
\hline WH6f_35 & 61.73 & 24.14 & 0.20 & & 5.97 & 7.22 & 0.75 & 100.01 & 0.30 & 747 & 1 & 360 \\
\hline WH6f_36 & 59.90 & 24.14 & 0.24 & & 6.35 & 7.42 & 0.72 & 98.76 & 0.31 & 753 & 1 & 370 \\
\hline WH6f_37 & 59.81 & 24.68 & 0.23 & & 6.41 & 7.33 & 0.70 & 99.15 & 0.31 & 756 & 1 & 380 \\
\hline WH6f_38 & 57.08 & 27.07 & 0.26 & & 8.17 & 6.19 & 0.48 & 99.24 & 0.41 & 806 & 1 & 390 \\
\hline WH6f_39 & 53.68 & 29.62 & 0.27 & & 11.62 & 4.57 & 0.26 & 100.02 & 0.58 & 846 & 1 & 400 \\
\hline WH6f_40 & 52.67 & 29.92 & 0.25 & & 12.06 & 4.26 & 0.23 & 99.39 & 0.60 & 847 & 1 & 410 \\
\hline WH6f_41 & 54.87 & 27.83 & 0.58 & & 10.48 & 5.13 & 0.36 & 99.23 & 0.52 & 839 & 1 & 420 \\
\hline WH6f_43 & 55.26 & 27.82 & 0.16 & & 10.51 & 5.29 & 0.28 & 99.33 & 0.51 & 840 & 1 & 440 \\
\hline WH6f_44 & 53.11 & 29.63 & 0.23 & & 12.14 & 4.53 & 0.19 & 99.83 & 0.59 & 849 & 1 & 450 \\
\hline WH6f_45 & 53.17 & 29.01 & 0.26 & & 11.15 & 4.66 & 0.25 & 98.50 & 0.56 & 846 & 1 & 460 \\
\hline WH6f_46 & 54.10 & 27.47 & 0.53 & & 10.16 & 5.55 & 0.30 & 98.10 & 0.49 & 836 & 1 & 470 \\
\hline WH6f_47 & 58.05 & 26.45 & 0.36 & & 7.59 & 6.54 & 0.58 & 99.57 & 0.38 & 790 & 1 & 480 \\
\hline WH6f_48 & 60.54 & 24.63 & 0.34 & & 6.29 & 7.30 & 0.74 & 99.83 & 0.31 & 753 & 1 & 490 \\
\hline WH6f_49 & 60.30 & 23.83 & 0.27 & & 5.91 & 7.25 & 0.61 & 98.17 & 0.30 & 749 & 1 & 500 \\
\hline WH6f_50 & 62.34 & 24.14 & 0.28 & & 5.86 & 7.49 & 0.78 & 100.90 & 0.29 & 740 & 1 & 510 \\
\hline WH6f_51 & 60.86 & 24.46 & 0.31 & & 6.55 & 7.22 & 0.68 & 100.08 & 0.32 & 760 & 1 & 520 \\
\hline WH6f_52 & 60.44 & 24.75 & 0.40 & & 6.71 & 7.10 & 0.65 & 100.06 & 0.33 & 766 & 1 & 530 \\
\hline WH6f_53 & 60.69 & 24.85 & 0.17 & & 6.48 & 7.24 & 0.69 & 100.11 & 0.32 & 758 & 1 & 540 \\
\hline WH6f_54 & 59.60 & 24.90 & 0.23 & & 6.87 & 7.18 & 0.62 & 99.40 & 0.33 & 768 & 1 & 550 \\
\hline WH6f_55 & 59.58 & 25.32 & 0.34 & & 6.83 & 7.11 & 0.50 & 99.68 & 0.34 & 772 & 1 & 560 \\
\hline WH6f_57 & 61.42 & 25.62 & 0.20 & & 6.82 & 6.90 & 0.61 & 101.57 & 0.34 & 772 & 1 & 580 \\
\hline WH6f_58 & 62.40 & 24.59 & 0.19 & & 6.17 & 7.12 & 0.70 & 101.17 & 0.31 & 754 & 1 & 590 \\
\hline WH6f_59 & 61.36 & 24.02 & 0.26 & & 6.12 & 7.44 & 0.74 & 99.95 & 0.30 & 747 & 1 & 600 \\
\hline WH6f_60 & 61.69 & 25.22 & 0.27 & & 6.85 & 7.01 & 0.66 & 101.68 & 0.34 & 770 & 1 & 610 \\
\hline WH6f_61 & 61.75 & 25.16 & 0.28 & & 6.66 & 7.17 & 0.54 & 101.56 & 0.33 & 767 & 1 & 620 \\
\hline WH6f_62 & 61.34 & 24.70 & 0.28 & & 6.62 & 7.44 & 0.61 & 100.99 & 0.32 & 760 & 1 & 630 \\
\hline WH6f_63 & 61.20 & 24.60 & 0.21 & & 6.83 & 7.24 & 0.64 & 100.71 & 0.33 & 766 & 1 & 640 \\
\hline WH6f_64 & 61.41 & 24.93 & 0.27 & & 6.64 & 7.08 & 0.60 & 100.94 & 0.33 & 766 & 1 & 650 \\
\hline
\end{tabular}


Table A3.6 continued

\begin{tabular}{|c|c|c|c|c|c|c|c|c|c|c|c|c|}
\hline Sample & $\mathrm{SiO}_{2}$ & $\mathrm{Al}_{2} \mathrm{O}_{3}$ & $\mathrm{FeO}$ & $\mathrm{MgO}$ & $\mathrm{CaO}$ & $\mathrm{Na}_{2} \mathrm{O}$ & $\mathrm{K}_{2} \mathrm{O}$ & Total & Xan & $\begin{array}{c}\mathrm{T} \\
\left({ }^{\circ} \mathrm{C}\right) \\
\end{array}$ & G & $\begin{array}{l}\text { Dist. } \\
(\mu \mathrm{m})\end{array}$ \\
\hline WH6g_3 & 61.66 & 24.41 & 0.32 & & 6.50 & 7.07 & 0.61 & 100.58 & 0.32 & 764 & 2 & 40 \\
\hline WH6g_4 & 60.82 & 24.67 & 0.35 & & 6.97 & 7.14 & 0.60 & 100.55 & 0.34 & 771 & 2 & 50 \\
\hline WH6g_5 & 61.29 & 24.39 & 0.36 & & 6.45 & 7.06 & 0.66 & 100.21 & 0.32 & 761 & 2 & 60 \\
\hline WH6g_6 & 61.91 & 24.39 & 0.25 & & 6.85 & 7.11 & 0.60 & 101.10 & 0.34 & 769 & 2 & 70 \\
\hline WH6g_7 & 61.85 & 24.39 & 0.34 & & 6.74 & 7.00 & 0.66 & 100.98 & 0.33 & 768 & 2 & 80 \\
\hline WH6g_8 & 61.52 & 24.45 & 0.24 & & 6.57 & 7.02 & 0.67 & 100.46 & 0.33 & 764 & 2 & 90 \\
\hline WH6g_9 & 61.67 & 24.49 & 0.27 & & 6.54 & 7.12 & 0.67 & 100.76 & 0.32 & 762 & 2 & 100 \\
\hline WH6g_10 & 62.06 & 24.29 & 0.27 & & 6.32 & 7.52 & 0.75 & 101.22 & 0.30 & 750 & 2 & 110 \\
\hline WH6g_11 & 62.18 & 24.22 & 0.22 & & 6.35 & 7.23 & 0.70 & 100.89 & 0.31 & 756 & 2 & 120 \\
\hline WH6g_12 & 61.43 & 24.54 & 0.22 & & 6.76 & 7.00 & 0.61 & 100.56 & 0.34 & 769 & 2 & 130 \\
\hline WH6g_13 & 61.44 & 24.70 & 0.16 & & 6.95 & 7.21 & 0.63 & 101.09 & 0.33 & 769 & 2 & 140 \\
\hline WH6g_14 & 61.31 & 24.46 & 0.21 & & 6.78 & 7.01 & 0.56 & 100.33 & 0.34 & 771 & 2 & 150 \\
\hline WH6g_15 & 61.79 & 24.49 & 0.26 & & 6.86 & 7.10 & 0.59 & 101.08 & 0.34 & 770 & 2 & 160 \\
\hline WH6g_16 & 60.61 & 25.18 & 0.19 & & 7.71 & 6.73 & 0.54 & 100.96 & 0.38 & 791 & 2 & 170 \\
\hline WH6g_17 & 60.74 & 25.46 & 0.24 & & 7.68 & 6.86 & 0.53 & 101.51 & 0.37 & 789 & 2 & 180 \\
\hline WH6g_18 & 61.71 & 24.51 & 0.24 & & 6.61 & 7.03 & 0.67 & 100.77 & 0.33 & 765 & 2 & 190 \\
\hline WH6g_19 & 62.53 & 24.51 & 0.24 & & 6.33 & 7.27 & 0.67 & 101.55 & 0.31 & 755 & 2 & 200 \\
\hline WH6g_20 & 62.30 & 24.33 & 0.30 & & 6.48 & 7.33 & 0.74 & 101.47 & 0.31 & 756 & 2 & 210 \\
\hline WH6g_21 & 61.69 & 24.81 & 0.18 & & 6.94 & 6.93 & 0.63 & 101.18 & 0.34 & 773 & 2 & 220 \\
\hline WH6g_22 & 62.56 & 24.55 & 0.24 & & 6.38 & 7.19 & 0.71 & 101.63 & 0.32 & 757 & 2 & 230 \\
\hline WH6g_25 & 59.33 & 26.62 & 0.17 & & 8.77 & 6.31 & 0.40 & 101.59 & 0.42 & 813 & 2 & 260 \\
\hline WH6g_26 & 61.12 & 25.58 & 0.18 & & 7.45 & 6.85 & 0.56 & 101.74 & 0.36 & 784 & 2 & 270 \\
\hline WH6g_27 & 61.80 & 24.28 & 0.17 & & 6.19 & 7.22 & 0.71 & 100.37 & 0.31 & 753 & 2 & 280 \\
\hline WH6g_28 & 61.55 & 24.61 & 0.19 & & 6.70 & 7.35 & 0.67 & 101.05 & 0.32 & 762 & 2 & 290 \\
\hline WH6g_29 & 60.82 & 24.70 & 0.19 & & 6.55 & 7.20 & 0.65 & 100.10 & 0.32 & 761 & 2 & 300 \\
\hline WH6g_30 & 61.57 & 24.55 & 0.30 & & 6.37 & 7.27 & 0.66 & 100.71 & 0.31 & 757 & 2 & 310 \\
\hline WH6g_32 & 62.10 & 24.16 & 0.23 & & 6.14 & 7.20 & 0.76 & 100.59 & 0.31 & 751 & 2 & 330 \\
\hline WH6g_33 & 61.70 & 24.42 & 0.16 & & 6.51 & 7.13 & 0.69 & 100.61 & 0.32 & 761 & 2 & 340 \\
\hline WH6g_34 & 61.18 & 24.74 & 0.29 & & 6.69 & 7.37 & 0.63 & 100.91 & 0.32 & 762 & 2 & 350 \\
\hline WH6g_35 & 61.36 & 24.58 & 0.17 & & 6.77 & 7.26 & 0.69 & 100.83 & 0.33 & 764 & 2 & 360 \\
\hline WH6g_36 & 61.39 & 24.51 & 0.21 & & 6.71 & 7.08 & 0.64 & 100.54 & 0.33 & 766 & 2 & 370 \\
\hline WH6g_37 & 60.74 & 24.60 & 0.18 & & 6.75 & 7.17 & 0.73 & 100.17 & 0.33 & 764 & 2 & 380 \\
\hline WH6g_38 & 61.05 & 24.78 & 0.26 & & 6.67 & 7.15 & 0.64 & 100.56 & 0.33 & 765 & 2 & 390 \\
\hline WH6g_39 & 61.47 & 23.56 & 0.30 & & 6.21 & 7.35 & 0.66 & 99.55 & 0.31 & 752 & 2 & 400 \\
\hline WH6g_40 & 61.67 & 25.05 & 0.22 & & 6.46 & 7.49 & 0.71 & 101.60 & 0.31 & 754 & 2 & 410 \\
\hline WH6g_41 & 61.96 & 23.98 & 0.18 & & 6.32 & 7.42 & 0.73 & 100.58 & 0.31 & 752 & 2 & 420 \\
\hline WH6g_42 & 61.82 & 24.13 & 0.21 & & 6.02 & 7.51 & 0.69 & 100.37 & 0.29 & 745 & 2 & 430 \\
\hline WH6g_43 & 62.73 & 24.24 & 0.25 & & 5.97 & 7.38 & 0.66 & 101.23 & 0.30 & 747 & 2 & 440 \\
\hline WH6g_44 & 62.64 & 23.88 & 0.18 & & 5.97 & 7.41 & 0.78 & 100.85 & 0.29 & 743 & 2 & 450 \\
\hline WH6g_45 & 62.75 & 23.54 & 0.21 & & 5.73 & 7.50 & 0.82 & 100.55 & 0.28 & 736 & 2 & 460 \\
\hline WH6g_46 & 62.11 & 23.83 & 0.35 & & 5.85 & 7.69 & 0.80 & 100.61 & 0.28 & 736 & 2 & 470 \\
\hline WH6g_47 & 62.74 & 23.72 & 0.21 & & 5.97 & 7.45 & 0.68 & 100.76 & 0.29 & 745 & 2 & 480 \\
\hline WH6g_48 & 62.35 & 24.70 & 0.25 & & 6.42 & 7.38 & 0.68 & 101.78 & 0.31 & 755 & 2 & 490 \\
\hline WH6g_49 & 61.84 & 24.56 & 0.25 & & 6.30 & 7.54 & 0.69 & 101.18 & 0.30 & 751 & 2 & 500 \\
\hline WH6g_53 & 62.11 & 24.58 & 0.20 & & 6.36 & 7.43 & 0.71 & 101.37 & 0.31 & 753 & 2 & 540 \\
\hline WH6g_54 & 62.87 & 24.65 & 0.18 & & 6.19 & 7.32 & 0.66 & 101.86 & 0.31 & 752 & 2 & 550 \\
\hline WH6g_56 & 62.30 & 24.43 & 0.12 & & 5.91 & 7.47 & 0.73 & 100.96 & 0.29 & 742 & 2 & 570 \\
\hline WH6g_57 & 62.92 & 24.39 & 0.19 & & 5.85 & 7.56 & 0.75 & 101.66 & 0.29 & 739 & 2 & 580 \\
\hline WH6g_58 & 62.74 & 24.47 & 0.23 & & 6.17 & 7.36 & 0.76 & 101.72 & 0.30 & 749 & 2 & 590 \\
\hline WH6g_59 & 62.10 & 24.24 & 0.23 & & 6.09 & 7.44 & 0.74 & 100.84 & 0.30 & 747 & 2 & 600 \\
\hline WH6g_60 & 62.14 & 24.75 & 0.25 & & 6.34 & 7.43 & 0.71 & 101.62 & 0.31 & 752 & 2 & 610 \\
\hline WH6g_61 & 61.13 & 24.72 & 0.20 & & 6.45 & 7.19 & 0.71 & 100.40 & 0.32 & 758 & 2 & 620 \\
\hline WH6g_62 & 61.64 & 25.06 & 0.33 & & 6.52 & 7.30 & 0.74 & 101.57 & 0.32 & 757 & 2 & 630 \\
\hline WH6g_63 & 61.68 & 24.98 & 0.16 & & 6.71 & 7.40 & 0.59 & 101.52 & 0.32 & 763 & 2 & 640 \\
\hline WH6g_64 & 62.00 & 24.39 & 0.22 & & 6.43 & 7.21 & 0.71 & 100.96 & 0.32 & 757 & 2 & 650 \\
\hline WH6g_65 & 62.15 & 24.81 & 0.22 & & 6.51 & 7.32 & 0.71 & 101.71 & 0.32 & 758 & 2 & 660 \\
\hline WH6g_66 & 62.06 & 24.88 & 0.20 & & 6.51 & 7.24 & 0.70 & 101.58 & 0.32 & 759 & 2 & 670 \\
\hline
\end{tabular}


Table A3.6 continued

\begin{tabular}{lcccccccccccc}
\hline Sample & $\mathrm{SiO}_{2}$ & $\mathrm{Al}_{2} \mathrm{O}_{3}$ & $\mathrm{FeO}$ & $\mathrm{MgO}$ & $\mathrm{CaO}$ & $\mathrm{Na}_{2} \mathrm{O}$ & $\mathrm{K}_{2} \mathrm{O}$ & Total & $\mathrm{XAn}$ & $\begin{array}{c}\mathrm{T} \\
\left({ }^{\circ} \mathrm{C}\right)\end{array}$ & $\begin{array}{c}\mathrm{G} \\
(\mu \mathrm{m})\end{array}$ \\
\hline WH6g_69 & 61.92 & 24.32 & 0.22 & & 6.18 & 7.68 & 0.61 & 100.93 & 0.30 & 748 & 2 & 700 \\
\hline
\end{tabular}

Major elements are given in $\mathrm{wt} \%, X \mathrm{An}$ are calculated on a mole fraction basis and temperatures

(T) are calculated using the Plagioclase-melt equilibria of Putirka (2005) and a pressure of 60 MPa. 


\section{Appendix 3}

Table A3.7: Major element compositions (given in wt\%) of core and rim analyses of Whakamaru plagioclase crystals 
Table A3.7

\begin{tabular}{|c|c|c|c|c|c|c|c|c|c|}
\hline Sample & $\mathrm{SiO}_{2}$ & $\mathrm{Al}_{2} \mathrm{O}_{3}$ & $\mathrm{FeO}$ & $\mathrm{CaO}$ & $\mathrm{Na}_{2} \mathrm{O}$ & $\mathrm{K}_{2} \mathrm{O}$ & TOTAL & X An & Position \\
\hline WH2K_1 & 60.37 & 24.71 & 0.24 & 7.18 & 8.28 & 0.54 & 101.31 & 0.31 & Rim \\
\hline WH2R_1 & 61.36 & 24.71 & 0.27 & 6.97 & 8.21 & 0.61 & 102.13 & 0.31 & Rim \\
\hline WH2S_1 & 60.99 & 24.18 & 0.24 & 6.72 & 8.63 & 0.69 & 101.45 & 0.29 & Rim \\
\hline WH2V_1 & 60.35 & 24.46 & 0.26 & 6.49 & 8.51 & 0.73 & 100.80 & 0.29 & Rim \\
\hline WH2AA_1 & 59.30 & 24.60 & 0.25 & 6.96 & 8.30 & 0.63 & 100.05 & 0.31 & Rim \\
\hline WH2ACā_1 & 61.42 & 24.54 & 0.26 & 6.56 & 8.44 & 0.62 & 101.85 & 0.29 & Rim \\
\hline WH2AD_- 1 & 60.30 & 24.26 & 0.25 & 6.66 & 8.23 & 0.62 & 100.32 & 0.30 & Rim \\
\hline WH2AE_- 1 & 60.11 & 24.21 & 0.31 & 6.94 & 8.20 & 0.57 & 100.34 & 0.31 & Rim \\
\hline WH2AG_1 & 60.36 & 24.24 & 0.31 & 6.89 & 8.30 & 0.60 & 100.71 & 0.30 & Rim \\
\hline WH3i_3 & 59.53 & 25.54 & 0.19 & 7.97 & 7.59 & 0.56 & 101.38 & 0.36 & Middle \\
\hline WH3i_4 & 61.77 & 23.70 & 0.36 & 6.19 & 8.58 & 0.68 & 101.29 & 0.28 & Middle \\
\hline WH3K_2 & 61.14 & 24.31 & 0.33 & 6.54 & 8.18 & 0.57 & 101.08 & 0.30 & Rim \\
\hline WH3_P1 & 61.69 & 23.32 & 0.29 & 5.99 & 7.95 & 0.72 & 99.97 & 0.28 & Core \\
\hline WH3_P2 & 61.97 & 23.34 & 0.30 & 6.24 & 8.08 & 0.66 & 100.59 & 0.29 & Rim \\
\hline WH3_Q1 & 59.13 & 24.01 & 0.27 & 7.00 & 7.34 & 0.63 & 98.38 & 0.33 & Core \\
\hline WH3_Q3 & 61.22 & 24.14 & 0.21 & 6.60 & 7.65 & 0.68 & 100.49 & 0.31 & Middle \\
\hline WH3_Q5 & 59.14 & 24.72 & 0.39 & 8.13 & 7.19 & 0.45 & 100.02 & 0.37 & Rim \\
\hline WH3R_1 & 61.98 & 23.96 & 0.16 & 6.55 & 8.27 & 0.69 & 101.61 & 0.29 & Rim \\
\hline WH3T_1 & 57.80 & 26.20 & 0.27 & 9.33 & 6.77 & 0.34 & 100.70 & 0.42 & Core \\
\hline WH3T_2 & 61.21 & 24.37 & 0.28 & 6.91 & 8.23 & 0.65 & 101.66 & 0.31 & Rim \\
\hline WH3_W 1 & 59.78 & 24.11 & 0.15 & 7.53 & 7.12 & 0.45 & 99.15 & 0.36 & Core \\
\hline WH3_W3 & 64.16 & 21.81 & 0.19 & 4.44 & 8.92 & 1.04 & 100.55 & 0.20 & Rim \\
\hline WH3_AI1 & 61.31 & 23.38 & 0.20 & 6.23 & 8.04 & 0.71 & 99.86 & 0.29 & Middle \\
\hline WH3_AI2 & 59.99 & 22.85 & 0.30 & 6.29 & 7.28 & 0.57 & 97.28 & 0.31 & Core \\
\hline WH4A 1 & 61.12 & 23.98 & 0.22 & 6.68 & 8.20 & 0.57 & 100.78 & 0.30 & Rim \\
\hline WH4B_1 & 60.16 & 24.46 & 0.29 & 7.08 & 8.15 & 0.59 & 100.74 & 0.31 & Rim \\
\hline WH4B_2 & 58.26 & 24.88 & 0.20 & 7.63 & 7.47 & 0.50 & 98.94 & 0.35 & Core \\
\hline WH4E_1 & 60.46 & 24.30 & 0.24 & 6.78 & 8.40 & 0.64 & 100.82 & 0.30 & Core \\
\hline WH4E_2 & 59.79 & 23.64 & 0.34 & 6.55 & 8.27 & 0.67 & 99.25 & 0.29 & Rim \\
\hline WH4F_1 & 60.95 & 23.85 & 0.26 & 6.50 & 8.38 & 0.62 & 100.55 & 0.29 & Core \\
\hline WH4F_2 & 60.73 & 23.98 & 0.15 & 6.72 & 8.32 & 0.61 & 100.51 & 0.30 & Rim \\
\hline WH4G_1 & 59.46 & 25.09 & 0.22 & 6.87 & 8.19 & 0.52 & 100.35 & 0.31 & Core \\
\hline WH4G_2 & 63.25 & 22.06 & 0.14 & 4.16 & 9.40 & 1.08 & 100.09 & 0.19 & Rim \\
\hline WH4H_1 & 60.62 & 24.14 & 0.23 & 6.65 & 8.45 & 0.61 & 100.69 & 0.29 & Rim \\
\hline WH4H_2 & 59.40 & 24.51 & 0.24 & 7.15 & 7.89 & 0.52 & 99.71 & 0.32 & Core \\
\hline WH4i_1 & 59.79 & 23.88 & 0.25 & 6.62 & 7.94 & 0.65 & 99.14 & 0.30 & Core \\
\hline WH4i_2 & 61.05 & 24.07 & 0.25 & 7.09 & 8.09 & 0.59 & 101.13 & 0.32 & Rim \\
\hline WH4J_1 & 61.15 & 24.29 & 0.26 & 6.72 & 8.33 & 0.66 & 101.41 & 0.30 & Core \\
\hline WH4J_2 & 61.52 & 24.30 & 0.26 & 7.01 & 8.29 & 0.62 & 102.00 & 0.31 & Rim \\
\hline WH4K_1 & 61.69 & 23.80 & 0.27 & 6.20 & 8.58 & 0.65 & 101.19 & 0.28 & Rim \\
\hline WH4L_1 & 60.71 & 24.46 & 0.19 & 6.89 & 8.12 & 0.55 & 100.92 & 0.31 & Rim \\
\hline WH4M_1 & 59.41 & 25.07 & 0.23 & 7.85 & 7.83 & 0.50 & 100.90 & 0.35 & Core \\
\hline WH4M_2 & 60.72 & 24.74 & 0.17 & 7.24 & 7.91 & 0.56 & 101.34 & 0.33 & Rim \\
\hline WH4N_1 & 60.20 & 23.99 & 0.27 & 6.70 & 8.07 & 0.65 & 99.87 & 0.30 & Rim \\
\hline WH4O_1 & 60.99 & 23.96 & 0.22 & 6.42 & 8.21 & 0.65 & 100.44 & 0.29 & Rim \\
\hline WH4P_1 & 59.68 & 25.28 & 0.29 & 8.15 & 7.69 & 0.48 & 101.58 & 0.36 & Core \\
\hline WH4P_2 & 58.87 & 26.05 & 0.29 & 8.68 & 7.26 & 0.44 & 101.58 & 0.39 & Middle \\
\hline WH4P_3 & 60.42 & 24.15 & 0.30 & 6.57 & 8.39 & 0.63 & 100.45 & 0.29 & Rim \\
\hline WH4Q_1 & 58.36 & 27.20 & 0.38 & 9.02 & 6.70 & 0.31 & 101.97 & 0.42 & Core \\
\hline WH4S_1 & 59.64 & 23.82 & 0.21 & 6.46 & 8.53 & 0.67 & 99.33 & 0.28 & Rim \\
\hline WH4T_1 & 60.16 & 24.10 & 0.20 & 6.80 & 8.12 & 0.63 & 100.01 & 0.31 & Core \\
\hline WH4T_2 & 60.62 & 23.67 & 0.20 & 6.47 & 8.50 & 0.68 & 100.14 & 0.29 & Rim \\
\hline WH4Y_1 & 60.94 & 24.69 & 0.20 & 7.01 & 8.12 & 0.67 & 101.64 & 0.31 & Rim \\
\hline WH4Z_1 & 61.67 & 24.50 & 0.31 & 6.80 & 8.46 & 0.64 & 102.37 & 0.30 & Rim \\
\hline WH4AA_1 & 61.50 & 23.94 & 0.33 & 6.53 & 8.50 & 0.74 & 101.53 & 0.29 & Core \\
\hline WH4AA_2 & 58.23 & 25.90 & 0.30 & 8.69 & 7.07 & 0.43 & 100.62 & 0.39 & Middle \\
\hline WH4AA_3 & 61.05 & 24.60 & 0.29 & 7.22 & 8.08 & 0.56 & 101.81 & 0.32 & Rim \\
\hline WH4AB_1 & 60.65 & 25.16 & 0.22 & 7.09 & 8.03 & 0.55 & 101.69 & 0.32 & Core \\
\hline WH4AB_2 & 59.48 & 24.73 & 0.29 & 7.00 & 8.24 & 0.58 & 100.33 & 0.31 & Rim \\
\hline WH4AE_1 & 60.54 & 24.69 & 0.29 & 6.95 & 8.27 & 0.60 & 101.33 & 0.31 & Rim \\
\hline WH4AF_1 & 60.79 & 24.83 & 0.25 & 6.99 & 8.18 & 0.59 & 101.64 & 0.31 & Rim \\
\hline WH4AF_2 & 59.18 & 26.06 & 0.36 & 8.41 & 7.44 & 0.45 & 101.90 & 0.38 & Core \\
\hline
\end{tabular}


Appendix 3

Table A3.7 continued

\begin{tabular}{|c|c|c|c|c|c|c|c|c|c|}
\hline WH4AJ_1 & 60.61 & 24.40 & 0.19 & 6.89 & 8.47 & 0.65 & 101.21 & 0.30 & Rim \\
\hline WH4AK_1 & 61.55 & 24.26 & 0.23 & 6.57 & 8.79 & 0.70 & 102.10 & 0.28 & Core \\
\hline WH4AK_2 & 60.73 & 24.56 & 0.27 & 7.07 & 8.23 & 0.65 & 101.51 & 0.31 & Rim \\
\hline WH4AL_1 & 60.55 & 25.31 & 0.22 & 7.24 & 8.01 & 0.60 & 101.93 & 0.32 & Core \\
\hline WH4AL_2 & 60.48 & 24.44 & 0.34 & 6.93 & 8.39 & 0.61 & 101.20 & 0.30 & Rim \\
\hline WH4AN_1 & 60.46 & 24.18 & 0.21 & 6.34 & 8.44 & 0.69 & 100.32 & 0.28 & Rim \\
\hline WH4AO_1 & 61.37 & 24.31 & 0.28 & 6.50 & 8.60 & 0.69 & 101.75 & 0.28 & Core \\
\hline WH4AO_2 & 55.97 & 26.65 & 0.30 & 9.86 & 6.74 & 0.41 & 99.94 & 0.44 & Rim \\
\hline WH6H_1 & 59.73 & 24.16 & 0.19 & 6.81 & 8.36 & 0.57 & 99.82 & 0.30 & Rim \\
\hline WH6K_1 & 60.04 & 24.43 & 0.17 & 6.95 & 8.32 & 0.70 & 100.60 & 0.30 & Rim \\
\hline WH6M_1 & 60.53 & 24.53 & 0.28 & 7.54 & 8.08 & 0.63 & 101.59 & 0.33 & Rim \\
\hline WH6N_2 & 60.34 & 23.95 & 0.27 & 6.52 & 8.50 & 0.65 & 100.22 & 0.29 & Rim \\
\hline WH6O_1 & 60.78 & 24.51 & 0.30 & 7.06 & 8.35 & 0.62 & 101.62 & 0.31 & Rim \\
\hline WH6Q_1 & 59.33 & 24.00 & 0.27 & 6.73 & 8.29 & 0.60 & 99.21 & 0.30 & Rim \\
\hline WH6S_1 & 59.84 & 24.02 & 0.18 & 6.42 & 8.13 & 0.64 & 99.24 & 0.29 & Rim \\
\hline WH6T_1 & 64.50 & 22.22 & 0.15 & 4.25 & 9.80 & 1.15 & 102.07 & 0.18 & Rim \\
\hline WH6T_2 & 60.93 & 23.71 & 0.19 & 5.61 & 8.89 & 0.73 & 100.06 & 0.25 & Core \\
\hline WH6AA_1 & 62.70 & 23.86 & 0.23 & 6.52 & 8.30 & 0.66 & 102.27 & 0.29 & Middle \\
\hline WH6AD_1 & 59.71 & 24.60 & 0.18 & 6.89 & 8.39 & 0.66 & 100.42 & 0.30 & Rim \\
\hline WH6AF_1 & 59.58 & 24.16 & 0.31 & 6.83 & 8.30 & 0.64 & 99.80 & 0.30 & Rim \\
\hline WH6AG_1 & 61.33 & 24.41 & 0.22 & 6.47 & 8.56 & 0.62 & 101.62 & 0.28 & Rim \\
\hline WH6AH_1 & 60.23 & 24.30 & 0.33 & 6.85 & 8.39 & 0.69 & 100.79 & 0.30 & Rim \\
\hline WH6AH_2 & 56.15 & 26.50 & 0.27 & 9.56 & 6.92 & 0.34 & 99.73 & 0.43 & Core \\
\hline WH6AI_1 & 60.45 & 23.99 & 0.19 & 6.71 & 8.38 & 0.58 & 100.29 & 0.30 & Core \\
\hline WH6AI_2 & 63.96 & 22.39 & 0.18 & 4.72 & 9.38 & 0.88 & 101.51 & 0.21 & Rim \\
\hline WH6AJ_1 & 60.68 & 23.95 & 0.33 & 6.77 & 8.22 & 0.68 & 100.64 & 0.30 & Rim \\
\hline WH6AP_1 & 54.88 & 28.16 & 0.23 & 12.12 & 5.41 & 0.25 & 101.05 & 0.55 & Core \\
\hline WH6AP_2 & 63.14 & 23.72 & 0.30 & 7.00 & 7.92 & 0.62 & 102.71 & 0.32 & Rim \\
\hline
\end{tabular}

Core and rim analyses of Whakamaru plagioclase crystals, position of analyses are illustrated in Appendix A4.2. Major elements are given in $\mathrm{wt} \%$ with $\mathrm{X}_{\mathrm{An}}$ calculated on a mole fraction basis. 


\section{Appendix 3}

Table A3.8: $\mathrm{Sr}, \mathrm{Ba}$ and $\mathrm{Mg}$ profiles of Whakamaru plagioclase crystals $\mathrm{CaO}$ concentrations are given in $\mathrm{Wt} \%$

$\mathrm{Sr}, \mathrm{Ba}, \mathrm{Mg}$ concentrations are given in $\mathrm{ppm}$ 
Table A3.8

\begin{tabular}{|c|c|c|c|c|c|c|c|}
\hline Sample & Group & $\begin{array}{c}\text { Distance } \\
(\mu \mathrm{m})\end{array}$ & X An & $\begin{array}{c}\mathrm{CaO} \\
(\mathrm{wt} \%) \\
\end{array}$ & $\begin{array}{c}\mathrm{Mg} \\
(\mathrm{ppm})\end{array}$ & $\begin{array}{c}\mathrm{Sr} \\
(\mathrm{ppm})\end{array}$ & $\begin{array}{c}\mathrm{Ba} \\
(\mathrm{ppm}) \\
\end{array}$ \\
\hline WH1h_L22 & 1 & 189 & 0.30 & 6.35 & 74 & 589 & 852 \\
\hline WH1h_L21 & 1 & 211 & 0.34 & 7.18 & 79 & 634 & 875 \\
\hline WH1h_L20 & 1 & 234 & 0.35 & 7.37 & 85 & 693 & 982 \\
\hline WH1h_L19 & 1 & 254 & 0.38 & 8.01 & 88 & 674 & 635 \\
\hline WH1h_L18 & 1 & 275 & 0.47 & 9.98 & 103 & 811 & 617 \\
\hline WH1h_L17 & 1 & 295 & 0.44 & 9.27 & 86 & 663 & 367 \\
\hline WH1h_L16 & 1 & 320 & 0.53 & 10.90 & 92 & 806 & 364 \\
\hline WH1h_L15 & 1 & 340 & 0.52 & 11.10 & 83 & 746 & 277 \\
\hline WH1h_L14 & 1 & 361 & 0.52 & 10.98 & 82 & 710 & 210 \\
\hline WH1h_L13 & 1 & 381 & 0.53 & 11.22 & 77 & 698 & 175 \\
\hline WH1h_L12 & 1 & 398 & 0.53 & 11.21 & 79 & 680 & 191 \\
\hline WH1h_L11 & 1 & 421 & 0.53 & 11.13 & 78 & 705 & 247 \\
\hline WH1h_L10 & 1 & 442 & 0.49 & 9.98 & 77 & 647 & 111 \\
\hline WH1h_L9 & 1 & 461 & 0.52 & 10.82 & 96 & 692 & 144 \\
\hline WH1h_L8 & 1 & 492 & 0.49 & 8.57 & 75 & 567 & 139 \\
\hline WH1h_L7 & 1 & 513 & 0.41 & 8.67 & 62 & 555 & 115 \\
\hline WH1h_L6 & 1 & 533 & 0.32 & 6.48 & 76 & 581 & 716 \\
\hline WH1h_L5 & 1 & 554 & 0.32 & 6.65 & 71 & 565 & 671 \\
\hline WH1h_L4 & 1 & 573 & 0.30 & 6.39 & 69 & 554 & 655 \\
\hline WH1h_L3 & 1 & 594 & 0.32 & 6.65 & 72 & 577 & 681 \\
\hline WH1h_L2 & 1 & 614 & 0.30 & 6.32 & 74 & 547 & 732 \\
\hline WH1h_L1 & 1 & 634 & 0.30 & 6.29 & 78 & 569 & 738 \\
\hline WH2b_L68 & 1 & 9 & 0.30 & 6.23 & 65 & 511 & 604 \\
\hline WH2b_L67 & 1 & 41 & 0.31 & 6.52 & 73 & 533 & 717 \\
\hline WH2b_L66 & 1 & 64 & 0.31 & 6.45 & 69 & 543 & 700 \\
\hline WH2b_L65 & 1 & 80 & 0.32 & 6.60 & 67 & 564 & 685 \\
\hline WH2b_L64 & 1 & 104 & 0.31 & 6.51 & 65 & 577 & 687 \\
\hline WH2b_L63 & 1 & 120 & 0.31 & 6.24 & 67 & 555 & 659 \\
\hline WH2b_L62 & 1 & 139 & 0.31 & 6.36 & 69 & 572 & 620 \\
\hline WH2b_L61 & 1 & 159 & 0.32 & 6.68 & 73 & 615 & 698 \\
\hline WH2b_L60 & 1 & 179 & 0.32 & 6.77 & 78 & 613 & 699 \\
\hline WH2b_L59 & 1 & 199 & 0.31 & 6.36 & 66 & 561 & 620 \\
\hline WH2b_L58 & 1 & 218 & 0.29 & 6.05 & 72 & 560 & 616 \\
\hline WH2b_L57 & 1 & 238 & 0.33 & 6.91 & 75 & 591 & 573 \\
\hline WH2b_L56 & 1 & 254 & 0.27 & 5.52 & 70 & 540 & 681 \\
\hline WH2b_L55 & 1 & 274 & 0.31 & 6.46 & 62 & 555 & 602 \\
\hline WH2b_L54 & 1 & 294 & 0.31 & 6.41 & 62 & 550 & 614 \\
\hline WH2b_L53 & 1 & 317 & 0.32 & 6.59 & 61 & 560 & 590 \\
\hline WH2b_L52 & 1 & 337 & 0.32 & 6.64 & 58 & 553 & 563 \\
\hline WH2b_L51 & 1 & 373 & 0.34 & 7.18 & 64 & 600 & 582 \\
\hline WH2b_L50 & 1 & 396 & 0.34 & 7.15 & 62 & 591 & 504 \\
\hline WH2b_L49 & 1 & 412 & 0.34 & 7.14 & 61 & 591 & 521 \\
\hline WH2b_L48 & 1 & 432 & 0.33 & 6.96 & 73 & 581 & 513 \\
\hline WH2b_L47 & 1 & 452 & 0.36 & 7.53 & 68 & 621 & 573 \\
\hline WH2b_L46 & 1 & 471 & 0.37 & 7.70 & 63 & 610 & 510 \\
\hline WH2b_L45 & 1 & 483 & 0.34 & 7.29 & 70 & 616 & 503 \\
\hline WH2b_L44 & 1 & 515 & 0.34 & 7.50 & 67 & 599 & 513 \\
\hline WH2b_L43 & 1 & 534 & 0.38 & 7.84 & 66 & 621 & 494 \\
\hline WH2b_L42 & 1 & 554 & 0.37 & 7.69 & 68 & 601 & 453 \\
\hline WH2b_L41 & 1 & 578 & 0.37 & 7.75 & 66 & 601 & 410 \\
\hline WH2b_L40 & 1 & 594 & 0.38 & 7.97 & 69 & 593 & 376 \\
\hline WH2b_L39 & 1 & 625 & 0.40 & 8.42 & 66 & 622 & 346 \\
\hline WH2b_L38 & 1 & 649 & 0.42 & 8.94 & 70 & 645 & 354 \\
\hline WH2b_L37 & 1 & 665 & 0.41 & 8.68 & 74 & 659 & 419 \\
\hline WH2b_L36 & 1 & 689 & 0.38 & 8.00 & 68 & 605 & 353 \\
\hline
\end{tabular}


Table A3.8 continued

\begin{tabular}{|c|c|c|c|c|c|c|c|}
\hline Sample & Group & $\begin{array}{c}\text { Distance } \\
(\mu \mathrm{m})\end{array}$ & X An & $\begin{array}{c}\mathrm{CaO} \\
(\mathrm{wt} \%)\end{array}$ & $\begin{array}{c}\mathrm{Mg} \\
(\mathrm{ppm})\end{array}$ & $\begin{array}{c}\mathrm{Sr} \\
(\mathrm{ppm})\end{array}$ & $\begin{array}{c}\mathrm{Ba} \\
(\mathrm{ppm})\end{array}$ \\
\hline WH2b_L34 & 1 & 732 & 0.40 & 8.52 & 71 & 563 & 332 \\
\hline WH2b_L33 & 1 & 752 & 0.41 & 8.69 & 72 & 601 & 393 \\
\hline WH2b_L32 & 1 & 772 & 0.41 & 8.55 & 69 & 593 & 342 \\
\hline WH2b_L31 & 1 & 791 & 0.40 & 8.44 & 78 & 555 & 290 \\
\hline WH2b_L30 & 1 & 815 & 0.41 & 8.68 & 67 & 583 & 302 \\
\hline WH2b_L29 & 1 & 835 & 0.44 & 9.18 & 70 & 602 & 288 \\
\hline WH2b_L28 & 1 & 854 & 0.43 & 9.06 & 67 & 572 & 252 \\
\hline WH2b_L27 & 1 & 874 & 0.47 & 9.85 & 79 & 676 & 336 \\
\hline WH2b_L26 & 1 & 902 & 0.48 & 10.04 & 85 & 698 & 388 \\
\hline WH2b_L25 & 1 & 922 & 0.36 & 7.77 & 82 & 622 & 450 \\
\hline WH2b_L24 & 1 & 937 & 0.42 & 9.25 & 78 & 635 & 338 \\
\hline WH2b_L23 & 1 & 961 & 0.45 & 9.49 & 76 & 626 & 309 \\
\hline WH2b_L22 & 1 & 981 & 0.44 & 8.82 & 72 & 580 & 270 \\
\hline WH2b_L21 & 1 & 1001 & 0.42 & 9.00 & 73 & 644 & 341 \\
\hline WH2b_L20 & 1 & 1020 & 0.42 & 8.89 & 74 & 636 & 353 \\
\hline WH2b_L19 & 1 & 1040 & 0.38 & 8.06 & 70 & 637 & 414 \\
\hline WH2b_L18 & 1 & 1060 & 0.41 & 8.65 & 74 & 667 & 412 \\
\hline WH2b_L12 & 1 & 1084 & 0.41 & 8.50 & 69 & 648 & 398 \\
\hline WH2b_L11 & 1 & 1107 & 0.38 & 8.10 & 77 & 654 & 534 \\
\hline WH2b_L10 & 1 & 1127 & 0.34 & 7.33 & 69 & 589 & 529 \\
\hline WH2b_L9 & 1 & 1147 & 0.32 & 6.88 & 72 & 599 & 602 \\
\hline WH2b_L8 & 1 & 1170 & 0.31 & 6.56 & 79 & 587 & 648 \\
\hline WH2b_L7 & 1 & 1190 & 0.34 & 7.19 & 75 & 585 & 561 \\
\hline WH2b_L6 & 1 & 1210 & 0.28 & 6.03 & 66 & 537 & 592 \\
\hline WH2b_L5 & 1 & 1230 & 0.27 & 5.83 & 77 & 499 & 580 \\
\hline WH2b_L4 & 1 & 1257 & 0.30 & 6.35 & 70 & 548 & 595 \\
\hline WH2b_L3 & 1 & 1277 & 0.30 & 6.28 & 71 & 521 & 569 \\
\hline WH2b_L4 & 1 & 1297 & 0.31 & 6.58 & 75 & 536 & 639 \\
\hline WH2d_L57 & 1 & 25 & 0.32 & 6.32 & 72 & 506 & 631 \\
\hline WH2d_L56 & 1 & 48 & 0.31 & 6.32 & 72 & 546 & 678 \\
\hline WH2d_L55 & 1 & 66 & 0.32 & 6.63 & 74 & 558 & 659 \\
\hline WH2d_L54 & 1 & 84 & 0.31 & 6.51 & 70 & 548 & 641 \\
\hline WH2d_L53 & 1 & 102 & 0.30 & 6.23 & 71 & 534 & 684 \\
\hline WH2d_L52 & 1 & 117 & 0.30 & 6.33 & 72 & 537 & 710 \\
\hline WH2d_L51 & 1 & 137 & 0.30 & 6.19 & 73 & 544 & 695 \\
\hline WH2d_L50 & 1 & 155 & 0.31 & 6.52 & 76 & 548 & 667 \\
\hline WH2d_L49 & 1 & 173 & 0.31 & 6.53 & 71 & 553 & 649 \\
\hline WH2d_L48 & 1 & 188 & 0.31 & 6.48 & 69 & 539 & 622 \\
\hline WH2d_L47 & 1 & 214 & 0.30 & 6.42 & 70 & 565 & 658 \\
\hline WH2d_L46 & 1 & 234 & 0.31 & 6.42 & 67 & 556 & 611 \\
\hline WH2d_L45 & 1 & 249 & 0.31 & 6.65 & 73 & 619 & 550 \\
\hline WH2d_L44 & 1 & 272 & 0.57 & 12.10 & 73 & 761 & 218 \\
\hline WH2d_L43 & 1 & 290 & 0.56 & 11.88 & 75 & 777 & 177 \\
\hline WH2d_L42 & 1 & 310 & 0.53 & 11.04 & 78 & 797 & 233 \\
\hline WH2d_L14 & 1 & 586 & 0.30 & 11.32 & 74 & 729 & 242 \\
\hline WH2d_L13 & 1 & 595 & 0.31 & 6.09 & 74 & 607 & 671 \\
\hline WH2d_L12 & 1 & 612 & 0.35 & 6.73 & 80 & 585 & 688 \\
\hline WH2d_L11 & 1 & 631 & 0.32 & 6.75 & 78 & 610 & 726 \\
\hline WH2d_L10 & 1 & 649 & 0.32 & 6.36 & 83 & 551 & 642 \\
\hline WH2d_L9 & 1 & 668 & 0.30 & 5.84 & 68 & 502 & 633 \\
\hline WH2d_L8 & 1 & 688 & 0.32 & 6.52 & 79 & 549 & 675 \\
\hline WH2d_L7 & 1 & 707 & 0.32 & 6.43 & 81 & 551 & 717 \\
\hline WH2d_L6 & 1 & 727 & 0.33 & 6.59 & 81 & 571 & 755 \\
\hline WH2d_L5 & 1 & 747 & 0.33 & 6.22 & 83 & 575 & 831 \\
\hline WH2d-L4 & 1 & 764 & 0.37 & 7.58 & 84 & 646 & 550 \\
\hline
\end{tabular}


Table A3.8 continued

\begin{tabular}{|c|c|c|c|c|c|c|c|}
\hline Sample & Group & $\begin{array}{c}\text { Distance } \\
(\mu \mathrm{m})\end{array}$ & X An & $\begin{array}{c}\mathrm{CaO} \\
(\mathrm{wt} \%)\end{array}$ & $\begin{array}{c}\mathrm{Mg} \\
(\mathrm{ppm})\end{array}$ & $\begin{array}{c}\mathrm{Sr} \\
(\mathrm{ppm})\end{array}$ & $\begin{array}{c}\mathrm{Ba} \\
(\mathrm{ppm})\end{array}$ \\
\hline WH2d_L2 & 1 & 800 & 0.32 & 6.54 & 74 & 565 & 678 \\
\hline WH2d_L1 & 1 & 820 & 0.33 & 6.59 & 77 & 590 & 842 \\
\hline WH6da_L2 & 1 & 10 & 0.32 & 6.65 & 73 & 554 & 689 \\
\hline WH6da_L3 & 1 & 31 & 0.30 & 6.24 & 68 & 557 & 741 \\
\hline WH6da_L4 & 1 & 53 & 0.31 & 6.42 & 71 & 568 & 740 \\
\hline WH6da_L5 & 1 & 73 & 0.32 & 6.57 & 69 & 553 & 650 \\
\hline WH6da_L6 & 1 & 92 & 0.32 & 6.62 & 67 & 539 & 617 \\
\hline WH6da_L7 & 1 & 111 & 0.32 & 6.58 & 71 & 569 & 652 \\
\hline WH6da_L8 & 1 & 136 & 0.32 & 6.15 & 63 & 517 & 558 \\
\hline WH6da_L9 & 1 & 150 & 0.33 & 6.87 & 74 & 589 & 627 \\
\hline WH6da_L10 & 1 & 169 & 0.31 & 6.35 & 68 & 571 & 541 \\
\hline WH6da_L11 & 1 & 189 & 0.31 & 6.52 & 63 & 504 & 349 \\
\hline WH6da_L12 & 1 & 208 & 0.41 & 8.38 & 58 & 541 & 245 \\
\hline WH6da_L13 & 1 & 227 & 0.44 & 9.12 & 58 & 562 & 205 \\
\hline WH6da_L14 & 1 & 251 & 0.51 & 10.50 & 79 & 652 & 257 \\
\hline WH6da_L15 & 1 & 271 & 0.50 & 10.43 & 76 & 669 & 228 \\
\hline WH6da_L16 & 1 & 285 & 0.52 & 10.87 & 75 & 710 & 232 \\
\hline WH6da_L17 & 1 & 305 & 0.45 & 9.33 & 80 & 708 & 340 \\
\hline WH6da_L18 & 1 & 324 & 0.42 & 8.68 & 75 & 609 & 296 \\
\hline WH6da_L19 & 1 & 343 & 0.47 & 8.65 & 64 & 574 & 260 \\
\hline WH6da_L20 & 1 & 365 & 0.49 & 10.20 & 73 & 643 & 312 \\
\hline WH6da_L21 & 1 & 387 & 0.47 & 9.59 & 88 & 714 & 493 \\
\hline WH6da_L22 & 1 & 406 & 0.38 & 7.92 & 85 & 692 & 653 \\
\hline WH6da_L23 & 1 & 428 & 0.33 & 6.72 & 70 & 563 & 595 \\
\hline WH6da_L24 & 1 & 450 & 0.31 & 6.58 & 67 & 538 & 617 \\
\hline WH6da_L25 & 1 & 466 & 0.32 & 6.69 & 71 & 561 & 660 \\
\hline WH6da_L26 & 1 & 493 & 0.33 & 6.95 & 69 & 562 & 641 \\
\hline WH6da_L27 & 1 & 508 & 0.34 & 7.03 & 72 & 567 & 673 \\
\hline WH6da_L28 & 1 & 532 & 0.30 & 6.28 & 74 & 557 & 821 \\
\hline WH6da_L29 & 1 & 551 & 0.33 & 6.96 & 74 & 554 & 682 \\
\hline WH6da_L30 & 1 & 571 & 0.33 & 6.75 & 68 & 545 & 635 \\
\hline WH6db_L2 & 1 & 11 & 0.33 & 6.94 & 73 & 548 & 612 \\
\hline WH6db_L3 & 1 & 33 & 0.40 & 8.22 & 75 & 569 & 502 \\
\hline WH6db_L4 & 1 & 56 & 0.35 & 7.21 & 70 & 541 & 499 \\
\hline WH6db_L5 & 1 & 78 & 0.38 & 7.85 & 82 & 605 & 556 \\
\hline WH6db_L6 & 1 & 98 & 0.37 & 7.84 & 73 & 546 & 444 \\
\hline WH6db_L7 & 1 & 120 & 0.38 & 7.93 & 77 & 587 & 457 \\
\hline WH6db_L8 & 1 & 142 & 0.37 & 7.59 & 75 & 558 & 445 \\
\hline WH6db_L9 & 1 & 162 & 0.34 & 7.13 & 74 & 553 & 470 \\
\hline WH6db_L10 & 1 & 184 & 0.41 & 8.57 & 71 & 546 & 386 \\
\hline WH6db_L11 & 1 & 206 & 0.51 & 10.58 & 66 & 498 & 242 \\
\hline WH6db_L12 & 1 & 228 & 0.55 & 11.37 & 78 & 601 & 350 \\
\hline WH6db_L13 & 1 & 262 & 0.33 & 6.88 & 71 & 536 & 548 \\
\hline WH6db_L14 & 1 & 290 & 0.31 & 6.39 & 64 & 478 & 487 \\
\hline WH6db_L15 & 1 & 309 & 0.32 & 6.61 & 79 & 571 & 663 \\
\hline WH6db_L16 & 1 & 329 & 0.33 & 6.67 & 73 & 546 & 633 \\
\hline WH6db_L17 & 1 & 351 & 0.32 & 6.47 & 71 & 533 & 631 \\
\hline WH6db_L18 & 1 & 370 & 0.33 & 6.82 & 75 & 580 & 713 \\
\hline WH6f_L1 & 1 & 10 & 0.33 & 6.83 & 75 & 560 & 810 \\
\hline WH6f_L2 & 1 & 30 & 0.33 & 6.70 & 78 & 548 & 725 \\
\hline WH6f_L3 & 1 & 52 & 0.32 & 6.41 & 76 & 545 & 762 \\
\hline WH6f_L4 & 1 & 71 & 0.32 & 6.83 & 77 & 549 & 653 \\
\hline WH6f_L5 & 1 & 91 & 0.35 & 7.28 & 85 & 588 & 708 \\
\hline
\end{tabular}


Table A3.8 continued

\begin{tabular}{|c|c|c|c|c|c|c|c|}
\hline Sample & Group & $\begin{array}{c}\text { Distance } \\
(\mu \mathrm{m})\end{array}$ & X An & $\begin{array}{c}\mathrm{CaO} \\
(\mathrm{wt} \%)\end{array}$ & $\begin{array}{c}\mathrm{Mg} \\
(\mathrm{ppm})\end{array}$ & $\begin{array}{c}\mathrm{Sr} \\
(\mathrm{ppm})\end{array}$ & $\begin{array}{c}\mathrm{Ba} \\
(\mathrm{ppm})\end{array}$ \\
\hline WH6f_L7 & 1 & 153 & 0.33 & 6.88 & 78 & 554 & 636 \\
\hline WH6f_L8 & 1 & 153 & 0.33 & 6.77 & 76 & 549 & 632 \\
\hline WH6f_L9 & 1 & 172 & 0.33 & 6.73 & 75 & 552 & 623 \\
\hline WH6f_L10 & 1 & 190 & 0.32 & 6.51 & 73 & 534 & 580 \\
\hline WH6f_L11 & 1 & 207 & 0.33 & 6.77 & 75 & 549 & 597 \\
\hline WH6f_L12 & 1 & 231 & 0.31 & 6.59 & 76 & 472 & 898 \\
\hline WH6f_L13 & 1 & 296 & 0.36 & 7.83 & 80 & 598 & 643 \\
\hline WH6f_L14 & 1 & 315 & 0.33 & 6.82 & 86 & 630 & 775 \\
\hline WH6f_L15 & 1 & 340 & 0.30 & 6.19 & 72 & 551 & 583 \\
\hline WH6f_L16 & 1 & 379 & 0.36 & 8.21 & 71 & 576 & 367 \\
\hline WH6f_L17 & 1 & 384 & 0.59 & 11.89 & 109 & 694 & 247 \\
\hline WH6f_L18 & 1 & 406 & 0.52 & 9.12 & 73 & 636 & 280 \\
\hline WH6f_L19 & 1 & 428 & 0.55 & 11.38 & 82 & 688 & 238 \\
\hline WH6f_L20 & 1 & 448 & 0.57 & 10.71 & 84 & 727 & 352 \\
\hline WH6f_L21 & 1 & 473 & 0.34 & 6.63 & 81 & 609 & 617 \\
\hline WH6f_L22 & 1 & 495 & 0.29 & 6.14 & 83 & 576 & 702 \\
\hline WH6f_L23 & 1 & 517 & 0.32 & 6.63 & 78 & 581 & 662 \\
\hline WH6f_L24 & 1 & 532 & 0.32 & 6.88 & 95 & 555 & 655 \\
\hline WH6f_L25 & 1 & 552 & 0.32 & 6.58 & 104 & 558 & 760 \\
\hline WH6f_L26 & 1 & 576 & 0.32 & 6.18 & 68 & 476 & 668 \\
\hline WH6f_L27 & 1 & 596 & 0.32 & 6.79 & 80 & 564 & 708 \\
\hline WH6f_L28 & 1 & 616 & 0.32 & 6.76 & 79 & 547 & 660 \\
\hline WH6f_L29 & 1 & 640 & 0.33 & 7.00 & 80 & 562 & 675 \\
\hline WH3e_L1 & 2 & 34 & 0.32 & 6.56 & 68 & 625 & 661 \\
\hline WH3e_L2 & 2 & 49 & 0.32 & 6.46 & 55 & 586 & 594 \\
\hline WH3e- L3 & 2 & 68 & 0.32 & 6.35 & 56 & 569 & 627 \\
\hline WH3e_L4 & 2 & 83 & 0.33 & 6.68 & 66 & 574 & 576 \\
\hline WH3e_L5 & 2 & 108 & 0.31 & 6.31 & 57 & 574 & 584 \\
\hline WH3e_L6 & 2 & 127 & 0.33 & 6.73 & 51 & 560 & 590 \\
\hline WH3e- L7 & 2 & 147 & 0.33 & 6.60 & 55 & 566 & 603 \\
\hline WH3e_L8 & 2 & 162 & 0.31 & 6.29 & 55 & 567 & 638 \\
\hline WH3e_L9 & 2 & 184 & 0.30 & 6.12 & 76 & 607 & 715 \\
\hline WH3e_L10 & 2 & 203 & 0.30 & 6.37 & 71 & 609 & 716 \\
\hline WH3e_L11 & 2 & 220 & 0.32 & 6.31 & 64 & 583 & 577 \\
\hline WH3e_L12 & 2 & 240 & 0.32 & 6.47 & 66 & 567 & 592 \\
\hline WH3e_L13 & 2 & 259 & 0.31 & 6.36 & 63 & 552 & 594 \\
\hline WH3e_L14 & 2 & 279 & 0.32 & 6.44 & 62 & 558 & 562 \\
\hline WH3e_L15 & 2 & 299 & 0.31 & 6.20 & 66 & 559 & 582 \\
\hline WH3e_L16 & 2 & 319 & 0.31 & 6.30 & 60 & 549 & 535 \\
\hline WH3e_L21 & 2 & 421 & 0.36 & 7.45 & 71 & 593 & 483 \\
\hline WH3e_L22 & 2 & 441 & 0.35 & 6.70 & 69 & 549 & 436 \\
\hline WH3e_L23 & 2 & 463 & 0.35 & 7.04 & 72 & 618 & 532 \\
\hline $\mathrm{WH} 3 \mathrm{e}_{-}^{-} \mathrm{L} 24$ & 2 & 483 & 0.37 & 7.60 & 79 & 637 & 530 \\
\hline WH3e_L25 & 2 & 505 & 0.33 & 6.21 & 62 & 525 & 456 \\
\hline WH3e_L26 & 2 & 524 & 0.29 & 6.00 & 72 & 623 & 623 \\
\hline WH3e_L27 & 2 & 544 & 0.31 & 6.15 & 73 & 570 & 569 \\
\hline WH3e_L28 & 2 & 564 & 0.29 & 5.55 & 66 & 550 & 576 \\
\hline WH3e_L30 & 2 & 613 & 0.28 & 5.78 & 48 & 592 & 660 \\
\hline WH3e_L31 & 2 & 632 & 0.31 & 6.18 & 59 & 585 & 570 \\
\hline WH3e_L32 & 2 & 657 & 0.31 & 6.33 & 54 & 627 & 618 \\
\hline WH3e_L33 & 2 & 671 & 0.31 & 6.39 & 62 & 590 & 633 \\
\hline WH3e_L34 & 2 & 691 & 0.31 & 6.16 & 60 & 574 & 624 \\
\hline WH3e_L35 & 2 & 708 & 0.31 & 6.08 & 58 & 536 & 634 \\
\hline WH3e_L36 & 2 & 728 & 0.32 & 6.49 & 57 & 612 & 713 \\
\hline WH3e-L37 & 2 & 747 & 0.33 & 6.51 & 61 & 629 & 732 \\
\hline
\end{tabular}


Appendix 3

Table A3.8 continued

\begin{tabular}{lccccccc}
\hline Sample & Group & $\begin{array}{c}\text { Distance } \\
(\mu \mathrm{m})\end{array}$ & $\mathrm{X} \mathrm{An}$ & $\begin{array}{c}\mathrm{CaO} \\
(\mathrm{wt} \%)\end{array}$ & $\begin{array}{c}\mathrm{Mg} \\
(\mathrm{ppm})\end{array}$ & $\begin{array}{c}\mathrm{Sr} \\
(\mathrm{ppm})\end{array}$ & $\begin{array}{c}\mathrm{Ba} \\
(\mathrm{ppm})\end{array}$ \\
\hline WH3e_L39 & 2 & 784 & 0.31 & 7.47 & 84 & 813 & 1323 \\
WH3e_L40 & 2 & 804 & 0.28 & 5.74 & 64 & 625 & 1017 \\
WH3e_L41 & 2 & 823 & 0.29 & 5.80 & 58 & 651 & 1091 \\
& & & & & & & \\
WH6b_L1 & 3 & 20 & 0.29 & 5.80 & 28 & 434 & 458 \\
WH6b_L2 & 3 & 41 & 0.28 & 5.89 & 29 & 456 & 505 \\
WH6b_L3 & 3 & 62 & 0.28 & 5.83 & 28 & 465 & 510 \\
WH6b_L4 & 3 & 83 & 0.28 & 5.74 & 27 & 440 & 478 \\
WH6b_L5 & 3 & 103 & 0.26 & 5.78 & 31 & 432 & 483 \\
WH6b_L8 & 3 & 166 & 0.28 & 5.53 & 32 & 466 & 708 \\
WH6b_L9 & 3 & 187 & 0.29 & 5.77 & 31 & 440 & 565 \\
WH6b_L10 & 3 & 208 & 0.26 & 5.38 & 26 & 416 & 562 \\
WH6b_L11 & 3 & 229 & 0.27 & 5.54 & 27 & 481 & 633 \\
WH6b_L12 & 3 & 249 & 0.25 & 5.44 & 28 & 478 & 633 \\
WH6b_L13 & 3 & 270 & 0.25 & 5.17 & 27 & 445 & 656 \\
WH6b_L14 & 3 & 291 & 0.20 & 4.93 & 25 & 433 & 712 \\
WH6b_L15 & 3 & 312 & 0.21 & 4.39 & 24 & 407 & 789 \\
WH6b_L16 & 3 & 333 & 0.26 & 3.98 & 20 & 355 & 559 \\
WH6b_L17 & 3 & 354 & 0.20 & 5.17 & 26 & 464 & 839 \\
WH6b_L18 & 3 & 375 & 0.21 & 4.47 & 22 & 367 & 632 \\
WH6b_L19 & 3 & 395 & 0.22 & 4.53 & 22 & 385 & 725 \\
WH6b_L20 & 3 & 416 & 0.20 & 4.28 & 22 & 343 & 632 \\
WH6b_L21 & 3 & 437 & 0.21 & 4.14 & 20 & 286 & 455 \\
WH6b_L22 & 3 & 458 & 0.22 & 4.10 & 19 & 307 & 527 \\
\hline & & & & & & &
\end{tabular}




\section{Appendix 3}

Table A3.9: Rare earth elements, $\mathrm{Sr}, \mathrm{Yb}$ and $\mathrm{Pb}$ analyses of Whakamaru

plagioclase crystals

$\mathrm{CaO}$ concentrations are given in $\mathrm{wt} \%$

Trace element concentrations are given in ppm 
Table A3.9

\begin{tabular}{|c|c|c|c|c|c|c|c|c|c|c|c|c|c|c|c|c|c|c|c|c|c|c|}
\hline Sample & Position & Spot & Group & X An & $\mathrm{CaO}$ & $\mathrm{Sr}$ & $\mathrm{Y}$ & $\mathrm{La}$ & $\mathrm{Ce}$ & $\operatorname{Pr}$ & $\mathrm{Nd}$ & $\mathrm{Sm}$ & $\mathrm{Eu}$ & Gd & $\mathrm{Tb}$ & Dy & Но & $\mathrm{Er}$ & $\mathrm{Tm}$ & $\mathrm{Yb}$ & $\mathrm{Lu}$ & $\mathrm{Pb}$ \\
\hline WH1h_32 & rim & 35 & 1 & 0.30 & 6.28 & 537 & 0.2 & 9.0 & 10.1 & 0.79 & 2.4 & 0.34 & 1.59 & 0.10 & b.d. & 0.11 & b.d. & b.d. & b.d. & b.d. & b.d. & 6.28 \\
\hline WH1h_33 & rim & 35 & 1 & 0.41 & 8.45 & 556 & 0.2 & 5.6 & 7.50 & 0.70 & 2.4 & 0.23 & 1.57 & 0.14 & 0.01 & b.d. & b.d. & 0.04 & 0.01 & b.d. & b.d. & 5.18 \\
\hline WH1h_34 & core & 35 & 1 & 0.54 & 10.9 & 697 & 0.7 & 4.0 & 6.20 & 0.63 & 2.4 & 0.47 & 1.74 & 0.43 & 0.02 & 0.27 & 0.02 & 0.03 & b.d. & 0.09 & 0.01 & 4.40 \\
\hline WH1h_35 & core & 35 & 1 & 0.56 & 11.4 & 768 & 0.2 & 3.4 & 4.80 & 0.45 & 1.5 & 0.27 & 1.94 & 0.26 & b.d. & 0.09 & 0.01 & 0.04 & b.d. & 0.11 & 0.01 & 4.89 \\
\hline WH1h_36 & rim & 35 & 1 & 0.30 & 6.34 & 540 & 0.2 & 9.1 & 10.5 & 0.83 & 2.2 & 0.07 & 1.55 & 0.07 & b.d. & 0.03 & 0.02 & b.d. & 0.01 & 0.02 & b.d. & 5.97 \\
\hline WH2b_66a & rim & 50 & 1 & 0.31 & 6.39 & 546 & 0.1 & 8.8 & 10.2 & 0.78 & 2.2 & 0.09 & 1.53 & 0.07 & b.d. & 0.05 & b.d. & 0.03 & 0.01 & 0.05 & b.d. & 6.75 \\
\hline WH2b_67a & rim & 50 & 1 & 0.37 & 7.69 & 583 & 0.2 & 9.0 & 11.8 & 0.93 & 2.5 & 0.23 & 1.65 & 0.20 & b.d. & 0.02 & b.d. & 0.04 & 0.01 & b.d. & b.d. & 5.79 \\
\hline WH2b_68a & core & 50 & 1 & 0.41 & 8.68 & 588 & 0.3 & 7.2 & 9.70 & 0.81 & 2.5 & 0.26 & 1.39 & 0.15 & 0.02 & 0.02 & 0.01 & 0.02 & b.d. & 0.01 & b.d. & 4.93 \\
\hline WH2b_69 & core & 50 & 1 & 0.47 & 9.83 & 632 & 1.1 & 8.3 & 12.4 & 1.11 & 3.6 & 0.5 & 1.51 & 0.38 & 0.04 & 0.22 & 0.03 & 0.06 & 0.02 & 0.02 & b.d. & 5.95 \\
\hline WH2b_70 & rim & 50 & 1 & 0.40 & 8.50 & 611 & 0.3 & 7.7 & 10.5 & 0.78 & 2.2 & 0.34 & 1.50 & 0.11 & 0.02 & 0.05 & b.d. & 0.01 & b.d. & 0.03 & 0.01 & 5.67 \\
\hline WH2b_71 & rim & 50 & 1 & 0.31 & 6.74 & 528 & 0.2 & 9.1 & 11.0 & 0.79 & 2.5 & 0.26 & 1.62 & 0.12 & 0.03 & 0.03 & 0.02 & b.d. & 0.01 & b.d. & 0.01 & 6.02 \\
\hline WH2d_58 & rim & 50 & 1 & 0.32 & 6.32 & 516 & 0.2 & 8.6 & 9.70 & 0.74 & 2.2 & 0.17 & 1.49 & 0.13 & 0.01 & 0.02 & 0.01 & b.d. & b.d. & b.d. & b.d. & 5.41 \\
\hline WH2d_59 & rim & 50 & 1 & 0.30 & 6.33 & 519 & 0.2 & 9.2 & 10.7 & 0.80 & 2.4 & 0.21 & 1.40 & 0.14 & 0.01 & 0.08 & b.d. & 0.05 & 0.01 & 0.01 & 0.01 & 6.12 \\
\hline WH2d_60 & core & 50 & 1 & 0.56 & 11.8 & 975 & 0.5 & 8.6 & 10.8 & 0.90 & 2.8 & 0.27 & 2.15 & 0.25 & 0.02 & 0.09 & b.d. & b.d. & 0.01 & b.d. & b.d. & 6.59 \\
\hline WH2d_61 & core & 50 & 1 & 0.58 & 12.3 & 734 & 0.6 & 5.2 & 7.50 & 0.73 & 2.3 & 0.44 & 1.73 & 0.08 & 0.03 & 0.13 & b.d. & 0.07 & 0.01 & 0.09 & b.d. & 5.99 \\
\hline WH2d_62 & rim & 50 & 1 & 0.34 & 7.08 & 567 & 0.2 & 9.8 & 11.1 & 0.83 & 2.4 & 0.14 & 1.55 & 0.10 & 0.02 & 0.03 & 0.01 & 0.01 & 0.01 & 0.03 & b.d. & 6.69 \\
\hline WH2d_63 & rim & 50 & 1 & 0.33 & 6.98 & 585 & 0.2 & 9.5 & 11.1 & 0.76 & 2.3 & 0.39 & 1.65 & 0.06 & 0.01 & 0.07 & b.d. & 0.03 & 0.02 & 0.01 & b.d. & 6.24 \\
\hline WH6da_23a & rim & 35 & 1 & 0.32 & 6.75 & 582 & 0.1 & 9.8 & 12.5 & 0.85 & 2.4 & 0.28 & 1.65 & 0.13 & 0.01 & 0.10 & b.d. & b.d. & b.d. & b.d. & b.d. & 7.34 \\
\hline
\end{tabular}


Appendix 3

\begin{tabular}{|c|c|c|c|c|c|c|c|c|c|c|c|c|c|c|c|c|c|c|c|c|c|c|}
\hline Sample & Position & Spot & Group & $\mathrm{X}$ An & $\mathrm{CaO}$ & $\mathrm{Sr}$ & $\bar{Y}$ & $\mathrm{La}$ & $\mathrm{Ce}$ & $\mathrm{Pr}$ & $\mathrm{Nd}$ & $\mathrm{Sm}$ & $\mathrm{Eu}$ & $\mathrm{Gd}$ & $\mathrm{Tb}$ & Dy & Ho & Er & $\mathrm{Tm}$ & $\mathrm{Yb}$ & $\mathrm{Lu}$ & $\mathrm{Pb}$ \\
\hline WH6da_24a & core & 35 & 1 & 0.52 & 10.9 & 727 & 0.4 & 7.5 & 11.8 & 1.05 & 3.2 & 0.43 & 2.11 & 0.12 & 0.03 & 0.15 & b.d. & 0.04 & b.d. & b.d. & 0.02 & 6.78 \\
\hline WH6da_25a & rim & 35 & 1 & 0.33 & 6.65 & 564 & 0.2 & 9.3 & 11.8 & 0.83 & 2.5 & 0.31 & 1.60 & 0.16 & 0.01 & 0.02 & 0.01 & 0.03 & 0.01 & 0.03 & 0.01 & 7.19 \\
\hline WH6db_20 & rim & 35 & 1 & 0.33 & 6.65 & 478 & 0.2 & 7.5 & 10.4 & 0.71 & 2.1 & 0.16 & 1.30 & 0.11 & 0.02 & 0.06 & b.d. & b.d. & b.d. & b.d. & b.d. & 5.82 \\
\hline WH6db_21 & core & 35 & 1 & 0.46 & 9.61 & 506 & 0.5 & 4.7 & 7.80 & 0.64 & 2.2 & 0.24 & 1.30 & 0.20 & 0.02 & 0.11 & 0.02 & 0.04 & 0.01 & 0.05 & b.d. & 5.93 \\
\hline WH6db_22 & rim & 35 & 1 & 0.32 & 6.94 & 501 & 0.2 & 8.1 & 11.0 & 0.80 & 2.5 & 0.22 & 1.41 & 0.16 & 0.01 & 0.05 & 0.01 & 0.05 & 0.01 & b.d. & 0.01 & 5.95 \\
\hline WH6f_31 & rim & 35 & 1 & 0.32 & 6.76 & 547 & 0.3 & 7.9 & 11.3 & 0.77 & 2.6 & 0.9 & 1.53 & 0.10 & b.d. & b.d. & b.d. & b.d. & b.d. & b.d. & b.d. & 6.75 \\
\hline WH6f 32 & rim & 35 & 1 & 0.32 & 6.18 & 520 & 0.1 & 8.5 & 11.2 & 0.74 & 2.3 & 0.22 & 1.46 & 0.16 & b.d. & 0.05 & b.d. & b.d. & b.d. & b.d. & b.d. & 6.63 \\
\hline WH6f_33 & rim & 35 & 1 & 0.30 & 5.91 & 562 & 0.1 & 8.5 & 11.2 & 0.76 & 1.8 & 0.12 & 1.46 & 0.04 & b.d. & b.d. & b.d. & b.d. & b.d. & 0.07 & b.d. & 6.49 \\
\hline WH6f_34 & rim & 35 & 1 & 0.34 & 5.91 & 556 & 0.2 & 7.2 & 9.40 & 0.61 & 1.7 & 0.23 & 1.51 & 0.02 & 0.03 & 0.06 & b.d. & 0.06 & b.d. & b.d. & 0.01 & 7.08 \\
\hline WH6f_35 & core & 35 & 1 & 0.59 & 11.9 & 741 & 0.4 & 4.8 & 7.90 & 0.67 & 2.0 & 0.26 & 1.99 & 0.16 & 0.02 & 0.10 & b.d. & 0.04 & b.d. & b.d. & 0.01 & 7.25 \\
\hline WH6f_36 & core & 35 & 1 & 0.52 & 9.12 & 554 & 0.3 & 3.2 & 5.50 & 0.40 & 1.5 & 0.21 & 1.41 & 0.06 & 0.01 & 0.08 & 0.01 & b.d. & b.d. & 0.02 & 0.01 & 5.62 \\
\hline WH6f_37 & rim & 35 & 1 & 0.33 & 6.66 & 603 & 0.2 & 8.7 & 11.2 & 0.72 & 1.7 & 0.21 & 1.63 & 0.18 & 0.01 & 0.08 & 0.01 & b.d. & b.d. & 0.02 & 0.01 & 7.66 \\
\hline WH6f_38 & rim & 35 & 1 & 0.32 & 6.41 & 533 & 0.2 & 7.9 & 10.8 & 0.72 & 2.3 & 0.24 & 1.42 & 0.10 & 0.00 & b.d. & 0.01 & 0.08 & b.d. & b.d. & 0.01 & 6.47 \\
\hline WH6f_39 & rim & 35 & 1 & 0.32 & 6.52 & 549 & 0.2 & 8.1 & 10.8 & 0.79 & 2.5 & 0.13 & 1.61 & 0.05 & b.d. & 0.03 & 0.02 & b.d. & b.d. & b.d. & 0.01 & 6.88 \\
\hline WH3e_45 & rim & 50 & 2 & 0.32 & 6.51 & 547 & 0.1 & 9.6 & 10.7 & 0.79 & 2.3 & 0.23 & 1.51 & 0.06 & b.d. & b.d. & b.d. & b.d. & b.d. & b.d. & b.d. & 6.31 \\
\hline WH3e_46 & rim & 50 & 2 & 0.32 & 6.48 & 554 & 0.2 & 9.6 & 10.7 & 0.79 & 2.4 & 0.12 & 1.48 & 0.11 & 0.01 & b.d. & 0.02 & 0.01 & b.d. & 0.03 & 0.01 & 6.15 \\
\hline WH3e_47 & rim & 50 & 2 & 0.36 & 7.47 & 606 & 0.2 & 8.5 & 9.70 & 0.80 & 2.3 & 0.36 & 1.53 & 0.13 & 0.01 & 0.10 & 0.02 & b.d. & b.d. & 0.06 & 0.01 & 6.55 \\
\hline WH3e_48 & rim & 50 & 2 & 0.32 & 6.56 & 575 & 0.1 & 8.8 & 10.3 & 0.74 & 2.1 & 0.12 & 1.57 & b.d. & b.d. & 0.06 & 0.01 & b.d. & b.d. & 0.03 & b.d. & 6.16 \\
\hline WH3e_49 & core & 50 & 2 & 0.29 & 5.94 & 590 & 0.1 & 9.2 & 9.40 & 0.61 & 1.7 & 0.15 & 1.4 & 0.15 & 0.02 & 0.04 & b.d. & b.d. & b.d. & b.d. & 0.01 & 6.42 \\
\hline
\end{tabular}


Table A3.9 continued

\begin{tabular}{lcccccccccccccccccccccccc}
\hline Sample & Position & Spot & Group & $\mathrm{X} \mathrm{An}$ & $\mathrm{CaO}$ & $\mathrm{Sr}$ & $\mathrm{Y}$ & $\mathrm{La}$ & $\mathrm{Ce}$ & $\mathrm{Pr}$ & $\mathrm{Nd}$ & $\mathrm{Sm}$ & $\mathrm{Eu}$ & $\mathrm{Gd}$ & $\mathrm{Tb}$ & $\mathrm{Dy}$ & $\mathrm{Ho}$ & $\mathrm{Er}$ & $\mathrm{Tm}$ & $\mathrm{Yb}$ & $\mathrm{Lu}$ & $\mathrm{Pb}$ \\
\hline WH6b_50 & core & 50 & 3 & 0.28 & 5.86 & 485 & 0.2 & 12.5 & 12.8 & 0.91 & 2.6 & 0.15 & 2.65 & b.d. & 0.01 & b.d. & 0.01 & b.d. & b.d. & b.d. & b.d. & 11.0 \\
WH6b_51 & rim & 50 & 3 & 0.27 & 5.69 & 479 & 0.1 & 8.9 & 9.50 & 0.75 & 2.3 & 0.14 & 1.99 & b.d. & 0.02 & 0.08 & 0.02 & 0.01 & 0.01 & b.d. & b.d. & 7.91 \\
WH6b_52 & rim & 50 & 3 & 0.21 & 4.27 & 332 & 0.1 & 7.7 & 8.80 & 0.63 & 2.2 & 0.16 & 1.43 & 0.02 & 0.01 & 0.03 & 0.01 & 0.02 & 0.01 & 0.06 & 0.01 & 6.56 \\
\hline
\end{tabular}

Position relates to location of the analysis in either the core or the rim.

Spot - denotes spot size diameter used in analysis in $\mu \mathrm{m}$

$\mathrm{X}$ An - calculated on a mole fraction basis

$\mathrm{CaO}$ in $\mathrm{wt} \%$ all other elements in ppm. 


\section{Appendix 3}

Table A3.10: Major element compositions (are given in wt $\%$ ) of Healy

plagioclase crystals 
Table A3.10

\begin{tabular}{|c|c|c|c|c|c|c|c|c|c|c|c|}
\hline Sample & $\mathrm{SiO}_{2}$ & $\mathrm{Al}_{2} \mathrm{O}_{3}$ & $\mathrm{FeO}$ & $\mathrm{CaO}$ & $\mathrm{Na}_{2} \mathrm{O}$ & $\mathrm{K}_{2} \mathrm{O}$ & Total & $\begin{array}{l}\text { Dist } \\
(\mu \mathrm{m})\end{array}$ & X An & $\begin{array}{c}\text { Temp } \\
{ }^{\circ} \mathrm{C}\end{array}$ & $\begin{array}{l}\mathrm{H}_{2} \mathrm{O} \\
\mathrm{wt} \%\end{array}$ \\
\hline X590b_2 & 58.40 & 27.30 & 0.39 & 9.36 & 6.18 & 0.19 & 101.81 & 0 & 0.45 & 733 & 8.84 \\
\hline X590b_4 & 58.22 & 27.46 & 0.39 & 9.05 & 6.12 & 0.11 & 101.35 & 20 & 0.45 & 733 & 8.79 \\
\hline X590b_5 & 57.86 & 27.39 & 0.51 & 9.34 & 6.06 & 0.15 & 101.32 & 30 & 0.46 & 735 & 8.83 \\
\hline X590b_6 & 57.59 & 27.44 & 0.52 & 9.20 & 6.18 & 0.17 & 101.10 & 40 & 0.45 & 732 & 8.82 \\
\hline X590b 7 & 57.90 & 27.40 & 0.48 & 9.56 & 6.14 & 0.16 & 101.64 & 50 & 0.46 & 735 & 8.83 \\
\hline X590b_8 & 57.90 & 27.46 & 0.44 & 9.30 & 5.95 & 0.17 & 101.22 & 60 & 0.46 & 735 & 8.85 \\
\hline X590b_9 & 58.35 & 27.61 & 0.49 & 9.49 & 5.99 & 0.12 & 102.06 & 70 & 0.46 & 737 & 8.82 \\
\hline X590b_10 & 57.93 & 27.33 & 0.42 & 9.43 & 6.11 & 0.15 & 101.38 & 80 & 0.46 & 735 & 8.83 \\
\hline X590b_11 & 58.68 & 27.66 & 0.51 & 9.48 & 6.19 & 0.13 & 102.65 & 90 & 0.45 & 735 & 8.81 \\
\hline X590b_20 & 58.75 & 27.88 & 0.49 & 9.42 & 6.15 & 0.14 & 102.83 & 180 & 0.45 & 735 & 8.82 \\
\hline X590b_21 & 58.24 & 27.73 & 0.40 & 9.20 & 6.13 & 0.09 & 101.80 & 190 & 0.45 & 735 & 8.78 \\
\hline X590b_22 & 58.26 & 27.66 & 0.40 & 9.38 & 6.18 & 0.13 & 102.01 & 200 & 0.45 & 734 & 8.81 \\
\hline X590b_23 & 58.37 & 27.74 & 0.45 & 9.47 & 6.33 & 0.13 & 102.49 & 210 & 0.45 & 734 & 8.80 \\
\hline X590b_24 & 58.10 & 27.85 & 0.41 & 9.41 & 6.22 & 0.17 & 102.16 & 220 & 0.45 & 733 & 8.83 \\
\hline X590b_25 & 58.45 & 27.75 & 0.43 & 9.19 & 6.09 & 0.15 & 102.04 & 230 & 0.45 & 733 & 8.82 \\
\hline X590b_26 & 57.87 & 27.64 & 0.43 & 9.47 & 5.98 & 0.13 & 101.52 & 240 & 0.46 & 737 & 8.83 \\
\hline X590b_27 & 58.11 & 27.55 & 0.37 & 9.57 & 6.07 & 0.13 & 101.80 & 250 & 0.46 & 737 & 8.83 \\
\hline X590b_28 & 58.06 & 27.15 & 0.43 & 9.06 & 6.31 & 0.16 & 101.17 & 260 & 0.44 & 730 & 8.81 \\
\hline X590b_30 & 58.43 & 27.25 & 0.48 & 9.13 & 6.21 & 0.15 & 101.66 & 280 & 0.44 & 732 & 8.81 \\
\hline X590b_31 & 58.76 & 27.18 & 0.46 & 9.15 & 6.22 & 0.12 & 101.89 & 290 & 0.45 & 733 & 8.79 \\
\hline X590b_32 & 58.40 & 27.61 & 0.45 & 9.25 & 6.16 & 0.16 & 102.03 & 300 & 0.45 & 733 & 8.82 \\
\hline X590b_33 & 58.39 & 27.67 & 0.46 & 9.87 & 6.06 & 0.12 & 102.57 & 310 & 0.47 & 739 & 8.84 \\
\hline X590b_34 & 57.76 & 27.75 & 0.55 & 9.49 & 5.86 & 0.11 & 101.53 & 320 & 0.47 & 739 & 8.83 \\
\hline X590b_35 & 58.03 & 27.78 & 0.39 & 9.33 & 6.04 & 0.12 & 101.68 & 330 & 0.46 & 736 & 8.81 \\
\hline X590b_36 & 57.73 & 27.75 & 0.44 & 9.47 & 6.07 & 0.10 & 101.55 & 340 & 0.46 & 737 & 8.80 \\
\hline X590b_37 & 57.26 & 27.49 & 0.48 & 9.54 & 5.97 & 0.13 & 100.86 & 350 & 0.47 & 738 & 8.83 \\
\hline X590b_39 & 57.96 & 27.77 & 0.45 & 9.63 & 5.86 & 0.11 & 101.78 & 370 & 0.47 & 740 & 8.84 \\
\hline X590b_40 & 58.19 & 27.54 & 0.52 & 9.57 & 5.93 & 0.12 & 101.87 & 380 & 0.47 & 738 & 8.83 \\
\hline X590b_41 & 58.18 & 27.71 & 0.35 & 9.34 & 6.17 & 0.14 & 101.88 & 390 & 0.45 & 734 & 8.81 \\
\hline X590b_42 & 58.17 & 27.78 & 0.49 & 9.52 & 6.00 & 0.12 & 102.08 & 400 & 0.46 & 737 & 8.83 \\
\hline X590b_43 & 57.98 & 27.93 & 0.38 & 9.57 & 5.85 & 0.20 & 101.92 & 410 & 0.47 & 737 & 8.89 \\
\hline X590b_44 & 57.76 & 27.48 & 0.39 & 9.65 & 6.07 & 0.12 & 101.47 & 420 & 0.46 & 738 & 8.83 \\
\hline X590b_45 & 58.15 & 27.43 & 0.40 & 9.70 & 6.11 & 0.12 & 101.91 & 430 & 0.46 & 738 & 8.82 \\
\hline X590b_46 & 58.65 & 27.50 & 0.52 & 9.25 & 6.09 & 0.13 & 102.13 & 440 & 0.45 & 734 & 8.81 \\
\hline X590b_47 & 58.74 & 27.52 & 0.45 & 9.25 & 6.33 & 0.14 & 102.43 & 450 & 0.44 & 732 & 8.80 \\
\hline X590b_48 & 58.70 & 27.62 & 0.43 & 9.15 & 6.11 & 0.15 & 102.17 & 460 & 0.45 & 733 & 8.81 \\
\hline X590b_49 & 58.30 & 27.43 & 0.42 & 9.30 & 6.04 & 0.10 & 101.58 & 470 & 0.46 & 736 & 8.80 \\
\hline X590b_50 & 57.69 & 27.33 & 0.47 & 9.17 & 6.04 & 0.16 & 100.87 & 480 & 0.45 & 733 & 8.83 \\
\hline X590b_51 & 58.11 & 27.27 & 0.44 & 9.32 & 6.19 & 0.16 & 101.48 & 490 & 0.45 & 733 & 8.82 \\
\hline X590b_52 & 58.14 & 27.22 & 0.41 & 8.91 & 6.20 & 0.09 & 100.97 & 500 & 0.44 & 732 & 8.77 \\
\hline X590b_53 & 58.23 & 27.42 & 0.49 & 9.14 & 6.22 & 0.12 & 101.61 & 510 & 0.45 & 732 & 8.79 \\
\hline X590b_54 & 58.24 & 27.46 & 0.43 & 9.39 & 6.09 & 0.11 & 101.72 & 520 & 0.46 & 736 & 8.80 \\
\hline X590b_55 & 57.81 & 27.60 & 0.50 & 9.35 & 6.09 & 0.12 & 101.47 & 530 & 0.46 & 735 & 8.81 \\
\hline X590b_56 & 57.98 & 27.56 & 0.35 & 9.39 & 6.10 & 0.15 & 101.53 & 540 & 0.46 & 735 & 8.83 \\
\hline X590b_57 & 57.92 & 27.41 & 0.45 & 8.84 & 6.05 & 0.15 & 100.83 & 550 & 0.44 & 731 & 8.81 \\
\hline X590b_58 & 58.21 & 27.30 & 0.38 & 9.19 & 6.18 & 0.14 & 101.39 & 560 & 0.45 & 733 & 8.81 \\
\hline X590b_59 & 58.12 & 27.37 & 0.43 & 9.04 & 6.29 & 0.13 & 101.37 & 570 & 0.44 & 731 & 8.79 \\
\hline X590b_60 & 58.32 & 27.54 & 0.40 & 9.07 & 6.17 & 0.13 & 101.63 & 580 & 0.44 & 732 & 8.80 \\
\hline X590b_61 & 60.00 & 27.09 & 0.41 & 9.13 & 6.24 & 0.13 & 102.99 & 590 & 0.44 & 732 & 8.80 \\
\hline X590b_62 & 59.67 & 27.37 & 0.42 & 8.69 & 6.26 & 0.12 & 102.53 & 600 & 0.43 & 728 & 8.78 \\
\hline X590b_63 & 59.79 & 26.74 & 0.34 & 8.56 & 6.67 & 0.13 & 102.22 & 610 & 0.41 & 722 & 8.77 \\
\hline X590b_64 & 59.22 & 26.59 & 0.39 & 8.09 & 6.84 & 0.17 & 101.29 & 620 & 0.39 & 714 & 8.80 \\
\hline X590b_65 & 59.84 & 26.63 & 0.32 & 8.23 & 6.72 & 0.17 & 101.90 & 630 & 0.40 & 717 & 8.80 \\
\hline X590b_66 & 59.61 & 26.77 & 0.31 & 8.30 & 6.74 & 0.15 & 101.88 & 640 & 0.40 & 718 & 8.79 \\
\hline X590b_67 & 60.39 & 26.43 & 0.41 & 8.27 & 6.73 & 0.16 & 102.39 & 650 & 0.40 & 718 & 8.79 \\
\hline X590b_68 & 59.93 & 26.35 & 0.33 & 8.13 & 6.73 & 0.15 & 101.61 & 660 & 0.40 & 716 & 8.79 \\
\hline X590b_69 & 60.31 & 26.47 & 0.36 & 8.05 & 6.70 & 0.19 & 102.09 & 670 & 0.39 & 715 & 8.81 \\
\hline X590b_70 & 60.51 & 26.43 & 0.36 & 7.85 & 6.83 & 0.17 & 102.16 & 680 & 0.38 & 711 & 8.81 \\
\hline X590b_71 & 60.91 & 25.84 & 0.43 & 7.46 & 6.77 & 0.16 & 101.56 & 690 & 0.38 & 708 & 8.82 \\
\hline X590b_72 & 60.61 & 25.84 & 0.22 & 7.10 & 7.31 & 0.22 & 101.30 & 700 & 0.34 & 694 & 8.91 \\
\hline X590b_73 & 61.01 & 25.60 & 0.32 & 7.10 & 7.07 & 0.17 & 101.27 & 710 & 0.35 & 698 & 8.87 \\
\hline X590b_74 & 60.40 & 25.60 & 0.36 & 7.55 & 7.15 & 0.17 & 101.23 & 720 & 0.36 & 704 & 8.84 \\
\hline X590b_75 & 60.82 & 26.13 & 0.36 & 7.92 & 6.84 & 0.15 & 102.23 & 730 & 0.39 & 713 & 8.80 \\
\hline X590b_76 & 60.17 & 26.47 & 0.43 & 8.20 & 6.56 & 0.14 & 101.96 & 740 & 0.41 & 720 & 8.78 \\
\hline X590b_77 & 58.82 & 27.07 & 0.35 & 8.44 & 6.19 & 0.17 & 101.03 & 750 & 0.43 & 726 & 8.80 \\
\hline X590b_78 & 58.97 & 27.06 & 0.34 & 8.90 & 6.49 & 0.12 & 101.88 & 760 & 0.43 & 727 & 8.78 \\
\hline X590b_79 & 59.02 & 26.64 & 0.34 & 8.39 & 6.60 & 0.18 & 101.18 & 770 & 0.41 & 720 & 8.80 \\
\hline X590b_80 & 56.19 & 28.44 & 0.47 & 10.34 & 5.62 & 0.15 & 101.21 & 780 & 0.50 & 744 & 8.95 \\
\hline X590b_81 & 57.13 & 28.15 & 0.30 & 9.95 & 5.69 & 0.11 & 101.34 & 790 & 0.49 & 743 & 8.88 \\
\hline X590b_83 & 58.06 & 27.36 & 0.41 & 9.37 & 6.15 & 0.11 & 101.46 & 810 & 0.45 & 735 & 8.80 \\
\hline
\end{tabular}


Table A3.10 continued

\begin{tabular}{|c|c|c|c|c|c|c|c|c|c|c|c|}
\hline Sample & $\mathrm{SiO}_{2}$ & $\mathrm{Al}_{2} \mathrm{O}_{3}$ & $\mathrm{FeO}$ & $\mathrm{CaO}$ & $\mathrm{Na}_{2} \mathrm{O}$ & $\mathrm{K}_{2} \mathrm{O}$ & Total & $\begin{array}{l}\text { Dist } \\
(\mu \mathrm{m})\end{array}$ & X An & $\begin{array}{c}\text { Temp } \\
{ }^{\circ} \mathrm{C}\end{array}$ & $\begin{array}{l}\mathrm{H}_{2} \mathrm{O} \\
\mathrm{wt} \%\end{array}$ \\
\hline X590b_85 & 58.66 & 27.63 & 0.47 & 8.97 & 6.08 & 0.12 & 101.94 & 830 & 0.45 & 733 & 8.80 \\
\hline X590b_86 & 59.88 & 26.40 & 0.41 & 8.31 & 6.68 & 0.12 & 101.80 & 840 & 0.40 & 720 & 8.77 \\
\hline X590b_87 & 58.92 & 27.28 & 0.44 & 8.35 & 6.36 & 0.12 & 101.47 & 850 & 0.42 & 724 & 8.77 \\
\hline X590b_88 & 59.03 & 27.05 & 0.32 & 8.70 & 6.55 & 0.12 & 101.78 & 860 & 0.42 & 725 & 8.77 \\
\hline X590b_89 & 59.44 & 27.07 & 0.30 & 8.10 & 6.58 & 0.15 & 101.65 & 870 & 0.40 & 718 & 8.79 \\
\hline X590b_90 & 59.26 & 26.85 & 0.33 & 8.66 & 6.56 & 0.19 & 101.85 & 880 & 0.42 & 723 & 8.81 \\
\hline X590b_91 & 59.26 & 26.05 & 0.29 & 8.26 & 6.77 & 0.15 & 100.78 & 890 & 0.40 & 717 & 8.79 \\
\hline X590b_92 & 59.92 & 26.14 & 0.39 & 7.73 & 6.70 & 0.14 & 101.01 & 900 & 0.39 & 712 & 8.79 \\
\hline X590b_93 & 60.19 & 26.32 & 0.46 & 7.93 & 7.10 & 0.12 & 102.12 & 910 & 0.38 & 710 & 8.79 \\
\hline X590b_94 & 59.63 & 26.57 & 0.40 & 8.00 & 6.74 & 0.20 & 101.54 & 920 & 0.39 & 714 & 8.82 \\
\hline X590b_95 & 58.78 & 26.82 & 0.38 & 8.67 & 6.29 & 0.15 & 101.09 & 930 & 0.43 & 727 & 8.80 \\
\hline X590b_96 & 58.26 & 27.13 & 0.36 & 8.90 & 6.32 & 0.14 & 101.11 & 940 & 0.43 & 729 & 8.79 \\
\hline X590b_97 & 58.48 & 27.61 & 0.43 & 9.45 & 6.04 & 0.11 & 102.11 & 950 & 0.46 & 737 & 8.81 \\
\hline X590b_98 & 58.13 & 27.33 & 0.37 & 9.32 & 6.04 & 0.16 & 101.35 & 960 & 0.46 & 734 & 8.83 \\
\hline X590b_99 & 57.89 & 27.55 & 0.39 & 9.39 & 6.10 & 0.14 & 101.45 & 970 & 0.46 & 735 & 8.82 \\
\hline X590b_100 & 57.76 & 27.34 & 0.40 & 9.05 & 6.15 & 0.13 & 100.82 & 980 & 0.45 & 732 & 8.80 \\
\hline X590d_2 & 58.14 & 27.03 & 0.35 & 9.36 & 5.88 & 0.12 & 100.88 & 0 & 0.46 & 738 & 8.82 \\
\hline X590d_3 & 57.36 & 27.23 & 0.39 & 9.77 & 5.74 & 0.09 & 100.58 & 10 & 0.48 & 742 & 8.85 \\
\hline X590d_4 & 57.30 & 27.35 & 0.47 & 9.35 & 5.84 & 0.13 & 100.44 & 20 & 0.47 & 737 & 8.84 \\
\hline X590d_5 & 59.31 & 26.36 & 0.36 & 8.31 & 6.41 & 0.14 & 100.89 & 30 & 0.41 & 722 & 8.78 \\
\hline X590d_6 & 58.95 & 26.28 & 0.45 & 8.26 & 6.45 & 0.15 & 100.53 & 40 & 0.41 & 721 & 8.79 \\
\hline X590d_7 & 58.53 & 26.38 & 0.44 & 8.19 & 6.32 & 0.15 & 100.00 & 50 & 0.41 & 722 & 8.79 \\
\hline X590d_8 & 59.49 & 26.93 & 0.36 & 8.54 & 6.34 & 0.14 & 101.81 & 60 & 0.42 & 725 & 8.79 \\
\hline X590d_9 & 60.29 & 26.96 & 0.36 & 8.67 & 6.45 & 0.13 & 102.85 & 70 & 0.42 & 726 & 8.78 \\
\hline X590d_10 & 59.29 & 26.67 & 0.31 & 8.54 & 6.08 & 0.11 & 101.01 & 80 & 0.43 & 729 & 8.78 \\
\hline X590d_11 & 59.23 & 26.53 & 0.30 & 8.06 & 6.51 & 0.13 & 100.77 & 90 & 0.40 & 719 & 8.78 \\
\hline X590d_12 & 58.25 & 26.12 & 0.32 & 8.05 & 6.27 & 0.15 & 99.16 & 100 & 0.41 & 721 & 8.79 \\
\hline X590d_13 & 57.60 & 26.27 & 0.38 & 8.23 & 6.43 & 0.14 & 99.06 & 110 & 0.41 & 721 & 8.78 \\
\hline X590d_15 & 58.07 & 25.78 & 0.47 & 8.06 & 6.36 & 0.17 & 98.90 & 130 & 0.41 & 720 & 8.80 \\
\hline X590d_16 & 57.44 & 25.96 & 0.29 & 7.99 & 6.30 & 0.16 & 98.13 & 140 & 0.41 & 720 & 8.79 \\
\hline X590d_17 & 57.71 & 25.83 & 0.38 & 8.32 & 6.24 & 0.14 & 98.62 & 150 & 0.42 & 725 & 8.79 \\
\hline X590d_18 & 57.91 & 25.68 & 0.41 & 8.07 & 6.30 & 0.16 & 98.52 & 160 & 0.41 & 721 & 8.79 \\
\hline X590d_19 & 57.79 & 25.90 & 0.38 & 8.18 & 6.35 & 0.13 & 98.74 & 170 & 0.41 & 722 & 8.78 \\
\hline X590d_20 & 57.81 & 25.66 & 0.42 & 7.72 & 6.56 & 0.18 & 98.35 & 180 & 0.39 & 713 & 8.81 \\
\hline X590d_21 & 58.77 & 26.79 & 0.38 & 8.43 & 6.65 & 0.13 & 101.15 & 190 & 0.41 & 721 & 8.77 \\
\hline X590d_22 & 59.14 & 26.83 & 0.42 & 8.54 & 6.69 & 0.15 & 101.78 & 200 & 0.41 & 721 & 8.79 \\
\hline X590d_23 & 58.86 & 26.90 & 0.37 & 8.35 & 6.53 & 0.18 & 101.18 & 210 & 0.41 & 721 & 8.80 \\
\hline X590d_24 & 59.70 & 27.10 & 0.37 & 8.52 & 6.51 & 0.18 & 102.38 & 220 & 0.42 & 722 & 8.80 \\
\hline X590d_25 & 59.12 & 27.12 & 0.41 & 8.83 & 6.60 & 0.17 & 102.24 & 230 & 0.42 & 724 & 8.80 \\
\hline X590d_26 & 59.23 & 26.86 & 0.35 & 8.63 & 6.57 & 0.14 & 101.78 & 240 & 0.42 & 724 & 8.78 \\
\hline X590d_27 & 58.87 & 26.86 & 0.41 & 8.44 & 6.63 & 0.13 & 101.35 & 250 & 0.41 & 721 & 8.78 \\
\hline X590d_28 & 57.76 & 27.10 & 0.39 & 8.61 & 6.47 & 0.13 & 100.46 & 260 & 0.42 & 725 & 8.78 \\
\hline X590d_30 & 55.95 & 27.21 & 0.44 & 8.98 & 6.33 & 0.16 & 99.06 & 280 & 0.44 & 729 & 8.80 \\
\hline X590d_32 & 55.42 & 27.86 & 0.30 & 9.97 & 5.85 & 0.14 & 99.54 & 300 & 0.48 & 741 & 8.88 \\
\hline X590d_33 & 55.53 & 27.83 & 0.37 & 9.74 & 5.84 & 0.12 & 99.43 & 310 & 0.48 & 740 & 8.85 \\
\hline X590d_34 & 55.63 & 27.77 & 0.39 & 10.11 & 5.80 & 0.09 & 99.80 & 320 & 0.49 & 743 & 8.87 \\
\hline X590d_35 & 56.93 & 27.43 & 0.30 & 9.29 & 6.25 & 0.15 & 100.35 & 330 & 0.45 & 733 & 8.81 \\
\hline X590d_36 & 57.85 & 26.50 & 0.31 & 8.38 & 6.62 & 0.18 & 99.85 & 340 & 0.41 & 720 & 8.80 \\
\hline X590d_37 & 58.54 & 26.31 & 0.32 & 7.89 & 6.92 & 0.16 & 100.13 & 350 & 0.38 & 711 & 8.80 \\
\hline X590d_38 & 58.20 & 26.12 & 0.31 & 8.02 & 6.58 & 0.16 & 99.39 & 360 & 0.40 & 717 & 8.80 \\
\hline X590d_39 & 56.83 & 26.40 & 0.33 & 8.12 & 6.54 & 0.16 & 98.38 & 370 & 0.40 & 718 & 8.79 \\
\hline X590d_40 & 57.01 & 26.88 & 0.42 & 8.81 & 6.48 & 0.15 & 99.75 & 380 & 0.43 & 726 & 8.79 \\
\hline X590d_41 & 58.78 & 27.21 & 0.32 & 8.63 & 6.63 & 0.12 & 101.69 & 390 & 0.42 & 723 & 8.77 \\
\hline X590d_42 & 59.16 & 26.96 & 0.53 & 8.61 & 6.66 & 0.14 & 102.06 & 400 & 0.41 & 722 & 8.78 \\
\hline X590d_43 & 58.97 & 26.87 & 0.36 & 8.97 & 6.35 & 0.14 & 101.67 & 410 & 0.43 & 729 & 8.79 \\
\hline X590d_44 & 59.43 & 26.97 & 0.42 & 8.49 & 6.46 & 0.18 & 101.93 & 420 & 0.42 & 723 & 8.80 \\
\hline X590d_45 & 59.60 & 26.85 & 0.47 & 8.41 & 6.69 & 0.16 & 102.18 & 430 & 0.41 & 720 & 8.79 \\
\hline X590d_46 & 59.26 & 26.79 & 0.47 & 8.55 & 6.62 & 0.10 & 101.79 & 440 & 0.41 & 723 & 8.76 \\
\hline X590d_47 & 58.22 & 26.74 & 0.46 & 8.41 & 6.68 & 0.14 & 100.64 & 450 & 0.41 & 720 & 8.78 \\
\hline X590d_48 & 58.87 & 26.66 & 0.37 & 8.37 & 6.64 & 0.15 & 101.05 & 460 & 0.41 & 720 & 8.78 \\
\hline X590d_49 & 59.67 & 26.41 & 0.38 & 8.36 & 6.76 & 0.16 & 101.74 & 470 & 0.40 & 718 & 8.79 \\
\hline X590d_50 & 59.30 & 27.01 & 0.43 & 8.48 & 6.68 & 0.14 & 102.04 & 480 & 0.41 & 721 & 8.78 \\
\hline X590d_51 & 58.69 & 27.33 & 0.44 & 8.78 & 6.19 & 0.14 & 101.58 & 490 & 0.44 & 729 & 8.79 \\
\hline X590d_52 & 59.65 & 26.67 & 0.40 & 8.34 & 6.57 & 0.16 & 101.79 & 500 & 0.41 & 720 & 8.79 \\
\hline X590d_53 & 60.29 & 26.71 & 0.42 & 8.29 & 6.89 & 0.15 & 102.74 & 510 & 0.40 & 716 & 8.79 \\
\hline X590d_54 & 58.38 & 26.69 & 0.32 & 8.48 & 6.59 & 0.17 & 100.64 & 520 & 0.41 & 721 & 8.80 \\
\hline X590d_55 & 57.31 & 27.69 & 0.30 & 9.11 & 6.02 & 0.12 & 100.55 & 530 & 0.45 & 734 & 8.80 \\
\hline X590d_56 & 56.84 & 28.33 & 0.41 & 10.06 & 5.66 & 0.09 & 101.40 & 540 & 0.49 & 744 & 8.88 \\
\hline X590d 57 & 56.75 & 28.24 & 0.50 & 9.85 & 5.71 & 0.12 & 101.18 & 550 & 0.48 & 742 & 8.88 \\
\hline
\end{tabular}


Table A3.10 continued

\begin{tabular}{|c|c|c|c|c|c|c|c|c|c|c|c|}
\hline Sample & $\mathrm{SiO}_{2}$ & $\mathrm{Al}_{2} \mathrm{O}_{3}$ & $\mathrm{FeO}$ & $\mathrm{CaO}$ & $\mathrm{Na}_{2} \mathrm{O}$ & $\mathrm{K}_{2} \mathrm{O}$ & Total & $\begin{array}{l}\text { Dist } \\
(\mu \mathrm{m})\end{array}$ & X An & $\begin{array}{c}\text { Temp } \\
{ }^{\circ} \mathrm{C} \\
\end{array}$ & $\begin{array}{l}\mathrm{H}_{2} \mathrm{O} \\
\mathrm{wt} \% \\
\end{array}$ \\
\hline X590d_59 & 57.00 & 28.12 & 0.44 & 9.66 & 5.86 & 0.12 & 101.19 & 570 & 0.47 & 740 & 8.85 \\
\hline X590d_60 & 56.60 & 27.97 & 0.47 & 9.66 & 5.83 & 0.11 & 100.64 & 580 & 0.47 & 740 & 8.85 \\
\hline X590d_61 & 57.25 & 28.10 & 0.36 & 9.76 & 5.95 & 0.11 & 101.54 & 590 & 0.47 & 739 & 8.84 \\
\hline X590d_62 & 57.04 & 28.17 & 0.44 & 9.69 & 6.00 & 0.13 & 101.48 & 600 & 0.47 & 738 & 8.84 \\
\hline X590d_63 & 57.15 & 28.16 & 0.51 & 9.77 & 6.00 & 0.14 & 101.73 & 610 & 0.47 & 738 & 8.85 \\
\hline X590d_64 & 57.25 & 27.74 & 0.40 & 9.60 & 6.18 & 0.10 & 101.27 & 620 & 0.46 & 737 & 8.80 \\
\hline X590d_65 & 57.83 & 27.47 & 0.33 & 9.36 & 6.26 & 0.12 & 101.36 & 630 & 0.45 & 734 & 8.80 \\
\hline X590d_66 & 57.68 & 27.49 & 0.45 & 9.17 & 6.36 & 0.10 & 101.26 & 640 & 0.44 & 732 & 8.78 \\
\hline X590d_67 & 57.72 & 28.02 & 0.49 & 9.45 & 6.00 & 0.13 & 101.80 & 650 & 0.46 & 737 & 8.83 \\
\hline X590d_68 & 57.45 & 27.97 & 0.47 & 9.73 & 6.08 & 0.14 & 101.85 & 660 & 0.47 & 737 & 8.84 \\
\hline X590d_69 & 57.89 & 27.34 & 0.48 & 9.10 & 6.29 & 0.16 & 101.26 & 670 & 0.44 & 730 & 8.81 \\
\hline X590d_70 & 57.66 & 27.66 & 0.46 & 9.10 & 6.43 & 0.11 & 101.42 & 680 & 0.44 & 730 & 8.78 \\
\hline X590d_71 & 57.41 & 27.30 & 0.48 & 9.00 & 6.39 & 0.14 & 100.72 & 690 & 0.43 & 729 & 8.79 \\
\hline X590d_72 & 57.29 & 27.38 & 0.47 & 9.53 & 6.11 & 0.11 & 100.89 & 700 & 0.46 & 737 & 8.81 \\
\hline X590d_73 & 59.21 & 27.25 & 0.40 & 9.40 & 6.13 & 0.13 & 102.52 & 710 & 0.45 & 735 & 8.81 \\
\hline X590d_74 & 58.99 & 27.36 & 0.31 & 9.48 & 6.18 & 0.14 & 102.46 & 720 & 0.46 & 735 & 8.82 \\
\hline X590d_75 & 58.93 & 27.08 & 0.37 & 8.82 & 6.41 & 0.15 & 101.75 & 730 & 0.43 & 727 & 8.79 \\
\hline X590d_76 & 57.11 & 27.90 & 0.38 & 9.27 & 6.07 & 0.11 & 100.85 & 740 & 0.45 & 735 & 8.80 \\
\hline X590d_77 & 57.63 & 27.86 & 0.31 & 8.90 & 6.50 & 0.16 & 101.36 & 750 & 0.43 & 726 & 8.80 \\
\hline X590d_78 & 58.09 & 27.45 & 0.50 & 8.94 & 6.30 & 0.19 & 101.47 & 760 & 0.43 & 728 & 8.82 \\
\hline X590d_79 & 57.97 & 26.67 & 0.40 & 8.83 & 6.60 & 0.15 & 100.62 & 770 & 0.42 & 725 & 8.79 \\
\hline X590d_80 & 58.29 & 26.69 & 0.41 & 8.32 & 6.63 & 0.16 & 100.50 & 780 & 0.41 & 719 & 8.79 \\
\hline X590d_81 & 59.42 & 26.57 & 0.34 & 8.19 & 6.70 & 0.16 & 101.39 & 790 & 0.40 & 717 & 8.80 \\
\hline X590d_82 & 60.09 & 26.70 & 0.39 & 8.19 & 6.75 & 0.13 & 102.25 & 800 & 0.40 & 717 & 8.78 \\
\hline X590d_83 & 59.65 & 26.54 & 0.43 & 8.24 & 6.89 & 0.18 & 101.93 & 810 & 0.39 & 715 & 8.80 \\
\hline X590d_84 & 60.19 & 26.59 & 0.44 & 7.92 & 6.73 & 0.15 & 102.02 & 820 & 0.39 & 714 & 8.80 \\
\hline X590d_85 & 60.16 & 25.97 & 0.30 & 7.29 & 7.04 & 0.15 & 100.91 & 830 & 0.36 & 702 & 8.84 \\
\hline X590d_86 & 59.92 & 26.03 & 0.37 & 7.35 & 7.11 & 0.19 & 100.98 & 840 & 0.36 & 701 & 8.86 \\
\hline X590d_87 & 59.34 & 25.90 & 0.28 & 7.56 & 7.07 & 0.14 & 100.29 & 850 & 0.37 & 705 & 8.82 \\
\hline X590d_88 & 58.94 & 26.34 & 0.33 & 7.77 & 6.72 & 0.18 & 100.28 & 860 & 0.39 & 712 & 8.82 \\
\hline X590d_89 & 59.42 & 26.19 & 0.32 & 7.77 & 6.89 & 0.17 & 100.75 & 870 & 0.38 & 710 & 8.82 \\
\hline X590d_90 & 59.72 & 26.18 & 0.34 & 7.78 & 6.93 & 0.17 & 101.13 & 880 & 0.38 & 709 & 8.82 \\
\hline X590d_91 & 59.53 & 26.82 & 0.36 & 7.94 & 6.86 & 0.15 & 101.66 & 890 & 0.39 & 712 & 8.80 \\
\hline X590d_92 & 57.52 & 27.78 & 0.46 & 9.12 & 6.34 & 0.13 & 101.35 & 900 & 0.44 & 731 & 8.79 \\
\hline X590d_93 & 57.04 & 27.18 & 0.36 & 9.03 & 6.44 & 0.13 & 100.19 & 910 & 0.43 & 729 & 8.79 \\
\hline X590d_94 & 56.76 & 27.22 & 0.29 & 8.74 & 6.41 & 0.14 & 99.56 & 920 & 0.43 & 726 & 8.79 \\
\hline X590d_95 & 56.65 & 27.12 & 0.33 & 9.01 & 6.25 & 0.17 & 99.51 & 930 & 0.44 & 730 & 8.81 \\
\hline X590d_96 & 57.12 & 26.76 & 0.37 & 8.81 & 6.32 & 0.13 & 99.51 & 940 & 0.43 & 728 & 8.79 \\
\hline X590d_97 & 57.13 & 26.87 & 0.33 & 8.94 & 6.35 & 0.15 & 99.77 & 950 & 0.43 & 729 & 8.79 \\
\hline X590d_98 & 57.50 & 26.93 & 0.36 & 8.88 & 6.33 & 0.14 & 100.13 & 960 & 0.43 & 729 & 8.79 \\
\hline X590d_99 & 58.12 & 26.38 & 0.29 & 8.24 & 6.71 & 0.17 & 99.92 & 970 & 0.40 & 717 & 8.80 \\
\hline X590d_100 & 59.13 & 26.41 & 0.43 & 8.13 & 6.75 & 0.15 & 101.00 & 980 & 0.40 & 716 & 8.79 \\
\hline X590d_101 & 58.12 & 26.79 & 0.35 & 8.51 & 6.45 & 0.14 & 100.36 & 990 & 0.42 & 724 & 8.78 \\
\hline X590d_102 & 58.54 & 26.70 & 0.42 & 8.31 & 6.75 & 0.15 & 100.87 & 1000 & 0.40 & 718 & 8.79 \\
\hline X590d_103 & 58.99 & 26.27 & 0.29 & 8.07 & 6.92 & 0.14 & 100.68 & 1010 & 0.39 & 713 & 8.79 \\
\hline X590d_104 & 59.65 & 26.16 & 0.44 & 8.06 & 6.82 & 0.20 & 101.34 & 1020 & 0.39 & 713 & 8.82 \\
\hline X590d_105 & 60.07 & 26.08 & 0.38 & 7.78 & 7.08 & 0.14 & 101.54 & 1030 & 0.37 & 708 & 8.81 \\
\hline X590d_106 & 59.80 & 25.86 & 0.32 & 7.44 & 6.95 & 0.16 & 100.52 & 1040 & 0.37 & 705 & 8.83 \\
\hline X590d_107 & 60.12 & 25.91 & 0.35 & 7.41 & 7.00 & 0.19 & 100.98 & 1050 & 0.37 & 703 & 8.85 \\
\hline X590d_108 & 59.74 & 25.96 & 0.36 & 7.55 & 7.15 & 0.13 & 100.88 & 1060 & 0.37 & 705 & 8.82 \\
\hline X590d_109 & 57.23 & 26.88 & 0.38 & 8.50 & 6.45 & 0.14 & 99.58 & 1070 & 0.42 & 724 & 8.78 \\
\hline X590d_110 & 55.12 & 27.92 & 0.50 & 10.13 & 5.61 & 0.11 & 99.39 & 1080 & 0.50 & 744 & 8.91 \\
\hline X590d 111 & 55.81 & 27.49 & 0.45 & 9.98 & 5.66 & 0.12 & 99.50 & 1090 & 0.49 & 743 & 8.89 \\
\hline X590d_112 & 56.18 & 27.23 & 0.53 & 9.70 & 5.89 & 0.09 & 99.62 & 1100 & 0.47 & 740 & 8.83 \\
\hline X590d_113 & 57.78 & 27.43 & 0.42 & 9.64 & 5.80 & 0.13 & 101.21 & 1110 & 0.48 & 740 & 8.86 \\
\hline X590d_114 & 58.07 & 26.97 & 0.33 & 9.04 & 6.22 & 0.10 & 100.73 & 1120 & 0.44 & 732 & 8.78 \\
\hline X590d_115 & 57.15 & 27.46 & 0.38 & 9.44 & 5.90 & 0.12 & 100.44 & 1130 & 0.47 & 738 & 8.83 \\
\hline X590d_116 & 56.38 & 27.55 & 0.37 & 9.13 & 6.02 & 0.15 & 99.60 & 1140 & 0.45 & 734 & 8.82 \\
\hline X590d_117 & 56.12 & 27.32 & 0.39 & 9.04 & 5.94 & 0.12 & 98.93 & 1150 & 0.45 & 735 & 8.81 \\
\hline X590d_118 & 56.42 & 26.82 & 0.42 & 8.98 & 6.21 & 0.14 & 98.98 & 1160 & 0.44 & 731 & 8.80 \\
\hline X590d_119 & 56.80 & 26.49 & 0.33 & 8.73 & 6.39 & 0.15 & 98.89 & 1170 & 0.43 & 726 & 8.79 \\
\hline X590d_120 & 57.03 & 27.07 & 0.29 & 9.40 & 6.12 & 0.12 & 100.03 & 1180 & 0.46 & 735 & 8.81 \\
\hline X590e_3 & 59.65 & 26.83 & 0.50 & 8.85 & 6.60 & 0.13 & 102.57 & 20 & 0.42 & 726 & 8.78 \\
\hline X590e $e^{-} 4$ & 58.26 & 26.45 & 0.42 & 8.86 & 6.38 & 0.18 & 100.54 & 30 & 0.43 & 727 & 8.81 \\
\hline X590e-5 & 59.26 & 26.74 & 0.46 & 8.70 & 6.67 & 0.17 & 102.00 & 40 & 0.41 & 722 & 8.80 \\
\hline X590e_-6 & 59.91 & 26.82 & 0.41 & 8.91 & 6.66 & 0.14 & 102.84 & 50 & 0.42 & 725 & 8.78 \\
\hline X590e_7 & 60.24 & 26.70 & 0.41 & 8.81 & 6.52 & 0.15 & 102.82 & 60 & 0.42 & 725 & 8.79 \\
\hline X590e $\_8$ & 59.83 & 26.91 & 0.38 & 8.38 & 6.62 & 0.13 & 102.24 & 70 & 0.41 & 721 & 8.78 \\
\hline $\mathrm{X} 590 \mathrm{e}^{-} 9$ & 59.48 & 26.88 & 0.35 & 8.52 & 6.65 & 0.13 & 102.01 & 80 & 0.41 & 722 & 8.77 \\
\hline
\end{tabular}


Table A3.10 continued

\begin{tabular}{|c|c|c|c|c|c|c|c|c|c|c|c|}
\hline Sample & $\mathrm{SiO}_{2}$ & $\mathrm{Al}_{2} \mathrm{O}_{3}$ & $\mathrm{FeO}$ & $\mathrm{CaO}$ & $\mathrm{Na}_{2} \mathrm{O}$ & $\mathrm{K}_{2} \mathrm{O}$ & Total & $\begin{array}{l}\text { Dist } \\
(\mu \mathrm{m})\end{array}$ & X An & $\begin{array}{c}\text { Temp } \\
{ }^{\circ} \mathrm{C}\end{array}$ & $\begin{array}{l}\mathrm{H}_{2} \mathrm{O} \\
\mathrm{wt} \%\end{array}$ \\
\hline X590e_11 & 59.94 & 26.38 & 0.39 & 8.33 & 6.87 & 0.16 & 102.07 & 100 & 0.40 & 716 & 8.80 \\
\hline X590e 12 & 59.74 & 26.55 & 0.36 & 8.48 & 6.75 & 0.15 & 102.02 & 110 & 0.41 & 720 & 8.78 \\
\hline X590e_13 & 59.57 & 26.71 & 0.41 & 8.62 & 6.69 & 0.15 & 102.15 & 120 & 0.41 & 722 & 8.78 \\
\hline $\mathrm{X} 590 \mathrm{e}_{-} 14$ & 59.09 & 26.87 & 0.45 & 8.55 & 6.54 & 0.15 & 101.66 & 130 & 0.42 & 723 & 8.79 \\
\hline $\mathrm{X} 590 \mathrm{e}^{-} 15$ & 59.18 & 26.90 & 0.41 & 8.76 & 6.39 & 0.16 & 101.80 & 140 & 0.43 & 726 & 8.80 \\
\hline $\mathrm{X} 590 \mathrm{e}_{-}^{-} 16$ & 60.24 & 26.66 & 0.32 & 8.66 & 6.61 & 0.11 & 102.60 & 150 & 0.42 & 724 & 8.76 \\
\hline $\mathrm{X} 590 \mathrm{e}_{-} 17$ & 59.62 & 27.18 & 0.39 & 9.03 & 6.43 & 0.10 & 102.74 & 160 & 0.43 & 730 & 8.77 \\
\hline X590e_18 & 58.64 & 27.07 & 0.32 & 8.93 & 6.39 & 0.12 & 101.48 & 170 & 0.43 & 729 & 8.78 \\
\hline X590e_19 & 58.60 & 27.02 & 0.45 & 8.80 & 6.36 & 0.12 & 101.35 & 180 & 0.43 & 728 & 8.78 \\
\hline X590e_20 & 59.23 & 26.71 & 0.43 & 8.81 & 6.06 & 0.12 & 101.36 & 190 & 0.44 & 732 & 8.79 \\
\hline X590e_21 & 59.18 & 26.73 & 0.37 & 8.60 & 6.73 & 0.12 & 101.73 & 200 & 0.41 & 722 & 8.77 \\
\hline X590e_22 & 59.38 & 26.63 & 0.39 & 8.48 & 6.78 & 0.12 & 101.78 & 210 & 0.41 & 720 & 8.77 \\
\hline X590e 23 & 59.82 & 26.77 & 0.35 & 8.61 & 6.53 & 0.17 & 102.25 & 220 & 0.42 & 723 & 8.80 \\
\hline $\mathrm{X} 590 \mathrm{e} \_24$ & 59.65 & 27.00 & 0.39 & 9.22 & 6.43 & 0.13 & 102.82 & 230 & 0.44 & 731 & 8.79 \\
\hline X590e_25 & 58.10 & 27.23 & 0.34 & 9.37 & 6.35 & 0.14 & 101.54 & 240 & 0.45 & 732 & 8.80 \\
\hline X590e_26 & 59.49 & 26.78 & 0.38 & 8.67 & 6.77 & 0.18 & 102.27 & 250 & 0.41 & 721 & 8.80 \\
\hline X590e_27 & 58.12 & 27.33 & 0.39 & 9.52 & 6.11 & 0.09 & 101.55 & 260 & 0.46 & 737 & 8.80 \\
\hline $\mathrm{X} 590 \mathrm{e} \_30$ & 57.91 & 27.73 & 0.44 & 9.41 & 6.15 & 0.10 & 101.73 & 290 & 0.46 & 736 & 8.80 \\
\hline X590e_ 32 & 58.50 & 27.59 & 0.39 & 9.32 & 6.28 & 0.11 & 102.19 & 310 & 0.45 & 733 & 8.79 \\
\hline X590e_33 & 58.82 & 27.68 & 0.44 & 9.61 & 6.05 & 0.14 & 102.74 & 320 & 0.46 & 737 & 8.83 \\
\hline $\mathrm{X} 590 \mathrm{e} \_34$ & 59.19 & 27.27 & 0.32 & 8.97 & 6.52 & 0.13 & 102.40 & 330 & 0.43 & 728 & 8.78 \\
\hline X590e_35 & 59.51 & 27.11 & 0.31 & 8.42 & 6.42 & 0.12 & 101.88 & 340 & 0.42 & 724 & 8.77 \\
\hline $\mathrm{X} 590 \mathrm{e}^{-} 36$ & 59.34 & 27.02 & 0.32 & 8.64 & 6.47 & 0.10 & 101.89 & 350 & 0.42 & 726 & 8.76 \\
\hline $\mathrm{X} 590 \mathrm{e}^{-} 37$ & 59.10 & 27.31 & 0.38 & 8.73 & 6.58 & 0.18 & 102.28 & 360 & 0.42 & 723 & 8.80 \\
\hline X590e_38 & 59.04 & 26.89 & 0.47 & 8.66 & 6.55 & 0.14 & 101.74 & 370 & 0.42 & 724 & 8.78 \\
\hline X590e_39 & 59.85 & 27.15 & 0.36 & 8.68 & 6.51 & 0.12 & 102.68 & 380 & 0.42 & 725 & 8.77 \\
\hline $\mathrm{X} 590 \mathrm{e}^{-} 40$ & 59.63 & 27.19 & 0.32 & 8.46 & 6.46 & 0.14 & 102.19 & 390 & 0.42 & 723 & 8.78 \\
\hline X590e_41 & 59.74 & 27.09 & 0.41 & 8.66 & 6.55 & 0.18 & 102.62 & 400 & 0.42 & 723 & 8.80 \\
\hline X590e_42 & 59.77 & 26.84 & 0.37 & 8.61 & 6.43 & 0.12 & 102.13 & 410 & 0.42 & 726 & 8.77 \\
\hline $\mathrm{X} 590 \mathrm{e}^{-} 43$ & 59.81 & 26.99 & 0.40 & 8.46 & 6.67 & 0.19 & 102.51 & 420 & 0.41 & 720 & 8.81 \\
\hline X590e_45 & 60.11 & 27.21 & 0.32 & 8.64 & 6.46 & 0.18 & 102.92 & 440 & 0.42 & 724 & 8.80 \\
\hline $\mathrm{X} 590 \mathrm{e} \_50$ & 59.45 & 26.95 & 0.28 & 8.58 & 6.58 & 0.16 & 101.99 & 490 & 0.42 & 723 & 8.79 \\
\hline X590e_51 & 58.29 & 27.04 & 0.35 & 8.35 & 6.39 & 0.15 & 100.57 & 500 & 0.42 & 723 & 8.79 \\
\hline X590e_52 & 58.44 & 26.98 & 0.37 & 8.35 & 6.48 & 0.12 & 100.74 & 510 & 0.41 & 722 & 8.77 \\
\hline X590e_53 & 59.10 & 27.29 & 0.29 & 8.52 & 6.75 & 0.12 & 102.09 & 520 & 0.41 & 721 & 8.77 \\
\hline $\mathrm{X} 590 \mathrm{e}^{-} 54$ & 59.23 & 27.00 & 0.45 & 8.49 & 6.52 & 0.15 & 101.84 & 530 & 0.42 & 723 & 8.78 \\
\hline $\mathrm{X} 590 \mathrm{e}-55$ & 59.22 & 27.18 & 0.41 & 8.46 & 6.63 & 0.14 & 102.04 & 540 & 0.41 & 721 & 8.78 \\
\hline $\mathrm{X} 590 \mathrm{e}^{-} 56$ & 59.29 & 26.90 & 0.40 & 8.44 & 6.62 & 0.14 & 101.80 & 550 & 0.41 & 721 & 8.78 \\
\hline X590e_57 & 58.63 & 26.97 & 0.41 & 8.54 & 6.49 & 0.19 & 101.23 & 560 & 0.42 & 722 & 8.81 \\
\hline $\mathrm{X} 590 \mathrm{e}^{-} 58$ & 58.72 & 27.11 & 0.49 & 8.48 & 6.58 & 0.19 & 101.56 & 570 & 0.41 & 721 & 8.81 \\
\hline X590e_59 & 58.05 & 26.90 & 0.52 & 8.50 & 6.46 & 0.14 & 100.57 & 580 & 0.42 & 724 & 8.78 \\
\hline X590e_60 & 58.42 & 26.99 & 0.35 & 8.39 & 6.72 & 0.15 & 101.01 & 590 & 0.40 & 719 & 8.78 \\
\hline X590e_61 & 57.56 & 26.89 & 0.46 & 8.59 & 6.54 & 0.12 & 100.15 & 600 & 0.42 & 724 & 8.77 \\
\hline X590e_62 62 & 59.46 & 27.08 & 0.46 & 8.51 & 6.71 & 0.15 & 102.37 & 610 & 0.41 & 720 & 8.79 \\
\hline X590e_63 & 59.65 & 27.02 & 0.40 & 8.51 & 6.55 & 0.12 & 102.25 & 620 & 0.41 & 723 & 8.77 \\
\hline X590e_64 & 59.43 & 26.99 & 0.46 & 8.39 & 6.59 & 0.15 & 102.01 & 630 & 0.41 & 721 & 8.79 \\
\hline X590e_65 & 59.18 & 26.96 & 0.37 & 8.29 & 6.49 & 0.18 & 101.47 & 640 & 0.41 & 720 & 8.80 \\
\hline X590e_66 & 59.18 & 26.94 & 0.37 & 8.64 & 6.66 & 0.14 & 101.92 & 650 & 0.41 & 722 & 8.78 \\
\hline X590e_67 & 59.13 & 27.32 & 0.38 & 8.56 & 6.67 & 0.14 & 102.21 & 660 & 0.41 & 722 & 8.78 \\
\hline X590e_ 68 & 57.80 & 27.54 & 0.42 & 8.62 & 6.35 & 0.14 & 100.87 & 670 & 0.43 & 726 & 8.79 \\
\hline X590e_69 & 58.45 & 27.39 & 0.37 & 9.10 & 6.44 & 0.13 & 101.89 & 680 & 0.44 & 729 & 8.79 \\
\hline X590e_70 & 58.75 & 27.42 & 0.43 & 8.89 & 6.25 & 0.13 & 101.88 & 690 & 0.44 & 730 & 8.79 \\
\hline X590e_71 & 59.04 & 27.32 & 0.40 & 8.81 & 6.57 & 0.15 & 102.29 & 700 & 0.42 & 725 & 8.79 \\
\hline X590e_72 & 59.01 & 27.58 & 0.37 & 8.46 & 6.51 & 0.16 & 102.09 & 710 & 0.41 & 722 & 8.79 \\
\hline X590e_73 & 59.16 & 27.24 & 0.39 & 8.50 & 6.58 & 0.18 & 102.04 & 720 & 0.41 & 721 & 8.80 \\
\hline X590e_74 & 59.31 & 27.12 & 0.32 & 8.32 & 6.82 & 0.13 & 102.02 & 730 & 0.40 & 718 & 8.78 \\
\hline X590e_75 & 58.82 & 26.64 & 0.31 & 8.15 & 6.68 & 0.13 & 100.74 & 740 & 0.40 & 718 & 8.78 \\
\hline $\mathrm{X} 590 \mathrm{e}^{-} 76$ & 58.04 & 27.07 & 0.33 & 8.61 & 6.44 & 0.10 & 100.59 & 750 & 0.42 & 726 & 8.76 \\
\hline X590e_77 & 58.21 & 27.05 & 0.28 & 8.83 & 6.43 & 0.15 & 100.95 & 760 & 0.43 & 727 & 8.79 \\
\hline X590e_78 & 58.30 & 27.02 & 0.37 & 8.34 & 6.61 & 0.16 & 100.79 & 770 & 0.41 & 720 & 8.79 \\
\hline X590e_79 & 58.67 & 27.26 & 0.36 & 8.48 & 6.54 & 0.15 & 101.47 & 780 & 0.41 & 722 & 8.78 \\
\hline X590e_80 & 58.81 & 27.11 & 0.48 & 8.43 & 6.50 & 0.11 & 101.44 & 790 & 0.41 & 723 & 8.77 \\
\hline X590e_81 & 58.79 & 27.04 & 0.33 & 8.24 & 6.39 & 0.14 & 100.93 & 800 & 0.41 & 722 & 8.78 \\
\hline X590e_ 82 & 58.41 & 27.25 & 0.37 & 8.70 & 6.45 & 0.16 & 101.34 & 810 & 0.42 & 725 & 8.79 \\
\hline X590e_83 & 58.76 & 26.68 & 0.29 & 7.92 & 6.77 & 0.13 & 100.55 & 820 & 0.39 & 714 & 8.78 \\
\hline X590e_84 & 58.57 & 26.55 & 0.39 & 8.00 & 6.93 & 0.15 & 100.59 & 830 & 0.39 & 712 & 8.80 \\
\hline X590e_85 & 58.95 & 26.68 & 0.43 & 8.19 & 6.74 & 0.14 & 101.13 & 840 & 0.40 & 717 & 8.79 \\
\hline X590e_86 & 59.37 & 26.43 & 0.47 & 8.04 & 6.64 & 0.17 & 101.13 & 850 & 0.40 & 716 & 8.80 \\
\hline X590e_87 & 59.95 & 26.41 & 0.50 & 7.72 & 6.82 & 0.17 & 101.56 & 860 & 0.38 & 710 & 8.82 \\
\hline X590e_88 & 57.96 & 27.35 & 0.44 & 8.83 & 6.33 & 0.14 & 101.05 & 870 & 0.43 & 728 & 8.79 \\
\hline
\end{tabular}


Table A3.10 continued

\begin{tabular}{|c|c|c|c|c|c|c|c|c|c|c|c|}
\hline Sample & $\mathrm{SiO}_{2}$ & $\mathrm{Al}_{2} \mathrm{O}_{3}$ & $\mathrm{FeO}$ & $\mathrm{CaO}$ & $\mathrm{Na}_{2} \mathrm{O}$ & $\mathrm{K}_{2} \mathrm{O}$ & Total & $\begin{array}{l}\text { Dist } \\
(\mu \mathrm{m})\end{array}$ & X An & $\begin{array}{c}\text { Temp } \\
{ }^{\circ} \mathrm{C}\end{array}$ & $\begin{array}{l}\mathrm{H}_{2} \mathrm{O} \\
\mathrm{wt} \% \\
\end{array}$ \\
\hline X590e_90 & 58.34 & 26.92 & 0.42 & 8.71 & 6.55 & 0.15 & 101.09 & 890 & 0.42 & 724 & 8.79 \\
\hline X590e_91 & 58.02 & 26.83 & 0.43 & 8.28 & 6.51 & 0.17 & 100.23 & 900 & 0.41 & 720 & 8.80 \\
\hline X590e_92 & 58.39 & 26.68 & 0.35 & 8.10 & 6.52 & 0.13 & 100.16 & 910 & 0.40 & 719 & 8.78 \\
\hline X590e_93 & 59.14 & 26.09 & 0.40 & 7.65 & 6.86 & 0.20 & 100.35 & 920 & 0.38 & 708 & 8.84 \\
\hline X590e_94 & 60.27 & 26.32 & 0.31 & 7.79 & 6.83 & 0.17 & 101.68 & 930 & 0.38 & 711 & 8.81 \\
\hline X590e_95 & 60.43 & 26.47 & 0.40 & 7.44 & 7.00 & 0.19 & 101.93 & 940 & 0.37 & 703 & 8.85 \\
\hline X590e_96 & 59.52 & 26.41 & 0.34 & 7.85 & 6.72 & 0.16 & 100.99 & 950 & 0.39 & 713 & 8.80 \\
\hline X590e_97 & 57.88 & 27.23 & 0.38 & 8.68 & 6.37 & 0.10 & 100.64 & 960 & 0.43 & 727 & 8.77 \\
\hline X590g_1 & 58.61 & 27.43 & 0.43 & 9.00 & 6.01 & 0.15 & 101.62 & 0 & 0.45 & 733 & 8.81 \\
\hline X590g_2 & 59.36 & 27.29 & 0.33 & 8.73 & 6.20 & 0.09 & 101.99 & 10 & 0.44 & 730 & 8.76 \\
\hline X590g_3 & 58.99 & 27.51 & 0.41 & 9.26 & 6.10 & 0.15 & 102.41 & 20 & 0.45 & 734 & 8.82 \\
\hline X590g_4 & 59.08 & 27.01 & 0.42 & 8.76 & 5.96 & 0.12 & 101.34 & 30 & 0.45 & 732 & 8.80 \\
\hline X590g_5 & 59.13 & 27.51 & 0.33 & 9.30 & 5.97 & 0.15 & 102.40 & 40 & 0.46 & 735 & 8.83 \\
\hline X590g_6 & 59.28 & 27.45 & 0.45 & 9.01 & 5.97 & 0.16 & 102.32 & 50 & 0.45 & 733 & 8.82 \\
\hline X590g_7 & 59.33 & 27.13 & 0.45 & 8.66 & 6.22 & 0.15 & 101.93 & 60 & 0.43 & 728 & 8.79 \\
\hline X590g_8 & 58.75 & 27.14 & 0.35 & 8.73 & 6.23 & 0.15 & 101.35 & 70 & 0.43 & 728 & 8.80 \\
\hline X590g_9 & 58.54 & 27.17 & 0.50 & 8.75 & 6.18 & 0.13 & 101.27 & 80 & 0.44 & 730 & 8.79 \\
\hline $\mathrm{X} 590 \mathrm{~g} \_10$ & 59.55 & 26.77 & 0.38 & 8.23 & 6.08 & 0.11 & 101.12 & 90 & 0.43 & 727 & 8.77 \\
\hline X590g_11 & 60.57 & 26.66 & 0.30 & 8.48 & 6.21 & 0.16 & 102.38 & 100 & 0.43 & 726 & 8.80 \\
\hline X590g_12 & 60.29 & 27.09 & 0.39 & 8.70 & 6.05 & 0.11 & 102.63 & 110 & 0.44 & 731 & 8.78 \\
\hline X590g_13 & 59.72 & 26.90 & 0.39 & 8.81 & 6.11 & 0.09 & 102.03 & 120 & 0.44 & 732 & 8.77 \\
\hline X590g_14 & 59.45 & 27.44 & 0.39 & 9.19 & 5.83 & 0.12 & 102.41 & 130 & 0.46 & 737 & 8.82 \\
\hline $\mathrm{X} 590 \mathrm{~g} \_15$ & 58.70 & 27.33 & 0.44 & 8.98 & 5.98 & 0.17 & 101.59 & 140 & 0.45 & 732 & 8.83 \\
\hline X590g_16 & 58.27 & 27.34 & 0.46 & 9.27 & 5.94 & 0.16 & 101.44 & 150 & 0.46 & 735 & 8.84 \\
\hline $\mathrm{X} 590 \mathrm{~g} \_17$ & 57.92 & 27.63 & 0.46 & 9.24 & 5.77 & 0.13 & 101.15 & 160 & 0.47 & 738 & 8.84 \\
\hline $\mathrm{X} 590 \mathrm{~g} \_18$ & 57.55 & 27.37 & 0.35 & 9.41 & 5.84 & 0.11 & 100.65 & 170 & 0.47 & 738 & 8.83 \\
\hline X590g_19 & 57.63 & 27.74 & 0.49 & 9.75 & 5.81 & 0.12 & 101.54 & 180 & 0.48 & 740 & 8.86 \\
\hline X590g_20 & 58.44 & 27.27 & 0.38 & 9.32 & 5.75 & 0.13 & 101.28 & 190 & 0.47 & 738 & 8.84 \\
\hline X590g_21 & 58.51 & 27.74 & 0.37 & 9.47 & 5.75 & 0.13 & 101.98 & 200 & 0.47 & 739 & 8.85 \\
\hline X590g_22 & 58.56 & 27.79 & 0.42 & 9.48 & 5.76 & 0.12 & 102.12 & 210 & 0.47 & 740 & 8.84 \\
\hline X590g_23 & 58.43 & 28.12 & 0.42 & 9.81 & 5.77 & 0.13 & 102.67 & 220 & 0.48 & 741 & 8.87 \\
\hline X590g_24 & 53.07 & 25.94 & 0.32 & 13.83 & 5.23 & 0.14 & 98.53 & 230 & 0.59 & 752 & 9.41 \\
\hline X590g_25 & 56.47 & 28.27 & 0.34 & 10.45 & 5.30 & 0.12 & 100.95 & 240 & 0.52 & 748 & 8.99 \\
\hline X590g_26 & 56.78 & 28.18 & 0.33 & 10.05 & 5.57 & 0.12 & 101.03 & 250 & 0.50 & 744 & 8.91 \\
\hline X590g_27 & 57.15 & 27.71 & 0.49 & 9.37 & 5.90 & 0.14 & 100.76 & 260 & 0.46 & 737 & 8.84 \\
\hline X590g_28 & 57.92 & 26.92 & 0.29 & 8.60 & 6.44 & 0.11 & 100.28 & 270 & 0.42 & 726 & 8.77 \\
\hline X590g_29 & 57.85 & 26.82 & 0.45 & 8.74 & 6.26 & 0.14 & 100.27 & 280 & 0.43 & 728 & 8.79 \\
\hline X590g_30 & 58.04 & 26.82 & 0.35 & 8.84 & 6.50 & 0.14 & 100.68 & 290 & 0.43 & 726 & 8.78 \\
\hline X590g_31 & 58.10 & 26.98 & 0.40 & 8.67 & 6.18 & 0.17 & 100.50 & 300 & 0.43 & 728 & 8.81 \\
\hline X590g_32 & 58.10 & 26.59 & 0.31 & 8.63 & 6.16 & 0.11 & 99.90 & 310 & 0.43 & 729 & 8.77 \\
\hline X590g_33 & 58.02 & 26.51 & 0.37 & 8.70 & 6.32 & 0.15 & 100.07 & 320 & 0.43 & 727 & 8.79 \\
\hline X590g_34 & 57.54 & 26.40 & 0.39 & 8.59 & 6.34 & 0.14 & 99.40 & 330 & 0.42 & 726 & 8.79 \\
\hline X590g_35 & 58.82 & 26.47 & 0.34 & 8.32 & 6.01 & 0.13 & 100.09 & 340 & 0.43 & 728 & 8.79 \\
\hline $\mathrm{X} 590 \mathrm{~g} \_36$ & 60.11 & 26.45 & 0.35 & 8.32 & 6.69 & 0.17 & 102.09 & 350 & 0.40 & 718 & 8.80 \\
\hline X590g_37 & 60.31 & 26.31 & 0.31 & 8.01 & 6.56 & 0.14 & 101.63 & 360 & 0.40 & 718 & 8.79 \\
\hline X590g_38 & 59.99 & 26.21 & 0.43 & 7.90 & 6.72 & 0.13 & 101.38 & 370 & 0.39 & 714 & 8.79 \\
\hline X590g_39 & 58.41 & 26.04 & 0.44 & 8.17 & 6.84 & 0.16 & 100.05 & 380 & 0.39 & 715 & 8.80 \\
\hline $\mathrm{X} 590 \mathrm{~g} \_40$ & 58.52 & 25.86 & 0.34 & 7.77 & 6.57 & 0.14 & 99.20 & 390 & 0.39 & 715 & 8.79 \\
\hline X590g_41 & 59.00 & 25.63 & 0.39 & 7.71 & 6.62 & 0.11 & 99.46 & 400 & 0.39 & 714 & 8.78 \\
\hline X590g_42 & 59.46 & 25.57 & 0.34 & 7.51 & 6.72 & 0.14 & 99.75 & 410 & 0.38 & 709 & 8.81 \\
\hline X590g_43 & 59.77 & 25.93 & 0.33 & 7.62 & 6.77 & 0.12 & 100.53 & 420 & 0.38 & 711 & 8.79 \\
\hline X590g 44 & 59.06 & 25.84 & 0.35 & 7.52 & 6.82 & 0.15 & 99.75 & 430 & 0.38 & 708 & 8.82 \\
\hline X590g_45 & 59.21 & 25.75 & 0.36 & 7.54 & 6.97 & 0.21 & 100.04 & 440 & 0.37 & 705 & 8.85 \\
\hline X590g_46 & 59.21 & 25.75 & 0.36 & 7.54 & 6.97 & 0.21 & 100.04 & 450 & 0.37 & 705 & 8.85 \\
\hline X590g_47 & 59.75 & 25.81 & 0.42 & 7.58 & 6.97 & 0.16 & 100.68 & 460 & 0.37 & 707 & 8.82 \\
\hline X590g_48 & 59.89 & 25.46 & 0.38 & 7.44 & 6.86 & 0.16 & 100.19 & 470 & 0.37 & 706 & 8.83 \\
\hline X590g_49 & 59.96 & 25.46 & 0.31 & 7.20 & 6.92 & 0.21 & 100.07 & 480 & 0.36 & 701 & 8.87 \\
\hline X590g_50 & 60.14 & 25.21 & 0.48 & 7.42 & 6.92 & 0.19 & 100.36 & 490 & 0.37 & 704 & 8.84 \\
\hline X590g_51 & 59.28 & 25.57 & 0.38 & 7.24 & 7.03 & 0.14 & 99.63 & 500 & 0.36 & 702 & 8.84 \\
\hline X590g_52 & 60.29 & 25.11 & 0.37 & 7.24 & 7.01 & 0.13 & 100.15 & 510 & 0.36 & 702 & 8.83 \\
\hline X590g_53 & 59.59 & 25.25 & 0.31 & 7.30 & 7.00 & 0.21 & 99.68 & 520 & 0.36 & 701 & 8.87 \\
\hline X590g_54 & 59.68 & 25.10 & 0.37 & 7.22 & 6.86 & 0.16 & 99.39 & 530 & 0.36 & 703 & 8.84 \\
\hline X590g_55 & 59.69 & 25.67 & 0.37 & 7.52 & 6.96 & 0.18 & 100.39 & 540 & 0.37 & 705 & 8.84 \\
\hline X590g_56 & 60.00 & 25.67 & 0.29 & 7.87 & 6.77 & 0.20 & 100.79 & 550 & 0.39 & 712 & 8.83 \\
\hline X590g_57 & 60.18 & 26.18 & 0.32 & 7.85 & 6.75 & 0.18 & 101.46 & 560 & 0.39 & 712 & 8.81 \\
\hline X590g_58 & 59.18 & 26.21 & 0.29 & 8.18 & 6.57 & 0.13 & 100.57 & 570 & 0.40 & 719 & 8.78 \\
\hline X590g_59 & 59.08 & 26.47 & 0.37 & 7.94 & 6.69 & 0.18 & 100.73 & 580 & 0.39 & 714 & 8.81 \\
\hline X590g_60 & 59.32 & 26.23 & 0.32 & 8.02 & 6.67 & 0.16 & 100.71 & 590 & 0.40 & 715 & 8.80 \\
\hline X590g_61 & 60.43 & 26.15 & 0.32 & 7.98 & 6.41 & 0.14 & 101.43 & 600 & 0.40 & 719 & 8.79 \\
\hline
\end{tabular}


Table A3.10 continued

\begin{tabular}{|c|c|c|c|c|c|c|c|c|c|c|c|}
\hline Sample & $\mathrm{SiO}_{2}$ & $\mathrm{Al}_{2} \mathrm{O}_{3}$ & $\mathrm{FeO}$ & $\mathrm{CaO}$ & $\mathrm{Na}_{2} \mathrm{O}$ & $\mathrm{K}_{2} \mathrm{O}$ & Total & $\begin{array}{l}\text { Dist } \\
(\mu \mathrm{m})\end{array}$ & X An & $\begin{array}{c}\text { Temp } \\
{ }^{\circ} \mathrm{C}\end{array}$ & $\begin{array}{l}\mathrm{H}_{2} \mathrm{O} \\
\mathrm{wt} \% \\
\end{array}$ \\
\hline X590g_63 & 60.68 & 26.24 & 0.34 & 8.22 & 6.38 & 0.14 & 101.99 & 620 & 0.41 & 722 & 8.78 \\
\hline X590g_64 & 60.20 & 26.40 & 0.36 & 8.30 & 6.55 & 0.13 & 101.95 & 630 & 0.41 & 721 & 8.78 \\
\hline X590g_65 & 59.77 & 26.41 & 0.43 & 8.08 & 6.53 & 0.17 & 101.39 & 640 & 0.40 & 718 & 8.80 \\
\hline X590g_66 & 59.97 & 26.40 & 0.30 & 8.19 & 6.62 & 0.13 & 101.62 & 650 & 0.40 & 719 & 8.78 \\
\hline X590g_67 & 58.73 & 25.96 & 0.39 & 8.31 & 6.32 & 0.22 & 99.93 & 660 & 0.42 & 721 & 8.83 \\
\hline X590g_68 & 58.61 & 25.83 & 0.32 & 8.03 & 6.34 & 0.14 & 99.27 & 670 & 0.41 & 721 & 8.78 \\
\hline X590g_69 & 59.83 & 26.44 & 0.33 & 8.28 & 6.26 & 0.13 & 101.27 & 680 & 0.42 & 724 & 8.78 \\
\hline X590g_70 & 59.97 & 26.38 & 0.44 & 8.30 & 6.36 & 0.16 & 101.61 & 690 & 0.42 & 723 & 8.79 \\
\hline X590g_71 & 59.82 & 26.72 & 0.40 & 8.42 & 6.41 & 0.15 & 101.93 & 700 & 0.42 & 723 & 8.79 \\
\hline X590g_72 & 59.68 & 26.62 & 0.50 & 8.24 & 6.45 & 0.15 & 101.64 & 710 & 0.41 & 721 & 8.79 \\
\hline X590g_73 & 59.62 & 26.38 & 0.41 & 8.17 & 6.31 & 0.14 & 101.03 & 720 & 0.41 & 722 & 8.78 \\
\hline X590g_74 & 59.33 & 27.22 & 0.33 & 8.64 & 6.27 & 0.15 & 101.93 & 730 & 0.43 & 727 & 8.79 \\
\hline X590g_75 & 58.73 & 26.91 & 0.27 & 8.78 & 6.20 & 0.17 & 101.07 & 740 & 0.43 & 728 & 8.81 \\
\hline X590g_76 & 58.94 & 27.11 & 0.36 & 8.77 & 6.28 & 0.17 & 101.64 & 750 & 0.43 & 727 & 8.81 \\
\hline X590g_77 & 58.30 & 27.12 & 0.45 & 8.95 & 6.07 & 0.17 & 101.06 & 760 & 0.44 & 731 & 8.82 \\
\hline X590g_78 & 58.10 & 27.28 & 0.48 & 8.99 & 6.12 & 0.15 & 101.12 & 770 & 0.44 & 731 & 8.81 \\
\hline X590g_79 & 58.01 & 26.95 & 0.31 & 8.91 & 6.31 & 0.16 & 100.65 & 780 & 0.43 & 728 & 8.80 \\
\hline $\mathrm{X} 590 \mathrm{~g} \_80$ & 58.75 & 27.06 & 0.36 & 8.77 & 6.29 & 0.15 & 101.38 & 790 & 0.43 & 728 & 8.79 \\
\hline X590g_81 & 58.54 & 26.83 & 0.42 & 8.94 & 6.28 & 0.17 & 101.17 & 800 & 0.44 & 729 & 8.81 \\
\hline X590g_82 & 59.08 & 27.12 & 0.38 & 8.73 & 6.36 & 0.16 & 101.84 & 810 & 0.43 & 726 & 8.80 \\
\hline X590g_83 & 59.74 & 26.94 & 0.34 & 8.91 & 6.37 & 0.17 & 102.46 & 820 & 0.43 & 728 & 8.80 \\
\hline X590g_84 & 59.48 & 27.23 & 0.41 & 8.78 & 6.36 & 0.17 & 102.44 & 830 & 0.43 & 727 & 8.80 \\
\hline X590g_85 & 59.36 & 27.02 & 0.40 & 8.50 & 6.41 & 0.11 & 101.80 & 840 & 0.42 & 725 & 8.77 \\
\hline X590g_89 & 58.99 & 26.35 & 0.36 & 8.19 & 6.44 & 0.17 & 100.50 & 850 & 0.41 & 720 & 8.80 \\
\hline X590g_90 & 58.88 & 26.47 & 0.33 & 8.43 & 6.39 & 0.12 & 100.63 & 860 & 0.42 & 724 & 8.77 \\
\hline X590g_91 & 58.51 & 26.59 & 0.43 & 8.66 & 6.28 & 0.10 & 100.58 & 870 & 0.43 & 728 & 8.77 \\
\hline X590g_93 & 57.55 & 27.29 & 0.33 & 8.61 & 6.04 & 0.12 & 99.93 & 890 & 0.44 & 730 & 8.78 \\
\hline X590g_94 & 57.31 & 27.18 & 0.39 & 9.16 & 6.20 & 0.11 & 100.35 & 900 & 0.45 & 733 & 8.79 \\
\hline X590g_95 & 57.25 & 27.17 & 0.30 & 9.23 & 6.25 & 0.10 & 100.30 & 910 & 0.45 & 734 & 8.78 \\
\hline X590g_96 & 57.99 & 27.31 & 0.42 & 9.19 & 6.00 & 0.11 & 101.03 & 920 & 0.46 & 735 & 8.81 \\
\hline X590g_97 & 58.19 & 26.99 & 0.37 & 9.01 & 5.94 & 0.15 & 100.65 & 930 & 0.45 & 734 & 8.82 \\
\hline X590g_98 & 58.31 & 26.90 & 0.31 & 9.19 & 6.02 & 0.16 & 100.88 & 940 & 0.45 & 734 & 8.83 \\
\hline X590g_99 & 58.17 & 27.05 & 0.34 & 9.00 & 6.20 & 0.13 & 100.89 & 950 & 0.44 & 731 & 8.79 \\
\hline X590g_100 & 57.85 & 27.15 & 0.40 & 8.88 & 6.10 & 0.11 & 100.49 & 960 & 0.44 & 732 & 8.79 \\
\hline X590g_101 & 56.95 & 27.10 & 0.36 & 9.03 & 5.96 & 0.14 & 99.54 & 970 & 0.45 & 734 & 8.82 \\
\hline X590g_102 & 57.47 & 26.90 & 0.38 & 8.93 & 6.11 & 0.16 & 99.95 & 980 & 0.44 & 731 & 8.81 \\
\hline $\mathrm{X} 590 \mathrm{~g} \_103$ & 58.07 & 26.86 & 0.41 & 9.04 & 6.09 & 0.13 & 100.60 & 990 & 0.45 & 733 & 8.80 \\
\hline X590g_104 & 57.51 & 26.90 & 0.44 & 8.85 & 6.09 & 0.12 & 99.90 & 1000 & 0.44 & 731 & 8.79 \\
\hline X590g_105 & 57.67 & 27.08 & 0.41 & 9.09 & 6.01 & 0.13 & 100.39 & 1010 & 0.45 & 734 & 8.81 \\
\hline X590g_106 & 57.05 & 27.39 & 0.53 & 9.25 & 5.93 & 0.15 & 100.29 & 1020 & 0.46 & 736 & 8.83 \\
\hline X590g_107 & 56.89 & 27.28 & 0.39 & 9.35 & 5.91 & 0.15 & 99.97 & 1030 & 0.46 & 736 & 8.84 \\
\hline X590g_108 & 56.29 & 27.25 & 0.48 & 9.22 & 5.97 & 0.13 & 99.34 & 1040 & 0.46 & 735 & 8.82 \\
\hline X590g_109 & 54.98 & 26.32 & 0.50 & 8.70 & 5.61 & 0.12 & 96.22 & 1050 & 0.46 & 736 & 8.82 \\
\hline $\mathrm{X} 590 \mathrm{~g} \_110$ & 57.47 & 27.18 & 0.42 & 9.02 & 6.29 & 0.12 & 100.50 & 1060 & 0.44 & 731 & 8.78 \\
\hline X590g_111 & 57.72 & 27.05 & 0.35 & 9.11 & 6.06 & 0.14 & 100.44 & 1070 & 0.45 & 733 & 8.81 \\
\hline X590Ba_2 & 59.52 & 26.41 & 0.43 & 8.25 & 6.43 & 0.15 & 101.18 & 0 & 0.41 & 721 & 8.79 \\
\hline X590Ba_3 & 59.95 & 26.75 & 0.44 & 8.32 & 6.22 & 0.15 & 101.83 & 10 & 0.42 & 724 & 8.79 \\
\hline X590Ba_4 & 59.14 & 27.49 & 0.40 & 9.35 & 6.05 & 0.14 & 102.57 & 20 & 0.46 & 735 & 8.82 \\
\hline X590Ba_5 & 58.77 & 28.12 & 0.32 & 9.86 & 5.55 & 0.13 & 102.75 & 30 & 0.49 & 743 & 8.91 \\
\hline X590Ba_6 & 59.04 & 27.22 & 0.37 & 8.51 & 6.17 & 0.14 & 101.44 & 40 & 0.43 & 727 & 8.79 \\
\hline X590Ba_7 & 57.10 & 27.93 & 0.40 & 9.91 & 5.48 & 0.12 & 100.94 & 50 & 0.50 & 744 & 8.91 \\
\hline $\mathrm{X} 590 \mathrm{Ba}^{-} 8$ & 57.16 & 28.52 & 0.40 & 10.07 & 5.39 & 0.11 & 101.66 & 60 & 0.50 & 746 & 8.94 \\
\hline X590Ba_9 & 57.12 & 27.96 & 0.45 & 9.85 & 5.57 & 0.12 & 101.08 & 70 & 0.49 & 743 & 8.90 \\
\hline X590Ba_10 & 58.63 & 27.62 & 0.37 & 9.46 & 5.87 & 0.14 & 102.09 & 80 & 0.47 & 738 & 8.84 \\
\hline X590Ba_11 & 58.91 & 27.44 & 0.42 & 9.03 & 6.18 & 0.16 & 102.13 & 90 & 0.44 & 731 & 8.81 \\
\hline X590Ba_12 & 59.25 & 27.14 & 0.37 & 8.84 & 5.97 & 0.12 & 101.70 & 100 & 0.45 & 733 & 8.80 \\
\hline X590Ba_13 & 58.56 & 27.40 & 0.40 & 9.05 & 5.89 & 0.14 & 101.42 & 110 & 0.46 & 735 & 8.82 \\
\hline X590Ba_14 & 60.53 & 26.61 & 0.43 & 8.18 & 6.23 & 0.17 & 102.15 & 120 & 0.42 & 722 & 8.80 \\
\hline X590Ba_15 & 60.63 & 26.17 & 0.30 & 7.75 & 6.43 & 0.15 & 101.44 & 130 & 0.40 & 716 & 8.79 \\
\hline X590Ba_16 & 60.13 & 26.32 & 0.35 & 8.00 & 6.57 & 0.16 & 101.54 & 140 & 0.40 & 717 & 8.80 \\
\hline X590Ba_17 & 57.67 & 27.32 & 0.39 & 9.31 & 5.86 & 0.11 & 100.66 & 150 & 0.46 & 738 & 8.82 \\
\hline X590Ba_18 & 57.92 & 27.05 & 0.33 & 8.91 & 5.96 & 0.11 & 100.29 & 160 & 0.45 & 734 & 8.80 \\
\hline X590Ba_19 & 58.15 & 27.00 & 0.48 & 8.72 & 5.95 & 0.12 & 100.42 & 170 & 0.44 & 732 & 8.79 \\
\hline X590Ba_20 & 59.77 & 26.97 & 0.43 & 8.35 & 6.41 & 0.17 & 102.12 & 180 & 0.41 & 722 & 8.80 \\
\hline X590Ba_21 & 60.48 & 26.40 & 0.36 & 7.98 & 6.48 & 0.12 & 101.83 & 190 & 0.40 & 719 & 8.77 \\
\hline X590Ba_22 & 59.58 & 26.62 & 0.42 & 7.93 & 6.31 & 0.15 & 101.00 & 200 & 0.41 & 720 & 8.79 \\
\hline X590Ba_23 & 59.89 & 26.78 & 0.43 & 8.16 & 6.25 & 0.14 & 101.65 & 210 & 0.42 & 723 & 8.79 \\
\hline X590Ba_24 & 60.11 & 26.92 & 0.44 & 8.28 & 6.44 & 0.18 & 102.37 & 220 & 0.41 & 721 & 8.80 \\
\hline X590Ba_25 & 59.35 & 26.44 & 0.42 & 7.71 & 6.33 & 0.15 & 100.41 & 230 & 0.40 & 717 & 8.79 \\
\hline
\end{tabular}


Table A3.10 continued

\begin{tabular}{|c|c|c|c|c|c|c|c|c|c|c|c|}
\hline Sample & $\mathrm{SiO}_{2}$ & $\mathrm{Al}_{2} \mathrm{O}_{3}$ & $\mathrm{FeO}$ & $\mathrm{CaO}$ & $\mathrm{Na}_{2} \mathrm{O}$ & $\mathrm{K}_{2} \mathrm{O}$ & Total & $\begin{array}{l}\text { Dist } \\
(\mu \mathrm{m})\end{array}$ & X An & $\begin{array}{c}\text { Temp } \\
{ }^{\circ} \mathrm{C} \\
\end{array}$ & $\begin{array}{l}\mathrm{H}_{2} \mathrm{O} \\
\mathrm{wt} \% \\
\end{array}$ \\
\hline X590Ba_27 & 56.88 & 27.95 & 0.39 & 9.73 & 5.71 & 0.14 & 100.79 & 250 & 0.48 & 741 & 8.88 \\
\hline X590Ba_28 & 57.78 & 28.16 & 0.39 & 10.09 & 5.55 & 0.13 & 102.11 & 260 & 0.50 & 744 & 8.93 \\
\hline X590Ba_29 & 55.27 & 29.83 & 0.40 & 12.08 & 4.52 & 0.08 & 102.18 & 270 & 0.59 & 754 & 9.41 \\
\hline X590Ba_30 & 54.36 & 30.26 & 0.40 & 12.54 & 4.38 & 0.07 & 102.02 & 280 & 0.61 & 753 & 9.53 \\
\hline X590Ba_31 & 54.52 & 30.46 & 0.52 & 12.40 & 4.14 & 0.07 & 102.10 & 290 & 0.62 & 753 & 9.62 \\
\hline X590Ba_32 & 53.74 & 30.91 & 0.42 & 12.86 & 4.02 & 0.09 & 102.03 & 300 & 0.64 & 751 & 9.76 \\
\hline X590Ba_33 & 54.65 & 29.97 & 0.49 & 12.02 & 4.49 & 0.08 & 101.69 & 310 & 0.59 & 754 & 9.42 \\
\hline X590Ba_34 & 53.51 & 30.54 & 0.49 & 12.78 & 4.50 & 0.11 & 101.91 & 320 & 0.61 & 753 & 9.53 \\
\hline X590Ba_35 & 54.18 & 30.10 & 0.48 & 12.45 & 4.28 & 0.10 & 101.59 & 330 & 0.61 & 753 & 9.58 \\
\hline X590Ba_36 & 53.40 & 30.64 & 0.42 & 12.83 & 4.09 & 0.08 & 101.47 & 340 & 0.63 & 752 & 9.72 \\
\hline X590Ba_37 & 53.75 & 30.35 & 0.36 & 12.74 & 4.27 & 0.07 & 101.55 & 350 & 0.62 & 753 & 9.61 \\
\hline X590Ba_38 & 53.82 & 30.64 & 0.46 & 12.92 & 4.00 & 0.10 & 101.93 & 360 & 0.64 & 751 & 9.78 \\
\hline X590Ba_39 & 53.95 & 30.23 & 0.44 & 12.53 & 4.12 & 0.06 & 101.34 & 370 & 0.62 & 753 & 9.65 \\
\hline X590Ba_40 & 55.67 & 29.62 & 0.39 & 11.58 & 4.57 & 0.11 & 101.94 & 380 & 0.58 & 753 & 9.34 \\
\hline X590Ba_41 & 57.99 & 27.95 & 0.48 & 9.60 & 5.74 & 0.13 & 101.88 & 390 & 0.48 & 740 & 8.86 \\
\hline X590Ba_42 & 59.00 & 27.52 & 0.41 & 9.13 & 5.77 & 0.13 & 101.95 & 400 & 0.46 & 737 & 8.83 \\
\hline X590Ba_43 & 59.45 & 26.73 & 0.37 & 8.07 & 6.28 & 0.17 & 101.07 & 410 & 0.41 & 721 & 8.80 \\
\hline X590Ba_44 & 58.76 & 26.83 & 0.42 & 8.62 & 6.09 & 0.15 & 100.88 & 420 & 0.44 & 729 & 8.80 \\
\hline X590Ba_46 & 58.02 & 27.57 & 0.36 & 9.49 & 5.81 & 0.12 & 101.37 & 430 & 0.47 & 739 & 8.84 \\
\hline X590Ba_47 & 58.86 & 27.02 & 0.44 & 8.78 & 6.16 & 0.11 & 101.37 & 440 & 0.44 & 731 & 8.78 \\
\hline X590Ba_48 & 59.72 & 26.58 & 0.41 & 8.63 & 6.26 & 0.15 & 101.76 & 450 & 0.43 & 727 & 8.79 \\
\hline X590Ba_49 & 60.44 & 26.48 & 0.38 & 8.16 & 6.18 & 0.12 & 101.76 & 460 & 0.42 & 724 & 8.77 \\
\hline X590Ba_50 & 59.97 & 26.77 & 0.44 & 8.74 & 5.88 & 0.14 & 101.94 & 470 & 0.45 & 732 & 8.81 \\
\hline X590Bb_1 & 57.78 & 27.29 & 0.38 & 9.25 & 5.76 & 0.13 & 100.58 & 0 & 0.47 & 738 & 8.84 \\
\hline X590Bb_3 & 58.53 & 27.55 & 0.46 & 9.42 & 5.73 & 0.17 & 101.86 & 10 & 0.47 & 738 & 8.87 \\
\hline X590Bb_4 & 59.64 & 27.18 & 0.34 & 9.27 & 5.83 & 0.14 & 102.39 & 20 & 0.46 & 737 & 8.84 \\
\hline X590Bb_5 & 59.22 & 26.34 & 0.29 & 8.38 & 6.31 & 0.15 & 100.69 & 30 & 0.42 & 724 & 8.79 \\
\hline X590Bb_6 & 60.72 & 26.57 & 0.41 & 7.96 & 6.61 & 0.14 & 102.41 & 40 & 0.40 & 716 & 8.78 \\
\hline X590Bb_7 & 60.01 & 26.66 & 0.41 & 8.17 & 6.52 & 0.15 & 101.91 & 50 & 0.41 & 719 & 8.79 \\
\hline X590Bb_8 & 59.78 & 26.64 & 0.45 & 8.46 & 6.48 & 0.16 & 101.97 & 60 & 0.42 & 723 & 8.79 \\
\hline X590Bb_9 & 61.01 & 26.73 & 0.37 & 8.11 & 6.45 & 0.17 & 102.84 & 70 & 0.41 & 719 & 8.80 \\
\hline X590Bb_12 & 61.72 & 25.98 & 0.36 & 7.58 & 6.67 & 0.18 & 102.49 & 100 & 0.38 & 710 & 8.82 \\
\hline $\mathrm{X} 590 \mathrm{Bb}{ }^{-} 13$ & 61.29 & 25.79 & 0.29 & 7.55 & 6.77 & 0.14 & 101.82 & 110 & 0.38 & 709 & 8.80 \\
\hline X590Bb_14 & 62.15 & 25.73 & 0.36 & 7.50 & 6.87 & 0.20 & 102.81 & 120 & 0.37 & 706 & 8.84 \\
\hline X590Bb_15 & 61.76 & 25.74 & 0.43 & 7.23 & 6.81 & 0.20 & 102.19 & 130 & 0.37 & 703 & 8.86 \\
\hline X590Bb_16 & 60.98 & 25.37 & 0.35 & 7.43 & 7.07 & 0.19 & 101.40 & 140 & 0.36 & 702 & 8.85 \\
\hline X590Bb_17 & 61.83 & 25.88 & 0.30 & 7.26 & 6.83 & 0.22 & 102.32 & 150 & 0.37 & 703 & 8.87 \\
\hline X590Bb_18 & 61.12 & 25.72 & 0.40 & 7.55 & 6.72 & 0.24 & 101.75 & 160 & 0.38 & 707 & 8.86 \\
\hline X590Bb_19 & 60.60 & 25.25 & 0.43 & 7.14 & 6.82 & 0.21 & 100.44 & 170 & 0.36 & 701 & 8.87 \\
\hline X590Bb_20 & 62.65 & 25.59 & 0.29 & 7.25 & 6.89 & 0.21 & 102.88 & 180 & 0.36 & 702 & 8.86 \\
\hline X590Bb_21 & 63.12 & 25.17 & 0.30 & 6.91 & 7.15 & 0.24 & 102.89 & 190 & 0.34 & 693 & 8.92 \\
\hline X590Bb_22 & 63.12 & 25.17 & 0.30 & 6.91 & 7.15 & 0.24 & 102.89 & 200 & 0.34 & 693 & 8.92 \\
\hline X590Bb_23 & 61.24 & 26.09 & 0.41 & 7.67 & 6.67 & 0.21 & 102.30 & 210 & 0.38 & 710 & 8.83 \\
\hline X590Bb_24 & 60.11 & 27.05 & 0.33 & 8.69 & 6.27 & 0.12 & 102.58 & 220 & 0.43 & 728 & 8.78 \\
\hline X590Bb_25 & 59.72 & 27.24 & 0.35 & 8.91 & 6.14 & 0.14 & 102.50 & 230 & 0.44 & 731 & 8.80 \\
\hline X590Bb_26 & 59.72 & 27.35 & 0.44 & 9.23 & 6.05 & 0.14 & 102.91 & 240 & 0.45 & 735 & 8.81 \\
\hline X590Bb_27 & 59.47 & 26.67 & 0.35 & 8.86 & 6.10 & 0.15 & 101.61 & 250 & 0.44 & 731 & 8.81 \\
\hline X590Bb_28 & 58.25 & 27.41 & 0.39 & 9.36 & 6.02 & 0.15 & 101.58 & 260 & 0.46 & 735 & 8.83 \\
\hline X590Bb_29 & 58.56 & 27.49 & 0.36 & 8.97 & 5.99 & 0.12 & 101.50 & 270 & 0.45 & 733 & 8.80 \\
\hline X590Bb_30 & 59.74 & 26.80 & 0.37 & 8.88 & 6.15 & 0.15 & 102.08 & 280 & 0.44 & 730 & 8.80 \\
\hline X590Bb_31 & 59.25 & 27.09 & 0.35 & 8.72 & 6.24 & 0.14 & 101.79 & 290 & 0.43 & 728 & 8.79 \\
\hline $\mathrm{X} 590 \mathrm{Bb} 32$ & 59.73 & 27.13 & 0.41 & 9.00 & 6.26 & 0.19 & 102.72 & 300 & 0.44 & 729 & 8.82 \\
\hline X590Bb_33 & 60.06 & 26.80 & 0.35 & 8.66 & 6.34 & 0.15 & 102.36 & 310 & 0.43 & 726 & 8.79 \\
\hline X590Bb_35 & 58.61 & 27.61 & 0.52 & 9.55 & 5.88 & 0.16 & 102.33 & 330 & 0.47 & 737 & 8.86 \\
\hline X590Bb_36 & 58.62 & 27.36 & 0.38 & 8.75 & 6.21 & 0.14 & 101.46 & 340 & 0.43 & 729 & 8.79 \\
\hline X590Bb_37 & 60.11 & 25.96 & 0.44 & 7.94 & 6.54 & 0.17 & 101.16 & 350 & 0.40 & 716 & 8.80 \\
\hline X590Bb_38 & 59.21 & 27.00 & 0.35 & 9.04 & 6.10 & 0.14 & 101.85 & 360 & 0.45 & 732 & 8.81 \\
\hline X590Bb_39 & 58.38 & 27.50 & 0.38 & 9.53 & 5.87 & 0.13 & 101.79 & 370 & 0.47 & 738 & 8.84 \\
\hline X590Bb_40 & 58.54 & 27.64 & 0.44 & 9.71 & 5.82 & 0.15 & 102.30 & 380 & 0.48 & 739 & 8.87 \\
\hline X590Bb_41 & 58.48 & 27.33 & 0.40 & 9.23 & 6.08 & 0.13 & 101.65 & 390 & 0.45 & 734 & 8.81 \\
\hline X590Bb_42 & 58.65 & 27.54 & 0.40 & 9.35 & 6.06 & 0.11 & 102.11 & 400 & 0.46 & 736 & 8.81 \\
\hline X590Bb_43 & 58.54 & 27.52 & 0.39 & 9.15 & 5.87 & 0.12 & 101.60 & 410 & 0.46 & 736 & 8.82 \\
\hline X590Bb_44 & 58.21 & 26.53 & 0.51 & 8.65 & 5.98 & 0.17 & 100.05 & 420 & 0.44 & 730 & 8.82 \\
\hline X590Bb2_2 & 58.55 & 26.32 & 0.31 & 7.95 & 6.17 & 0.16 & 99.45 & 10 & 0.41 & 721 & 8.80 \\
\hline $\mathrm{X} 590 \mathrm{Bb} 2 \_3$ & 59.37 & 26.13 & 0.35 & 8.13 & 6.28 & 0.14 & 100.39 & 20 & 0.41 & 722 & 8.78 \\
\hline $\mathrm{X} 590 \mathrm{Bb} 2 \_4$ & 59.45 & 26.30 & 0.41 & 7.96 & 6.28 & 0.14 & 100.54 & 30 & 0.41 & 720 & 8.79 \\
\hline $\mathrm{X} 590 \mathrm{Bb} 2 \_5$ & 61.25 & 26.35 & 0.31 & 7.88 & 6.73 & 0.15 & 102.67 & 40 & 0.39 & 713 & 8.80 \\
\hline $\mathrm{X} 590 \mathrm{Bb} 2 \_6$ & 60.71 & 26.47 & 0.44 & 7.89 & 6.44 & 0.15 & 102.11 & 50 & 0.40 & 717 & 8.79 \\
\hline
\end{tabular}


Table A3.10 continued

\begin{tabular}{|c|c|c|c|c|c|c|c|c|c|c|c|}
\hline Sample & $\mathrm{SiO}_{2}$ & $\mathrm{Al}_{2} \mathrm{O}_{3}$ & $\mathrm{FeO}$ & $\mathrm{CaO}$ & $\mathrm{Na}_{2} \mathrm{O}$ & $\mathrm{K}_{2} \mathrm{O}$ & Total & $\begin{array}{l}\text { Dist } \\
(\mu \mathrm{m})\end{array}$ & X An & $\begin{array}{c}\text { Temp } \\
{ }^{\circ} \mathrm{C} \\
\end{array}$ & $\begin{array}{l}\mathrm{H}_{2} \mathrm{O} \\
\mathrm{wt} \% \\
\end{array}$ \\
\hline $\mathrm{X} 590 \mathrm{Bb} 2 \_8$ & 60.74 & 26.58 & 0.38 & 7.81 & 6.57 & 0.17 & 102.26 & 70 & 0.39 & 714 & 8.81 \\
\hline X590Bb2_9 & 61.02 & 26.30 & 0.38 & 7.96 & 6.64 & 0.17 & 102.47 & 80 & 0.39 & 715 & 8.80 \\
\hline $\mathrm{X} 590 \mathrm{Bb} 2{ }^{-} 10$ & 58.31 & 27.31 & 0.36 & 8.96 & 5.99 & 0.17 & 101.09 & 90 & 0.45 & 732 & 8.83 \\
\hline X590Bb2_12 & 60.07 & 27.20 & 0.30 & 8.27 & 6.08 & 0.17 & 102.09 & 110 & 0.42 & 725 & 8.80 \\
\hline $\mathrm{X} 590 \mathrm{Bb} 2 \_13$ & 61.01 & 26.62 & 0.34 & 7.74 & 6.47 & 0.19 & 102.38 & 120 & 0.39 & 714 & 8.82 \\
\hline X590Bb2_14 & 59.58 & 26.48 & 0.35 & 8.17 & 6.26 & 0.13 & 100.97 & 130 & 0.42 & 723 & 8.78 \\
\hline $\mathrm{X} 590 \mathrm{Bb} 2 \_16$ & 60.23 & 26.66 & 0.38 & 8.58 & 6.00 & 0.20 & 102.06 & 150 & 0.44 & 728 & 8.83 \\
\hline X590Bb2_19 & 60.35 & 26.43 & 0.34 & 7.98 & 6.44 & 0.14 & 101.66 & 180 & 0.40 & 719 & 8.78 \\
\hline X590Bb2_21 & 59.34 & 27.38 & 0.42 & 8.96 & 5.91 & 0.15 & 102.14 & 200 & 0.45 & 734 & 8.82 \\
\hline X590Bb2_22 & 59.76 & 27.23 & 0.37 & 8.89 & 6.30 & 0.13 & 102.67 & 210 & 0.43 & 729 & 8.78 \\
\hline $\mathrm{X} 590 \mathrm{Bb} 2 \_23$ & 60.24 & 27.08 & 0.38 & 8.77 & 6.06 & 0.10 & 102.64 & 220 & 0.44 & 732 & 8.78 \\
\hline X590Bb2_24 & 58.24 & 26.97 & 0.28 & 8.95 & 6.24 & 0.15 & 100.84 & 230 & 0.44 & 730 & 8.80 \\
\hline X590Bb2_25 & 59.65 & 26.69 & 0.32 & 8.25 & 6.52 & 0.14 & 101.56 & 240 & 0.41 & 721 & 8.78 \\
\hline X590Bb2_26 & 57.92 & 27.60 & 0.39 & 9.19 & 6.03 & 0.09 & 101.21 & 250 & 0.45 & 736 & 8.79 \\
\hline X590Bb2_27 & 60.54 & 26.05 & 0.35 & 7.63 & 6.79 & 0.18 & 101.54 & 260 & 0.38 & 709 & 8.82 \\
\hline X590Bb2_28 & 60.50 & 26.62 & 0.36 & 8.29 & 6.60 & 0.17 & 102.53 & 270 & 0.41 & 719 & 8.80 \\
\hline X590Bb2_30 & 58.91 & 27.61 & 0.40 & 9.56 & 5.52 & 0.21 & 102.22 & 290 & 0.48 & 739 & 8.93 \\
\hline $\mathrm{X} 590 \mathrm{Bb} 2 \_31$ & 56.39 & 29.34 & 0.45 & 11.00 & 5.03 & 0.11 & 102.31 & 300 & 0.54 & 751 & 9.12 \\
\hline $\mathrm{X} 590 \mathrm{Bb} 2 \_32$ & 57.23 & 27.49 & 0.38 & 9.32 & 5.91 & 0.15 & 100.49 & 310 & 0.46 & 736 & 8.84 \\
\hline X590Bb2_33 & 58.01 & 27.69 & 0.35 & 9.47 & 5.86 & 0.13 & 101.51 & 320 & 0.47 & 738 & 8.84 \\
\hline $\mathrm{X} 590 \mathrm{Bb} 2 \_34$ & 58.11 & 27.63 & 0.46 & 9.31 & 5.82 & 0.13 & 101.46 & 330 & 0.47 & 738 & 8.83 \\
\hline X590Bb2_35 & 59.41 & 27.32 & 0.35 & 9.00 & 6.05 & 0.12 & 102.25 & 340 & 0.45 & 733 & 8.80 \\
\hline $\mathrm{X} 590 \mathrm{Bb} 2 \_36$ & 59.40 & 27.40 & 0.35 & 9.01 & 6.00 & 0.14 & 102.31 & 350 & 0.45 & 733 & 8.81 \\
\hline $\mathrm{X} 590 \mathrm{Bb} 2 \_37$ & 59.81 & 27.50 & 0.38 & 8.89 & 6.01 & 0.20 & 102.79 & 360 & 0.44 & 731 & 8.84 \\
\hline X590Be_2 & 57.61 & 26.80 & 0.41 & 8.97 & 6.43 & 0.15 & 100.36 & 0 & 0.43 & 728 & 8.79 \\
\hline X590Be_3 & 57.45 & 26.89 & 0.39 & 8.70 & 6.45 & 0.10 & 99.98 & 10 & 0.42 & 727 & 8.76 \\
\hline X590Be_4 4 & 57.42 & 26.62 & 0.42 & 9.36 & 6.25 & 0.12 & 100.18 & 20 & 0.45 & 734 & 8.80 \\
\hline X590Be_5 & 58.23 & 26.57 & 0.37 & 8.43 & 6.56 & 0.16 & 100.32 & 30 & 0.41 & 721 & 8.79 \\
\hline X590Be_6 & 59.30 & 25.97 & 0.39 & 8.15 & 6.69 & 0.18 & 100.69 & 40 & 0.40 & 716 & 8.81 \\
\hline X590Be_7 & 59.79 & 26.06 & 0.43 & 8.05 & 6.91 & 0.14 & 101.38 & 50 & 0.39 & 713 & 8.79 \\
\hline X590Be_8 & 57.91 & 25.46 & 0.37 & 7.89 & 6.61 & 0.14 & 98.39 & 60 & 0.39 & 716 & 8.79 \\
\hline X590Be_9 & 58.38 & 26.17 & 0.39 & 8.04 & 6.87 & 0.19 & 100.03 & 70 & 0.39 & 713 & 8.82 \\
\hline X590Be_10 & 57.80 & 26.77 & 0.39 & 9.24 & 6.20 & 0.15 & 100.55 & 80 & 0.45 & 733 & 8.81 \\
\hline X590Be_11 & 56.70 & 27.40 & 0.37 & 9.80 & 5.85 & 0.13 & 100.26 & 90 & 0.48 & 740 & 8.86 \\
\hline X590Be_12 & 57.05 & 27.49 & 0.39 & 9.67 & 5.80 & 0.13 & 100.52 & 100 & 0.48 & 740 & 8.86 \\
\hline X590Be_13 & 56.99 & 27.38 & 0.48 & 10.01 & 5.76 & 0.12 & 100.74 & 110 & 0.49 & 742 & 8.88 \\
\hline X590Be_14 & 55.93 & 27.30 & 0.31 & 10.28 & 5.63 & 0.12 & 99.56 & 120 & 0.50 & 745 & 8.92 \\
\hline X590Be_15 & 58.60 & 26.86 & 0.46 & 9.08 & 6.34 & 0.15 & 101.48 & 130 & 0.44 & 730 & 8.80 \\
\hline X590Be_16 & 58.99 & 26.70 & 0.44 & 8.83 & 6.38 & 0.14 & 101.47 & 140 & 0.43 & 728 & 8.79 \\
\hline X590Be_17 & 57.68 & 26.73 & 0.41 & 8.88 & 6.31 & 0.10 & 100.11 & 150 & 0.43 & 730 & 8.77 \\
\hline X590Be_18 & 57.39 & 27.04 & 0.43 & 9.19 & 6.20 & 0.14 & 100.40 & 160 & 0.45 & 732 & 8.81 \\
\hline X590Be_19 & 58.05 & 26.40 & 0.47 & 8.28 & 6.50 & 0.18 & 99.88 & 170 & 0.41 & 720 & 8.81 \\
\hline X590Be_20 & 59.96 & 26.41 & 0.49 & 8.44 & 6.63 & 0.12 & 102.06 & 180 & 0.41 & 722 & 8.77 \\
\hline X590Be_21 & 60.54 & 26.56 & 0.49 & 8.15 & 6.74 & 0.19 & 102.66 & 190 & 0.40 & 715 & 8.81 \\
\hline X590Be_22 & 58.86 & 26.56 & 0.55 & 8.78 & 6.32 & 0.16 & 101.23 & 200 & 0.43 & 727 & 8.80 \\
\hline X590B1_1 & 58.55 & 27.52 & 0.46 & 9.36 & 5.65 & 0.15 & 101.68 & 0 & 0.47 & 739 & 8.87 \\
\hline X590B1_3 & 59.17 & 26.61 & 0.31 & 8.76 & 6.13 & 0.15 & 101.14 & 20 & 0.44 & 730 & 8.80 \\
\hline X590B1_4 & 59.67 & 26.98 & 0.40 & 9.12 & 6.13 & 0.13 & 102.43 & 30 & 0.45 & 733 & 8.80 \\
\hline X590B1_5 & 59.27 & 27.18 & 0.35 & 9.28 & 6.12 & 0.17 & 102.37 & 40 & 0.45 & 733 & 8.83 \\
\hline X590B1_6 & 59.00 & 27.53 & 0.48 & 9.14 & 6.14 & 0.13 & 102.41 & 50 & 0.45 & 733 & 8.80 \\
\hline X590B1 7 & 56.58 & 28.39 & 0.42 & 10.70 & 5.36 & 0.08 & 101.52 & 60 & 0.52 & 749 & 8.99 \\
\hline X590B1_8 & 55.81 & 29.05 & 0.44 & 11.31 & 5.11 & 0.11 & 101.83 & 70 & 0.55 & 751 & 9.13 \\
\hline X590B1_9 & 55.87 & 29.29 & 0.45 & 11.18 & 5.15 & 0.07 & 101.99 & 80 & 0.54 & 752 & 9.08 \\
\hline X590B1_10 & 55.76 & 29.31 & 0.40 & 11.55 & 4.83 & 0.10 & 101.95 & 90 & 0.57 & 753 & 9.24 \\
\hline X590B1_11 & 56.06 & 29.48 & 0.43 & 11.64 & 4.70 & 0.10 & 102.41 & 100 & 0.57 & 753 & 9.29 \\
\hline X590B1_12 & 56.06 & 29.52 & 0.38 & 11.42 & 5.00 & 0.13 & 102.52 & 110 & 0.55 & 751 & 9.19 \\
\hline X590B1_13 & 55.76 & 29.11 & 0.40 & 11.01 & 5.10 & 0.10 & 101.48 & 120 & 0.54 & 751 & 9.09 \\
\hline X590B1_14 & 58.76 & 27.27 & 0.52 & 9.10 & 6.11 & 0.15 & 101.90 & 130 & 0.45 & 732 & 8.81 \\
\hline X590B1_15 & 59.90 & 26.96 & 0.38 & 8.27 & 6.21 & 0.13 & 101.85 & 140 & 0.42 & 725 & 8.78 \\
\hline X590B1_16 & 58.47 & 27.60 & 0.34 & 8.87 & 6.17 & 0.20 & 101.65 & 150 & 0.44 & 729 & 8.83 \\
\hline X590B1_19 & 59.99 & 26.98 & 0.48 & 8.86 & 6.31 & 0.19 & 102.81 & 180 & 0.43 & 727 & 8.82 \\
\hline X590B1_20 & 59.79 & 27.28 & 0.45 & 9.05 & 6.14 & 0.13 & 102.84 & 190 & 0.45 & 732 & 8.80 \\
\hline X590B1_21 & 58.84 & 26.55 & 0.43 & 8.82 & 6.28 & 0.18 & 101.10 & 200 & 0.43 & 728 & 8.81 \\
\hline X590B1_22 & 59.55 & 26.95 & 0.49 & 8.56 & 6.45 & 0.17 & 102.18 & 210 & 0.42 & 724 & 8.80 \\
\hline X590B1_23 & 59.73 & 26.95 & 0.33 & 8.57 & 6.46 & 0.15 & 102.20 & 220 & 0.42 & 724 & 8.79 \\
\hline X590B1_24 & 58.86 & 27.02 & 0.42 & 8.85 & 6.14 & 0.18 & 101.47 & 230 & 0.44 & 729 & 8.82 \\
\hline X590B1_25 & 58.11 & 28.22 & 0.36 & 10.07 & 5.77 & 0.12 & 102.66 & 240 & 0.49 & 742 & 8.89 \\
\hline X590B1_32 & 59.46 & 26.99 & 0.34 & 8.76 & 6.35 & 0.15 & 102.06 & 310 & 0.43 & 727 & 8.79 \\
\hline
\end{tabular}


Table A3.10 continued

\begin{tabular}{|c|c|c|c|c|c|c|c|c|c|c|c|}
\hline Sample & $\mathrm{SiO}_{2}$ & $\mathrm{Al}_{2} \mathrm{O}_{3}$ & $\mathrm{FeO}$ & $\mathrm{CaO}$ & $\mathrm{Na}_{2} \mathrm{O}$ & $\mathrm{K}_{2} \mathrm{O}$ & Total & $\begin{array}{l}\text { Dist } \\
(\mu \mathrm{m})\end{array}$ & X An & $\begin{array}{c}\text { Temp } \\
{ }^{\circ} \mathrm{C} \\
\end{array}$ & $\begin{array}{l}\mathrm{H}_{2} \mathrm{O} \\
\mathrm{wt} \% \\
\end{array}$ \\
\hline X590B1_34 & 59.27 & 27.51 & 0.40 & 8.89 & 6.25 & 0.11 & 102.44 & 330 & 0.44 & 731 & 8.78 \\
\hline X590B1_35 & 59.42 & 27.18 & 0.44 & 9.08 & 6.19 & 0.14 & 102.44 & 340 & 0.44 & 732 & 8.80 \\
\hline X590B1_36 & 61.14 & 26.14 & 0.35 & 8.06 & 6.79 & 0.21 & 102.69 & 350 & 0.39 & 713 & 8.82 \\
\hline X590B1_37 & 60.44 & 26.78 & 0.41 & 8.44 & 6.41 & 0.16 & 102.64 & 360 & 0.42 & 723 & 8.79 \\
\hline X590B1_38 & 59.39 & 27.25 & 0.39 & 9.01 & 6.18 & 0.19 & 102.42 & 370 & 0.44 & 730 & 8.83 \\
\hline X609j_11 & 60.11 & 26.65 & 0.46 & 9.00 & 5.97 & 0.19 & 102.39 & 100 & 0.45 & 732 & 8.84 \\
\hline X609j_12 & 59.27 & 26.72 & 0.37 & 8.87 & 6.29 & 0.17 & 101.70 & 110 & 0.43 & 728 & 8.81 \\
\hline X609j_13 & 58.93 & 26.30 & 0.40 & 8.46 & 6.00 & 0.23 & 100.33 & 120 & 0.43 & 726 & 8.85 \\
\hline $\mathrm{X} 609 \mathrm{j} \_14$ & 59.27 & 27.03 & 0.39 & 8.85 & 6.08 & 0.17 & 101.80 & 130 & 0.44 & 730 & 8.82 \\
\hline X609j_15 & 58.87 & 26.74 & 0.36 & 9.19 & 6.09 & 0.11 & 101.37 & 140 & 0.45 & 734 & 8.80 \\
\hline X609j_16 & 59.30 & 26.79 & 0.42 & 9.38 & 6.16 & 0.16 & 102.21 & 150 & 0.45 & 734 & 8.83 \\
\hline X609j_17 & 59.79 & 26.99 & 0.41 & 8.78 & 6.20 & 0.15 & 102.32 & 160 & 0.44 & 729 & 8.80 \\
\hline X609j_18 & 59.46 & 27.07 & 0.37 & 8.75 & 6.27 & 0.19 & 102.10 & 170 & 0.43 & 727 & 8.81 \\
\hline X609j_19 & 60.31 & 26.00 & 0.28 & 8.22 & 6.54 & 0.15 & 101.51 & 180 & 0.41 & 720 & 8.79 \\
\hline X609j_20 & 60.92 & 26.20 & 0.33 & 8.00 & 6.62 & 0.17 & 102.22 & 190 & 0.40 & 716 & 8.80 \\
\hline X609j_21 & 60.03 & 26.56 & 0.34 & 8.67 & 6.51 & 0.16 & 102.28 & 200 & 0.42 & 724 & 8.79 \\
\hline X609j_22 & 60.13 & 26.54 & 0.33 & 8.50 & 6.25 & 0.16 & 101.91 & 210 & 0.42 & 726 & 8.80 \\
\hline X609j_24 & 59.75 & 26.96 & 0.36 & 9.03 & 6.27 & 0.14 & 102.52 & 230 & 0.44 & 730 & 8.80 \\
\hline X609j_25 & 59.90 & 26.66 & 0.42 & 8.69 & 6.26 & 0.16 & 102.09 & 240 & 0.43 & 727 & 8.80 \\
\hline X609j_28 & 58.69 & 27.45 & 0.45 & 8.95 & 6.21 & 0.15 & 101.90 & 270 & 0.44 & 730 & 8.80 \\
\hline X609j_29 & 58.53 & 27.78 & 0.37 & 9.41 & 6.18 & 0.10 & 102.37 & 280 & 0.45 & 735 & 8.80 \\
\hline X609j_30 & 60.05 & 27.03 & 0.49 & 8.64 & 6.53 & 0.15 & 102.88 & 290 & 0.42 & 724 & 8.79 \\
\hline X609j_31 & 59.36 & 27.34 & 0.41 & 8.75 & 6.23 & 0.12 & 102.21 & 300 & 0.43 & 729 & 8.78 \\
\hline X609j_32 & 57.80 & 27.46 & 0.41 & 9.22 & 6.22 & 0.13 & 101.24 & 310 & 0.45 & 733 & 8.80 \\
\hline X609j_33 & 58.81 & 27.49 & 0.48 & 8.80 & 6.34 & 0.17 & 102.10 & 320 & 0.43 & 727 & 8.80 \\
\hline X609j_34 & 59.15 & 27.15 & 0.54 & 8.87 & 6.37 & 0.15 & 102.22 & 330 & 0.43 & 728 & 8.79 \\
\hline X609j_35 & 58.84 & 27.30 & 0.29 & 9.31 & 6.33 & 0.13 & 102.19 & 340 & 0.45 & 732 & 8.79 \\
\hline X609j_36 & 60.74 & 25.94 & 0.36 & 7.56 & 6.83 & 0.21 & 101.64 & 350 & 0.37 & 707 & 8.85 \\
\hline X609j_37 & 60.66 & 26.16 & 0.36 & 7.68 & 6.91 & 0.17 & 101.95 & 360 & 0.38 & 708 & 8.82 \\
\hline X609j_38 & 60.36 & 26.04 & 0.28 & 7.75 & 6.99 & 0.21 & 101.63 & 370 & 0.38 & 707 & 8.84 \\
\hline X609j_39 & 59.85 & 26.22 & 0.38 & 7.64 & 6.88 & 0.17 & 101.14 & 380 & 0.38 & 708 & 8.82 \\
\hline X609j_40 & 59.95 & 26.97 & 0.35 & 8.00 & 6.60 & 0.19 & 102.06 & 390 & 0.40 & 715 & 8.81 \\
\hline X609j_41 & 61.00 & 25.95 & 0.42 & 7.61 & 6.80 & 0.13 & 101.91 & 400 & 0.38 & 710 & 8.80 \\
\hline X609j_42 & 61.21 & 25.96 & 0.45 & 7.46 & 6.92 & 0.14 & 102.14 & 410 & 0.37 & 706 & 8.81 \\
\hline X609j_43 & 60.81 & 26.14 & 0.39 & 7.69 & 6.91 & 0.15 & 102.09 & 420 & 0.38 & 709 & 8.81 \\
\hline X609j_44 & 60.89 & 26.21 & 0.40 & 7.63 & 6.62 & 0.16 & 101.91 & 430 & 0.39 & 712 & 8.81 \\
\hline X609j_45 & 60.23 & 25.83 & 0.44 & 7.60 & 6.89 & 0.13 & 101.12 & 440 & 0.38 & 709 & 8.80 \\
\hline X609j_46 & 60.73 & 25.55 & 0.40 & 7.61 & 6.91 & 0.22 & 101.42 & 450 & 0.37 & 706 & 8.85 \\
\hline X609j_47 & 61.40 & 25.74 & 0.35 & 7.83 & 6.97 & 0.15 & 102.44 & 460 & 0.38 & 710 & 8.81 \\
\hline X609j_48 & 61.08 & 26.09 & 0.40 & 7.86 & 6.86 & 0.18 & 102.47 & 470 & 0.38 & 711 & 8.81 \\
\hline X609j_49 & 59.57 & 26.07 & 0.39 & 8.27 & 6.85 & 0.21 & 101.35 & 480 & 0.40 & 715 & 8.82 \\
\hline X609j_50 & 59.46 & 26.11 & 0.36 & 8.07 & 6.73 & 0.17 & 100.90 & 490 & 0.39 & 715 & 8.80 \\
\hline X609j_51 & 59.33 & 26.19 & 0.52 & 8.39 & 6.71 & 0.17 & 101.30 & 500 & 0.40 & 719 & 8.80 \\
\hline X609j_52 & 57.79 & 27.20 & 0.40 & 9.56 & 6.45 & 0.13 & 101.54 & 510 & 0.45 & 733 & 8.80 \\
\hline X609j_53 & 57.56 & 27.01 & 0.35 & 9.53 & 5.89 & 0.15 & 100.49 & 520 & 0.47 & 738 & 8.85 \\
\hline X609j_54 & 58.35 & 27.27 & 0.28 & 9.27 & 6.23 & 0.21 & 101.60 & 530 & 0.45 & 731 & 8.84 \\
\hline X609j_55 & 58.09 & 27.24 & 0.39 & 9.62 & 5.98 & 0.11 & 101.44 & 540 & 0.47 & 739 & 8.82 \\
\hline X609j_56 & 57.53 & 27.73 & 0.38 & 9.93 & 5.84 & 0.15 & 101.56 & 550 & 0.48 & 740 & 8.88 \\
\hline X609j_57 & 57.17 & 27.77 & 0.33 & 9.69 & 5.89 & 0.12 & 100.97 & 560 & 0.47 & 739 & 8.85 \\
\hline X609j_58 & 56.93 & 27.68 & 0.42 & 9.98 & 5.94 & 0.12 & 101.07 & 570 & 0.48 & 741 & 8.86 \\
\hline X609j_59 & 57.02 & 27.43 & 0.32 & 9.92 & 5.82 & 0.12 & 100.63 & 580 & 0.48 & 741 & 8.87 \\
\hline X609j_60 & 56.97 & 27.74 & 0.38 & 9.78 & 5.96 & 0.13 & 100.95 & 590 & 0.47 & 739 & 8.84 \\
\hline X609j_61 & 57.35 & 27.57 & 0.30 & 9.89 & 5.79 & 0.10 & 101.00 & 600 & 0.48 & 742 & 8.86 \\
\hline X609j_62 & 57.70 & 27.40 & 0.40 & 10.16 & 6.02 & 0.14 & 101.82 & 610 & 0.48 & 740 & 8.87 \\
\hline X609j_63 & 57.80 & 27.65 & 0.46 & 9.80 & 5.79 & 0.14 & 101.64 & 620 & 0.48 & 741 & 8.87 \\
\hline X609j_64 & 57.62 & 28.04 & 0.39 & 9.71 & 5.97 & 0.11 & 101.85 & 630 & 0.47 & 739 & 8.83 \\
\hline X609j_65 & 57.32 & 27.88 & 0.36 & 10.00 & 5.97 & 0.10 & 101.64 & 640 & 0.48 & 741 & 8.85 \\
\hline X609j_66 & 56.34 & 27.58 & 0.39 & 9.84 & 5.92 & 0.13 & 100.20 & 650 & 0.48 & 740 & 8.85 \\
\hline X609j_67 & 56.76 & 27.49 & 0.38 & 9.81 & 5.80 & 0.11 & 100.36 & 660 & 0.48 & 741 & 8.86 \\
\hline X609j_68 & 56.78 & 27.23 & 0.42 & 9.50 & 5.94 & 0.13 & 100.00 & 670 & 0.47 & 738 & 8.83 \\
\hline X609j_69 & 57.11 & 27.48 & 0.38 & 9.89 & 5.81 & 0.10 & 100.76 & 680 & 0.48 & 742 & 8.86 \\
\hline X609j_70 & 57.02 & 27.83 & 0.32 & 10.08 & 5.92 & 0.10 & 101.27 & 690 & 0.48 & 742 & 8.85 \\
\hline X609j_71 & 57.18 & 28.06 & 0.30 & 10.10 & 5.52 & 0.12 & 101.28 & 700 & 0.50 & 745 & 8.93 \\
\hline X609j_72 & 57.12 & 28.03 & 0.40 & 10.12 & 5.51 & 0.09 & 101.27 & 710 & 0.50 & 746 & 8.91 \\
\hline X609j_74 & 56.24 & 28.54 & 0.36 & 10.60 & 5.53 & 0.11 & 101.39 & 730 & 0.51 & 747 & 8.96 \\
\hline X609j_75 & 55.78 & 28.47 & 0.35 & 10.79 & 5.33 & 0.09 & 100.81 & 740 & 0.53 & 749 & 9.01 \\
\hline X609j_76 & 55.30 & 28.34 & 0.39 & 10.86 & 5.35 & 0.15 & 100.39 & 750 & 0.52 & 748 & 9.05 \\
\hline X609j_77 & 55.58 & 28.37 & 0.49 & 10.86 & 5.25 & 0.10 & 100.65 & 760 & 0.53 & 750 & 9.04 \\
\hline $\mathrm{X} 609 \mathrm{j} \_78$ & 56.28 & 28.13 & 0.35 & 10.49 & 5.49 & 0.11 & 100.85 & 770 & 0.51 & 747 & 8.96 \\
\hline
\end{tabular}


Table A3.10 continued

\begin{tabular}{|c|c|c|c|c|c|c|c|c|c|c|c|}
\hline Sample & $\mathrm{SiO}_{2}$ & $\mathrm{Al}_{2} \mathrm{O}_{3}$ & $\mathrm{FeO}$ & $\mathrm{CaO}$ & $\mathrm{Na}_{2} \mathrm{O}$ & $\mathrm{K}_{2} \mathrm{O}$ & Total & $\begin{array}{l}\text { Dist } \\
(\mu \mathrm{m})\end{array}$ & X An & $\begin{array}{c}\text { Temp } \\
{ }^{\circ} \mathrm{C} \\
\end{array}$ & $\begin{array}{l}\mathrm{H}_{2} \mathrm{O} \\
\mathrm{wt} \% \\
\end{array}$ \\
\hline X609j_80 & 56.19 & 28.30 & 0.38 & 10.57 & 5.44 & 0.11 & 100.98 & 790 & 0.51 & 748 & 8.97 \\
\hline X609j_81 & 55.93 & 28.54 & 0.34 & 10.67 & 5.35 & 0.08 & 100.92 & 800 & 0.52 & 749 & 8.99 \\
\hline X609j_82 & 55.55 & 28.23 & 0.38 & 10.41 & 5.55 & 0.12 & 100.24 & 810 & 0.51 & 746 & 8.95 \\
\hline X609j_83 & 58.25 & 26.60 & 0.44 & 8.73 & 6.38 & 0.17 & 100.56 & 820 & 0.43 & 726 & 8.80 \\
\hline X609j_84 & 58.36 & 26.64 & 0.42 & 8.52 & 6.52 & 0.13 & 100.60 & 830 & 0.42 & 723 & 8.78 \\
\hline X609j_85 & 58.55 & 26.58 & 0.43 & 8.79 & 6.47 & 0.11 & 100.93 & 840 & 0.43 & 727 & 8.77 \\
\hline X609j_86 & 58.41 & 26.88 & 0.38 & 8.89 & 6.28 & 0.16 & 100.99 & 850 & 0.43 & 729 & 8.80 \\
\hline X609j_87 & 57.45 & 27.17 & 0.32 & 9.30 & 5.94 & 0.11 & 100.29 & 860 & 0.46 & 737 & 8.81 \\
\hline X609j_88 & 57.22 & 27.08 & 0.40 & 9.04 & 6.12 & 0.15 & 100.02 & 870 & 0.45 & 732 & 8.81 \\
\hline X609j_89 & 57.37 & 27.29 & 0.41 & 9.27 & 6.09 & 0.11 & 100.54 & 880 & 0.45 & 735 & 8.80 \\
\hline X609j_90 & 56.00 & 27.83 & 0.41 & 10.32 & 5.75 & 0.12 & 100.43 & 890 & 0.49 & 744 & 8.91 \\
\hline X609k_1 & 67.13 & 21.85 & 0.92 & 6.21 & 5.33 & 0.83 & 102.27 & 0 & 0.37 & 691 & 9.25 \\
\hline X609k_2 & 58.12 & 27.44 & 0.44 & 9.00 & 5.98 & 0.14 & 101.12 & 10 & 0.45 & 733 & 8.81 \\
\hline X609k_3 & 58.73 & 27.34 & 0.32 & 9.18 & 6.32 & 0.17 & 102.05 & 20 & 0.44 & 730 & 8.81 \\
\hline X609k_4 & 59.46 & 27.00 & 0.46 & 8.98 & 6.43 & 0.15 & 102.48 & 30 & 0.43 & 728 & 8.79 \\
\hline X609k_5 & 57.19 & 27.29 & 0.27 & 9.17 & 5.84 & 0.15 & 99.93 & 40 & 0.46 & 736 & 8.84 \\
\hline X609k_6 & 57.57 & 27.59 & 0.47 & 9.38 & 5.71 & 0.19 & 100.90 & 50 & 0.47 & 737 & 8.88 \\
\hline X609k_7 & 58.57 & 27.69 & 0.41 & 9.45 & 5.72 & 0.13 & 101.97 & 60 & 0.47 & 739 & 8.86 \\
\hline X609k_9 & 58.95 & 27.28 & 0.36 & 9.10 & 6.08 & 0.20 & 101.96 & 80 & 0.45 & 731 & 8.84 \\
\hline X609k_10 & 59.71 & 27.11 & 0.48 & 8.69 & 6.64 & 0.18 & 102.81 & 90 & 0.42 & 722 & 8.80 \\
\hline X609k_11 & 59.49 & 27.01 & 0.47 & 9.21 & 5.68 & 0.16 & 102.02 & 100 & 0.47 & 737 & 8.86 \\
\hline X609k_12 & 58.18 & 27.24 & 0.42 & 9.00 & 5.56 & 0.11 & 100.51 & 110 & 0.47 & 739 & 8.83 \\
\hline X609k_13 & 58.58 & 27.30 & 0.40 & 9.10 & 6.25 & 0.12 & 101.74 & 120 & 0.44 & 732 & 8.79 \\
\hline X609k_14 & 59.60 & 26.56 & 0.34 & 8.33 & 6.47 & 0.17 & 101.48 & 130 & 0.41 & 721 & 8.80 \\
\hline X609k_15 & 60.71 & 25.95 & 0.35 & 7.57 & 6.77 & 0.21 & 101.57 & 140 & 0.38 & 708 & 8.84 \\
\hline X609k_16 & 60.67 & 26.21 & 0.35 & 7.92 & 6.65 & 0.20 & 102.00 & 150 & 0.39 & 714 & 8.82 \\
\hline X609k_17 & 61.08 & 26.02 & 0.31 & 7.43 & 6.76 & 0.20 & 101.79 & 160 & 0.37 & 706 & 8.84 \\
\hline X609k_18 & 60.33 & 26.64 & 0.34 & 8.03 & 6.58 & 0.13 & 102.04 & 170 & 0.40 & 718 & 8.78 \\
\hline X609k_19 & 59.85 & 26.97 & 0.36 & 8.65 & 6.35 & 0.16 & 102.33 & 180 & 0.43 & 726 & 8.80 \\
\hline X609k_20 & 59.40 & 27.05 & 0.38 & 8.82 & 6.08 & 0.14 & 101.87 & 190 & 0.44 & 731 & 8.80 \\
\hline X609k_21 & 59.71 & 26.87 & 0.36 & 8.78 & 6.14 & 0.17 & 102.03 & 200 & 0.44 & 729 & 8.81 \\
\hline X609k_22 & 58.84 & 27.25 & 0.36 & 9.14 & 6.02 & 0.15 & 101.76 & 210 & 0.45 & 734 & 8.82 \\
\hline X609k_23 & 58.64 & 27.77 & 0.37 & 9.42 & 5.88 & 0.16 & 102.24 & 220 & 0.47 & 737 & 8.85 \\
\hline X609k_24 & 60.64 & 26.70 & 0.47 & 8.41 & 6.41 & 0.14 & 102.77 & 230 & 0.42 & 723 & 8.78 \\
\hline X609k_25 & 60.89 & 26.49 & 0.39 & 8.30 & 6.29 & 0.17 & 102.54 & 240 & 0.42 & 723 & 8.80 \\
\hline X609k_26 & 59.90 & 26.99 & 0.30 & 8.81 & 6.11 & 0.16 & 102.27 & 250 & 0.44 & 730 & 8.81 \\
\hline X609k_27 & 59.27 & 27.34 & 0.31 & 8.89 & 6.01 & 0.14 & 101.96 & 260 & 0.45 & 732 & 8.81 \\
\hline X609k_28 & 61.23 & 25.73 & 0.32 & 7.32 & 6.94 & 0.17 & 101.70 & 270 & 0.36 & 703 & 8.84 \\
\hline X609k_29 & 61.21 & 26.03 & 0.39 & 7.34 & 6.93 & 0.19 & 102.09 & 280 & 0.36 & 703 & 8.85 \\
\hline X609k_30 & 60.86 & 26.30 & 0.27 & 7.88 & 6.57 & 0.17 & 102.05 & 290 & 0.39 & 715 & 8.81 \\
\hline X609k_31 & 59.89 & 25.90 & 0.41 & 7.60 & 6.68 & 0.16 & 100.64 & 300 & 0.38 & 711 & 8.81 \\
\hline X609k_32 & 61.09 & 26.34 & 0.38 & 7.92 & 6.72 & 0.14 & 102.60 & 310 & 0.39 & 714 & 8.79 \\
\hline X609k_33 & 60.16 & 26.54 & 0.44 & 8.32 & 6.58 & 0.17 & 102.21 & 320 & 0.41 & 720 & 8.80 \\
\hline X609k_34 & 60.67 & 26.33 & 0.44 & 7.84 & 6.94 & 0.17 & 102.38 & 330 & 0.38 & 710 & 8.82 \\
\hline X609k_35 & 59.75 & 26.43 & 0.42 & 8.16 & 6.43 & 0.19 & 101.38 & 340 & 0.41 & 719 & 8.81 \\
\hline X609k_36 & 58.71 & 27.38 & 0.44 & 9.04 & 6.27 & 0.12 & 101.97 & 350 & 0.44 & 731 & 8.79 \\
\hline X609k_37 & 58.85 & 27.61 & 0.33 & 8.98 & 6.10 & 0.13 & 102.02 & 360 & 0.44 & 732 & 8.80 \\
\hline X609k_38 & 59.20 & 26.45 & 0.36 & 7.83 & 6.39 & 0.18 & 100.42 & 370 & 0.40 & 716 & 8.81 \\
\hline X609k_39 & 60.91 & 26.10 & 0.35 & 7.75 & 6.82 & 0.16 & 102.10 & 380 & 0.38 & 710 & 8.81 \\
\hline X609k_40 & 60.79 & 26.13 & 0.41 & 7.69 & 6.66 & 0.17 & 101.85 & 390 & 0.39 & 712 & 8.81 \\
\hline X609k_41 & 61.42 & 26.13 & 0.39 & 7.42 & 6.99 & 0.20 & 102.56 & 400 & 0.37 & 703 & 8.86 \\
\hline X609k 42 & 61.29 & 26.15 & 0.39 & 7.30 & 6.67 & 0.19 & 102.00 & 410 & 0.37 & 706 & 8.84 \\
\hline X609k_43 & 60.23 & 26.09 & 0.38 & 7.82 & 6.68 & 0.19 & 101.40 & 420 & 0.39 & 712 & 8.82 \\
\hline X609k_44 & 58.69 & 27.45 & 0.39 & 9.28 & 6.17 & 0.15 & 102.14 & 430 & 0.45 & 733 & 8.81 \\
\hline X609k_45 & 59.15 & 26.21 & 0.45 & 7.76 & 6.57 & 0.18 & 100.31 & 440 & 0.39 & 713 & 8.81 \\
\hline X609k_46 & 58.75 & 26.04 & 0.42 & 8.21 & 6.59 & 0.19 & 100.21 & 450 & 0.40 & 718 & 8.81 \\
\hline X609k_51 & 58.99 & 26.95 & 0.47 & 8.70 & 6.32 & 0.18 & 101.61 & 500 & 0.43 & 726 & 8.81 \\
\hline X609k_52 & 59.32 & 27.31 & 0.35 & 8.76 & 6.19 & 0.11 & 102.05 & 510 & 0.44 & 730 & 8.78 \\
\hline X609k_53 & 59.59 & 27.02 & 0.38 & 8.81 & 6.40 & 0.16 & 102.35 & 520 & 0.43 & 727 & 8.80 \\
\hline X609k_54 & 59.17 & 27.30 & 0.35 & 8.79 & 6.19 & 0.17 & 101.97 & 530 & 0.44 & 729 & 8.81 \\
\hline X609k_55 & 58.84 & 27.02 & 0.23 & 8.69 & 6.40 & 0.18 & 101.37 & 540 & 0.42 & 725 & 8.81 \\
\hline X609k_56 & 59.48 & 26.89 & 0.38 & 8.55 & 6.42 & 0.15 & 101.87 & 550 & 0.42 & 724 & 8.79 \\
\hline $\mathrm{X} 609 \mathrm{k} \_57$ & 59.77 & 26.69 & 0.41 & 8.38 & 6.29 & 0.14 & 101.67 & 560 & 0.42 & 725 & 8.78 \\
\hline X609k_58 & 59.55 & 26.30 & 0.40 & 8.22 & 6.59 & 0.18 & 101.24 & 570 & 0.40 & 718 & 8.80 \\
\hline X609k_59 & 58.87 & 26.07 & 0.39 & 8.15 & 6.19 & 0.20 & 99.87 & 580 & 0.42 & 722 & 8.82 \\
\hline X609k_60 & 60.68 & 26.34 & 0.38 & 7.85 & 6.86 & 0.21 & 102.31 & 590 & 0.38 & 710 & 8.83 \\
\hline X609k_61 & 60.40 & 25.91 & 0.46 & 7.60 & 6.99 & 0.16 & 101.53 & 600 & 0.37 & 706 & 8.82 \\
\hline X609k_62 & 59.78 & 26.31 & 0.35 & 8.19 & 6.63 & 0.22 & 101.49 & 610 & 0.40 & 717 & 8.83 \\
\hline X609k_63 & 60.53 & 26.13 & 0.36 & 7.81 & 6.82 & 0.17 & 101.81 & 620 & 0.38 & 711 & 8.81 \\
\hline
\end{tabular}


Table A3.10 continued

\begin{tabular}{|c|c|c|c|c|c|c|c|c|c|c|c|}
\hline Sample & $\mathrm{SiO}_{2}$ & $\mathrm{Al}_{2} \mathrm{O}_{3}$ & $\mathrm{FeO}$ & $\mathrm{CaO}$ & $\mathrm{Na}_{2} \mathrm{O}$ & $\mathrm{K}_{2} \mathrm{O}$ & Total & $\begin{array}{l}\text { Dist } \\
(\mu \mathrm{m})\end{array}$ & X An & $\begin{array}{c}\text { Temp } \\
{ }^{\circ} \mathrm{C} \\
\end{array}$ & $\begin{array}{l}\mathrm{H}_{2} \mathrm{O} \\
\mathrm{wt} \% \\
\end{array}$ \\
\hline X609k_66 & 59.02 & 27.78 & 0.46 & 9.47 & 5.91 & 0.12 & 102.77 & 650 & 0.47 & 738 & 8.83 \\
\hline X609k_67 & 57.83 & 27.97 & 0.52 & 9.67 & 6.02 & 0.12 & 102.12 & 660 & 0.47 & 738 & 8.83 \\
\hline X609k_68 & 58.10 & 27.64 & 0.40 & 9.14 & 6.33 & 0.13 & 101.74 & 670 & 0.44 & 731 & 8.79 \\
\hline X609k_69 & 58.91 & 27.25 & 0.27 & 8.81 & 6.23 & 0.15 & 101.62 & 680 & 0.43 & 729 & 8.80 \\
\hline X609k_70 & 58.55 & 27.35 & 0.42 & 9.08 & 6.07 & 0.13 & 101.60 & 690 & 0.45 & 733 & 8.80 \\
\hline X609k_71 & 65.30 & 21.63 & 0.91 & 6.10 & 5.43 & 0.65 & 100.02 & 700 & 0.37 & 694 & 9.14 \\
\hline X6091_1 & 60.94 & 25.38 & 0.40 & 6.88 & 7.27 & 0.16 & 101.03 & 0 & 0.34 & 692 & 8.90 \\
\hline X6091_2 & 61.10 & 25.29 & 0.31 & 6.75 & 7.24 & 0.22 & 100.91 & 10 & 0.34 & 690 & 8.94 \\
\hline X6091_3 & 61.60 & 25.49 & 0.30 & 7.01 & 7.17 & 0.16 & 101.73 & 20 & 0.35 & 696 & 8.87 \\
\hline X6091_4 & 61.39 & 25.36 & 0.38 & 6.94 & 7.11 & 0.19 & 101.37 & 30 & 0.35 & 695 & 8.89 \\
\hline X6091_5 & 62.48 & 25.15 & 0.36 & 6.43 & 7.35 & 0.22 & 101.98 & 40 & 0.32 & 683 & 8.98 \\
\hline X6091_6 & 62.62 & 25.07 & 0.32 & 6.44 & 7.34 & 0.22 & 102.01 & 50 & 0.32 & 683 & 8.98 \\
\hline X6091_7 & 62.09 & 24.33 & 0.33 & 6.15 & 7.52 & 0.24 & 100.66 & 60 & 0.31 & 675 & 9.05 \\
\hline X6091_8 & 61.92 & 24.98 & 0.30 & 6.33 & 7.20 & 0.23 & 100.97 & 70 & 0.32 & 683 & 8.99 \\
\hline X6091_9 & 61.67 & 24.88 & 0.32 & 6.62 & 6.94 & 0.27 & 100.70 & 80 & 0.34 & 690 & 8.95 \\
\hline X6091_10 & 62.01 & 24.86 & 0.35 & 6.71 & 7.30 & 0.23 & 101.45 & 90 & 0.33 & 688 & 8.95 \\
\hline X6091_11 & 61.92 & 25.00 & 0.25 & 6.56 & 7.44 & 0.19 & 101.37 & 100 & 0.32 & 684 & 8.96 \\
\hline X6091_12 & 62.62 & 24.87 & 0.39 & 6.43 & 7.30 & 0.23 & 101.84 & 110 & 0.32 & 683 & 8.99 \\
\hline X6091_14 & 61.34 & 25.70 & 0.39 & 7.05 & 7.13 & 0.20 & 101.80 & 130 & 0.35 & 696 & 8.89 \\
\hline X6091_15 & 60.03 & 26.58 & 0.33 & 8.11 & 6.76 & 0.16 & 101.96 & 140 & 0.39 & 716 & 8.79 \\
\hline X6091_16 & 60.32 & 26.03 & 0.37 & 7.85 & 6.74 & 0.17 & 101.49 & 150 & 0.39 & 713 & 8.81 \\
\hline X6091_17 & 59.55 & 26.19 & 0.37 & 7.49 & 6.79 & 0.13 & 100.53 & 160 & 0.38 & 708 & 8.81 \\
\hline X6091_18 & 61.19 & 25.66 & 0.37 & 7.23 & 6.89 & 0.20 & 101.54 & 170 & 0.36 & 702 & 8.86 \\
\hline X6091_19 & 62.30 & 25.42 & 0.42 & 7.08 & 7.11 & 0.19 & 102.51 & 180 & 0.35 & 697 & 8.88 \\
\hline X6091_20 & 62.49 & 25.76 & 0.33 & 7.10 & 6.94 & 0.23 & 102.85 & 190 & 0.36 & 699 & 8.89 \\
\hline X6091_21 & 61.73 & 25.54 & 0.35 & 6.75 & 7.05 & 0.20 & 101.62 & 200 & 0.34 & 693 & 8.91 \\
\hline X6091_22 & 61.37 & 25.90 & 0.38 & 7.22 & 7.12 & 0.15 & 102.15 & 210 & 0.36 & 700 & 8.85 \\
\hline X6091_23 & 61.20 & 26.09 & 0.42 & 7.21 & 7.00 & 0.15 & 102.08 & 220 & 0.36 & 702 & 8.84 \\
\hline X6091_24 & 61.05 & 25.85 & 0.34 & 7.15 & 7.15 & 0.17 & 101.70 & 230 & 0.35 & 698 & 8.86 \\
\hline X6091_25 & 61.04 & 25.68 & 0.28 & 7.14 & 7.21 & 0.20 & 101.56 & 240 & 0.35 & 696 & 8.89 \\
\hline X6091_26 & 60.69 & 25.86 & 0.34 & 7.49 & 7.15 & 0.17 & 101.70 & 250 & 0.36 & 703 & 8.84 \\
\hline X6091_27 & 60.85 & 25.89 & 0.25 & 7.25 & 7.01 & 0.19 & 101.46 & 260 & 0.36 & 701 & 8.86 \\
\hline X6091_28 & 59.47 & 26.31 & 0.37 & 8.31 & 6.42 & 0.18 & 101.07 & 270 & 0.41 & 721 & 8.81 \\
\hline X6091_30 & 59.88 & 26.45 & 0.30 & 7.77 & 6.55 & 0.16 & 101.11 & 290 & 0.39 & 714 & 8.80 \\
\hline X6091_31 & 60.00 & 26.60 & 0.40 & 8.00 & 6.52 & 0.16 & 101.68 & 300 & 0.40 & 717 & 8.80 \\
\hline X6091_32 & 58.91 & 27.05 & 0.41 & 8.33 & 6.44 & 0.14 & 101.29 & 310 & 0.41 & 722 & 8.78 \\
\hline X6091_33 & 60.11 & 26.61 & 0.33 & 7.97 & 6.69 & 0.17 & 101.88 & 320 & 0.39 & 715 & 8.80 \\
\hline X6091_34 & 60.30 & 26.17 & 0.29 & 7.65 & 6.78 & 0.16 & 101.35 & 330 & 0.38 & 710 & 8.81 \\
\hline X6091_35 & 61.08 & 25.99 & 0.30 & 7.25 & 6.96 & 0.18 & 101.76 & 340 & 0.36 & 702 & 8.85 \\
\hline X6091_36 & 61.08 & 25.83 & 0.34 & 7.43 & 7.02 & 0.17 & 101.88 & 350 & 0.37 & 704 & 8.84 \\
\hline X6091_37 & 60.92 & 26.41 & 0.40 & 7.89 & 6.80 & 0.16 & 102.58 & 360 & 0.39 & 713 & 8.80 \\
\hline X6091_38 & 60.95 & 26.57 & 0.27 & 7.79 & 6.94 & 0.17 & 102.70 & 370 & 0.38 & 709 & 8.82 \\
\hline X6091_39 & 60.69 & 26.32 & 0.40 & 7.85 & 6.77 & 0.20 & 102.22 & 380 & 0.39 & 711 & 8.82 \\
\hline X6091_40 & 59.94 & 26.55 & 0.40 & 7.71 & 6.56 & 0.13 & 101.28 & 390 & 0.39 & 714 & 8.79 \\
\hline X6091_41 & 59.36 & 27.18 & 0.39 & 8.43 & 6.67 & 0.16 & 102.18 & 400 & 0.41 & 720 & 8.79 \\
\hline X6091_42 & 59.64 & 26.64 & 0.29 & 8.42 & 6.64 & 0.14 & 101.76 & 410 & 0.41 & 721 & 8.78 \\
\hline X6091_43 & 60.50 & 26.40 & 0.33 & 8.06 & 6.77 & 0.17 & 102.23 & 420 & 0.39 & 715 & 8.80 \\
\hline X6091_44 & 59.92 & 26.64 & 0.44 & 8.29 & 6.64 & 0.17 & 102.12 & 430 & 0.40 & 719 & 8.80 \\
\hline X6091_45 & 59.08 & 27.11 & 0.41 & 8.65 & 6.36 & 0.19 & 101.80 & 440 & 0.42 & 725 & 8.81 \\
\hline X6091_46 & 60.03 & 27.00 & 0.32 & 8.75 & 6.35 & 0.13 & 102.58 & 450 & 0.43 & 728 & 8.78 \\
\hline X6091_47 & 60.00 & 26.93 & 0.40 & 8.59 & 6.38 & 0.17 & 102.47 & 460 & 0.42 & 725 & 8.80 \\
\hline X6091_50 & 60.02 & 26.94 & 0.37 & 8.77 & 6.10 & 0.15 & 102.35 & 490 & 0.44 & 730 & 8.80 \\
\hline X6091_51 & 60.09 & 26.87 & 0.33 & 8.73 & 6.29 & 0.16 & 102.48 & 500 & 0.43 & 727 & 8.80 \\
\hline X6091_52 & 59.39 & 26.98 & 0.40 & 9.02 & 6.12 & 0.14 & 102.05 & 510 & 0.44 & 732 & 8.80 \\
\hline X6091_53 & 58.81 & 27.31 & 0.39 & 8.93 & 6.17 & 0.16 & 101.76 & 520 & 0.44 & 730 & 8.81 \\
\hline X6091_54 & 58.53 & 27.25 & 0.32 & 8.65 & 6.23 & 0.18 & 101.16 & 530 & 0.43 & 727 & 8.81 \\
\hline X6091_55 & 58.79 & 26.88 & 0.38 & 8.93 & 6.16 & 0.12 & 101.27 & 540 & 0.44 & 732 & 8.79 \\
\hline X6091_56 & 59.46 & 26.97 & 0.36 & 8.54 & 6.19 & 0.12 & 101.64 & 550 & 0.43 & 728 & 8.78 \\
\hline X6091_57 & 59.96 & 26.63 & 0.42 & 8.29 & 6.56 & 0.13 & 101.99 & 560 & 0.41 & 721 & 8.77 \\
\hline X6091_58 & 59.84 & 26.68 & 0.28 & 8.46 & 6.39 & 0.16 & 101.82 & 570 & 0.42 & 724 & 8.79 \\
\hline X6091_59 & 59.48 & 26.52 & 0.33 & 8.42 & 6.39 & 0.15 & 101.29 & 580 & 0.42 & 723 & 8.79 \\
\hline X6091_60 & 59.49 & 26.64 & 0.43 & 8.19 & 6.58 & 0.15 & 101.48 & 590 & 0.40 & 719 & 8.79 \\
\hline X6091_61 & 58.76 & 26.71 & 0.34 & 8.15 & 6.41 & 0.17 & 100.54 & 600 & 0.41 & 720 & 8.80 \\
\hline X6091_62 & 59.87 & 26.77 & 0.32 & 8.03 & 6.35 & 0.16 & 101.50 & 610 & 0.41 & 720 & 8.80 \\
\hline X6091_63 & 60.12 & 26.51 & 0.40 & 8.16 & 6.59 & 0.16 & 101.94 & 620 & 0.40 & 718 & 8.79 \\
\hline X6091_64 & 60.48 & 26.08 & 0.39 & 7.94 & 6.65 & 0.12 & 101.65 & 630 & 0.39 & 716 & 8.78 \\
\hline X6091_65 & 60.33 & 26.16 & 0.39 & 8.02 & 6.75 & 0.18 & 101.83 & 640 & 0.39 & 714 & 8.81 \\
\hline X6091_66 & 60.14 & 24.74 & 0.30 & 6.85 & 7.16 & 0.16 & 99.35 & 650 & 0.34 & 694 & 8.89 \\
\hline X6091_67 & 59.67 & 25.77 & 0.37 & 7.69 & 6.60 & 0.22 & 100.32 & 660 & 0.39 & 711 & 8.84 \\
\hline
\end{tabular}


Table A3.10 continued

\begin{tabular}{|c|c|c|c|c|c|c|c|c|c|c|c|}
\hline Sample & $\mathrm{SiO}_{2}$ & $\mathrm{Al}_{2} \mathrm{O}_{3}$ & $\mathrm{FeO}$ & $\mathrm{CaO}$ & $\mathrm{Na}_{2} \mathrm{O}$ & $\mathrm{K}_{2} \mathrm{O}$ & Total & $\begin{array}{l}\text { Dist } \\
(\mu \mathrm{m})\end{array}$ & X An & $\begin{array}{c}\text { Temp } \\
{ }^{\circ} \mathrm{C} \\
\end{array}$ & $\begin{array}{l}\mathrm{H}_{2} \mathrm{O} \\
\mathrm{wt} \% \\
\end{array}$ \\
\hline X6091_69 & 60.04 & 26.29 & 0.35 & 7.65 & 6.65 & 0.21 & 101.18 & 680 & 0.38 & 711 & 8.83 \\
\hline X6091_70 & 60.20 & 26.23 & 0.36 & 7.82 & 6.96 & 0.20 & 101.77 & 690 & 0.38 & 709 & 8.83 \\
\hline X6091_71 & 60.53 & 26.41 & 0.36 & 7.79 & 6.59 & 0.21 & 101.89 & 700 & 0.39 & 713 & 8.83 \\
\hline X6091_72 & 58.61 & 26.67 & 0.30 & 8.55 & 6.30 & 0.18 & 100.60 & 710 & 0.42 & 725 & 8.81 \\
\hline X6091_73 & 59.32 & 27.12 & 0.44 & 8.90 & 6.48 & 0.18 & 102.44 & 720 & 0.43 & 726 & 8.81 \\
\hline X6091_74 & 58.65 & 27.32 & 0.42 & 9.16 & 5.97 & 0.14 & 101.67 & 730 & 0.45 & 735 & 8.82 \\
\hline X6091 75 & 57.23 & 27.37 & 0.46 & 9.12 & 5.89 & 0.15 & 100.23 & 740 & 0.46 & 735 & 8.83 \\
\hline X6091_76 & 58.07 & 27.39 & 0.55 & 9.15 & 6.05 & 0.16 & 101.36 & 750 & 0.45 & 733 & 8.82 \\
\hline X6091_77 & 59.21 & 27.29 & 0.48 & 8.73 & 6.30 & 0.14 & 102.16 & 760 & 0.43 & 728 & 8.79 \\
\hline X6091_78 & 58.29 & 27.33 & 0.37 & 8.98 & 6.18 & 0.17 & 101.31 & 770 & 0.44 & 730 & 8.81 \\
\hline X6091_79 & 57.90 & 27.03 & 0.43 & 9.06 & 6.10 & 0.15 & 100.66 & 780 & 0.45 & 732 & 8.81 \\
\hline X6091_80 & 58.37 & 26.94 & 0.39 & 8.85 & 6.32 & 0.15 & 101.03 & 790 & 0.43 & 728 & 8.80 \\
\hline X609p_81 & 60.01 & 26.13 & 0.41 & 7.62 & 6.94 & 0.17 & 101.28 & 800 & 0.37 & 707 & 8.83 \\
\hline X609p_82 & 59.28 & 26.57 & 0.31 & 8.47 & 6.61 & 0.12 & 101.37 & 810 & 0.41 & 722 & 8.77 \\
\hline X609p_83 & 58.63 & 27.03 & 0.38 & 8.87 & 6.27 & 0.12 & 101.31 & 820 & 0.44 & 730 & 8.78 \\
\hline X609p_84 & 58.40 & 27.47 & 0.33 & 9.29 & 6.13 & 0.12 & 101.74 & 830 & 0.45 & 734 & 8.80 \\
\hline X609p_85 & 58.55 & 27.53 & 0.42 & 9.44 & 6.06 & 0.18 & 102.17 & 840 & 0.46 & 735 & 8.85 \\
\hline X609p_86 & 58.57 & 27.79 & 0.42 & 9.03 & 6.13 & 0.13 & 102.07 & 850 & 0.45 & 732 & 8.80 \\
\hline X609p_87 & 58.67 & 27.15 & 0.34 & 8.42 & 6.26 & 0.14 & 100.97 & 860 & 0.42 & 725 & 8.78 \\
\hline X609p_88 & 60.94 & 25.60 & 0.34 & 7.33 & 6.98 & 0.20 & 101.39 & 870 & 0.36 & 702 & 8.86 \\
\hline X609p_89 & 60.15 & 25.84 & 0.33 & 7.57 & 6.89 & 0.18 & 100.95 & 880 & 0.37 & 707 & 8.83 \\
\hline X609p_90 & 64.70 & 22.20 & 0.75 & 5.83 & 6.10 & 0.61 & 100.19 & 890 & 0.33 & 681 & 9.17 \\
\hline X609p_4 & 60.49 & 26.53 & 0.35 & 8.00 & 6.88 & 0.14 & 102.41 & 30 & 0.39 & 713 & 8.79 \\
\hline X609p_5 & 59.15 & 27.70 & 0.45 & 9.23 & 6.10 & 0.10 & 102.74 & 40 & 0.45 & 735 & 8.79 \\
\hline X609p_6 & 58.65 & 27.93 & 0.45 & 9.34 & 5.95 & 0.12 & 102.44 & 50 & 0.46 & 737 & 8.82 \\
\hline X609p_7 & 58.68 & 28.10 & 0.49 & 9.73 & 5.82 & 0.13 & 102.95 & 60 & 0.48 & 740 & 8.86 \\
\hline X609p_8 & 58.94 & 27.70 & 0.40 & 9.13 & 5.90 & 0.15 & 102.22 & 70 & 0.46 & 735 & 8.83 \\
\hline X609p_9 & 59.29 & 27.73 & 0.48 & 9.09 & 5.98 & 0.11 & 102.68 & 80 & 0.45 & 735 & 8.80 \\
\hline X609p_10 & 60.45 & 26.75 & 0.34 & 7.94 & 6.79 & 0.16 & 102.43 & 90 & 0.39 & 713 & 8.80 \\
\hline X609p_11 & 60.30 & 27.09 & 0.32 & 8.59 & 6.43 & 0.16 & 102.88 & 100 & 0.42 & 724 & 8.79 \\
\hline X609p_12 & 59.26 & 27.39 & 0.34 & 8.59 & 6.44 & 0.16 & 102.19 & 110 & 0.42 & 724 & 8.80 \\
\hline X609p_13 & 59.10 & 27.33 & 0.40 & 8.95 & 6.16 & 0.13 & 102.06 & 120 & 0.44 & 731 & 8.79 \\
\hline X609p_14 & 58.92 & 27.42 & 0.41 & 9.22 & 6.09 & 0.12 & 102.18 & 130 & 0.45 & 734 & 8.80 \\
\hline X609p_15 & 58.90 & 27.77 & 0.36 & 9.35 & 6.12 & 0.13 & 102.63 & 140 & 0.45 & 735 & 8.81 \\
\hline X609p_16 & 59.15 & 27.71 & 0.34 & 8.89 & 6.14 & 0.14 & 102.37 & 150 & 0.44 & 731 & 8.80 \\
\hline X609p_18 & 59.61 & 27.32 & 0.39 & 8.90 & 6.23 & 0.12 & 102.58 & 170 & 0.44 & 730 & 8.78 \\
\hline X609p_19 & 59.16 & 27.69 & 0.38 & 8.86 & 6.23 & 0.15 & 102.48 & 180 & 0.44 & 729 & 8.80 \\
\hline X609p_20 & 58.82 & 26.64 & 0.31 & 8.52 & 6.30 & 0.12 & 100.72 & 190 & 0.42 & 726 & 8.77 \\
\hline X609p_21 & 58.27 & 26.55 & 0.39 & 8.48 & 6.23 & 0.16 & 100.09 & 200 & 0.43 & 726 & 8.80 \\
\hline X609p_22 & 58.82 & 27.36 & 0.35 & 8.94 & 6.18 & 0.16 & 101.80 & 210 & 0.44 & 730 & 8.81 \\
\hline X609p_23 & 59.98 & 26.76 & 0.37 & 8.20 & 6.42 & 0.12 & 101.85 & 220 & 0.41 & 722 & 8.77 \\
\hline X609p_24 & 60.93 & 26.38 & 0.36 & 7.94 & 6.69 & 0.21 & 102.52 & 230 & 0.39 & 713 & 8.83 \\
\hline X609p_25 & 69.46 & 17.78 & 1.15 & 4.30 & 4.16 & 1.15 & 98.00 & 240 & 0.33 & 664 & 9.66 \\
\hline X609p_26 & 57.81 & 28.06 & 0.38 & 9.62 & 5.72 & 0.11 & 101.69 & 250 & 0.48 & 741 & 8.86 \\
\hline X609p_27 & 58.21 & 27.30 & 0.42 & 8.82 & 6.21 & 0.14 & 101.10 & 260 & 0.44 & 729 & 8.80 \\
\hline X609p_28 & 59.54 & 26.26 & 0.29 & 8.48 & 6.22 & 0.12 & 100.91 & 270 & 0.43 & 727 & 8.78 \\
\hline X609p_29 & 57.75 & 26.47 & 0.31 & 8.65 & 6.37 & 0.15 & 99.69 & 280 & 0.43 & 726 & 8.79 \\
\hline X609p_30 & 58.98 & 27.05 & 0.39 & 8.66 & 6.37 & 0.14 & 101.58 & 290 & 0.43 & 726 & 8.78 \\
\hline X609p_31 & 59.35 & 27.09 & 0.35 & 8.56 & 6.30 & 0.16 & 101.81 & 300 & 0.42 & 726 & 8.80 \\
\hline X609p_32 & 58.62 & 27.05 & 0.41 & 8.29 & 6.37 & 0.16 & 100.89 & 310 & 0.41 & 722 & 8.79 \\
\hline X609p_33 & 58.07 & 26.58 & 0.39 & 8.35 & 6.47 & 0.12 & 99.99 & 320 & 0.41 & 723 & 8.77 \\
\hline X609p 34 & 58.13 & 26.58 & 0.37 & 8.18 & 6.39 & 0.14 & 99.79 & 330 & 0.41 & 721 & 8.79 \\
\hline X609p_35 & 57.86 & 26.25 & 0.32 & 7.87 & 6.34 & 0.17 & 98.81 & 340 & 0.40 & 718 & 8.80 \\
\hline X609p_36 & 58.17 & 26.51 & 0.34 & 8.43 & 6.38 & 0.17 & 100.00 & 350 & 0.42 & 723 & 8.80 \\
\hline X609p_37 & 59.41 & 26.39 & 0.28 & 8.33 & 6.40 & 0.13 & 100.95 & 360 & 0.41 & 723 & 8.78 \\
\hline X609p_38 & 58.37 & 26.24 & 0.30 & 8.09 & 6.25 & 0.09 & 99.34 & 370 & 0.41 & 724 & 8.76 \\
\hline X609p_39 & 58.15 & 26.72 & 0.31 & 8.49 & 6.28 & 0.13 & 100.08 & 380 & 0.42 & 726 & 8.78 \\
\hline X609p_40 & 58.04 & 26.63 & 0.33 & 8.36 & 6.28 & 0.12 & 99.77 & 390 & 0.42 & 725 & 8.78 \\
\hline X609p_41 & 59.40 & 26.81 & 0.39 & 8.01 & 6.82 & 0.15 & 101.57 & 400 & 0.39 & 714 & 8.79 \\
\hline X609p_42 & 59.44 & 26.85 & 0.43 & 8.33 & 6.61 & 0.17 & 101.83 & 410 & 0.41 & 719 & 8.80 \\
\hline X609p_43 & 59.61 & 26.71 & 0.33 & 8.14 & 6.72 & 0.16 & 101.65 & 420 & 0.40 & 716 & 8.79 \\
\hline X609p_44 & 60.63 & 26.61 & 0.39 & 8.17 & 6.72 & 0.17 & 102.69 & 430 & 0.40 & 716 & 8.80 \\
\hline X609p_45 & 59.70 & 26.65 & 0.46 & 8.34 & 6.36 & 0.14 & 101.66 & 440 & 0.42 & 723 & 8.78 \\
\hline X609p_46 & 60.30 & 27.02 & 0.36 & 8.51 & 6.50 & 0.12 & 102.81 & 450 & 0.42 & 724 & 8.77 \\
\hline X609p_47 & 59.99 & 27.33 & 0.43 & 8.67 & 6.32 & 0.16 & 102.90 & 460 & 0.43 & 727 & 8.79 \\
\hline X609p_48 & 59.29 & 27.05 & 0.43 & 8.49 & 6.61 & 0.15 & 102.02 & 470 & 0.41 & 722 & 8.78 \\
\hline X609p_49 & 59.03 & 26.99 & 0.50 & 8.72 & 6.41 & 0.13 & 101.78 & 480 & 0.43 & 727 & 8.78 \\
\hline X609p_50 & 58.79 & 27.37 & 0.40 & 8.72 & 6.29 & 0.14 & 101.70 & 490 & 0.43 & 728 & 8.79 \\
\hline X609p_51 & 58.78 & 27.24 & 0.48 & 8.75 & 6.38 & 0.13 & 101.76 & 500 & 0.43 & 727 & 8.78 \\
\hline
\end{tabular}


Table A3.10 continued

\begin{tabular}{|c|c|c|c|c|c|c|c|c|c|c|c|}
\hline Sample & $\mathrm{SiO}_{2}$ & $\mathrm{Al}_{2} \mathrm{O}_{3}$ & $\mathrm{FeO}$ & $\mathrm{CaO}$ & $\mathrm{Na}_{2} \mathrm{O}$ & $\mathrm{K}_{2} \mathrm{O}$ & Total & $\begin{array}{l}\text { Dist } \\
(\mu \mathrm{m})\end{array}$ & X An & $\begin{array}{c}\text { Temp } \\
{ }^{\circ} \mathrm{C} \\
\end{array}$ & $\begin{array}{l}\mathrm{H}_{2} \mathrm{O} \\
\mathrm{wt} \% \\
\end{array}$ \\
\hline X609p_53 & 58.98 & 26.69 & 0.53 & 8.32 & 6.41 & 0.17 & 101.09 & 520 & 0.41 & 722 & 8.80 \\
\hline X609p_54 & 59.72 & 27.09 & 0.43 & 8.61 & 6.60 & 0.15 & 102.60 & 530 & 0.42 & 723 & 8.79 \\
\hline X609p_55 & 60.58 & 26.63 & 0.45 & 7.81 & 6.77 & 0.14 & 102.38 & 540 & 0.39 & 713 & 8.79 \\
\hline X609p_56 & 60.27 & 26.44 & 0.38 & 7.73 & 6.67 & 0.18 & 101.67 & 550 & 0.39 & 712 & 8.82 \\
\hline X609p_57 & 60.16 & 26.65 & 0.31 & 7.94 & 6.85 & 0.17 & 102.08 & 560 & 0.39 & 712 & 8.81 \\
\hline X609p_58 & 59.00 & 26.80 & 0.33 & 8.34 & 6.29 & 0.14 & 100.90 & 570 & 0.42 & 724 & 8.78 \\
\hline X609p_59 & 58.51 & 26.89 & 0.50 & 8.49 & 6.16 & 0.16 & 100.71 & 580 & 0.43 & 727 & 8.80 \\
\hline X609p_60 & 59.34 & 26.92 & 0.46 & 8.49 & 6.49 & 0.15 & 101.85 & 590 & 0.42 & 723 & 8.79 \\
\hline X609p_61 & 59.93 & 26.88 & 0.32 & 8.39 & 6.54 & 0.17 & 102.22 & 600 & 0.41 & 721 & 8.80 \\
\hline X609p_62 & 59.77 & 26.70 & 0.40 & 8.31 & 6.41 & 0.13 & 101.71 & 610 & 0.41 & 723 & 8.78 \\
\hline X609p_63 & 60.41 & 26.63 & 0.46 & 7.99 & 6.90 & 0.13 & 102.52 & 620 & 0.39 & 713 & 8.79 \\
\hline X609p_64 & 59.77 & 26.75 & 0.35 & 8.41 & 6.43 & 0.18 & 101.90 & 630 & 0.42 & 722 & 8.80 \\
\hline X609p_65 & 58.58 & 27.56 & 0.33 & 9.08 & 6.08 & 0.13 & 101.76 & 640 & 0.45 & 733 & 8.81 \\
\hline X609p_66 & 58.79 & 27.22 & 0.31 & 8.58 & 6.36 & 0.13 & 101.40 & 650 & 0.42 & 726 & 8.78 \\
\hline X609p_67 & 59.62 & 26.79 & 0.33 & 8.30 & 6.73 & 0.12 & 101.89 & 660 & 0.40 & 719 & 8.77 \\
\hline X609p_68 & 59.01 & 27.11 & 0.42 & 8.45 & 6.44 & 0.13 & 101.57 & 670 & 0.42 & 724 & 8.78 \\
\hline X609p_69 & 59.54 & 27.11 & 0.48 & 8.70 & 6.34 & 0.15 & 102.32 & 680 & 0.43 & 727 & 8.79 \\
\hline X609p_70 & 59.11 & 27.65 & 0.34 & 8.98 & 6.25 & 0.11 & 102.42 & 690 & 0.44 & 731 & 8.78 \\
\hline X609p_71 & 59.00 & 27.11 & 0.35 & 8.61 & 6.52 & 0.11 & 101.70 & 700 & 0.42 & 725 & 8.77 \\
\hline X609p_72 & 59.44 & 27.17 & 0.40 & 8.94 & 6.22 & 0.14 & 102.31 & 710 & 0.44 & 730 & 8.79 \\
\hline X609p_73 & 58.96 & 27.15 & 0.46 & 8.85 & 6.39 & 0.16 & 101.97 & 720 & 0.43 & 727 & 8.80 \\
\hline X609p_74 & 58.71 & 27.41 & 0.41 & 8.76 & 6.15 & 0.15 & 101.59 & 730 & 0.44 & 729 & 8.80 \\
\hline X609p_75 & 59.25 & 26.96 & 0.31 & 8.47 & 6.34 & 0.14 & 101.48 & 740 & 0.42 & 725 & 8.79 \\
\hline X609p_76 & 58.94 & 26.87 & 0.40 & 8.36 & 6.52 & 0.23 & 101.32 & 750 & 0.41 & 719 & 8.83 \\
\hline X609p_77 & 59.24 & 27.07 & 0.30 & 8.67 & 6.49 & 0.13 & 101.90 & 760 & 0.42 & 725 & 8.78 \\
\hline X609p_78 & 59.61 & 26.67 & 0.33 & 8.28 & 6.55 & 0.17 & 101.61 & 770 & 0.41 & 720 & 8.80 \\
\hline X609p_79 & 60.36 & 26.56 & 0.38 & 7.91 & 6.88 & 0.18 & 102.28 & 780 & 0.38 & 711 & 8.82 \\
\hline X609p_80 & 60.33 & 26.65 & 0.38 & 7.95 & 6.63 & 0.16 & 102.11 & 790 & 0.39 & 715 & 8.80 \\
\hline X609p_81 & 60.01 & 26.13 & 0.41 & 7.62 & 6.94 & 0.17 & 101.28 & 800 & 0.37 & 707 & 8.83 \\
\hline X609p_82 & 59.28 & 26.57 & 0.31 & 8.47 & 6.61 & 0.12 & 101.37 & 810 & 0.41 & 722 & 8.77 \\
\hline X609p_83 & 58.63 & 27.03 & 0.38 & 8.87 & 6.27 & 0.12 & 101.31 & 820 & 0.44 & 730 & 8.78 \\
\hline X609p_84 & 58.40 & 27.47 & 0.33 & 9.29 & 6.13 & 0.12 & 101.74 & 830 & 0.45 & 734 & 8.80 \\
\hline X609p_85 & 58.55 & 27.53 & 0.42 & 9.44 & 6.06 & 0.18 & 102.17 & 840 & 0.46 & 735 & 8.85 \\
\hline X609p_86 & 58.57 & 27.79 & 0.42 & 9.03 & 6.13 & 0.13 & 102.07 & 850 & 0.45 & 732 & 8.80 \\
\hline X609p_87 & 58.67 & 27.15 & 0.34 & 8.42 & 6.26 & 0.14 & 100.97 & 860 & 0.42 & 725 & 8.78 \\
\hline X609p_88 & 60.94 & 25.60 & 0.34 & 7.33 & 6.98 & 0.20 & 101.39 & 870 & 0.36 & 702 & 8.86 \\
\hline X609p_89 & 60.15 & 25.84 & 0.33 & 7.57 & 6.89 & 0.18 & 100.95 & 880 & 0.37 & 707 & 8.83 \\
\hline X609p 90 & 64.70 & 22.20 & 0.75 & 5.83 & 6.10 & 0.61 & 100.19 & 890 & 0.33 & 681 & 9.17 \\
\hline
\end{tabular}

Major elements are given in $\mathrm{wt} \%, X \mathrm{An}$ are calculated on a mole fraction basis and temperatures (temp) and $\mathrm{H}_{2} \mathrm{O}$ concentration (are given in wt\%) are calculated using the Plagioclase-melt equilibria of Putirka (2005) and a pressure of $60 \mathrm{MPa}$. Distance represents the distance from the start of the profile and correlates with 'S' on the relevant backscattered electron image 


\section{Appendix 3}

Table A3.11: Major element compositions (given in wt\%) of Taupo plagioclase crystals 
Appendix 3

Table A3.11

\begin{tabular}{|c|c|c|c|c|c|c|c|c|c|c|c|}
\hline Sample & $\mathrm{SiO}_{2}$ & $\mathrm{Al}_{2} \mathrm{O}_{3}$ & $\mathrm{FeO}$ & $\mathrm{CaO}$ & $\mathrm{Na}_{2} \mathrm{O}$ & $\mathrm{K}_{2} \mathrm{O}$ & Total & $\begin{array}{r}\text { Dist } \\
(\mu \mathrm{m})\end{array}$ & $\begin{array}{c}X \\
\text { An } \\
\end{array}$ & $\begin{array}{c}\text { Temp } \\
\left({ }^{\circ} \mathrm{C}\right)\end{array}$ & $\begin{array}{c}\mathrm{H}_{2} \mathrm{O} \\
(\mathrm{wt} \%) \\
\end{array}$ \\
\hline TA1a_2 & 58.23 & 25.74 & 0.33 & 8.50 & 6.82 & 0.27 & 99.89 & 20 & 0.40 & 762 & 8.27 \\
\hline TAla 3 & 60.13 & 25.45 & 0.34 & 8.18 & 6.88 & 0.26 & 101.23 & 30 & 0.39 & 758 & 8.27 \\
\hline TA1a 4 & 58.95 & 25.99 & 0.39 & 8.72 & 6.59 & 0.31 & 100.94 & 40 & 0.42 & 766 & 8.31 \\
\hline TA1a 5 & 58.14 & 26.09 & 0.35 & 8.56 & 6.84 & 0.25 & 100.24 & 50 & 0.40 & 763 & 8.27 \\
\hline TA1a 6 & 58.66 & 25.65 & 0.31 & 8.44 & 6.69 & 0.29 & 100.04 & 60 & 0.40 & 763 & 8.29 \\
\hline TAla 7 & 57.59 & 25.54 & 0.31 & 8.48 & 6.62 & 0.27 & 98.81 & 70 & 0.41 & 765 & 8.28 \\
\hline TAla 8 & 58.57 & 26.81 & 0.33 & 9.03 & 6.51 & 0.23 & 101.48 & 80 & 0.43 & 773 & 8.28 \\
\hline TA1a 9 & 58.24 & 26.64 & 0.33 & 9.00 & 6.49 & 0.23 & 100.92 & 90 & 0.43 & 773 & 8.28 \\
\hline TA1a 10 & 58.61 & 26.36 & 0.30 & 8.94 & 6.41 & 0.25 & 100.85 & 100 & 0.43 & 772 & 8.30 \\
\hline TA1a 11 & 58.32 & 26.47 & 0.33 & 8.84 & 6.52 & 0.26 & 100.73 & 110 & 0.42 & 770 & 8.29 \\
\hline TA1a 12 & 59.48 & 25.91 & 0.31 & 8.54 & 6.89 & 0.31 & 101.44 & 120 & 0.40 & 761 & 8.29 \\
\hline TA1a 13 & 57.89 & 25.96 & 0.28 & 8.84 & 6.71 & 0.26 & 99.94 & 130 & 0.42 & 768 & 8.28 \\
\hline TA1a 14 & 57.87 & 26.27 & 0.31 & 9.03 & 6.53 & 0.23 & 100.24 & 140 & 0.43 & 772 & 8.28 \\
\hline TA1a 15 & 57.71 & 26.60 & 0.27 & 8.75 & 6.36 & 0.26 & 99.94 & 150 & 0.43 & 771 & 8.30 \\
\hline TA1a 16 & 58.07 & 26.73 & 0.41 & 9.03 & 6.55 & 0.28 & 101.06 & 160 & 0.43 & 771 & 8.31 \\
\hline TA1a 17 & 58.74 & 26.31 & 0.28 & 9.00 & 6.53 & 0.26 & 101.11 & 170 & 0.43 & 771 & 8.30 \\
\hline TA1a 18 & 58.90 & 26.14 & 0.44 & 8.95 & 6.60 & 0.24 & 101.27 & 180 & 0.42 & 770 & 8.28 \\
\hline TA1a 19 & 57.62 & 25.48 & 0.32 & 8.64 & 6.50 & 0.27 & 98.83 & 190 & 0.42 & 768 & 8.29 \\
\hline TA1a 20 & 58.71 & 26.20 & 0.36 & 8.87 & 6.41 & 0.28 & 100.84 & 200 & 0.43 & 771 & 8.31 \\
\hline TA1a 21 & 58.23 & 25.81 & 0.33 & 8.64 & 6.68 & 0.30 & 99.98 & 210 & 0.41 & 765 & 8.30 \\
\hline TA1a 22 & 58.32 & 26.06 & 0.27 & 8.70 & 6.60 & 0.24 & 100.18 & 220 & 0.42 & 768 & 8.27 \\
\hline TA1a 23 & 58.96 & 26.86 & 0.25 & 8.63 & 6.56 & 0.26 & 101.51 & 230 & 0.41 & 767 & 8.28 \\
\hline TA1a 24 & 58.19 & 26.47 & 0.44 & 8.55 & 6.62 & 0.25 & 100.52 & 240 & 0.41 & 766 & 8.27 \\
\hline TA1a 25 & 59.15 & 26.29 & 0.33 & 8.45 & 6.79 & 0.23 & 101.23 & 250 & 0.40 & 763 & 8.26 \\
\hline TA1a 26 & 60.05 & 25.75 & 0.34 & 8.33 & 6.88 & 0.25 & 101.59 & 260 & 0.40 & 760 & 8.26 \\
\hline TA1a 27 & 59.52 & 25.51 & 0.28 & 7.89 & 6.90 & 0.28 & 100.37 & 270 & 0.38 & 754 & 8.28 \\
\hline TA1a 28 & 59.66 & 25.39 & 0.32 & 7.74 & 6.93 & 0.30 & 100.34 & 280 & 0.37 & 750 & 8.29 \\
\hline TA1a 29 & 59.71 & 25.41 & 0.30 & 7.86 & 6.93 & 0.28 & 100.48 & 290 & 0.38 & 753 & 8.28 \\
\hline TA1a 30 & 59.56 & 25.50 & 0.25 & 7.74 & 7.15 & 0.28 & 100.47 & 300 & 0.37 & 748 & 8.28 \\
\hline TA1a 31 & 59.29 & 25.29 & 0.22 & 7.61 & 7.14 & 0.34 & 99.89 & 310 & 0.36 & 745 & 8.32 \\
\hline TA1a 32 & 59.53 & 25.44 & 0.30 & 7.83 & 7.03 & 0.33 & 100.45 & 320 & 0.37 & 750 & 8.30 \\
\hline TA1a 33 & 60.50 & 25.27 & 0.31 & 7.88 & 7.07 & 0.33 & 101.34 & 330 & 0.37 & 750 & 8.30 \\
\hline TA1a 34 & 60.26 & 25.17 & 0.26 & 7.67 & 6.92 & 0.31 & 100.59 & 340 & 0.37 & 749 & 8.30 \\
\hline TA1a 35 & 59.54 & 24.79 & 0.28 & 7.73 & 7.02 & 0.29 & 99.65 & 350 & 0.37 & 749 & 8.29 \\
\hline TA1a 36 & 59.44 & 25.24 & 0.22 & 7.60 & 7.06 & 0.33 & 99.90 & 360 & 0.37 & 746 & 8.31 \\
\hline TA1a 37 & 59.05 & 25.00 & 0.24 & 7.53 & 7.08 & 0.41 & 99.31 & 370 & 0.36 & 743 & 8.36 \\
\hline TA1a 38 & 58.93 & 25.77 & 0.47 & 8.13 & 7.06 & 0.30 & 100.66 & 380 & 0.38 & 754 & 8.28 \\
\hline TA1a 39 & 58.29 & 25.54 & 0.26 & 8.01 & 6.74 & 0.31 & 99.15 & 390 & 0.39 & 756 & 8.30 \\
\hline TA1a 41 & 60.65 & 25.49 & 0.24 & 7.89 & 6.96 & 0.34 & 101.58 & 410 & 0.38 & 751 & 8.31 \\
\hline TA1a 42 & 59.83 & 25.39 & 0.21 & 7.72 & 7.21 & 0.32 & 100.68 & 420 & 0.37 & 746 & 8.31 \\
\hline TA1a 43 & 59.74 & 25.72 & 0.26 & 7.77 & 6.82 & 0.33 & 100.63 & 430 & 0.38 & 752 & 8.31 \\
\hline TA1a 44 & 59.20 & 25.63 & 0.20 & 8.12 & 6.96 & 0.30 & 100.40 & 440 & 0.39 & 755 & 8.29 \\
\hline TA1a 45 & 59.20 & 25.53 & 0.29 & 8.06 & 6.94 & 0.30 & 100.32 & 450 & 0.38 & 755 & 8.29 \\
\hline TA1a 46 & 58.91 & 25.33 & 0.36 & 7.71 & 6.98 & 0.34 & 99.63 & 460 & 0.37 & 749 & 8.31 \\
\hline TA1a 47 & 59.45 & 25.29 & 0.29 & 7.65 & 7.11 & 0.31 & 100.10 & 470 & 0.37 & 747 & 8.30 \\
\hline TA1a 48 & 58.65 & 25.86 & 0.34 & 7.89 & 6.77 & 0.27 & 99.77 & 480 & 0.39 & 755 & 8.28 \\
\hline TA1a 49 & 59.11 & 25.78 & 0.34 & 7.92 & 7.00 & 0.32 & 100.45 & 490 & 0.38 & 751 & 8.30 \\
\hline TA1a 50 & 58.17 & 25.36 & 0.31 & 7.69 & 6.81 & 0.29 & 98.63 & 500 & 0.38 & 752 & 8.29 \\
\hline TA1a 51 & 59.15 & 25.99 & 0.31 & 8.10 & 6.94 & 0.27 & 100.76 & 510 & 0.39 & 756 & 8.27 \\
\hline TA1a 52 & 60.12 & 25.29 & 0.27 & 7.73 & 6.88 & 0.32 & 100.61 & 520 & 0.38 & 751 & 8.30 \\
\hline TA1a 53 & 59.96 & 25.59 & 0.30 & 7.95 & 6.58 & 0.28 & 100.66 & 530 & 0.39 & 759 & 8.29 \\
\hline TA1a 54 & 60.40 & 25.53 & 0.16 & 7.89 & 6.97 & 0.32 & 101.27 & 540 & 0.38 & 752 & 8.30 \\
\hline TA1a 55 & 60.16 & 25.36 & 0.23 & 7.84 & 6.87 & 0.30 & 100.77 & 550 & 0.38 & 753 & 8.29 \\
\hline TA1a 56 & 58.88 & 25.78 & 0.26 & 8.19 & 6.88 & 0.30 & 100.28 & 560 & 0.39 & 757 & 8.28 \\
\hline TA1a 57 & 59.24 & 25.79 & 0.23 & 7.98 & 6.96 & 0.25 & 100.45 & 570 & 0.38 & 755 & 8.26 \\
\hline TA1a 58 & 59.55 & 26.45 & 0.28 & 7.97 & 7.04 & 0.29 & 101.58 & 580 & 0.38 & 752 & 8.28 \\
\hline TA1a 59 & 58.94 & 25.86 & 0.27 & 8.05 & 7.00 & 0.32 & 100.44 & 590 & 0.38 & 753 & 8.30 \\
\hline TA1a 60 & 59.65 & 25.57 & 0.24 & 8.31 & 6.82 & 0.27 & 100.86 & 600 & 0.40 & 760 & 8.27 \\
\hline TA1a 61 & 59.30 & 26.07 & 0.25 & 7.79 & 6.91 & 0.27 & 100.59 & 610 & 0.38 & 752 & 8.28 \\
\hline TA1a 63 & 58.12 & 26.08 & 0.40 & 7.96 & 6.79 & 0.28 & 99.61 & 630 & 0.39 & 756 & 8.28 \\
\hline TA1a 64 & 59.39 & 26.65 & 0.27 & 7.96 & 6.75 & 0.28 & 101.30 & 640 & 0.39 & 756 & 8.28 \\
\hline TA1a 65 & 58.61 & 26.50 & 0.36 & 8.06 & 7.12 & 0.27 & 100.91 & 650 & 0.38 & 753 & 8.27 \\
\hline TA1a 66 & 59.95 & 26.28 & 0.28 & 8.00 & 7.10 & 0.29 & 101.90 & 660 & 0.38 & 752 & 8.28 \\
\hline TA1a 67 & 59.99 & 26.08 & 0.32 & 7.70 & 7.05 & 0.27 & 101.41 & 670 & 0.37 & 749 & 8.28 \\
\hline TA1a 68 & 58.32 & 26.23 & 0.28 & 7.91 & 7.00 & 0.28 & 100.02 & 680 & 0.38 & 752 & 8.28 \\
\hline TA1a 69 & 59.97 & 26.27 & 0.28 & 7.68 & 7.17 & 0.32 & 101.68 & 690 & 0.37 & 746 & 8.30 \\
\hline TA1a 70 & 59.82 & 26.10 & 0.28 & 7.69 & 7.29 & 0.33 & 101.50 & 700 & 0.36 & 744 & 8.31 \\
\hline TA1a 71 & 59.88 & 25.94 & 0.26 & 7.34 & 7.39 & 0.30 & 101.11 & 710 & 0.35 & 738 & 8.32 \\
\hline TA1a 72 & 59.79 & 26.22 & 0.20 & 7.27 & 7.40 & 0.35 & 101.23 & 720 & 0.34 & 736 & 8.35 \\
\hline TA1a 73 & 59.88 & 25.95 & 0.28 & 7.51 & 7.32 & 0.33 & 101.27 & 730 & 0.36 & 741 & 8.32 \\
\hline TA1a 74 & 60.53 & 25.74 & 0.30 & 7.31 & 7.55 & 0.32 & 101.73 & 740 & 0.34 & 735 & 8.33 \\
\hline TA1a 78 & 58.79 & 25.59 & 0.25 & 7.25 & 7.35 & 0.31 & 99.53 & 780 & 0.35 & 737 & 8.32 \\
\hline TA1a 79 & 60.22 & 25.99 & 0.32 & 7.62 & 7.39 & 0.38 & 101.92 & 790 & 0.36 & 741 & 8.34 \\
\hline TA1a 80 & 59.64 & 25.85 & 0.23 & 7.44 & 7.52 & 0.34 & 101.01 & 800 & 0.35 & 737 & 8.34 \\
\hline TA1a 84 & 60.19 & 25.59 & 0.39 & 7.48 & 7.37 & 0.33 & 101.34 & 840 & 0.35 & 740 & 8.33 \\
\hline TA1a 85 & 59.98 & 25.77 & 0.31 & 7.57 & 7.45 & 0.33 & 101.41 & 850 & 0.35 & 740 & 8.32 \\
\hline
\end{tabular}


Table A3.11 continued

\begin{tabular}{|c|c|c|c|c|c|c|c|c|c|c|c|}
\hline Sample & $\mathrm{SiO}_{2}$ & $\mathrm{Al}_{2} \mathrm{O}_{3}$ & $\mathrm{FeO}$ & $\mathrm{CaO}$ & $\mathrm{Na}_{2} \mathrm{O}$ & $\mathrm{K}_{2} \mathrm{O}$ & Total & $\begin{array}{l}\text { Dist } \\
(\mu \mathrm{m})\end{array}$ & $\begin{array}{c}X \\
\text { An } \\
\end{array}$ & $\begin{array}{c}\text { Temp } \\
\left({ }^{\circ} \mathrm{C}\right)\end{array}$ & $\begin{array}{c}\mathrm{H}_{2} \mathrm{O} \\
\left(\mathrm{wt}^{\circ} \%\right) \\
\end{array}$ \\
\hline TA1a 86 & 59.38 & 26.01 & 0.19 & 7.60 & 7.17 & 0.31 & 100.65 & 860 & 0.36 & 745 & 8.31 \\
\hline TA1a 87 & 59.05 & 25.88 & 0.37 & 7.77 & 7.41 & 0.27 & 100.75 & 870 & 0.36 & 745 & 8.28 \\
\hline TA1a 88 & 59.55 & 26.10 & 0.33 & 7.46 & 7.25 & 0.35 & 101.04 & 880 & 0.36 & 741 & 8.33 \\
\hline TA1a 89 & 59.55 & 25.84 & 0.27 & 7.68 & 7.34 & 0.30 & 100.98 & 890 & 0.36 & 744 & 8.30 \\
\hline TA1a 90 & 59.73 & 26.17 & 0.31 & 7.58 & 7.24 & 0.29 & 101.32 & 900 & 0.36 & 744 & 8.30 \\
\hline TA1a 91 & 59.78 & 25.98 & 0.26 & 7.95 & 7.08 & 0.34 & 101.39 & 910 & 0.38 & 750 & 8.31 \\
\hline TA1a 93 & 60.33 & 25.68 & 0.30 & 7.32 & 7.17 & 0.36 & 101.16 & 930 & 0.35 & 740 & 8.34 \\
\hline TA1a 94 & 59.59 & 25.86 & 0.39 & 7.48 & 7.26 & 0.33 & 100.91 & 940 & 0.36 & 741 & 8.32 \\
\hline TA1a 96 & 59.49 & 25.51 & 0.21 & 7.35 & 7.40 & 0.32 & 100.28 & 960 & 0.35 & 738 & 8.33 \\
\hline TA1a 97 & 60.31 & 26.11 & 0.25 & 7.39 & 7.42 & 0.36 & 101.83 & 970 & 0.35 & 737 & 8.35 \\
\hline TA1a 98 & 59.22 & 26.19 & 0.32 & 7.30 & 7.25 & 0.31 & 100.58 & 980 & 0.35 & 739 & 8.32 \\
\hline TA1a 99 & 59.27 & 26.22 & 0.30 & 7.48 & 7.31 & 0.32 & 100.89 & 990 & 0.35 & 741 & 8.32 \\
\hline TA1a 100 & 60.35 & 25.66 & 0.19 & 7.60 & 7.41 & 0.29 & 101.50 & 1000 & 0.36 & 742 & 8.30 \\
\hline TA1a 101 & 60.22 & 25.67 & 0.30 & 7.52 & 7.42 & 0.35 & 101.47 & 1010 & 0.35 & 739 & 8.33 \\
\hline TA1a 103 & 60.02 & 25.87 & 0.33 & 7.41 & 7.40 & 0.29 & 101.33 & 1030 & 0.35 & 740 & 8.31 \\
\hline TA1a 104 & 60.20 & 25.98 & 0.31 & 7.41 & 7.35 & 0.35 & 101.60 & 1040 & 0.35 & 739 & 8.34 \\
\hline TA1a 105 & 59.40 & 25.82 & 0.24 & 7.37 & 7.28 & 0.34 & 100.44 & 1050 & 0.35 & 740 & 8.33 \\
\hline TA1a 106 & 59.71 & 25.92 & 0.27 & 7.40 & 7.53 & 0.30 & 101.12 & 1060 & 0.35 & 737 & 8.32 \\
\hline TA1a 107 & 59.63 & 26.02 & 0.30 & 7.32 & 7.58 & 0.38 & 101.22 & 1070 & 0.34 & 734 & 8.37 \\
\hline TA1a 108 & 59.53 & 25.13 & 0.34 & 7.10 & 7.15 & 0.28 & 99.53 & 1080 & 0.35 & 739 & 8.31 \\
\hline TA1a 110 & 60.33 & 25.64 & 0.24 & 7.51 & 7.55 & 0.35 & 101.62 & 1100 & 0.35 & 737 & 8.34 \\
\hline TA1a 112 & 60.71 & 25.46 & 0.25 & 7.29 & 7.60 & 0.34 & 101.65 & 1120 & 0.34 & 734 & 8.35 \\
\hline TA1a 114 & 60.65 & 25.79 & 0.34 & 7.26 & 7.54 & 0.37 & 101.95 & 1140 & 0.34 & 733 & 8.36 \\
\hline TA1a 118 & 59.94 & 25.41 & 0.25 & 7.24 & 7.26 & 0.33 & 100.42 & 1180 & 0.35 & 738 & 8.33 \\
\hline TA1a 119 & 57.97 & 24.95 & 0.35 & 6.67 & 7.27 & 0.40 & 97.59 & 1190 & 0.33 & 727 & 8.41 \\
\hline TA1a 121 & 60.80 & 25.69 & 0.26 & 7.16 & 7.56 & 0.37 & 101.84 & 1210 & 0.34 & 731 & 8.37 \\
\hline TA1c 3 & 58.65 & 26.88 & 0.35 & 9.02 & 6.47 & 0.29 & 101.65 & 20 & 0.43 & 771 & 8.32 \\
\hline TA1c 4 & 58.42 & 26.78 & 0.34 & 8.81 & 6.39 & 0.28 & 101.03 & 30 & 0.43 & 770 & 8.31 \\
\hline TA1c 5 & 58.84 & 26.82 & 0.33 & 8.94 & 6.64 & 0.24 & 101.82 & 40 & 0.42 & 770 & 8.28 \\
\hline TA1c 6 & 58.87 & 26.84 & 0.30 & 8.97 & 6.41 & 0.21 & 101.60 & 50 & 0.43 & 774 & 8.28 \\
\hline TA1c 7 & 58.93 & 27.02 & 0.28 & 8.90 & 6.42 & 0.25 & 101.80 & 60 & 0.43 & 772 & 8.30 \\
\hline TA1c 8 & 58.57 & 26.83 & 0.33 & 8.56 & 6.59 & 0.29 & 101.16 & 70 & 0.41 & 765 & 8.30 \\
\hline TA1c 9 & 59.80 & 26.21 & 0.33 & 8.08 & 6.74 & 0.24 & 101.41 & 80 & 0.39 & 759 & 8.26 \\
\hline TA1c 10 & 60.38 & 25.54 & 0.27 & 7.39 & 7.03 & 0.32 & 100.93 & 90 & 0.36 & 744 & 8.31 \\
\hline TA1c 11 & 60.47 & 25.47 & 0.38 & 7.48 & 7.08 & 0.33 & 101.21 & 100 & 0.36 & 744 & 8.32 \\
\hline TA1c 12 & 59.29 & 26.00 & 0.34 & 8.36 & 6.62 & 0.29 & 100.91 & 110 & 0.40 & 762 & 8.29 \\
\hline TA1c 13 & 59.17 & 26.29 & 0.40 & 8.20 & 6.54 & 0.30 & 100.90 & 120 & 0.40 & 761 & 8.30 \\
\hline TA1c 14 & 58.91 & 26.23 & 0.40 & 8.62 & 6.71 & 0.28 & 101.15 & 130 & 0.41 & 764 & 8.29 \\
\hline TAlc 15 & 58.93 & 26.15 & 0.26 & 8.44 & 6.72 & 0.32 & 100.83 & 140 & 0.40 & 761 & 8.31 \\
\hline TA1c 16 & 58.57 & 25.90 & 0.36 & 8.20 & 6.61 & 0.31 & 99.96 & 150 & 0.40 & 760 & 8.30 \\
\hline TA1c 17 & 59.53 & 25.33 & 0.27 & 7.67 & 6.90 & 0.33 & 100.02 & 160 & 0.37 & 749 & 8.31 \\
\hline TA1c 18 & 60.67 & 25.73 & 0.36 & 7.36 & 7.04 & 0.32 & 101.48 & 170 & 0.36 & 743 & 8.31 \\
\hline TAlc 19 & 60.10 & 25.52 & 0.37 & 7.47 & 7.05 & 0.30 & 100.81 & 180 & 0.36 & 745 & 8.30 \\
\hline TA1c 20 & 59.82 & 25.64 & 0.37 & 7.76 & 7.13 & 0.37 & 101.09 & 190 & 0.37 & 746 & 8.33 \\
\hline TA1c 21 & 59.63 & 25.94 & 0.36 & 7.73 & 6.98 & 0.31 & 100.95 & 200 & 0.37 & 750 & 8.30 \\
\hline TA1c 22 & 57.83 & 25.19 & 0.31 & 7.80 & 6.82 & 0.32 & 98.27 & 210 & 0.38 & 752 & 8.30 \\
\hline TA1c 23 & 59.55 & 25.27 & 0.17 & 7.55 & 7.09 & 0.36 & 99.98 & 220 & 0.36 & 744 & 8.33 \\
\hline TA1c 24 & 60.04 & 25.96 & 0.38 & 7.90 & 6.77 & 0.32 & 101.36 & 230 & 0.38 & 754 & 8.30 \\
\hline TA1c 25 & 59.46 & 26.10 & 0.18 & 7.88 & 6.94 & 0.27 & 100.82 & 240 & 0.38 & 753 & 8.27 \\
\hline TA1c 26 & 59.26 & 25.83 & 0.34 & 8.15 & 6.81 & 0.32 & 100.71 & 250 & 0.39 & 757 & 8.30 \\
\hline TA1c 27 & 59.14 & 26.34 & 0.37 & 8.45 & 6.68 & 0.26 & 101.24 & 260 & 0.41 & 764 & 8.27 \\
\hline TA1c 28 & 59.54 & 26.00 & 0.30 & 8.24 & 6.86 & 0.26 & 101.20 & 270 & 0.39 & 759 & 8.27 \\
\hline TA1c 29 & 59.66 & 26.14 & 0.28 & 8.29 & 6.72 & 0.29 & 101.37 & 280 & 0.40 & 761 & 8.29 \\
\hline TA1c 30 & 59.53 & 26.08 & 0.35 & 8.15 & 6.85 & 0.27 & 101.23 & 290 & 0.39 & 758 & 8.27 \\
\hline TA1c 31 & 60.11 & 26.03 & 0.21 & 7.93 & 7.03 & 0.28 & 101.60 & 300 & 0.38 & 752 & 8.28 \\
\hline TA1c 32 & 60.42 & 25.77 & 0.33 & 7.87 & 7.06 & 0.32 & 101.78 & 310 & 0.37 & 750 & 8.30 \\
\hline TA1c 33 & 59.56 & 25.93 & 0.26 & 7.94 & 7.03 & 0.30 & 101.03 & 320 & 0.38 & 752 & 8.29 \\
\hline TA1c 34 & 59.53 & 26.45 & 0.24 & 8.36 & 7.08 & 0.28 & 101.93 & 330 & 0.39 & 757 & 8.27 \\
\hline TA1c 36 & 59.64 & 25.91 & 0.39 & 8.19 & 6.77 & 0.30 & 101.19 & 350 & 0.39 & 758 & 8.29 \\
\hline TA1c 37 & 59.33 & 25.79 & 0.35 & 8.01 & 6.83 & 0.31 & 100.62 & 360 & 0.39 & 755 & 8.30 \\
\hline TA1c 38 & 59.86 & 26.32 & 0.24 & 8.10 & 6.98 & 0.28 & 101.77 & 370 & 0.38 & 755 & 8.27 \\
\hline TA1c 39 & 59.99 & 26.17 & 0.23 & 7.96 & 6.98 & 0.30 & 101.63 & 380 & 0.38 & 753 & 8.29 \\
\hline TA1c 41 & 59.64 & 26.31 & 0.23 & 8.10 & 6.93 & 0.29 & 101.50 & 400 & 0.39 & 755 & 8.28 \\
\hline TA1c 42 & 59.85 & 26.10 & 0.31 & 8.04 & 6.74 & 0.26 & 101.29 & 410 & 0.39 & 758 & 8.27 \\
\hline TA1c 43 & 59.33 & 26.26 & 0.29 & 8.14 & 6.63 & 0.31 & 100.96 & 420 & 0.40 & 759 & 8.30 \\
\hline TA1c 44 & 58.65 & 26.62 & 0.30 & 8.80 & 6.44 & 0.25 & 101.08 & 430 & 0.42 & 770 & 8.29 \\
\hline TA1c 45 & 59.23 & 26.48 & 0.32 & 8.52 & 6.65 & 0.29 & 101.49 & 440 & 0.41 & 764 & 8.29 \\
\hline TA1c 46 & 59.17 & 26.24 & 0.29 & 8.62 & 6.71 & 0.33 & 101.35 & 450 & 0.41 & 763 & 8.32 \\
\hline TA1c 47 & 59.46 & 26.50 & 0.31 & 8.46 & 6.70 & 0.24 & 101.66 & 460 & 0.41 & 764 & 8.26 \\
\hline TA1c 48 & 59.44 & 26.51 & 0.36 & 8.56 & 6.50 & 0.26 & 101.64 & 470 & 0.41 & 767 & 8.29 \\
\hline TA1c 49 & 58.99 & 26.30 & 0.33 & 8.18 & 6.69 & 0.27 & 100.76 & 480 & 0.40 & 760 & 8.27 \\
\hline TA1c 51 & 58.74 & 26.86 & 0.26 & 8.89 & 6.43 & 0.22 & 101.40 & 500 & 0.43 & 773 & 8.28 \\
\hline TA1c 52 & 58.58 & 27.14 & 0.35 & 9.17 & 6.48 & 0.28 & 101.99 & 510 & 0.43 & 773 & 8.32 \\
\hline TA1c 53 & 58.16 & 26.67 & 0.36 & 8.99 & 6.52 & 0.26 & 100.96 & 520 & 0.43 & 771 & 8.30 \\
\hline TA1c 57 & 60.54 & 25.79 & 0.27 & 7.75 & 6.99 & 0.32 & 101.66 & 560 & 0.37 & 749 & 8.30 \\
\hline
\end{tabular}


Appendix 3

Table A3.11 continued

\begin{tabular}{|c|c|c|c|c|c|c|c|c|c|c|c|}
\hline Sample & $\mathrm{SiO}_{2}$ & $\mathrm{Al}_{2} \mathrm{O}_{3}$ & $\mathrm{FeO}$ & $\mathrm{CaO}$ & $\mathrm{Na}_{2} \mathrm{O}$ & $\mathrm{K}_{2} \mathrm{O}$ & Total & $\begin{array}{l}\text { Dist } \\
(\mu \mathrm{m})\end{array}$ & $\begin{array}{c}X \\
\text { An } \\
\end{array}$ & $\begin{array}{c}\text { Temp } \\
\left({ }^{\circ} \mathrm{C}\right)\end{array}$ & $\begin{array}{c}\mathrm{H}_{2} \mathrm{O} \\
\left(\mathrm{wt}^{\circ} \%\right) \\
\end{array}$ \\
\hline TA1c 58 & 59.84 & 25.92 & 0.32 & 7.93 & 6.83 & 0.32 & 101.17 & 570 & 0.38 & 754 & 8.30 \\
\hline TAlc 59 & 59.99 & 26.21 & 0.29 & 8.15 & 7.01 & 0.33 & 101.98 & 580 & 0.38 & 754 & 8.30 \\
\hline TA1c 60 & 59.72 & 26.32 & 0.24 & 8.12 & 6.84 & 0.30 & 101.54 & 590 & 0.39 & 757 & 8.29 \\
\hline TA1c 61 & 59.79 & 26.49 & 0.15 & 8.10 & 7.06 & 0.32 & 101.91 & 600 & 0.38 & 753 & 8.30 \\
\hline TA1c 62 & 59.28 & 26.44 & 0.33 & 7.86 & 6.90 & 0.30 & 101.11 & 610 & 0.38 & 753 & 8.29 \\
\hline TA1c 63 & 58.83 & 26.44 & 0.25 & 8.14 & 6.80 & 0.28 & 100.74 & 620 & 0.39 & 758 & 8.28 \\
\hline TA1c 64 & 59.16 & 26.23 & 0.20 & 7.91 & 6.85 & 0.32 & 100.67 & 630 & 0.38 & 753 & 8.30 \\
\hline TA1c 65 & 59.28 & 26.51 & 0.24 & 7.84 & 7.14 & 0.29 & 101.30 & 640 & 0.37 & 749 & 8.29 \\
\hline TA1c 66 & 59.86 & 26.35 & 0.27 & 8.16 & 6.92 & 0.31 & 101.86 & 650 & 0.39 & 756 & 8.29 \\
\hline TA1c 68 & 59.90 & 26.55 & 0.28 & 7.80 & 7.05 & 0.33 & 101.91 & 670 & 0.37 & 749 & 8.31 \\
\hline TA1c 69 & 58.84 & 26.05 & 0.29 & 7.76 & 6.76 & 0.35 & 100.04 & 680 & 0.38 & 752 & 8.32 \\
\hline TA1c 70 & 59.60 & 26.34 & 0.23 & 7.81 & 7.19 & 0.31 & 101.47 & 690 & 0.37 & 748 & 8.30 \\
\hline TA1c 71 & 59.11 & 26.21 & 0.24 & 7.91 & 6.98 & 0.30 & 100.76 & 700 & 0.38 & 752 & 8.29 \\
\hline TA1c 72 & 58.67 & 26.61 & 0.33 & 8.09 & 6.98 & 0.27 & 100.95 & 710 & 0.38 & 755 & 8.27 \\
\hline TA1c 73 & 59.53 & 26.27 & 0.25 & 7.91 & 7.21 & 0.27 & 101.44 & 720 & 0.37 & 750 & 8.27 \\
\hline TA1c 75 & 59.81 & 26.13 & 0.26 & 7.82 & 7.15 & 0.32 & 101.50 & 740 & 0.37 & 748 & 8.30 \\
\hline TA1c 77 & 58.95 & 27.28 & 0.22 & 8.69 & 6.55 & 0.27 & 101.97 & 760 & 0.42 & 767 & 8.29 \\
\hline TA1c 78 & 57.14 & 27.64 & 0.24 & 9.62 & 6.40 & 0.20 & 101.24 & 770 & 0.45 & 780 & 8.31 \\
\hline TA1c 79 & 57.73 & 27.73 & 0.33 & 9.14 & 6.35 & 0.25 & 101.52 & 780 & 0.44 & 775 & 8.32 \\
\hline TA1c 80 & 57.47 & 27.53 & 0.25 & 9.14 & 6.43 & 0.23 & 101.05 & 790 & 0.43 & 774 & 8.30 \\
\hline TA1c 81 & 57.47 & 27.53 & 0.26 & 9.26 & 6.25 & 0.23 & 100.98 & 800 & 0.44 & 778 & 8.32 \\
\hline TA1c 82 & 57.70 & 27.84 & 0.20 & 9.22 & 6.44 & 0.19 & 101.59 & 810 & 0.44 & 776 & 8.28 \\
\hline TA1c 83 & 57.79 & 27.61 & 0.22 & 9.16 & 6.12 & 0.23 & 101.13 & 820 & 0.45 & 778 & 8.33 \\
\hline TA1c 84 & 58.00 & 27.75 & 0.18 & 9.41 & 6.12 & 0.21 & 101.68 & 830 & 0.45 & 780 & 8.34 \\
\hline TA1c 86 & 57.65 & 28.04 & 0.19 & 9.63 & 6.14 & 0.18 & 101.83 & 850 & 0.46 & 783 & 8.34 \\
\hline TA1c 87 & 56.77 & 27.87 & 0.28 & 9.67 & 6.02 & 0.23 & 100.83 & 860 & 0.46 & 783 & 8.38 \\
\hline TA1c 88 & 56.09 & 28.18 & 0.20 & 9.79 & 6.24 & 0.21 & 100.70 & 870 & 0.46 & 782 & 8.35 \\
\hline TA1c 89 & 55.95 & 27.55 & 0.14 & 9.50 & 6.03 & 0.22 & 99.38 & 880 & 0.46 & 782 & 8.36 \\
\hline TA1c 90 & 57.03 & 28.05 & 0.19 & 9.74 & 6.06 & 0.19 & 101.24 & 890 & 0.47 & 784 & 8.36 \\
\hline TA1c 91 & 56.94 & 28.18 & 0.30 & 10.10 & 5.86 & 0.17 & 101.54 & 900 & 0.48 & 789 & 8.42 \\
\hline TA1c 92 & 56.67 & 28.20 & 0.24 & 10.19 & 6.11 & 0.23 & 101.62 & 910 & 0.47 & 786 & 8.41 \\
\hline TA1c 95 & 56.55 & 28.38 & 0.17 & 10.43 & 5.71 & 0.19 & 101.42 & 940 & 0.50 & 791 & 8.49 \\
\hline TA1c 99 & 56.86 & 28.45 & 0.21 & 10.39 & 5.71 & 0.16 & 101.78 & 980 & 0.50 & 792 & 8.47 \\
\hline TA1c 100 & 56.79 & 28.15 & 0.29 & 10.05 & 5.88 & 0.18 & 101.34 & 990 & 0.48 & 788 & 8.41 \\
\hline TA1c 101 & 55.56 & 27.76 & 0.36 & 9.52 & 5.90 & 0.23 & 99.34 & 1000 & 0.46 & 783 & 8.39 \\
\hline TA1c 102 & 56.50 & 28.04 & 0.31 & 9.90 & 6.15 & 0.22 & 101.12 & 1010 & 0.46 & 784 & 8.37 \\
\hline TA1c 103 & 56.63 & 27.82 & 0.28 & 9.61 & 6.07 & 0.21 & 100.63 & 1020 & 0.46 & 782 & 8.36 \\
\hline TA1c 104 & 56.63 & 28.06 & 0.24 & 9.63 & 6.14 & 0.23 & 100.93 & 1030 & 0.46 & 781 & 8.36 \\
\hline TA1c 105 & 56.79 & 27.92 & 0.38 & 9.61 & 6.04 & 0.26 & 100.99 & 1040 & 0.46 & 782 & 8.39 \\
\hline TA1c 106 & 57.52 & 27.99 & 0.21 & 9.82 & 6.20 & 0.20 & 101.94 & 1050 & 0.46 & 783 & 8.35 \\
\hline TA1c 107 & 56.78 & 28.18 & 0.24 & 9.97 & 5.96 & 0.26 & 101.39 & 1060 & 0.47 & 785 & 8.43 \\
\hline TA1c 108 & 56.27 & 28.81 & 0.21 & 10.90 & 5.40 & 0.19 & 101.77 & 1070 & 0.52 & 796 & 8.62 \\
\hline TA1c 110 & 59.12 & 27.02 & 0.25 & 8.57 & 6.58 & 0.26 & 101.80 & 1090 & 0.41 & 766 & 8.28 \\
\hline TA1c 111 & 55.83 & 27.52 & 0.31 & 9.80 & 5.84 & 0.20 & 99.50 & 1100 & 0.48 & 787 & 8.40 \\
\hline TA1c 112 & 56.68 & 27.40 & 0.31 & 9.51 & 5.93 & 0.22 & 100.04 & 1110 & 0.46 & 783 & 8.37 \\
\hline TA1c 113 & 56.42 & 27.48 & 0.23 & 9.72 & 5.97 & 0.19 & 100.01 & 1120 & 0.47 & 785 & 8.37 \\
\hline TA1c 114 & 55.62 & 27.59 & 0.22 & 9.21 & 5.98 & 0.23 & 98.86 & 1130 & 0.45 & 780 & 8.35 \\
\hline TA1c 115 & 55.49 & 27.32 & 0.22 & 9.40 & 6.00 & 0.20 & 98.63 & 1140 & 0.46 & 782 & 8.35 \\
\hline TA1c 116 & 55.68 & 27.12 & 0.18 & 9.20 & 6.08 & 0.27 & 98.53 & 1150 & 0.45 & 778 & 8.36 \\
\hline TA1c 117 & 55.94 & 27.21 & 0.21 & 9.23 & 6.15 & 0.24 & 98.98 & 1160 & 0.45 & 778 & 8.34 \\
\hline TA1c 118 & 56.18 & 27.10 & 0.29 & 9.24 & 6.39 & 0.22 & 99.42 & 1170 & 0.44 & 776 & 8.30 \\
\hline TA1c 119 & 56.49 & 26.99 & 0.23 & 8.99 & 6.12 & 0.29 & 99.11 & 1180 & 0.44 & 775 & 8.35 \\
\hline TA1c 120 & 56.90 & 26.92 & 0.29 & 9.18 & 6.22 & 0.25 & 99.75 & 1190 & 0.44 & 777 & 8.33 \\
\hline TA1c 121 & 57.94 & 26.78 & 0.28 & 8.91 & 6.44 & 0.25 & 100.60 & 1200 & 0.43 & 771 & 8.30 \\
\hline TA1c 122 & 57.73 & 26.20 & 0.42 & 8.09 & 6.56 & 0.26 & 99.26 & 1210 & 0.40 & 761 & 8.27 \\
\hline TA1c 123 & 57.88 & 26.09 & 0.20 & 7.72 & 7.01 & 0.29 & 99.17 & 1220 & 0.37 & 750 & 8.29 \\
\hline TA1c 127 & 58.57 & 26.07 & 0.24 & 8.45 & 6.62 & 0.29 & 100.25 & 1260 & 0.41 & 764 & 8.29 \\
\hline TA1c 128 & 58.24 & 26.08 & 0.19 & 8.60 & 6.58 & 0.28 & 99.98 & 1270 & 0.41 & 766 & 8.30 \\
\hline TA1c 129 & 58.41 & 25.95 & 0.28 & 8.18 & 6.57 & 0.21 & 99.60 & 1280 & 0.40 & 763 & 8.25 \\
\hline TA1c 130 & 59.12 & 25.60 & 0.20 & 7.99 & 6.61 & 0.27 & 99.78 & 1290 & 0.39 & 759 & 8.28 \\
\hline TA1c 131 & 58.38 & 25.60 & 0.35 & 8.06 & 6.53 & 0.27 & 99.19 & 1300 & 0.40 & 761 & 8.28 \\
\hline TA1c 132 & 59.20 & 25.76 & 0.29 & 7.95 & 6.80 & 0.28 & 100.28 & 1310 & 0.39 & 756 & 8.28 \\
\hline TA1c 133 & 59.32 & 25.84 & 0.28 & 7.84 & 6.92 & 0.25 & 100.46 & 1320 & 0.38 & 753 & 8.27 \\
\hline TA1c 134 & 58.91 & 25.71 & 0.27 & 7.76 & 6.80 & 0.25 & 99.70 & 1330 & 0.38 & 754 & 8.26 \\
\hline TA1c 135 & 58.83 & 25.22 & 0.32 & 7.86 & 6.82 & 0.28 & 99.33 & 1340 & 0.38 & 754 & 8.28 \\
\hline TA1c 136 & 59.11 & 25.34 & 0.25 & 7.44 & 7.05 & 0.28 & 99.46 & 1350 & 0.36 & 745 & 8.29 \\
\hline TA1c 137 & 58.69 & 25.42 & 0.36 & 7.94 & 6.82 & 0.26 & 99.50 & 1360 & 0.39 & 756 & 8.27 \\
\hline TA1c 138 & 58.51 & 25.83 & 0.31 & 7.89 & 6.76 & 0.30 & 99.60 & 1370 & 0.39 & 755 & 8.29 \\
\hline TA1c 139 & 58.71 & 25.75 & 0.31 & 8.03 & 6.70 & 0.32 & 99.82 & 1380 & 0.39 & 757 & 8.30 \\
\hline TA1c 140 & 58.60 & 25.71 & 0.28 & 7.79 & 7.01 & 0.30 & 99.68 & 1390 & 0.37 & 750 & 8.29 \\
\hline TA1c 141 & 58.57 & 25.86 & 0.28 & 8.15 & 6.79 & 0.27 & 99.91 & 1400 & 0.39 & 759 & 8.27 \\
\hline TA1c 142 & 57.60 & 25.39 & 0.28 & 7.85 & 6.77 & 0.28 & 98.18 & 1410 & 0.38 & 755 & 8.28 \\
\hline TA1d 1 & 56.76 & 26.40 & 0.43 & 8.66 & 6.42 & 0.23 & 98.89 & 20 & 0.42 & 770 & 8.28 \\
\hline TA1d 2 & 57.03 & 26.33 & 0.31 & 8.36 & 6.07 & 0.29 & 98.39 & 30 & 0.42 & 769 & 8.33 \\
\hline TA1d 3 & 56.84 & 26.00 & 0.33 & 8.59 & 6.44 & 0.28 & 98.47 & 40 & 0.42 & 768 & 8.30 \\
\hline
\end{tabular}


Appendix 3

Table A3.11 continued

\begin{tabular}{|c|c|c|c|c|c|c|c|c|c|c|c|}
\hline Sample & $\mathrm{SiO}_{2}$ & $\mathrm{Al}_{2} \mathrm{O}_{3}$ & $\mathrm{FeO}$ & $\mathrm{CaO}$ & $\mathrm{Na}_{2} \mathrm{O}$ & $\mathrm{K}_{2} \mathrm{O}$ & Total & $\begin{array}{l}\text { Dist } \\
(\mu \mathrm{m})\end{array}$ & $\begin{array}{c}X \\
\text { An } \\
\end{array}$ & $\begin{array}{c}\text { Temp } \\
\left({ }^{\circ} \mathrm{C}\right)\end{array}$ & $\begin{array}{c}\mathrm{H}_{2} \mathrm{O} \\
(\mathrm{wt} \%) \\
\end{array}$ \\
\hline TA1d 4 & 57.28 & 26.10 & 0.36 & 8.39 & 6.49 & 0.26 & 98.87 & 50 & 0.41 & 765 & 8.28 \\
\hline TA1d 5 & 57.90 & 25.32 & 0.27 & 7.64 & 6.87 & 0.30 & 98.30 & 60 & 0.37 & 750 & 8.29 \\
\hline TA1d 6 & 58.43 & 25.38 & 0.33 & 7.43 & 6.90 & 0.27 & 98.74 & 70 & 0.37 & 748 & 8.28 \\
\hline TA1d 7 & 58.30 & 25.78 & 0.34 & 7.99 & 6.55 & 0.33 & 99.28 & 80 & 0.40 & 758 & 8.31 \\
\hline TA1d 8 & 57.99 & 25.44 & 0.24 & 7.52 & 6.75 & 0.27 & 98.20 & 90 & 0.37 & 751 & 8.28 \\
\hline TA1d 9 & 59.18 & 25.12 & 0.34 & 7.93 & 6.60 & 0.24 & 99.42 & 100 & 0.39 & 759 & 8.26 \\
\hline TA1d 10 & 58.95 & 25.61 & 0.29 & 7.90 & 6.63 & 0.29 & 99.68 & 110 & 0.39 & 757 & 8.29 \\
\hline TA1d 11 & 58.72 & 25.09 & 0.36 & 7.31 & 6.72 & 0.27 & 98.46 & 120 & 0.37 & 749 & 8.28 \\
\hline TA1d 12 & 58.16 & 25.09 & 0.25 & 7.75 & 6.53 & 0.35 & 98.13 & 130 & 0.39 & 755 & 8.32 \\
\hline TA1d 13 & 57.30 & 25.49 & 0.33 & 7.94 & 6.63 & 0.30 & 97.98 & 140 & 0.39 & 757 & 8.30 \\
\hline TA1d 14 & 58.62 & 25.42 & 0.32 & 7.73 & 6.76 & 0.28 & 99.11 & 150 & 0.38 & 753 & 8.28 \\
\hline TA1d 15 & 58.50 & 25.36 & 0.26 & 7.65 & 6.52 & 0.30 & 98.59 & 160 & 0.39 & 755 & 8.30 \\
\hline TA1d 16 & 57.38 & 25.53 & 0.29 & 7.79 & 6.83 & 0.25 & 98.07 & 170 & 0.38 & 754 & 8.26 \\
\hline TA1d 17 & 57.58 & 24.81 & 0.31 & 7.32 & 6.77 & 0.28 & 97.07 & 180 & 0.37 & 748 & 8.29 \\
\hline TA1d 18 & 57.37 & 25.13 & 0.43 & 7.37 & 6.99 & 0.30 & 97.59 & 190 & 0.36 & 745 & 8.31 \\
\hline TA1d 21 & 58.98 & 25.78 & 0.36 & 7.84 & 6.80 & 0.27 & 100.02 & 200 & 0.38 & 755 & 8.27 \\
\hline TA1d 22 & 59.27 & 25.80 & 0.38 & 7.63 & 7.01 & 0.33 & 100.41 & 210 & 0.37 & 747 & 8.31 \\
\hline TA1d 23 & 59.75 & 25.93 & 0.34 & 7.81 & 6.99 & 0.28 & 101.09 & 220 & 0.38 & 751 & 8.28 \\
\hline TA1d 24 & 59.26 & 26.11 & 0.36 & 7.95 & 6.96 & 0.30 & 100.92 & 230 & 0.38 & 753 & 8.29 \\
\hline TA1d 25 & 59.08 & 25.66 & 0.30 & 7.64 & 6.94 & 0.29 & 99.90 & 240 & 0.37 & 749 & 8.29 \\
\hline TA1d 26 & 58.88 & 25.98 & 0.28 & 7.58 & 6.69 & 0.30 & 99.70 & 250 & 0.38 & 752 & 8.29 \\
\hline TA1d 27 & 60.07 & 25.58 & 0.40 & 7.53 & 6.51 & 0.31 & 100.39 & 260 & 0.38 & 753 & 8.30 \\
\hline TA1d 28 & 60.75 & 25.78 & 0.38 & 7.77 & 6.98 & 0.27 & 101.94 & 270 & 0.37 & 751 & 8.28 \\
\hline TA1d 29 & 60.54 & 25.93 & 0.35 & 7.97 & 6.66 & 0.28 & 101.74 & 280 & 0.39 & 758 & 8.28 \\
\hline TA1d 30 & 60.51 & 25.39 & 0.27 & 7.44 & 7.12 & 0.33 & 101.05 & 290 & 0.36 & 743 & 8.32 \\
\hline TA1d 31 & 59.94 & 25.58 & 0.29 & 7.76 & 6.93 & 0.33 & 100.82 & 300 & 0.37 & 750 & 8.31 \\
\hline TA1d 32 & 61.05 & 25.62 & 0.35 & 7.46 & 6.88 & 0.26 & 101.61 & 310 & 0.37 & 749 & 8.28 \\
\hline TA1d 33 & 58.77 & 25.99 & 0.29 & 7.67 & 6.67 & 0.30 & 99.68 & 320 & 0.38 & 753 & 8.29 \\
\hline TA1d 34 & 60.20 & 26.05 & 0.29 & 7.68 & 6.92 & 0.30 & 101.44 & 330 & 0.37 & 750 & 8.29 \\
\hline TA1d 35 & 60.15 & 26.30 & 0.31 & 7.81 & 6.93 & 0.27 & 101.77 & 340 & 0.38 & 752 & 8.28 \\
\hline TA1d 36 & 61.22 & 25.22 & 0.43 & 6.74 & 7.22 & 0.41 & 101.24 & 350 & 0.33 & 728 & 8.41 \\
\hline TA1d 37 & 58.34 & 25.31 & 0.36 & 7.59 & 6.73 & 0.32 & 98.64 & 360 & 0.38 & 751 & 8.30 \\
\hline TA1d 38 & 58.86 & 25.12 & 0.32 & 7.52 & 6.81 & 0.29 & 98.92 & 370 & 0.37 & 749 & 8.29 \\
\hline TA1d 39 & 59.08 & 25.53 & 0.32 & 7.56 & 7.10 & 0.30 & 99.90 & 380 & 0.36 & 746 & 8.30 \\
\hline TA1d 40 & 60.06 & 24.87 & 0.35 & 6.80 & 7.20 & 0.32 & 99.60 & 390 & 0.34 & 732 & 8.36 \\
\hline TA1d 41 & 59.36 & 25.15 & 0.33 & 7.18 & 7.08 & 0.31 & 99.41 & 400 & 0.35 & 740 & 8.32 \\
\hline TA1d 42 & 58.66 & 24.64 & 0.37 & 6.90 & 7.37 & 0.33 & 98.27 & 410 & 0.33 & 731 & 8.36 \\
\hline TA1d 43 & 59.83 & 24.26 & 0.30 & 6.20 & 7.13 & 0.36 & 98.07 & 420 & 0.32 & 721 & 8.43 \\
\hline TA1d 44 & 60.98 & 24.48 & 0.28 & 6.70 & 7.08 & 0.36 & 99.87 & 430 & 0.34 & 731 & 8.38 \\
\hline TA1d 45 & 60.55 & 24.36 & 0.31 & 6.80 & 6.85 & 0.31 & 99.18 & 440 & 0.35 & 737 & 8.34 \\
\hline TA1d 46 & 61.14 & 24.98 & 0.29 & 6.98 & 7.13 & 0.40 & 100.92 & 450 & 0.34 & 734 & 8.38 \\
\hline TA1d 47 & 61.02 & 24.78 & 0.31 & 7.00 & 7.25 & 0.33 & 100.69 & 460 & 0.34 & 734 & 8.35 \\
\hline TA1d 48 & 60.18 & 25.29 & 0.40 & 7.15 & 7.23 & 0.35 & 100.61 & 470 & 0.35 & 737 & 8.35 \\
\hline TA1d 50 & 58.09 & 24.60 & 0.34 & 6.86 & 6.90 & 0.35 & 97.14 & 490 & 0.35 & 737 & 8.36 \\
\hline TA1d 51 & 59.94 & 25.04 & 0.23 & 7.02 & 7.51 & 0.36 & 100.09 & 500 & 0.33 & 730 & 8.37 \\
\hline TA1d 52 & 59.01 & 25.86 & 0.26 & 7.84 & 7.19 & 0.29 & 100.45 & 510 & 0.37 & 749 & 8.28 \\
\hline TA1d 53 & 59.08 & 26.51 & 0.26 & 8.46 & 7.30 & 0.33 & 101.94 & 520 & 0.38 & 754 & 8.29 \\
\hline TA1d 54 & 58.98 & 25.79 & 0.34 & 7.92 & 6.68 & 0.33 & 100.04 & 530 & 0.39 & 756 & 8.31 \\
\hline TA1d 55 & 59.07 & 25.69 & 0.41 & 8.08 & 7.40 & 0.32 & 100.96 & 540 & 0.37 & 748 & 8.30 \\
\hline TA1d 56 & 60.02 & 24.79 & 0.25 & 6.78 & 7.32 & 0.40 & 99.55 & 550 & 0.33 & 728 & 8.41 \\
\hline TA1d 57 & 59.77 & 25.44 & 0.25 & 7.50 & 6.49 & 0.29 & 99.73 & 560 & 0.38 & 754 & 8.29 \\
\hline TA1d 58 & 59.07 & 25.78 & 0.27 & 7.90 & 7.08 & 0.27 & 100.38 & 570 & 0.38 & 752 & 8.27 \\
\hline TA1d 59 & 59.35 & 25.79 & 0.26 & 7.61 & 6.87 & 0.31 & 100.18 & 580 & 0.37 & 749 & 8.30 \\
\hline TA1d 60 & 59.13 & 25.30 & 0.34 & 7.11 & 7.47 & 0.32 & 99.67 & 590 & 0.34 & 733 & 8.34 \\
\hline TA1d 61 & 58.98 & 25.54 & 0.25 & 7.60 & 7.20 & 0.31 & 99.87 & 600 & 0.36 & 745 & 8.30 \\
\hline TA1d 62 & 58.85 & 26.01 & 0.20 & 7.75 & 6.99 & 0.31 & 100.11 & 610 & 0.37 & 750 & 8.30 \\
\hline TA1d 63 & 59.97 & 25.70 & 0.25 & 7.63 & 7.03 & 0.36 & 100.94 & 620 & 0.37 & 746 & 8.33 \\
\hline TA1d 64 & 59.67 & 25.56 & 0.25 & 7.63 & 6.84 & 0.23 & 100.18 & 630 & 0.38 & 752 & 8.26 \\
\hline TA1d 65 & 59.58 & 25.44 & 0.31 & 7.44 & 7.24 & 0.28 & 100.29 & 640 & 0.36 & 742 & 8.30 \\
\hline TA1d 66 & 58.62 & 25.79 & 0.16 & 7.58 & 6.85 & 0.31 & 99.31 & 650 & 0.37 & 749 & 8.30 \\
\hline TA1d 67 & 59.90 & 25.57 & 0.28 & 7.43 & 6.92 & 0.29 & 100.39 & 660 & 0.37 & 747 & 8.29 \\
\hline TA1d 68 & 60.21 & 25.58 & 0.25 & 7.73 & 6.84 & 0.31 & 100.92 & 670 & 0.38 & 751 & 8.30 \\
\hline TA1d 69 & 58.71 & 25.49 & 0.22 & 7.57 & 6.88 & 0.25 & 99.12 & 680 & 0.37 & 750 & 8.27 \\
\hline TA1d 70 & 58.78 & 25.44 & 0.35 & 7.28 & 7.01 & 0.32 & 99.16 & 690 & 0.36 & 743 & 8.32 \\
\hline TA1d 71 & 57.89 & 25.37 & 0.24 & 7.65 & 6.93 & 0.27 & 98.35 & 700 & 0.37 & 750 & 8.28 \\
\hline TA1d 72 & 58.38 & 25.75 & 0.31 & 7.68 & 6.71 & 0.30 & 99.12 & 710 & 0.38 & 753 & 8.29 \\
\hline TA1d 73 & 58.29 & 25.64 & 0.23 & 7.78 & 6.82 & 0.26 & 99.02 & 720 & 0.38 & 754 & 8.27 \\
\hline TA1d 74 & 58.07 & 25.51 & 0.29 & 7.63 & 6.95 & 0.36 & 98.82 & 730 & 0.37 & 747 & 8.33 \\
\hline TA1d 75 & 59.47 & 25.21 & 0.25 & 7.67 & 6.99 & 0.31 & 99.91 & 740 & 0.37 & 748 & 8.30 \\
\hline TA1d 76 & 59.80 & 26.02 & 0.17 & 7.93 & 6.94 & 0.27 & 101.13 & 750 & 0.38 & 754 & 8.27 \\
\hline TA1d 77 & 60.44 & 25.63 & 0.37 & 7.32 & 7.20 & 0.29 & 101.25 & 760 & 0.35 & 741 & 8.31 \\
\hline TA1d 78 & 60.02 & 25.80 & 0.23 & 7.97 & 7.03 & 0.28 & 101.32 & 770 & 0.38 & 753 & 8.28 \\
\hline TA1d 79 & 59.72 & 25.95 & 0.35 & 7.82 & 6.90 & 0.32 & 101.05 & 780 & 0.38 & 752 & 8.30 \\
\hline TA1d 80 & 59.31 & 25.97 & 0.30 & 7.72 & 6.98 & 0.30 & 100.57 & 790 & 0.37 & 750 & 8.29 \\
\hline TA1d 81 & 59.35 & 25.67 & 0.28 & 7.39 & 7.32 & 0.28 & 100.28 & 800 & 0.35 & 741 & 8.30 \\
\hline TA1d 82 & 58.35 & 26.12 & 0.23 & 8.02 & 6.79 & 0.32 & 99.84 & 810 & 0.39 & 755 & 8.30 \\
\hline
\end{tabular}


Table A3.11 continued

\begin{tabular}{|c|c|c|c|c|c|c|c|c|c|c|c|}
\hline Sample & $\mathrm{SiO}_{2}$ & $\mathrm{Al}_{2} \mathrm{O}_{3}$ & $\mathrm{FeO}$ & $\mathrm{CaO}$ & $\mathrm{Na}_{2} \mathrm{O}$ & $\mathrm{K}_{2} \mathrm{O}$ & Total & $\begin{array}{l}\text { Dist } \\
(\mu \mathrm{m})\end{array}$ & $\begin{array}{c}X \\
\text { An } \\
\end{array}$ & $\begin{array}{c}\text { Temp } \\
\left({ }^{\circ} \mathrm{C}\right)\end{array}$ & $\begin{array}{c}\mathrm{H}_{2} \mathrm{O} \\
(\mathrm{wt} \%) \\
\end{array}$ \\
\hline TA1d 83 & 59.18 & 25.90 & 0.39 & 8.01 & 7.03 & 0.28 & 100.79 & 820 & 0.38 & 753 & 8.28 \\
\hline TA1d 84 & 59.77 & 25.57 & 0.21 & 7.36 & 7.02 & 0.30 & 100.23 & 830 & 0.36 & 744 & 8.30 \\
\hline TA1d 85 & 59.13 & 25.79 & 0.29 & 7.79 & 7.11 & 0.40 & 100.50 & 840 & 0.37 & 746 & 8.34 \\
\hline TA1d 86 & 60.63 & 25.88 & 0.31 & 7.73 & 6.88 & 0.32 & 101.75 & 850 & 0.38 & 751 & 8.30 \\
\hline TA1d 88 & 60.40 & 25.78 & 0.28 & 7.63 & 7.03 & 0.33 & 101.45 & 870 & 0.37 & 747 & 8.31 \\
\hline TA1d 89 & 59.10 & 25.97 & 0.29 & 7.91 & 7.00 & 0.30 & 100.56 & 880 & 0.38 & 752 & 8.29 \\
\hline TA1d 90 & 58.47 & 25.94 & 0.28 & 7.69 & 7.09 & 0.27 & 99.74 & 890 & 0.37 & 749 & 8.28 \\
\hline TA1d 91 & 59.85 & 25.82 & 0.29 & 7.50 & 7.20 & 0.30 & 100.95 & 900 & 0.36 & 744 & 8.30 \\
\hline TA1d 92 & 60.64 & 25.50 & 0.25 & 7.40 & 7.20 & 0.29 & 101.29 & 910 & 0.36 & 742 & 8.30 \\
\hline TA1d 93 & 60.16 & 25.76 & 0.25 & 7.99 & 6.87 & 0.35 & 101.38 & 920 & 0.38 & 753 & 8.31 \\
\hline TA1d 94 & 60.21 & 25.86 & 0.33 & 7.93 & 7.07 & 0.33 & 101.72 & 930 & 0.38 & 750 & 8.30 \\
\hline TA1d 95 & 60.49 & 25.29 & 0.29 & 7.43 & 7.30 & 0.31 & 101.11 & 940 & 0.35 & 741 & 8.32 \\
\hline TA1d 96 & 59.59 & 25.51 & 0.28 & 7.40 & 7.33 & 0.35 & 100.45 & 950 & 0.35 & 739 & 8.34 \\
\hline TA1d 97 & 59.14 & 25.55 & 0.29 & 7.56 & 7.23 & 0.29 & 100.07 & 960 & 0.36 & 744 & 8.29 \\
\hline TA1d 98 & 59.11 & 25.71 & 0.26 & 7.52 & 7.21 & 0.29 & 100.10 & 970 & 0.36 & 744 & 8.30 \\
\hline TA1d 99 & 59.55 & 25.53 & 0.32 & 7.66 & 7.03 & 0.34 & 100.42 & 980 & 0.37 & 747 & 8.31 \\
\hline TA1d 100 & 59.07 & 25.80 & 0.28 & 8.07 & 6.80 & 0.28 & 100.30 & 990 & 0.39 & 757 & 8.28 \\
\hline TA1d 101 & 58.62 & 26.31 & 0.35 & 8.88 & 6.77 & 0.29 & 101.22 & 1000 & 0.41 & 766 & 8.29 \\
\hline TA1d 103 & 59.06 & 26.91 & 0.30 & 8.85 & 6.42 & 0.25 & 101.80 & 1020 & 0.43 & 771 & 8.29 \\
\hline TA1d 104 & 58.15 & 26.73 & 0.40 & 9.07 & 6.58 & 0.24 & 101.16 & 1030 & 0.43 & 772 & 8.29 \\
\hline TAlj 1 & 58.99 & 26.55 & 0.35 & 8.37 & 6.38 & 0.27 & 100.91 & 20 & 0.41 & 766 & 8.29 \\
\hline TAlj 2 & 58.25 & 26.16 & 0.34 & 8.66 & 6.27 & 0.23 & 99.91 & 30 & 0.43 & 772 & 8.29 \\
\hline TAli 3 & 57.84 & 26.80 & 0.41 & 8.69 & 6.29 & 0.26 & 100.29 & 40 & 0.43 & 771 & 8.31 \\
\hline TAlj 4 & 59.94 & 25.39 & 0.30 & 7.22 & 7.14 & 0.36 & 100.34 & 50 & 0.35 & 739 & 8.34 \\
\hline TAli 5 & 60.23 & 25.37 & 0.33 & 6.96 & 7.17 & 0.31 & 100.36 & 60 & 0.34 & 735 & 8.34 \\
\hline TAli 6 & 59.94 & 25.53 & 0.25 & 7.24 & 7.10 & 0.36 & 100.41 & 70 & 0.35 & 739 & 8.35 \\
\hline TAli 7 & 59.75 & 25.34 & 0.29 & 7.55 & 7.15 & 0.33 & 100.42 & 80 & 0.36 & 744 & 8.32 \\
\hline TA1j 8 & 59.52 & 25.56 & 0.28 & 7.79 & 6.81 & 0.31 & 100.28 & 90 & 0.38 & 752 & 8.30 \\
\hline TA1j 9 & 59.42 & 25.88 & 0.20 & 7.71 & 6.96 & 0.27 & 100.43 & 100 & 0.37 & 751 & 8.28 \\
\hline TA $1 \mathrm{j} 10$ & 59.47 & 25.65 & 0.33 & 7.52 & 7.05 & 0.28 & 100.31 & 110 & 0.36 & 746 & 8.29 \\
\hline TA1j 11 & 60.03 & 25.49 & 0.29 & 7.70 & 6.99 & 0.35 & 100.85 & 120 & 0.37 & 748 & 8.32 \\
\hline TA1j 12 & 59.45 & 25.21 & 0.28 & 7.60 & 7.03 & 0.30 & 99.87 & 130 & 0.37 & 747 & 8.30 \\
\hline TA1j 13 & 59.42 & 25.72 & 0.29 & 7.59 & 7.06 & 0.37 & 100.45 & 140 & 0.36 & 745 & 8.33 \\
\hline TA1j 14 & 59.03 & 25.98 & 0.30 & 7.61 & 7.10 & 0.27 & 100.29 & 150 & 0.37 & 747 & 8.28 \\
\hline TA1j 15 & 58.94 & 25.91 & 0.29 & 7.84 & 6.69 & 0.30 & 99.98 & 160 & 0.39 & 755 & 8.29 \\
\hline TA1j 16 & 59.55 & 25.96 & 0.23 & 7.80 & 6.78 & 0.24 & 100.56 & 170 & 0.38 & 755 & 8.26 \\
\hline TA1j 17 & 58.95 & 25.91 & 0.36 & 7.69 & 6.82 & 0.30 & 100.02 & 180 & 0.38 & 752 & 8.29 \\
\hline TA1j 18 & 59.90 & 25.73 & 0.27 & 7.35 & 6.99 & 0.29 & 100.51 & 190 & 0.36 & 745 & 8.30 \\
\hline TA1j 19 & 59.08 & 25.52 & 0.23 & 7.62 & 6.90 & 0.33 & 99.67 & 200 & 0.37 & 749 & 8.31 \\
\hline TA1j 20 & 59.54 & 25.68 & 0.30 & 7.82 & 6.83 & 0.31 & 100.47 & 210 & 0.38 & 753 & 8.29 \\
\hline TA1j 21 & 59.31 & 26.12 & 0.25 & 7.69 & 6.93 & 0.28 & 100.57 & 220 & 0.37 & 750 & 8.28 \\
\hline TA $1 \mathrm{j} 22$ & 59.34 & 25.79 & 0.33 & 7.73 & 6.78 & 0.29 & 100.25 & 230 & 0.38 & 753 & 8.29 \\
\hline TA1j 23 & 59.28 & 25.95 & 0.24 & 7.80 & 6.87 & 0.28 & 100.43 & 240 & 0.38 & 753 & 8.28 \\
\hline TA1j 24 & 59.11 & 26.09 & 0.25 & 7.92 & 6.86 & 0.24 & 100.47 & 250 & 0.38 & 756 & 8.26 \\
\hline TA1j 25 & 59.63 & 25.60 & 0.34 & 7.79 & 6.97 & 0.26 & 100.57 & 260 & 0.38 & 752 & 8.27 \\
\hline TA1j 26 & 58.98 & 25.83 & 0.20 & 7.76 & 6.78 & 0.29 & 99.84 & 270 & 0.38 & 753 & 8.29 \\
\hline TA1j 27 & 59.26 & 25.64 & 0.26 & 7.62 & 6.89 & 0.27 & 99.93 & 280 & 0.37 & 750 & 8.28 \\
\hline TA1j 28 & 58.99 & 25.80 & 0.30 & 7.89 & 6.87 & 0.30 & 100.15 & 290 & 0.38 & 753 & 8.29 \\
\hline TA1j 29 & 58.88 & 25.82 & 0.32 & 7.69 & 7.00 & 0.31 & 100.01 & 300 & 0.37 & 749 & 8.30 \\
\hline TA1j 30 & 59.21 & 25.82 & 0.22 & 7.60 & 6.94 & 0.27 & 100.05 & 310 & 0.37 & 749 & 8.28 \\
\hline TA1j 31 & 59.42 & 25.62 & 0.25 & 7.37 & 6.86 & 0.32 & 99.84 & 320 & 0.37 & 746 & 8.31 \\
\hline TA $1 \mathrm{j} 32$ & 60.05 & 25.67 & 0.25 & 7.36 & 7.14 & 0.31 & 100.79 & 330 & 0.36 & 742 & 8.32 \\
\hline TA1j 33 & 59.59 & 25.56 & 0.28 & 7.30 & 6.77 & 0.32 & 99.82 & 340 & 0.37 & 746 & 8.31 \\
\hline TA1j 34 & 59.53 & 25.44 & 0.22 & 7.46 & 6.84 & 0.30 & 99.79 & 350 & 0.37 & 748 & 8.30 \\
\hline TA1j 35 & 59.39 & 25.75 & 0.28 & 7.67 & 7.00 & 0.28 & 100.36 & 360 & 0.37 & 749 & 8.28 \\
\hline TA1j 36 & 58.96 & 25.65 & 0.29 & 7.79 & 6.72 & 0.31 & 99.72 & 370 & 0.38 & 754 & 8.30 \\
\hline TA1j 37 & 59.26 & 25.92 & 0.25 & 7.95 & 6.88 & 0.27 & 100.52 & 380 & 0.38 & 755 & 8.27 \\
\hline TA1j 38 & 60.00 & 25.85 & 0.29 & 7.72 & 7.10 & 0.27 & 101.22 & 390 & 0.37 & 749 & 8.28 \\
\hline TA1j 39 & 59.39 & 26.06 & 0.25 & 7.77 & 6.92 & 0.34 & 100.73 & 400 & 0.38 & 750 & 8.31 \\
\hline TA1j 40 & 59.41 & 25.80 & 0.34 & 7.82 & 7.00 & 0.27 & 100.63 & 410 & 0.38 & 752 & 8.27 \\
\hline TA1j 41 & 58.87 & 25.58 & 0.25 & 8.14 & 6.81 & 0.28 & 99.93 & 420 & 0.39 & 758 & 8.28 \\
\hline TA $1 \mathrm{j} 42$ & 58.98 & 25.68 & 0.30 & 8.00 & 6.89 & 0.25 & 100.10 & 430 & 0.39 & 756 & 8.26 \\
\hline TA1j 43 & 59.28 & 25.77 & 0.30 & 7.86 & 7.07 & 0.33 & 100.61 & 440 & 0.37 & 749 & 8.31 \\
\hline TA1j 45 & 58.01 & 26.04 & 0.25 & 7.61 & 6.88 & 0.28 & 99.07 & 460 & 0.37 & 750 & 8.29 \\
\hline TA1j 46 & 59.17 & 25.74 & 0.23 & 7.87 & 6.79 & 0.29 & 100.09 & 470 & 0.38 & 754 & 8.29 \\
\hline TA1j 47 & 59.81 & 25.84 & 0.23 & 8.03 & 6.82 & 0.26 & 100.99 & 480 & 0.39 & 757 & 8.27 \\
\hline TA1j 48 & 58.88 & 26.11 & 0.29 & 7.99 & 6.70 & 0.29 & 100.27 & 490 & 0.39 & 757 & 8.29 \\
\hline TA1j 49 & 57.57 & 25.69 & 0.31 & 8.01 & 6.47 & 0.29 & 98.32 & 500 & 0.40 & 761 & 8.29 \\
\hline TA1j 50 & 57.85 & 26.13 & 0.22 & 7.95 & 6.68 & 0.27 & 99.10 & 510 & 0.39 & 757 & 8.28 \\
\hline TA1j 51 & 57.49 & 25.74 & 0.20 & 7.93 & 6.74 & 0.27 & 98.36 & 520 & 0.39 & 757 & 8.27 \\
\hline TA1j 52 & 57.17 & 25.48 & 0.33 & 7.85 & 6.61 & 0.30 & 97.73 & 530 & 0.39 & 757 & 8.29 \\
\hline TA1j 54 & 57.93 & 26.01 & 0.29 & 7.92 & 6.77 & 0.31 & 99.22 & 550 & 0.39 & 755 & 8.29 \\
\hline TA1j 55 & 57.66 & 25.89 & 0.27 & 7.92 & 6.80 & 0.32 & 98.85 & 560 & 0.38 & 754 & 8.30 \\
\hline TA1j 56 & 58.60 & 25.84 & 0.27 & 7.56 & 7.04 & 0.31 & 99.62 & 570 & 0.37 & 746 & 8.30 \\
\hline TA1i 57 & 58.66 & 25.81 & 0.29 & 7.83 & 6.98 & 0.34 & 99.91 & 580 & 0.38 & 750 & 8.31 \\
\hline
\end{tabular}


Appendix 3

Table A3.11 continued

\begin{tabular}{|c|c|c|c|c|c|c|c|c|c|c|c|}
\hline Sample & $\mathrm{SiO}_{2}$ & $\mathrm{Al}_{2} \mathrm{O}_{3}$ & $\mathrm{FeO}$ & $\mathrm{CaO}$ & $\mathrm{Na}_{2} \mathrm{O}$ & $\mathrm{K}_{2} \mathrm{O}$ & Total & $\begin{array}{l}\text { Dist } \\
(\mu \mathrm{m})\end{array}$ & $\begin{array}{c}X \\
\text { An } \\
\end{array}$ & $\begin{array}{c}\text { Temp } \\
\left({ }^{\circ} \mathrm{C}\right)\end{array}$ & $\begin{array}{c}\mathrm{H}_{2} \mathrm{O} \\
(\mathrm{wt} \%) \\
\end{array}$ \\
\hline TA1i 58 & 59.23 & 25.68 & 0.22 & 7.77 & 6.91 & 0.27 & 100.08 & 590 & 0.38 & 752 & 8.27 \\
\hline TA1j 59 & 58.37 & 25.85 & 0.16 & 7.74 & 6.98 & 0.33 & 99.44 & 600 & 0.37 & 749 & 8.31 \\
\hline TA1j 60 & 59.03 & 25.84 & 0.29 & 7.84 & 6.76 & 0.34 & 100.09 & 610 & 0.38 & 753 & 8.31 \\
\hline TA1j 61 & 59.28 & 25.98 & 0.30 & 7.78 & 6.97 & 0.29 & 100.59 & 620 & 0.38 & 751 & 8.28 \\
\hline TA1j 62 & 58.83 & 26.24 & 0.25 & 7.97 & 6.89 & 0.31 & 100.49 & 630 & 0.38 & 754 & 8.29 \\
\hline TA1j 63 & 58.47 & 26.28 & 0.25 & 7.92 & 6.87 & 0.31 & 100.10 & 640 & 0.38 & 754 & 8.29 \\
\hline TA1j 64 & 58.46 & 26.23 & 0.24 & 7.84 & 6.85 & 0.26 & 99.86 & 650 & 0.38 & 754 & 8.27 \\
\hline TA1j 65 & 58.47 & 26.14 & 0.22 & 7.69 & 6.87 & 0.26 & 99.64 & 660 & 0.38 & 752 & 8.27 \\
\hline TA1j 66 & 57.99 & 26.00 & 0.29 & 8.01 & 6.92 & 0.31 & 99.53 & 670 & 0.38 & 754 & 8.29 \\
\hline TA1j 67 & 58.43 & 25.75 & 0.33 & 7.94 & 6.85 & 0.25 & 99.56 & 680 & 0.38 & 756 & 8.26 \\
\hline TA1j 68 & 57.98 & 25.31 & 0.28 & 7.83 & 7.00 & 0.26 & 98.65 & 690 & 0.38 & 752 & 8.27 \\
\hline TA1j 69 & 58.74 & 25.66 & 0.21 & 7.74 & 6.91 & 0.30 & 99.55 & 700 & 0.38 & 751 & 8.29 \\
\hline TA1j 70 & 59.06 & 25.56 & 0.24 & 7.71 & 6.92 & 0.30 & 99.79 & 710 & 0.37 & 750 & 8.30 \\
\hline TA1j 71 & 59.49 & 26.04 & 0.19 & 7.86 & 6.95 & 0.30 & 100.83 & 720 & 0.38 & 752 & 8.29 \\
\hline TA1j 72 & 57.96 & 25.72 & 0.28 & 7.66 & 6.77 & 0.28 & 98.67 & 730 & 0.38 & 752 & 8.28 \\
\hline TA1j 73 & 58.25 & 26.05 & 0.36 & 7.81 & 6.96 & 0.38 & 99.82 & 740 & 0.37 & 749 & 8.33 \\
\hline TA1j 74 & 58.59 & 25.98 & 0.26 & 7.52 & 6.98 & 0.29 & 99.61 & 750 & 0.37 & 747 & 8.30 \\
\hline TA1j 75 & 58.66 & 26.06 & 0.33 & 7.75 & 6.95 & 0.30 & 100.06 & 760 & 0.37 & 751 & 8.29 \\
\hline TA1j 76 & 58.40 & 25.84 & 0.34 & 7.76 & 7.12 & 0.30 & 99.76 & 770 & 0.37 & 748 & 8.29 \\
\hline TA1j 77 & 59.32 & 25.92 & 0.29 & 7.47 & 6.95 & 0.31 & 100.25 & 780 & 0.37 & 747 & 8.30 \\
\hline TA1j 78 & 59.84 & 25.54 & 0.40 & 7.77 & 7.13 & 0.29 & 100.96 & 790 & 0.37 & 748 & 8.29 \\
\hline TA1j 79 & 59.35 & 26.32 & 0.25 & 7.59 & 6.81 & 0.30 & 100.62 & 800 & 0.37 & 750 & 8.29 \\
\hline TA1j 80 & 58.93 & 26.06 & 0.30 & 7.81 & 6.85 & 0.34 & 100.28 & 810 & 0.38 & 752 & 8.31 \\
\hline TA1j 81 & 57.89 & 26.14 & 0.31 & 7.91 & 6.98 & 0.31 & 99.54 & 820 & 0.38 & 752 & 8.30 \\
\hline TA1j 82 & 58.44 & 26.03 & 0.30 & 7.83 & 6.81 & 0.33 & 99.72 & 830 & 0.38 & 753 & 8.30 \\
\hline TA1j 83 & 59.79 & 26.18 & 0.29 & 8.05 & 6.64 & 0.25 & 101.19 & 840 & 0.40 & 760 & 8.26 \\
\hline TA1j 84 & 59.92 & 25.89 & 0.32 & 7.86 & 6.77 & 0.27 & 101.03 & 850 & 0.38 & 755 & 8.28 \\
\hline TA1j 85 & 58.37 & 26.25 & 0.30 & 8.00 & 6.83 & 0.27 & 100.01 & 860 & 0.39 & 756 & 8.27 \\
\hline TA1j 86 & 58.01 & 26.24 & 0.27 & 7.83 & 6.84 & 0.25 & 99.44 & 870 & 0.38 & 754 & 8.27 \\
\hline TA1j 87 & 57.87 & 26.34 & 0.22 & 7.91 & 6.79 & 0.30 & 99.42 & 880 & 0.38 & 755 & 8.29 \\
\hline TA1j 88 & 57.76 & 25.93 & 0.38 & 7.80 & 6.72 & 0.32 & 98.91 & 890 & 0.38 & 754 & 8.30 \\
\hline TA1j 89 & 58.89 & 25.96 & 0.18 & 7.74 & 7.06 & 0.30 & 100.14 & 900 & 0.37 & 749 & 8.29 \\
\hline TA1j 90 & 59.79 & 25.94 & 0.32 & 7.64 & 6.93 & 0.31 & 100.94 & 910 & 0.37 & 749 & 8.30 \\
\hline TA1j 91 & 59.48 & 25.65 & 0.25 & 7.83 & 6.29 & 0.29 & 99.78 & 920 & 0.40 & 761 & 8.30 \\
\hline TA1j 92 & 59.47 & 26.32 & 0.19 & 7.80 & 6.91 & 0.27 & 100.96 & 930 & 0.38 & 753 & 8.27 \\
\hline TA1j 93 & 59.01 & 26.03 & 0.28 & 7.66 & 6.77 & 0.27 & 100.02 & 940 & 0.38 & 753 & 8.28 \\
\hline TA1j 94 & 59.01 & 25.88 & 0.33 & 7.77 & 6.83 & 0.26 & 100.08 & 950 & 0.38 & 753 & 8.27 \\
\hline TA1j 95 & 57.42 & 25.17 & 0.23 & 7.45 & 6.78 & 0.30 & 97.35 & 960 & 0.37 & 749 & 8.30 \\
\hline TA1j 96 & 58.71 & 25.63 & 0.32 & 7.35 & 7.25 & 0.30 & 99.56 & 970 & 0.35 & 741 & 8.31 \\
\hline TA1j 97 & 58.67 & 25.91 & 0.24 & 7.28 & 7.01 & 0.33 & 99.44 & 980 & 0.36 & 742 & 8.33 \\
\hline TA1j 98 & 59.46 & 26.13 & 0.27 & 7.81 & 6.77 & 0.37 & 100.81 & 990 & 0.38 & 752 & 8.33 \\
\hline TA1j 99 & 59.16 & 26.30 & 0.34 & 8.04 & 6.75 & 0.31 & 100.90 & 1000 & 0.39 & 757 & 8.29 \\
\hline TA1j_100 & 59.11 & 25.97 & 0.34 & 8.04 & 6.68 & 0.30 & 100.45 & 1010 & 0.39 & 758 & 8.29 \\
\hline TA1j 101 & 58.63 & 26.26 & 0.26 & 7.98 & 6.82 & 0.28 & 100.24 & 1020 & 0.39 & 756 & 8.28 \\
\hline TA1j 102 & 59.16 & 26.33 & 0.24 & 7.96 & 6.67 & 0.28 & 100.64 & 1030 & 0.39 & 758 & 8.28 \\
\hline TA1j 103 & 58.28 & 26.18 & 0.22 & 7.73 & 6.81 & 0.29 & 99.51 & 1040 & 0.38 & 752 & 8.29 \\
\hline TA1j 104 & 58.32 & 26.13 & 0.24 & 7.88 & 6.84 & 0.25 & 99.66 & 1050 & 0.38 & 755 & 8.27 \\
\hline TA1j 105 & 58.18 & 26.16 & 0.29 & 7.82 & 6.86 & 0.22 & 99.53 & 1060 & 0.38 & 755 & 8.25 \\
\hline TA1j 106 & 57.98 & 26.23 & 0.28 & 7.87 & 6.71 & 0.35 & 99.42 & 1070 & 0.39 & 754 & 8.32 \\
\hline TA1j 107 & 58.19 & 26.15 & 0.30 & 7.99 & 6.77 & 0.27 & 99.66 & 1080 & 0.39 & 757 & 8.27 \\
\hline TA1j_108 & 59.34 & 26.03 & 0.39 & 8.00 & 6.57 & 0.34 & 100.67 & 1090 & 0.39 & 758 & 8.31 \\
\hline TA1j 109 & 59.22 & 26.04 & 0.26 & 7.88 & 6.59 & 0.32 & 100.31 & 1100 & 0.39 & 757 & 8.30 \\
\hline TA1j 110 & 58.97 & 26.24 & 0.30 & 8.01 & 6.69 & 0.27 & 100.48 & 1110 & 0.39 & 758 & 8.28 \\
\hline TA1j 111 & 58.73 & 26.31 & 0.30 & 7.91 & 6.68 & 0.28 & 100.20 & 1120 & 0.39 & 757 & 8.28 \\
\hline TA1j 112 & 57.60 & 26.36 & 0.24 & 8.02 & 6.87 & 0.31 & 99.40 & 1130 & 0.39 & 755 & 8.29 \\
\hline TA1j 113 & 58.05 & 26.12 & 0.29 & 8.06 & 6.91 & 0.29 & 99.73 & 1140 & 0.39 & 755 & 8.28 \\
\hline TA1j 114 & 59.06 & 26.19 & 0.30 & 7.99 & 6.89 & 0.33 & 100.76 & 1150 & 0.38 & 754 & 8.30 \\
\hline TA1j 115 & 59.65 & 25.98 & 0.30 & 7.86 & 6.83 & 0.31 & 100.93 & 1160 & 0.38 & 753 & 8.30 \\
\hline TA1j 116 & 59.28 & 25.92 & 0.27 & 8.10 & 6.68 & 0.31 & 100.56 & 1170 & 0.39 & 758 & 8.30 \\
\hline TA1j 117 & 59.07 & 25.95 & 0.24 & 8.06 & 6.88 & 0.28 & 100.47 & 1180 & 0.39 & 756 & 8.28 \\
\hline TA1j 118 & 58.11 & 26.34 & 0.35 & 8.23 & 6.60 & 0.26 & 99.89 & 1190 & 0.40 & 762 & 8.27 \\
\hline TA1j 119 & 59.51 & 26.09 & 0.32 & 7.94 & 7.03 & 0.30 & 101.20 & 1200 & 0.38 & 752 & 8.29 \\
\hline TA1j 120 & 60.15 & 25.96 & 0.38 & 7.75 & 6.89 & 0.34 & 101.47 & 1210 & 0.38 & 750 & 8.31 \\
\hline TA1j 121 & 59.21 & 26.24 & 0.19 & 7.89 & 6.99 & 0.33 & 100.84 & 1220 & 0.38 & 751 & 8.30 \\
\hline TA1j 122 & 58.73 & 26.03 & 0.33 & 7.66 & 6.97 & 0.31 & 100.02 & 1230 & 0.37 & 749 & 8.30 \\
\hline TA1j 123 & 58.06 & 25.93 & 0.36 & 7.80 & 6.91 & 0.30 & 99.36 & 1240 & 0.38 & 752 & 8.29 \\
\hline TA1j 124 & 57.20 & 25.87 & 0.29 & 7.59 & 6.67 & 0.36 & 97.97 & 1250 & 0.38 & 751 & 8.33 \\
\hline TA1j 125 & 57.49 & 25.93 & 0.23 & 7.84 & 6.66 & 0.28 & 98.43 & 1260 & 0.39 & 756 & 8.28 \\
\hline TA1j 126 & 58.59 & 26.10 & 0.30 & 7.61 & 6.85 & 0.29 & 99.74 & 1270 & 0.37 & 750 & 8.29 \\
\hline TA1j 127 & 59.16 & 25.59 & 0.22 & 7.47 & 7.01 & 0.32 & 99.76 & 1280 & 0.36 & 745 & 8.31 \\
\hline TA1j 128 & 59.77 & 25.55 & 0.33 & 7.21 & 7.37 & 0.33 & 100.56 & 1290 & 0.34 & 736 & 8.34 \\
\hline TA1j 129 & 60.55 & 25.65 & 0.38 & 7.67 & 6.99 & 0.30 & 101.53 & 1300 & 0.37 & 749 & 8.29 \\
\hline TA1j_130 & 59.78 & 25.69 & 0.29 & 7.65 & 7.14 & 0.33 & 100.89 & 1310 & 0.36 & 746 & 8.31 \\
\hline TA1j 131 & 60.77 & 25.36 & 0.33 & 7.06 & 7.23 & 0.36 & 101.11 & 1320 & 0.34 & 735 & 8.36 \\
\hline TA1j 132 & 60.65 & 25.23 & 0.28 & 6.77 & 7.21 & 0.36 & 100.50 & 1330 & 0.33 & 730 & 8.38 \\
\hline TA1i 133 & 59.23 & 25.74 & 0.36 & 7.40 & 7.15 & 0.33 & 100.22 & 1340 & 0.36 & 742 & 8.32 \\
\hline
\end{tabular}


Table A3.11 continued

\begin{tabular}{|c|c|c|c|c|c|c|c|c|c|c|c|}
\hline Sample & $\mathrm{SiO}_{2}$ & $\mathrm{Al}_{2} \mathrm{O}_{3}$ & $\mathrm{FeO}$ & $\mathrm{CaO}$ & $\mathrm{Na}_{2} \mathrm{O}$ & $\mathrm{K}_{2} \mathrm{O}$ & Total & $\begin{array}{l}\text { Dist } \\
(\mu \mathrm{m})\end{array}$ & $\begin{array}{c}X \\
\text { An } \\
\end{array}$ & $\begin{array}{c}\text { Temp } \\
\left({ }^{\circ} \mathrm{C}\right)\end{array}$ & $\begin{array}{c}\mathrm{H}_{2} \mathrm{O} \\
(\mathrm{wt} \%)\end{array}$ \\
\hline TA1j_134 & 59.14 & 25.64 & 0.29 & 7.49 & 7.05 & 0.30 & 99.91 & 1350 & 0.36 & 745 & 8.30 \\
\hline TA2b 2 & 75.29 & 14.09 & 1.94 & 1.69 & 3.90 & 2.76 & 99.66 & 20 & 0.14 & & \\
\hline TA2b 3 & 58.96 & 26.99 & 0.34 & 8.97 & 6.20 & 0.21 & 101.65 & 30 & 0.44 & 776 & 8.30 \\
\hline TA2b 4 & 59.36 & 26.96 & 0.33 & 8.51 & 6.34 & 0.28 & 101.77 & 40 & 0.42 & 768 & 8.31 \\
\hline TA2b 5 & 59.35 & 26.90 & 0.37 & 8.52 & 6.28 & 0.24 & 101.66 & 50 & 0.42 & 770 & 8.29 \\
\hline TA2b 6 & 58.95 & 26.77 & 0.42 & 8.59 & 6.46 & 0.30 & 101.49 & 60 & 0.42 & 767 & 8.31 \\
\hline TA2b 7 & 56.89 & 27.97 & 0.34 & 9.79 & 5.83 & 0.24 & 101.06 & 70 & 0.47 & 785 & 8.43 \\
\hline TA2b 8 & 57.06 & 27.85 & 0.35 & 9.51 & 5.78 & 0.26 & 100.80 & 80 & 0.47 & 783 & 8.42 \\
\hline TA2b 9 & 60.07 & 25.86 & 0.22 & 7.09 & 7.00 & 0.30 & 100.54 & 90 & 0.35 & 740 & 8.32 \\
\hline TA2b 10 & 60.42 & 25.78 & 0.19 & 7.28 & 6.91 & 0.30 & 100.89 & 100 & 0.36 & 744 & 8.31 \\
\hline TA2b 12 & 60.70 & 26.06 & 0.26 & 7.82 & 6.78 & 0.33 & 101.95 & 120 & 0.38 & 753 & 8.31 \\
\hline TA2b 13 & 60.22 & 26.22 & 0.30 & 7.69 & 6.83 & 0.29 & 101.56 & 130 & 0.38 & 751 & 8.29 \\
\hline TA2b 15 & 60.06 & 26.37 & 0.32 & 7.80 & 6.97 & 0.38 & 101.90 & 150 & 0.37 & 749 & 8.33 \\
\hline TA2b 17 & 60.36 & 26.20 & 0.24 & 7.88 & 6.79 & 0.29 & 101.76 & 170 & 0.38 & 755 & 8.28 \\
\hline TA2b 20 & 59.80 & 26.15 & 0.25 & 7.99 & 6.71 & 0.33 & 101.23 & 200 & 0.39 & 756 & 8.31 \\
\hline TA2b 21 & 59.35 & 26.71 & 0.29 & 7.92 & 6.68 & 0.31 & 101.26 & 210 & 0.39 & 756 & 8.30 \\
\hline TA2b 22 & 59.05 & 26.13 & 0.25 & 7.68 & 6.50 & 0.25 & 99.85 & 220 & 0.39 & 757 & 8.27 \\
\hline TA2b 23 & 58.32 & 26.27 & 0.26 & 8.27 & 6.56 & 0.28 & 99.96 & 230 & 0.40 & 763 & 8.29 \\
\hline TA2b 24 & 57.77 & 26.66 & 0.32 & 8.80 & 6.25 & 0.25 & 100.04 & 240 & 0.43 & 773 & 8.31 \\
\hline TA2b 25 & 58.12 & 26.62 & 0.32 & 8.63 & 6.12 & 0.22 & 100.04 & 250 & 0.43 & 774 & 8.30 \\
\hline TA2b 26 & 58.68 & 26.59 & 0.31 & 8.39 & 6.36 & 0.28 & 100.60 & 260 & 0.41 & 767 & 8.30 \\
\hline TA2b 27 & 58.24 & 26.32 & 0.32 & 8.23 & 6.32 & 0.27 & 99.70 & 270 & 0.41 & 766 & 8.29 \\
\hline TA2b 28 & 58.22 & 26.61 & 0.36 & 8.56 & 6.18 & 0.24 & 100.17 & 280 & 0.43 & 772 & 8.30 \\
\hline TA2b 29 & 57.83 & 26.91 & 0.27 & 8.65 & 6.17 & 0.25 & 100.07 & 290 & 0.43 & 772 & 8.31 \\
\hline TA2b 30 & 58.17 & 26.61 & 0.33 & 8.78 & 6.23 & 0.24 & 100.36 & 300 & 0.43 & 773 & 8.30 \\
\hline TA2b 31 & 57.63 & 27.05 & 0.34 & 8.70 & 6.25 & 0.20 & 100.17 & 310 & 0.43 & 773 & 8.27 \\
\hline TA2b 32 & 57.30 & 27.64 & 0.31 & 9.00 & 6.12 & 0.26 & 100.64 & 320 & 0.44 & 776 & 8.34 \\
\hline TA2b 33 & 56.08 & 27.32 & 0.37 & 9.61 & 5.81 & 0.21 & 99.40 & 330 & 0.47 & 785 & 8.40 \\
\hline TA2b 35 & 56.84 & 27.08 & 0.26 & 8.99 & 5.90 & 0.20 & 99.27 & 350 & 0.45 & 780 & 8.33 \\
\hline TA2b 36 & 55.33 & 27.61 & 0.28 & 9.45 & 5.72 & 0.21 & 98.59 & 360 & 0.47 & 785 & 8.40 \\
\hline TA2b 37 & 54.20 & 27.66 & 0.36 & 9.49 & 5.55 & 0.23 & 97.49 & 370 & 0.48 & 786 & 8.45 \\
\hline TA2b 49 & 58.02 & 27.71 & 0.36 & 8.96 & 6.31 & 0.24 & 101.59 & 490 & 0.43 & 774 & 8.30 \\
\hline TA2b 50 & 57.73 & 27.06 & 0.35 & 9.04 & 6.17 & 0.23 & 100.59 & 500 & 0.44 & 776 & 8.32 \\
\hline TA2b 51 & 57.11 & 27.61 & 0.30 & 9.15 & 5.56 & 0.21 & 99.94 & 510 & 0.47 & 785 & 8.40 \\
\hline TA2b 52 & 58.53 & 27.32 & 0.29 & 8.62 & 6.36 & 0.21 & 101.34 & 520 & 0.42 & 771 & 8.27 \\
\hline TA2b 53 & 57.66 & 27.76 & 0.61 & 9.24 & 5.78 & 0.23 & 101.29 & 530 & 0.46 & 782 & 8.38 \\
\hline TA 2 b 54 & 57.66 & 27.39 & 0.37 & 8.89 & 6.34 & 0.24 & 100.88 & 540 & 0.43 & 773 & 8.30 \\
\hline TA2b 55 & 58.08 & 27.28 & 0.25 & 8.82 & 6.08 & 0.24 & 100.74 & 550 & 0.44 & 775 & 8.32 \\
\hline TA2b 56 & 58.40 & 27.17 & 0.29 & 8.66 & 6.37 & 0.27 & 101.17 & 560 & 0.42 & 769 & 8.30 \\
\hline TA2b 57 & 58.56 & 27.03 & 0.37 & 8.50 & 6.44 & 0.33 & 101.24 & 570 & 0.41 & 765 & 8.33 \\
\hline TA2b 58 & 58.29 & 26.85 & 0.45 & 8.13 & 6.58 & 0.28 & 100.59 & 580 & 0.40 & 761 & 8.29 \\
\hline TA2b 59 & 57.28 & 27.16 & 0.29 & 8.59 & 6.28 & 0.25 & 99.84 & 590 & 0.42 & 771 & 8.30 \\
\hline TA2b 60 & 56.73 & 27.21 & 0.36 & 8.78 & 6.10 & 0.25 & 99.42 & 600 & 0.44 & 774 & 8.32 \\
\hline TA2b 61 & 57.34 & 26.71 & 0.33 & 8.66 & 6.20 & 0.26 & 99.50 & 610 & 0.43 & 772 & 8.31 \\
\hline TA2b 62 & 54.39 & 26.02 & 0.29 & 11.32 & 6.04 & 0.26 & 98.33 & 620 & 0.50 & 791 & 8.55 \\
\hline TA2b 63 & 57.58 & 27.42 & 0.23 & 9.12 & 5.82 & 0.25 & 100.42 & 630 & 0.46 & 780 & 8.38 \\
\hline TA2b 64 & 57.86 & 28.14 & 0.26 & 9.45 & 5.85 & 0.26 & 101.81 & 640 & 0.46 & 782 & 8.40 \\
\hline TA2b 65 & 56.92 & 27.95 & 0.29 & 9.28 & 6.00 & 0.22 & 100.65 & 650 & 0.45 & 781 & 8.35 \\
\hline TA2b 66 & 57.25 & 27.52 & 0.22 & 9.30 & 5.92 & 0.23 & 100.45 & 660 & 0.46 & 781 & 8.37 \\
\hline TA2b 67 & 56.39 & 28.02 & 0.28 & 9.50 & 5.81 & 0.22 & 100.22 & 670 & 0.47 & 784 & 8.40 \\
\hline TA2b 68 & 56.14 & 27.96 & 0.30 & 9.63 & 5.73 & 0.23 & 99.99 & 680 & 0.47 & 785 & 8.43 \\
\hline TA2b 69 & 56.27 & 27.73 & 0.29 & 9.36 & 5.91 & 0.22 & 99.78 & 690 & 0.46 & 782 & 8.37 \\
\hline TA2b 70 & 56.51 & 27.14 & 0.29 & 8.96 & 6.16 & 0.27 & 99.34 & 700 & 0.44 & 775 & 8.34 \\
\hline TA2b 71 & 58.21 & 27.45 & 0.30 & 9.01 & 6.24 & 0.24 & 101.46 & 710 & 0.44 & 775 & 8.31 \\
\hline TA2b 72 & 58.41 & 27.35 & 0.31 & 8.84 & 6.26 & 0.22 & 101.40 & 720 & 0.43 & 774 & 8.29 \\
\hline TA2b 73 & 58.14 & 27.53 & 0.35 & 8.62 & 6.12 & 0.25 & 101.02 & 730 & 0.43 & 773 & 8.31 \\
\hline TA2b 74 & 58.46 & 27.31 & 0.26 & 8.49 & 6.43 & 0.26 & 101.21 & 740 & 0.42 & 767 & 8.29 \\
\hline TA 2 b 75 & 57.70 & 27.02 & 0.27 & 8.38 & 6.39 & 0.27 & 100.03 & 750 & 0.41 & 766 & 8.30 \\
\hline TA2b 76 & 57.85 & 27.18 & 0.34 & 8.51 & 6.38 & 0.20 & 100.47 & 760 & 0.42 & 770 & 8.26 \\
\hline TA2b 77 & 57.67 & 27.17 & 0.33 & 8.36 & 6.34 & 0.27 & 100.15 & 770 & 0.41 & 767 & 8.30 \\
\hline TA2b 78 & 58.07 & 26.88 & 0.36 & 8.50 & 6.48 & 0.25 & 100.54 & 780 & 0.41 & 767 & 8.28 \\
\hline TA2b 79 & 59.26 & 26.37 & 0.18 & 7.74 & 6.75 & 0.29 & 100.58 & 790 & 0.38 & 753 & 8.29 \\
\hline TA2b 81 & 59.00 & 26.39 & 0.25 & 7.74 & 6.79 & 0.30 & 100.47 & 810 & 0.38 & 753 & 8.29 \\
\hline TA2b 82 & 58.88 & 26.37 & 0.27 & 7.89 & 6.78 & 0.27 & 100.47 & 820 & 0.39 & 755 & 8.27 \\
\hline TA2b 83 & 58.71 & 26.72 & 0.27 & 7.90 & 6.63 & 0.28 & 100.51 & 830 & 0.39 & 757 & 8.28 \\
\hline TA2b 84 & 58.80 & 26.32 & 0.29 & 8.22 & 6.45 & 0.24 & 100.32 & 840 & 0.41 & 765 & 8.27 \\
\hline TA2b 85 & 59.08 & 26.34 & 0.29 & 7.73 & 6.78 & 0.31 & 100.53 & 850 & 0.38 & 752 & 8.30 \\
\hline TA2b 86 & 59.32 & 26.42 & 0.25 & 8.18 & 6.63 & 0.33 & 101.13 & 860 & 0.40 & 759 & 8.31 \\
\hline TA2b 87 & 59.07 & 26.07 & 0.31 & 7.56 & 6.72 & 0.35 & 100.09 & 870 & 0.38 & 750 & 8.33 \\
\hline TA2b 88 & 57.74 & 25.88 & 0.24 & 7.64 & 6.55 & 0.27 & 98.31 & 880 & 0.39 & 756 & 8.28 \\
\hline TA2b 89 & 58.18 & 26.30 & 0.24 & 8.21 & 6.48 & 0.28 & 99.69 & 890 & 0.41 & 763 & 8.29 \\
\hline TA2b 90 & 58.53 & 26.06 & 0.31 & 7.81 & 6.73 & 0.26 & 99.70 & 900 & 0.38 & 755 & 8.27 \\
\hline TA2b 91 & 59.03 & 26.39 & 0.25 & 7.88 & 6.55 & 0.28 & 100.39 & 910 & 0.39 & 758 & 8.29 \\
\hline TA2b 92 & 58.94 & 25.87 & 0.20 & 7.58 & 6.58 & 0.37 & 99.55 & 920 & 0.38 & 751 & 8.34 \\
\hline
\end{tabular}


Appendix 3

Table A3.11 continued

\begin{tabular}{|c|c|c|c|c|c|c|c|c|c|c|c|}
\hline Sample & $\mathrm{SiO}_{2}$ & $\mathrm{Al}_{2} \mathrm{O}_{3}$ & $\mathrm{FeO}$ & $\mathrm{CaO}$ & $\mathrm{Na}_{2} \mathrm{O}$ & $\mathrm{K}_{2} \mathrm{O}$ & Total & $\begin{array}{r}\text { Dist } \\
(\mu \mathrm{m})\end{array}$ & $\begin{array}{c}X \\
\text { An } \\
\end{array}$ & $\begin{array}{c}\text { Temp } \\
\left({ }^{\circ} \mathrm{C}\right)\end{array}$ & $\begin{array}{c}\mathrm{H}_{2} \mathrm{O} \\
(\mathrm{wt} \%) \\
\end{array}$ \\
\hline TA2d 1 & 59.14 & 26.67 & 0.29 & 8.09 & 6.75 & 0.28 & 101.22 & 20 & 0.39 & & \\
\hline TA2d 2 & 59.60 & 26.24 & 0.33 & 7.41 & 7.06 & 0.31 & 100.95 & 30 & 0.36 & 744 & 8.31 \\
\hline TA2d 3 & 60.09 & 26.26 & 0.30 & 7.62 & 6.86 & 0.30 & 101.42 & 40 & 0.37 & 750 & 8.30 \\
\hline TA2d 6 & 59.77 & 26.80 & 0.30 & 7.96 & 6.80 & 0.26 & 101.88 & 70 & 0.39 & 756 & 8.27 \\
\hline TA2d 8 & 59.14 & 27.06 & 0.23 & 8.23 & 6.62 & 0.29 & 101.56 & 90 & 0.40 & 761 & 8.29 \\
\hline TA2d 9 & 58.81 & 27.18 & 0.27 & 8.28 & 6.72 & 0.26 & 101.51 & 100 & 0.40 & 761 & 8.27 \\
\hline TA2d 16 & 59.57 & 26.38 & 0.30 & 7.75 & 6.81 & 0.31 & 101.13 & 170 & 0.38 & 752 & 8.30 \\
\hline TA2d 17 & 59.32 & 26.57 & 0.34 & 7.57 & 6.92 & 0.23 & 100.96 & 180 & 0.37 & 750 & 8.26 \\
\hline TA2d 18 & 59.17 & 27.13 & 0.33 & 8.24 & 6.52 & 0.28 & 101.67 & 190 & 0.40 & 763 & 8.29 \\
\hline TA2d 19 & 59.26 & 26.60 & 0.31 & 7.92 & 6.82 & 0.26 & 101.17 & 200 & 0.38 & 755 & 8.27 \\
\hline TA2d 20 & 59.11 & 26.20 & 0.57 & 7.80 & 6.57 & 0.31 & 100.55 & 210 & 0.39 & 756 & 8.30 \\
\hline TA2d 21 & 58.95 & 26.51 & 0.20 & 7.95 & 6.93 & 0.32 & 100.85 & 220 & 0.38 & 753 & 8.30 \\
\hline TA2d 22 & 59.17 & 26.40 & 0.31 & 7.93 & 6.81 & 0.29 & 100.92 & 230 & 0.39 & 755 & 8.28 \\
\hline TA2d 23 & 59.12 & 26.24 & 0.27 & 7.95 & 6.88 & 0.29 & 100.74 & 240 & 0.38 & 754 & 8.28 \\
\hline TA2d 24 & 58.83 & 26.47 & 0.26 & 8.12 & 6.63 & 0.28 & 100.59 & 250 & 0.40 & 760 & 8.28 \\
\hline TA2d 25 & 59.40 & 26.64 & 0.28 & 7.83 & 6.67 & 0.25 & 101.08 & 260 & 0.39 & 757 & 8.26 \\
\hline TA2d 26 & 58.76 & 26.47 & 0.33 & 8.13 & 6.67 & 0.29 & 100.65 & 270 & 0.40 & 759 & 8.29 \\
\hline TA2d 27 & 59.25 & 26.26 & 0.25 & 7.70 & 6.59 & 0.25 & 100.30 & 280 & 0.39 & 756 & 8.27 \\
\hline TA2d 28 & 58.80 & 26.50 & 0.35 & 8.17 & 6.80 & 0.33 & 100.95 & 290 & 0.39 & 757 & 8.31 \\
\hline TA2d 29 & 59.82 & 26.19 & 0.30 & 8.24 & 6.73 & 0.29 & 101.57 & 300 & 0.40 & 760 & 8.29 \\
\hline TA2d 33 & 59.21 & 26.92 & 0.36 & 8.46 & 6.63 & 0.25 & 101.83 & 340 & 0.41 & 765 & 8.27 \\
\hline TA2d 34 & 58.51 & 27.00 & 0.24 & 8.37 & 6.58 & 0.26 & 100.96 & 350 & 0.41 & 764 & 8.28 \\
\hline TA2d 35 & 58.62 & 26.87 & 0.30 & 8.67 & 6.48 & 0.21 & 101.15 & 360 & 0.42 & 770 & 8.26 \\
\hline TA2d 36 & 58.04 & 27.06 & 0.41 & 8.50 & 6.53 & 0.25 & 100.79 & 370 & 0.41 & 766 & 8.28 \\
\hline TA2d 37 & 58.68 & 26.99 & 0.33 & 8.37 & 6.47 & 0.29 & 101.13 & 380 & 0.41 & 765 & 8.30 \\
\hline TA2d 38 & 58.76 & 26.98 & 0.40 & 8.42 & 6.45 & 0.26 & 101.27 & 390 & 0.41 & 766 & 8.28 \\
\hline TA2d 39 & 58.71 & 26.86 & 0.31 & 8.80 & 6.25 & 0.23 & 101.16 & 400 & 0.43 & 773 & 8.30 \\
\hline TA2d 40 & 58.31 & 27.08 & 0.31 & 9.20 & 6.30 & 0.27 & 101.46 & 410 & 0.44 & 775 & 8.33 \\
\hline TA2d 41 & 58.52 & 27.24 & 0.20 & 8.89 & 6.42 & 0.28 & 101.55 & 420 & 0.43 & 771 & 8.31 \\
\hline TA2d 42 & 58.58 & 27.00 & 0.23 & 8.62 & 6.47 & 0.31 & 101.21 & 430 & 0.42 & 767 & 8.32 \\
\hline TA2d 43 & 58.34 & 27.11 & 0.35 & 8.57 & 6.54 & 0.25 & 101.16 & 440 & 0.41 & 767 & 8.28 \\
\hline TA2d 44 & 58.30 & 26.87 & 0.26 & 8.38 & 6.60 & 0.21 & 100.61 & 450 & 0.41 & 765 & 8.25 \\
\hline TA2d 45 & 59.06 & 26.35 & 0.27 & 8.09 & 6.69 & 0.32 & 100.78 & 460 & 0.39 & 758 & 8.30 \\
\hline TA2d 46 & 59.02 & 26.89 & 0.28 & 8.28 & 6.60 & 0.30 & 101.37 & 470 & 0.40 & 762 & 8.29 \\
\hline TA2d 47 & 59.72 & 26.65 & 0.39 & 8.26 & 6.59 & 0.25 & 101.86 & 480 & 0.40 & 763 & 8.27 \\
\hline TA2d 48 & 59.48 & 26.77 & 0.29 & 8.33 & 6.33 & 0.28 & 101.48 & 490 & 0.41 & 766 & 8.30 \\
\hline TA2d 49 & 59.63 & 26.49 & 0.33 & 7.85 & 6.88 & 0.28 & 101.46 & 500 & 0.38 & 753 & 8.28 \\
\hline TA2d 50 & 59.23 & 26.43 & 0.26 & 7.92 & 6.76 & 0.28 & 100.89 & 510 & 0.39 & 756 & 8.28 \\
\hline TA2d 51 & 58.96 & 26.40 & 0.35 & 7.94 & 6.80 & 0.31 & 100.77 & 520 & 0.39 & 755 & 8.29 \\
\hline TA2d 52 & 59.12 & 26.05 & 0.38 & 8.14 & 6.70 & 0.28 & 100.67 & 530 & 0.40 & 759 & 8.28 \\
\hline TA2d 53 & 59.52 & 26.10 & 0.28 & 7.89 & 6.70 & 0.33 & 100.82 & 540 & 0.39 & 755 & 8.31 \\
\hline TA2d 54 & 60.10 & 26.30 & 0.34 & 8.08 & 6.68 & 0.27 & 101.78 & 550 & 0.39 & 759 & 8.28 \\
\hline TA2d 57 & 59.35 & 26.34 & 0.34 & 7.89 & 6.96 & 0.33 & 101.21 & 580 & 0.38 & 752 & 8.30 \\
\hline TA2d 58 & 58.85 & 26.44 & 0.40 & 8.02 & 6.62 & 0.30 & 100.63 & 590 & 0.39 & 758 & 8.29 \\
\hline TA2d 59 & 58.86 & 26.57 & 0.28 & 7.97 & 6.68 & 0.25 & 100.61 & 600 & 0.39 & 758 & 8.27 \\
\hline TA2d 60 & 58.54 & 26.29 & 0.34 & 8.32 & 6.77 & 0.25 & 100.51 & 610 & 0.40 & 761 & 8.27 \\
\hline TA2d 61 & 59.34 & 26.69 & 0.37 & 8.07 & 6.73 & 0.29 & 101.50 & 620 & 0.39 & 758 & 8.29 \\
\hline TA2d 62 & 59.35 & 26.19 & 0.35 & 8.14 & 6.65 & 0.31 & 100.98 & 630 & 0.40 & 759 & 8.30 \\
\hline TA2d 63 & 59.38 & 26.47 & 0.30 & 8.24 & 6.73 & 0.29 & 101.40 & 640 & 0.40 & 760 & 8.29 \\
\hline TA2d 64 & 59.31 & 26.55 & 0.46 & 8.02 & 6.88 & 0.26 & 101.49 & 650 & 0.39 & 756 & 8.27 \\
\hline TA2d 65 & 58.52 & 26.71 & 0.37 & 8.44 & 6.65 & 0.28 & 100.97 & 660 & 0.41 & 763 & 8.29 \\
\hline TA2d 66 & 58.63 & 26.96 & 0.33 & 8.34 & 6.71 & 0.23 & 101.21 & 670 & 0.40 & 763 & 8.26 \\
\hline TA2d 67 & 59.19 & 26.65 & 0.29 & 8.13 & 6.70 & 0.27 & 101.23 & 680 & 0.40 & 759 & 8.28 \\
\hline TA2d 68 & 59.36 & 26.46 & 0.34 & 8.57 & 6.57 & 0.31 & 101.61 & 690 & 0.41 & 765 & 8.31 \\
\hline TA2d 69 & 59.12 & 26.61 & 0.49 & 8.51 & 6.29 & 0.24 & 101.26 & 700 & 0.42 & 770 & 8.29 \\
\hline TA2d 70 & 59.00 & 26.51 & 0.32 & 8.31 & 6.60 & 0.27 & 101.02 & 710 & 0.40 & 763 & 8.28 \\
\hline TA2d 71 & 59.57 & 26.83 & 0.42 & 8.25 & 6.53 & 0.30 & 101.90 & 720 & 0.40 & 762 & 8.30 \\
\hline TA2i 2 & 57.11 & 25.86 & 0.27 & 7.94 & 6.74 & 0.28 & 98.19 & 30 & 0.39 & 756 & 8.28 \\
\hline TA2i 3 & 57.69 & 26.88 & 0.26 & 8.85 & 6.50 & 0.28 & 100.45 & 40 & 0.42 & 770 & 8.31 \\
\hline TA2i 4 & 57.48 & 26.92 & 0.33 & 8.63 & 6.47 & 0.24 & 100.07 & 50 & 0.42 & 769 & 8.28 \\
\hline TA2i 5 & 57.08 & 26.73 & 0.26 & 8.87 & 6.38 & 0.24 & 99.56 & 60 & 0.43 & 772 & 8.29 \\
\hline TA2i 6 & 57.94 & 26.48 & 0.36 & 8.46 & 6.59 & 0.25 & 100.09 & 70 & 0.41 & 765 & 8.27 \\
\hline TA2i 7 & 57.32 & 26.82 & 0.41 & 8.66 & 6.65 & 0.24 & 100.11 & 80 & 0.41 & 767 & 8.27 \\
\hline TA2i 8 & 57.07 & 27.04 & 0.26 & 8.63 & 6.69 & 0.24 & 99.93 & 90 & 0.41 & 766 & 8.27 \\
\hline TA2i 9 & 57.03 & 26.90 & 0.32 & 8.90 & 4.60 & 0.24 & 97.99 & 100 & 0.51 & 791 & 8.62 \\
\hline TA2i 10 & 56.68 & 27.11 & 0.25 & 8.79 & 6.32 & 0.22 & 99.38 & 110 & 0.43 & 773 & 8.29 \\
\hline TA2i 11 & 56.76 & 27.11 & 0.23 & 8.91 & 6.37 & 0.26 & 99.64 & 120 & 0.43 & 772 & 8.31 \\
\hline TA2i 12 & 57.25 & 27.14 & 0.34 & 8.80 & 6.27 & 0.24 & 100.03 & 130 & 0.43 & 773 & 8.30 \\
\hline TA2i 13 & 57.43 & 26.26 & 0.29 & 7.80 & 6.77 & 0.24 & 98.79 & 140 & 0.38 & 755 & 8.26 \\
\hline TA2i 14 & 57.88 & 26.32 & 0.27 & 8.12 & 6.59 & 0.25 & 99.43 & 150 & 0.40 & 761 & 8.27 \\
\hline TA2i 15 & 57.10 & 26.18 & 0.43 & 8.03 & 6.72 & 0.30 & 98.77 & 160 & 0.39 & 757 & 8.29 \\
\hline TA2i 16 & 57.17 & 26.29 & 0.29 & 7.93 & 6.78 & 0.26 & 98.72 & 170 & 0.39 & 756 & 8.27 \\
\hline TA2i 17 & 58.07 & 26.45 & 0.38 & 8.03 & 6.71 & 0.28 & 99.91 & 180 & 0.39 & 758 & 8.28 \\
\hline TA2i 18 & 58.48 & 26.64 & 0.31 & 8.23 & 6.74 & 0.33 & 100.73 & 190 & 0.40 & 758 & 8.31 \\
\hline TA2i 19 & 59.03 & 26.61 & 0.35 & 8.39 & 6.62 & 0.32 & 101.32 & 200 & 0.40 & 762 & 8.31 \\
\hline
\end{tabular}


Table A3.11 continued

\begin{tabular}{|c|c|c|c|c|c|c|c|c|c|c|c|}
\hline Sample & $\mathrm{SiO}_{2}$ & $\mathrm{Al}_{2} \mathrm{O}_{3}$ & $\mathrm{FeO}$ & $\mathrm{CaO}$ & $\mathrm{Na}_{2} \mathrm{O}$ & $\mathrm{K}_{2} \mathrm{O}$ & Total & $\begin{array}{l}\text { Dist } \\
(\mu \mathrm{m})\end{array}$ & $\begin{array}{c}X \\
\text { An } \\
\end{array}$ & $\begin{array}{c}\text { Temp } \\
\left({ }^{\circ} \mathrm{C}\right)\end{array}$ & $\begin{array}{c}\mathrm{H}_{2} \mathrm{O} \\
(\mathrm{wt} \%) \\
\end{array}$ \\
\hline $\begin{array}{ll}\text { TA2i } & 20 \\
\text { TA2i } & 21\end{array}$ & $\begin{array}{l}58.52 \\
58.18\end{array}$ & $\begin{array}{l}26.39 \\
26.47\end{array}$ & $\begin{array}{l}0.31 \\
0.38\end{array}$ & $\begin{array}{l}8.18 \\
8.11\end{array}$ & $\begin{array}{l}6.59 \\
6.73\end{array}$ & $\begin{array}{l}0.25 \\
0.28\end{array}$ & $\begin{array}{l}100.24 \\
100.15\end{array}$ & $\begin{array}{l}210 \\
220\end{array}$ & $\begin{array}{l}0.40 \\
0.39\end{array}$ & $\begin{array}{l}762 \\
759\end{array}$ & $\begin{array}{l}8.27 \\
8.28\end{array}$ \\
\hline TA2i 22 & 57.37 & 26.40 & 0.30 & 8.27 & 6.55 & 0.24 & 99.13 & 230 & 0.40 & 764 & 8.27 \\
\hline ТА $2 \mathrm{i} 23$ & 57.56 & 26.14 & 0.31 & 8.04 & 6.47 & 0.26 & 98.78 & 240 & 0.40 & 762 & 8.28 \\
\hline ТA2i 24 & 57.33 & 26.16 & 0.35 & 7.71 & 6.77 & 0.29 & 98.61 & 250 & 0.38 & 753 & 8.29 \\
\hline TA2i 25 & 58.54 & 26.66 & 0.34 & 8.27 & 6.70 & 0.31 & 100.81 & 260 & 0.40 & 760 & 8.30 \\
\hline TA2i 26 & 57.87 & 26.41 & 0.23 & 7.96 & 6.85 & 0.32 & 99.63 & 270 & 0.38 & 754 & 8.30 \\
\hline TA2i 27 & 57.72 & 26.57 & 0.28 & 8.19 & 6.43 & 0.28 & 99.46 & 280 & 0.41 & 763 & 8.29 \\
\hline TA2i 28 & 57.13 & 26.59 & 0.24 & 8.20 & 6.38 & 0.27 & 98.80 & 290 & 0.41 & 765 & 8.29 \\
\hline TA2i 29 & 56.40 & 26.52 & 0.25 & 8.38 & 6.58 & 0.25 & 98.38 & 300 & 0.41 & 764 & 8.27 \\
\hline TA2i 30 & 56.54 & 26.55 & 0.31 & 8.57 & 6.49 & 0.22 & 98.68 & 310 & 0.42 & 768 & 8.27 \\
\hline TA2i 31 & 57.17 & 26.77 & 0.27 & 8.70 & 6.43 & 0.23 & 99.57 & 320 & 0.42 & 770 & 8.28 \\
\hline TA2i 32 & 57.13 & 26.68 & 0.26 & 8.52 & 6.31 & 0.28 & 99.17 & 330 & 0.42 & 768 & 8.31 \\
\hline TA2i 33 & 58.02 & 26.15 & 0.20 & 8.16 & 6.67 & 0.32 & 99.52 & 340 & 0.40 & 759 & 8.30 \\
\hline TA2i 40 & 57.41 & 26.17 & 0.31 & 7.85 & 6.59 & 0.25 & 98.58 & 410 & 0.39 & 758 & 8.27 \\
\hline TA2i 41 & 58.41 & 26.44 & 0.33 & 8.00 & 6.79 & 0.30 & 100.27 & 420 & 0.39 & 756 & 8.29 \\
\hline TA2i 42 & 59.27 & 26.58 & 0.30 & 8.30 & 6.87 & 0.27 & 101.60 & 430 & 0.39 & 759 & 8.27 \\
\hline TA2i 46 & 59.49 & 26.69 & 0.35 & 8.14 & 6.80 & 0.30 & 101.77 & 470 & 0.39 & 757 & 8.29 \\
\hline TA2i 47 & 58.99 & 26.79 & 0.42 & 8.01 & 6.93 & 0.30 & 101.43 & 480 & 0.38 & 754 & 8.29 \\
\hline TA2i 48 & 58.76 & 26.88 & 0.33 & 8.24 & 6.89 & 0.28 & 101.39 & 490 & 0.39 & 758 & 8.28 \\
\hline TA2i 49 & 59.03 & 26.60 & 0.35 & 8.33 & 6.87 & 0.32 & 101.50 & 500 & 0.39 & 758 & 8.30 \\
\hline TA2i 50 & 57.85 & 26.33 & 0.30 & 7.83 & 6.85 & 0.28 & 99.43 & 510 & 0.38 & 753 & 8.28 \\
\hline TA2i 51 & 58.94 & 26.68 & 0.41 & 7.91 & 6.68 & 0.30 & 100.91 & 520 & 0.39 & 756 & 8.29 \\
\hline TA2i 52 & 58.91 & 26.41 & 0.30 & 8.08 & 6.78 & 0.30 & 100.77 & 530 & 0.39 & 757 & 8.29 \\
\hline TA2i 53 & 58.32 & 26.33 & 0.33 & 7.82 & 6.67 & 0.28 & 99.74 & 540 & 0.39 & 756 & 8.28 \\
\hline TA2i 54 & 58.58 & 26.55 & 0.37 & 8.01 & 6.74 & 0.30 & 100.56 & 550 & 0.39 & 757 & 8.29 \\
\hline TA2i 55 & 58.58 & 26.57 & 0.44 & 8.09 & 6.70 & 0.29 & 100.66 & 560 & 0.39 & 758 & 8.28 \\
\hline TA2i 56 & 57.89 & 26.63 & 0.35 & 8.03 & 6.78 & 0.34 & 100.01 & 570 & 0.39 & 755 & 8.31 \\
\hline TA2i 57 & 57.65 & 26.29 & 0.30 & 8.01 & 6.75 & 0.30 & 99.30 & 580 & 0.39 & 757 & 8.29 \\
\hline TA2i 58 & 57.47 & 26.55 & 0.39 & 8.41 & 6.72 & 0.31 & 99.84 & 590 & 0.40 & 762 & 8.30 \\
\hline TA2i 59 & 57.83 & 26.40 & 0.20 & 8.30 & 6.71 & 0.25 & 99.69 & 600 & 0.40 & 762 & 8.27 \\
\hline TA2i 60 & 57.65 & 26.22 & 0.36 & 8.51 & 6.55 & 0.23 & 99.52 & 610 & 0.41 & 767 & 8.27 \\
\hline TA2i 62 & 58.39 & 27.13 & 0.34 & 8.82 & 6.53 & 0.24 & 101.44 & 630 & 0.42 & 770 & 8.28 \\
\hline TA2i 63 & 57.20 & 27.37 & 0.29 & 9.12 & 6.33 & 0.25 & 100.56 & 640 & 0.44 & 775 & 8.32 \\
\hline TA2i 64 & 56.42 & 27.35 & 0.33 & 9.30 & 5.99 & 0.23 & 99.62 & 650 & 0.46 & 781 & 8.36 \\
\hline TA2i 65 & 56.56 & 27.32 & 0.27 & 8.78 & 6.38 & 0.24 & 99.55 & 660 & 0.43 & 771 & 8.29 \\
\hline TA2i 66 & 56.66 & 27.06 & 0.33 & 8.88 & 6.24 & 0.27 & 99.44 & 670 & 0.43 & 773 & 8.32 \\
\hline TA2i 67 & 58.36 & 26.61 & 0.41 & 8.55 & 6.26 & 0.31 & 100.51 & 680 & 0.42 & 768 & 8.33 \\
\hline TA3a 9 & 55.66 & 27.70 & 0.46 & 9.78 & 5.79 & 0.19 & 99.57 & 20 & 0.48 & 787 & 8.41 \\
\hline TA3a 10 & 58.03 & 27.45 & 0.43 & 9.16 & 6.33 & 0.24 & 101.64 & 30 & 0.44 & 775 & 8.32 \\
\hline TA3a 11 & 57.51 & 27.59 & 0.47 & 9.59 & 6.13 & 0.21 & 101.50 & 40 & 0.46 & 782 & 8.35 \\
\hline TA3a 12 & 57.13 & 27.91 & 0.43 & 9.88 & 5.80 & 0.18 & 101.33 & 50 & 0.48 & 788 & 8.41 \\
\hline TA3a 13 & 56.44 & 28.33 & 0.43 & 10.50 & 5.69 & 0.18 & 101.57 & 60 & 0.50 & 792 & 8.50 \\
\hline TA3a 14 & 54.75 & 28.32 & 0.34 & 10.23 & 5.57 & 0.20 & 99.40 & 70 & 0.50 & 791 & 8.51 \\
\hline TA3a 15 & 54.48 & 28.85 & 0.52 & 11.03 & 5.30 & 0.17 & 100.35 & 80 & 0.53 & 797 & 8.66 \\
\hline TA3a 20 & 56.35 & 27.94 & 0.24 & 9.89 & 5.81 & 0.22 & 100.46 & 130 & 0.48 & 787 & 8.43 \\
\hline TA3a 21 & 56.22 & 28.46 & 0.30 & 10.26 & 5.48 & 0.15 & 100.87 & 140 & 0.50 & 794 & 8.51 \\
\hline TA3a 22 & 56.16 & 28.90 & 0.26 & 10.52 & 5.35 & 0.15 & 101.34 & 150 & 0.52 & 796 & 8.57 \\
\hline TA3a 23 & 56.44 & 28.46 & 0.41 & 10.00 & 5.87 & 0.21 & 101.39 & 160 & 0.48 & 787 & 8.42 \\
\hline TA3a 24 & 56.79 & 28.43 & 0.42 & 9.86 & 5.77 & 0.25 & 101.51 & 170 & 0.48 & 786 & 8.45 \\
\hline TA3a 25 & 56.92 & 27.83 & 0.40 & 9.56 & 5.90 & 0.21 & 100.81 & 180 & 0.47 & 784 & 8.38 \\
\hline TA3a 26 & 57.20 & 28.09 & 0.42 & 9.82 & 5.83 & 0.21 & 101.57 & 190 & 0.48 & 787 & 8.41 \\
\hline TA3a 27 & 57.82 & 27.87 & 0.43 & 9.42 & 5.98 & 0.19 & 101.71 & 200 & 0.46 & 783 & 8.35 \\
\hline TA3a 28 & 58.22 & 27.17 & 0.40 & 9.02 & 6.24 & 0.25 & 101.29 & 210 & 0.44 & 775 & 8.32 \\
\hline TA3a 29 & 57.34 & 28.04 & 0.38 & 9.66 & 6.16 & 0.22 & 101.80 & 220 & 0.46 & 782 & 8.36 \\
\hline TA3a 30 & 57.20 & 28.14 & 0.35 & 10.19 & 5.74 & 0.23 & 101.86 & 230 & 0.49 & 789 & 8.48 \\
\hline TA3a 31 & 57.07 & 27.66 & 0.45 & 9.29 & 6.11 & 0.23 & 100.80 & 240 & 0.45 & 779 & 8.34 \\
\hline TA3a 32 & 58.21 & 26.85 & 0.26 & 8.73 & 6.32 & 0.25 & 100.61 & 250 & 0.43 & 771 & 8.30 \\
\hline TA3a 33 & 56.94 & 27.35 & 0.32 & 9.17 & 6.33 & 0.25 & 100.36 & 260 & 0.44 & 775 & 8.32 \\
\hline TA3a 34 & 57.64 & 27.21 & 0.34 & 9.03 & 6.47 & 0.26 & 100.96 & 270 & 0.43 & 772 & 8.30 \\
\hline TA3a 35 & 57.15 & 27.11 & 0.35 & 8.89 & 6.34 & 0.26 & 100.10 & 280 & 0.43 & 772 & 8.31 \\
\hline TA3a 36 & 57.85 & 26.86 & 0.38 & 9.02 & 6.04 & 0.25 & 100.39 & 290 & 0.45 & 777 & 8.34 \\
\hline TA3a 37 & 57.54 & 27.19 & 0.25 & 9.12 & 6.05 & 0.23 & 100.37 & 300 & 0.45 & 779 & 8.34 \\
\hline TA3a 38 & 57.29 & 27.35 & 0.30 & 9.13 & 6.40 & 0.23 & 100.68 & 310 & 0.44 & 775 & 8.30 \\
\hline TA3a 39 & 57.28 & 27.42 & 0.36 & 9.17 & 6.33 & 0.25 & 100.81 & 320 & 0.44 & 775 & 8.32 \\
\hline TA3a 40 & 57.30 & 26.87 & 0.33 & 8.83 & 5.43 & 0.23 & 98.99 & 330 & 0.47 & 783 & 8.40 \\
\hline TA3a 41 & 57.63 & 26.99 & 0.40 & 8.85 & 6.35 & 0.27 & 100.49 & 340 & 0.43 & 772 & 8.31 \\
\hline TA3a 43 & 57.67 & 26.76 & 0.53 & 9.02 & 6.21 & 0.23 & 100.42 & 360 & 0.44 & 776 & 8.31 \\
\hline TA3a 44 & 57.62 & 27.50 & 0.36 & 9.24 & 6.08 & 0.24 & 101.04 & 370 & 0.45 & 779 & 8.35 \\
\hline TA3a 45 & 57.70 & 27.39 & 0.29 & 9.00 & 6.29 & 0.20 & 100.87 & 380 & 0.44 & 776 & 8.28 \\
\hline TA3a 46 & 57.89 & 26.71 & 0.39 & 8.48 & 6.53 & 0.27 & 100.28 & 390 & 0.41 & 766 & 8.29 \\
\hline TA3a 47 & 57.99 & 26.71 & 0.43 & 8.57 & 6.63 & 0.28 & 100.61 & 400 & 0.41 & 765 & 8.29 \\
\hline TA3a 48 & 58.01 & 26.43 & 0.38 & 8.11 & 6.65 & 0.27 & 99.85 & 410 & 0.40 & 760 & 8.28 \\
\hline TA3a 49 & 57.98 & 26.18 & 0.30 & 8.44 & 6.45 & 0.29 & 99.64 & 420 & 0.41 & 765 & 8.30 \\
\hline TA3a 50 & 57.69 & 26.25 & 0.24 & 8.34 & 6.80 & 0.28 & 99.59 & 430 & 0.40 & 760 & 8.28 \\
\hline
\end{tabular}


Table A3.11 continued

\begin{tabular}{|c|c|c|c|c|c|c|c|c|c|c|c|}
\hline Sample & $\mathrm{SiO}_{2}$ & $\mathrm{Al}_{2} \mathrm{O}_{3}$ & $\mathrm{FeO}$ & $\mathrm{CaO}$ & $\mathrm{Na}_{2} \mathrm{O}$ & $\mathrm{K}_{2} \mathrm{O}$ & Total & $\begin{array}{r}\text { Dist } \\
(\mu \mathrm{m})\end{array}$ & $\begin{array}{c}X \\
\text { An } \\
\end{array}$ & $\begin{array}{c}\text { Temp } \\
\left({ }^{\circ} \mathrm{C}\right)\end{array}$ & $\begin{array}{c}\mathrm{H}_{2} \mathrm{O} \\
(\mathrm{wt} \%) \\
\end{array}$ \\
\hline TA3a 51 & 57.89 & 26.28 & 0.27 & 8.07 & 6.72 & 0.26 & 99.49 & 440 & 0.39 & 759 & 8.27 \\
\hline TA3a 52 & 59.60 & 26.00 & 0.36 & 8.00 & 6.67 & 0.25 & 100.86 & 450 & 0.39 & 759 & 8.27 \\
\hline TA3a 53 & 58.92 & 25.89 & 0.37 & 7.97 & 6.76 & 0.30 & 100.20 & 460 & 0.39 & 756 & 8.29 \\
\hline TA3a 54 & 59.12 & 26.01 & 0.32 & 7.77 & 6.97 & 0.31 & 100.50 & 470 & 0.37 & 750 & 8.29 \\
\hline TA3a 56 & 58.76 & 26.44 & 0.33 & 7.89 & 6.82 & 0.31 & 100.55 & 490 & 0.38 & 754 & 8.30 \\
\hline TA3a 57 & 58.56 & 26.69 & 0.33 & 8.13 & 6.68 & 0.28 & 100.66 & 500 & 0.40 & 760 & 8.28 \\
\hline TA3a 58 & 59.12 & 26.67 & 0.27 & 8.28 & 6.73 & 0.29 & 101.35 & 510 & 0.40 & 760 & 8.29 \\
\hline TA3a 59 & 59.87 & 25.91 & 0.31 & 7.75 & 7.08 & 0.27 & 101.20 & 520 & 0.37 & 749 & 8.28 \\
\hline TA3a 60 & 60.32 & 24.97 & 0.24 & 6.84 & 7.25 & 0.36 & 99.99 & 530 & 0.34 & 731 & 8.38 \\
\hline ТА $3 \mathrm{a} 61$ & 60.75 & 25.51 & 0.24 & 6.98 & 7.28 & 0.35 & 101.11 & 540 & 0.34 & 733 & 8.36 \\
\hline TA3a 62 & 59.95 & 25.63 & 0.44 & 7.59 & 7.03 & 0.34 & 100.98 & 550 & 0.37 & 746 & 8.32 \\
\hline TA3a 63 & 59.11 & 26.20 & 0.19 & 7.74 & 6.99 & 0.30 & 100.53 & 560 & 0.37 & 750 & 8.29 \\
\hline TA3a 65 & 58.43 & 26.74 & 0.29 & 8.39 & 6.73 & 0.28 & 100.85 & 580 & 0.40 & 762 & 8.28 \\
\hline TA3a 66 & 58.52 & 26.49 & 0.27 & 8.16 & 6.78 & 0.27 & 100.48 & 590 & 0.39 & 759 & 8.27 \\
\hline TA3a 67 & 58.03 & 26.81 & 0.36 & 8.47 & 6.25 & 0.29 & 100.20 & 600 & 0.42 & 768 & 8.32 \\
\hline TA3a 68 & 58.72 & 26.54 & 0.28 & 8.53 & 6.37 & 0.26 & 100.71 & 610 & 0.42 & 769 & 8.29 \\
\hline ТA3a 69 & 58.55 & 26.84 & 0.30 & 8.62 & 6.34 & 0.24 & 100.89 & 620 & 0.42 & 770 & 8.29 \\
\hline TA3a 70 & 58.59 & 26.89 & 0.37 & 8.61 & 6.37 & 0.26 & 101.09 & 630 & 0.42 & 769 & 8.29 \\
\hline TA3a 71 & 57.80 & 26.93 & 0.38 & 8.47 & 6.46 & 0.23 & 100.26 & 640 & 0.41 & 768 & 8.27 \\
\hline TA3a 72 & 58.27 & 26.55 & 0.30 & 8.60 & 6.35 & 0.27 & 100.35 & 650 & 0.42 & 769 & 8.30 \\
\hline TA3a 73 & 58.00 & 26.68 & 0.34 & 8.78 & 6.47 & 0.23 & 100.50 & 660 & 0.42 & 771 & 8.28 \\
\hline TA3f 1 & 60.16 & 23.81 & 0.24 & 5.39 & 8.18 & 0.61 & 98.39 & 20 & 0.26 & 684 & 8.78 \\
\hline TA3f 2 & 61.74 & 24.72 & 0.33 & 5.72 & 7.97 & 0.57 & 101.05 & 30 & 0.27 & 694 & 8.68 \\
\hline TA3f 3 & 61.16 & 24.48 & 0.27 & 5.70 & 8.00 & 0.61 & 100.22 & 40 & 0.27 & 693 & 8.70 \\
\hline TA3f 4 & 59.48 & 24.38 & 0.30 & 5.73 & 8.01 & 0.57 & 98.47 & 50 & 0.27 & 694 & 8.67 \\
\hline TA3f 5 & 59.87 & 24.33 & 0.25 & 5.82 & 8.21 & 0.63 & 99.11 & 60 & 0.27 & 692 & 8.71 \\
\hline TA3f 7 & 60.45 & 24.62 & 0.23 & 5.99 & 8.00 & 0.61 & 99.90 & 80 & 0.28 & 699 & 8.65 \\
\hline TA3f 8 & 59.30 & 25.48 & 0.23 & 7.25 & 7.53 & 0.53 & 100.31 & 90 & 0.34 & 729 & 8.44 \\
\hline TA3f 9 & 58.38 & 25.78 & 0.15 & 7.35 & 7.13 & 0.44 & 99.22 & 100 & 0.35 & 739 & 8.38 \\
\hline TA3f 10 & 56.83 & 26.32 & 0.20 & 7.87 & 7.01 & 0.38 & 98.62 & 110 & 0.37 & 749 & 8.33 \\
\hline TA3f 11 & 58.31 & 26.08 & 0.27 & 7.83 & 7.09 & 0.39 & 99.97 & 120 & 0.37 & 747 & 8.34 \\
\hline TA3f 12 & 57.17 & 25.46 & 0.23 & 7.26 & 7.42 & 0.42 & 97.96 & 130 & 0.34 & 734 & 8.39 \\
\hline TA3f 13 & 57.08 & 26.01 & 0.17 & 7.77 & 7.11 & 0.41 & 98.54 & 140 & 0.37 & 746 & 8.35 \\
\hline TA3f 14 & 58.06 & 26.08 & 0.33 & 7.32 & 7.32 & 0.38 & 99.49 & 150 & 0.35 & 737 & 8.36 \\
\hline TA3f 15 & 59.21 & 24.62 & 0.26 & 6.35 & 7.58 & 0.58 & 98.60 & 160 & 0.31 & 713 & 8.55 \\
\hline TA3f 16 & 58.65 & 25.42 & 0.36 & 7.39 & 7.41 & 0.42 & 99.65 & 170 & 0.35 & 736 & 8.38 \\
\hline TA3f 17 & 58.66 & 26.70 & 0.18 & 7.74 & 6.86 & 0.40 & 100.54 & 180 & 0.38 & 749 & 8.34 \\
\hline TA $3 f \quad 18$ & 57.46 & 25.95 & 0.21 & 8.11 & 7.03 & 0.39 & 99.13 & 190 & 0.38 & 752 & 8.33 \\
\hline TA3f 19 & 58.99 & 25.72 & 0.19 & 7.43 & 7.33 & 0.45 & 100.10 & 200 & 0.35 & 737 & 8.39 \\
\hline TA3f 20 & 58.08 & 25.15 & 0.20 & 6.87 & 7.39 & 0.48 & 98.17 & 210 & 0.33 & 726 & 8.44 \\
\hline TA3f 21 & 57.01 & 26.61 & 0.23 & 8.06 & 6.98 & 0.46 & 99.35 & 220 & 0.38 & 750 & 8.37 \\
\hline TA3f 22 & 57.32 & 25.93 & 0.22 & 7.37 & 7.41 & 0.41 & 98.65 & 230 & 0.35 & 736 & 8.37 \\
\hline TA3f 23 & 58.75 & 25.67 & 0.24 & 7.31 & 7.32 & 0.40 & 99.68 & 240 & 0.35 & 736 & 8.37 \\
\hline TA3f 24 & 58.74 & 25.70 & 0.26 & 7.31 & 7.39 & 0.47 & 99.86 & 250 & 0.34 & 734 & 8.41 \\
\hline TA3f 25 & 60.31 & 24.68 & 0.32 & 6.05 & 7.84 & 0.52 & 99.71 & 260 & 0.29 & 704 & 8.59 \\
\hline TA3f 26 & 60.77 & 24.15 & 0.25 & 5.93 & 8.00 & 0.64 & 99.73 & 270 & 0.28 & 697 & 8.68 \\
\hline TA3f 27 & 59.62 & 24.93 & 0.17 & 6.04 & 7.95 & 0.51 & 99.21 & 280 & 0.29 & 703 & 8.59 \\
\hline TA3f 28 & 59.11 & 24.95 & 0.10 & 6.17 & 7.90 & 0.62 & 98.85 & 290 & 0.29 & 704 & 8.62 \\
\hline TA3f 29 & 49.83 & 20.96 & 0.41 & 5.04 & 6.54 & 0.55 & 83.34 & 300 & 0.29 & 701 & 8.65 \\
\hline TA3f 30 & 59.31 & 24.57 & 0.25 & 6.14 & 7.85 & 0.64 & 98.77 & 310 & 0.29 & 703 & 8.63 \\
\hline TA3f 31 & 60.50 & 24.86 & 0.27 & 5.90 & 7.88 & 0.59 & 100.00 & 320 & 0.28 & 699 & 8.65 \\
\hline TA $3 f 32$ & 60.45 & 24.80 & 0.20 & 6.02 & 8.04 & 0.61 & 100.11 & 330 & 0.28 & 699 & 8.65 \\
\hline TA3f 33 & 60.42 & 24.84 & 0.25 & 6.12 & 7.89 & 0.57 & 100.09 & 340 & 0.29 & 704 & 8.60 \\
\hline TA3f 34 & 59.30 & 24.62 & 0.34 & 6.28 & 7.85 & 0.61 & 98.99 & 350 & 0.30 & 707 & 8.60 \\
\hline TA3f 35 & 60.30 & 24.15 & 0.30 & 5.71 & 8.00 & 0.59 & 99.05 & 360 & 0.27 & 694 & 8.69 \\
\hline TA3f 36 & 61.14 & 24.16 & 0.20 & 5.29 & 8.19 & 0.71 & 99.69 & 370 & 0.25 & 679 & 8.85 \\
\hline TA3f 37 & 61.52 & 24.19 & 0.16 & 5.26 & 8.32 & 0.66 & 100.11 & 380 & 0.25 & 678 & 8.85 \\
\hline TA $3 f 38$ & 60.90 & 24.17 & 0.15 & 5.24 & 8.34 & 0.64 & 99.43 & 390 & 0.25 & 677 & 8.84 \\
\hline TA3f 39 & 61.13 & 23.67 & 0.17 & 4.98 & 8.23 & 0.77 & 98.96 & 400 & 0.24 & 670 & 8.95 \\
\hline TA3f 40 & 61.30 & 23.34 & 0.22 & 4.70 & 8.45 & 0.79 & 98.79 & 410 & 0.22 & 660 & 9.06 \\
\hline TA3f 41 & 62.39 & 23.41 & 0.19 & 4.68 & 8.47 & 0.74 & 99.87 & 420 & 0.22 & 660 & 9.04 \\
\hline TA3f 42 & 62.15 & 23.25 & 0.19 & 4.64 & 8.57 & 0.80 & 99.59 & 430 & 0.22 & 657 & 9.09 \\
\hline TA3f 43 & 62.78 & 23.24 & 0.20 & 4.36 & 8.97 & 0.80 & 100.35 & 440 & 0.20 & 645 & 9.23 \\
\hline TA3f 46 & 64.76 & 22.43 & 0.60 & 3.85 & 6.82 & 2.79 & 101.24 & 470 & 0.20 & 625 & 10.01 \\
\hline TA3f 50 & 63.71 & 23.94 & 0.16 & 4.73 & 8.04 & 0.75 & 101.32 & 510 & 0.23 & 667 & 8.98 \\
\hline TA3h 1a & 56.69 & 27.36 & 0.36 & 8.79 & 6.35 & 0.25 & 99.80 & 20 & 0.43 & 771 & 8.30 \\
\hline TA3h 1 & 57.41 & 26.46 & 0.38 & 7.91 & 6.90 & 0.31 & 99.37 & 30 & 0.38 & 753 & 8.29 \\
\hline TA3h 2 & 56.81 & 26.70 & 0.34 & 8.22 & 6.66 & 0.25 & 98.98 & 40 & 0.40 & 762 & 8.27 \\
\hline TA3h 3 & 57.16 & 26.91 & 0.34 & 8.68 & 6.43 & 0.27 & 99.79 & 50 & 0.42 & 769 & 8.30 \\
\hline TA3h 4 & 58.19 & 26.66 & 0.44 & 8.24 & 6.50 & 0.24 & 100.26 & 60 & 0.41 & 764 & 8.27 \\
\hline TA3h 5 & 57.81 & 26.80 & 0.37 & 8.66 & 6.34 & 0.30 & 100.29 & 70 & 0.42 & 769 & 8.32 \\
\hline TA3h 6 & 57.89 & 27.08 & 0.37 & 8.44 & 6.47 & 0.26 & 100.50 & 80 & 0.41 & 766 & 8.28 \\
\hline TA3h 7 & 57.84 & 26.95 & 0.36 & 8.64 & 6.55 & 0.25 & 100.57 & 90 & 0.42 & 768 & 8.28 \\
\hline TA3h 8 & 58.17 & 26.69 & 0.19 & 8.32 & 6.59 & 0.23 & 100.19 & 100 & 0.41 & 764 & 8.26 \\
\hline
\end{tabular}


Table A3.11 continued

\begin{tabular}{|c|c|c|c|c|c|c|c|c|c|c|c|}
\hline Sample & $\mathrm{SiO}_{2}$ & $\mathrm{Al}_{2} \mathrm{O}_{3}$ & $\mathrm{FeO}$ & $\mathrm{CaO}$ & $\mathrm{Na}_{2} \mathrm{O}$ & $\mathrm{K}_{2} \mathrm{O}$ & Total & $\begin{array}{r}\text { Dist } \\
(\mu \mathrm{m})\end{array}$ & $\begin{array}{c}X \\
\text { An } \\
\end{array}$ & $\begin{array}{c}\text { Temp } \\
\left({ }^{\circ} \mathrm{C}\right)\end{array}$ & $\begin{array}{c}\mathrm{H}_{2} \mathrm{O} \\
\left(\mathrm{wt}^{\circ} \%\right) \\
\end{array}$ \\
\hline TA3h 9 & 57.59 & 26.91 & 0.29 & 8.44 & 6.61 & 0.24 & 100.09 & 110 & 0.41 & 765 & 8.27 \\
\hline TA3h 10 & 57.04 & 27.26 & 0.34 & 8.52 & 6.58 & 0.24 & 99.98 & 120 & 0.41 & 766 & 8.27 \\
\hline TA3h 11 & 58.29 & 25.81 & 0.27 & 7.25 & 7.05 & 0.26 & 98.92 & 130 & 0.36 & 743 & 8.29 \\
\hline TA3h 12 & 59.38 & 25.31 & 0.27 & 7.17 & 7.30 & 0.36 & 99.79 & 140 & 0.34 & 736 & 8.36 \\
\hline TA3h 13 & 58.78 & 26.08 & 0.27 & 7.69 & 6.92 & 0.29 & 100.03 & 150 & 0.37 & 750 & 8.29 \\
\hline TA3h 14 & 58.54 & 25.92 & 0.34 & 7.59 & 6.87 & 0.30 & 99.56 & 160 & 0.37 & 749 & 8.30 \\
\hline TA3h 15 & 58.74 & 25.87 & 0.23 & 7.22 & 7.11 & 0.27 & 99.44 & 170 & 0.35 & 741 & 8.30 \\
\hline TA3h 16 & 58.72 & 25.67 & 0.20 & 7.40 & 7.18 & 0.27 & 99.44 & 180 & 0.36 & 743 & 8.29 \\
\hline TA3h 17 & 59.45 & 25.78 & 0.37 & 7.48 & 6.97 & 0.30 & 100.34 & 190 & 0.37 & 747 & 8.30 \\
\hline TA3h 18 & 60.65 & 25.66 & 0.22 & 7.15 & 7.19 & 0.33 & 101.19 & 200 & 0.35 & 738 & 8.34 \\
\hline TA3h 19 & 61.28 & 25.41 & 0.25 & 6.93 & 7.43 & 0.36 & 101.65 & 210 & 0.33 & 730 & 8.38 \\
\hline TA $3 \mathrm{~h} 20$ & 61.21 & 25.31 & 0.30 & 6.66 & 7.57 & 0.37 & 101.42 & 220 & 0.32 & 723 & 8.42 \\
\hline TA3h 21 & 60.16 & 25.71 & 0.30 & 7.10 & 7.39 & 0.27 & 100.93 & 230 & 0.34 & 735 & 8.32 \\
\hline TA3h 22 & 58.82 & 26.78 & 0.34 & 8.17 & 6.78 & 0.27 & 101.16 & 240 & 0.39 & 759 & 8.27 \\
\hline TA3h 23 & 57.85 & 26.37 & 0.36 & 7.95 & 6.61 & 0.25 & 99.38 & 250 & 0.39 & 759 & 8.26 \\
\hline TA3h 24 & 57.14 & 26.69 & 0.27 & 8.30 & 6.59 & 0.27 & 99.26 & 260 & 0.40 & 763 & 8.28 \\
\hline TA3h 25 & 58.84 & 26.86 & 0.35 & 8.55 & 6.65 & 0.21 & 101.46 & 270 & 0.41 & 767 & 8.25 \\
\hline TA3h 28 & 59.16 & 27.17 & 0.28 & 8.30 & 6.69 & 0.30 & 101.90 & 300 & 0.40 & 761 & 8.29 \\
\hline TA3h 29 & 58.71 & 27.76 & 0.29 & 8.86 & 6.27 & 0.24 & 102.13 & 310 & 0.43 & 773 & 8.31 \\
\hline TA3h 30 & 57.87 & 27.97 & 0.35 & 9.08 & 6.17 & 0.18 & 101.61 & 320 & 0.44 & 778 & 8.29 \\
\hline TA3h 32 & 58.08 & 27.54 & 0.31 & 9.13 & 6.15 & 0.20 & 101.42 & 340 & 0.45 & 778 & 8.31 \\
\hline TA3h 33 & 58.74 & 27.41 & 0.29 & 8.93 & 6.33 & 0.17 & 101.86 & 350 & 0.43 & 775 & 8.26 \\
\hline TA3h 35 & 58.53 & 27.40 & 0.34 & 9.02 & 6.29 & 0.25 & 101.82 & 370 & 0.44 & 774 & 8.31 \\
\hline TA3h 36 & 57.94 & 28.21 & 0.45 & 8.98 & 6.05 & 0.20 & 101.82 & 380 & 0.45 & 778 & 8.31 \\
\hline TA3h 39 & 57.19 & 27.85 & 0.34 & 9.32 & 6.20 & 0.21 & 101.12 & 410 & 0.45 & 779 & 8.32 \\
\hline TA3h 40 & 57.65 & 27.81 & 0.31 & 9.32 & 6.08 & 0.22 & 101.37 & 420 & 0.45 & 780 & 8.34 \\
\hline TA3h 41 & 57.80 & 27.81 & 0.33 & 9.55 & 6.01 & 0.23 & 101.72 & 430 & 0.46 & 782 & 8.37 \\
\hline TA3h 42 & 57.78 & 27.82 & 0.31 & 9.24 & 6.14 & 0.21 & 101.51 & 440 & 0.45 & 779 & 8.32 \\
\hline TA3h 43 & 57.82 & 27.71 & 0.29 & 9.18 & 6.23 & 0.18 & 101.41 & 450 & 0.44 & 778 & 8.29 \\
\hline TA3h 45 & 57.80 & 27.80 & 0.43 & 9.15 & 6.21 & 0.23 & 101.61 & 470 & 0.44 & 777 & 8.32 \\
\hline TA3h 46 & 57.65 & 27.64 & 0.34 & 9.05 & 6.18 & 0.22 & 101.06 & 480 & 0.44 & 777 & 8.31 \\
\hline TA3h 47 & 57.31 & 27.71 & 0.27 & 9.12 & 6.05 & 0.22 & 100.68 & 490 & 0.45 & 779 & 8.33 \\
\hline TA3h 48 & 56.93 & 27.89 & 0.36 & 9.45 & 6.06 & 0.21 & 100.89 & 500 & 0.46 & 782 & 8.35 \\
\hline TA3q 2 & 57.93 & 26.49 & 0.36 & 8.10 & 6.77 & 0.31 & 99.95 & 20 & 0.39 & 757 & 8.29 \\
\hline TA3q 3 & 58.20 & 26.04 & 0.37 & 7.84 & 6.70 & 0.29 & 99.44 & 30 & 0.39 & 755 & 8.29 \\
\hline TA3q 4 & 57.83 & 26.91 & 0.28 & 8.80 & 6.30 & 0.30 & 100.42 & 40 & 0.43 & 771 & 8.33 \\
\hline TA3q 5 & 58.32 & 26.87 & 0.30 & 9.16 & 6.30 & 0.23 & 101.18 & 50 & 0.44 & 776 & 8.31 \\
\hline TA3q 6 & 57.29 & 27.13 & 0.26 & 9.20 & 6.20 & 0.26 & 100.34 & 60 & 0.44 & 777 & 8.34 \\
\hline TA3q 7 & 57.41 & 27.98 & 0.30 & 9.80 & 5.98 & 0.22 & 101.69 & 70 & 0.47 & 784 & 8.40 \\
\hline TA3q 8 & 56.99 & 28.00 & 0.30 & 10.12 & 5.57 & 0.20 & 101.18 & 80 & 0.50 & 791 & 8.49 \\
\hline TA3q 9 & 56.90 & 27.18 & 0.33 & 9.11 & 6.08 & 0.24 & 99.84 & 90 & 0.45 & 778 & 8.34 \\
\hline TA $3 q$ & 57.31 & 26.83 & 0.29 & 8.57 & 6.39 & 0.24 & 99.63 & 100 & 0.42 & 769 & 8.28 \\
\hline TA3q 11 & 59.15 & 26.12 & 0.31 & 7.50 & 6.68 & 0.31 & 100.07 & 110 & 0.38 & 751 & 8.30 \\
\hline TA3q 12 & 59.69 & 26.04 & 0.30 & 7.91 & 6.70 & 0.31 & 100.94 & 120 & 0.39 & 756 & 8.30 \\
\hline TA3q 13 & 59.50 & 26.05 & 0.33 & 7.45 & 7.06 & 0.31 & 100.71 & 130 & 0.36 & 744 & 8.31 \\
\hline TA3q 14 & 60.81 & 25.56 & 0.28 & 7.47 & 6.99 & 0.29 & 101.41 & 140 & 0.37 & 746 & 8.30 \\
\hline TA3q 15 & 58.68 & 26.02 & 0.24 & 7.72 & 6.78 & 0.30 & 99.74 & 150 & 0.38 & 752 & 8.29 \\
\hline TA $3 \mathrm{q} 16$ & 59.73 & 25.77 & 0.33 & 7.56 & 6.86 & 0.26 & 100.50 & 160 & 0.37 & 750 & 8.27 \\
\hline TA3q 17 & 58.26 & 25.27 & 0.25 & 7.40 & 6.86 & 0.30 & 98.34 & 170 & 0.37 & 747 & 8.30 \\
\hline TA3q 18 & 59.99 & 25.90 & 0.22 & 7.44 & 6.98 & 0.35 & 100.88 & 180 & 0.36 & 744 & 8.33 \\
\hline TA $3 q$ & 59.20 & 26.10 & 0.28 & 7.64 & 7.16 & 0.29 & 100.66 & 190 & 0.36 & 746 & 8.29 \\
\hline TA3q 20 & 59.28 & 26.28 & 0.22 & 7.66 & 7.10 & 0.34 & 100.87 & 200 & 0.37 & 746 & 8.31 \\
\hline TA3q 21 & 58.33 & 25.74 & 0.29 & 7.26 & 7.01 & 0.31 & 98.93 & 210 & 0.36 & 742 & 8.31 \\
\hline TA3q 22 & 58.31 & 25.96 & 0.35 & 7.61 & 7.08 & 0.33 & 99.64 & 220 & 0.37 & 746 & 8.31 \\
\hline TA3q 23 & 58.42 & 25.86 & 0.21 & 7.23 & 6.88 & 0.30 & 98.90 & 230 & 0.36 & 744 & 8.31 \\
\hline TA3q 24 & 58.84 & 25.67 & 0.31 & 7.49 & 6.88 & 0.28 & 99.48 & 240 & 0.37 & 748 & 8.29 \\
\hline TA3q 25 & 59.72 & 25.55 & 0.30 & 7.34 & 7.02 & 0.39 & 100.31 & 250 & 0.36 & 741 & 8.35 \\
\hline TA3q 26 & 59.89 & 26.21 & 0.28 & 7.60 & 6.74 & 0.35 & 101.08 & 260 & 0.38 & 750 & 8.32 \\
\hline TA3q 27 & 59.60 & 26.13 & 0.34 & 7.70 & 6.93 & 0.31 & 101.02 & 270 & 0.37 & 750 & 8.30 \\
\hline TA3q 28 & 58.04 & 25.55 & 0.31 & 7.28 & 6.68 & 0.33 & 98.19 & 280 & 0.37 & 747 & 8.32 \\
\hline TA $3 q 29$ & 57.17 & 24.99 & 0.32 & 7.32 & 6.99 & 0.29 & 97.08 & 290 & 0.36 & 744 & 8.30 \\
\hline TA3q 34 & 57.14 & 26.98 & 0.27 & 8.89 & 6.41 & 0.24 & 99.94 & 340 & 0.43 & 772 & 8.29 \\
\hline TA $3 \mathrm{q} 35$ & 56.23 & 27.98 & 0.44 & 9.88 & 5.76 & 0.22 & 100.50 & 350 & 0.48 & 787 & 8.44 \\
\hline TA3q 36 & 55.74 & 28.23 & 0.35 & 10.51 & 5.49 & 0.21 & 100.53 & 360 & 0.51 & 793 & 8.56 \\
\hline TA3q 37 & 55.49 & 27.96 & 0.33 & 10.15 & 5.75 & 0.21 & 99.88 & 370 & 0.49 & 789 & 8.46 \\
\hline TA3q 38 & 55.73 & 27.98 & 0.31 & 10.30 & 5.67 & 0.20 & 100.19 & 380 & 0.50 & 791 & 8.49 \\
\hline TA3q 39 & 56.13 & 27.38 & 0.33 & 9.08 & 6.34 & 0.23 & 99.48 & 390 & 0.44 & 775 & 8.30 \\
\hline TA $3 q 40$ & 56.13 & 27.15 & 0.27 & 8.46 & 6.19 & 0.28 & 98.47 & 400 & 0.42 & 769 & 8.32 \\
\hline TA $3 \mathrm{q} 41$ & 56.28 & 27.00 & 0.32 & 8.65 & 6.30 & 0.21 & 98.76 & 410 & 0.43 & 772 & 8.28 \\
\hline TA3q 42 & 56.85 & 27.01 & 0.41 & 8.76 & 6.27 & 0.25 & 99.55 & 420 & 0.43 & 772 & 8.30 \\
\hline TA3q 43 & 57.37 & 26.80 & 0.29 & 8.55 & 6.17 & 0.23 & 99.42 & 430 & 0.43 & 772 & 8.29 \\
\hline TA $3 q 44$ & 58.62 & 26.77 & 0.39 & 8.91 & 6.47 & 0.24 & 101.41 & 440 & 0.43 & 772 & 8.29 \\
\hline TA $3 q 45$ & 58.66 & 26.92 & 0.28 & 8.79 & 6.33 & 0.26 & 101.24 & 450 & 0.43 & 771 & 8.31 \\
\hline TA3q 46 & 58.02 & 26.92 & 0.31 & 8.59 & 6.21 & 0.23 & 100.28 & 460 & 0.43 & 772 & 8.29 \\
\hline TA $3 \mathrm{q} 47$ & 57.61 & 26.92 & 0.29 & 8.94 & 6.37 & 0.24 & 100.38 & 470 & 0.43 & 773 & 8.30 \\
\hline
\end{tabular}


Table A3.11 continued

\begin{tabular}{|c|c|c|c|c|c|c|c|c|c|c|c|}
\hline Sample & $\mathrm{SiO}_{2}$ & $\mathrm{Al}_{2} \mathrm{O}_{3}$ & $\mathrm{FeO}$ & $\mathrm{CaO}$ & $\mathrm{Na}_{2} \mathrm{O}$ & $\mathrm{K}_{2} \mathrm{O}$ & Total & $\begin{array}{r}\text { Dist } \\
(\mu \mathrm{m})\end{array}$ & $\begin{array}{c}X \\
\text { An } \\
\end{array}$ & $\begin{array}{c}\text { Temp } \\
\left({ }^{\circ} \mathrm{C}\right)\end{array}$ & $\begin{array}{c}\mathrm{H}_{2} \mathrm{O} \\
\left(\mathrm{wt}^{\circ} \%\right) \\
\end{array}$ \\
\hline TA3a 48 & 57.38 & 26.76 & 0.36 & 8.53 & 6.57 & 0.28 & 99.89 & 480 & 0.41 & 765 & 8.29 \\
\hline TA3q 49 & 56.75 & 26.92 & 0.36 & 9.01 & 6.49 & 0.22 & 99.74 & 490 & 0.43 & 773 & 8.28 \\
\hline TA $3 \mathrm{q} 50$ & 57.16 & 27.05 & 0.35 & 8.62 & 6.46 & 0.25 & 99.89 & 500 & 0.42 & 768 & 8.29 \\
\hline TA $3 \mathrm{q} 51$ & 57.14 & 27.25 & 0.27 & 8.88 & 6.18 & 0.22 & 99.94 & 510 & 0.44 & 775 & 8.30 \\
\hline TA3q 52 & 57.22 & 26.79 & 0.37 & 8.85 & 6.34 & 0.23 & 99.79 & 520 & 0.43 & 773 & 8.29 \\
\hline TA3q 53 & 57.42 & 27.34 & 0.26 & 9.20 & 6.41 & 0.26 & 100.88 & 530 & 0.44 & 774 & 8.32 \\
\hline TA3q 54 & 56.95 & 27.34 & 0.43 & 9.32 & 6.27 & 0.25 & 100.55 & 540 & 0.44 & 777 & 8.33 \\
\hline TA $3 q 55$ & 56.38 & 27.31 & 0.32 & 9.15 & 6.13 & 0.24 & 99.52 & 550 & 0.45 & 778 & 8.33 \\
\hline TA3q 56 & 57.58 & 26.54 & 0.39 & 8.16 & 6.82 & 0.30 & 99.78 & 560 & 0.39 & 757 & 8.29 \\
\hline TA $3 q 57$ & 58.13 & 26.01 & 0.26 & 7.98 & 6.75 & 0.28 & 99.40 & 570 & 0.39 & 757 & 8.28 \\
\hline TA $3 q 58$ & 61.23 & 24.13 & 0.61 & 6.78 & 6.17 & 0.71 & 99.62 & 580 & 0.36 & 736 & 8.55 \\
\hline TA4a 2 & 59.86 & 26.14 & 0.32 & 7.64 & 7.13 & 0.33 & 101.42 & 20 & 0.36 & 746 & 8.31 \\
\hline TA4a 3 & 60.15 & 25.71 & 0.23 & 7.35 & 7.46 & 0.32 & 101.21 & 30 & 0.35 & 737 & 8.33 \\
\hline TA4a 4 & 59.34 & 26.53 & 0.32 & 8.29 & 6.98 & 0.33 & 101.77 & 40 & 0.39 & 756 & 8.30 \\
\hline TA4a 5 & 58.55 & 25.73 & 0.30 & 7.57 & 7.17 & 0.37 & 99.70 & 50 & 0.36 & 743 & 8.34 \\
\hline TA4a 7 & 59.52 & 26.16 & 0.32 & 7.65 & 7.45 & 0.31 & 101.41 & 70 & 0.36 & 742 & 8.31 \\
\hline TA4a 8 & 58.18 & 26.06 & 0.24 & 7.42 & 7.22 & 0.28 & 99.40 & 80 & 0.36 & 742 & 8.30 \\
\hline ТА $4 \mathrm{a} 9$ & 58.45 & 25.78 & 0.34 & 7.45 & 7.32 & 0.34 & 99.67 & 90 & 0.35 & 740 & 8.33 \\
\hline TA4a 10 & 59.33 & 25.34 & 0.32 & 7.33 & 7.24 & 0.35 & 99.92 & 100 & 0.35 & 739 & 8.34 \\
\hline TA4a 11 & 59.38 & 25.42 & 0.21 & 7.46 & 7.14 & 0.30 & 99.91 & 110 & 0.36 & 744 & 8.30 \\
\hline TA $4 \mathrm{a} 12$ & 58.77 & 25.52 & 0.31 & 7.25 & 6.98 & 0.29 & 99.11 & 120 & 0.36 & 743 & 8.30 \\
\hline TA4a 13 & 58.17 & 25.60 & 0.31 & 7.47 & 7.18 & 0.27 & 99.00 & 130 & 0.36 & 744 & 8.29 \\
\hline TA4a 14 & 57.81 & 25.40 & 0.36 & 7.14 & 7.03 & 0.31 & 98.06 & 140 & 0.35 & 740 & 8.32 \\
\hline TA4a 15 & 56.62 & 25.77 & 0.27 & 7.71 & 6.71 & 0.30 & 97.38 & 150 & 0.38 & 753 & 8.29 \\
\hline TA4a 17 & 57.81 & 26.31 & 0.26 & 8.12 & 6.82 & 0.31 & 99.63 & 170 & 0.39 & 757 & 8.29 \\
\hline TA4a 18 & 59.84 & 26.41 & 0.24 & 8.15 & 6.83 & 0.32 & 101.78 & 180 & 0.39 & 757 & 8.30 \\
\hline TA4a 21 & 59.86 & 26.00 & 0.27 & 7.85 & 7.27 & 0.33 & 101.57 & 210 & 0.37 & 747 & 8.31 \\
\hline TA4a 22 & 58.45 & 25.78 & 0.21 & 8.07 & 6.82 & 0.31 & 99.63 & 220 & 0.39 & 756 & 8.29 \\
\hline TA4a 23 & 59.72 & 26.49 & 0.31 & 7.83 & 7.36 & 0.28 & 101.98 & 230 & 0.36 & 746 & 8.28 \\
\hline TA4a 30 & 60.54 & 25.85 & 0.30 & 7.56 & 7.19 & 0.34 & 101.78 & 300 & 0.36 & 743 & 8.32 \\
\hline TA4a 31 & 60.06 & 25.84 & 0.35 & 7.31 & 7.47 & 0.29 & 101.32 & 310 & 0.35 & 737 & 8.32 \\
\hline TA4a 32 & 58.66 & 25.53 & 0.24 & 7.16 & 7.02 & 0.28 & 98.87 & 320 & 0.35 & 742 & 8.30 \\
\hline TA4a 34 & 58.37 & 26.88 & 0.27 & 8.61 & 6.43 & 0.20 & 100.77 & 340 & 0.42 & 770 & 8.26 \\
\hline TA4a 36 & 59.43 & 26.81 & 0.29 & 8.16 & 7.02 & 0.29 & 101.98 & 360 & 0.38 & 755 & 8.28 \\
\hline TA4a 38 & 58.43 & 26.92 & 0.28 & 8.65 & 6.61 & 0.22 & 101.10 & 380 & 0.41 & 768 & 8.26 \\
\hline TA4a 39 & 57.42 & 26.73 & 0.37 & 8.64 & 6.71 & 0.24 & 100.11 & 390 & 0.41 & 766 & 8.27 \\
\hline TA4a 41 & 59.45 & 26.42 & 0.31 & 8.56 & 6.64 & 0.27 & 101.64 & 410 & 0.41 & 765 & 8.29 \\
\hline TA4a 42 & 58.48 & 26.40 & 0.34 & 8.34 & 6.59 & 0.24 & 100.38 & 420 & 0.41 & 764 & 8.26 \\
\hline TA4a 43 & 59.27 & 26.76 & 0.30 & 8.50 & 6.75 & 0.27 & 101.84 & 430 & 0.40 & 763 & 8.28 \\
\hline TA4a 45 & 56.21 & 26.37 & 0.24 & 8.76 & 6.33 & 0.26 & 98.16 & 450 & 0.43 & 771 & 8.31 \\
\hline TA4a 48 & 59.38 & 26.89 & 0.35 & 8.38 & 6.59 & 0.30 & 101.88 & 480 & 0.41 & 763 & 8.30 \\
\hline TA4a 52 & 57.94 & 26.99 & 0.31 & 8.97 & 6.70 & 0.28 & 101.18 & 520 & 0.42 & 768 & 8.29 \\
\hline TA4a 53 & 57.04 & 26.44 & 0.33 & 8.60 & 6.53 & 0.27 & 99.19 & 530 & 0.41 & 767 & 8.29 \\
\hline TA4a 59 & 59.28 & 26.49 & 0.38 & 8.06 & 6.82 & 0.26 & 101.30 & 590 & 0.39 & 757 & 8.27 \\
\hline TA4a 60 & 58.57 & 26.84 & 0.17 & 8.54 & 6.63 & 0.27 & 101.01 & 600 & 0.41 & 765 & 8.28 \\
\hline TA4a 61 & 58.88 & 27.10 & 0.21 & 8.59 & 6.66 & 0.28 & 101.72 & 610 & 0.41 & 765 & 8.29 \\
\hline TA4a 62 & 58.27 & 27.18 & 0.36 & 8.87 & 6.68 & 0.28 & 101.62 & 620 & 0.42 & 768 & 8.29 \\
\hline TA4a 68 & 58.22 & 26.74 & 0.27 & 8.78 & 6.72 & 0.29 & 101.02 & 680 & 0.41 & 766 & 8.30 \\
\hline TA4a 69 & 58.15 & 27.16 & 0.30 & 8.52 & 6.58 & 0.26 & 100.98 & 690 & 0.41 & 766 & 8.28 \\
\hline TA4a 70 & 58.27 & 27.37 & 0.31 & 8.94 & 6.66 & 0.24 & 101.78 & 700 & 0.42 & 770 & 8.28 \\
\hline TA4a 71 & 58.04 & 26.63 & 0.32 & 8.46 & 6.83 & 0.26 & 100.53 & 710 & 0.40 & 762 & 8.27 \\
\hline TA4c 3 & 57.96 & 26.80 & 0.34 & 8.59 & 6.78 & 0.28 & 100.73 & 20 & 0.41 & 763 & 8.28 \\
\hline TA4c 4 & 58.43 & 27.01 & 0.40 & 8.38 & 7.00 & 0.30 & 101.51 & 30 & 0.39 & 758 & 8.28 \\
\hline TA4c 5 & 58.48 & 27.32 & 0.33 & 8.93 & 6.56 & 0.30 & 101.91 & 40 & 0.42 & 769 & 8.31 \\
\hline TA4c 6 & 58.60 & 26.77 & 0.37 & 8.46 & 6.94 & 0.26 & 101.40 & 50 & 0.40 & 760 & 8.27 \\
\hline TA4c 10 & 60.79 & 25.79 & 0.31 & 7.12 & 7.63 & 0.30 & 101.94 & 90 & 0.33 & 732 & 8.35 \\
\hline TA4c 11 & 59.54 & 26.17 & 0.22 & 7.76 & 7.47 & 0.28 & 101.44 & 100 & 0.36 & 744 & 8.29 \\
\hline TA4c 12 & 59.83 & 26.01 & 0.21 & 7.50 & 7.40 & 0.33 & 101.28 & 110 & 0.35 & 740 & 8.32 \\
\hline TA4c 13 & 59.79 & 26.43 & 0.30 & 7.95 & 7.19 & 0.23 & 101.89 & 120 & 0.37 & 752 & 8.25 \\
\hline TA4c 17 & 57.11 & 27.93 & 0.38 & 9.81 & 6.21 & 0.19 & 101.63 & 160 & 0.46 & 783 & 8.35 \\
\hline TA4c 18 & 56.69 & 28.42 & 0.43 & 10.14 & 5.88 & 0.21 & 101.77 & 170 & 0.48 & 788 & 8.44 \\
\hline TA4c 19 & 56.32 & 28.59 & 0.33 & 10.31 & 5.93 & 0.19 & 101.66 & 180 & 0.49 & 789 & 8.43 \\
\hline TA4c 25 & 56.55 & 28.64 & 0.42 & 10.14 & 5.92 & 0.21 & 101.89 & 240 & 0.48 & 787 & 8.43 \\
\hline TA4c 31 & 56.57 & 28.58 & 0.37 & 10.47 & 5.75 & 0.25 & 101.99 & 300 & 0.49 & 789 & 8.52 \\
\hline TA4c 33 & 56.42 & 28.41 & 0.33 & 10.23 & 5.96 & 0.20 & 101.55 & 320 & 0.48 & 788 & 8.43 \\
\hline TA4c 40 & 58.11 & 27.83 & 0.26 & 9.09 & 6.38 & 0.23 & 101.91 & 390 & 0.43 & 775 & 8.30 \\
\hline TA4c 45 & 59.57 & 26.57 & 0.33 & 7.75 & 7.15 & 0.31 & 101.69 & 440 & 0.37 & 747 & 8.30 \\
\hline TA4c 46 & 59.75 & 26.43 & 0.31 & 7.80 & 7.31 & 0.33 & 101.92 & 450 & 0.36 & 745 & 8.31 \\
\hline TA4c 47 & 60.06 & 25.96 & 0.26 & 7.47 & 7.29 & 0.29 & 101.33 & 460 & 0.36 & 742 & 8.30 \\
\hline TA4c 53 & 58.99 & 26.88 & 0.28 & 7.88 & 7.26 & 0.31 & 101.59 & 520 & 0.37 & 748 & 8.29 \\
\hline TA4c 54 & 59.21 & 26.74 & 0.28 & 8.19 & 6.56 & 0.23 & 101.20 & 530 & 0.40 & 763 & 8.26 \\
\hline TA4c 62 & 58.00 & 27.58 & 0.29 & 9.07 & 6.59 & 0.25 & 101.79 & 610 & 0.43 & 771 & 8.29 \\
\hline TA4c 63 & 57.99 & 27.23 & 0.33 & 8.92 & 6.69 & 0.23 & 101.39 & 620 & 0.42 & 769 & 8.27 \\
\hline TA4c 64 & 58.19 & 27.18 & 0.39 & 8.91 & 6.63 & 0.24 & 101.55 & 630 & 0.42 & 770 & 8.28 \\
\hline
\end{tabular}


Table A3.11 continued

\begin{tabular}{|c|c|c|c|c|c|c|c|c|c|c|c|}
\hline Sample & $\mathrm{SiO}_{2}$ & $\mathrm{Al}_{2} \mathrm{O}_{3}$ & $\mathrm{FeO}$ & $\mathrm{CaO}$ & $\mathrm{Na}_{2} \mathrm{O}$ & $\mathrm{K}_{2} \mathrm{O}$ & Total & $\begin{array}{l}\text { Dist } \\
(\mu \mathrm{m})\end{array}$ & $\begin{array}{c}X \\
\text { An } \\
\end{array}$ & $\begin{array}{c}\text { Temp } \\
\left({ }^{\circ} \mathrm{C}\right)\end{array}$ & $\begin{array}{c}\mathrm{H}_{2} \mathrm{O} \\
(\mathrm{wt} \%) \\
\end{array}$ \\
\hline TA4c 65 & 58.72 & 27.61 & 0.24 & 9.17 & 6.42 & 0.25 & 102.41 & 640 & 0.43 & $\begin{array}{l}774 \\
775\end{array}$ & $\begin{array}{l}8.31 \\
8\end{array}$ \\
\hline TA4c 66 & 58.88 & 27.71 & 0.30 & 9.25 & 6.52 & 0.20 & 102.86 & 650 & 0.43 & 775 & 8.28 \\
\hline TA4c 67 & 58.71 & 27.73 & 0.38 & 8.94 & 6.48 & 0.25 & 102.50 & 660 & 0.43 & 771 & 8.29 \\
\hline TA4c 68 & 58.51 & 27.52 & 0.24 & 9.11 & 6.78 & 0.24 & 102.41 & 670 & 0.42 & 770 & 8.27 \\
\hline ТА4c 69 & 58.32 & 27.44 & 0.33 & 8.67 & 6.71 & 0.25 & 101.73 & 680 & 0.41 & 766 & 8.27 \\
\hline TA4c 70 & 58.20 & 27.32 & 0.38 & 8.85 & 6.63 & 0.29 & 101.67 & 690 & 0.42 & 768 & 8.30 \\
\hline TA4f 1 & 66.55 & 21.62 & 0.90 & 5.82 & 5.71 & 1.19 & 101.78 & 20 & 0.33 & 713 & 8.88 \\
\hline TA4f 2 & 55.20 & 27.38 & 0.33 & 8.71 & 6.83 & 0.22 & 98.66 & 30 & 0.41 & 765 & 8.25 \\
\hline TA4f 6 & 59.05 & 26.37 & 0.29 & 8.69 & 6.72 & 0.23 & 101.35 & 70 & 0.41 & 766 & 8.26 \\
\hline TA4f 7 & 59.66 & 26.47 & 0.32 & 8.30 & 6.95 & 0.29 & 101.99 & 80 & 0.39 & 757 & 8.28 \\
\hline TA4f 8 & 58.85 & 26.58 & 0.29 & 8.51 & 6.69 & 0.28 & 101.19 & 90 & 0.41 & 763 & 8.28 \\
\hline TA4f 9 & 59.35 & 26.51 & 0.25 & 8.61 & 6.84 & 0.29 & 101.84 & 100 & 0.40 & 762 & 8.28 \\
\hline TA4f 11 & 58.22 & 26.47 & 0.19 & 8.91 & 6.56 & 0.26 & 100.60 & 120 & 0.42 & 769 & 8.29 \\
\hline TA4f 13 & 58.76 & 26.99 & 0.29 & 9.14 & 6.38 & 0.29 & 101.85 & 140 & 0.43 & 773 & 8.33 \\
\hline TA4f 14 & 58.70 & 27.17 & 0.30 & 9.14 & 6.30 & 0.31 & 101.92 & 150 & 0.44 & 773 & 8.35 \\
\hline TA4f 15 & 57.82 & 27.20 & 0.40 & 9.37 & 6.32 & 0.21 & 101.32 & 160 & 0.45 & 778 & 8.31 \\
\hline TA4f 16 & 58.36 & 26.74 & 0.27 & 8.91 & 6.43 & 0.24 & 100.94 & 170 & 0.43 & 772 & 8.29 \\
\hline TA4f 17 & 58.49 & 26.92 & 0.31 & 8.79 & 6.58 & 0.23 & 101.33 & 180 & 0.42 & 769 & 8.27 \\
\hline TA4f 18 & 58.81 & 26.78 & 0.30 & 8.80 & 6.67 & 0.23 & 101.58 & 190 & 0.42 & 768 & 8.27 \\
\hline TA4f 21 & 58.07 & 27.48 & 0.35 & 8.94 & 6.00 & 0.25 & 101.10 & 220 & 0.44 & 776 & 8.34 \\
\hline TA4f 25 & 57.16 & 27.75 & 0.34 & 9.49 & 6.28 & 0.24 & 101.26 & 260 & 0.45 & 778 & 8.34 \\
\hline TA4f 26 & 57.02 & 27.94 & 0.32 & 9.63 & 6.22 & 0.23 & 101.35 & 270 & 0.46 & 780 & 8.35 \\
\hline TA4f 27 & 57.17 & 27.90 & 0.42 & 9.40 & 6.37 & 0.26 & 101.52 & 280 & 0.44 & 776 & 8.34 \\
\hline TA4f 28 & 57.31 & 27.41 & 0.24 & 9.40 & 6.09 & 0.27 & 100.73 & 290 & 0.45 & 779 & 8.37 \\
\hline TA4f 31 & 58.12 & 27.61 & 0.35 & 9.20 & 6.26 & 0.29 & 101.82 & 320 & 0.44 & 775 & 8.35 \\
\hline TA4f 33 & 57.05 & 28.28 & 0.41 & 9.75 & 6.18 & 0.22 & 101.89 & 340 & 0.46 & 782 & 8.36 \\
\hline TA4f 34 & 56.15 & 28.61 & 0.33 & 10.13 & 5.88 & 0.18 & 101.27 & 350 & 0.48 & 788 & 8.42 \\
\hline TA4f 35 & 55.94 & 28.59 & 0.44 & 10.50 & 5.69 & 0.18 & 101.34 & 360 & 0.50 & 792 & 8.50 \\
\hline TA4f 36 & 57.23 & 27.48 & 0.36 & 9.47 & 6.39 & 0.24 & 101.17 & 370 & 0.44 & 777 & 8.33 \\
\hline TA4f 37 & 57.63 & 27.14 & 0.37 & 9.08 & 6.56 & 0.26 & 101.04 & 380 & 0.43 & 771 & 8.30 \\
\hline TA4f 38 & 57.94 & 27.26 & 0.37 & 9.32 & 6.39 & 0.20 & 101.47 & 390 & 0.44 & 777 & 8.30 \\
\hline TA4f 40 & 58.11 & 27.34 & 0.32 & 8.82 & 6.34 & 0.28 & 101.19 & 410 & 0.43 & 771 & 8.32 \\
\hline TA4f 42 & 57.73 & 27.40 & 0.31 & 9.02 & 6.57 & 0.32 & 101.33 & 430 & 0.42 & 769 & 8.33 \\
\hline TA4f 43 & 56.94 & 27.66 & 0.29 & 9.28 & 6.52 & 0.23 & 100.91 & 440 & 0.43 & 774 & 8.30 \\
\hline TA4f 44 & 57.13 & 27.36 & 0.32 & 9.18 & 6.54 & 0.26 & 100.79 & 450 & 0.43 & 772 & 8.30 \\
\hline TA4f 45 & 57.42 & 27.20 & 0.38 & 9.15 & 6.30 & 0.26 & 100.70 & 460 & 0.44 & 775 & 8.33 \\
\hline TA4f 46 & 57.73 & 27.26 & 0.41 & 9.38 & 6.43 & 0.23 & 101.42 & 470 & 0.44 & 776 & 8.31 \\
\hline TA4f 47 & 57.77 & 27.57 & 0.38 & 9.18 & 6.31 & 0.24 & 101.45 & 480 & 0.44 & 775 & 8.32 \\
\hline TA4f 48 & 57.49 & 27.50 & 0.36 & 9.50 & 6.51 & 0.28 & 101.64 & 490 & 0.44 & 775 & 8.34 \\
\hline TA4f 49 & 57.43 & 27.72 & 0.40 & 9.14 & 6.40 & 0.26 & 101.34 & 500 & 0.43 & 774 & 8.31 \\
\hline TA4f 50 & 57.36 & 27.60 & 0.40 & 9.42 & 6.57 & 0.20 & 101.56 & 510 & 0.44 & 776 & 8.28 \\
\hline TA4f 51 & 56.94 & 27.63 & 0.30 & 9.56 & 6.36 & 0.24 & 101.03 & 520 & 0.45 & 778 & 8.33 \\
\hline TA4f 52 & 57.08 & 27.73 & 0.32 & 9.61 & 6.18 & 0.23 & 101.15 & 530 & 0.46 & 780 & 8.36 \\
\hline TA4f 53 & 56.44 & 28.20 & 0.34 & 9.92 & 6.10 & 0.24 & 101.24 & 540 & 0.47 & 783 & 8.40 \\
\hline TA4f 54 & 56.63 & 28.24 & 0.34 & 10.14 & 5.87 & 0.19 & 101.41 & 550 & 0.48 & 788 & 8.43 \\
\hline TA4f 55 & 56.46 & 28.30 & 0.30 & 10.29 & 6.03 & 0.18 & 101.56 & 560 & 0.48 & 788 & 8.41 \\
\hline TA4f 56 & 55.92 & 28.51 & 0.32 & 10.45 & 5.97 & 0.18 & 101.34 & 570 & 0.49 & 789 & 8.44 \\
\hline TA4f 57 & 55.92 & 28.81 & 0.41 & 10.40 & 5.84 & 0.20 & 101.58 & 580 & 0.49 & 790 & 8.46 \\
\hline TA4f 58 & 56.14 & 28.23 & 0.42 & 10.32 & 6.00 & 0.20 & 101.29 & 590 & 0.48 & 788 & 8.42 \\
\hline TA4f 59 & 56.33 & 28.30 & 0.35 & 10.14 & 5.98 & 0.23 & 101.32 & 600 & 0.48 & 786 & 8.43 \\
\hline TA4f 60 & 56.26 & 28.07 & 0.33 & 9.97 & 5.96 & 0.17 & 100.76 & 610 & 0.48 & 787 & 8.39 \\
\hline TA4f 61 & 56.35 & 28.29 & 0.37 & 10.33 & 5.92 & 0.17 & 101.43 & 620 & 0.49 & 789 & 8.43 \\
\hline TA4f 62 & 56.50 & 28.41 & 0.44 & 10.27 & 5.75 & 0.23 & 101.61 & 630 & 0.49 & 789 & 8.49 \\
\hline TA4f 64 & 56.14 & 28.66 & 0.37 & 10.25 & 5.99 & 0.19 & 101.59 & 650 & 0.48 & 788 & 8.42 \\
\hline TA4f 65 & 55.99 & 28.23 & 0.32 & 10.21 & 5.78 & 0.22 & 100.75 & 660 & 0.49 & 788 & 8.47 \\
\hline TA4f 66 & 55.85 & 28.30 & 0.35 & 10.33 & 5.86 & 0.24 & 100.92 & 670 & 0.49 & 788 & 8.47 \\
\hline TA4f 67 & 55.81 & 28.48 & 0.40 & 10.15 & 5.81 & 0.18 & 100.82 & 680 & 0.49 & 789 & 8.44 \\
\hline TA4f 68 & 56.12 & 27.75 & 0.37 & 9.96 & 6.07 & 0.20 & 100.47 & 690 & 0.47 & 785 & 8.38 \\
\hline TA4f 69 & 56.72 & 27.70 & 0.38 & 9.47 & 6.09 & 0.22 & 100.58 & 700 & 0.46 & 781 & 8.35 \\
\hline TA4f 70 & 56.72 & 27.82 & 0.37 & 9.49 & 6.16 & 0.21 & 100.76 & 710 & 0.45 & 780 & 8.34 \\
\hline TA4f 71 & 57.26 & 27.46 & 0.52 & 9.58 & 6.41 & 0.23 & 101.46 & 720 & 0.45 & 778 & 8.32 \\
\hline TA4f 72 & 57.29 & 27.57 & 0.34 & 9.31 & 6.24 & 0.23 & 100.98 & 730 & 0.45 & 777 & 8.32 \\
\hline TA4f 73 & 56.90 & 27.69 & 0.32 & 9.38 & 6.33 & 0.26 & 100.88 & 740 & 0.44 & 776 & 8.34 \\
\hline TA4f 74 & 56.77 & 27.47 & 0.46 & 9.51 & 6.37 & 0.23 & 100.80 & 750 & 0.45 & 778 & 8.32 \\
\hline TA4f 75 & 56.58 & 27.45 & 0.37 & 9.36 & 6.13 & 0.26 & 100.15 & 760 & 0.45 & 778 & 8.36 \\
\hline TA4f 76 & 56.84 & 27.48 & 0.35 & 9.45 & 6.46 & 0.22 & 100.81 & 770 & 0.44 & 777 & 8.31 \\
\hline TA4f 77 & 56.89 & 27.82 & 0.33 & 9.64 & 6.21 & 0.26 & 101.14 & 780 & 0.45 & 779 & 8.37 \\
\hline TA4f 78 & 56.81 & 27.66 & 0.32 & 9.56 & 6.31 & 0.24 & 100.89 & 790 & 0.45 & 779 & 8.34 \\
\hline TA4f 79 & 57.09 & 27.55 & 0.38 & 9.41 & 6.18 & 0.20 & 100.81 & 800 & 0.45 & 780 & 8.32 \\
\hline TA4f 80 & 57.11 & 27.76 & 0.37 & 9.50 & 6.11 & 0.23 & 101.08 & 810 & 0.46 & 780 & 8.36 \\
\hline TA4f 81 & 56.84 & 27.68 & 0.41 & 9.38 & 6.37 & 0.24 & 100.91 & 820 & 0.44 & 776 & 8.32 \\
\hline TA4f 82 & 56.92 & 27.92 & 0.34 & 9.62 & 6.08 & 0.20 & 101.08 & 830 & 0.46 & 783 & 8.35 \\
\hline TA4f 83 & 56.54 & 27.29 & 0.32 & 9.35 & 6.37 & 0.28 & 100.15 & 840 & 0.44 & 775 & 8.34 \\
\hline TA4f 84 & 56.33 & 27.85 & 0.38 & 9.36 & 6.28 & 0.20 & 100.39 & 850 & 0.45 & 779 & 8.31 \\
\hline TA4f 85 & 56.70 & 27.69 & 0.37 & 9.52 & 6.29 & 0.24 & 100.81 & 860 & 0.45 & 778 & 8.34 \\
\hline
\end{tabular}


Table A3.11 continued

\begin{tabular}{lccccccccccc}
\hline Sample & $\mathrm{SiO}_{2}$ & $\mathrm{Al}_{2} \mathrm{O}_{3}$ & $\mathrm{FeO}$ & $\mathrm{CaO}$ & $\mathrm{Na}_{2} \mathrm{O}$ & $\mathrm{K}_{2} \mathrm{O}$ & Total & $\begin{array}{c}\text { Dist } \\
(\mu \mathrm{m})\end{array}$ & $\begin{array}{c}\mathrm{X} \\
\mathrm{An}\end{array}$ & $\begin{array}{c}\mathrm{Temp} \\
\left({ }^{\circ} \mathrm{C}\right)\end{array}$ & $\begin{array}{c}\mathrm{H}_{2} \mathrm{O} \\
(\mathrm{wt} \%)\end{array}$ \\
\hline TA4f 86 & 56.80 & 27.67 & 0.29 & 9.70 & 6.26 & 0.24 & 100.96 & 870 & 0.46 & 780 & 8.36 \\
TA4f 87 & 57.17 & 27.77 & 0.41 & 9.42 & 6.21 & 0.23 & 101.21 & 880 & 0.45 & 779 & 8.34 \\
TA4f 88 & 56.95 & 27.67 & 0.38 & 9.70 & 6.60 & 0.27 & 101.56 & 890 & 0.44 & 776 & 8.33 \\
TA4f 89 & 57.27 & 27.61 & 0.23 & 9.90 & 6.20 & 0.25 & 101.46 & 900 & 0.46 & 782 & 8.39 \\
TA4f 90 & 57.25 & 27.10 & 0.46 & 9.21 & 6.45 & 0.24 & 100.70 & 910 & 0.44 & 774 & 8.30 \\
TA4f 91 & 57.22 & 27.21 & 0.34 & 8.93 & 6.54 & 0.26 & 100.50 & 920 & 0.42 & 770 & 8.29 \\
TA4f 92 & 57.58 & 27.27 & 0.29 & 9.11 & 6.54 & 0.26 & 101.05 & 930 & 0.43 & 772 & 8.30 \\
TA4f 93 & 58.06 & 27.15 & 0.36 & 9.17 & 6.85 & 0.26 & 101.85 & 940 & 0.42 & 769 & 8.28 \\
TA4f 94 & 56.88 & 27.65 & 0.28 & 9.30 & 6.46 & 0.23 & 100.79 & 950 & 0.44 & 775 & 8.30 \\
TA4f 95 & 57.18 & 27.63 & 0.37 & 9.32 & 6.33 & 0.25 & 101.07 & 960 & 0.44 & 776 & 8.33 \\
TA4f 96 & 57.24 & 27.45 & 0.33 & 8.87 & 6.64 & 0.27 & 100.80 & 970 & 0.42 & 768 & 8.29 \\
TA4f 97 & 58.11 & 26.97 & 0.30 & 8.54 & 6.71 & 0.27 & 100.91 & 980 & 0.41 & 764 & 8.28 \\
TA4f 98 & 57.38 & 26.62 & 0.25 & 8.41 & 6.60 & 0.25 & 99.51 & 990 & 0.41 & 764 & 8.27 \\
TA4f 99 & 57.77 & 26.68 & 0.29 & 8.69 & 6.78 & 0.28 & 100.49 & 1000 & 0.41 & 764 & 8.29 \\
TA4f 100 & 57.77 & 26.88 & 0.24 & 8.81 & 6.74 & 0.26 & 100.71 & 1010 & 0.41 & 766 & 8.28 \\
TA4f 101 & 57.78 & 26.86 & 0.28 & 8.75 & 6.79 & 0.28 & 100.74 & 1020 & 0.41 & 765 & 8.28 \\
TA4f 102 & 58.23 & 26.64 & 0.32 & 8.54 & 6.88 & 0.26 & 100.87 & 1030 & 0.40 & 762 & 8.27 \\
TA4f 103 & 57.94 & 27.18 & 0.41 & 8.72 & 6.55 & 0.25 & 101.05 & 1040 & 0.42 & 768 & 8.28 \\
TA4f 104 & 57.78 & 26.68 & 0.45 & 8.83 & 6.84 & 0.29 & 100.86 & 1050 & 0.41 & 764 & 8.29 \\
\hline
\end{tabular}

Major elements are given in $\mathrm{wt} \%, X \mathrm{An}$ are calculated on a mole fraction basis and temperatures (temp) and $\mathrm{H}_{2} \mathrm{O}$ concentration (wt\%) are calculated using the Plagioclase-melt equilibria of Putirka (2005) and a pressure of $100 \mathrm{MPa}$. Distance represents the distance from the start of the profile and correlates with ' $\mathrm{S}$ ' on the relevant backscatter image 


\section{Appendix 4}

Figure A4.1: Backscattered electron images and $X_{\text {An }}$ profiles of Whakamaru plagioclase crystals. Vertical dash lines represent the crystal core. 
Figure A4.1

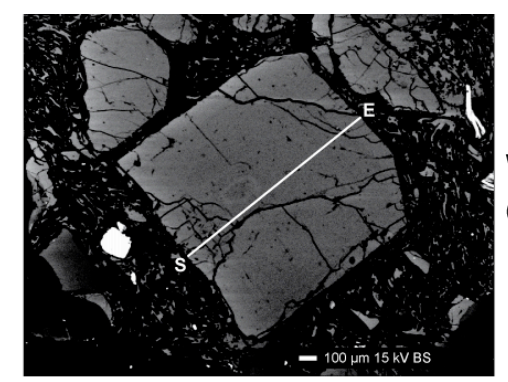

WH1 b

Group 2
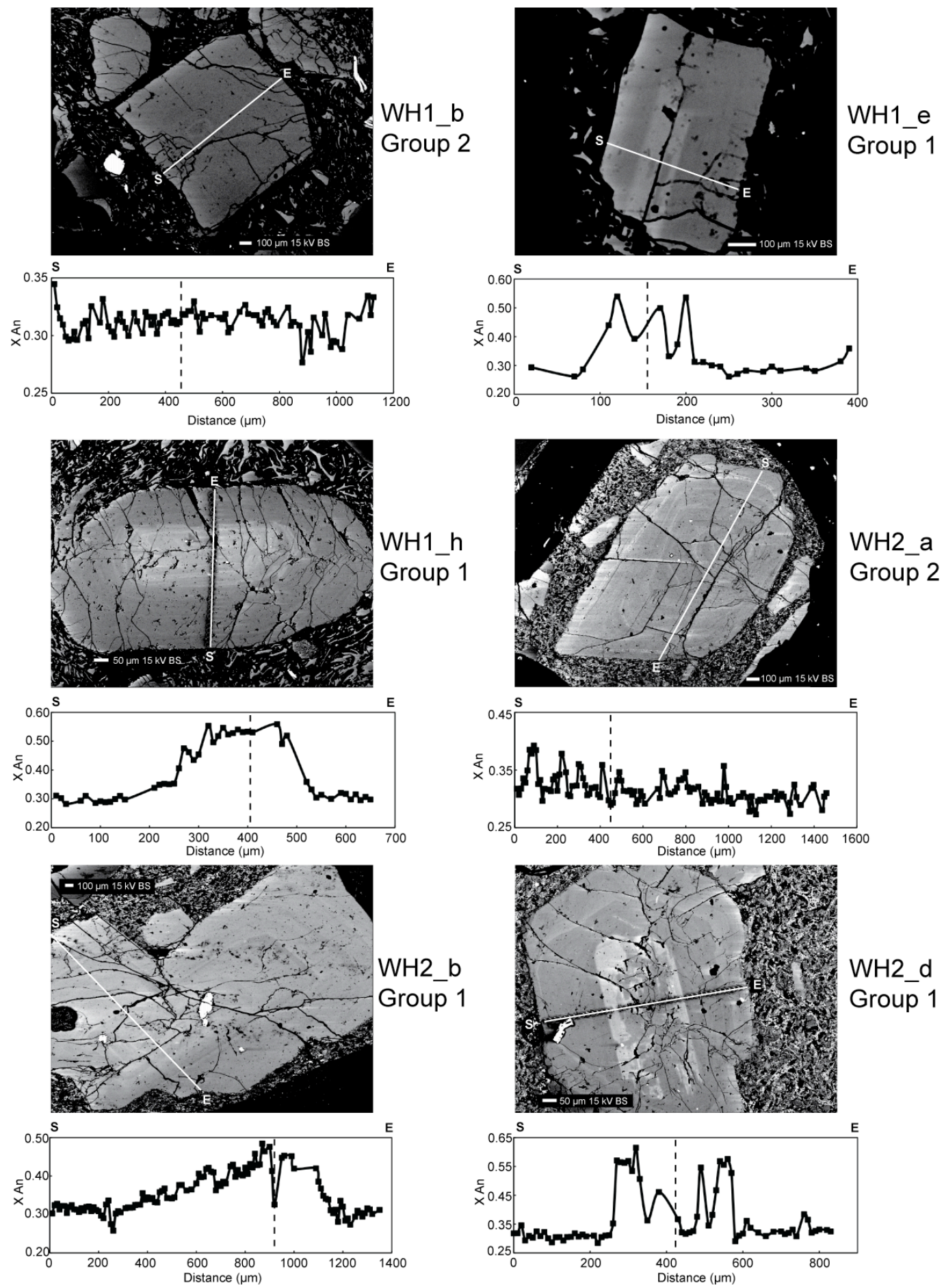
Figure A4.1 continued

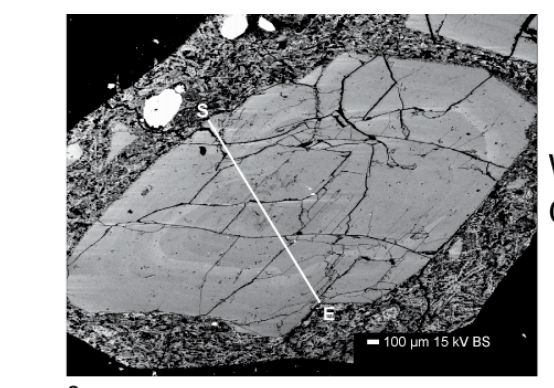

WH2_f

Group 2

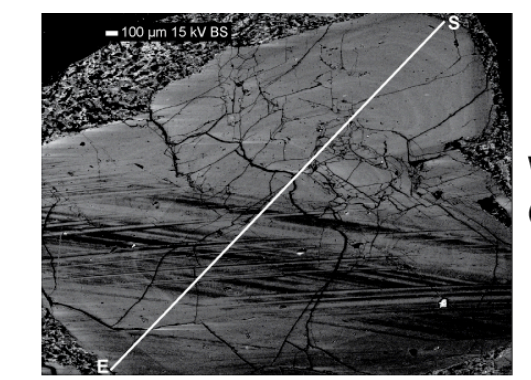

WH2_g

Group 3
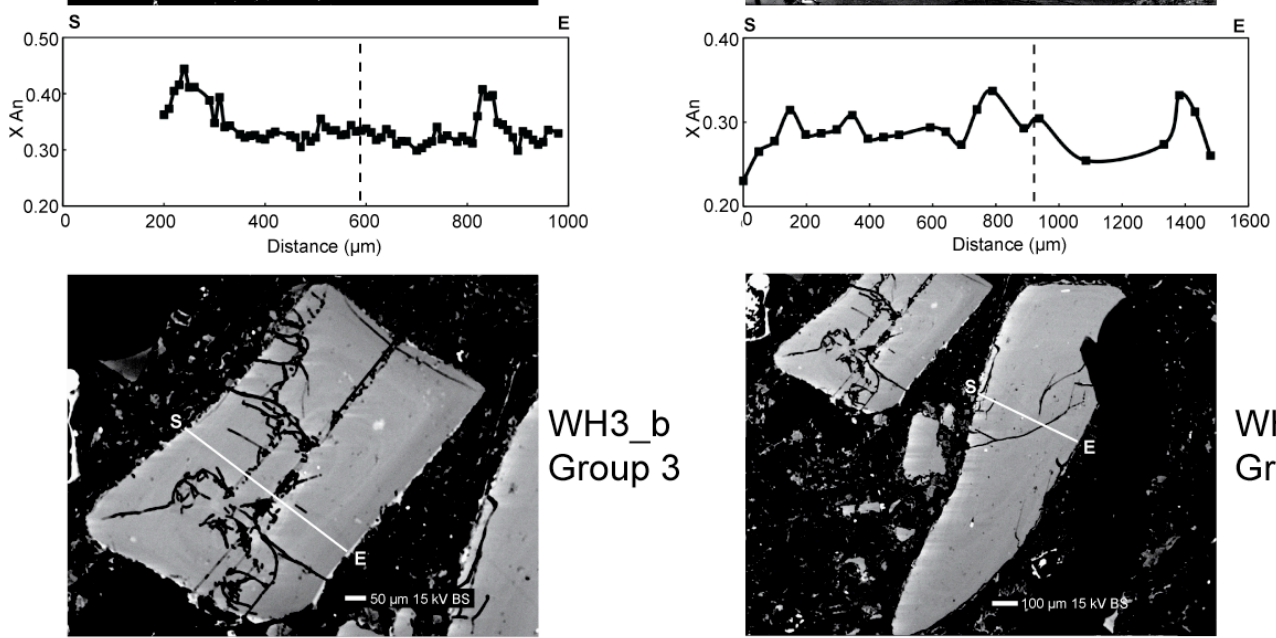

WH3_b

Group 3

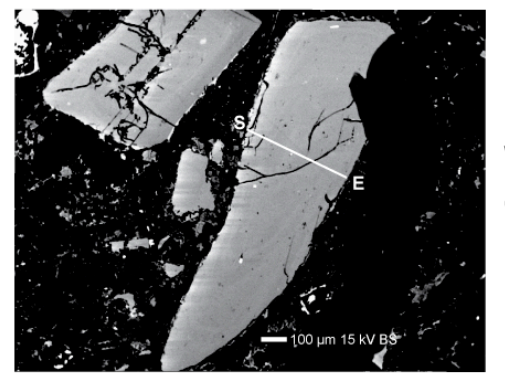

WH3_c

Group 2
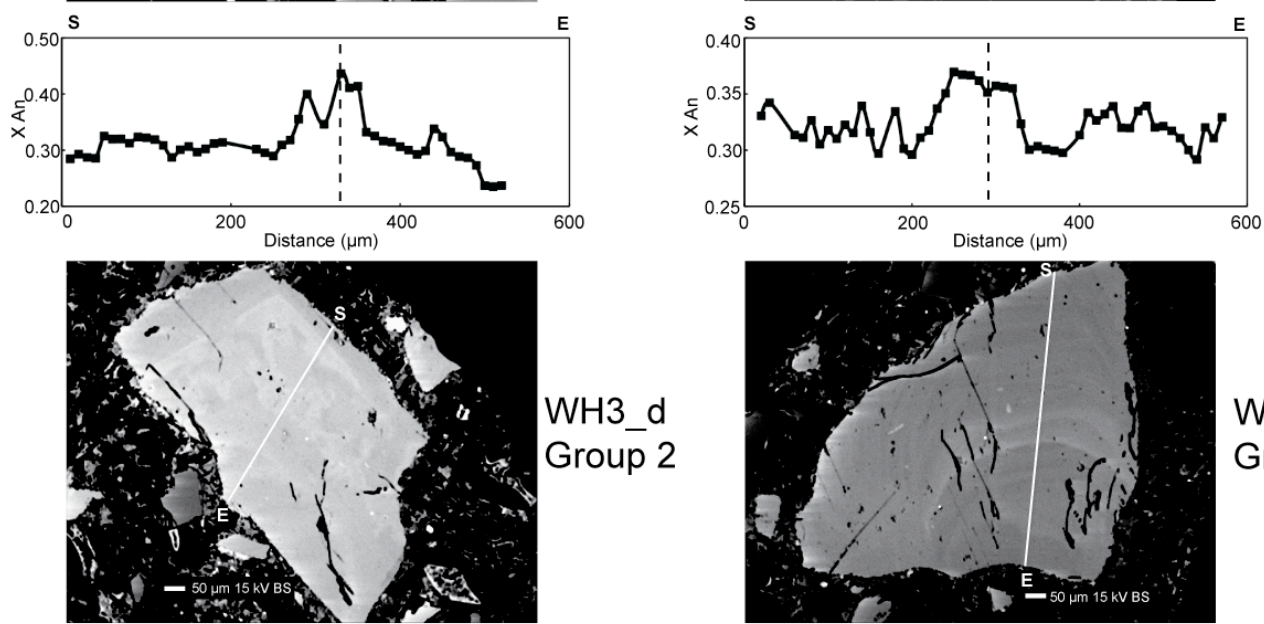

WH3 d

Group 2

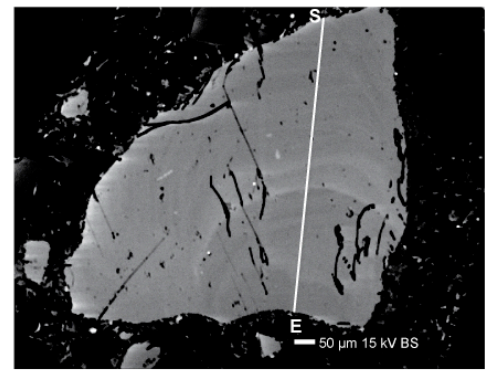

WH3 e

Group 2
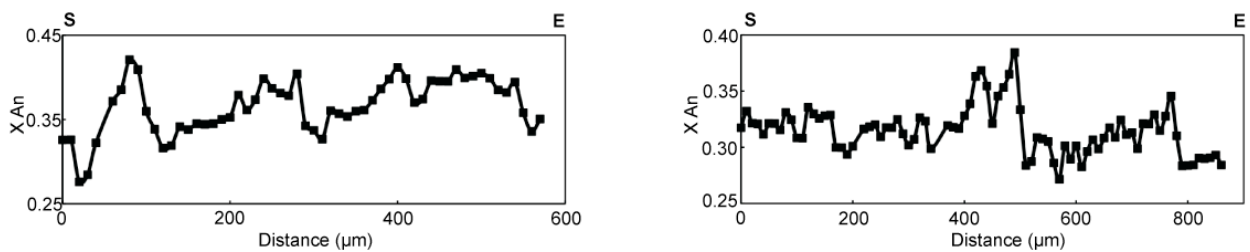
Figure A4.1 continued

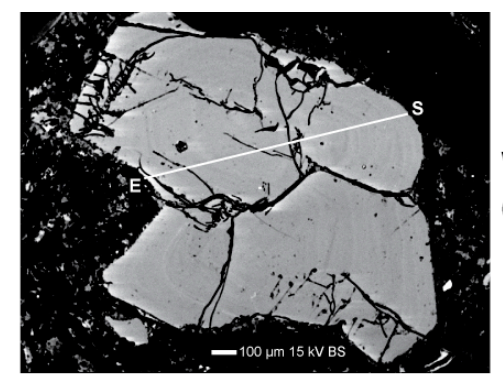

WH3 g

Group 2

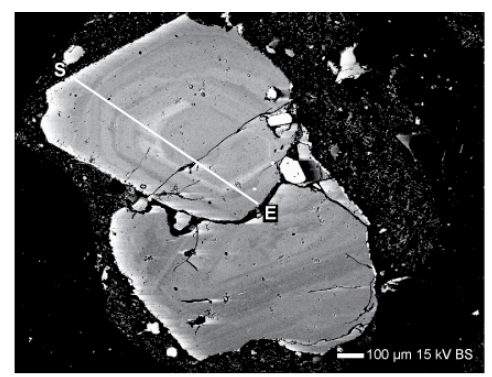

WH5_d

Group 2
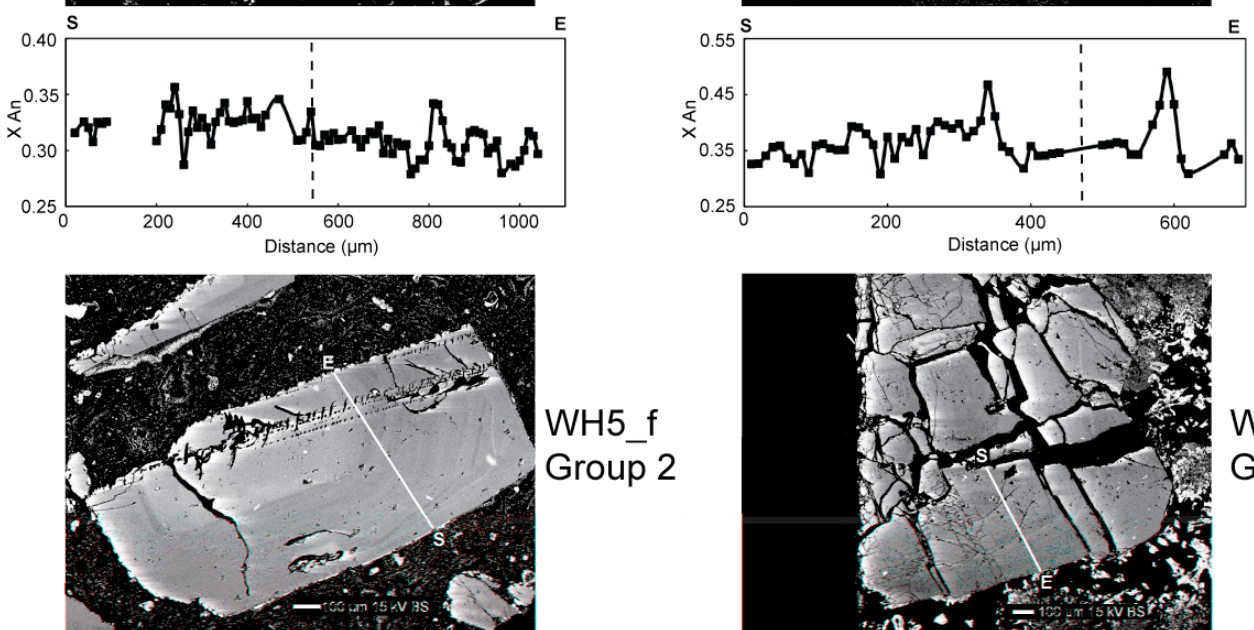

WH5_f

Group 2

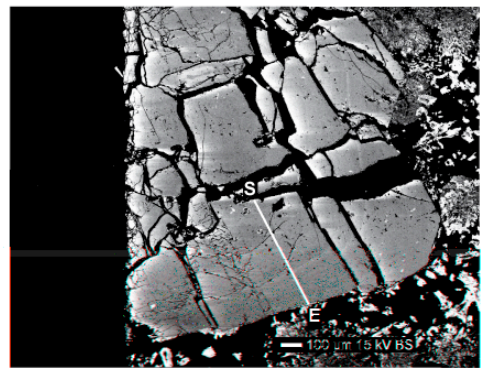

WH6_b

Group 3
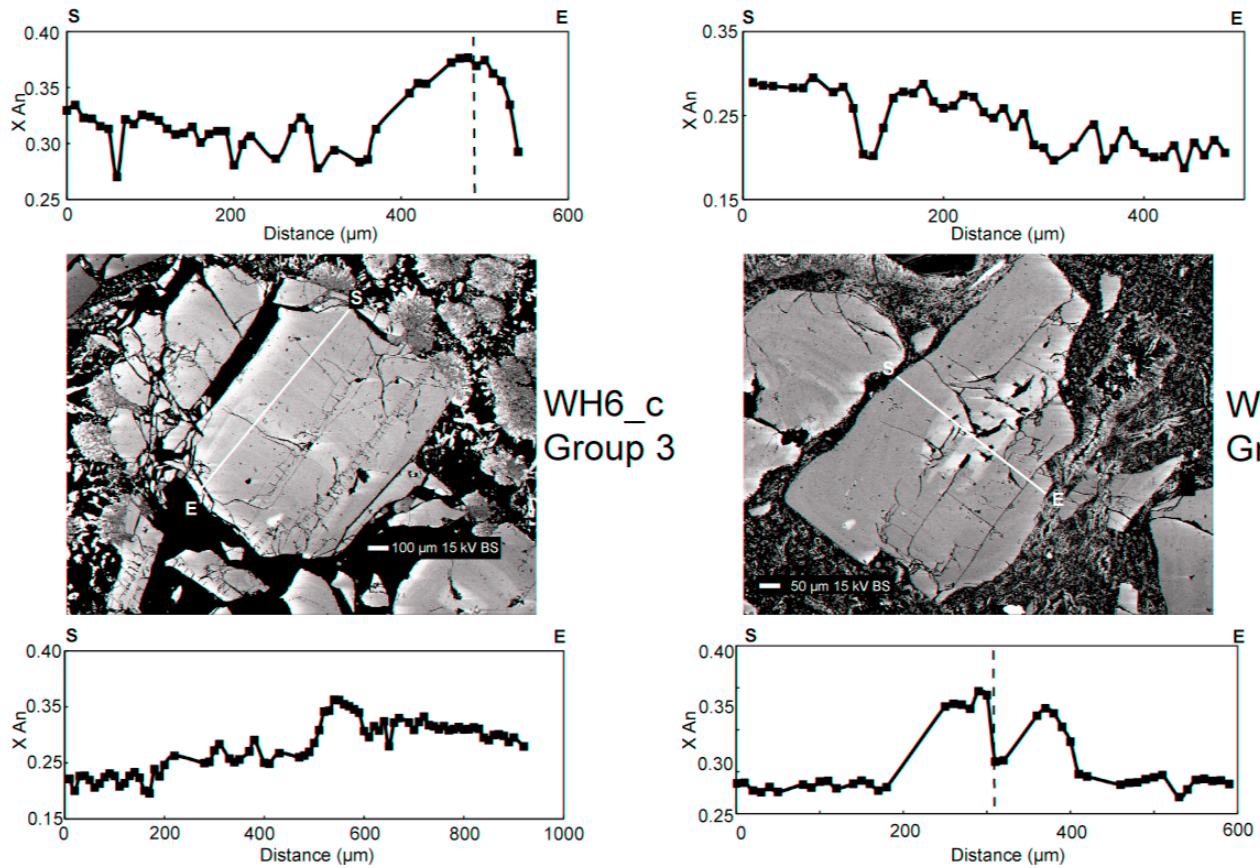
Figure A4.1 continued
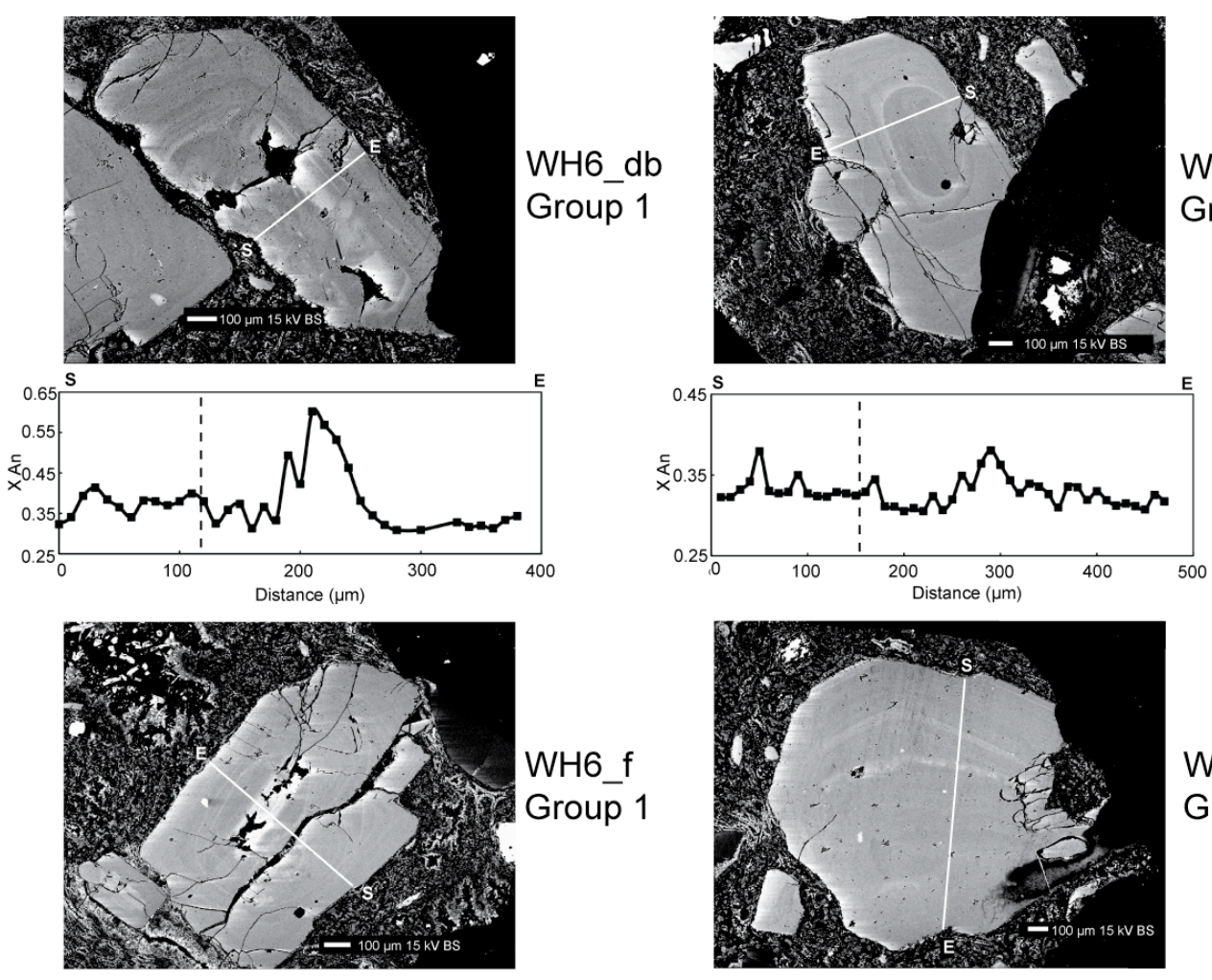

WH6 e

Group 2
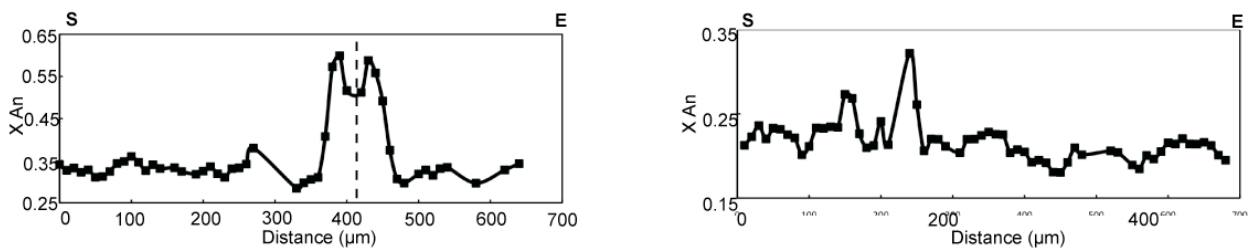


\section{Appendix 4}

Figure A4.2: Backscattered electron mages of Whakamaru plagioclase crystals.

Spot analyses of $A n$ concentration are given in mol\% 
Figure A4.2

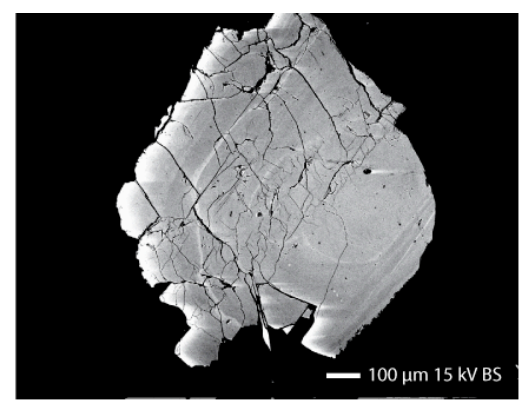

WH1_t

Group 2

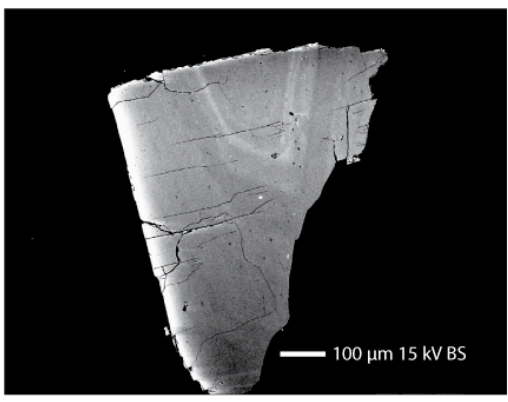

WH1_u

Group 2

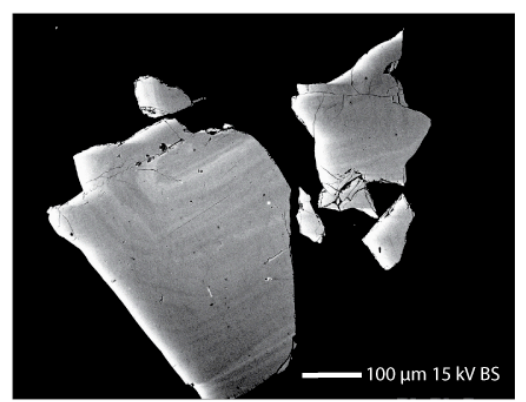

WH1_w

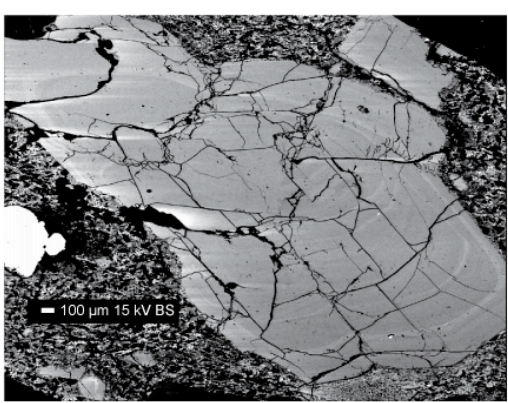

WH2_c

Group 2

Group 2

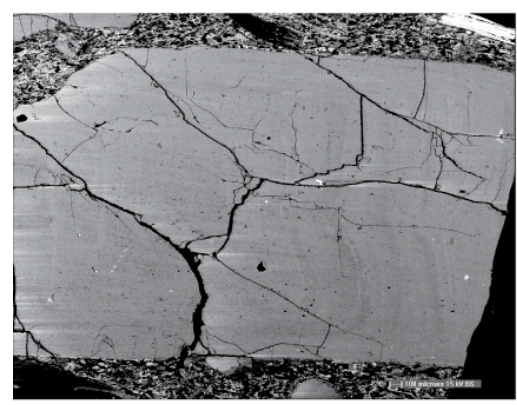

WH2 e

Group 2

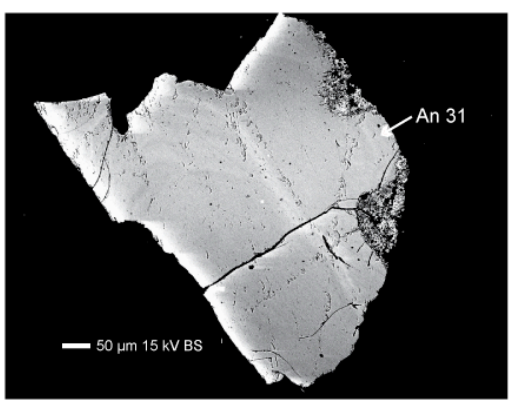

WH2_k

Group 2

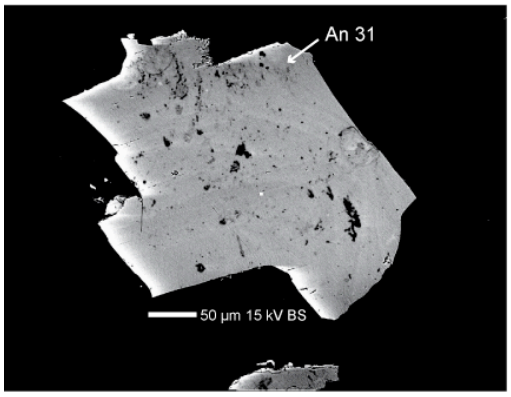

WH2_r

Group 2

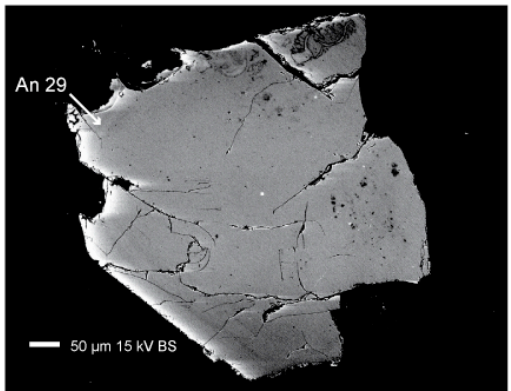

WH2_s

Group 2 
Figure A4.2 continued
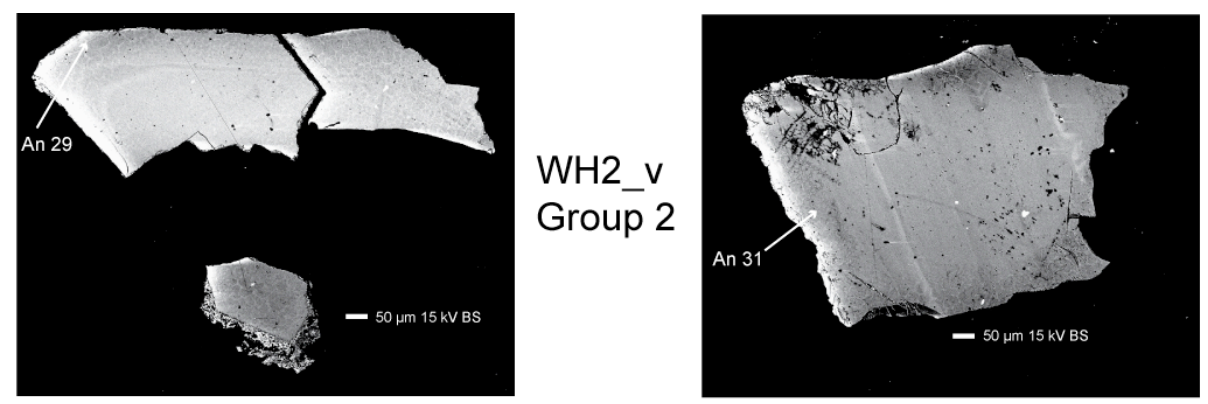

WH2_aa

Group 2
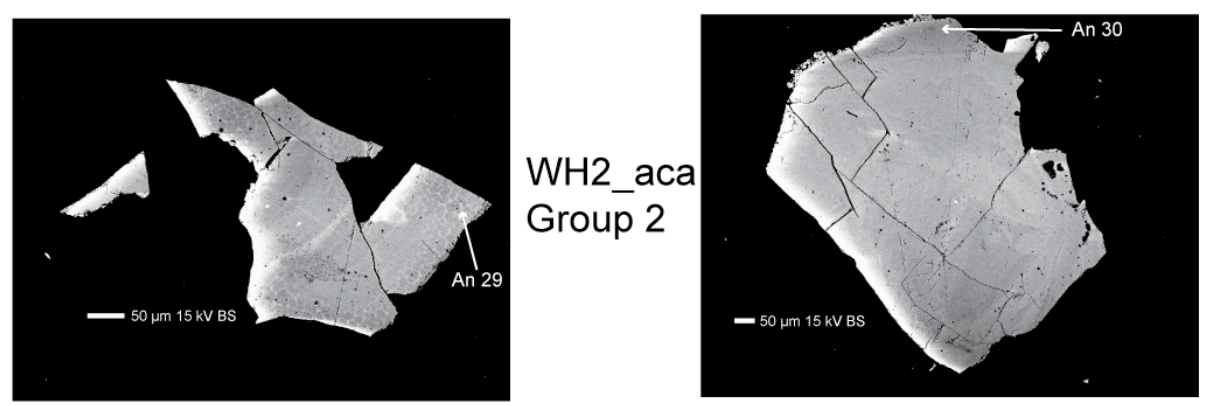

WH2_ad

Group 2
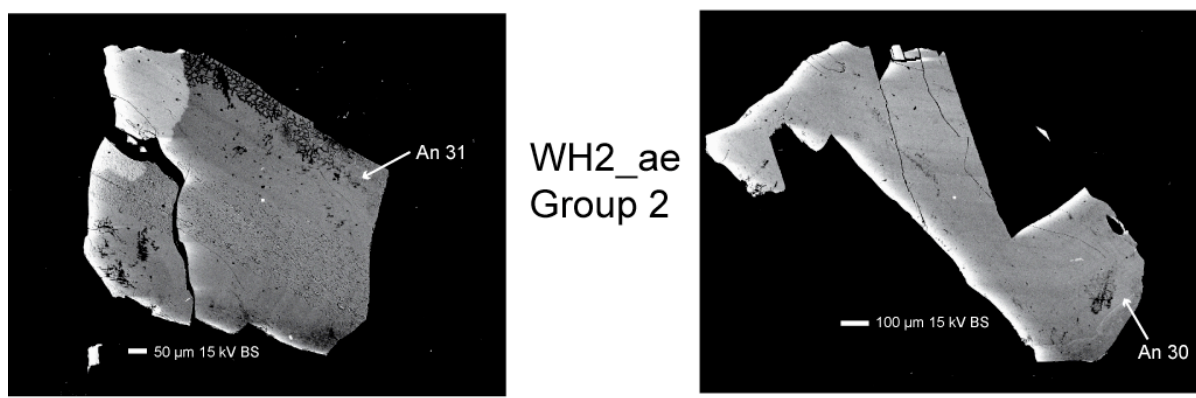

WH2_ag

Group 2
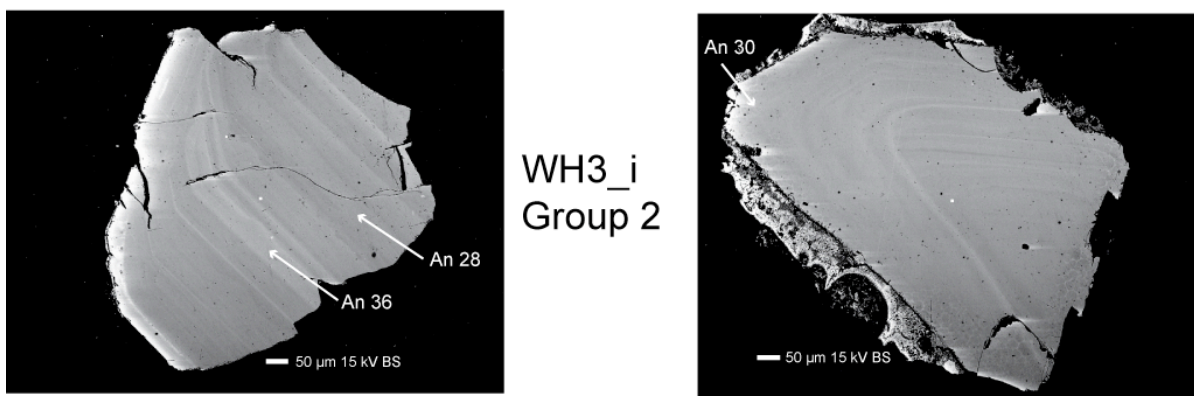

WH3_k

Group 2 
Figure A4.2 continued

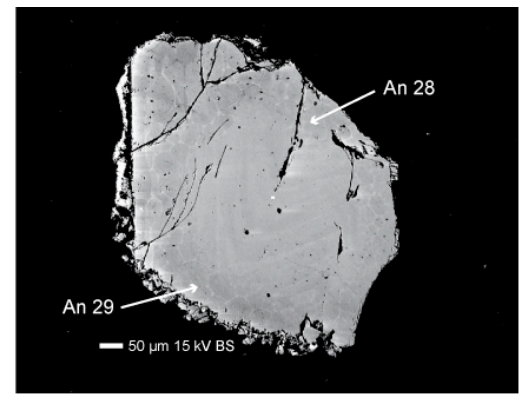

WH3_p

Group 3

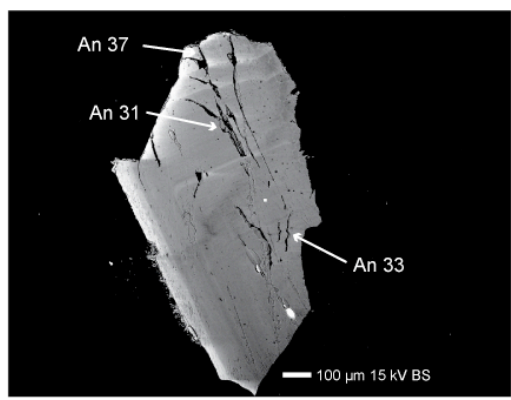

WH3_q

Group 2

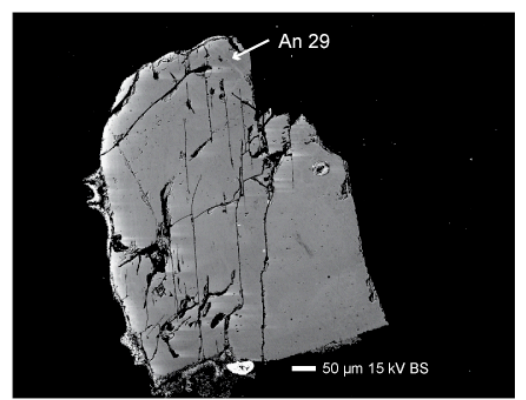

WH3_r

Group 2

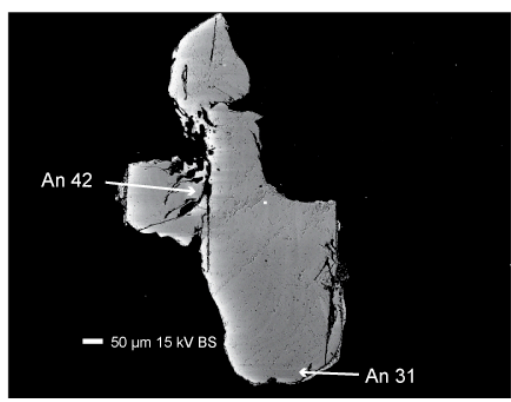

WH3_t

Group 1
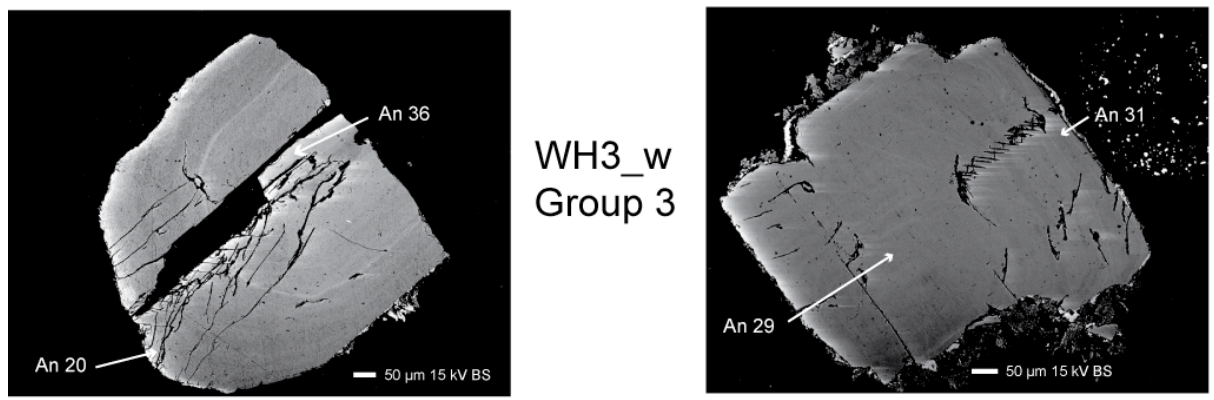

WH3 ai

Group 2
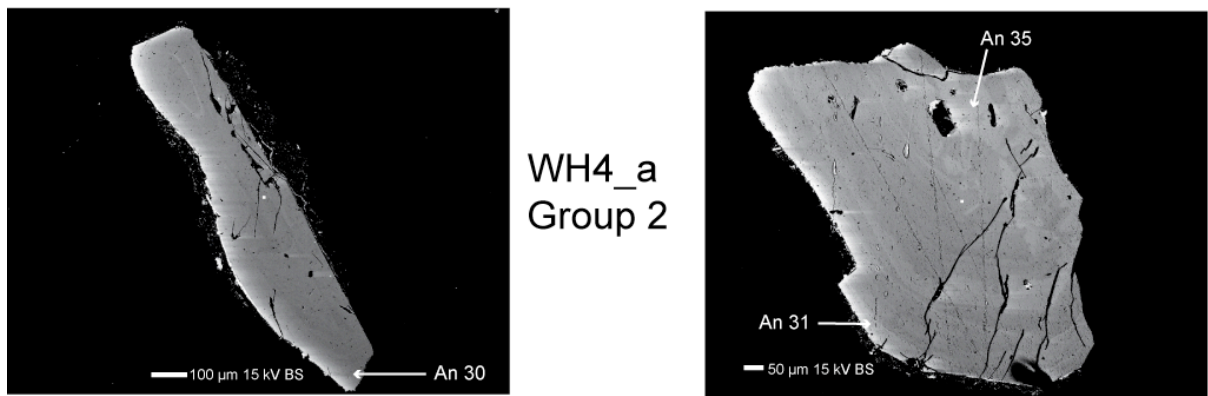

WH4_b

Group 2 
Figure A4.2 continued

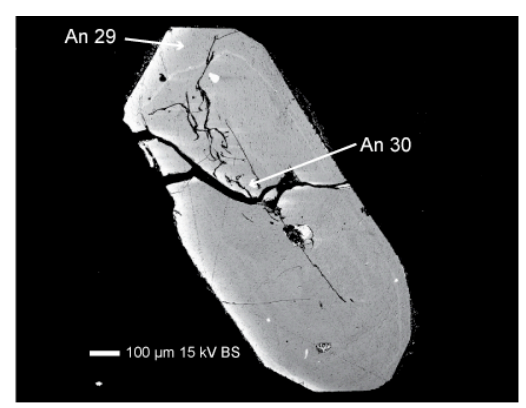

WH4_e

Group 2

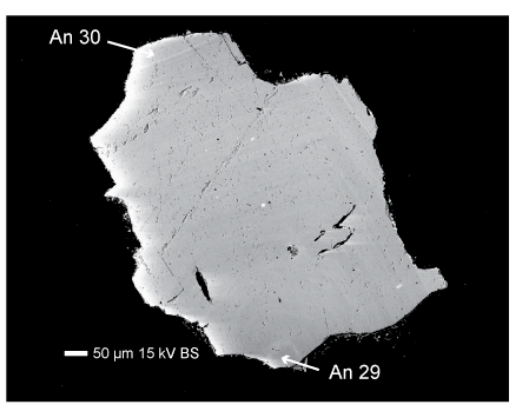

WH4_f

Group 2

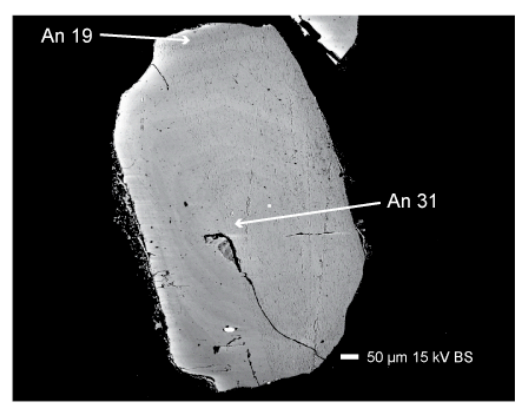

WH4_g

Group 3

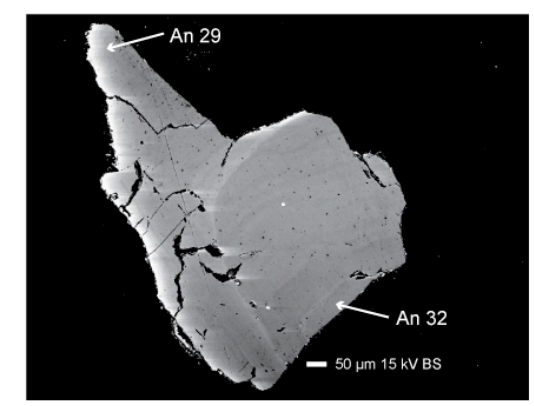

WH4_h

Group 2

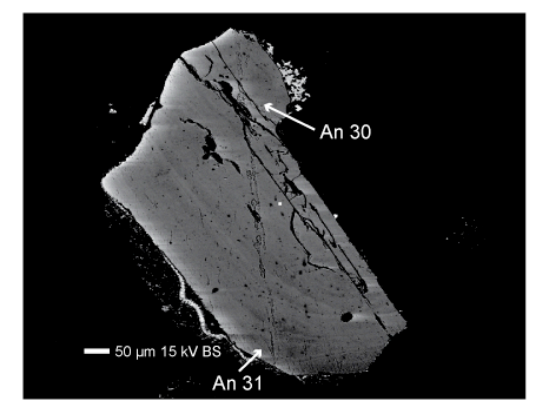

WH4 j

Group 2

Group 2

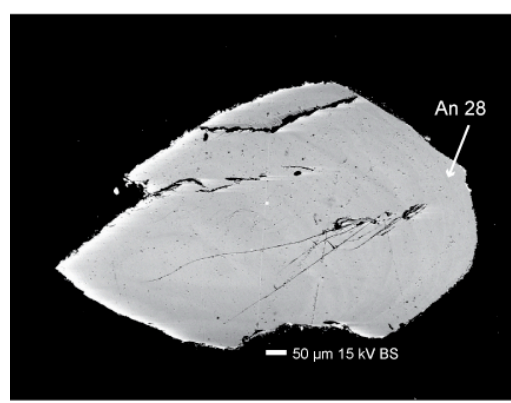

WH4_k

Group 2

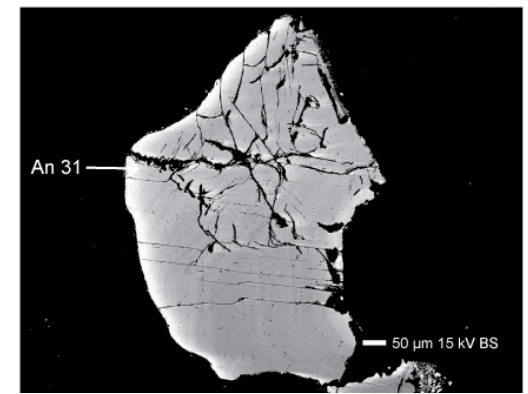

WH4_I

Group 2 
Figure A4.2 continued
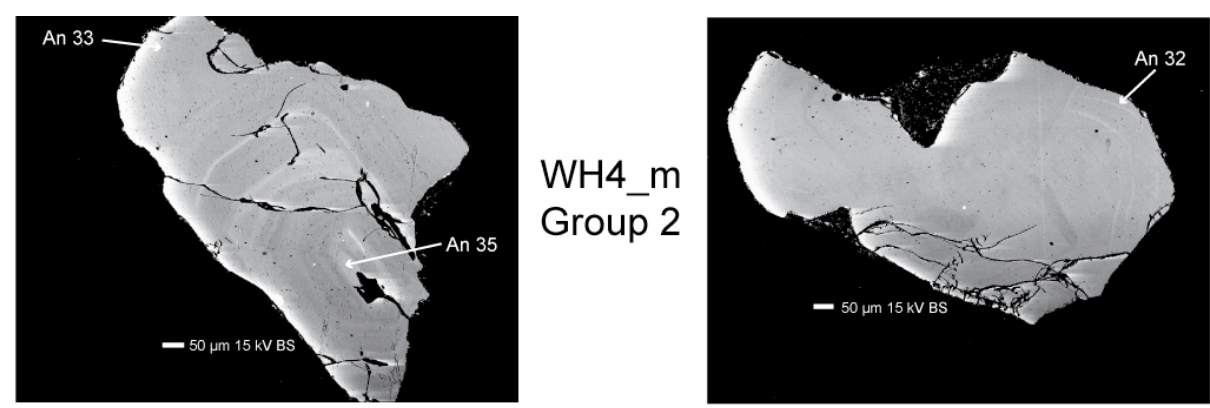

WH4_n

Group 2

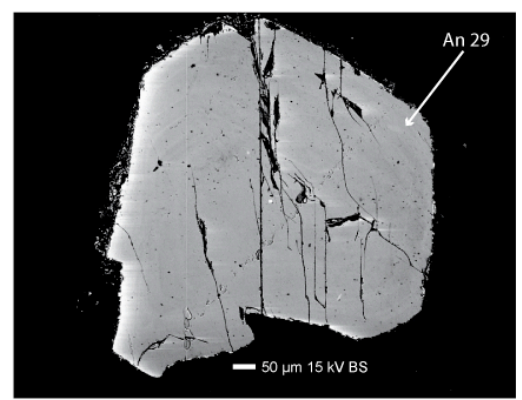

WH4_o

Group 3

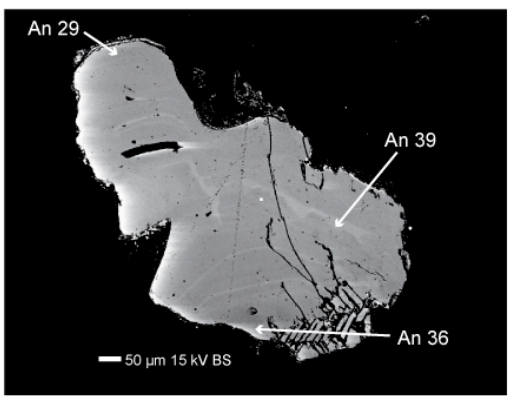

WH4_p

Group 2
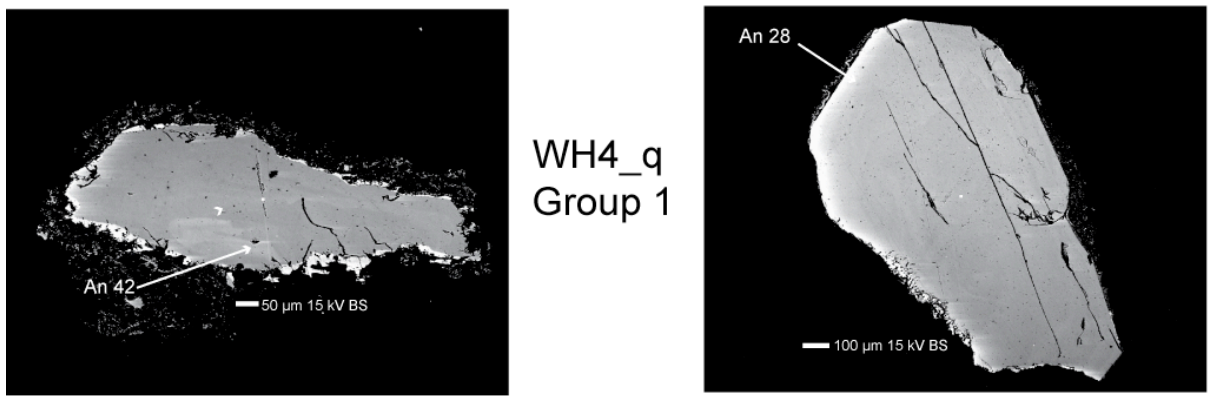

WH4 s

Group 2

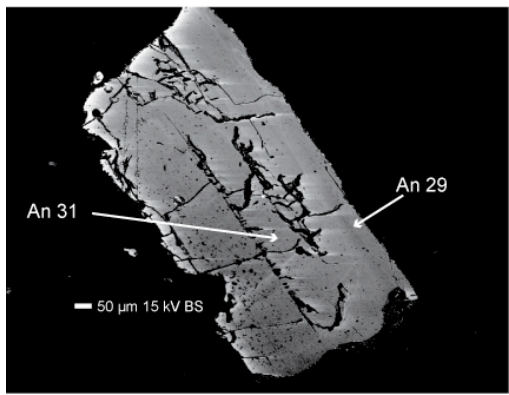

WH4_t

Group 2

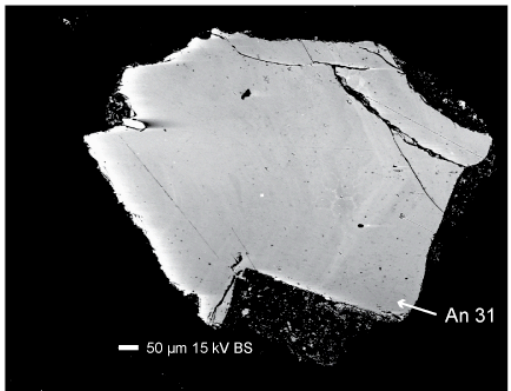

WH4_y

Group 2 
Figure A4.2 continued
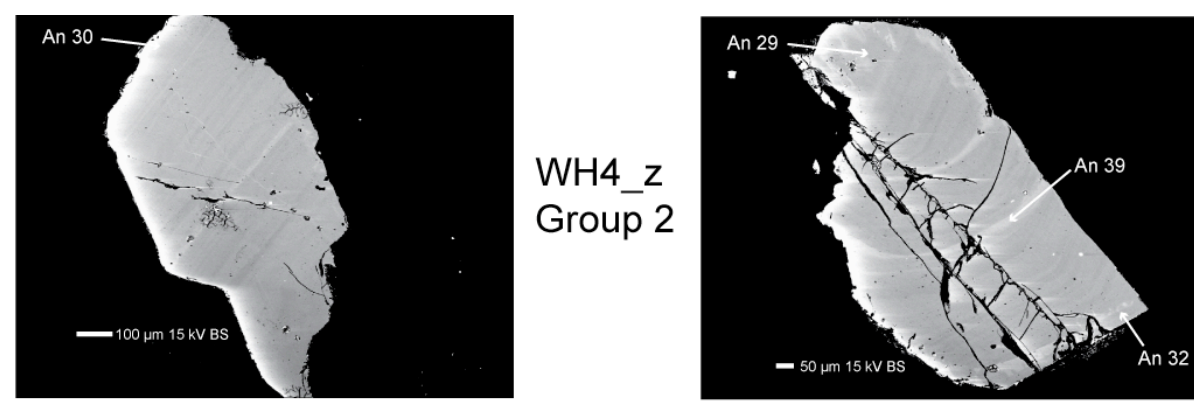

WH4_aa

Group 2
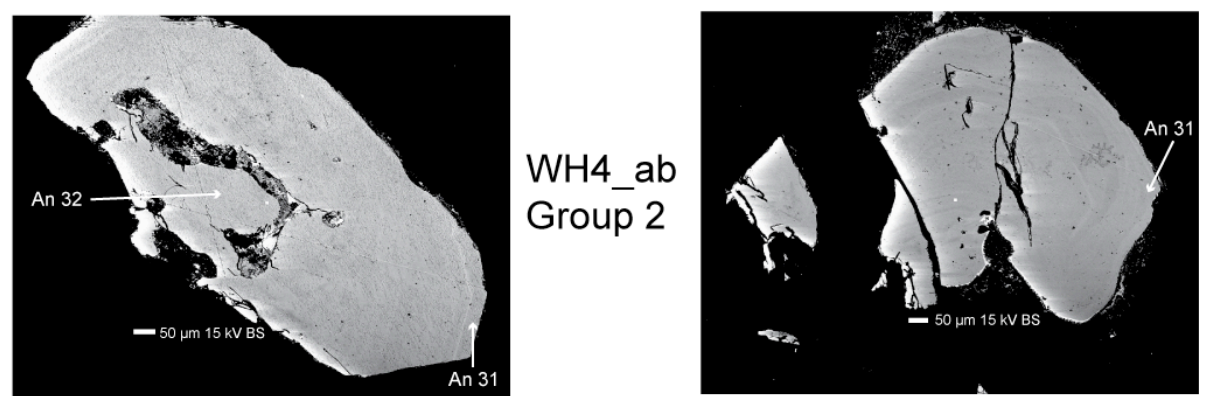

WH4 ae

Group 2

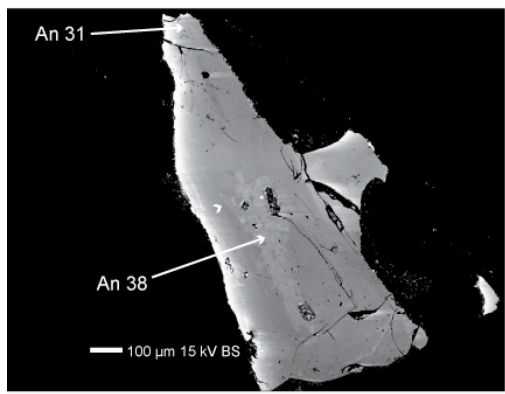

WH4_af

Group 2

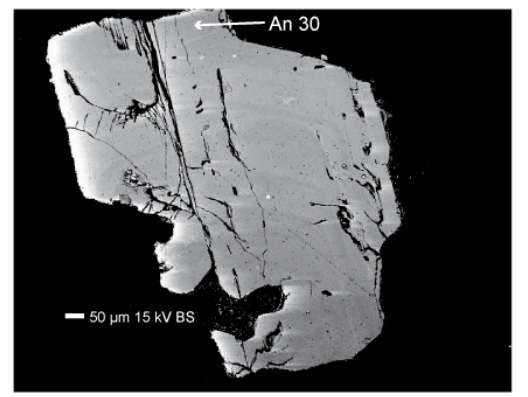

WH4_aj

Group 2
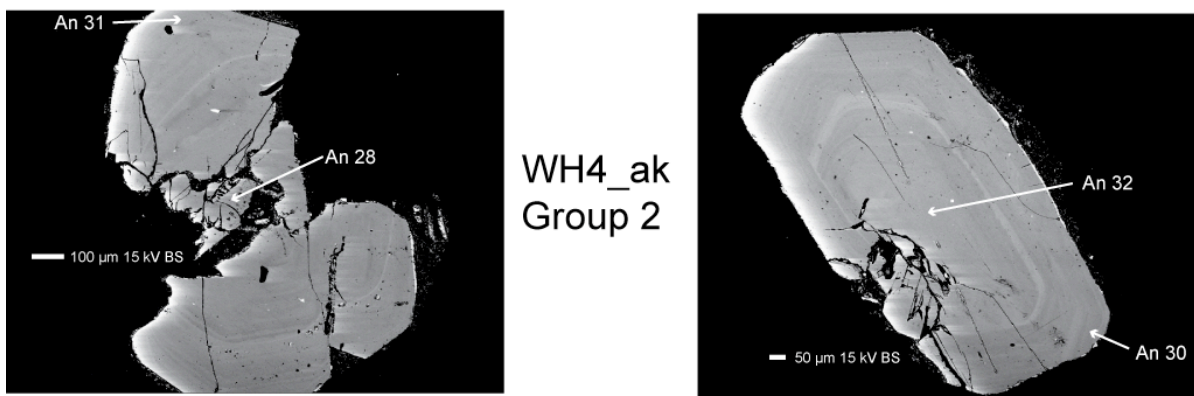

WH4_al

Group 2 
Figure A4.2 continued
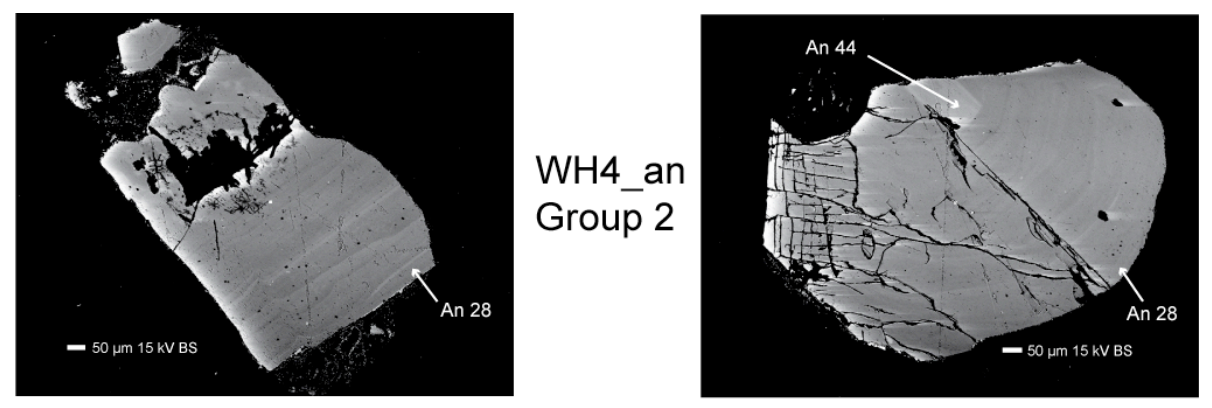

WH4_ao

Group 1

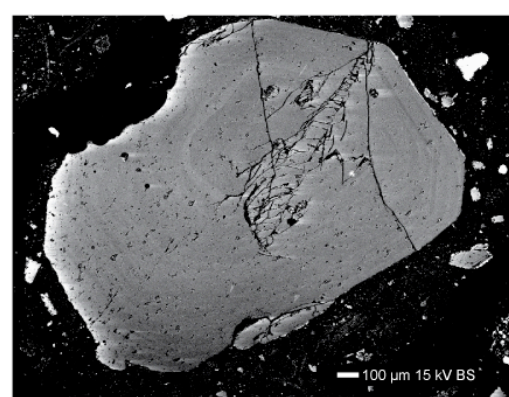

WH5 b

Group 2

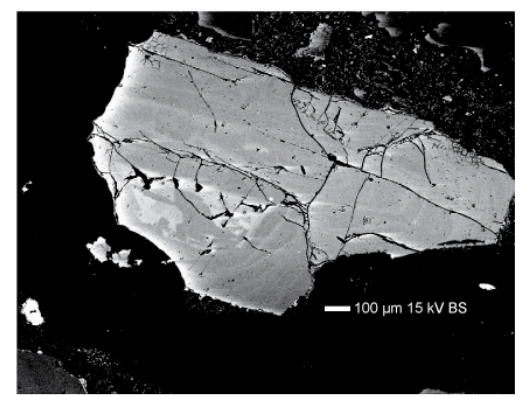

WH5_c

Group 1

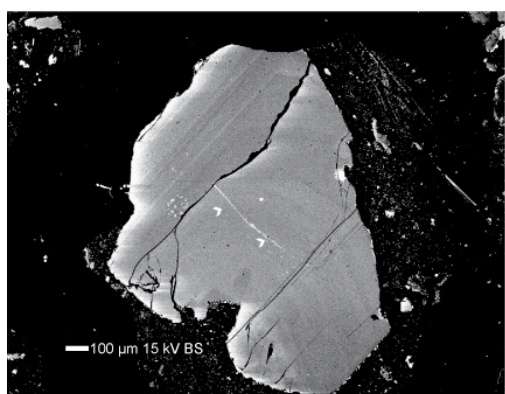

WH5_e

Group 2

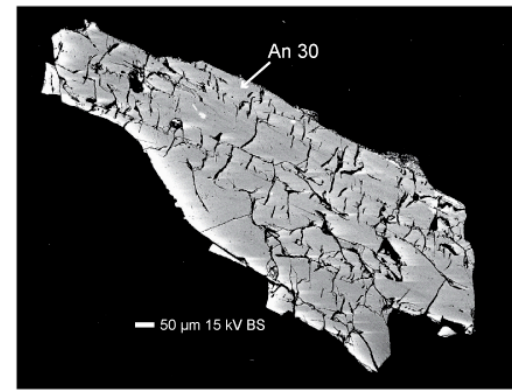

WH6_h

Group 2
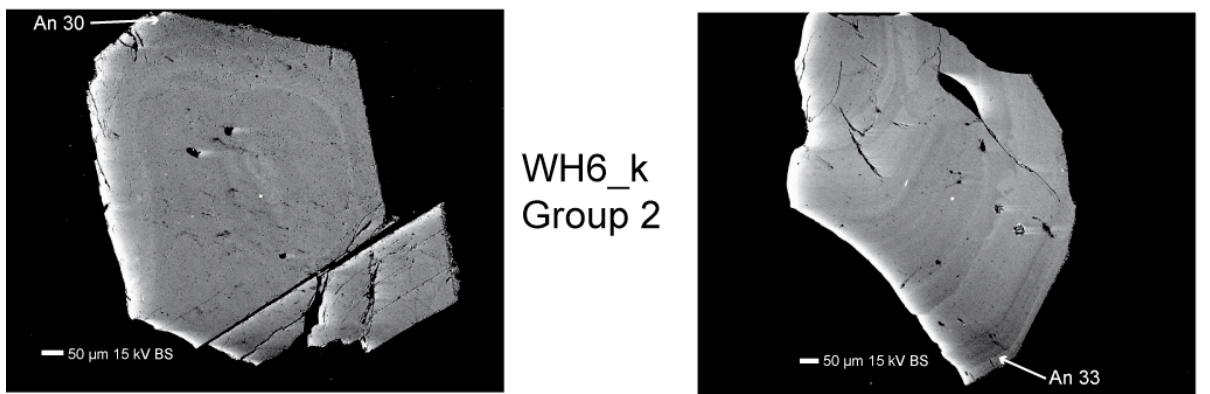

WH6_m

WH6_k

Group 2

Group 2 
Figure A4.2 continued
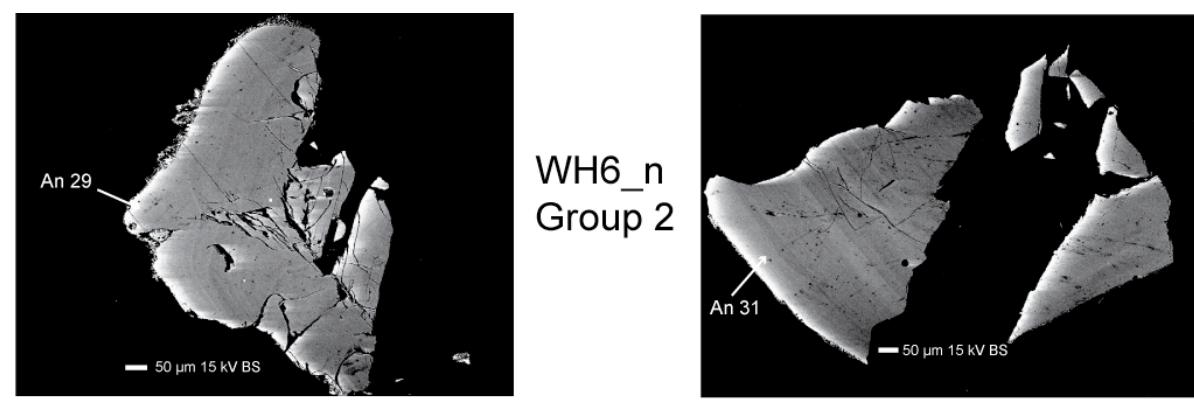

WH6_O

Group 2
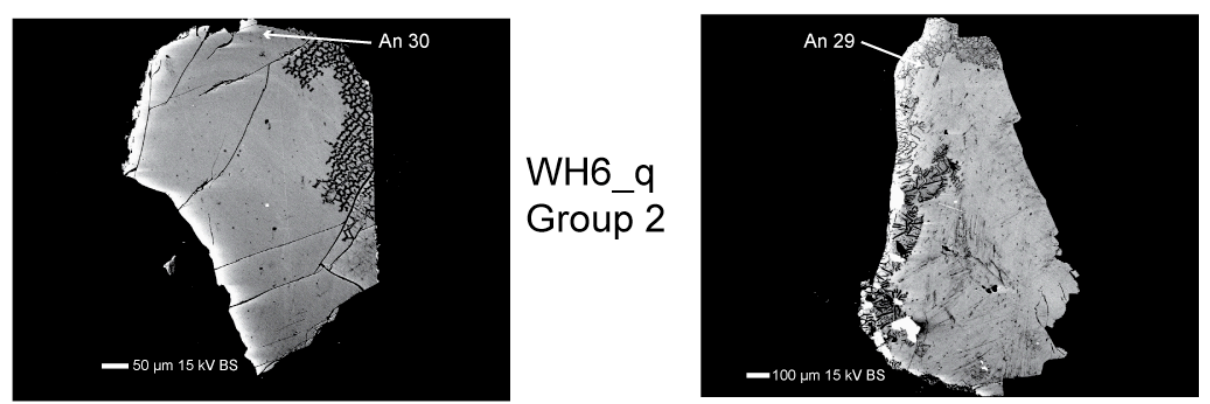

WH6_s

Group 2

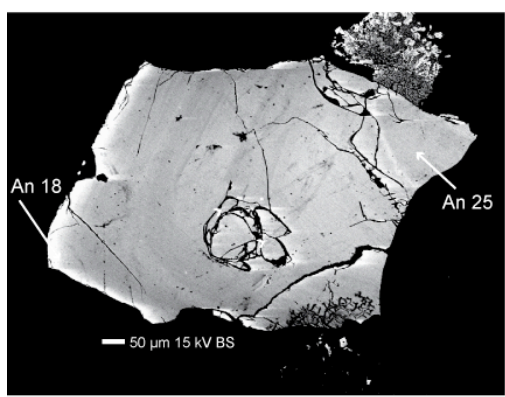

WH6_t

Group 3

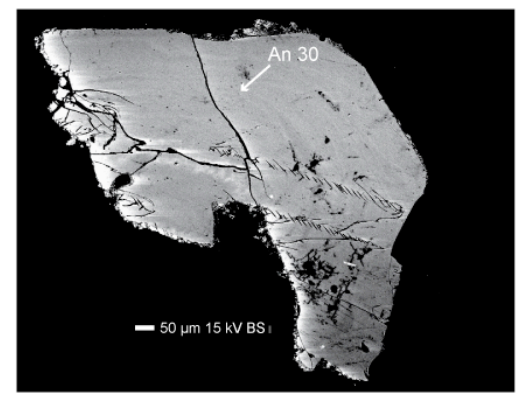

WH6_aa

Group 2
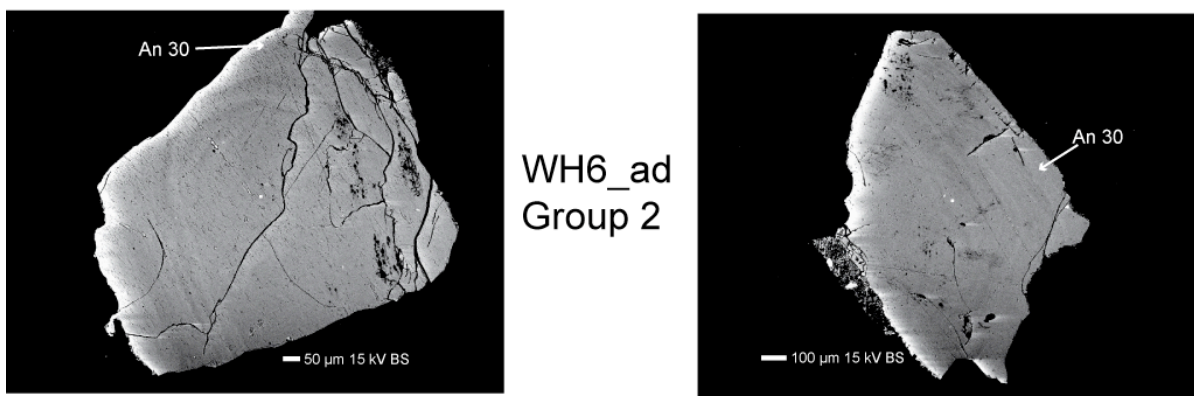

WH6_af

Group 2 
Figure A4.2 continued
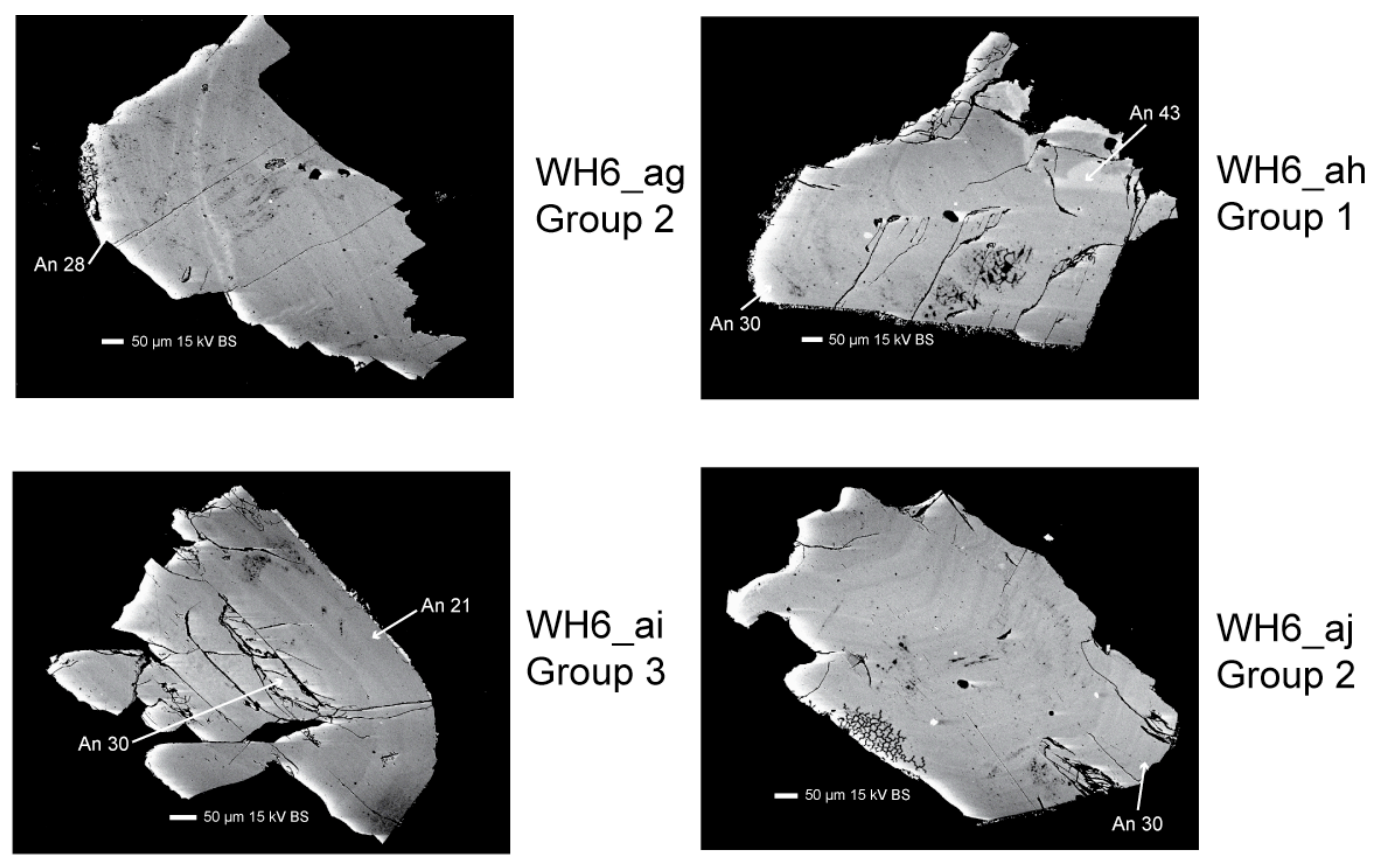

WH6_aj

Group 2

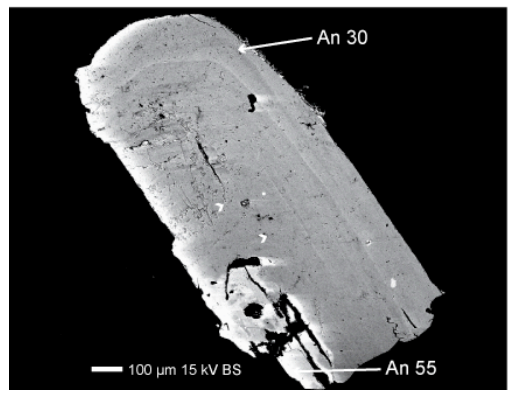

WH6_ap

Group 3 


\section{Appendix 4}

Figure A4.3: Cathodoluminescence images of Whakamaru quartz crystals 
Figure A4.3
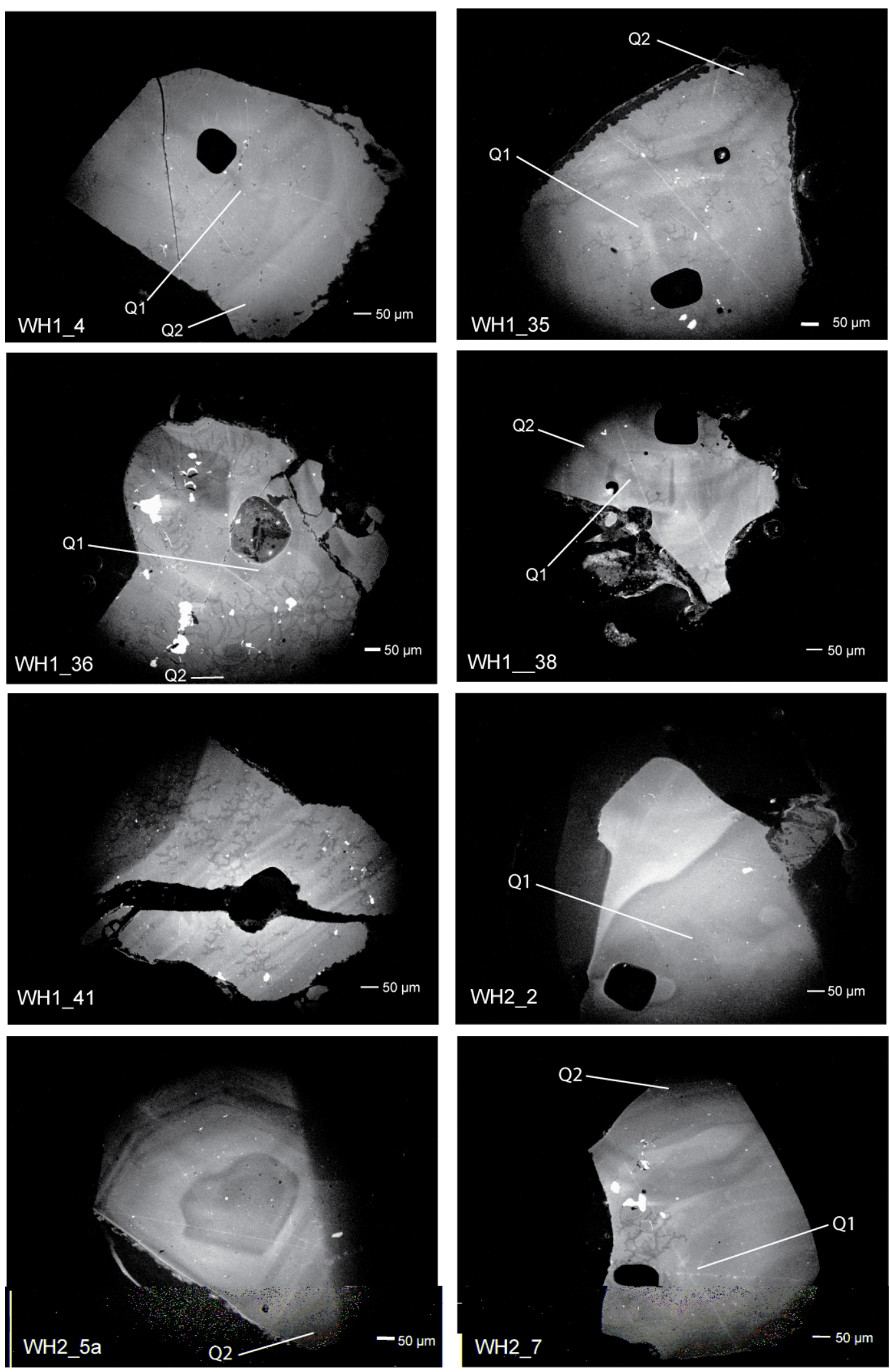


\section{Appendix 4}

Figure A4.4: Backscattered electron images of Healy plagioclase crystals 
Figure A4.4
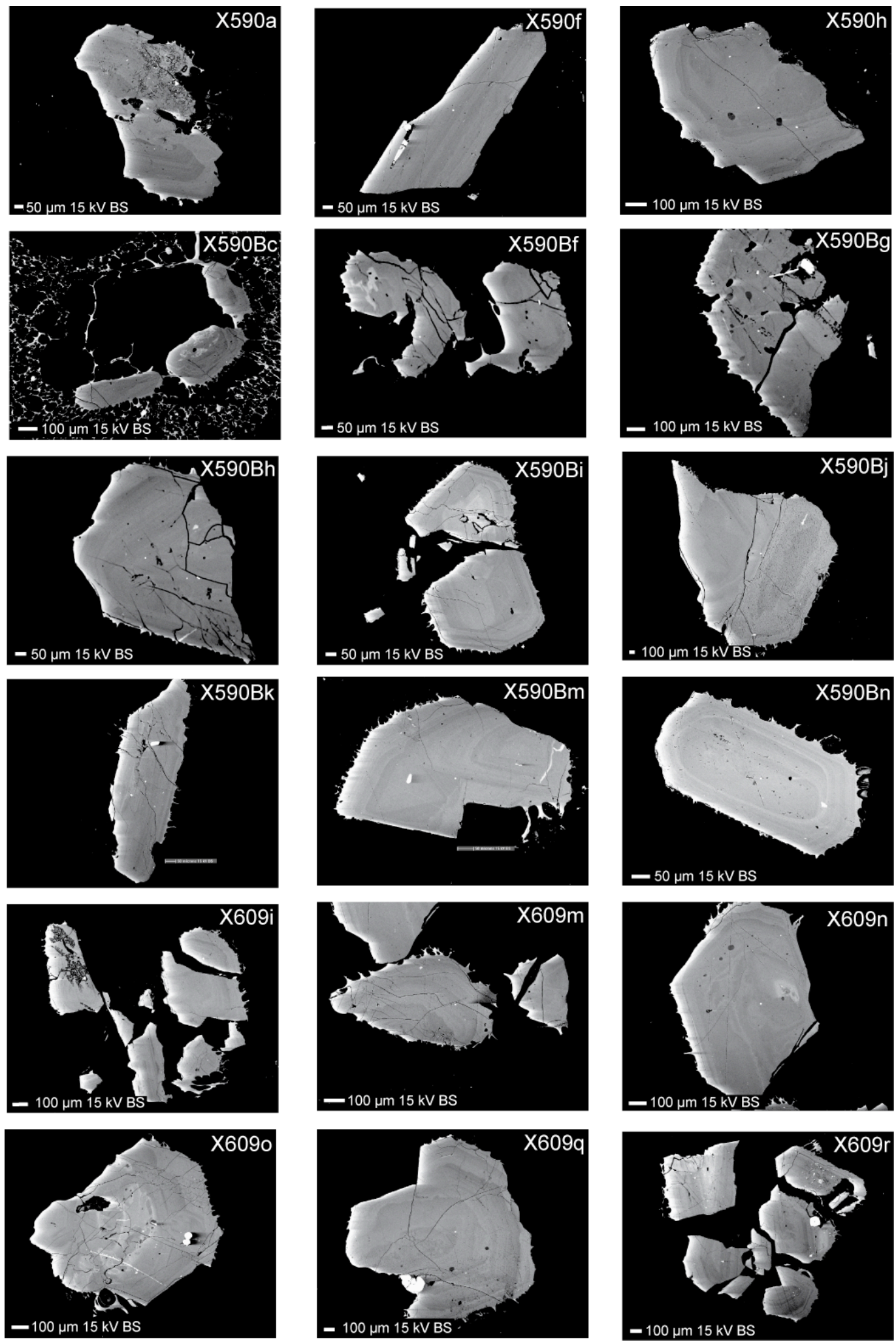


\section{Appendix 4}

Figure A4.5: Backscattered electron images of Taupo plagioclase crystals 
Figure A4.5
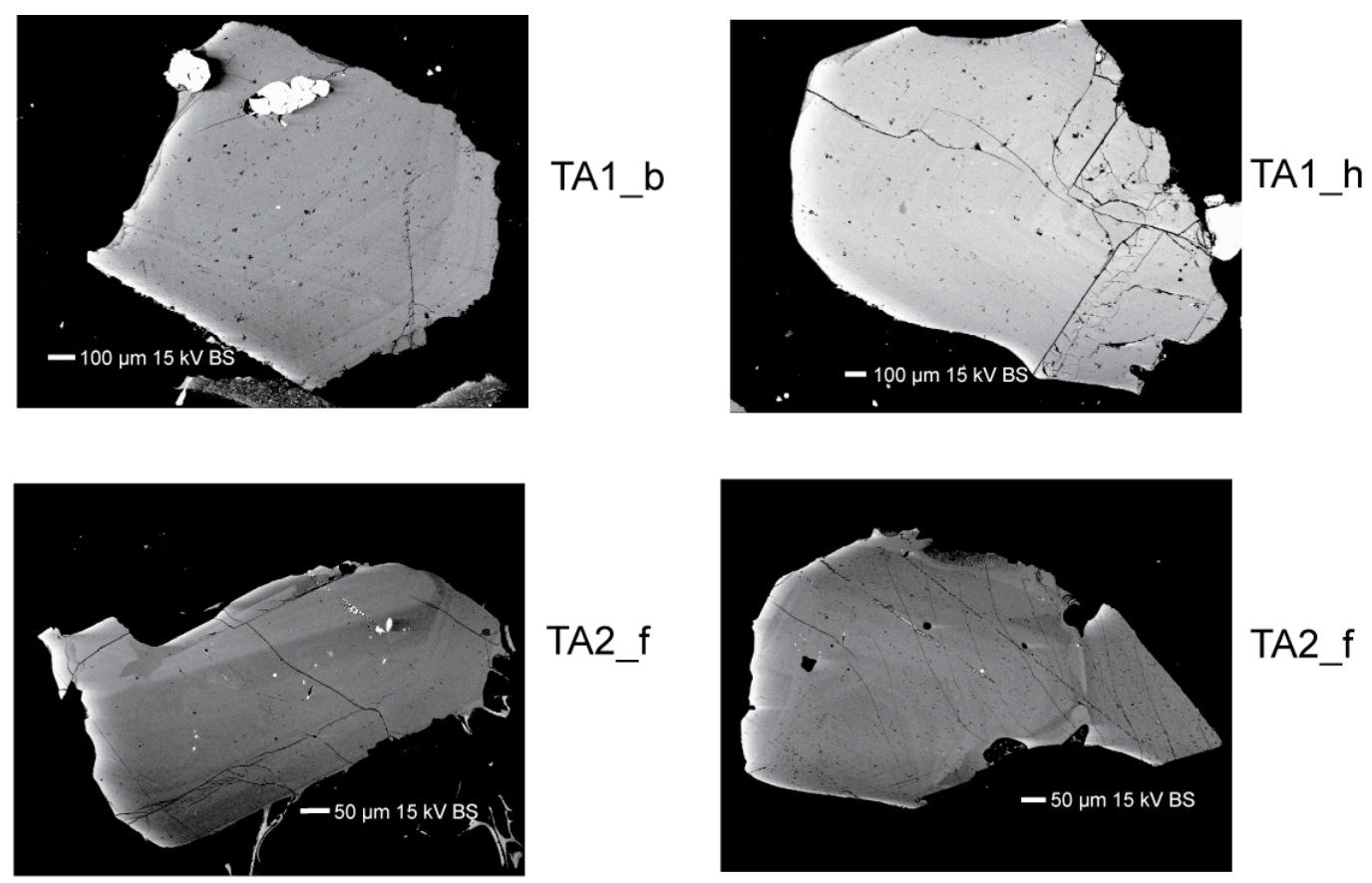

TA2 $\_f$
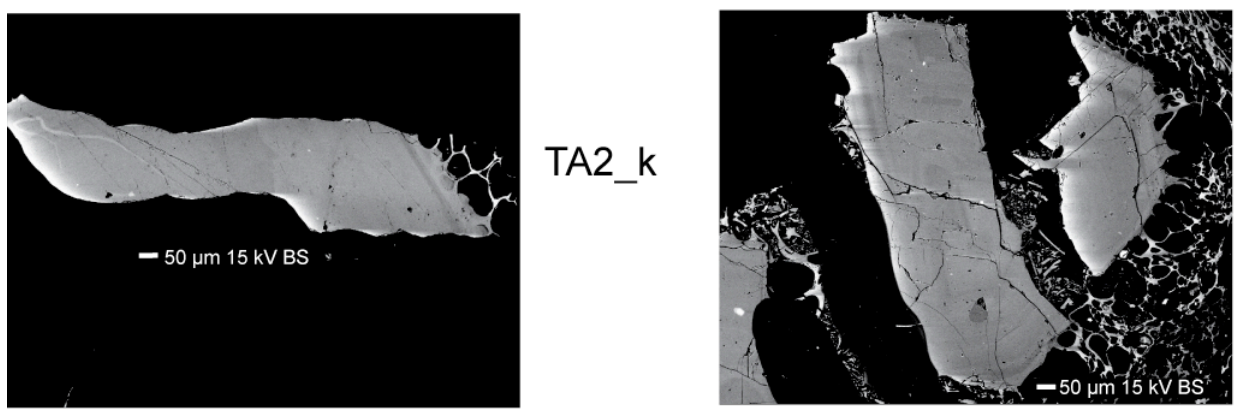

TA3_b
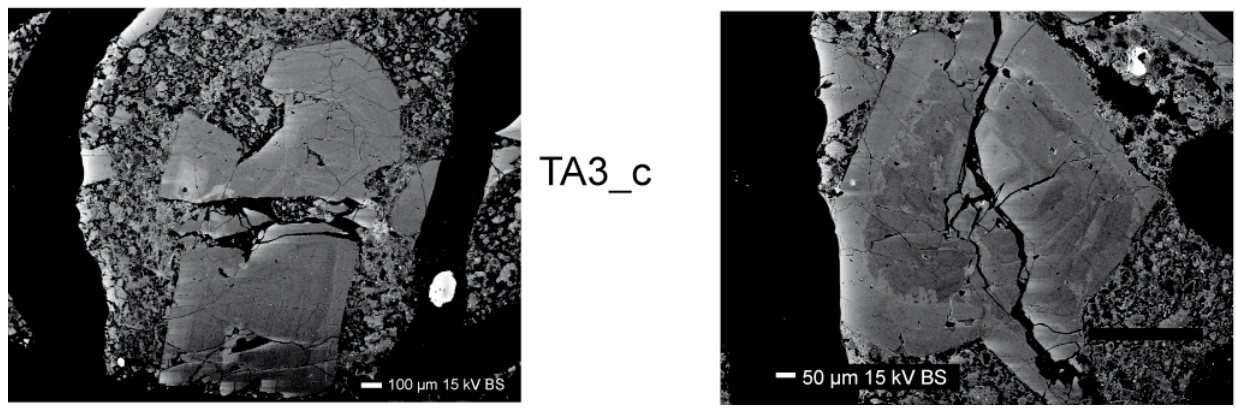

TA3_d 
Figure A4.5 continued

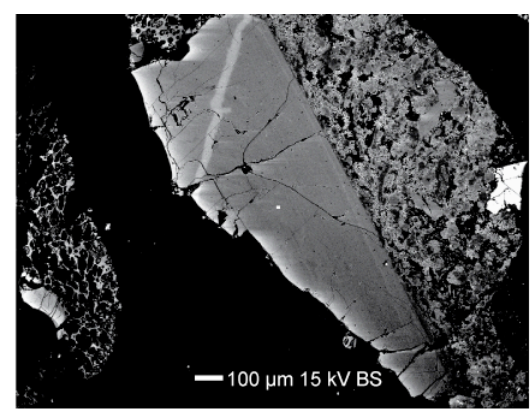
TA3_e

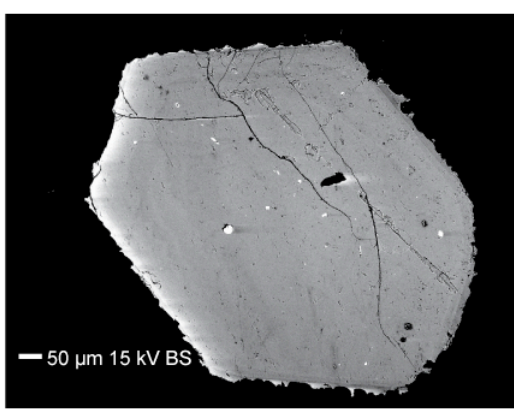

TA3_g
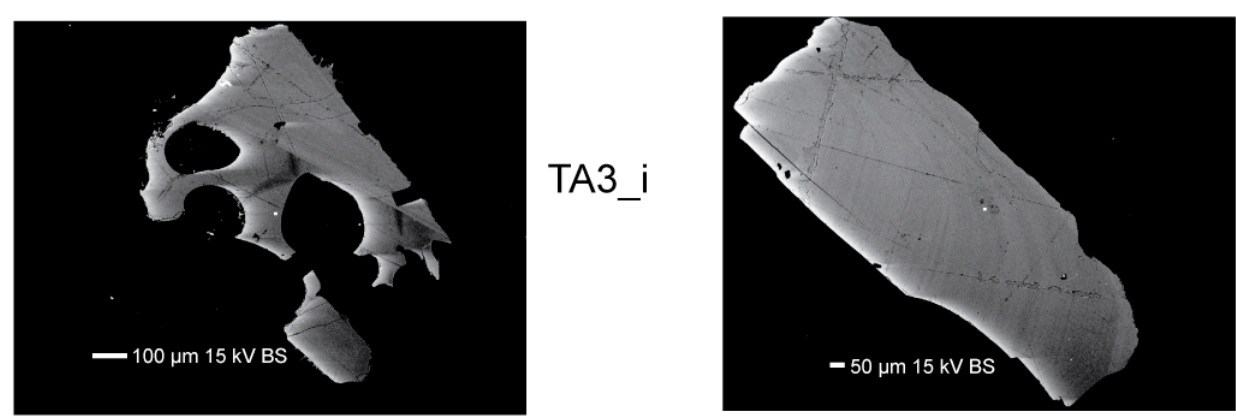

TA3_k

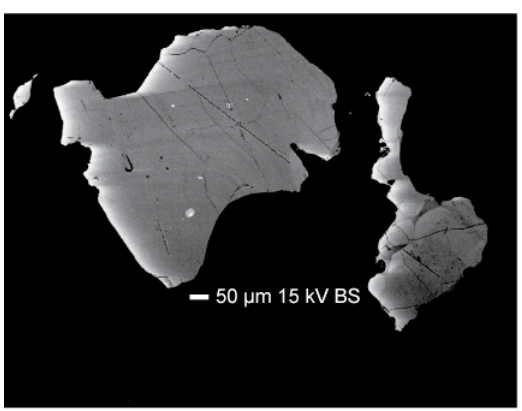

TA3 I

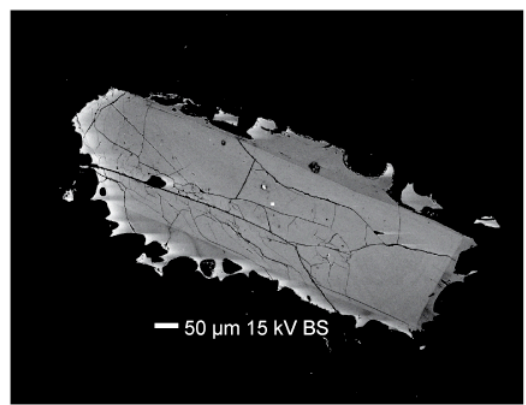

TA3_p
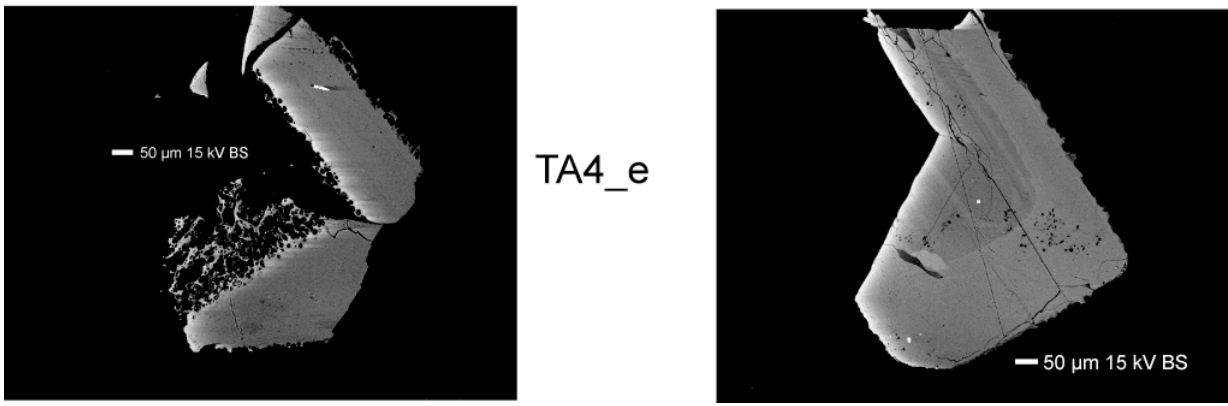

TA4_g 
Figure A4.5 continued
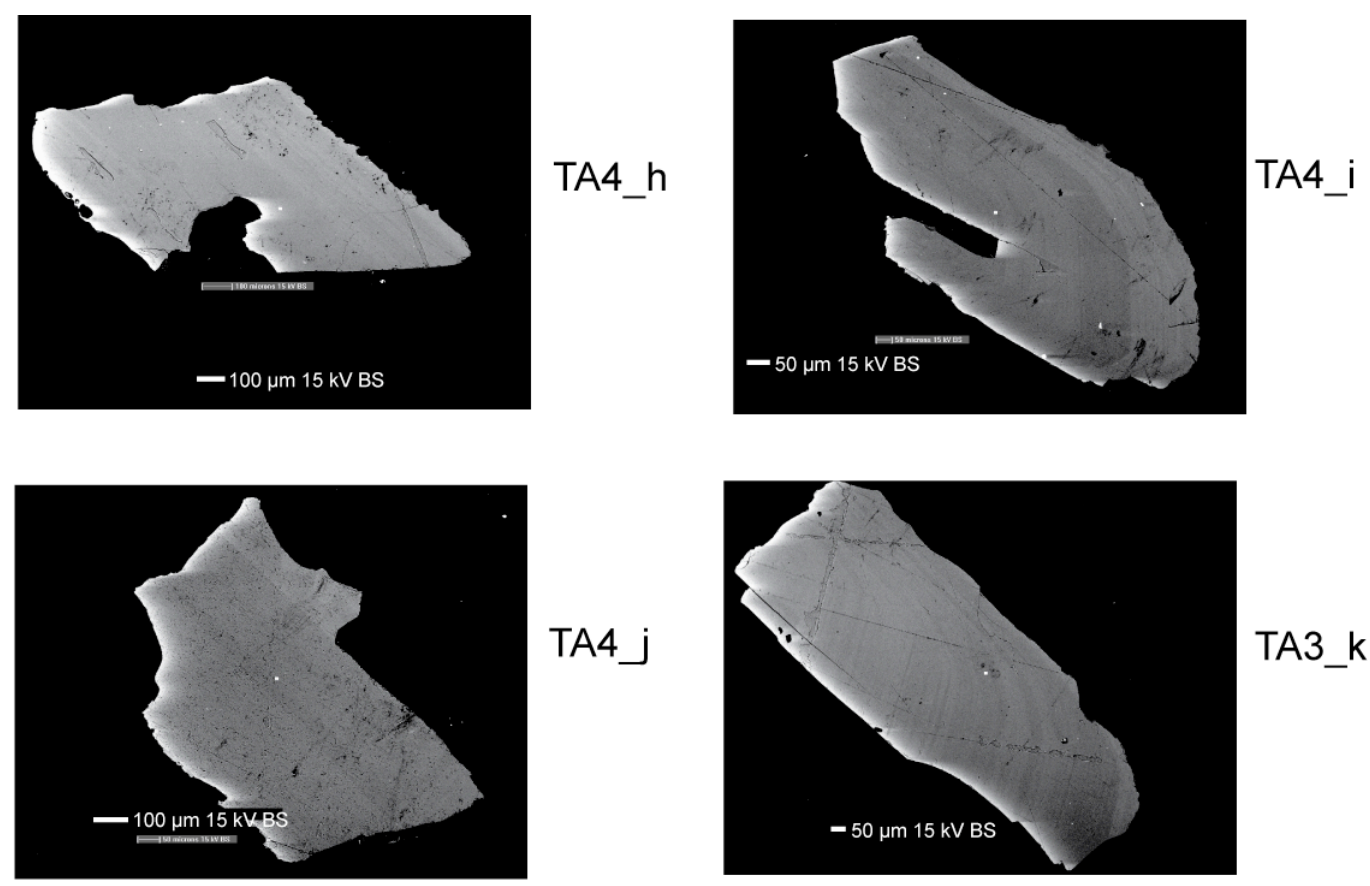

TA3_k

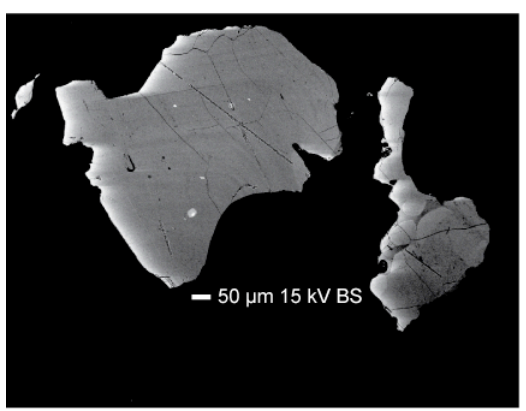

TA3 I

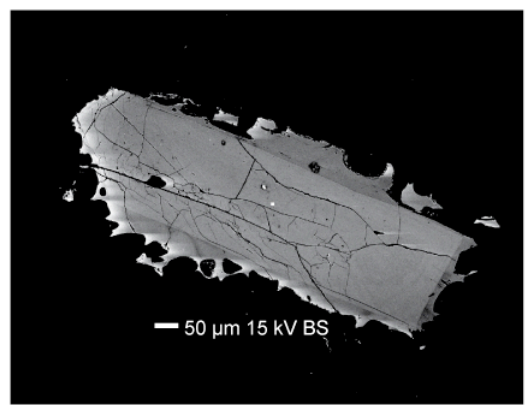

TA3_p
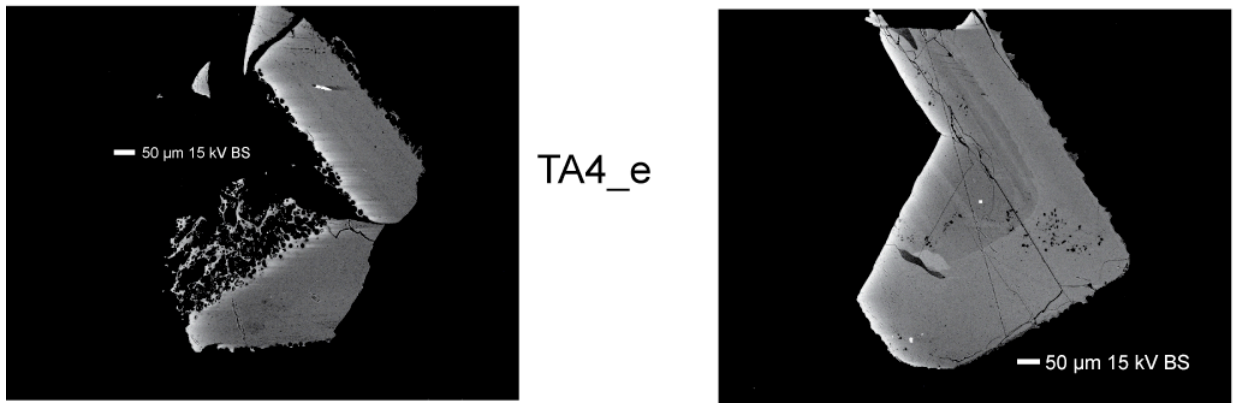

TA4_g 